

\section{DISCLAIMER}

This document was prepared as an account of work sponsored by an agency of the United States Government. Neither the United States Government nor the University of Callfornia nor any of their employees, makes any warranty, express or implied, or assumes any legal liability or responsibility for the accuracy, completeness, or usefulness of any information, apparatus, product, or process disclosed, or represents that its use would not infringe privately owned rights. Reference herein to any specific commercial product, process, or service by trade name, trademark, manufacturer, or otherwise, does not necessarily constitute or imply its endorsement, recommendation, or favoring by the United States Government or the University of California. The views and opinions of authors expressed herein do not necessarily state or reflect those of the United States Government or the University of California, and shall not be used for advertising or product endorsement purposes.

This report has been reproduced

directly from the best available copy.

\section{Available to DOE and DOE contractors from the Office of Scientific and Technical Information \\ P.O. Box 62, Oak Ridge, IN 37831}

Prices available from (615) 576-8401, FTS 626-8401

Available to the public from the

National Technical Information Service

U.S. Department of Commerce

5285 Port Royal Rd.,

Springfield, VA 22161 


\section{DISCLAIMER}

Portions of this document may be illegible in electronic image products. Images are produced from the best available original document. 
G.2.2 Work sheets

G.2.3 Bill of materials

G.2.4 Assembly procedures

G.2.5 Certificates of conformance

G.2.6 Artwork

G.2.7 Electronic test data

G.2.7.1 Electronic test procedure: Actel camera, PWA with gain and offset control

G.3 Mechanical assembly log

G.3.1 Operations sheet

G.3.2 Work sheets

G.3.3 Bill of materials

G.3.4 Assembly procedures

G.3.5 Test procedures

G.3.5.1 Calibration data files

G.3.5.2 Environmental acceptance test procedures

G.3.5.2.1 Random vibration test data

H. Certification log for star tracker A (ST 314)

H.1 Summary technical data

H.2 Board assembly log

H.2.1 Operations sheet

H.2.2 Work sheets

H.2.3 Bill of materials

H.2.4 Assembly procedures

H.2.5 Certificates of conformance

H.2.6 Artwork

H.2.7 Electronic test data

H.2.7.1 Electronic test procedure: Actel camera, PWA with gain and offset control

H.3 Mechanical assembly log

H.3.1 Operations sheet

H,3,2 Work sheets

H.3.3 Bill of materials

H.3.4 Assembly procedures

H.3.5 Test procedures

H.3.5.1 Calibration data files

H.3.5.2 Environmental acceptance test procedures

H.3.5.2.1 Random vibration test data

H.3.5.2.2 Thermal cycle test data

I. Miscellaneous

I.1 Clementine Sensor Test Acceptance Procedure for ST 313

I.2 Clementine Sensor Test Acceptance Procedure for ST 314 


\section{INTRODUCTION}

The Clementine flight unit star tracker is the latest model of the Ballistic Missile Defense Organization (BMDO), formerly SDIO, lineage wide-field-of-view star tracker camera designs. The star tracker focal plane, optics, and pointing algorithms were first demonstrated in 1987. Previous papers $[1,2]$ describe previous models, along with performance expectations. The Clementine vintage, also described in Ref [3], has improvements in radiation resistance, solar rejection baffles, low distortion fiber optics plate, and quaternion angle finding algorithms. With these improvements, the star tracker system reliably determined quaternions throughout the life of the mission.

\section{CLEMENTINE MISSION}

The Clementine spacecraft was launched on schedule on January 25, 1994 from Vandenberg Air Force Base (CA). After 25 days in lunar transit, which included a week in low earth orbit and the remainder in phasing loops, the spacecraft was inserted into an elliptical polar lunar orbit where it successfully spent 71 days performing a systematic mapping of the moon. The spacecraft left the moon on May 4, 1994 and was starting the Earth/Moon phasing loops for gravity assist boost towards the near-Earth asteroid Geographos when the spacecraft suffered a software failure causing complete loss of attitude control system propellant and putting the spacecraft in an $81 \mathrm{rpm}$ spin. The spacecraft could not be despun to a low enough rate to permit further acquisition of resolvable images, nor could the spacecraft be pointed to a specified direction. As a result there was no possibility of completing the Geographos phase of the mission. Refs [4,5] provide good overviews and insight into utility of the Clementine data which has been analyzed.

\section{STAR TRACKER CAMERA MISSION GOALS}

The primary purpose of the Clementine mission was to flight qualify and test the state-of-the-art sensor payload for Department of Defense (DoD) applications. A secondary objective was to produce data of interest to the scientific community. The star tracker camera was selected for the mission because it was a light-weight, medium accuracy star tracker, which was capable of meeting the pointing and navigation requirements of the Clementine flight plan. It served double-duty as a very wide field of view imager (for lunar horizon glow studies) and as a Cherenkov radiation detector with the aperture closed using extremely long integration times.

\section{PROGRAM CONSTRAINTS AND GUDELINES}

The Clementine program was conceived to be a demonstration of DoD/BMDO sponsored technologies for space applications in a deep space environment. It had an overriding goal of meeting the scheduled launch of $25 \mathrm{Jan} 1994$, which was achieved (funding start was March 1992). Maintaining the program within cost was the secondary constraint, with technical performance requirements allowed to float somewhat as the third leg of this well known triad.

The LLNL cameras used on Clementine were derivatives of earlier cameras developed under the LLNL Brilliant Pebbles (BP) Flight Test Program. Modifications to the camera were made to insure camera survivability for the planned 7-month mission. These consisted primarily of using MIL-STD-883B electronics components where practical, up-screening of commercial-grade electronics components, and modifying the camera structures to insure that the electronics were suitable for steady-state operation in a space environment (BP cameras were implemented to operate only for the relatively short duration of a sounding rocket flight).

\section{DESCRIPTION}

The star tracker stellar compass, hardware shown in Fig. 1, consists of stellar compass software and the physical camera. The hardware consists of a lens, baffle, and a small camera module (consisting of the CCD, camera electronics, and housing). These are described in this section. Table 1 summarizes the camera technical specifications. A functional block diagram is shown in Fig. 2. 


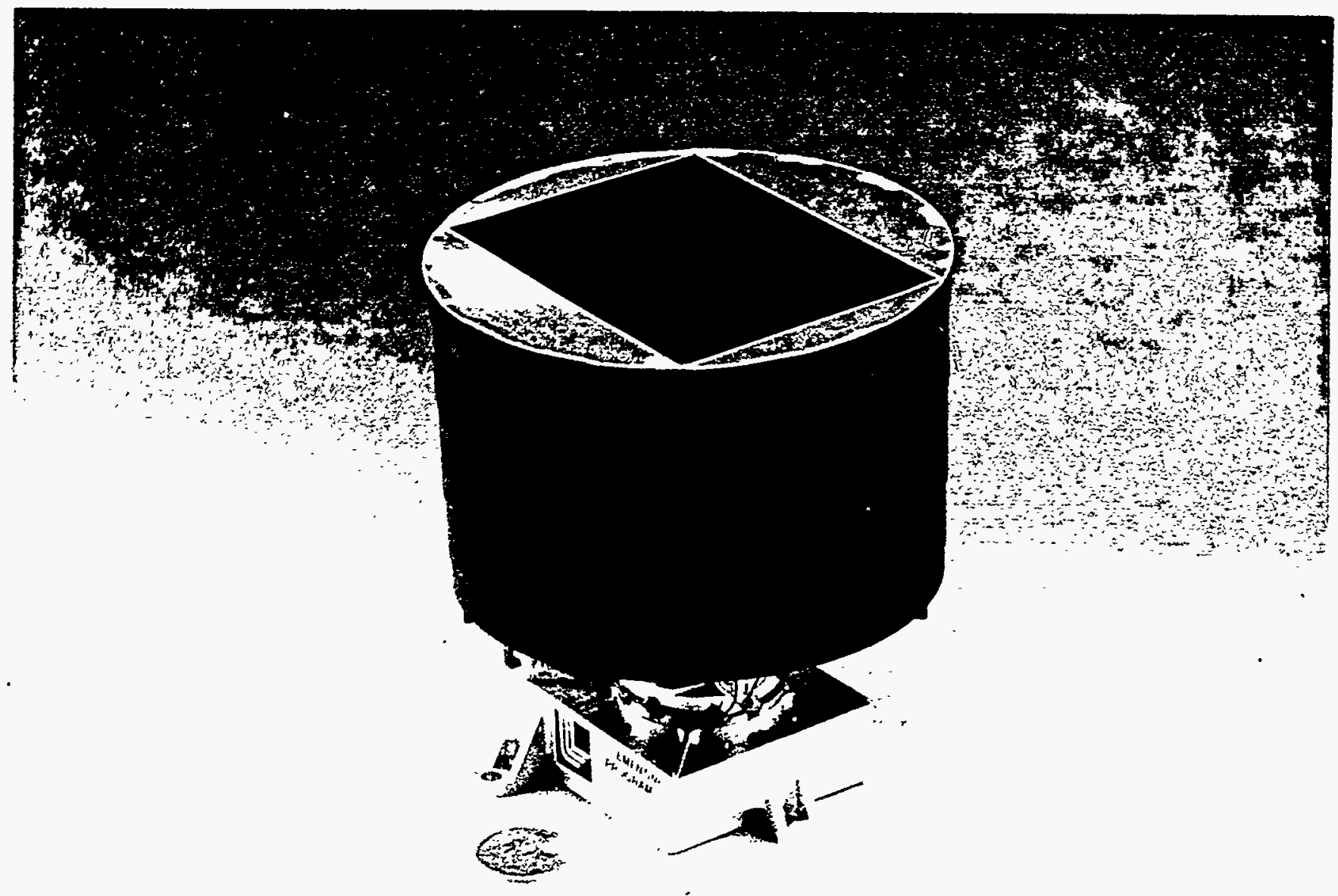

Fig. 1. Clementine star tracker camera.

\subsection{Stellar Compass Software}

The stellar compass software is a robust set of algorithms resistant to errors induced by noise and moderate amounts of scattered stray light. The major algorithm steps for the camera are:

- sweep each line for potential stars, using self-adjusting differential requirement

- perform blobifying routine to outline potential stars

- find peak pixel reading in each blob

- check blob shape against nominal stellar blur

- find local star background

- find local star centroid and mass

- order star masses

- take top (10) stars to triangulation, with selection weighting towards outer FPA pixels

- list triangles formed by star group

- match triangles to star atlas-derived triangles

- calculate quality of best match

- . output match quality and quaternion for navigation use

A number of features that are seen in many high-accuracy star trackers, such as magnitude matching for each star after rough triangulation and "S"-curve correction of the centroid algorithm are not employed. Nor is distortion of the lens corrected on the as-built unit. Without these features, the centroiding algorithm, which is a simple mass-centroid calculation, will return up to $1 / 25$ pixel error for some star center locations with respect to the focal plane. These features were not included because the accuracy of the star tracker was sufficient to meet mission requirements without the additonal algorithm steps. 
Table 1. Star Tracker Camera Performance Characteristics.

\begin{tabular}{|l|l|}
\hline Attribute & Characteristic \\
\hline Focal Plane Arrays & \\
Type & Thomson TH7883-F02-01-B/T \\
& Si CCD -0.4 to 1.1 microns \\
Pull Frame Device \\
Array Size & $384 \times 576$ \\
Pixel Size & $8.83 \times 13.25 \mathrm{~mm}$ \\
CCD Operating Temperature & $23 \times 23$ microns \\
& $10^{\circ} \mathrm{C}$ Maximum (Clementine spacecraft \\
\hline specific)
\end{tabular}




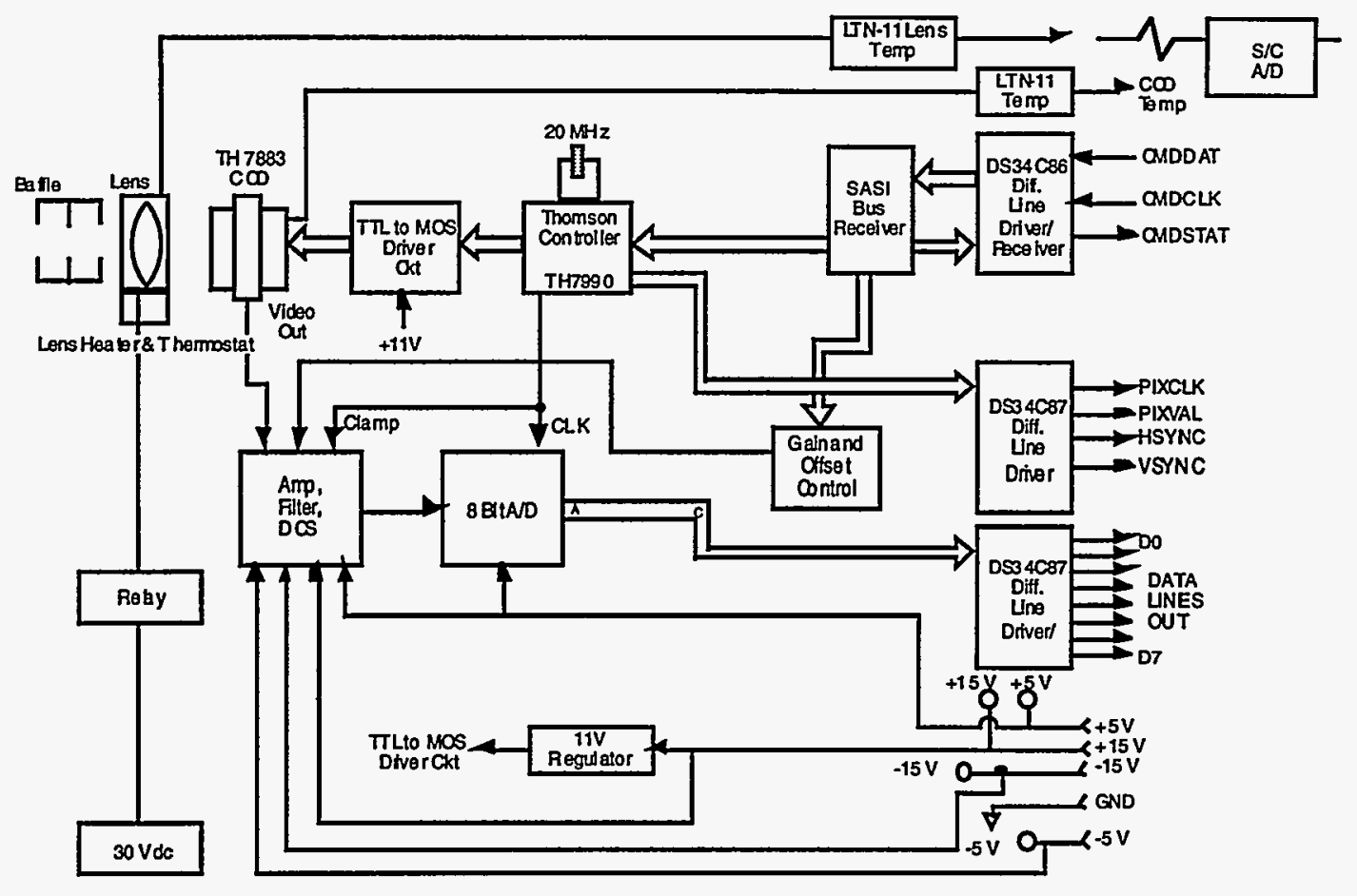

Fig. 2 Clementine star tracker camera functional block diagram.

Accuracy of the present star tracker is limited by the distortion pattern in the fiber optic faceplates located in the rear of the star tracker lens and on the focal plane array. Zero-shear faceplates were ordered for the Clementine built star tracker units, which decreased the rms distortion in the lens to roughly $200 \mu \mathrm{rad} \mathrm{rms}$, with the peak distortion values at the edges of the focal plane (where stars are dimmer as imaged through the lens and are infrequently selected for triangle matching). With at least 5 stars required for a positive match, the contribution of a single star in the corner of the FPA to the overall pitch or yaw pointing error is reduced. Other sources of pointing error are noise influence on the mass centroiding error and the "S"curve error from the algorithm itself.

The end result of the algorithms implemented on the Clementine flight unit passed ground tests with $<100 \mu \mathrm{rad}$ rms pitch/yaw error and $<450 \mu \mathrm{rad} \mathrm{ms}$ roll error. These tests were repeated zenith viewing throughout the night, with quaternions fit to an equatorial earth motion model. Zenith viewing reduces atmospheric refraction effects. Temporal noise in most star fields was on the order of 20 to $30 \mu \mathrm{rad} \mathrm{ms}$, with occasional jumps in pointing quaternion seen as a star drifted onto (or off) a distorted fiber optic section. If a distortion correction algorithm were implemented, the noise level of $30 \mu \mathrm{rad}$ pitch/yaw and $200 \mu \mathrm{rad}$ roll would be achieved.

Perhaps the most unique features of this star tracker code are the adaptable threshold sweep, which allows operation even with degraded stray light and camera noise conditions. This algorithm group floats with background increase and with low frequency background changes across the field of view. Rows are processed left to right, and pixels that are $\mathrm{N}$ counts higher than the preceding neighbor are flagged as possible bright spots. The algorithm starts with a high threshold value (i.e. 10), and lowers the threshold by 1 count and re-scans the line until not more than 1 candidate star pixel is found. For example, if there are 3 pixels with a signal increase of 2 counts, no candidates will be found at 3 threshold, but 3 will be found at a 2 threshold. This causes the entire line to be discarded, since the noise is on the order of the brightest possible real star. Even if the pixel did pass the star test for this line, noise values would cause centroiding results to be inaccruate.

For Clementine, the on-board star atlas was a trimmed and adjusted version of the SAO catalog which included 464 stars. This set guaranteed that there would be 5 stars of $\mathrm{m}_{\mathrm{V}} 4.5$ or greater in the field of view at all times. The set was also adjusted to accomodate the color sensitivity of the $\mathrm{CCD}$.

In flight, the star tracker camera reliably provided quaternion updates to the spacecraft throughout the life of the mission when the solar exclusion angle was respected, with 1 exception. Early in the mission, after stage separation, star matches 
were not achieved for a period of an hour. Later analysis of downlinked images showed that the 10 brightest blobs in the FPA were space debris resulting from the separation, which is a condition that was not expected in the default software.

\subsection{Optical System (Ref Appendix C)}

The star tracker lens was specified and built to have a $42^{\circ} \times 28^{\circ}$ field of view. This sizing results in a pixel IFOV of $1.3 \mathrm{mrad}$, which is small enough to provide the requisite quaternion accuracy. The collection aperture of the lens is maximized for the greatest possible light gathering capability. At $\mathrm{F} / 1.25, \mathrm{~m}_{\mathrm{V}}=4.5 \mathrm{G} 0$ stars provide an integrated star signal that is 15 times the electronic noise from the focal plane. This level of signal gathering capability, matched with the wide field of view, ensures a 99.9\% probability that 5 stars above minimum threshold will be available for the algorithm set for all possible quaternion pointing vectors. This allows the star tracker to handle the "lost in space" condition with a single star image frame and no other apriori knowledge of location.

To avoid chromatic aberrations that would shift star centroids with star color temperature at the edges of the field of view, and to maximize imaging F/number, a concentric optical design was adopted. For extension into a long-life space mission, only radiation resistance glass, including fiber optic faceplate material, was included in the optical path. Use of the radiation resistant material reduces transmission in the shorter wavelength regions of the CCD response, virtually blocking all light below $500 \mathrm{~nm}$, however, for doses on the order of $10 \mathrm{KRad} \mathrm{Si}$, the net transmission gains throughout the life of the mission compensate the early transmission loss. Fig. 3 depicts the optical system with baffle.

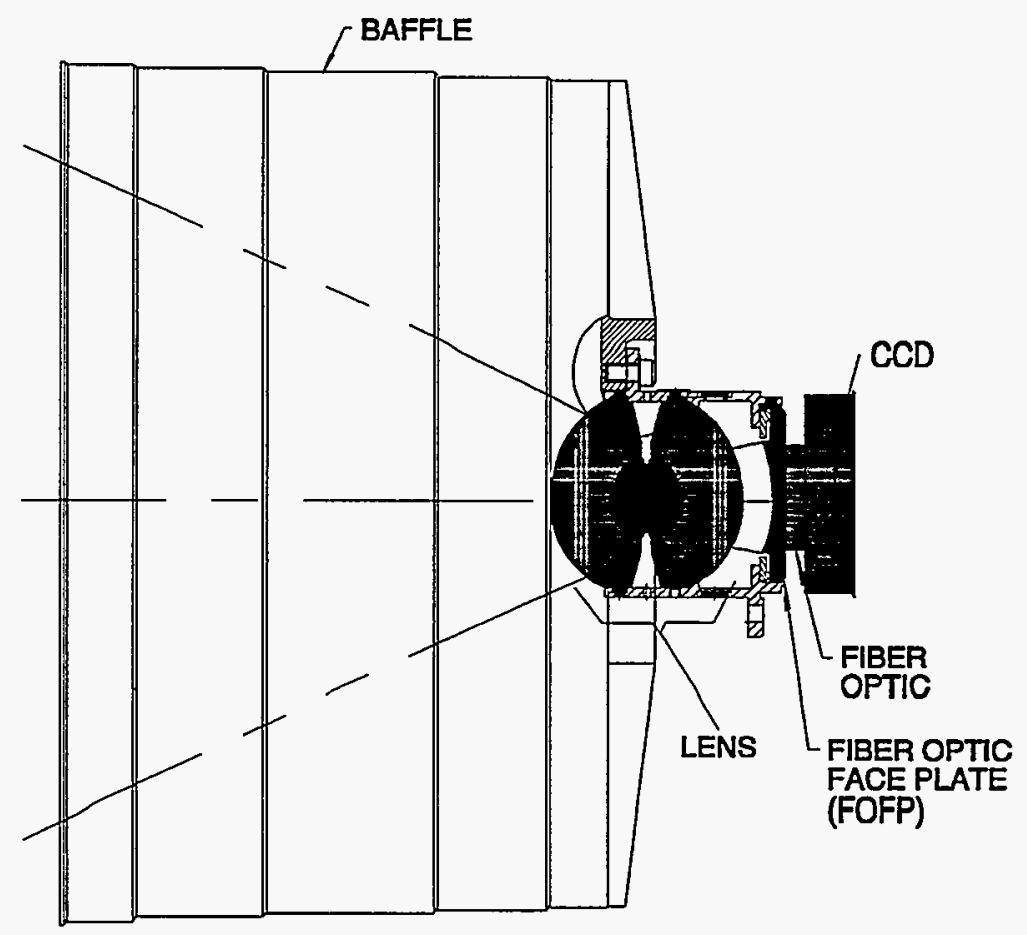

Figure 3. Star tracker optical system showing the image plane at the fiber optic face plate, the concentric lens elements and the single stage baffle.

\subsection{Baffle}

Small amounts of scattered sunlight can be much brighter than the image of the dim stars needed by the sensor for proper operation. (The sun is 12 to 13 orders of magnitude brighter than the stars used for navigation.) Without a baffle, operation would only be possible when the sun, solar-illuminated moon, and solar-illuminate earth are all behind the star tracker line of sight and not illuminating spacecraft structure in the forward hemisphere of the star tracker line of sight. A baffle was designed to allow operation with more general sun/earth/moon constraints. 
Stray light reduction requirements for the camera were expressed in Point Source Transmittance (PST), which is defined as the ratio of flux reaching the FPA of a sensor to the flux at the aperture of the sensor. The design goal PST of the star tracker baffle/ lens opto-mechanical package was set at $10^{-7}$ PST, which yields a signal of 5 counts when the full solar illumination is incident (outside the rejection angle) on the star tracker camera at nominal integration time and gain settings.

Both flight star trackers were tested using a $1 \mathrm{~kW}$ quartz tungsten halogen lamp source for illumination. Testing was performed both outdoors and in the high bay assembly area for the Clementine camera. Both test areas had significant amounts of aerosol particulates, that contributed to the stray light readings. Aerosol magnitudes were typically $<5 \times 10^{-7}$ equivalent PST, which made a correction of the aerosol signal to $10 \%$ accuracy well below the critical $10^{-7}$ PST testing goal. Scattering was in the range of $10^{-4}$ to $10^{-5}$ PST when the illumination source glanced off any structure (except baffle vanes) forward of the lens. The image saturated when the illumination source directly lighted optical surfaces. The results for the two flight units is given in Figs. 4 and 5, showing that the baffle blackening, vane sharpness, and dimensional layout combined to meet the stray light reduction goals.

The baffle was allowed to extend 3 inches past the star tracker lens vertex, and provided operation when the sun/earth/moon were outside a $65^{\circ} \times 80^{\circ}$ angle exclusion zone. (The rectangular field of view is a result of rectangular baffle openings that pass the star tracker field of view.) Internal surfaces are coated with a MIL-F-495 Cu-black process on Ni-plated aluminum, which provided reflectance as low as industry standards Ball black and Martin black processes. Baffle construction, discussed later in this paper, was accomplished with adhesive.

\subsection{Camera Electronics (Ref Appendix D)}

The camera electronics are built around a Thomson TH7883 CCD, a Thomson TH7990 CCD controller and an Actel field programmable gate array (FPGA). The Actel FPGA controls operation of the TH7990 CCD controller and analog circuits (Gain, Offset and Double Correlated Sampling\{DCS\}) on the camera, generates video timing and additionally implements functions of the synchronous addressable serial interface (SASI) bus protocol receiver. The camera received commands from the Clementine Sensor Imaging Processor (SIP) via the SASI bus. The commands are received and processed by the Actel FPGA. The FPGA controls the operating modes of the camera by controlling the operating mode of the TH7990. The camera returns digitized video to the SIP. This is represented functionally in Fig. 6.

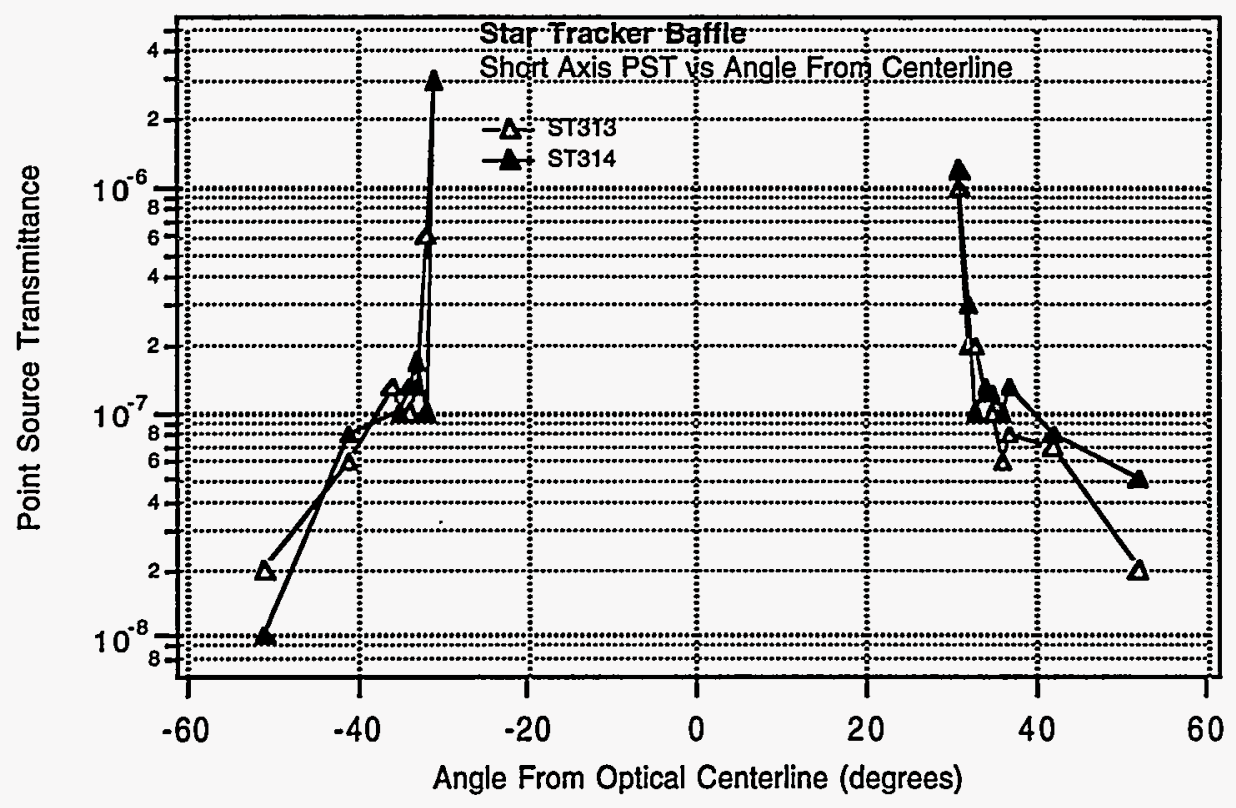

Figure 4. PST vs angle for the short axis of the flight star tracker cameras. 


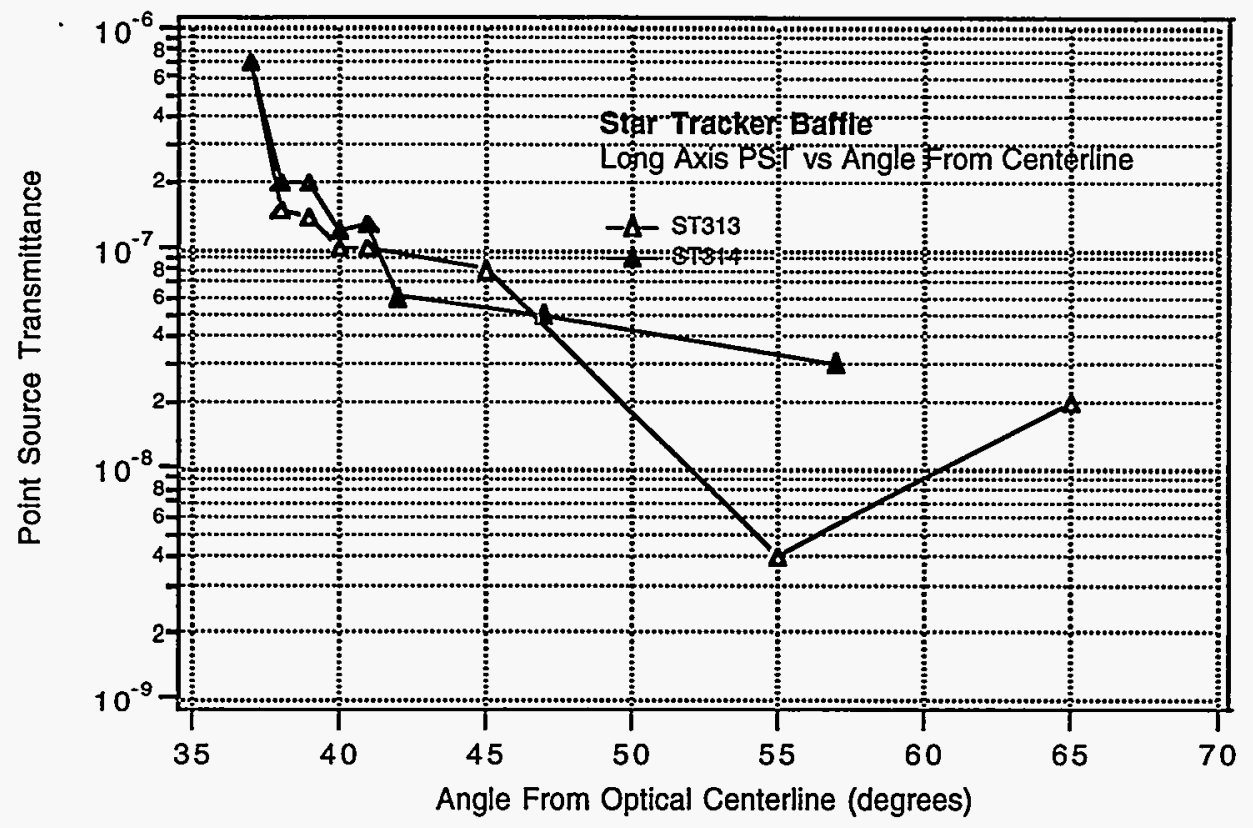

Figure 5. PST vs angle for the long axis of the flight star tracker cameras.

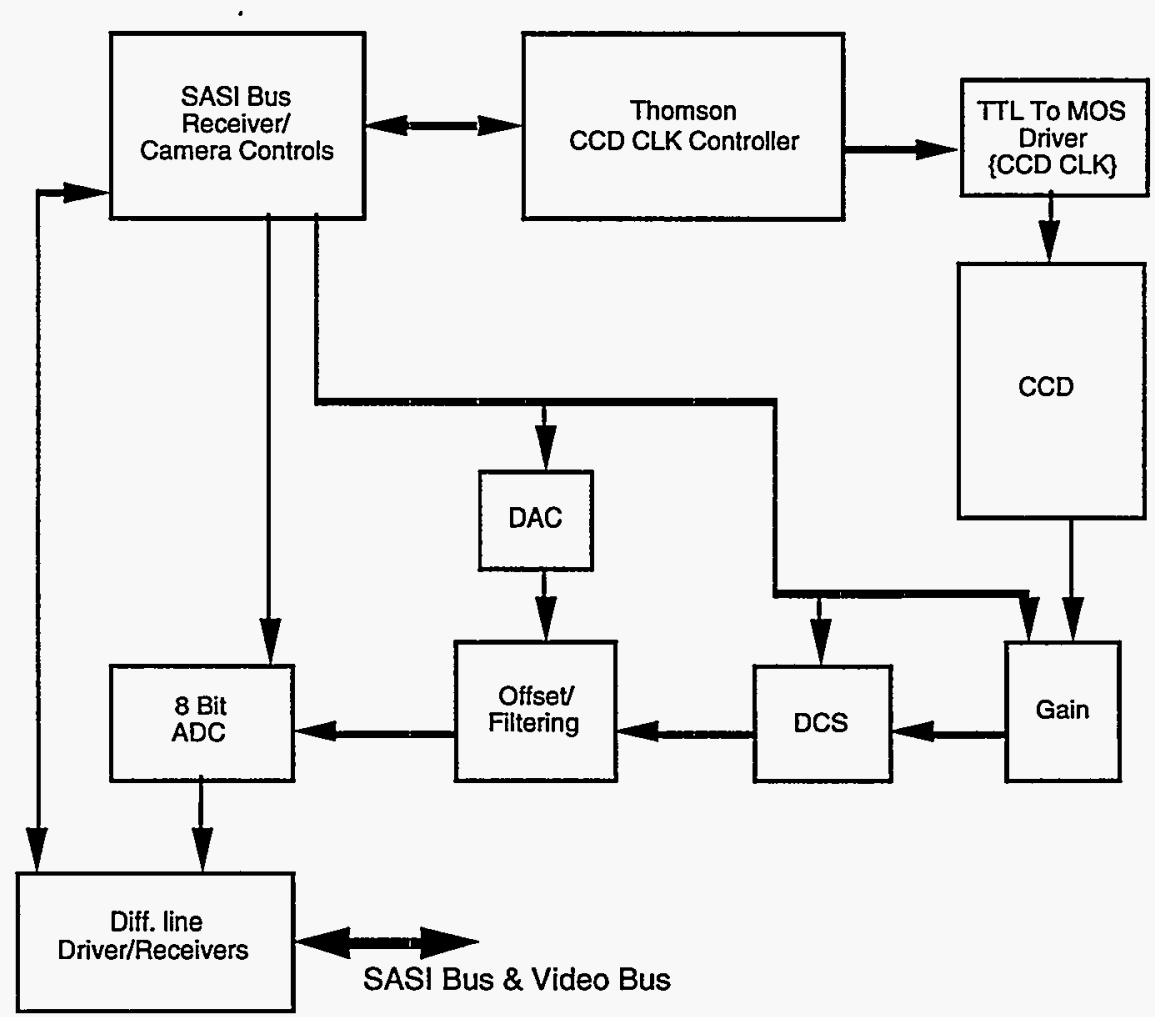

Figure 6. Star tracker camera electronics functional block diagram. 
Numerous camera commands were accommodated through the use of a Synchronous Addressible Serial Interface (SASI) interface protocol system utilized throughout the spacecraft system. The digital control interface electronics included in the electronics design decoded the SASI commands, and responded to respective commands with changes in camera settings. A status word was produced by the camera which echoed back the result of directed changes to the camera settings.

The camera has two modes of integration control, precision integration control or SASI control. The mode is selected by setting the control bit (BIT 3 or parameter $\mathrm{ID}=0$ ) either HI for precision control or LOW for SASI control. If precision integration control is selected, 13 bits of integration data must be loaded into the command data registers at parameter ID 2 and 3 with bit 4 of the command data register at $\mathrm{ID} 3$ being the MSB. Integration time in this mode equals $(\mathrm{n}+1) * 94.4$ $\mu$ seconds. The minimum acceptable $n$ is 1 , resulting in a minimum integration time for the star tracker of $188.8 \mu$ seconds. In the SASI control mode, integration is initiated by bringing the control bit ( bit 0 of the parameter $\mathrm{ID}=1$ ) LOW. The control bit must be LOW for at least $100 \mu$ seconds. Readout is initiated by bringing the same bit $\mathrm{HI}$. In the precision control mode, integration is initiated by a $\mathrm{HI}$ to LOW transition of the same control bit ( bit 0 at parameter $\mathrm{ID}=1$ ). Readout will occur automatically after the pre-set integration time. The control bit must be returned $\mathrm{HI}$ before initiating the next integration cycle and left $\mathrm{HI}$ for at least $100 \mu$ seconds.

In the analog domain, the output of the CCD is buffered through an emitter-follower before global gain is applied. Camera gain is selected by setting one and only one of the gain control bits (bits 4-6 at parameter $\mathrm{ID}=0$ ) $\mathrm{HI}$ which switches a gain resistor. The camera has three gain setting of $350 \mathrm{e}^{-/ b i t}, 150 \mathrm{e}^{-/} \mathrm{bit}$ and $75 \mathrm{e}^{-/ b i t}$. After global gain is applied, DCS is applied. Gain is applied to the signal before the DCS so as not to introduce excess noise to signal which would then be amplified. Timing for the DCS is achieved in an Actel FPGA. Offset is applied to the signal after DCS. Camera offset is selected by setting a 5 bit control word (bits $0-4$ at parameter $\mathrm{ID}=5$ ) which is sent to a digital to analog converter (DAC). One LSB equals an offset of 8 gray levels. The maximum offset equals 248 gray levels. After offset the signal is converted to digital value by the flash analog to digital converter.

\subsection{Camera Construction (Ref Appendix E)}

The measured mass of the two Clementine flight star tracker cameras was 280 grams and 286 grams. The camera consisted of a camera module, lens assembly and light baffle. The camera module, the core unit utilized on this camera and the Clementine UV/Visible and HiRes cameras, contained a Thomson CSF 7883 CCD and a flexible printed wiring assembly (PWA). The lens assembly consisted of radiation-resistant Cerium-doped glass, aluminum housing and a thermostatically controlled Nichrome lens heater. The light baffle is a single stage device discussed earlier. This camera was designed to survive a $19.8 \mathrm{~g} \mathrm{rms}, 60$ second duration launch during launch aboard a Titan II G launch vehicle, and operate in space for the seven month duration Clementine mission.

Fig. 7 depicts the camera module. The PWA has three rigid sections (main, CCD and connector) where electronic components are mounted. These sections are connected by flexible lengths which allow the PWA to be folded over on itself. The main section contains most of the components and has it's thermal planes at the four corners exposed on both sides. These corners are clamped between the two pieces of the camera module for structural support and heat transport from the board. The space between the two camera parts at these corners is custom adjusted based on PWA thickness measurements so there is a $0.0005 \pm 0.0001$ inch compression of the PWA corners. This compression insures adequate contact pressure for heat transfer while maintaining the structural integrity of the printed wiring board.

The PWA is folded so that the CCD area is located beneath a tongue in the camera housing. This metal tongue is situated between the $C C D$ and the CCD section of the PWA. Compliant thermal shims are located at the two interfaces. The CCD and the PWA are pressed tightly against this metal tongue with a metal retainer and No 2-56 fastners to thermally sink the CCD.

The main mechanical structure provides a precision surface for referencing to the lens housing via a spacer. The CCD in turn is aligned to the fiber optic faceplate (FOFP) at the back of the lens, and bonded to this FOFP with a curing, transmissive optical couplant. The focus spacer is custom-lapped to the finished height to within 0.0002 inches total indicated runout to insure parallelism. Further, a $0.0003 \pm 0.0001$ inch gap between the FOFP and the CCD face is achieved. This gap is filled with Dow Corning 93-500 optical couplant, cementing the lens to the CCD. 

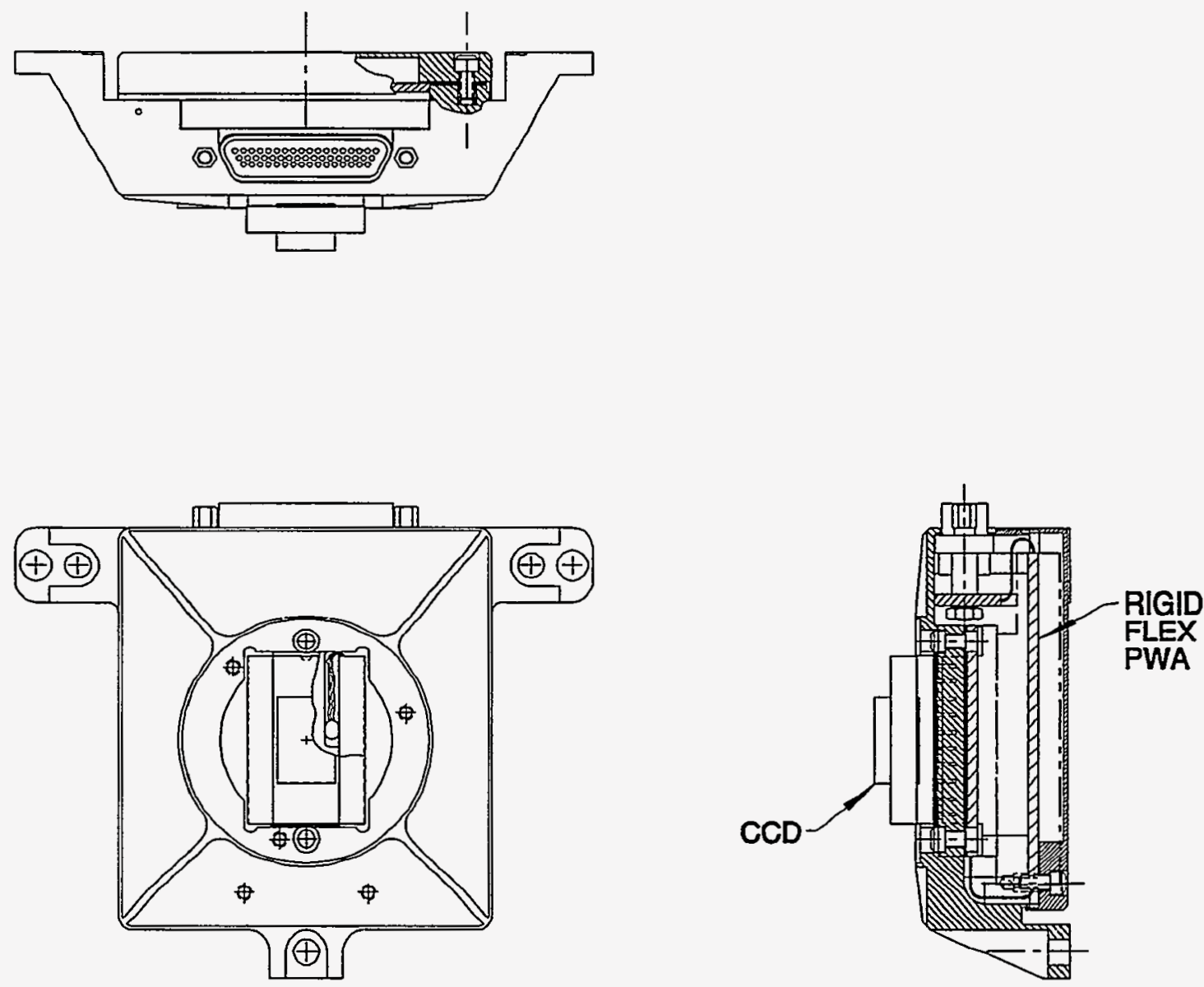

Figure 7. Camera module used for the star tracker camera.

Heat is transported from the components, the printed wiring board (PWB), through the aluminum housing and to the spacecraft's camera thermal management system. Hot electronic parts use thermal grease between the part and the PWB. The PWB is designed with two 1-oz thermal planes near the outer surface of both board sides. Further, thermal vias are located under expected hot components. The camera housing and end cover have integral heat paths with specific sections sized for low thermal resistance. A separate path for heat generated by the CCD is provided with use of an $\mathrm{Al} 1100-0$ thermal strap, to insure that the temperature gradient between the CCD and camera cold plate is minimized. The flexible CCD thermal strap was fastened at the outside of the camera housing and then directly to the camera's heat pipe. Heat from the electronics is removed at the three mouning feet, and at the four corners of the camera's end cover. At all part interfaces (e.g. PWA to camera housing) a thin layer of Dow Corning 340 thermal grease is used to minimize thermal resistance.

The baffle is shown as part of Fig 1. All material is copper oxide black Al 7075. The baffle is fabricated by machining the cylinder with support steps for the vanes, and machining the 0.010 " thick vanes. With the outside diameter of the vanes undersized to the baffle inside diameter by 0.020 inches, each vane is successively bonded to the cylinder at it's outside diamter with a low outgassing adhesive. The aluminum is electrolis deposited with a .0001 " to .0002 " nickel protectant then electro-deposited with $.0003^{\prime \prime}$ copper plated using a geometry-specific anode. This is then put in a boiling Ebanol soultion at $214^{\circ} \mathrm{F}$ for an experimentally derived period of time (typically tens of minutes). A deionized water rinse, and air drying completes the process. At final camera assembly a single layer of silver teflon tape is applied to the outer surface of the outer vane.

To protect the lens against extreme cold, a 450-ohm Nichrome heater with a bimetallic switch turns the heater on when the unit drops below $-6^{\circ} \mathrm{C}$. The $1 / 2$-inch wide heater strip is pressed against the outer diameter of the lens housing with an aluminum clamp, and the bimetallic switch is fastened to a flat on the clamp. The heater is powered by spacecraft $30 \pm 6 \mathrm{Vdc}$. 


\section{ENGINEERING HOUSEKEEPING DATA CHANNELS}

Several parameters were monitored to track the health of the cameras over the mission duration. These were image quality (dark level), CCD temperature, lens temperature, camera current levels, camera voltage levels and lens heater current. Additionally, switches were monitored to indicate ON/OFF status.

Temperatures were measured with Fenwall LTN-11 thermistors (purchased with calibration curves), with each thermistor bonded in place with Tra-Bond 2151 thermally conductive adhesive. The CCD thermistor was mounted flush with the backside of the alumina carrier package of the CCD, and was captured by a machined slot in the camera housing. The lens thermistor was bonded to a flat on the lens heater clamp, and was left exposed as the protective "coffee can" prevented significant radiative heat transfer effects on its measurement.

\section{INTERFACES}

Camera interfaces (optical, mechanical, thermal, electrical and communication) were defined with the spacecraft integrator (Naval Research Laboratory) prior to, and modified during, camera development. An interface control document (ICD), Ref [6], provided working constraints between LLNL and NRL.

The camera is bolted to the spacecraft at the camera mounting plate with three No 4-40 fasteners. A single Al 1100-0 CCD thermal strap is attached at the camera and directly to the camera heat pipe (part of the spacecraft Thermal Control System). To minimize particulate contamination to the lens and to minimize external, radiative thermal loads, NRL provided an enclosure for this camera (star tracker "coffee can"). The "coffee can" had a cover which was normally closed and could be opened when operation of the camera was required. The camera communicated to the spacecraft processor via a synchronous addressable serial interface (SASI) bus protocol based on the Goddard Flight Center (GSFC) 650C custom PMOS process digital integrated circuit. Digital lines were CMOS tri-stated differential line drivers and receivers based on RS-422.

\section{FLIGHT QUALIFICATION DESIGN, ANALYSIS \&TESTING}

Cameras were designed, analyzed, developed and subjected to critical peer review (design reviews and test data reviews). Each camera was subjected to extensive testing to measure compliance with interface definitions and show basic functionality, determine compliance with environmental test requiremnents, and to characterize the electro-optical preformance in response to expected viewing scenes. Prototype units were built to act as a pathfinder during each phase of development testing. These prototypes were also aggressively used in integration activities to find problems early thereby maintaining schedule. Appendix E.1 shows the star tracker camera structural analysis report.

Environmental testing was performed in compliance with the Clementine program guidelines and MIL-STD 1540B "Test Requirements for Space Vehicles". Tests included radiation (for the CCD and electronic components), random vibration, thermal cycling, thermal vacuum and electronic burn-in. Table 2 summarizes the test environments. Test data may be seen in appendices of the certification logs for each camera.

\section{CHARACTERIZATION AND CALIBRATION}

Extensive pre-flight calibration data were acquired using an automated calibration facility at LLNL. In a typical calibration configuration, a sensor was mounted inside an environmental chamber whose temperature was varied from $-20^{\circ}$ to $20^{\circ} \mathrm{C}$, the expected operating temperatures for the mission. Depending on the measurement types the sensors saw either a flat diffused light source or an off-axis collimator with various pinholes as the point source. A custom board controlled the sensor parameters from the host computer; the video signal was acquired using a commercial image processor. During data acquisition many thermal parameters such as FPA and chamber temperatures were monitored and recorded as part of the image structure. All calibration processes were fully automated enabling us to acquire data quickly while reducing operator errors.

Pre-flight calibration measurements for the star tracker provided critical alignment data for integration to the spacecraft. These were location of the optical center of the lens relative to the $C C D$ ( $x, y$ pixel coordinate), and optical boresight relative to the mounting feet of the camera (mechanical center). A two-dimensional angle map made in the laboratory, at roughly $0.5^{\circ}$ increments, was made using a collimated source to determine the net $h=f\left(\theta_{x}, \theta_{y}\right)$ star centroid mapping function. This data 
set was fit to the nominal $h=\sin (\theta)$ mapping function of the lens to determine best fit for center pixel $\left(\theta_{0}\right)$ and focal length. A verification an $d$ further refinement of this curve fit was made with the camera zenith-looking, then calculating a leastsquares fit of the resulting quaternions taken over a several hour period.

Additional camera performance parameters measured included radiometric sensitivity; FPA uniformity; gain and offset scale factors; temporal / spatial noise; dark noise dependence on FPA temperatures, integration times or input voltage levels, spectral response of FPA; optical distortion map; point spread function and electronic warm-up time. Appendix F presents the available summary reports on calibration of the flight star trackers.

Due to the criticality of the star tracker to the flight control of the mission, exhasutive tests were performed on the lifetime of the optics, coatings, focal plane performance, and electronics performance under the mission required radiation dose.

Table 2. Clementine star tracker camera environmental analysis and testing.

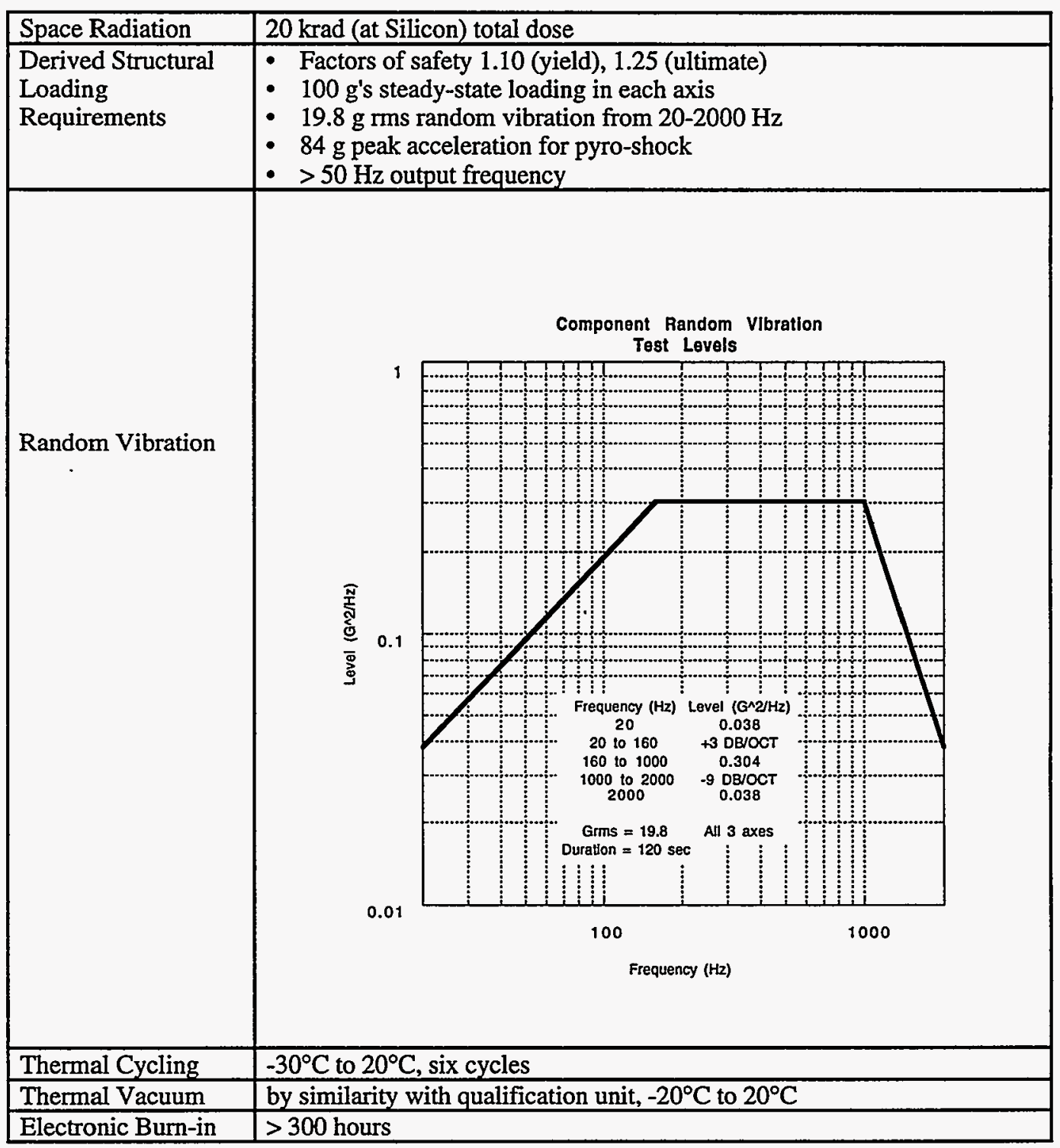




\section{CLEMENTINE MISSION DATA}

Mission data from the two star tracker cameras provided a myriad of raw star tracker images, useful for verifying the navigational capabilities of the camera, and a group of images to detect possible lunar horizon glow. The horizon glow data was gathered by pointing at the limb of the moon just before sunrise, detecting solar corona and possible scattering of dust particles (if present) close to the surface. The navigational requirements of the spacecraft were met using the star tracker/IMU combination as evidenced by the overalpping (correct pointing) of the mosaic UV/Visible and NIR lunar images.

The large set of Clementine images is accessible in various forms on the Internet at three locations (as of this writing):

http://flgsvr.wr.usgs.gov:80/clementine (United States Geological Survey, Lunar Institute) http://www.nrl.navy.mil/clementine/clementine.html (United States Naval Research Laboratory) http://Clementine.s1.gov (United States Department of Energy, Lawrence Livermore National Laboratory)

Section 15 of this document is a sampling of imagery captured by the star tracker camera during this mission.

Beyond images, engineering data for the two star tracker units has been collected for engineering evaluation. Data available is described in section 6 of this document. Fig. 8 shows sample data for the CCD and lens temperatures on star tracker A during orbit 72. Graphs for the various parameters are shown in section 16 of this document.

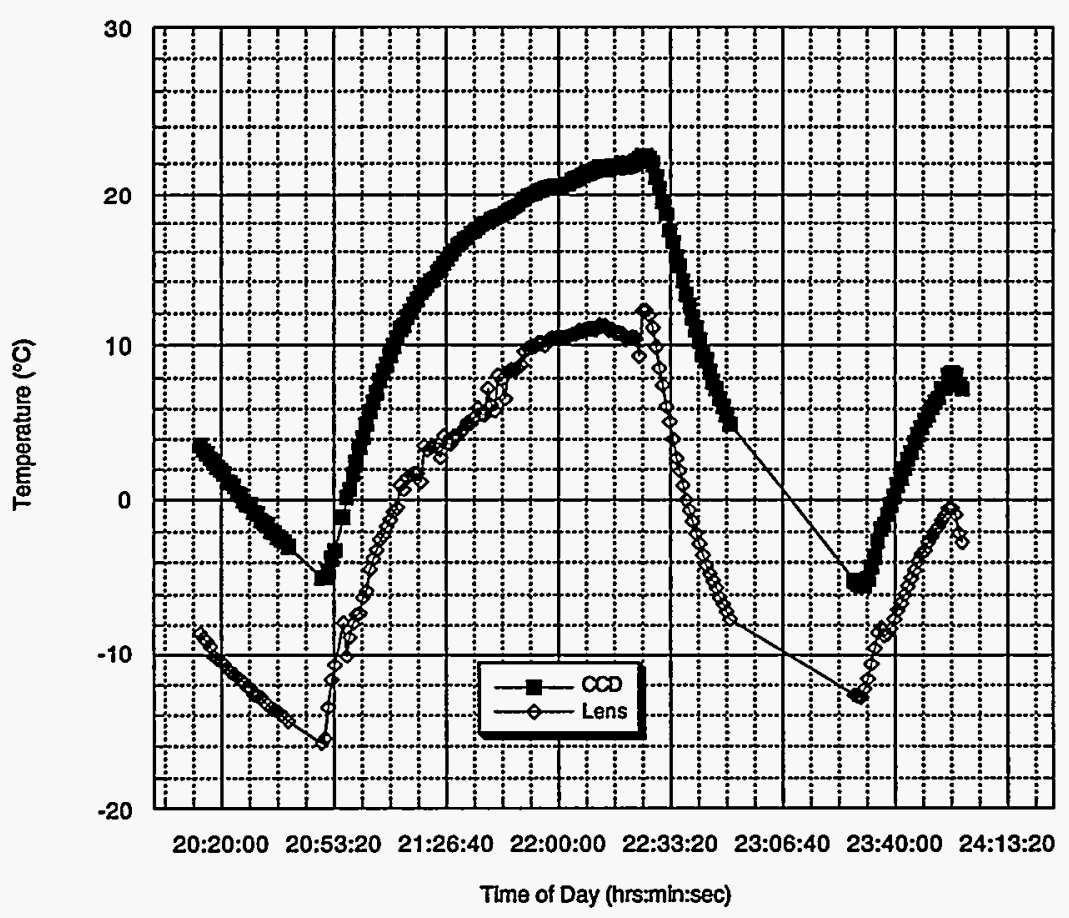

Figure 9. Star tracker A CCD and lens temperature for roughly one orbit on March 12, 1994. The CCD temperature exceeds the desired $10^{\circ} \mathrm{C}$ maximum value, but did not impair the star tracker stellar compass ability to achieve star matches. 


\section{LESSONS LEARNED}

While the star tracker was very successful at meeting the mission objectives of this space flight, improvements could be implemented to reduce quaternion error and design complexity, without increasing the cost or mass of the star tracker camera. The most significant improvement of this version of the camera, applicable to extended space flights, would be the inclusion of an Multi-Phased Pin (MPP) focal plane array. The present CCD array will suffer increases in dark current with moderate levels (typical multi-year flights) of solar-flare radiation. In order to accommodate the solar flare potential for Clementine, the CCD temperature was specified to be controlled to less than $8^{\circ} \mathrm{C}$ through heat strapping to the spacecraft thermal control system (at a heat pipe). Cooling the $\mathrm{CCD}$ is a method effective in reducing dark current. At the maximum radiation requirement, the dark current variation, pixel-to-pixel, would have been large enough, even with the temperature limit, to degrade performance. MPP type arrays are much more radiation tolerant, and would not suffer in potential moderate radiation exposure.

Algorithm improvements can also be implemented to reduce quaternion error. These include a noise-reduction step and a signal processing improvement. Noise reduction would be accomplished by subtracting the nominal fixed pattern noise from the array, while software improvements would include distortion mapping and correction and " $S$ "-curve error seen with the mass centroiding algorithm.

\section{CONCLUSIONS}

The star tracker stellar compass, as part of the suite of 6 light-weight, low power imagers [Refs 7 through 11] which were space-qualified for future Department of Defense flights, served as an integral part of the navigation system of the Clementine camera, providing accurate quaternion updates throughout the life of the Clementine mission. It is a spacequalified, proven, viable moderate-accuracy camera package, which, when coupled with the stellar compass software on the Clementine R3000 processor, provided quaternion data at $5 \mathrm{~Hz}$ rate. This system proved to produce valid quaternions for $\mathrm{CCD}$ temperatures up to $27^{\circ} \mathrm{C}, 17^{\circ}$ above the limit specified prior to launch, demonstrating robustness beyond expectations.

\section{ACKNOWLEDGEMENTS}

- This work was performed by LLNL under the auspices of the U.S. Department of Energy by Lawrence Livermore National Laboratory under contract No. W-7405-ENG-48.

- $\quad$ Funding was provided by the U.S. Ballistic Missile Defense Office.

- The lens was designed and built by Optical Corporation of America - Applied Optics under LLNL subcontract B208983.

- $\quad$ CCDs were purchased from Thomson CSF under LLNL subcontract B999999.

- Special thanks to the core members of the LLNL Clementine team responsible for the star tracker stellar compasses. Without their unselfish, dedicated efforts this would not have been possible.

\section{LLNL Clementine Team}

Management:

Optical:

Electronics:

Mechanical:

Software:

Fabrication:

Calibration:

Integration:

Subcontracts:

TID:

Administrative:
Lyn Pleasance, Mike Shannon, Arno Ledebuhr Izzy Lewis, Travis White Joe Kordas, Bill Bryson, Darron Nielsen, Mercedes Dickerson, Don Antleman, Gil Zaragoza, Wes Strubahr, Dean Hadley, Bob Hugenberger

Bob Priest, Mike Richardson, Preston Carter, Darryll Pines, Al Harrall, Bill Taylor, Tom Gorman, Gil Wong, Riley Martin, P.C. Wigley, Jim Dickie, Phil Stephan, Jeff Robinson, Jim Nally, George Cameron

Bruce Wilson, Diana Sackett, Hal Brand, Ernie Arnold, Mike Wilson

Ed Schmitt, Bill Rice, Ken Leach, Kathy Coatney, Dottie DaRonco, Diana Silva, Joe Burris

Hye-Sook Park, Doug Dobie, Ted Feretta, Linda Ott, Mark McKernan, Phil

Rob Hills, Noel Sewall

Bob Callaghan, Bill Whalen, Margaret Cooke, Kelly Miller

Kirk Hadley, Merry Oman

Emma Harris, Stephanie Ryan, Karma Thomas, Fran Brubeck 


\section{REFERENCES}

1. SCIENCE, ,Vol 266, S. Nozette, et al, "The Clementine Mission to the Moon: Scientific Overview", plus six additional related articles by various authors, pp $1835-1862,16$ Dec 1994.

2. M. J. Shannon, "The Clementine Satellite", LLNL document UCRL-52000-94-6, Energy \& Technology Review, June 1994.

3. J. F. Kordas, et al, "The Star Tracker Stellar Compass for the Clementine Mission", SPIE paper 2466-10, April 1995.

4. I. Lewis, et al,"WFOV Star Tracker Camera", LLNL document UCRL-JC-105345 (Preprint), prepared for the SPIE International Symposium Optical Engineering \& Photonics in Aerospace Sensing, April 1991.

5. S. McGrogan, et al, "The Stellar Compass", Intelligent Decisions Inc report to LLNL, February 1992 (v15b).

6. R. E. Priest, et al, "Sensor Integration Project Star Tracker Camera Interface Control Document", LLNL document C1-S1-010.

7. J. F. Kordas, et al, "UV/Visible Camera for the Clementine Mission", SPIE paper 2478-42, April 1995.

8. A. G. Ledebuhr, et al, "High Resolution Camera and LIDAR Ranging System for the Clementine Mission", SPIE paper 2472-08, April 1995.

9. R. E. Priest, et al, "Near-Infrared Camera for the Clementine Mission", SPIE paper 2475-52, April 1995.

10. R. E. Priest, et al, "The Clementine Longwave Infrared Camera", SPIE paper 2475-53, April 1995.

11. L. D. Pleasance and R. E. Priest, "Clementine Sensors: Engineering and Technology Workshop", LLNL document UCRL-MI-120834, June 1994.

\section{MUSSION IMAGERY}

This section presents a sampling of images collected by the two star tracker cameras over the course of the Clementine mission. These were produced primarily in the early stages of the mission. Complete imagery is best accessed via the Internet (see section 10 for address locations).

\section{MISSION ENGINEERING HOUSEKEEPING DATA}

CCD and lens temperatures were tracked to monitor the "health" of both cameras, with the goal that such data would be tagged to individual images (in PDS format). The section in this document graphs temperature versus time for the CCD and lens temperatures, and CCD temperature vs variable conductance heat pipe (VCHP) temperature to track the systematic $\Delta T$. These are plotted in ten-day batches beginning from the day before launch (24th day of the year) when pre-launch tests were performed. There are various other graphs scattered throughout this package which were produced to examine various phenomena during the course of the mission. 


\section{Section 15}

\section{Star Tracker Mission Imagery}



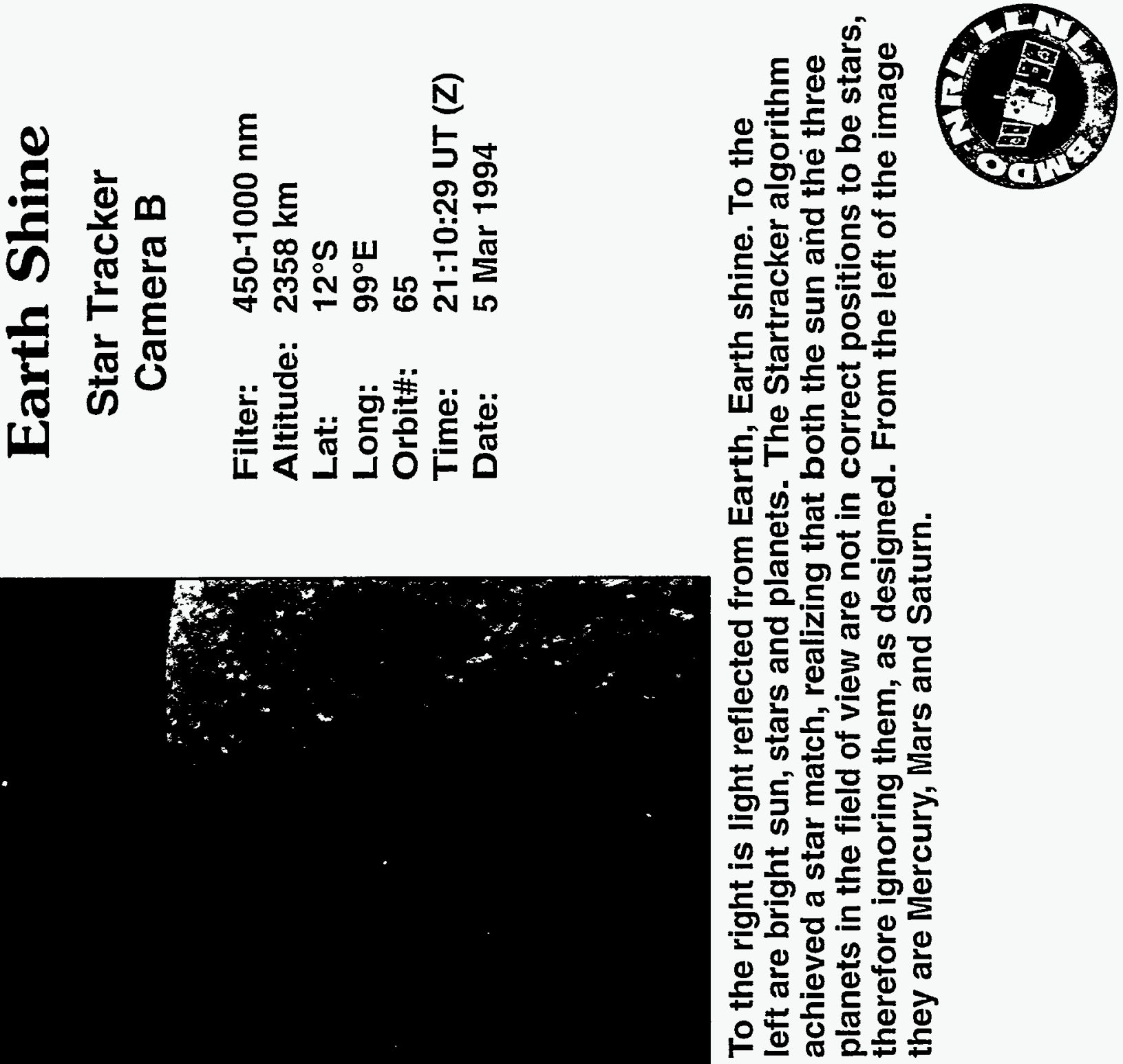


\section{Star Tracker View Of Earth's Limb}

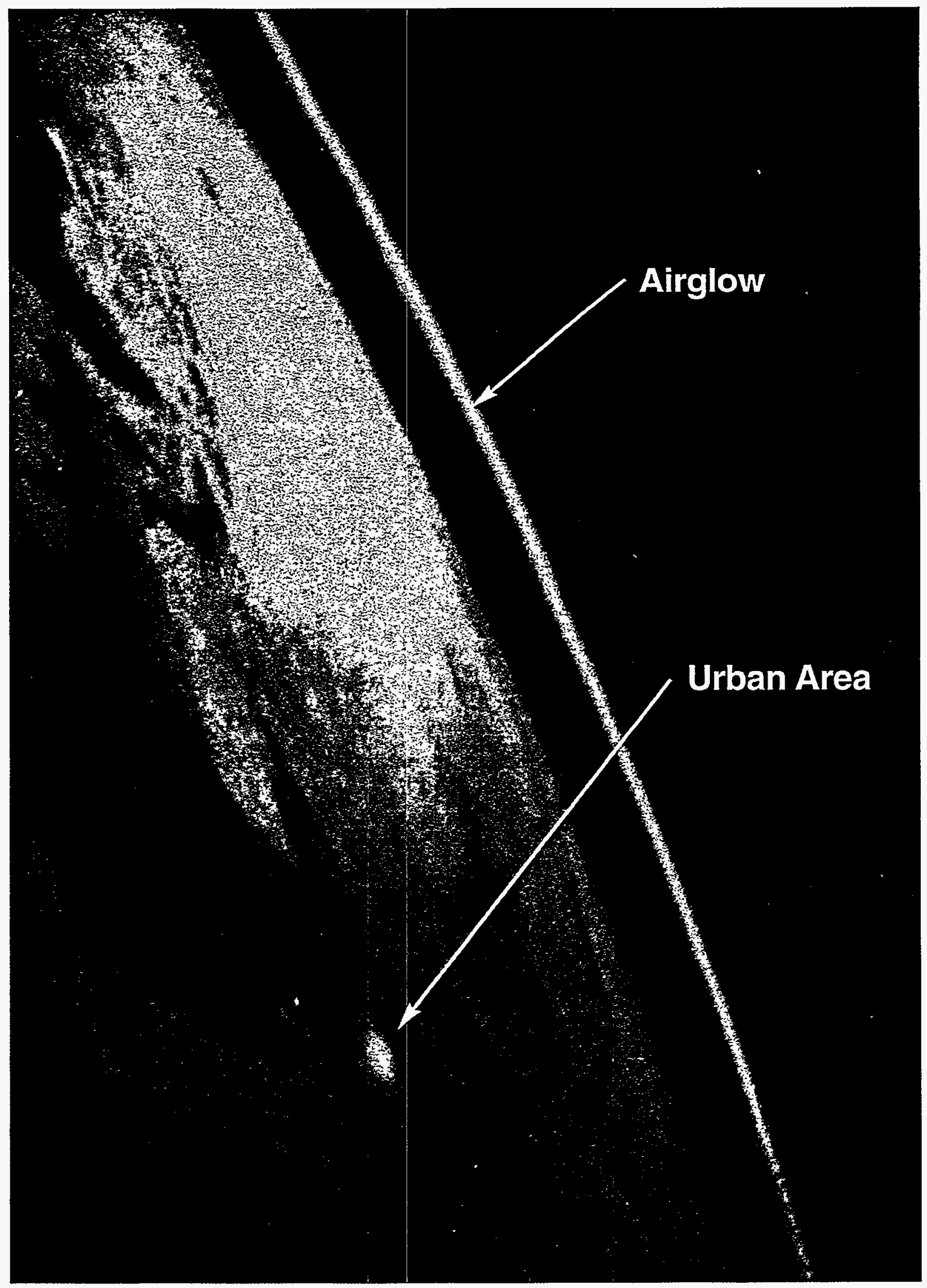




\title{
Clementine Spacecraft
}

\author{
Star Tracker Image: eaa00114.000
}

UTC: 1994-01-27T05:42:51.652

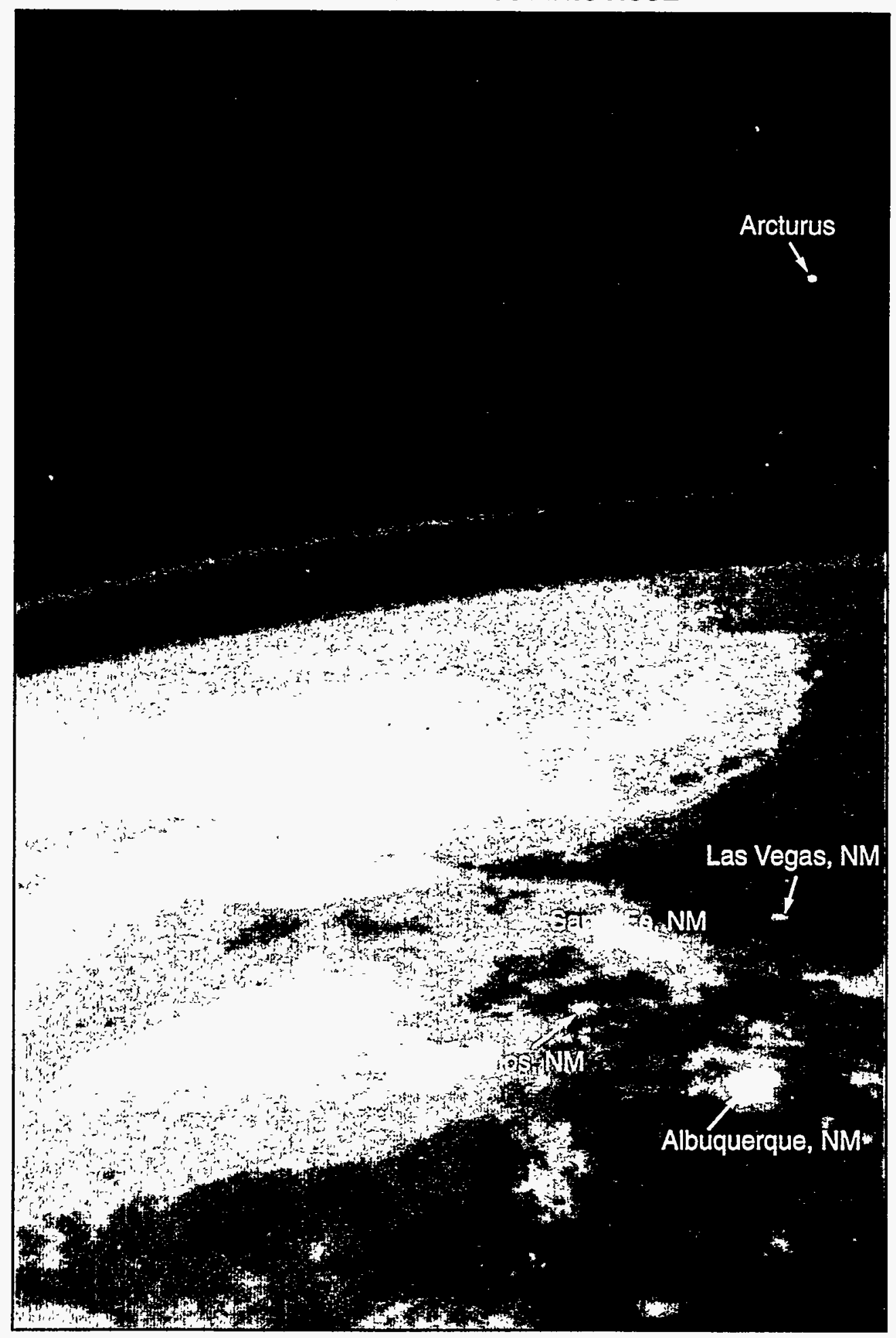




\section{Clementine Spacecraft}

Star Tracker Image: EAA02190.000 UTC: 1994-1-31T14:47:46.707 GMT

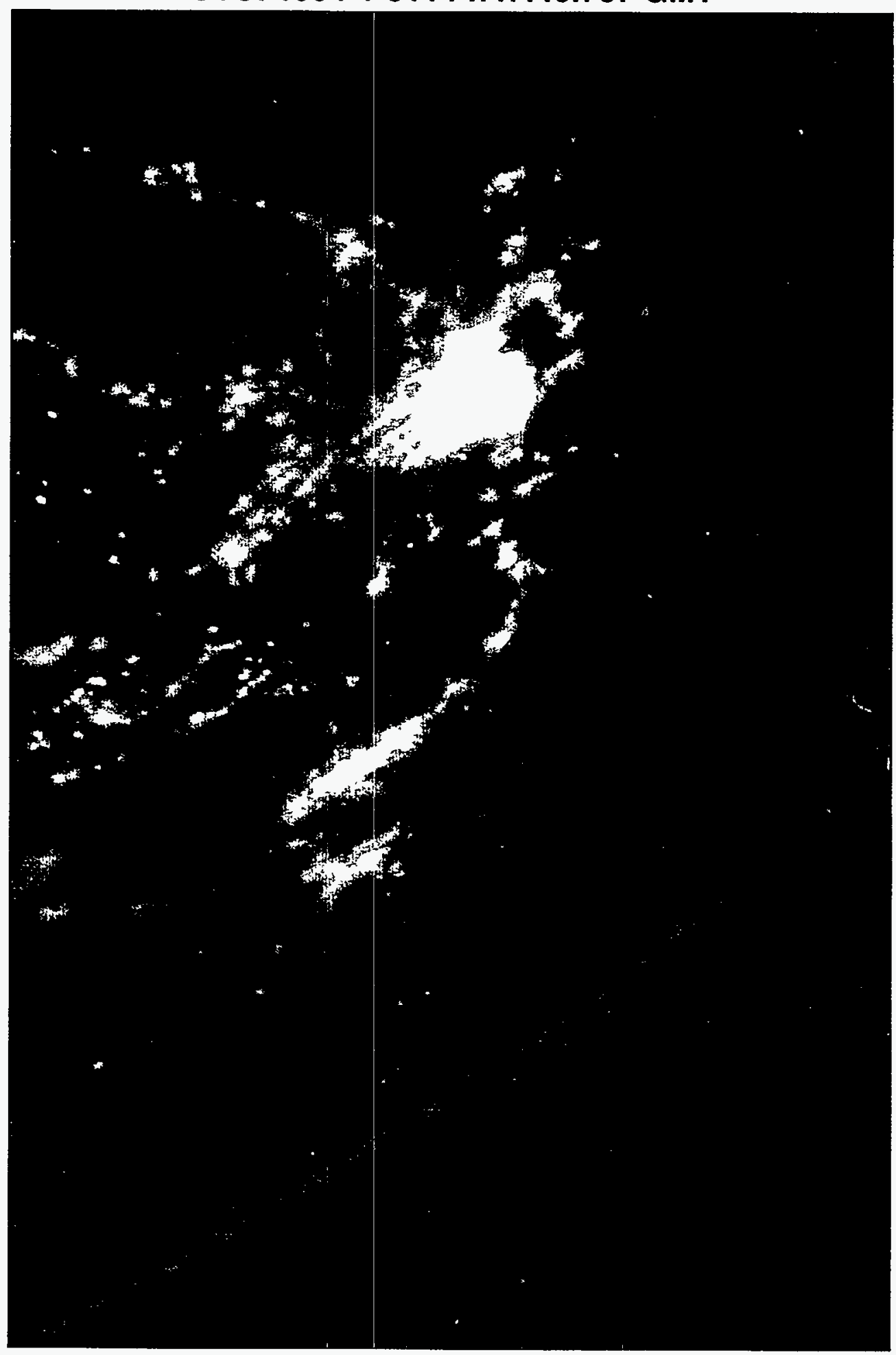

Tokyo and Vicinity 
Section 16

\section{Mission Engineering Housekeeping Data}


S-16

$120-129$ 
Clementine

Star Tracker A CCD Temperature

Start Time: 29-APR-94 22:06:41.630 GMT

File: sort12n.PC1

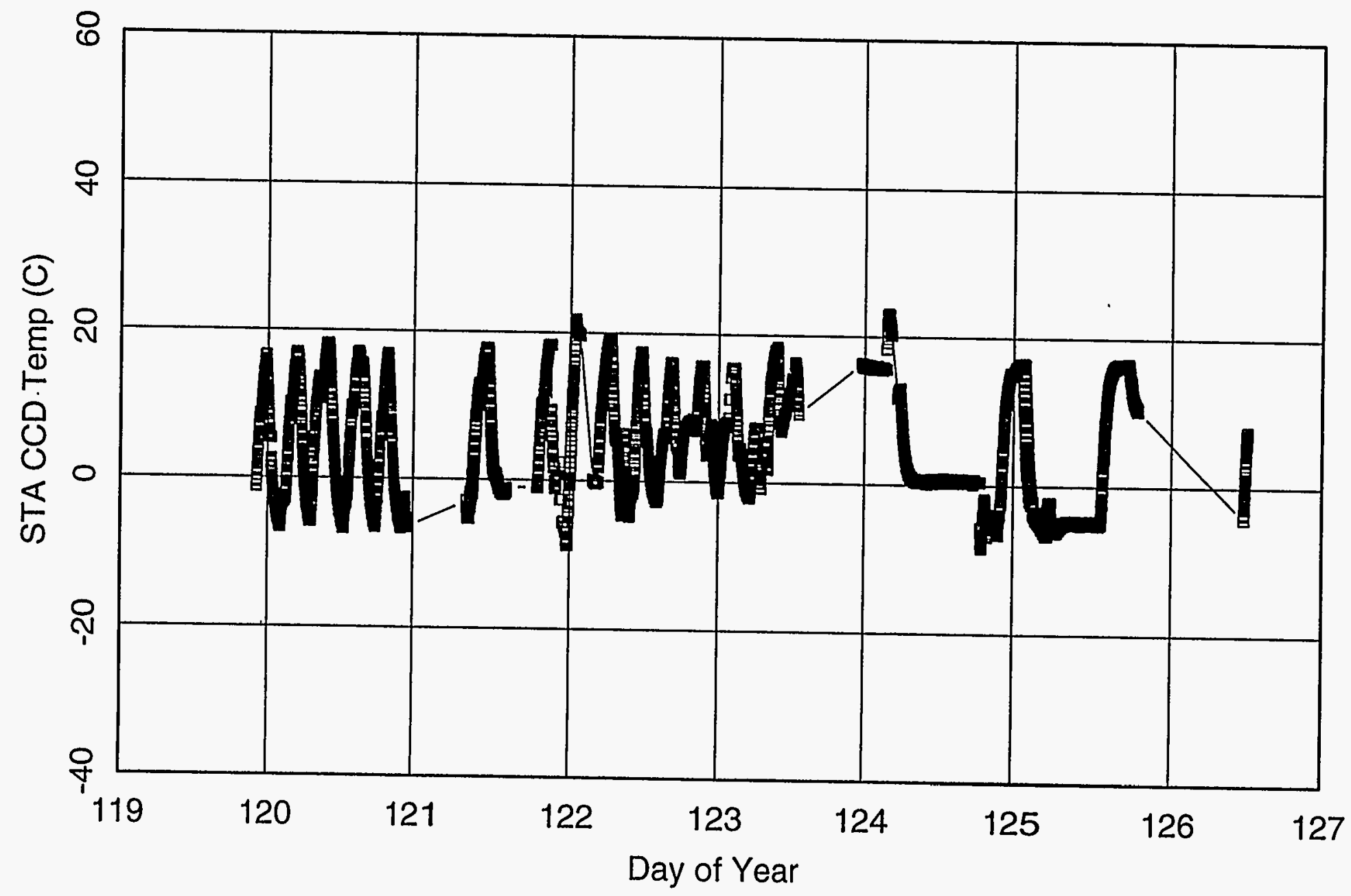


Clementine

Star Tracker A Lens Temperature

Start Time: 29-APR-94 22:06:41.630 GMT

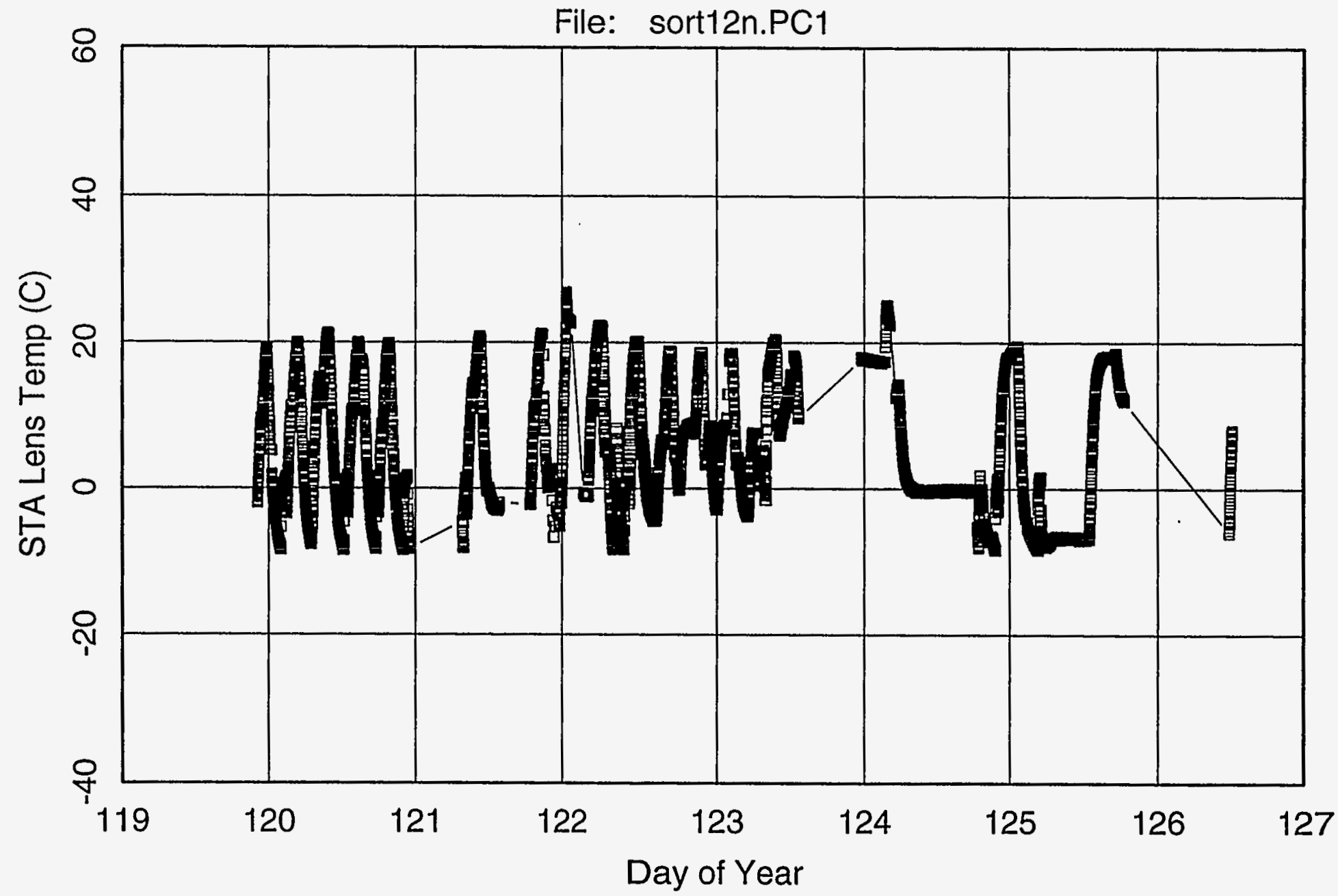

REP/LLNL created: Wed May 11 12:01:23 PDT 1994 


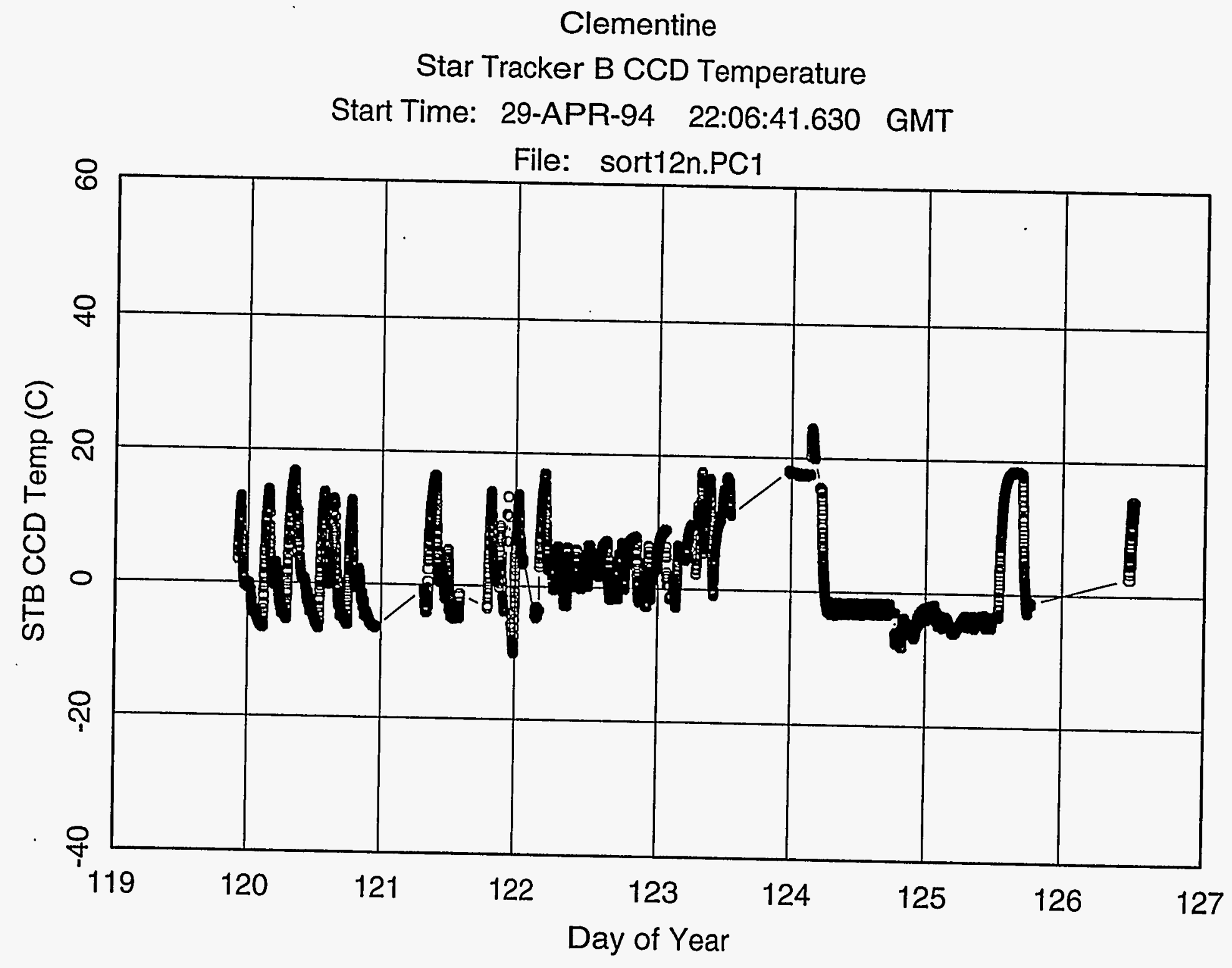

REP/LLNL created: Wed May 11 12:01:37 PDT 1994 


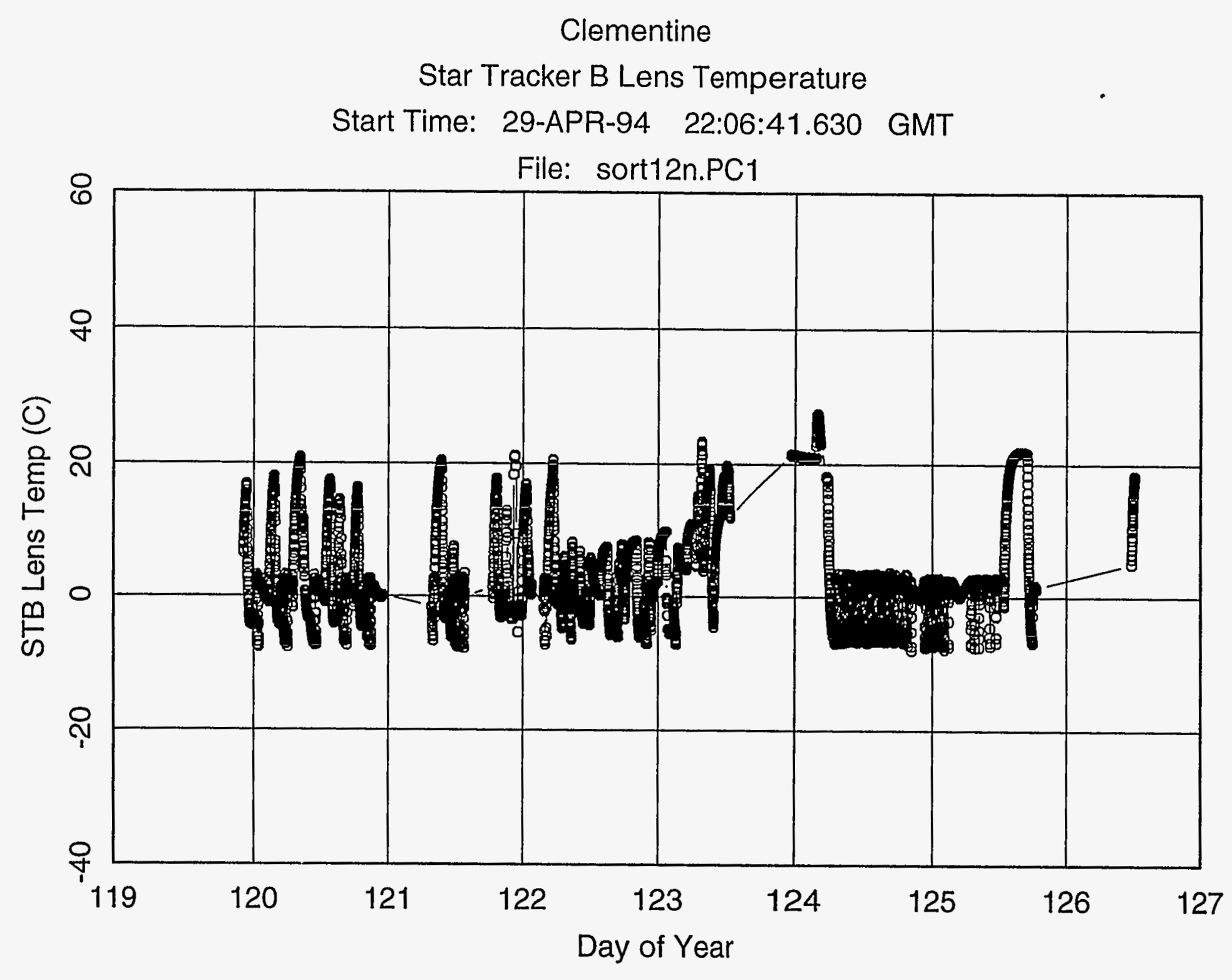

REP/LLNL created: Wed May 11 12:02:14 PDT 1994 


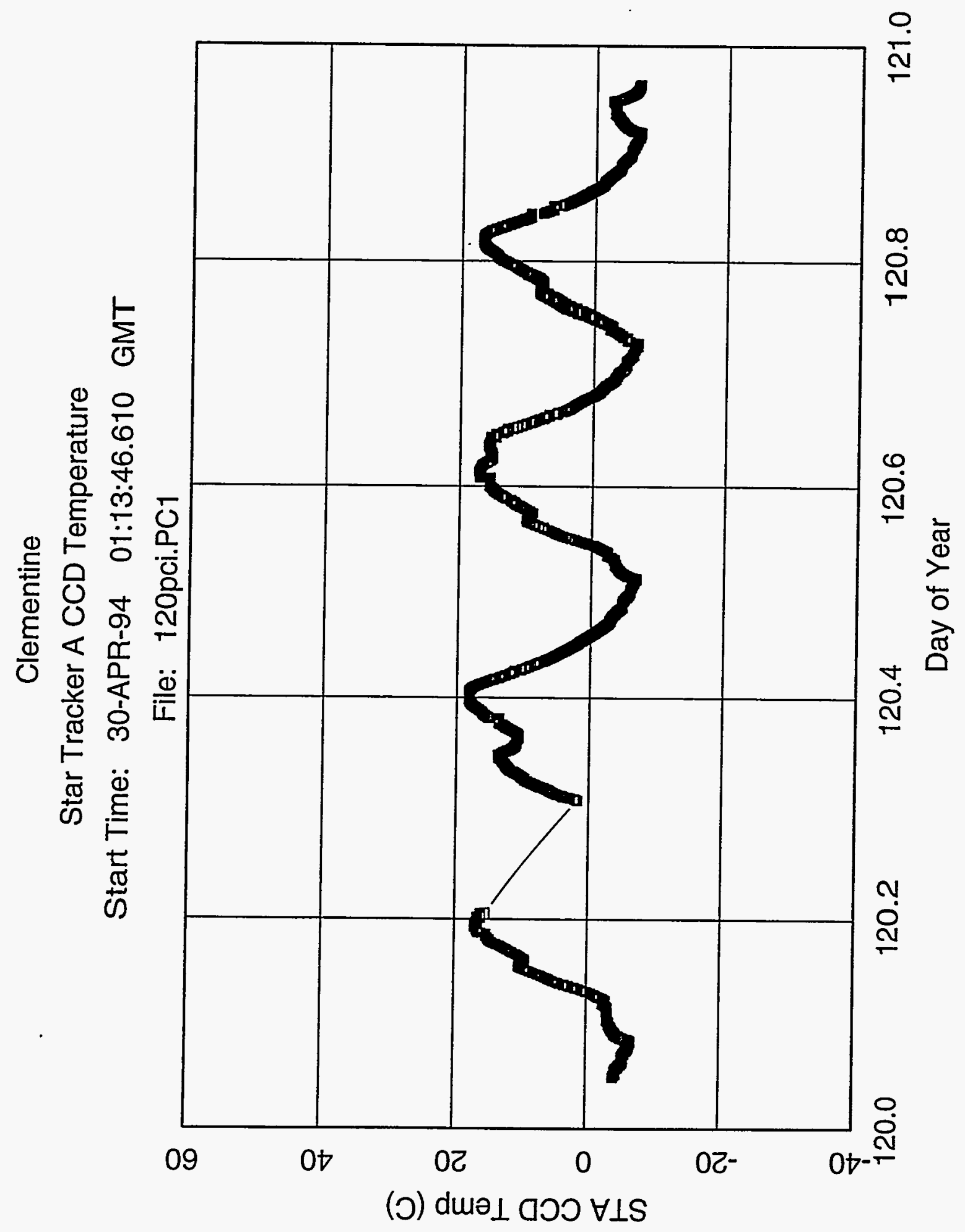

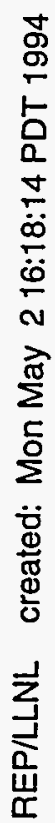




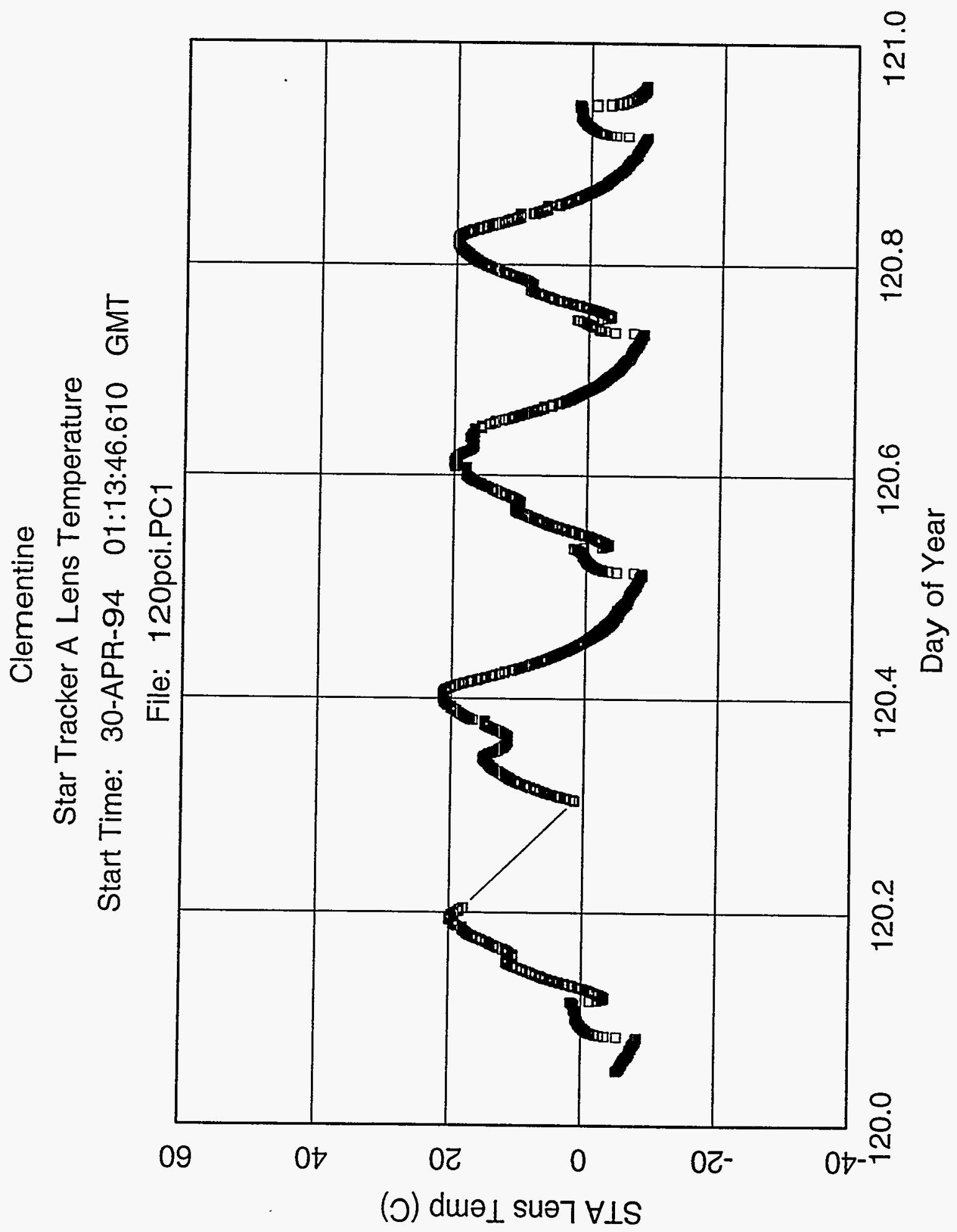

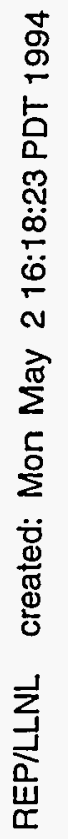




\section{Clementine}

Star Tracker B CCD Temperature

Start Time: $30-A P R-94 \quad$ 01:13:46.610 GMT

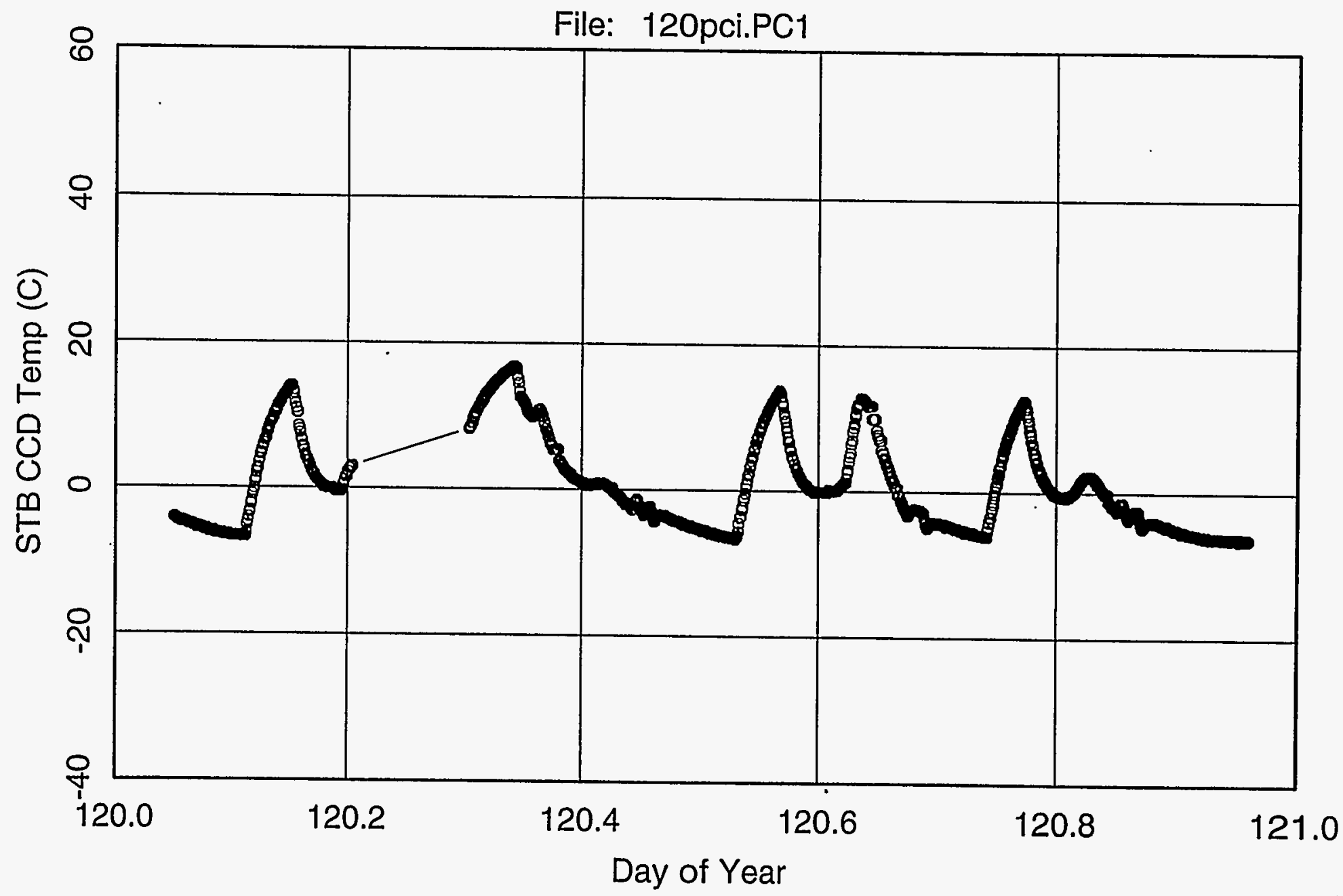




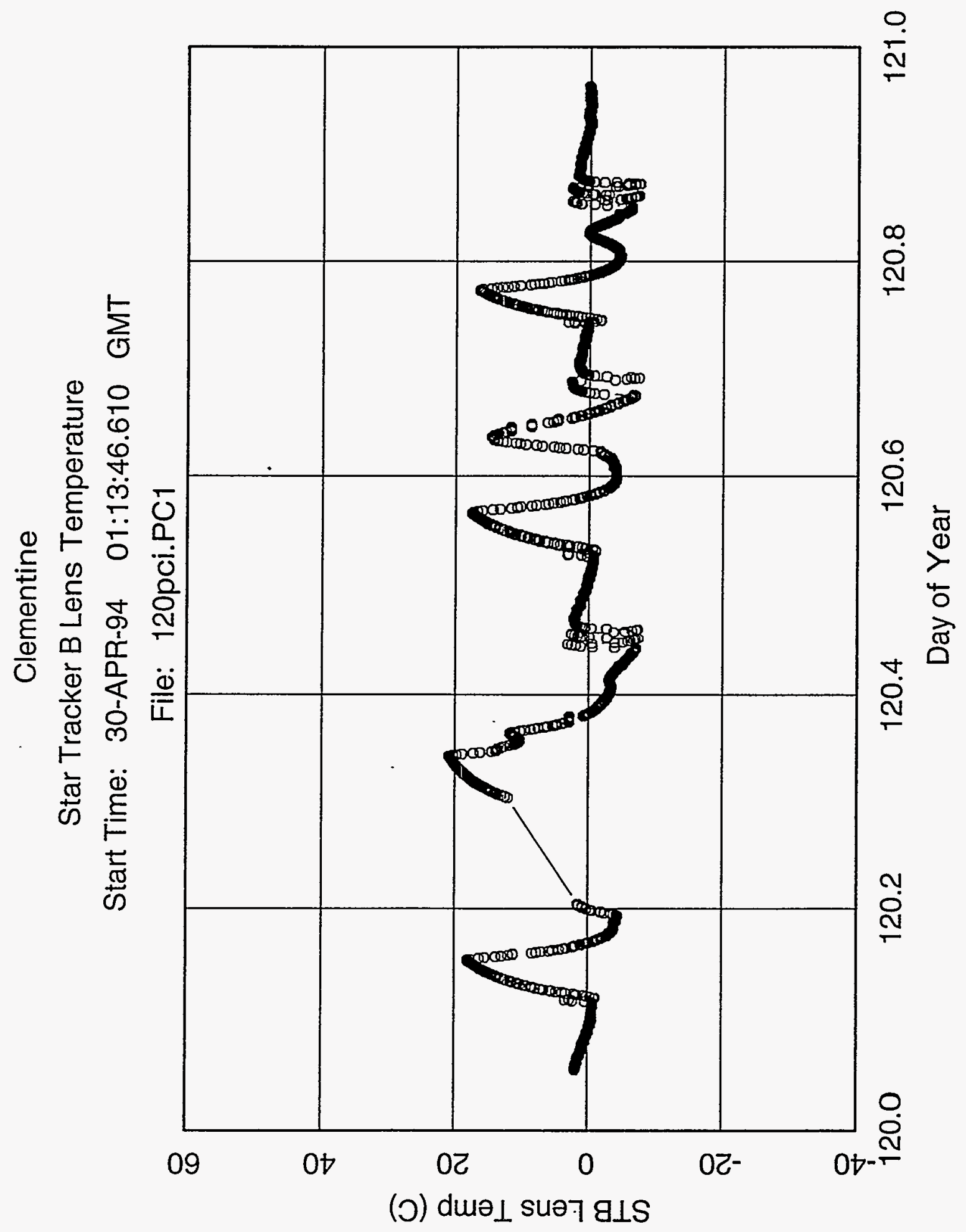

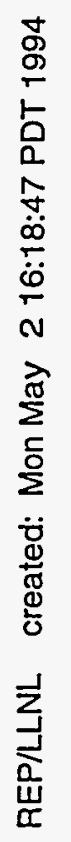




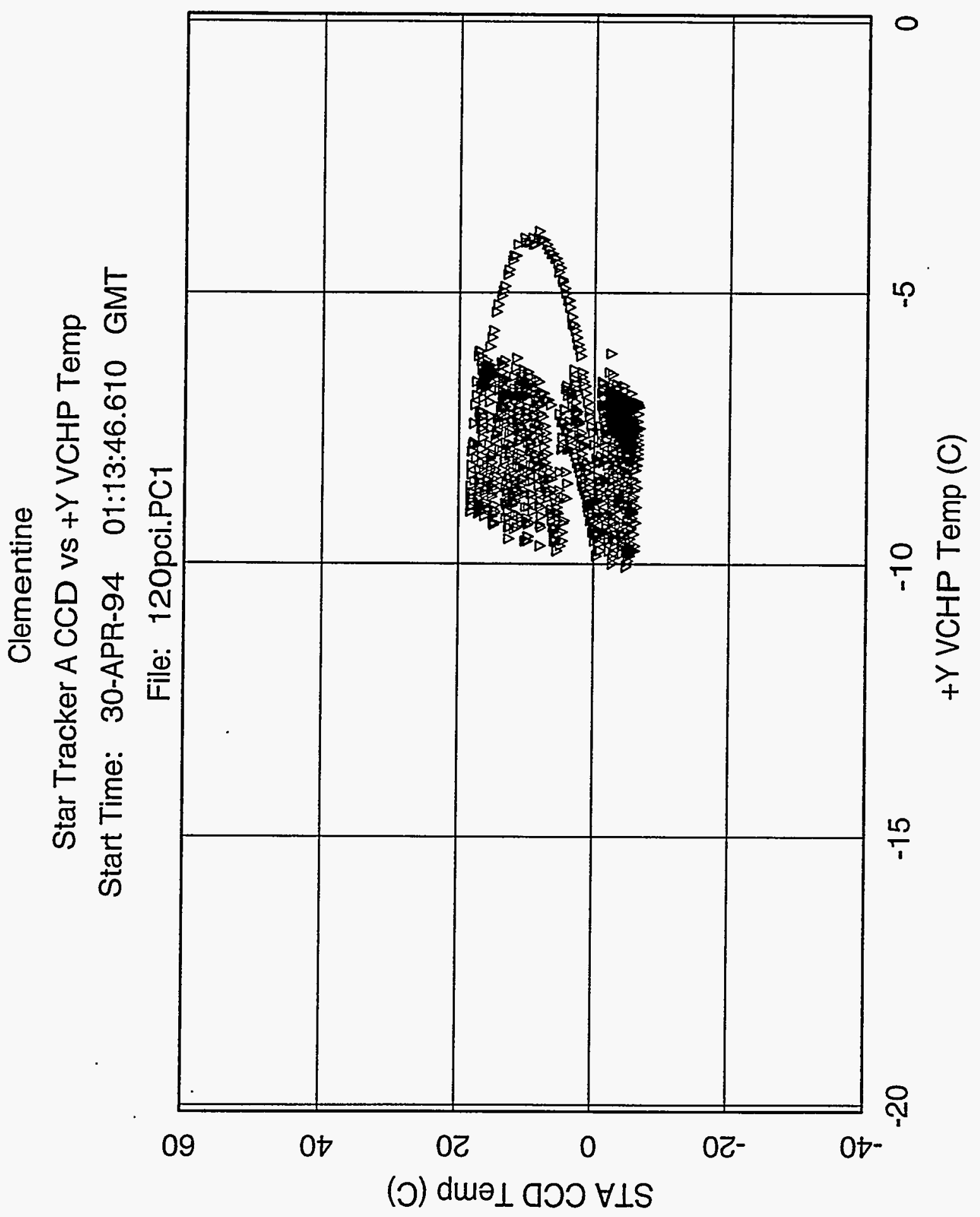

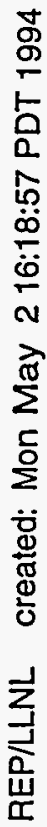




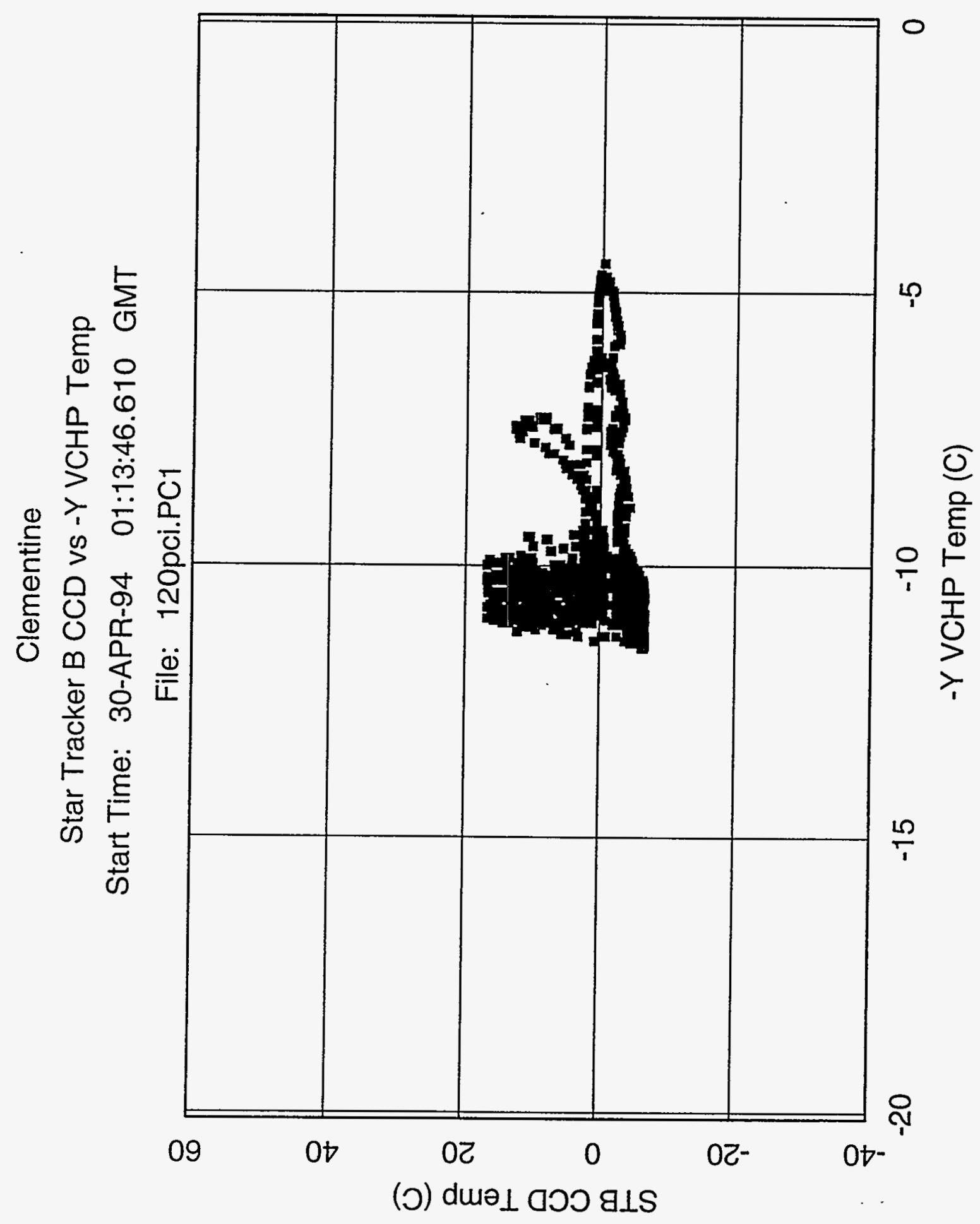

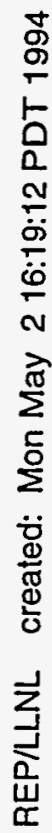


S-16

$110-119$ 


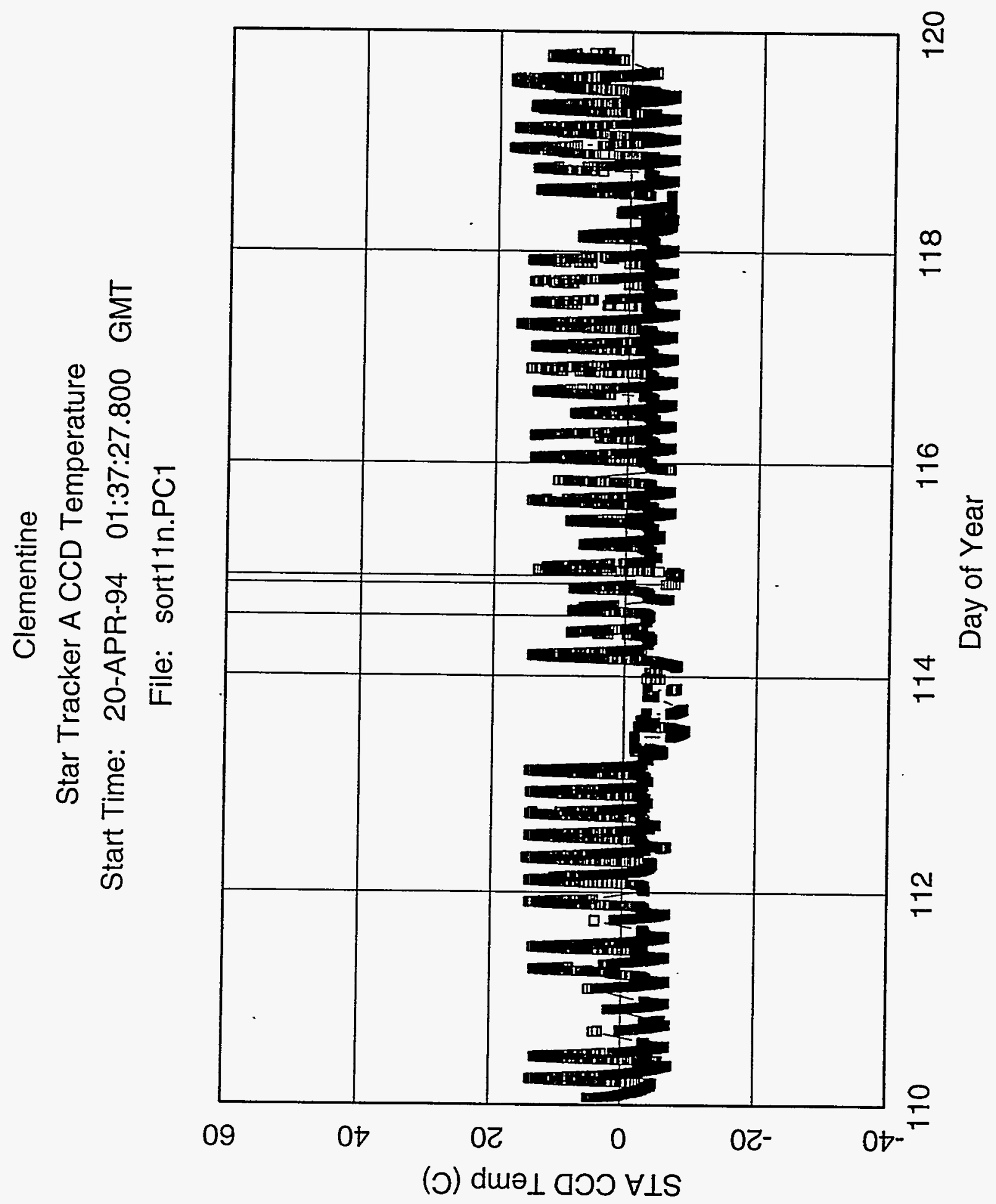

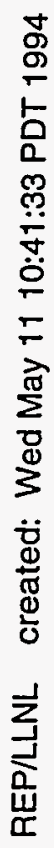




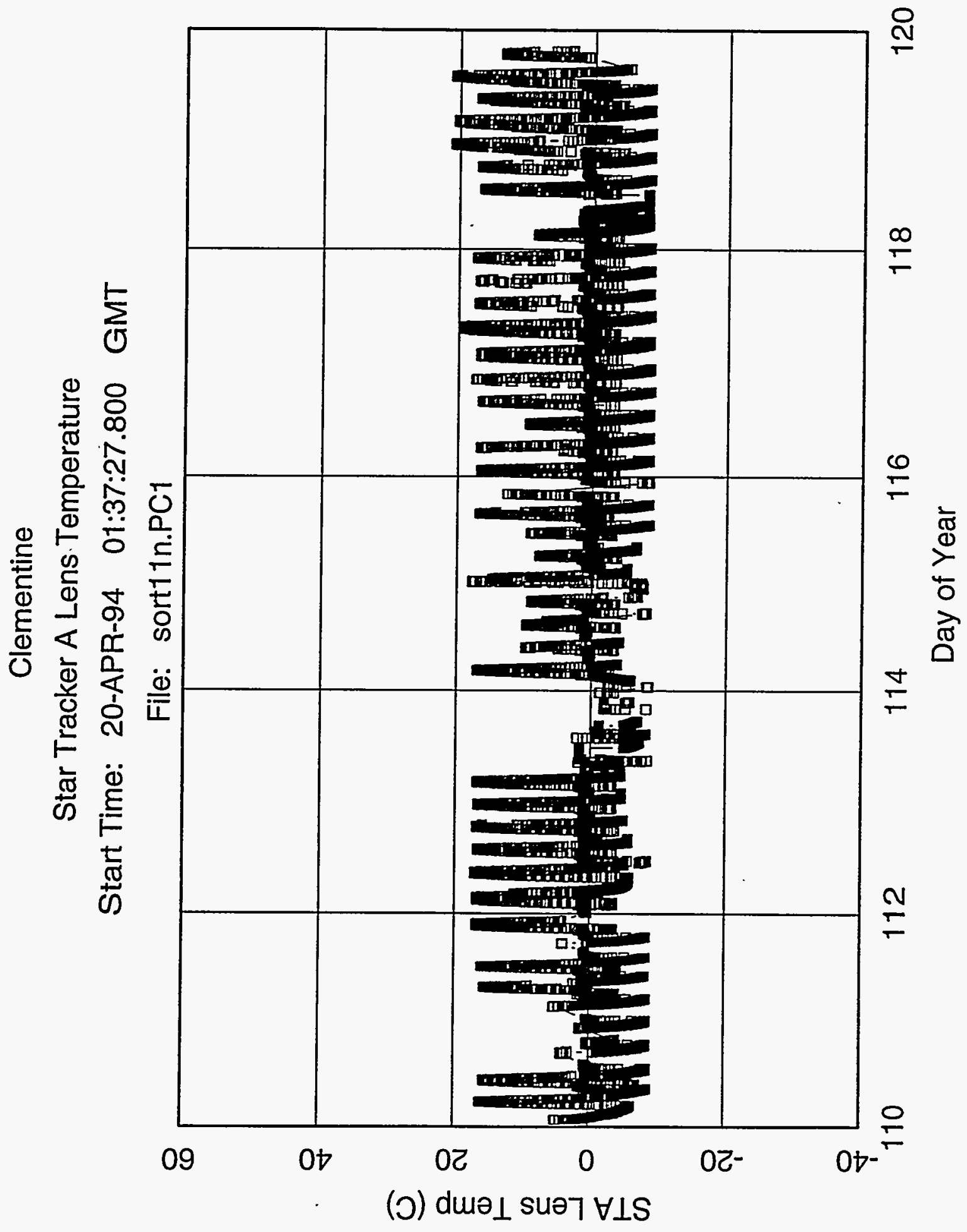

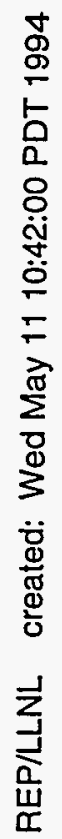




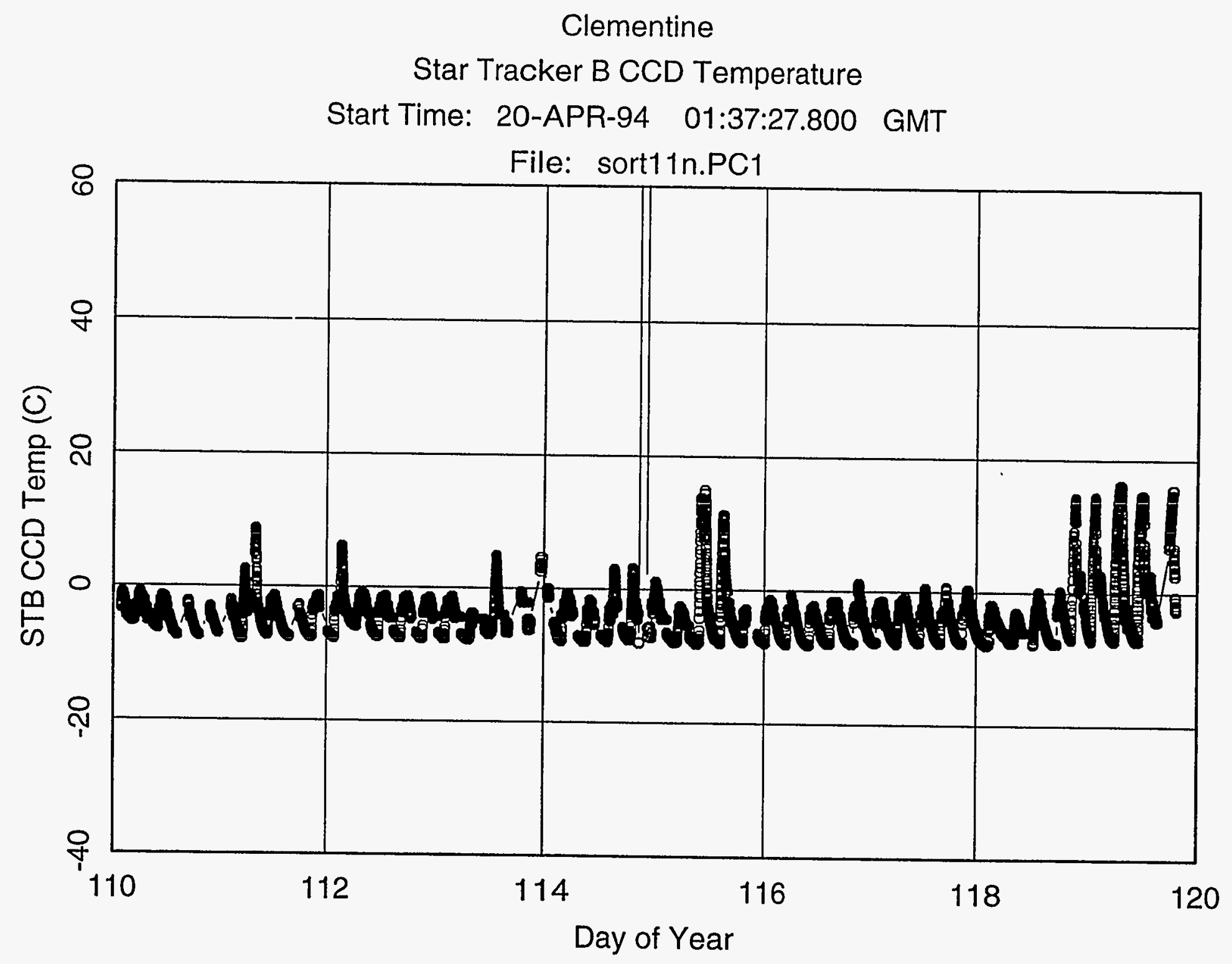

REP/LLNL created: Wed May 11 10:42:25 PDT 1994 


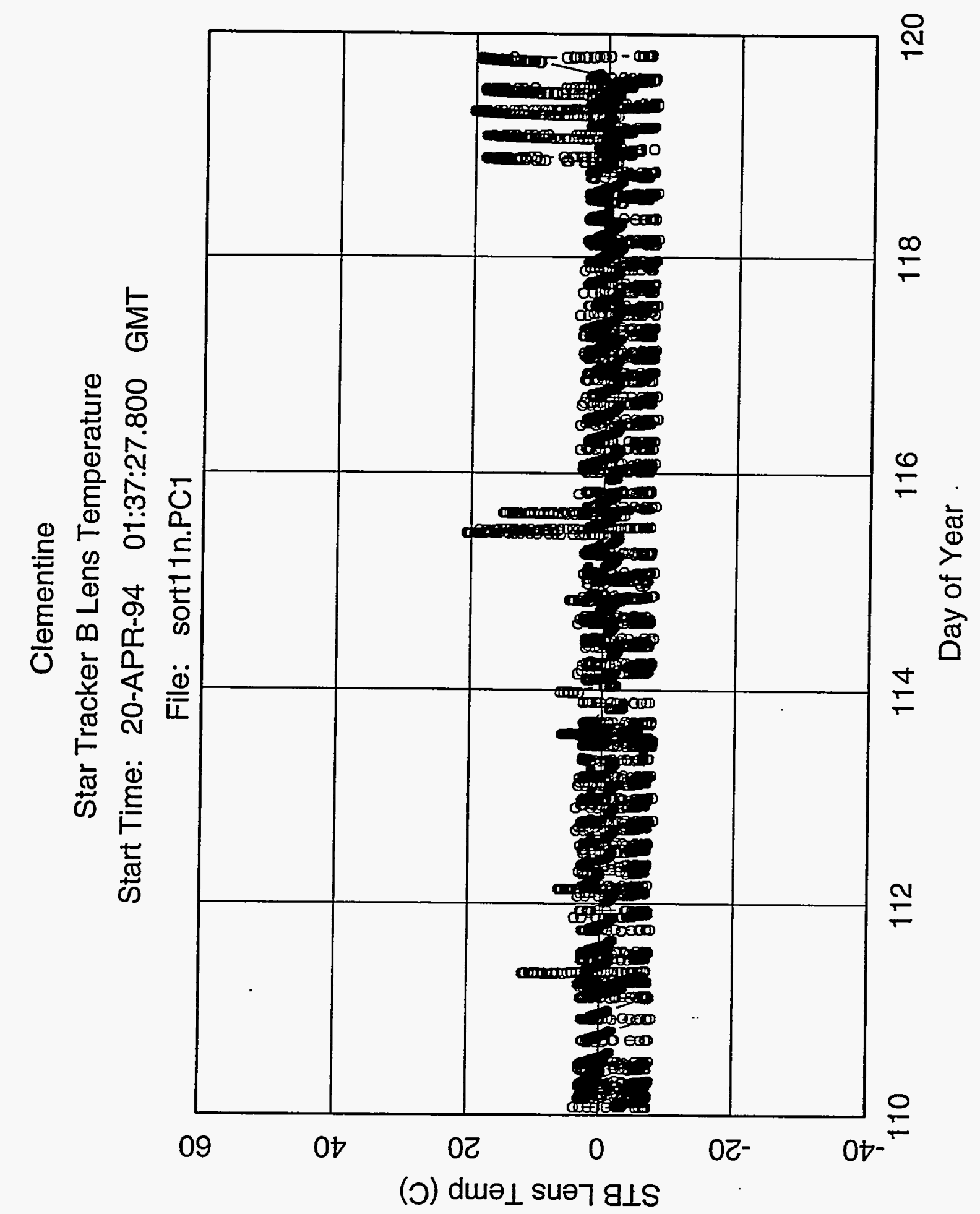

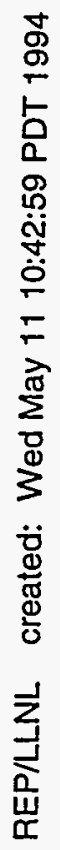




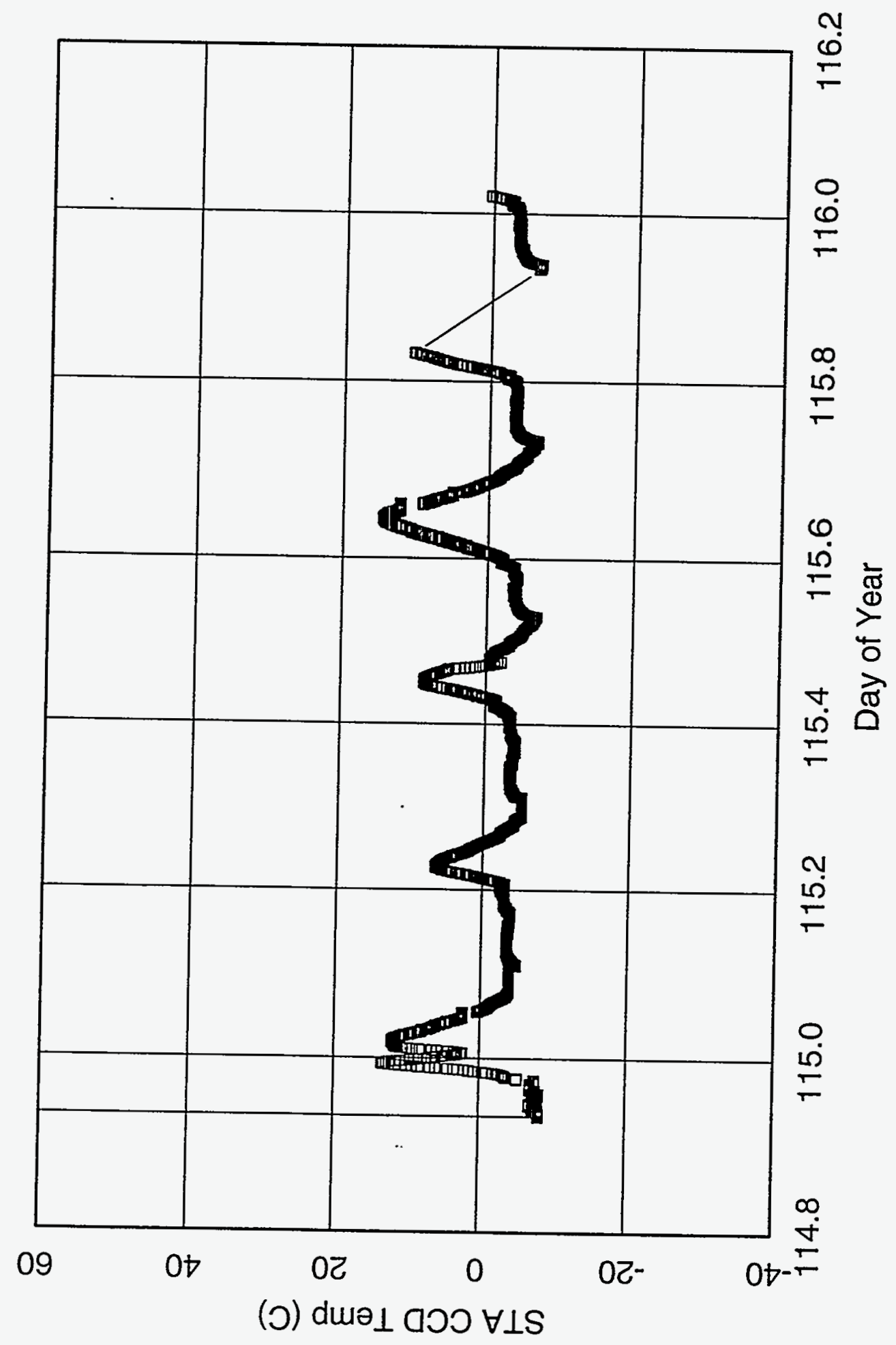

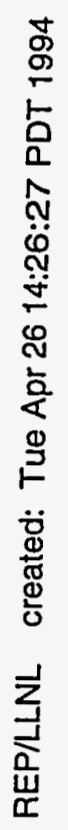




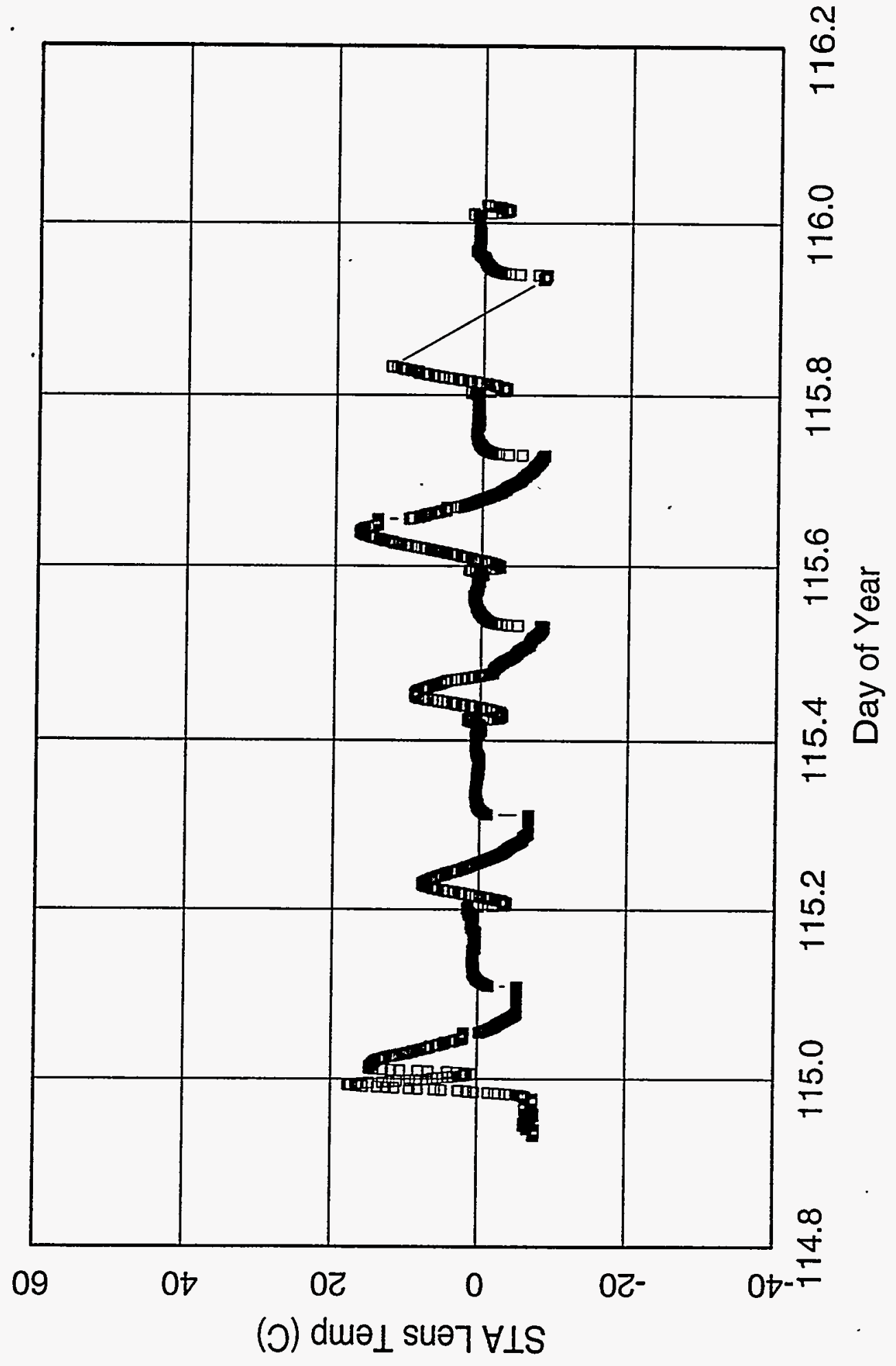




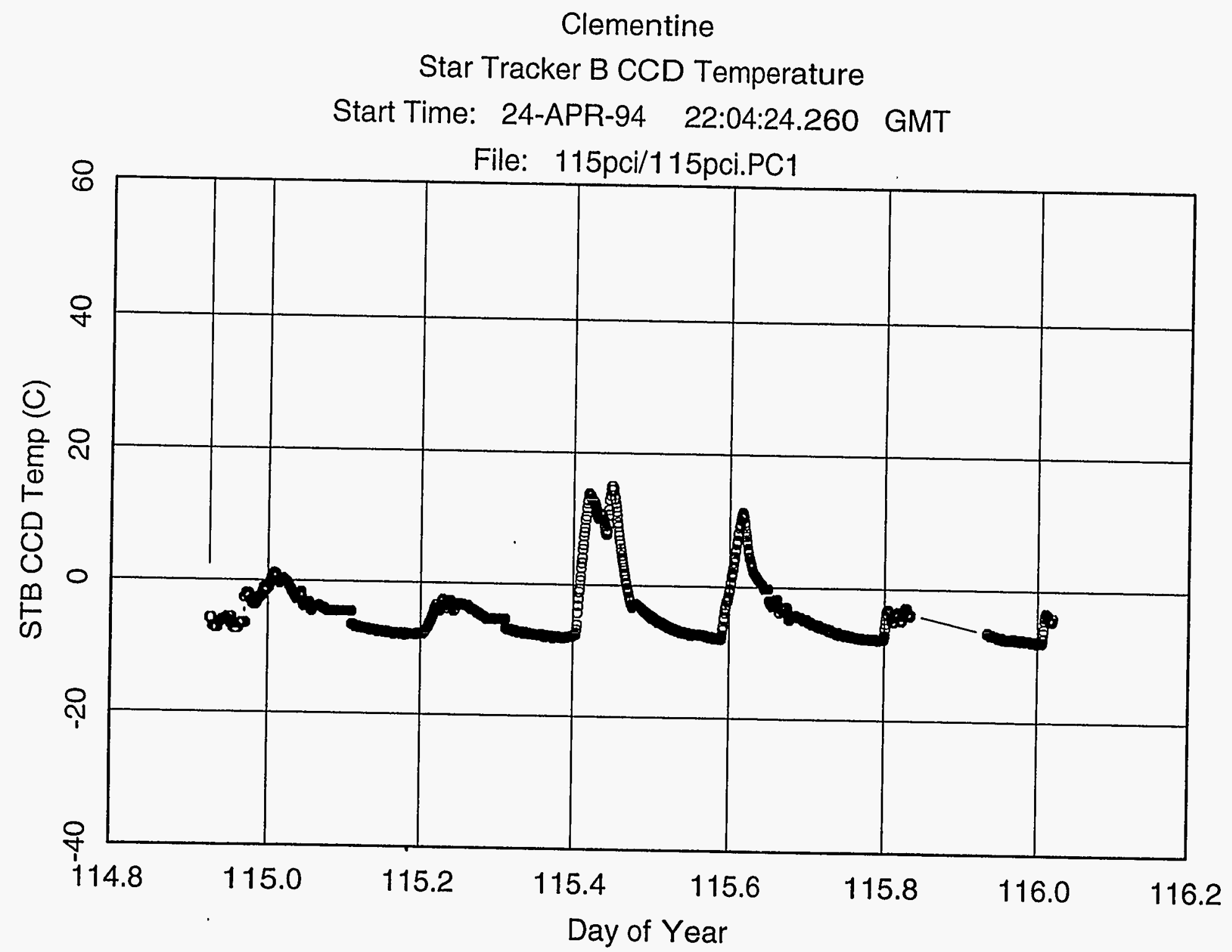

REP/LLNL created: Tue Apr 26 14:26:35 PDT 1994 
S-16

$100-109$ 
Clementine

Star Tracker B Lens Temperature

Start Time: 24-APR-94 22:04:24.260 GMT

File: $115 \mathrm{pci} / 115 \mathrm{pci} . \mathrm{PC} 1$

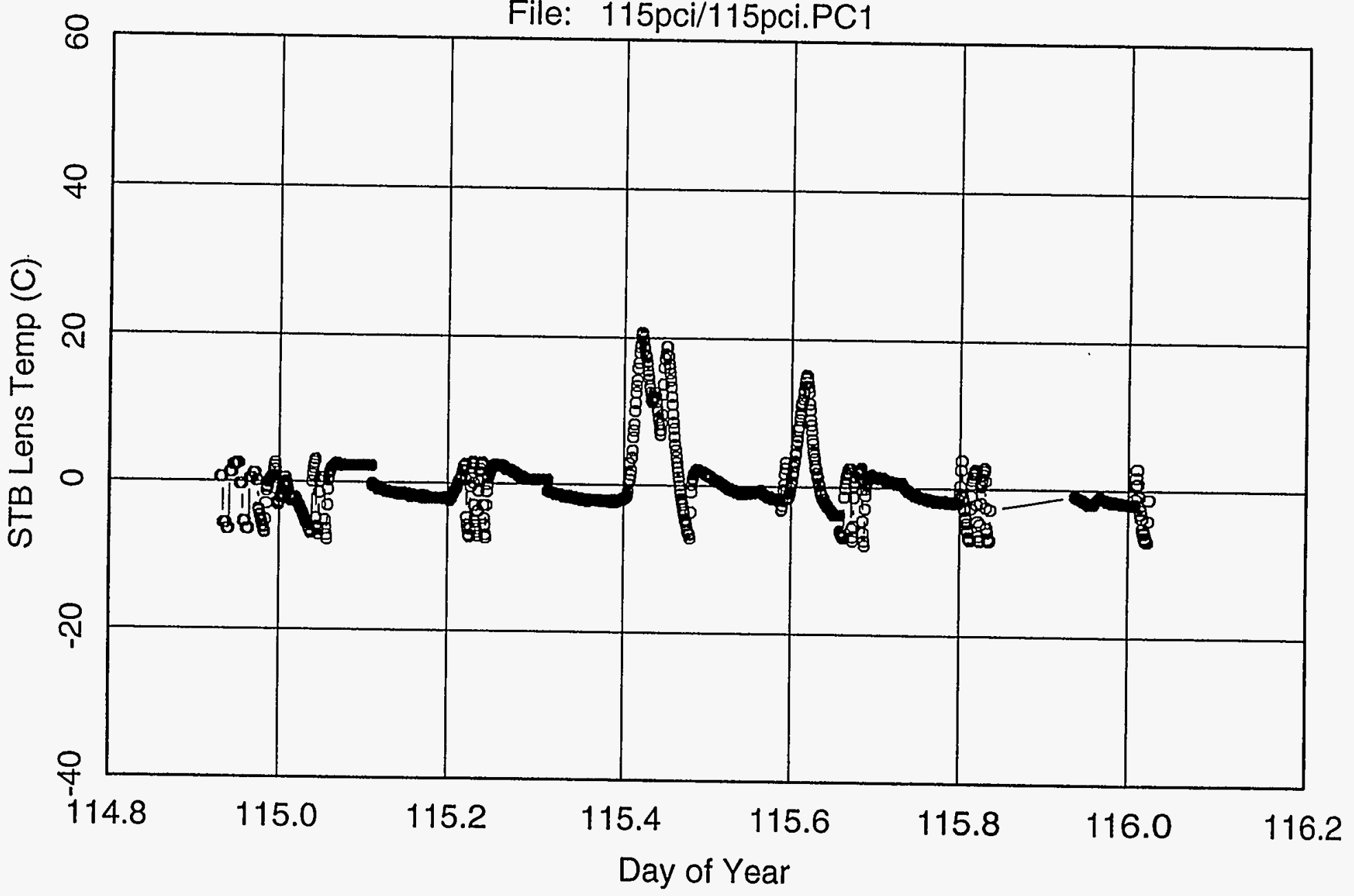

REP/LLNL created: Tue Apr 26 14:26:40 PDT 1994 
Clementine

Star Tracker A CCD Temperature

Start Time: $10-A P R-94 \quad$ 06:21:50.500 GMT

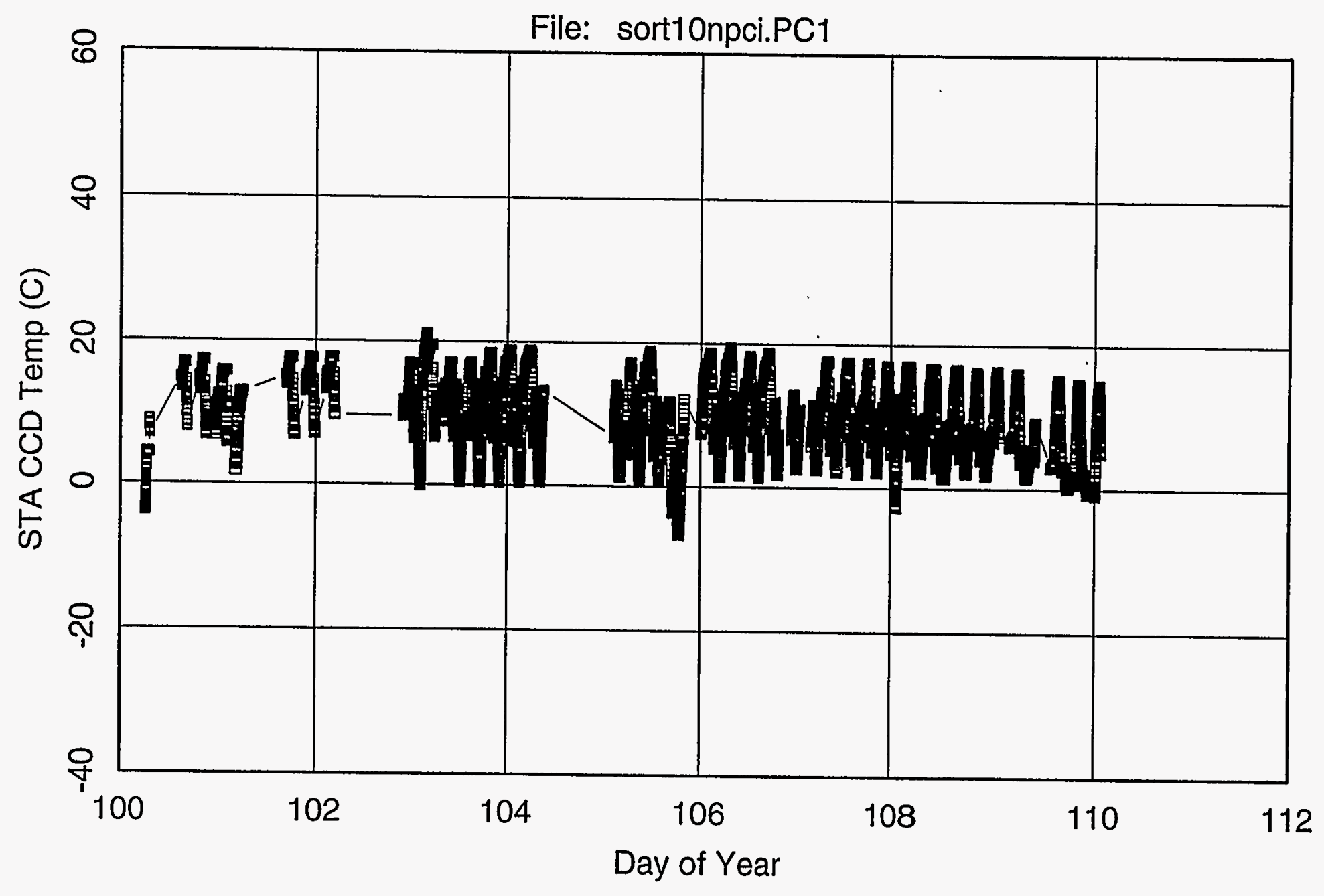


Clementine

Star Tracker A Lens Temperature

Start Time: $10-A P R-94 \quad$ 06:21:50.500 GMT

File: sort10npci.PC1

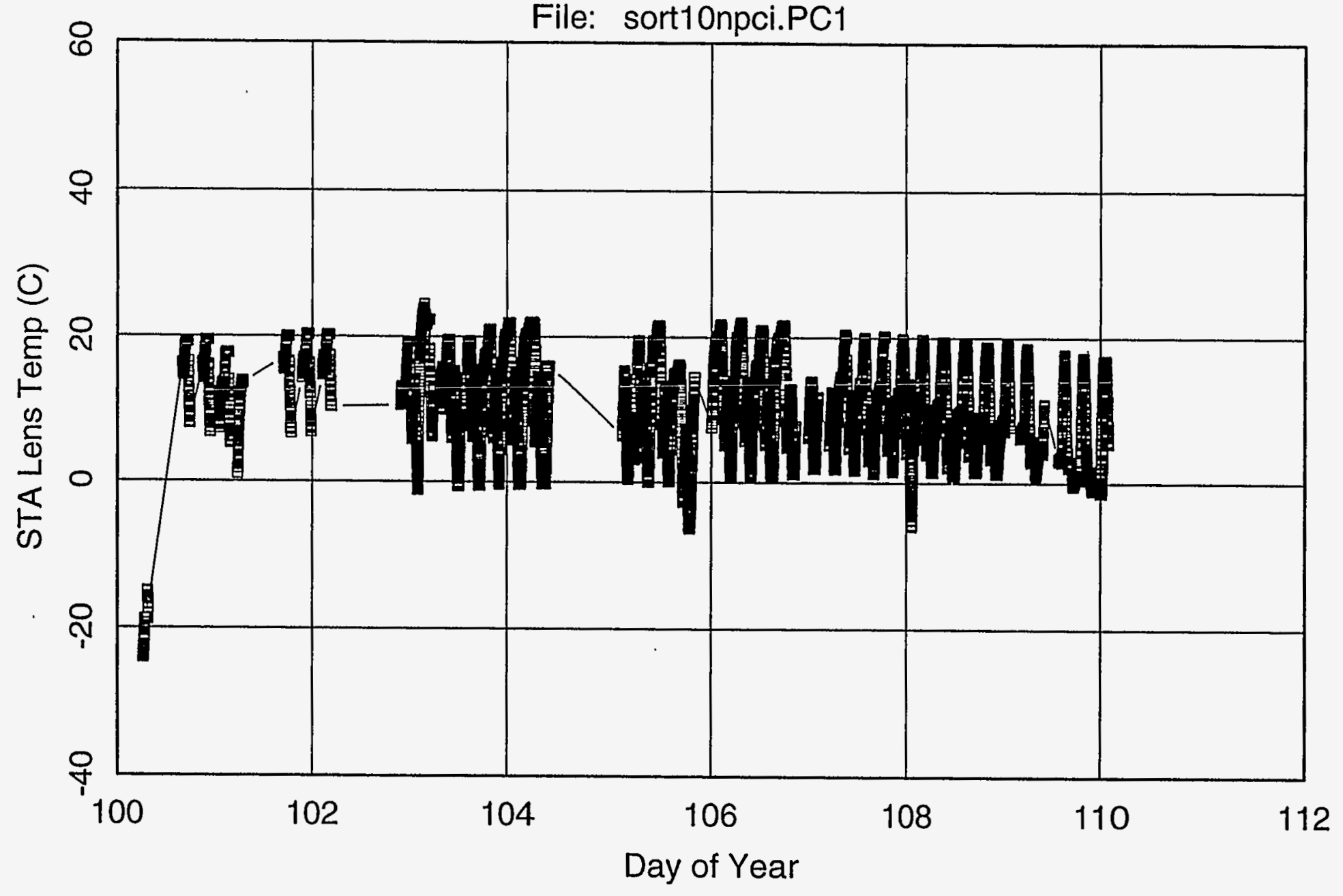

REP/LLNL created: Mon Apr 25 10:33:48 PDT 1994 


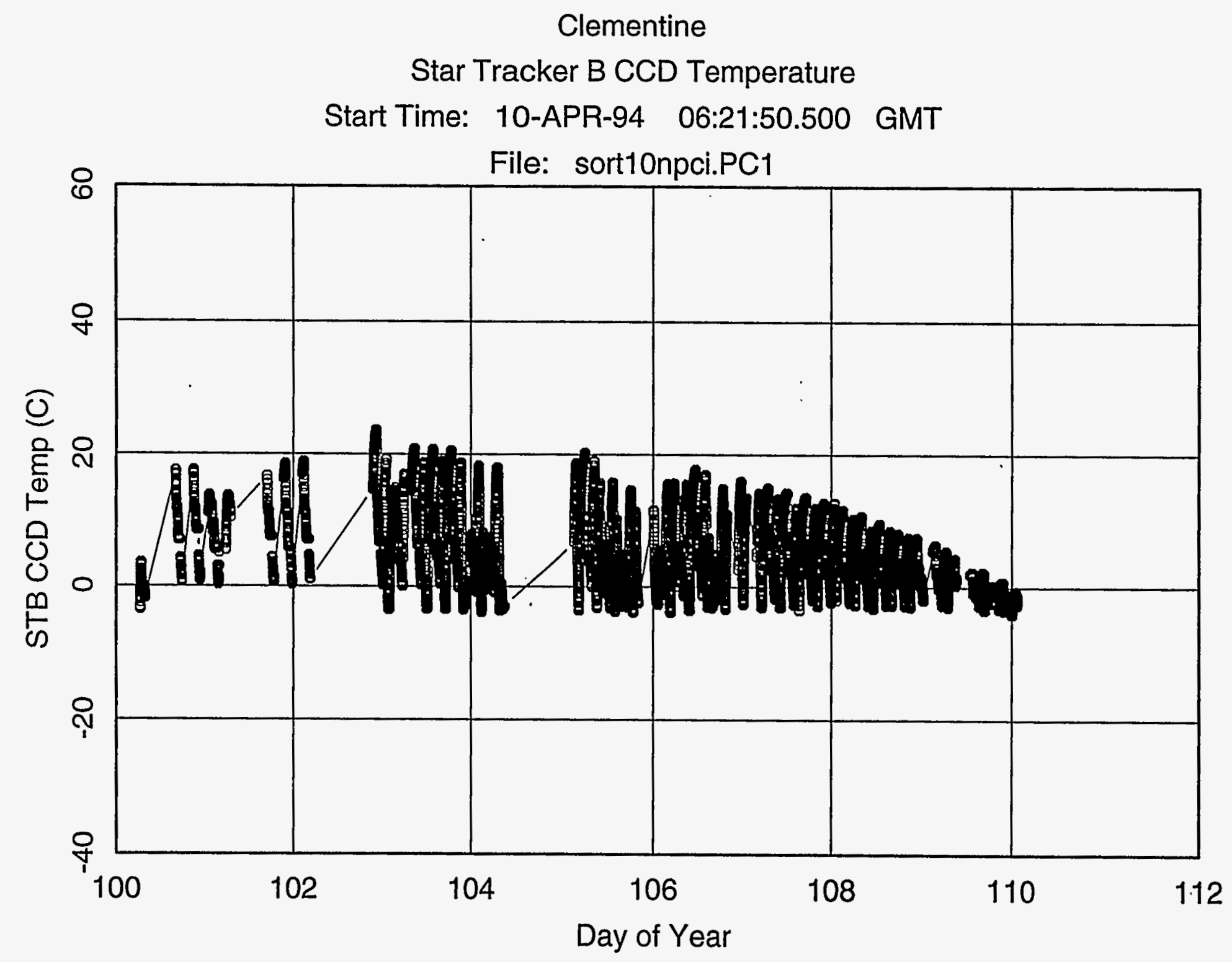

REP/LLNL created: Mon Apr 25 10:34:07 PDT 1994 


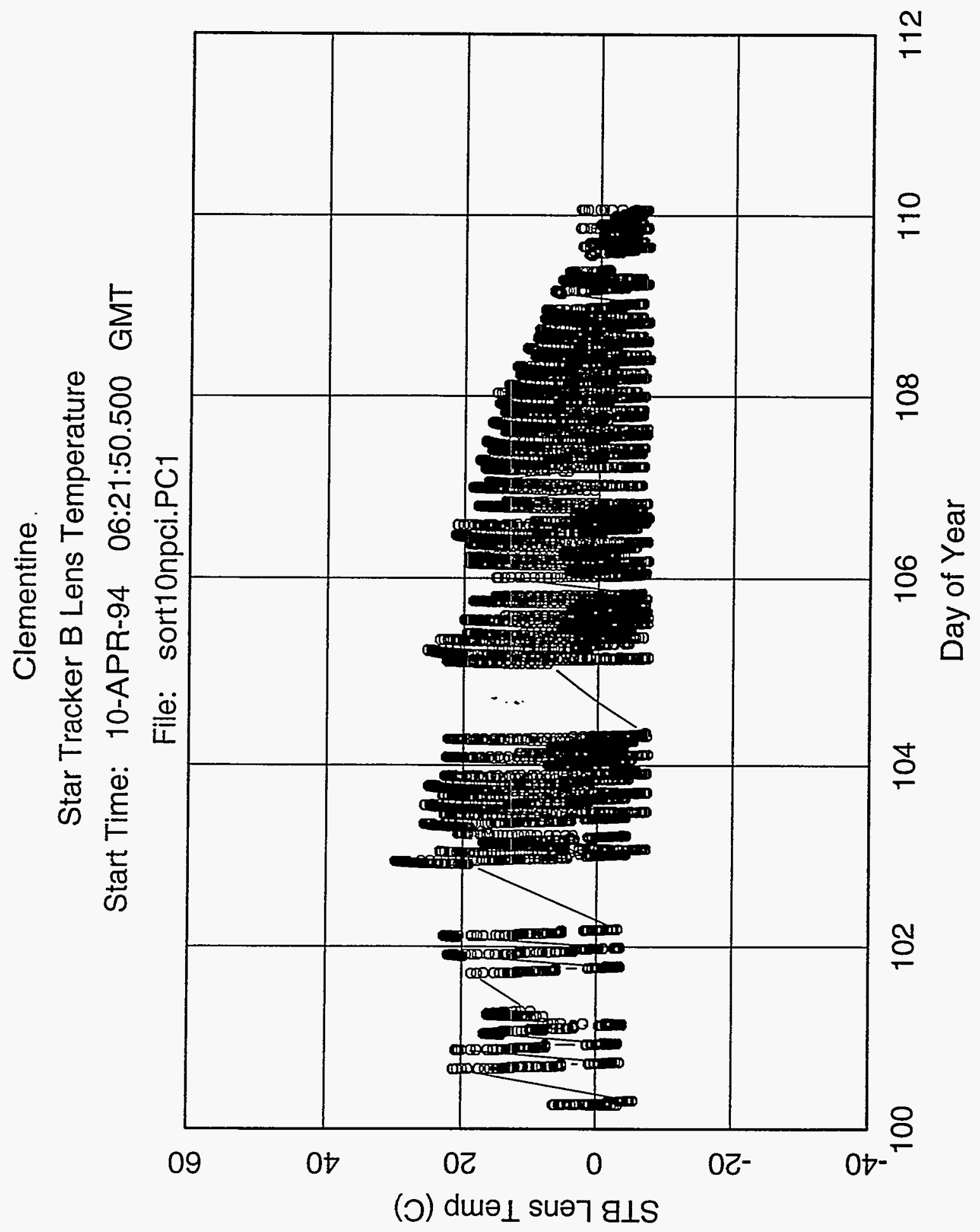

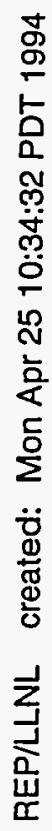




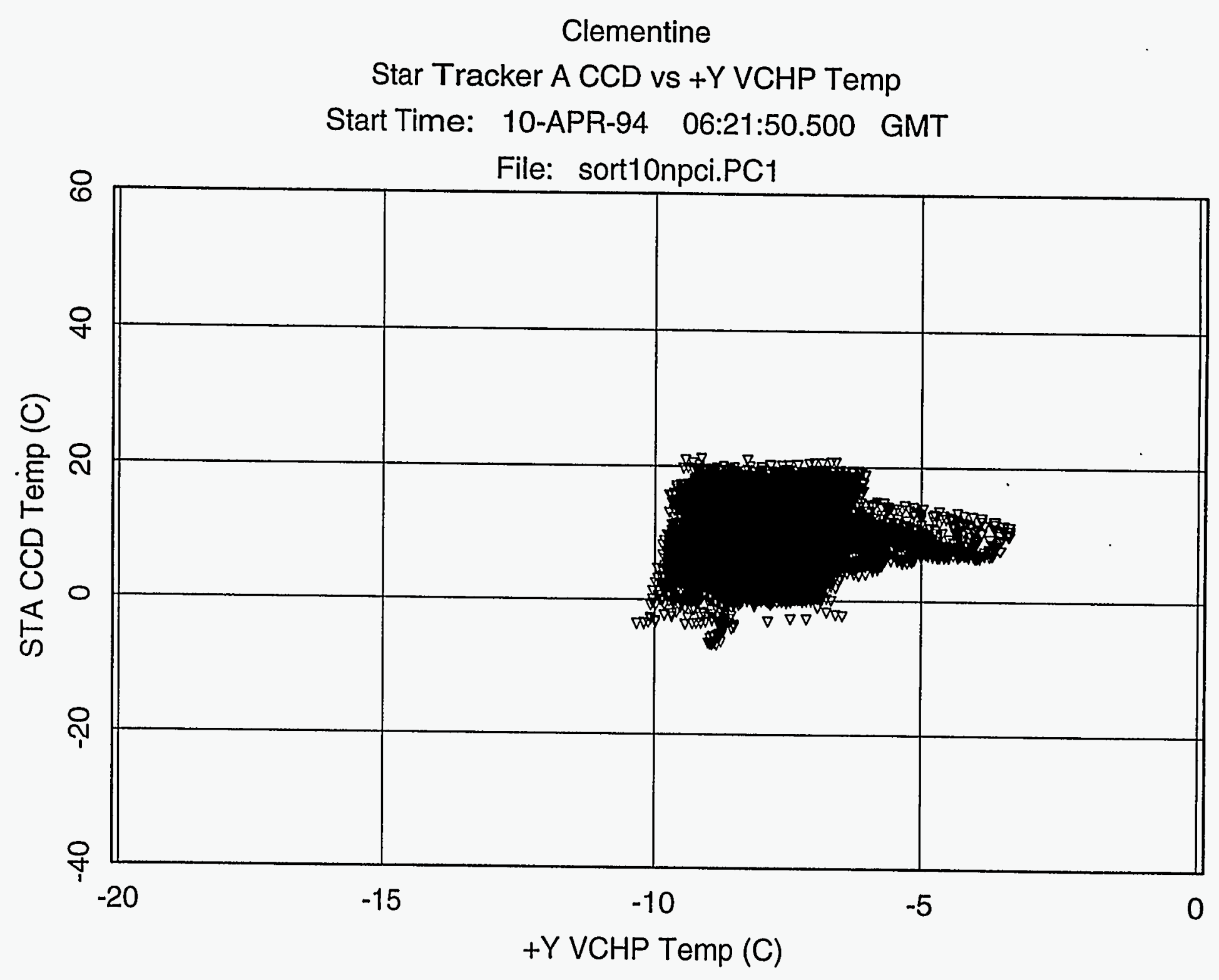

REP/LLNL created: Mon Apr 25 10:34:53 PDT 1994 
Clementine

Star Tracker B CCD vs -Y VCHP Temp

Start Time: 10 -APR-94 06:21:50.500 GMT

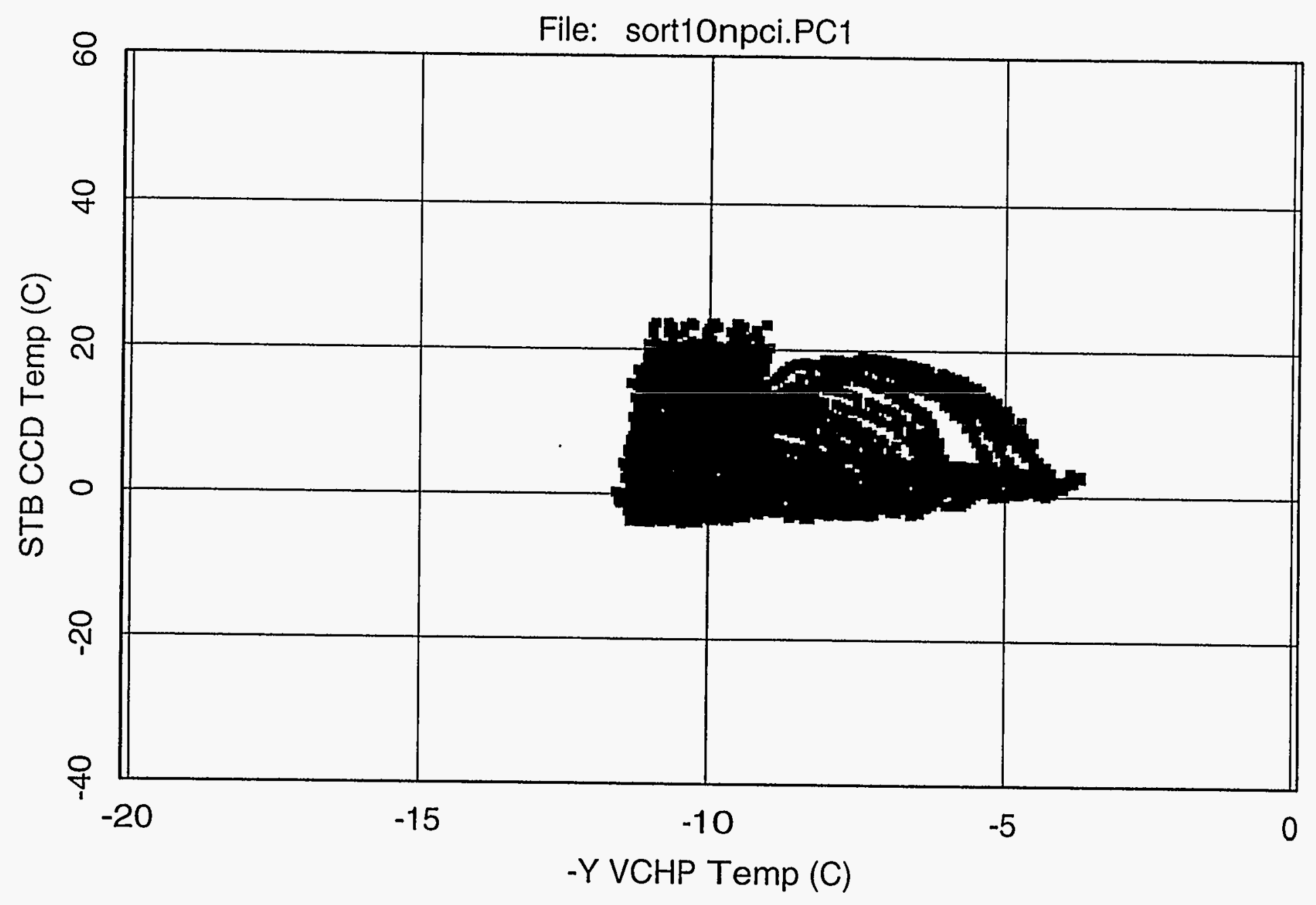

REP/LLNL created: Mon Apr 25 10:35:40 PDT 1994 


$$
\begin{gathered}
S-16 \\
90-99
\end{gathered}
$$


Clementine

Star Tracker A CCD Temperature

Start Time: 31-MAR-94 06:38:58.900 GMT

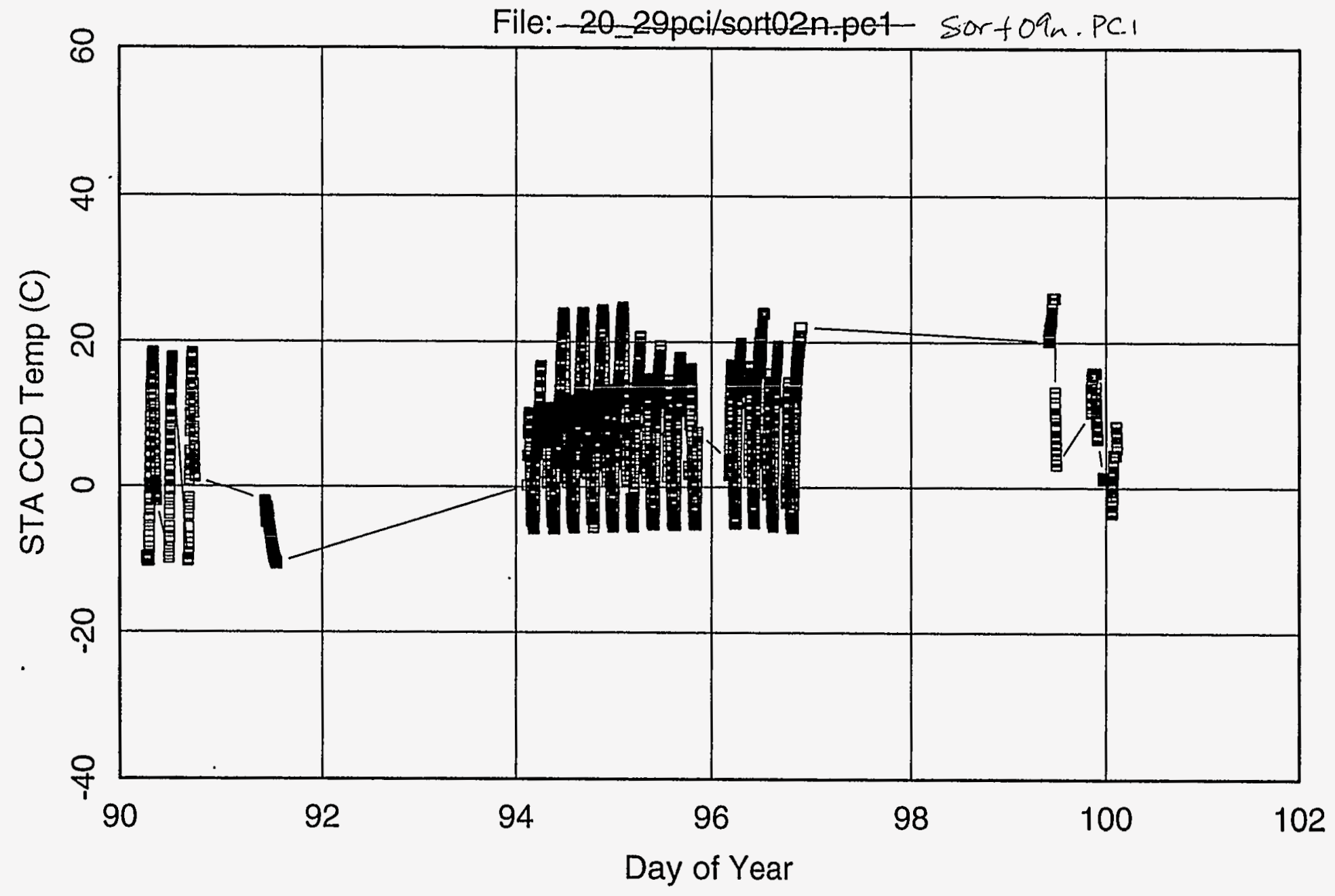

REP/LLNL created: Thu Apr 21 16:52:05 PDT 1994 


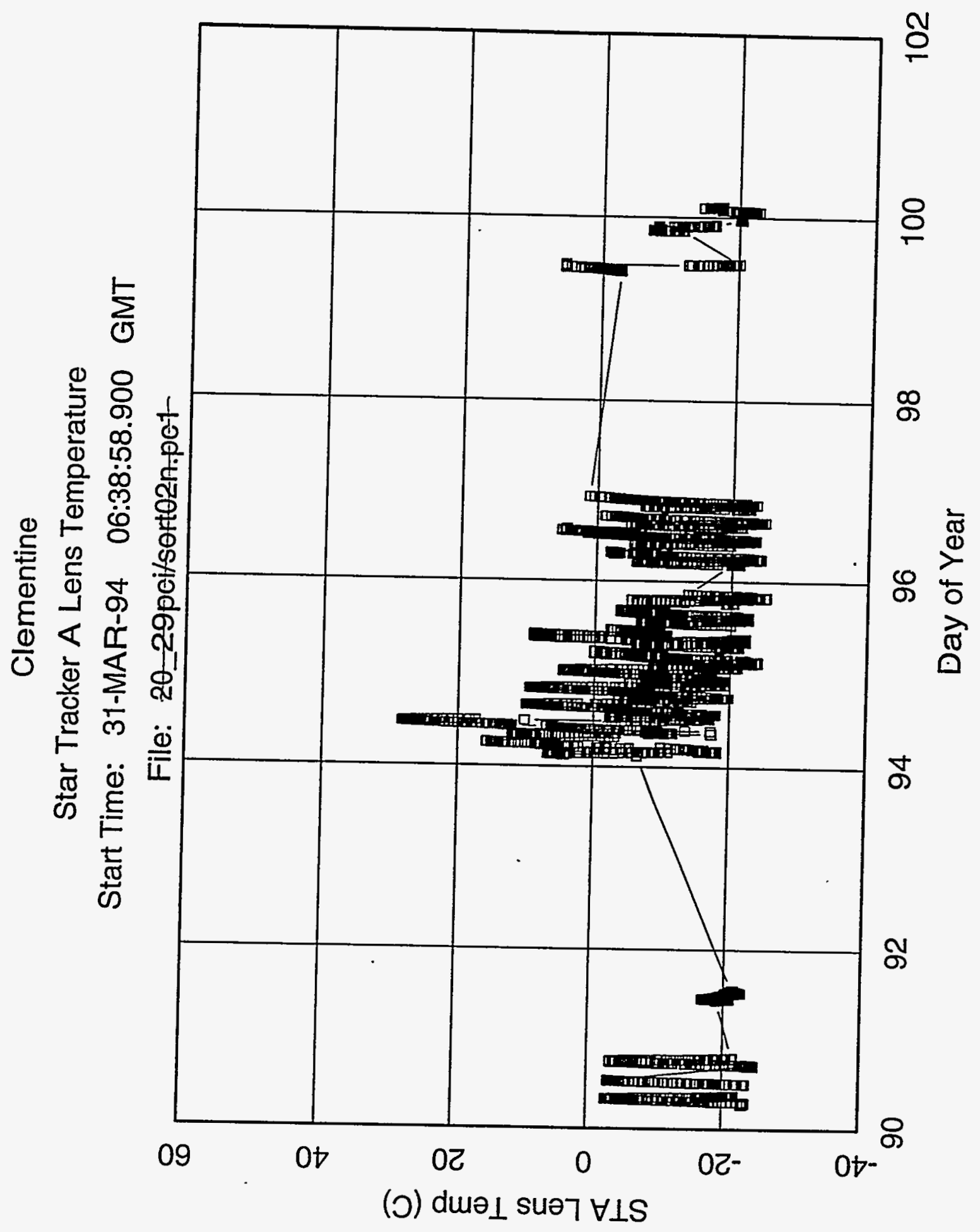

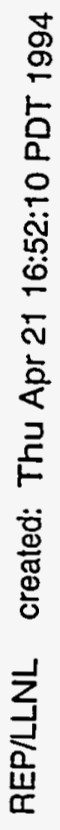


Clementine

Star Tracker B CCD Temperature

Start Time: 31-MAR-94 06:38:58.900 GMT

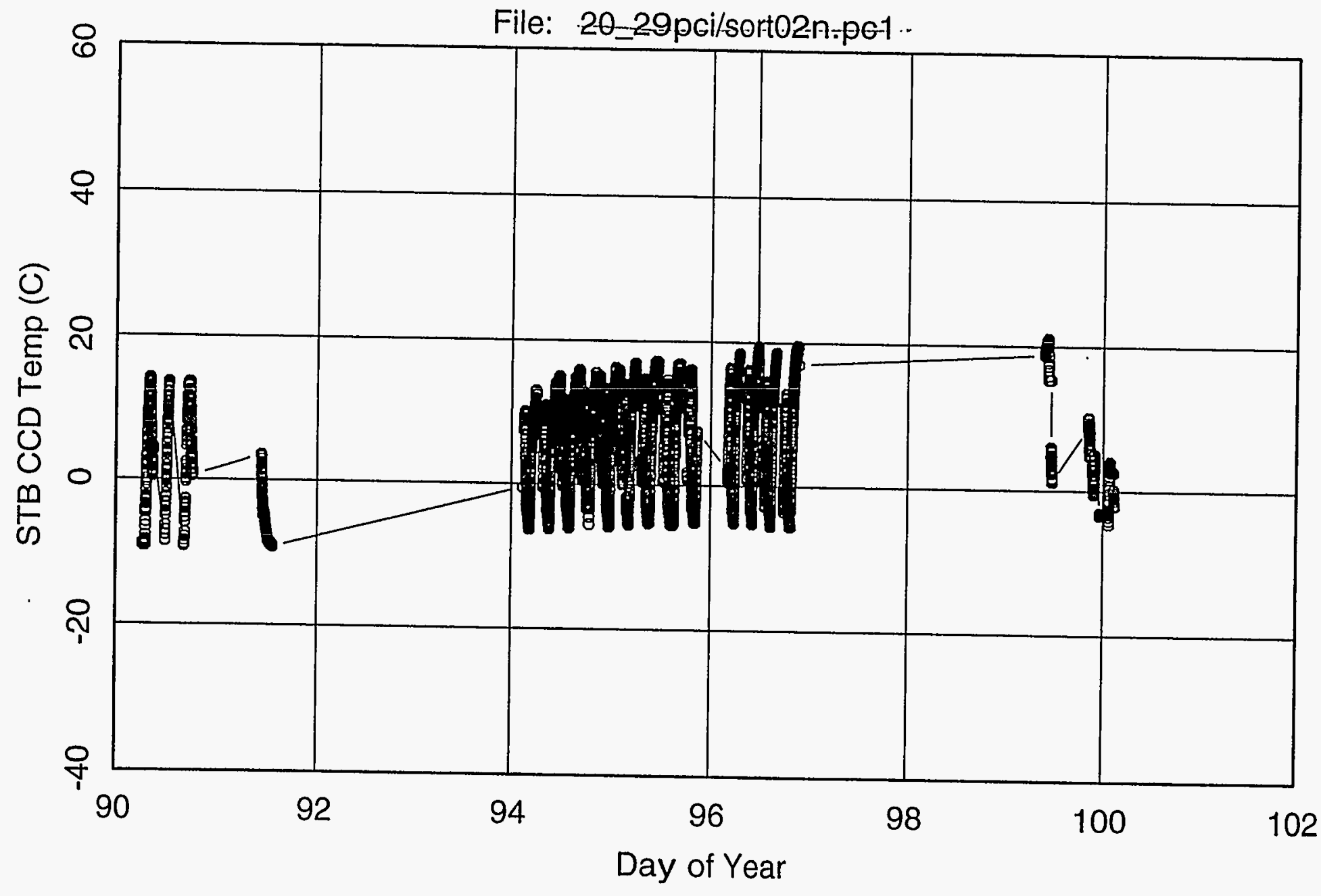

REP/LLNL created: Thu Apr 21 16:52:16 PDT 1994 


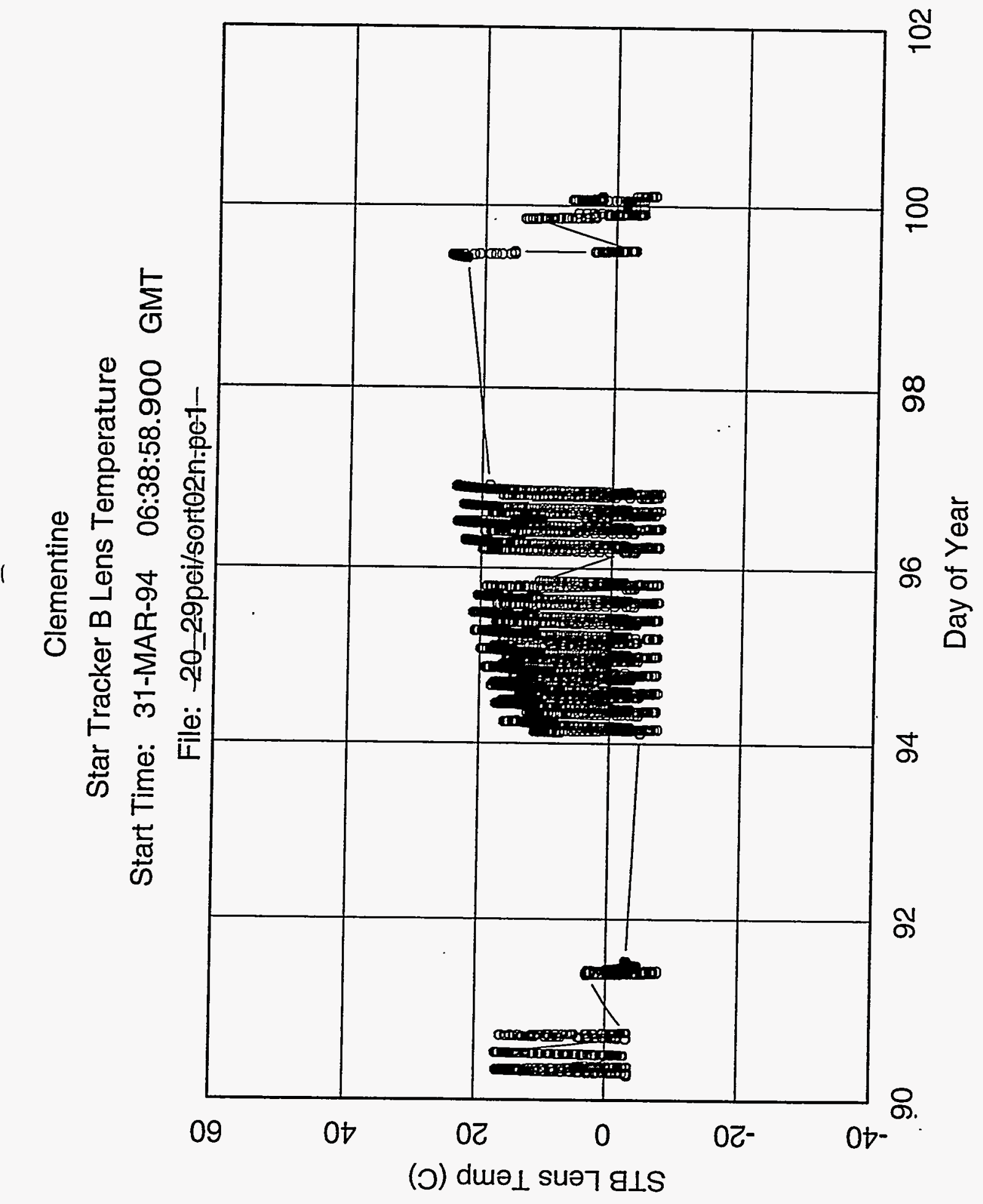

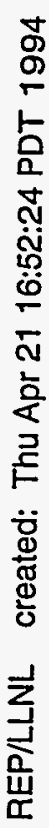




\section{Clementine}

Star Tracker A CCD Temperature

Start Time: 31-MAR-94 06:38:58.900 GMT

File: sort09n.PC1

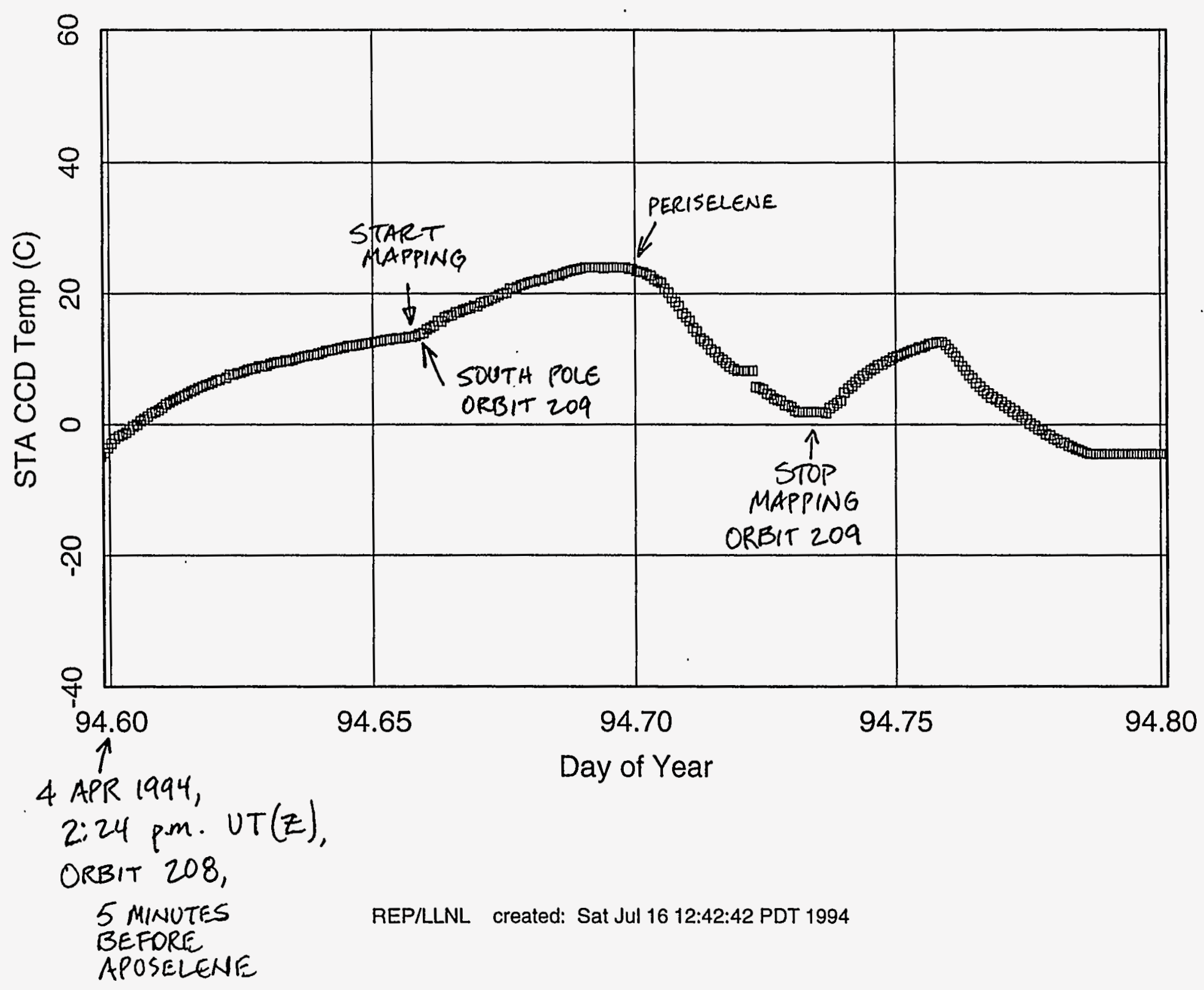




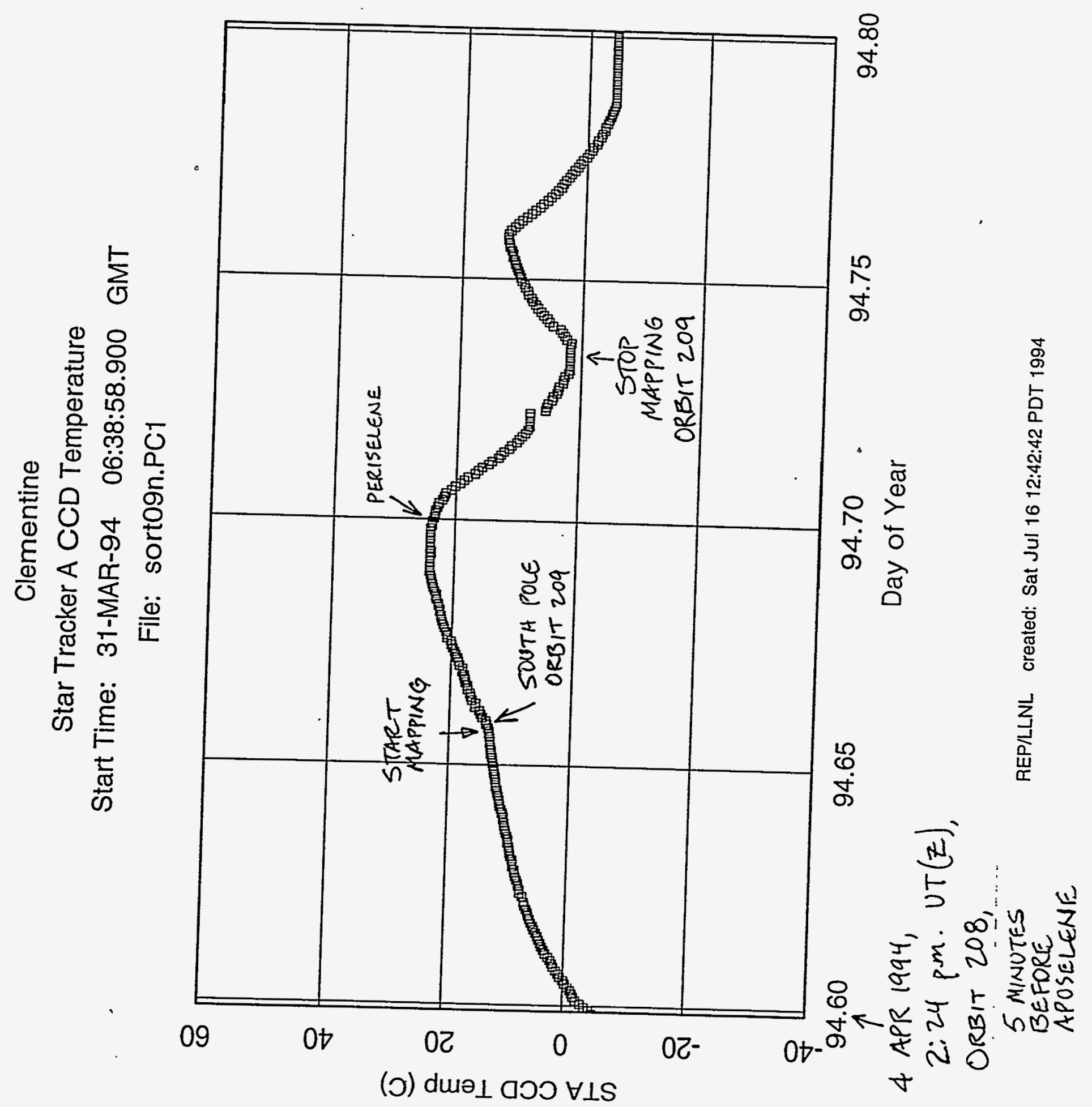




\section{Clementine}

Star Tracker A Lens Temperature

Start Time: $31-M A R-94 \quad$ 06:38:58.900 GMT

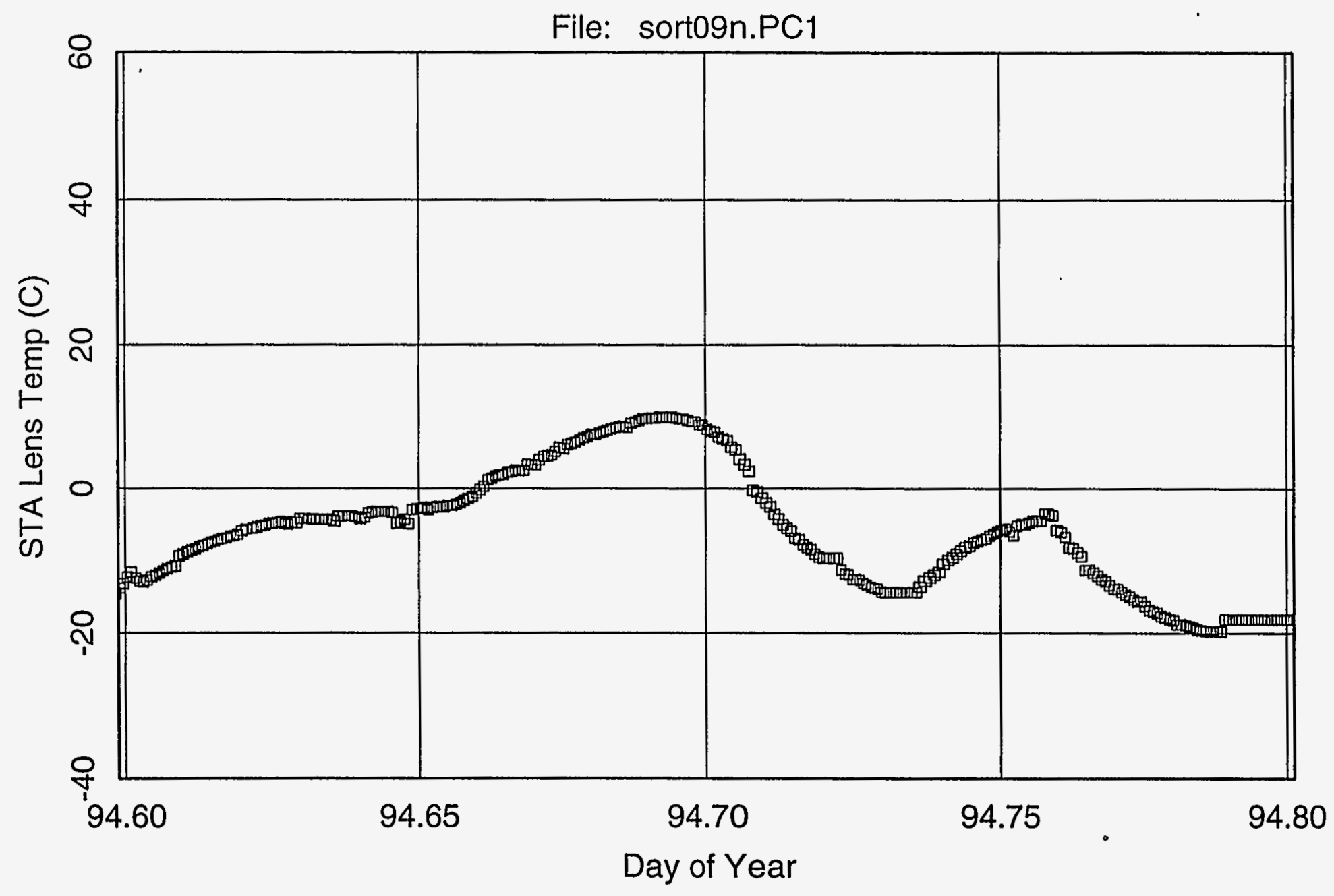

REP/LLNL created: Sat Jul 16 12:44:05 PDT 1994 


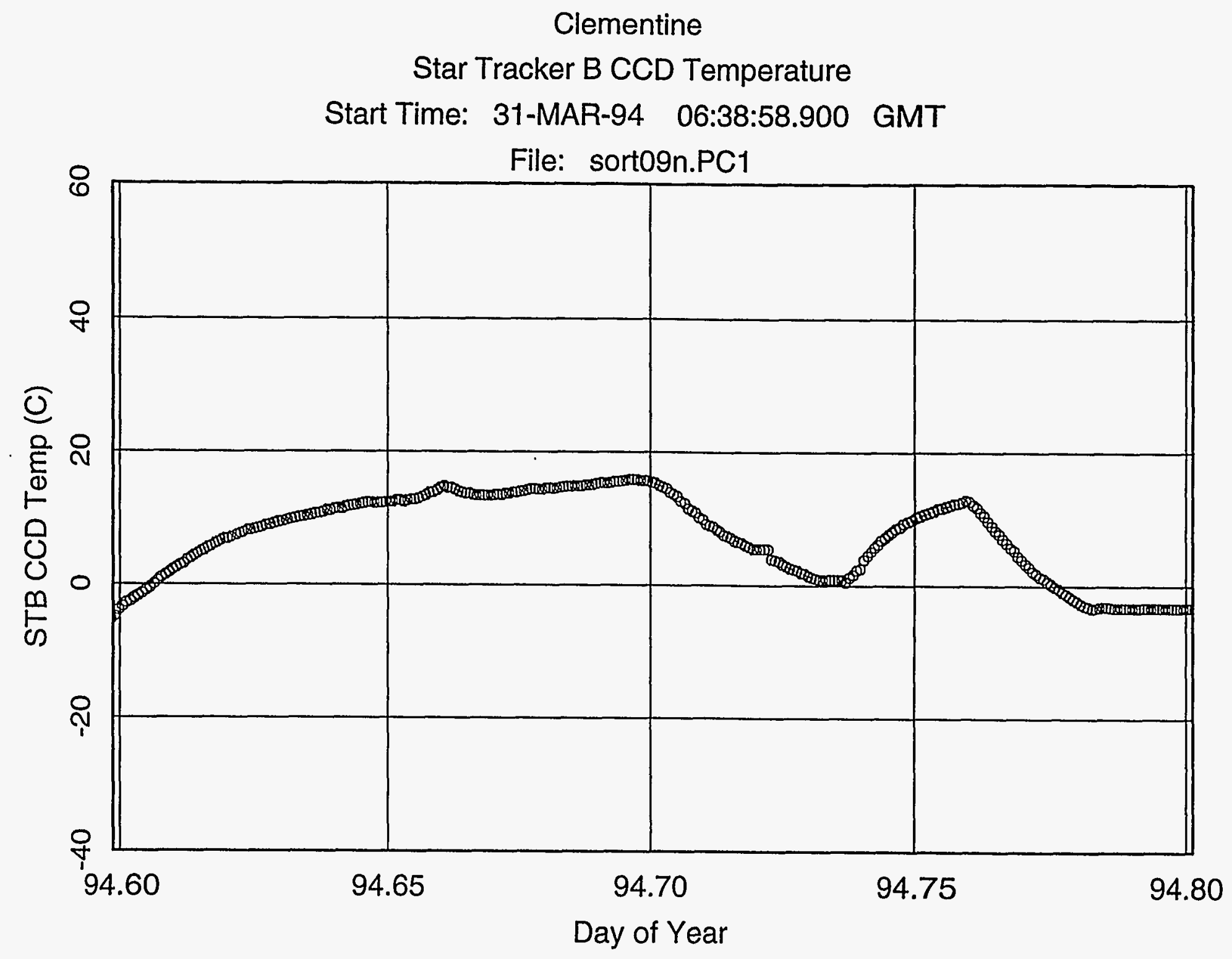

REP/LLNL created: Sat Jul 16 12:45:53 PDT 1994 
Clementine

Star Tracker B Lens Temperature

Start Time: $31-M A R-94 \quad$ 06:38:58.900 GMT

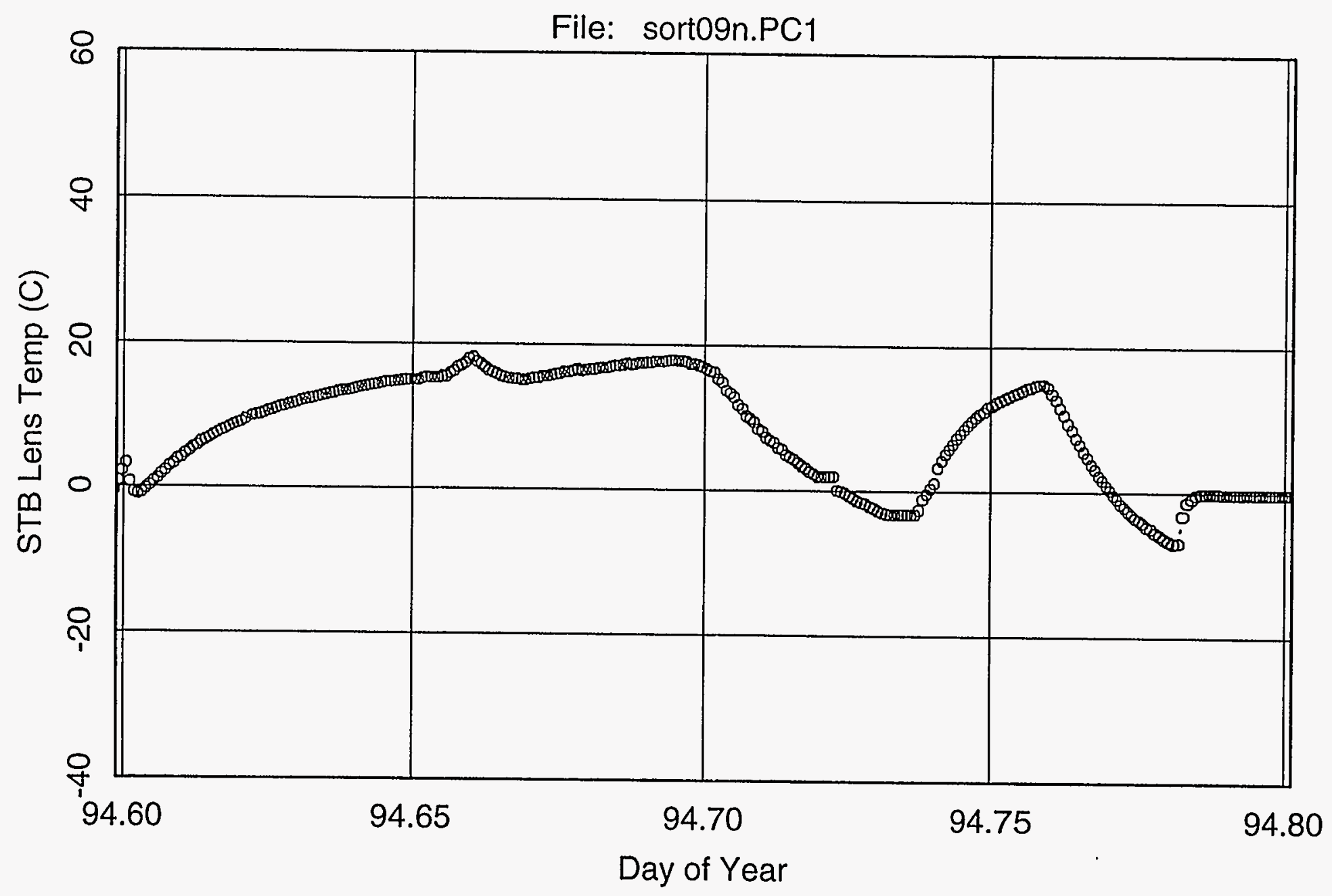

REP/LLNL created: Sat Jul 16 12:47:34 PDT 1994 
S-16

$80-89$ 


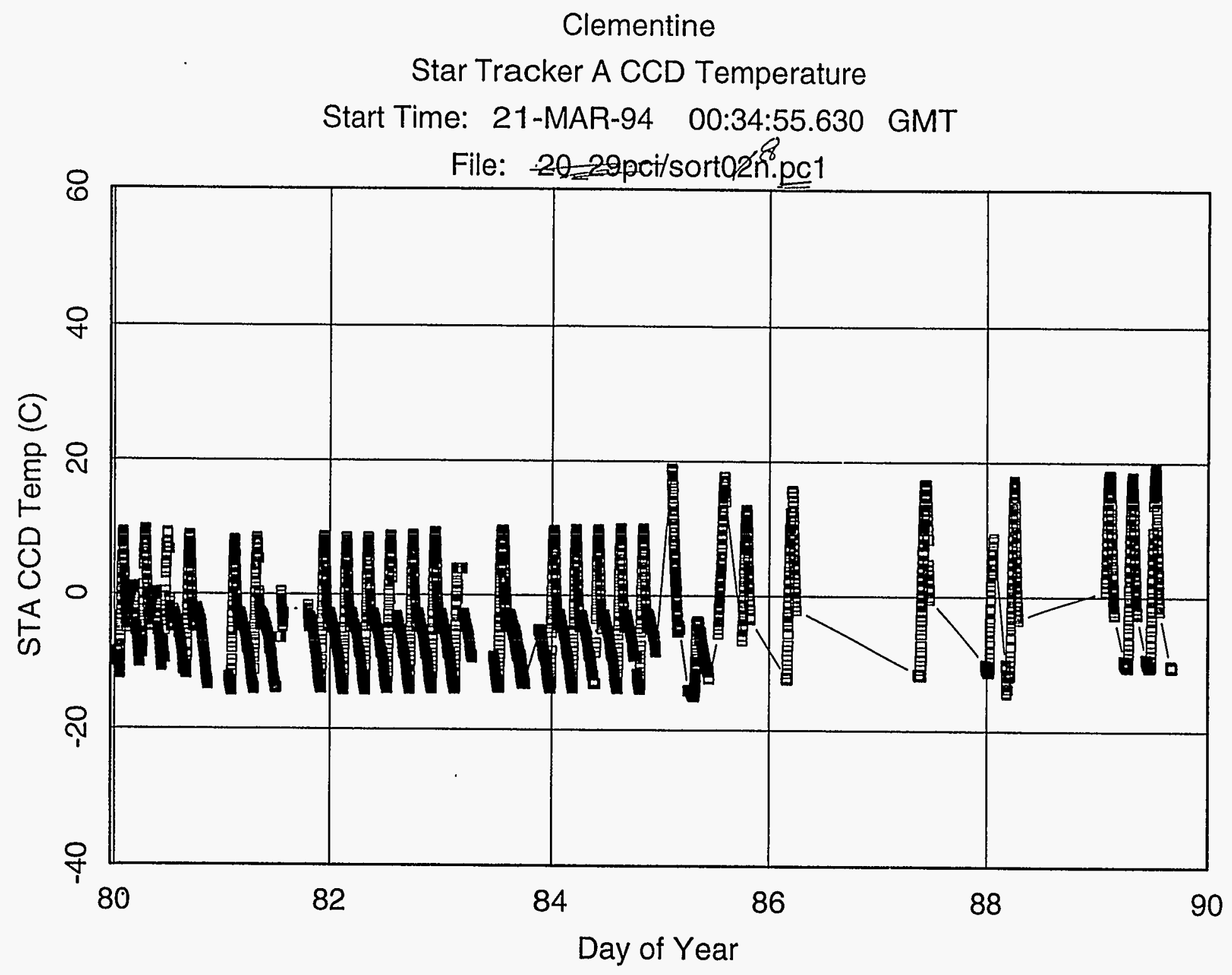

REP/LLNL created: Thu Apr 21 16:50:47 PDT 1994 


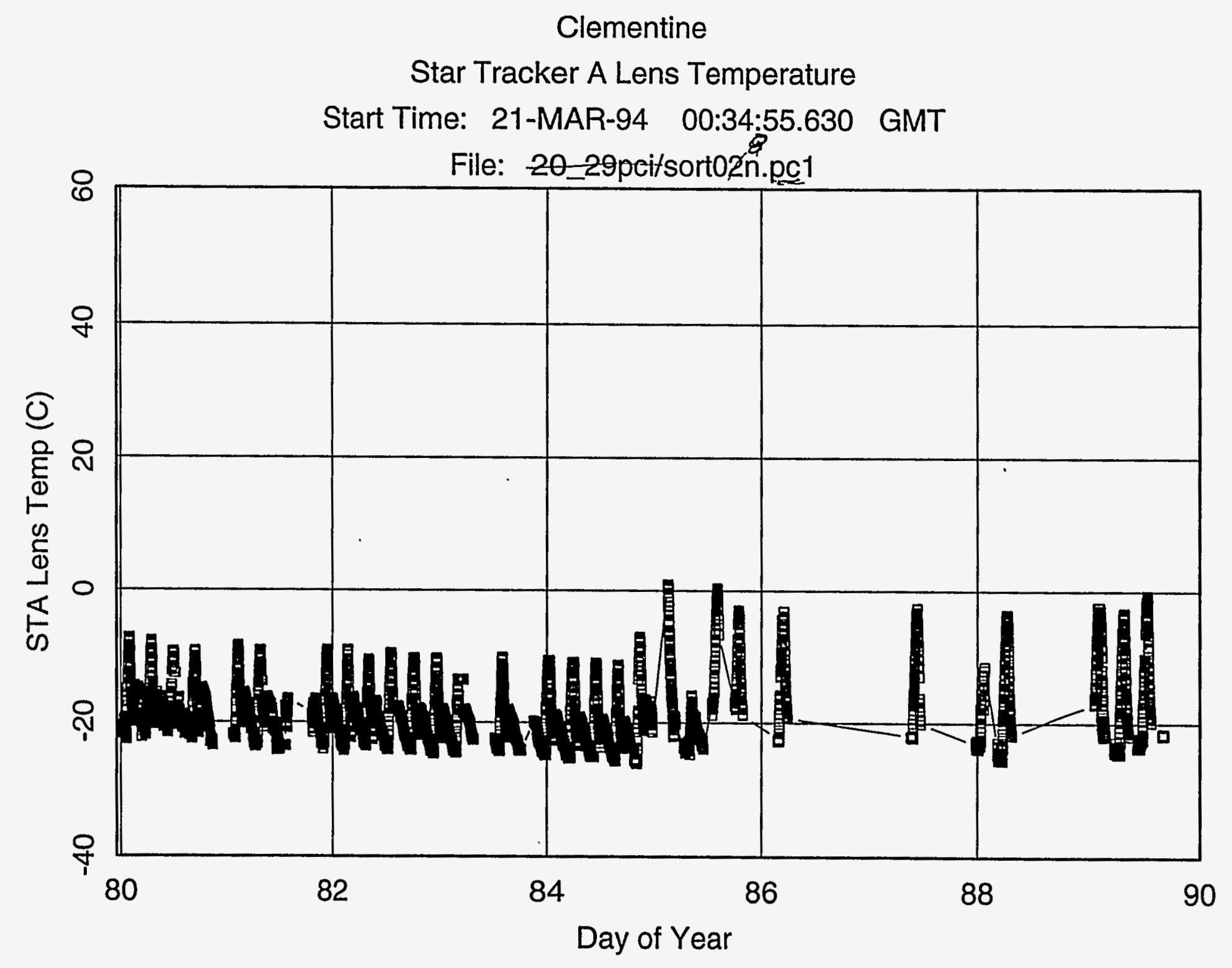

REP/LLNL created: Thu Apr 21 16:50:57 PDT 1994 
Clementine

Star Tracker B CCD Temperature

Start Time: 21-MAR-94 00:34:55.630 GMT

File: $20 \equiv 29 p c i /$ sorto2n.pc1

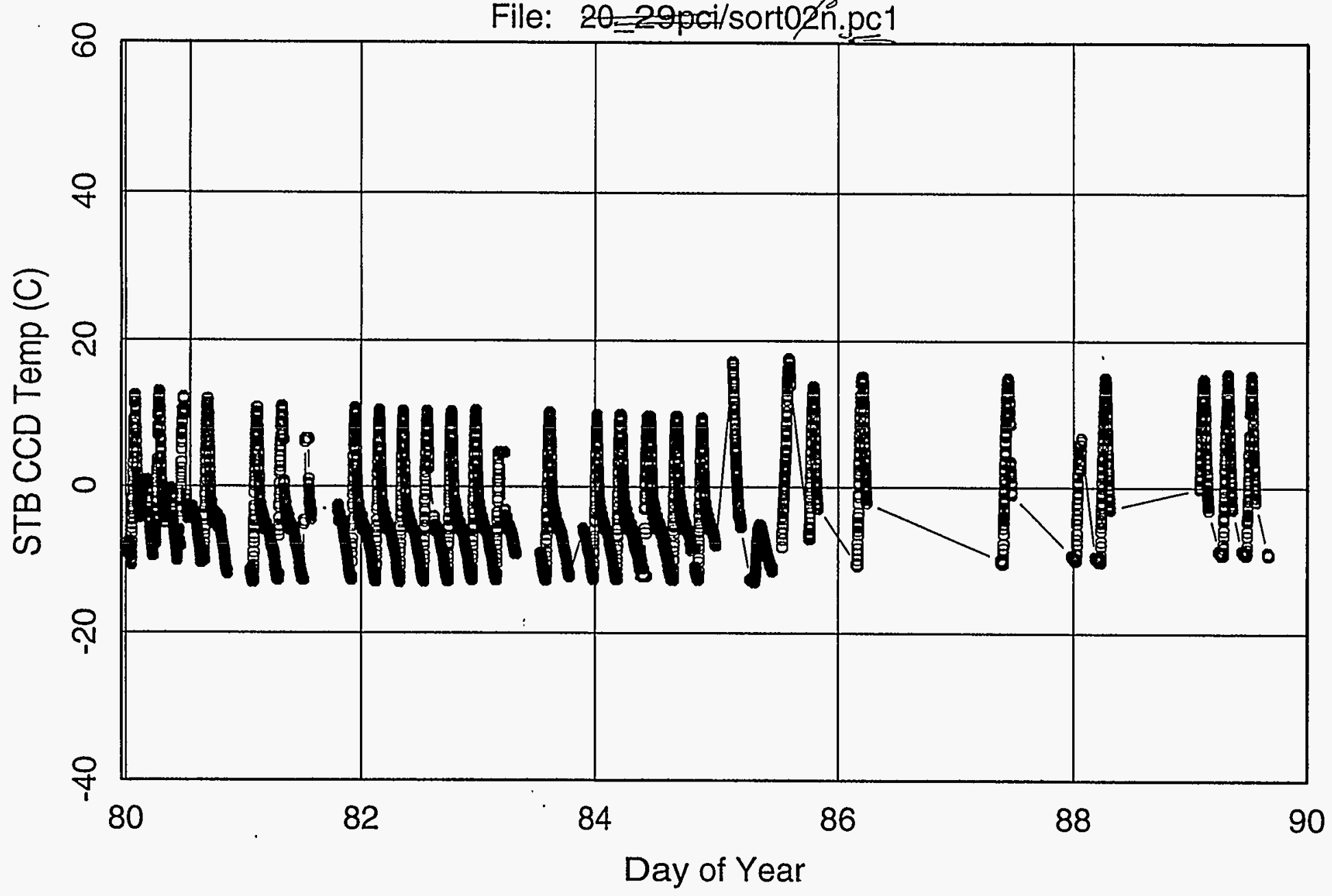

REP/LLNL created: Thu Apr 21 16:51:06 PDT 1994 


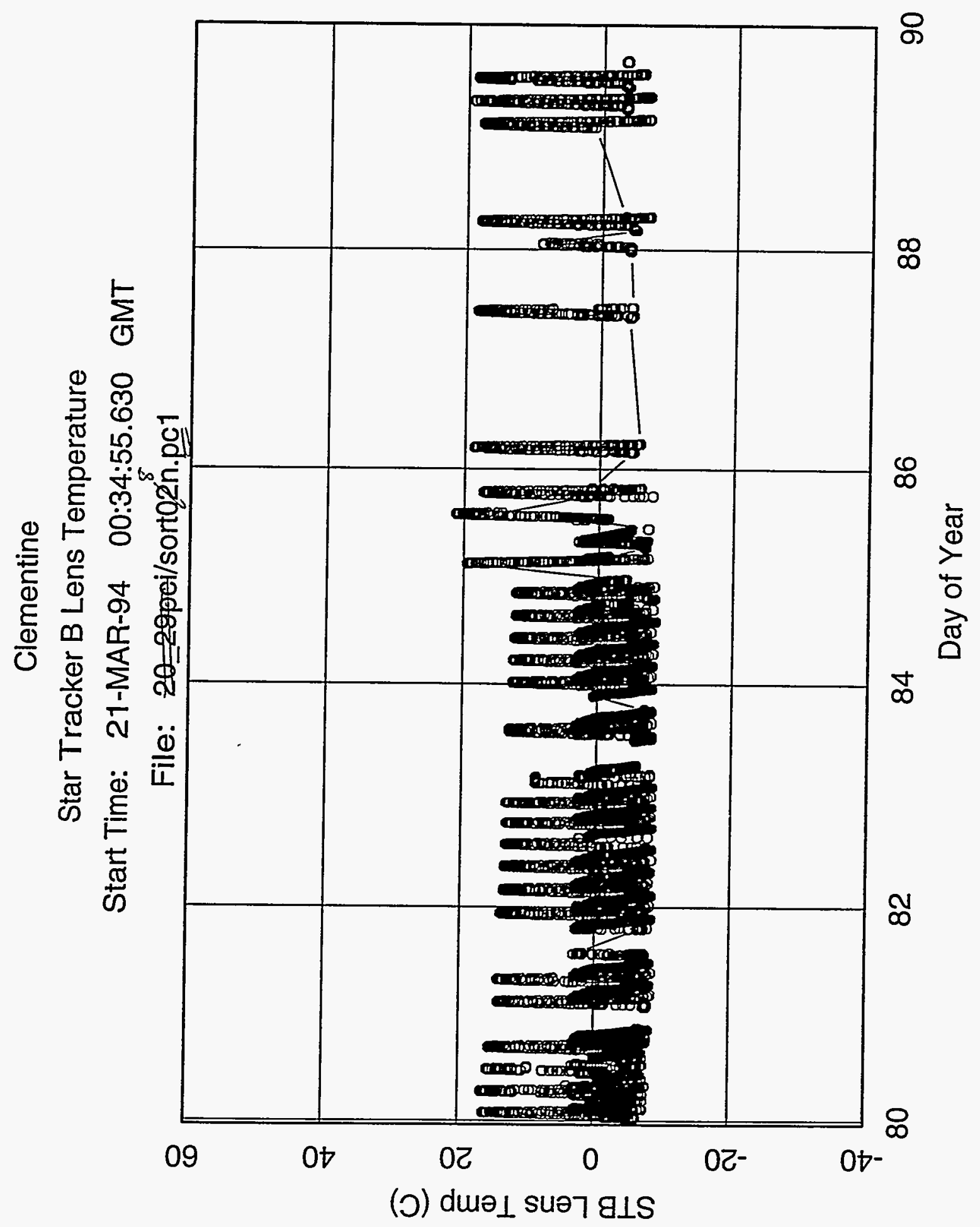

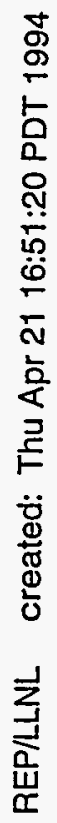


Clementine

Star Tracker A CCD vs + Y VCHP Temp

Start Time: 21-MAR-94 00:34:55.630 GMT

File: $80 \_89 \mathrm{pci} / \mathrm{sort08n.PC1}$

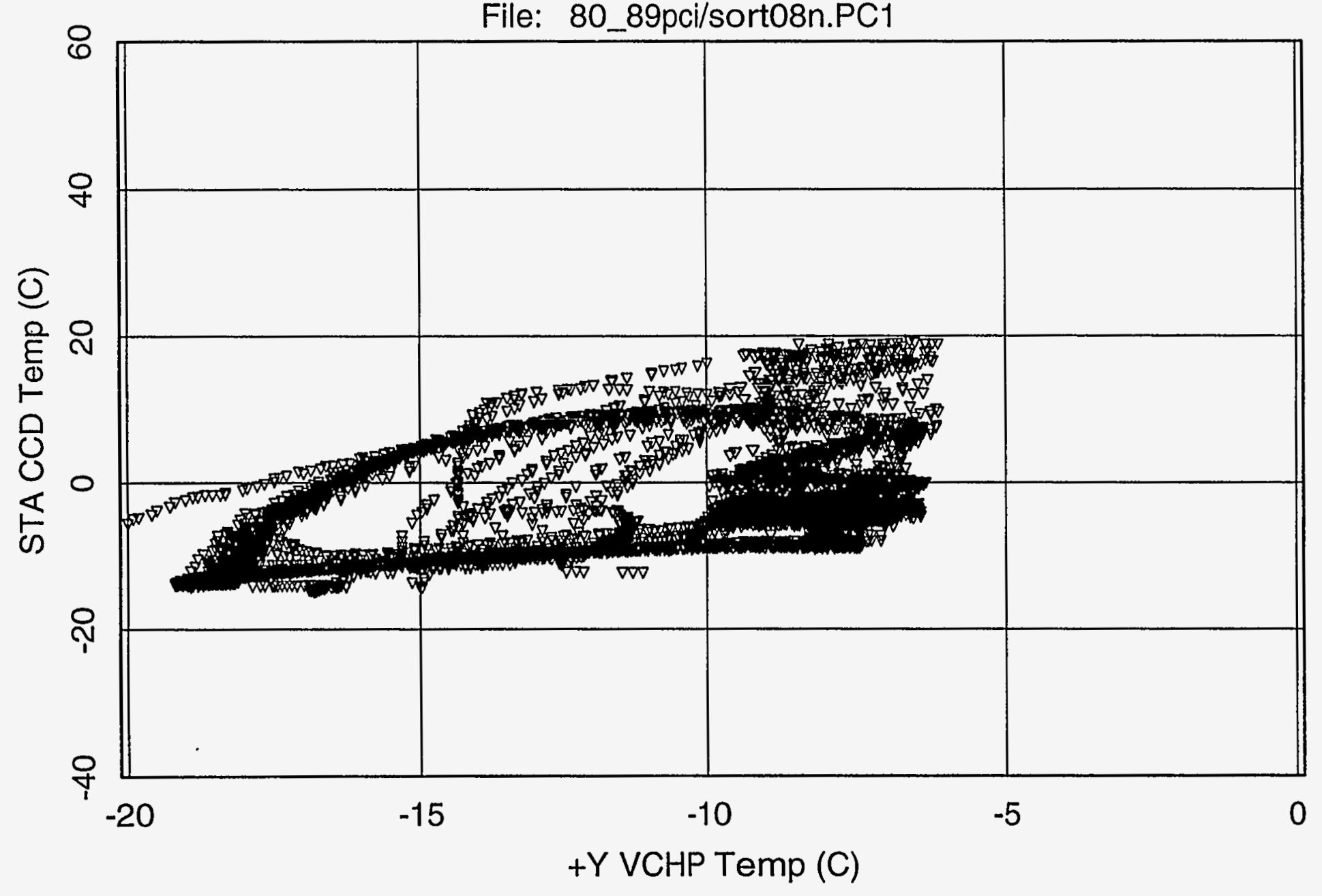

REP/LLNL created: Thu Apr 21 15:24:58 PDT 1994 
Clementine

Star Tracker B CCD vs - Y VCHP Temp

Start Time: $21-M A R-94$ 00:34:55.630 GMT

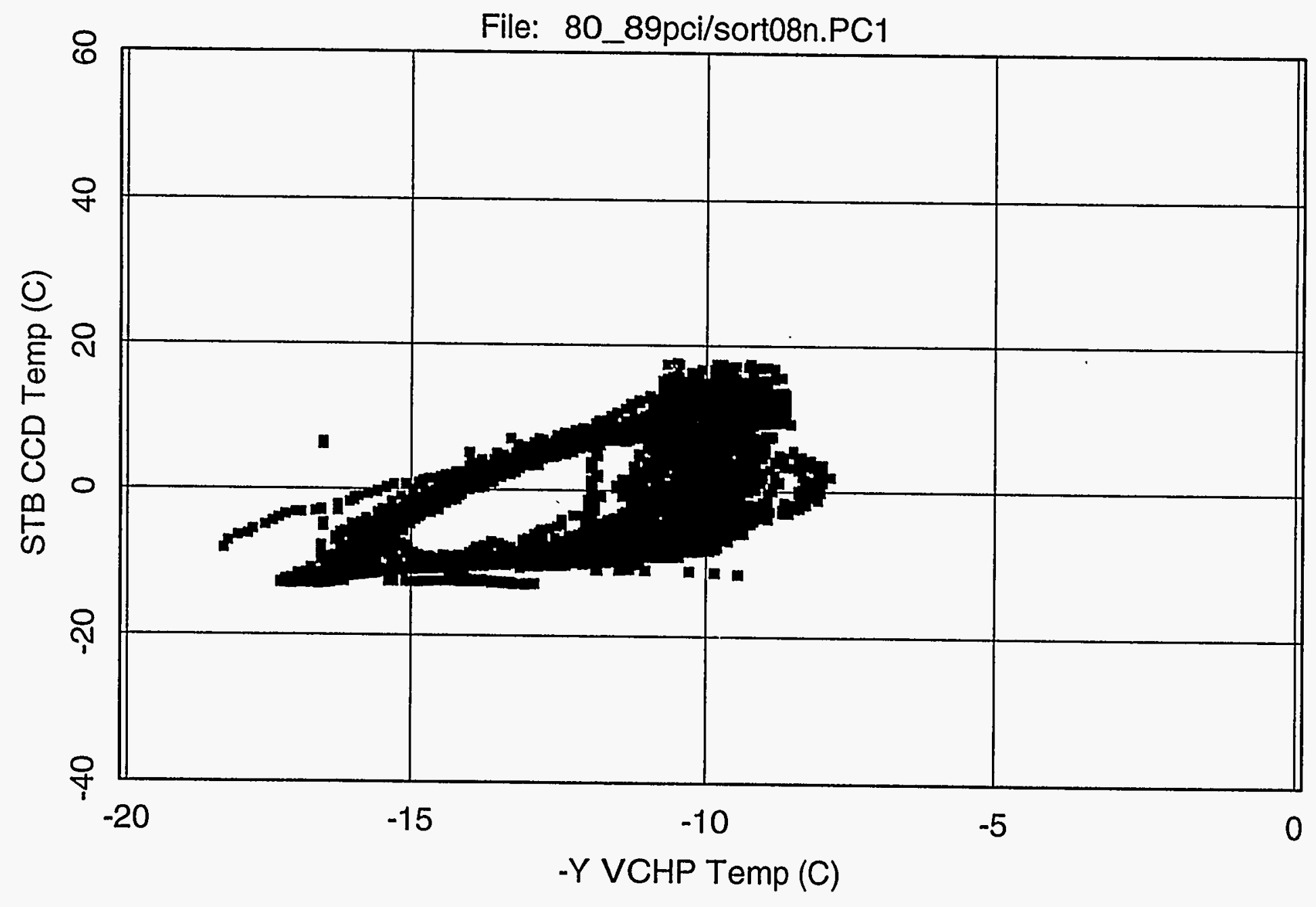

REP/LLNL created: Thu Apr 21 15:25:25 PDT 1994 


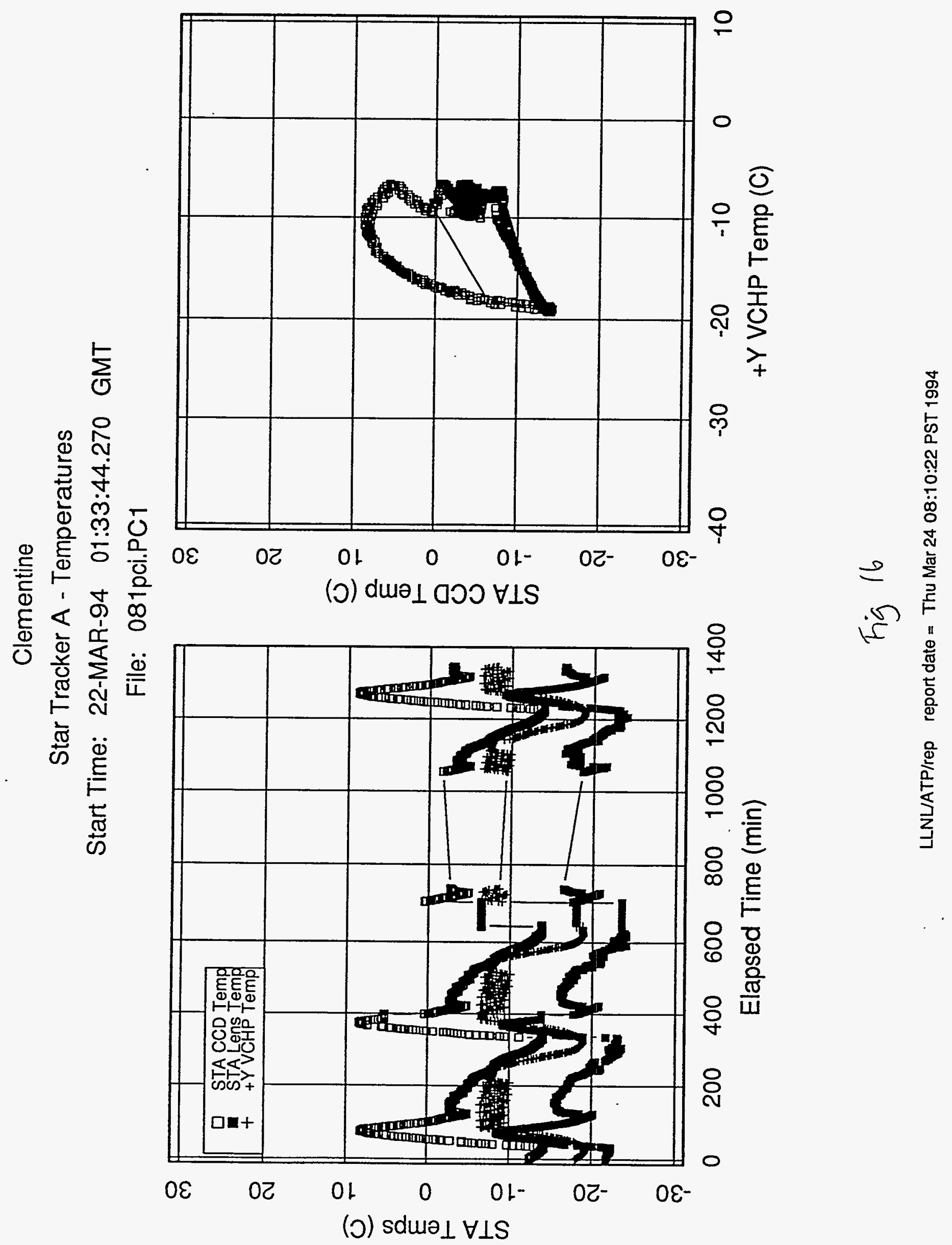


Clementine

Star Tracker A - Temperatures

Start Time: 05-MAR-94 01:53:34.180 GMT

File: 064pci.pc1
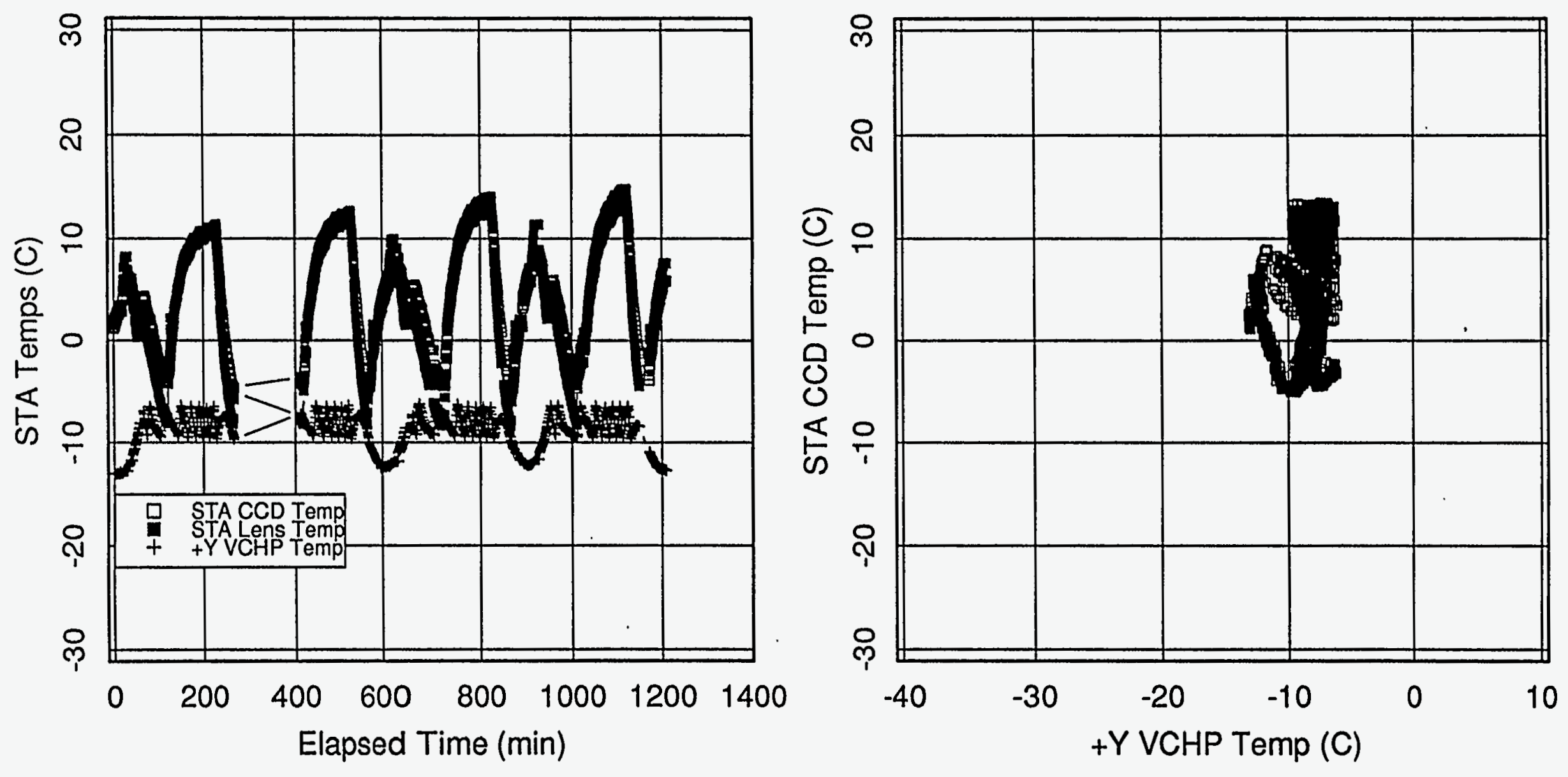

Fig 14 


\section{Clementine}

Star Tracker B - Temperatures

Start Time: $22-M A R-94 \quad 01: 33: 44.270$ GMT

File: 081 pci.PC1
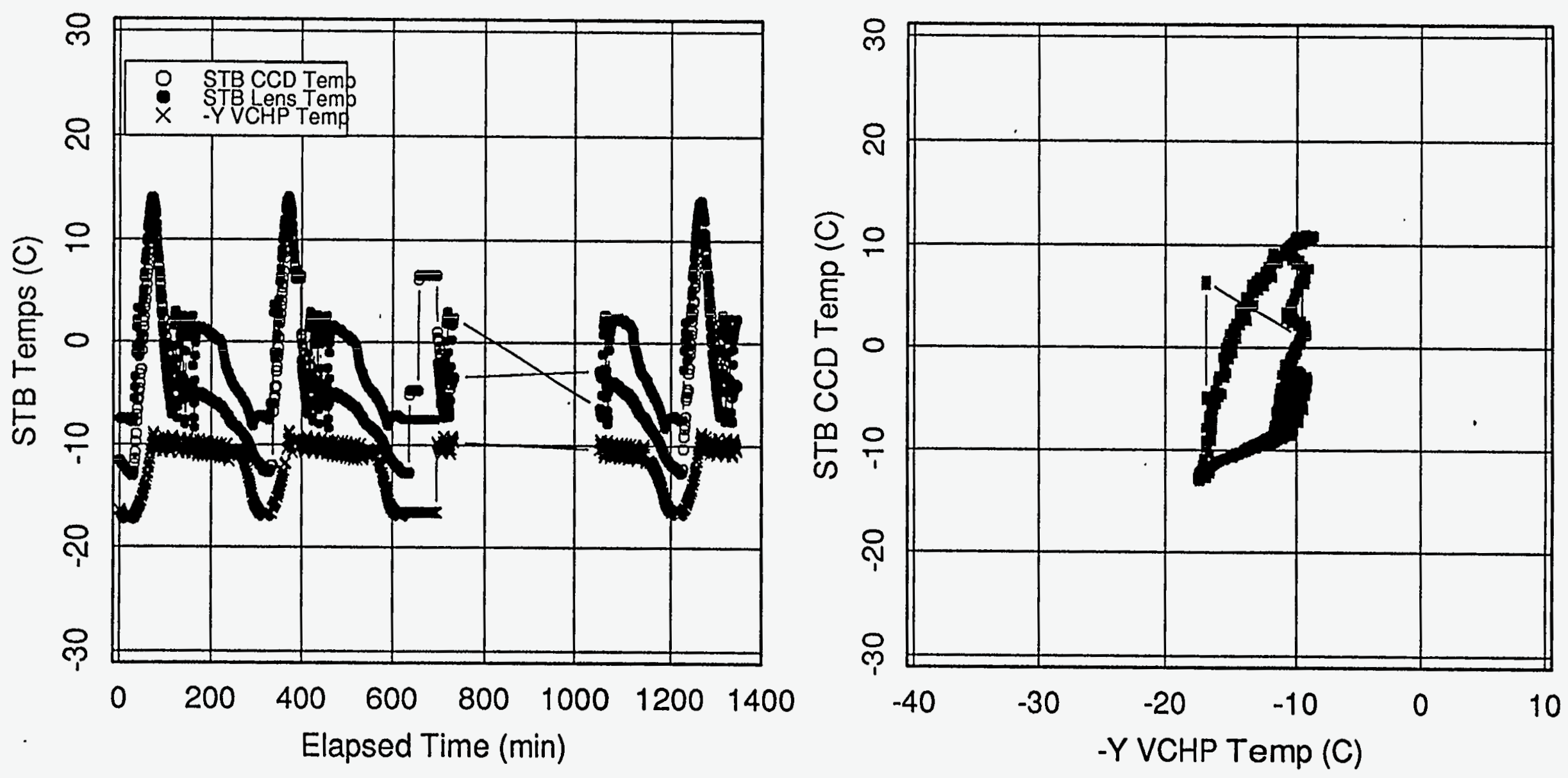

Fig 17

LLNL/ATP/rep report date $=$ Thu Mar 24 08:10:40 PST 1994 


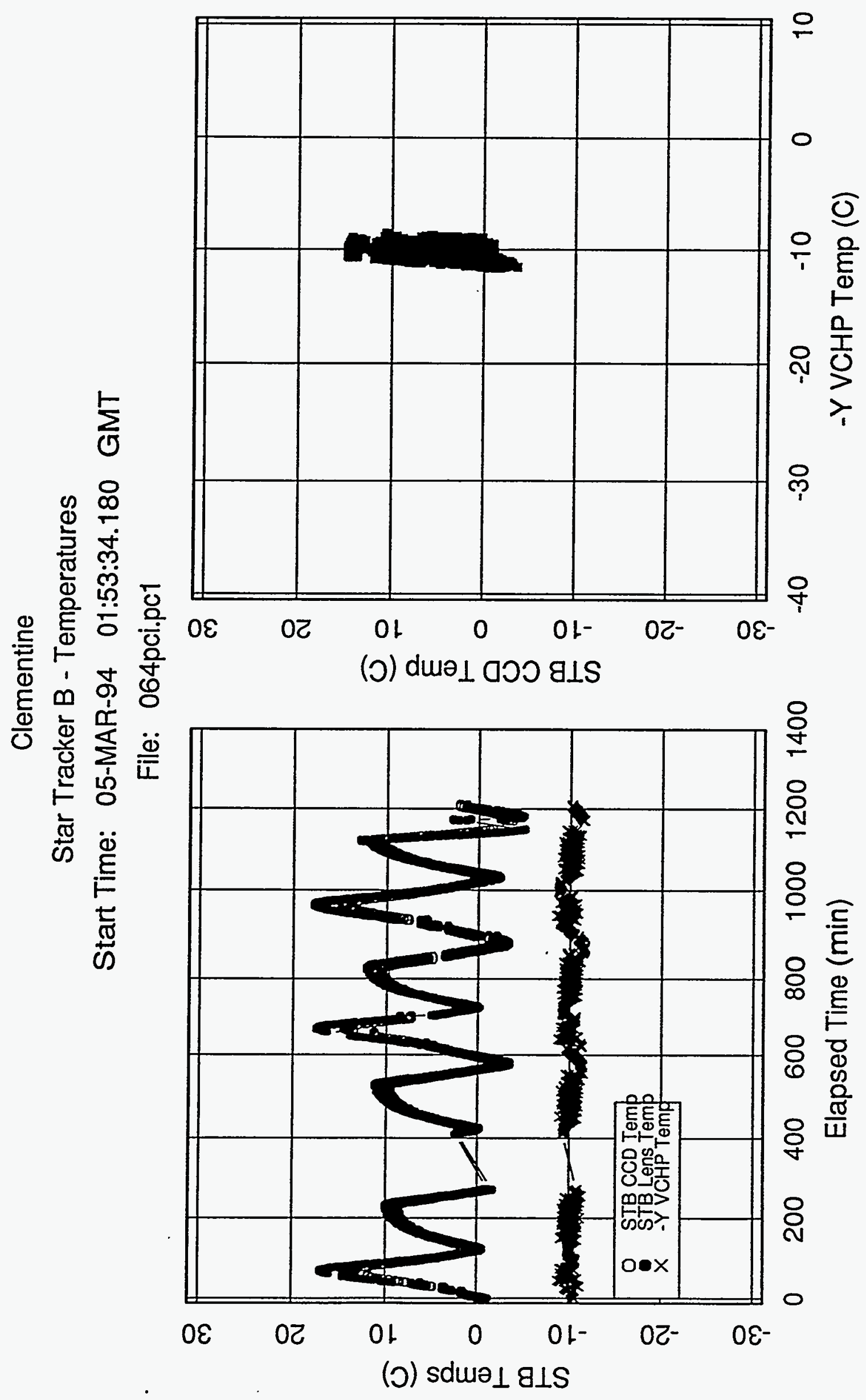

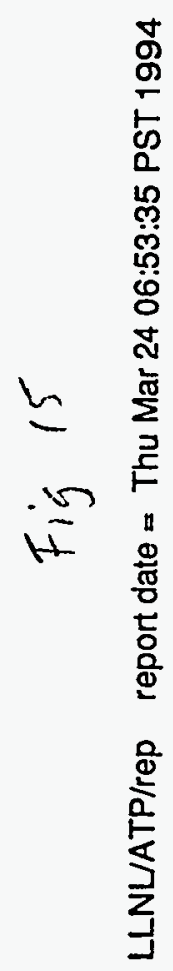


S-16

$70-79$ 
Clementine

Star Tracker A CCD Temperature

Start Time: 11-MAR-94 00:06:59.520 GMT

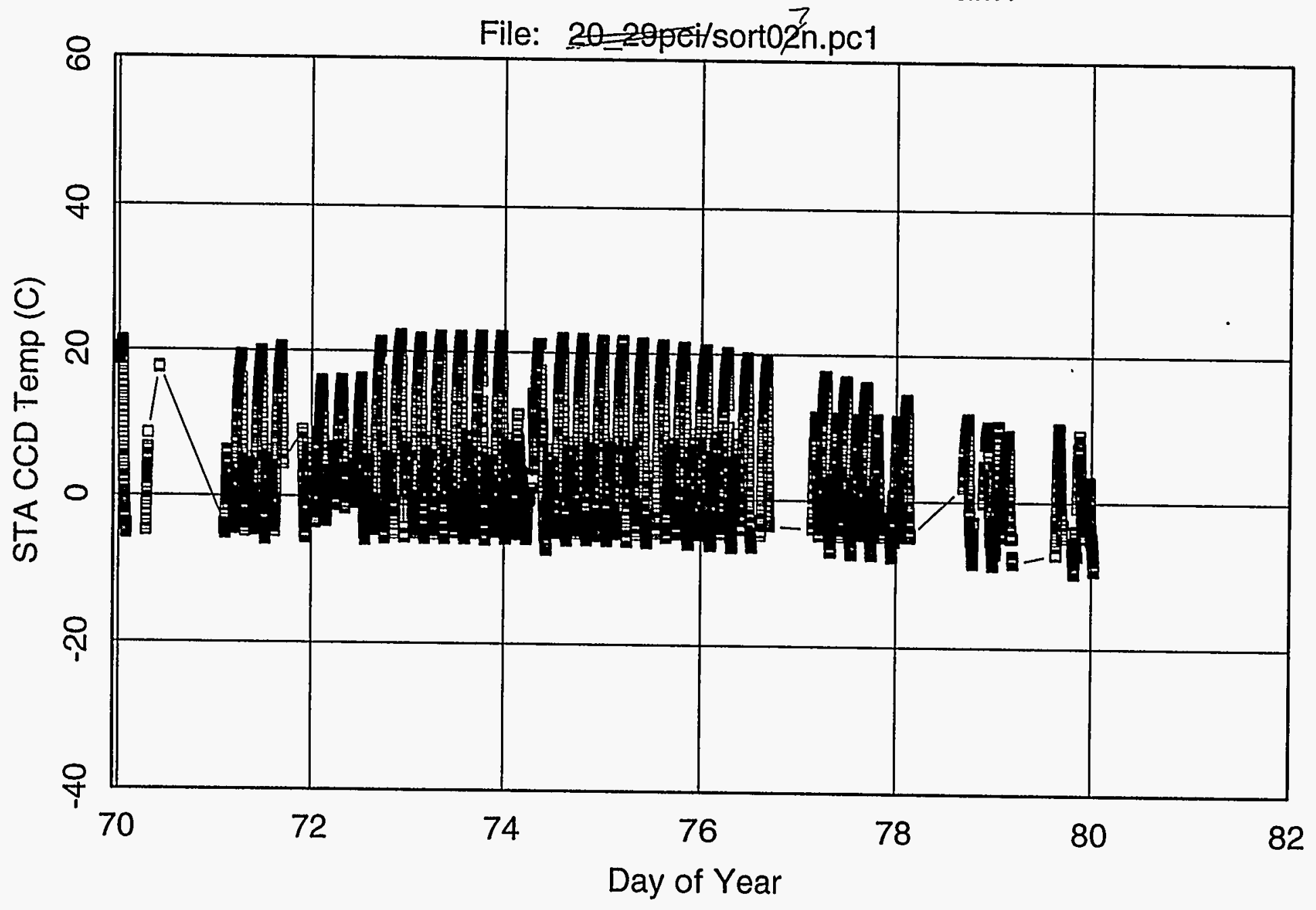

REP/LLNL created: Thu Apr 21 16:48:38 PDT 1994 
Clementine

Star Tracker A Lens Temperature

Start Time: 11-MAR-94 00:06:59.520 GMT

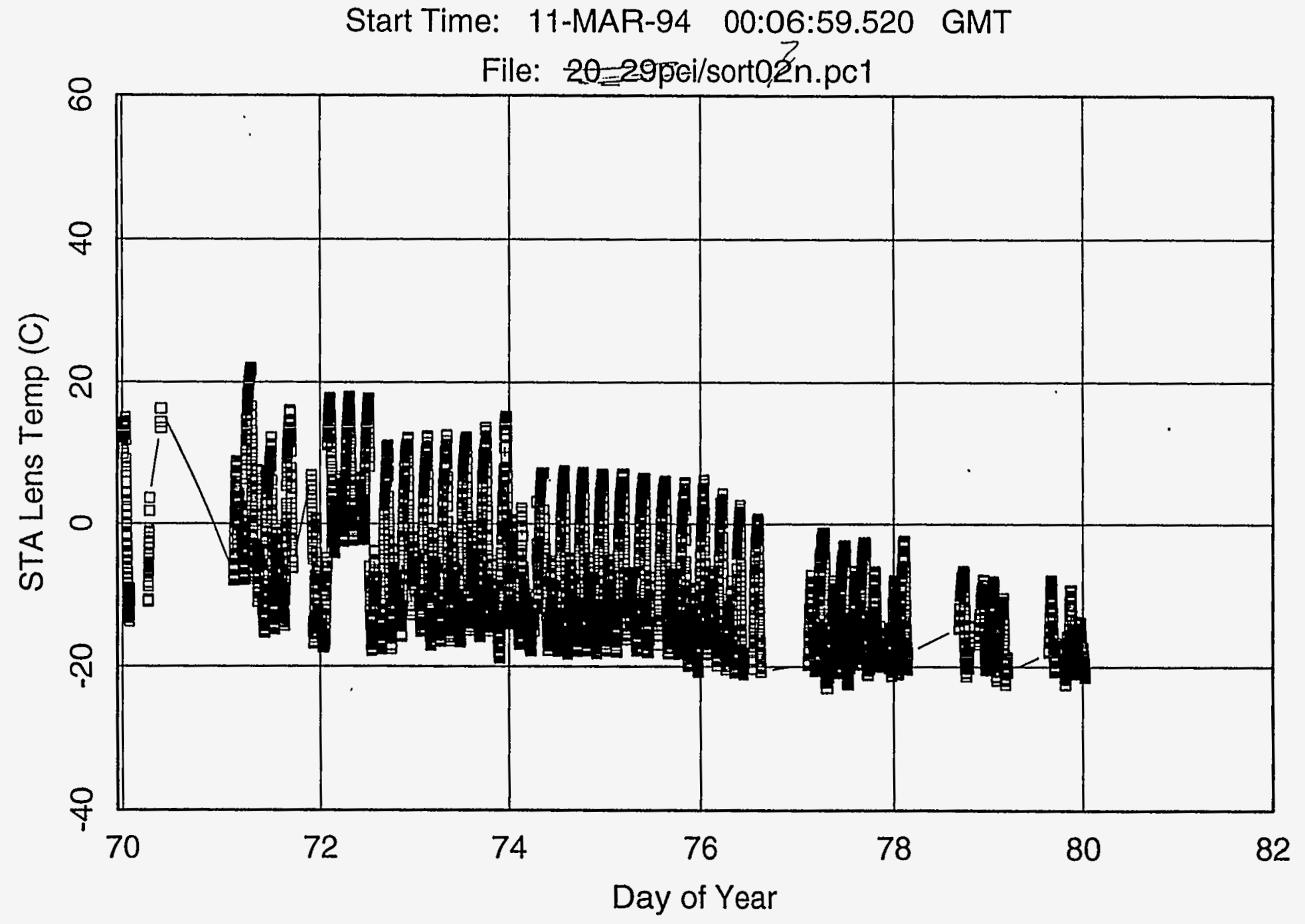

REP/LLNL created: Thu Apr 21 16:48:48 PDT 1994 
Clementine

Star Tracker B CCD Temperature

Start Time: 11-MAR-94 00:06:59.520 GMT

File: 20-20pei/sorto?n.pc1

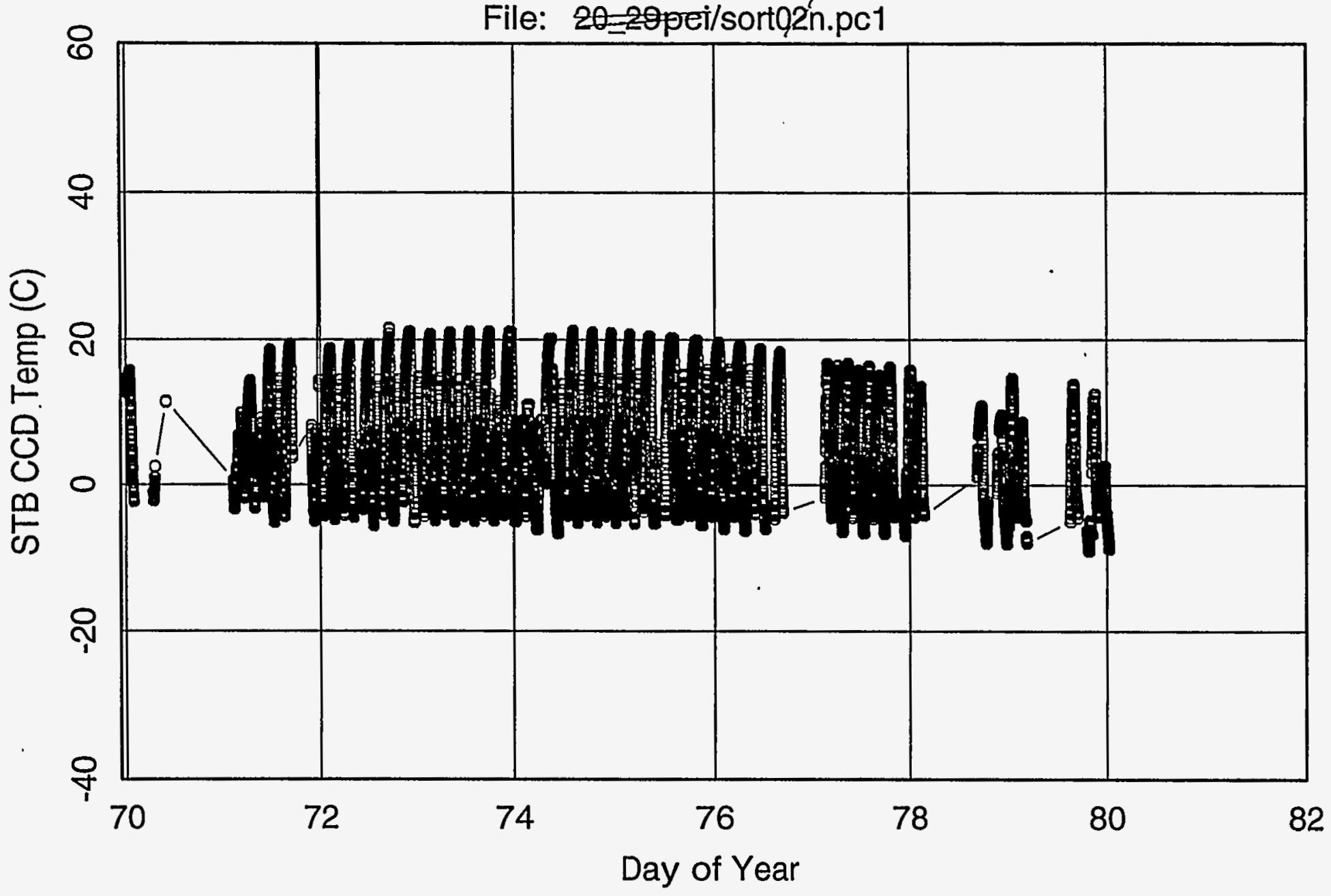


Clementine

Star Tracker B Lens Temperature

Start Time: 11-MAR-94 00:06:59.520 GMT

File: 2029pei/sort02n.pc1

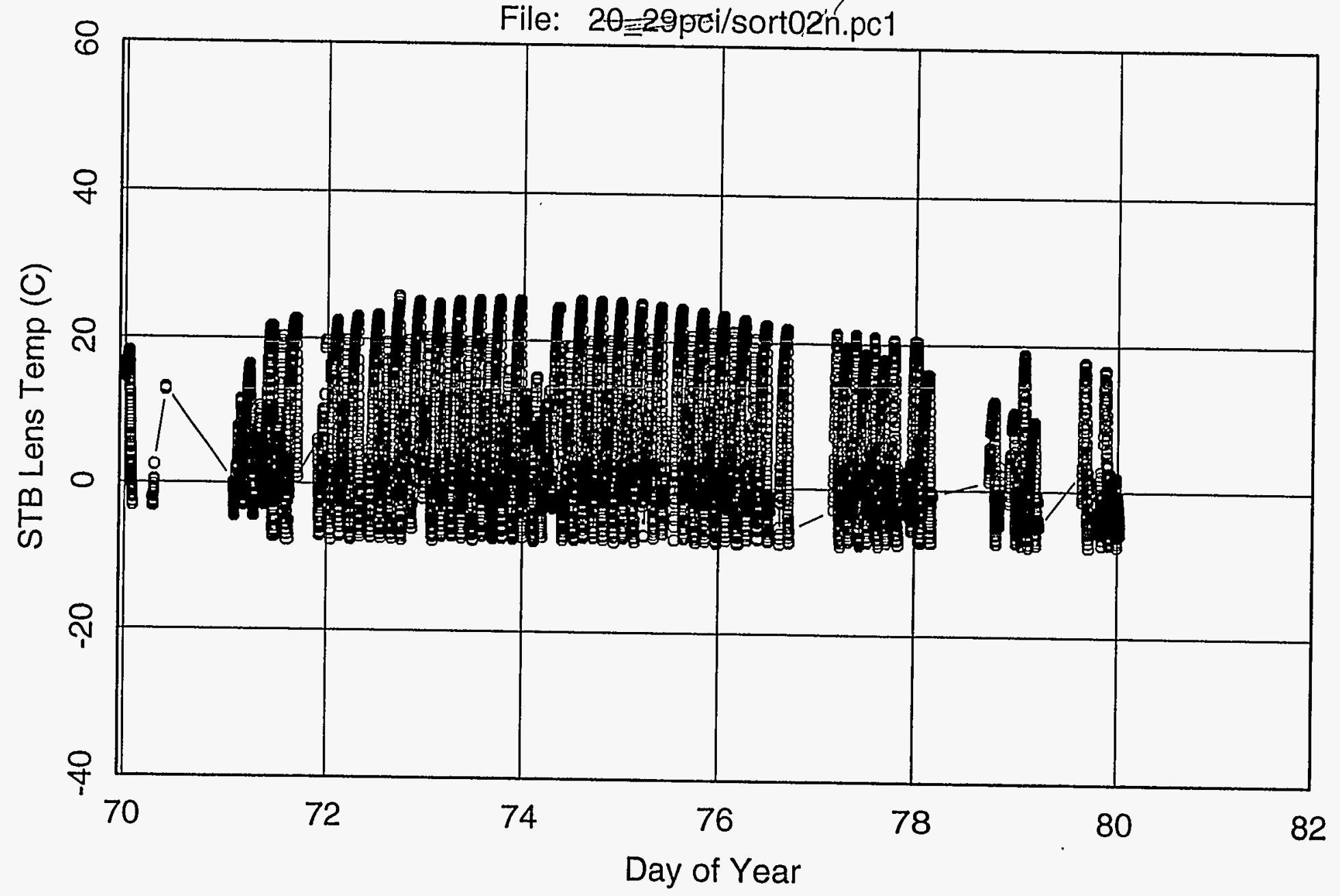




\section{Clementine}

Star Tracker A CCD Temperature

Start Time: 11-MAR-94 00:06:59.520 GMT

File: 07nsort.PC1

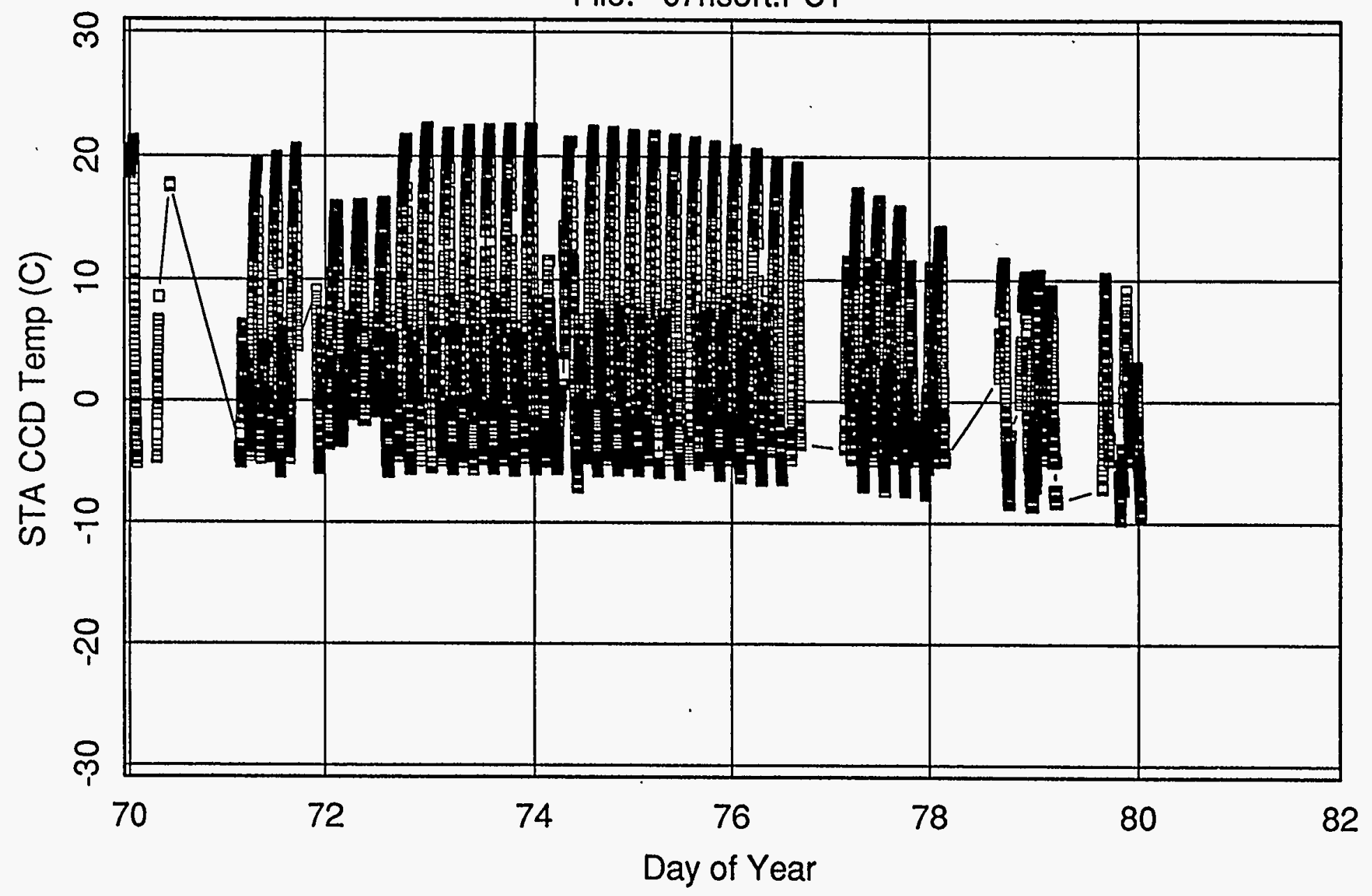




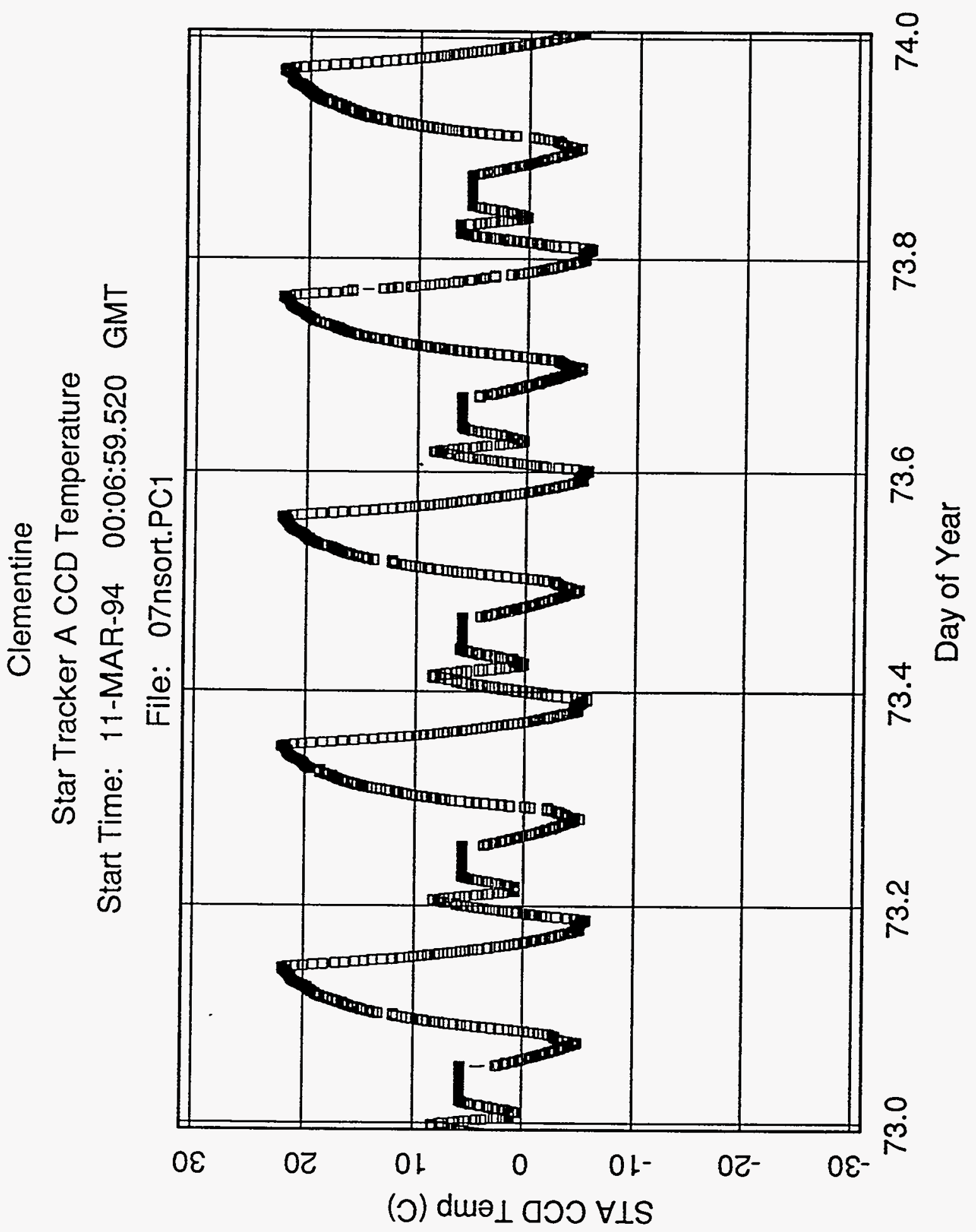

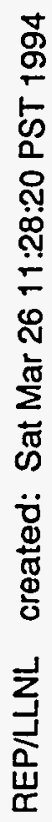




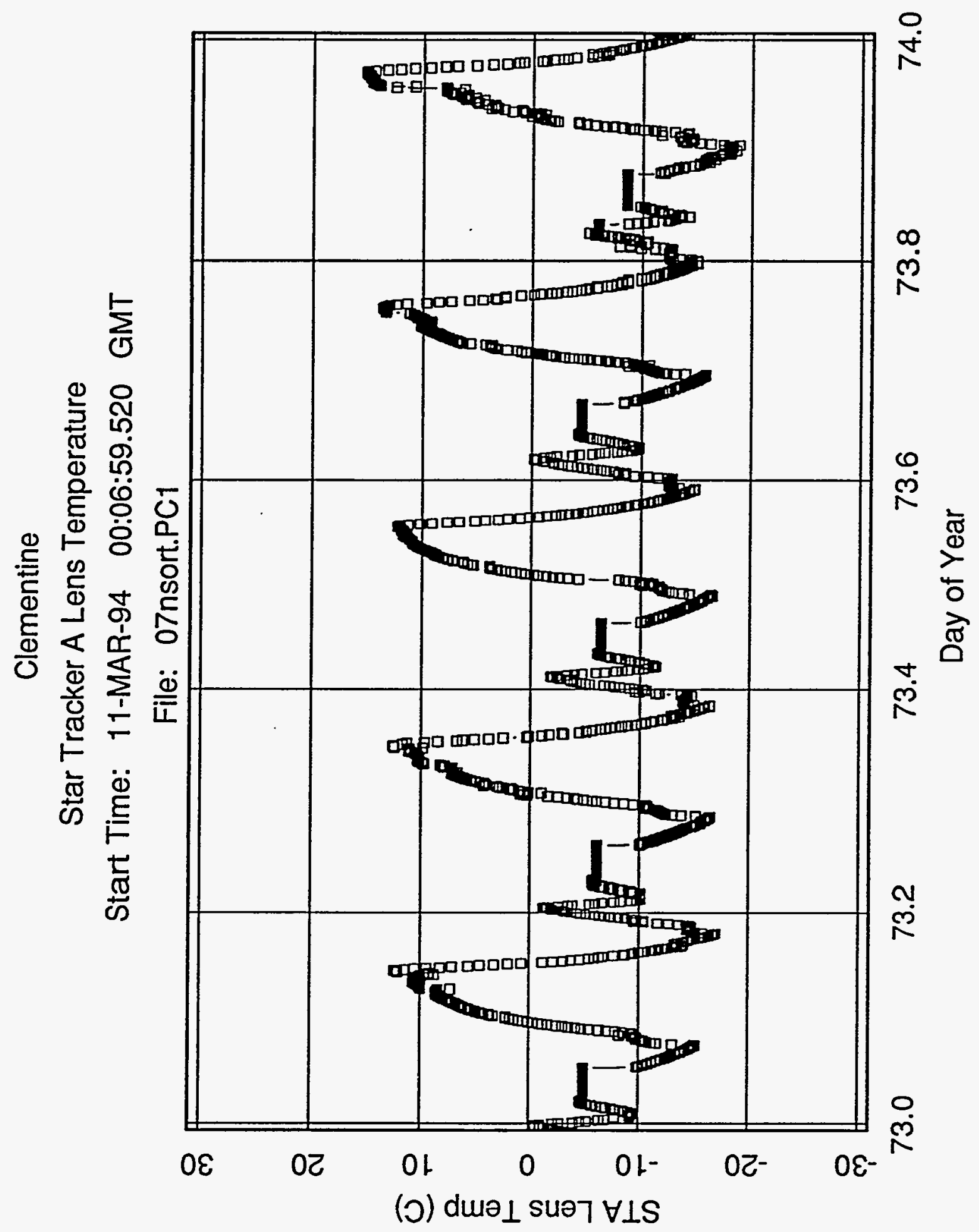

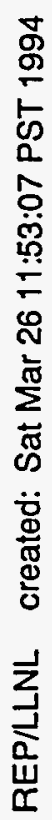




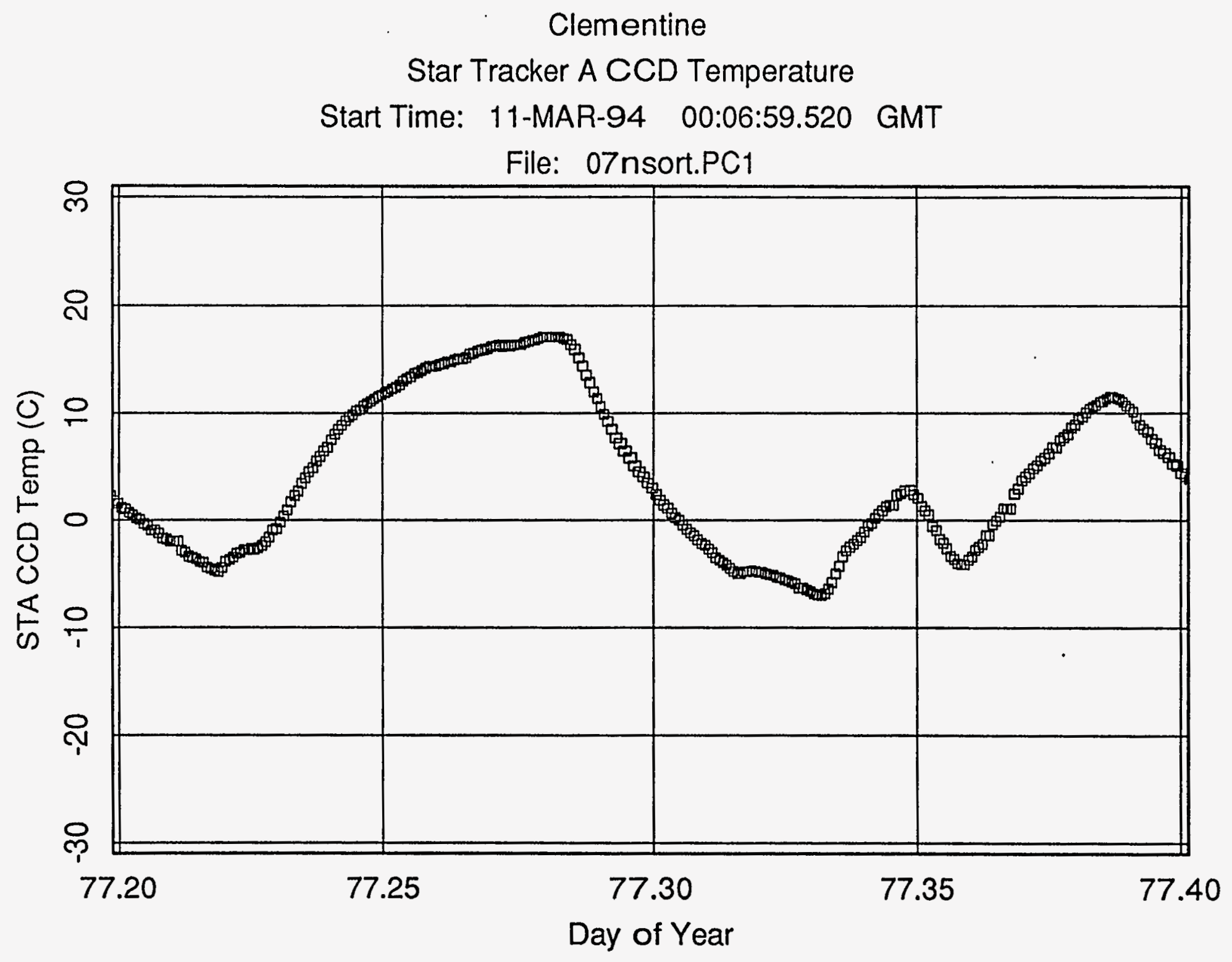

REP/LLNL created: Sat Mar 26 11:39:23 PST 1994 


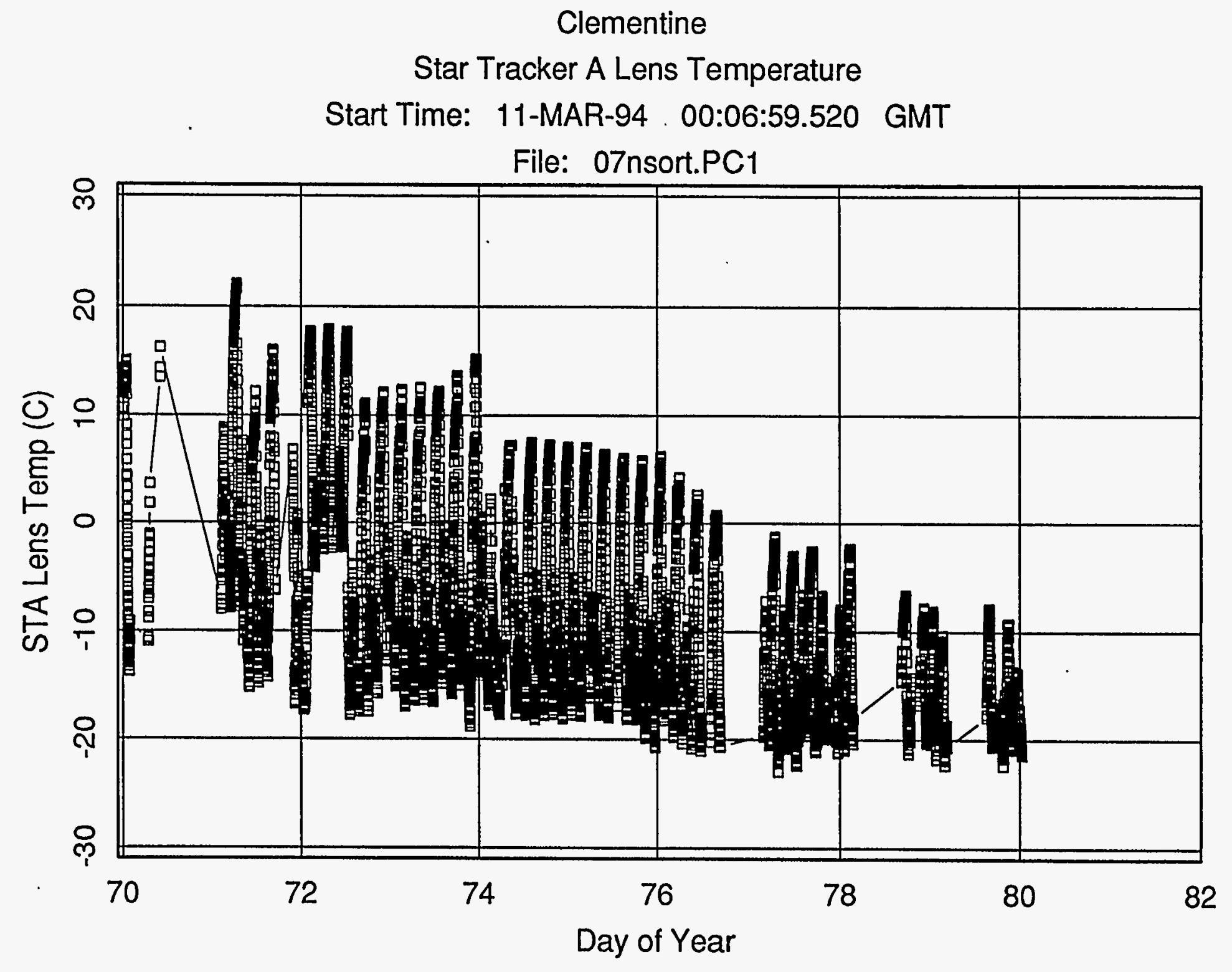

REP/LLNL created: Fri Mar 25 21:37:53 PST 1994 


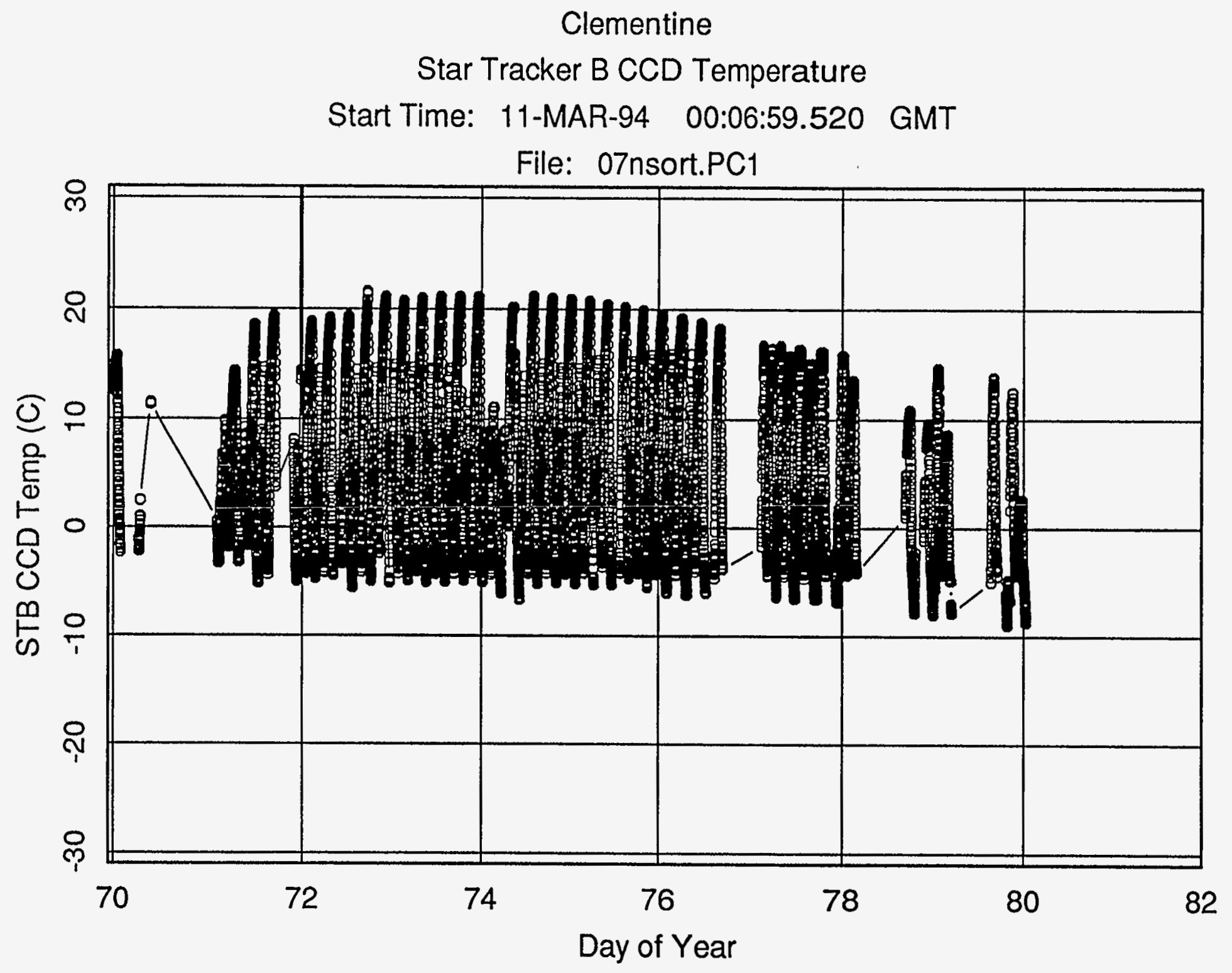

REP/LLNL created: Fri Mar 25 21:38:17 PST 1994 
Clementine

Star Tracker B Lens Temperature

Start Time: 11-MAR-94 00:06:59.520 GMT

File: $07 n s o r t . P C 1$

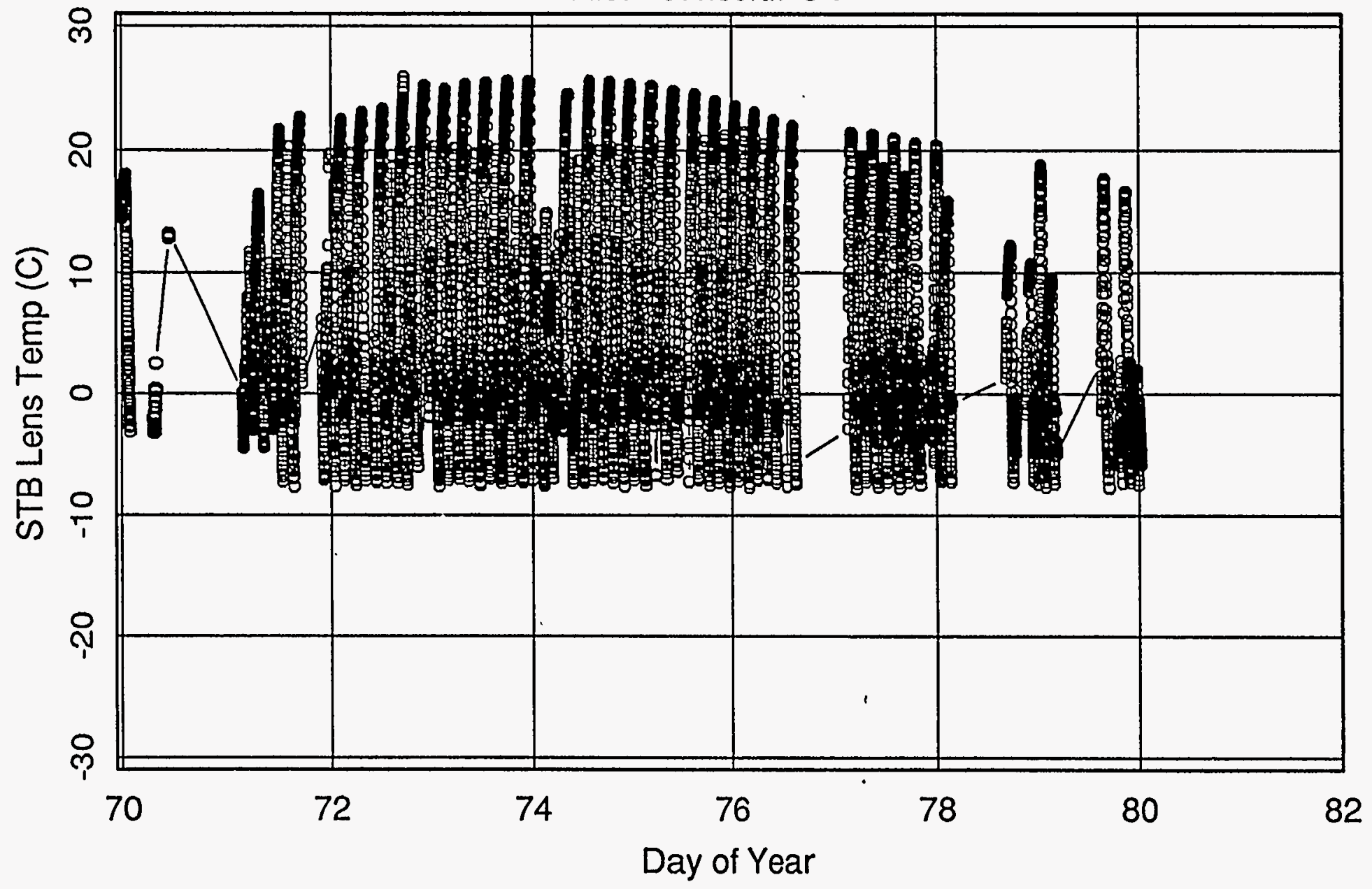




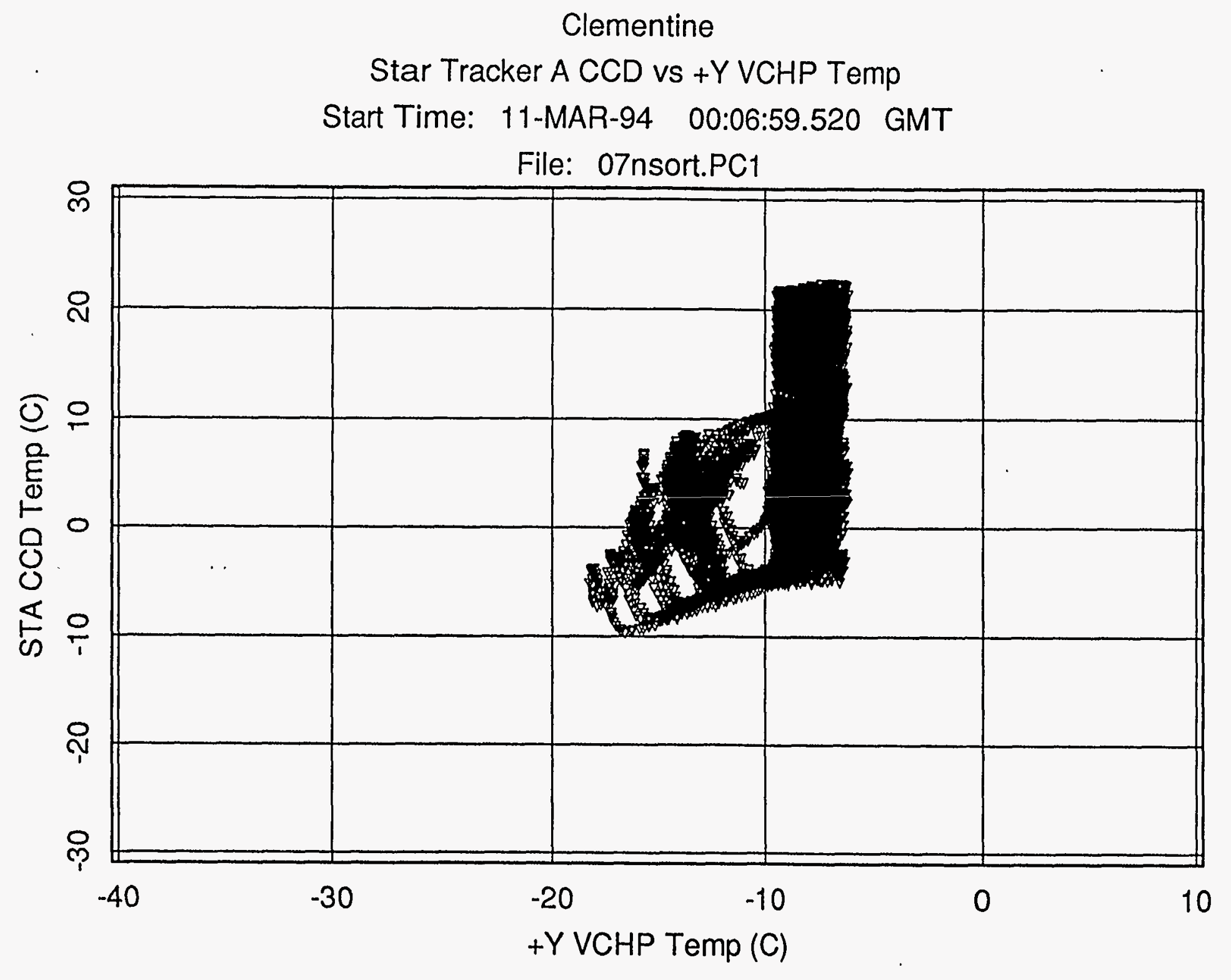

REP/LLNL created: Fri Mar 25 21:38:54 PST 1994 
Clementine

Star Tracker B CCD vs - Y VCHP Temp

Start Time: 11-MAR-94 00:06:59.520 GMT

File: $07 n$ sort.PC1

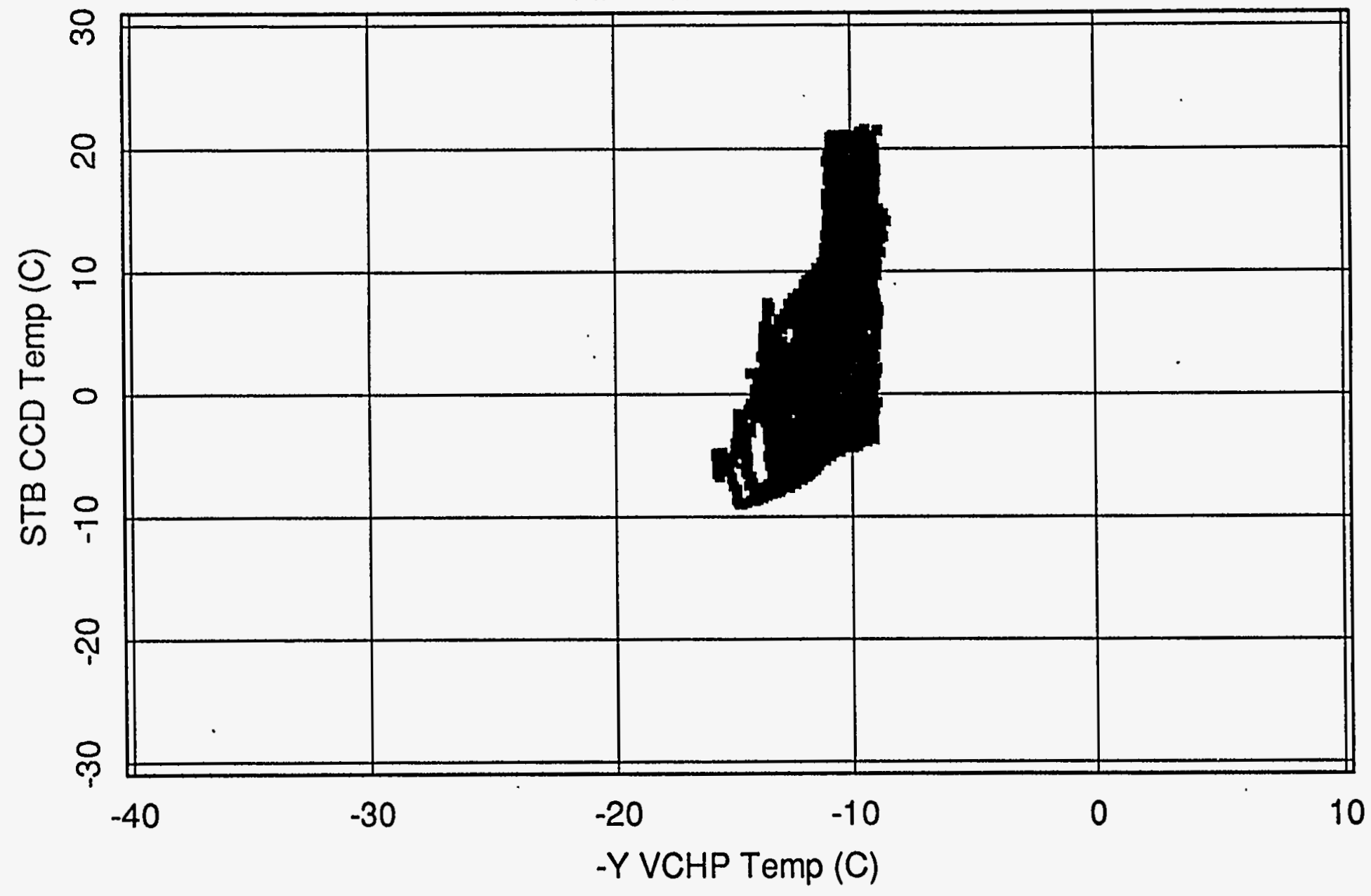

REP/LLNL created: Fri Mar 25 21:40:04 PST 1994 


$$
\begin{gathered}
S-16 \\
60-69
\end{gathered}
$$




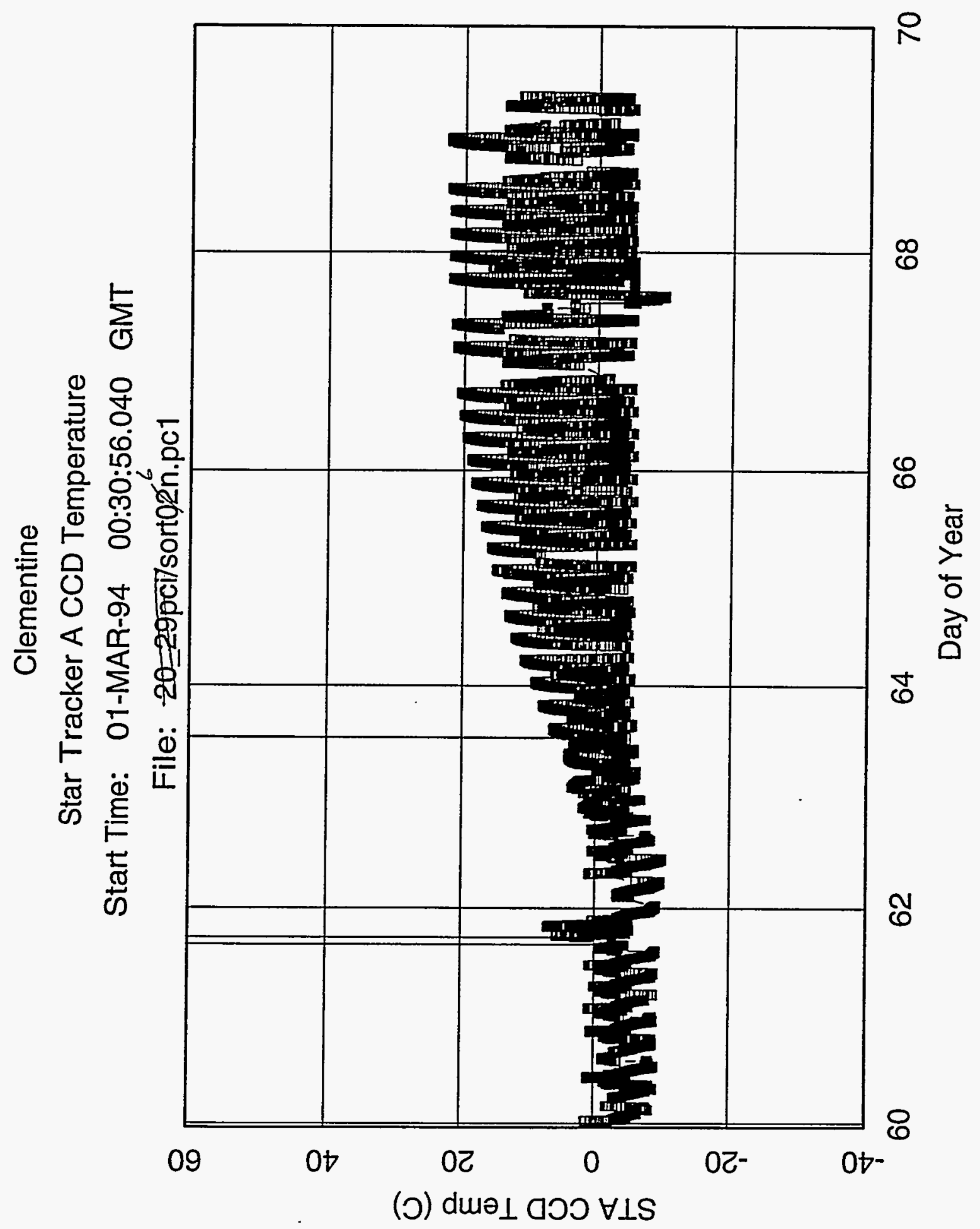

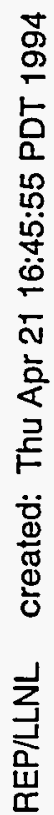




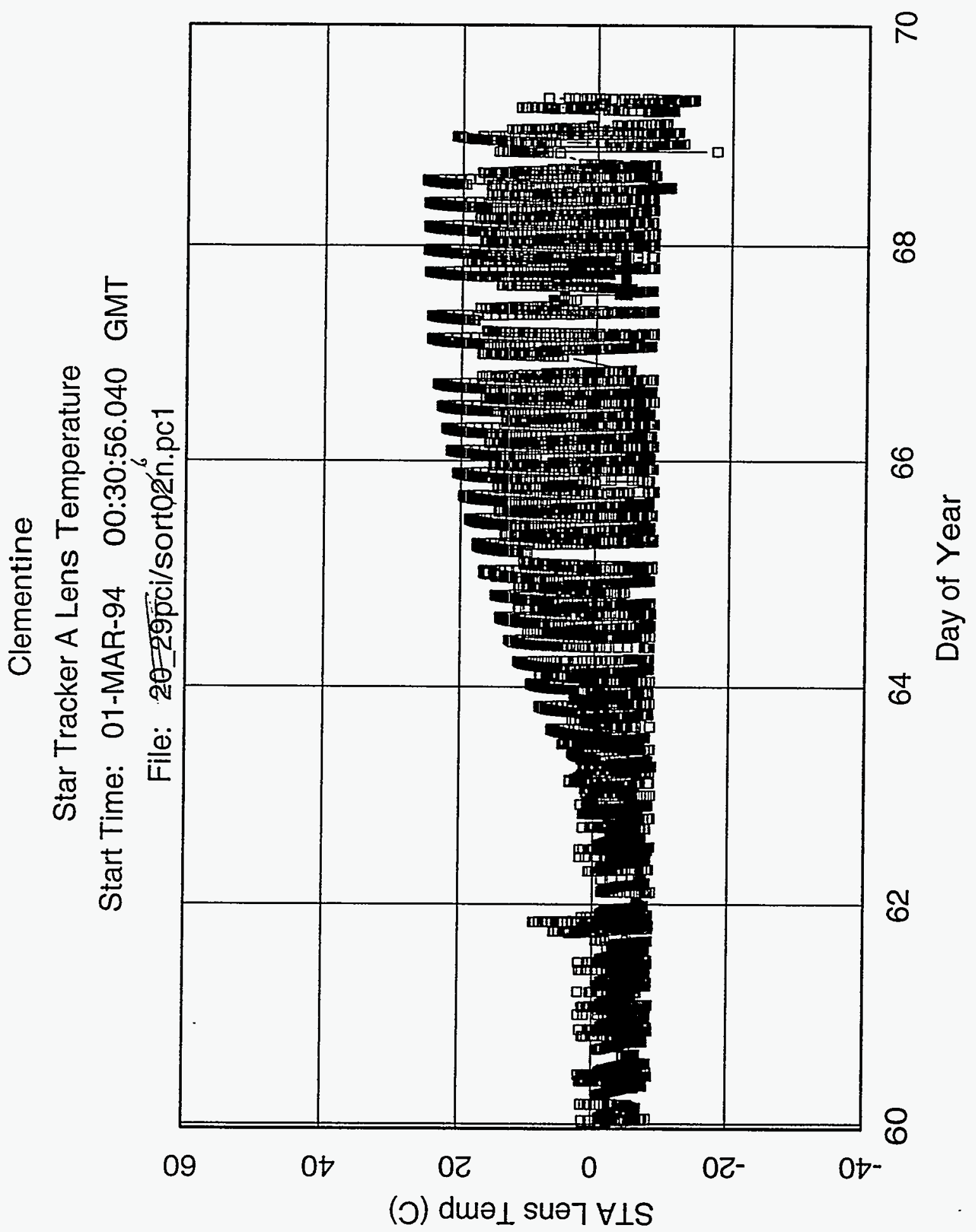

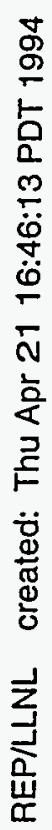




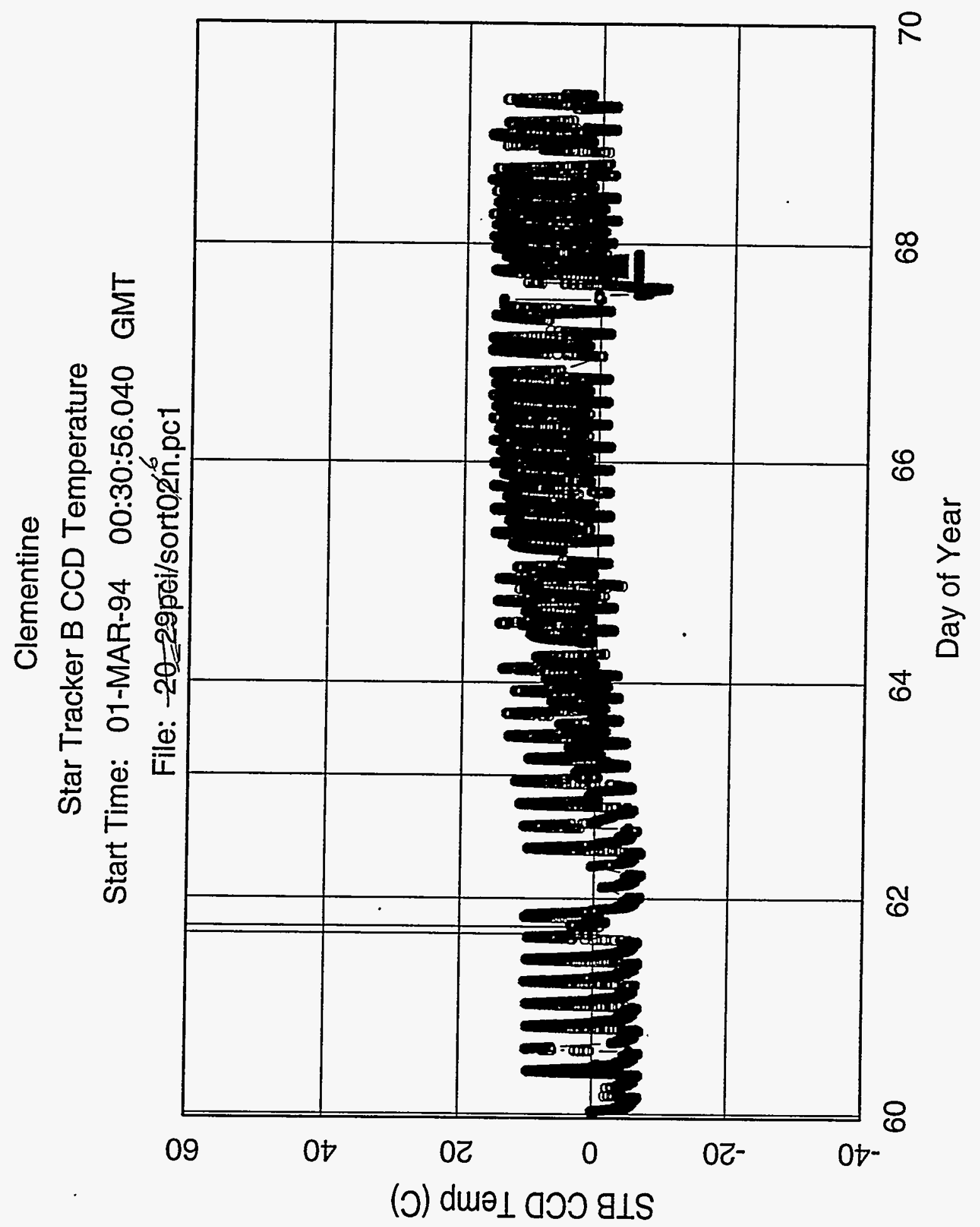

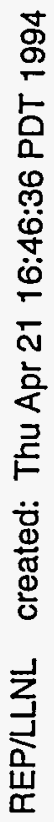




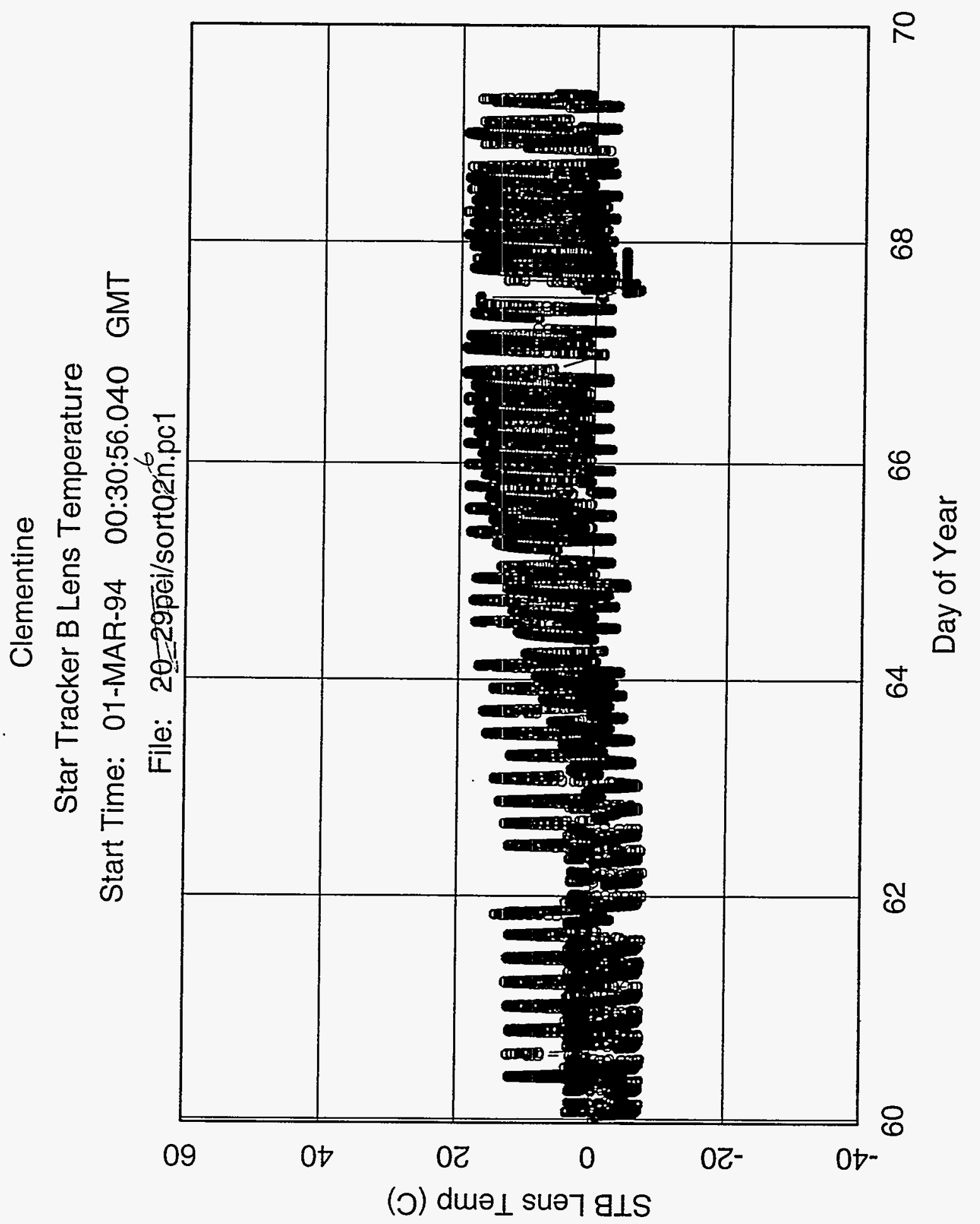

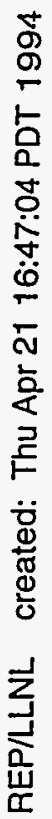




\section{S-16}

$$
50-59
$$




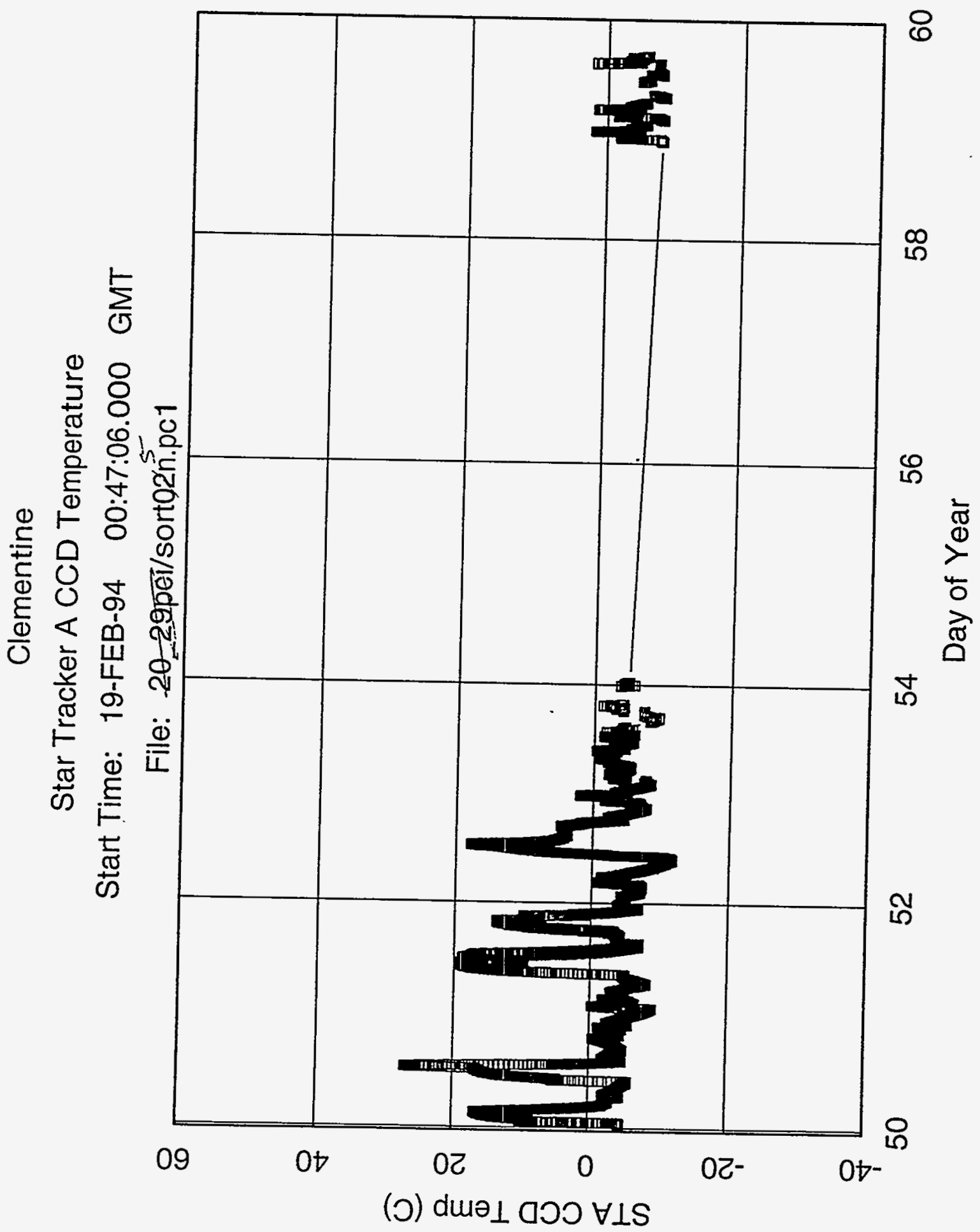

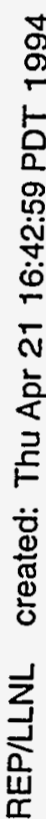




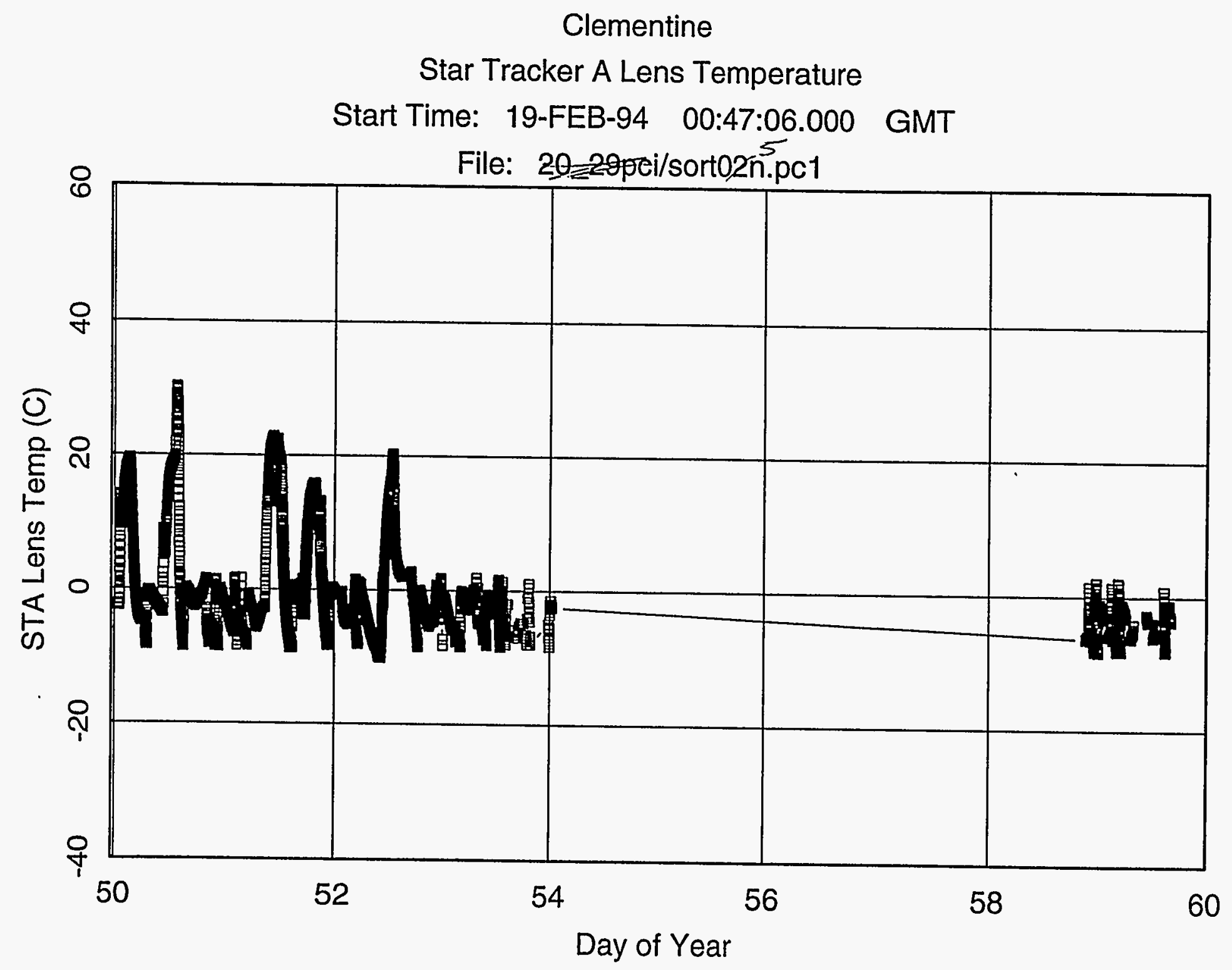

REP/LLNL created: Thu Apr 21 16:43:10 PDT 1994 


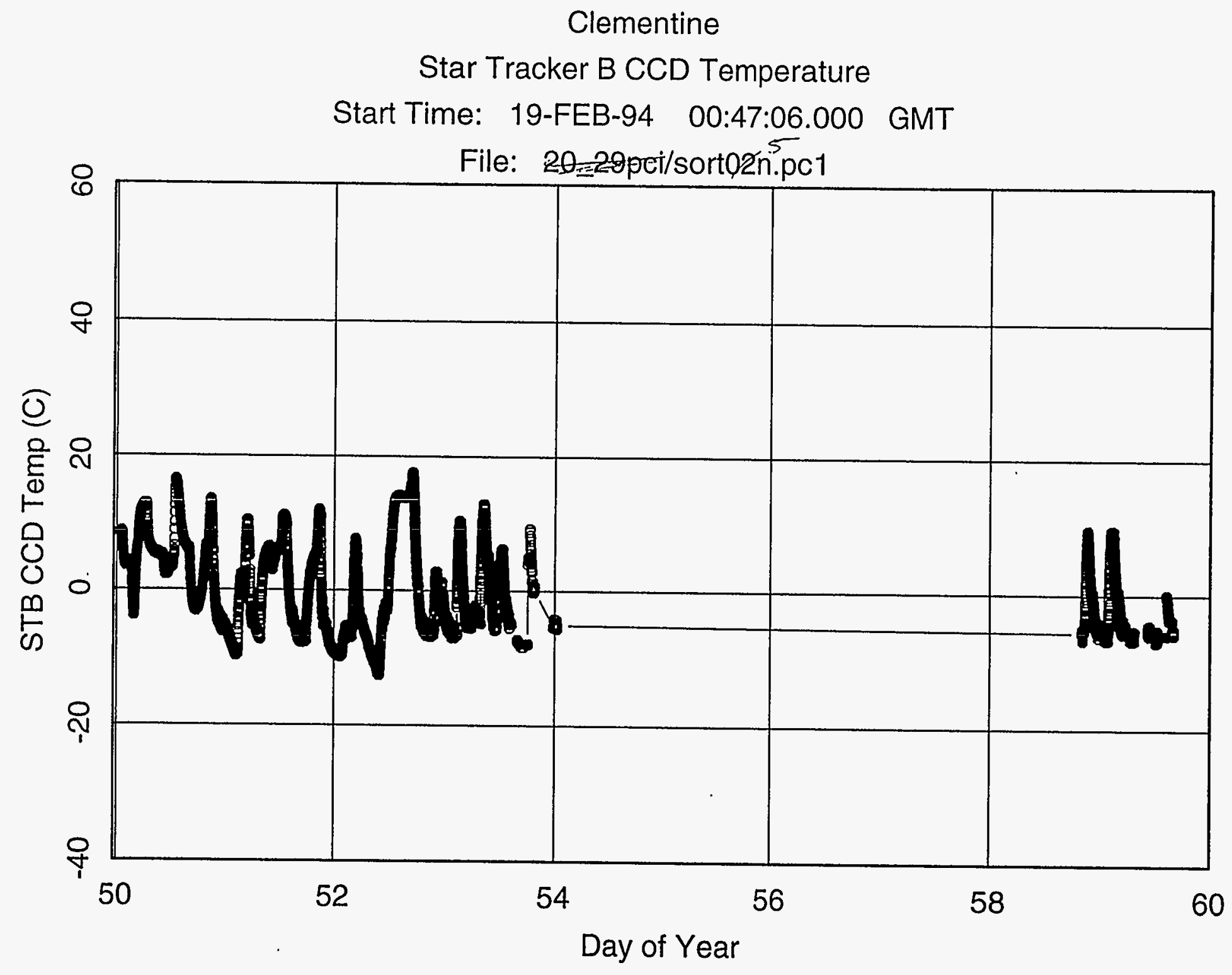

REP/LLNL created: Thu Apr 21 16:43:26 PDT 1994 


\section{Clementine}

Star Tracker B Lens Temperature

Start Time: $19-F E B-94 \quad$ 00:47:06.000 GMT

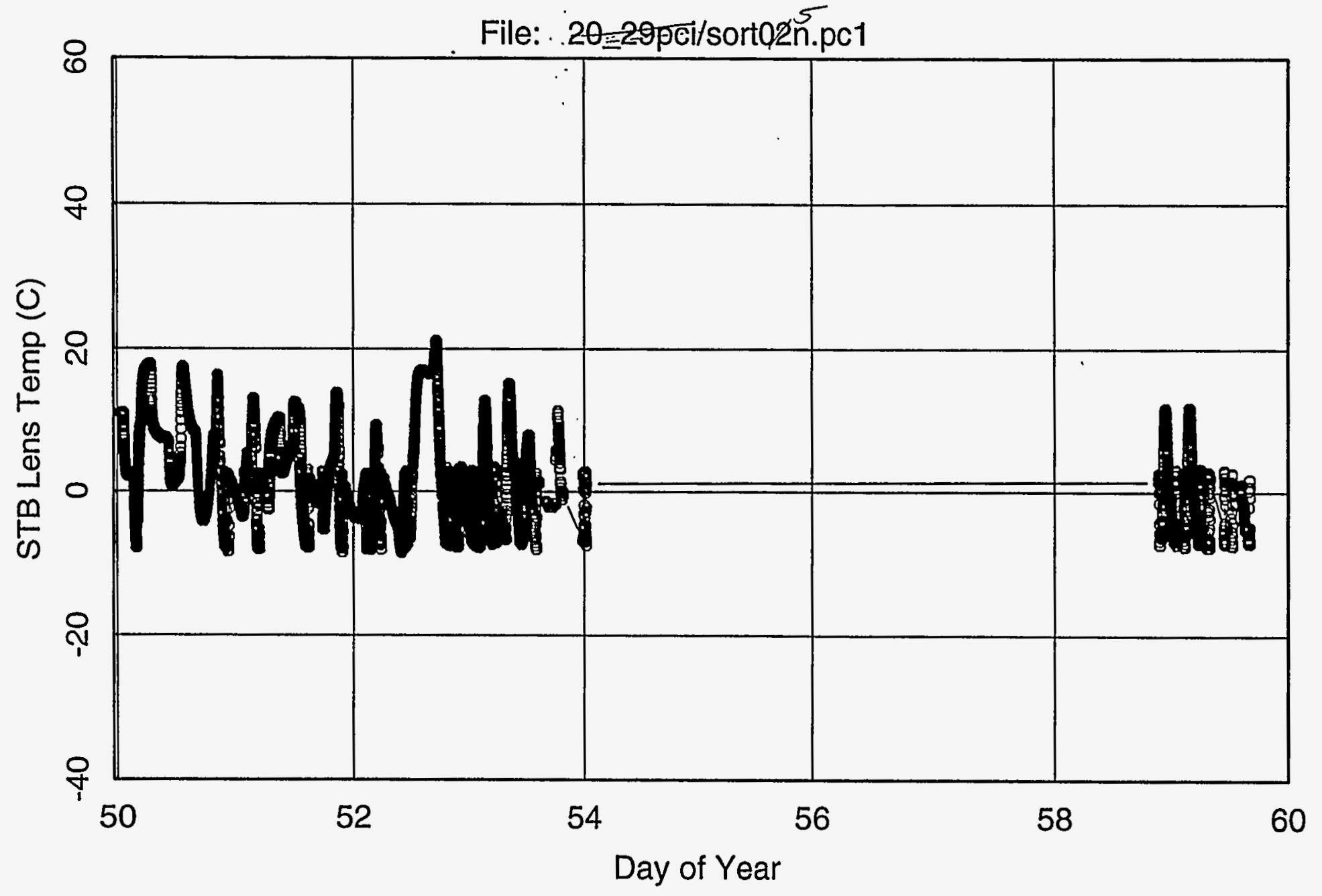




\section{S-16}

$40-49$ 


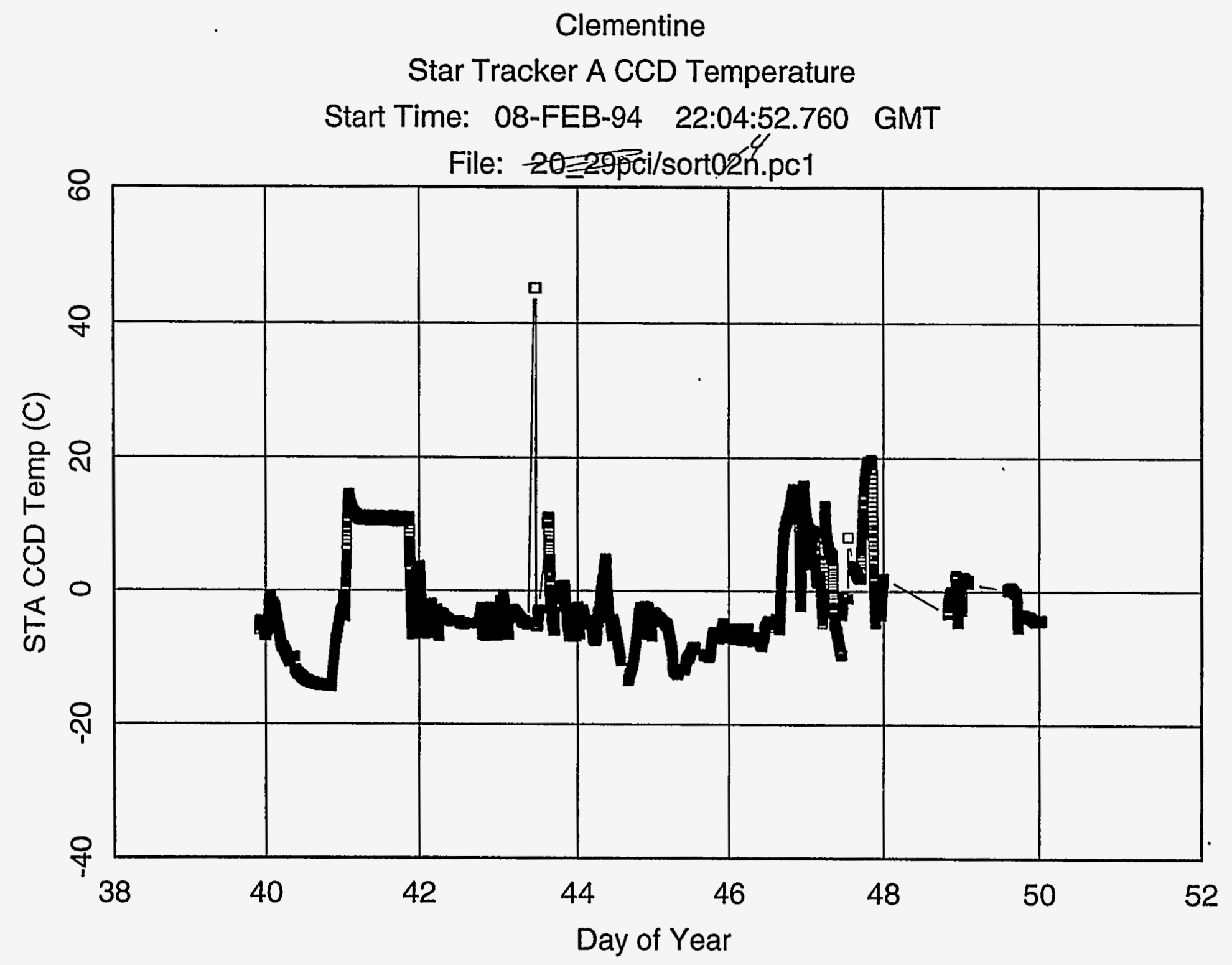

REP/LLNL created: Thu Apr 21 16:38:42 PDT 1994 


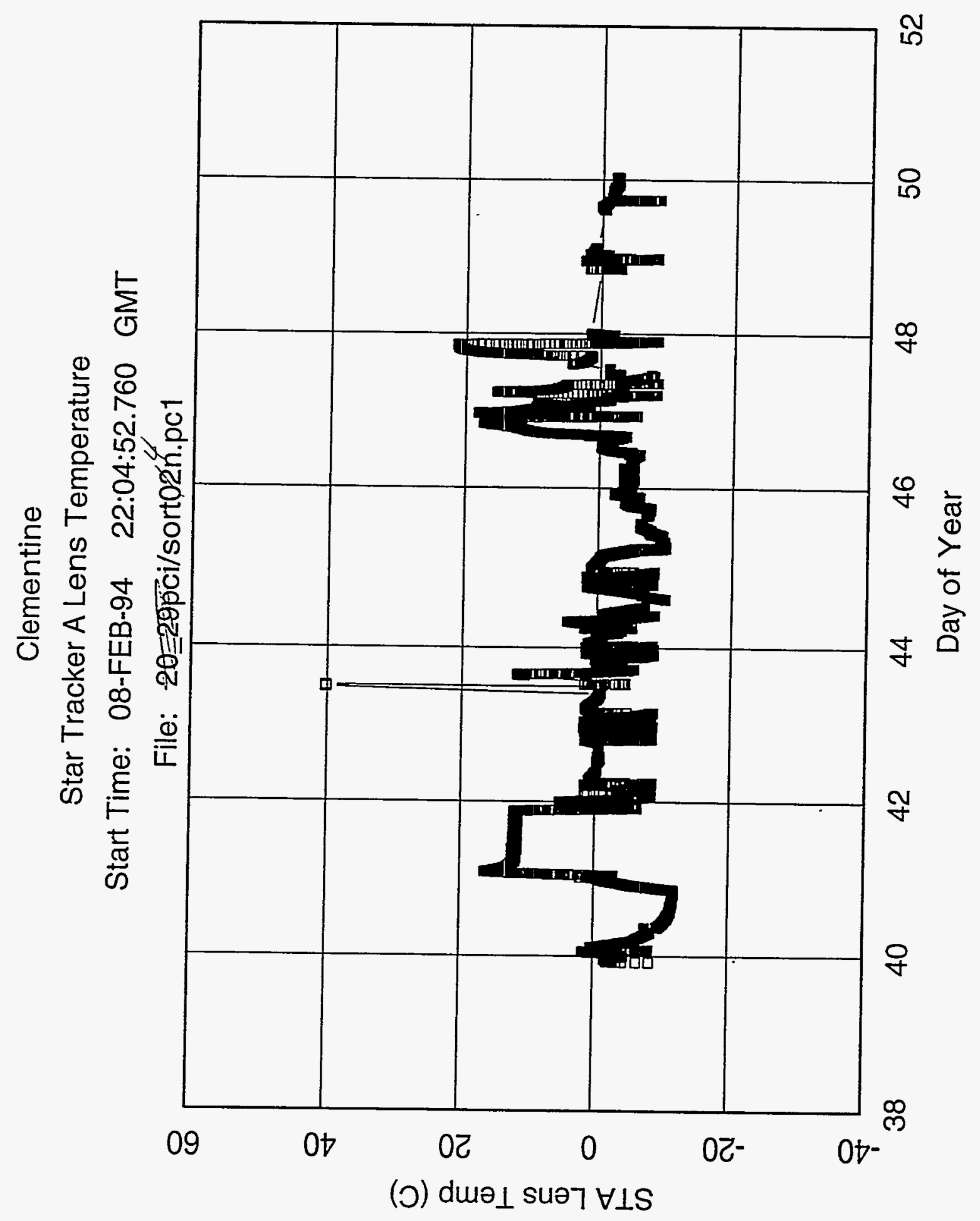

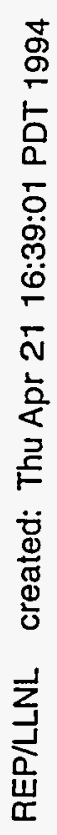




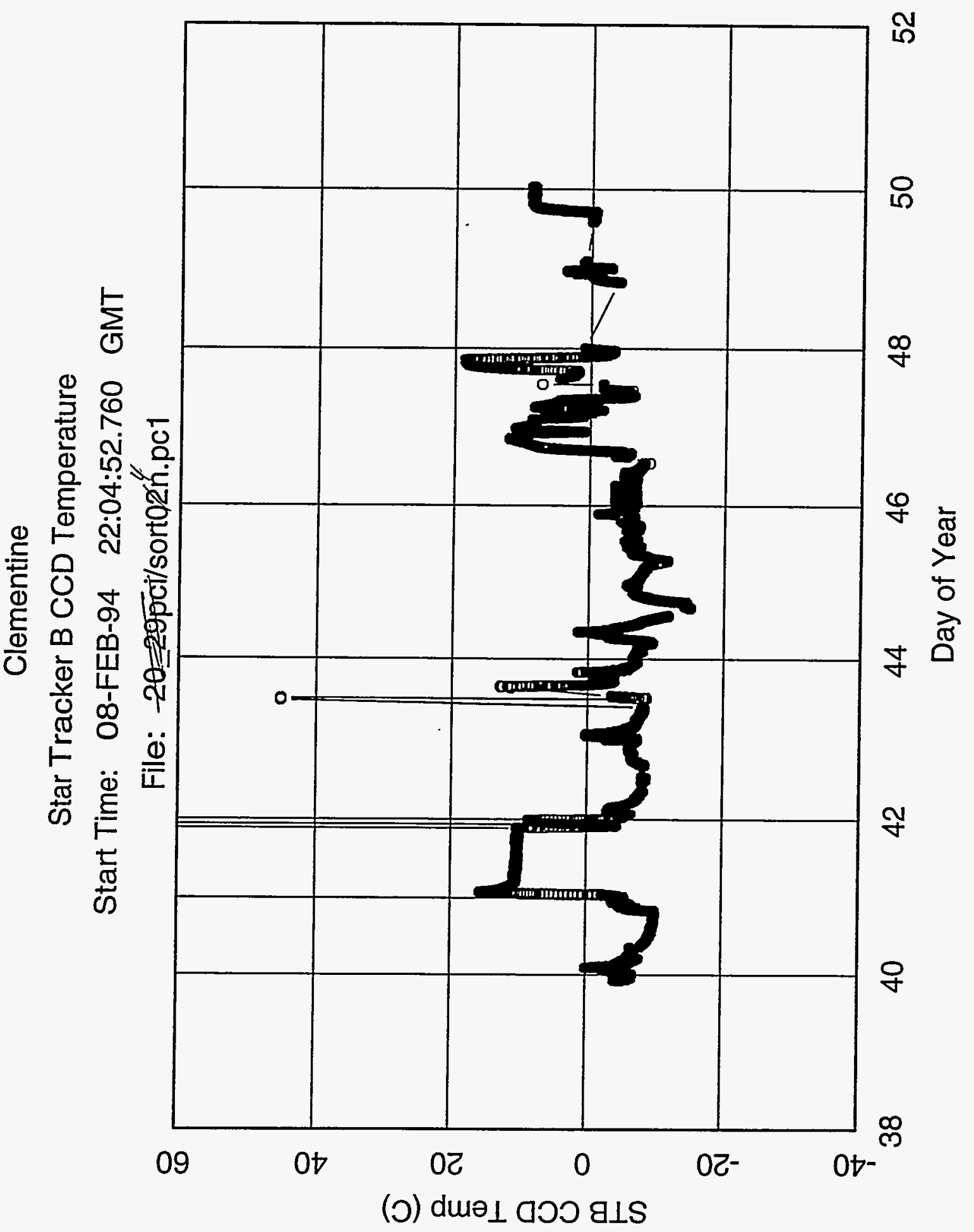

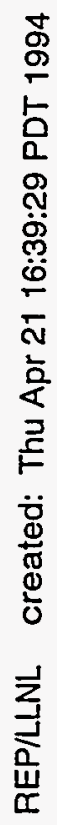




\section{Clementine}

Star Tracker B Lens Temperature

Start Time: 08-FEB-94 22:04:52.760 GMT

File: 20

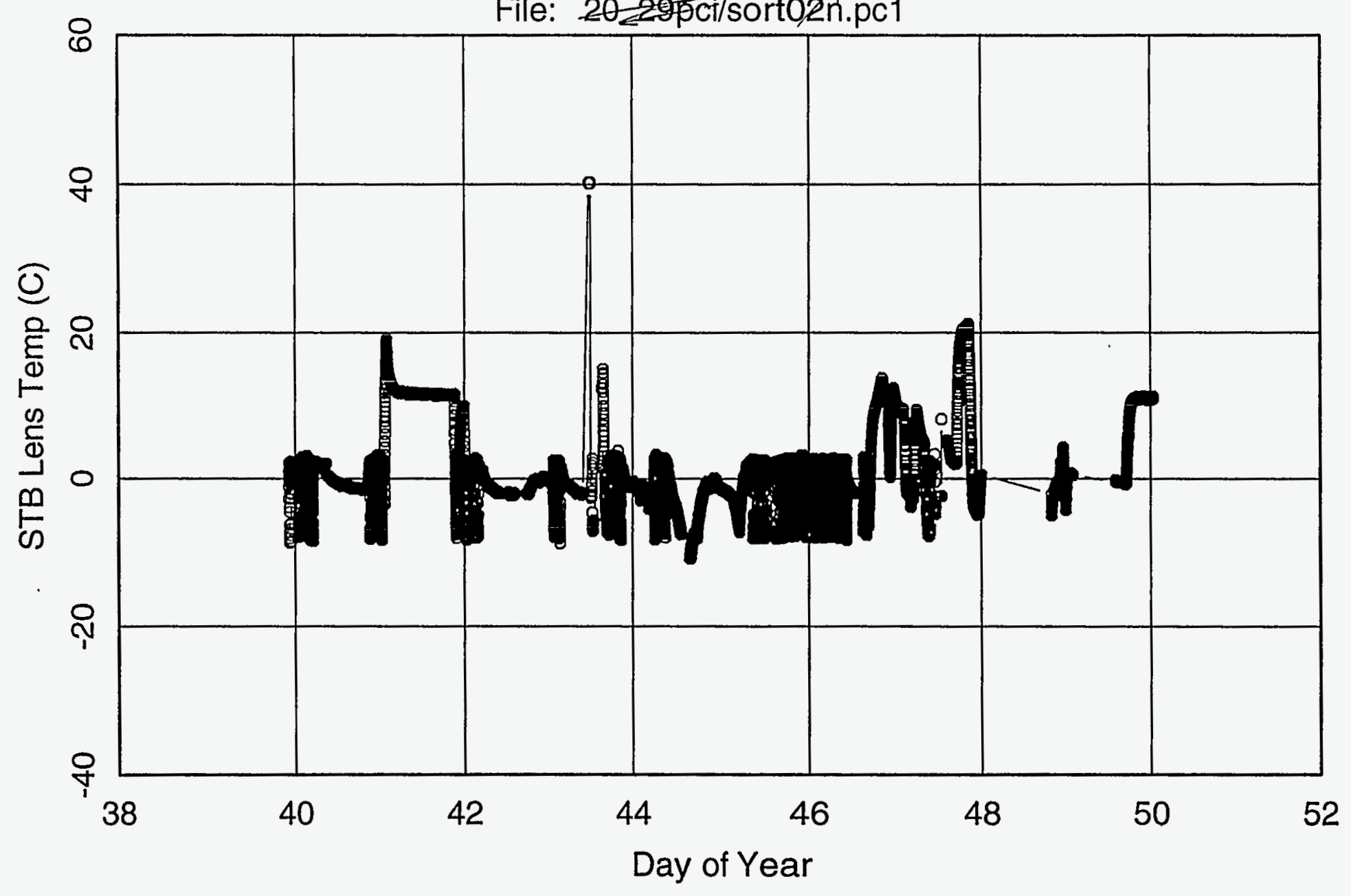


Clementine

Star Tracker A - Temperatures

Start Time: $15-F E B-94 \quad 20: 41: 52.380$ GMT

File: D046204P.PC1

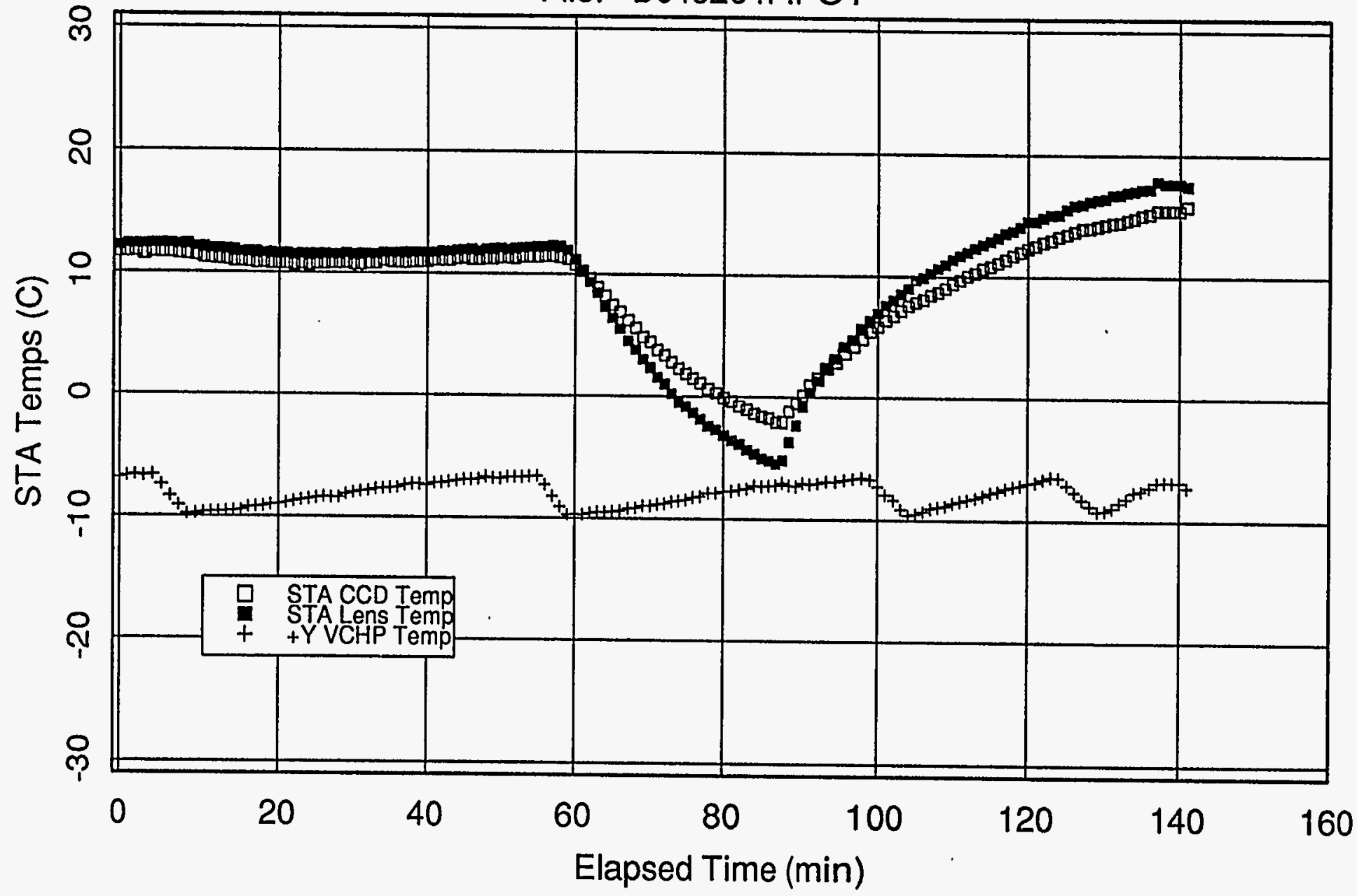

LLNL - ATP report date $=$ Wed Feb 16 12:03:14 PST 1994 directory $=$ /a/laverda/zz/clemwork/d046204px/SENSOR 


$$
\begin{gathered}
\text { S-16 } \\
30-39
\end{gathered}
$$




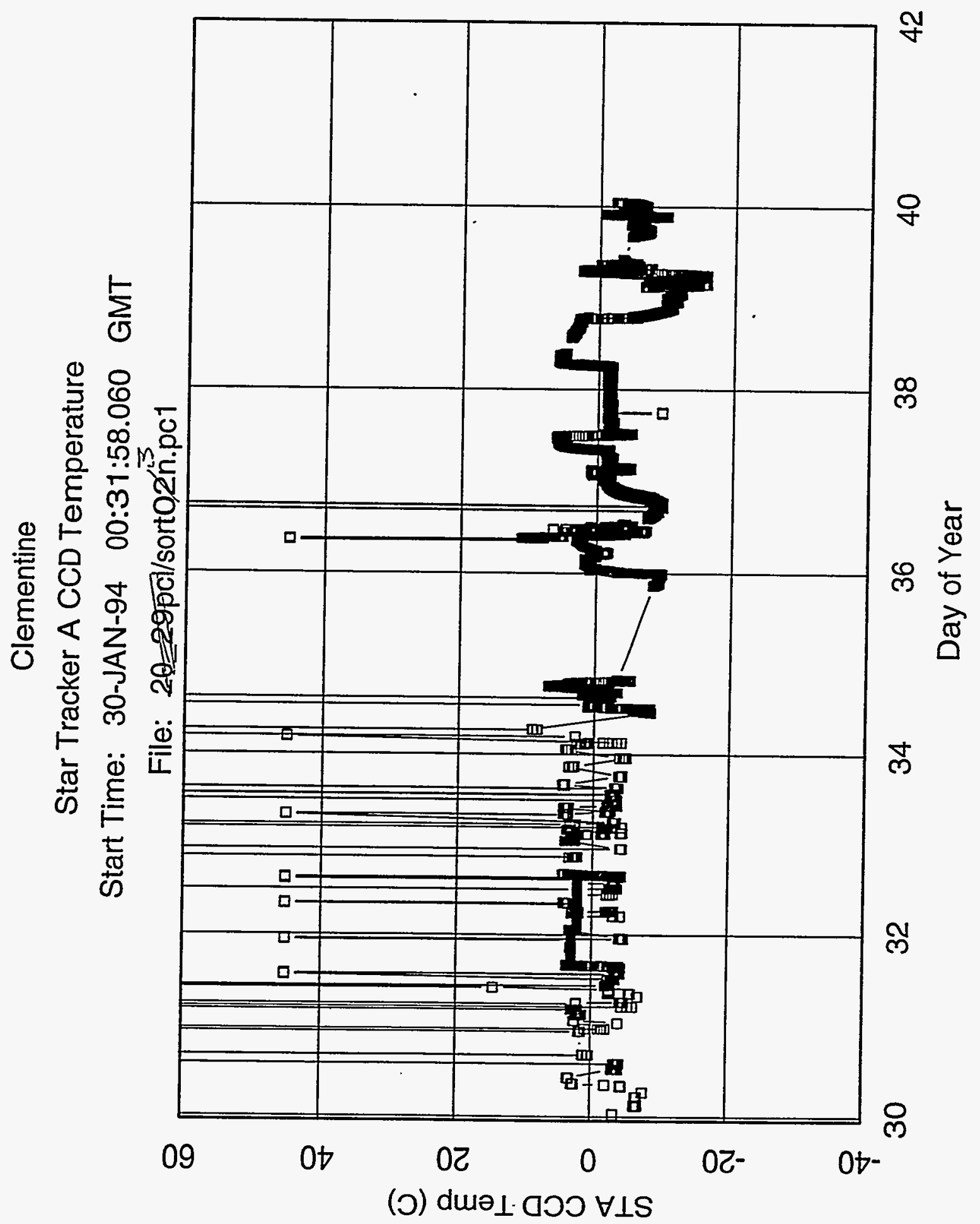

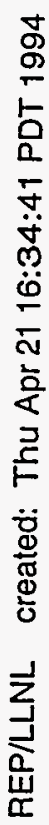




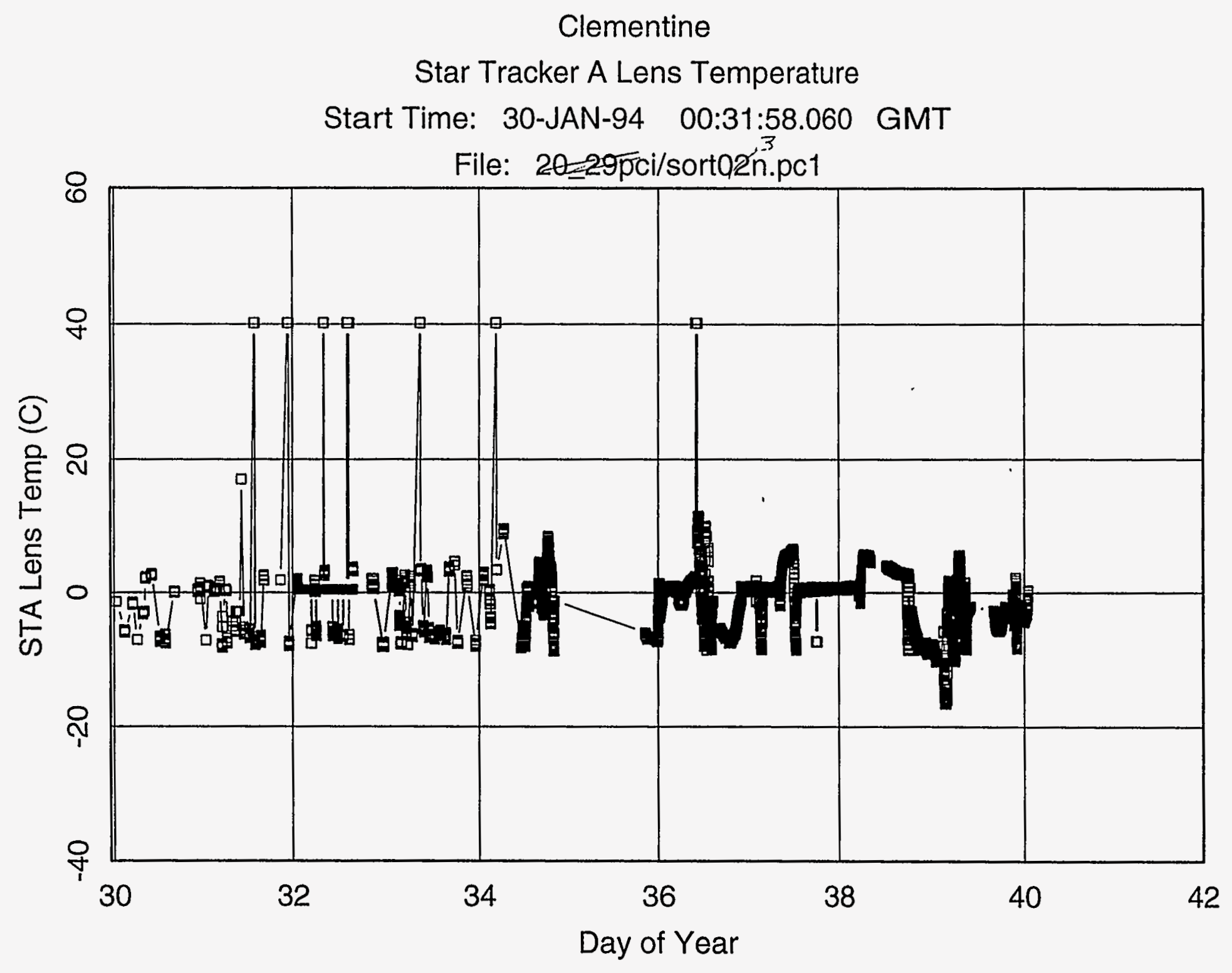

REP/LLNL created: Thu Apr 21 16:34:58 PDT 1994 
Clementine

Star Tracker B CCD Temperature

Start Time: 30-JAN-94 00:31:58.060 GMT

File: $2029 \bar{p}$ ci/sorto2n.pc1

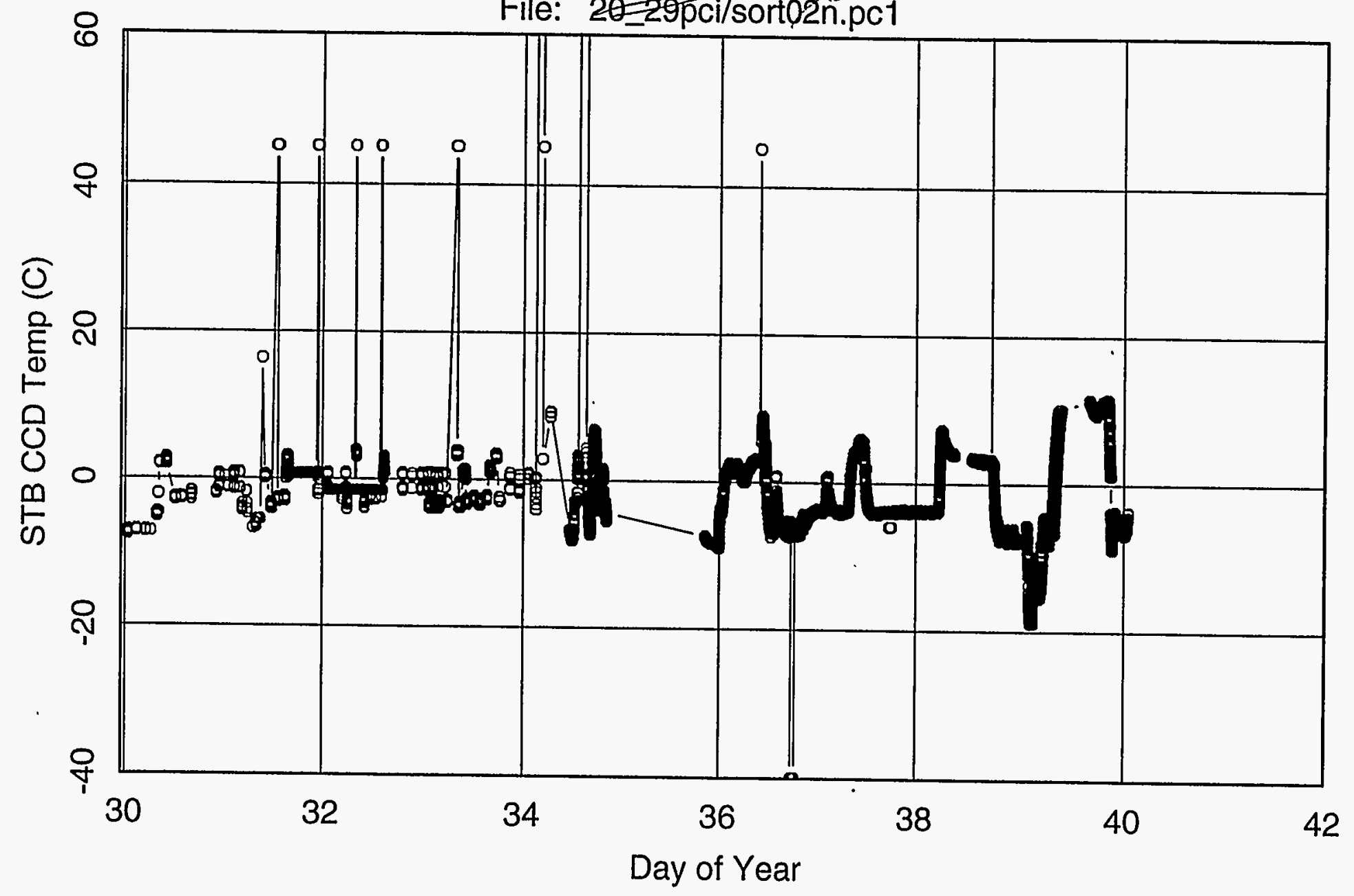

REP/LLNL created: Thu Apr 21 16:35:23 PDT 1994 


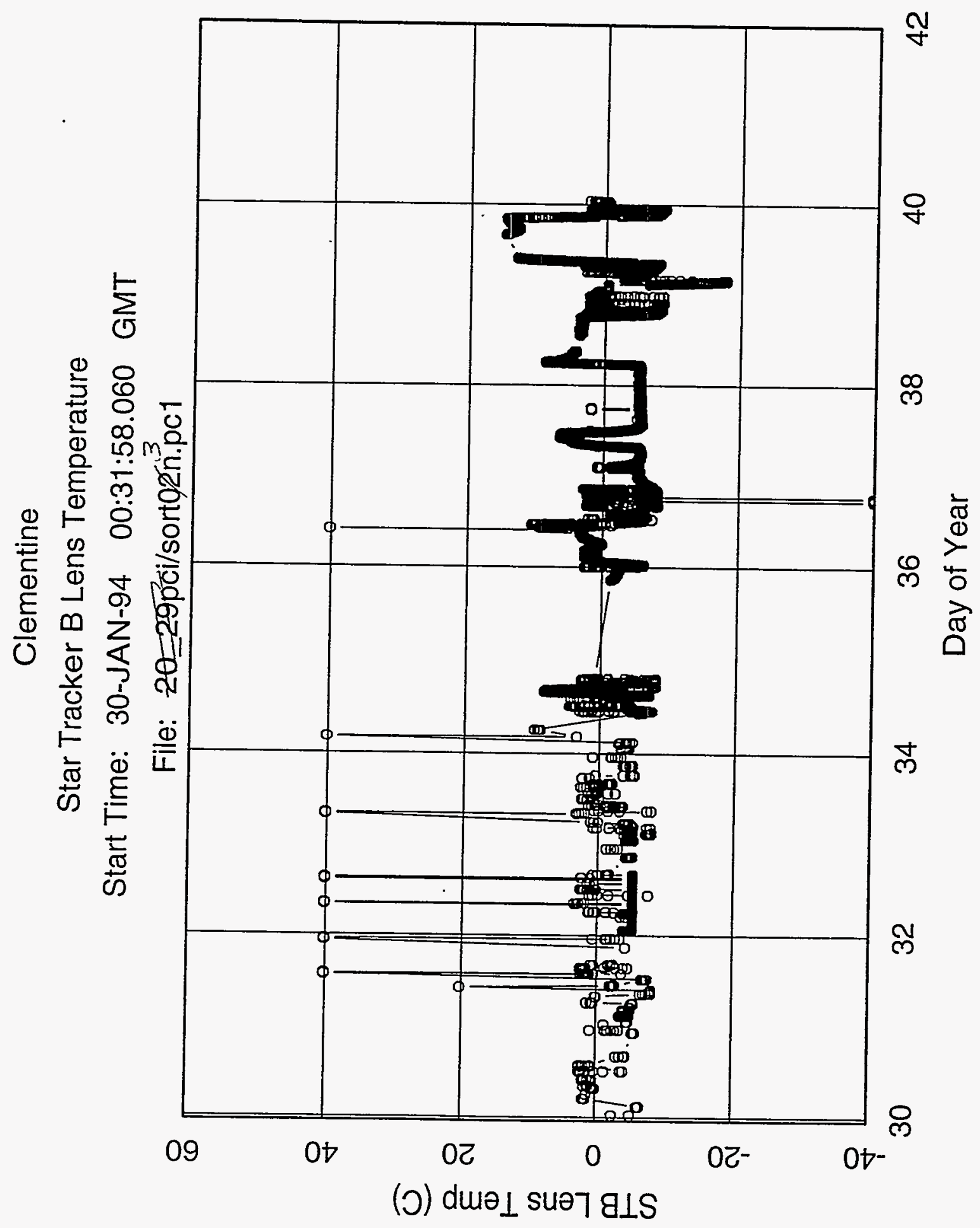

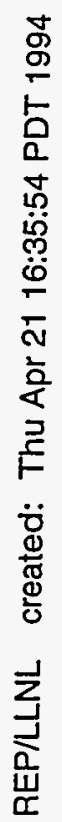




\section{S-16}

$20-29$ 


\section{Clementine}

Star Tracker A CCD Temperature

Start Time: 24-JAN-94 06:20:47.970 GMT

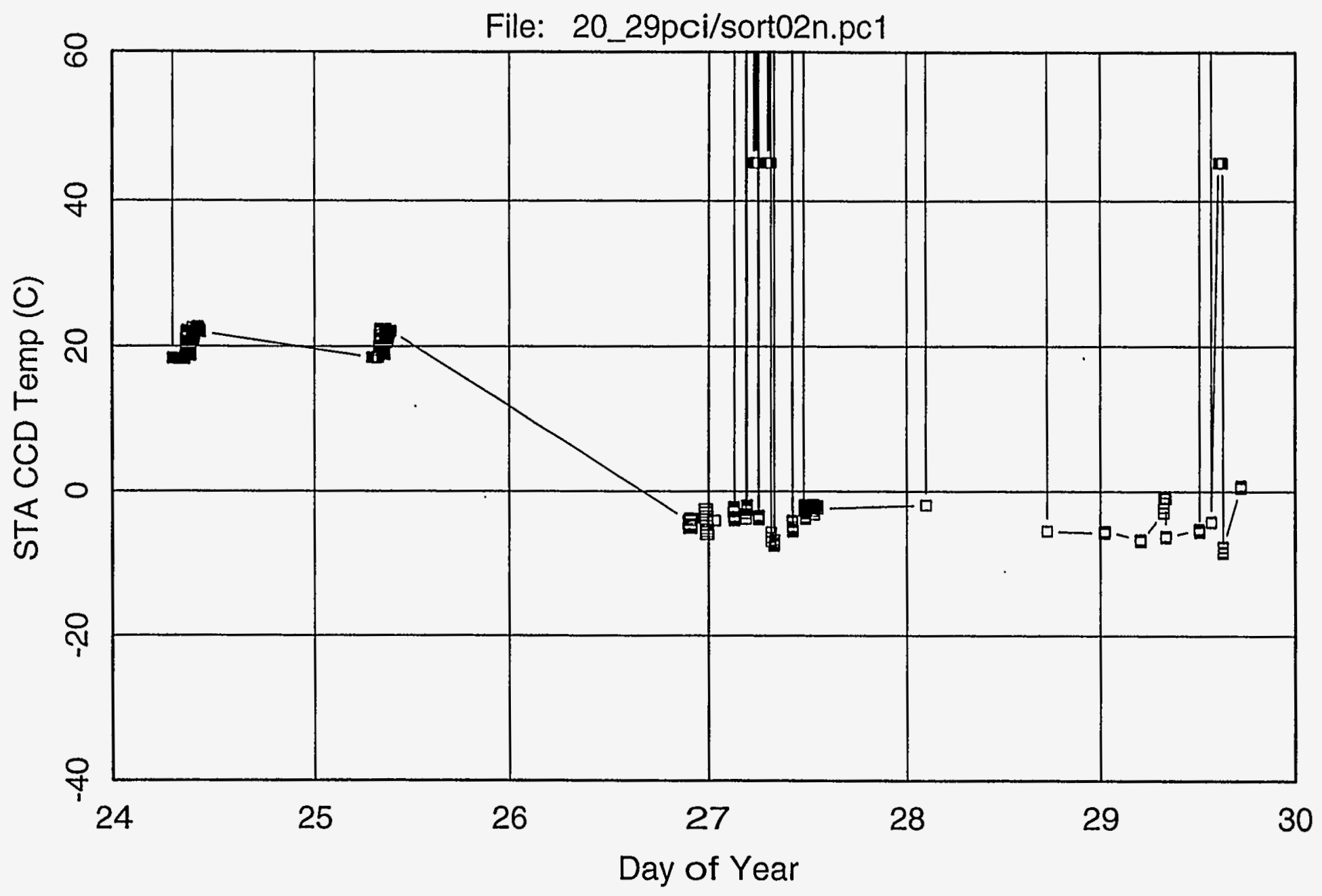


Clementine

Star Tracker A Lens Temperature

Start Time: 24-JAN-94 06:20:47.970 GMT

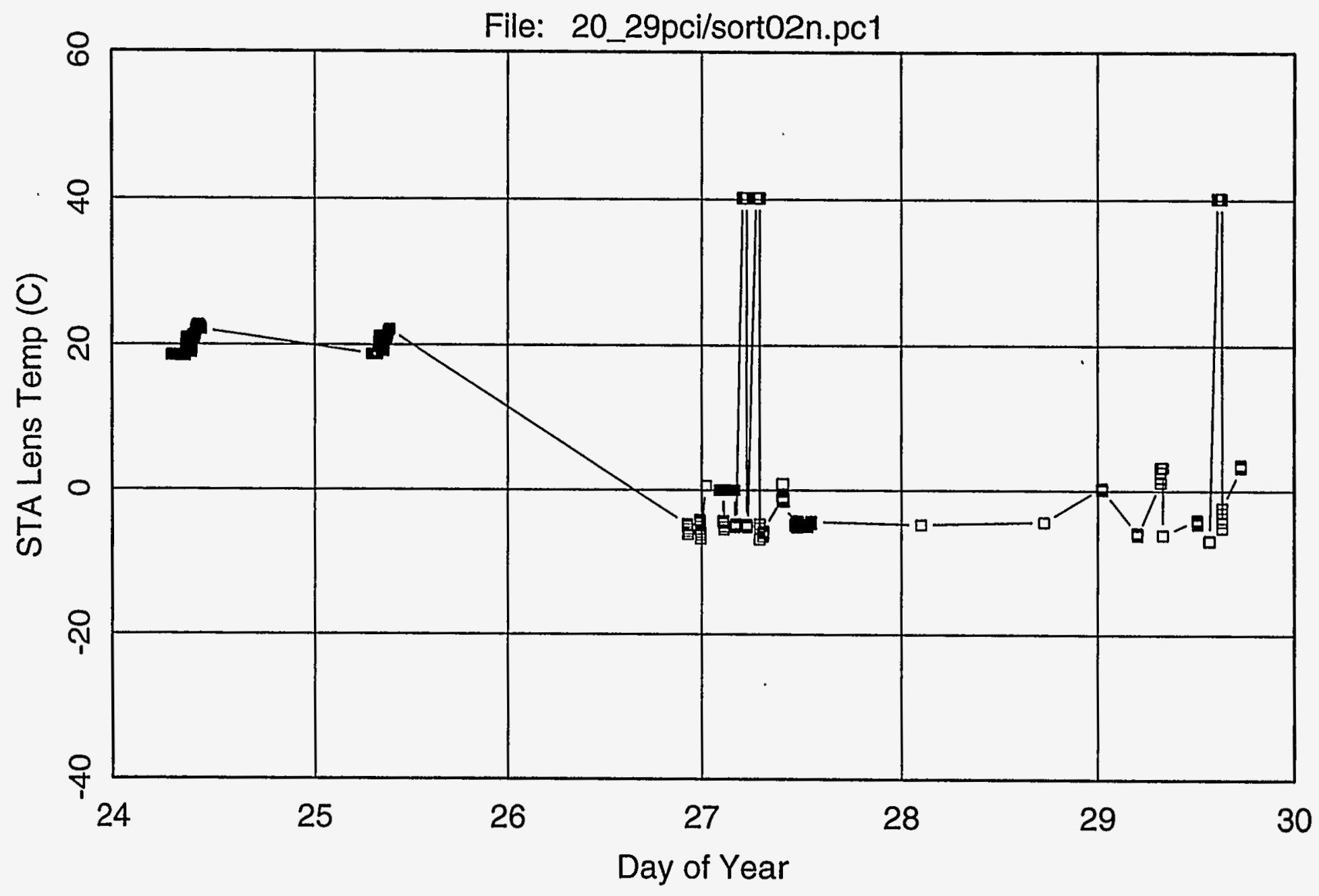

REP/LLNL created: Thu Apr 21 16:32:39 PDT 1994 
Clementine

Star Tracker B CCD Temperature

Start Time: $24-J A N-94$ 06:20:47.970 GMT

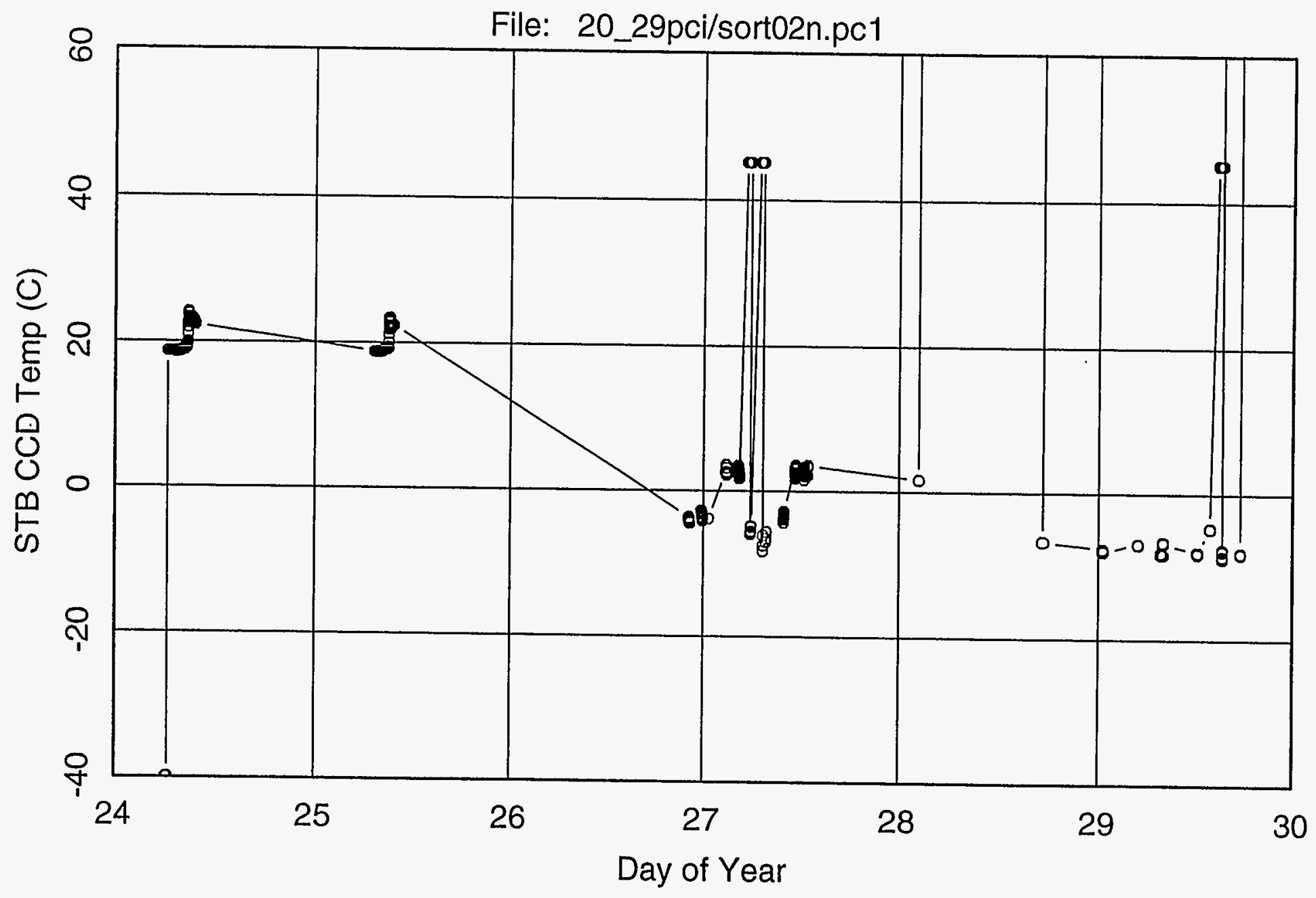

REP/LLNL created: Thu Apr 21 16:32:49 PDT 1994 


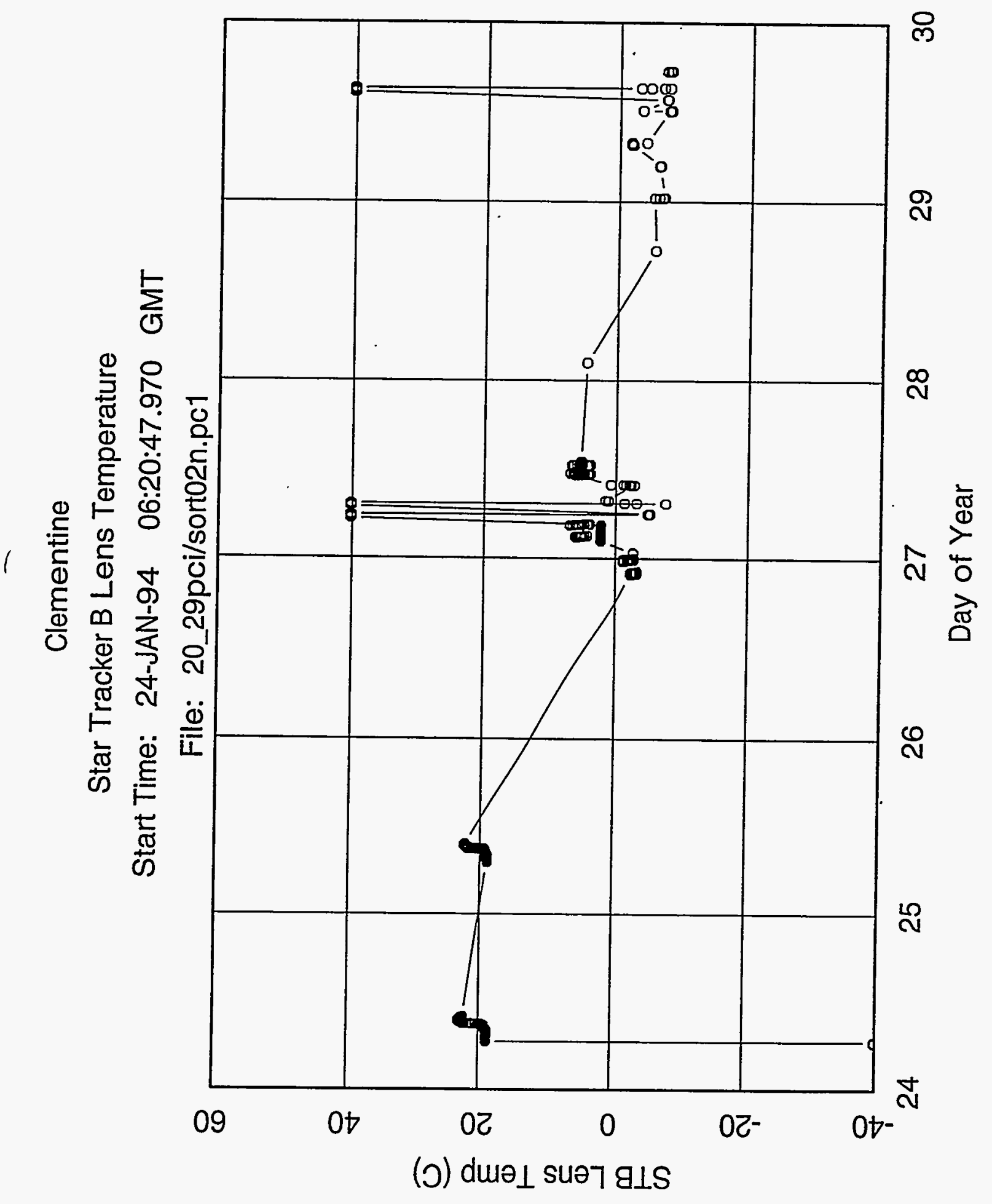

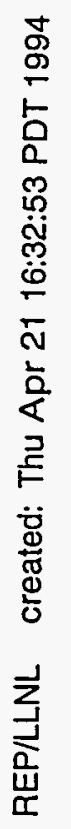




\section{Clementine}

Star Tracker A - Temperatures

Start Time: 25-JAN-94 07:07:44.950 GMT

File: a025024d.pc1
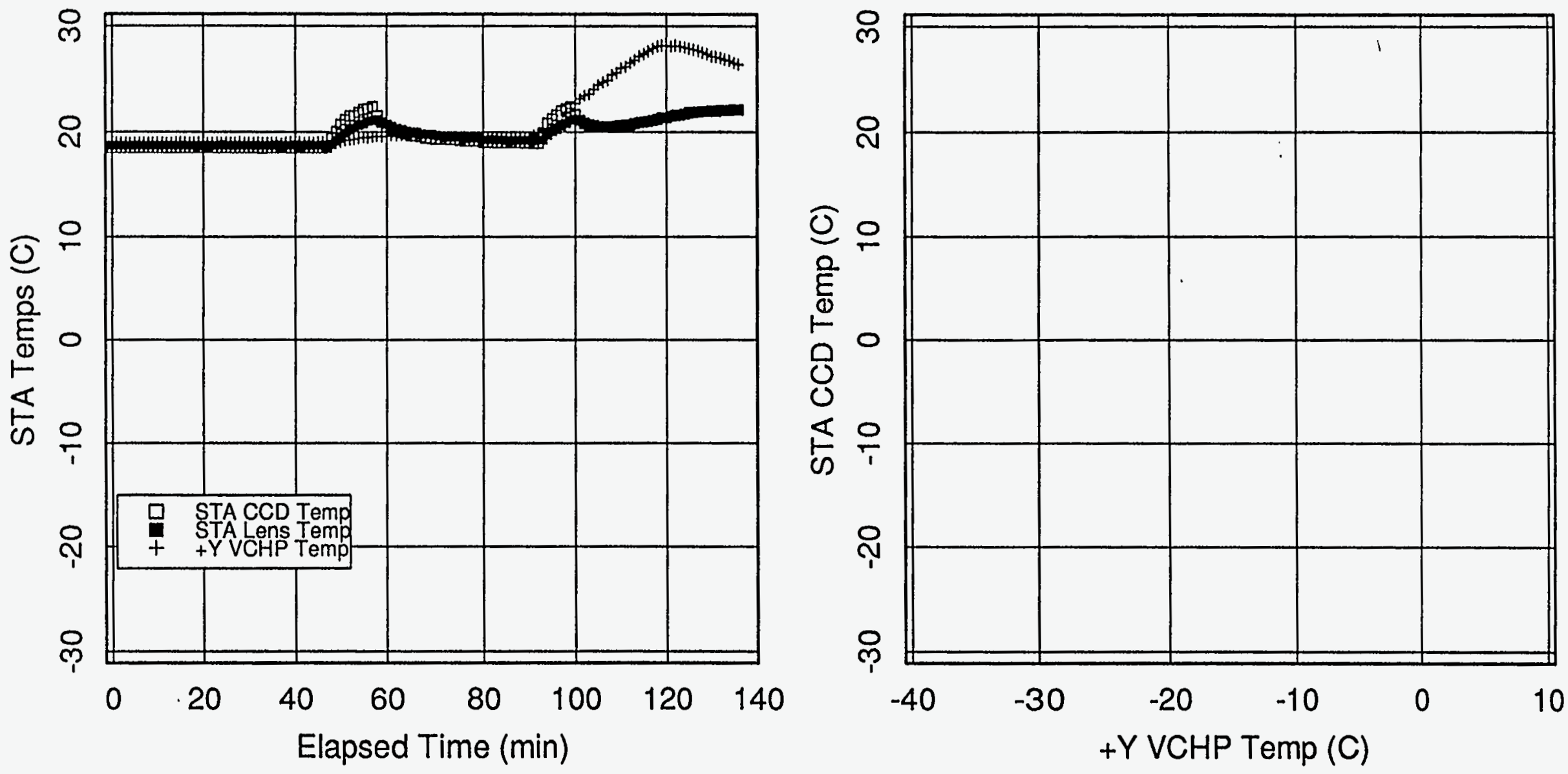


\section{Clementine \\ Star Tracker $\mathscr{A}^{\prime 3}-$ Temperatures}

Start Time: $25-J A N-94 \quad$ 07:07:44.950 GMT

File: a025024d.pc1
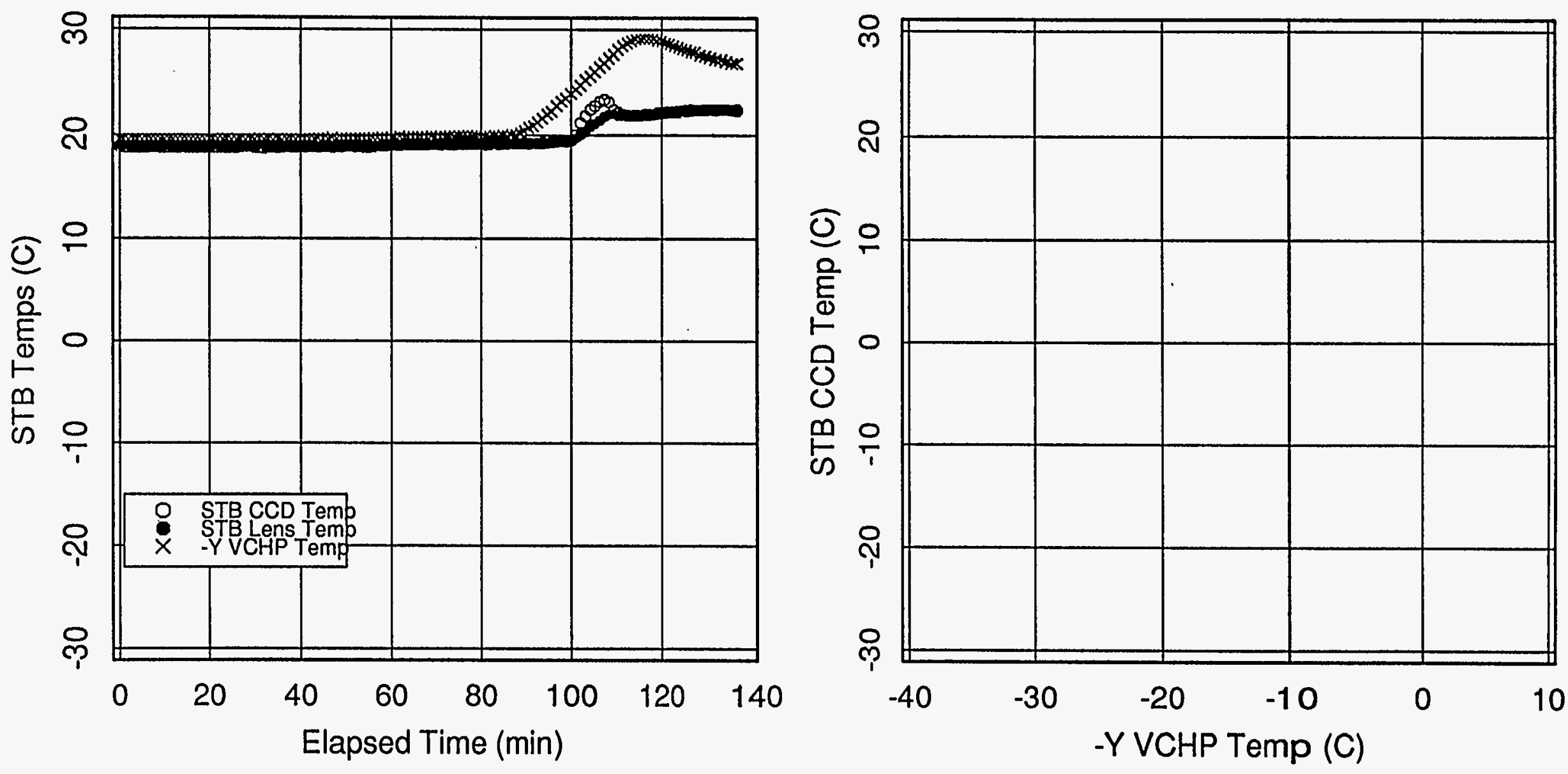
Appendix A General 


\section{Appendix A.1 \\ Clementine Sensor Suite Quality Assurance Stamp Procedure \\ (C1-EE-014)}




\begin{tabular}{|c|c|}
\hline $\begin{array}{c}\text { CLEMENTINE } \\
\text { Sensors Integration Project }\end{array}$ & $\begin{array}{c}\text { ENGINEERING NOTE } \\
\text { C1-EE-014 }\end{array}$ \\
\hline CLEMENTINE SENSOR SUITE & $\begin{array}{ll}\text { ASSY: } & \text { General EE } \\
\text { ORIG: } & \text { B R }\end{array}$ \\
\hline Quality Assurance Stamp Procedure & $\begin{array}{l}\text { DATE: } 22 \text { DEC } 1992 \\
\text { APPR: } \omega_{1}()^{2}{ }^{2}\end{array}$ \\
\hline
\end{tabular}

Abstract:

This document presents the procedures associated with the issuance and use of Quality Assurance stamps within the Clementine Sensor Integration Project. 


\section{Purpose}

To establish a control system that will identify authorized Inspector / Operators and designated personnel.

\section{Scope}

This procedure applies to all personnel involved with the use of Quality Assurance (QA) Stamps.

\section{Assignment of QA Stamps}

3.1 QA stamps will be issued to personnel certified in the following categories per Mil-Std2000: C-Instructor / Examiner, D-Inspector, E-Operator, H-Process Examiner and

R-Restricted Operator / Inspector. In addition certain designated personnel will also be issued QA stamps.

3.1.1 QA stamps in a round configuration with blue ink will be issued to category $C, D$, and certain designated personnel as specified by the Quality Assurance Manager.

3.1.2 QA stamps in a triangle configuration with red ink will be issued to category $C$, and certain designated personnel as specified by the Quality Assurance Manager.

3.1.3 QA stamps in a round configuration with green ink will be issued to operator category $E$ and $F$ personnel and certain designated personnel as specified by the Quality Assurance Manager.

3.2 Upon issuance of a QA stamp the Quality Assurance Manager or their designee will fill out a stamp assignment form as shown in Appendix A. This form will be filed in the QA office. It will remain on file for a minimum of one year after the termination of the contract.

\section{Maintenance of Stamp Status}

4.1 Each person issued a QA stamp shall be responsible for the use and safekeeping of that stamp.

4.2 Stamps will be used only on applicable documents that require signature verification.

4.3 Revocation of stamps shall be required under the following circumstances:

a. Proficiency requirements herein are not met.

b. New techniques have been developed which require new skills.

c. Certificate holder or designated personnel changes employer or project.

d. There is a reason to question proficiency or workmanship.

e. Failure to recertify within specified time limits.

4.4 QA stamps that have been retired shall not be reissued for a period of at least 6 months. 


\section{Use of QA Stamps}

5.1 QA stamps in a round configuration with blue ink will be used only when an inspected process, rework or assembly step is complete and or meets standards.

5.2 QA stamps in a triangle configuration with red ink will be used only when the inspected assembly or item has completed a major stage in assembly or test. These include but are not limited to the following:
a: Ready for test.
b. Ready for conformal coat.
c. Ready for mechanical assembly
d. Ready for calibration
e. Ready for environmental test
f. Ready to ship.

5.3 QA stamps in a round configuration with green ink will be used only by operators and certain designated personnel for in process steps. 
APPENDIX A

STAMP ASSIGNMENT FORM

(See 3.2)

DATE ISSUED:

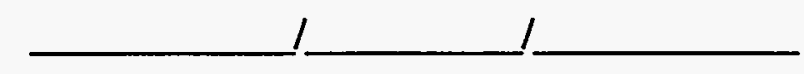

NAME:

SIGNATURE:

INITIAL:

NUMBER OF STAMP

ISSUED:

CATAGORY STATUS:

PROJECT NAME:

DATE TERMINATED:

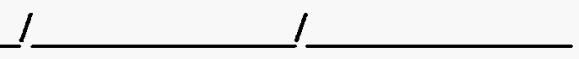




\section{Appendix A.2 \\ Printed Wiring Board Inspection Forms (C1-EE-020)}




\begin{tabular}{|c|c|c|}
\hline $\begin{array}{c}\text { CLEMENTINE } \\
\text { Sensors Integration Project } \\
\end{array}$ & $\begin{array}{l}\text { C1-EE-020 } \\
\text { Rev } 00\end{array}$ & \\
\hline \multirow{2}{*}{$\begin{array}{l}\text { TITLE: } \\
\text { CLEMENTINE SENSOR SUITE } \\
\text { Printed Wiring Board Inspection Forms }\end{array}$} & $\begin{array}{ll}\text { ASSY: } & \text { All } \\
\text { ORIG: } & \text { B. R. Quamme } \\
\end{array}$ & 문 \\
\hline & $\begin{array}{l}\text { DATE: } 9 \text { Feb. } 1993 \\
\text { APPR:COL }\end{array}$ & \\
\hline
\end{tabular}

\section{Abstract:}

This document provides inspection report forms for Clementine Sensor printed wiring boards. This document includes forms for bare board visual inspection, cross sectioning reports and assembly solder inspections. Reports shall include but are not limited to the information described in this document. 


\section{PWB Bare Board Visual Inspection}

Requester:

Mil-STD-2000: IPC-A600D, Class 3:

Board Serial \# Inspector Number or Initial

Date: Manufacturer

\begin{tabular}{|c|c|c|c|c|c|c|c|}
\hline Inspection & $\begin{array}{l}\text { MIL-P- } \\
551110 \\
\text { Para } \\
\end{array}$ & Acc & Rel & Inspection & $\begin{array}{l}\text { MIL-P. } \\
55110 \\
\text { Para } \\
\end{array}$ & Acc & Rel \\
\hline Visual & $4.8 .1 . / 3.5$ & $\square$ & $\square$ & $\begin{array}{l}\text { Plating and Coating } \\
\text { Thickness }\end{array}$ & 3.6 .9 & $\square$ & $\square$ \\
\hline Edges of PWB & 3.5.1 & $\square$ & $\square$ & Soldermask Thickness & 3.6.8 & $\square$ & $\square$ \\
\hline Surface Imperfections & 3.5 .2 & $\square$ & $\square$ & Plated-Thru Hole & 3.6.7.2 & $\square$ & $\square$ \\
\hline Subsurface Imperfections & 3.5 .3 & $\square$ & $\square$ & Annular Ring (External) & 3.6.7 & $\square$ & $\square$ \\
\hline Marking & 3.5.4 & $\square$ & $\square$ & Unsupported Hole & 3.6.7.1 & $\square$ & $\square$ \\
\hline Workmanship & 3.5 .5 & $\square$ & $\square$ & Conductor Spacing & 3.6.4 & $\square$ & $\square$ \\
\hline Solderability & 3.5 .6 & $\square$ & $\square$ & Conductor Pattern & 3.6 .5 & $\square$ & $\square$ \\
\hline Surface & 3.5 .6 .1 & $\square$ & $\square$ & Layer to Layer Registration & 3.6 .6 & $\square$ & $\square$ \\
\hline Hole & 3.5 .6 .2 & $\square$ & $\square$ & $\begin{array}{l}\text { Solder Mask Adhesion \& } \\
\text { Cure }\end{array}$ & 3.7 .1 & $\square$ & $\square$ \\
\hline Thermal Stress & 3.5 .7 & $\square$ & $\square$ & Plating Adhesion & 3.7 .2 & $\square$ & $\square$ \\
\hline Dimensional & $\begin{array}{l}3.6 / 3.6 .1 / \\
4.8 .3\end{array}$ & $\square$ & $\square$ & Conductor Edge Outgrowth & 3.7 .3 & $\square$ & $\square$ \\
\hline Hole Pattern & 3.6 .2 & $\square$ & $\square$ & Repair & 3.10 .5 & $\square$ & $\square$ \\
\hline Bow \& Twist & 3.6 .3 & $\square$ & $\square$ & & & & \\
\hline
\end{tabular}




\section{PWB Cross Section Summary}

Requester:

Mil-P-55110:

IPC-A600D, Class 3:

Part \#:

Lab ID: Lab Tech:

Date:

Thermal Shock:

Y/N Solder Float:

$\mathrm{Y} / \mathrm{N}$

Board Summary (Fill in after completing page 3, if applicable)

\begin{tabular}{lccc|c|c} 
Feature & None & Minor & Reject & $\begin{array}{l}\text { Measurement } \\
\text { if applicable }\end{array}$ & $\begin{array}{l}\text { Photograph \# } \\
\text { if applicable }\end{array}$ \\
\hline Epoxy Smear & $\square$ & $\square$ & $\square$ & & \\
Epoxy Etch & $\square$ & $\square$ & $\square$ & \\
Nail Heading & $\square$ & $\square$ & $\square$ & \\
Nodules & $\square$ & $\square$ & $\square$ & \\
Wicking & $\square$ & $\square$ & $\square$ & \\
Fiber Protrusion & $\square$ & $\square$ & $\square$ & \\
Resin Recession & $\square$ & $\square$ & $\square$ & \\
Plating Voids & $\square$ & $\square$ & $\square$ & \\
Delamination & $\square$ & $\square$ & $\square$ & \\
Neg. Etchback & $\square$ & $\square$ & $\square$ & \\
Plating Folds & $\square$ & $\square$ & $\square$ & \\
Blow Holes & $\square$ & $\square$ & $\square$ & \\
Hole Wall Pull & $\square$ & $\square$ & $\square$ & $\square$ \\
Laminate Voids & $\square$ & $\square$ & $\square$
\end{tabular}

Tin / Lead Thickness Surface Copper Thickness

Minimum Hole Wall Copper Thickness Maximum Mis-Registration Comments: 


\section{PWB Cross Section Detail}

\begin{tabular}{|c|c|c|c|c|c|c|c|}
\hline Inspection & $\begin{array}{l}\text { MIL-P. } \\
55110 \\
\text { Para }\end{array}$ & Acc & Rej & Inspection & $\begin{array}{l}\text { MIL-P- } \\
55110 \\
\text { Para }\end{array}$ & Acc & ReJ \\
\hline Material & $\begin{array}{l}3.4 .1 .1 \\
3.4 .1 .2\end{array}$ & $\square$ & [ & Undercutting & 3.8 .6 & & [ \\
\hline Traceability & 3.5.4.1 & $\square$ & [ & Annular Ring (Intemal) & 3.8 .7 & & L \\
\hline Thermal Stress & 3.5 .7 & & & Dielectric Layer Thickness & 3.8 .8 & & \\
\hline Conductor Spacing & 3.6.4 & & & Laminate Voids & 3.8 .9 & & {[} \\
\hline Layer to Layer Registration & 3.6 .6 & & & Resin Recession & 3.8 .10 & & \\
\hline $\begin{array}{l}\text { Plating and Coating } \\
\text { Thickness }\end{array}$ & 3.6 .9 & & & Lifted Lands & 3.8 .11 & & \\
\hline Construction Integrity & 3.8 & & & Plated-Thru Holes & 3.9 & & $\square$ \\
\hline Plated Copper Thickness & 3.8 .2 & & & Thermal Stress & 3.9 .1 & & \\
\hline Plating Voids & 3.8 .3 & $\square$ & & $\begin{array}{l}\text { Electrical \& Environmental } \\
\text { Requirements }\end{array}$ & $\begin{array}{l}3.10 \\
4.8 .7\end{array}$ & & L \\
\hline Resin Smear and Etchback & 3.8 .5 & $\square$ & & Circuitry & $\begin{array}{l}3.10 .3 \\
4.8 .7 .3\end{array}$ & & $\square$ \\
\hline $\begin{array}{l}\text { Hole Cleaning (Smear } \\
\text { Removal) }\end{array}$ & 3.8.5.1 & $\square$ & & Circuitry Continuity & 3.10.3.2 & & L \\
\hline Negative Etchback & 3.8.5.2 & $\square$ & {[} & Circuit Shorts & 3.10.3.3 & $\square$ & $\square$ \\
\hline Etchback & & $\square$ & $\Gamma$ & Repair. & 3.10 .5 & $\square$ & $\square$ \\
\hline
\end{tabular}




\section{PWB Assembly/Solder Inspection}

Requester: Mil-STD-2000: IPC-A600D, Class 3:

Board Serial \# Inspector Number or Initial

Date: Operator/Technician Number or Initial

Board Summary (Fill in after completing Visual-Inspection, if applicable)

\begin{tabular}{|c|c|c|c|c|c|c|c|}
\hline \multicolumn{4}{|c|}{ Visual-Inspection, Mil-Std-2000 Table XI } & \multicolumn{4}{|c|}{ Visual-Inspection, Mil-Std-2000 Table XI } \\
\hline Solder Defects & & Acc & Rej & Solder Defects & & Acc & Rej \\
\hline Non-soldered connections & A101 & $\square$ & $\square$ & Bridging & A102 & $\square$ & $\square$ \\
\hline Rosin Connection & A103 & $\square$ & $\square$ & Cold solder joint & A104 & $\square$ & $\square$ \\
\hline Fractured or disturbed & A105 & $\square$ & $\square$ & Insufficient solder & A106 & $\square$ & $\square$ \\
\hline $\begin{array}{l}\text { Excessive solder, lead not } \\
\text { discernible }\end{array}$ & A107 & $\square$ & $\square$ & Poor wetting & A108 & $\square$ & $\square$ \\
\hline Solder Splattering & A109 & $\square$ & $\square$ & $\begin{array}{l}\text { Pits, Pinholes, Holes, or } \\
\text { voids }\end{array}$ & A110 & $\square$ & $\square$ \\
\hline $\begin{array}{l}\text { Dewetting of solder } \\
\text { connection areas }\end{array}$ & A112 & $\square$ & $\square$ & $\begin{array}{l}\text { Solder points, peaks, or } \\
\text { icicles }\end{array}$ & A114 & $\square$ & $\square$ \\
\hline $\begin{array}{l}\text { Flux residue, oils, greases } \\
\text { on assembly }\end{array}$ & A115 & $\square$ & $\square$ & $\begin{array}{l}\text { Improper tinning of stranded } \\
\text { wire }\end{array}$ & A116 & $\square$ & $\square$ \\
\hline Overheated solder & A117 & $\square$ & $\square$ & $\begin{array}{l}\text { Unfilled plated through } \\
\text { hole,(when fill is required by } \\
\text { drawing) }\end{array}$ & A118 & $\square$ & $\square$ \\
\hline $\begin{array}{l}\text { Contaminants in solder } \\
\text { connection }\end{array}$ & A119 & $\square$ & $\square$ & Excess solder in bend radius & A120 & $\square$ & $\square$ \\
\hline $\begin{array}{l}\text { All other solder defects } \\
\text { except those listed as level } \\
\text { B process indicators }\end{array}$ & A121 & $\square$ & $\square$ & & & & \\
\hline
\end{tabular}




\begin{tabular}{|c|c|c|c|c|c|c|c|}
\hline Visual-Inspection, & lil-Std-2 & Table & $\mathbf{X I}$ & Visual-Inspection, & il-Std-2 & Tabl & $X I$ \\
\hline Assembly Defects & & Acc & $\mathbf{R e j}$ & Assembly Defects & & Acc & Roj \\
\hline $\begin{array}{l}\text { Improper Transmission of } \\
\text { stress of leads and wires } \\
\text { (improper stress relief) }\end{array}$ & $A 130$ & $\square$ & & $\begin{array}{l}\text { Metal cased components } \\
\text { mounted over circuit path } \\
\text { (not insulated) }\end{array}$ & A131 & & \\
\hline $\begin{array}{l}\text { Uninsulated wires or } \\
\text { component leads routed } \\
\text { over the circuit path where } \\
\text { shorting is possible }\end{array}$ & A132 & $\square$ & & $\begin{array}{l}\text { Charring, buming, or } \\
\text { damage to insulation } \\
\text { (affecting electrical } \\
\text { operation) }\end{array}$ & A133 & & \\
\hline Birdcaged wire & A134 & & & Cut or nicked leads or wires & A135 & & \\
\hline $\begin{array}{l}\text { Leads or wires scraped, } \\
\text { exposing metal or stretched }\end{array}$ & A136 & $\square$ & $\square$ & $\begin{array}{l}\text { Lead clinched beyond } \\
\text { allowable limits (electrical } \\
\text { clearance insufficient) }\end{array}$ & A137 & $\square$ & \\
\hline $\begin{array}{l}\text { Excessive lead length } \\
\text { (electrical clearance } \\
\text { insufficient) }\end{array}$ & A138 & $\square$ & & Insufficient lead length & A139 & & \\
\hline Excessive wicking & A140 & & & $\begin{array}{l}\text { Improper insulation } \\
\text { clearance }\end{array}$ & A141 & & \\
\hline Excessive terminal fill & A142 & $\square$ & $\square$ & Improper lead bend radius & A143 & $\square$ & \\
\hline $\begin{array}{l}\text { Improper lead bend } \\
\text { clearance }\end{array}$ & A144 & $\square$ & & $\begin{array}{l}\text { Unclinched components } \\
\text { where clinching is required }\end{array}$ & A145 & & \\
\hline $\begin{array}{l}\text { Component has improper } \\
\text { clearance to adjacent } \\
\text { components }\end{array}$ & A146 & $\square$ & $\square$ & $\begin{array}{l}\text { Component has improper } \\
\text { clearance above the PWB }\end{array}$ & A147 & & \\
\hline $\begin{array}{l}\text { Component not sufficiently } \\
\text { supported }\end{array}$ & A148 & $\square$ & & $\begin{array}{l}\text { Glass-cased components } \\
\text { not protected by buffer } \\
\text { material when epoxy } \\
\text { conformal coating is used }\end{array}$ & A149 & $\square$ & \\
\hline $\begin{array}{l}\text { Component less than } 1 / 16 \\
\text { inch }(1.6 \mathrm{~mm}) \text { to edge of } \\
\text { PWB causing interference }\end{array}$ & A150 & $\square$ & & $\begin{array}{l}\text { Component obscures } \\
\text { termination or another } \\
\text { component (unless design } \\
\text { dictates otherwise) }\end{array}$ & A151 & & \\
\hline $\begin{array}{l}\text { Physical damage of } \\
\text { components }\end{array}$ & A152 & $\square$ & & $\begin{array}{l}\text { Improper vertical mounted } \\
\text { component clearance }\end{array}$ & A153 & $\square$ & $\square$ \\
\hline Improper terminal swaging & A154 & & $\square$ & $\begin{array}{l}\text { Leads cut after final } \\
\text { soldering }\end{array}$ & A155 & $\square$ & $\square$ \\
\hline Wrong parts used & A156 & & $\square$ & $\begin{array}{l}\text { Wrong orientation of } \\
\text { polarized components }\end{array}$ & $A 157$ & $\square$ & $\square$ \\
\hline
\end{tabular}




\begin{tabular}{|c|c|c|c|c|c|c|c|}
\hline \multicolumn{4}{|c|}{ Visual-Inspection, Mil-Std-2000 Table XI } & \multicolumn{4}{|c|}{ Visual-Inspection, Mil-Std-2000 Table XI } \\
\hline Assembly Defects & & Acc & Rej & Assembly Defects & & Acc & Rej \\
\hline $\begin{array}{l}\text { Component improperly } \\
\text { spaced or located }\end{array}$ & A158 & $\square$ & $\square$ & Damage to wire or strands & A159 & $\square$ & \\
\hline $\begin{array}{l}\text { Pattern delaminated (after } \\
\text { solder) }\end{array}$ & A180 & & & $\begin{array}{l}\text { Burned, scorched PWB or } \\
\text { parts }\end{array}$ & A181 & $\square$ & \\
\hline $\begin{array}{l}\text { Excessive warp or twist (after } \\
\text { solder) }\end{array}$ & A182 & & & Delamination of base material & A184 & & \\
\hline $\begin{array}{l}\text { Separation of conductor } \\
\text { pattern }\end{array}$ & A185 & & $\square$ & & & & \\
\hline
\end{tabular}




\section{Appendix A.3 \\ Clementine Sensor Suite Failure Reporting, Analysis and Corrective Action System \\ (C1-EE-021)}




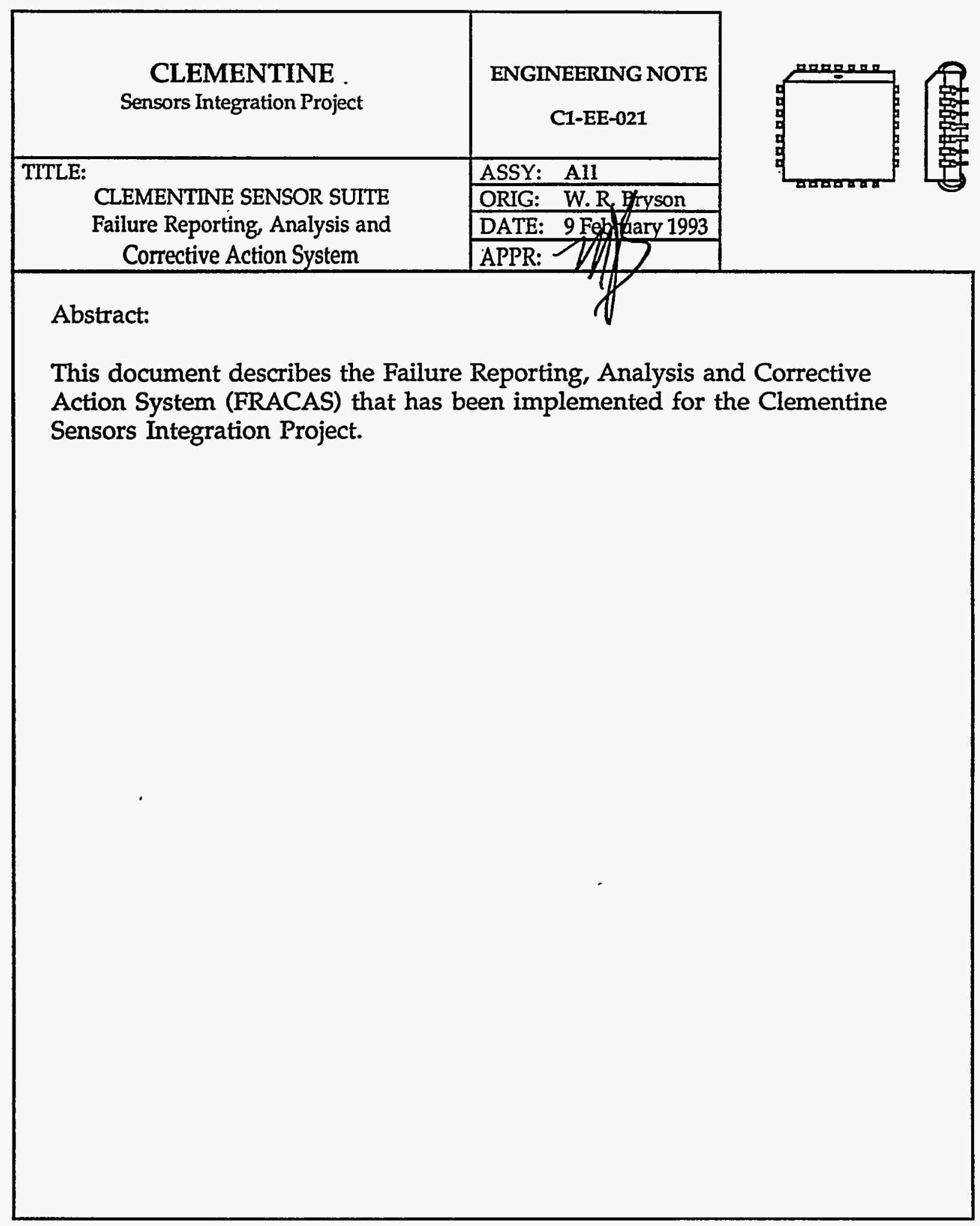




\subsection{Introduction}

A closed loop system for reporting, analysis, and correction of failures will be in effect for failures occurring during the assembly and testing phase of the Clementine Sensor Integration Project. The FRACAS will determine whether failures are caused by design deficiencies, human error, defective parts, infant mortality, test equipment, environmental exposure, or software. Once the cause of the failure is determined, timely corrective action will be initiated to prevent recurrence. The corrective action will then be followed up to make certain that it is effective.

\subsection{Roles and Responsibilities}

Implementation, direction, and monitoring of the FRACAS is the responsibility of the LLNL Quality Assurance Group (QAG), they will review and record all discrepant material, inspection and test records, and other quality reports to ascertain the existence of quality or reliability problems. They will assure that all failures and follow-up actions occurring during the acceptance test phase are documented to enable resolution of all failures. A Test Discrepancy Report (TDR) is initiated by the cognizant test engineer immediately upon failure occurrence. The project lead engineer is responsible for the FRACA recommendations. The LLNL QAG follows up on each FRACA action to assure that adequate corrective action is implemented to correct the cause of the discrepant condition.

\subsection{Procedures}

The procedures described herein are based on established FRACA procedures and provide a closed loop system to report, analyze and correct failures encountered during all assembly and acceptance testing.

\subsection{Discrepancy Reporting}

All failures, unusual events or anomalies occurring during the assembly or acceptance test phase are reported. All TDRs will be flagged as to the level of concern (Red, Yellow or Green). The LLNL QAG will use the TDR form contained in Appendix $A$ to record data and information. The cognizant test engineer assures that the appropriate information is included and that the TDR is complete and accurate. The project lead engineer performs a preliminary analysis of all failure reports and informs the LLNL QAG, program management, and engineering of any needed changes. Failures requiring a design change are evaluated and recommendations are made to change the baseline design.

\subsection{Distribution}

All TDRs are filed at LLNL and provided to SDIO in the form of a monthly report. Any Red or Yellow level event will be tracked in subsequent reports until they are closed out. The TDR report number is referenced in all "as-built" equipment logs and a master data base enables location of the TDR copy in the QA files. Distribution of the original and additional reproduced copies is as follows: 
- Original TDR - The original copy remains with the failed sensor, unit, assembly, module, or part and performs the function of a shop traveler until the failure analysis is completed. Upon completion and close-out of the TDR, the original is made a part of the "as-built" documentation package.

- Backup Copy - The backup copy is provided to the LLNL QAG. This copy remains in a suspense file until the FRACA is completed. A copy of the completed and approved original copy is received by LLNL QAG for close-out of the TDR.

- Additional Copies - Reproductions of the original TDR are provided to the cognizant test engineer and are included in the monthly report to SDIO. Copies of the completed original TDR are provided to the cognizant test engineer and to LLNL QAG for formal TDR close-out.

\subsection{Additional TDRs}

Additional TDRs are used to document the event sequence on any hardware item that is removed from the original failed item, and the first TDR always remains with the original failed unit. Additional TDRs are minimized to maintain only those necessary to document completely the event sequence from higher-level assemblies to the failed part or component. In each case where a new TDR is initiated, the previous TDR shall be referenced to provide two-way traceability from the initial failure occurrence to the final corrective action. Appendix B provides an example that illustrates the manner in which the TDR's are prepared and copies are distributed.

\subsection{Failure Analysis}

A failure analysis is performed on all TDRs prepared for assembly or acceptance test failures. The failure analysis determines the cause so that necessary corrective action can be taken to maintain sensor reliability. The failure analyses and investigations are performed to the level of detail necessary to resolve the problem. Based on the following types of data, the LLNL QAG and project lead engineer mutually determine which failed parts require detailed failure analysis:

- Data provided by the FRACAS

- Narrative engineering reports

- Personal contact with engineering and test personnel

- The level of concern (Red, Yellow or Green)

Red and yellow level concerns may require convening a Material Review Board to assist in the analysis.

All failure analysis reports are to be closed out within 30 days of the failure occurrence. A written rationale is provided for any extensions beyond this period. Clementine management is automatically alerted to ineffective corrective actions. If 
LLNL does not have the facilities for in-depth analysis, they will arrange for the use of an independent laboratory facility to perform such analyses.

If the cause of the problem cannot be determined within 30 days, the LLNL QAG will perform measurements and tests on assemblies and parts. When physical and chemical analyses are necessary, they will be performed by LLNL departments or competent testing laboratories. Whenever it is necessary to conduct extensive or indepth examinations of failed components, the LLNL QAG will ask the manufacturer of the device or a qualified test laboratory to perform the analysis.

Each failed part analysis will result in one of the following decisions:

- Inherent Weakness - This decision is made if there is an inherent weakness in the part that would require redesign by the manufacturer, selection of a new vendor, or change in the part type used.

- Misapplication of Component or Part - This decision is made if the failure is caused by the misapplication of the item in the electrical, mechanical, or environmental design of the equipment, thus requiring equipment redesign.

- Random Part Failures - This decision is made only if the failure is caused by random part failures; i.e., an inherent part failure rate.

- Human Error - This decision is made if the failure is caused by human error.

Corrective action requests are forwarded to the responsible individual who will then provide a response with a description of the actions taken. These actions are monitored to assure that the corrective measures have effectively resolved the problem. Summaries of the failure reports, analyses, and corrective actions are maintained for SDIO review.

\subsection{Disposition of Failed Parts and Material}

The disposition of failed parts and material after the completion of the FRACA is as directed by the LLNL QAG.

\subsection{Reporting}

A formal failure analysis report is prepared by the laboratory or group tasked to perform the investigation. The report original is filed with the TDR original and a copy of the report is forwarded to the LLNL QAG and the TDR files.

\subsection{Corrective Action}

The LLNL QAG periodically reviews the status of each TDR to assess the progress of the FRACAS. Required corrective action must be implemented before the close-out of the TDR. Close-out of the TDR is initiated by the project lead engineer after corrective action is undertaken. The TDR is closed out when both the project lead 
engineer and the LLNL QAG representative have signed the original TDR and have forwarded a copy to the LLNL QAG files.

\subsection{TDR Completion Instructions}

The original TDR serves as the master upon which all update information is entered. Figure 1 describes the TDR form in detail with instructions for each block item. The TDR is divided into four major sections.

\subsection{Hardware Description and Environmental Data}

The originator completes this section. It identifies the hardware levels and conditions under which the failure occurred.

\subsection{Description of the Discrepancy:}

The originator completes this section. It defines the nature of the report, describes the problem(s) encountered, identifies parts or modules replaced, and provides other pertinent data. A continuation sheet is used if more space is required.

\subsection{Removed Hardware Results}

This section records the results of investigations and analyses performed and conclusions covering the reasons for the failures or problem. Reference to failure analysis reports or other documents is made in this section. The continuation sheet is used if more space is required.

\subsection{Corrective Action}

This section describes the recommended corrective action. Corrective action document numbers as well as narrative indicating completion and corrective actions are included. A continuation sheet is used if more space is required. Closeout of the TDR is accomplished by authorized signatures from the project lead engineer and the LLNL QAG.

\subsection{Failure Analysis Report}

A formal Failure Analysis Report is completed by the cognizant test engineer responsible for the failure analysis. The format depends on the nature and severity of the failure, but in all cases the following information is included:

1. Name of the test engineer responsible for performing the analysis.

2. Name of the laboratory or subcontractor performing the detailed analysis.

3. Date the failed parts were made available to the analyst.

4. Date the analysis was completed.

5. Serial number of the TDR. 
6. Classification of Failure (Modes): A statement of the primary defect or damage as determined by the analyst; e.g., Capacitor Shorted.

7. Narrative discussion of the cause of the problem. For example, the analyst shall describe the procedures used in locating and defining the defect or damage and a statement of the results obtained. Methods used by the analyst, such as electrical or mechanical measurements, X-rays, destructive physical analysis (DPA), or other user tests are included in the discussion.

8. Responsibility for Failures: A statement identifying the area or functional organization which in the analyst's opinion was principally responsible for the defects or damage is included. For example, the responsibility may be assigned to the manufacturing function, the quality organization or the test organization.

9. Recommendations: The analyst's recommendation for improving the situation is included. As applicable, recommendations may include a revision of manufacturing or handling processes, revision of a specification, revision to the design or a component, or a change to another component known to be of better quality and higher reliability.

\subsection{FRACAS Definitions}

During the conduct of FRACA activities, the following definitions will apply:

- Failure Analysis Laboratory - Facilities where detailed investigation(s) are performed on failed parts, components, or assemblies

- Failure Analysis - Investigations required to determine mode and causes of significant failure or malfunctions so that necessary corrective action can be taken to improve reliability

- Failure Cause - Reason (external to the device) that the condition that resulted in failure exists (e.g., improper cleaning, excessive temperature, or contaminated solder)

- Failure Mechanism - The physical or chemical condition within the device from which the failure directly resulted (e.g., cracked wire, surface contamination, or shorted internal parts)

- Failure - Any trouble in a part or assembly evidenced by one or more relevant characteristics not conforming to specified limits. 


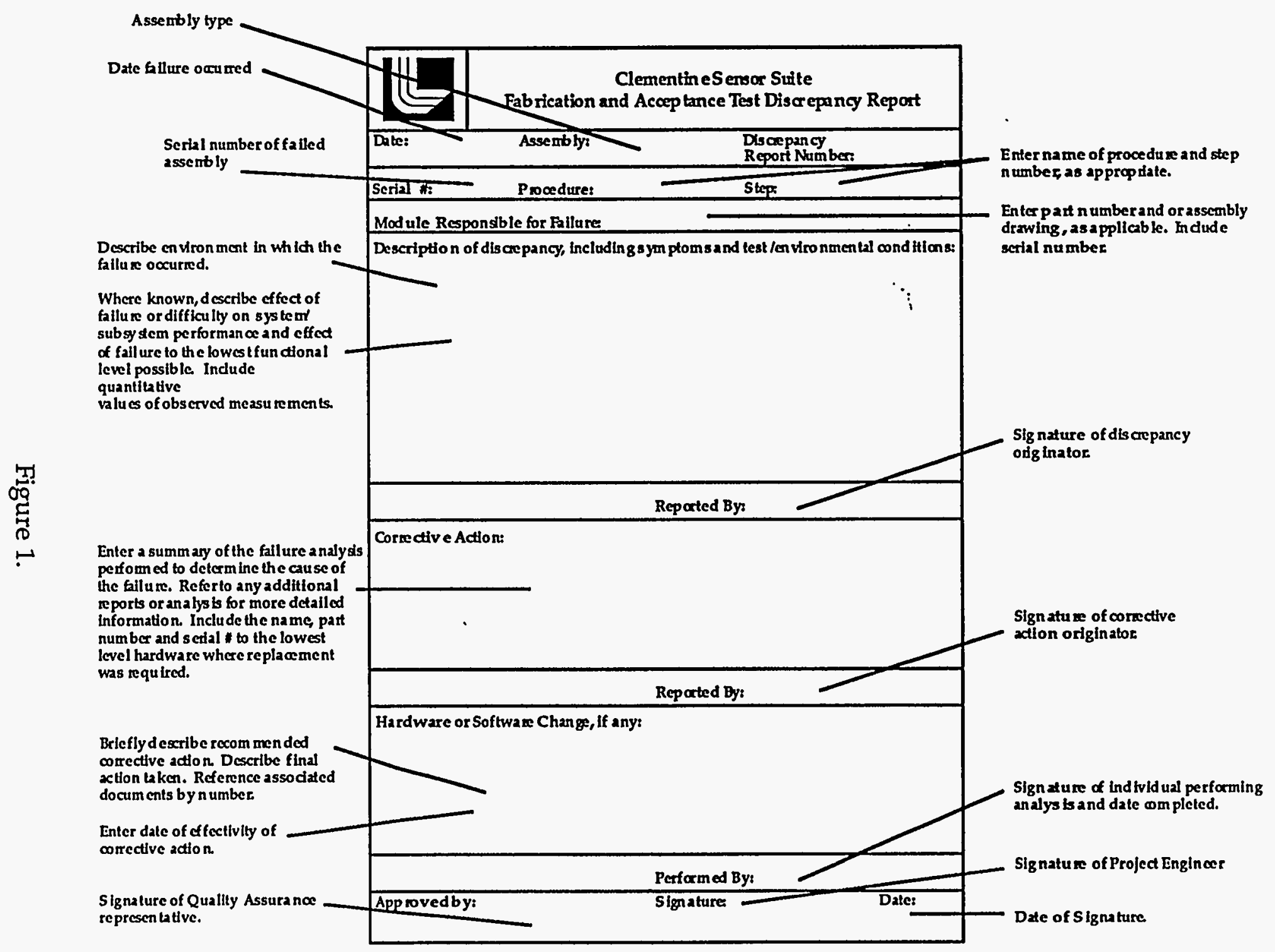


Appendix A

A1. See the following page for "Clementine Sensor Suite Fabrication and Acceptance Test Discrepancy Report" form. 


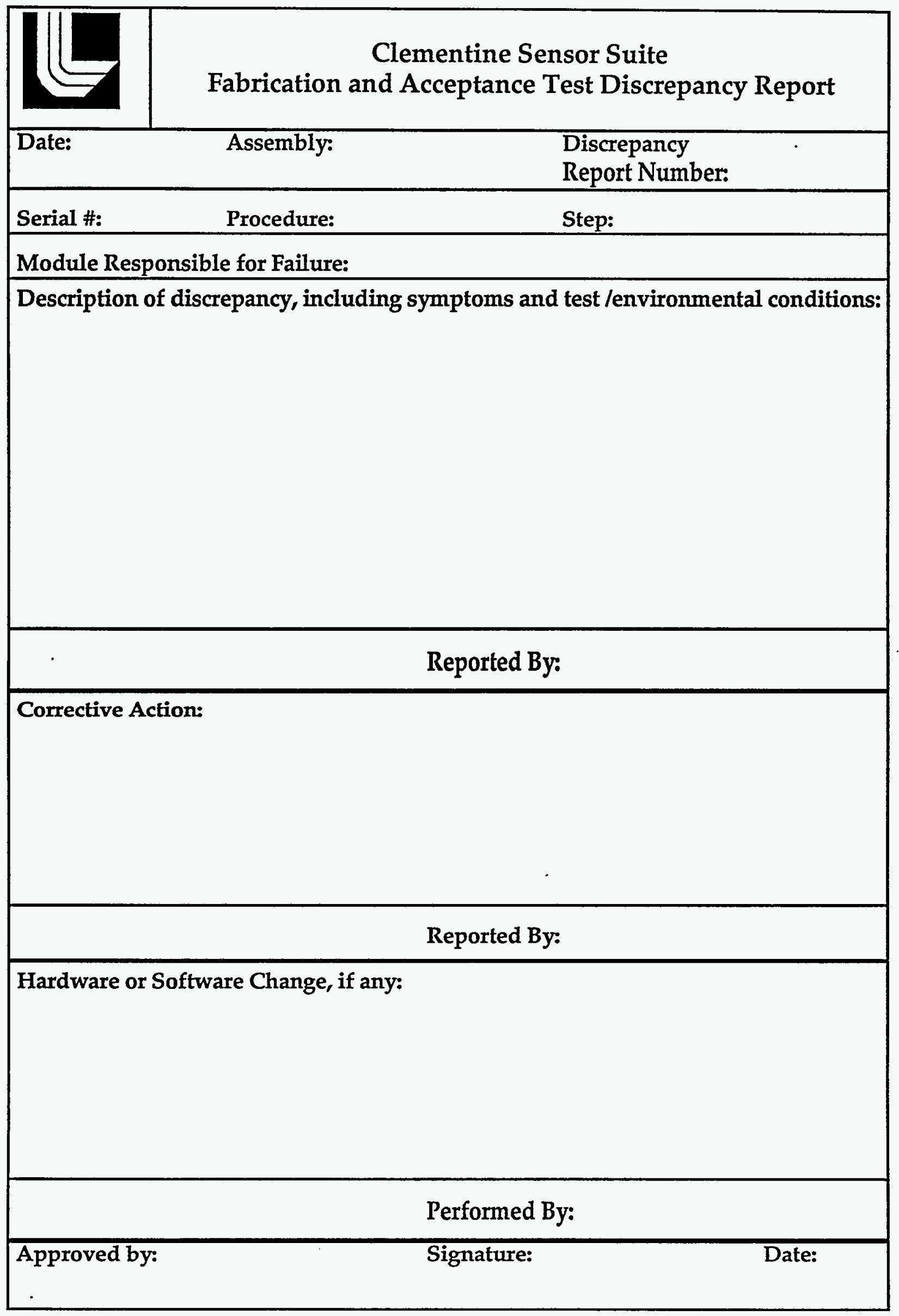




\section{Appendix B}

\section{TDR Example}

A test failure occurs during LIDAR acceptance testing, and the fault is isolated to the Range Receiver module. The following steps are taken:

1. The top half of the TDR form is prepared for the LIDAR.

2. After the LIDAR is disassembled and the Range Receiver module is removed, the Range Receiver module identification data, including name, part number and serial number, is entered in the "Hardware or Software Change, if any:" block on the LIDAR TDR.

3. A Range Receiver module level TDR is prepared and the LIDAR TDR report number is entered in the space provided for "Description of Discrepancy, including Symptoms and Test or Environmental Conditions." In like manner, the Range Receiver module level TDR report number is referenced on the LIDAR TDR in the space provided for "Hardware or Software Change, if any:"

4. The TDRs are distributed as follows:

- The backup copy of the LIDAR TDR and the Range Receiver module TDR is sent to the LLNL QAG.

- The original LIDAR TDR remains with the LIDAR documentation package, and the original of the Range Receiver module TDR remains with the failed Range Receiver module to function as a shop traveler during the FRACA and Range Receiver module repair.

- A copy of each of the LIDAR and Range Receiver module TDR original is reproduced and provided to the project lead engineer and to SDIO. .

5. If further failure analysis is required on the failed parts removed from the module, a third-level TDR is prepared for the parts. The part's level TDR original will accompany the failed parts through failure analysis.

6. When the analysis is completed, the "Corrective Action" block of the parts TDR is completed, and the analysis and repair/inspection data is entered on the module TDR in the "Hardware or Software Change, if any:" and "Corrective Action" blocks.

7. The data from the Range Receiver module and part-level TDRs are summarized on the LIDAR TDR original; and the test engineer and the QAG complete the "Effectivity," "Approved" and "Date" blocks on the original. 
8. The parts TDR (original) is retained by the LINL QAG. The Range Receiver module TDR (original) is filed with the Range Receiver module "as-built" documentation package. The LIDAR TDR (original) is filed with the LIDAR "as-built" package, and two copies of the parts, Range Receiver module and LIDAR TDRs (originals) are distributed as follows:

- Test Engineer (one copy for file)

- LLNL QAG (one copy to close out the FRACA suspense file)

- SDIO in the monthly report 


\section{Appendix A.4 \\ Clementine Sensor Suite Parts Program \\ (C1-EE-022)}




\section{Clementine Sensor Suite}

Parts Program

\begin{tabular}{|c|c|c|c|c|}
\hline & Date & Rev. & Date & Approval \\
\hline Prepared by: w. K. Bryson & $3 / 3 / 93$ & & & \\
\hline Reviewed by: J.\%. Kordas & $3 / 5 / 93$ & & & \\
\hline 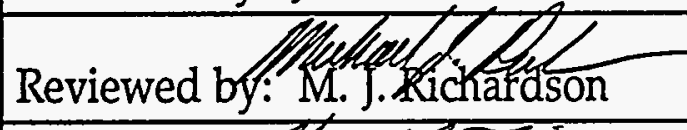 & $3 / 4 / 93$ & & & \\
\hline Reviewed by: T.F. Tiasing ify & $3 / 8 / 53$ & & & \\
\hline Reviewed by: M s & $3 / 8 / 93$ & & & \\
\hline Approved by: L & $3 / 12 / 5$ & & & \\
\hline
\end{tabular}

\section{University of California \\ IU Lawrence Livermore National Laboratory}

C1-EE-022

Revision 00 


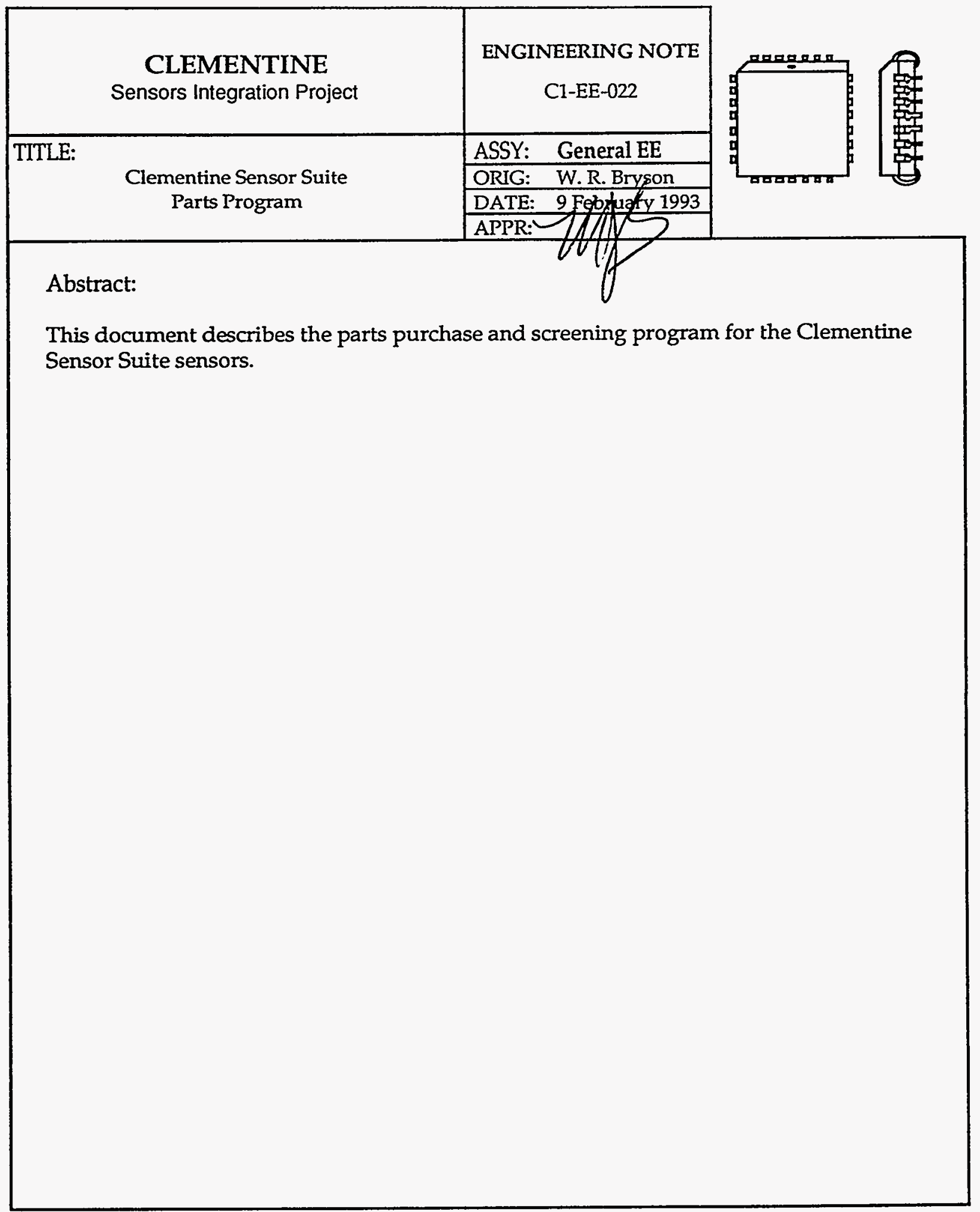




\section{Introduction}

This document describes the requirements for the purchase and screening of EE components for the Clementine Sensor Suite. The objective is to assure that only the highest reliability parts are used in the Clementine Sensor Suite.

\section{Parts Purchase}

Active components will be purchased to the highest grade available according to the precedence shown in Table 1 below. All other parts will be purchased with the highest reliability level available within program constraints. All components will be screened per this document, as required, based on their purchased reliability level.

\begin{tabular}{|l|l|l|}
\hline Precedence & Grade & Description \\
\hline 1 & MIL-M-38510 & $/ 883 \mathrm{~B}, \mathrm{JAN}, \mathrm{J}$. \\
\hline 2 & $\begin{array}{l}\text { Extended } \\
\text { Temp. }\end{array}$ & $\begin{array}{l}\text { Ceramic Package, } \\
-55 \text { to }+125^{\circ} \mathrm{C} \text { Operating Range } \\
\text { Program Screening Required }\end{array}$ \\
\hline 3 & $\begin{array}{l}\text { Industrial- } \\
\text { Ceramic }\end{array}$ & $\begin{array}{l}\text { Ceramic Package, } \\
0 \text { to }+85^{\circ} \mathrm{C} \text { Operating Range } \\
\text { Program Screening Required }\end{array}$ \\
\hline 4 & $\begin{array}{l}\text { Commercial- } \\
\text { Ceramic }\end{array}$ & $\begin{array}{l}\text { Ceramic Package, } \\
0 \text { to }+70^{\circ} \mathrm{C} \text { Operating Range } \\
\text { Program Screening Required }\end{array}$ \\
\hline 5 & $\begin{array}{l}\text { Industrial- } \\
\text { Plastic }\end{array}$ & $\begin{array}{l}\text { Plastic Package, } \\
0 \text { to }+85^{\circ} \mathrm{C} \text { Operating Range } \\
\text { Program Screening Required }\end{array}$ \\
\hline 6 & $\begin{array}{l}\text { Commercial- } \\
\text { Plastic }\end{array}$ & $\begin{array}{l}\text { Plastic Package, } \\
0 \text { to }+70^{\circ} \mathrm{C} \text { Operating Range } \\
\text { Program Screening Required }\end{array}$ \\
\hline 7 & $\begin{array}{l}\text { Special } \\
\text { Program Specific Requirements } \\
\text { Program Screening Required }\end{array}$ \\
\hline
\end{tabular}

Table 1. Parts Purchase Precedence 


\section{Parts Screening}

Part screening is directed toward insuring that all components used in the Clementine Sensor Suite are free from incipient failures and to precipitate failure of any marginal components. The screening tests and procedures are those known to uncover potential failure mechanisms of the components.

The screening applied to a procured component after delivery will be fitted to that component in relation to the reliability level of the procured version. That is, the higher the reliability level of the procured component, the less screening required in the post procurement test program. The screening program is also varied according to component type and their respective reliability history.

Regardless of the purchased reliability level of components, all components will be subjected to supplementary screening and inspections that will result in a reliability level equivalent to parts specified in the QPL.

The program screening, test and inspection requirements, with the specific methods defined by the applicable test documents and military standards are presented in the flow diagrams given in Figures 2 thru 15. The electrical parameters that may be measured during screening are identified in Table 2. Specific parameters measured will be tailored to the exact application of that component. Full screening tests and inspections are required on industrial and commercial grade components, while supplemental screening tests will be performed on components that have been subjected to some level of reliability oriented processing and testing not considered sufficient for this application. 


\begin{tabular}{|c|c|}
\hline Part Type & Parameters to be Tested \\
\hline $\begin{array}{l}\text { Integrated Circuits } \\
\text { Delay Lines } \\
\text { (Digital, CMOS, } \\
\text { ECL) }\end{array}$ & $\begin{array}{l}\text { ICCH, ICCL, IIH, IIL, IOH, IOL, IOZH, IOZL, VIN, VIL, } \\
\text { VIK, VOH, TPLH, TPHL, TAA, TACS, TOE, TOHZ, } \\
\text { TCHZ, T-RISE, T-FALL, T-SKEW, Functional } \\
\text { Performance }\end{array}$ \\
\hline $\begin{array}{l}\text { Integrated Circuits } \\
\text { (Linear) }\end{array}$ & $\begin{array}{l}\mathrm{ICC}, \text { VOS, } \pm \mathrm{IB}, \pm \mathrm{VO}, \mathrm{CMRR}, \mathrm{PSRR}, \pm \mathrm{CMV}, \mathrm{IDO}, \mathrm{IDG}, \\
\text { ISOH, ISOHL, ISINK, VOH, VOL, GBWP, } \pm \text { SLEW RATE, } \\
\text { TPDHL, TPDLH, Functional Performance }\end{array}$ \\
\hline Oscillators & Frequency, Wave form Linearity, Supply Current \\
\hline $\begin{array}{l}\text { Transistors } \\
\text { (General) }\end{array}$ & $\begin{array}{l}\text { hFE, ICBO, VCE(SAT), VBE(SAT), ICES, ICEO, IEBO, } \\
\text { VBE, BVCER, BVCES, ICEX }\end{array}$ \\
\hline FET's (General) & $\begin{array}{l}\text { BVDSS, IDSS, ID-ON, VSD, RDSON, GFS, VP, VSTH, ID- } \\
\text { OFF, IGSS, VDS-ON, VGS-OFF }\end{array}$ \\
\hline SCR's & VGT, IGT, IDRM, IRRM, VTM, IH \\
\hline Diodes (Rectifiers) & VF, IR \\
\hline Diodes (Zeners) & $\mathrm{VZ}, \mathrm{ZZ}, \mathrm{VF}$ \\
\hline Capacitors & Capacitance, DF, IR, DCL, ESR \\
\hline $\begin{array}{l}\text { Resistors } \\
\text { Resistor Networks }\end{array}$ & DC Resistance \\
\hline Coils and Inductors & Inductance, Q, DC Resistance, DWV \\
\hline Transformers & Inductance, Turns Ratio, DC Resistance, DWV \\
\hline Connectors & $\overline{D W V}$ \\
\hline
\end{tabular}

Table 2. Electrical Parameter to be Tested at Final Test

\section{Applicable Documents}

The flow diagrams given in Figures 2 thru 15 refer to various military standards and test methods. A military standard will be listed in the lower left hand corner of a block in the flow diagram. The applicable test method is listed in the lower right hand corner of the block. See Figure 1 below for an example that refers to MIL-STD-883D, test method 1015. 


\section{POWER BURN-IN \\ (DYNAMIC) \\ 883D TM1015}

Figure 1.

\section{Summary}

Active components will be purchased according to the precedence presented in Table 1 . All passive components will be purchased to the highest reliability levels consistent with project requirements. All components will be subjected to some level of screening or testing prior to use in Clementine Sensor Suite sensors. 
PROCUREMENT ADDITIONAL PROCESSING

LEVEL

\begin{tabular}{|l|l|l|}
\hline MIL-M-38510 \\
CLASS S OR B
\end{tabular}$\rightarrow-\begin{aligned} & \text { DESTRUCTIVE } \\
& \text { PHYSICAL } \\
& \text { ANALYSIS }\end{aligned} \quad \rightarrow \begin{aligned} & \text { RECEIVING } \\
& \text { INSPECTION } \\
& \text { EXTERNAL VISUAL } \\
& \text { 100\% ELECTICAL }\end{aligned}$
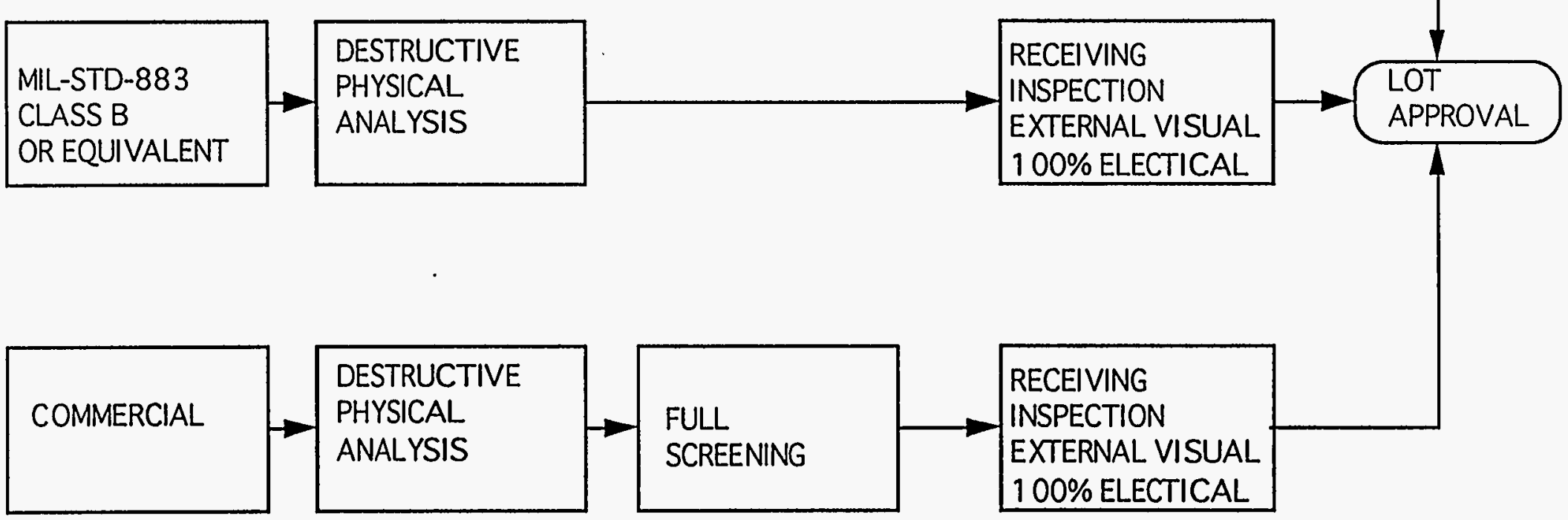

Figure 2. Overview of Integrated Circuit Screening 
PROCUREMENT

LEVEL

\begin{tabular}{|l|l|l|l|}
\hline $\begin{array}{l}\text { JANS OR } \\
\text { JANTXV } \\
\text { PHYSICAL } \\
\text { ANALYSIS }\end{array}$ & $\longrightarrow$ & $\begin{array}{l}\text { RECEIVING } \\
\text { INSPECTION } \\
\text { EXTERNAL VISUAL } \\
100 \% \text { ELECTICAL }\end{array}$ \\
\hline
\end{tabular}
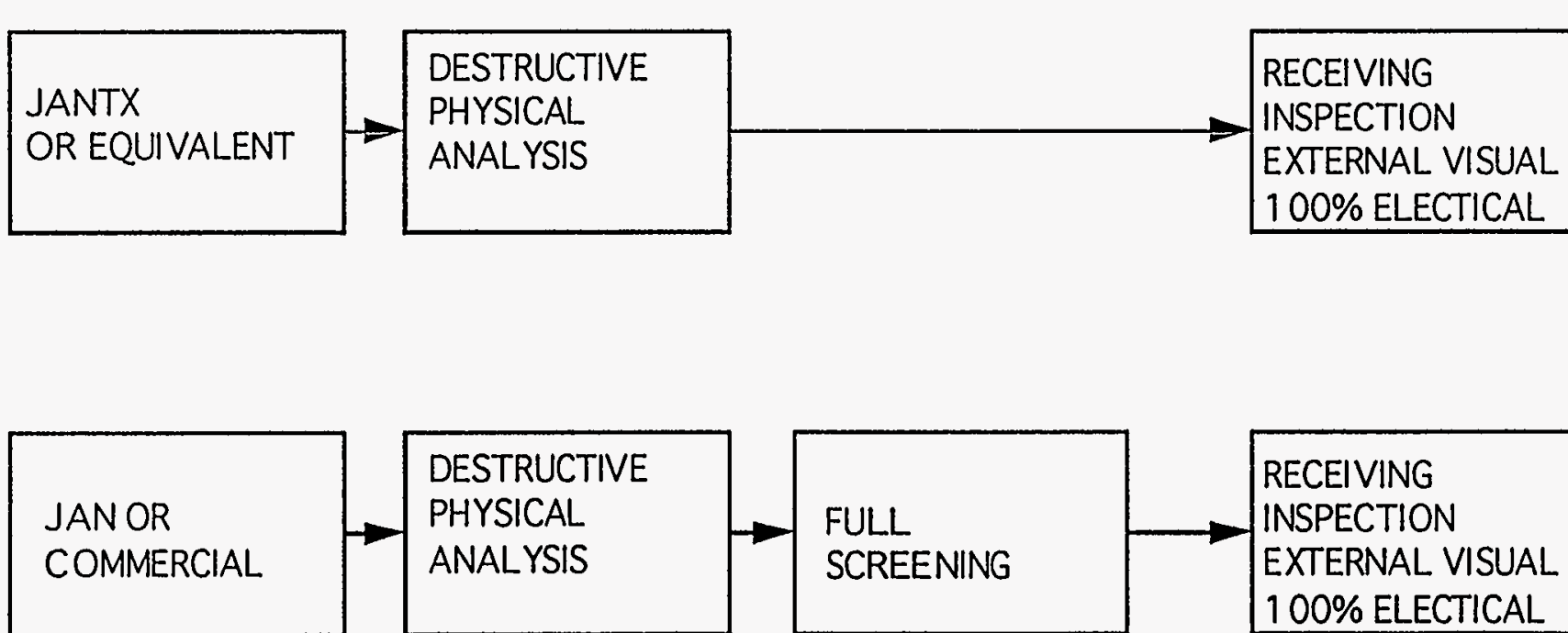

\section{DESTRUCTIVE}

PHYSICAL

ANALYSIS

SCREENING

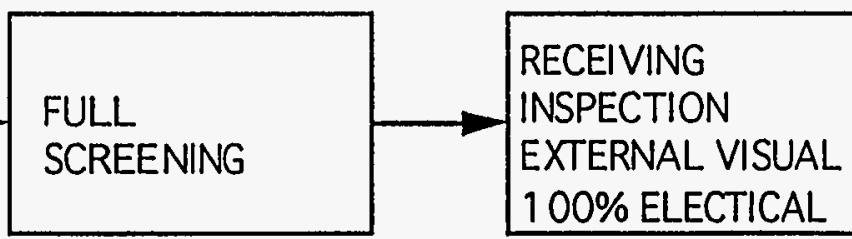

Figure 3. Overview of Discrete Semiconductor Screening 
PROCUREMENT LEVEL
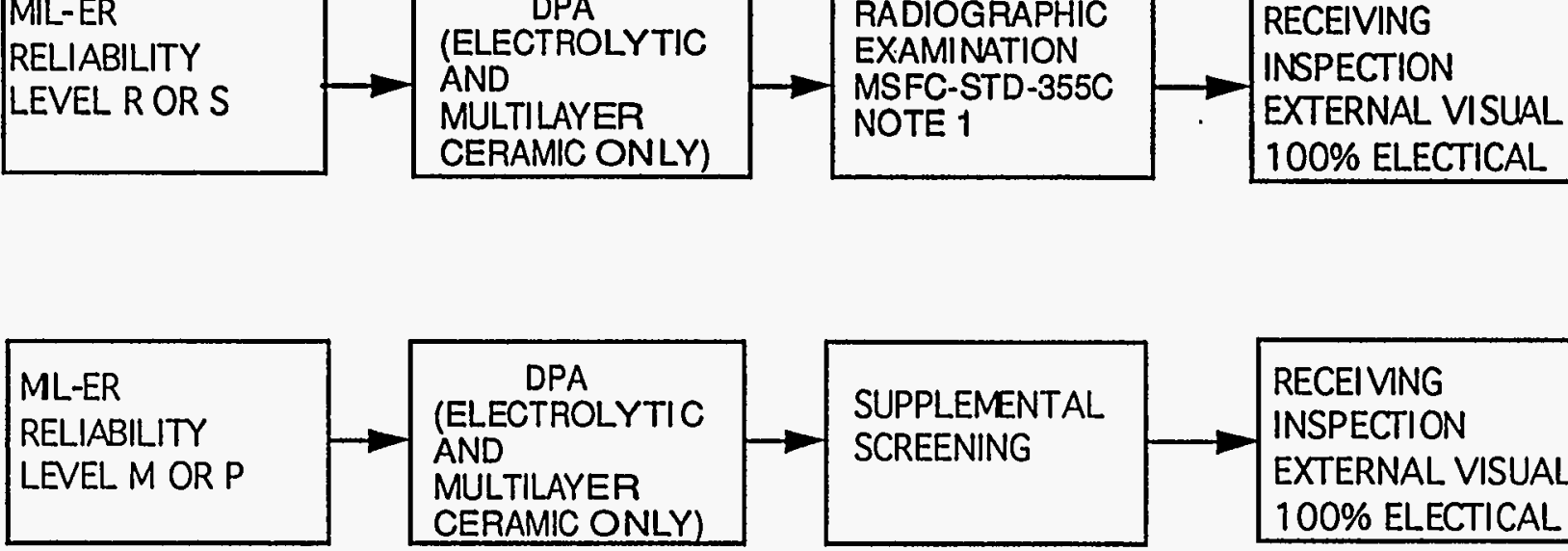

RELIABILITY (ELECTROLYTIO

MULTILAYER $100 \%$ ELECTICAL
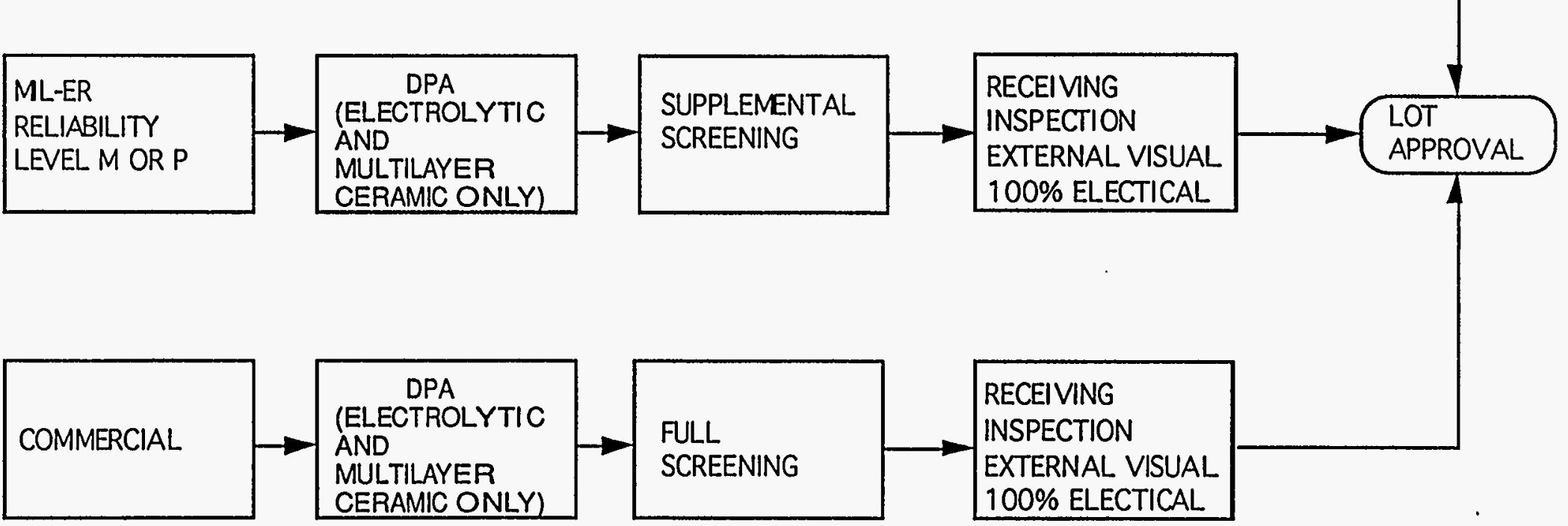

NOTE 1: APPLICABLE TO CKR11 THRU CKR14 ONLY

Figure 4. Ovenview of Capacitor Screening 


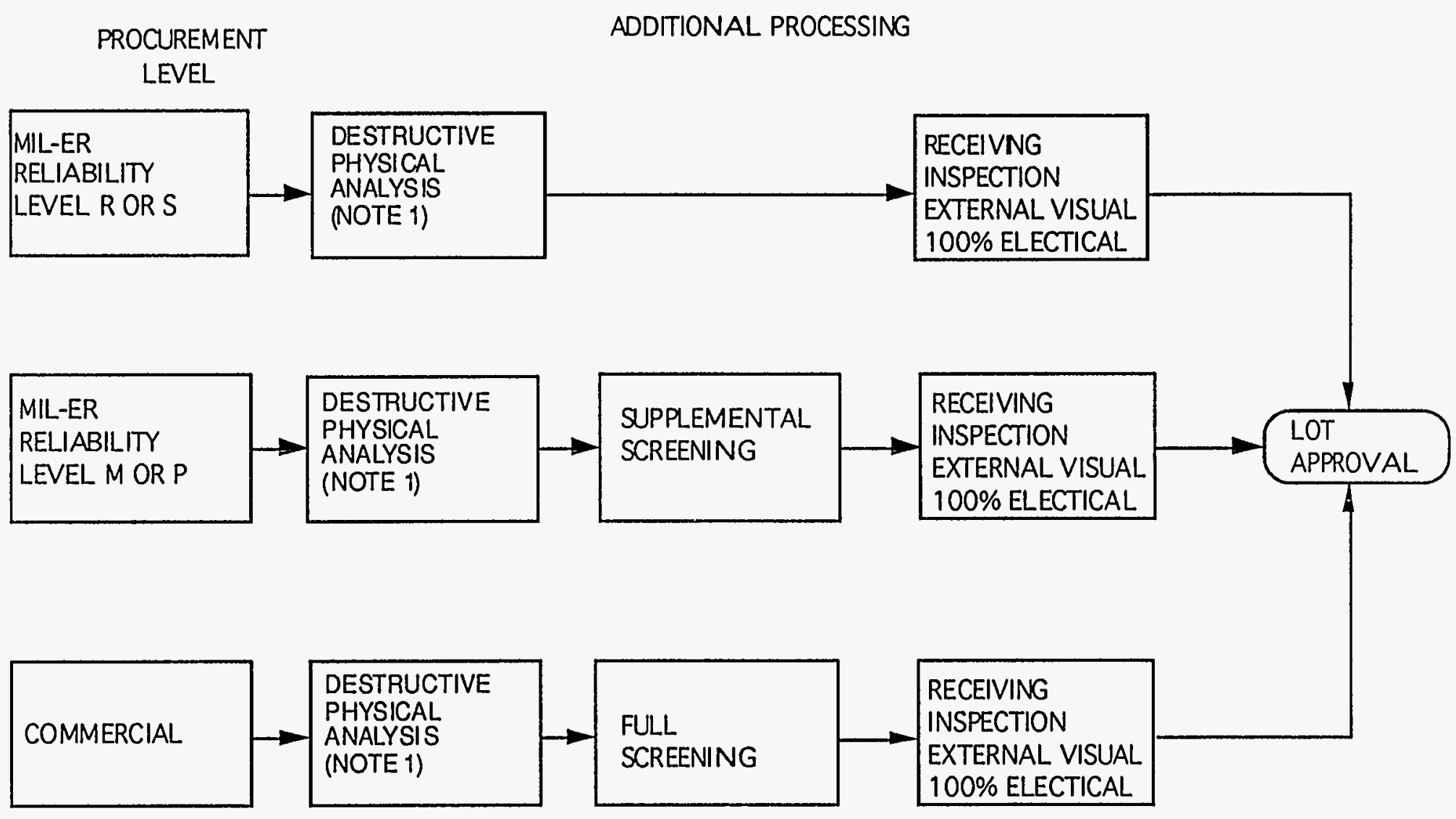

NOTE 1: APPLICABLE TO CRYSTALS, FILTERS AND RELAYS ONLY

Figure 5. Overview of Other Passive Part Screening 
COMMERCIAL GRADE FULL SCREEN
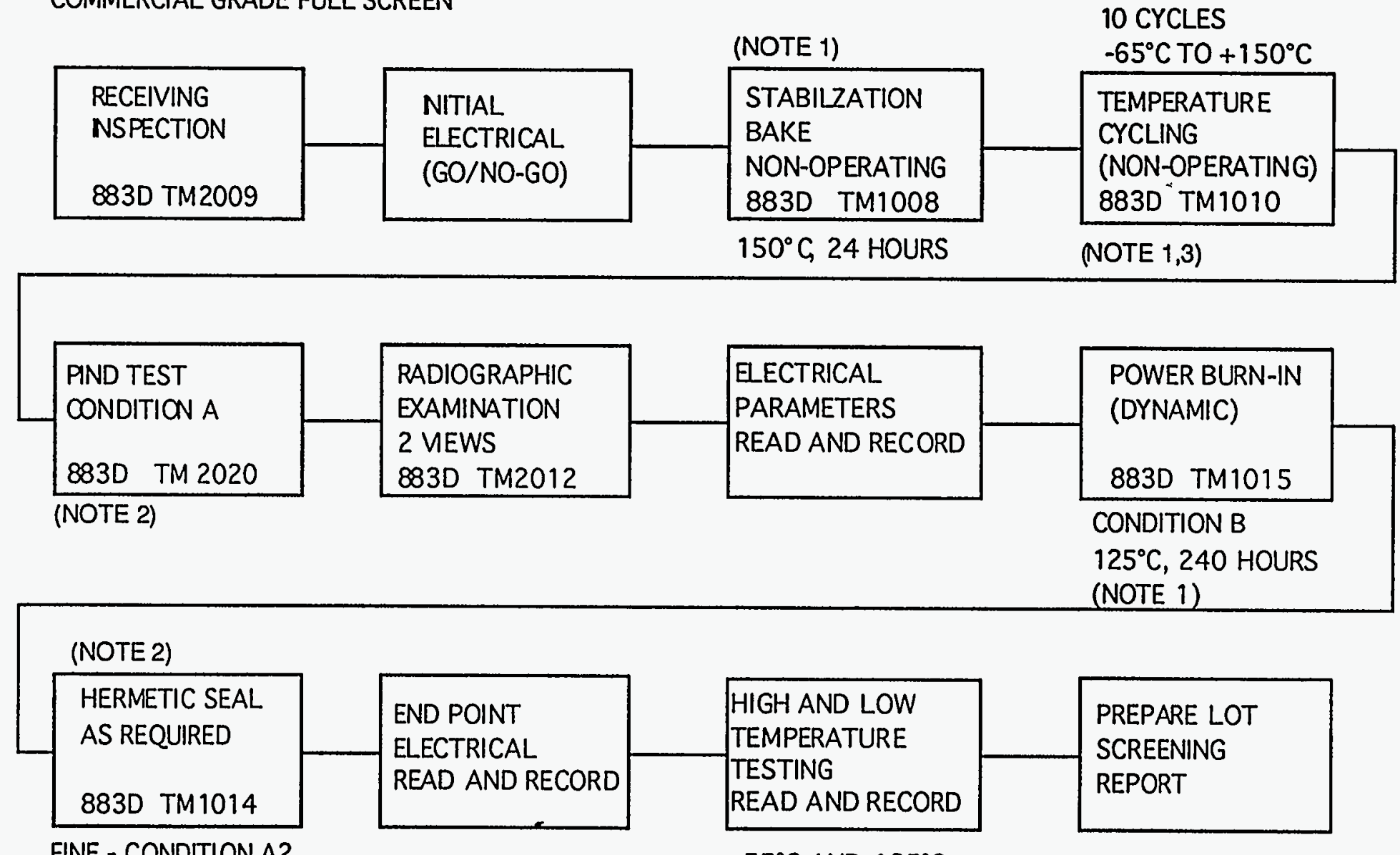

FINE - CONDITION A2 GROSS - CONDITION C $-55^{\circ} \mathrm{C}$ AND $125^{\circ} \mathrm{C}$ (NOTE 1)

NOTE 1: PARTS WITH KNOWN TEMP LIMITS ARE TESTED AT REDUCED TEMPERATURES NOTE 2: NOT APPROPRIATE FOR PLASTIC PARTS

NOTE 3: SAMPLE OF LOT TESTED FOR PLASTIC PARTS

Figure 6. Detailed Integrated Circuit Screening 
COMMERCIAL GRADE FULL SCREEN
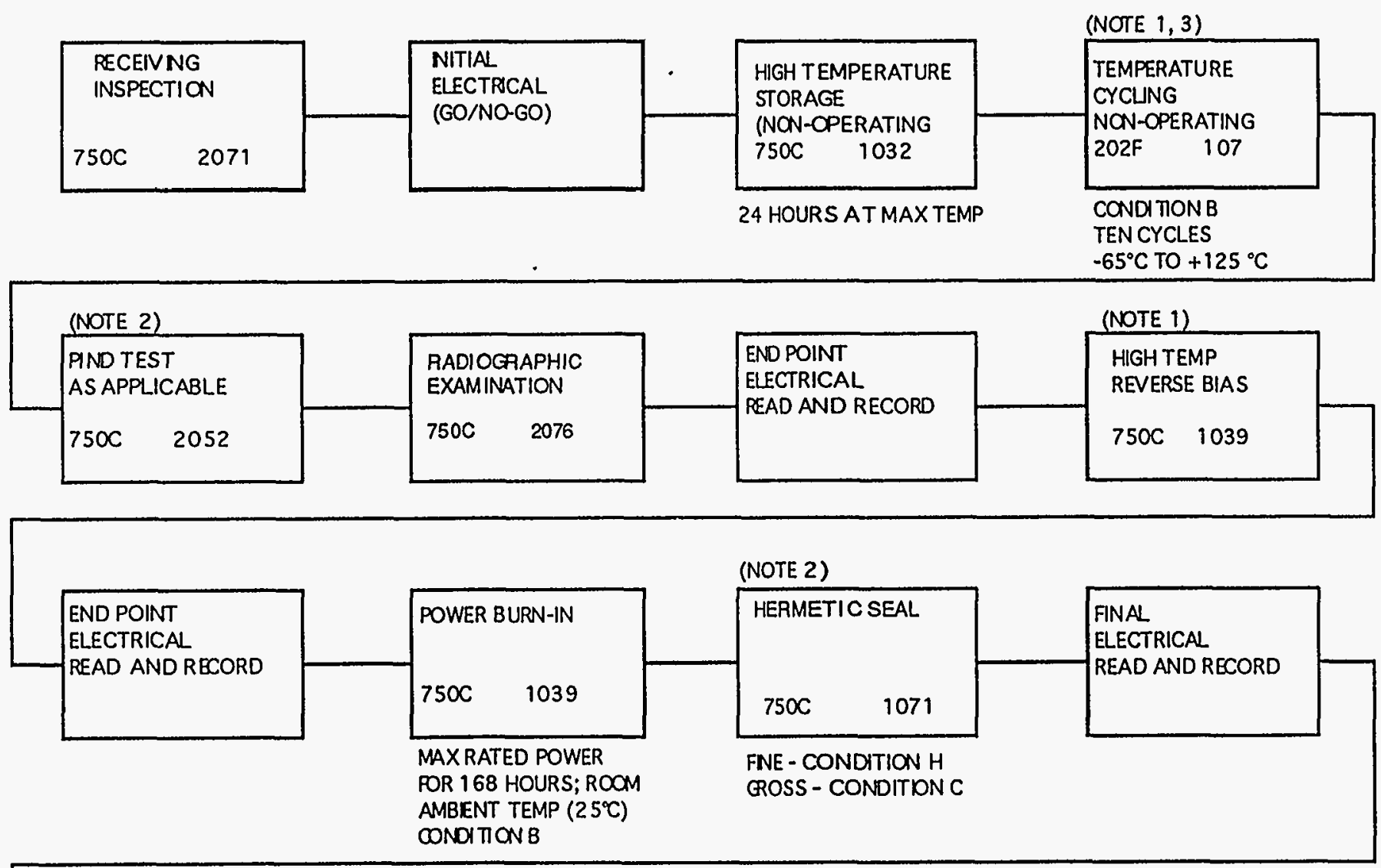

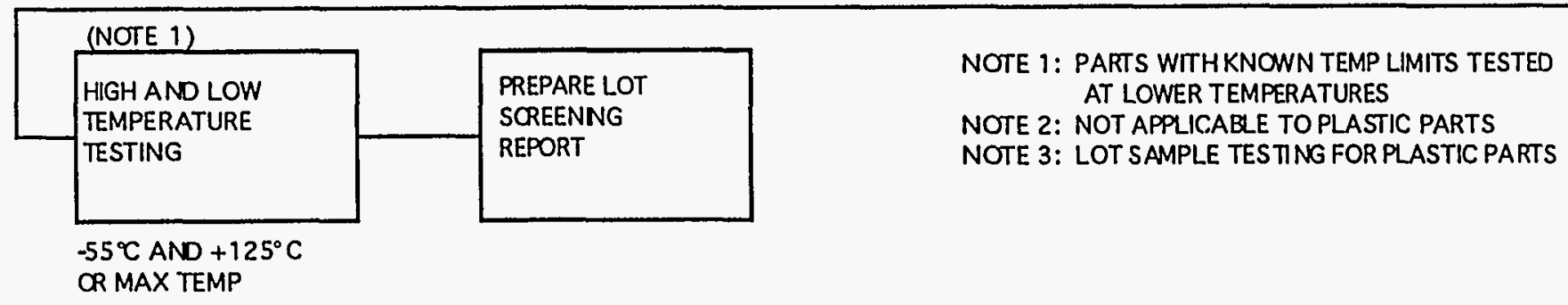

Figure 7. Detailed Transistor Screening 
COMMERCIAL GRADE FULL SCREEN

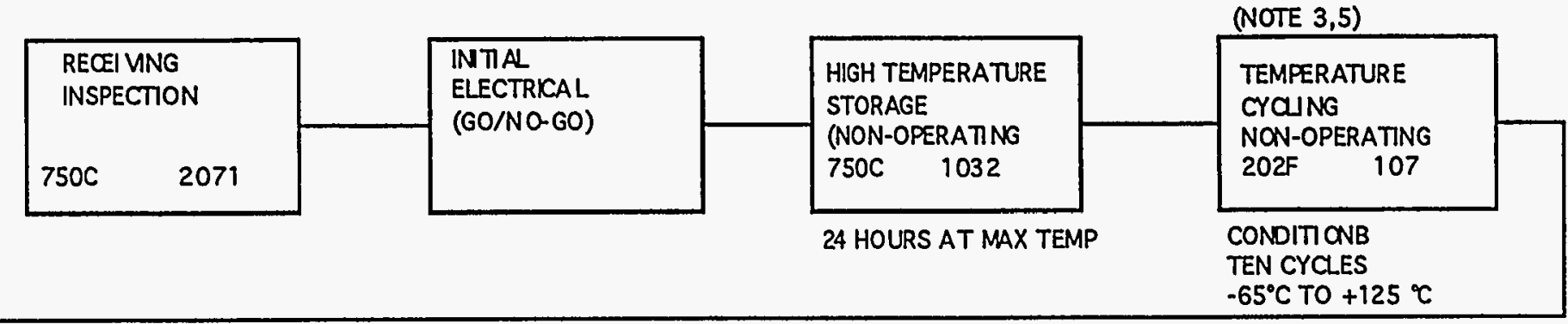

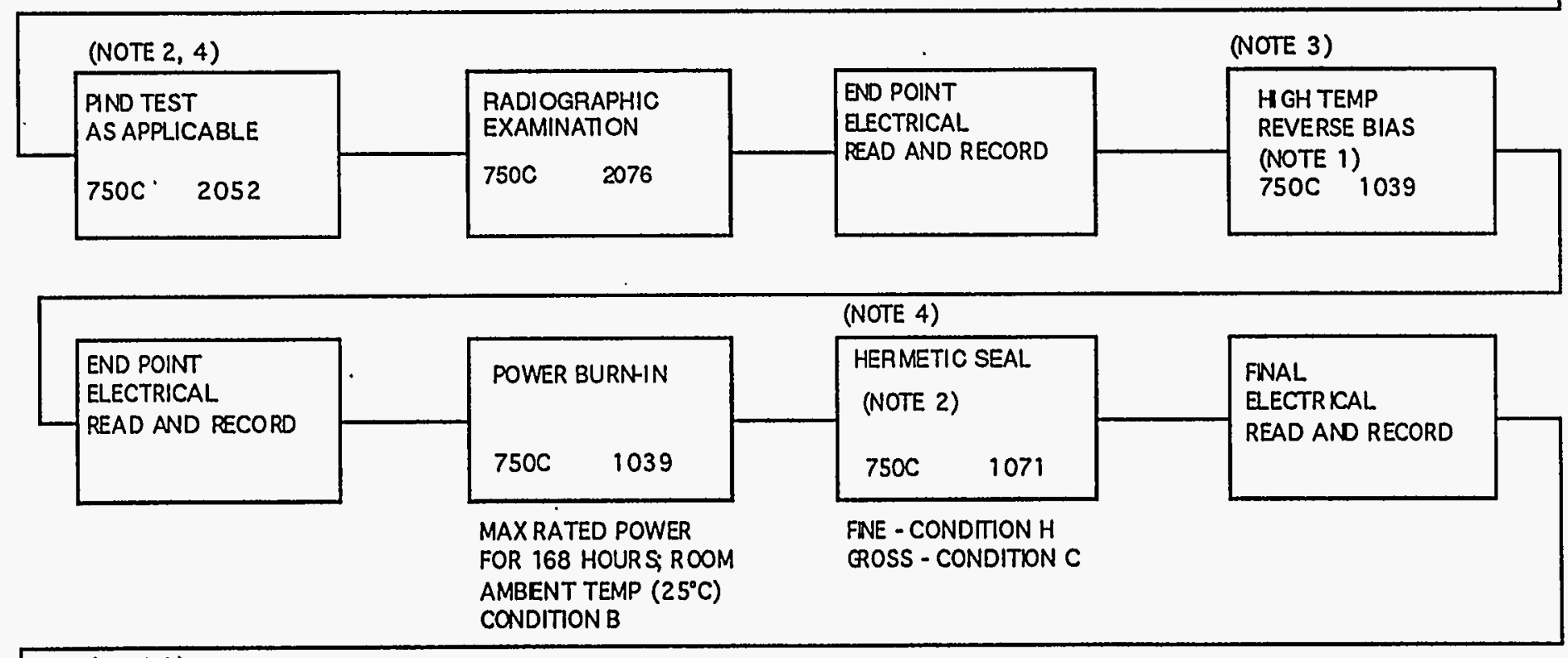

\begin{tabular}{|l|l|}
\hline (NOTE 3) & $\begin{array}{l}\text { PREPARE LOT } \\
\text { HIGH AND LOW } \\
\text { TEMPERATURE } \\
\text { TESTING }\end{array}$ \\
\cline { 2 - 3 } & REPORT \\
\hline
\end{tabular}

NOTE 1: NOT APPLICABLE TO ZENER AND REERENCE NOTE 2: NOT APPLICABLE TO DIODES WITHOUT CAVITY NOTE 3: PARTS WITH KNOWN TEMP LIMITS TESTED AT LOWER TEMPERATURES

NOTE 4: NOT APPLICAQLE FOR PLASTIC PARTS

$-55^{\circ} \mathrm{C}$ AND $+125^{\circ} \mathrm{C}$

NOTE 5: LOT SAMPLES ONLY FOR PLASTICPARTS

OR MAX TEMP

Figure 8. Detailed Diode Screening 
COMMERCIAL GRADE FULL SCREEN

(1)

\begin{tabular}{|l|}
\hline RECEIVING \\
INSPECTION
\end{tabular}

(2)

\begin{tabular}{|c|c|}
\hline \multicolumn{2}{|c|}{$\begin{array}{l}\text { HERMETIC SEAL } \\
\text { (NOTE1) }\end{array}$} \\
\hline $202 F$ & 112 \\
\hline
\end{tabular}

GROSS-CONDITION A

FINE-CONDITION C

PROCEDLRE IIIA
(3)

RADIOGRAPHIC

EXAMINATION

MSFC-STD-355C

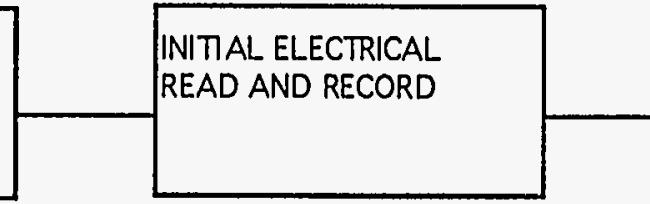

(NOTE 2)

(1)

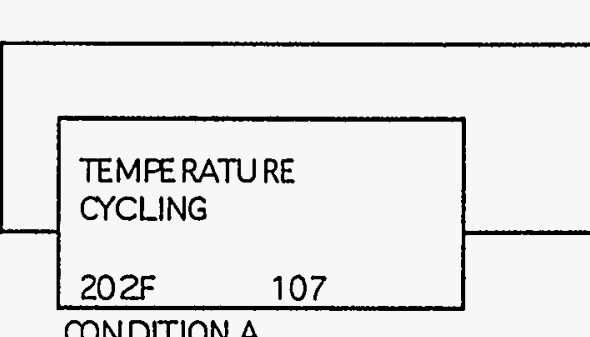

CONDITIONA

10 CYCLES,

MAX OPERATNG

TEMPERATURE

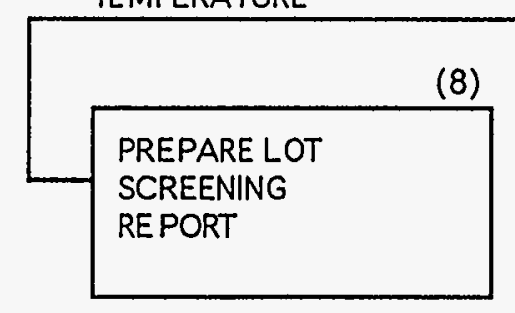

(5)

VOTAGE
CONDITIONING
(NOTE 3) ML-G-39006
OR MIL-C-39003

OR MIL-C-39003

$\sqrt{\square}$

(6)

SURGE
QRRENT
TEST

(7)

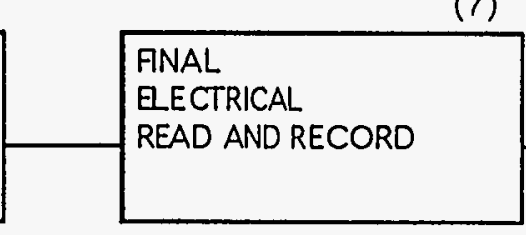

MIL-STD-975

APPENDIX B

NOTE1: APPLICABLE TOHERMETICALLY SEALED DEVICES AND DEVICES

WTHOUT SLEEVNG AROUND BODY

NOTE 2: NOT APPLICABLE TO FILM TYPE TANTALUM CAPACITORS

NOTE 3: VOLTAGE CONDITIONING AT 100\% RATED VOLTAGE AND $85{ }^{\circ} \mathrm{C}$

SUPPLEMENTAL SCREENING REQUIRES STEPS 1 THRU 8

Figure 9. Detailed Tantalum Capacitor Screening 
(1)

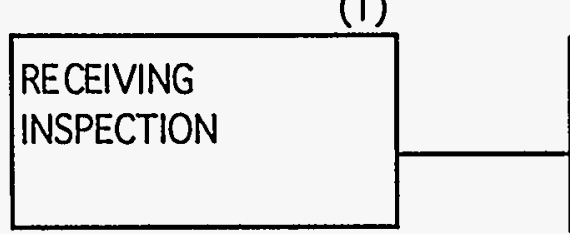

(2)

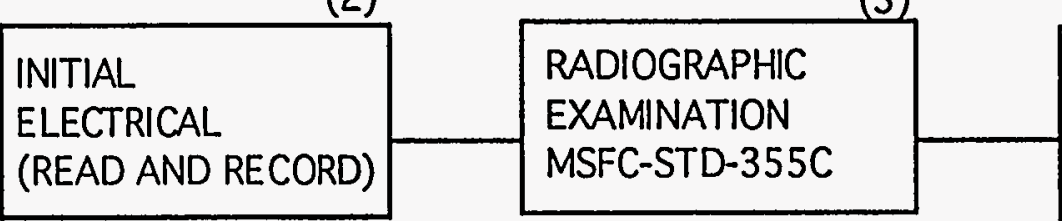

TEMPERATURE CYCLING

$202 F$ 107

CONDITION A 10 CYCLES

$-55{ }^{\circ} \mathrm{C}$ TO $85{ }^{\circ} \mathrm{C}$

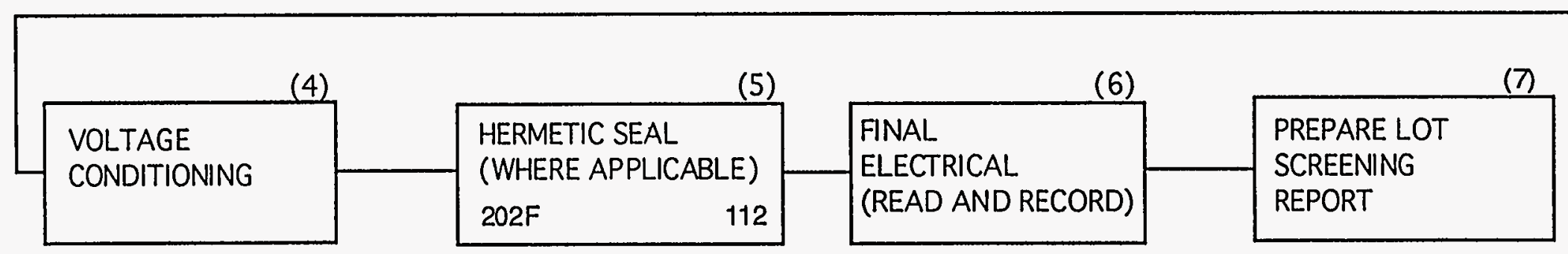

48 HOURS @ MAXTEMP, $200 \%$ OF RATED VOLTAGE

M OR P LEVEL SUPPLEMENTAL SCREEN: STEPS 1 THRU 7, EXCEPT THAT STEP 2 IS A GO / NOTO TEST AND STEP 3 IS APPLICABLE TO CKR11 THRU CKR14 ONLY

Figure 10. Detailed Ceramic Capacitor Screening 
(1)

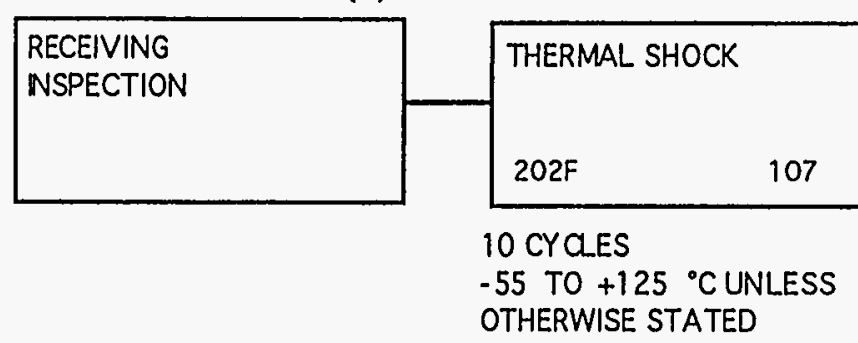

(2)

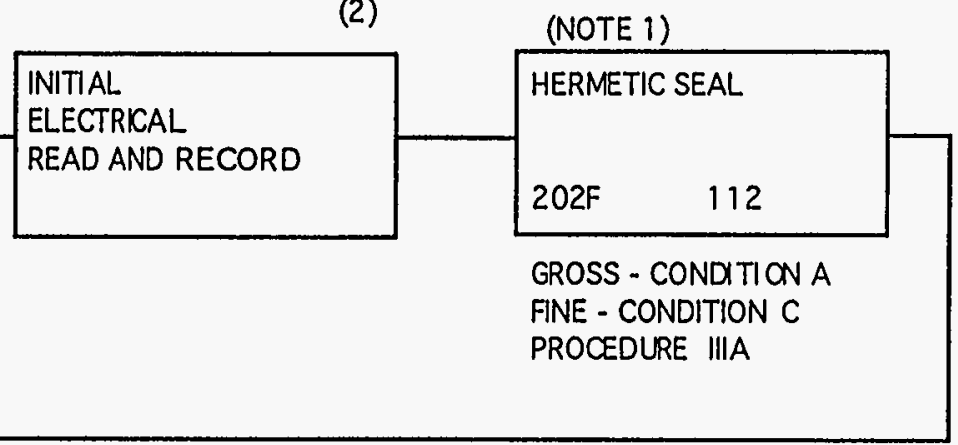

(5)

(6)

\begin{tabular}{|c|c|}
\hline \multirow[t]{2}{*}{$\begin{array}{l}\text { SHORT TIME } \\
\text { OVERLOAD } \\
\text { (NOTE 1) }\end{array}$} & $\begin{array}{l}\text { POWER VOLTAGE } \\
\text { CONDITIONING }\end{array}$ \\
\hline & $\begin{array}{l}100 \text { HOURS @ RATED } \\
\text { POWER AND } \\
\text { TEMPERATURE }\end{array}$ \\
\hline
\end{tabular}

(4)

\section{FINAL}

ELECTRICAL

READ AND RECORD

\begin{tabular}{|l|l|}
\hline \multicolumn{1}{|c|}{$(6)$} \\
\begin{tabular}{|l|l|}
\hline RADIOGRAPHIC \\
EXAMINATION \\
MSFC-STD-355C \\
(NOTE 2)
\end{tabular} \\
\cline { 2 - 2 }
\end{tabular}

NOTE 1: METAL FILM ONLY PER MIL-R-55182

NOTE 2: FOR METAL FILM

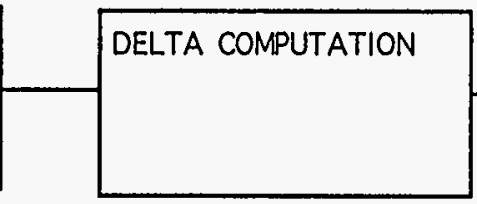

TWO VIEWS

SUPPLE MENTAL SCREENING REQURES STEPS 1 THRU 7

Figure 11. Detailed Resistor Screening 
COMMERCIAL GRADE FULL SCREEN

(1)

RECEIVING
INSPECTION

(2)

\begin{tabular}{|l|}
\hline INITIAL \\
ELECTRICAL \\
$($ GO / NO-GO) \\
\hline
\end{tabular}

RADIOGRAPHC
EXAMINATION
MSFC-STD-355C
(NOTE 1)

(3)

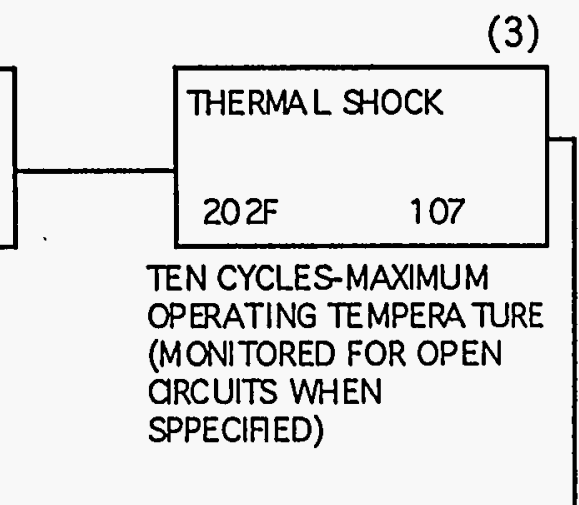

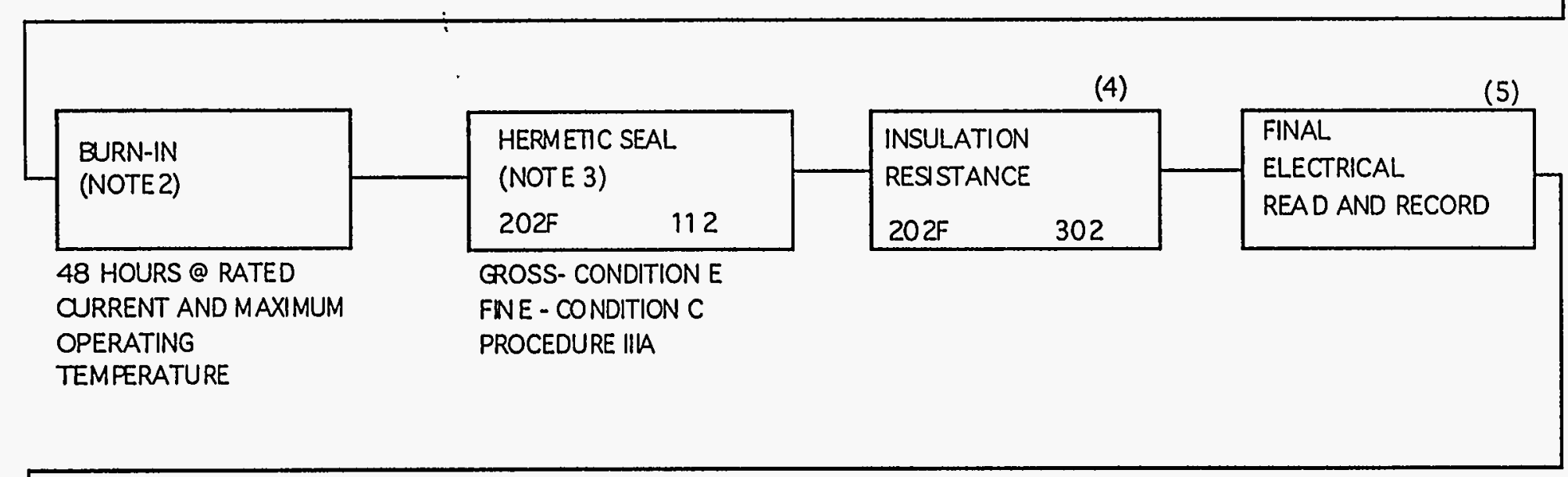

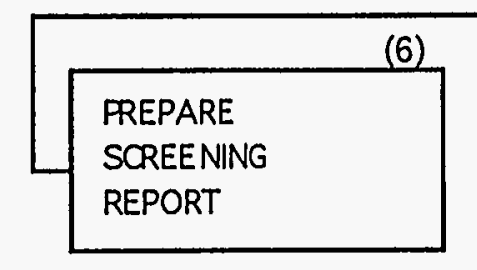

* Electrical parameters: NDUCTANCE DCRESISTANCE Q(QUALITYFACTOR)

SUPPLEMENTAL SCREENING REQUIRES ST EPS 1 THRU 6
NOTE 1 : APPLICABLE WHEN SPEAFIED BY DEVICE DRAWING

NOTE 2: APPLICABLE TO MOLDED, RF DEVCES PER MIL-C39010

NOTE 3: A PPLICABLE ONLY TO HERMETIC DEVICES

Figure 12. Detailed Inductor Screening 
COMMERCIAL GRADE FULL SCREEN

(1)

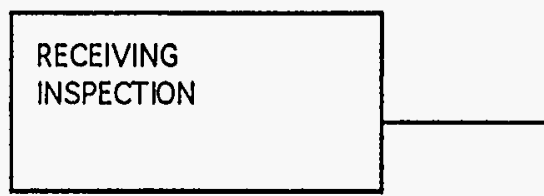

\section{INITIAL}

ELECTRICAL

READ AND RECORD *

(2)

RADIOGRAPHIC

EXAMINATION

MSFC-STD-355C

(NOTE 2)
(3)

THERMAL SHOCK

$202 F$

107

TEN CYCLES-MAXIMUM

OPERATING TEMPERATURE

(MONITORED FOR OPEN

CIRCUITS WHE N SPPECIFIED)

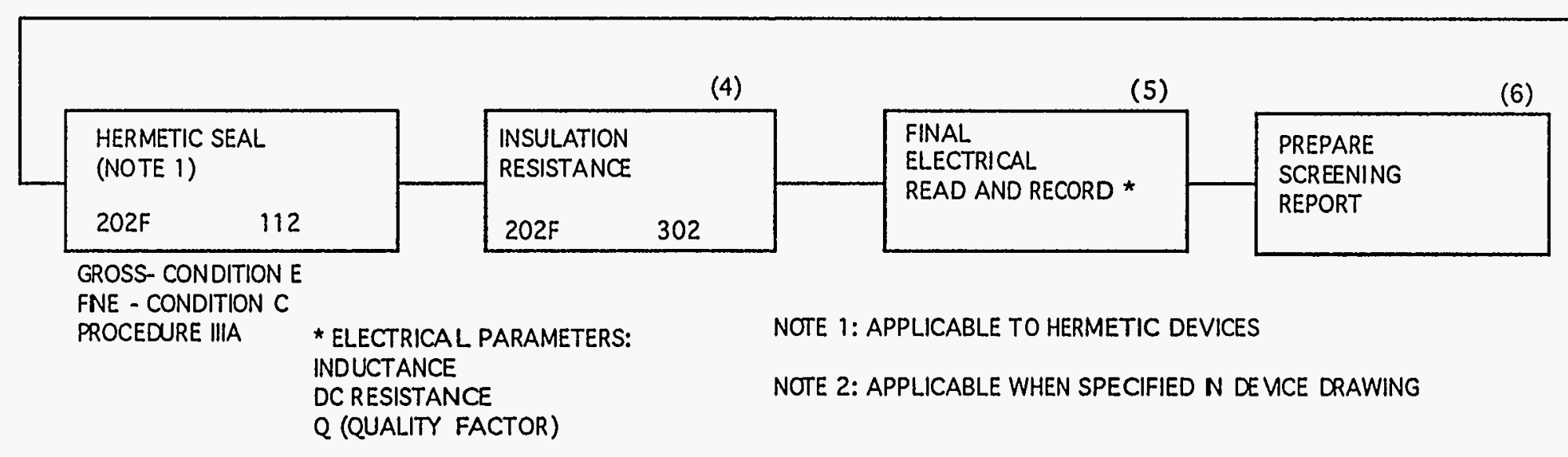

SUPPLEMENTAL SCREENING REQUIRES STEPS 1 THRU 6, EXCEPT THAT STEP 2 IS A GO/ NO-GO TEST.

Figure 13. Detailed Transformer Screening 
COMMERCIAL GRADE FULLSCREEN

(1).
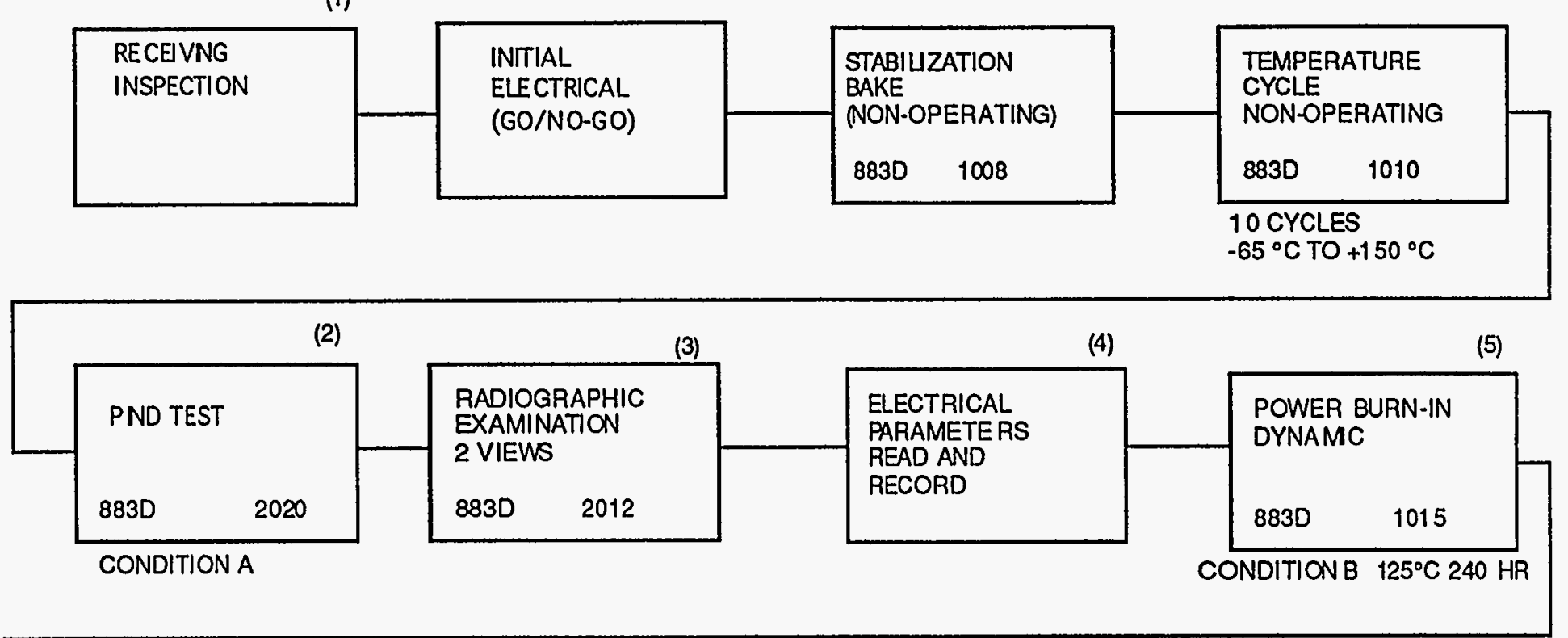

(6)

(7)

(8)

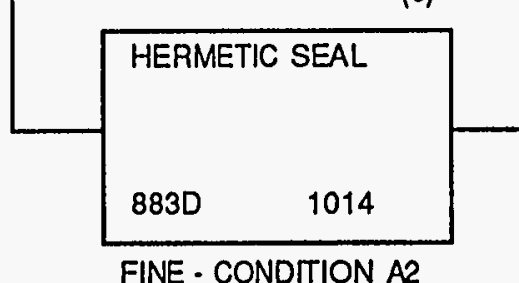

GROSS - CONDITION

HGH AND LOW
TEMPERATURE
TESTING
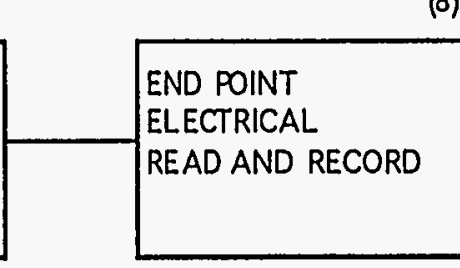

PREPARE LOT

SCREENING

$-55^{\circ} \mathrm{CAND}+125^{\circ} \mathrm{C}$

NOTE 1

- NOTE 1: PARTS WITH KNOWN TEMP UMITS USE REDUCED TEMPERATURES

PARTIAL SCREENING REQUIRES STEPS 1 THRU 8, EXCEP T THE DURATION OF STEP 5 IS 96 HOURS

Figure 14. Detailed Crystal Oscillator Screening 
COMMERCIAL GRADE FULL SCREEN

(1)

\begin{tabular}{|l|}
\hline RECEIVING \\
INSPECTION \\
\cline { 2 - 3 }
\end{tabular}

(2)

\begin{tabular}{|l|l|l|}
\hline $\begin{array}{l}\text { DIELECTRIC } \\
\text { WITHSTANDING } \\
\text { VOLTAGE } \\
\text { GO /NO-GO }\end{array}$ & \begin{tabular}{|l|l|}
\hline OUTGASSING \\
BAKE
\end{tabular} \\
\cline { 2 - 3 }
\end{tabular}

72 HOURS @ $+90^{\circ} \mathrm{C}$

AND 10 E-5 TORR

(NOTE 1)

NOTE 1: PARTS WITH KNOWN TEMPERATURE LIMITS WILL HAVE REDUCED TEMPERATURES

SUPPLEMENTAL SCREEN:

STEPS 1 THROUGH 3 ONLY, ONLY IF THE OUTGASSING BAKE HAS BEEN DONE BY THE MANUFACTURER

Figure 15. Detailed Connector Screening 


\section{Appendix A.5 \\ Clementine Sensor Suite Waiver Procedure (C1-S0-006)}




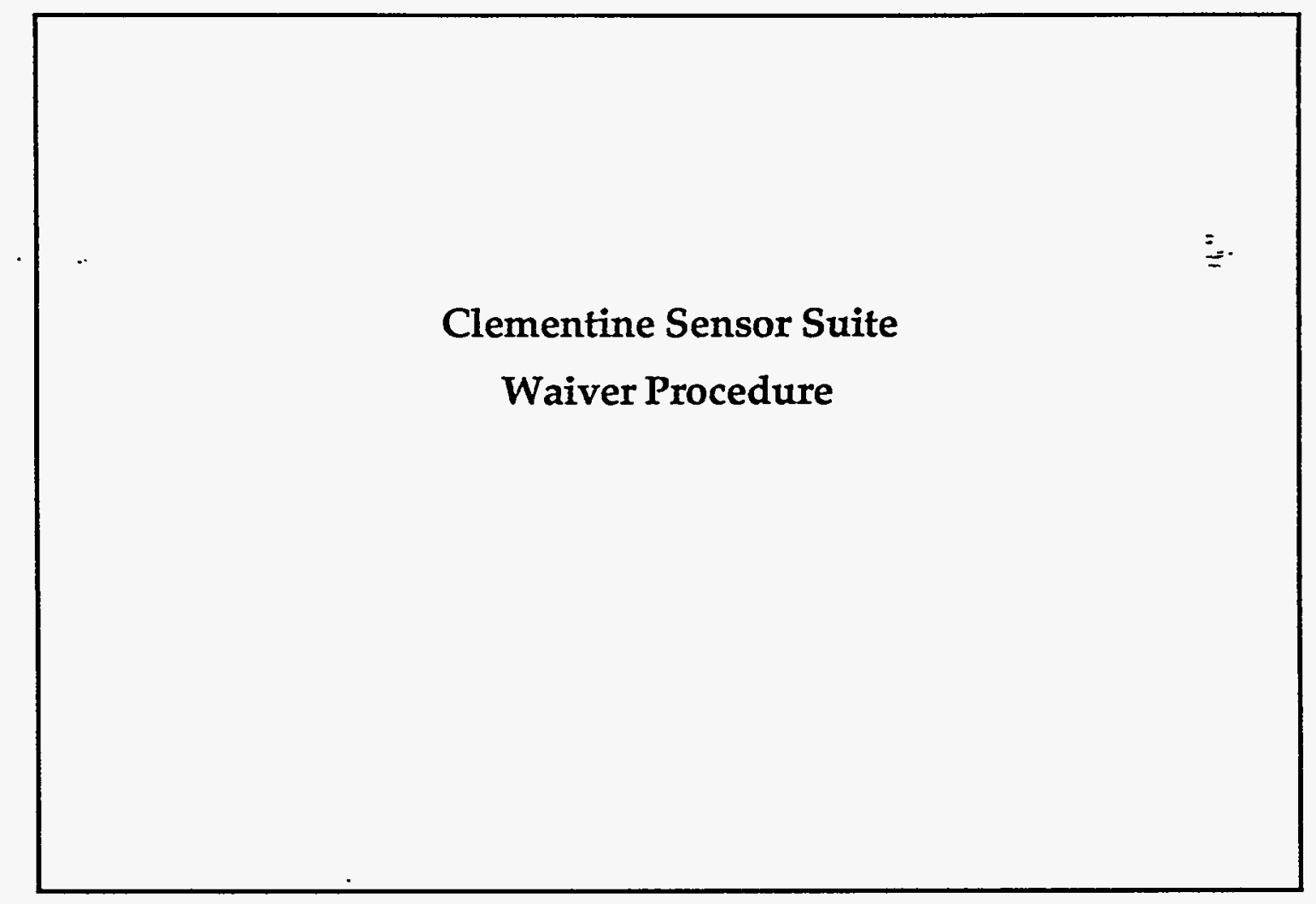

\begin{tabular}{|c|c|c|c|c|}
\hline & Date & Rev. & Date & Approval \\
\hline Prepared by: w.R. Bryson & $15 \operatorname{Mar} 93$ & & & \\
\hline Reviewed by: J. F. Kordas fo Kalh & 18 MAR 93 & & & \\
\hline Reviewed by: E. H. Schmitts S/unt & 18 megs & & & \\
\hline Reviewed by: R. E. Priest S S Jis & $16 \mathrm{Mar} 93$ & & & \\
\hline Reviewed by: R. F. Hills & 15 MAR 93 & & & \\
\hline Reviewed by: M.J.Shz & $8 \mathrm{Mar} 93$ & & & \\
\hline Approved by: L. D. Plegs & 31 Ahes DB & & & \\
\hline
\end{tabular}

University of California

III Lawrence Livermore National Laboratory

\begin{tabular}{c|c}
\hline 15 March 93 & C1-S0-006 \\
Waiver Procedure & Revision 00
\end{tabular}




\begin{tabular}{|c|c|}
\hline $\begin{array}{c}\text { CLEMENTINE } \\
\text { Sensors Integration Project }\end{array}$ & $\begin{array}{c}\text { ENGINEERING NOTE } \\
\text { C1-S0-006 }\end{array}$ \\
\hline $\begin{array}{cc}\text { TITLE: } & \text { Clementine Sensor Suite } \\
& \text { Waiver Procedure }\end{array}$ & $\begin{array}{|ll|}\text { ASSY: } & \text { All } \\
\text { ORIG: } & \text { W. R. Brvson } \\
\text { DATE: } & 15 \text { March. } 1993 \\
\text { APPR: } & \\
\end{array}$ \\
\hline
\end{tabular}

Abstract:

This document describes the conditions and methods for use of formal waivers in the Clementine Sensor Integration Project. 


\section{Scope}

This document describes the formal waiver procedure that applies to any component that fails to meet the Clementine mission requirements.

\section{Purpose}

In order to meet the mission reliability requirements, all components and piece parts (refered to as components from here on) are required to meet certain minimum standards. If any component does not meet these standards, then a procedure is required to determine the effects of this deficiency, explore possible alternative routes and ultimately accept the component as it is or the reject it. This procedure describes the LLNL Clementine Sensor Integration Project's Waiver Procedure.

\section{Conditions Requiring Waivers}

In all cases where a component fails to meet the mission radiation environment, fails to meet the required screening procedure or does not meet purchase/manufacture specifications, a formal waiver must be requested. These conditions shall include but are not limited to the following:

1) EE Parts that do not meet the $20 \mathrm{Krad}(\mathrm{Si})$ mission requirement.

2) EE Parts that are not single event upset immune.

3) EE Parts that are not single event latchup immune.

4) EE Parts that do not meet the Clementine Sensor Integration Project Parts

- Program requirements, C1-EE-022.

5) Purchased or manufactured parts, components or subsystems that do not meet their specifications or standards.

\section{Handling of Waiver Requests}

4.1 Any purchased or manufactured part, component or subsystem (referred to as parts from here on) that requires a waiver, shall have a failure modes and analysis (on the affected system) done to determine the possible consequences to the mission.

4.2 A formal waiver request shall be prepared for the part outlining the results of 4.1 and providing alternatives to using the part. The waiver should be signed by the cognizant engineer and shall include her/his recommendation for acceptance or denial of the waiver. See Appendix A for a sample of the waiver request form.

4.3 Waivers shall be approved/disapproved by the Clementine/DSPSE waiver review committee. This committee is comprised of two representatives from LLNL, two from the NRL and one from SDIO. Waivers may be resolved formally, through meetings, or informally through telephone and FAX communications. The SDIO chairperson will determine the resolution process.

4.4 A record of waiver requests, approvals and denials shall be kept by the Clementine Quality Assurance Group. 
DSPSE Approval Need Date:

\section{Waiver Request}

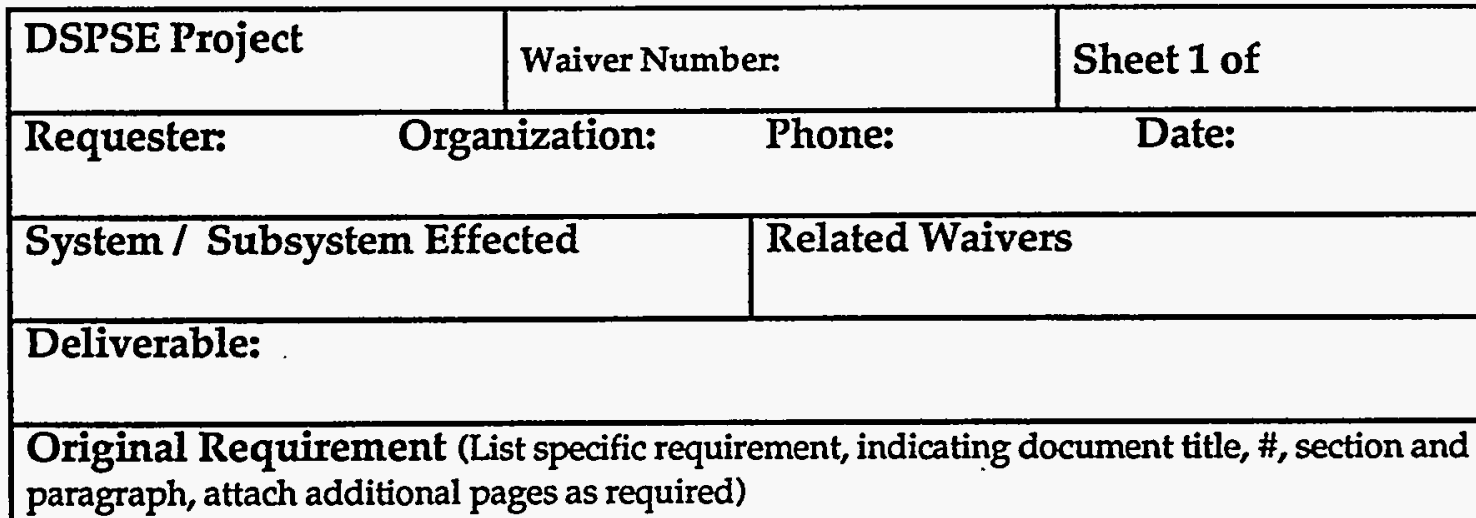

paragraph, attach additional pages as required)

Waiver Requested (Be Specific, attach additional pages as required)

Justification for Waiver: (attach additional pages as required)

Effect on Performance of Deliverable (If waiver is approved, attach additional pages as required)

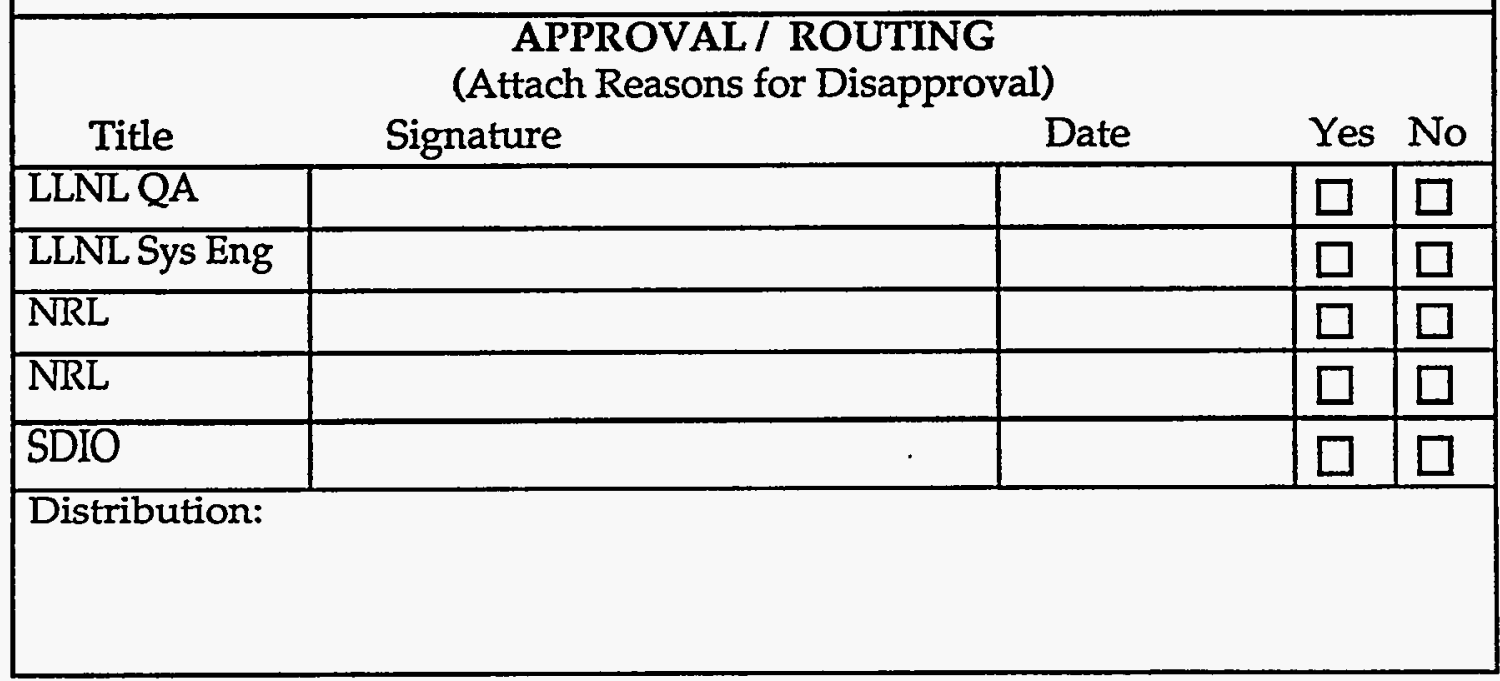




\section{Appendix A.6 \\ Parylene Conformal Coating \\ (C1-S0-009)}




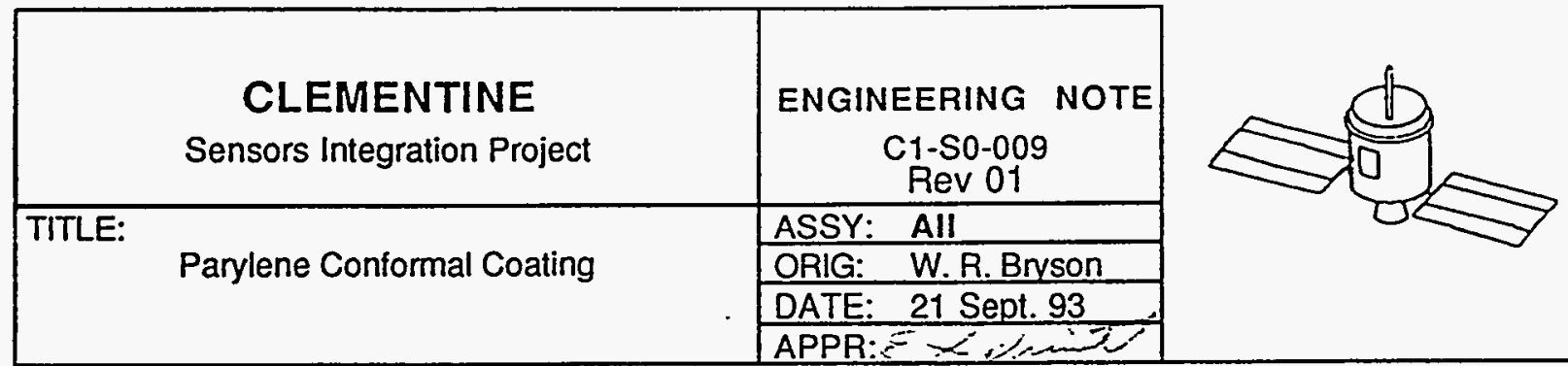

Abstract:

This document describes the requirements for inspection, cleaning, masking, priming and application of Parylene conformal coatings. 
$=$ Scope

-7is document describes the requirements for inspection, cleaning, masking, ziming and application of Parylene conformal coatings.

\section{$2 \quad$ Inspection}

=1 All printed wiring assemblies shall be inspected prior to conformal wating. This inspection is to insure that the assembly has received no camage during verification and testing, that it is free of all contamination, all saking and gluing operations have been completed and all fasteners hare zeen torqued. All rework must be completed at this point. The Assembly Log =ust be current and complete. The date of this final inspection and any iscrepancies shall be recorded in the Assembly Log.

\section{之. Final Cleaning}

The cleaning of substrates is an extremely important step and is critical to staining good adhesion of Parylene. Reagent grade or equivalent solvents izall be used for all cleaning operations. Surface contamination, such as ionic Id organic residues, and especially finger prints and residual solder fluxes, zust be removed. These contaminants are difficult to detect but, if not = $=$ moved, can cause reduction in or loss of adhesion.

\section{Caution:}

All printed wiring assemblies are to be handled with clean room gloves or finger cots from this point on.

Printed wiring assemblies are to be stored in a New anti static bag with desiccant during transportation and storage from this point on.

The shelf life of the solution prepared in 3.3 is 24 hours. Dispose of this solution after that time.

Isopropyl alcohol is poisonous.

All waste disposal must be in accordance with Federal, state and local laws and regulations in addition to LLNL and DOE rules and regulations.

E.1 All printed wiring assemblies shall be given a final cleaning in the E-eon degreaser prior to conformal coating. This cleaning shall be done ¿zcording to posted cleaning procedures.

$\equiv 2$ Assemblies shall to be allowed to air dry for at least 30 minutes. 
इ3 Prepare a Silane A174 solution using the following proportions:

$1.0 \mathrm{ml} \mathrm{A174}$

$5.0 \mathrm{ml}$ De-ionized Water

$1000 \mathrm{ml}$ reagent grade isopropyl alcohol

Allow this solution to stand overnight or stir for two hours prior to use.

\$4 Immerse the printed wiring assembly in reagent grade isopropyl ¿cohol for 10 minutes.

5. Immerse the printed wiring assembly in the Silane A174 solution -.epared in 3.3 for 30 minutes.

Io Remove the printed wiring assembly from the Silane A174 solution and allow to air dry for 30 minutes. Suspend the assembly to insure that any solution draining off does not contact the assembly.

5.7 Rinse the printed wiring assembly in reagent grade isopropyl alcohol ior 5 minutes.

इ3 Allow the printed wiring assembly to air dry for 30 minutes.

$\subseteq \quad$ Bake and Vacuum Drying

Cleaned printed wiring assemblies must be baked to remove all moisture and rolatiles.

$\leq 1$ Place the printed wiring assembly in a suitable temperature chamber and bake at $95 \pm 5^{\circ} \mathrm{C}$ for 6 hours.

12 Transfer the printed wiring assembly to a vacuum chamber and pump intil the pressure in the vacuum chamber stabilizes at less than $10^{-6}$ torr.

$\leq 3$ Allow the printed wiring board to remain in the vacuum chamber for $\equiv$ least 6 hours.

$\div \quad$ Back fill the vacuum chamber with dry nitrogen, remove the assembly End place in a new clean antistatic bag with desiccant.

Note: Handle the assembly with new, clean room gloves or finger cots. 


\section{इ $\quad$ Masking Prior to Parylene Coating}

5.: Mask all areas of the assembly that are not to be Parylene coated according to the appropriate procedure using Techform TC-530. Allow the =sking to cure.

\section{$6 \quad$ Parylene Coating}

6:- Apply a 0.5 to 1.0 mil coating of Parylene using the methods describad in appendix $\mathrm{A}$ of this document.

$6=$ Upon completion of the coating process, remove the assembly immediately to a clean antistatic bag with desiccant. All further operations on the assembly must be completed in a clean room environment. 
Appendix A.

P:spared by Joseph W. Burris

Section 1: Operating Procedure.

1.: This section details the techniques required to perform Parylene deposition with the Specialty Coating Systems, Inc. Model 2010.

$1=\quad$ Cold Trap Operation

Warning: Operation of cryogenic devices poses the threat of severe injury. Refer to Section 2.4 for safety precautions required when operating the Model 2010 cold trap.

\section{Mechanical Chiller}

The Model 2010 is equipped with a mechanical chilling unit, inclucing a cold trap thimble which inserts into the cold trap housing. For operation of this unit, follow the manufacturer's instructions.

Note: The mechanical chiller is equipped with a " $\mathrm{T}$ " type thermocouple which measures the temperature of the probe. This thermocouple may be used to monitor cold trap temperature during a coating cycle. If this temperature is being monitored, the vaporizer heaters should not be enabled until the cold trap probe is below $-75^{\circ} \mathrm{C}$. If this temperature is not being monitored, the mechanical chiller should be allowed to operate for at least 45 minutes prior to initinting the vaporizer heaters. (This is done to ensure that the cold trap is a: low enough temperature to adequately capture Parylene process byproducts and hence protect the vacuum pump.)

\section{$I \equiv \quad$ Automatic Coating Cycle}

\section{Preparation}

1. Check the log book located on the front door of the PDS 2010 :or the following:

A) Not more than 9 Parylene coating runs have been made since the last vacuum pump oil change.

B) Not more than 100 grams of Parylene dimer have been processed since the last vacuum pump oil change.

Note 1: Vacuum pump oil changes will be noted in the log book remarks column. 
Note 2: If either A or B above has been exceeded contact maintenance person listed on right side panel of PDS 2010 (proceed no further until vacuum pump oil has been changed).

2. Open the front door of the PDS 2010 and check the vacuum pump oil level located in the lower right-hand corner. The oil level should be between the "Full" arrow and the "Add" arrow. The oil should not appear cloudy, dirty, or otherwise contaminated.

Note: Any problems with oil level or clarity contact maintenance person listed on right-side panel of PDS 2010. Proceed no further until problems are corrected.

3. Weigh the Parylene dimer to be processed and enter the amount in the log book.

4. Place the Parylene dimer in the "dimer boat" and load into the vaporizer through the access port which is located in the lower front compartment.

5. Treat all surfaces of the baffle, chamber interior, and cold trap thimble with a release agent (2\% soap solution). Refer to Section 3.1.1.

6. Insert the baffle in the inlet opening. Use high-temperature tape to retain the baffle securely in position.

Important: Be sure to tape the small gap which may exist at the rear side of the baffle/inlet port interface (the side closest to the center of the chamber). Failure to tape this gap results in a monomer gas path which leads directly to the substrate, without passing through the baffle. This could have a detrimental impact on coating quality.

7. Hang parts to be coated from the fixture and place the fixture on the chamber base. Allow clearance around pump outlet and avoid direct contact with the inlet baffle. Enter board size, type of board anc the number of boards being processed into the log book.

Note: It is important that a glass witness plate (located next to the PDS 2010) also be hung from the fixture for each coating run. This allows coating thickness to be measured.

8. Make sure the o-rings and gaskets and their matching surfaces are very clean. Lower chamber over the base, insert cold trap thimble into the cold trap housing, close and seal the vaporizer access door. 
9. Start the mechanical chiller.

\section{$\underline{\text { Start-Up }}$}

10. Switch on Main Power. The white indicator will be illuminated, the computer will initialize, and the vacuum and temperature controllers will illuminate. Enter the "Start Time" in the log book.

11. Switch "on" the furnace/gauge, evacuate, vaporizer, and alarm rocker switches. Press cold trap thimble so that it is flat against the cold trap housing to form a vacuum seal.

\section{Computer Control Sequence}

With all control switches enabled as above, the computer will automatically control the deposition process in the following sequence:

12-1. Furnace and gauge tube heaters come on and heat up to the set point value (SU). Pump comes on and begins pumping down the system:

- Vaporizer is disabled.

- Fault alarm is disabled.

12-2. When the furnace and gauge tube heater are within the allowable deviations of their setpoint $\left( \pm 15^{\circ} \mathrm{C}\right)$, the pump pressure is below base pressure as indicated by the " $\mathrm{L}$ " light on the vacuum controller, and the protracted pump down timer has timed out:

- The vaporizer is enabled and begins to ramp up.

- The fault alarm remains disabled.

12-3. When the vaporizer exceeds $90^{\circ} \mathrm{C}$, coating has begun:

- Fault alarm monitoring is enabled.

- End of run monitoring is enabled.

12-4. If the furnace or gauge tube should go out of their allowable limits, or the pump pressure exceeds 100 , a fault alarm will be indicated:

- Red Fault Light comes on.

- Audio alarm is sounded (this can be silenced by turning off the alarm rocker switch).

- The 5 minute fault alarm timer is initiated. If the fault does not clear before the time elapses, then a shut down will be initiated as described in item 12-6.

12-5. When the coating run has completed:

- Vaporizer will hold at a temperature of $175^{\circ} \mathrm{C}$. 
- The pump pressure will go below base pressure.

- The 5 minute end of run timer begins timing out before initiating a shut down as described in item 12-6.

12-6. A controlled shutdown will occur when end-of-run or a fault condition has been indicated:

- The furnace, gauge tube, and vaporizer heaters are disabled. vacuum.

- The pump remains on to secure the process by preserving the

\section{End of Run}

13. Turn off the cold tap.

14. Place the vacuum switch in the vent position. After venting, push the vacuum switch in the center off position. The chamber is now ready to be unloaded.

In order to preclude contamination and accumulation of water vapor, evacuate the vacuum system before shutting down the equipment.

15. Unload chamber and clean unit, refer to Section 3.1.1.

\section{$1 . \quad$ Successive Runs}

If a another run is desired, the following preparation must be taken:

1. Turn off the heater output control switches.

Important: DO NOT re-enable the furnace/gauge tube heaters at this time by leaving the furnace/gauge tube control switch on and pressing the computer reset button. If the furnace and gauge heaters remain at operating temperatures when the computer is reset, it will be interpreted as a brief power interruption, and the vaporizer heaters will be enabled prematurely.

2. Remove and clean the cold trap thimble. (Beware of extremely cold temperature, wear protective gloves.)

3. Hang parts on fixture (Caution: the chamber base inlet and baffle may be hot.)

4. After the vaporizer has cooled below $90^{\circ} \mathrm{C}$, load a new charge of Parylene dimer. Loading the vaporizer above this temperature will cause immediate vaporization of Parylene dimer, causing pump down 
problems and possibly degradation of the subsequent coating run (wear protective gloves if vaporizer has not cooled completely).

5. Reseal chamber, could trap thimble, and vaporizer door.

6. Re-start the cold trap.

7. Turn on the heater control switches and place the vacuum switch to Evacuate (observe pump down rate for possible leaks).

8. Push the computer reset button to restart the program.

9. See items 13, 14, and 15 above for "end of run" procedures. 


\section{Section 2: Machine Safety}

The ..odel 2010 Parylene Deposition System contains potential safety hazards to opzators and service personnel if appropriate precautions are not followed. These potential hazards include:

- Electric shock

- Thermal burns

- Contact freeze injury by cryogenic apparatus

- Catastrophic loss of vacuum/implosion

The isllowing sections describe the precautions which should be reviewed and ojserved prior to operation of this unit. Unless service is being perio:-ned by qualified and authorized personnel, all access panels to the Mocie 2010 cabinet should be closed whenever the machine is powered.

\subsection{Vapor and Pyrolysis Section}

Unce normal operating conditions, the vaporizer and pyrolysis furnace and neart: components are maintained at temperatures which can cause burns on cor:tact, and are powered at 110 volts AC. These areas are enclosed within the $2[10$ cabinet and should not be touched any time the machine is powered or cizing cool down after a coating cycle.

\subsection{Dimer Loading Door}

The loading door heating element is controlled as a part of the vaporizer. A metal shield covers the heating element to protect against electric shock. However, when the vaporizer is enabled, this shield becomes hot. This part of tine coating unit should not be touched during heat-up, deposition, or cool dow.. after a coating cycle. Wear protective gloves if it becomes necessary to ope- ine loading door when the door is hot.

\subsection{Deposition Chamber Vacuum Sensor}

The ciamber vacuum sensor must be heated to prevent deposition of Partlene on the sensing elements. Protective gloves should be worn if it becozes necessary to handle the heating element or the sensor itself when ther $\equiv-e$ hot.

\subsection{Cold Trap}

The ?.'odel 2010 is available with a mechanical chiller unit in lieu of the liquic nitrogen system. The surface of the thimble with this configuration cari $=$ zach temperatures below negative $120^{\circ} \mathrm{C}$. Caution should be exercised to avo: $\dot{c}$ direct skin contact with the thimble of a mechanical chiller cold trap when it is cold. 


\subsection{Inlet Baffle}

Proiesive gloves should be worn when removing the inlet baffle from the deposition chamber after a coating run. This baffle may become heated to tempzatures in excess of $200^{\circ} \mathrm{C}$ via radiation from the pyrolysis furnace durizs deposition.

\subsection{Glass Viewports}

Glass viewport(s) are provided to allow viewing of the substrate and fixturing durin: the coating process. A viewport which is damaged or improperly instali:ad poses a potential implosion threat while the chamber is under vacuin. Such an implosion would likely damage the substrate and/or the coatirg equipment, and could possible cause personal injury.

Do ncs operate the Model 2010 if one of the viewports is cracked or improserly installed. Avoid impacts to the viewport surfaces while the syster is under vacuum. 


\section{Section. 3. Maintenance Procedures}

\subsection{Routine Maintenance and Inspections}

As wit: any coating process, substrate and equipment cleanliness are the keys to a nigi quality coating. Keeping the Model 2010 free from dust, dirt, and grime, joth inside and out, will insure a clean substrate and good Parylene deposizion. Conscientious observance of the following instructions can help assure smooth operation with minimal downtime.

\subsubsection{Parylene Deposition Removal}

The na:ure of the Parylene coating process necessitates the periodic removal of the Farylene that is deposited on the interior surfaces of the coating chamire and related components.

\section{Applining Release Agent}

To aid the removal of the deposited film is imperative that a release agent be appliec to all surfaces that will be coated and subsequently stripped. A $2 \%$ mixture of "Micro® Laboratory Cleaning Solution" (manufactured by Interizzional Product Corp.) with de ionized water is an effective release ager: Application is most effectively performed with a spray bottle and a lint-ie: cloth. Components for application include:

- interior of coating chamber and base

- inlet baffle

- cold trap thimble and housing

- piping between coating chamber and cold trap

- any other items that appear in the coating chamber that will be stripped of film (reusable fixturing, witness strips, etc.)

Once P $\equiv-$ ylene has been deposited, a Micro, soap interface between the Parye-2 film and the coating chamber interior has been established. This Micros soap interface will remain until the Parylene film has been removed. It is ::0: necessary to apply the release agent to the Parylene film itself, but only :o the bare, uncoated surfaces that will receive a coating during the first depos:ion cycle after cleaning.

NOIE: It is not necessary nor desirable to apply Microß soap to any o-ring or gask:

\section{Parrie-a Coating Removal}

The :0. owing items should be cleaned when the coating becomes excessively hear:, $=$ listers or separates from the surface. 
- Deposition Chamber

- Viewing Port

- Inlet Baffle

- Chamber Ports, Inlet and Exit

Paryleze deposits thicker than .001 inch on the chamber interior walls, base and bafie should be stripped. Avoid using sharp tools for removing deposits, as thes an nick the surfaces making it more difficult to remove deposits the next tirie.

Do not $=y$ to remove thin coatings. However, sections of coating that pull away irom the surfaces can cause problems if they are not removed. The main problem which can occur is collapsing (or pulling completely away) of the cozing when the system has been loaded for a run. When the system is placec under vacuum, air entrapped under the coating will migrate, possibly pulling the coating away completely. If this happens in the deposition chambe, the coating will surround the fixture, preventing the dimer from depositing properly. If this happens in the pump out port, the collapsed coating could reduce or eliminate the vacuum needed to achieve an accepte-le quality coating.

\section{Cold I $=0$ Thimble}

To insire the coldest possible cold trap thimble surfaces, deposits should be remore: after each run. Also, corrosive compounds are produced (in small amouniz) as a by-product of Parylene deposition and are subsequently condereed on the thimble surface. Therefore, regular cleaning is imperative to prevent corrosion and pitting of the cold trap thimble. See MACHINE SAFET: (Section 3) for precautions required when handling cryogenic appa-z:ss.

Non-merallic Abrasive pads, such as "Scotch Brite", have been found to be usefui iar removing the thin layers of polymer that deposit on the lower portion of the thimble.

\subsubsection{Vacuum Integrity}

Vacu: = leaks are usually due to contamination of sealing surfaces and orings. The contamination, in most cases, has been found to be small particles of tra $\geq:=d$ polymer. It is good operating practice to check the sealing surfaces of the r:porizer access door, chamber ring, and cold trap thimble flange prior to punzing the system down. For leak detection, the use of solvents is NOT recorf:anded. Solvent flammability and noxious vapor creation could resul: $i$ - serious injury or equipment damage. Use of a helium leak detection svste $n$ :s the approved method. 


\subsubsection{Vac:-in Pump}

The oil in tie vacuum pump not only provides lubrication and wearprotection fir the pumps internal components, but also performs a critical role in the fump's ability to reach its ultimate pressure. For optimum performance, the pump oil should be keep free from foreign particles and excessive condensable vapors. The Model 2010 includes both a cold trap and a wire mesh inlet screen to protect the pump from most contaminants. However, $2 \leqslant$ with any oil-lubricated device, the pump will require routine oil changes. (Refer to the documentation supplied by the manufacturer for a complete description of operation and service to the vacuum pump.)

Oil changes :or the Model 2010 vacuum pump should be scheduled based upon the fo:

- A $\quad 10$ coating runs.

- A $\quad$-er a process throughput of 120 grams of Parylene dimer.

- Azytime that the cold trap has exceeded (been higher than) $-75{ }^{\circ} \mathrm{C}$ du-ing deposition (such as when the $\mathrm{LN}_{2}$ source has been exhausted dicing a run).

- Mienever the oil appears cloudy, dirty, or otherwise contaminated.

- Mien, after a coating cycle has been performed, the machine is scieduled to be idle for more than one (1) week. (Changing the oil beiore periods of non-use will prevent corrosion of pump components during storage.)

NOTE: The system base pressure should be regularly monitored. Increases not attribut= 1 to vacuum leaks or outgassing usually indicate a deterioration of the puming system. This deterioration is usually due to the passage of process br-:-=oducts that are not effectively trapped by the cold trap thimble. In some insinces, lower cold trap temperatures will alleviate this condition. Normally, t: $:$ lower system base pressures can be restored by cleaning the inlet screen $\equiv t$ the pump inset and/or changing the pump oil.

\subsubsection{Vacuin Pump}

The vacuut-gauge is heated to $140^{\circ} \mathrm{C}$ to protect if from Parylene build-up. However, $t: \geq$ small port in the chamber base to which the gauge is connected is subject to zuild-up. This port should be regularly inspected and stripped as polymer bu $\mathrm{d}$-up could interfere with the vacuum readings.

\subsubsection{Vapo-izer}

The vaporizar and access door are subject to Parylene dimer film and ash build up. Trese areas should be cleaned when these conditions are noted in order to prevent coating contamination. 
Dimer Boミ:

A 2\% Micros soap solution, when used with a non-metallic abrasive pad (such as "Scotch Brite") has been found to be effective at cleaning the dark residue whici accumulates in the dimer boat after a coating run. Regular removal of tis residue will keep the dimer boat free from contaminants and extend its useful life. (If several runs are performed without removing this residue, it tends to harden and becomes more difficult to remove.) 


\section{Appendix A.7 \\ Sensor Integration Project StarTracker Camera Interface Control Document \\ (C1-S1-010)}




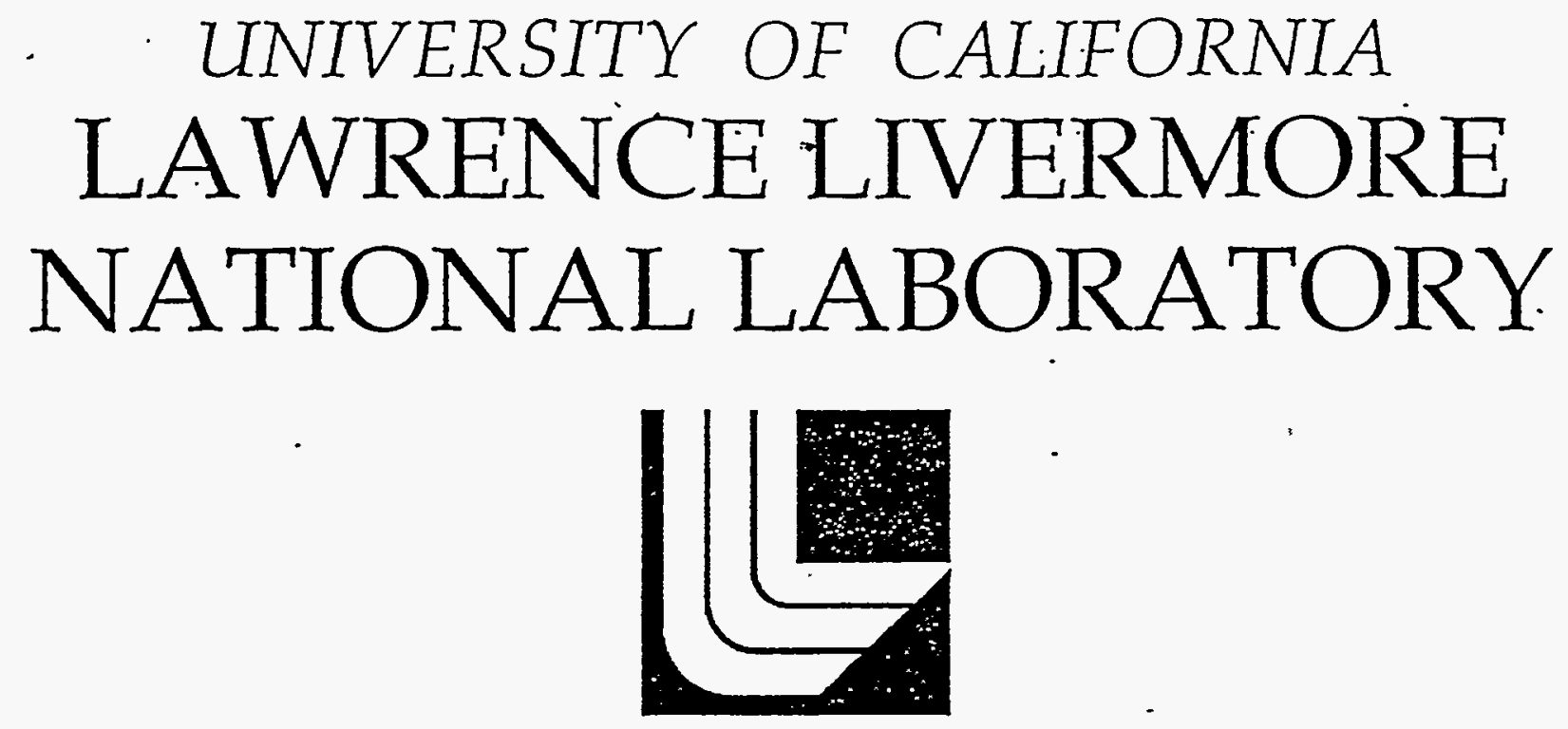

SENSOR INTEGRATION PROJECT

STAR TRACKER CAMERA

- INTERFACE CONTROL DOCUMENT

5 May 1993

C1-S1-010 Rev OC

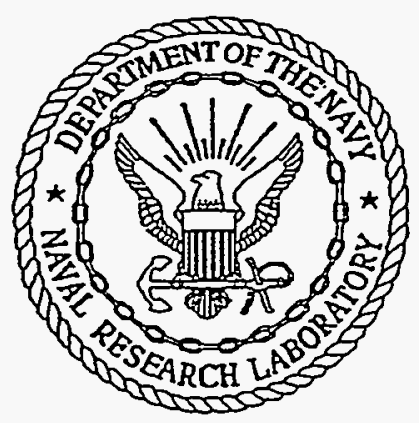

NAVAL RESEARCH LABORATORY NAVAL CENTER FOR SPACE TECHNOLOGY 


\section{Star Trackèr Camera \\ Interface Control Document}

Approved By.

Lt. Col. P. Kustan

Program Manager

Strategic Defense Initiative Organization
Approyed By:

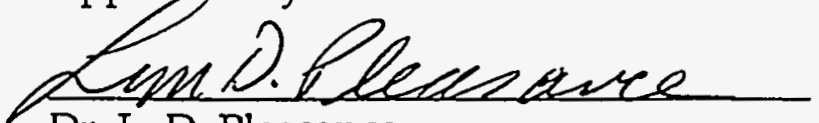

Dr. L. D. Pleasance

Program Manager

Lawrence Livermore National Laboratory
Appoved By:

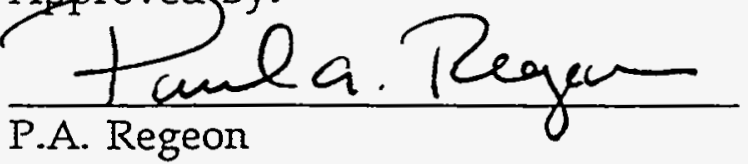

Program Manager

Naval Research Laboratory 


\section{RECORD OF CHANGES}

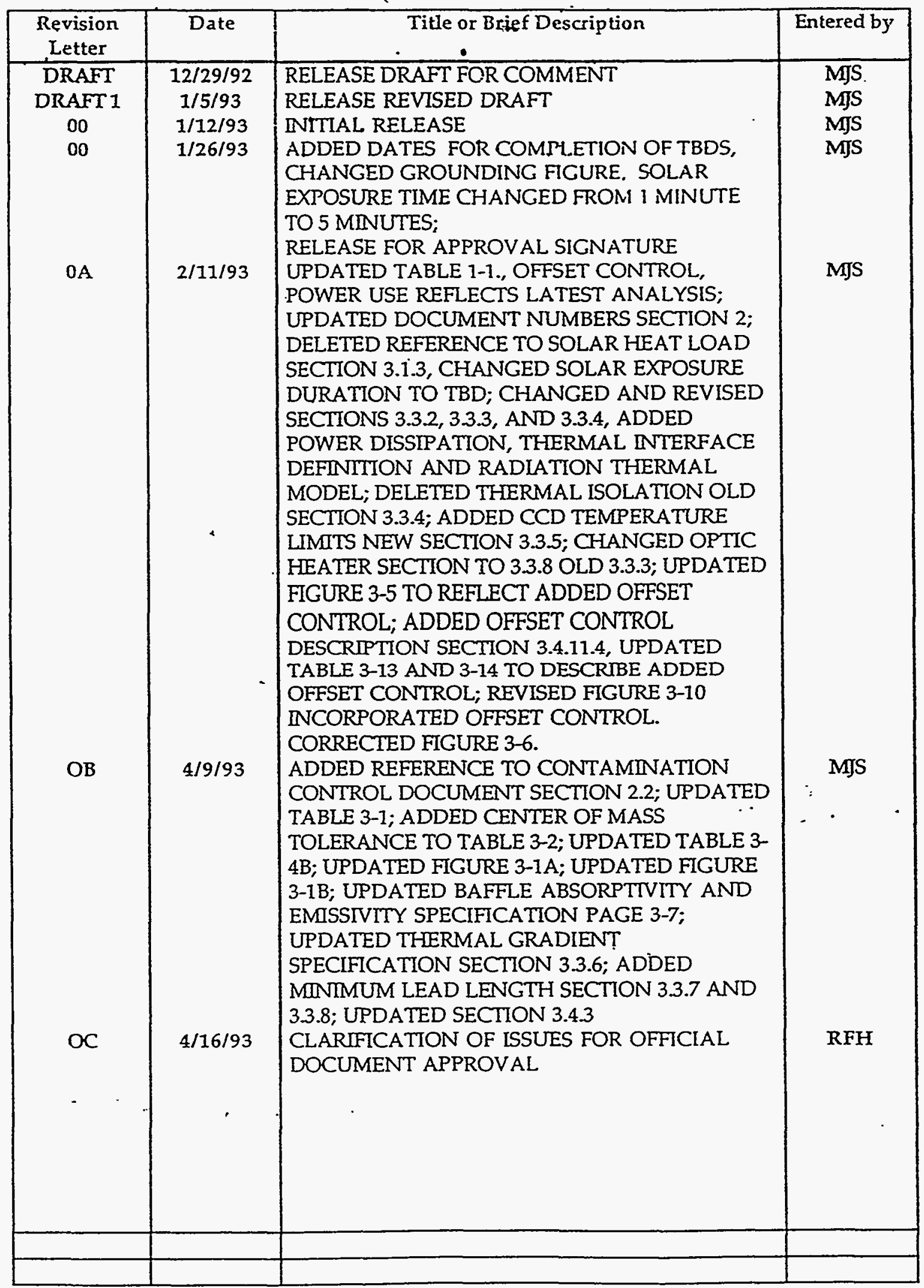




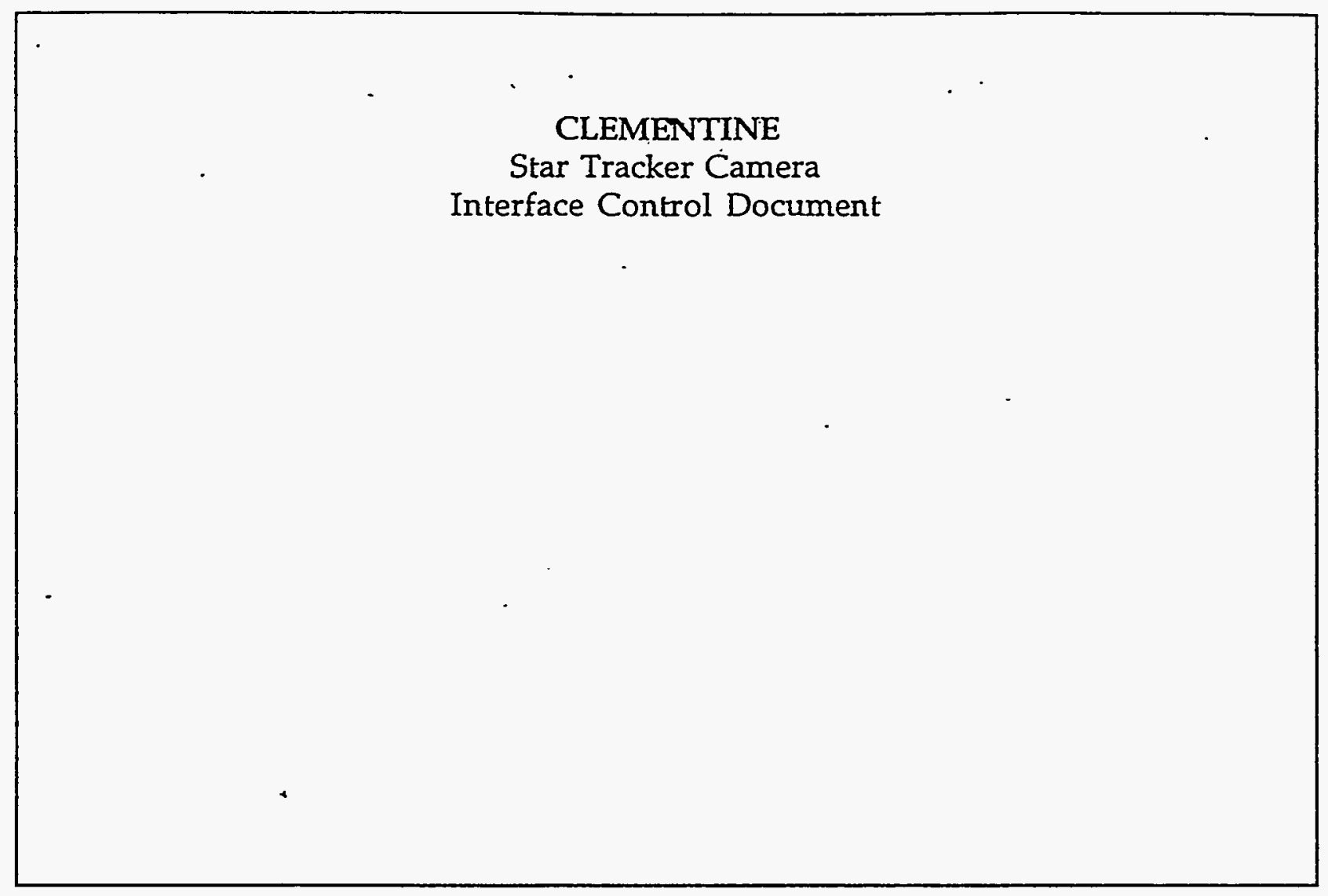

\begin{tabular}{|c|c|c|c|}
\hline & Date & \multicolumn{2}{|l|}{ Approval } \\
\hline Prepared by: R. E. Priest & $4 \mathrm{May}_{23}$ & \\
\hline Prepared.by:J.F. Kordas & $6 M_{a y}^{\prime} 93$ & \multicolumn{2}{|c|}{ Thands } \\
\hline Reviewed by: I.T. Lewis & $6 \mathrm{may} 93$ & \multicolumn{2}{|c|}{-logy Lemi } \\
\hline Reviewed by: A.G. Ledebuhr & $7 \mathrm{MAy} 93$ & \multicolumn{2}{|c|}{ huv D. Sedebur } \\
\hline Reviewed by: R. F. Hills & 7 MAY 93 & \multicolumn{2}{|c|}{ Roblat t Hilbl. } \\
\hline Reviewed by: M.J. Shannon & olfoy 93 & \multicolumn{2}{|c|}{ WX } \\
\hline Approved by: L.D. Pleasance & $6 x t a y$ & \multicolumn{2}{|c|}{ thlemen- } \\
\hline 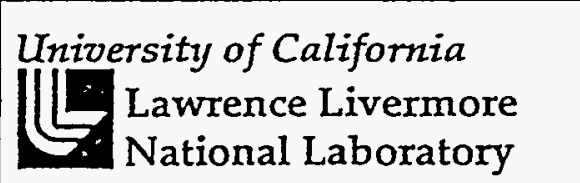 & \multicolumn{2}{|c|}{$\begin{array}{l}\text { Star Tracker Camera } \\
\text { Interface Control } \\
\text { Document }\end{array}$} & $\begin{array}{l}\text { C1-S1-010 } \\
\text { Revision: } 0 \mathrm{C}\end{array}$ \\
\hline
\end{tabular}


- This document contains the best information available as the date of release. Below is a list of items which are currently TBD or are to be changed at a later date. These will be updated when new information becomes available based on ongoing analysis and or tests.

Section 1.4 Sensor General Characteristics Document "Star Tracker Camera Performance Specification, LLNL ENC1-S1-006 will be available 1 June 1993.

Section 3.3. Thermal Interfaces Thermal interfaces are by analysis only at this time. Data obtained in May 1993 from prototype testing will be used to update that information presented. 


\section{TABLE OF CONTENTS}

1.

Scope.

.3.

1.1 .

Purpose.

1.2.

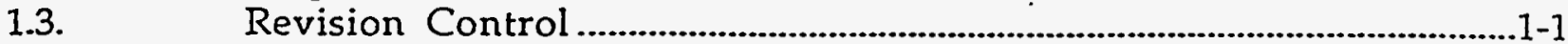

1.4. Sensor General Characteristics..........................................................................1-1

2.

DOCUMENTS

3.

INTERFACE DEFINITION

Size and Mass Properties Summary .............................................................

Dynamic Properties ............................................................................................

Thermal Interface ....................................................................................

Temperature Limitations.................................................................................

Base Plate Temperature Limitations .........................................................3-4

CCD Temperature Limitations ..................................................................3-4

Ground Testing Temperature Limitations ............................................3-5.

Lens Temperature Limitations.................................................................. $3-5$

Star Tracker Power Dissipation...................................................................3-5

Incident Radiation Thermal Model........................................................3-5

Thermal Interfaces......................................................................................

Thermal Gradients ................................................................................

Temperature Measurement...........................................................................

Optics Heaters …............................................................................................

Electrical Interface .....................................................................................

Steady State Voltages....................................................................................

Power Converter Load Transients ............................................................3-9

Power Converter Ripple...............................................................................3-10

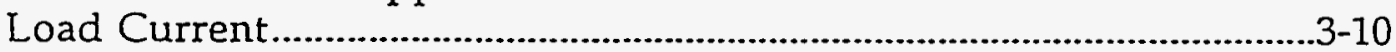

Other Considerations............................................................................

Grounding ..........................................................................................

STC Electrical Interconnections.............................................................

Video Frame Format..............................................................................

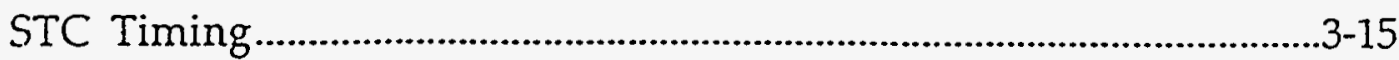

Interface Timing.................................................................................. $3-15$ 


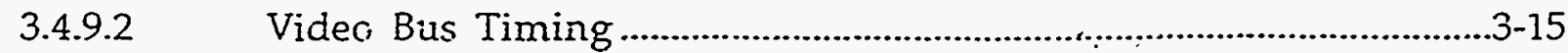

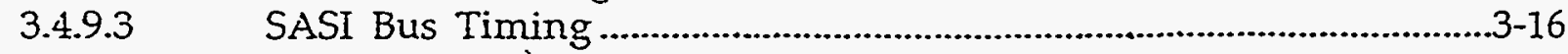

3.4.10.

3.4.11.

Command Verification

3-16

3.4.11.1

Operation.

.3-16

3.4.11.2

Power On Initialization

.3-16

3.4.11.3

3.4.11.4

Integration Control.

3-19

Gain Control.

3-19

3.4 .11 .5

Offset Control

3-19

Magnetic.

3-19

3.4 .11 .6

High Voltages

.3-19 


\section{SCOPE}

1.1. Scope

This document is the interface control document (ICD) for the Star Tracker Camera (STC). It identifies the optical, mechanical, thermal and etectrical interfaces for the wide field of view (WFOV) Stat Tracker Camera (STC) to be used on the deep space program science experiment (DSPSE) spacecraft (Clementine).

\subsection{Purpose}

The purpose of this document is to define the optical, mechanical, thermal and electrical interfaces for the STC on DSPSE.

\subsection{Revision Control}

This document contains the sole and controlling definition of the interface for the STC supplied by LLNL for use on the DSPSE spacecraft under construction for the SDIO by the NRL. Revision of this document will be made only under the written authority of the LLNL Sensor Integration Project Manager. Upon acceptance by signature of the information in this document requests for revision may be initiated by either the LLNL or the NRL Program Managers for consideration by a formal, regular and timely procedure conducted under the auspices of the SDIO Program Manager. Subsequent revisions will be incorporated into all relevant documents upon the written direction from the SDIO Program Manager.

\subsection{Sensor General Characteristics}

As information, the gèneral characteristics of the STC are summarized in Table 1-1. Details are contained in the Star Tracker Camera Performance Specification, LLNL document ENC1-S1-006. 


\section{LIST OF ILLUSTRATIONS}

\begin{tabular}{|c|l|c|}
\hline Number & Title & Page \\
\hline $3-1$. & STC Interface Control Drawing & $3-3$ \\
$3-1 A$. & Sensor Thermal Model For Evaluating Incident Radiation Thermal & $3-6$ \\
& Loads & $3-8$ \\
$3-1$ B. & Star.Tracker Camera Thermal Interface Definition and & \\
& Specification & $3-11$ \\
$3-2$. & Poiver Supply/STC Single Point Grounding & $3-11$ \\
$3-3$. & Grounding Of Power Cable Shields & $3-11$ \\
$3-4$. & Grounding Of Command \& Data Cable Shields & $3-13$ \\
$3-5$. & STC Functional Block Diagram & $3-17$ \\
$3-6$. & Video Timing & $3-18$ \\
$3-7$. & Timing Diagram & $3-18$ \\
$3-8$. & Timing Diagram & $3-18$ \\
$3-9$. & SASI Command Bytes & $3-21$ \\
\hline $3-10$. & Star Tracker Operational Flow Diagram & \\
\hline
\end{tabular}

\section{LIST OF TABLES}

\begin{tabular}{|c|l|c|}
\hline Number & Title & Page \\
\hline 1-1. & Star Tracker Camera Characteristics & $1-2$ \\
$3-1$. & STC Contamination Exposure Duration & $3-1$ \\
$3-2$. & Star Tracker Camera Size and Mass Property Estimate & $3-2$ \\
$3-3$. & Thermal Interface Temperature Requirements & $3-5$ \\
$3-4$ A. & STC Power Dissipation & $3-5$ \\
$3-4$ B. & Thermal Interface Summary & $3-8$ \\
$3-5$. & STC Analog Temperature Sensors . & $3-9$ \\
$3-6$. & Steady State Voltage Limits & $3-9$ \\
$3-7$. & Load Transient Limits & $3-10$ \\
$3-8$. & Power Supply Ripple Limits & $3-10$ \\
$3-9$. & Current Requirements & $3-10$ \\
$3-10$. & Signal Symbols & $3-12$ \\
$3-11$. & Connector Pin Assignments & $3-14$ \\
$3-12$. & Signal Descriptions & $3-15$ \\
3-13. & Camera Commands & $3-20$ \\
3-14. & Camera Commands That Return Status Data & $3-20$ \\
\hline
\end{tabular}


Table 1-1. Star Tracker Camera Characteristics

\begin{tabular}{|c|c|}
\hline Attribute & Characteristic \\
\hline $\begin{array}{l}\text { Focal Plane Arrays } \\
\text { Type } \\
\text { Pixel Format } \\
\text { Array Size } \\
\text { Pixel Size } \\
\text { CCD Operating Temperature }\end{array}$ & $\begin{array}{l}\text { Thomson TH7883-F02-01-B/T } \\
\text { Si CCD - } 0.4 \text { to } 1.1 \text { microns } \\
384 \times 576 \\
8.83 \times 13.25 \mathrm{~mm} \\
23 \times 23 \text { microns } \\
10^{\circ} \mathrm{C} \text { Maximum (Clementine spacecraft specific) }\end{array}$ \\
\hline $\begin{array}{l}\text { Optics } \\
\text { Type } \\
\text { Aperture } \\
\text { Focal Length } \\
\text { Speed }\end{array}$ & $\begin{array}{l}\text { Concentric Refractive } \\
14.0 \mathrm{~mm} \text { diameter. } \\
17.5 \mathrm{~mm} \\
\text { F/1.25 }\end{array}$ \\
\hline $\begin{array}{l}\text { Imaging } \\
\text { Spectral Range } \\
\text { Array FOV } \\
\text { IFOV } \\
\text { Point Spread } \\
\text { Noise Characteristics }\end{array}$ & $\begin{array}{l}0.4 \text { to } 1.1 \text { microns } \\
28.9^{\circ} \times 43.4^{\circ} \\
1.314 \times 1.314 \text { milli-radians } \\
20 \%-40 \% \text { of image blur energy in } 23 \mu \mathrm{m} \text { square and } \\
>80 \% \text { in } 75 \mu \mathrm{m} \text { square } \\
<120 \text { electrons @ } 20^{\circ} \mathrm{C} \text { for } 50 \mathrm{~ms} \text { integration time. } \\
\text { Dark current and non-uniformity are limiting for } \\
\text { longer integration times. }\end{array}$ \\
\hline $\begin{array}{l}\quad \text { Electronics } \\
\text { A/D Resolution } \\
\text { Frame Rate } \\
\text { Readout Time } \\
\text { Digitization } \\
\text { Readout Noise } \\
\text { Integration Time } \\
\text { Offset Control } \\
\text { Average Power } \\
\quad \text { Camera } \\
\quad \text { Lens Heater }\end{array}$ & $\begin{array}{l}8 \mathrm{bits} \\
<10 \mathrm{~Hz} \\
54.8 \mathrm{msec} \\
75,150,350 \mathrm{e}^{-/} \text {count } \\
60 \mathrm{e}^{-\mathrm{RMS}} \\
0.2-773 \mathrm{~ms} \text { (typical }=150 \mathrm{~ms}) \\
248 \text { gray level offset; } 5 \text { bit control word; } \mathrm{LSB}=8 \text { gray } \\
\text { levels } \\
\leq 3.6 \text { Watts (nominal) } \\
\leq 1.95 \text { Watts (50\% duty cycle @36 v) }\end{array}$ \\
\hline $\begin{array}{l}\text { Physical } \\
\text { Envelope } \\
\text { Mass } \\
\end{array}$ & $\begin{array}{l}11.7 \mathrm{~cm} \times 11.7 \mathrm{~cm} \times 13.2 \mathrm{~cm} \\
\leq 364 \mathrm{~g} \text { (Includes Baffle Assembly) }\end{array}$ \\
\hline $\begin{array}{c}\text { Thermal } \\
\text { CCD Temperature } \\
\text { Operating } \\
\text { Non-Operating } \\
\text { Optics Temperature } \\
\text { Operating } \\
\text { Non-operating } \\
\text { Base plate Temperature } \\
\text { Operating } \\
\text { Non-Operating }\end{array}$ & $\begin{array}{l}-20 \text { to }+10^{\circ} \mathrm{C} \\
-40 \text { to }+85^{\circ} \mathrm{C} \\
-20 \text { to }+40^{\circ} \mathrm{C} \\
-30 \text { to }+70^{\circ} \mathrm{C} \\
-20 \text { to }+2^{\circ} \mathrm{C} \\
-30 \text { to }+70^{\circ} \mathrm{C}\end{array}$ \\
\hline
\end{tabular}


2. DOCUMENTS

2.1. Controlling Interface Drawings

\begin{tabular}{|lll|}
\hline Source & Drawing Number & \multicolumn{1}{c|}{ Tifle } \\
\hline LLNL & AAA92-100839-0B & $\begin{array}{l}\text { Star Tracker Camera Mechanical Interface } \\
\text { Control }\end{array}$ \\
\hline
\end{tabular}

\subsection{Reference Documents}

\begin{tabular}{|c|c|c|}
\hline Source & Drawing Number & Title \\
\hline LLNL & LEA92-3128-01-0C & $\begin{array}{l}\text { Schematic ACTEL Camera w/ Gain and Offset } \\
\text { Control (Address 3) }\end{array}$ \\
\hline LLNL & LEA92-3128-11-0C & $\begin{array}{l}\text { Schematic ACTEL Camera w/ Gain and Offset } \\
\text { Control (Address 6) }\end{array}$ \\
\hline LLNL & C1-AAA92-106282-00 & Star Tracker Camera Document Tree \\
\hline LLNL & AAA92-104603-0E & Circuit Board ICD (ACTEL Camera) \\
\hline
\end{tabular}

\begin{tabular}{|c|c|c|}
\hline Source & Documents & Title. \\
\hline LLNL & DN61033-30520-02 & Synchronous Addressable Serial Interface (SASI) \\
\hline LLNL & C1-EE-031 & Actel Camera \\
\hline LLNL & C1-EE-007 & Actel Camera, Power Dissipation Analysis \\
\hline LLNL & C1-EE-032 & Actel Camera, Timing Report \\
\hline LLNL & ENC1-S1-005 & Star Tracker Thermal Circuit Analysis \\
\hline Mil Spec & MIL-HDBK-340 & $\begin{array}{l}\text { Application Guidelines for MIL-STD-1540B; Test } \\
\text { Requirements for Space Vehicles, Section 5.6.2: } \\
\text { Rationale for Definition of Thermal Uncertainty } \\
\text { Margin. }\end{array}$ \\
\hline LLNL & ENC1-S1-006 & Star Tracker Camera Performance Specification \\
\hline Mil Spec & MIL-STD-1246 & $\begin{array}{l}\text { Product Cleanliness Levels and Contamination } \\
\text { Control Program }\end{array}$ \\
\hline LLNL & C1-EE-019 & Spacecraft Shielding and Grounding \\
\hline LLNL & $\mathrm{C} 1-\mathrm{S} 0-008$ & $\begin{array}{l}\text { Clementine Sensor Clean Room Exposure Time } \\
\text { Limits }\end{array}$ \\
\hline
\end{tabular}




\section{INTERFACE DEFINITION}

The optical, mechanical, thermal and electrical interfaces are defined in this section.

\subsection{Optical Interface}

\subsubsection{Field of View}

The STC must be mounted with-a 100\% unobstructed field-of-view of 63 by 75 degrees defined per AAA92-100839, under all operating conditions.

\subsubsection{Solar Exclusion Angle}

A solar exclusion angle of 63 by 75 degrees will be maintained during camera imaging.

\subsubsection{Exposure to Sun Light}

$$
\begin{aligned}
& 68 \times 705 \\
& 64 \times 80
\end{aligned}
$$

The STC has been exposed to direct solar illumination for a period up to five minutes with no apparent degradation in performance. However, this represents a test of one and does not reflect the stress of cumulative effects of multiple exposures nor have these effects been adequately evaluated through analysis or additional tests to give confidence that the STC would survive if routinely operated in this mode. Other than inadvertent exposure, if a requirement exists during spacecraft operation to expose the STC to direct solar illumination, a formal waiver must be requested from SDIO.

\subsubsection{Contamination Control}

The STC and all surfaces within the partially sealed compartment of the contamination control cover must meet a Level 700 particulate standard per MILSTD-1246 at the time of launch. Meeting this cleanliness requirement can be achieved by controlling the particulate level of the storage environment.

\subsubsection{Cleanliness Level Verification}

Cleanliness level will be verified by analysis of exposure conditions and verified periodically using ' witness samples.

\subsubsection{Contamination Exposure Duration}

Appropriate combinations of clean room levels and duration of exposure are sufficient to meet end-use cleanliness requirements. The time integrated total exposure of a clean room class will result in a level 700 particulate specification. These clean room classes are defined in Table 3-1.

Table 3-1. STC Contamination Exposure Duration

\begin{tabular}{|c|c|}
\hline Clean Room Class & Exposure Duration \\
\hline 100 & 12 years \\
1000 & 2 years \\
10000 & 150 days \\
100000 & 20 days \\
\hline
\end{tabular}




\subsection{Mechanical Interface}

The STC consists of one component with a mechanical interface as shown in Figure 3-1 (AAA92-100839).

\subsubsection{Size and Mass Properties Summary}

The geometric envelope, mass, center of mass and center of mass inertial properties of the STC are shown in Table 3-2. The camera coordinate axis used in the mass properties determination is defined in Figure 3-1.

\section{Table 3-2. Star Tracker Camera Size and Mass Property Estimate}

\begin{tabular}{|c|c|c|c|c|c|c|c|}
\hline Envelope $(\mathrm{cm})$ & Mass(g) & \multicolumn{6}{|c|}{ Moment of Inertia Tensor $\left(\mathrm{kg}_{\mathrm{g}} \mathrm{m}^{2}\right)$} \\
\hline $\begin{array}{c}11.68 \mathrm{~cm} \\
\text { diameter } \times 13.00 \\
\mathrm{~cm} \text { long }\end{array}$ & 364 (Maximum) & $\left.\begin{array}{lll}I_{i i} & I_{i j} & I_{i k} \\
I_{j i} & I_{j j} & I_{j k} \\
I_{k i} & I_{k j} & I_{k k}\end{array}\right]$ & $=$ & $\begin{array}{r}4.22 \\
0.006 \\
-0.019\end{array}$ & $\begin{array}{l}0.006 \\
4.25 \\
0.000\end{array}$ & $\begin{array}{c}-0.019 \\
0.000 \\
3.16\end{array}$ & $\times 10^{-4}$ \\
\hline \multicolumn{2}{|c|}{ Center of Mass ( $\pm 5 \%$ ) } & \multicolumn{6}{|c|}{$\mathrm{i}=-0.02 \mathrm{~cm}, \mathrm{j}=-0.01 \mathrm{~cm}, \mathrm{k}=3.76 \mathrm{~cm}$} \\
\hline
\end{tabular}

\subsubsection{Dynamic Properties}

There are no moving parts within the STC. 


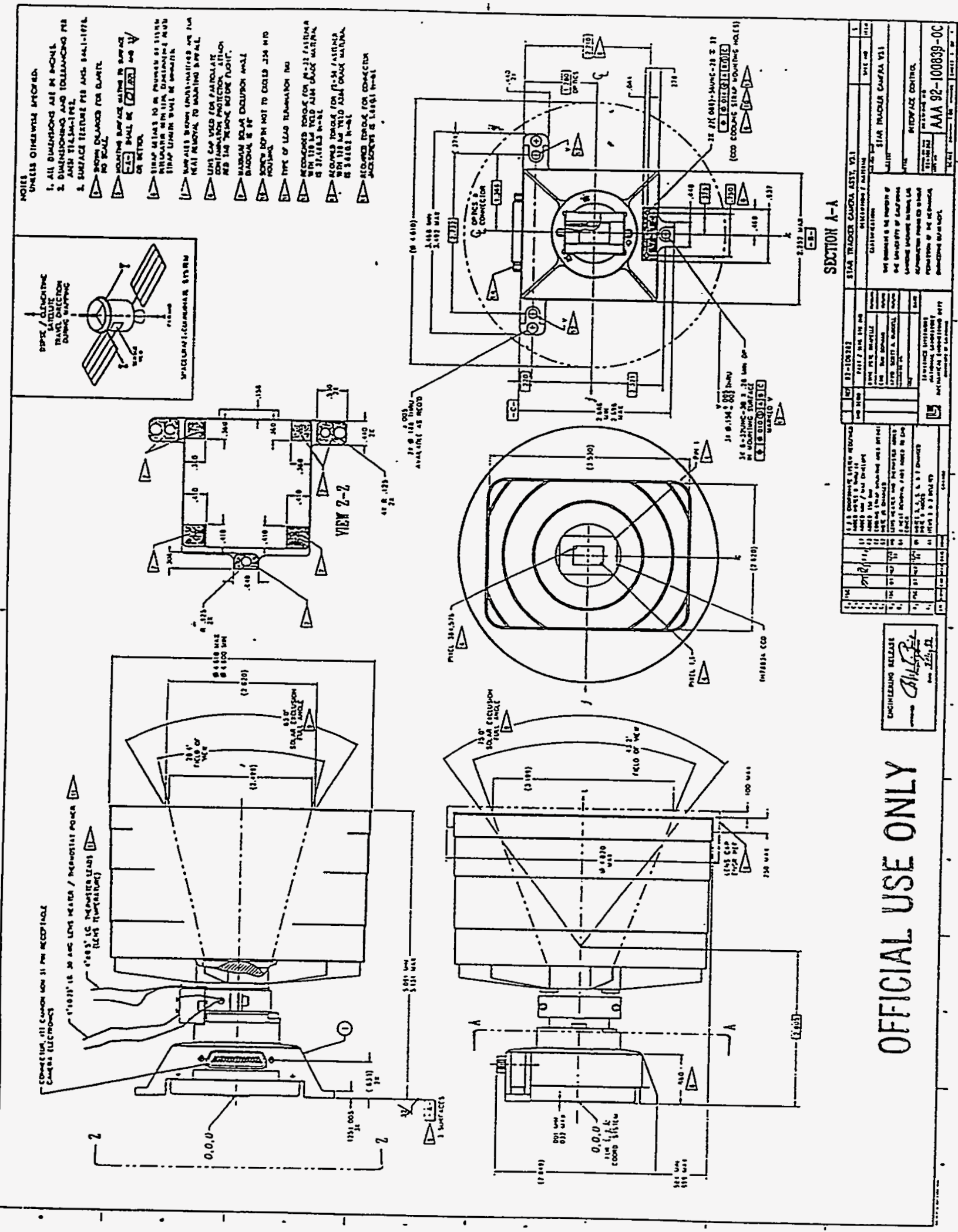

Figure 3-1. STC Interface Control Drawing 


\subsection{Thermal Interface}

\subsubsection{Temperature Limitations}

Temperature limitations placed upon the STTC are in terms of the Base Plate temperature, $C C D$ temperature and the lens temperature. The base plate temperature limits are specified to protect the electronic and mechanical parts from thermal damage. The CCD temperature limits are primarily concerned with achieving required $C C D$ performance. The lens temperature limits are concerned with the performance of the STC optics and the protecting them from thermal . damage. The various temperature limits are described below:

a) Operational-In-Spec - This is the temperature range which is required in order to achieve STC performance requirements.

b) Operation-Out-Spec - This is the temperature range which is required in order to prevent damage to the STC while maintaining a functional state. Damage and/or a reduction in reliability can occur to the STC because the electronic junction temperatures are outside operating limits. This temperature limit will prevent the worst case electronic component from exceeding its maximum, derated, junction temperature. Maximum junction temperatures are derated according to thermal design and reliability requirements.

c) Non-Operating - This is the temperature range which is required in order to prevent damage to the STC when it is in an unpowered state. Damage can occur to electronic, mechanical, and optical components because storage temperatures are violated.

\subsubsection{Base Plate Temperature Limitations}

The base plate temperature is defined as the temperature at the Side Mounting Tabs and Center Mounting Tab interfaces defined in Section 3.3.3. All base plate temperature limits are summarized in Table 3-3.

\subsubsection{CCD Temperature Limitations}

The STC electro-optical performance is related to the temperature of the imaging Charge Coupled Device (CCD). The colder the CCD the lower the dark current which improves the signal-to-noise ratio.

The CCD temperature is defined by the CCD case temperature measured by the $C C D$ temperature sensor described in Section 3.3.7. All CCD temperature limits are summarized in Table 3-3. 


\subsubsection{Ground Testing Temperature Limitations}

During ground testing, at no time is the temperature of the base plate or the CCD to be low enough to allow condensation to form upon the STC. All other base plate and $C C D$ temperature limits apply.

\subsubsection{Lens Temperature Limitations}

The lens temperature is defined by the lens temperature sensor described in Section 3.3.7. The Operational-In-Spec temperature limits are required in order to achieve STC performance requirements. The Operational-Out-Spec and Non-Operating temperature limits are required in order to prevent damage to the optical components. The lens temperature limits are summarized in Table 3-3.

Table 3-3. Thermal Interface-Temperature Requirements

\begin{tabular}{|c|c|}
\hline Temperature Limitation & Requirement \\
\hline $\begin{array}{l}\text { Base Plate: } \\
\text { Operational-In-Spec } \\
\text { Operational-Out-Spec } \\
\text { Non-Operating }\end{array}$ & $\begin{array}{l}-20^{\circ} \mathrm{C} \text { to } 2^{\circ} \mathrm{C} \\
-20^{\circ} \mathrm{C} \text { to } 10^{\circ} \mathrm{C} \\
-40^{\circ} \mathrm{C} \text { to } 70^{\circ} \mathrm{C}\end{array}$ \\
\hline $\begin{array}{l}\text { Operational-In-Spec } \\
\text { Operational-Out-Spec } \\
\text { Non-Operating }\end{array}$ & $\begin{array}{l}-20^{\circ} \mathrm{C} \text { to } 10^{\circ} \mathrm{C} \\
-20^{\circ} \mathrm{C} \text { to } 60^{\circ} \mathrm{C} \\
-40^{\circ} \mathrm{C} \text { to } 85^{\circ} \mathrm{C}\end{array}$ \\
\hline $\begin{array}{l}\text { Operational-In-Spec } \\
\text { Operational-Out-Spec } \\
\text { Non-Operating }\end{array}$ & $\begin{array}{l}-20^{\circ} \mathrm{C} \text { to } 40^{\circ} \mathrm{C} \\
-30^{\circ} \mathrm{C} \text { to } 70^{\circ} \mathrm{C} \\
-30^{\circ} \mathrm{C} \text { to } 70^{\circ} \mathrm{C}\end{array}$ \\
\hline
\end{tabular}

\subsubsection{Star Tracker Power Dissipation}

The results of power dissipation analysis for the STC are presented in Table 3-4A. Shown are the nominal and maximum $(+20 \%$ margin) for each of the camera operational modes. Also shown is the lens heater power dissipation.

Table 3-4A. STC Power Dissipation

\begin{tabular}{|c|c|c|c|c|c|c|c|c|c|}
\hline \multirow{3}{*}{ Camera Component } & \multicolumn{6}{|c|}{ Power Dissipation (Watts) } & & \multirow{2}{*}{\multicolumn{2}{|c|}{ 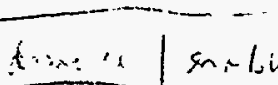 }} \\
\hline & Id & & Inte & rate & Rea & lout & & & \\
\hline & Nom. & Max. & Nom. & Max. & Nom. & Max. & $6 \pi$ & & \\
\hline Actel Camera & 3.64 & 4.37 & 3.63 & 4.36 & 3.64 & 4.37 & 310 & & \\
\hline $\begin{array}{l}\text { Lens Heater } \\
100 \% \text { duty cycle @ } 24 \text { Vdc } \\
100 \% \text { duty cycle @ } 36 \text { Vdc }\end{array}$ & & & & & & & & & \\
\hline
\end{tabular}

\subsubsection{Incident Radiation Thermal Model}

External thermal loads from incident radiation upon the STC Baffle and Optics is conducted through the STC housing and into the base plate. The amount of heat transfer into the base plate from this source is a function of the flux of incident radiation, the base plate temperature, and how the sensor is thermally integrated with the spacecraft. As previously stated, the sensor housing is required to be insulated from thermal radiation emanating from other sensors and systems of the 
spacecraft. The baffle and optical path are the only parts of the sensor which are exposed to thermal radiation from sources external to the spacecraft. The CCD temperature is the key requirement which must be considered when integrating the sensor with the spacecraft. The sensor model shown in Figure 3-1B. should be used to evaluate the thermal integration design.

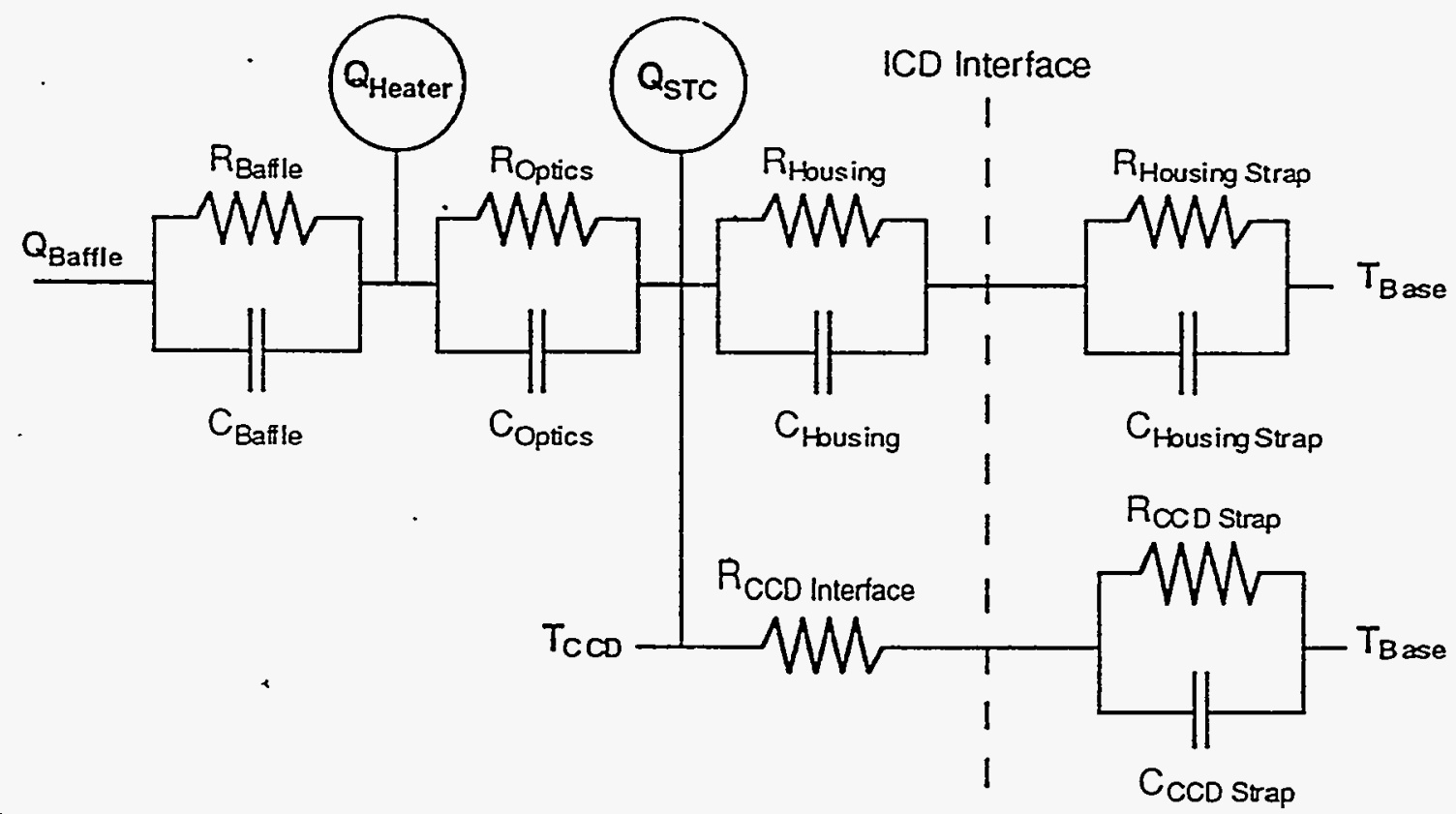

Where:

CBaffle

CCCD Strap

CHousing

CHousing Strap

COptics

QBaffle

QHeater

QSTC

RBaffle

RCCD Interface

RCCD Strap

RHousing

RHousing CCD

ROptics

TBase

TCCD

Lumpedthermal capacitance of the baffle $-80 \mathrm{~W}$-s $/{ }^{\circ} \mathrm{K}$.

Lumped thermal capacitance of the CCD strap - integrator responsibility. Lumped thermal capacitance of the camera housing assembly $-150 \mathrm{~W}$-s $/{ }^{\circ} \mathrm{K}$.

Lumped thermal capacitance of the housing strap - integrator responsibility.

Lumped thermal capacitance of the optical housing assembly $-36 \mathrm{~W}-\mathrm{s} /{ }^{\circ} \mathrm{K}$.

Is the heat transfer of the baffle.

Is the heat generated by the optical housing heater.

Is the heat generated by the sensor.

Lumped thermal capacitance of the baffle $-60^{\circ} \mathrm{K} / \mathrm{W}$.

Lumped thermal resistance between the CCD strap interface and the CCD $-6^{\circ} \mathrm{K} / \mathrm{W}$.

Lumped thermal resistance of the CCD strap - integrator responsibility.

Lumped thermal resistance of the camera housing assembly $-1.8^{\circ} \mathrm{K} / \mathrm{W}$.

Lumped thermal resistance of the housing strap - integrator responsibility.

Lumped thermal resistance of the optical housing assembly $-2^{\circ} \mathrm{K} / \mathrm{W}$.

Temperature of the sensor bench.

CCD temperature

Figure 3-1A. Sensor Thermal Model For Evaluating Incident Radiation Thermal Loads 
It is recommended that the sensor bench include a $25 \%$ margin in heat load to insure, with a $95 \%$ certainty ${ }^{1}$, that the bench will be able to reject the design heat load.

The following information will support the integration of the sensor into the thermal radiation environment of the spacecraft:

Baffle material: Aluminum

Hemispherical total solar absorptivity of all blackened baffle surfaces:

Hemispherical total IR emissivity of all blackened baffle surfaces:

Hemispherical total solar absorptivity of the baffle face: Hemispherical total IR emissivity of the baffle face: Hemispherical total solar absorptivity of the optics: Hemisplierical total IR emissivity of the optics: $\geq 0.95$

Hemispherical total solar absorptivity of un-blackened external surfaces of the baffle:

Hemispherical total solar absorptivity of un-blackened external surfaces of the baffle:

$\geq 0.95$

$\leq 0.15$

$\geq 0.75$

$\geq 0.40$

$\geq 0.95$

$\geq 0.4$

$\geq 0.1$

LLNL recommends that the sensor be integrated into the spacecraft so that only the reflective face of the baffle and the internal paths of the baffle are exposed to thermal radiation. The entire outside of the baffle should be insulated. This will minimize the amount of heat transfer to and from the sensor and sẹnsor base plate.

\subsubsection{Thermal Interfaces}

The STC is conductively cooled/heated during the mission. The STC contains eight thermal interfaces. These interfaces are depicted as part of the mechanical interface control drawing in Fig. 3-1. Fig. 3-1B. depicts the fraction of electrical power dissipated at each thermal interface for a typical application and the maximum allowable total thermal contact resistance permitted at each interface. The thermal contact resistance shall be equal to or less than the stated values. The fractional power given at each interface is for electrical power dissipation only and does not include heat dissipation due to heat load from external sources. Table 3-4B. summarizes the data presented in Figure 3-1B.

1 MIL-HDBK-340: Application Guidelines for MIL-STD-1540B; Test Requirements for Space Vehicles, Section 5.6.2: Rationale for Definition of Thermal Uncertaintv Margin, p. 21. 
Table 3-4B. Thermal Interface Summary

\begin{tabular}{|l|c|c|}
\hline Interface & Fractional Power & $\begin{array}{c}\text { Thermal Resistance } \\
\left({ }^{\circ} \mathrm{C} / \mathrm{W}\right)\end{array}$ \\
\hline Heat Strap & 0.15 & 0.05 \\
End Cover Corners (4) & $(.21+.21+.04+.04)=$ & $1.6(\mathrm{each})$ \\
& 0.50 & 0.10 \\
Center Mounting Tab & 0.11 & $0.06(\mathrm{each})$ \\
Side Mounting Tabs(2) & $(.12+12)=0.24$ & . \\
\hline
\end{tabular}

[Note: \% of Heat (Fractional Power) is independant of the operational Mode of the Sensorl
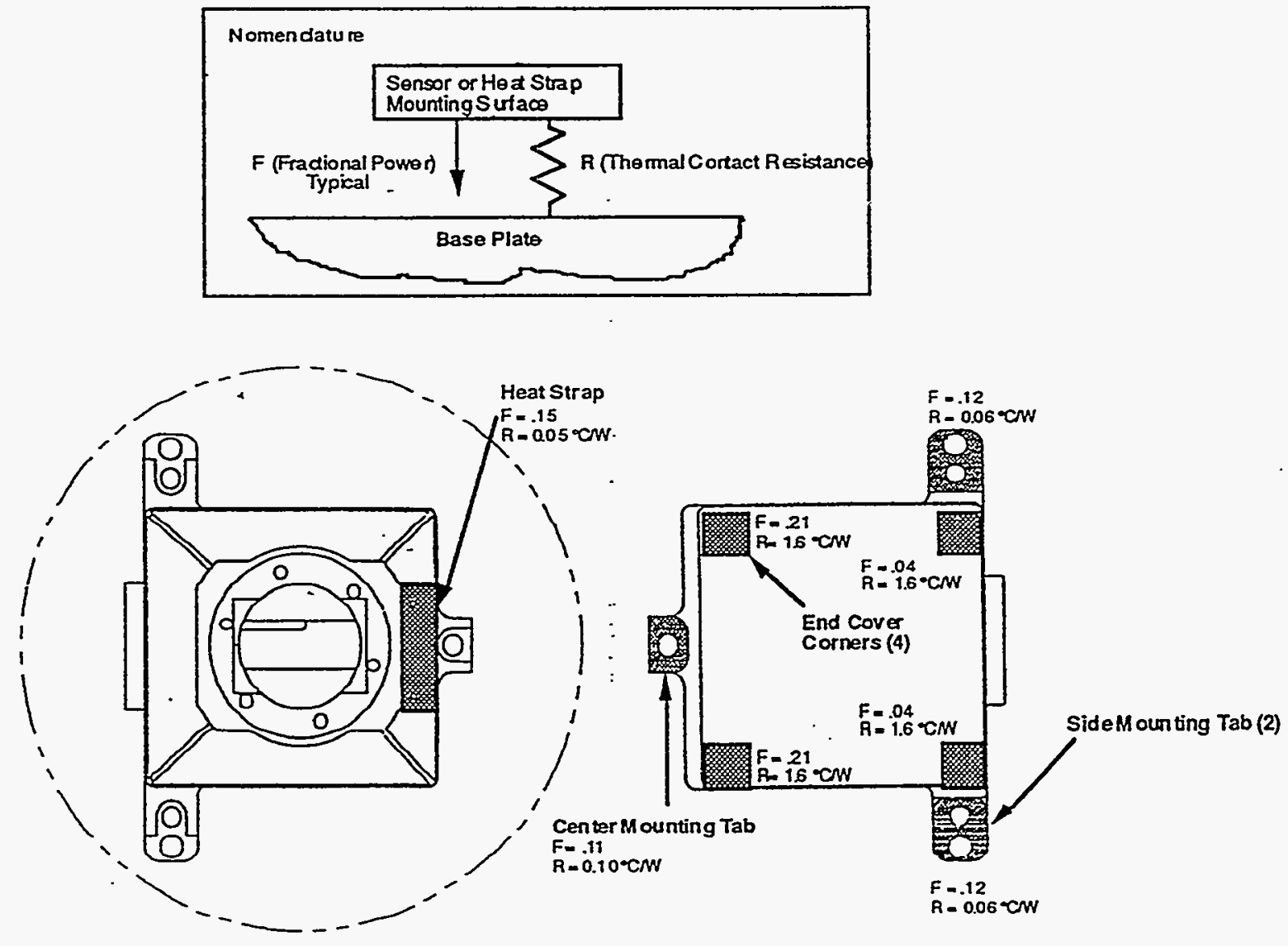

Figure 3-1B. Star Tracker Camera Thermal Interface Definition and Specification

\subsubsection{Thermal Gradients}

Thermal gradients on the mounting surfaces of the STC must be controlled to $\leq 3.3^{\circ} \mathrm{C} / \mathrm{cm}\left(15^{\circ} \mathrm{F} /\right.$ in) over the area of the three mounting tabs. The STC temperature must not change at a rate greater than $2^{\circ} \mathrm{C}$ per minute.

\subsubsection{Temperature Measurement}

Two analog temperature sensors are used in the STC, one senses the CCD temperature and the other is attached to the lens. The signal from the CCD 
temperature sensor is transmitted via the 51 pin connector on the STC while the lens temperature sensor uses flying leads. Lead length for the thermistor is $10.2 \pm 0.6 \mathrm{~cm}$. The specifications for these sensors are given in Table 3-5.

Table 3-5. STC Analog. Temperature Sensors

\begin{tabular}{|c|c|c|c|c|c|}
\hline \multirow[t]{2}{*}{ Item } & \multicolumn{2}{|c|}{ Transducer Range } & \multicolumn{2}{|c|}{$\begin{array}{c}\text { Part Operating } \\
\text { Range }\end{array}$} & \multirow[t]{2}{*}{ Transducer } \\
\hline & Min & Max. & Mir. & Max. & \\
\hline $\begin{array}{l}\text { CCD Temperature } \\
\text { Lens Temperature }\end{array}$ & $\begin{array}{l}-30^{\circ} \mathrm{C} \\
-30^{\circ} \mathrm{C}\end{array}$ & $\begin{array}{l}70^{\circ} \mathrm{C} \\
70^{\circ} \mathrm{C}\end{array}$ & $\begin{array}{l}-20^{\circ} \mathrm{C} \\
-20^{\circ} \mathrm{C}\end{array}$ & $\begin{array}{l}10^{\circ} \mathrm{C} \\
40^{\circ} \mathrm{C}\end{array}$ & $\begin{array}{l}\text { LTN-11 thermistor, Fenwall } \\
\text { Electronics } 137-562 Z X T-D O Z \\
\text { LTN-11 thermistor, Fenwall } \\
\text { Electronics } 137-562 Z X T-D O Z\end{array}$ \\
\hline
\end{tabular}

\subsubsection{Optics Heaters}

The STC is equipped with a thermostatically controlled lens heater which will be set to turn on at $-6^{\circ} \mathrm{C}^{2}$. The thermostat is an "open on temperature increase" type, thereby maintaining the lens temperature at or above the $-5^{\circ} \mathrm{C}$ setting. Flying leads are used to supply power to the heater and thermostat. Lead length is $10.2 \pm 016 \mathrm{~cm}$. The heater resistance is fixed at $450 \pm 45 \Omega$.

\subsection{Electrical Interface}

The following section defines the power requirements, the control signals to and the data signals from the STC.

\subsubsection{Steady State Voltages}

The STC requires an external power system that must provide on/off switching, short circuit protection, overload protection, line and load regulation. The STC nominal input voltages at the STC power connector are shown in Table 3-6. The voltages are required to meet the maximum and minimal limits shown excluding noise, ripple, and transients.

Table 3-6. Steady State Voltage Limits

\begin{tabular}{|c|c|c|c|}
\hline Input & Minimum & Nominal & Maximum \\
\hline$+15 \mathrm{Vdc}$ & $+14.75 \mathrm{Vdc}$ & $+15 \mathrm{Vdc}$ & $+15.25 \mathrm{Vdc}$ \\
\hline$+5 \mathrm{Vdc}$ & $+4.85 \mathrm{Vdc}$ & $+5 \mathrm{Vdc}$ & $+5.25 \mathrm{Vdc}$ \\
\hline$-15 \mathrm{Vdc}$ & $-15.25 \mathrm{Vdc}$ & $-15 \mathrm{Vdc}$ & $-14.75 \mathrm{Vdc}$ \\
\hline$-5 \mathrm{Vdc}$ & $-5.25 \mathrm{Vdc}$ & $-5 \mathrm{Vdc}$ & $-4.75 \mathrm{Vdc}$ \\
\hline
\end{tabular}

\subsubsection{Power Converter Load Transients}

Single event switching transients to the STC will be limited to those shown in Table 3-7. The voltage will return to its steady state within 12 milliseconds after the single event switching has ended.

2 The lens heater temperature is set to turn on at $-6^{\circ} \mathrm{C}$ due to the limited availability of preset thermostats. 
Table 3-7. Load Transient Limits

\begin{tabular}{|c|c|c|}
\hline Voltage & Minimum & Maximum \\
\hline$+15 \mathrm{Vdc}$ &.$+14.2 \mathrm{Vdc}$ & $+15.8 \mathrm{Vdc}$ \\
\hline$-15 \mathrm{Vdc}$ & $-15.8 \mathrm{Vdc}$ & $-14.2 \mathrm{Vdc}$ \\
\hline$+5 \mathrm{Vdc}$ & $+4.75 \mathrm{Vdc}$ & $+5.4 \mathrm{Vdc}$ \\
\hline$-5 \mathrm{Vdc}$ & $-5.4 \mathrm{Vdc}$ & $-4.6 \mathrm{Vdc}$ \\
\hline
\end{tabular}

\subsubsection{Power Converter Ripple}

Power supply ripple limits are shown in Table 3-8.

Table 3-8 Power Supply Ripple Limits

\begin{tabular}{|c|c|}
\hline Frequency & Limit \\
\hline 0 to $50 \mathrm{KHz}$ & $25 \mathrm{mV}_{\mathrm{p}-\mathrm{p}}$ \\
\hline $50 \mathrm{KHz}$ to $100 \mathrm{KHz}$ & $+12.04 \mathrm{~dB} / \mathrm{oct}$ \\
\hline $100 \mathrm{KHz}$ to $500 \mathrm{KHz}$ & $100 \mathrm{mV}$ p-p \\
\hline $500 \mathrm{KHz}$ to $1 \mathrm{MHz}$ & $+12.04 \mathrm{~dB} / \mathrm{oct}$ \\
\hline $1 \mathrm{MHz}$ to $50 \mathrm{MHz}$ & $400 \mathrm{mV}_{\mathrm{p}-\mathrm{p}}$ \\
\hline
\end{tabular}

\subsubsection{Load Current}

Power supply current values are shown in Table 3-9. The values provided for the $+5 \mathrm{Vdc}$ digital power are for when the data bus is disabled and enabled respectively and reflect a resistive $150 \Omega$ termination.

Table 3-9. Current Requirements

\begin{tabular}{|c|c|c|}
\hline \multirow{2}{*}{ Voltage } & \multicolumn{2}{|c|}{ Current } \\
\cline { 2 - 3 } & Nominal & Maximum \\
\hline +5 Vdc Analog & $0.140 \mathrm{~A}$ & $0.155 \mathrm{~A}$ \\
\hline+5 Vdc Digital & $0.040 \mathrm{~A} / 0.300 \mathrm{~A}$ & $.060 \mathrm{~A} / 0.330 \mathrm{~A}$ \\
\hline$-5 \mathrm{Vdc}$ & $0.040 \mathrm{~A}$ & $0.060 \mathrm{~A}$ \\
\hline$+15 \mathrm{Vdc}$ & $0.130 \mathrm{~A}$ & $0.140 \mathrm{~A}$ \\
\hline$-15 \mathrm{Vdc}$ & $0.015 \mathrm{~A}$ & $0.030 \mathrm{~A}$ \\
\hline
\end{tabular}

\subsubsection{Other Considerations}

STC turn-on surge current does not exceed $300 \%$ of the average current for more than 10 milliseconds. The STC does not require any sequencing of input voltages.

\subsubsection{Grounding}

The power supply single point grounding system is specified in Figure 3-2. No power current will flow through the chassis. Power cable shield grounding is shown in Figure 3-3. These shields are grounded only at the power source. Data cable shielding is shown in Figure 3-4. These shields are only grounded at the $\mathrm{SIP} / \mathrm{DHU}$ end. 


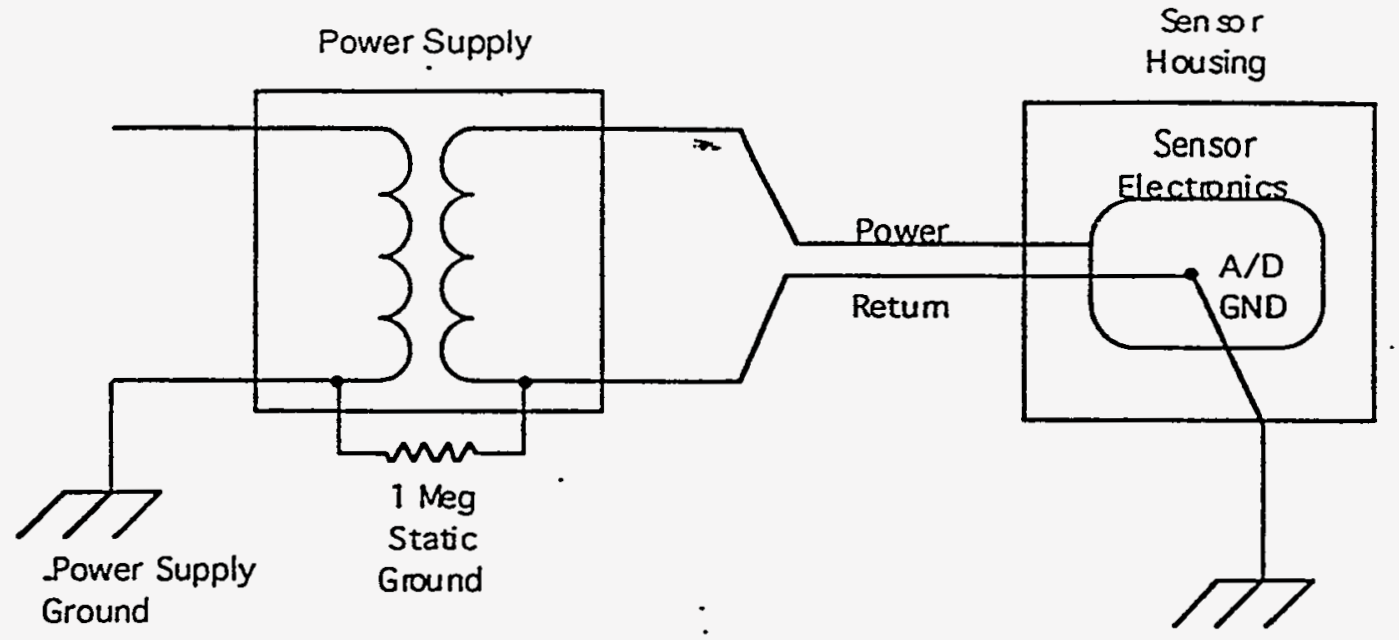

Figure 3-2. Power Supply/STC Single Point Grounding

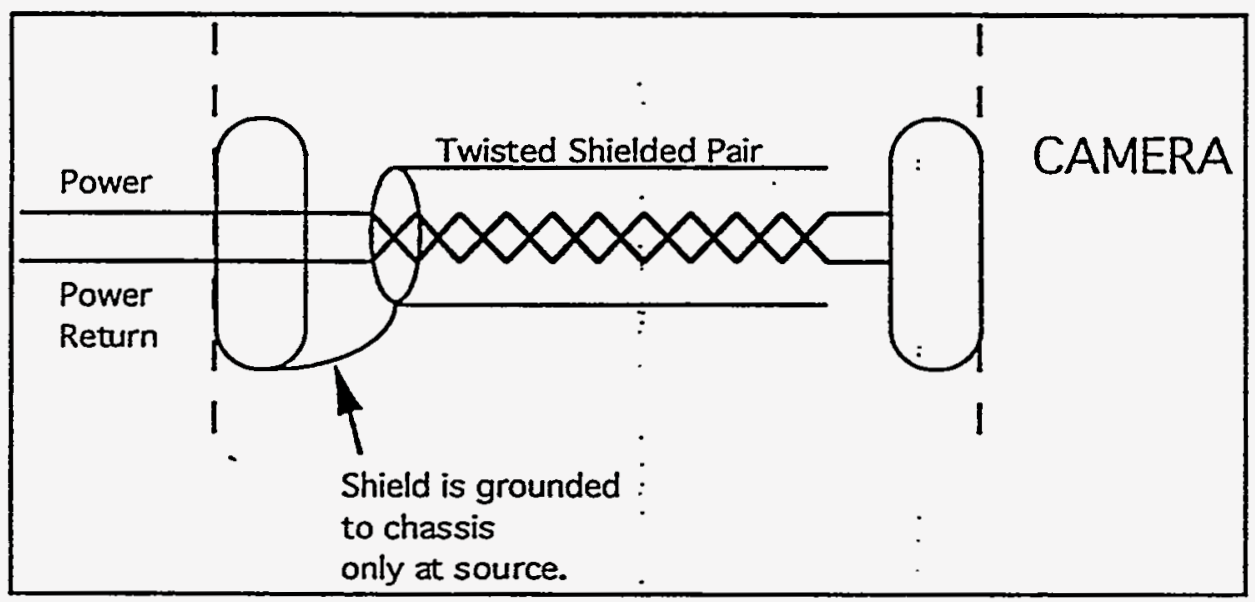

Figure 3-3. Grounding Ọf Power Cable Shields

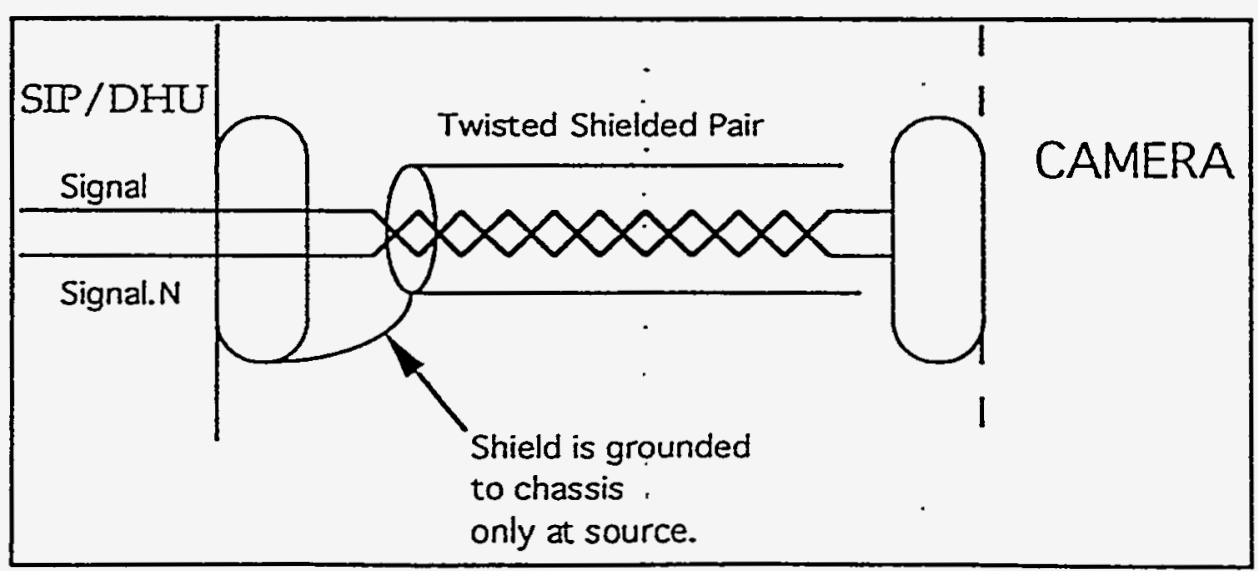

Figure 3-4. Grounding Of Command \& Data Cable Shields 


\subsubsection{STC Electrical Interconnections}

A functional block diagram of the STC is shown in Figure 3-5. The STC interfaces .

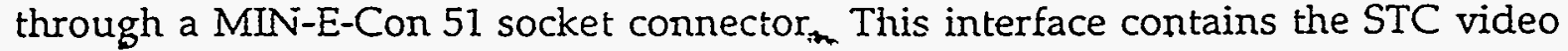
bus data and control signals, the SASI bus command interface, analog temperature signals, shields, and power. Table 3-10 lists the symbols used to define the signals.

All digital signals are based on RS-422. CMOS tri-stated differential line drivers and receivers are used for these signals. Table 3-11 defines pin assignments and signal types. Table 3-12 describes the signals. Signal timing information is defined in paragraphs 3.4.9.1 through 3.4.9.3. When the STC is enabled these signals will drive the bus; when the STC is disabled these signals will be tri-stated and not drive the bus.

Table 3-10. Signal Symbols

\begin{tabular}{|l|l|}
\hline \multicolumn{1}{|c|}{ Symbol } & \multicolumn{1}{|c|}{ Description } \\
\hline Odiff & Output CMOS Differential Driver \\
\hline Idiff & Input CMOS Differential Receiver \\
\hline Ihc & CMOS HC Input \\
\hline Ohc & CMOS HC Open Collector Output (HC05) \\
\hline Iopt & Opto-Isolator Input (HCPL-6231) \\
\hline DPWR & Power For Digital Circuits \\
\hline DRTN & Ground Return Digital \\
\hline APWR & Power For Analog Circuits \\
\hline ARTN & Ground Retum Analog \\
\hline PWR24 & Power For Filter Motor \\
\hline RTN24 & Ground Return For Filter Motor Power \\
\hline SHLD & Shield (Tied To Chassis) \\
\hline SPG & Single Point Ground \\
\hline
\end{tabular}




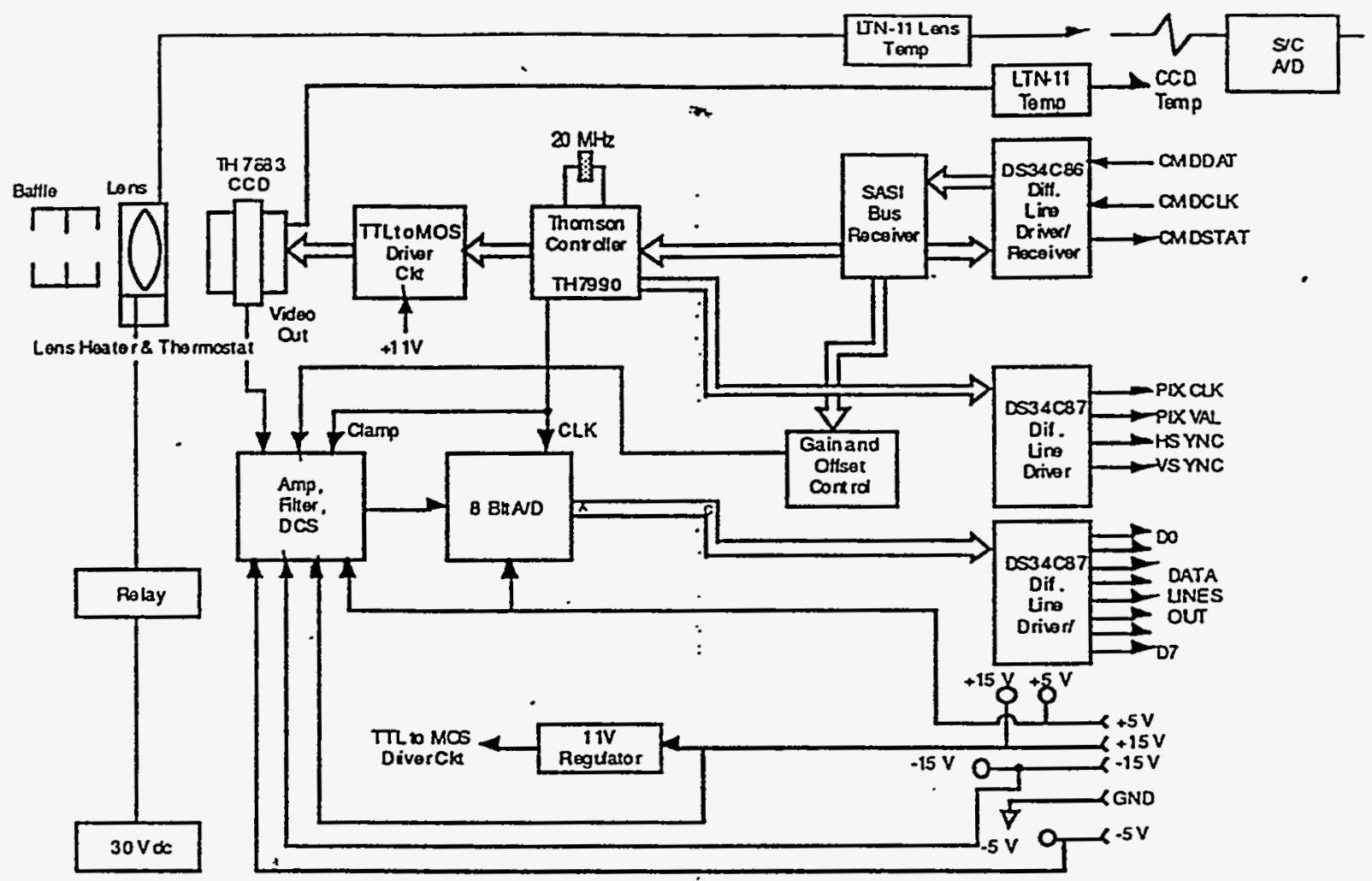

Figure 3-5. STC Functional Block Diagram

\subsubsection{Video Frame Format}

The video image frame format of the STC is 580 lines $X 384$ pixels/line. The first and last two lines are masked resulting in a total of 576 optically active lines. 
Table 3-11. Connector Pin Assignments

\begin{tabular}{|c|c|c|}
\hline \multicolumn{3}{|c|}{ CONNECTOR DATA: } \\
\hline \multicolumn{2}{|c|}{$\begin{array}{l}\text { Tlanufacturer: } \\
\text { Part No.: } \\
\text { Host Interface Eonnector }\end{array}$} & $\begin{array}{l}\text { MIN-E-CON 51 pn Sucket } \\
\text { M83513/4CO6N } \\
\mathrm{Jl}\end{array}$ \\
\hline PIN \# & SIGNAL NAME & TYPE \\
\hline 1 & N.C. & \\
\hline$\underline{2}$ & SHIELD & SHLD \\
\hline 3 & -5 VIN & APWR \\
\hline 4 & $-15 \mathrm{VIN}$ & APWR \\
\hline$\overline{5}$ & ARTM & ARTN \\
\hline 6 & TEMP & $\Omega /{ }^{\circ} \mathrm{C}$ \\
\hline 7 & SHIELD & SHLD \\
\hline 8 & SHIELD & SHLD \\
\hline 9 & CMDCLK & Idiff \\
\hline 10 & PIXVAL & Odiff \\
\hline 11 & HSYNCN & Odiff \\
\hline 12 & HSYNC & Odiff \\
\hline 13 & D6. & Odiff \\
\hline 14 & $\mathrm{D4}$ & Odiff \\
\hline 15 & $\overline{\mathrm{D} 2 \mathrm{~N}}$ & Odiff \\
\hline 16 & $\mathrm{D} 2$ & Odiff \\
\hline 17 & $\overline{D O}$ & Odiff \\
\hline 18 & PIXCLK & Odiff \\
\hline 19 & N.C. & \\
\hline 20 & $\overline{\text { DRTN }}$ & $\overline{\text { DRTN }}$ \\
\hline 21 & $\overline{D R T N}$ & DRTN \\
\hline 22 & ARTN & ARTN \\
\hline$\overline{23}$ & ARTN & ARTN \\
\hline 24 & TEMPR & RTN \\
\hline 25 & CMDSTATN & Odiff \\
\hline 26 & CMDCLKN & Idiff \\
\hline 27 & PIXVAL.N & Odiff \\
\hline 28 & VSYNCN & Odiff \\
\hline 29 & D7N & Odiff \\
\hline 30 & $\overline{D 6 N}$ & Odiff \\
\hline 31 & $\overline{D 4 N}$ & Odiff \\
\hline 32 & D3N & Odiff \\
\hline 33 & DIN & Odiff \\
\hline 34 & D0.N & Odiff \\
\hline 35 & PIXCLKN & Odiff \\
\hline 36 & SPG & SPG \\
\hline 37 & $+5 \mathrm{VNN}$ & DPWR \\
\hline 38 & + SVIN & DPWR \\
\hline 39 & +15 VIN & APWR \\
\hline 40 & +5 VADN & APWR \\
\hline 41 & SHIELD & SHLD \\
\hline 42 & CMDSTAT & Odiff \\
\hline 43 & CMDDAT & Idiff \\
\hline 44 & CMDDAT.N & Idiff \\
\hline 45 & VSWNC & Odiff \\
\hline 46 & D7 & Odiff \\
\hline 47 & D5.N & $\overline{\text { Odiff }}$ \\
\hline 48 & $\mathrm{D} 5$ & Odiff \\
\hline 49 & D3 & Odiff \\
\hline 50 & $\mathrm{Dl}$ & Odiff \\
\hline$\overline{5 l}$ & SHIELD & SHLD \\
\hline
\end{tabular}


Table 3-12. Signal Descriptions

\begin{tabular}{|c|c|c|}
\hline SICNAL & SIGNAL NAME & DESCRIPTION \\
\hline VSYNC & Vertical Sync out & $\begin{array}{l}\text { VSYNC is a positive going vertical synchronization level which occurs } \\
\text { after the photo-cherge integration period and brackets the transfer of } \\
\text { each field of digital video data. The source of this signal is the ACTEL } \\
\text { array. It is set active (HI) at the beginning of a frame and stays HI until } \\
\text { the frame has been completely clocked out of the A/D converter. It } \\
\text { returns to the inactive LO state after the falling edge of the last } \\
\text { PIXVAL signal of the frame. Data is valid when both VSYNC and } \\
\text { PIXVAL are asserted at the same time. The frame start is controlled } \\
\text { externally through the SASI command. }\end{array}$ \\
\hline HSYNC & Horizontal Sync out & $\begin{array}{l}\text { HSYNC is the horizontal symchronization pulse which precedes the } \\
\text { transfer of each horizontal line of digital video pixel data. The HSYNC } \\
\text { pulse will occur when PIXVAL is not true and have duration of at } \\
\text { least one cycle of the PIXCLK. This signal goes HI prior to each } \\
\text { horizontal line of data and then returns LO before the data is available. } \\
\text { During HSYNC (HSYNCHI) the PLXVAL signal will be LO. The } \\
\text { HSYNC signal must go high at least one clock cycle after the negative } \\
\text { transition of the PIXVAL signal and go low at least } 1 \text { dock cyde prior to } \\
\text { the assertion of PIXVAL. }\end{array}$ \\
\hline PIXVAL & Pixel Valid out & $\begin{array}{l}\text { PIXVAL is a signal which brackets each line of data. It must go high } \\
\text { before the first valid pixel data appears on the DO-D7 data lines and } \\
\text { remain itigh until after all valid pixel data is transferred for each line. } \\
\text { Data transfer occurs only when PDXVLL is high. } \\
\text { Pixel Valid goes LO at the end of each horizontal line of valid image } \\
\text { data and then returns HI for the beginning of the next data line. }\end{array}$ \\
\hline PIXCLK & Pixel Clock out & $\begin{array}{l}\text { PIXCLK is the signal used to enable latching of the digital video data } \\
\text { appearing on the DO-D7 data lines. The source of this signal is the } \\
\text { ACTEL array. This signal clocks the output data bits from the } \\
\text { differential line drivers into the DSPSE Spacecaft Controller } \\
\text { interface's data latch. Data is valid on the rising edge of this signal with } \\
\text { a setup time of at least } 50 \mathrm{~ns} \text { and stays valid until the falling edge. The } \\
\text { clock is HI for a minimum of } 60 \mathrm{~ns} \text {. }\end{array}$ \\
\hline D0-D7 & Data lines (8) & $\begin{array}{l}\text { Data lines ( } 8 \text { ). These lines contain the } 8 \text { bits of data for each pixel D7 } \\
\text { is the most significant bit. (see Host Timing section) }\end{array}$ \\
\hline CMDCLK & Command Cock in & $\begin{array}{l}\text { Command Clock in. This is the command clock for the SASI bus. (see } \\
\text { Host Interface section) }\end{array}$ \\
\hline CMDDAT & Command Data in & $\begin{array}{l}\text { Command Data in. This is the command data for the SASI bus. (see } \\
\text { Host Interface section) }\end{array}$ \\
\hline CMDSTAT & Command Status out & $\begin{array}{l}\text { Command Status out. This is the command status data for the SASI } \\
\text { bus. (see Host Timing Interface section) }\end{array}$ \\
\hline TEMP & Camera CCD Temperature & $\begin{array}{l}\text { Camera CCD Temperature. This signal and its return are connected to } \\
\text { an LTN-11.. This device is a composite thermistor. }\end{array}$ \\
\hline
\end{tabular}

\subsubsection{STC Timing}

\subsubsection{Interface Timing}

The STC interface consists of two separate buses. One is the video bus that contains all the control signals and video image data. It is detailed in paragraph 3.4.9.2. The other is the SASI bus that handles the command and status data and is detailed in paragraph 3.4.9.3.

\subsubsection{Video Bus Timing}

The video bus consists of 4 control signals and 8 data lines. Control signals are: VSYNC, HSYNC, PIXVAL, and PIXCLK which are described in Table 3-12. The data lines are: D0 through D7. Figures 3-6 through 3-8 show the video timing. 


\subsubsection{SASI Bus Timing}

The synchronous addressable serial interface (SASI) bus protocol is based on a Goddard Flight Center (GSFC) 650C custom PMOS process digital integrated circuit. For a complete description of the SASI bus refer to design note DN61033-30520-02 called out in the Applicable Documents section of this document.

The SASI bus is made up of three control signals. The control signals are CMDCLK, CMDDAT, and CMDSTAT. The SASI receiver in the STC is configured as a baseline SASI receiver. From a software perspective a command received over the SASI is made up of two bytes. One byte is the address byte and the other is the data byte as shown in Figure 3-9. The upper 3 bits of the address byte contain the subsystem identification. These 3 bits are used by the receiver hardware to determine if it has been addressed. The next 4 bits are used for sub-addressing within the subsystem to define the data parameter identification. By using 4 bits, 16 different commands may be defined. The remaining bit in the address byte is the New Data Flag (NDF) register. When a data byte is sent with NDF set to a logic HI, it is latched into the appropriate command register. The SASI receiver sends the contents of the appropriate command register to the hos.t SASI controller as a status data byte when a command is received with the NDF bit set to a logic LOW level. This capability, as described below is used to verify camera.commands. The subsystem ID's for commands to the STC are 3 and 6 (two units). It is allocated 5 parameter ID slots, 0 through 3 and 5. The STC will respond to either hex SASI addresses $60-6 \mathrm{~B}$ or C0-CB.

\subsubsection{Command Verification}

The camera can return the contents of each of the five command registers. The contents of the command registers directly reflect the command sent to each command register. Refer to Table 3-13. for the camera commands and Table 3-14. for the return status data. Unused bits will be read back in an unknown state. Status values echoed back at the end of a register set operation (NDF HIGH) are the value of the register set for the previous operation.

\subsubsection{Operation}

\subsubsection{Power On Initialization}

After applying power, the camera must be initialized. This is done with a SASI command to the camera that asserts the initialization bit (logic LOW) followed by a command that removes the initialization bit (logic HI). Timing is not critical but the second command should immediately follow the first. The camera is initialized on the LOW to HI transition. Next, the camera gain must be set to some nominal value. This is also performed through a SASI command by setting one of the gain bits HI. At this point the camera is in stand-by mode. The video bus is tri-stated and it is continuously clearing its dark charge. Integration and readout can now be controlled through the SASI port. Schematically this is shown in Figure 3-10. 


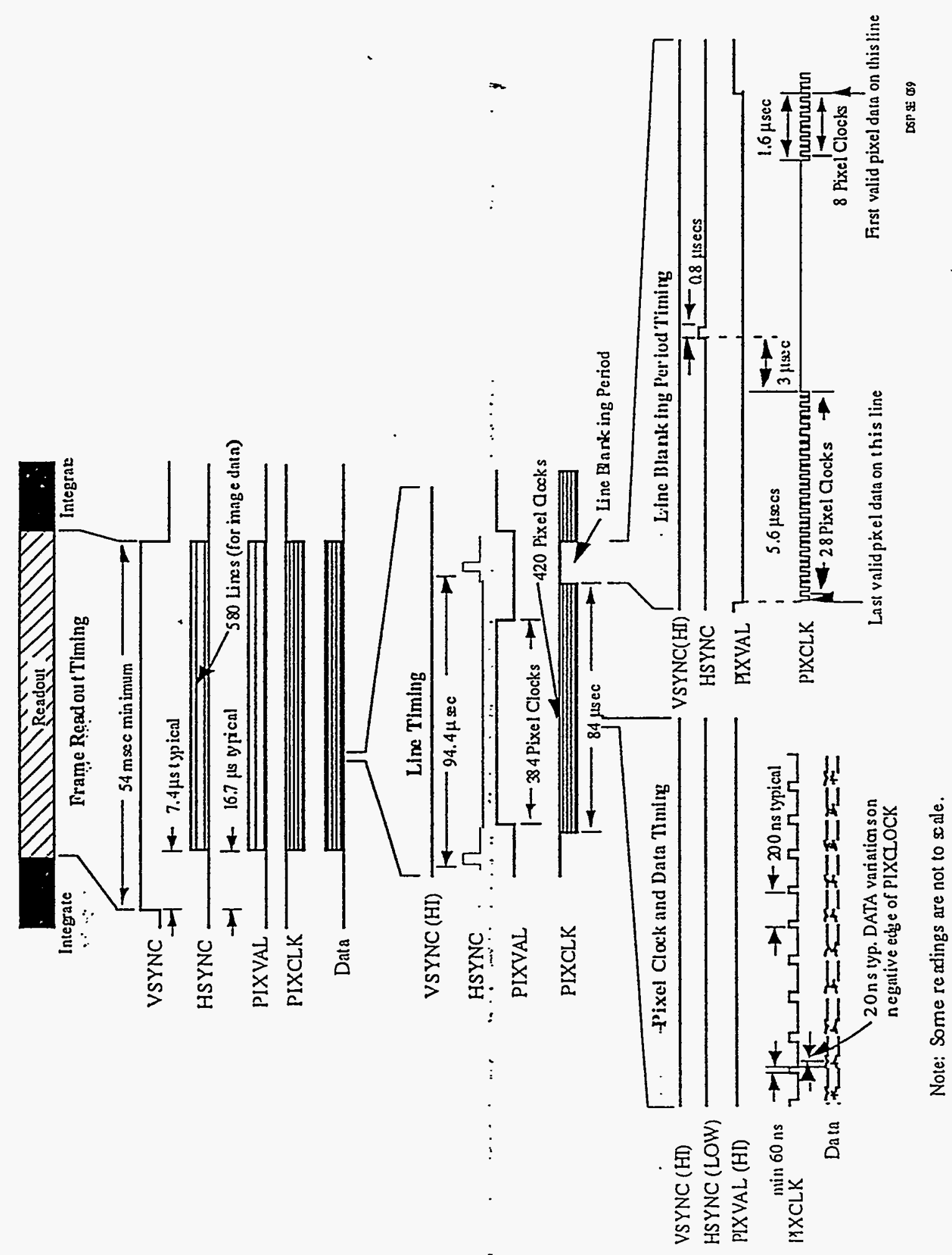

Figure 3-6. Vịdeo Timing 


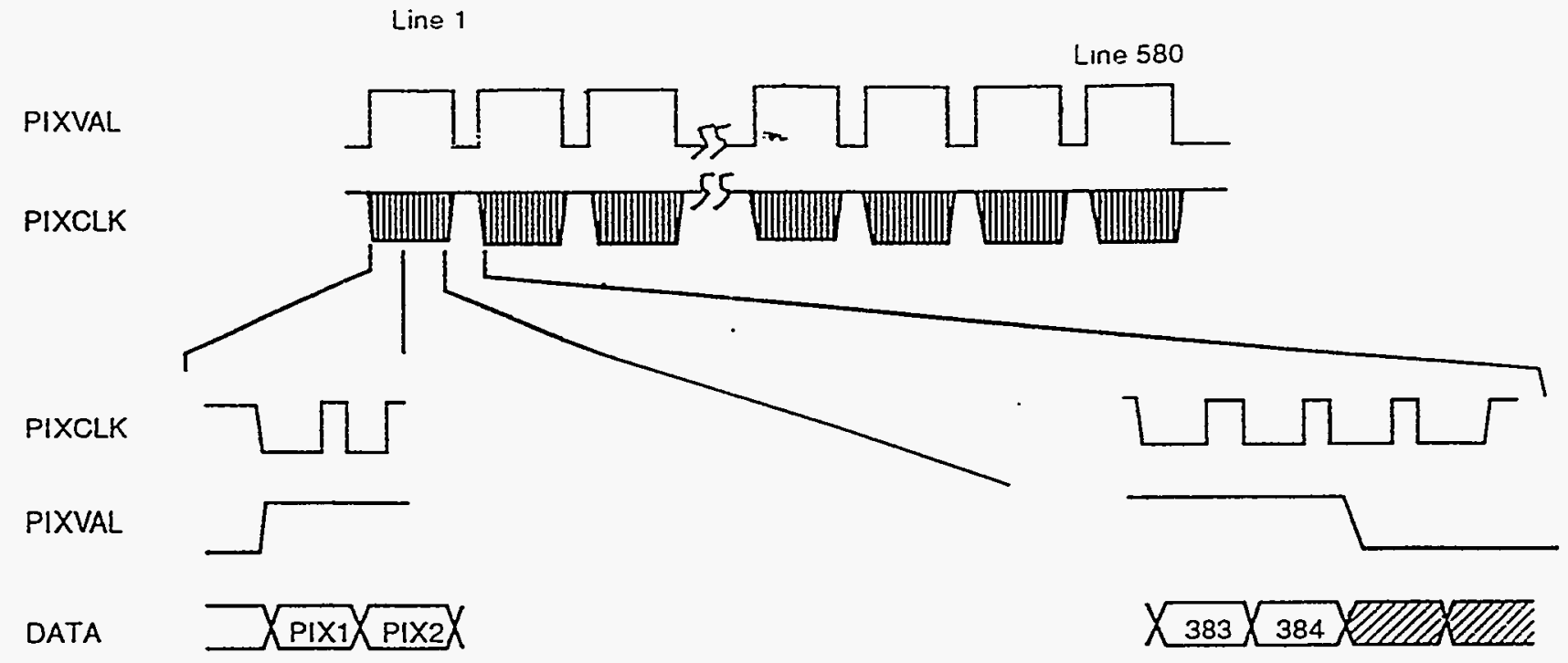

Figure 3-7. Timing Diagram

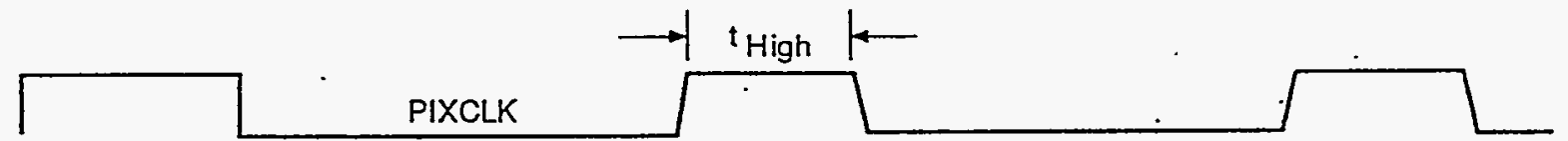

PIXVAL, HSYNC, VSYNC, Data

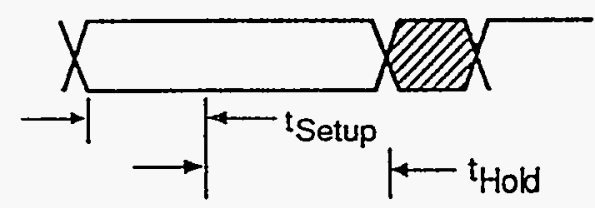

\begin{tabular}{|c|c|c|c|c|}
\hline Parameter & Description & Min imum & Maximum & Units \\
\hline thigh & PIXCLK High & 60 & 100 & ns \\
\hline${ }^{t}$ Setup & $\begin{array}{l}\text { Rising Edge Of PIXVAL,HSYNC, } \\
\text { VSYNC, \& Data Valid To Rising } \\
\text { Edge of PIXCLK }\end{array}$ & 50 & - & ns \\
\hline thold & $\begin{array}{l}\text { Rising Edge Of PIXCLK To Falling } \\
\text { Edge Of PIXVAL, VSYNC, Or Invalid } \\
\text { Data }\end{array}$ & 30 & & ns \\
\hline
\end{tabular}

Figure 3-8. Timing Diagram

ADDRESS BYTE

DATABYTE

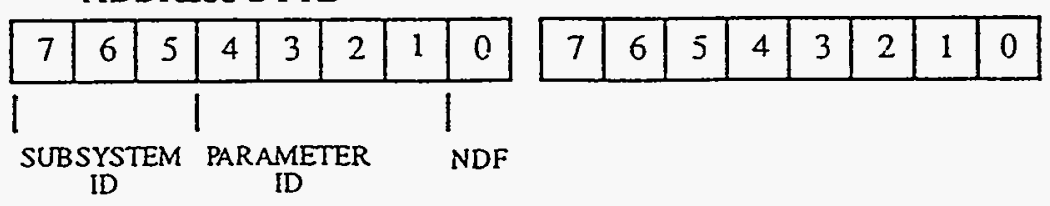

Figure 3-9 SASI Command Bytes 


\subsubsection{Integration Control}

The integration control mode is selected by setting the control bit (bit 3 of parameter $I D=0$ ) either HI for precision control or LOW for SASI control. Note that if precision integration control is selected, 13 bits of integration data must be loaded into the command data registers at parameter ID 2 and 3 with bit 4 of the command data register at ID 3 being the MSB. Integration time in this mode equals $(n+1) * 94.4$ $\mu$ sec. The Minimum acceptable $\mathrm{n}$ is 1 , resulting in a minimum integration time for the Star Tracker of $188.8 \mu \mathrm{sec}$. In the SASI control mode, integration is initiated by bringing the control bit ( bit 0 of the parameter ID =1) LOW. Readout is initiated by bringing the same bit HI. In the precision control mode, integration is initiated by a HI to LOW transition of the same control bit ( bit 0 at parameter ID $=1$ ). Readout will occur automatically after the pre-set integration time. The control bit must be returned HI before initiating the next integration cycle and left HI for at least 100 Hseconds.

\subsubsection{Gain Control}

Camera gain is selected by setting one and only one of the gain control bits (bits 4-6 at parameter ID $=0$ ) HI. See Table 3-13. for gain values which correspond to the bit selected.

\subsubsection{Offset Control}

Camera offset is selected by setting a 5 bit control word (bits $0-4$ at parameter ID $=5$ ). One LSB equals an offset of 8 gray levels. The maximum offset equals 248 gray levels.

\subsubsection{Magnetic ·}

The STC produces no magnetic dipoles.

\subsubsection{High Voltages}

There are no voltages greater than 36 volts in the STC. 
Table 3-13. Camera Commands

\begin{tabular}{|c|c|c|}
\hline Parameter ID & Data Byte & Description \\
\hline 0 & $\begin{array}{l}\text { Bit } 0 \\
\text { Bit } 1 \\
\text { Bit } 2 \\
\text { Bit } 3 \\
\\
\text { Bit } 4 \\
\text { Bit } 5 \\
\text { Bit } 6 \\
\text { Bit } 7 \\
\end{array}$ & $\begin{array}{l}\text { Enable data bus (HI enabled, LOW tri-stated) } \\
\text { Initialize camera (low to high transition) } \\
\text { Reserved (set to } 0 \text { ) } \\
\text { Integration mode } \\
\qquad \quad 0=\text { SASI control } \\
\quad I=\text { Precision control } \\
\text { Gain Select (HI }=350 \mathrm{e}^{-/} / \mathrm{bit} \text { ) } \\
\text { Gain Select (HI }=150 \mathrm{e}^{-/} / \mathrm{bit} \text { ) } \\
\text { Gain Select }\left(\mathrm{HI}=75 \mathrm{e}^{-} / \mathrm{bit} \text { ) }\right. \\
\text { Reserved (Set to 0) }\end{array}$ \\
\hline 1 & $\begin{array}{r}\text { Bit } 0 \\
\text { Bits } 1-7\end{array}$ & $\begin{array}{l}\text { Image (start integration } \\
\text { SASI control mode } \\
0=\text { Integrate } \\
1=\text { Readout } \\
\text { Precision Control Mode } \\
\text { High to Low starts integration } \\
\text { Reserved (Set to 0) }\end{array}$ \\
\hline 2 & 8 Bits & $\begin{array}{l}\text { Integration control } \\
\text { Bit } 0 \text { is LSB (LSB }=94.4 \mu \mathrm{sec})\end{array}$ \\
\hline 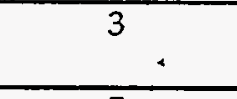 & 5 Bits & $\begin{array}{l}\text { Integration Control } \\
\text { Bit } 4 \text { is MSB } \\
\end{array}$ \\
\hline 5 & 5 Bits & Offset Control, Bit 4 is MSB \\
\hline
\end{tabular}

Note: Parameter ID 0 Bits 4-6 (Gain Select) are mutually exclusive. Only one can be set high at a time. Having two gain bits set at the same time yields an undetermined gain state.

Table 3-14. Camera Commands That Return Status Data

\begin{tabular}{|l|c|c|l|l|}
\hline \multicolumn{1}{|c|}{ Address } & NDF & Data & \multicolumn{1}{|c|}{ SASI Status Return } & \multicolumn{1}{c|}{ Comments } \\
\hline $\begin{array}{l}0110000 \text { or } \\
1100000\end{array}$ & 0 & don't care & $\begin{array}{l}\text { Contents of Command Data } \\
\text { Register at parameter ID 0 }\end{array}$ & $\begin{array}{l}\text { Only bits 0,1 and } \\
\text { 3-6 are important }\end{array}$ \\
\hline $\begin{array}{l}0110001 \text { or } \\
1100001\end{array}$ & 0 & don't care & $\begin{array}{l}\text { Contents of Command Data } \\
\text { Register at parameter ID 1 }\end{array}$ & $\begin{array}{l}\text { Only bit 0 is } \\
\text { important }\end{array}$ \\
\hline $\begin{array}{l}0110010 \text { or } \\
1100010\end{array}$ & 0 & don't care & $\begin{array}{l}\text { Contents of Command Data } \\
\text { Register at parameter ID 2 }\end{array}$ & $\begin{array}{l}\text { 8 bits of } \\
\text { integration, Bit 0 } \\
\text { is LSB }\end{array}$ \\
\hline $\begin{array}{l}0110011 \text { or } \\
1100011\end{array}$ & 0 & don't care & $\begin{array}{l}\text { Contents of Command Data } \\
\text { Register at parameter ID 3 }\end{array}$ & $\begin{array}{l}\text { L bits of } \\
\text { integration Bit 4 is } \\
\text { MSB }\end{array}$ \\
\hline $\begin{array}{l}0110101 \text { or } \\
1100101\end{array}$ & 0 & don't care & $\begin{array}{l}\text { Contents of Command Data } \\
\text { Register at parameter ID 5 }\end{array}$ & $\begin{array}{l}5 \text { bits of offset } \\
\text { Bit 4 is MSB }\end{array}$ \\
\hline
\end{tabular}




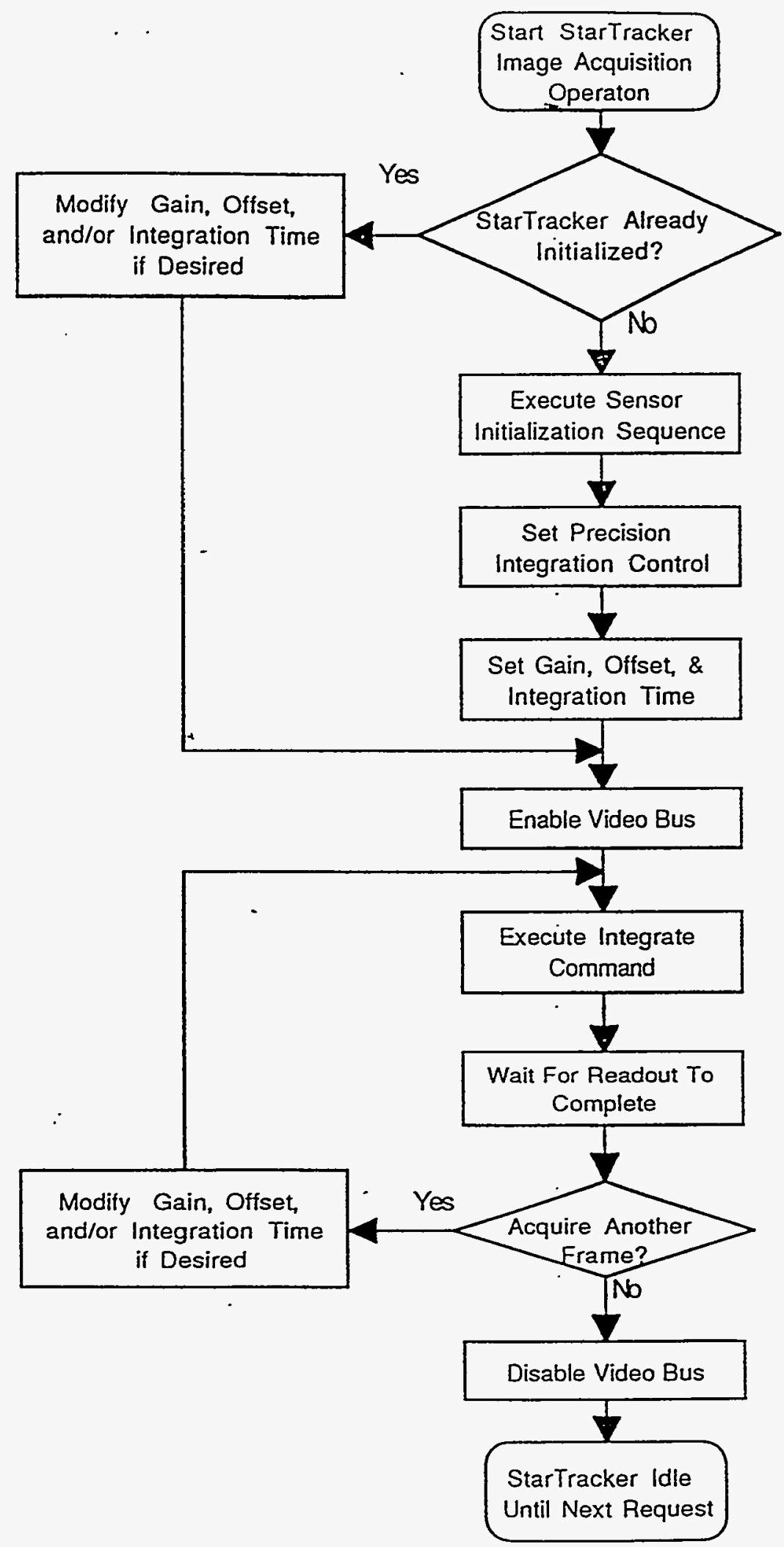

Figure 3-10. Star Tracker Operational Flow Diagram 


\section{Appendix A.8 \\ Clementine Sensor Suite Reliability Analysis \\ (C1-EE-002)}




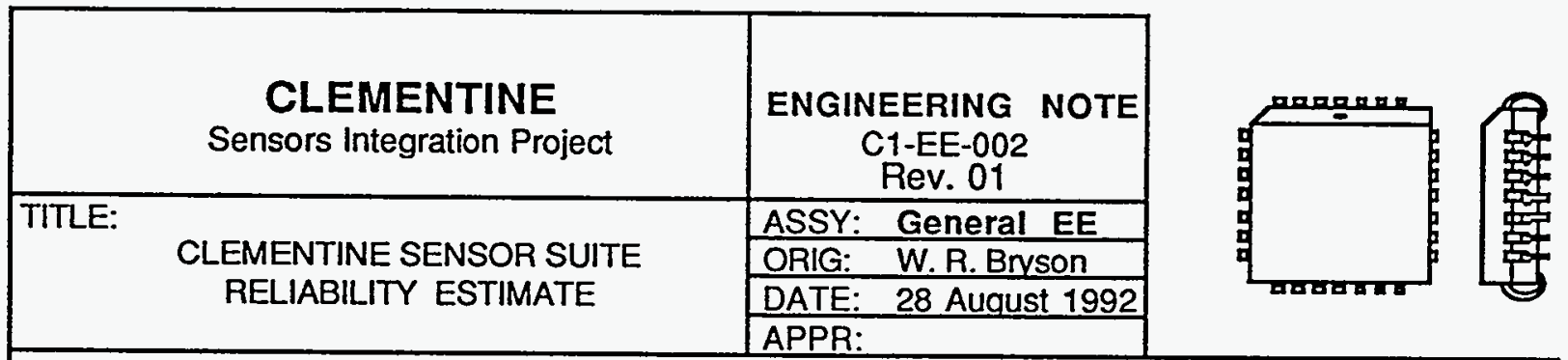

Abstract:

This document is a White Paper discussing the use of a combination of commercial and MIL-SPEC parts in the Clementine sensors. It also presents a detailed failure rate per $10^{6}$ hours estimate and an estimate of probability of success for the sensors during a 7 month (5280 hour) mission. 


\title{
CLEMENTINE SENSOR SUITE RELIABILITY ESTIMATE
}

\author{
William R. Bryson \\ Mark S. Strauch \\ August 21, 1992
}

Lawrence Livermore National Laboratory 


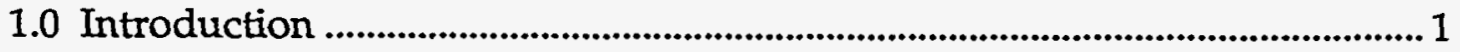

1.1 Mission Objectives ................................................................................. 1

1.2 Mission Sensors .................................................................................. 1

1.3 Reliability Estimate Summary ............................................................... 1

Table 1 - Mission Sensor Performance ............................................. 2

Table 2 - System Level Reliability ...................................................... 2

2.0 Reliability Estimate Methods and Assumptions ............................................... 3

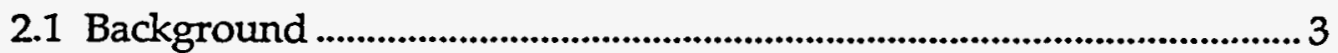

2.2 Temperature Environment Assumptions ............................................

2.3 Reliability Calculation Method Based on MIL-HDBK-217F............... 4

2.3.1 Microcircuits ........................................................................... 4

2.3.2 Discrete Semiconductors ...................................................... 5

2.3.3 Capacitors...................................................................................

2.3.4 Opto-Isolators ........................................................................... 9

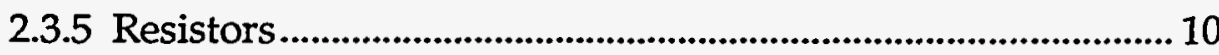

2.3.6 Quartz Oscillators .................................................................10

2.3.7 Inductive Devices ...................................................................... 11

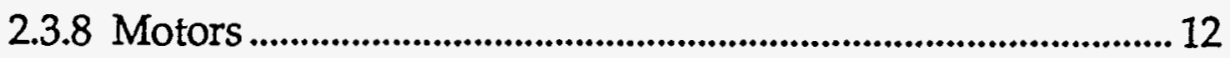

2.3.9 Printed Circuit Board Connectors............................................ 12

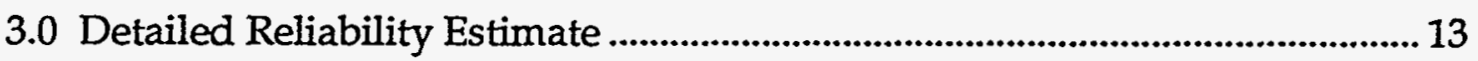

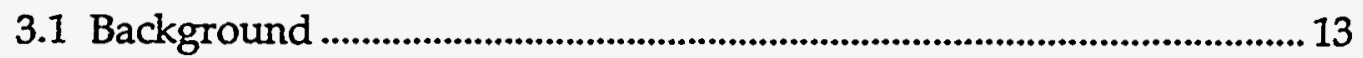

3.2 Board Level Detailed Reliability Estimates ........................................... 13

Table 3a. Actel Camera Semiconductors .......................................... 14

Table 3b. Actel Camera Capacitors................................................. 15

Table 3c. Actel Camera Other Passive Components ....................... 16

Table 4a. Filter Wheel Semiconductors .............................................17

Table 4b. Filter Wheel Passive Components .................................. 18

Table 5a. Range Receiver Semiconductors ...................................... 19

Table 5b. Range Receiver Passive Components............................... 20

Table 6a. LIDAR System Controller Semiconductors ...................... 21

Table 6b. LIDAR System Controller Resistors and

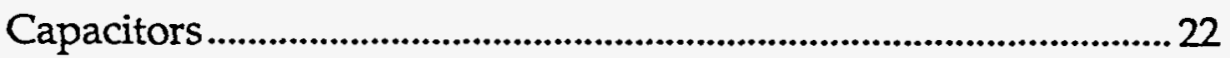

Table 6c. LIDAR System Controller Other Passive

Components ....................................................................................... 23

3.3 Star Tracker Reliability Estimate................................................................. 24 
Table 7. Actel Camera Estimated Failures per $10^{6}$ Hours ...............2. 24

Table 8. Actel Reliability Estimate .....................................................24

3.4 UV / Visible Reliability Estimate............................................................24

Table 9. UV/Vis Camera Estimated Failures per $10^{6}$ Hours .........25

Table 10. UV/Vis Reliability Estimate ..............................................25

3.5 LIDAR Reliability Estimate ................................................................... 25

Table 11. LIDAR Estimated Failures per $10^{6}$ Hours .......................25

Table 12. LIDAR Reliability Estimate............................................... 26

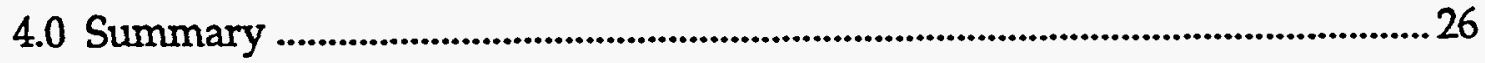

Table 13. Sensor Reliability Estimates .............................................26 


\subsection{Introduction}

The purpose of this paper is to document the results of the reliability estimate done for a number of sensors developed by the Lawrence Livermore National Laboratory (LLNL) under the sponsorship of SDIO. The sensors, slated for use on Clementine, will be used in lunar orbit to obtain wide spectral band imagery of the lunar surface followed by a fly-by of a near earth asteroid for the same purpose.

\subsection{Mission Objectives}

Clementine is the name for a deep space exploration (DSPSE) experiment which will be launched in January 1994 with a two month mission in lunar orbit followed by a fly-by of a near earth asteroid in August 1994. The purpose of this experiment is to:

1) Demonstrate the survivability and performance of SDIO developed technologies when exposed to a deep space environment.

2) Obtain wide band spectral imagery of both the lunar surface and the surface of a near earth asteroid (Geographos).

3) Conduct other experiments during the mission relating to autonomous navigation while in lunar orbit as well as in transit to the asteroid.

The Clementine probe is slated for launch in January 1994 with lunar mapping occurring in the March / April 1994 time frame and asteroid fly by in late August 1994.

\subsection{Mission Sensors}

The mission sensors are two Star Trackers, used for navigation updates, one UV/Visible sensor and a Near Wave IR (NIR) sensor, used to image the surface of the moon and the asteroid, a Long Wave IR (LWIR) sensor, used for thermal measurement of the lunar terminator and a Laser Imaging Radar (LIDAR) which can be used in a high resolution imagery mode or in a ranging mode. Sensor and laser transmitter performance are summarized in Table 1.

\subsection{Reliability Estimate Summary}

A reliability estimate was calculated for each sensor using the methods defined by MIL-HDBK-217F . The results for each sensor, treated as a system, are summarized in Table 2 . Two duty cycles are assumed for the sensors, $100 \%$ and

\footnotetext{
${ }^{1}$ Reliability Prediction of Electronic Equipment, MIL-HDBK-217F, Department of Defense, December 2, 1991
} 
$30 \%$. "Off time" reliability is assumed to be 1 . Mission duration is assumed to be 7 months or 5280 hours. The reliability of the near infrared sensor (NIR), the long wave infrared sensor (LWIR) and the LIDAR laser transmitter has not been estimated. These are procured items and will be reported on at later date. For details on the estimate completed for the other sensors, refer to section 3, Detailed Reliability Estimate.

\begin{tabular}{|c|c|c|c|c|c|}
\hline Sensor & FOV & IFOV & F\# & Spedral Band & Comment \\
\hline Star Tracker & $28^{\circ} \times 42^{\circ}$ & $\begin{array}{c}1.3 \\
\text { mrad }\end{array}$ & 1.0 & $0.4-1.0 \mu \mathrm{m}$ & $\begin{array}{l}\text { Used for navigation - } \\
\text { update rate sensors }\end{array}$ \\
\hline UV/Visible & $4.2^{\circ} \times 5.6^{\circ}$ & $\begin{array}{c}255 \\
\mu \mathrm{rad}\end{array}$ & 2.0 & $0.2-1.1 \mu \mathrm{m}$ & 6 Selectable filters \\
\hline $\begin{array}{l}\text { LIDAR High } \\
\text { Resdution Camera }\end{array}$ & $0.3^{\circ} \times 0.4^{\circ}$ & $\begin{array}{l}18 \times 36 \\
\mu \mathrm{rad}\end{array}$ & 10 & $0.4-0.85 \mu \mathrm{m}$ & $\begin{array}{l}\text { High resolution sensor } \\
\text { with } 6 \text { selectable filters }\end{array}$ \\
\hline $\begin{array}{l}\text { LIDAR Range } \\
\text { Receiver }\end{array}$ & $n / a$ & $\begin{array}{l}1.0 \\
\text { mrad }\end{array}$ & $\mathrm{n} / \mathrm{a}$ & $n / a$ & $\begin{array}{l}\text { Avalanche photo } \\
\text { diode+range gate; } \\
\text { range measurement }\end{array}$ \\
\hline $\begin{array}{l}\text { LIDAR Laser } \\
\text { Transmiter }\end{array}$ & $n / a$ & $n / a$ & $\mathrm{n} / \mathrm{a}$ & $1.06 \mu \mathrm{m}$ & $\begin{array}{l}180 \text { mJ; } 500 \mu \text { radian } \\
\text { beam divergence }\end{array}$ \\
\hline NIR & $5.6^{\circ} \times 5.6^{\circ}$ & $\begin{array}{c}385 \\
\mu \mathrm{rad}\end{array}$ & 5 & $1-3.1 \mu \mathrm{m}$ & 6 selectable filters \\
\hline LWIR & $1.0^{\circ} \times 1.0^{\circ}$ & $\begin{array}{c}143 \\
\mu \mathrm{rad}\end{array}$ & 2.3 & $9-12 \mu \mathrm{m}$ & $\begin{array}{l}\text { Thermal measurement } \\
\text { of lunar terminator }\end{array}$ \\
\hline
\end{tabular}

Table 1 - Mission Sensor Performance

\begin{tabular}{|l|c|c|c|}
\hline & $\lambda_{\mathrm{p}}$ & \multicolumn{2}{|c|}{ Reliability } \\
\cline { 3 - 4 } Sensor & failures/106hours & $\mathbf{1 0 0 \%}$ Duty & $\mathbf{3 0 \%}$ Duty \\
\hline Star Tracker & 4.3444 & 0.9773 & 0.9931 \\
UV/Visible & 5.3986 & 0.9719 & 0.9915 \\
LIDAR & 8.7382 & 0.9549 & 0.9862 \\
LIDAR Laser Transmitter & (TBD) & (TBD) & (TBD) \\
NIR & (TBD) & (TBD) & (TBD) \\
LWIR & (TBD) & (TBD) & (TBD) \\
\hline
\end{tabular}

Table 2 - System Level Reliability 


\subsection{Reliability Estimate Methods and Assumptions}

\subsection{Background}

There are a number of predictive models used throughout both the national and international electronics industry for assessing the long term reliability of electronic components ${ }^{2}$. The methodology most familiar is that described in MIL-HDBK-217F. This is the method that has been employed by LLNL to calculate the reliability of the sensors slated for use on the Clementine spacecraft.

As a basis for comparison to the results of MIL-HDBK-217F, LLNL has employed the Bellcore reliability model 3 to determine sensor reliability estimates. Use of this approach yielded estimates for reliability comparable to those determined from MIL-HDBK-217F.

One other method which has been applied recently to the Clementine sensor electronics is the automotive electronics reliability model ${ }^{4}$ which is based on extensive empirical data from automotive warranty claims. Application of this approach is inappropriate for space based electronics due to the substantial environmental differences. In addition using the base failure rates as derived by MIL-HDBK-217E includes a double penalty many failure rate factors. For this reason, the application of this model to calculate a reliability estimate for the Clementine sensors is not considered appropriate and its use would yield erroneous results.

\subsection{Temperature Environment Assumptions}

At this time a detailed thermal analysis of the sensor suite has not been completed. We have therefore made the following assumptions about the thermal environment sensor components will be exposed to. These assumptions are based on design goals. As the temperature analysis becomes complete, this reliability estimate will be updated to reflect more accurate conditions.

Optical Bench

Microcircuit Junction Temp

Discrete Semiconductor Junction Temp

Passive Component Temperature

Connector Temperature

$0 \pm 10^{\circ} \mathrm{C}$
$70^{\circ} \mathrm{C}$
$50^{\circ} \mathrm{C}$
$30^{\circ} \mathrm{C}$
$10^{\circ} \mathrm{C}$

$0 \pm 10^{\circ} \mathrm{C}$

$50^{\circ} \mathrm{C}$

$10^{\circ} \mathrm{C}$

\footnotetext{
${ }^{2}$ A Survey of Reliability-Prediction Procedures for Microelectronic Devices, IEEE Transactions on Reliability, Vol. 41, No. 1, March 1992.

${ }^{3}$ Reliability Prediction Procedure for Electronic Equipment, Bell Communications Research, Technical Reference TR-NWT-0000332, Issue 3, September 1990.

4 Automotive Electronic Reliability Prediction, SAE 870050, William K. Denson and Mary G.

Priore, IIT Research Institute.
} 


\subsection{Reliability Calculation Method Based on MIL-HDBK-217F}

The reliability of each of the Clementine sensors was calculated using the methods of MIL-HDBK-217F. A description of each of the models used is presented below, along with the applicable assumptions and definitions.

\subsubsection{Microcircuits}

For microcircuits the part failure rate is calculated using the following equation from MIL-HDBK-217F, page 5-3:

$$
\begin{aligned}
\lambda_{\mathrm{P}} & =\left(\mathrm{C}_{1} \pi_{\mathrm{T}}+\mathrm{C}_{2} \pi_{\mathrm{E}}\right) \pi_{\mathrm{Q}} \pi_{\mathrm{L}} \\
& \text { where: } \\
\lambda_{\mathrm{P}} & =\text { part failures } / 10^{6} \text { hours } \\
\mathrm{C}_{1} & =\text { complexity factor }- \text { die complexity failure rate, Section } 5.1 \\
\mathrm{C}_{2} & =\text { package factor - package failure rate, Section } 5.9 \\
\pi_{\mathrm{T}} & =\text { temperature factor, Section } 5.8 \\
\pi_{\mathrm{Q}} & =\text { part quality factor, Section } 5.10 \\
\pi_{\mathrm{E}} & =\text { environment factor, Section } 5.10 \\
\pi_{\mathrm{L}} & =\text { learning (maturity) factor, Section } 5.10
\end{aligned}
$$

The factors shown above are derived using the applicable rules of MIL-HDBK217F. For MIL-STD-883 Class B parts, which will be used in all the sensors where appropriate, the part quality factor is 2.0. Other microelectronic circuits will be screened to the following test methods of MIL-STD-883D, TM 1015 (class S burnin), TM 5004 (final electricals at temperature extremes), TM 2012 (radiography), and TM 2009 (external visual). Per section 5.10 of MIL-HDBK-217F, the quality factor for these parts is 3.8 .

The environmental factor for space flight for all microcircuits is 0.5 , again per section 5.10 .

The complexity factor, package factor, temperature factor and maturity factor varies for each part and package type. These will be presented in the detailed reliability estimate for each part. 


\subsubsection{Discrete Semiconductors}

Two types of discrete semiconductors are used in the sensor design. Each is evaluated as described below.

\section{$\underline{\text { Diodes }}$}

Diode failure rates are calculated using the model defined in MIL-HDBK-217F, Section 6.1, page 6-2.

$$
\begin{aligned}
\lambda_{\mathrm{p}} & =\lambda_{\mathrm{b}} \pi_{\mathrm{T}} \pi_{S} \pi_{c} \pi_{Q} \pi_{E} \\
& \text { where: } \\
\lambda_{\mathrm{p}} & =\text { part failures } / 10^{6} \text { hours } \\
\lambda_{\mathrm{b}} & =\text { base failure rate, Section } 6.1 \\
\pi_{\mathrm{T}} & =\text { temperature factor, Section } 6.1 \\
\pi_{S} & =\text { electrical stress factor, Section } 6.1 \\
\pi_{c} & =\text { contact construction factor, Section } 6.1 \\
\pi_{Q} & =\text { quality factor, Section } 6.1 \\
\pi_{E} & =\text { environment factor, Section } 6.1
\end{aligned}
$$

The base failure rate, which is based on diode type and application, is provided in Section 6.1. With one exception, all diodes are low frequency switching diodes. The base failure rate for low frequency switching diodes is 0.001 failures $/ 10^{6}$ hours. The exception is a voltage reference diode that has a base failure rate of 0.002 failures $/ 10^{6}$ hours.

The temperature factor is based on junction temperature, which for this estimate is assumed to be $50^{\circ} \mathrm{C}$ and hence a temperature factor of 2.2 is assigned to all diodes.

The electrical stress factor diodes is based on the voltage stress ratio. The voltage stress ratio is different for each diode and the electrical stress factor is shown in the detailed reliability estimate.

All diodes are metallurgical bonded and the contact construction factor is 1.0.

Except for the JANTXV parts which have a quality factor of 0.7 , all others are assigned a value of 8.0 .

The environment factor for space applications is 0.5 . 


\section{$\underline{\text { Transistors }}$}

Three type of transistors are used in the sensor designs. These are low frequency bipolar, low frequency silicon FET and MOSFETs. The reliability models are presented below.

\section{Low Frequency Bipolar}

The failure rate for low frequency bipolar transistors is calculated from MIL-HDBK-217F, Section 6.3, pages 6-6 through 6-7.

$$
\begin{aligned}
\lambda_{\mathrm{P}} & =\lambda_{\mathrm{B}} \pi_{\mathrm{T}} \pi_{\mathrm{A}} \pi_{\mathrm{R}} \pi_{\mathrm{S}} \pi_{\mathrm{Q}} \pi_{\mathrm{E}} \\
& \text { where: } \\
\lambda_{\mathrm{P}} & =\text { part failure rate } / 10^{6} \text { hours } \\
\lambda_{\mathrm{B}} & =\text { base failure, Section } 6.3 \\
\pi_{\mathrm{T}} & =\text { temperature factor, Section } 6.3 \\
\pi_{\mathrm{A}} & =\text { application factor, Section } 6.3 \\
\pi_{\mathrm{R}} & =\text { power rating factor, Section } 6.3 \\
\pi_{\mathrm{S}} & =\text { voltage stress factor, Section } 6.3 \\
\pi_{\mathrm{Q}} & =\text { quality factor, Section } 6.3 \\
\pi_{\mathrm{E}} & =\text { environment factor, Section } 6.3
\end{aligned}
$$

The base failure rate for low frequency bipolar transistors is 0.00074 failures $/ 10^{6}$ hours.

The temperature factor is 1.7 based on a junction temperature for the transistor of $50^{\circ} \mathrm{C}$.

All transistors are being used as linear amplifiers and the resulting application factor is 1.5 .

The rated power is less than 0.5 watts, thus the power rating factor is 0.77 .

The voltage stress factor of 0.11 based on a ratio of $V_{c e} / V_{c e o}$ of $\leq 0.3$ (applied collector to emitter voltage / maximum rated collector to emitter voltage).

All transistors are screened plastic parts but no credit is allowed for screening, therefore the quality factor is 8.0.

The environment factor for a space based application is 0.5 . 


\section{Low Frequency Si FET}

The failure rate model for low frequency silicon FET transistors is obtained from MIL-HDBK-217F, Section 6.4, page 6-8.

$$
\begin{aligned}
\lambda_{\mathrm{P}} & =\lambda_{\mathrm{B}} \pi_{\mathrm{T}} \pi_{\mathrm{A}} \pi_{\mathrm{Q}} \pi_{\mathrm{E}} \\
& \text { where: } \\
\lambda_{\mathrm{P}} & =\text { part failure rate } / 10^{6} \text { hours } \\
\lambda_{\mathrm{B}} & =\text { base failure, Section } 6.4 \\
\pi_{\mathrm{T}} & =\text { temperature factor, Section } 6.4 \\
\pi_{\mathrm{A}} & =\text { application factor, Section } 6.4 \\
\pi_{\mathrm{Q}} & =\text { quality factor, Section } 6.4 \\
\pi_{\mathrm{E}} & =\text { environment factor, Section } 6.4
\end{aligned}
$$

For the JFET transistors the base failure rate is 0.0045 failures $/ 10^{6}$ hours and for MOSFETs the rate is 0.012 failures $/ 10^{6}$ hours.

The temperature factor is 1.6 based on a junction temperature of $50^{\circ} \mathrm{C}$.

All FETs are used as linear amplifiers with a rated power of $\leq 2$ watts which results in an application factor of 1.5.

As with the bipolar transistors, no credit is allowed for screening and the quality factor for screened plastic parts is 8.0.

The environment factor for space applications is 0.5 .

\subsubsection{Capacitors}

Two types of capacitors are used in the sensor designs. These are fixed ceramic chips and solid tantalum chips.

\section{Ceramic Chip Capacitor}

The failure rate equation for the chip type ceramic capacitor is given in $\mathrm{ML}$ HDBK-217F, Section 10.11, page 10-20 and is reproduced below. 


$$
\begin{aligned}
\lambda_{p} & =\lambda_{\mathrm{B}} \pi_{\mathrm{CV}} \pi_{\mathrm{Q}} \pi_{\mathrm{E}} \\
& \text { where: } \\
\lambda_{\mathrm{p}} & =\text { part failure rate } / 10^{6} \text { hours } \\
\lambda_{\mathrm{B}} & =\text { base failure, Section } 10.11 \\
\pi_{\mathrm{CV}} & =\text { capacitance factor, Section } 10.11 \\
\pi_{\mathrm{Q}} & =\text { quality factor, Section } 10.11 \\
\pi_{\mathrm{E}} & =\text { environment factor, Section } 10.11
\end{aligned}
$$

The base failure rate for ceramic chip capacitors is 0.0028 failures $/ 10^{6}$ hours which is based on a maximum temperature rating of $125^{\circ} \mathrm{C}$, an operating temperature of $30^{\circ} \mathrm{C}$ and a stress factor (ratio of operating to rated voltage) of 0.3 .

The capacitance factor is a function of the capacitor value, refer to the detailed reliability estimate for the actual values.

All ceramic capacitors will be procured at $S$ reliability level resulting in a quality factor of 0.03 .

The environment factor for space applications is 0.5 .

\section{$\underline{\text { Solid Tantalum Capacitors }}$}

MIL-HDBK-217F does not address solid tantalum capacitors as specified in MIL-C-55365, General Specification for Capacitor, Fixed, Electrolytic (Tantalum), Chip, Established Reliability. Therefore we are using Section 10.12 of MIHDBK-217F, Capacitors, Fixed, Electrolytic, Tantalum, Solid as a basis to estimate the failure rate of solid tantalum chip capacitors.

The failure rate model for solid tantalum capacitors is given in MIL HDBK-217F, Section 10.12, page 10-21.

$$
\begin{aligned}
\lambda_{\mathrm{P}}= & \lambda_{\mathrm{B}} \pi_{\mathrm{CV}} \pi_{\mathrm{SR}} \pi_{\mathrm{Q}} \pi_{\mathrm{E}} \\
& \text { where: } \\
\lambda_{\mathrm{P}}= & \text { part failure rate } / 10^{6} \text { hours } \\
\lambda_{\mathrm{B}}= & \text { base failure, Section } 10.12 \\
\pi_{\mathrm{CV}}= & \text { capacitance factor, Section } 10.12 \\
\pi_{\mathrm{SR}} & =\text { series resistance factor, Section } 10.12 \\
\pi_{\mathrm{Q}} & =\text { quality factor, Section } 10.12 \\
\pi_{\mathrm{E}} & =\text { environment factor, Section } 10.12
\end{aligned}
$$


The base failure rate for solid tantalum capacitors is .0067 failures $/ 10^{6}$ hours. This is based an operating temperature of $30^{\circ} \mathrm{C}$ and a stress factor (ratio of operating to rated voltage) of 0.3 .

The capacitance factor is a function of the capacitor value, refer to the detailed reliability estimate for the actual values.

The series resistance factor is based on a circuit resistance (ratio of the effective resistance between the capacitor and the power supply to the voltage applied to the capacitor) of $>0.1$ to 0.2 which results in a factor of 0.27 .

Most parts will be procured at $\mathrm{D}$ reliability level and the corresponding quality factor is 0.001 . Those parts procured as commercial components have a quality factor of 10 .

The environment factor for space applications is 0.4 .

\subsubsection{Opto-Isolators}

Opto-isolators are used on several boards and the failure rate equation as defined in Section 6.11, page 6-19, of MIL-HDBK-217F and is presented below.

$$
\begin{aligned}
\lambda_{\mathrm{P}} & =\lambda_{\mathrm{B}} \pi_{\mathrm{T}} \pi_{\mathrm{Q}} \pi_{\mathrm{E}} \\
& \text { where: } \\
\lambda_{\mathrm{P}} & =\text { part failure rate } / 10^{6} \text { hours } \\
\lambda_{\mathrm{B}} & =\text { base failure, Section } 6.11 \\
\pi_{\mathrm{T}} & =\text { temperature factor, Section } 6.11 \\
\pi_{\mathrm{Q}} & =\text { quality factor, Section } 6.11 \\
\pi_{\mathrm{E}} & =\text { environment factor, Section } 6.11
\end{aligned}
$$

The base failure rate for an opto-isolator is 0.013 failures $/ 10^{6}$ hours.

Based on a junction temperature of $50^{\circ} \mathrm{C}$, the temperature factor is 2.1 .

Although the parts are screened, no credit is allowed for parts screening, therefore the quality factor is 8.0 .

As before, the environmental factor for space applications is 0.5 . 


\subsubsection{Resistors}

Fixed film resistors are used throughout the sensor design. Because the jumpers used in the designs are $0 \Omega$ chip resistors, they have been included with resistors for this estimate. The failure rate equation is given in Section 9.2, page 9-3, of MIL-HDBK-217F.

$$
\begin{aligned}
\lambda_{\mathrm{P}} & =\lambda_{\mathrm{B}} \pi_{\mathrm{R}} \pi_{\mathrm{Q}} \pi_{\mathrm{E}} \\
& \text { where: } \\
\lambda_{\mathrm{P}} & =\text { part failure rate } / 10^{6} \text { hours } \\
\lambda_{\mathrm{B}} & =\text { base failure, Section } 9.2 \\
\pi_{\mathrm{R}} & =\text { resistance factor, Section } 9.2 \\
\pi_{\mathrm{Q}} & =\text { quality factor, Section } 9.2 \\
\pi_{\mathrm{E}} & =\text { environment factor, Section } 9.2
\end{aligned}
$$

The base failure rate of 0.0013 failures $/ 10^{6}$ hours for fixed film resistors is based on an ambient temperature of $30^{\circ} \mathrm{C}$ and a stress factor of 0.5 (ratio of operating power to rated power).

All resistors values, except one, are $<.1 \mathrm{Meg}$ ohms which defines the resistance factor of 1.0. The resistor with a value $>0.1 \mathrm{Meg} \mathrm{ohm}$ has a resistance factor of 1.1.

Because these are procured to an S quality level, the quality factor is 0.03 .

The environment factor for space applications is 0.5 .

\subsubsection{Quartz Oscillators}

The failure rate model for quartz oscillators is given in Section 19.1, page 19-1, of MIL-HDBK-217F.

$$
\begin{aligned}
& \lambda_{\mathrm{P}}= \lambda_{\mathrm{B}} \pi_{\mathrm{Q}} \pi_{\mathrm{E}} \\
& \text { where: } \\
& \lambda_{\mathrm{P}}=\text { part failure rate } / 10^{6} \text { hours } \\
& \lambda_{\mathrm{B}}=\text { base failure, Section } 19.1 \\
& \pi_{\mathrm{Q}}=\text { quality factor, Section } 19.1 \\
& \pi_{\mathrm{E}}=\text { environment factor, Section } 19.1
\end{aligned}
$$


The base failure rate for quartz oscillators is frequency dependent, refer to the detailed reliability estimate section for numerical values.

The quality factor is 2.1 based on commercial component procurement.

The environment factor is 0.5 for space applications.

\subsubsection{Inductive Devices}

The reliability model for fixed inductors is defined in Section 11.2, page 11-3, of MIL-HDBK-217F and is presented below.

$$
\begin{aligned}
\lambda_{\mathrm{P}} & =\lambda_{\mathrm{B}} \pi_{\mathrm{C}} \pi_{\mathrm{Q}} \pi_{\mathrm{E}} \\
& \text { where: } \\
\lambda_{\mathrm{P}} & =\text { part failure rate } / 10^{6} \text { hours } \\
\lambda_{\mathrm{B}} & =\text { base failure, Section } 11.2 \\
\pi_{\mathrm{C}} & =\text { construction factor, Section } 11.2 \\
\pi_{\mathrm{Q}} & =\text { quality factor, Section } 11.2 \\
\pi_{\mathrm{E}} & =\text { environment factor, Section } 11.2
\end{aligned}
$$

The base failure rate of 0.0004 failures $/ 10^{6}$ hours for fixed inductors is based on a temperature of $30^{\circ} \mathrm{C}$ and a maximum operating temperature of $125^{\circ} \mathrm{C}$.

All inductors are fixed (as opposed to variable), therefore the construction factor is 1.0 .

The sensor designs use a mix of MIL-STD and commercial inductors. For the non MIL parts we are using the lowest quality factor listed in MIL-HDBK-217F. That is 20 . For those devices that are purchased at an $S$ level of reliability the quality factor is 0.03 .

The environment factor is 0.5 for space applications. 


\subsubsection{Motors}

The failure rate for the stepper motors is defined by Section 12.1, page 12-1 of MIL-HDBK-217F.

$$
\begin{aligned}
\lambda_{\mathrm{P}}= & {\left[\frac{\mathrm{t}^{2}}{\alpha_{B}^{3}}+\frac{1}{\alpha_{\mathrm{W}}}\right] \times 10^{6} \text { Failures } / 10^{6} \text { hours } } \\
\text { where: } & \\
\alpha_{\mathrm{B}}= & \text { Weibull characteristic life } \\
& \text { for motor bearings } \\
\alpha_{\mathrm{W}}= & \text { Weibull characteristic life } \\
& \quad \text { for motor windings }
\end{aligned}
$$

The Weibull characteristics for both the bearings and windings are based on ambient temperature as well as operating time at that temperature. Two operating temperatures were selected, $-10^{\circ} \mathrm{C}$ and $+40^{\circ} \mathrm{C}$ with corresponding operating times of 50 hours and 200 hours. For non-constant temperature operation, the method defined in Section 12.1, page 12-2 was used to calculate a weighted characteristic life for both the bearings and the windings. See the section on detailed reliability estimate for numerical results.

\subsubsection{Printed Circuit Board Connectors}

The failure rate model, presented below, for printed circuit board connectors is given in Section 15.2, page 15-4 of MIL-HDBK-217F.

$$
\begin{aligned}
\lambda_{\mathrm{P}}= & \lambda_{\mathrm{B}} \pi_{\mathrm{K}} \pi_{\mathrm{P}} \pi_{\mathrm{E}} \\
& \text { where: } \\
\lambda_{\mathrm{P}} & =\text { part failure rate } / 10^{6} \text { hours } \\
\lambda_{\mathrm{B}}= & \text { base failure, Section } 15.2 \\
\pi_{\mathrm{K}} & =\text { mating/ unmating factor, Section } 15.2 \\
\pi_{\mathrm{P}} & =\text { active pins factor, Section } 15.2 \\
\pi_{\mathrm{E}} & =\text { environment factor, Section } 15.2
\end{aligned}
$$

The base failure rate for printed circuit board connectors is based on the operating temperature. For a temperature of $10^{\circ} \mathrm{C}$ it is .00017 failures $/ 10^{6}$ hours. 
The mating/unmating factor is 1.0 which is based on an allowable 0 to 0.5 mating/unmating cycles/1000 hours.

The active pins factor is a function of the number of active pins in the connector. For each connector this data is provided in the detailed reliability estimate section.

The environmental factor is 0.8 based on a space environment and procurement of commercial connectors.

\subsection{Detailed Reliability Estimate}

\subsection{Background}

All of the sensors that are to be used in the Clementine sensor suite are modular in nature. The core of all sensors is the Actel Camera. Star Trackers require only an Actel Camera board. A UV / Visible camera is a combination of an Actel Camera board and a Filter Wheel board. Likewise, a LIDAR is comprised of an Actel Camera board, a Filter Wheel board, a Range Receiver board and a LIDAR System Controller board.

To avoid unnecessary duplication of data, the detailed estimate for each board will be presented in section 3.2. Sections 3.3 thru 3.5 will combine the estimates for each of the individual boards into sensors and present a sensor by sensor reliability estimate.

\subsection{Board Level Detailed Reliability Estimates}

The following tables represent the parts lists and all of the parameters used to derive our reliability estimates. Table 3 presents the Actel Camera board. Table 4 represents the Filter Wheel board. Table 5 represents the Range Receiver board and table 6 presents the LIDAR System Controller board. 
ACTEL Camera

MICROCIRCUITS

\begin{tabular}{|c|c|c|c|c|c|c|c|c|c|c|}
\hline Part No. & Description & No. & $\mathrm{C}_{1}$ & $\overline{C_{2}}$ & $\Pi_{\mathrm{T}}$ & $\Pi_{\mathrm{E}}$ & $\Pi_{Q}$ & $\Pi_{\mathrm{L}}$ & $\lambda_{P}$ & Comments \\
\hline LM317LM/At & REGULAATOR, ADJUSTABLE & 2 & 0.01 & 0.0034 & 2.8 & 0.5 & 3.8 & 1.0 & 0.22333 & Custom screening program \\
\hline DS34C86M/A+ & DRIVER, LINE, QUAD, CMOS & 1 & 0.01 & 0.0072 & 2.8 & 0.5 & 3.8 & 1.0 & 0.11889 & Custom screening program \\
\hline DS34C87M/At & $\begin{array}{l}\text { RECEIVER, LINE, QUAD, } \\
\text { CMOS }\end{array}$ & 4 & 0.01 & 0.0072 & 2.8 & 0.5 & 3.8 & 1.0 & 0.47555 & Custom screening program \\
\hline LF353M & $\begin{array}{l}\text { ANPI IFIER, WDE BAND, } \\
\text { DUAL, JEET INPUT }\end{array}$ & 2 & 0.01 & 0.0034 & 2.8 & 0.5 & 3.8 & 1.0 & 0.22333 & Custom screening program \\
\hline LF442CM & $\begin{array}{l}\text { AMPLIFIER, DUAL,JFET } \\
\text { INPUT }\end{array}$ & 1 & 0.01 & 0.0034 & 2.8 & 0.5 & 3.8 & 1.0 & 0.11167 & Custom screening program \\
\hline TSC4426COA & DRIVER, DUAL, INVERTING & 5 & 0.01 & 0.0034 & 2.8 & 0.5 & 3.8 & 1.0 & 0.55833 & Custom screening program \\
\hline TSC4428COA & $\begin{array}{l}\text { DRRER, DUAL, NON } \\
\text { INVERTING }\end{array}$ & 1 & 0.01 & 0.0034 & 2.8 & 0.5 & 3.8 & 1.0 & 0.11167 & Custom screening program \\
\hline CLC501AJ920 & AMPLIFIER, CLAMPING & 2 & 0.01 & 0.0034 & 2.8 & 0.5 & 3.8 & 1.5 & 0.33500 & Custom screening program \\
\hline $54 A C 74 / 883$ & FIIP-FLOP, DUAL, J-K & 2 & 0.01 & 0.0071 & 1.3 & 0.5 & 2.0 & 1.0 & 0.06570 & $883 / B$ Screening \\
\hline AD558TE/883 & $\begin{array}{l}\text { CONVERTER, DIGTAL TO } \\
\text { ANALOG }\end{array}$ & 1 & 0.02 & 0.0071 & 2.8 & 0.5 & 2.0 & 1.0 & 0.11786 & 883/B Screening \\
\hline MP7684KS & $\begin{array}{l}\text { CONVERTER, ANALOG TO } \\
\text { DIGITAL }\end{array}$ & 1 & 0.06 & 0.0130 & 2.8 & 0.5 & 3.8 & 1.0 & 0.65594 & Custom screening program \\
\hline LM385BZ-1.2 & REFERENCE, VOLTAGE & 1 & 0.01 & 0.0034 & 2.8 & 0.5 & 3.8 & 1.0 & 0.11167 & Custom screening program \\
\hline REF01CS & REFERENCE, VOLTAGE & 1 & 0.01 & 0.0034 & 2.8 & 0.5 & 3.8 & 1.0 & 0.11167 & Custom screening program \\
\hline A1020A-1JQ44E & $\begin{array}{l}\text { GATEARRAY, FELD } \\
\text { PROGRAMMABLE }\end{array}$ & 1 & 0.03 & 0.0167 & 2.8 & 0.5 & 2.0 & 1.0 & 0.20494 & 883/B Screening \\
\hline CCD78X3 & CHARGE COUTLED DEVICE & 1 & 0.06 & 0.0096 & 2.8 & 0.5 & 2.0 & 1.0 & 0.34183 & 883/B Screening \\
\hline TH7990 & CONTROLLER OCD & 1 & 0.02 & 0.0167 & 0.6 & 0.5 & 3.8 & 1.0 & 0.07712 & Custom screening program \\
\hline AD590JH/883 & SENSOR, TEMIPERATURE & 1 & 0.01 & 0.0006 & 2.8 & 0.5 & 2.0 & 1.0 & 0.05597 & 883/B Screening \\
\hline
\end{tabular}

DIODES

\begin{tabular}{|c|c|c|c|c|c|c|c|c|c|c|}
\hline Part No. & Description & No. & $\lambda_{\mathrm{B}}$ & $\Pi_{\mathrm{s}}$ & $\Pi_{\mathrm{T}}$ & $\Pi_{E}$ & $\Pi_{Q}$ & $\Pi_{\mathrm{C}}$ & $\lambda_{\mathrm{p}}$ & Comments \\
\hline 4150-ISM & $\begin{array}{l}\text { DIODE, SWITCAINC, } 50 \\
\text { VOLT, 200 MA }\end{array}$ & 1 & 0.001 & 0.0054 & 2.2 & 0.5 & $\overline{5.5}$ & 1.0 & 0.00003 & Hermetic commercial \\
\hline BAT54S & $\begin{array}{l}\text { DIODE, SCHOTTKY, } 30 \\
\text { VOLT, 200MA }\end{array}$ & 2 & 0.001 & 0.1900 & 2.2 & 0.5 & 8.0 & 1.0 & 0.00339 & Plastic SOT-23 \\
\hline
\end{tabular}

TRANSISTORS

\begin{tabular}{|c|c|c|c|c|c|c|c|c|c|c|}
\hline Part No. & Description & No. & $\lambda_{\mathrm{B}}$ & $\Pi_{A}$ & $\Pi_{\mathrm{T}}$ & $\Pi_{\mathrm{E}}$ & $\Pi_{Q}$ & $\Pi_{\mathrm{R}}$ & $\lambda_{\mathrm{P}}$ & Comments \\
\hline MMBT3904 & $\mathrm{NIN}, 40 \mathrm{~V}, 200 \mathrm{MA}, 225 \mathrm{MW}$ & $\overline{3}$ & 0.00074 & 1.5000 & 1.7 & 0.5 & 8.0 & .58 & 0.01328 & Plastic SOT-23 \\
\hline SST215 & $\begin{array}{l}\text { FET, DMOS, NCHANNEL, } \\
\text { LATERAL }\end{array}$ & 3 & 0.01200 & 1.5000 & 1.6 & 0.5 & 8.0 & 1.00 & 0.35612 & Plastic SOT-23 \\
\hline
\end{tabular}

Table 3a. Actel Camera Semiconductors 
CHIP CAPACITORS

\begin{tabular}{|c|c|c|c|c|c|c|c|c|c|}
\hline Part No. & Description & No. & Value(pF) & $\lambda_{\mathrm{B}}$ & $\Pi_{\mathrm{CV}}$ & $\Pi_{Q}$ & $\Pi_{\mathrm{E}}$ & $\lambda_{\mathrm{P}}$ & Comments \\
\hline & CAP, CHUP, CERAMIC & 53 & 100000 & 0.00028 & 2.3488 & 0.03 & 0.5 & 0.000519 & MIL-SPEC component \\
\hline & CAP, CHIP, CERAMIC & 4 & 220 & 0.00028 & 1.1270 & 0.03 & 0.5 & 0.000019 & MIL-SPEC component \\
\hline & CAP, CHIP, CERAMIC & 1 & 220000 & 0.00028 & 2.5819 & 0.03 & 0.5 & 0.000011 & MIL-SPEC component \\
\hline & CAP, CHIIP, CERAMIC & 1 & 2200 & 0.00028 & 1.4857 & 0.03 & 0.5 & 0.000006 & MIL-SPEC component \\
\hline & CAP, CHIP, CERAMIC & 2 & 22000 & 0.00028 & 1.9586 & 0.03 & 0.5 & 0.000016 & MIL-SPEC component \\
\hline & CAP, CHIP, CERAMIC & 1 & 15 & 0.00028 & 0.8166 & 0.03 & 0.5 & 0.000003 & MIL-SPEC component \\
\hline & CAP, CHIP, CERAMIC & 5 & 3300 & 0.00028 & 1.5598 & 0.03 & 0.5 & 0.000033 & MIL-SPEC component \\
\hline & CAP, CHIP, CERAMIC & 2 & 10000 & 0.00028 & 1.7818 & 0.03 & 0.5 & 0.000015 & MIL-SPEC component \\
\hline & CAP, CFIP, CERAMIC & 3 & 39 & 0.00028 & 0.9158 & 0.03 & 0.5 & 0.000011 & MIL-SPEC component \\
\hline & CAP, CHIP, CERAMIC & 2 & 270 & 0.00028 & 1.1551 & 0.03 & 0.5 & 0.000010 & MIL-SPEC component \\
\hline & CAP, CHIIP, CERAMIC & 1 & 10 & 0.00028 & 0.7778 & 0.03 & 0.5 & 0.000003 & MIL-SPEC component \\
\hline
\end{tabular}

TANTALUM CAPACITORS

\begin{tabular}{|c|c|c|c|c|c|c|c|c|c|c|}
\hline Part No. & Description & No. & Value $(\mu F)$ & $\lambda_{\mathrm{B}}$ & $\Pi_{\mathrm{CV}}$ & $\Pi_{Q}$ & $\Pi_{E}$ & $\Pi_{\mathrm{SR}}$ & $\lambda_{\mathrm{P}}$ & Comments \\
\hline & CAP,CFUP,TANT & 5 & 4.7 & 0.00667 & 1.2041 & 0.001 & 0.4 & 0.270 & 0.000004 & Series R / PS Volt $=\sim 0.15$ \\
\hline & CAP, CHIP, TANT & 1 & 47 & 0.00667 & 1.5873 & 10.000 & 0.4 & 0.270 & 0.011428 & Commercial Part \\
\hline & CAP, CHIP, TANT & 9 & 22 & 0.00667 & 1.4491 & 0.001 & 0.4 & 0.270 & 0.000009 & Series R / PS Volt $=\sim 0.15$ \\
\hline & CAP, CHIP, TANT & 5 & 6.8 & 0.00667 & 1.2586 & 0.001 & 0.4 & 0.270 & 0.000005 & Series R / PS Volt $=\sim 0.15$ \\
\hline & CAP, CHIP, TANT & 4 & 10 & 0.00667 & 1.3183 & 0.001 & 0.4 & 0.270 & 0.000004 & Series R / PS Volt $=\sim 0.15$ \\
\hline & CAP, CHIP, TANT & 2 & 1.0 & 0.00667 & 1.0000 & 0.001 & 0.4 & 0.270 & 0.000001 & Series R / PS Volt $=\sim 0.15$ \\
\hline
\end{tabular}

Table 3b. Actel Camera Capacitors 
RESISTORS

\begin{tabular}{|c|c|c|c|c|c|c|c|c|c|}
\hline Part No. & Description & No. & Value $(\mathrm{k} \Omega)$ & $\lambda_{\mathrm{B}}$ & $\Pi_{R}$ & $\Pi_{Q}$ & $\Pi_{\mathrm{E}}$ & $\lambda_{\mathrm{P}}$ & Comments \\
\hline & RES, CFHP, FLLM & 1 & $1 \mathrm{Meg} \Omega$ & $\overline{0.0013}$ & $\overline{1.1}$ & 0.03 & $\overline{0.2}$ & 0.000009 & Stress ratio $=0.4$, temp $=30^{\circ} \mathrm{C}$ \\
\hline & RES, CHIP, FLM & 81 & $\begin{array}{c}<.1 \mathrm{Meg} \\
\Omega\end{array}$ & 0.0013 & 1.0 & 0.03 & 0.2 & 0.000632 & Stress ratio $=0.4$, temp $=30^{\circ} \mathrm{C}$ \\
\hline
\end{tabular}

CRYSTALS

\begin{tabular}{|l|c|c|c|c|c|c|c|c|l|l|}
\hline Part No. & Description & No. & $\mathrm{MHz}$ & $\lambda_{\mathrm{B}}$ & $\Pi_{\mathrm{Q}}$ & $\Pi_{\mathrm{E}}$ & & & $\lambda_{\mathrm{P}}$ & Comments \\
\hline & CRYSTAL 20MHz & 1 & 20 & 0.0259 & 2.1 & 0.5 & & & 0.027188 & Hermetic non MIL part \\
\hline
\end{tabular}

\section{INDUCTORS}

\begin{tabular}{|l|c|c|c|c|c|c|c|c|l|l|}
\hline Part No. & Description & No. & Value & $\lambda_{\mathrm{B}}$ & $\Pi_{\mathrm{C}}$ & $\Pi_{\mathrm{Q}}$ & $\Pi_{\mathrm{E}}$ & & $\lambda_{\mathrm{P}}$ & Comments \\
\hline & INDOCTOR, $100 \mathrm{\mu H}$ & 5 & $100 \mu \mathrm{H}$ & 0.00037 & 1.0 & 0.03 & 0.5 & & 0.000028 & QPL part \\
\hline
\end{tabular}

CONNECTORS

\begin{tabular}{|l|c|c|c|c|c|c|c|c|c|l|}
\hline Part No. & Description & No. & Pins & $\lambda_{\mathrm{B}}$ & $\Pi_{\mathrm{K}}$ & $\Pi_{\mathrm{Q}}$ & $\Pi_{\mathrm{E}}$ & & $\lambda_{\mathrm{P}}$ & Comments \\
\hline & $\begin{array}{c}\text { CONNECTOR.51 PIN, } \\
\text { MICRO MINIATURE }\end{array}$ & 1 & 51 & 0.00017 & 1.0 & 9.72 & 0.8 & & 0.001323 & Non mil part \\
\hline
\end{tabular}

Table 3c. Actel Camera Other Passive Components 
Filter Wheel

MICROCIRCUITS

\begin{tabular}{|c|c|c|c|c|c|c|c|c|c|c|}
\hline Part No. & Description & No. & $\overline{C_{1}}$ & $\mathrm{C}_{2}$ & $\Pi_{\mathrm{T}}$ & $\Pi_{\mathrm{E}}$ & $\Pi_{Q}$ & $\Pi_{\mathrm{L}}$ & $\lambda_{P}$ & Comments \\
\hline$\overline{\mathrm{DS34C} 86 \mathrm{M} / \mathrm{A}+}$ & $\begin{array}{l}\text { RECEVIVR, LINE, QUAD, } \\
\text { CMOS }\end{array}$ & 1 & 0.01 & 0.0072 & 2.8 & 0.5 & 3.8 & 1.0 & 0.11889 & Custom screening program \\
\hline DS34C87M/A+ & DRIVER, LINE, QUAD, CMOS & 1 & 0.01 & 0.0072 & 2.8 & 0.5 & 3.8 & 1.0 & 0.11889 & Custom screening program \\
\hline NE555 & TIMER, PRECISION & 1 & 0.01 & 0.0034 & 2.8 & 0.5 & 3.8 & 1.0 & 0.11167 & Custom screening program \\
\hline A1020A-1JQ44E & $\begin{array}{l}\text { GATE ARRAY, FIELD } \\
\text { PROGRAMMABLE }\end{array}$ & 1 & 0.03 & 0.0167 & 2.8 & 0.5 & 2.0 & 1.0 & 0.20494 & 883/B Screening \\
\hline UGS3140HH & SWTTCH, HALL EFFECT & 3 & 0.01 & 0.0012 & 2.8 & 0.5 & 3.8 & 1.0 & 0.32246 & Custom screening program \\
\hline
\end{tabular}

DIODES

\begin{tabular}{|l|c|c|c|c|c|c|c|c|l|l|}
\hline Part No. & Description & No. & $\lambda_{\mathrm{B}}$ & $\Pi_{\mathrm{S}}$ & $\Pi_{\mathrm{T}}$ & $\Pi_{\mathrm{E}}$ & $\Pi_{\mathrm{Q}}$ & $\Pi_{\mathrm{C}}$ & $\lambda_{\mathrm{P}}$ & Comments \\
\hline $4150-\mathrm{ISM}$ & $\begin{array}{c}\text { DroDES SWIICHING,50 } \\
\text { VoLT, 200MA }\end{array}$ & 5 & 0.001 & 0.0054 & 2.2 & 0.5 & 5.5 & 1.0 & 0.00017 & Hermetic Part \\
\hline
\end{tabular}

OPTO ISOLATORS

\begin{tabular}{|l|c|c|c|c|c|c|c|c|l|l|}
\hline Part No. & Description & No. & $\lambda_{\mathrm{B}}$ & $\Pi_{\mathrm{T}}$ & $\Pi_{\mathrm{Q}}$ & $\Pi_{\mathrm{E}}$ & & & $\lambda_{\mathrm{P}}$ & Comments \\
\hline AQV101A & ISOLATR PHOTODIODE & 5 & 0.013 & 2.1 & 8.0 & 0.5 & & 0.10733 & Plastic screened part \\
\hline
\end{tabular}

Table 4a. Filter Wheel Semiconductors 
CHIP CAPACITORS

\begin{tabular}{|c|c|c|c|c|c|c|c|c|c|}
\hline Part No. & Description & No. & Value(pF) & $\lambda_{\mathrm{B}}$ & $\Pi_{\mathrm{CV}}$ & $\Pi_{Q}$ & $\Pi_{\mathrm{E}}$ & $\lambda_{\mathrm{p}}$ & Comments \\
\hline & CAR, CAIIP, CERAMIC & $\overline{11}$ & 10000 & 0.00028 & 1.7818 & 0.03 & 0.5 & 0.000082 & S level reliability \\
\hline & CAP, CHP, CERAMIC & 4 & 10 & 0.00082 & 0.7778 & 0.03 & 0.5 & 0.000038 & S level reliability \\
\hline & CAP, CFIP, CERAMIC & 6 & 100 & 0.00028 & 1.0253 & 0.03 & 0.5 & 0.000026 & S level reliability \\
\hline & CAP, CHIP, CERAMIC & 1 & 100000 & 0.00028 & 2.3488 & 0.03 & 0.5 & 0.000010 & S level reliability \\
\hline
\end{tabular}

TANTALUM CAPACITORS

\begin{tabular}{|c|c|c|c|c|c|c|c|c|c|c|}
\hline Part No. & Description & No. & Value $(\mu \mathrm{F})$ & $\lambda_{\mathrm{B}}$ & $\Pi_{\mathrm{cV}}$ & $\Pi_{Q}$ & $\Pi_{\mathrm{E}}$ & $\Pi_{\mathrm{SR}}$ & $\lambda_{\mathrm{P}}$ & Comments \\
\hline & CAP,CHUP,TANI & 5 & 1.0 & 0.00667 & $\overline{1.0000}$ & 0.001 & 0.4 & 0.27 & $\overline{0.000004}$ & Series R / PS Volt $=-0.15$ \\
\hline & CAP, CHIP, TANT & 2 & 0.68 & 0.00667 & 0.9548 & 0.001 & 0.4 & 0.27 & 0.000001 & Series R / PS Volt $=\sim 0.15$ \\
\hline & CAP, CFIP, TANT & 4 & 2.2 & 0.00667 & 1.0992 & 0.001 & 0.4 & 0.27 & 0.000003 & Series $R /$ PS Volt $=\sim 0.15$ \\
\hline & CAP, CHIP, TANT & 2 & 10.0 & 0.00667 & 1.3183 & 10.0 & 0.4 & 0.27 & 0.018982 & Commercial Part \\
\hline
\end{tabular}

RESISTORS

\begin{tabular}{|l|c|c|c|c|c|c|c|c|c|l|}
\hline Part No. & Description & No. & Value(k $\Omega)$ & $\lambda_{\mathrm{B}}$ & $\Pi_{\mathrm{R}}$ & $\Pi_{\mathrm{Q}}$ & $\Pi_{\mathrm{E}}$ & & $\lambda_{\mathrm{P}}$ & Comments \\
\hline & RES, CHII, FLL & 20 & $<.1 \mathrm{Meg} \Omega$ & 0.0013 & 1.0 & 0.03 & 0.2 & & 0.000156 & MIL-SPEC Parts \\
\hline
\end{tabular}

INDUCTORS (FERRITE BEADS)

\begin{tabular}{|l|c|c|c|c|c|c|c|c|l|l|}
\hline Part No. & Description & No. & Value & $\lambda_{\mathrm{B}}$ & $\Pi_{\mathrm{C}}$ & $\Pi_{\mathrm{Q}}$ & $\Pi_{\mathrm{E}}$ & & $\lambda_{\mathrm{P}}$ & Comments \\
\hline & BEAD, FERRIIE & 10 & Ferrite & 0.00039 & 1.0 & 20.0 & 0.5 & & 0.039000 & Commercial ferrites \\
\hline
\end{tabular}

CONNECTORS

\begin{tabular}{|c|c|c|c|c|c|c|c|c|c|}
\hline Part No. & Description & No. & Pins &.$\lambda_{\mathrm{B}}$ & $\Pi_{K}$ & $\Pi_{Q}$ & $\Pi_{\mathrm{E}}$ & $\lambda_{P}$ & Comments \\
\hline & $\begin{array}{l}\text { ONNECTOR, }, \mathrm{PL}, \mathrm{ML} \\
\text { GINATURE }\end{array}$ & 1 & 9 & 0.00017 & 1.0 & 2.44 & 0.8 & 0.000332 & Non mil part \\
\hline
\end{tabular}

STEPPER MOTOR

\begin{tabular}{|l|c|c|c|c|c|c|c|c|c|l|}
\hline Part No. & Description & No. & Temp( C) & $\begin{array}{c}\text { Time } \\
\text { (hrs) }\end{array}$ & $\alpha$ & $\alpha_{W T}$ & $\alpha_{\mathrm{B}}$ & $\alpha_{\mathrm{W}}$ & $\lambda_{\mathrm{P}}$ & Comments \\
\hline & MOTOR STEPPER & 1 & -10.00 & 50.0 & 1075.3 & $1.4 \mathrm{E}+07$ & 5103.1 & $6.2 \mathrm{E}+05$ & $2.08 \mathrm{E}-06$ & \\
& & & 40.00 & 200.0 & 80224.8 & $5.0 \mathrm{E}+05$ & & & & \\
\hline
\end{tabular}

Table 4b. Filter Wheel Passive Components 
LIDAR Range Receiver MICROCIRCUITS

\begin{tabular}{|c|c|c|c|c|c|c|c|c|c|c|}
\hline Part No. & Description & No. & $\mathrm{C}_{1}$ & $\mathrm{C}_{2}$ & $\Pi_{\mathrm{T}}$ & $\Pi_{\mathrm{E}}$ & $\Pi_{Q}$ & $\Pi_{\mathrm{L}}$ & $\lambda_{\mathrm{p}}$ & Comments \\
\hline $\mathrm{LM} 307 \mathrm{M} / \mathrm{A}+$ & AMPLIFIAR, OPERAMIONAL & $\overline{1}$ & 0.01 & 0.0034 & 2.8 & $\overline{0.5}$ & $\overline{3.8}$ & 1.0 & 0.11167 & Custom screening program \\
\hline LM317LM/A+ & REGULATOR, VOLTAGE & 1 & 0.01 & 0.0034 & 2.8 & 0.5 & 3.8 & 1.0 & 0.11167 & Custom screening program \\
\hline LM360M & $\begin{array}{l}\text { COMPARATOR, DIFF, HICH } \\
\text { STPED }\end{array}$ & 1 & 0.01 & 0.0034 & 2.8 & 0.5 & 3.8 & 1.0 & 0.11167 & Custom screening program \\
\hline CLC410AJE & $\begin{array}{l}\text { AMPLIFIER, VIDEO, WITH } \\
\text { DISABLE }\end{array}$ & 1 & 0.01 & 0.0034 & 2.8 & 0.5 & 3.8 & 1.5 & 0.16750 & Custom screening program \\
\hline $\mathrm{DC} / \mathrm{DC}$ CONV & CONVERTER, DC / DC & 1 & 0.01 & 0.0016 & 2.8 & 0.5 & 3.8 & 1.5 & 0.16237 & Mfg. custom part \\
\hline CLC520AJE & $\begin{array}{l}\text { AMIPIFIER, OPERATIONAL, } \\
\text { AGC }\end{array}$ & 1 & 0.01 & 0.0062 & 2.8 & 0.5 & 3.8 & 1.5 & 0.17548 & Custom screening program \\
\hline A747MW/883B & $\begin{array}{l}\text { AMPLIFIER, OPERATIONAL, } \\
\text { DUAL }\end{array}$ & 1 & 0.01 & 0.0037 & 2.8 & 0.5 & 2.0 & 1.0 & 0.05907 & 883/B Screening \\
\hline
\end{tabular}

\section{DIODES}

\begin{tabular}{|c|c|c|c|c|c|c|c|c|c|c|}
\hline Part No. & Description & No. & $\lambda_{\mathrm{B}}$ & $\Pi_{\mathrm{s}}$ & $\Pi_{\mathrm{T}}$ & $\Pi_{\mathrm{E}}$ & $\Pi_{Q}$ & $\Pi_{\mathrm{C}}$ & $\lambda \mathrm{p}$ & Comments \\
\hline JANTXV1N914 & $\begin{array}{l}\text { DTODE, SWITCHING, } 100 \\
\text { VOLT }\end{array}$ & $\overline{1}$ & $\overline{0.001}$ & 0.1900 & $\overline{2.2}$ & 0.5 & 0.7 & 1.0 & 0.00015 & QPL component \\
\hline JANTXV1N823-1 & REFERENCE, ZENER, TC & 1 & 0.002 & 0.1900 & 1.6 & 0.5 & 0.7 & 1.0 & 0.00022 & QPL component \\
\hline HSMS-2820 & $\begin{array}{l}\text { DIODE, SCHOTTKY } \\
\text { BARRIER }\end{array}$ & 2 & 0.001 & 0.1900 & 2.2 & 0.5 & 8.0 & 1.0 & 0.00339 & Plastic screened component \\
\hline
\end{tabular}

PHOTO DIODES

\begin{tabular}{|c|c|c|c|c|c|c|c|c|}
\hline Part No. & Description & No. & $\lambda_{\mathrm{B}}$ & $\Pi_{\mathrm{T}}$ & $\Pi_{Q}$ & $\Pi_{\mathrm{E}}$ & $\lambda_{\mathrm{P}}$ & Comments \\
\hline C30954E/883B & $\begin{array}{l}\text { DTODEPHOTO } \\
\text { AVALANCHE }\end{array}$ & $\overline{1}$ & 0.004 & 2.1 & 2.4 & 0.50 & 0.009907 & JAN Quality due to $883 / \mathrm{B}$ screen \\
\hline
\end{tabular}

TRANSISTORS

\begin{tabular}{|c|c|c|c|c|c|c|c|c|c|c|}
\hline Part No. & Description & No. & $\lambda_{\mathrm{B}}$ & $\Pi_{\mathbf{A}}$ & $\Pi_{\mathrm{T}}$ & $\Pi_{\mathrm{E}}$ & $\Pi_{Q}$ & $\Pi_{R}$ & $\lambda_{\mathrm{P}}$ & Comments \\
\hline 2 N7002 & $\begin{array}{l}\text { NPN, VHF/UHF, } 15 \mathrm{~V}, 50 \\
\mathrm{MA}, 225 \mathrm{MW}\end{array}$ & 4 & 0.00740 & 1.5000 & 1.7 & 0.5 & 8.0 & .58 & 0.17710 & Screened plastic SOT-23 \\
\hline SST4416 & FEET, N-CHAANNEL, $350 \mathrm{MW}$ & 1 & 0.00740 & 1.5000 & 1.6 & 0.5 & 8.0 & 0.68 & 0.04964 & Screened plastic SOT-23 \\
\hline BF9965 & $\begin{array}{l}\text { MOSFET, DUAL, } 20 \text { VOLT, } \\
200 \mathrm{MW}\end{array}$ & 1 & 0.01200 & 1.5000 & 1.6 & 0.5 & 8.0 & & 0.11871 & Screened plastic SOT-23 \\
\hline
\end{tabular}

Table 5a. Range Receiver Semiconductors 
CHIP CAPACITORS

\begin{tabular}{|c|c|c|c|c|c|c|c|c|c|}
\hline Part No. & Description & No. & Value(pF) & $\lambda_{\mathrm{B}}$ & $\Pi \mathrm{CV}$ & $\Pi_{Q}$ & $\Pi_{\mathrm{E}}$ & $\lambda \mathrm{p}$ & Comments \\
\hline & CAP,CHIP, CERAMIC & 1 & 1000 & 0.00028 & 1.3516 & 0.03 & 0.5 & 0.000006 & MiL-SPEC component \\
\hline & CAP, CHIP, CERAMC & 2 & 1000 & 0.00125 & 1.3516 & 0.03 & 0.5 & 0.000051 & MIL-SPEC, 1000 volt rating \\
\hline & CAP, CHIP, CERAMIC & 7 & 10000 & 0.00028 & 1.7818 & 0.03 & 0.5 & 0.000052 & MIL-SPEC component \\
\hline & CAP, CHIP, CERAMIC & 2 & 10000 & 0.00125 & 1.7818 & 0.03 & 0.5 & 0.000067 & MIL-SPEC, 1000 volt rating \\
\hline & CAP, CHIP, CERAMIC & 1 & 820 & 0.00028 & 1.3198 & 0.03 & 0.5 & 0.000006 & MIL-SPEC component \\
\hline & CAP, CHIP, CERAMIC & 19 & 100000 & 0.00028 & 2.3488 & 0.03 & 0.5 & 0.000186 & MIL-SPEC component \\
\hline & CAP, CHIP, CERAMIC & 1 & 220 & 0.00028 & 1.1270 & 0.03 & 0.5 & 0.000005 & MIL-SPEC component \\
\hline & CAP, CHIP, CERAMIC & 1 & 10 & 0.00028 & 0.7778 & 0.03 & 0.5 & 0.000003 & MIL-SPEC component \\
\hline & CAP, CHIP, CERAMIC & 6 & 4700 & 0.00125 & 1.6274 & 0.03 & 0.5 & 0.000183 & MIL-SPEC, 25 volt rating \\
\hline
\end{tabular}

\section{TANTALUM CAPACITORS}

\begin{tabular}{|l|c|c|c|c|c|c|c|c|c|l|}
\hline Part No. & Description & No. & Value $(\mu \mathrm{F})$ & $\lambda_{\mathrm{B}}$ & $\Pi_{\mathrm{CV}}$ & $\Pi_{\mathrm{Q}}$ & $\Pi_{\mathrm{E}}$ & $\Pi_{\mathrm{SR}}$ & $\lambda_{\mathrm{P}}$ & Comments \\
\hline & CAI,CHII, IANI & 6 & 6.8 & 0.00667 & 1.2586 & 0.001 & 0.4 & 0.27 & 0.000005 & Mil parts \\
\hline
\end{tabular}

\section{RESISTORS}

\begin{tabular}{|c|c|c|c|c|c|c|c|c|c|}
\hline Part No. & Description & No. & Value $(\mathrm{k} \Omega)$ & $\lambda_{\mathrm{B}}$ & $\Pi_{R}$ & $\Pi_{Q}$ & $\Pi_{\mathrm{E}}$ & $\lambda_{\mathrm{p}}$ & Comments \\
\hline & RES, CHIIP, FLM & 64 & $<.1 \mathrm{Meg} \Omega$ & 0.0013 & 1.0 & 0.03 & $\overline{0.2}$ & 0.000499 & Stress ratio $=0.4$, temp $=30^{\circ} \mathrm{C}$ \\
\hline & RES, CHIP, FLM & 1 & $1 \operatorname{Meg} \Omega$ & 0.0013 & 1.1 & 0.03 & 0.2 & 0.000009 & Stress ratio $=0.4$, temp $=30^{\circ} \mathrm{C}$ \\
\hline
\end{tabular}

\section{INDUCTORS}

\begin{tabular}{|c|c|c|c|c|c|c|c|c|c|}
\hline Part No. & Description & No. & Value & $\lambda_{\mathrm{B}}$ & $\Pi_{C}$ & $\Pi_{Q}$ & $\Pi_{\mathrm{E}}$ & $\lambda_{\mathrm{P}}$ & Comments \\
\hline & INDOCTOR, 100 HF & 4 & $100 \mu \mathrm{H}$ & 0.0004 & 1.0 & $\overline{0.03}$ & $\overline{0.5}$ & 0.000024 & QPL part \\
\hline & BEAD, FERRITE & 6 & Ferrite & 0.00039 & 1.0 & 20.00 & 0.5 & 0.023400 & Commercial ferrites \\
\hline
\end{tabular}

CONNECTORS

\begin{tabular}{|l|c|c|c|c|c|c|c|c|l|l|}
\hline Part No. & Description & No. & Pins & $\lambda_{\mathrm{B}}$ & $\Pi_{\mathrm{K}}$ & $\Pi_{\mathrm{Q}}$ & $\Pi_{\mathrm{E}}$ & & $\lambda_{\mathrm{P}}$ & Comments \\
\hline & $\begin{array}{c}\text { CONNECTOKR ISPIN, } \\
\text { MCRO MINATURE }\end{array}$ & 1 & 15 & 0.00017 & 1.0 & 3.28 & 0.5 & & 0.000279 & Commercial part \\
\hline
\end{tabular}

Table 5b. Range Receiver Passive Components 
LIDAR System Controller MICROCIRCUITS

\begin{tabular}{|c|c|c|c|c|c|c|c|c|c|c|}
\hline Part No. & Description & No. & $\mathrm{C}_{1}$ & $\overline{C_{2}}$ & $\Pi_{\mathrm{T}}$ & $\Pi_{\mathrm{E}}$ & $\Pi_{Q}$ & $\Pi_{\mathrm{L}}$ & $\lambda_{\mathrm{P}}$ & Comments \\
\hline LM117HVH/883 & RECULATOR, VOLTAGE & 1 & 0.01 & 0.00027 & 2.8 & 0.5 & 2.0 & 1.0 & 0.05564 & QPL part \\
\hline DS34C86M/A+ & DRIVER, LINE, QUAD, CMOS & 1 & 0.01 & 0.0072 & 2.8 & 0.5 & 3.8 & 1.0 & 0.11889 & Custom screening program \\
\hline DS34C87M/At & $\begin{array}{l}\text { RECEIVER, LINE, QUAD, } \\
\text { CMOS }\end{array}$ & 4 & 0.01 & 0.0072 & 2.8 & 0.5 & 3.8 & 1.0 & 0.47555 & Custom screening program \\
\hline $74 \mathrm{HC} 05 \mathrm{M}$ & $\begin{array}{l}\text { INVERTER, HEX, OPEN } \\
\text { COLLECTOR }\end{array}$ & 1 & 0.01 & 0.0062 & 1.3 & 0.5 & 3.8 & 1.0 & 0.06067 & Custom screening program \\
\hline 54HA373LMQB & $\begin{array}{l}\text { LATCH, TRANSPARENT, } \\
\text { NON-INVERTNG, OCTÁL }\end{array}$ & 1 & 0.01 & 0.0071 & 1.3 & 0.5 & 2.0 & 1.0 & 0.03285 & QPL part \\
\hline AD558TE/883 & $\begin{array}{l}\text { CONVERTER, DIGITAL TO } \\
\text { ANALOG }\end{array}$ & 2 & 0.02 & 0.0071 & 2.8 & 0.5 & 2.0 & 1.0 & 0.23572 & QPL part \\
\hline A1020-1JQ44E & $\begin{array}{l}\text { GATE ARRAY, FIELD } \\
\text { PROGRAMAMABLE }\end{array}$ & 2 & 0.034 & 0.0167 & 2.8 & 0.5 & 2.0 & 1.0 & 0.40988 & 883/B screened component \\
\hline AS83C154 & MICRO PROCESSOR, 8 BIT & 1 & 0.14 & 0.0167 & 0.6 & 0.5 & 3.8 & 1.0 & 0.34975 & Custom screening program \\
\hline LMA9050 & GATE ARRAY & 1 & 0.04 & 0.0100 & 0.6 & 0.5 & 3.8 & 1.0 & 0.10988 & Custom screening program \\
\hline HM4-6617B-8 & PROM, 2KX16 & 2 & 0.00085 & 0.0118 & 0.6 & 0.5 & 2.0 & 1.0 & 0.02568 & 883/B screened component \\
\hline
\end{tabular}

OPTO ISOLATORS

\begin{tabular}{|c|c|c|c|c|c|c|c|c|}
\hline Part No. & Description & No. & $\lambda_{\mathrm{B}}$ & $\Pi_{\mathrm{T}}$ & $\Pi_{Q}$ & $\Pi_{\mathrm{E}}$ & $\lambda_{\mathrm{P}}$ & Comments \\
\hline HCPL2631/883B & ISOLATOR, OPICAL & 1 & 0.013 & 2.1 & 2.4 & 0.5 & 0.03220 & JAN quality factor, $883 / \mathrm{B}$ screen \\
\hline
\end{tabular}

TRANSISTORS

\begin{tabular}{|c|c|c|c|c|c|c|c|c|c|c|}
\hline Part No. & Description & No. & $\lambda_{\mathrm{B}}$ & $\Pi_{\mathrm{A}}$ & $\Pi_{\mathrm{T}}$ & $\Pi_{\mathrm{E}}$ & $\Pi_{Q}$ & $\Pi_{\mathrm{R}}$ & $\lambda_{\mathrm{p}}$ & Comments \\
\hline IFR9020 & $\begin{array}{l}\text { FET, P-CHANNEI, REP?, } \\
\text { AVALANCHE }\end{array}$ & 1 & 0.01200 & 1.5000 & 1.6 & 0.5 & 8.0 & & 0.11871 & \\
\hline
\end{tabular}

Table 6a. LIDAR System Controller Semiconductors 
CHIP CAPACITORS

\begin{tabular}{|c|c|c|c|c|c|c|c|c|c|}
\hline Part No. & Description & No. & Value(pF) & $\lambda_{\mathrm{B}}$ & $\Pi_{\mathrm{CV}}$ & $\Pi_{Q}$ & $\Pi_{\mathrm{E}}$ & $\lambda_{\mathrm{P}}$ & Comments \\
\hline & CAP,CHUP,CERAMIC & 23 & 33000 & 0.00028 & 2.0562 & 0.03 & $\overline{0.5}$ & 0.000197 & S reliability level \\
\hline & CAP, CIM, CERAMIC & 6 & 10000 & 0.00028 & 1.7818 & 0.03 & 0.5 & 0.000045 & S reliability level \\
\hline & CAP, CFIP, CERAMIC & 1 & 330 & 0.00028 & 1.1832 & 0.03 & 0.5 & 0.000005 & S reliability level \\
\hline & CAP, CFIP, CERAMIC & 6 & 100000 & 0.00028 & 2.3488 & 0.03 & 0.5 & 0.000059 & S reliability level \\
\hline
\end{tabular}

TANTALUM CAPACITORS

\begin{tabular}{|c|c|c|c|c|c|c|c|c|c|c|}
\hline Part No. & Description & No. & Value $(\mu \mathrm{F})$ & $\lambda_{\mathrm{B}}$ & $\Pi_{\mathrm{CV}}$ & $\Pi_{Q}$ & $\Pi_{\mathrm{E}}$ & $\Pi_{\mathrm{SR}}$ & $\lambda_{\mathrm{P}}$ & Comments \\
\hline & CAP, CHIP, TANT & 5 & 1.0 & 0.00667 & 1.0000 & 0.001 & 0.4 & 0.3 & 0.000004 & MIL-SPEC part \\
\hline & CAP, CFIR, TANT & 3 & 22.0 & 0.00667 & 1.4491 & 0.001 & 0.4 & 0.3 & 0.000004 & MIL-SPEC part \\
\hline & CAP, CHP, TANT & 2 & 15.0 & 0.00667 & 1.3840 & 0.001 & 0.4 & 0.3 & 0.000002 & MIL-SPEC part \\
\hline & CAP, CHIP, TANT & 1 & 4.7 & 0.00667 & 1.2041 & 0.001 & 0.4 & 0.3 & 0.000001 & MIL-SPEC part \\
\hline & CAP, CHIP, TANT & 2 & 1.0 & 0.00667 & 1.0000 & 0.001 & 0.4 & 0.3 & 0.000002 & MIL-SPEC part \\
\hline
\end{tabular}

\section{RESISTORS}

\begin{tabular}{|c|c|c|c|c|c|c|c|c|c|}
\hline Part No. & Description & No. & Value $(\mathrm{k} \Omega)$ & $\lambda_{\mathrm{B}}$ & $\Pi_{R}$ & $\Pi_{Q}$ & $\Pi_{\mathrm{E}}$ & $\lambda_{P}$ & Comments \\
\hline & RES,CHIP, FLM & 33 & $\begin{array}{c}<.1 \mathrm{Meg} \\
\Omega\end{array}$ & $\overline{0.0013}$ & 1.0 & 0.03 & 0.2 & 0.000257 & Stress ratio $=0.4$, temp $=30^{\circ} \mathrm{C}$ \\
\hline
\end{tabular}

Table 6b. LIDAR System Controller Resistors and Capacitors 


\section{CRYSTALS}

\begin{tabular}{|l|c|c|c|c|c|c|c|c|l|l|}
\hline Part No. & Description & No. & $\mathrm{MHz}$ & $\lambda_{\mathrm{B}}$ & $\Pi_{\mathrm{Q}}$ & $\Pi_{\mathrm{E}}$ & & & $\lambda_{\mathrm{P}}$ & Comments \\
\hline & CRYSIAL, 12MHZ & 1 & 12 & 0.0230 & 2.1 & 0.5 & & 0.024174 & Hermetic commercial \\
& CRYSTAL, 30 MHZ & 1 & 30 & 0.0284 & 2.1 & 0.5 & & 0.029845 & Hermetic commercial \\
\hline
\end{tabular}

INDUCTORS
\begin{tabular}{|l|c|c|c|c|c|c|c|c|l|l|}
\hline Part No. & Description & No. & Value & $\lambda_{\mathrm{B}}$ & $\Pi_{\mathrm{C}}$ & $\Pi_{\mathrm{Q}}$ & $\Pi_{\mathrm{E}}$ & & $\lambda_{\mathrm{P}}$ & Comments \\
\hline & BEAD, FERRITE & 2 & Ferrite & 0.00039 & 1.0 & 20.0 & 0.5 & & 0.007800 & Commercial, Quality factor $=20$ \\
& TRANSPORMER, PUISE & 1 & & 0.00240 & $\mathrm{n} / \mathrm{a}$ & 5.0 & 0.5 & & 0.006000 & Commercial, Quality factor $=5$ \\
& INDUCTOR & 6 & $10,100 \mu \mathrm{H}$ & 0.00037 & 1.0 & 0.03 & 0.5 & 0.000033 & Mil part \\
\hline
\end{tabular}

\section{CONNECTORS}

\begin{tabular}{|c|c|c|c|c|c|c|c|c|c|}
\hline Part No. & Description & No. & Pins & $\lambda_{\mathrm{B}}$ & $\Pi_{\mathrm{K}}$ & $\Pi_{Q}$ & $\Pi_{E}$ & $\lambda_{\mathrm{P}}$ & Comments \\
\hline & $\begin{array}{l}\text { CONNECTOR, SIPIN, } \\
\text { MICRO MINIATURE }\end{array}$ & 2 & 51 & $\overline{0.00017}$ & 1.0 & 9.72 & 0.5 & 0.001653 & Screened commercial part \\
\hline & $\begin{array}{l}\text { CONNECTOR 15 PIN, } \\
\text { MICRO MINIATURE, }\end{array}$ & 3 & 15 & 0.00017 & 1.0 & 3.28 & 0.5 & 0.000836 & Screened commercial part \\
\hline & $\begin{array}{l}\text { CONNECTOR, PIN, MICRO } \\
\text { MINIATURE }\end{array}$ & 1 & 9 & 0.00017 & 1.0 & 2.44 & 0.5 & 0.000207 & Screened commercial part \\
\hline
\end{tabular}

Table 6c. LIDAR System Controller Other Passive Components 


\subsection{Star Tracker Reliability Estimate}

When the estimated failure rates for the individual components comprising the Actel Camera board are added together the estimated failure rate per $10^{6}$ hours is as shown in table 7 below.

\begin{tabular}{|l|c|}
\hline Sub-System Board & Failures per 10 $0^{6}$ Hours \\
\hline Actel Camera Board & 4.34446 \\
\hline
\end{tabular}

Table 7. Actel Camera Estimated Failures per $10^{6}$ Hours

The equation used to convert estimated failures per $10^{6}$ hours to an estimated probability of success is as follows:

$$
\begin{aligned}
& \text { Estimated probability of success }=\exp \left(-\mathrm{T}_{\mathrm{m}} \lambda_{\mathrm{p}} / 10^{6}\right) \\
& \text { Where: } \\
& \mathrm{T}_{\mathrm{m}}=\text { Mission duration in hours } \\
& \lambda_{\mathrm{p}}=\text { Estimated failure rate per } 10^{6} \text { hours }
\end{aligned}
$$

Using this equation the estimated probability of success for a Star Tracker for a 7 month ( 5280 hour) mission is as shown in table 8.

\begin{tabular}{|c|c|}
\hline Duty Cycle & $\begin{array}{c}\text { Estimated } \\
\text { Probability of } \\
\text { Success }\end{array}$ \\
\hline $100 \%$ & 0.9773 \\
$30 \%$ & 0.9931 \\
\hline
\end{tabular}

Table 8. Actel Reliability Estimate

\subsection{UV / Visible Reliability Estimate}

The UV / Visible Camera is comprised of an Actel Camera board and a Filter Wheel board. When the estimated failure rates for the individual components comprising these boards are added together the estimated failure rate per $10^{6}$ hours is as shown in table 9 below. 


\begin{tabular}{|l|c|}
\hline Sub-System Board & Failures per 106 Hours \\
\hline Actel Camera & 4.34446 \\
Filter Wheel & 1.05414 \\
Total & 5.39860 \\
\hline
\end{tabular}

Table 9. UV/Vis Camera Estimated Failures per $10^{6}$ Hours

Using the equation given in section 3.3 above, the estimated probability of success for a UV / Visible camera for a 7 month ( 5280 hour) mission is as shown in table 10.

\begin{tabular}{|c|c|}
\hline Duty Cycle & $\begin{array}{c}\text { Estimated } \\
\text { Probability of } \\
\text { Success }\end{array}$ \\
\hline $100 \%$ & 0.9719 \\
$30 \%$ & 0.9915 \\
\hline
\end{tabular}

Table 10. UV/Vis Reliability Estimate

\subsection{LIDAR Reliability Estimate}

The LIDAR is comprised of an Actel Camera board and a Filter Wheel board, a Range Receiver board and a System Controller. When the estimated failure rates for the individual components comprising these boards are added together the estimated failure rate per $10^{6}$ hours is as shown in table 11 below.

\begin{tabular}{|l|c|}
\hline Sub-System Board & Failures per $\mathbf{1 0}^{\mathbf{6}}$ Hours \\
\hline Actel Camera & 4.34446 \\
Filter Wheel & 1.05414 \\
Range Receiver & 1.27361 \\
System Controller & 2.06601 \\
Total & 8.73822 \\
\hline
\end{tabular}

Table 11. LIDAR Estimated Failures per $10^{6}$ Hours 
Using the equation given in section 3.3 above, the estimated probability of success for the LIDAR for a 7 month ( 5280 hour) mission is as shown in table 12.

\begin{tabular}{|c|c|}
\hline Duty Cycle & $\begin{array}{c}\text { Estimated } \\
\text { Probability of } \\
\text { Success }\end{array}$ \\
\hline $100 \%$ & 0.9549 \\
$30 \%$ & 0.9862 \\
\hline
\end{tabular}

Table 12. LIDAR Reliability Estimate

\subsection{Summary}

The Clementine Sensor Suite sensors are assembled from a mix of commercial and MIL-SPEC components. All of the components used are subjected to a screening program, either MIL-STD-883 class B or a custom program. The estimated failure rates per $10^{6}$ hours for the Clementine Sensor Suite sensors, using MIL-HDBK-217F, has been calculated. This failure rate has been converted into a probability of success figure for each sensor. Those figures are given in table 13 below.

\begin{tabular}{|c|c|c|}
\hline Sensor & $\begin{array}{c}\text { Estimated } \\
\text { Probability of } \\
\text { Success, 100 \% } \\
\text { Duty Cycle }\end{array}$ & $\begin{array}{c}\text { Estimated } \\
\text { Probability of } \\
\text { Success, 30 \% } \\
\text { Duty Cycle }\end{array}$ \\
\hline Star Tracker & 0.9773 & 0.9931 \\
UV/Vis & 0.9719 & 0.9915 \\
LIDAR & 0.9549 & 0.9862 \\
\hline
\end{tabular}

Table 13. Sensor Reliability Estimates 
Appendix B

Configuration 


\section{Appendix B.1}

StarTracker Camera Document Tree

(C1-AAA92-106282 Tab 01) 


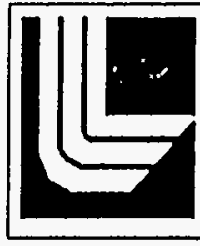

Clementine

Configuration Management

Document Tree \#: $\quad$ C1-AAA92-106282 TAB01

Title:

Star Tracker Camera Assy, V3.1

Next Higher Tree:

None

Serial Number:

File Name:

Software/Op. System: Excel 4.0/Macintosh

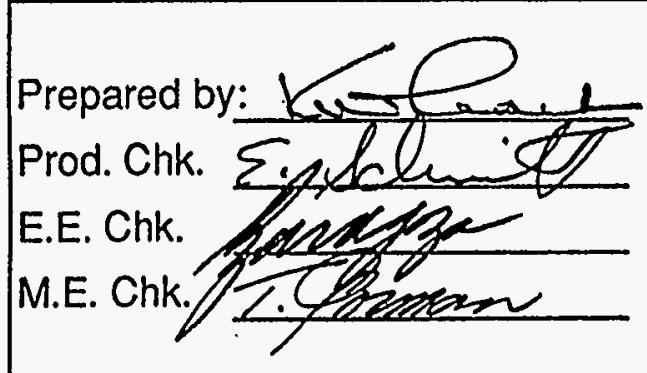

Date: $\quad 3 / 17 / 93$

Date: $4 / 2 / 93$

Date: $4-15-93$

Date:
E.E.Apvd. h L / indm Date: 4/22/23

M.E. Apvd. (1) woidain

Date: $4 / 2 / 53$

Q.A. Apred LAt Date: 3 May 93

Engr. Risd fofet $Q_{\text {: hist }}$ Date: $10 \mathrm{May} 93$

\begin{tabular}{|c||c|c|c|c|c|c|c|c|c|c|c|}
\hline \multicolumn{8}{|c|}{ REVISION HISTORY } & & & & \\
\hline Level & 00 & $O A$ & $O B$ & & & & & & & \\
\hline Date & 5.10 .93 & 5.28 .93 & 6.18 .93 & & & & & & & & \\
\hline & Kue & LuS & LSE & & & & & & &. & \\
\hline
\end{tabular}




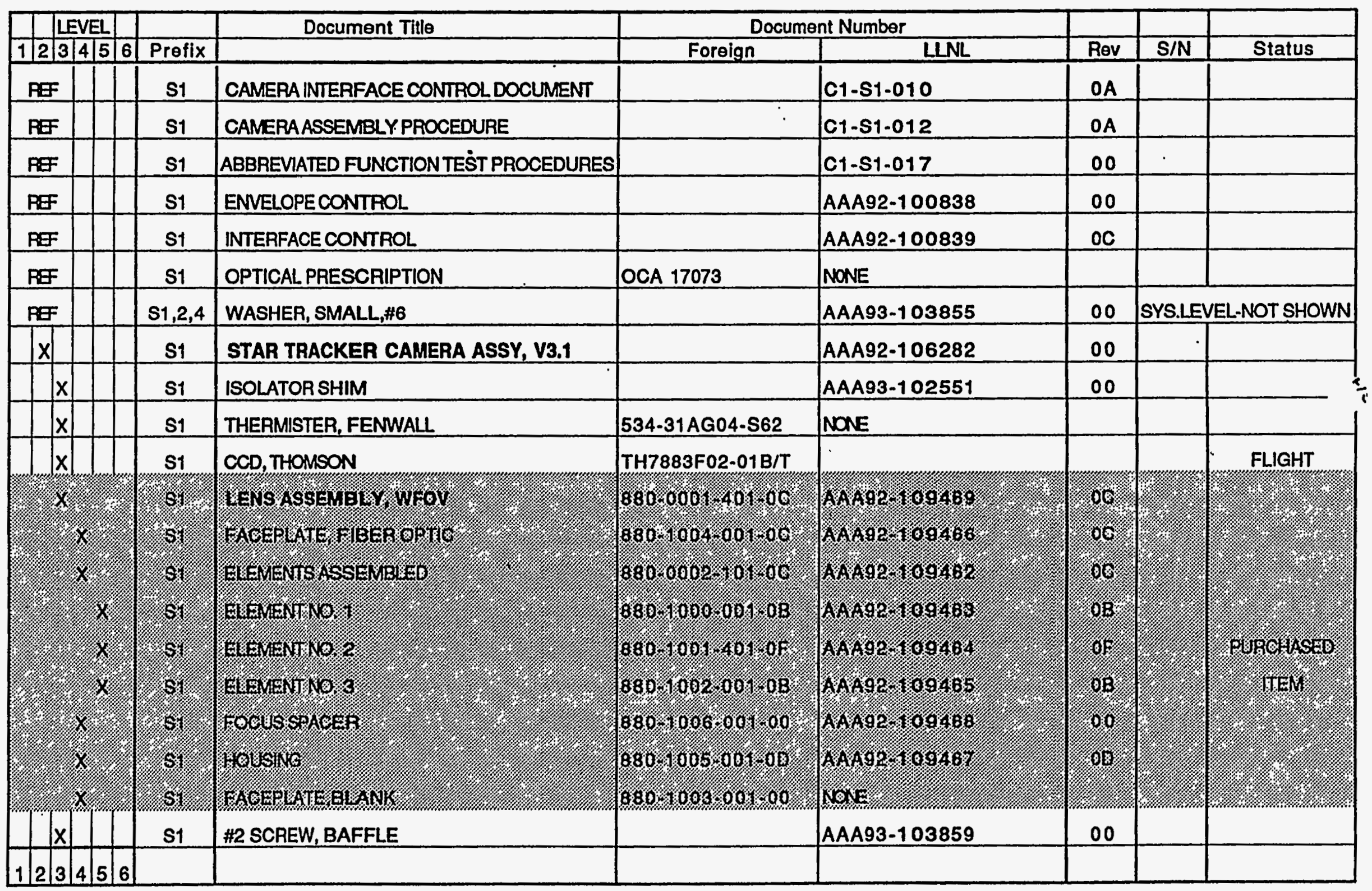




\begin{tabular}{|c|c|c|c|c|c|c|c|c|c|}
\hline & \multicolumn{2}{|c|}{ LEVEL } & & Document Title & \multicolumn{2}{|c|}{ Document Number } & & & \\
\hline 12 & $3 / 4$ & 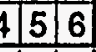 & Prefix & & Forelgn & LLNL & Rev & $S / N$ & Status \\
\hline & $x$ & & s1 & HEATER,LENS, MINCO & HK17402-9311 & NONE & & & \\
\hline & $x$ & & s1 & LENS STANDOFF & & AAA93-102550 & $O A$ & & \\
\hline & $x$ & & s1 & SWITCH, SUNDSTRAND & $974.0014-774$ & NONE & & & \\
\hline & $x$ & & s1 & CLAMP, LENS HEATEA & & AAA93-102221 & $O A$ & & \\
\hline & $x$ & & s1 & BAFFLE \| ASSY & & AAA93-103815 & 00 & & \\
\hline & $x$ & () & s1 & BASE, BAFFLE \| & & AAA93-103798 & 00 & & \\
\hline & $\underline{x}$ & 6 & s1 & COVER & & AAA93-102598 & 00 & & \\
\hline & $x$ & ? & s1 & VANE, BASE & & AAA93-103799 & 00 & & \\
\hline & $x$ & 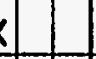 & s1 & VANENO.1 & $880.1021 .001 .0 \AA$ & AAA92.108747 & OA & & \\
\hline & $\mathrm{X}$ & 8 & s1 & VANENO. 2 & $880.1022 .001 .0 \mathrm{~A}$ & AAA92-108746 & OA & & \\
\hline & $x$ & 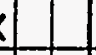 & s1 & VANE NO. 3 & $880-1023-001-0 \mathrm{~A}$ & AAA92-108745 & $O A$ & & \\
\hline & $x$ & 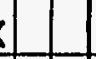 & s1 & VANENO. 4 & $880-1024-001-0 \mathrm{~A}$ & AAA92-108744 & OA & & \\
\hline & $x$ & & s1 & CAMERA ASSY & & AAA92-106277 & $\mathrm{OB}$ & & \\
\hline & $\underline{x}$ & 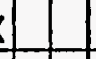 & S1 & CAMERA HOUSING & & AAA92-106258 & $O C$ & & \\
\hline & $\mathrm{x}$ & 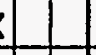 & s1 & BUSHING, JACKPOST, MDM CONN. & & AAA93-101167 TAB08 & 00 & & \\
\hline & $x$ & 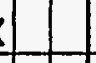 & s1 & CIRCUIT BOARD PAD & 800.3068 & AAA92-104621 & 00 & & \\
\hline & $x$ & 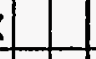 & s1 & ENDCOVER & & AAA92-106249 & OA & & \\
\hline & $x$ & & s1 & SHIM, LOWER, END COVER & & AAA93-102610 & 00 & & \\
\hline & $\mathrm{x}$ & 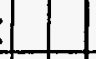 & s1 & SHIM, UPPER, END COVER & & AAA93-102609 & $\mathbf{O A}$ & & \\
\hline & $x$ & & s1 & CONNECTORBRACKET & & AAA92-106257 & OA & & \\
\hline & $\mathrm{x}$ & & s1 & PAD, CCD THERMAL & & AAA93-102243 & 00 & & \\
\hline 12 & \begin{tabular}{|l|l|}
3 & 4 \\
\end{tabular} & 56 & & & & & & & \\
\hline
\end{tabular}




\begin{tabular}{|c|c|c|c|c|c|c|c|c|c|}
\hline & LEVE & & & Document Title & Docu & nt Number & & & \\
\hline 12 & \begin{tabular}{|l|l|l|} 
& 415 \\
\end{tabular} & \begin{tabular}{|l|l|}
5 & 6 \\
\end{tabular} & Prefix & & Forolgn & UNL & Rev & $\mathbf{S} / \mathbf{N}$ & Status \\
\hline & $x$ & & s1 & THERMISTOR, FENWALI & 137-562-ZXT-DO2 & & & & \\
\hline & $\mathrm{x}$ & & s1 & ICD, CAMERA & & AAA92-104603 & OF & & \\
\hline & $x$ & & s1 & ST2A CAMERA ASSY, w. GAIN \& OFFSET CON & & LEA92-3128-03 & OA & . & \\
\hline & $|x|$ & & s1 & SCHEMATIC, CAMERA, ST2A & & LEA92-3128-01 & OC & & \\
\hline & & $x$ & s1 & ARTWORK & & LEA92-3128.02 & 00 & & \\
\hline & & $x \mid$ & s1 & BILL OF MATERIALS & & LEA92-3128-04 & $O D$ & & \\
\hline & & $x$ & s1 & SPACER (CONN. STANDOFF) & & AAA92-104616-TAB01 & OC & & \\
\hline & & $\mathbf{x}$ & s1 & MTG. HARDWARE & $800-3043$ & AAA92-104607-TAB01 & 00 & & \\
\hline & & $x$ & s1 & NUT, PCB RETAINER & & AAA92-109126 & $O A$ & & \\
\hline & & $x$ & s1 & ASSEMBLYPROCEDURE & & LEA92-3128-05 & OB & & \\
\hline & & $\mathrm{x}$ & s1 & TEST PROCEDURE & & LEA92-3128-06 & 00 & & \\
\hline & & $\mathrm{x}$ & s1 & FAB DRAWING & & LEA92-3128-07 & $O A$ & & \\
\hline & & $x$ & s1 & CAMERA ACTEL ARRAY-U26 (ADDRESS \#6) & & LEA92-3128-08 & 00 & & \\
\hline & & $x$ & s1 & DOUBLE CORRELATED SAMPLING & (FILE: DCS 1) & LEA92-3128-48 & 00 & & \\
\hline & & $x$ & s1 & CAMERA INTEGRATION TIMER & (FILE: INTI3BI1) & LEA92-3128-58 & 00 & & \\
\hline & & $x$ & s1 & FRAME ENABLE & (FILE:FRCOUNT) & LEA92-3128-68 & 00 & & \\
\hline & & $x$ & s1 & SASI RECEIVER & (FILE: SASIRCVO) & LEA92-3128-78 & 00 & & \\
\hline $1 / 2$ & $|3| 4 \mid t$ & 56 & & & & & & & \\
\hline
\end{tabular}




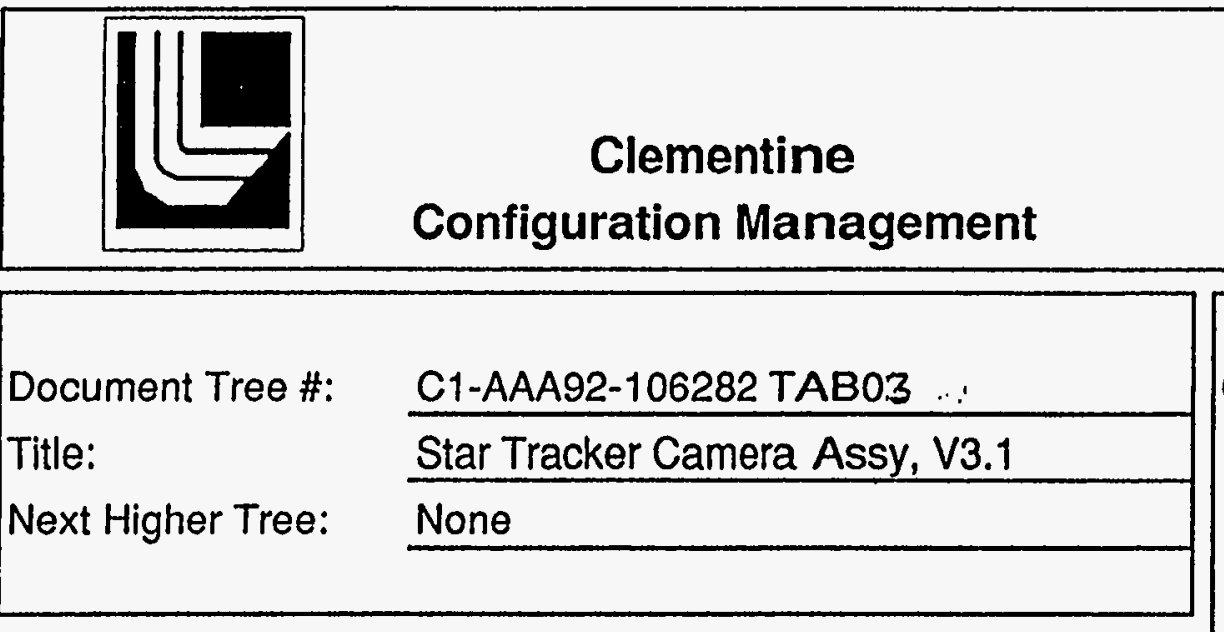

\section{Comments:}

Star Tracker Camera C1-AAA92-106282 Tab02 uses a ST2A Camera Board

Serial Number:

File Name:

Software/Op. System: Excel 4.0/Macintosh

\section{Star Tracker Camera}

-

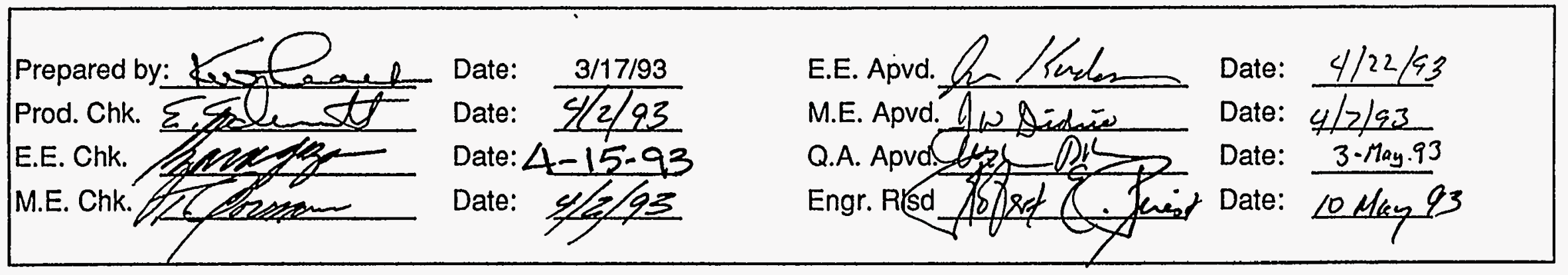

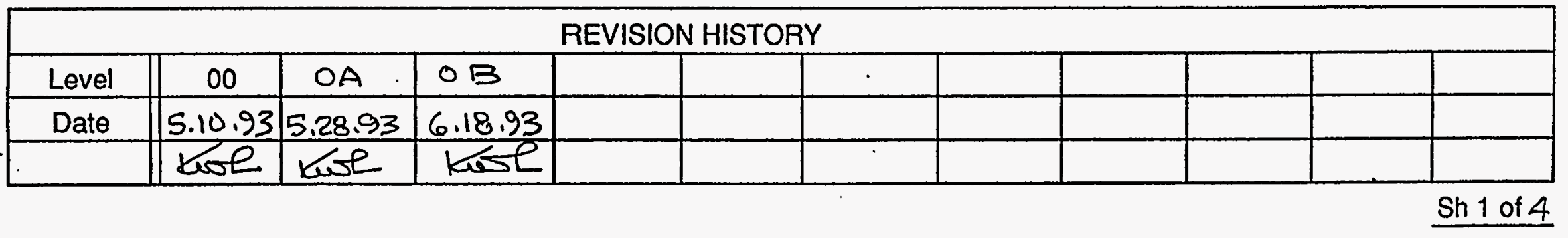



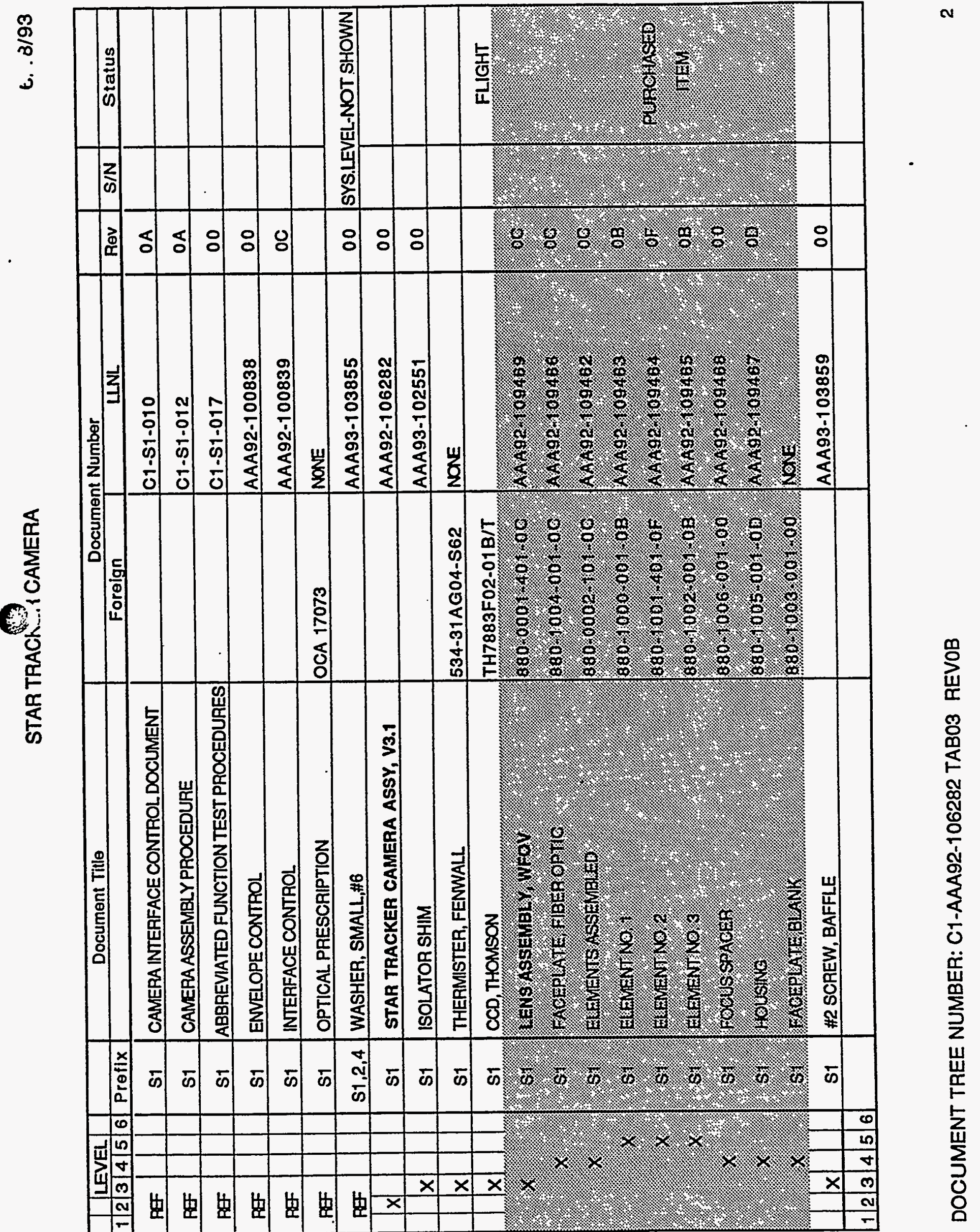


\begin{tabular}{|c|c|c|c|c|c|c|c|c|c|}
\hline & \multicolumn{2}{|c|}{ LEVEL } & & \multirow[t]{2}{*}{ Document Title } & \multicolumn{2}{|c|}{ Document Number } & & & \\
\hline 12 & \begin{tabular}{|l|l|}
3 & 4 \\
\end{tabular} & 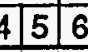 & Prefix & & Foreign & LNL & Rev & $\mathrm{S} / \mathrm{N}$ & Status \\
\hline & $\mathrm{x}$ & & s1 & HEATER,LENS, MINCO & HK17402-9311 & NONE & & & \\
\hline & $x$ & & S1 & LENS STANDOFF & & AAA93-102550 & $O A$ & & \\
\hline & $x$ & & s1 & SWITCH, SUNDSTRAND & $974-0014-774$ & NONE & & & \\
\hline & $x$ & & s1 & CLAMP, LENS HEATER & & AAA93-102221 & $O A$ & & \\
\hline & $x$ & & s1 & BAFFLE \| ASSY & & AAA93-103815 & 00 & & \\
\hline & $x$ & 女) & S1 & BASE, BAFFLE ॥ & & AAA93-103798 & 00 & & \\
\hline & $x$ & 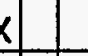 & s1 & COVER & & AAA93-102598 & 00 & & \\
\hline & $x$ & $x$ & s1 & VANE, BASE & & AAA93-103799 & 00 & & \\
\hline & $x$ & $x$ & s1 & VANE NO. 1 & $880.1021-001.0 \mathrm{~A}$ & AAA92-108747 & $O A$ & & \\
\hline & $x$ & $x$ & s1 & VANE NO. 2 & $880-1022-001-0 \mathrm{~A}$ & AAA92-108746 & OA & & \\
\hline & $x$ & 女 & s1 & VANE NO. 3 & $880-1023-001-0 A$ & AAA92-108745 & $O A$ & & \\
\hline & $x$ & 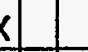 & s1 & VANENO. 4 & $880-1024-001.0 \mathrm{~A}$ & AAA92-108744 & $O A$ & & \\
\hline & $x$ & & s1 & CAMERA ASSY & & AAA92-106277 & $\mathrm{OB}$ & & \\
\hline & $x$ & $\underline{\underline{x}}$ & s1 & CAMERA HOUSING & & AAA92-106258 & OC & & \\
\hline & $x$ & 女 & s1 & BUSHING, JACKPOST, MDM CONN. & & AAA93-101167 TAB08 & 00 & - & \\
\hline & $x$ & < & S1 & CIRCUIT BOARD PAD & $800-3068$ & AAA92-104621 & 00 & & \\
\hline & $x$ & ( & s1 & END COVER & & AAA92-106249 & OA & - & \\
\hline & $x$ & 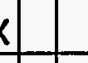 & s1 & SHIM, LOWER, END COVER & & AAA93-102610 & 00 & & \\
\hline & $x$ & < & s1 & SHIM, UPPER, END COVER & & AAA93-102609 & $\mathrm{OA}$ & & \\
\hline & $x$ & 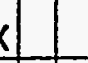 & s1 & CONNECTORBRACKET & & AAA92-106257 & $O A$ & & \\
\hline & $x$ & 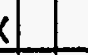 & s1 & PAD, CCD THERMAL & & AAA93-102243 & 00 & & \\
\hline 12 & 34 & 45 & & & & & & & \\
\hline
\end{tabular}




\begin{tabular}{|c|c|c|c|c|c|c|c|c|c|}
\hline & LEVE & ELL & & Document Title & Docu & nt Number & & & \\
\hline $1 \sqrt{2}$ & $2 \longdiv { 3 } 4$ & $75 \sqrt{6}$ & Prefix & & Foreign & LLNL & Rev & S/N & Status \\
\hline & $x$ & & S1 & THERMISTOR, FENWAL & 137-562-ZXT-DO2 & & & & \\
\hline & $x$ & $x$ & s1 & ICD, CAMERA & & AAA92-104603 & OF & & \\
\hline & $x$ & & s1 & ST2A CAMERA ASSY, w. GAIN \& OFFSET CON & & LEA92-3128.03 & OA & 1 & \\
\hline & $x$ & 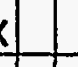 & s1 & SCHEMATIC, CAMERA, ST2A & & LEA92-3128-11 & OC & & \\
\hline & & $x$ & s1 & ARTWORK & & LEA92-3128-02 & 00 & & \\
\hline & & $x$ & s1 & BILL OF MATERIALS & & LEA92-3128-14 & OD & & \\
\hline & & $y$ & s1 & SPACER (CONN. STANDOFF) & & AAA92-104616-TAB01 & OC & & - \\
\hline & & 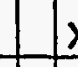 & S1 & MTG. HARDWARE & $800-3043$ & AAA92-104607-TAB01 & 00 & & \\
\hline & & $x$ & s1 & NUT, PCB RETAINER & & AAA92-109126 & OA & & \\
\hline & & $x$ & s1 & ASSEMBLYY PROCEDURE & & LEA92-3128-05 & OB & & \\
\hline & & $x$ & s1 & TESTPROCEDURE & & LEA92-3128-16 & 00 & & \\
\hline & & $x$ & s1 & FAB DRAWING & & LEA92-3128-07 & OA & $\therefore$ & \\
\hline & & $x$ & S1 & CAMERA ACTEL ARRAY-U26 (ADDRESS \#6) & & LEA92-3128-18 & 00 & & \\
\hline & & $x$ & s1 & DOUBLE CORRELATED SAMPLING & (FILE: DCS_1) & LEA92-3128-48 & 00 & & \\
\hline & & $x$ & s1 & CAMERA INTEGRATION TIMER & (FILE: INTI3BI1) & LEA92-3128-58 & 00 & & \\
\hline & & $x$ & s1 & FRAME ENABLE & (FILE: FRCOUNT) & LEA92-3128-68 & 00 & & \\
\hline & & $x$ & s1 & SASI RECEIVER & (FILE: SASIRCVO) & LEA92-3128-78 & 00 & & \\
\hline 112 & 2034 & 456 & & & & & & & \\
\hline
\end{tabular}




\section{Appendix C \\ Optical System}




\section{Appendix C.1 \\ Clementine WFOV StarTracker Lens Specification (C1-S1-002)}




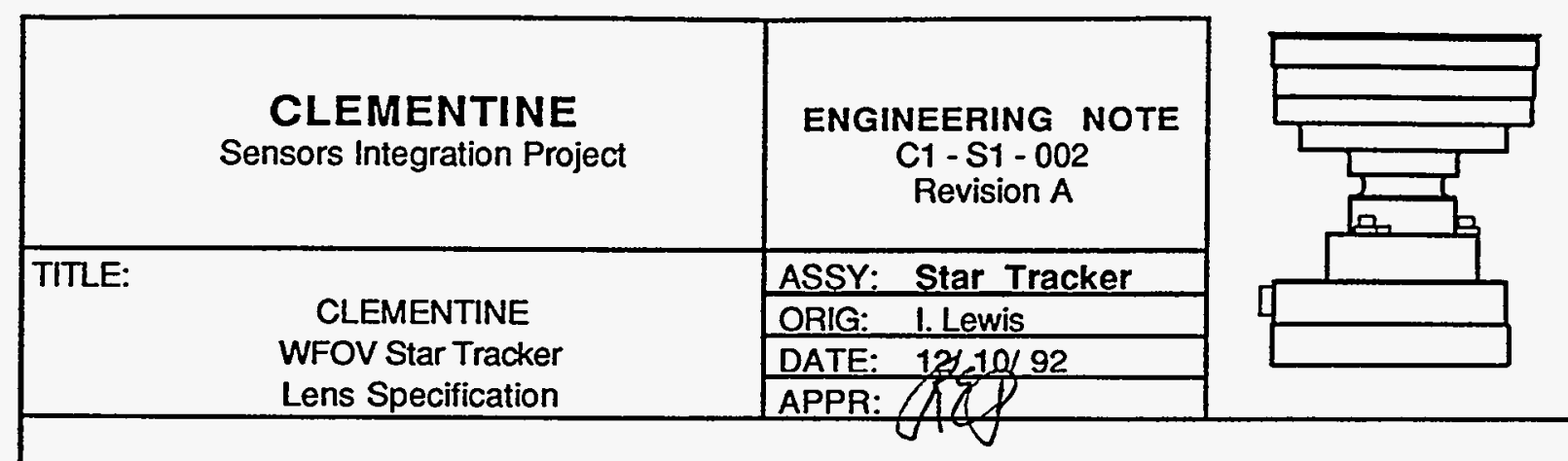

This document is the Revision OA level of the optical lens assembly performance specification for the WFOV Star Tracker lens. Parameters specified must be met in an as-manufactured assembly and over all specified environmental conditions.

Changes from the Revision 00 specification are significant, and as such are not summarized in a change sheet. 


\section{CLEMENTINE}

WFOV Star Tracker

Lens Specification

\begin{tabular}{|c|c|c|c|c|}
\hline & Date & Rev. & Date & Approval \\
\hline Prepared by: I. T. Lewis & $12 / 10 / 92$ & A & 1299 & Ptemi \\
\hline \multicolumn{5}{|l|}{ Prepared by: $\quad$ R. E. Priest } \\
\hline \multicolumn{5}{|l|}{ Reviewed by: A. G. Ledebuhr } \\
\hline \multicolumn{5}{|l|}{ Reviewed by: M. J. Shannon } \\
\hline \multicolumn{5}{|l|}{ Approved by: L. D. Pleasance } \\
\hline $\begin{array}{l}\text { University of California } \\
\text { Lawrence Livermore } \\
\text { National Laboratory }\end{array}$ & $\begin{array}{r}\text { CLEMENT } \\
\text { WFOV Star Trac } \\
\text { Specificati }\end{array}$ & $\begin{array}{l}\text { E } \\
\text { Lens } \\
\text { Lens }\end{array}$ & & ion: A \\
\hline
\end{tabular}




\section{Introduction}

This document describes the optical performance parameters required for the Clementine project Star Tracker Camera lens. Parameters must be met in an as-manufactured assembly. Design and manufacturing tolerances can be budgeted as desired to achieve the required end performance. A suggested design drawing package is included in the appendix of this specification which can be manufactured to meet the requirements of this specification.

The Star Tracker lens assembly will be a $17.5 \mathrm{~mm}$ calibrated focal length concentric lens with a $14.0 \mathrm{~mm}$ entrance pupil diameter. The lens will be used to take images of stars. The images are then processed to determine the quaternoin of the star tracker and thus of the spacecraft. The camera will have a CCD focal plane and will be used to take images in the 0.4 to $1.0 \mu \mathrm{m}$ spectral range.

The performance parameters given in this specification and their paragraph numbers are:

Parameter

Paragraph Number

Optical Parameters

EPD

1.1

QFL

1.2

Spectral Band

1.3

Format

1.4

Image Quality

1.5

Transmission

1.6

Distortion

1.7

Physical Parameters

Mass

2.1

Envelope

2.2

Alignment

2.3

Mechanical Interface Control

2.4

\begin{tabular}{|l|c}
\hline $\begin{array}{c}\text { University of California } \\
\text { Lawrence Livermore } \\
\text { National Laboratory }\end{array}$ & $\begin{array}{c}\text { CLEMENTINE } \\
\text { WFOV Star Tracker Lens } \\
\text { Specifications }\end{array}$ \\
\hline
\end{tabular}

Revision: A

Page: 2 
Environmental Requirements

Operating Ambient Media

Operating Ambient Temperature

3.2

Storage Ambient Temperature

3.3

Storage Ambient Humidity

3.4

Ambient Pressure Profile

3.5

Outgassing

Quasi-Static Acceleration Loads

Random Vibration

3.8

Shock Spectrum

3.9

Thermal Cycles

3.10

Radiation Requirements

3.11

Storage Lifetime

3.12

Operating Lifetime

3.13

Environmental Test Order

3.14

Cleanliness

3.15

Verification and Test Matrix

4.0

Applicable Documents

5.0
CLEMENTINE WFOV Star Tracker Lens Specifications

Revision: A

Page: 3 


\section{Optical Parameters}

\subsection{Entrance Pupil Diameter}

The entrance pupil diameter of the lens shall be $\geq 14.0 \mathrm{~mm}$.

\subsection{Calibrated Focal Length}

The best fit focal length parameter, $f$, shall be $17.5 \pm 0.3 \mathrm{~mm}$. Focal length $(f)$ to be determined by curve fitting 9 points evenly spaced across the lens full diagonal to an $f \cdot$ sine $(\theta)$ curve.

\subsection{Spectral Band}

The spectral band of the lens shall be 0.4 to $1.0 \mu \mathrm{m}$.

\subsection{Format}

All optical specifications must be met over a $8.8 \times 13.2 \mathrm{~mm}$ image format.

\subsection{Image Quality}

Greater than $80 \%$ of the energy imaged through the lens shall be contained within a $75 \times 75$ $\mu \mathrm{m}$ square centered on the image located at the rear of the fiber optic faceplate (FOFP). In this centration and location, the central $25 \mu \mathrm{m} \times 25 \mu \mathrm{m}$ square shall contain between $20 \%$ and $40 \%$ of the total energy in the image. Object distance is infinity. Testing to be performed on-axis only, in air, with focus set for best performance in air.

\subsection{Transmission}

Transmission of the lens must be greater than the values listed at the following wavelengths:

$0.4 \mu \mathrm{m}: 0 \% ; 0.5 \mu \mathrm{m}: 39 \% ; 0.6 \mu \mathrm{m}: 54 \% ; 0.8 \mu \mathrm{m}: 56 \% ; 1.0 \mu \mathrm{m}: 57 \%$

Transmission values include the concentric lens and the FOFP. Transmission requirements are on-axis only.

CLEMENTINE WFOV Star Tracker Lens Specifications
Revision: A

Page: 4 


\subsection{Distortion}

The deviation from an $f \cdot \sin (\theta)$ mapping using best fit $f$ and $\theta$ centroid pixels for the lens and FOFP shall vary by less than $20 \mu \mathrm{m}$ difference between any 2 points located $0.6 \mathrm{~mm}$ apart at the FPA. Points shall be sampled on a $2^{\circ}$ grid spacing through the entire focal plane. Testing will be provided by LLNL.

\section{$1.8 \quad$ MTF}

The MTF shall be measured as part of the acceptance test procedure on-axis only. MTF shall be measured with a point source color spectrum within $20 \%$ relative intensity of a G0 star (or a $5900 \mathrm{~K}$ blackbody) over the 0.4 to $1.0 \mu \mathrm{m}$ spectral range. MTF shall be reported as a function of frequency at the single focal plane defined by the location of the fiber optic faceplate. MTF is required on-axis only.

\section{Physical Parameters}

\section{$2.1 \quad$ Mass}

The lens assembly shall mass less than $48 \mathrm{~g}$.

\subsection{Envelope}

The lens assembly, exclusive of mounting tabs or flanges, shall fit within a 1.1 inch diameter by 1.4 inch long cylinder or equivalent volume.

\subsection{Alignment}

Light entering the lens perpendicular to the mounting surface plane shall be imaged within $150 \mu \mathrm{m}$ true position of the center of the pilot diameter.

\subsection{Mechanical Interface Control}

Mechanical interface control shall be per AAA92-100839-00.

\section{Environmental Requirements}

The lens is required to perform within specifications during test and calibration on the ground, survive through environmental acceptance test procedures (ATP), through the actual launch environment, and finally for the duration of the mission. The camera is not operated during launch. No G load specifications are in force during operation.

\begin{tabular}{|l|c|c|}
\hline $\begin{array}{l}\text { University of California } \\
\text { Lawrence Livermore } \\
\text { National Laboratory }\end{array}$ & $\begin{array}{c}\text { CLEMENTINE } \\
\text { WFOV Star Tracker Lens } \\
\text { Specifications }\end{array}$ & $\begin{array}{c}\text { Revision: A } \\
\text { Page: 5 }\end{array}$ \\
\hline
\end{tabular}




\subsection{Operating Ambient Media}

The lens will be operated in air (ground testing) and in space. Testing may be performed in air, with data supplied on vacuum focal shift.

\subsection{Operating Ambient Temperature}

The ambient operating temperature range shall be $-20^{\circ} \mathrm{C}$ to $40^{\circ} \mathrm{C}$.

\subsection{Storage Ambient Temperature}

The ambient storage temperature range shall be $-30^{\circ} \mathrm{C}$ to $70^{\circ} \mathrm{C}$.

\subsection{Storage Ambient Humidity}

The ambient storage humidity shall be 0 to $95 \%$ relative humidity. (Noncondensing.)

\subsection{Ambient Pressure Profile}

The lens assembly shall not be damaged by a rapid depressurization. Maximum depressurization rate is $0.8 \mathrm{psi} / \mathrm{sec}$. Vacuum testing levels shall be $\leq 10^{-5}$ torr to demonstrate environmental compatibility.

\subsection{Outgassing}

All materials used in the assembly shall exhibit less than $1 \%$ total material loss and less than $0.1 \%$ collected volatile condensible material per ASTM-E-595-77/84. Material data may be taken from NTIS N91-14437, NASA report RP 1124 Revision 2, November 1990, "Outgassing data for selecting spacecraft materials".

\subsection{Quasi-Static Acceleration Loads}

The unit shall be designed to survive $\pm 15 \mathrm{G}$ loading in the three principal axes. Testing to these loads is not required.

\subsection{Random Vibration}

The unit shall survive $14.0 \mathrm{~g}$ rms random vibration per figure 2 . 


\subsection{Shock Spectrum}

The unit shall withstand a $294 \mathrm{~g}$ 3- $\sigma$ peak-to-peak acceleration. This time series acceleration is consistent with the shock spectrum per figure 3 , attenuated through at least 1 additional interface from the LLNL sensor attachment interface to the spacecraft to the lens assembly attachment point. Testing is not required for the shock spectrum compliance.

\subsection{Thermal Cycles}

The unit shall withstand thermal cycling from $-30^{\circ} \mathrm{C}$ to $+70^{\circ} \mathrm{C}$ at $\leq 3^{\circ} \mathrm{C} / \mathrm{min}$ over 6 cycles. Testing to begin at room temperature, drop at the specified rate to $-30^{\circ} \mathrm{C}$, dwell for 2 hours, then rise to $+70^{\circ} \mathrm{C}$, dwell for 2 hours, then repeat, returning to room temperature. All other test unit and flight unit tests to be performed after thermal cycling.

\subsection{Radiation Requirements}

The unit shall meet all performance specifications after a total dose of 20 kilorads (Si). Analysis to be provided by LLNL.

\subsection{Storage Lifetime}

The storage lifetime of the unit shall be 5 years.

\subsection{Operating Lifetime}

The operating lifetime shall be 2 years on the ground. The mission mean design life is 1 year.

\subsection{Environmental Test Order}

Performance testing of all optical parameters shall be at room temperature and pressure only. Optical parameters to be tested either before or after section tests. Image quality (II $1.5)$ to be tested both before and after section 3 tests. Image quality tests after section 3 tests will be performed by LLNL on the deliverable items for which LLNL is responsible for section 3 testing.

\subsection{Cleanliness}

Optical assemblies must be delivered with all internal surfaces meeting a 300 particulate standard and all internal and external surfaces meeting a Level $\mathrm{C}$ molecular standard per MIL-STD-1246. External surfaces shall meet a 750 particulate standard, cleanable to a 300

\begin{tabular}{|l|c|c|}
\hline $\begin{array}{l}\text { University of California } \\
\text { Lawrence Livermore } \\
\text { National Laboratory }\end{array}$ & $\begin{array}{c}\text { CLEMENTINE } \\
\text { WFOV Star Tracker Lens } \\
\text { Specifications }\end{array}$ & $\begin{array}{c}\text { Revision: A } \\
\text { Page: } 7\end{array}$ \\
\hline
\end{tabular}


standard. Cleanliness verification shall be per analysis and no witness samples or inspection are required.

Figure 1 Deleted.

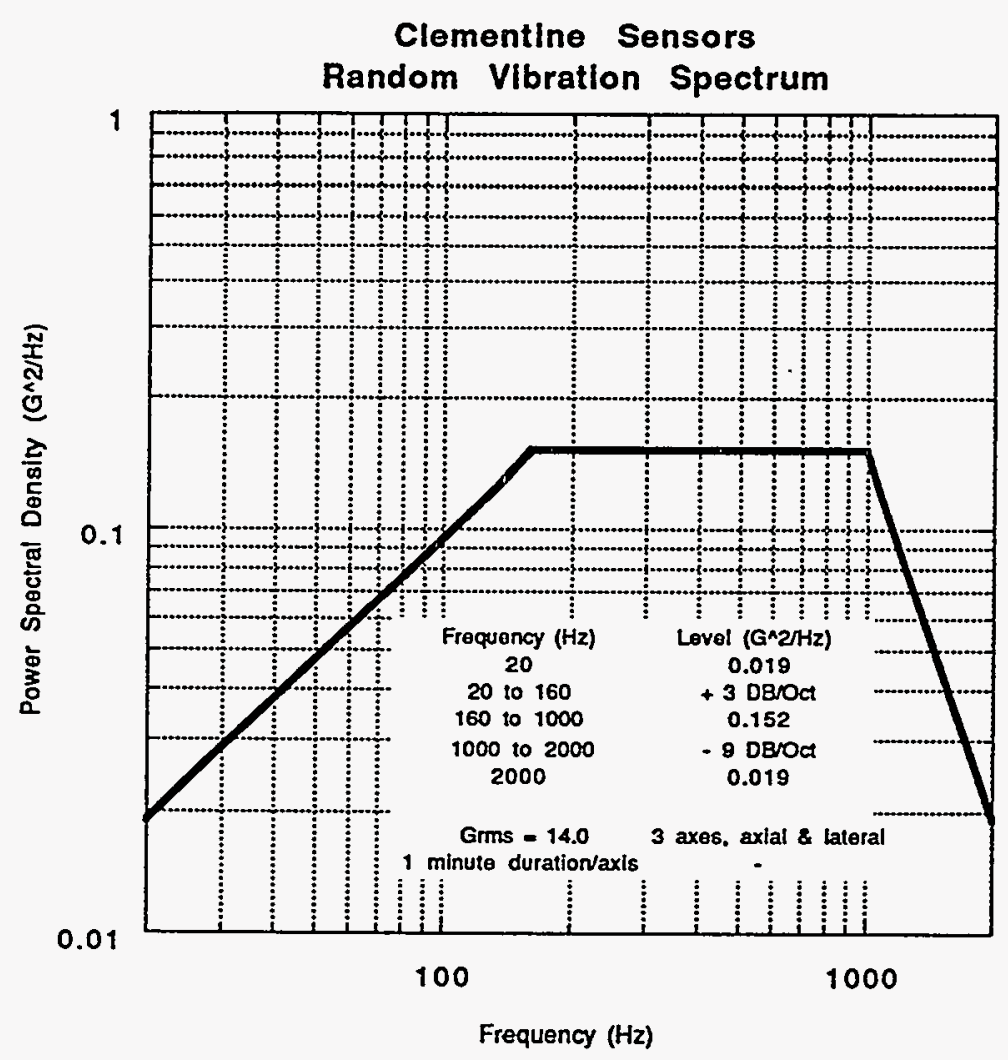

Figure 2 - CLEMENTINE Random Vibration Spectrum Component Test Level Specification

\begin{tabular}{|l|c|c|}
\hline $\begin{array}{l}\text { University of California } \\
\text { Lawrence Livermore } \\
\text { National Laboratory }\end{array}$ & $\begin{array}{c}\text { CLEMENTINE } \\
\text { WFOV Star Tracker Lens } \\
\text { Specifications }\end{array}$ & $\begin{array}{c}\text { Revision: A } \\
\text { Page: } 8\end{array}$ \\
\hline
\end{tabular}




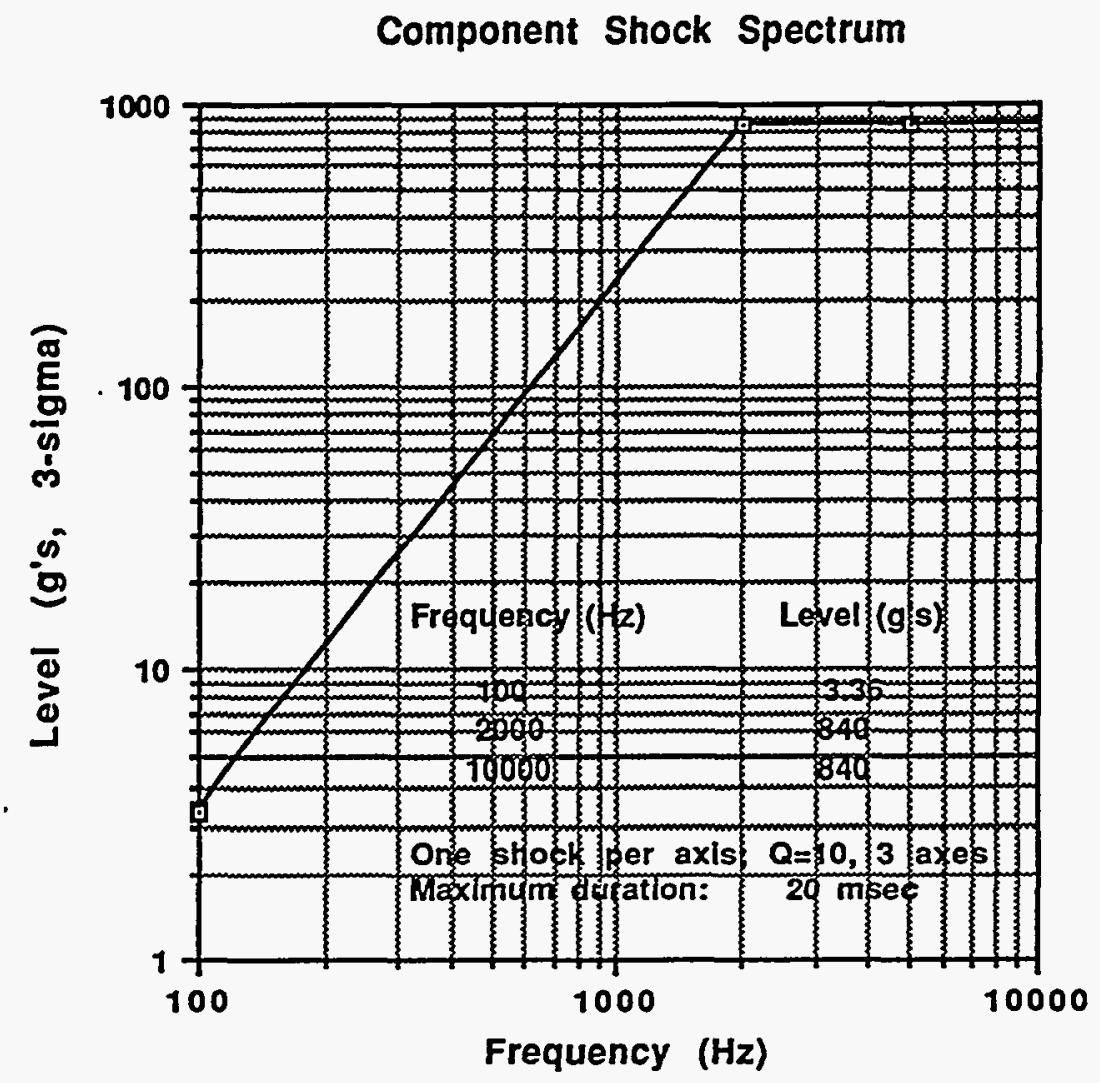

Figure 3 - CLEMENTINE Shock Spectrum Component Test Level Specification

\subsection{Verification and Test Matrix}

Table 1 describes the test requirements for the specification paragraphs within this document. The verification methods to be used are: 1) test, 2) analysis, 3) inspection. When 2 boxes are checked in table 1, both methods shall be enforced. $A$ " 1 " in the box indicates that the parameter must be verified for the test unit acceptance test. $A$ " $P$ " in the box signifies that the parameter must be verified on each prototype unit. An " $F$ " indicates that the item must be verified (or measured) for the flight units.

CLEMENTINE WFOV Star Tracker Lens Specifications
Revision: A

Page: 9 
Table 1 Verification Matrix

\begin{tabular}{|l|l|l|l|l|}
\hline Section & Requirement & Test & Analysis & Inspection \\
\hline 1.1 & Entrance Pupil Diameter & $1, \mathrm{P}, \mathrm{F}$ & & \\
\hline 1.2 & Calibrated Focal Length & $1, \mathrm{P}, \mathrm{F}$ & & \\
\hline 1.3 & Spectral Band & N/A & & \\
\hline 1.5 & Format & N/A & & \\
\hline 1.6 & Transmission & $1, \mathrm{P}, \mathrm{F}$ & & \\
\hline 1.7 & Distortion & $1, \mathrm{P}, \mathrm{F}$ & & \\
\hline 1.8 & MTF & $11, \mathrm{P}^{1}, \mathrm{~F} 1$ & & \\
\hline 2.1 & Mass & $1, \mathrm{P}, \mathrm{F}$ & & \\
\hline 2.2 & Envelope & & & $1, \mathrm{P}, \mathrm{F}$ \\
\hline 2.3 & Alignment & & & $1, \mathrm{P}, \mathrm{F}$ \\
\hline 2.4 & Mechanical Interface Control & & & $1, \mathrm{P}, \mathrm{F}$ \\
\hline 3.1 & Operating Ambient Media & & 1 & \\
\hline 3.2 & Operating Ambient Temperature & & 1 & \\
\hline 3.3 & Storage Ambient Temperature & $1, \mathrm{P}^{1}, \mathrm{~F}^{1}$ & & \\
\hline 3.4 & Storage Ambient Humidity & & 1 & \\
\hline 3.5 & Ambient Pressure Profile & $1, \mathrm{P}^{1}, \mathrm{~F}^{1}$ & & \\
\hline 3.6 & Outgassing & & 1 & \\
\hline 3.7 & Quasi-Static Acceleration Loads & & 1 & \\
\hline 3.8 & Random Vibration & $1, \mathrm{P}^{1}, \mathrm{~F}^{1}$ & 1 & \\
\hline 3.9 & Shock Spectrum & & 1 & \\
\hline 3.10 & Thermal Cycles & $1, \mathrm{P}^{1}, \mathrm{~F}^{1}$ & & \\
\hline 3.11 & Radiation Requirements & & 11 & \\
\hline 3.12 & Storage Lifetime & & 1 & \\
\hline 3.13 & Operating Lifetime & & & \\
\hline 3.14 & Environmental Test Order & & & \\
\hline 3.15 & Cleanliness & & $1, \mathrm{P}, \mathrm{F}$ \\
\hline
\end{tabular}

1 Testing to be performed by LLNL.

2 This test is encompassed by the thermal cycle testing in $\$ 3.10$.

\begin{tabular}{|l|c|c|}
\hline $\begin{array}{l}\text { University of California } \\
\text { Lawrence Livermore } \\
\text { National Laboratory }\end{array}$ & $\begin{array}{c}\text { CLEMENTINE } \\
\text { WFOV Star Tracker Lens } \\
\text { Specifications }\end{array}$ & Revision: A \\
\hline
\end{tabular}




\subsection{Applicable Documents}

The following documents are applicable when appropriate to deliverable hardware:

MIL O 13830A

MIL M 13508

MIL F 48616

Min C 48497

MIL C 675

MIL-STD-1246
Optical components for fire control instruments; general specification governing the manufacturing, assembly, and inspection of

Mirror, front surface aluminized for optical elements Filter (coating), Infrared interference: general specification 4 'Coatings, single or multi-layer, interference: durability requirements 4

Coating of glass optical elements: anti-reflection Product cleanliness levels and contamination control program 
Appendix D

Electronic System 


\section{Appendix D.1 \\ Actel Camera Array Test Procedure (C1-EE-034)}




\section{Actel Camera Array Test Procedure}

C1-EE-034

\begin{tabular}{|c|c|c|c|c|}
\hline & Date & Rev. & Date & Approval \\
\hline Prepared by: Darron Nielsen & $5 / 3 / 43$ & & & \\
\hline Reviewed by: J.F. Kordas & $5 / 3 / 93$ & & & \\
\hline Reviewed by: W.R. Bryson & $5 / 3 / 93$ & & & \\
\hline Reviewed by: E.H. Schinfitt & $3-m b y-93$ & & & \\
\hline Approved by: M.s Sighan & $5 / 3 / 93$ & & & \\
\hline
\end{tabular}

\begin{tabular}{|l|c|c|}
\hline $\begin{array}{l}\text { University of California } \\
\text { Lawrence Livermore } \\
\text { National Laboratory }\end{array}$ & $\begin{array}{c}\text { 29-April-93 } \\
\text { Actel Camera Array Test } \\
\text { Procedure } \\
\text { C1-EE-034 }\end{array}$ & Revision 00 \\
\hline
\end{tabular}




\section{TABLE OF CONTENTS}

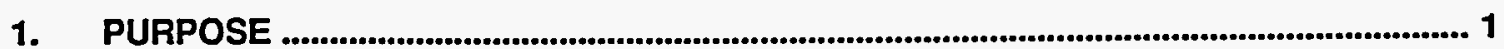

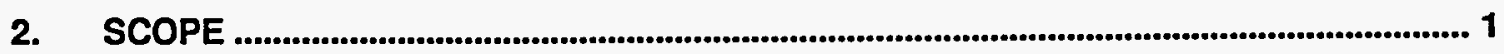

3. REQUIRED DOCUMENTS AND TEST EQUIPMENT ................................................... 1

3.1 Required Documents ...................................................................................... 1

3.2 Required Test Equipment ................................................................................... 1

3.3 Conditions and Requirements .................................................................. 2

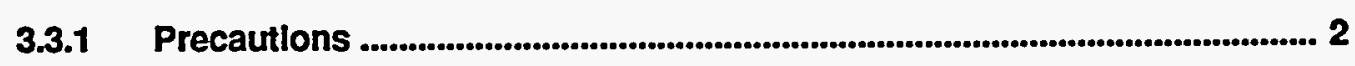

Cleanliness and Environment ..................................................................... 2

3.5 Quality Assurance (QA) Provisions ..................................................................... 3

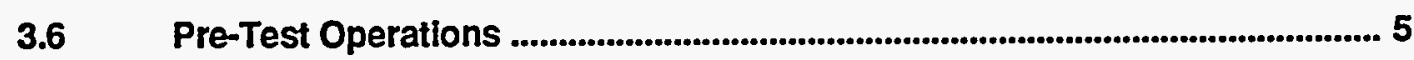

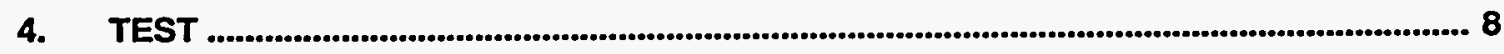




\section{Purpose}

1.1 This document is the chip level test procedure for the Actel Camera Arrays. You will need to know how the Actel Camera Array test board and software work.

2. Scope.

- This document describes equipment and procedures required to verify the electrical performance of Actel Camera Arrays

- All tests in this procedure are to be performed before Testing any arrays in the Actel Camera Array test board.

3. Required Documents and Test Equipment.

3.1 Required Documents

- Actel Camera Array Test Board Certification C1-EE-033

- Schematic of Camera [Actel] tester

\subsection{Required Test Equipment}

- Macintosh with LabView and NB-DIO-32F, GPIB, NB-MIO-16

- Tektronix 540, Digital Oscilloscope, HP plotter

- HP8116A pulse/function Generator

- $\quad$ Fluke 77 or 87 Multimeter

- Lambda Dual Regulated power supply 


\subsection{Conditions and Requirements}

\subsubsection{Precautions}

(1) Responsibility for Safety. All personnel are responsible for maintaining a safe work environment. The Test Conductor or cognizant operator shall assure that appropriate safe practices are implemented during these operations, and that operations are performed in a proper order.

(2) ESDS Equipment. The test specimen contains electrostaticsensitive devices which are exposed at the electrical interfaces. Therefore, it shall be handled per MIL-STD-1686 Class 1. The test specimen, the test operator (using wrist straps), and related electrical test equipment shall be connected to a common ground before any electrical mating or de-mating operations, and during the use of any electrical test equipment probes. There shall be no "hot-plugging" of the test specimen with any test equipment.

(3) Examine socket For Bad pins and Debris. Before installing any flight Actel arrays.

\subsection{Cleanliness and Environment}

(1) Standard laboratory conditions of atmospheric temperature, pressure, and humidity are acceptable for the testing defined herein.

(2) Normal housekeeping standards will be required. If appropriate, the unit may be cleaned prior to installation into the next assembly, or prior to return to storage. 


\subsection{Quality Assurance (QA) Provisions}

QA provisions operative during activities defined in this procedure shall be as specified in the project's QA Plan. This section identifies the interfaces between QA and test personnel. QA and test personnel are jointly responsible for the effectiveness of these interfaces in implementing the QA provisions.

(1) QA shall be notified, in advance, of performance of any activities described in this procedure. A QA Inspector may monitor those activities as is deemed necessary or appropriate, in accordance with the project QA Plan. The inspector shall verify that the proper revision of this procedure is used, and that the required Certification Log is in proper order. QA will then give the "OK to Test" prior to the start of test activities.

(2) The QA Inspector shall verify: that calibration is current for all measuring equipment used in these operations, and will not expire prior to completion of these operations; that applicable project-specific electrical-support test equipment (STE) has been properly certified and tagged; and that applicable lifting and handling STE has been properly proof tested and tagged.

(3) The QA Inspector may assist in assuring that the precautionary and environmental requirements stated in 3.1 and 3.2 are met. He shall also, at his discretion, assist in the inspection of test setups prior to application of power to a test specimen, and prior to any mechanism-assisted lifts or moves.

(4) Upon the occurrence of a test anomaly (any event that deviates from the planned procedures, exceeds normal variations, or generates unexpected data), operation of the test article shall be stopped immediately. All other test conditions and parameters shall be maintained (except as those conditions may pose an immediate hazard). The QA Inspector shall be notified that a test anomaly has occurred.

(5) The QA Inspector or Test Conductor (with QA concurrence) shall note each test anomaly on the Failure Reporting And Corrective Action System (FRACAS). The Inspector and the Test Conductor shall review the anomaly. Minor troubleshooting may be done to determine the cause of the anomaly; however, no disassembly or other actions that present a risk to the test article shall be allowed. If the anomaly is found to result from human error or test equipment problems that have not affected the test article, corrective action shall be taken and testing may continue. All troubleshooting steps and results shall be recorded on the FRACAS. The Test Conductor shall supervise any troubleshooting or retesting required in resolving test anomalies. 
Quality Assurance (QA) Provisions (continuation)

(6) If a test anomaly cannot be resolved as described above, the Project Engineer shall be notified. If the action indicates that a rework or repair may be required, the anomaly and troubleshooting results shall be noted in the Action ltem List (AIL) portion of the Certification Log, Fracus report and a Material Discrepancy Report (MDR) shall be initiated (if required) and processed as prescribed in the QA Plan.

(7) The QA Inspector shall stamp log entries as appropriate, attesting to the proper completion of these operations as previously approved in this procedure document. 


\subsection{Pre-Test Operations}

\section{CAUTION \\ ESD SENSITIVE HARDWARE. \\ HANDLE PER MIL-STD-1686 Class 1}

(1) Assure readiness to test, including the following items:

(a) Visual examination of the test item and its interfaces, including any special test instrumentation .

(b) Calibration is current for measuring instruments

(c) Proper edition of the procedure, and QA approval of any unincorporated redlines.

(d) Notification of QA of the time that testing will begin.

(2) Record the "Occasion for Test" on all Data Sheets.

(3) On the applicable data sheets, record the required information for measuring equipment to be used in the test. Verify that all such equipment bears current calibration stickers, and that calibration will not expire prior to the end of the test.

(4) Have completed Actel Camera Array Test Board Certification C1-EE-033.

(5) Solicit and obtain the QA Inspector's "OK to Continue." 


\section{$3.7 \quad$ TEST}

Test Start Date:

Equipment Used

Enter Name of LabView programs to Use

Name

Date Created
Date Modified

\section{NOTES:}

Test Conductors:

Test Completion Date:

Calibration In-date

$\begin{array}{ll}\text { Name: } & \text { Initials: __ Date } \\ \text { Name: } & \text { Initials: ___ Date }\end{array}$


Functions to Be tested

1. Sasi Functions

Check bits can be set and cleared and read back.

Name: Initials: Date

2. Double Correlated Sampling

TP14 is OL2

TP15 is ORfet

TP16 is OR

Name:

Initials:

Date

3. Precision Integration mode Check and Frame Enable \{frame xfer of UV-vis arrays\}

TP9 SM1

TP10 SMO

TP11 EOL

TP3 VSync \{frame enable\}

TP13 VTC

Name:

Initials:

Date

4. Test Initialization

TP8 T2

TP7 Init

Name:

Initials:

Date

DATA is to go in certification log of camera that array is going into. 


\section{Appendix D.2}

\section{Schematics}




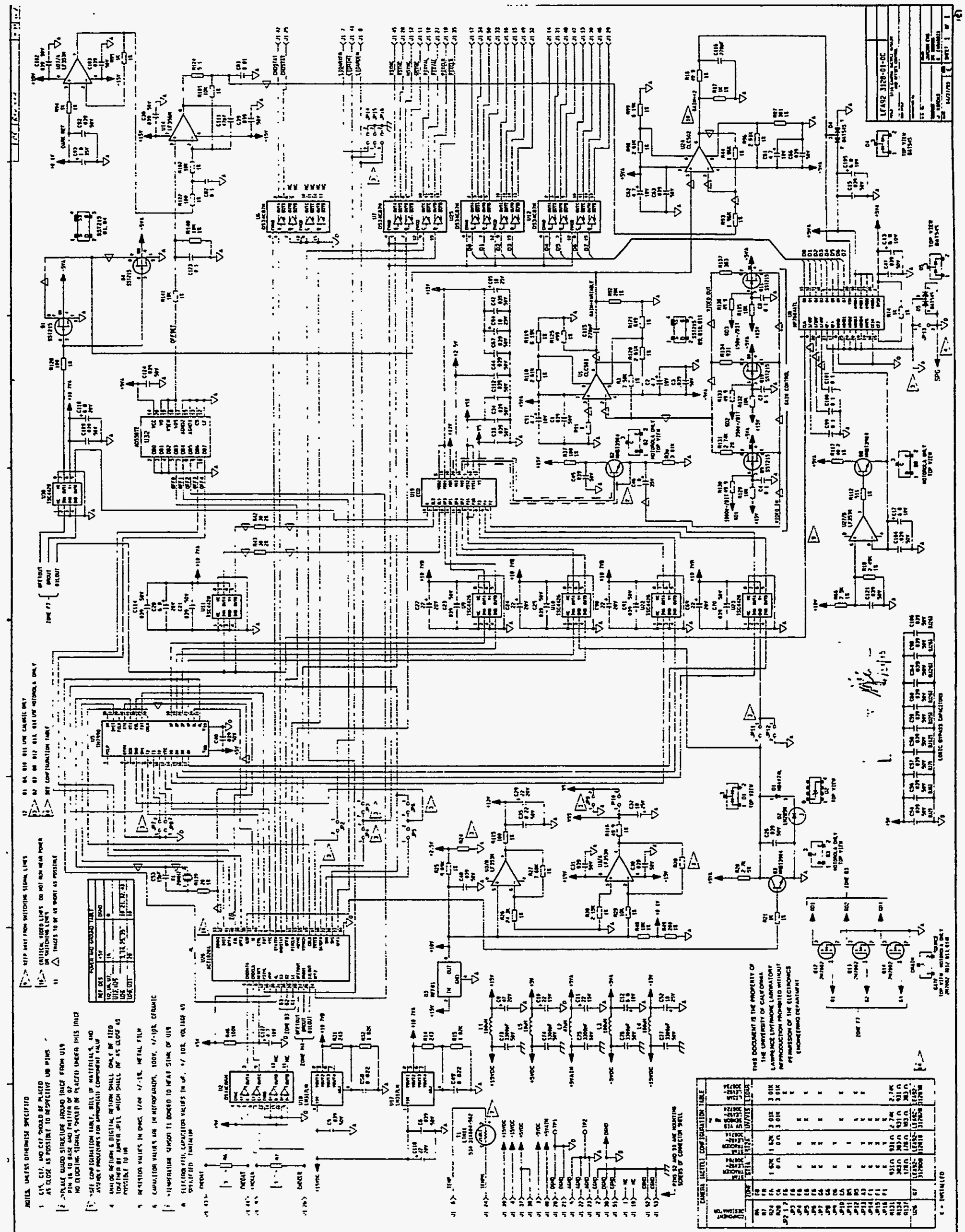




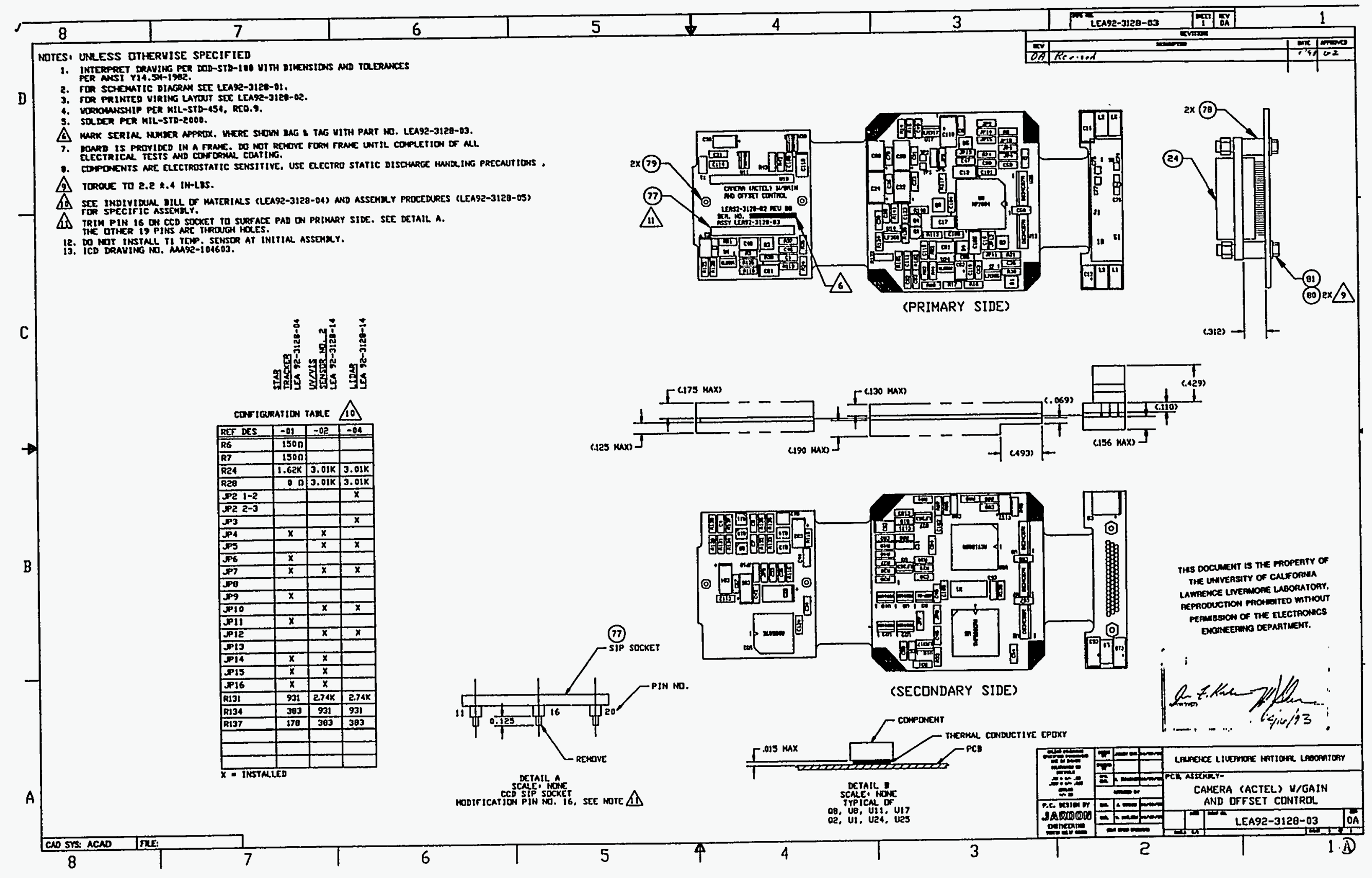




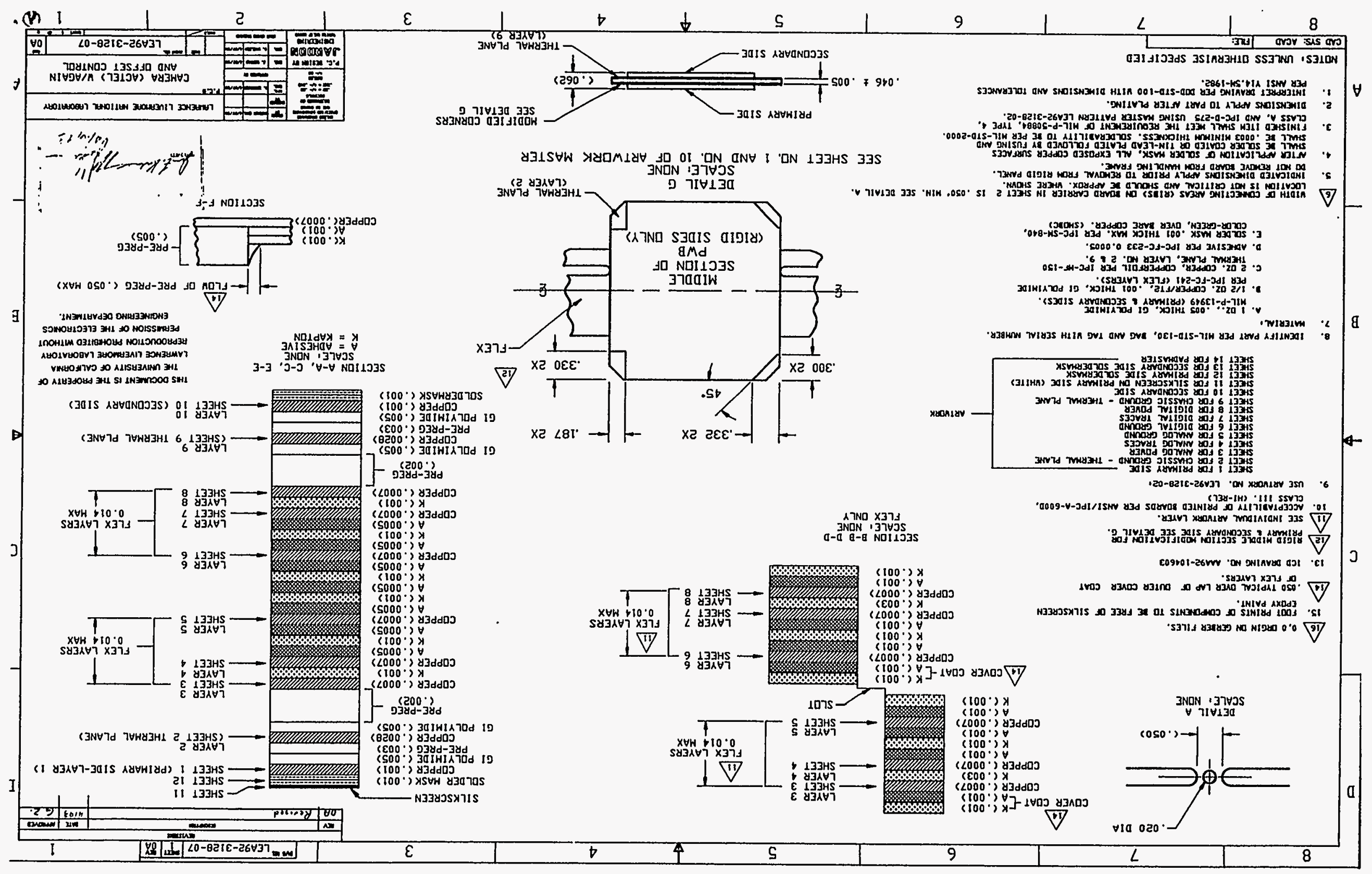




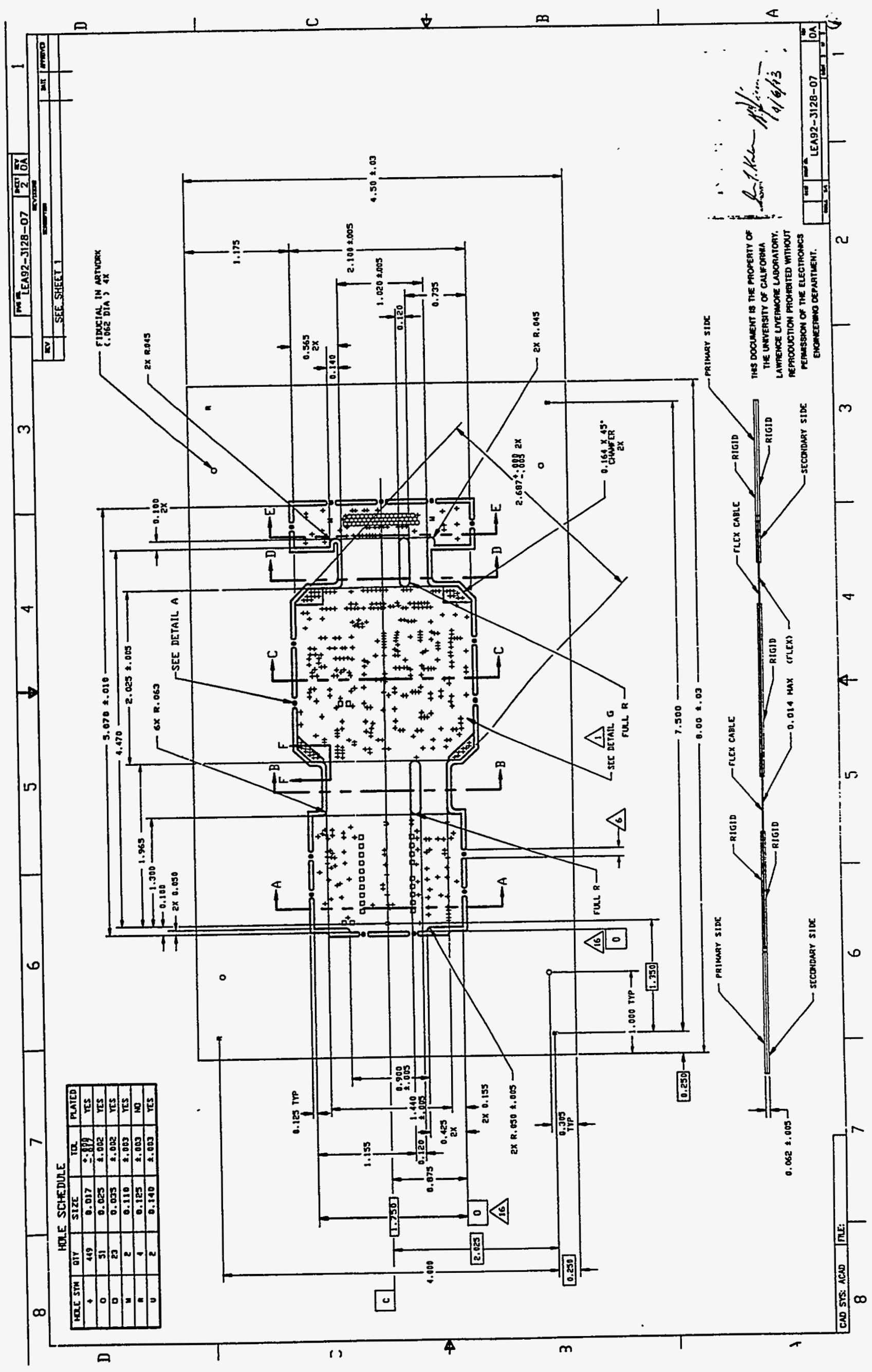




\section{Appendix D.3}

\section{Electromagnetic Compatibility Tests (C1-EE-030)}




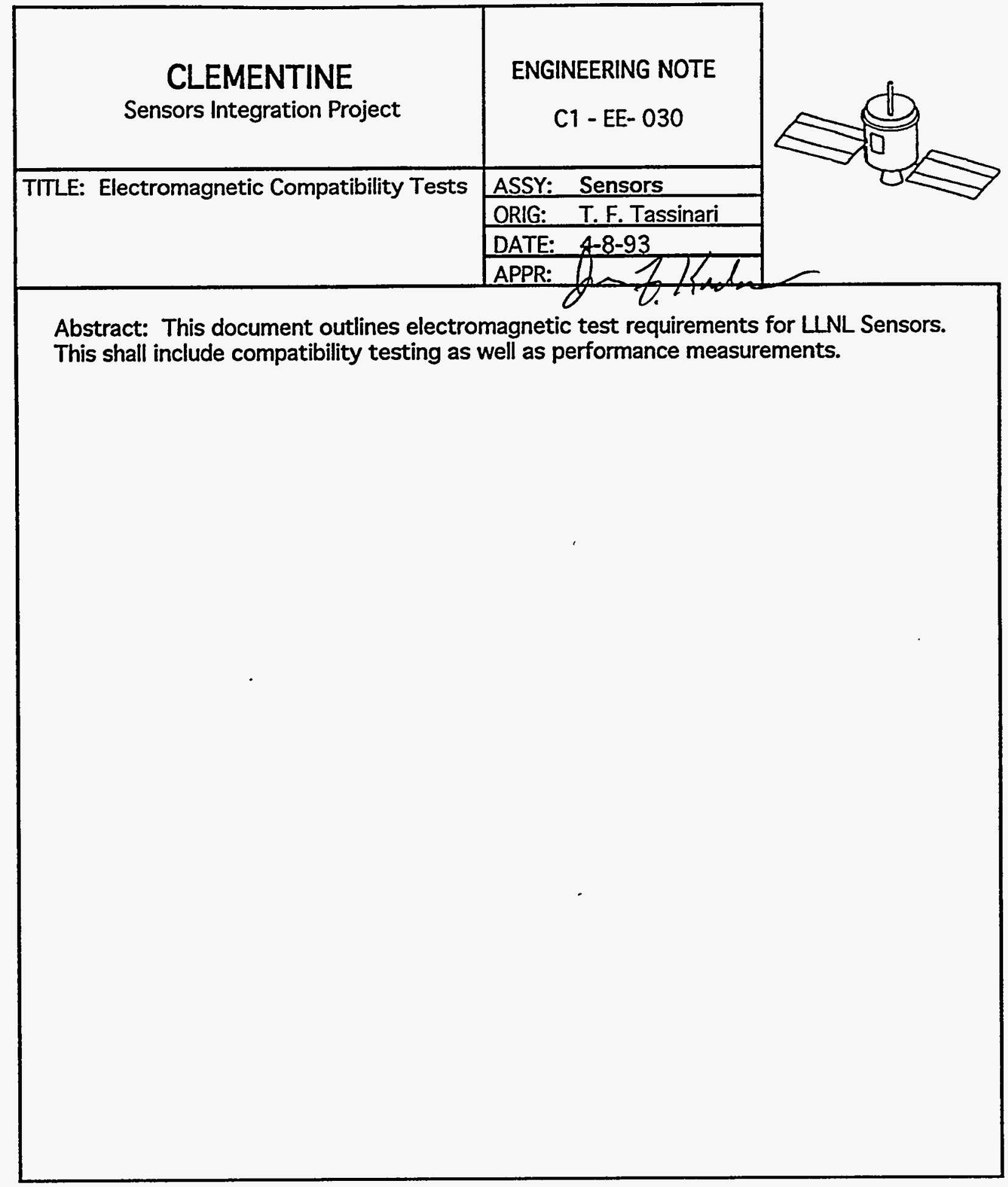




\section{SCOPE}

This document outlines the electromagnetic test requirements for LLNL sensors.

\section{REQUIREMENTS}

\subsection{Reference Documents and Drawings}

a MIL-STD-1686A, Handling ESD Sensitive Equipment.

b. MIL-STD-461C, Electromagnetic Emission and Susceptibility Requirements for the Control of Electromagnetic Interference.

c. MIL-STD-462, Electromagnetic Interference Characteristics, Measurement of.

\subsection{Electrostatic Discharge (ESD) Control Requirements}

The sensor assembly is susceptible to ESD damage and shall be treated as a Class 1 sensitivity device per MIL-STD-1686A.

\section{Sensor Electromagnetic Compatibility}

These tests are intended to be be conducted and evaluated at the input to the Sensor Power Supply (SPS). The purpose is to determine the Electromagnetic compatibility of the SPS and the sensor as a system.

The sensor, when connected to the SPS, shall not be susceptible to, nor shall it radiate emission levels greater than those specified in MIL-STD-461, Electromagnetic Interference Characteristics, Requirements for Equipment, herein after referred to as "MIL-STD-461" as delineated in this subsection. Levels greater than those specified shall be identified to LLNL. The sensor has been designed to operate without malfunction, undesirable response, or deviation from specified performance tolerances when subjected to these electromagnetic environments. Compliance shall be proven 
using the procedures of MIL-STD-462, Electromagnetic Interference Characteristics, Measure of, and an approved EMI test plan.

The following requirements are based on MIL-STD-461 and MIL-STD462 and have been modified for the DSPSE program. The tests shall be run as a system.

\subsubsection{Conducted Emission}

The sensor shall meet the conducted emissions levels defined below:

a. CE01 - As specified in MIL-STD-461C.

b. CE03 - Narrowband only as specified in MIL-STD-461C.

c. CE07 - As specified in MIL-STD-461C with the following exception: paragraph 5.2 b) shall be modified to read: "DC leads: +50 percent, -50 percent of nominal line voltage."

\subsubsection{Conducted Susceptibility}

The sensor shall not exhibit malfunctions, degradation of performance, or deviation from specifications when subjected to the levels defined below:

a. CS01 - As specified in MIL-STD-461C tailored by Figure 1-1

b. CSO2 - As specified in MIL-STD-461C with the following exception: paragraph 7.2 shall be modified to read: "...when subjected to 0.5 volt from a 50 -ohm source."

c. CSO6 - Section 11.2 a. only and as modified to read: "E1 $= \pm 30$ Volts peak".

\subsubsection{Radiated Emissions}

The sensor shall be not radiate emissions in excess of the levels defined below:

a. RE02 - Broadband as specified in MIL-STD-461C. Narrowband as tailored by Figure 1-2.

\subsubsection{Radiated Susceptibility}

The sensor shall not exhibit malfunctions, degradation of performance, or deviation from specifications when subjected to the levels defined below:

a. RS03 - As specified in MIL-STD-461C with a 50\% duty cycle,

\begin{tabular}{|l|l|lll|}
\hline$\amalg \begin{array}{l}\text { Lawrence Livermore } \\
\text { National Laboratory }\end{array}$ & Page & 3 & of & 8 \\
\hline
\end{tabular}


$1 \mathrm{KHz}$ square wave modulation, and the following modifications:

Frequency Range

$14 \mathrm{KHz}$ to $30 \mathrm{MHz}$

$30 \mathrm{MHz}$ to $10 \mathrm{GHz}$

Above $10 \mathrm{GHz}$
E-Field (Volts/meter).

1

5

N/A

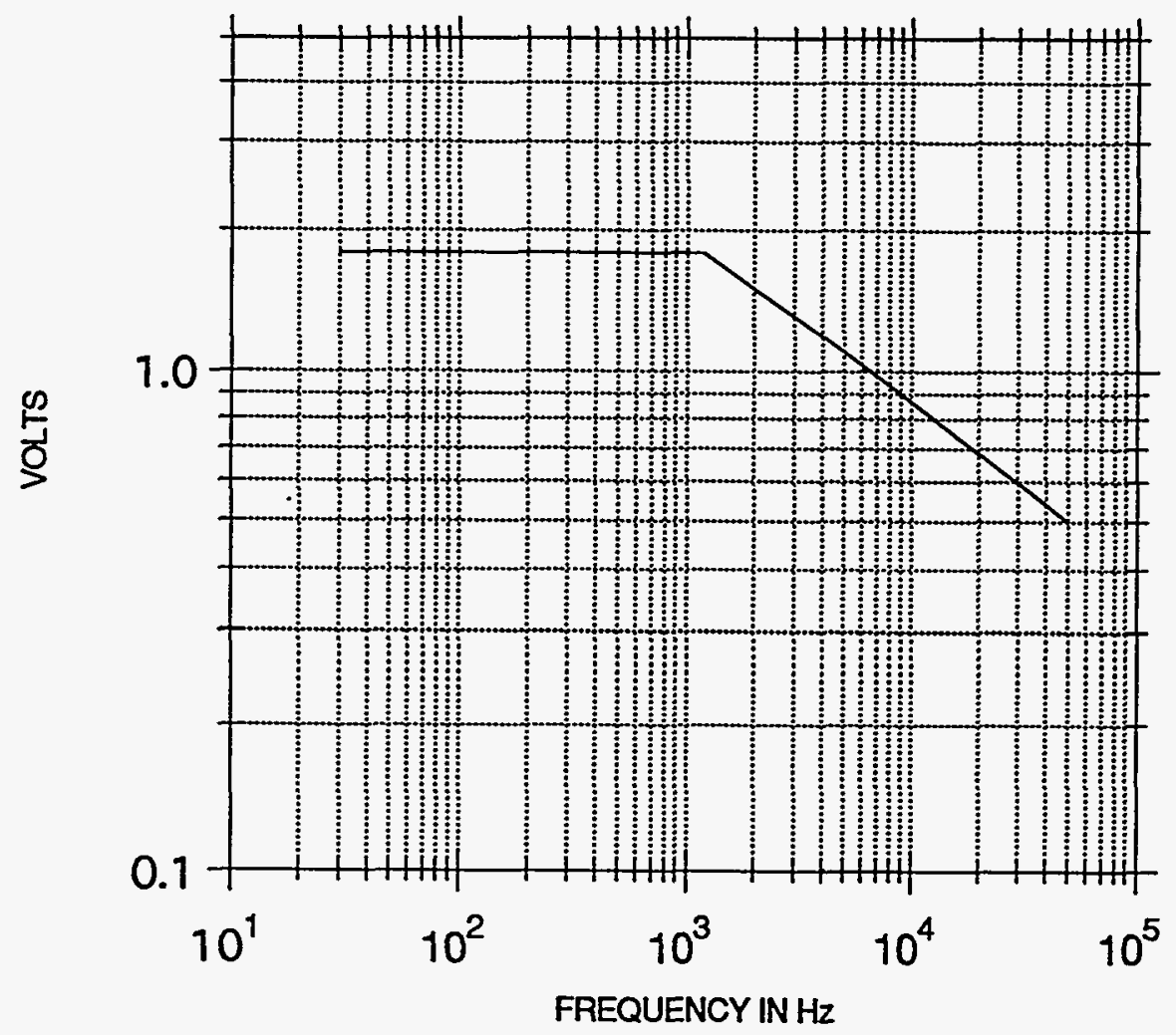

Figure 1-1. Limit For CSO1 Susceptibility 


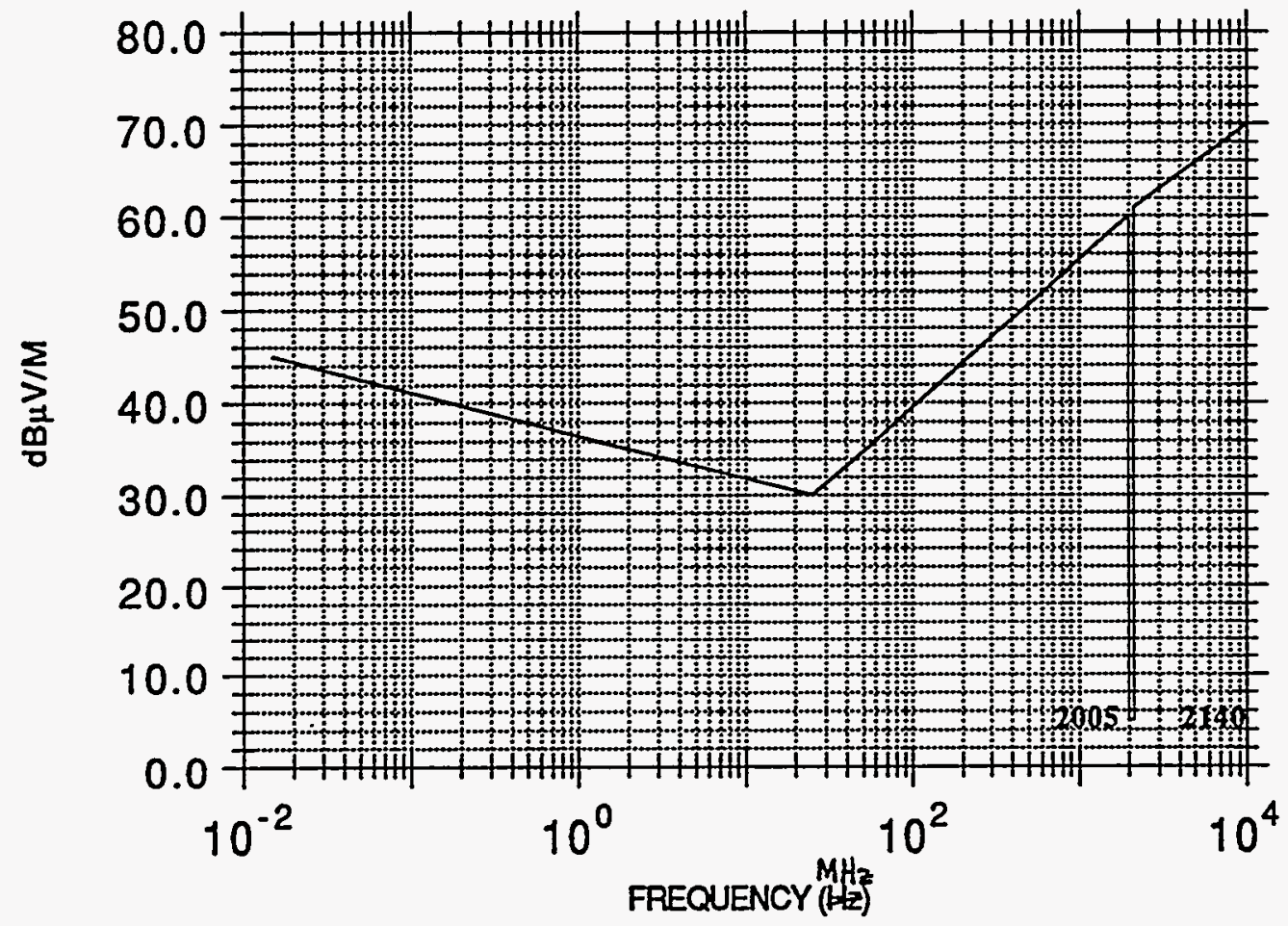

Figure 1-2. Limit For REO2 Narrowband Emissions

\subsection{Susceptibility Criteria}

The Sensor susceptibility shall be broken into two sections, the imager susceptibility (for all sensors) and the ranger susceptibility (for Hires Lidar only). These criteria shall serve to deem a sensor susceptible when subjected to specified RSO3, CSO1, CSO2 and CSO6 test levels.

\begin{tabular}{|l|l|lll|}
\hline$\amalg \begin{array}{l}\text { Lawrence Livermore } \\
\text { National Laboratory }\end{array}$ & Page $\quad 5 \quad$ of 8 \\
\hline
\end{tabular}




\subsubsection{Image Susceptibility Criteria}

When subjected to RSO3, CSO1, CSO2 and CSO6, data frames are acquired and analyzed. The noise floor histogram shall be examined and shall not exceed the levels indicated in table 1.

\begin{tabular}{|c|c|c|}
\hline Test & Gain & Max Level \\
\hline RSO3 & $150 \mathrm{e}^{1 / b i t}$ & Ambient $+0.5^{*}$ (one grey level) \\
\hline CS01 & $150 \mathrm{e}^{1 / b i t}$ & Ambient $+0.5^{*}$ (one grey level) \\
\hline CS02 & $150 \mathrm{e}^{1 / b i t}$ & Ambient $+0.5^{*}$ (one grey level) \\
\hline CS06 & $150 \mathrm{e}^{1 / b i t}$ & Ambient $+0.5^{*}$ (one grey level) \\
\hline
\end{tabular}

\section{Table 1}

\subsubsection{Ranger Susceptibility Criteria}

When subjected to RSO3, CSO1, CSO2 and CSO6, the range data are monitored at a given discriminator threshold. The false alarm rate (F.A.R.) shall be determined for each test and shall not exceed the levels indicated in table 2 . The rate is simply the ratio of false targets per 100 shots. This criteria is only applicable to the HiRes Lidar Sensor.

\begin{tabular}{|c|c|c|c|}
\hline Test & Threshold (mV) & Ambient F.A.R. & Max F.A.R \\
\hline RS03 & 10 & 0 & 1 \\
\hline CS01 & 10 & 0 & 1 \\
\hline CS02 & 10 & 0 & 1 \\
\hline CS06 & 10 & 0 & 1 \\
\hline
\end{tabular}

Table 2

\section{Sensor Electromagnetic Performance}

These tests are intended to be be conducted and evaluated at the input to the sensor. The purpose is to determine the Electromagnetic performance of the sensor by itself.

The following tests and requirements are based on MIL-STD-461 and MIL-STD-462. 


\subsection{Conducted Emission}

The conducted emission levels of the sensor by itself shall be evaluated as defined below:

a. CE01 - As specified in MIL-STD-461C.

b. CE03 - Narrowband only as specified in MIL-STD-461C.

c. CEO7 - As specified in MIL-STD-461C with the following

exception: paragraph $5.2 \mathrm{~b}$ ) shall be modified to read: "DC leads:

+50 percent, -50 percent of nominal line voltage."

\subsection{Conducted Susceptibility}

The conducted susceptibility levels of the sensor by itself shall be evaluated as defined below:

a. CS01 - As specified in MIL-STD-461C tailored by Figure 11.(ratioed to $10 \%$ of specific line voltage so as to not damage sensor)

b. CSO2 - As specified in MIL-STD-461C with the following exception: paragraph 7.2 shall be modified to read: "...when subjected to 0.5 volt from a $50-\mathrm{ohm}$ source."(ratioed to $10 \%$ of specific line voltage so as to not damage sensor)

\subsection{Radiated Emissions}

\subsubsection{Sensor}

The sensor radiated emission levels, not including cables, shall be evaluated as defined below:

RE02 - Broadband as specified in MIL-STD-461C. Narrowband as tailored by Figure 1-2.

\subsubsection{Components}

The radiated emission levels from the cryo cooler and stepper motor shall be evaluated as defined below:

RE01 - Magnetic field direction and intensity from DC to $1 \mathrm{KHz}$.

Optional- add $1 \mathrm{KHz}$ to $50 \mathrm{KHz}$

\begin{tabular}{|l|l|l|}
\hline$\amalg$ & Lawrence Livermore \\
National Laboratory & 7 of 8 \\
\hline
\end{tabular}




\subsection{Radiated Susceptibility}

The sensor radiated susceptibility levels of the sensor by itself shall be evaluated at the levels defined below:

a. RS03 - As specified in MIL-STD-461C with a 50\% duty cycle, $1 \mathrm{KHz}$ square wave modulation, and the following modifications:

Erequency Range

$14 \mathrm{KHz}$ to $30 \mathrm{MHz}$

$30 \mathrm{MHz}$ to $10 \mathrm{GHz}$

Above $10 \mathrm{GHz}$
E-Field (Volts/meter). 2

10

N/A 


\section{Appendix E Mechanical System}




\section{Appendix E.1 \\ StarTracker Camera Structural Analysis \\ (C1-S1-008)}




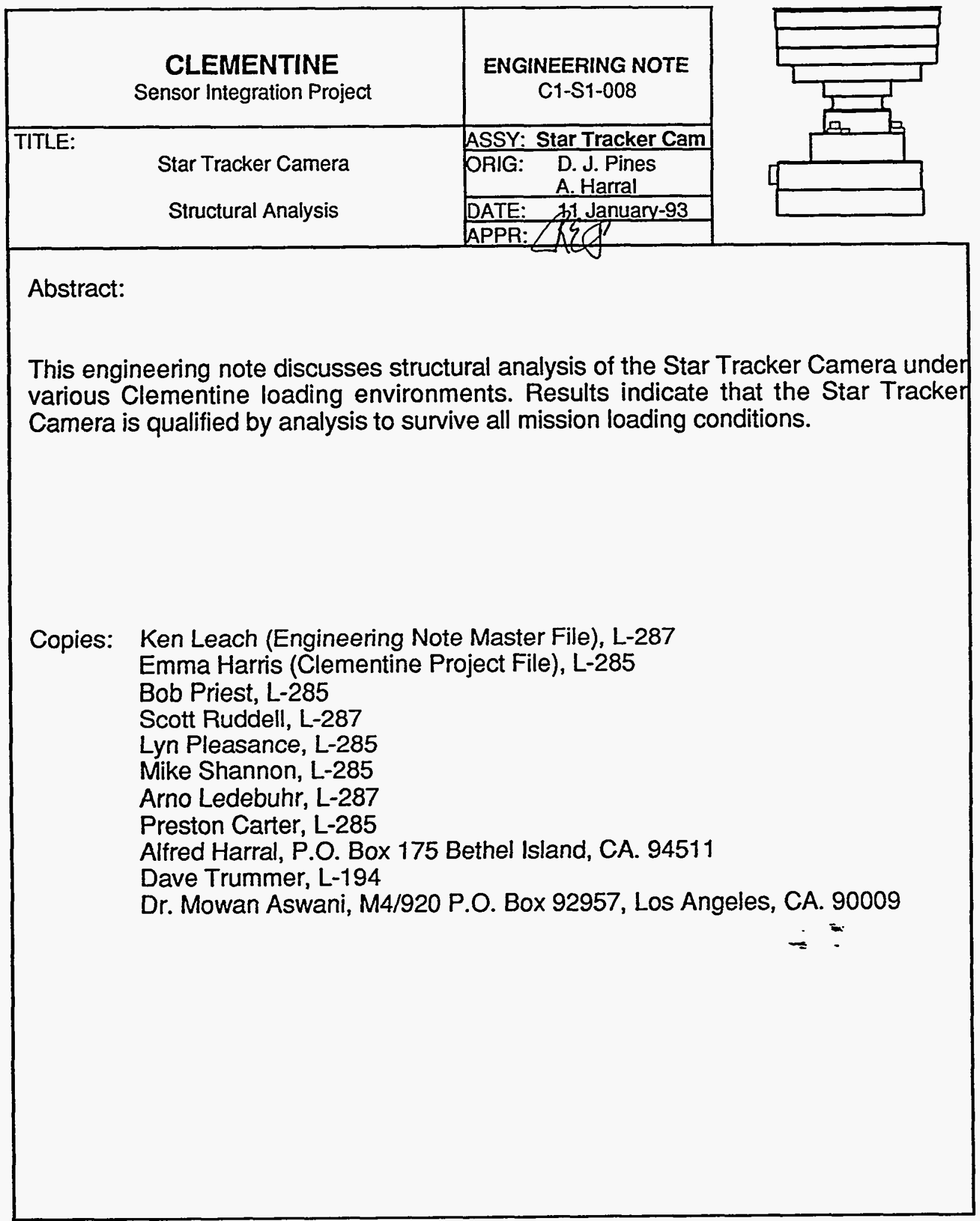

\begin{tabular}{|l|l|l|}
\hline \multirow{L}{*}{$\begin{array}{l}\text { Lawrence Livermore } \\
\text { National Laboratory }\end{array}$} & 1 & Total Document Pages: 90 \\
\hline
\end{tabular}




\subsection{Scope}

The scope of this Engineering Note is to demonstrate that the Star Tracker Camera is qualified by analysis to meet all loading requirements seen by the Deep Space Program Science Experiment-DSPSE spacecraft.

\subsection{Requirements}

The requirements for qualification of payload components are detailed in the Engineering and Test Specficification Plan document dated September 1992 and are summarized here for completeness:

\subsection{Camera Mission Survivability}

Table 1.0: Derived Requirements for Qualification

\begin{tabular}{|l|l|}
\hline Loading Condition & Requirements \\
\hline Steady-State & $\begin{array}{l}100 \mathrm{~g}^{\prime} \text { ' loading in each axis } \\
\text { (applied separately) }\end{array}$ \\
\hline Random Vibration & $\begin{array}{l}14 \mathrm{~g}^{\prime} \mathrm{rms} \text { loading with frequency } \\
\text { content from } 20 \text { to } 2000 \mathrm{~Hz} \\
\text { (Loading applied simultaneously in all } \\
\text { three axis) }\end{array}$ \\
\hline Pyro-shock-(for $20 \mathrm{msec})$ & $\begin{array}{l}\text { Peak acceleration }=501 \mathrm{~g} \text { 's with frequency } \\
\text { content from } 100 \text { to } 10000 \mathrm{~Hz} \text { and } \\
\text { attenuated through } 5 \text { interfaces with a } \\
\text { transmissibilty of } 0.168 \text {.(Loading applied } \\
\text { simultaneously in all three axis) }\end{array}$ \\
\hline
\end{tabular}

\subsection{Frequency Content}

The Engineering and Test Specification Plan did not explicitly establish a frequency content requirement for Star Tracker Camera components. LLNL chooses to adopt a requirement which states that all structural modes must have frequency content $>50 \mathrm{~Hz}$.

\subsection{Camera Design Factors of Safety}

\section{Table 2.0: DSPSE Design Factors of Safety}

\begin{tabular}{|l|l|}
\hline Mechanical Property & Factor of Safety \\
\hline Yield & 1.10 \\
Ultimate & 1.25 \\
Local Buckling & 1.10 \\
General Instability & 1.25 \\
Fitting Factor & 1.15 \\
Static Test & 1.05 \\
\hline
\end{tabular}




\subsection{Deflection}

The Engineering and Test Specification Plan did not explicitly establish a deflection requirement for internal and external components of the Star Tracker. LLNL chooses to adopt a requirement which states that the clearance between internal components be maintained at all times.

\subsection{Star Tracker Camera Structural Model}

To meet the above derived requirements for flight qualification a threedimensional Star Tracker finite element model-FEM, with 342 solid and 800 shell elements, was developed from the most recent camera design drawings dated November 18, 1992. From these drawings six components of the camera were modelled. They included the Baffle Assembly, Lens Assembly, Camera Housing, Mounting Brackets and the two Actel Circuit Boards connected by a flexible hinge. This model was used for determining the mode shapes and natural frequencies of the Star Tracker. In addition, this model was also used to determine the survivability of the camera under various loading environments which include transportation, launch and mission maneuvers. Figures 1-3 show the unloaded model, an exploded view of the internal parts which make up the camera and an illustration of the boundary nodes used to simulate how the camera mounts to the sensor platform. The actual mounting brackets were analyzed individually in separate FEM's. All external loading conditions were applied in camera body-fixed- $(x, y, z)$ frame for one particular Star Tracker Camera. To transform to spacecraft body fixed coordinates-(X,Y,Z), the following direction cosine matrices must be applied:

$$
\begin{aligned}
& {\left[\begin{array}{l}
x \\
y \\
z
\end{array}\right]_{1}=\left[\begin{array}{ccc}
-\cos (21) & \sin (48.5) \sin (21) & -\cos (48.5) \sin (21) \\
0 & \cos (48.5) & \sin (48.5) \\
\sin (21) & \sin (48.5) \cos (21) & -\cos (48.5) \cos (21)
\end{array}\right]\left[\begin{array}{l}
X \\
Y \\
Z
\end{array}\right] ;} \\
& {\left[\begin{array}{l}
x \\
y \\
z
\end{array}\right]_{2}=\left[\begin{array}{ccc}
-\cos (21) & -\sin (40.5) \sin (21) & -\cos (40.5) \sin (21) \\
0 & \cos (40.5) & -\sin (40.5) \\
\sin (21) & \sin (40.5) \cos (21) & \cos (40.5) \cos (21)
\end{array}\right]\left[\begin{array}{l}
X \\
Y \\
Z
\end{array}\right] \div=}
\end{aligned}
$$

\subsection{Mass Budget of Modelled Components}

The mass budget for the modelled Star Tracker components is given in Table 3.0. Using these mass properties and the geometry of the camera the moments of inertia and center of mass of the Star Tracker's FEM were computed and are summarized in Table 4.0.

\begin{tabular}{|l|l|l|}
\hline IL $\begin{array}{l}\text { Lawrence Livermore } \\
\text { National Laboratory }\end{array}$ & 3 & Total Document Pages: 90 \\
\hline
\end{tabular}


Table 3.0: Mass Budget of Star Tracker

\begin{tabular}{|l|c|}
\hline Component & Mass-(grams) \\
\hline $\begin{array}{l}\text { Camera Housing } \\
\text { (Top Cover, End Cover, Four Gussets, Four } \\
\begin{array}{l}\text { Corner Posts, Remaining Walls, CCD, } \\
\text { Connector, Actel Circuit Boards and Misc.) }\end{array}\end{array}$ \\
\hline $\begin{array}{l}\text { Lens Assembly } \\
\text { Elements w/ cellsHousingMisc }\end{array}$ & 34 \\
\hline $\begin{array}{l}\text { Focus Spacer } \\
\text { (Thermal Management, Lens Heater \& } \\
\text { Thermostat) }\end{array}$ & 41 \\
\hline $\begin{array}{l}\text { Baffle Assembly } \\
\text { (Vanes, Housing, Six Gussets) }\end{array}$ & 60 \\
\hline Mounting Brackets & 12 \\
\hline Total Mass Budget & 282 \\
\hline
\end{tabular}

Table 4.0: Inertia and Center of Mass Properties of Star Tracker

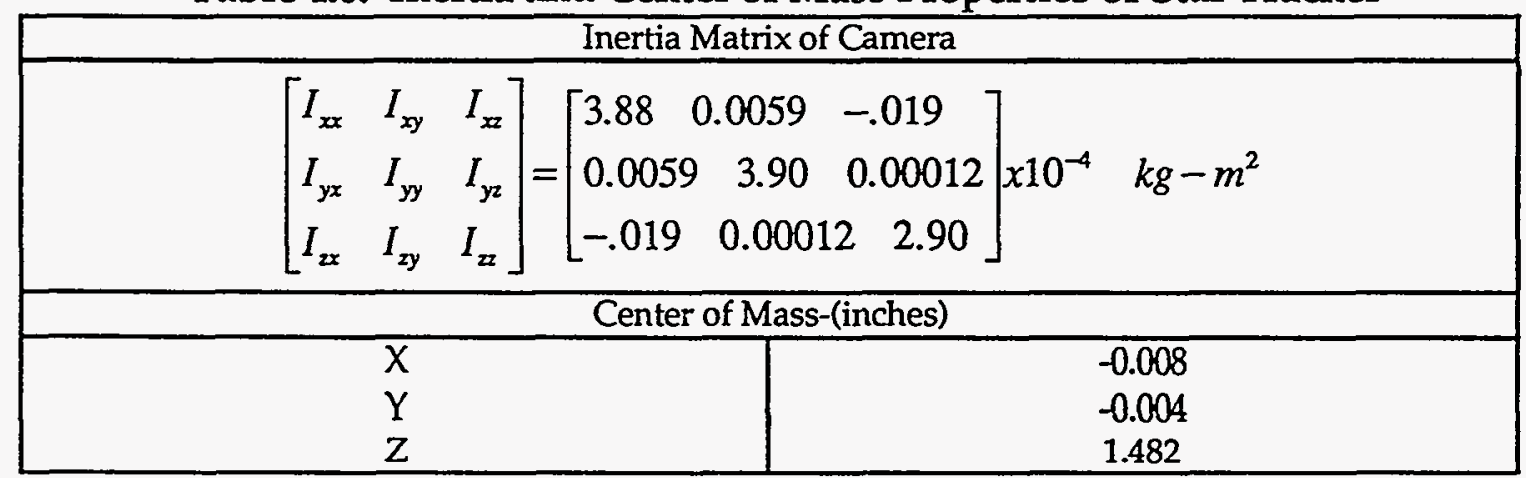

\subsection{Material Properties of Components}

The camera is made of Aluminum 6061-T651 and is structurally adequate even though this Aluminum alloy was selected primarily for its high thermal conductivity rather than for its strength. The mechanical material properties of Aluminum 6061-T651 are listed in Table 5.0.

Table 5.0: Mechanical Properties of Aluminum 6061-T651

\begin{tabular}{|l|l|}
\hline Property & Value \\
\hline Density & $0.09 \mathrm{lb} / \mathrm{in}^{3}$ \\
Young's Modulus & $1 \times 10^{7} \mathrm{psi}$ \\
Shear Modulus & $3.76 \times 10^{6} \mathrm{psi}$ \\
Bulk Modulus & $9.804 \times 10^{6} \mathrm{psi}$ \\
Poisson's Ratio & 0.33 \\
Yield Strength & $39 \mathrm{ksi}$ \\
Ultimate Strength & $42 \mathrm{ksi}$ \\
\hline
\end{tabular}


The refractive elements in the Lens Assembly are made from an optical glass derivative which has a density of $2.2 \mathrm{~kg} / \mathrm{m}^{3}$. Each element is bonded to its cell using Dow Corning 93-500 optical couplant. Reflective elements are nickel-plated aluminum for the primary and aluminum flashed on fused silica for the secondary.

\subsection{Modal Analysis}

The first five mode shapes and natural frequencies of the Star Tracker camera were calculated using LLNL NIKE3D finite element code. Table 6.0 summarizes the eigenanalysis performed by this software tool. Figures 4-8 illustrate the corresponding mode shapes. Notice that the first two modes are cantilever bending where the housing top cover and the baffle base deform allowing the baffle to swing from side to side. There is slightly more stiffness in the $Y-Y$ direction due to the narrower geometry of the top cover of the housing in the $Y$ direction.

The 40 mil thick top cover of the housing and the four 45 mil thick stiffening gussets control the frequency content of modes 1 and 2. Increasing the thickness of these parts raises the frequencies of modes 1 and 2. But this is not necessary since the $50 \mathrm{~Hz}$ lower limit is well exceeded by the present configuration. Higher modes occur in the baffle vanes corresponding to radial extension and tranverse vibration.

Table 6.0: Modal Analysis Summary

\begin{tabular}{|c|c|c|}
\hline Mode Number & Natural Frequency-Hz & Mode Shape \\
\hline 1 & 213 & $\begin{array}{c}\text { Cantilever Bending } \\
(x-x) \\
\text { Cantilever Bending } \\
\text { (y-y) } \\
\text { Vane \#4 } \\
\text { Radial Ext. } \\
\text { Vane \#4 } \\
3\end{array}$ \\
4 & 219 & $\begin{array}{c}\text { Transverse } \\
\text { Vane \#3 }= \\
\text { Radial Ext. }\end{array}$ \\
\hline
\end{tabular}

\subsection{Stress Analysis}

Although most of the Clementine mission loading conditions are benign, there are instances, when the entire spacecraft including the payload are subjected to severe loading conditions. This occurs during first, second and third stage separation of the Titan IIG and during the TLI transfer burn. This section discusses the state of stress in each of the components under steady-state, random vibration and pyroshock loading environments. The Actel circuit boards are treated separately since they are not directly in the load bearing path of the inputs. 


\subsection{Steady-State}

For spacecraft sensor qualification, the Engineering and Test Specification Plan recommends that the sensor be subjected to a steady-state load according to its weight-(See Figure 9.0). Thus, the applied g-loading is found by extracting the value of the ordinate which corresponds to the sensor weight and multiplying this value by 2. Following this procedure, a steady-state loading of $100 \mathrm{~g}^{\prime} \mathrm{s}$ was applied separately in each of the principal orthogonal axis of the Star Tracker. The state of stress was calculated using the NIKE3D finite element code. Table 7.0 gives the maximum effective stress occurring in each of the camera components for each of the principal orthogonal axis. The safety factors are given in the right column of Table 7.0 against the Yield Strength of Aluminum 6061-T651. Figures 10-19 show the finite element mesh with fringes of effective stress and the deflections amplified by a factor of 20 for each steady-state loading condition. Figures 20-22 show the state of stress in the mounting brackets and the deformation for the $100 \mathrm{~g}$ steady-state $\mathrm{Z}$ acceleration.

Table 7.0: Steady-State Peak Effective Stresses-(ksi)

\begin{tabular}{|c|c|c|c|c|}
\hline $\begin{array}{c}\text { Camera } \\
\text { Component }\end{array}$ & $x$ & $y$ & $z$ & $\begin{array}{l}\text { Qualification } \\
\text { Exceeded By }\end{array}$ \\
\hline $\begin{array}{c}\text { Camera } \\
\text { Housing } \\
\text { (Sides) }\end{array}$ & 9.88 & 9.2 & 8.42 & 3.9 \\
\hline $\begin{array}{c}\text { Camera } \\
\text { Housing } \\
\text { (Top Cover) }\end{array}$ & 12.6 & 16.6 & 10.5 & 2.3 \\
\hline $\begin{array}{c}\text { Camera } \\
\text { Housing } \\
\text { (Top Cover } \\
\text { Gussets) }\end{array}$ & 14.4 & 15.1 & 10.1 & 2.6 \\
\hline Focus Spacer & 2.7 & 2.9 & 1.97 & 13 \\
\hline Lens Housing & 0.49 & 0.56 & 0.21 & 70 \\
\hline $\begin{array}{l}\text { Baffle Base } \\
\text { Ring }\end{array}$ & 1.4 & 1.5 & 0.40 & 26 \\
\hline Baffle Gussets & 2.3 & 2.1 & 2.0 & $-17 \cdot$ \\
\hline $\begin{array}{c}\text { Baffle Back } \\
\text { Disk }\end{array}$ & 0.93 & 0.86 & 0.60 & 42 \\
\hline $\begin{array}{l}\text { Baffle Outer } \\
\text { Cylinder }\end{array}$ & 0.43 & 0.38 & 0.56 & 70 \\
\hline Baffle Vanes & 0.05 & 0.05 & 1.64 & 4.3 \\
\hline $\begin{array}{c}\text { Mounting } \\
\text { Bracket }\end{array}$ & 2.22 & 2.32 & 3.77 & 10 \\
\hline
\end{tabular}


The deflections for the steady-state loading condition were calculated and the maximum deflections are located at the end of the baffle. These deflections are summarized in Table 8.0 for each axis.

Table 8.0: Maximum Deflections at end of Baffle

\begin{tabular}{|c|c|}
\hline Direction & Deflection-(inches) \\
\hline$X$ & 0.029 \\
$Y$ & 0.028 \\
$Z$ & 0.010 \\
\hline
\end{tabular}

\subsection{Random Vibration}

Random vibration qualification of the star tracker is based on the camera being able to surve the structural acoustic environment of the Titan IIG during first, second and third stage ignitions. The response spectrum for this loading is shown in Figure 23 which is equivalent to $14 \mathrm{~g}^{\prime} \mathrm{s}$ rms loading from 20 to $2000 \mathrm{~Hz}$. The lack of phase information is this figure implies that there are an infinite number of time domain curves which when transformed yields the same frequency domain spectrum. Three such acceleration versus time curves, used as input to LLNL DYNA3D finite element code, in the $X, Y$ and $Z$ directions were generated to simulate the environment of the Titan IIG PSD response. These curves are shown - in Figures 24-26. Since the runtime was prohibitive on a $486 / 33 \mathrm{MHz}$ computer, Dave Trummer of LLNL ran the random vibration dynamic analysis, with this input, on the YMP Cray using the DYNA3D code. The results are shown in Figures 27-31. The maximum stress of $5.0 \mathrm{ksi}$ occurs at 0.0058 seconds in element \#219 corresponding to the top cover of the camera housing. The summary of maximum stresses and deflections are give in Table 9.

The duration of 70 milli-seconds was chosen to limit the computation time of each run. This arbitrary truncation of the time series is not expected to affect the simulated value of the peak effective stress in each component. This is because the $70 \mathrm{~ms}$ time series contains approximately 10 cycles of mode 1 . Therefore, during this time period all transients are expected to have died out, leaving only steady-state random behaviour associated with the spectrum.$$
\div
$$

\subsubsection{Damping and Exponential Decay}

The viscous damping factor for solid aluminum is between 1-5\% of critical due to internal friction. The coulomb damping for a structure with tightly bolted joints is between $5-10 \%$ of critical due to resistance to slippage at the joints. Using the cantilever bending natural frequency and estimating the damping to be $5 \%$ of critical, the time and number of cycles to damp out a step load has been calculated. For an initial deflection of 30 mils, the baffle will decay by $95 \%$ after approximately 10 cycles to a deflection of 1.5 mils. Figure 32 shows the baffle ring

\begin{tabular}{|l|l|l|}
\hline$\amalg \begin{array}{l}\text { Lawrence Livermore } \\
\text { National Laboratory }\end{array}$ & 7 & Total Document Pages: 90 \\
\hline
\end{tabular}


down for a damping factor of $5 \%$ of critical and also plots the decay times to reach $95 \%$ of steady-state value for damping factors from 1-10\% of critical.

\subsection{Pyro-shock}

Similar to qualification under the random vibration specification, pyro-shock qualification of the star tracker requires surviving short duration loads imparted by the Titan IIG during final stage separation. The Engineering and Test Specification Plan document gives a representative shock response spectrum for sensor qualification under loads occurring at the launch vehicle/spacecraft adapter interface-(See Figure 33). The frequency content of the response spectrum extends from 100 to $10,000 \mathrm{~Hz}$. However, below $1,000 \mathrm{~Hz}$ there is very little energy content in the shock. The Star Tracker Camera is located 5 interfaces removed from the shock source and an attenuation factor of 0.7 is used for the transmission loss at each interface. The total attenuation for the shock is therefore $0.7^{5}$, or an overall factor of 0.168 . Jim Houghton at NRL has simulated the pyroshock pulse at its source on a shaker and measured the acceleration vs time history. This acceleration vs time shock pulse has a duration of approximately 20 ms. It is shown, attenuated by a factor of 0.168 , in Figures 34-35 and was used as input for the dynamic analysis with the DYNA3D code.

Dave Trummer of LLNL also ran the pyro-shock analysis on the YMP Cray. The results are shown in Figures 36-40 and Table 9. Here the resulting stress values are corrected for the square root of 3 overload. Notice that the maximum stress is only $3.79 \mathrm{ksi}$ even though the peak accelerations are over $220 \mathrm{G}$ 's. The reason that this stress level is not higher, is that the high accelerations of pyro-shock pulse occur at a much higher frequency than the natural frequency of the Star Tracker Camera. The transmissibility is low at this level of frequency mismatch.

Table: 9.0: Stresses under Steady-State, PSD and Pyro-shock Loadings

\begin{tabular}{|c|c|c|c|}
\hline Loading direction & $\begin{array}{l}\text { Time of maximum } \\
\text { stress (sec) }\end{array}$ & $\begin{array}{c}\text { Maximum effective } \\
\text { stress (ksi) }\end{array}$ & $\begin{array}{c}\text { Maximum } \\
\text { deflection (in.) at } \\
\text { end of Baff]le }\end{array}$ \\
\hline \hline X100 G's & steady state & 12.6 & 0.029 \\
\hline Y 100 G's & steady state & 16.6 & 0.028 \\
\hline Z 100 G's & steady state & 10.5 & 0.010 \\
\hline \hline X Pyro-shock & 0.0162 & 2.19 & 0.003 \\
\hline Y Pyro-shock & 0.0071 & 1.62 & 0.004 \\
\hline Z Pyro-shock & 0.0069 & 1.62 & 0.004 \\
\hline \hline X 14 Grms random & 0.0185 & 2.2 & 0.011 \\
\hline Y14 Grms random & 0.0058 & 5.0 & 0.013 \\
\hline Z14 Grms random & 0.0059 & 5.0 & 0.009 \\
\hline
\end{tabular}




\subsection{Fatigue During Life Testing}

Figures 41 and 42 are a Constant-Life Diagram for the fatigue behavior of 6061-T6 aluminum alloy. The maximum stress calculated in the Star Tracker Camera is $16.6 \mathrm{ksi}$ and the fatigue life for an alternating stress (+ and -) of this level, taken from the diagram, is approximately $2.8 \mathrm{E}+06$ cycles. The mode 1 cantilever bending natural frequency of the camera is $219 \mathrm{~Hz}$ in the $Y-Y$ direction and the random vibration testing lasts 60 seconds in each axis, and there would be 13,140 cycles in each test. If the camera were to undergo a full stress reversal of $16.6 \mathrm{ksi}$ for each and every cycle, then it could survive 213 minutes of testing before fatigue would be a problem.

\subsection{Bolt Loads and Safety Factors}

The yield safety factors for the various bolted joints of the camera have been calculated for the steady-state $100 \mathrm{~g}$ load in the direction that causes the maximum bolt load. The INGRID mesh generation code was used to calculate the part masses and CG locations. The bolts are high strength cap screws with a yield stress of 150-155 ksi and an ultimate stress of $170 \mathrm{ksi}$. Table 10 lists the maximum load and yield safety factor for each bolted joint.

Table 10: Bolted joint yield safety factors

\begin{tabular}{|c|c|c|c|c|}
\hline Bolted joint & $\begin{array}{c}\text { Cap screw } \\
\text { number and size }\end{array}$ & $\begin{array}{c}\text { Maximum bolt } \\
\text { load (lb) }\end{array}$ & $\begin{array}{c}\text { Cap screw } \\
\text { yield force (lb) }\end{array}$ & $\begin{array}{c}\text { Cap screw yield } \\
\text { safety factor }\end{array}$ \\
\hline $\begin{array}{c}\text { Lens housing to } \\
\text { baffle }\end{array}$ & 3 ea. 2-56 & $\begin{array}{c}49 \text { lb from } 100 \mathrm{G} \text { 's } \\
\text { Y acceleration }\end{array}$ & 566 & 12 \\
\hline $\begin{array}{c}\text { Camera housing } \\
\text { to lens housing }\end{array}$ & 3 ea. 2-56 & $\begin{array}{c}16 \mathrm{lb} \text { from } 100 \mathrm{G} \text { 's } \\
\text { Y acceleration }\end{array}$ & 566 & 35 \\
\hline $\begin{array}{c}\text { Camera } \\
\text { mounting } \\
\text { brackets }\end{array}$ & 3 ea. 6-32 & $\begin{array}{c}35 \mathrm{lb} \text { from 100 G's } \\
\text { Y acceleration }\end{array}$ & 1377 & 39 \\
\hline $\begin{array}{c}\text { Camera housing } \\
\text { bottom cover }\end{array}$ & 4 ea. 2-56 & $\begin{array}{c}0.5 \mathrm{lb} \text { from 100 G's } \\
\text { Z acceleration }\end{array}$ & 566 & 110 \\
\hline
\end{tabular}

\subsection{Circuit Board Stress Analysis}

A 3D finite element model of the $2 \times 2$ in. square ACTEL circuit board was generated. The model simulates the board thickness of 58.5 mils and 28 layers with 196 shell elements with average material properties. The mode shapes and natural frequencies plus the response to steady-state acceleration loading was analyzed using the NIKE3D code. The equivalent Young's modulus for the $\mathbf{2 8}$ layer stack up of the circuit board is $2.58 \mathrm{E}+06 \mathrm{psi}$. The 30 gram mass of the board was uniformly distributed over the entire board and the four corners were clamped as shown in Figure 42. Table 11 and Figures 43-47 show the first four mode shapes and natural frequencies of the board. Figure 48 shows the circuit board under a steady-state $100 \mathrm{G}$ 's of acceleration normal to the board ( $\mathrm{Z}$ direction). The maximum stress is $1.6 \mathrm{ksi}$ and is located in the board corners and 
the center deflection is 2.7 mils. The radius of curvature can be used in estimating the loading on the mounted components. The board has a width of approximately two inches and a center deflection of 2.7 mils results in a radius of curvature of $185 \mathrm{in}$.

Table 11: ACTEL circuit board mode shapes and natural frequencies

\begin{tabular}{|c|c|l|}
\hline Mode number & \multicolumn{1}{|c|}{$\begin{array}{c}\text { Natural frequency } \\
\mathbf{( H z )}\end{array}$} & \multicolumn{1}{|c|}{ Mode shape } \\
\hline 1 & 740 & Panel breathing Z-Z \\
\hline 2 & 1405 & Center twisting \\
\hline 3 & 1680 & Edges deflecting \\
\hline 4 & 2340 & Complex breathing Z-Z \\
\hline
\end{tabular}

A separate 2D finite element plane strain model was used with the NIKE2D code to calculate the stress developed in the circuit board during assembly when the four cap screws are torqued to $6.3 \mathrm{in}$.-1b. Each of the 28 layers with its material property listed in Table 12 was included in the model. The steady-state $100 \mathrm{G}$ 's acceleration load produces much less stress than when the board is clamped in place during assembly. Figures $49-54$ show a section of one corner of the board clamped with a bolt load of $254 \mathrm{lb}$ at the corner (left edge in the Figure). After the bolt load is applied, the center of the board is then forced to a deflection of 10 mils (four times the deflection produced at $100 \mathrm{G}$ s). Table 13 lists the maximum effective stress in each layer. The lowest ultimate safety factor is 1.2 , however, the effective stresses are composed of primarily compressive components.

Analysis of component stresses in soldered joints will be covered in a separate engineering note.

Table 12: Material Properties

\begin{tabular}{|c|c|c|c|c|c|}
\hline Material & $\begin{array}{l}\text { Density- } \\
\text { (lb/in3) }\end{array}$ & $\begin{array}{l}\text { Elastic } \\
\text { Modulus } \\
\text { Mpsi }\end{array}$ & $\begin{array}{l}\text { Poisson's } \\
\text { Ratio }\end{array}$ & $\begin{array}{l}\text { Yield } \\
\text { Strength } \\
\text { (ksi) }\end{array}$ & $\begin{array}{l}\text { Ultimate } \\
\text { Strength } \\
\text { (ksi) }\end{array}$ \\
\hline $\begin{array}{c}\text { Solder Mask } \\
60 \mathrm{Sn}-40 \mathrm{~Pb}\end{array}$ & 0.308 & 4.35 & 0.42 & 5.0 & $=7.6$ \\
\hline $\begin{array}{l}\text { Copper Clad } \\
\& \text { Copper Foil }\end{array}$ & 0.321 & 17.0 & 0.33 & 10.0 & 32.0 \\
\hline Glass/Capton & 0.009 & 2.5 & 0.4 & - & 35.0 \\
\hline $\begin{array}{l}\text { Pyralux } \\
\text { Adhesive }\end{array}$ & 0.0397 & 0.22 & 0.45 & - & 3.5 \\
\hline Kapton & 0.35 & 0.33 & 0.35 & - & 20.0 \\
\hline
\end{tabular}


Table 13: Steady-State Peak Effective Stresses in Actel 2x2 Circuit Board using 2-56 cap screws torqued to $6.3 \mathrm{lb}$-in.

\begin{tabular}{|c|c|c|c|}
\hline $\begin{array}{c}\text { Circuit board } \\
\text { material }\end{array}$ & $\begin{array}{c}\text { Maximum effective } \\
\text { stress at 0.36 mil of } \\
\text { compression and a } \\
\text { 254 lb load } \\
\text { (ksi) }\end{array}$ & $\begin{array}{c}\text { Maximum effective } \\
\text { stress at } 0.36 \\
\text { mil of compression } \\
\text { plus 10 mils of } \\
\text { deflection (ksi) }\end{array}$ & $\begin{array}{c}\text { Ultimate safety } \\
\text { factor at 0.36 mil of } \\
\text { compression plus 10 } \\
\text { mils of center } \\
\text { deflection }\end{array}$ \\
\hline $\begin{array}{c}\text { Solder mask } \\
\text { 60Sn-40Pb }\end{array}$ & 5.48 & 5.13 & 1.5 \\
\hline $\begin{array}{c}\text { Copper clad \& } \\
\text { Copper foil }\end{array}$ & 10.48 & 10.38 & 3.1 \\
\hline $\begin{array}{c}\text { Glass/Kapton } \\
\text { (FR-4) }\end{array}$ & 9.30 & 9.48 & 6.3 \\
\hline $\begin{array}{c}\text { Pyralux } \\
\text { adhesive }\end{array}$ & 2.93 & 3.01 & 1.2 \\
\hline Kapton & 5.44 & 5.22 & 3.8 \\
\hline
\end{tabular}

Dynamic analysis was performed on an earlier version of the $2 \times 2$ circuit board. Results from that study indicated that the board had a peak stress of $0.4 \mathrm{ksi}$ corresponding to a maximum deflection of 0.0048 inches at the center.

\subsection{Stress Analysis Summary}

Table 14 summarizes the highest stress seen in each component under all three loading conditions. Notice that the highest stress is seen under steady-state loading in the top cover of the camera housing. The stress is $16.6 \mathrm{ksi}$ and is well below the Yield Strength-(39 ksi) of 6061-T651 Aluminum. Thus, the minimum factor of safety is 2.3 which is well above the design factor of safety-(1.10) given in the Engineering and Test Specification document.

Table 14: Star Tracker Camera Yield Safety Factors for Different Environments

\begin{tabular}{|c|c|c|c|c|c|c|c|}
\hline & \multicolumn{3}{|c|}{$\begin{array}{l}\text { Highest Stress in } \\
\text { the component-ksi }\end{array}$} & \multicolumn{3}{|c|}{$\begin{array}{l}\text { Yield Safety Factor against } \\
\text { qualification Loads }\end{array}$} & $\begin{array}{l}\text { Yield } \\
\text { Safety }\end{array}$ \\
\hline $\begin{array}{c}\text { Star } \\
\text { Tracker }\end{array}$ & $\begin{array}{l}\mathrm{S}-\mathrm{S} \\
100^{\prime} \mathrm{g}\end{array}$ & $\begin{array}{c}\text { PSD } \\
14 \mathrm{gs}^{\prime} \\
\mathrm{rms}\end{array}$ & PYRO* & $\begin{array}{c}\text { S-S } \\
100^{\circ} g\end{array}$ & $\begin{array}{c}\text { PSD } \\
14 \mathrm{gs}^{\prime} \\
\mathrm{rms}\end{array}$ & PYRO & $\begin{array}{c}\mathrm{S}=\mathrm{S} \\
\mathrm{Design} \\
14^{\prime} \mathrm{gs}\end{array}$ \\
\hline $\begin{array}{l}\text { Camera } \\
\text { Housing }\end{array}$ & 16.6 & 3.79 & & 2.3 & 10.3 & & 16.4 \\
\hline $\begin{array}{l}\text { Housing } \\
\text { Gussets }\end{array}$ & 15.1 & 2.7 & & 2.6 & 14.4 & & 18.6 \\
\hline $\begin{array}{c}\text { Baffle } \\
\text { Gussets }\end{array}$ & 2.3 & 1.0 & & 17 & 39 & & 121 \\
\hline Vane \#1 & 9.05 & $<0.1$ & & 4.3 & $>39$ & & 30.7 \\
\hline $\begin{array}{l}\text { Mounting } \\
\text { Brackets }\end{array}$ & 3.77 & $<0.5$ & & 10.3 & $>39$ & & 73.5 \\
\hline
\end{tabular}


${ }^{*}$ Not computed for individual parts

6.0 Star Tracker Structural Analysis Summary

Camera meets all mission requirements and is qualified by analysis.

\subsection{References}

J. Houghton, "Engineering Specification and Test Plan", NRL Document, September, 1992.

\subsection{Appendix}

\subsection{Qualification of Camera using Static Analysis}

A separate analysis was done to verify that a static analysis at a steady-state 100 G's in each of the three orthogonal axes qualifies a Star Tracker Camera sized payload to survive the dynamic Titan IIG testing and launch environments. A mock payload was generated with similar mass properties and mode frequencies to the Star Tracker Camera. The finite element model of this mock payload had a much smaller number of elements than the complete Star Tracker Camera finite element model. Because of its reduced size, both the steady-state and dynamic analysis could be performed on this model within a reasonable amount of computer run time. Figures 55-57 and Table 15 show the first four mode shapes and natural frequencies of the mock payload. The first two modes are cantilever bending modes similar to those of the Star Tracker Camera.

Table 15: Mock payload mode shapes and natural frequencies

\begin{tabular}{|c|c|l|}
\hline Mode number & \multicolumn{1}{|c|}{$\begin{array}{c}\text { Natural frequency } \\
(\mathbf{H z})\end{array}$} & \multicolumn{1}{|c|}{ Mode shape } \\
\hline 1 & 265 & Cantilever bending $X-X$ \\
\hline 2 & 265 & Cantilever bending $Y-Y$ \\
\hline 3 & 675 & Mock baffle panel breathing \\
\hline 4 & 840 & Mock baffle panel bending \\
\hline
\end{tabular}

Figures 58-61 show the steady-state stresses and deflections of the mock payload calculated for the $100 \mathrm{~g} \mathrm{X}, Y$, and $Z$ acceleration conditions applied separately. Figures 62-68 show the dynamic stresses and deflections calculated for the $\mathbf{2 0}$ ms pyro-shock loading five interfaces removed from the source. Three unique pryoshock loading conditions were applied simultaneously in the three orthogonal directions. This loads the model in all three directions as a vector sum and is also an over load by a factor of the square root of 3 because of the vector sum. Finally Figures 69-75 show the dynamic stresses and deflections calculated for the mock payload being exposed to $60 \mathrm{~ms}$ of acceleration vs time random vibration from three 14 Grms PSD curves applied simultaneously in the three orthogonal 
directions. Here there is also an overload by a factor of the square root of 3 because of the vector sum. The analysis is linear elastic and the dynamic values in Table 16 have been divided by 1.732 to correct for the square root of 3 overload.

In all cases in Table 16, the stress and deflection calculated for the steady-state loading is larger than that for the dynamic loading. If the steady-state calculations show large safety factors, then the steady-state analysis is sufficient and the dynamic analysis is not necessary. However, if the safety factors are near 1.0 then the dynamic analysis is necessary and may uncover some structural weaknesses.

Table 16: Summary of the mock payload steady state and dynamic comparison

\begin{tabular}{||l|c|c|c|}
\hline \multicolumn{1}{|c|}{ Loading direction } & $\begin{array}{c}\text { Time of maximum } \\
\text { stress (sec) }\end{array}$ & $\begin{array}{c}\text { Maximum effective } \\
\text { stress (ksi) }\end{array}$ & $\begin{array}{c}\text { Maximum } \\
\text { deflection at end } \\
\text { of Baffle (in.) }\end{array}$ \\
\hline \hline X 100 G's & steady state & 3.38 & 0.016 \\
\hline Y 100 G's & steady state & 3.38 & 0.016 \\
\hline Z 100 G's & steady state & 0.84 & 0.002 \\
\hline \hline X Pyro-shock & 0.01425 & 1.26 & 0.0021 \\
\hline Y Pyro-shock & 0.01609 & 2.35 & 0.0046 \\
\hline Z Pyro-shock & 0.00761 & 0.95 & 0.0014 \\
\hline \hline X14 Grms random & 0.0488 & 2.09 & 0.0072 \\
\hline Y14 Grms random & 0.0321 & 3.16 & 0.0125 \\
\hline Z14 Grms random & 0.0012 & 0.40 & 0.0091 \\
\hline
\end{tabular}




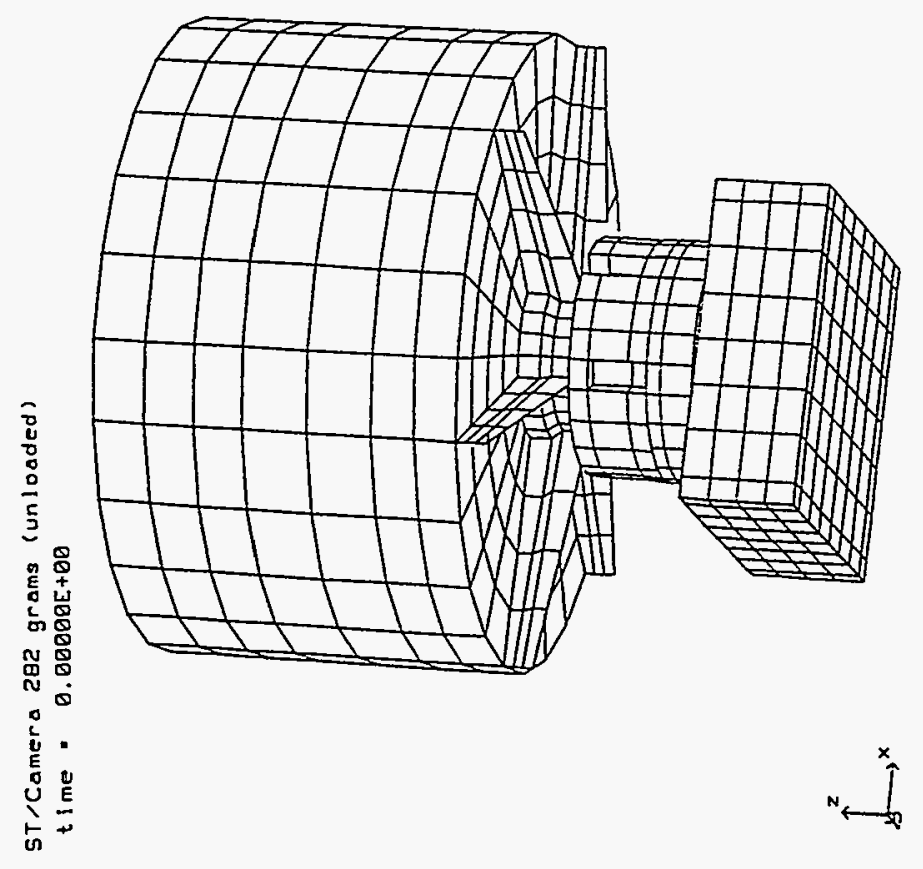

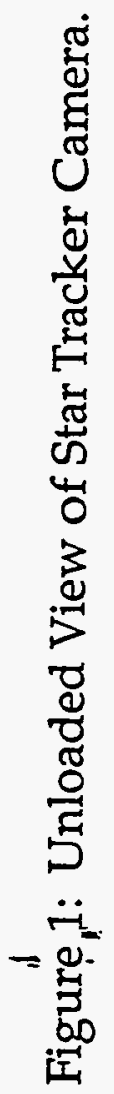

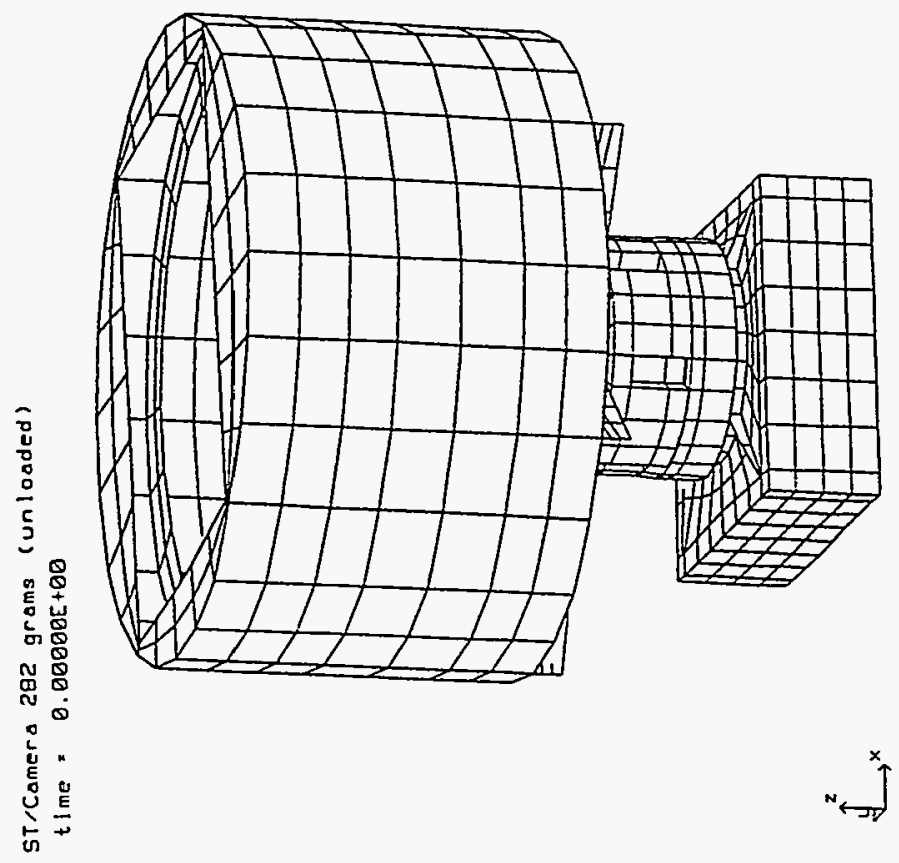


ST/Camera 282 grams exploded view

time $=0.00000 \mathrm{E}+00$

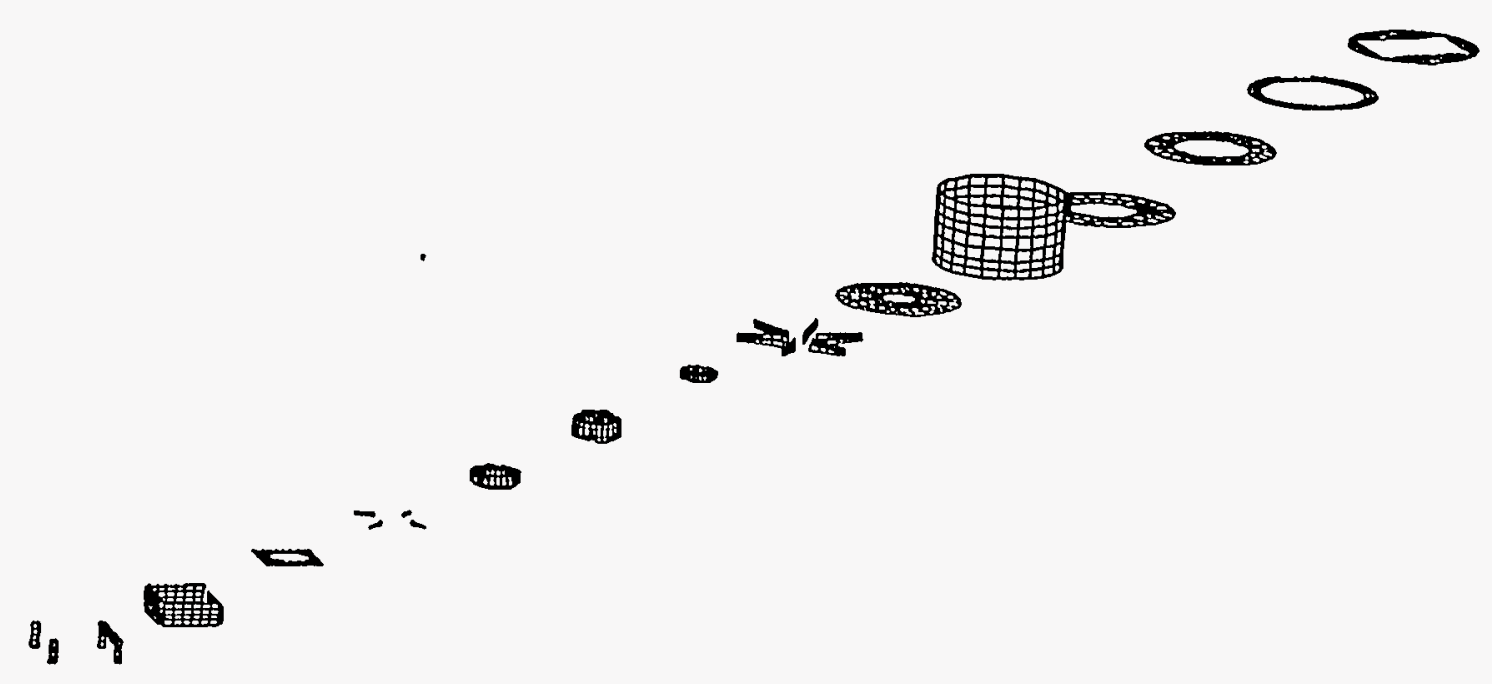

$\underbrace{\mathcal{H}^{2}} \mathrm{x}^{\mathrm{x}}$

Figure 2: Exploded View of Star Tracker Camera Components. 

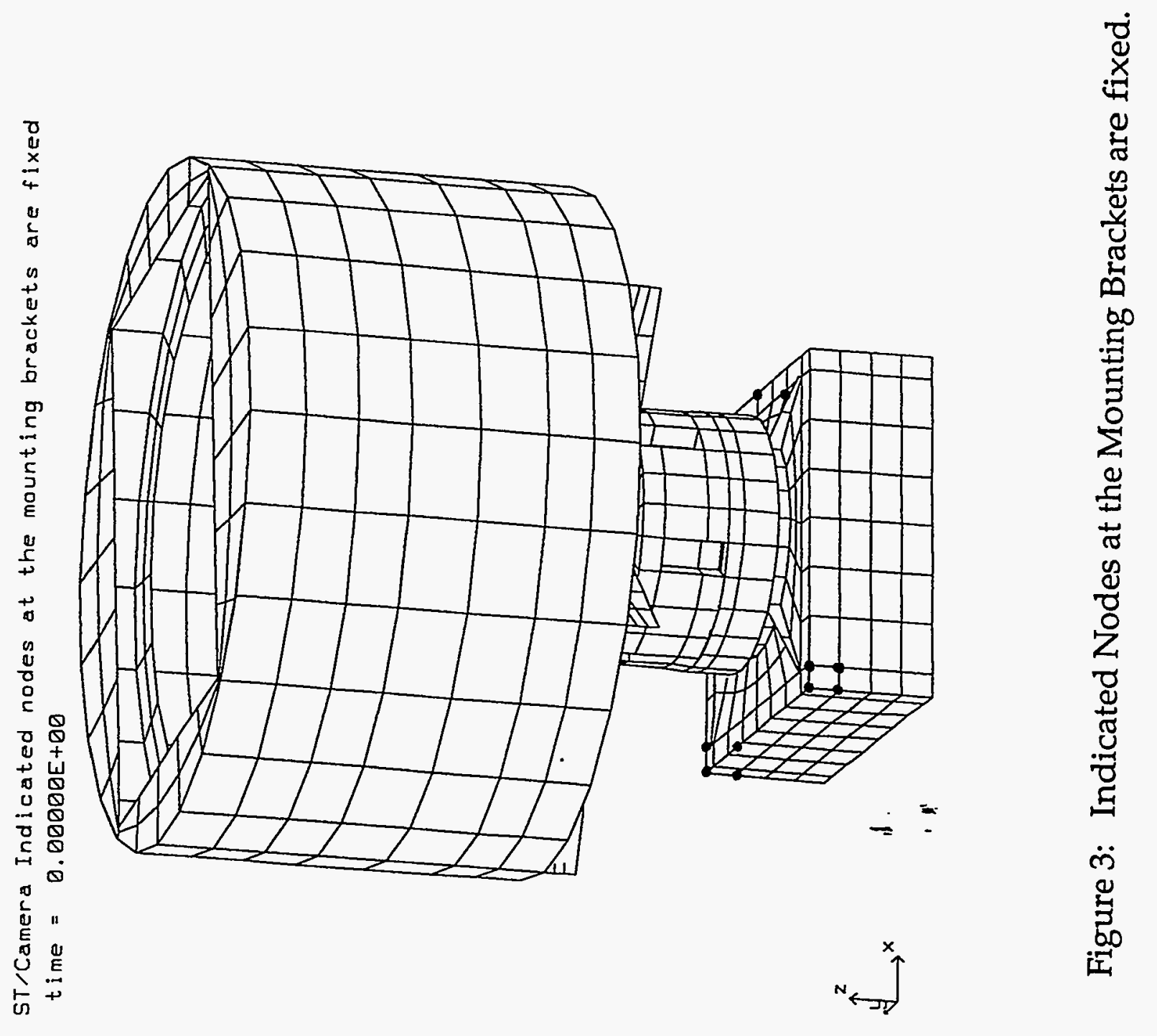


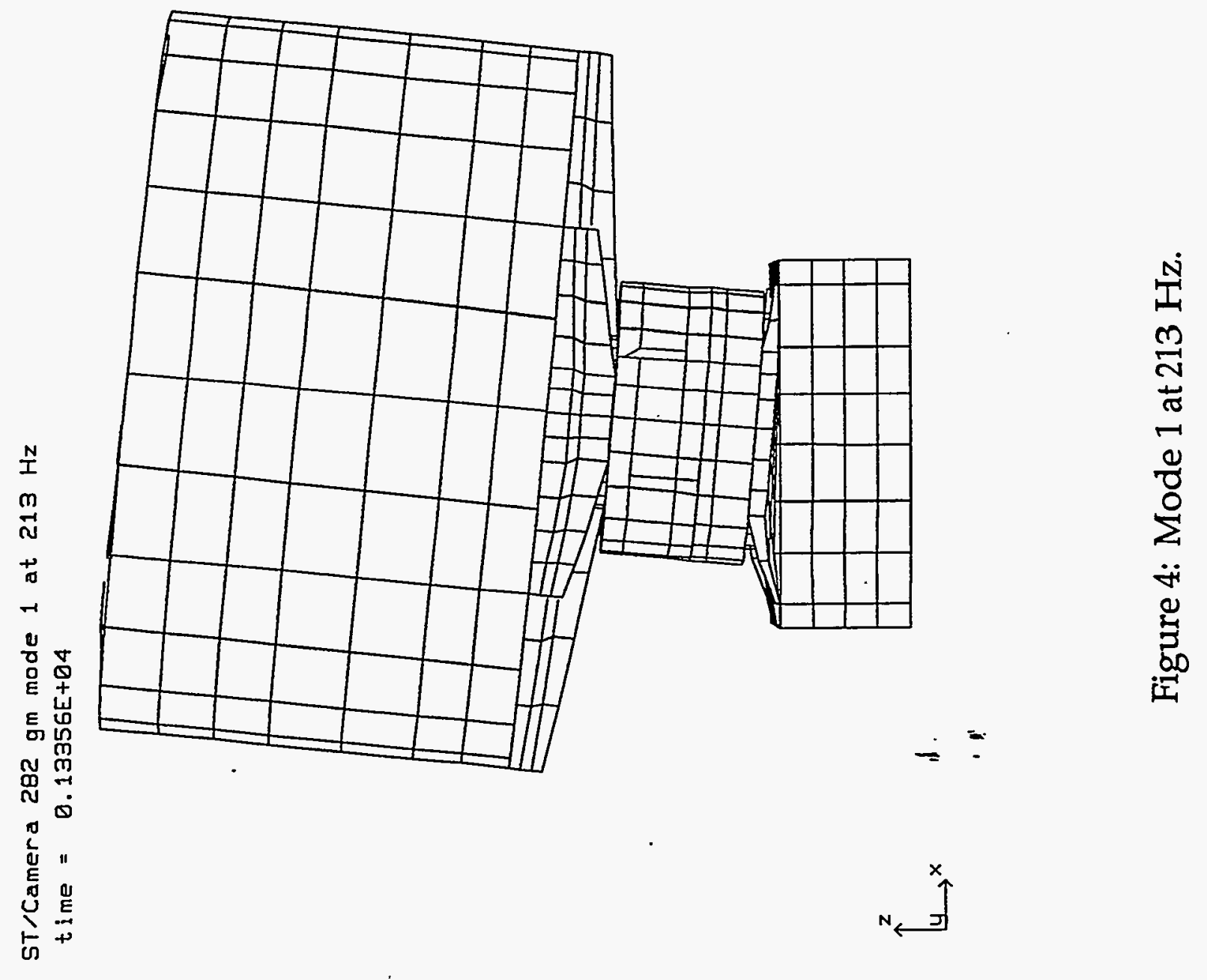


$S T / C a m e r a$ mode 2 at $219 \mathrm{~Hz}$

time $=0.13746 E+04$

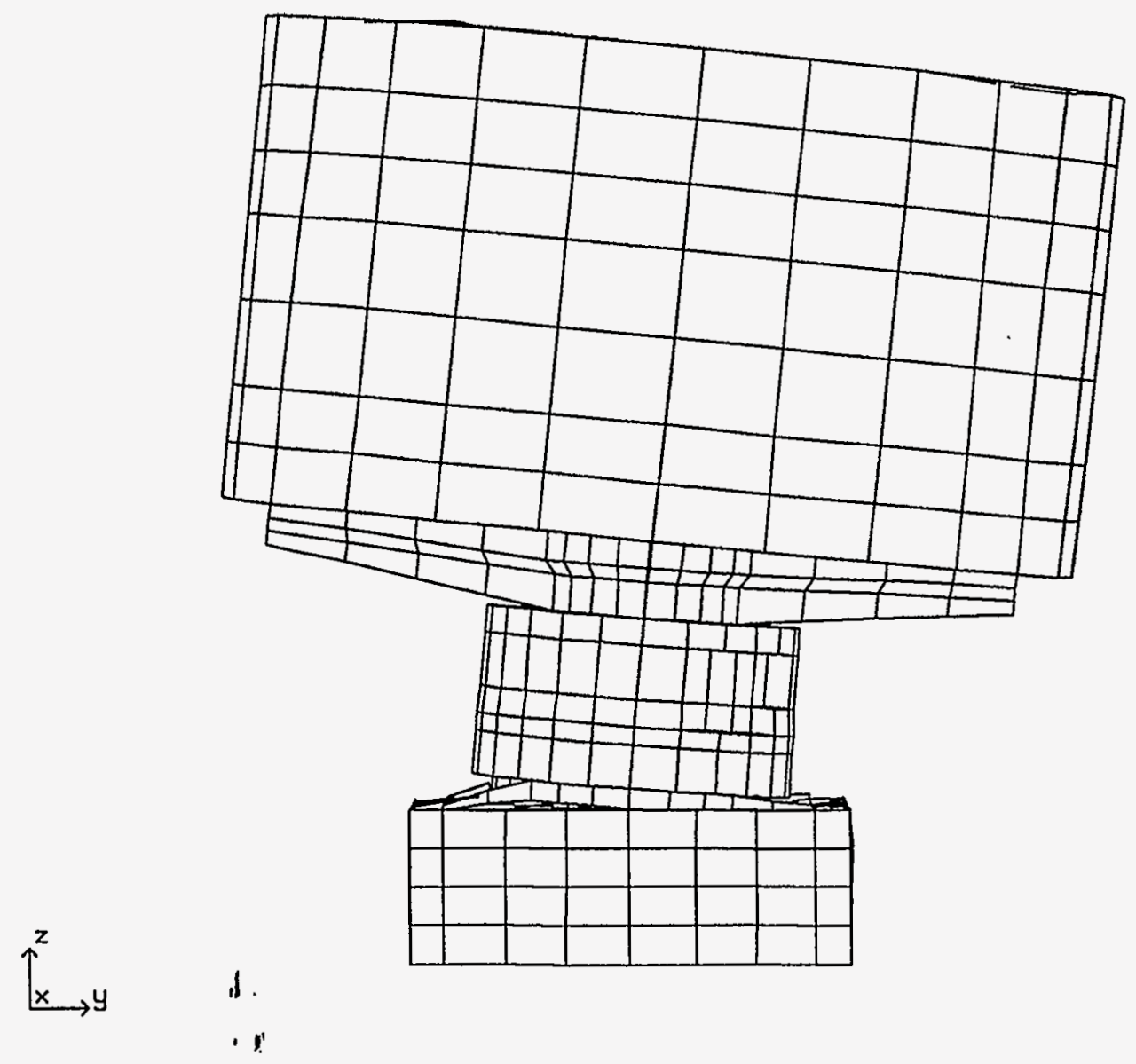

Figure 5: Mode 2 at $219 \mathrm{~Hz}$. 
ST/Camera mode $\exists$ at $286 \mathrm{~Hz}$

time $=0.17956 E+04$

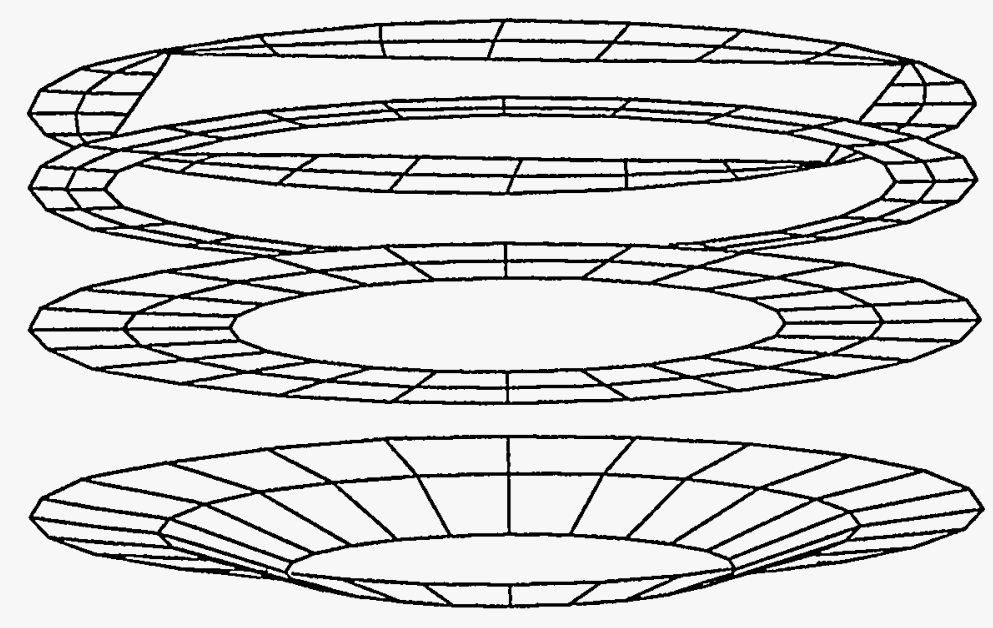

$\varlimsup_{y \rightarrow x}^{z}$

Figure 6: Mode 3 at $286 \mathrm{~Hz}$. 
ST/Camera mode 4 at $353 \mathrm{~Hz}$

time $=0.22193 \mathrm{E}+04$

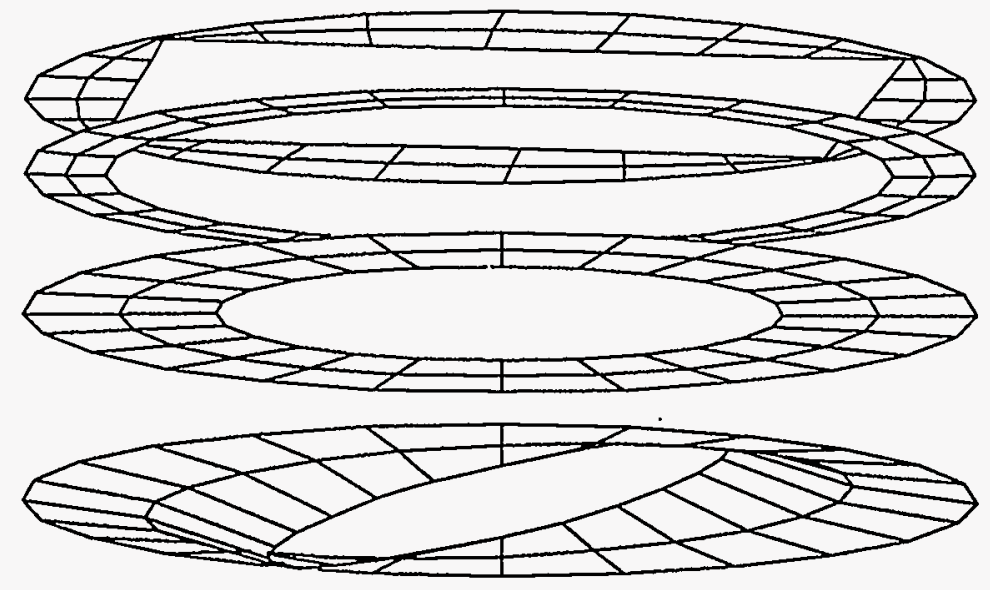

$\uparrow_{y \rightarrow x}^{2}$

Figure 7: Mode 4 at $353 \mathrm{~Hz}$. 
ST/Camera mode 5 at $422 \mathrm{~Hz}$

time $=0.26495 E+04$

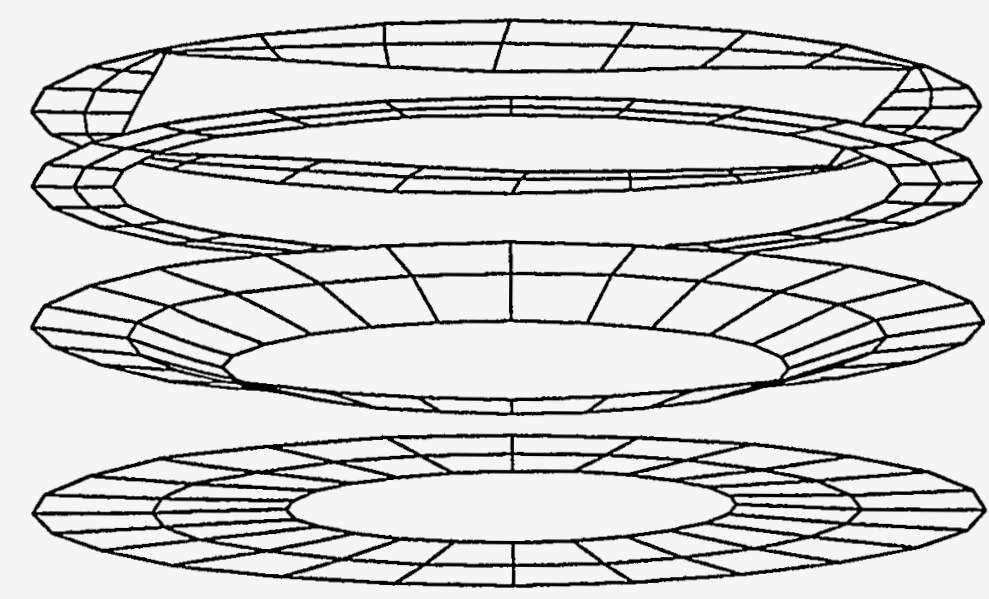

$\uparrow_{y \rightarrow x}^{2}$

Figure 8: Mode 5 at $422 \mathrm{~Hz}$. 


\subsubsection{General Component Steady State Accelerations}

The component(s) shall be shown by analysis or test to be capable of withstanding a steady state inertial acceleration load in each of its 3 principal orthogonal axis. If a test is used to fulfill this requirement, the applicable loads are taken directly from Figure 3.1.2-1 of the DSPSE Structural Analysis Plan. If the components are qualified by analysis, use loads that are equal to the test loads multiplied by a factor of 2 .

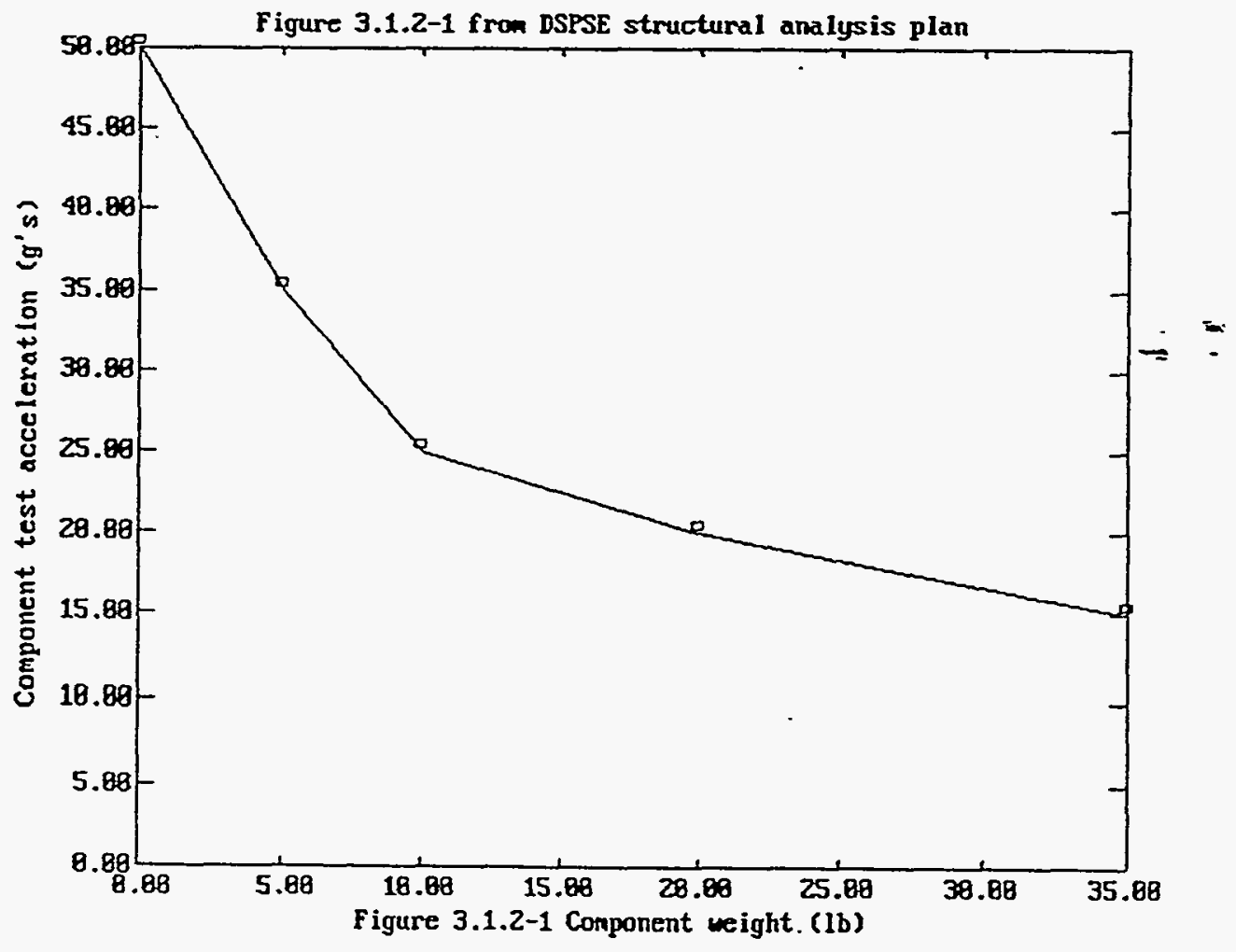




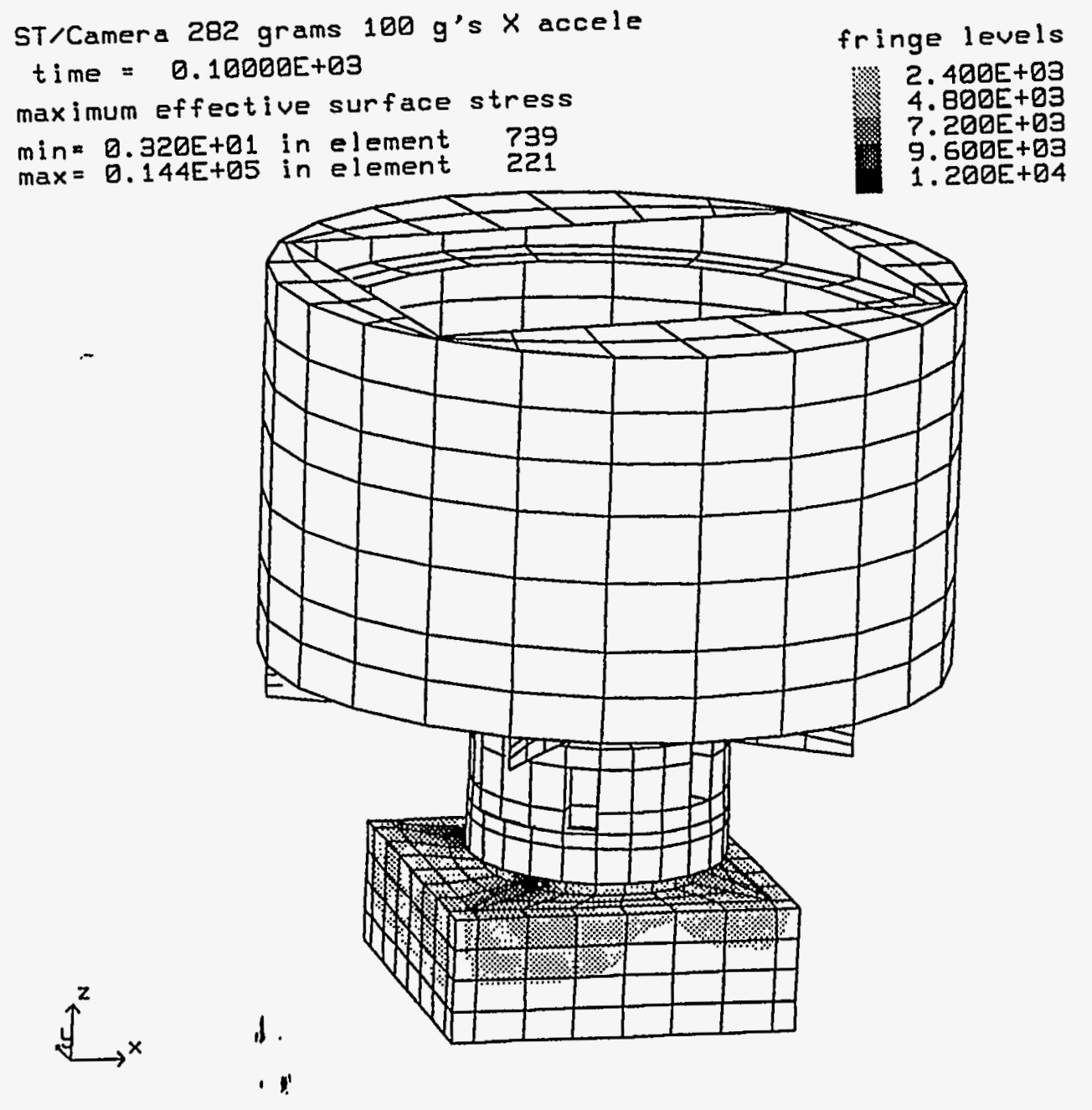

Figure 10: Star Tracker Camera Steady-State Stress Fringes under xdirection loading. 
ST/Camera 282 grams 100 g's $X$ accele

time $=0.10000 E+03$

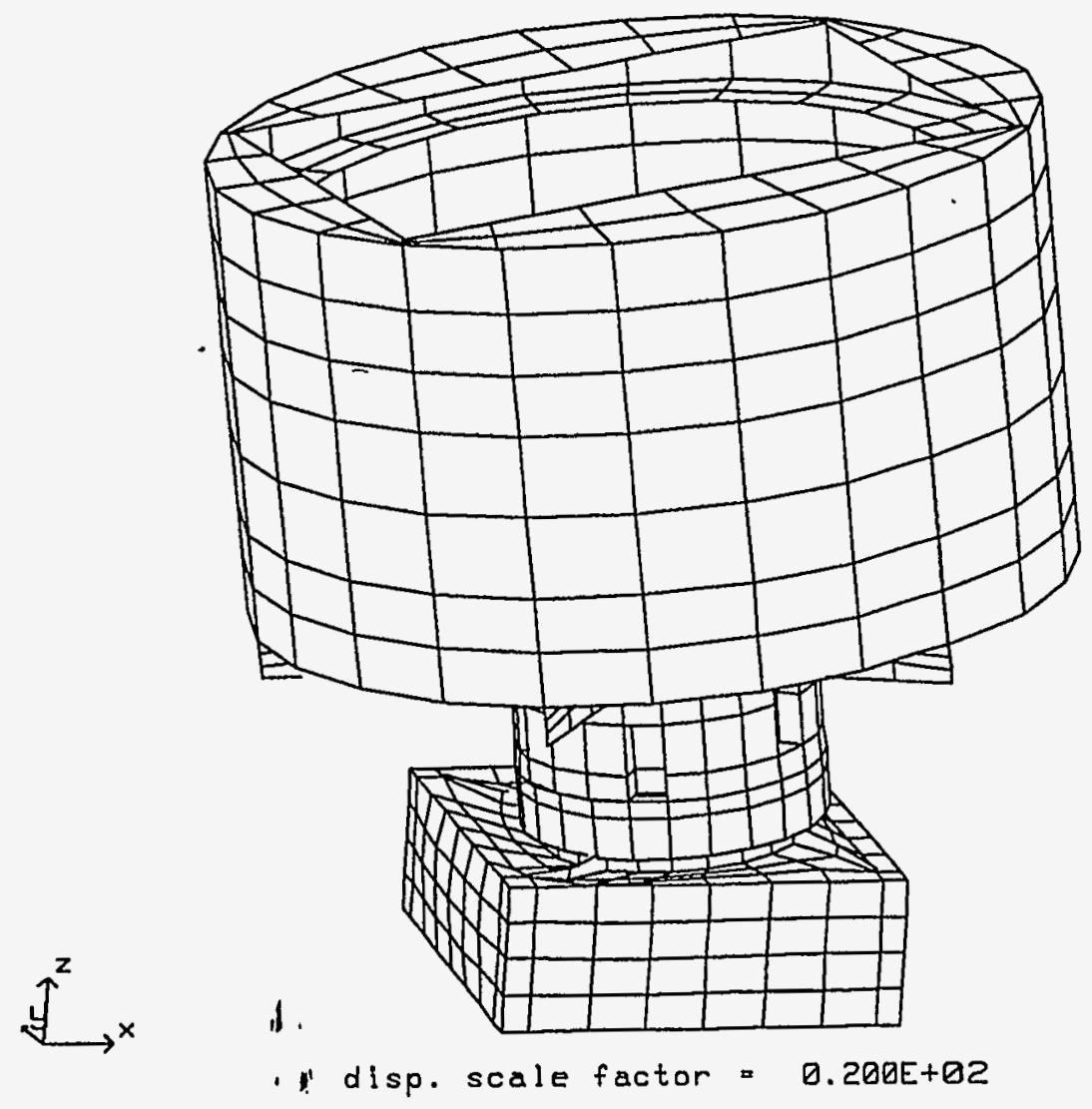

Figure 11: Star Tracker Camera Deflection under $x$-direction loading. 
ST/Camera 282 grams $100 \mathrm{~g}$ 's $X$ accele

time $=0.10000 E+03$

maximum effective surface stress

$\mathrm{min}=0.157 \mathrm{E}+03$ in element 89

$\max =0.144 E+05$ in element 221

fringe levels

\% 2. 400E+03

4. $800 \mathrm{E}+03$

. $200 \mathrm{E}+03$

9. 60日E +03

1. $200 E+04$

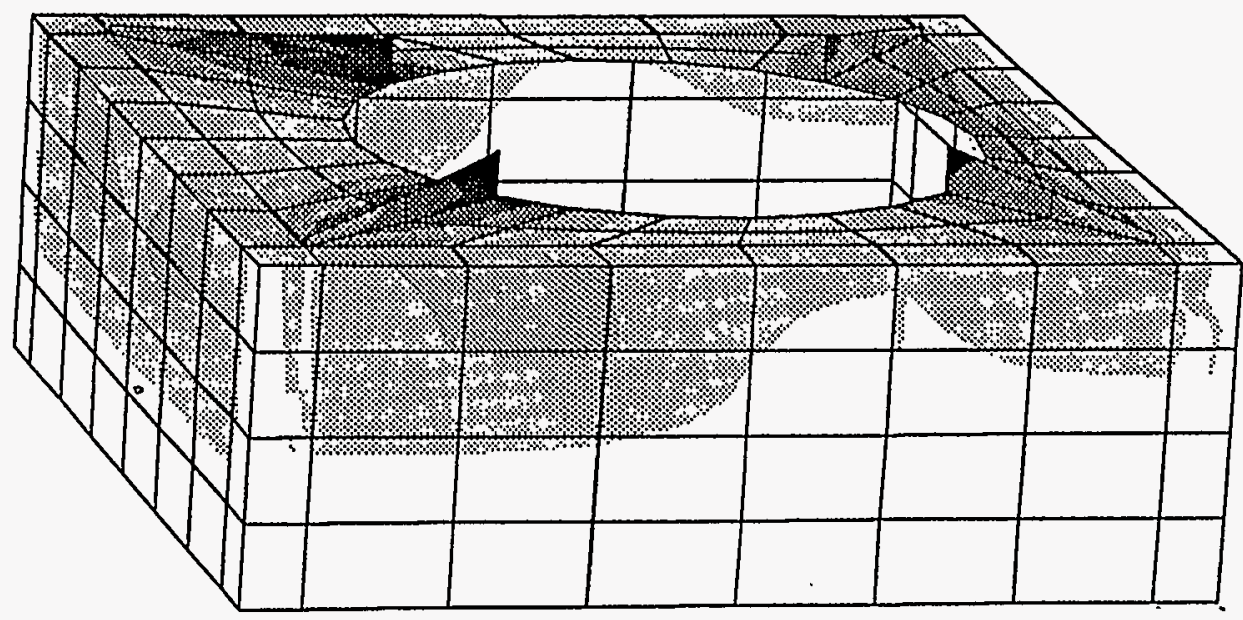

$\underbrace{2} x^{x}$

Figure 12: Enlarged View of Stress Fringes on Top Cover of Camera Housing under $x$-direction loading. 


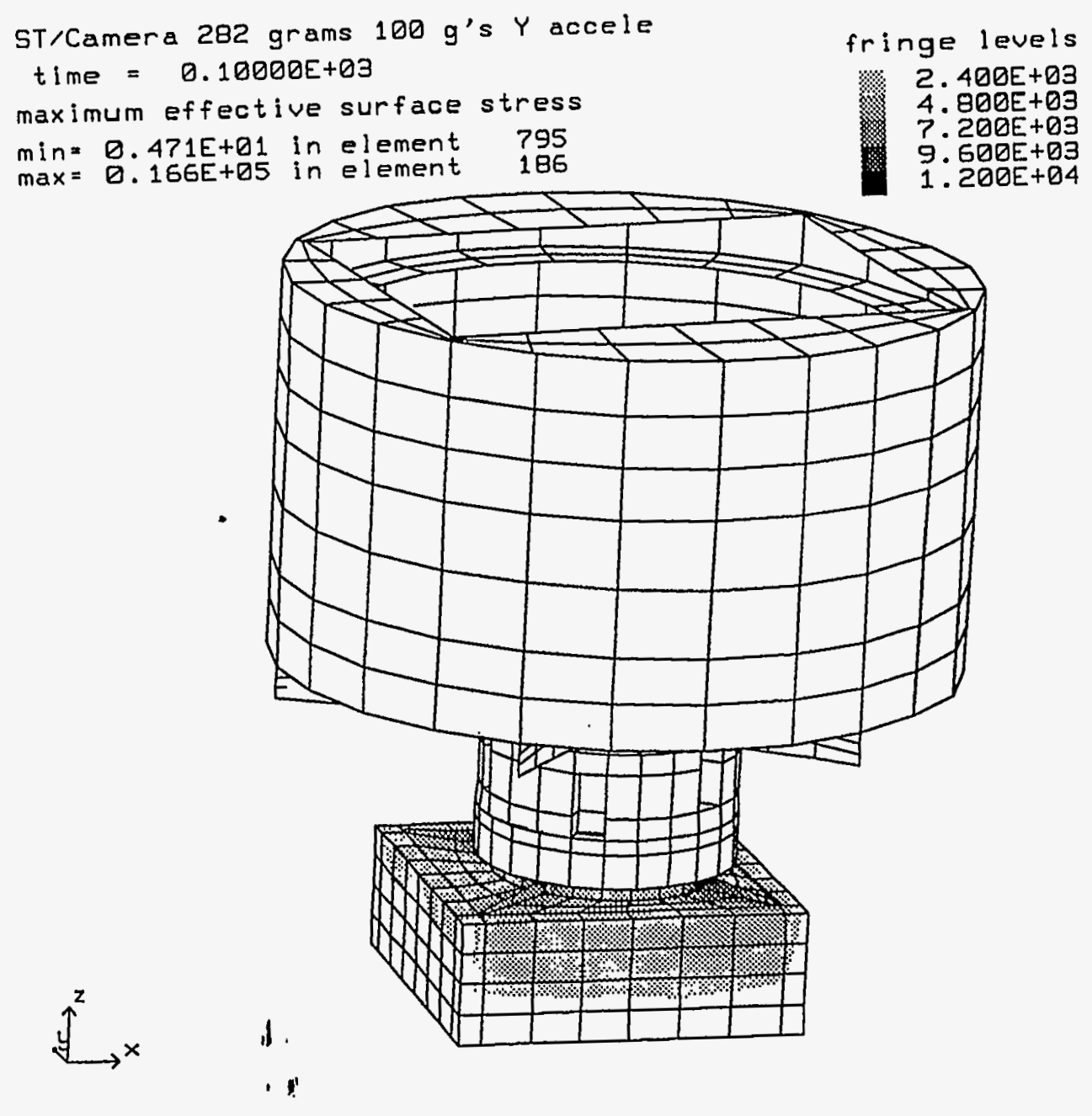

Figure 13: Star Tracker Camera Steady-State Stress Fringes under ydirection loading. 
ST/Camera 282 grams $100 \mathrm{~g}$ 's $Y$ accele

time $=0.10000 E+03$

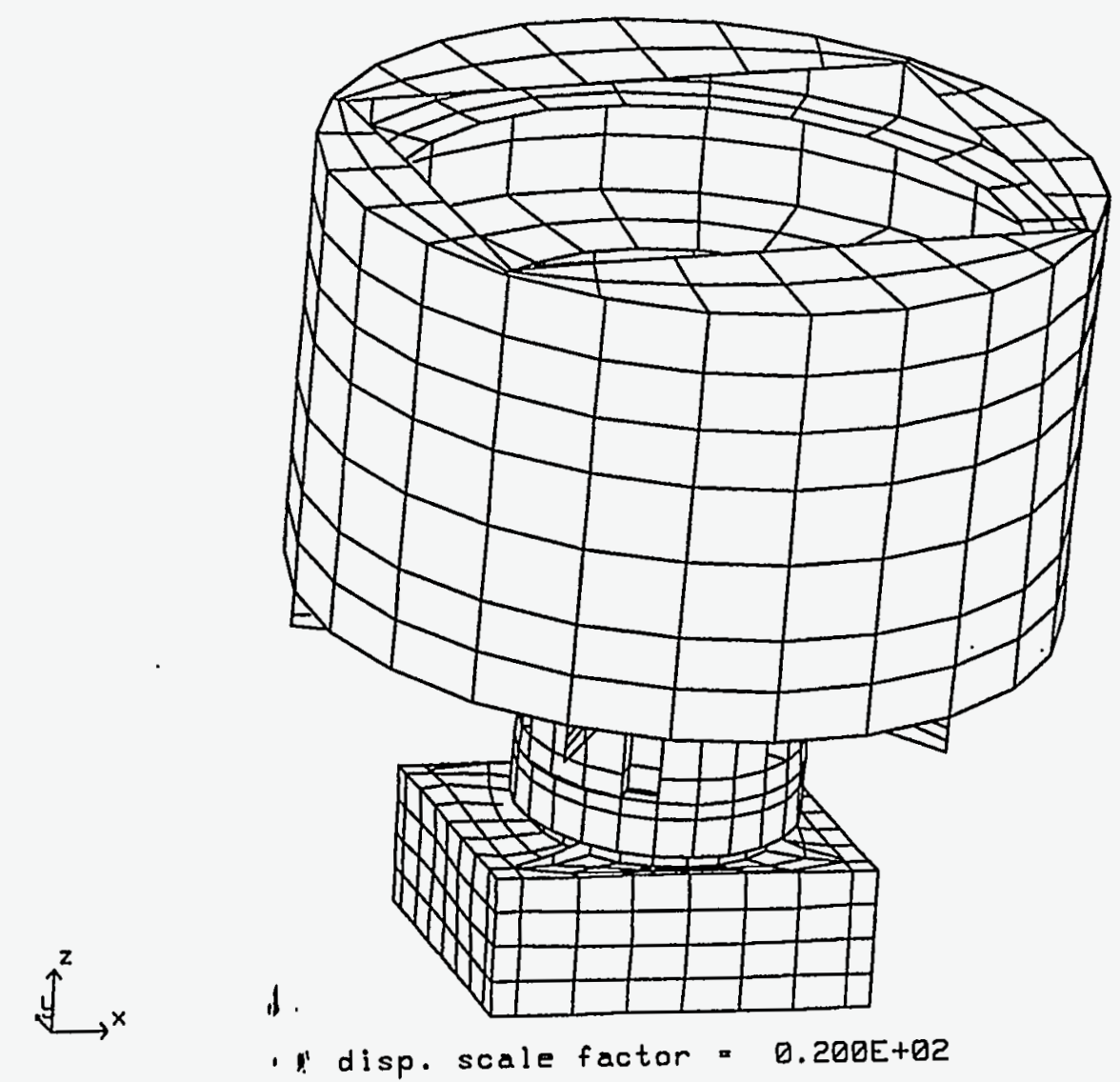

Figure 14: Star Tracker Camera Deflection under $y$-direction loading. 
ST/Camera 282 grams $100 \mathrm{~g}$ 's $Y$ accele

\section{time $=0.10000 E+03$}

maximum effective surface stress

$\min =0.396 E+03$ in element

$\max =0.166 \mathrm{E}+05$ in element

186 fringe levels

\% 2. 400E+03

$4.800 E+03$

$7.200 E+03$

ง. $600 E+03$

1. $200 \mathrm{E}+04$

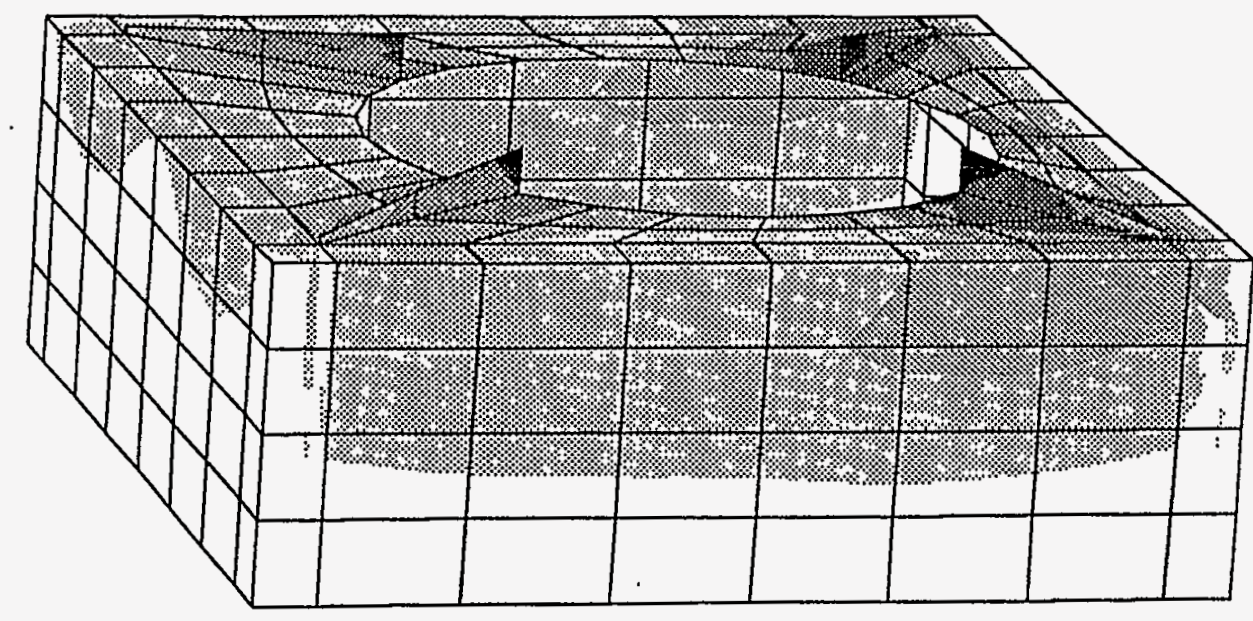

$\overbrace{}^{2} \times$

Figure 15: Enlarged View of Stress Fringes on Top Cover of Camera Housing under y-direction loading. 


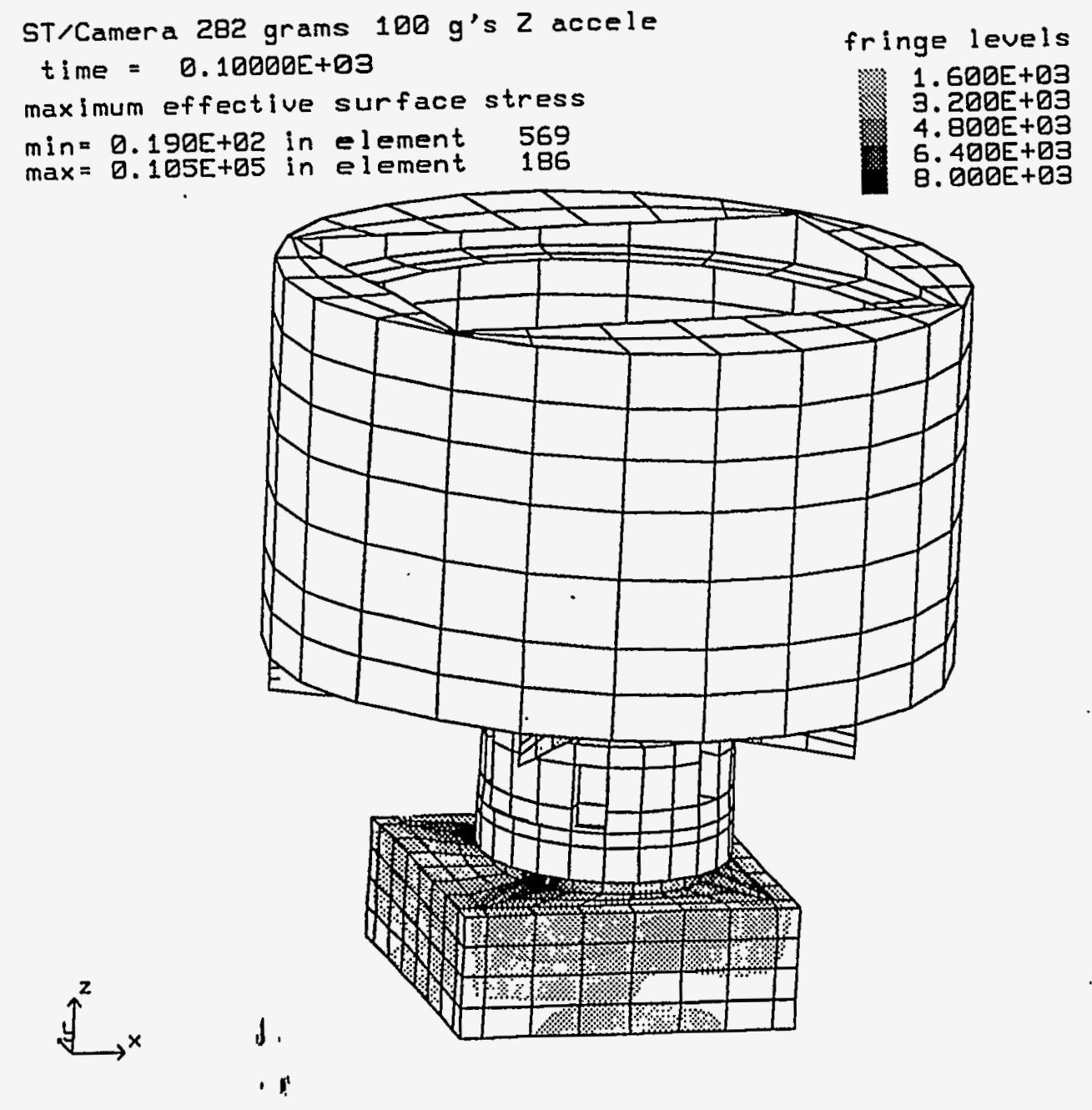

Figure 16: Star Tracker Camera Steady-State Stress Fringes under zdirection loading. 
ST/Camera 282 grams $100 \mathrm{~g}$ 's $Z$ accele

time $=0.10000 \mathrm{E}+03$

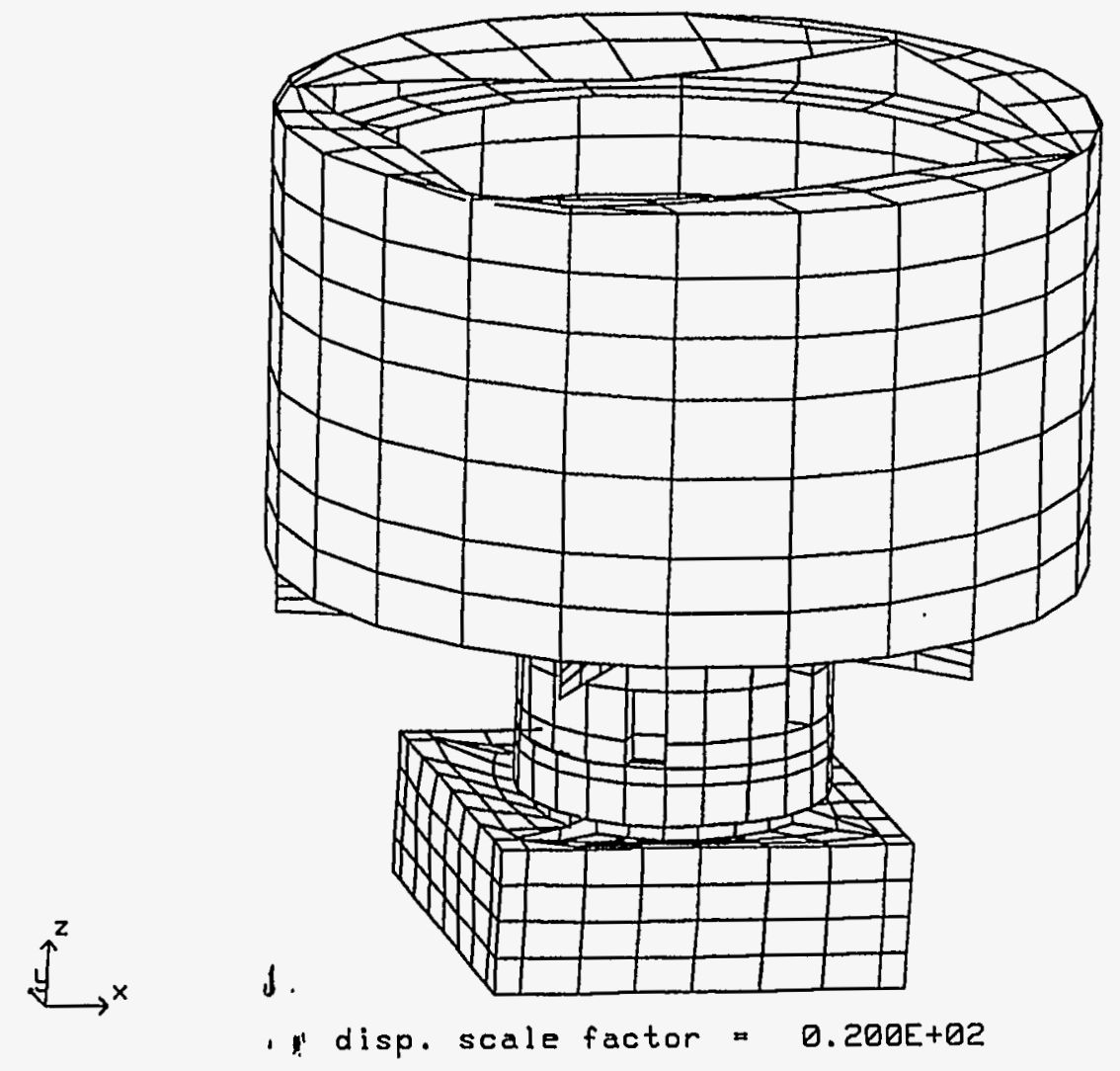

Figure 17: Star Tracker Camera Deflection under z-direction loading. 
ST/Camera 282 grams $100 \mathrm{~g}$ 's $Z$ accele time $=0.10000 \mathrm{E}+03$

maximum effective surface stress

$\min =0.326 E+03$ in element 130

$\max =0.105 E+05$ in element 186

fringe levels

\% $1.600 E+03$

3. $200 \mathrm{E}+03$

4. $800 \mathrm{E}+03$

4. $400 E+03$

8. $000 E+03$

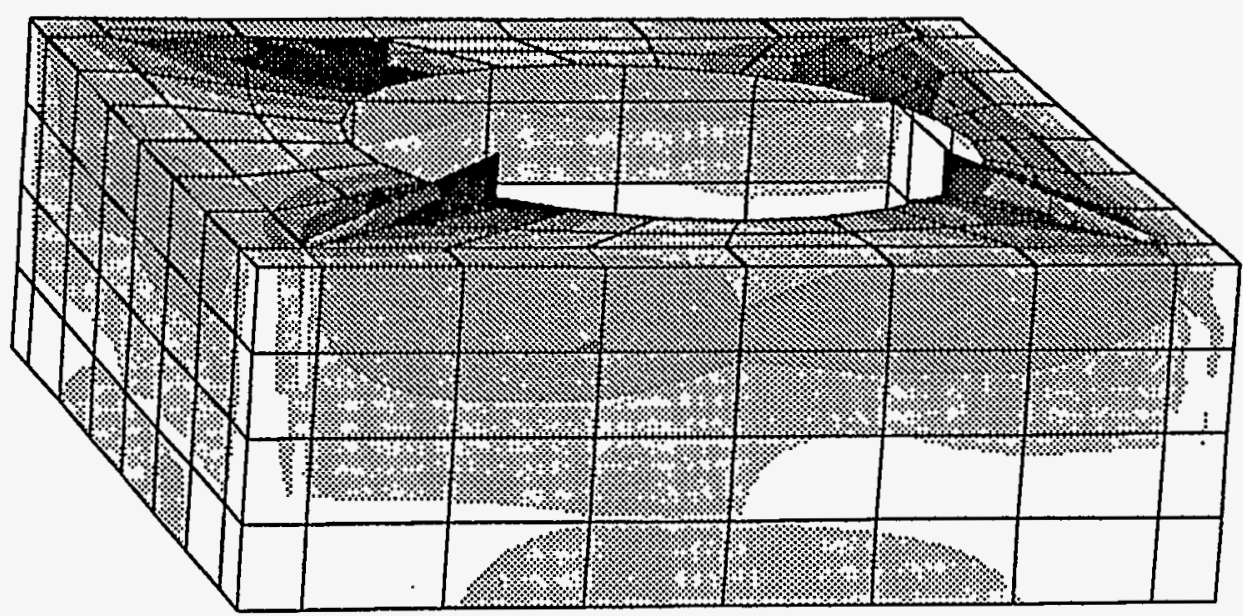

$\underbrace{2} x^{x} d$

Figure 18: Enlarged View of Stress Fringes on Top Cover of Camera Housing under z-direction loading. 
Vane \#4 with 6 spot welds $-100 \mathrm{~g}^{\prime}$ s acceleration time $=0.10000 E+03$

finge levels

maximum effective surface stress

$\min =0.318 E+03$ in element

$\max =0.905 E+04$ in element

170

1. $100 \mathrm{E}+03$

2. $400 E+03$

. $600 \mathrm{E}+03$

$4.800 \mathrm{E}+03$

$6.000 E+03$

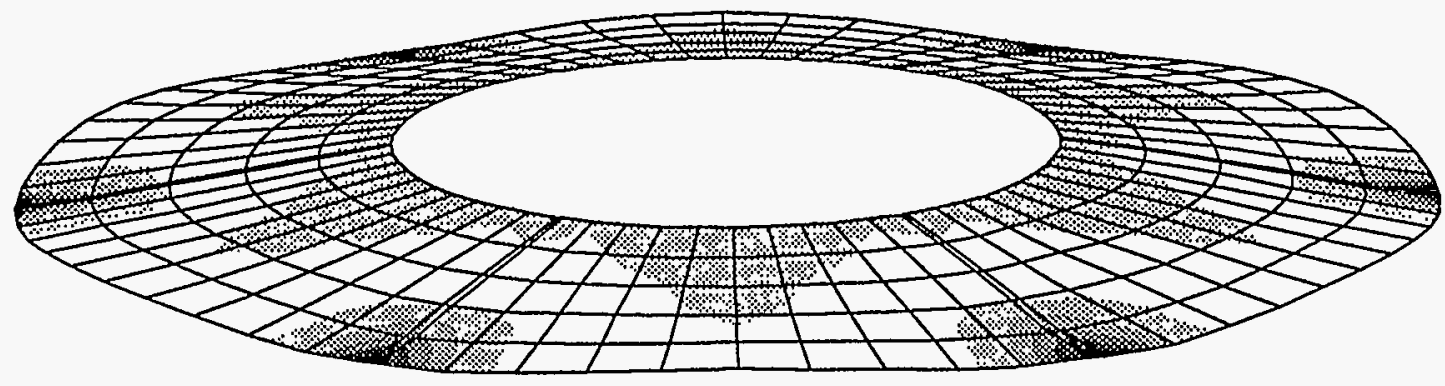

$d$

- disp. scale factor $=0.100 E+02$

Figure 19: Steady-State Stress Fringes in Vane \#4 under z-direction loading. 


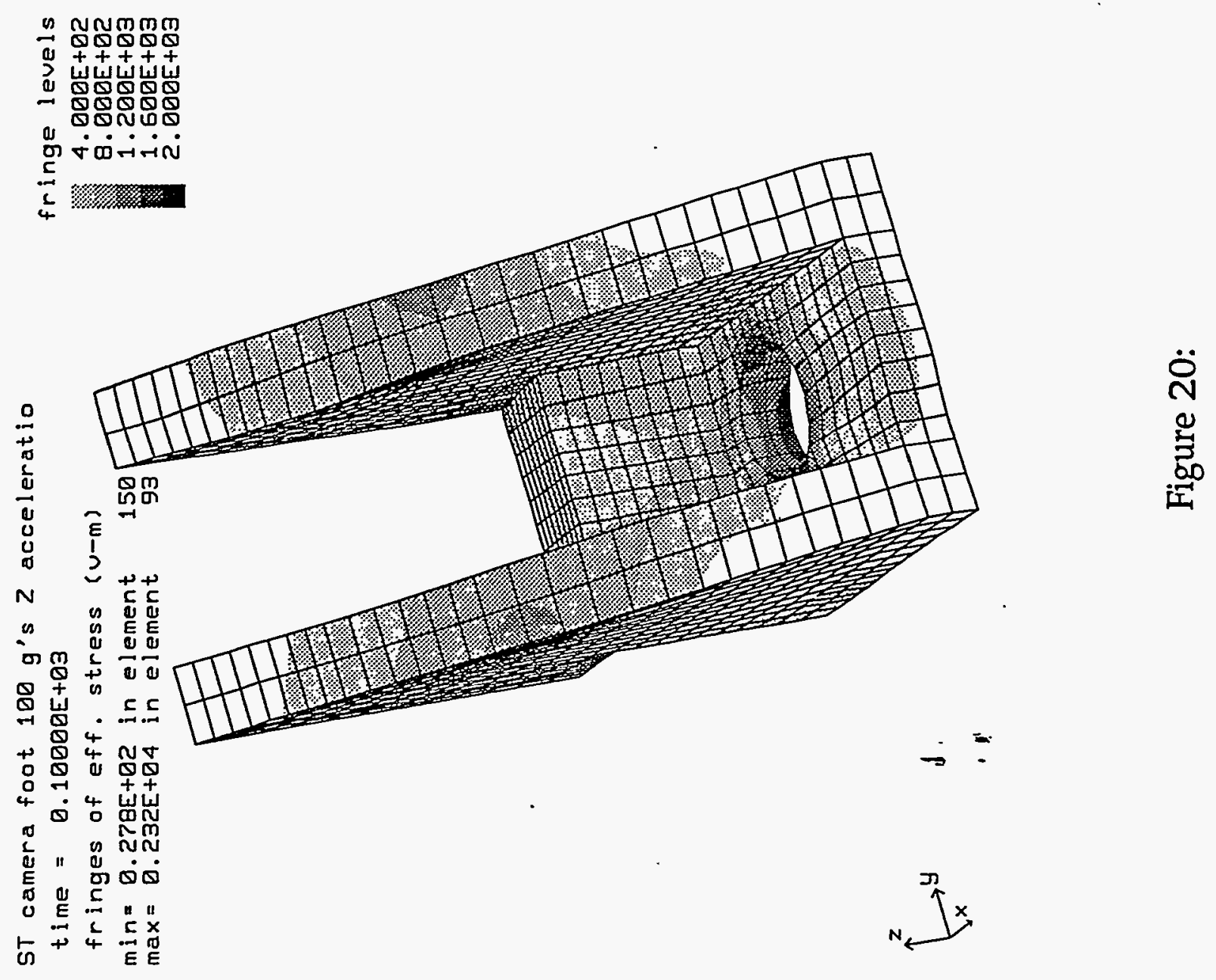


ST camera foot $100 \mathrm{~g}^{\prime} \mathrm{s} Z$ acceleratio

time $=0.10000 E+03$

maximum effective surface stress

$\min =0.994 E+02$ in element

$\max =0.167 \mathrm{E}+04$ in element

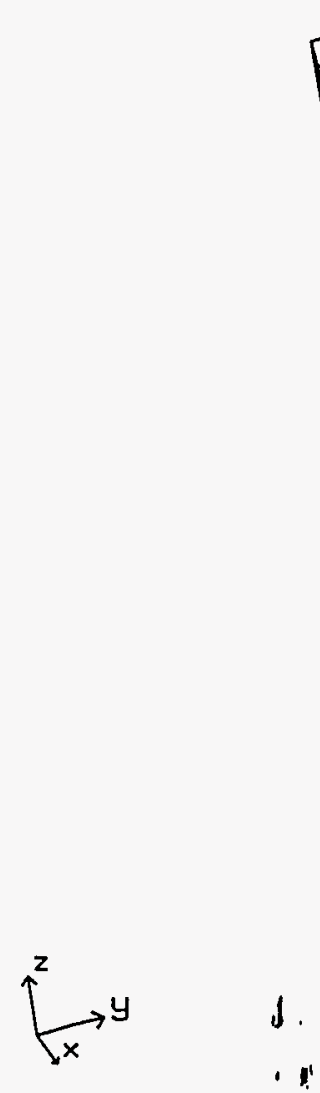

fringe levels

4. $400 \mathrm{E}+02$

4. $000 E+02$
$8.000 E+02$
$1.200 E+03$

$1 \cdot 600 E+03$

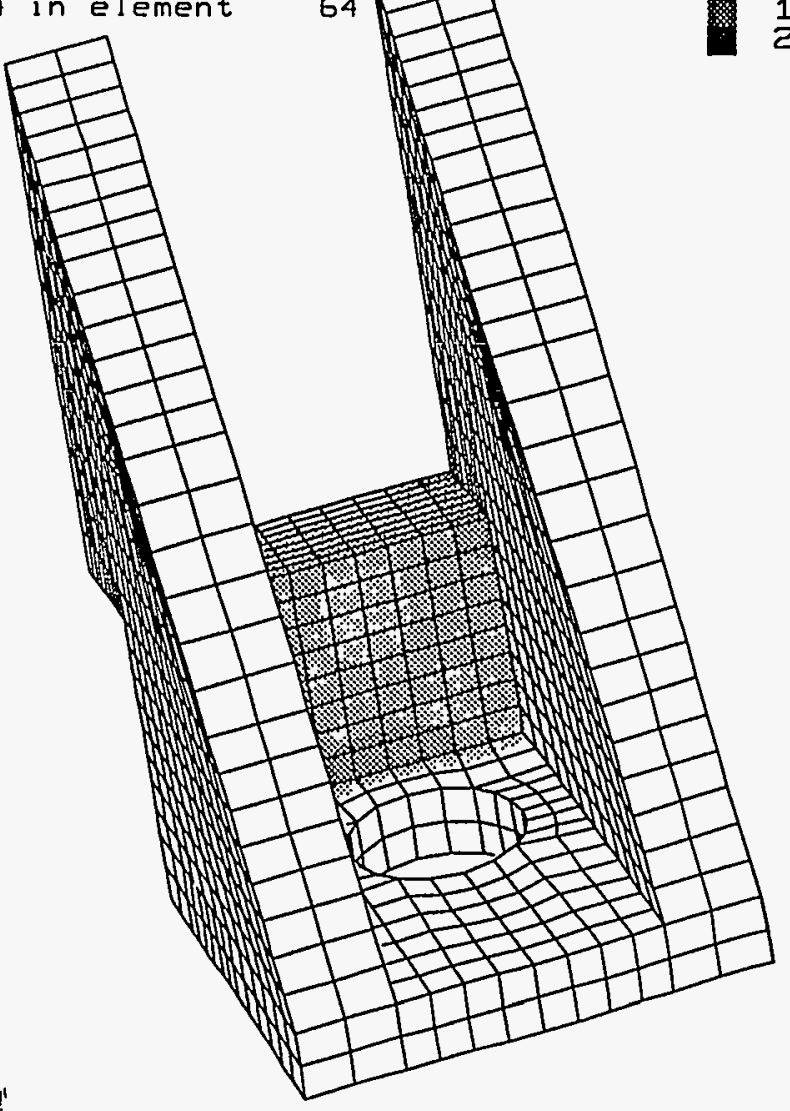

Figure 21: 


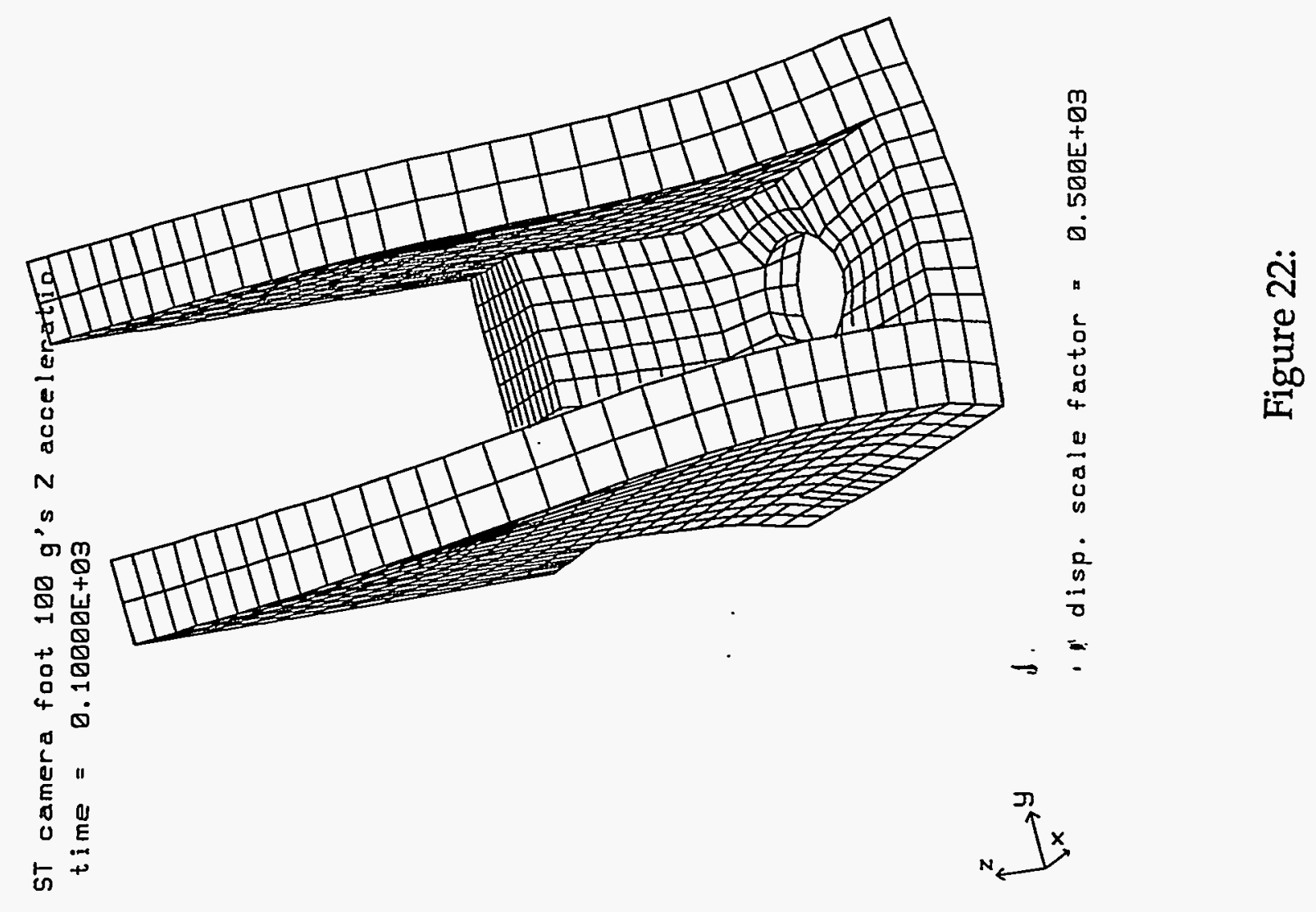




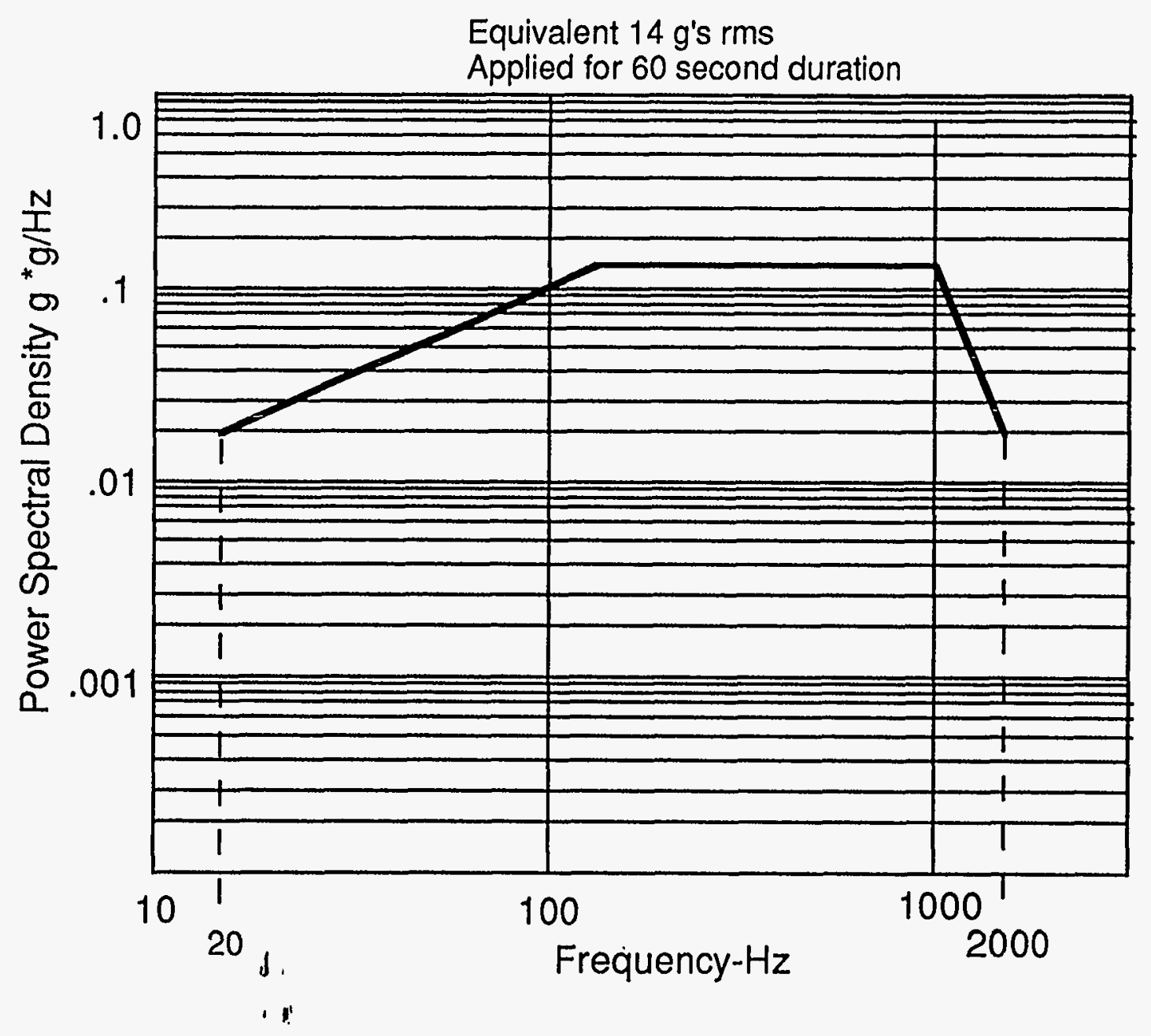

Figure 23: DSPSE Protoflight Random Vibration Spectrum Test Level 


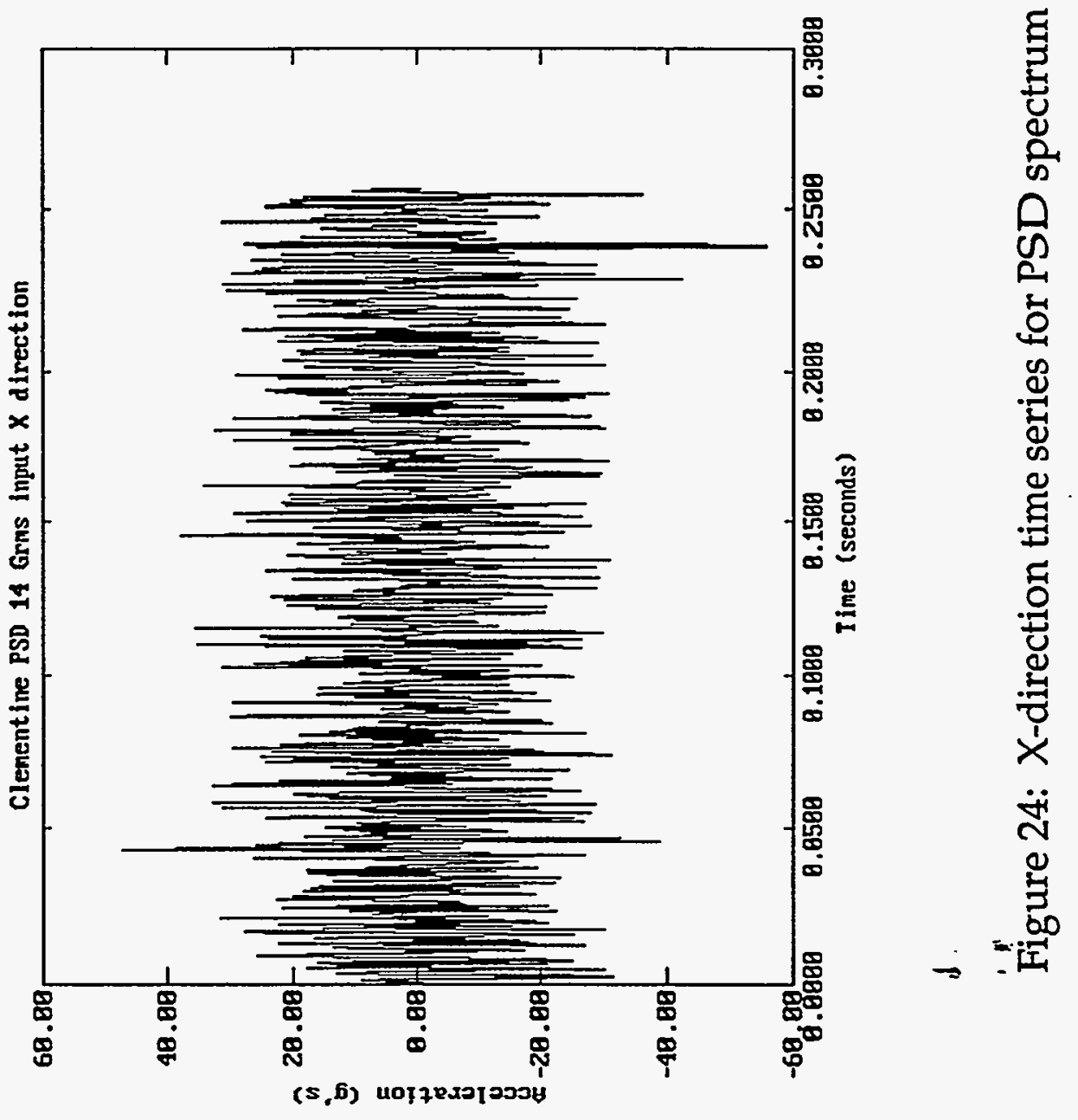




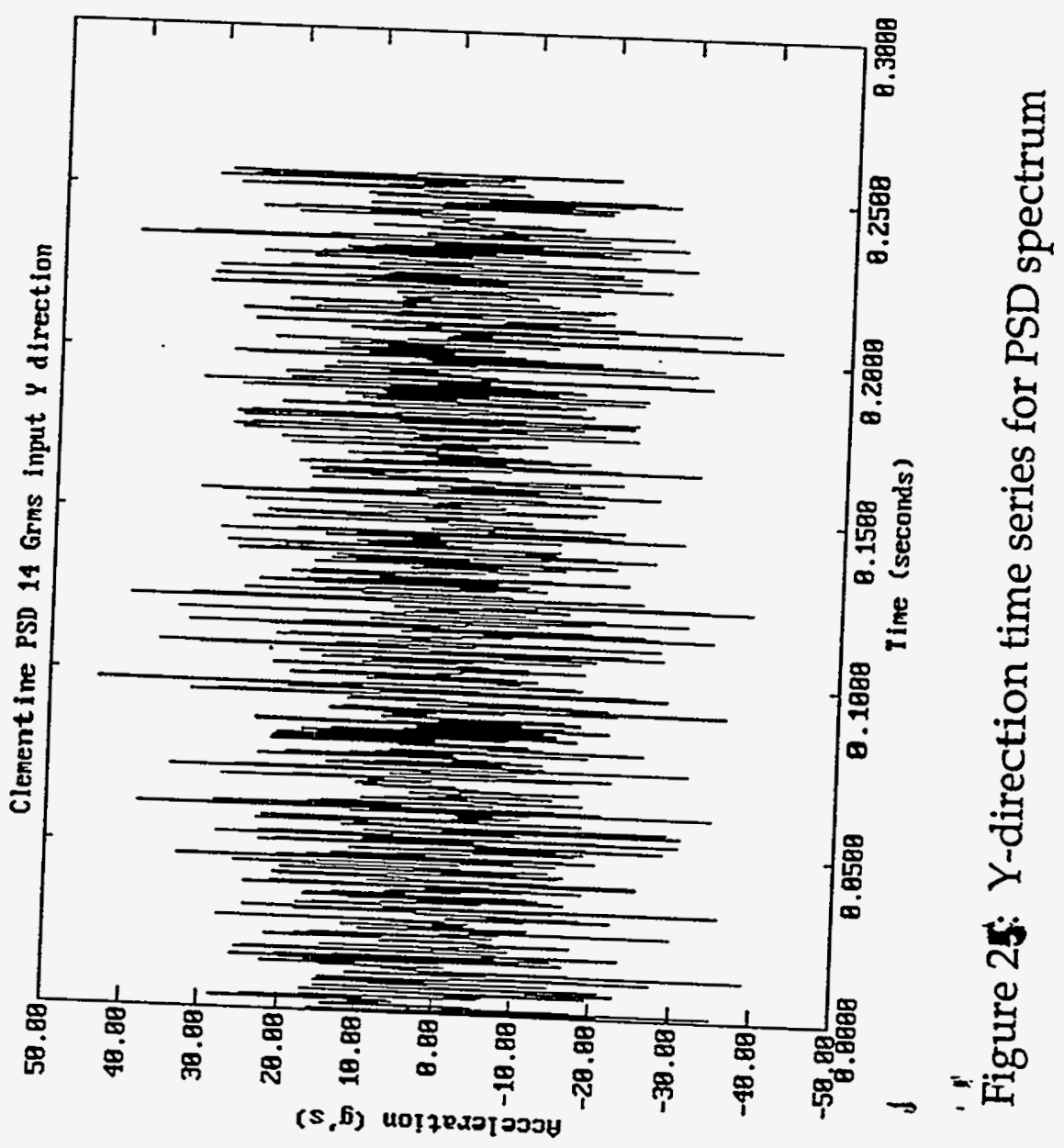




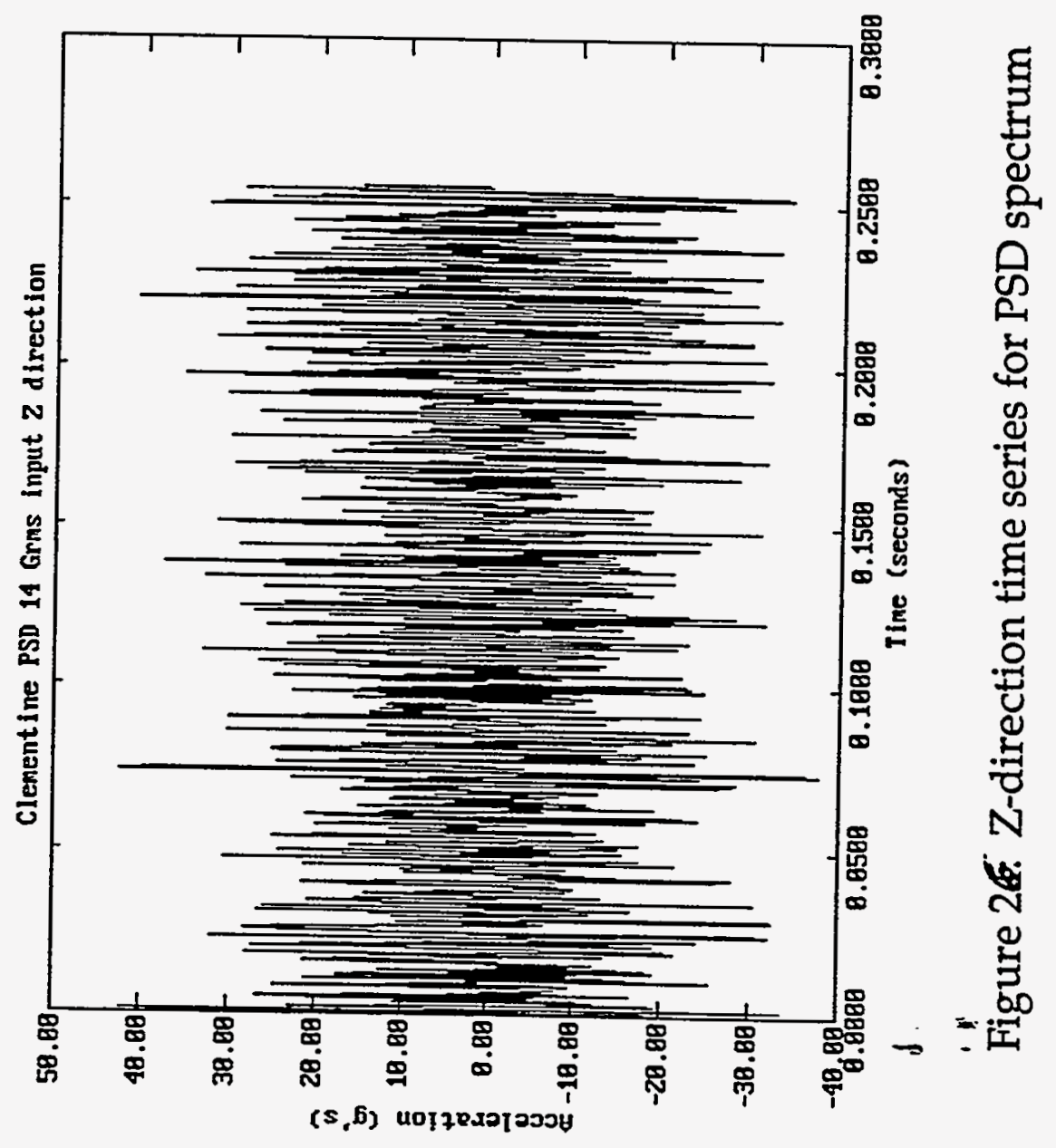




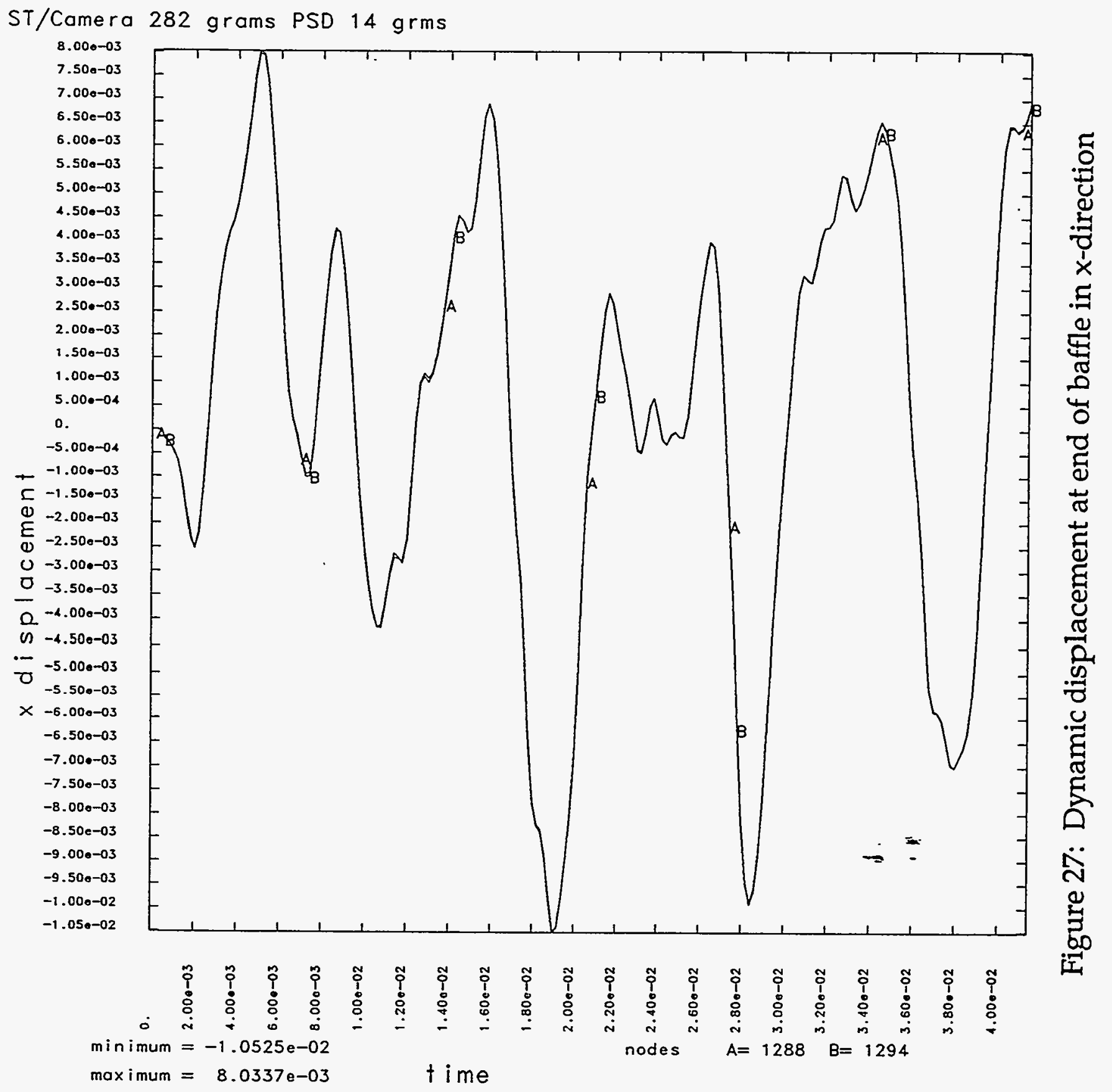




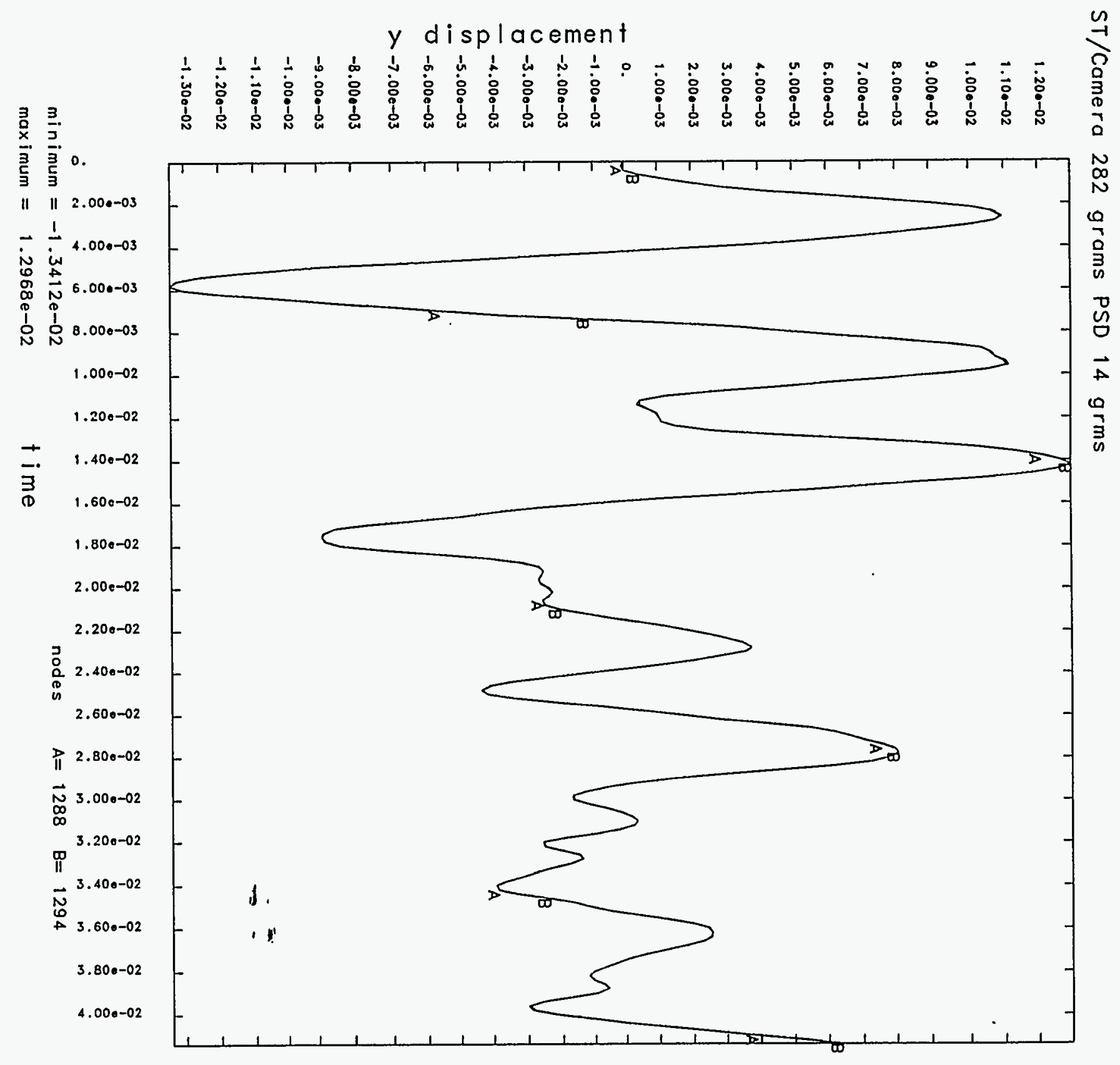

Figure 28: Dynamic displacement at end of baffle in y-direction 


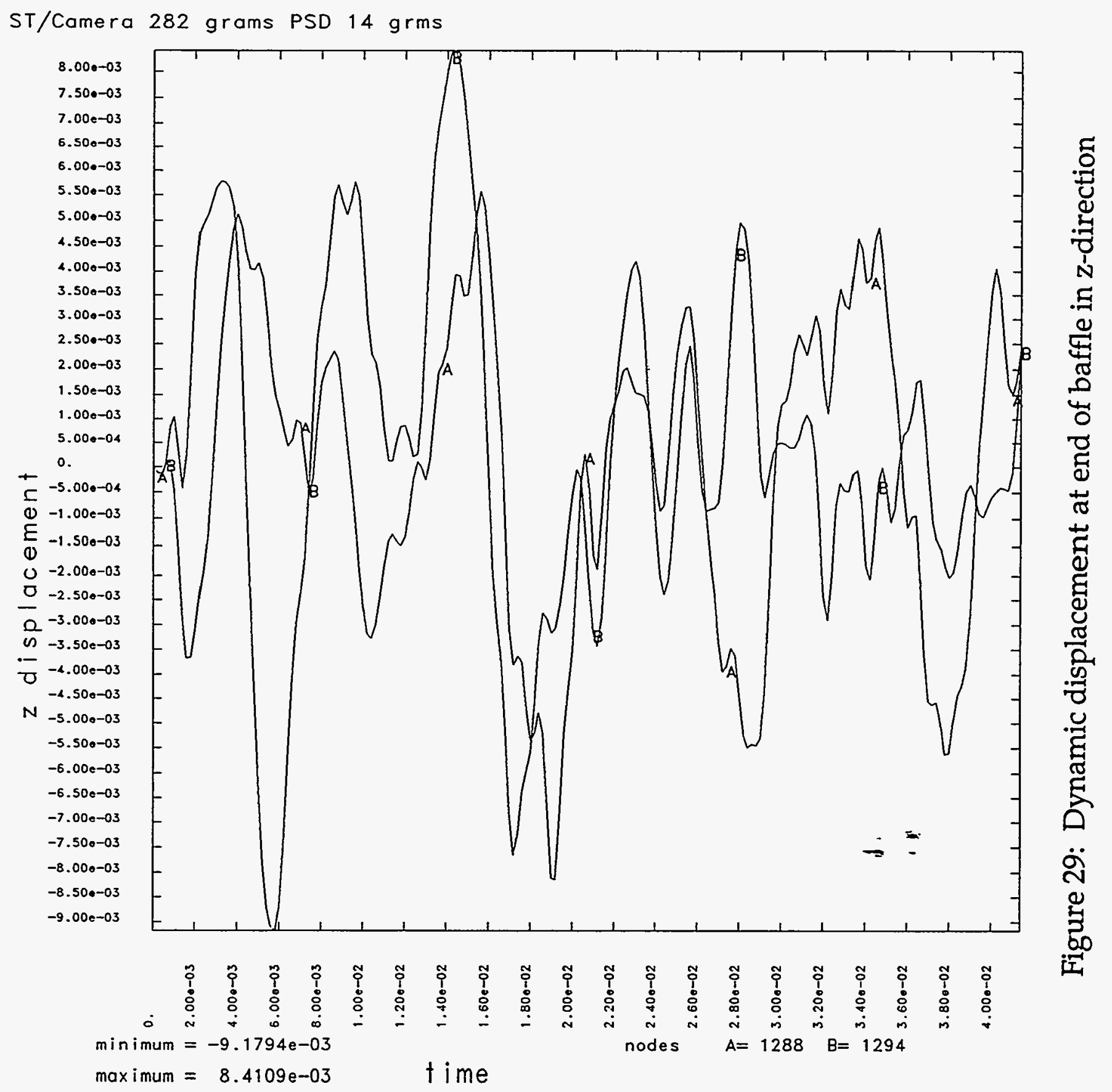


ST/Camera 282 grams PSD 14 grms

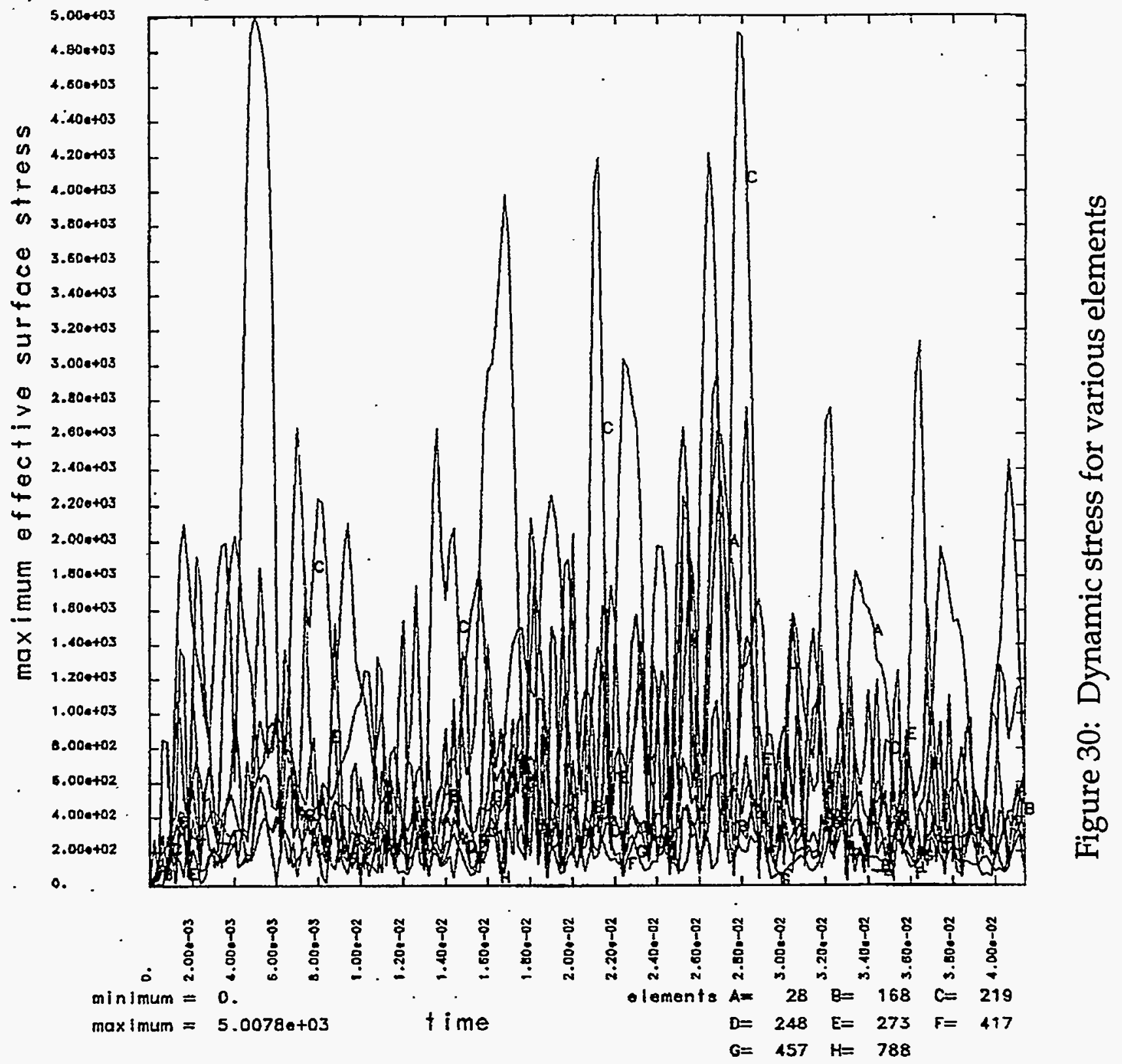


ST/Camera 282 grams PSD 14 grms

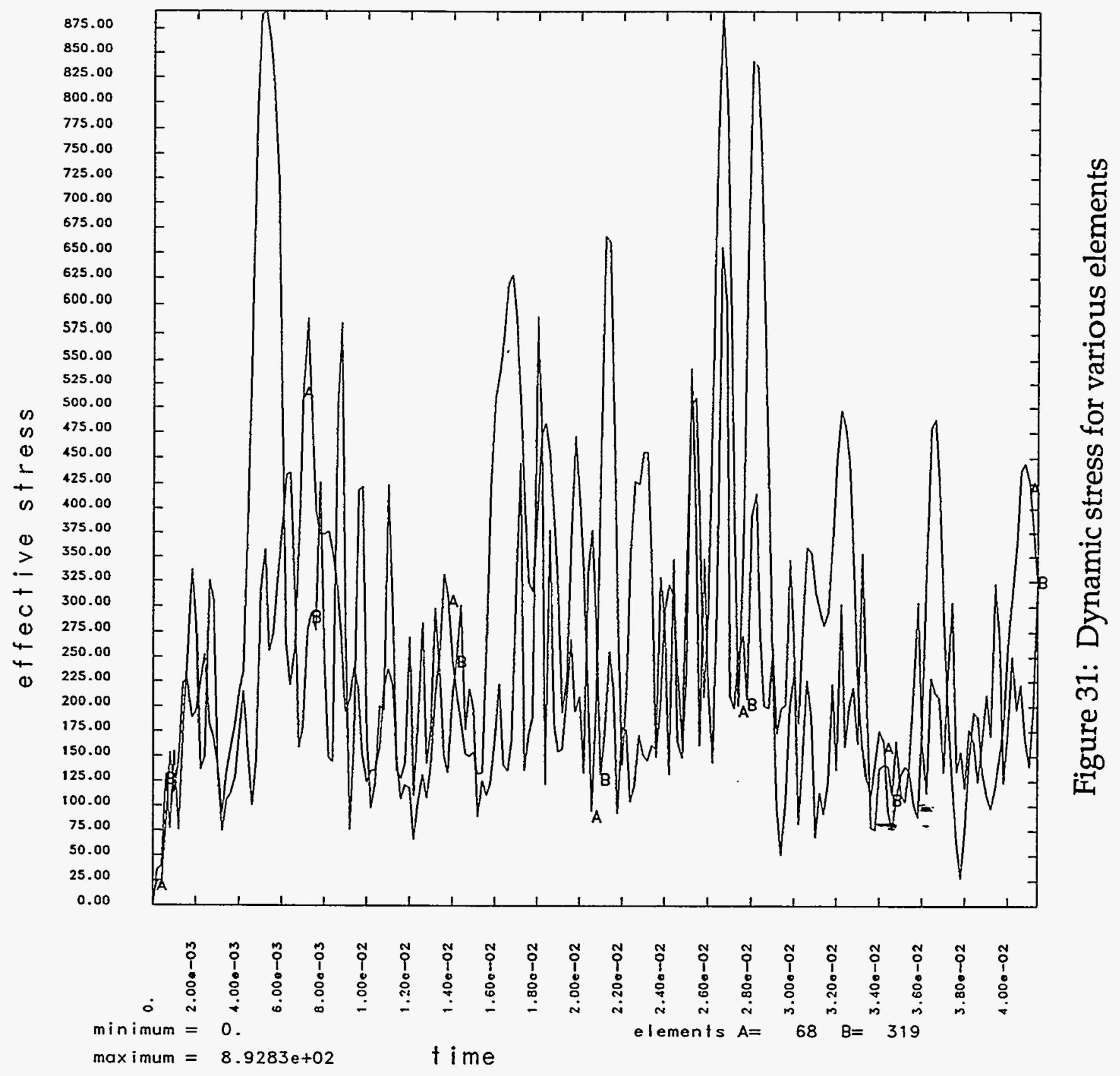




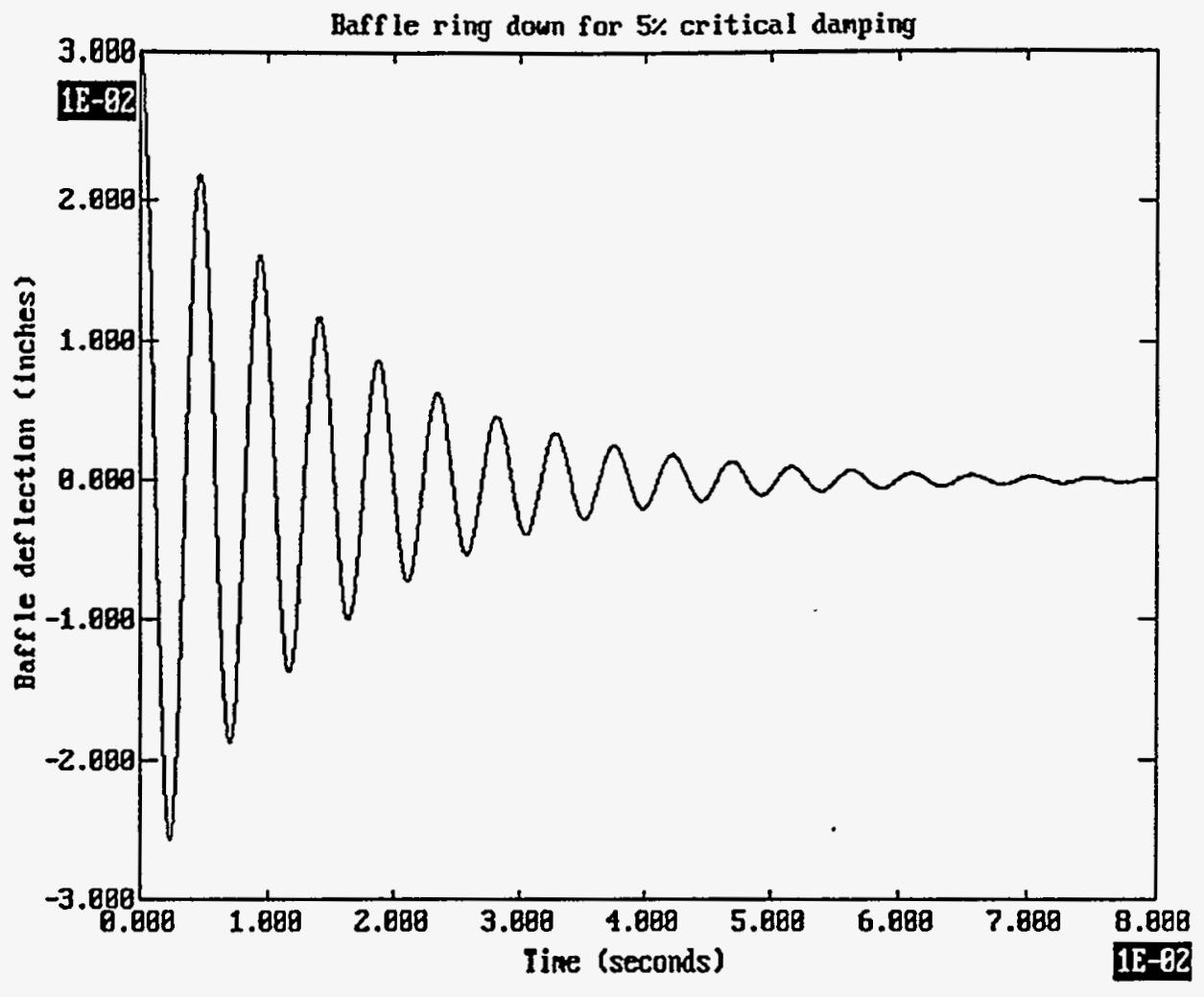

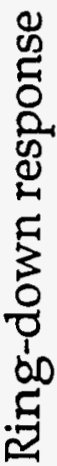

लं

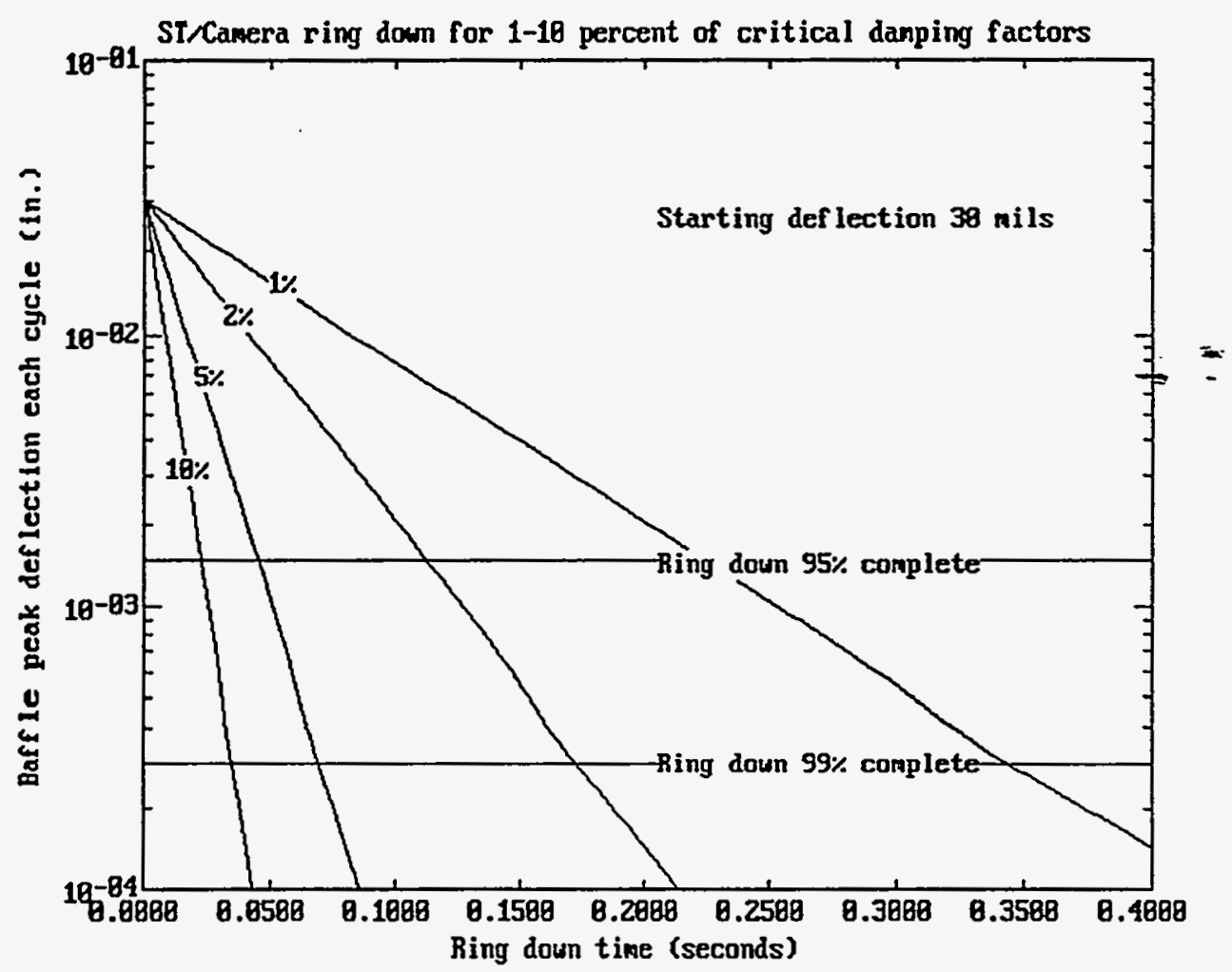




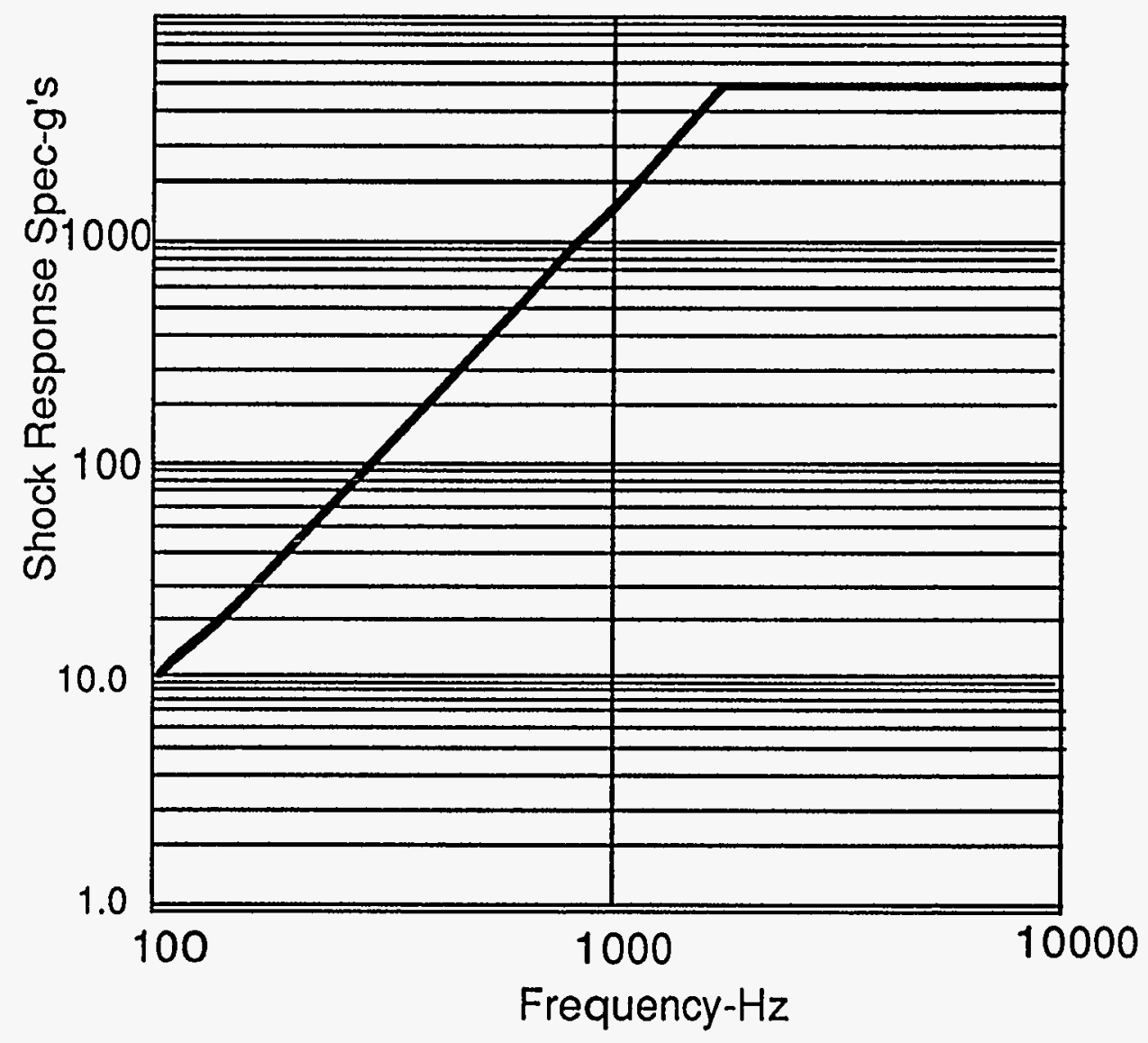

Five Interfaces between the pyroshock and Sensor Bench

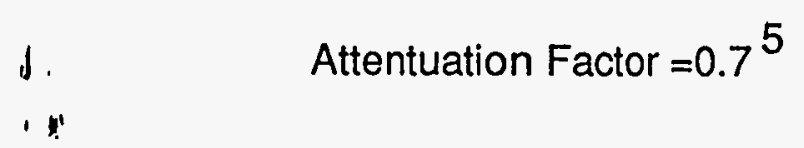

Figure 33: Pyro-shock Response Spectrum 


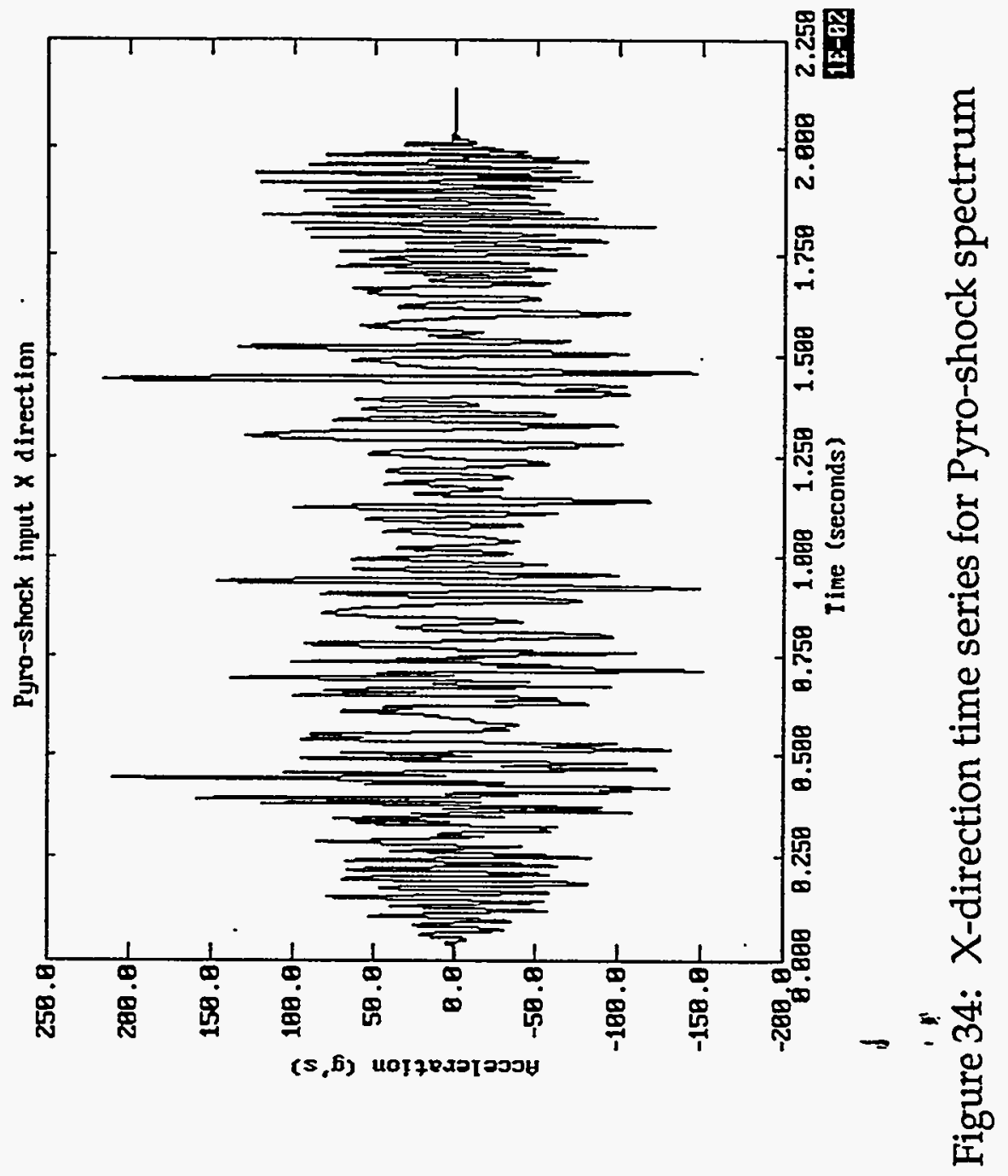




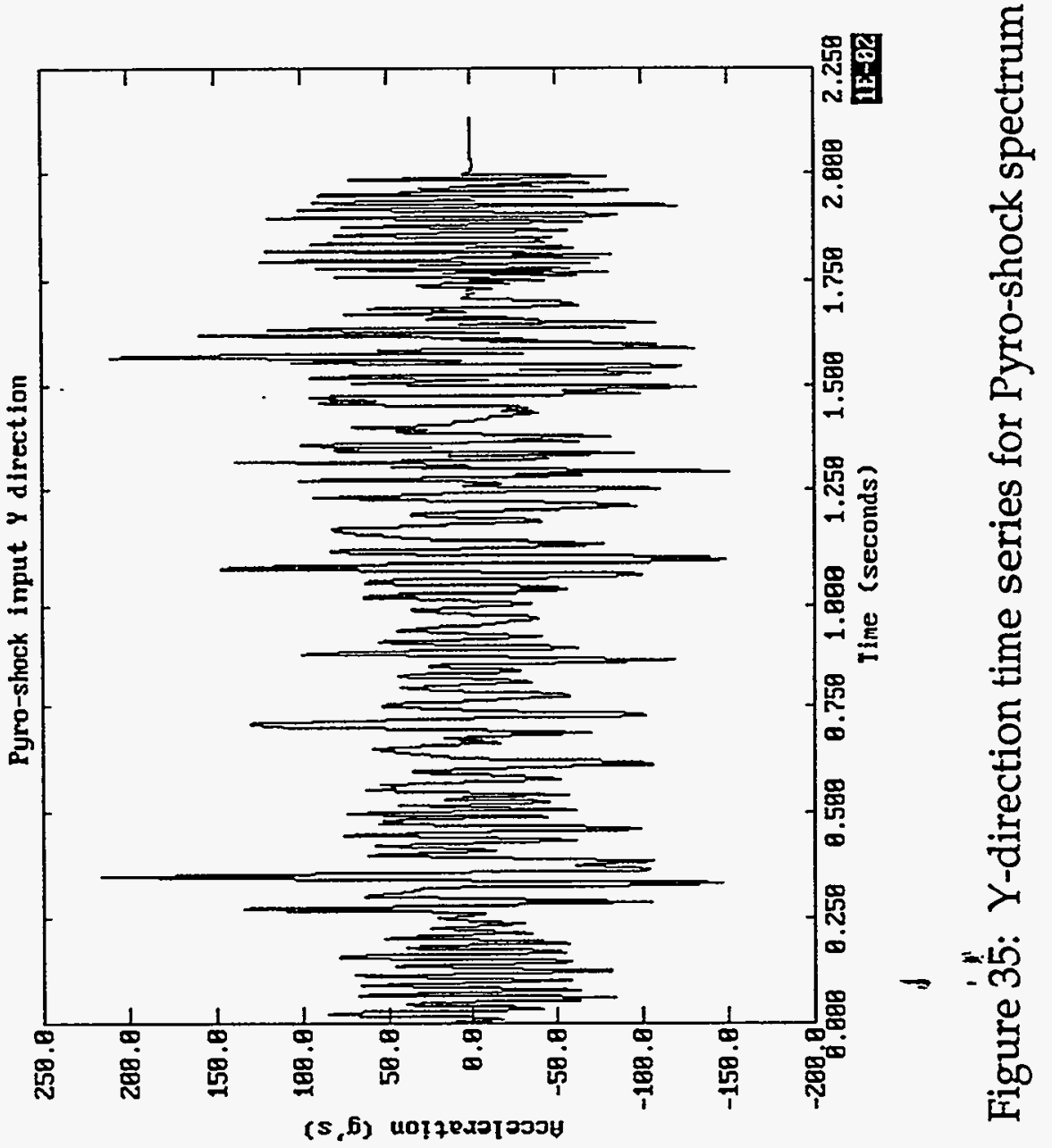


ST/Camera 282 grams pyro-shock at interface 5

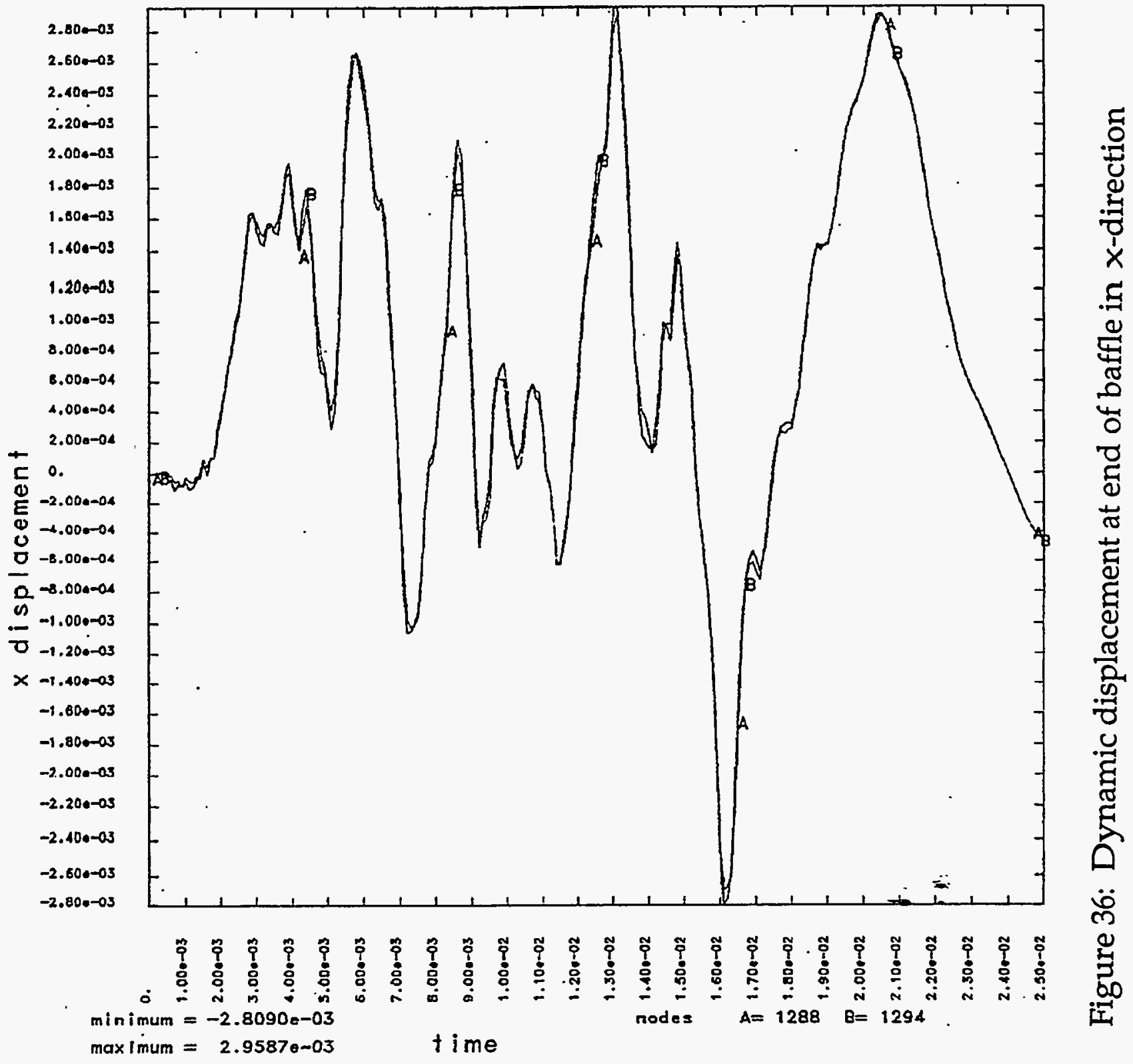




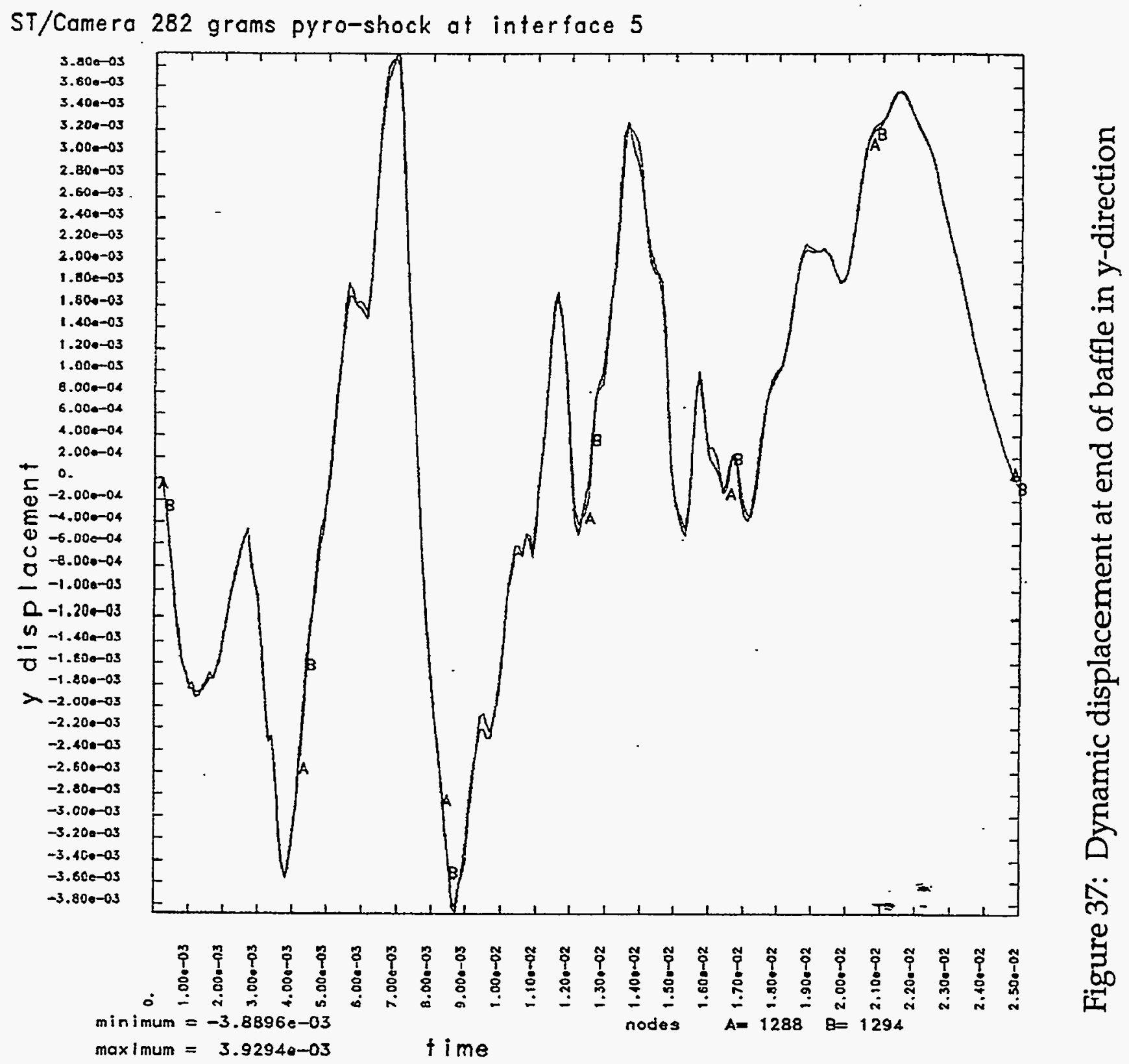




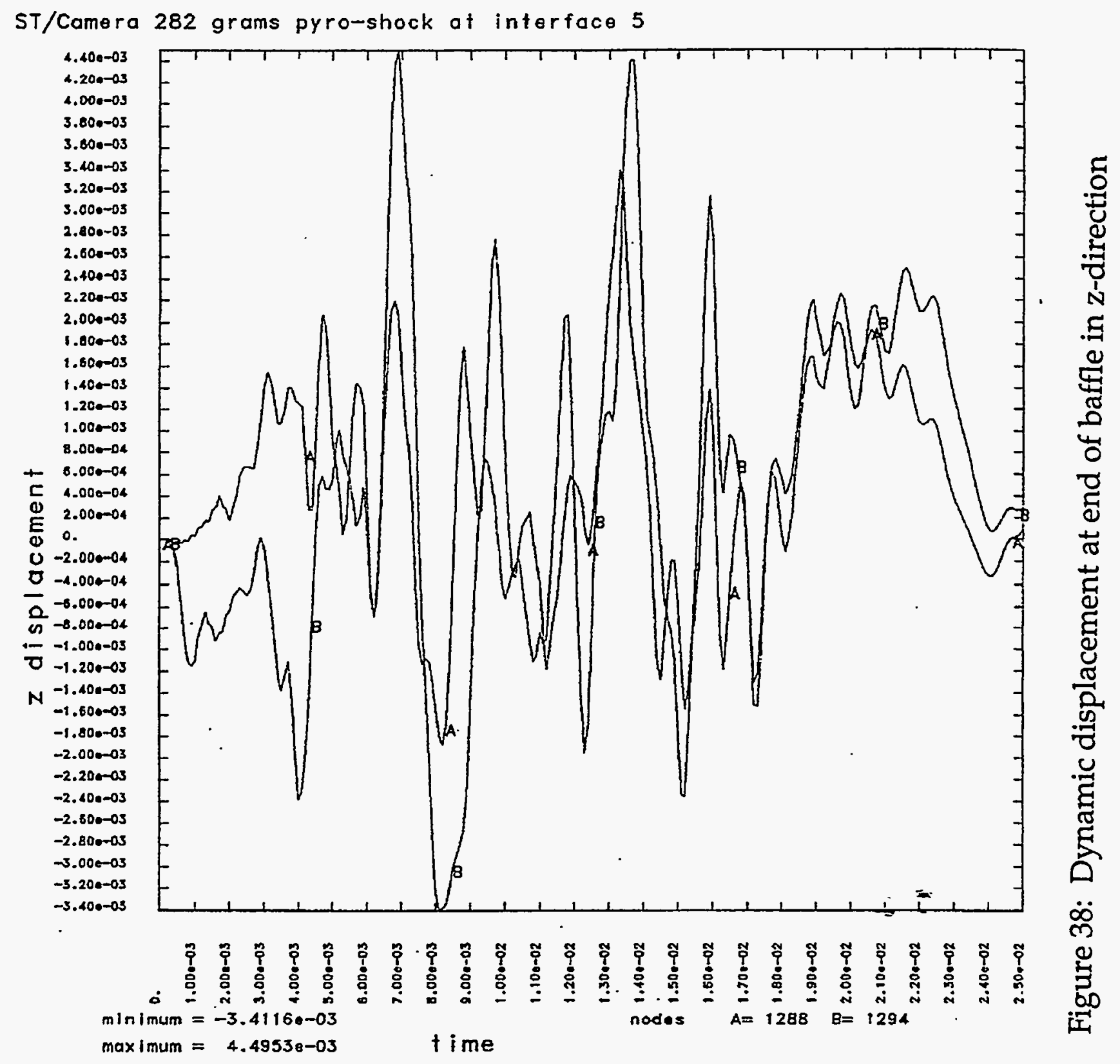


ST/Camera 282 grams pyro-shock at interface 5

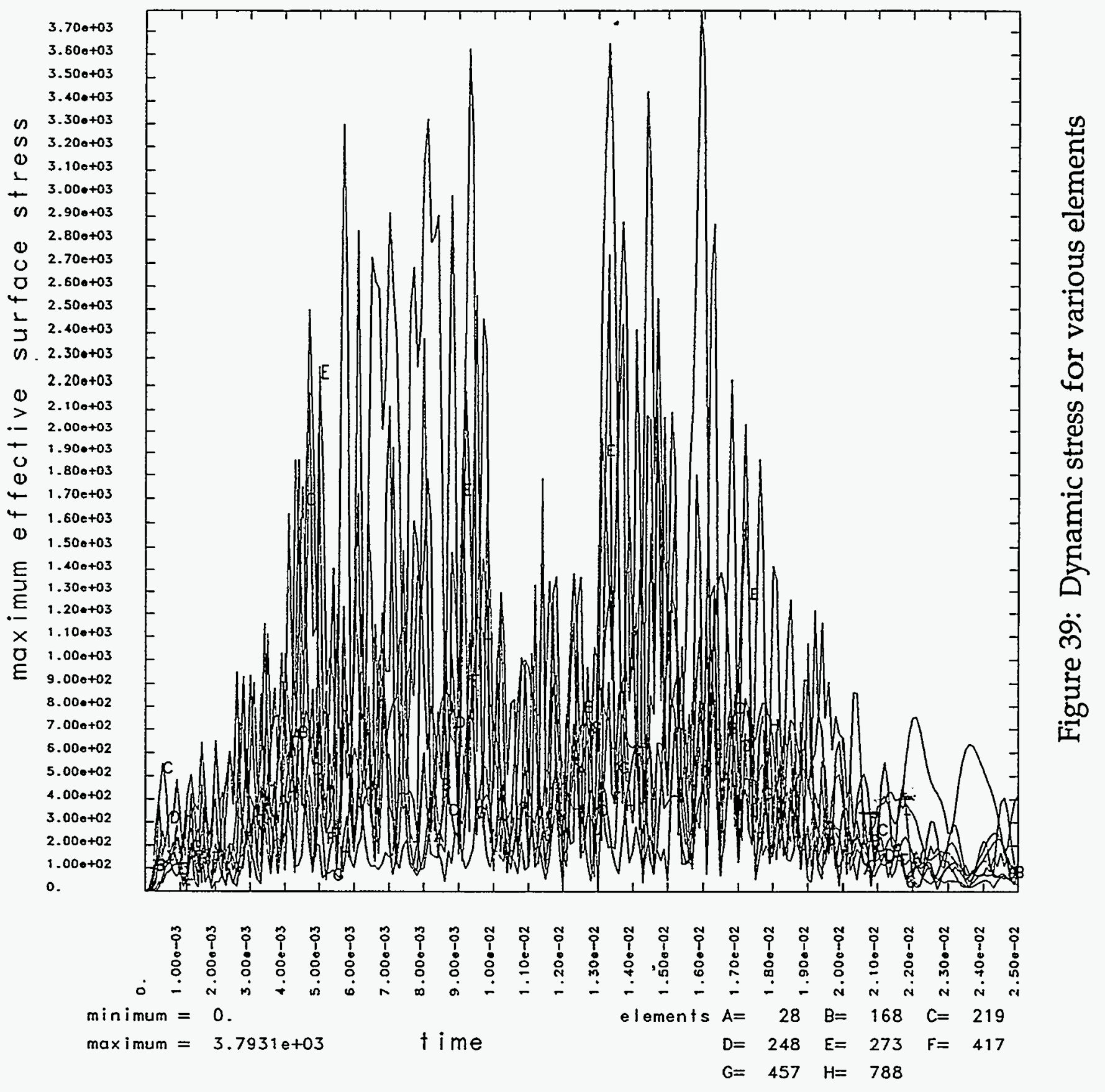


ST/Camera 282 grams pyro-shock of interface 5

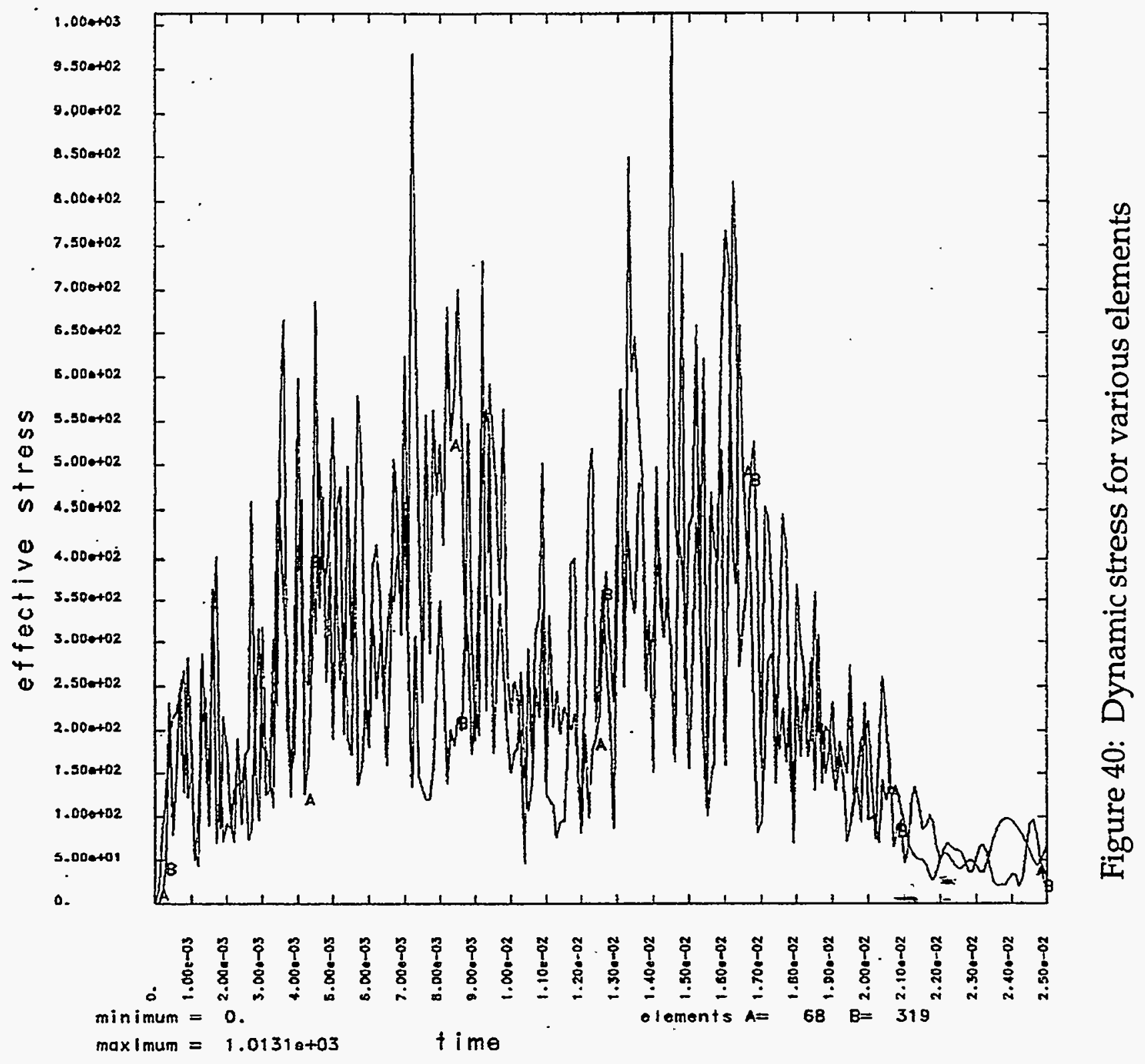



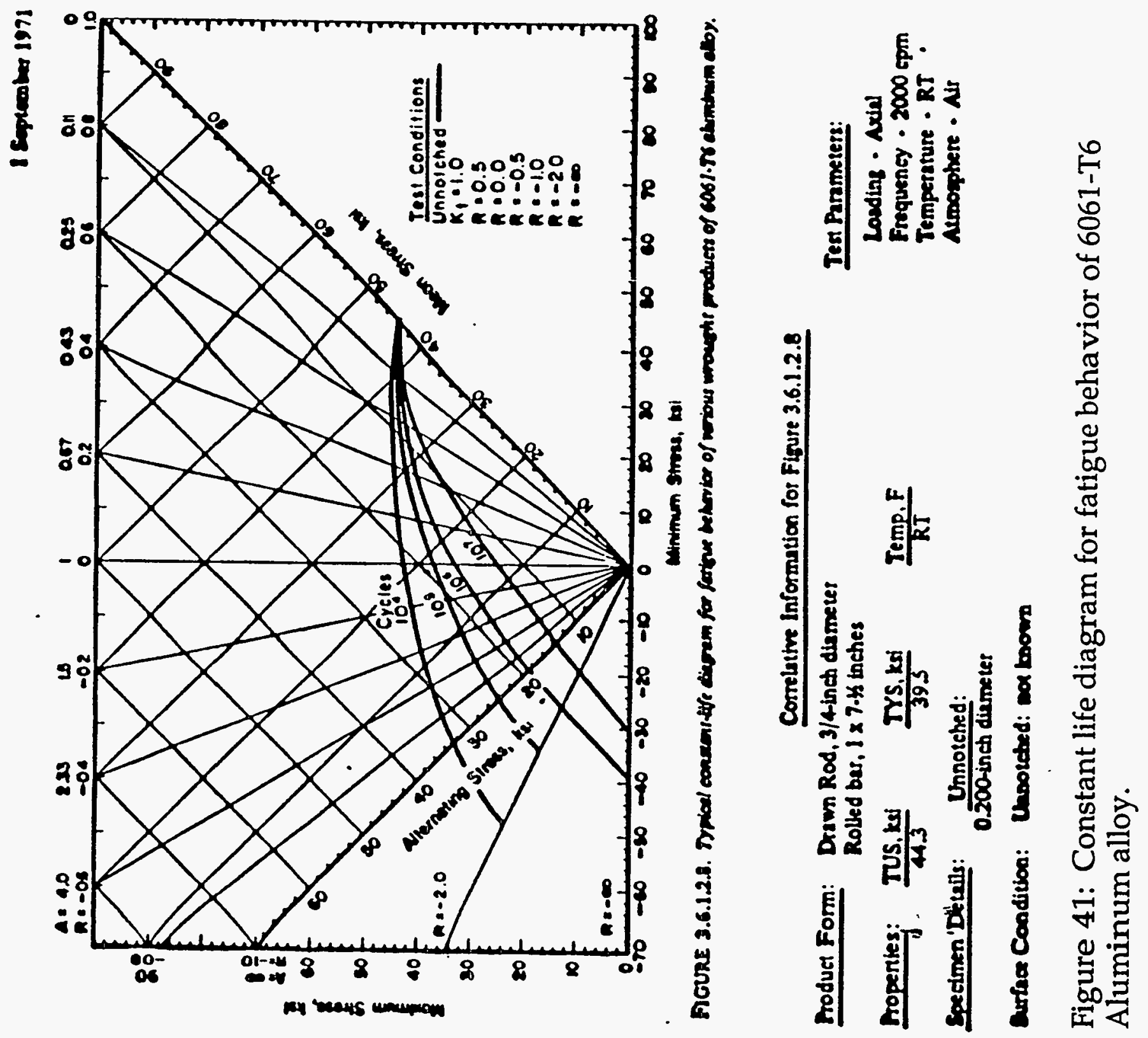


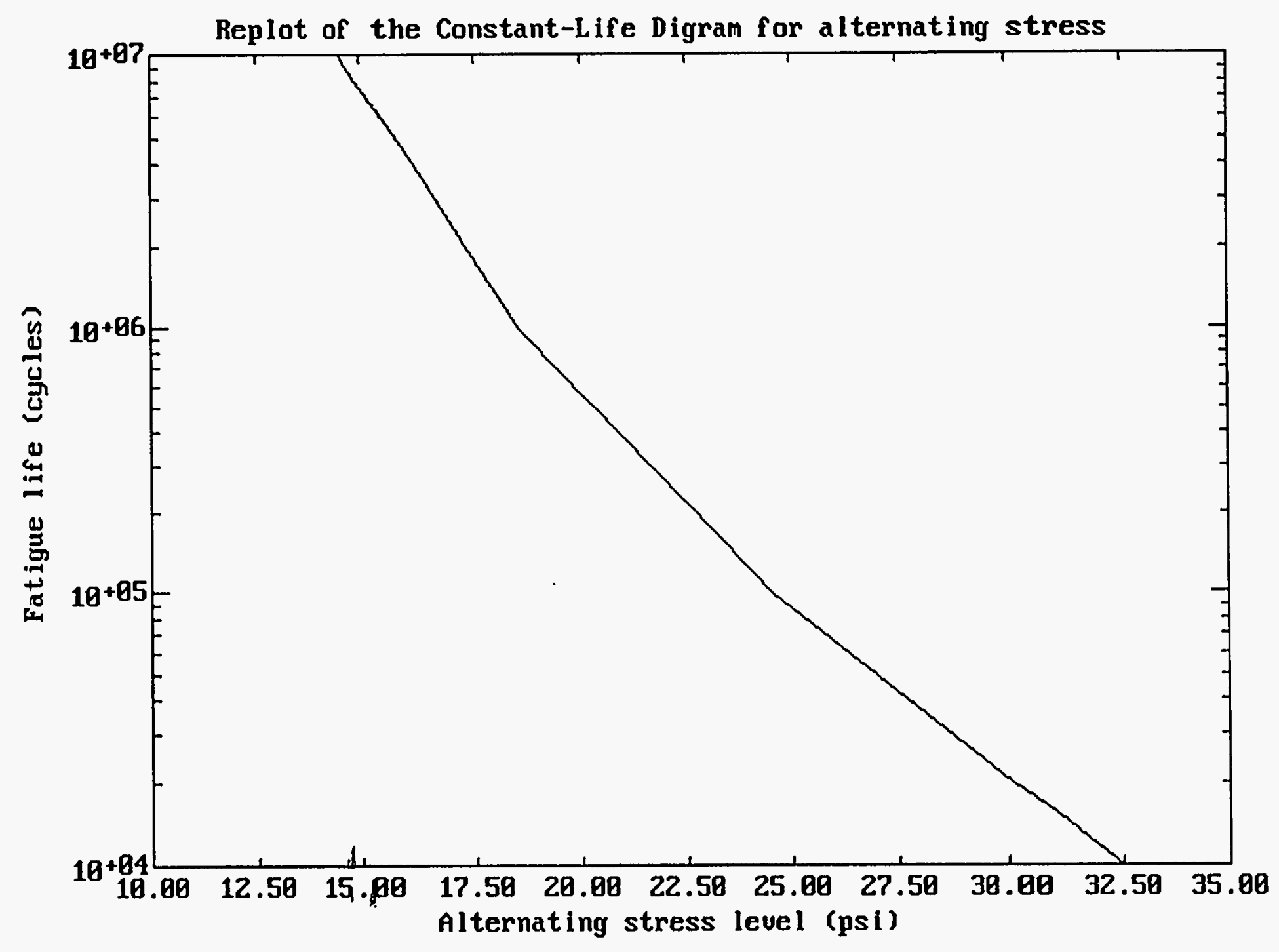

Figure 42: Fatigue life. 
Circuit board $2 \times 228$ layers $30 \mathrm{gm}$ (unloaded)

time $=0.46413 E+04$

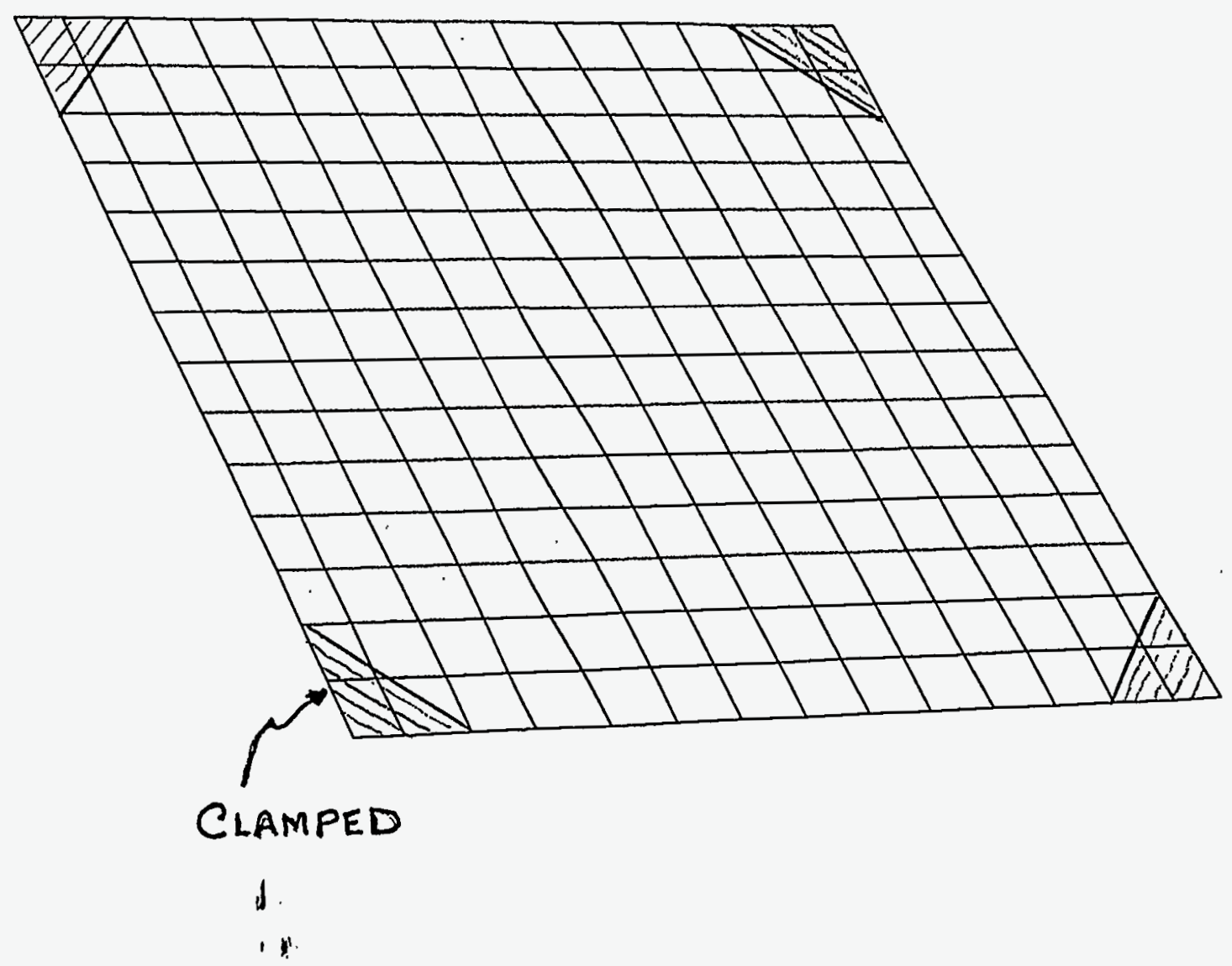

Figure 43: Unloaded circuit board showing clamped locations 
Circuit board mode 1 at $740 \mathrm{~Hz}$

time $=0.46413 E+04$

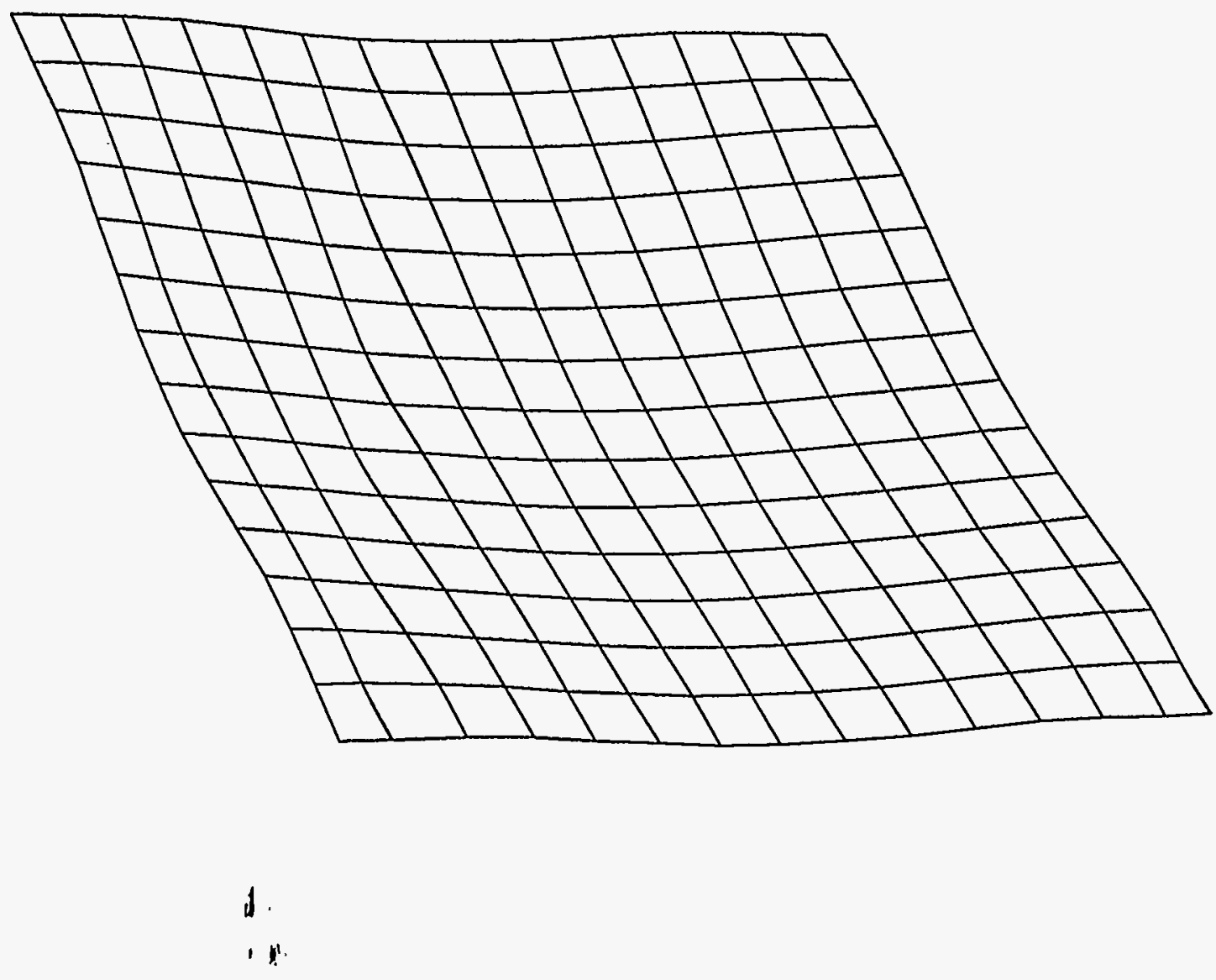

Figure 44: Mode 1 at $740 \mathrm{~Hz}$. 
Circult board mode 2 at $1405 \mathrm{~Hz}$

time $=0.89209 E+04$

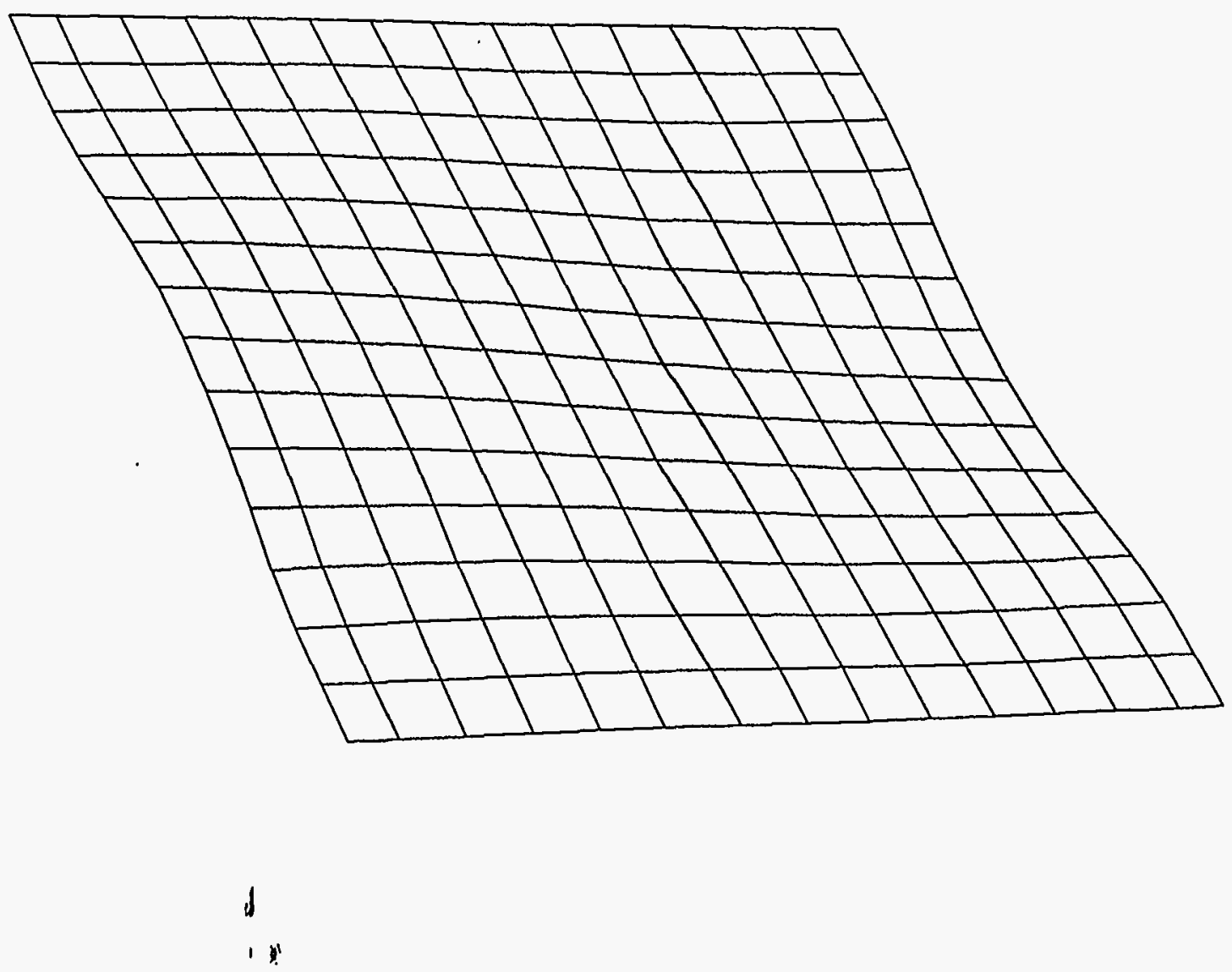

Figure 45: Mode 2 at $1405 \mathrm{~Hz}$. 
Circuit board mode 3 at $1680 \mathrm{~Hz}$

time $=0.10550 E+05$

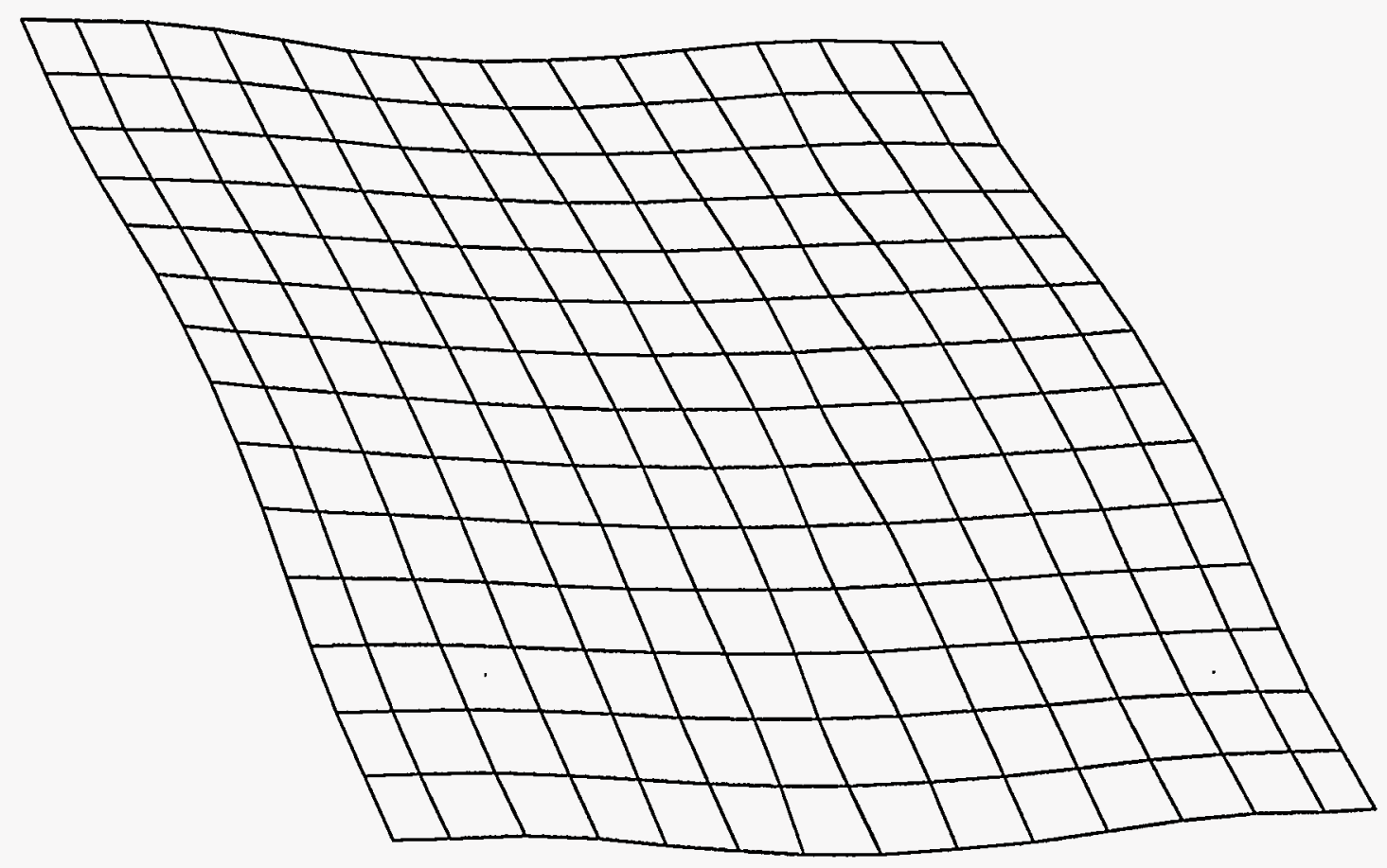

$$
1
$$

Figure 46: Mode 3 at $1680 \mathrm{~Hz}$. 
Circuit board mode 4 at 2340

time $=0.14694 \mathrm{E}+05$

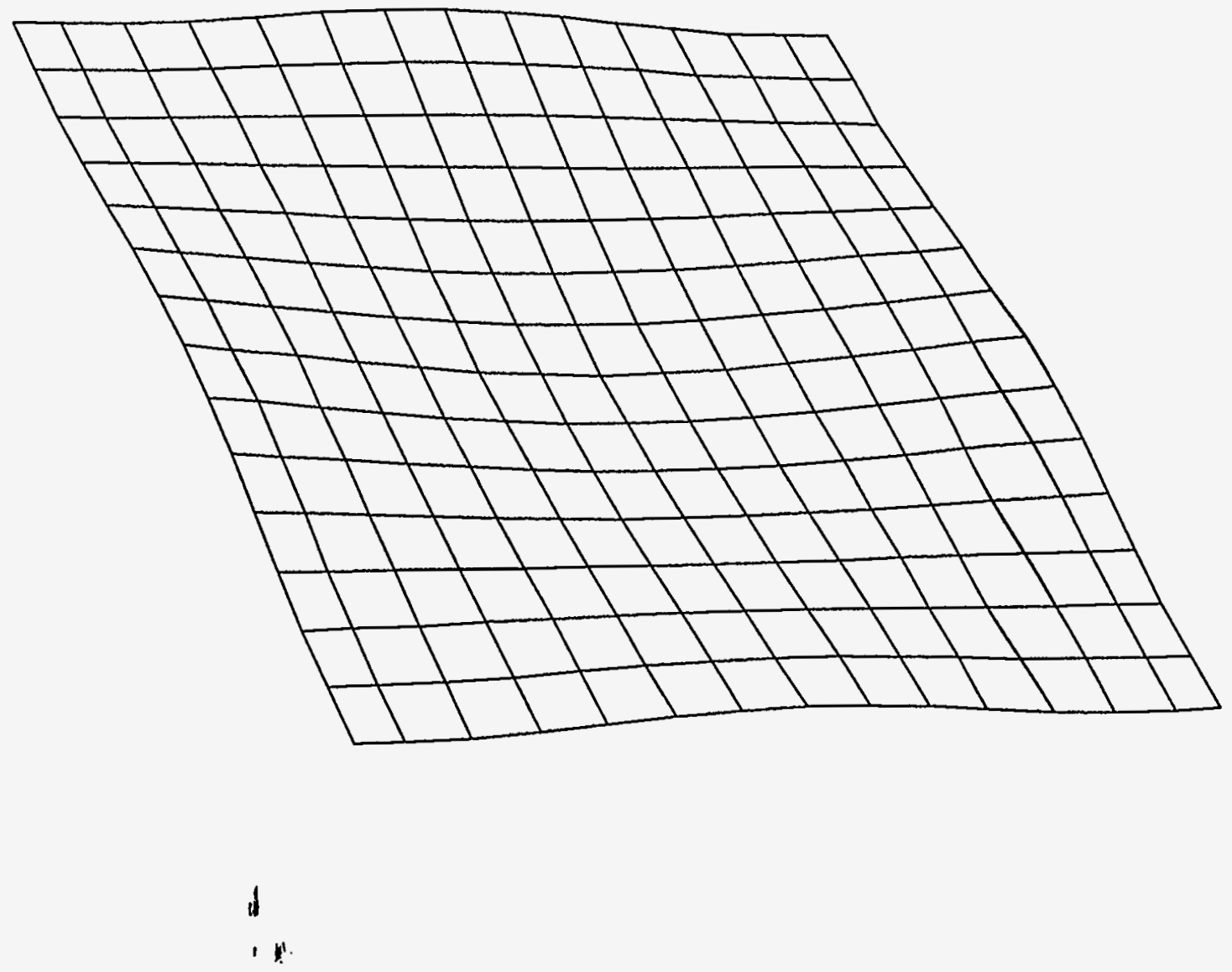

Figure 47: Mode 4 at $2340 \mathrm{~Hz}$. 

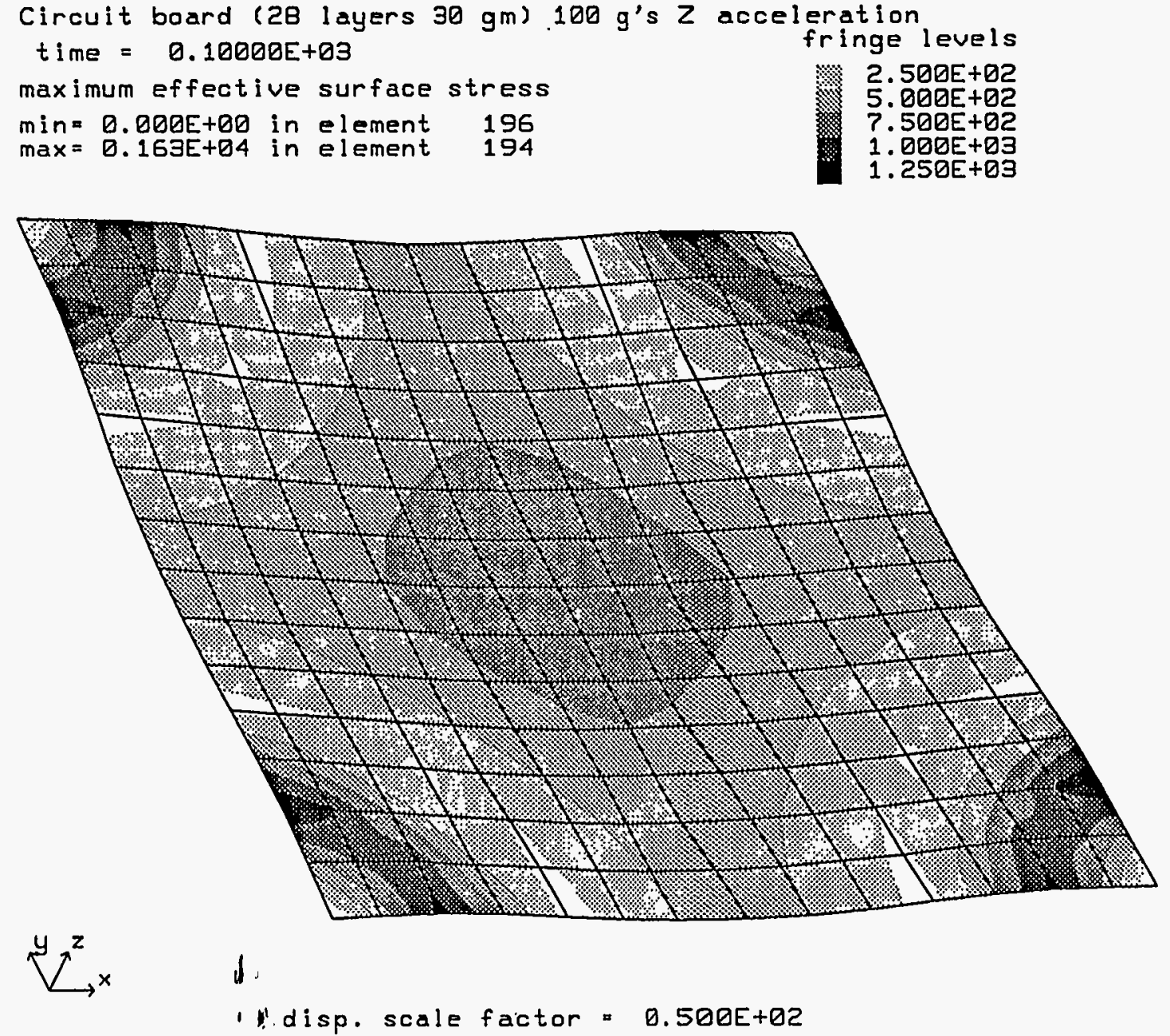

Figure 48: Stress fringes in circuit board induced by $\mathrm{z}$-direction loading 


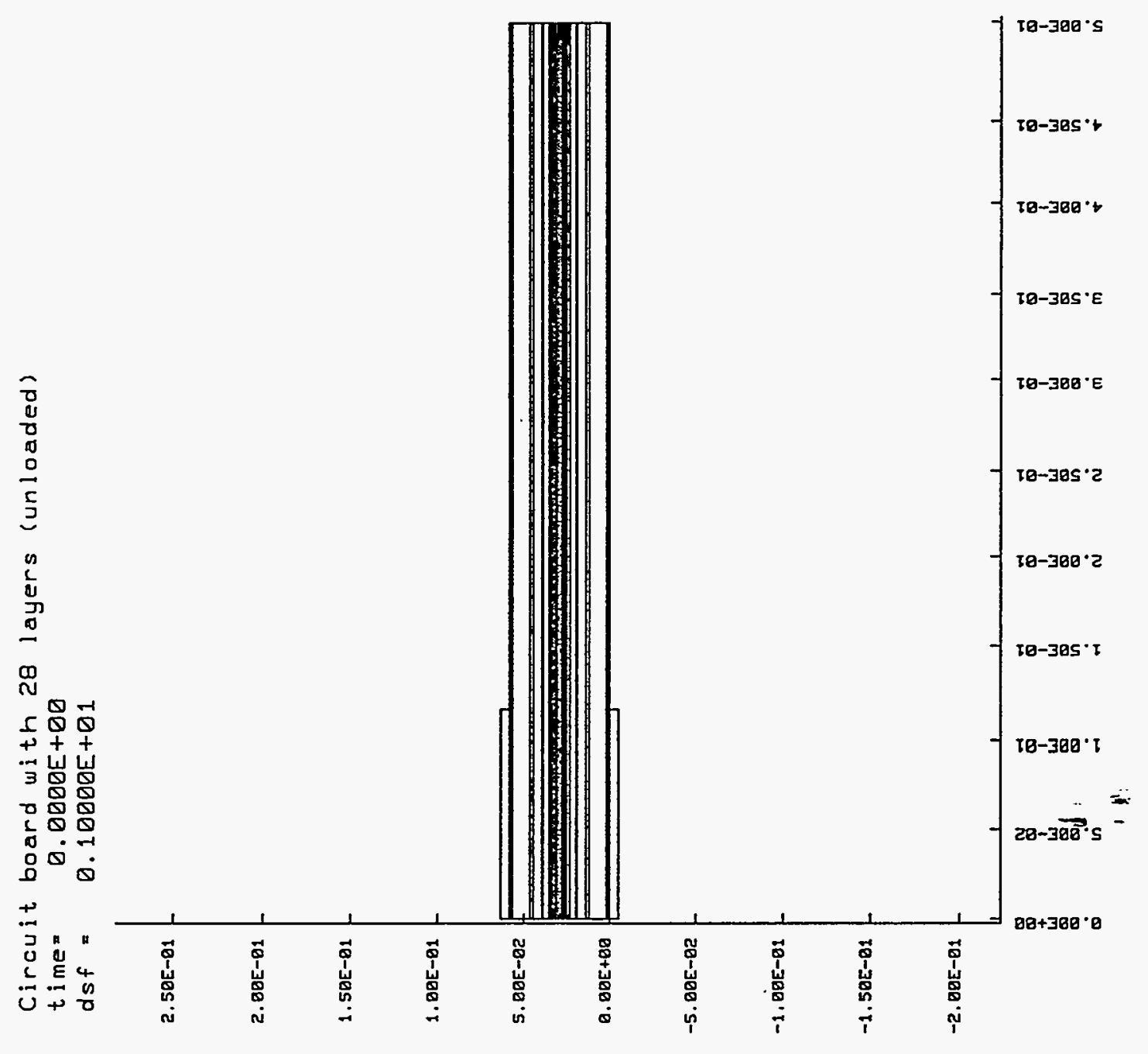

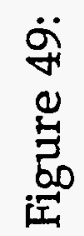


Circuit board clamped at 254 ib

time $=\quad 5.0000 E-04$ fringes of effective stress

$d s f=0.10000 E+01$

minual = $1.226 E+00$ maxual: $1.048 E+04$

fringe levels

\section{1. $600 E+03$ \\ 3. $200 \mathrm{q}+03$ \\ 4. \\ 6.40日E+03 \\ 8. $\mathrm{QQEE}+03$}

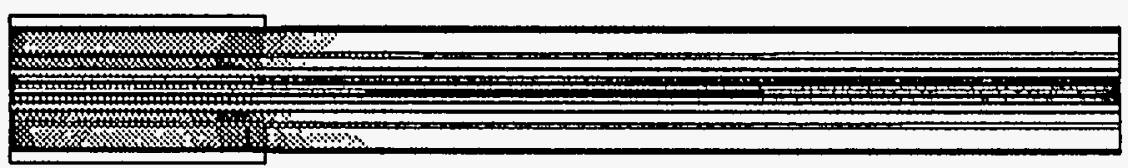

1

Figure 50: 
Circuit board clamped at $254 \mathrm{lb}$

time $\quad 5.0000 E-04$ fringes of effectlve stress

ds $f=0.10000 E+01$

minval=1.226E+00

maxval = $1.848 E+04$

fringe levels

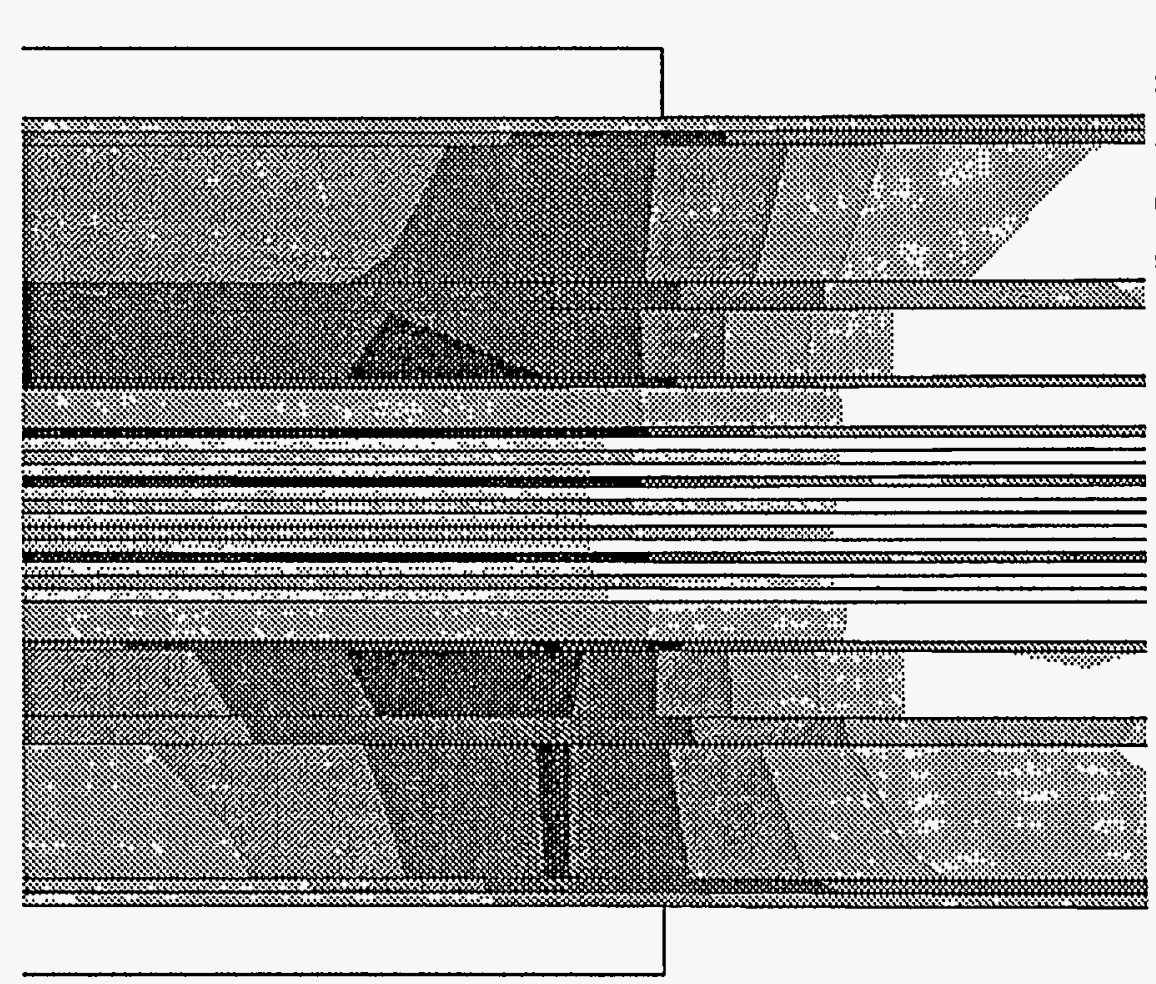

$1.600 \mathrm{E}+03$

3.200E+03

3.

$4.8005+03$

$6.400 \mathrm{x}+03$

.00日E +03

Zoom in on high stress area

1

Figure 51: 
Circuit board clamped with $10 \mathrm{mils}$ center deflection time= 1. 0000E-03 fringes of effective stress

$d s f=0.10000 E+01$

minual $=3.482 E+\theta E$ maxual = 1.03BE+04

fringe levels

$1.600 \mathrm{E}+03$

3.200E+ 03

4.806E+03

4. $808 E+03$

$6.400 \mathrm{E}+03$

B. 000E+03

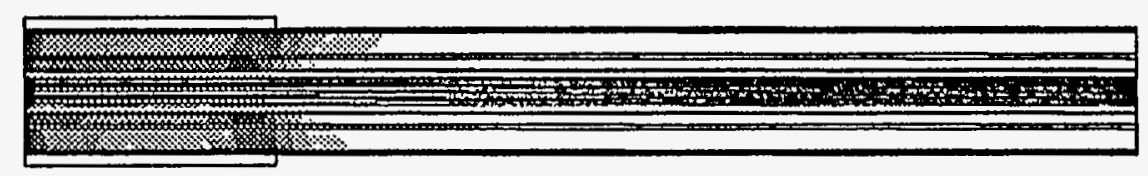

Figure 52: 


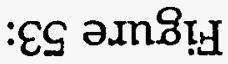

1

eaje ssadzs 46!̣ uo u! wooz

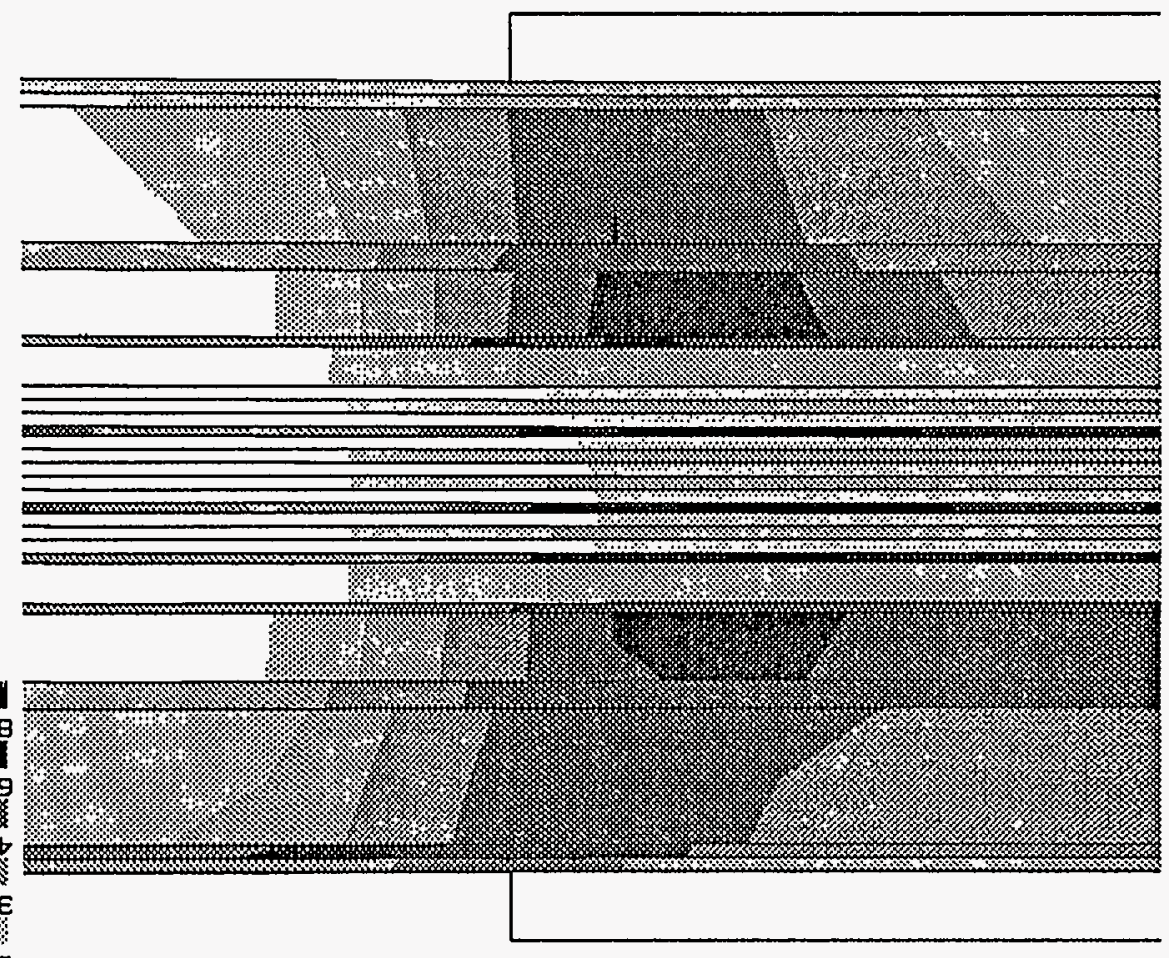

$80+3000^{\circ}$ $\varepsilon 0+3006 \cdot 9$

$\varepsilon 0+3008^{\circ} t$

$\varepsilon b+3002 \cdot \varepsilon$

$80+3009 \cdot 1$

slanal abuldt

$60+38 \varepsilon 0 \cdot 1 \cdot 18 \cap \times 8 w$

$00+750 b^{\circ} \cdot E=\operatorname{lonU} \omega$

$\tau B+70000 \tau \cdot \theta=f 5 p$

ssajis anizoatta to sabuidt $\varepsilon \theta-30000 \cdot 1$

$\therefore$ a

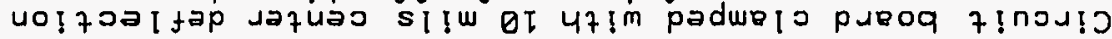



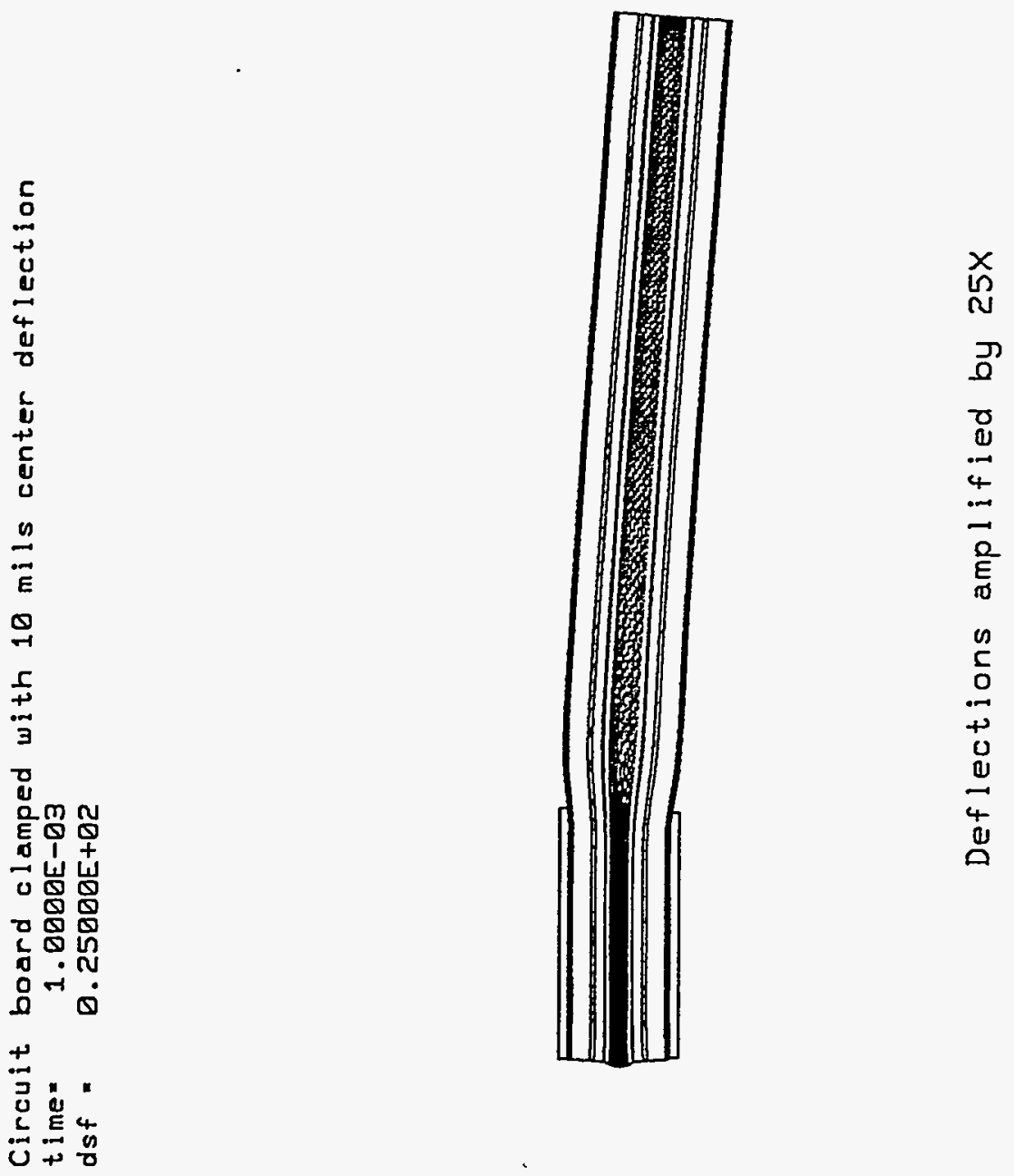

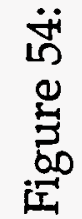


Appendix Figures

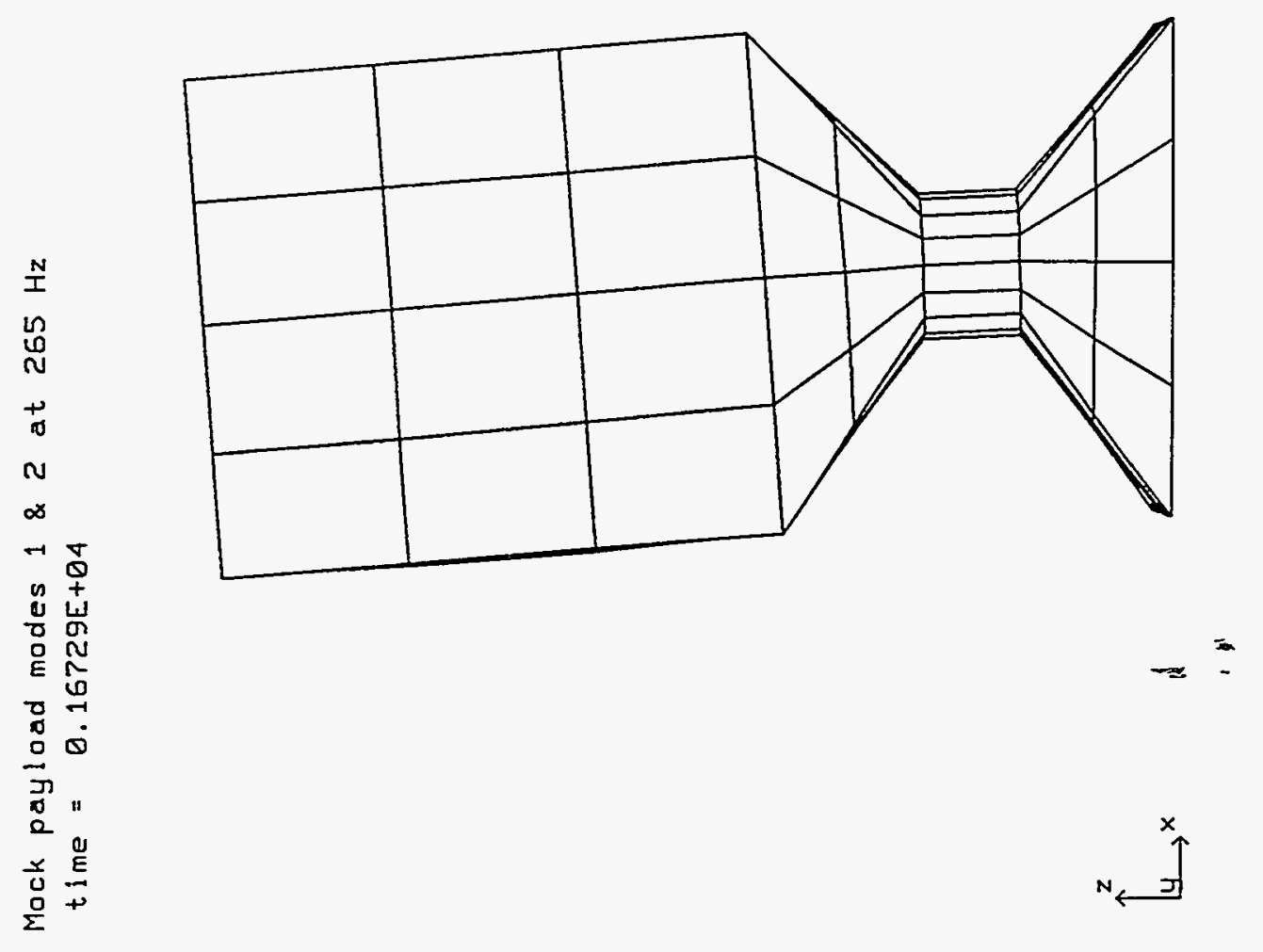

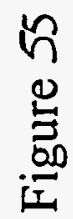




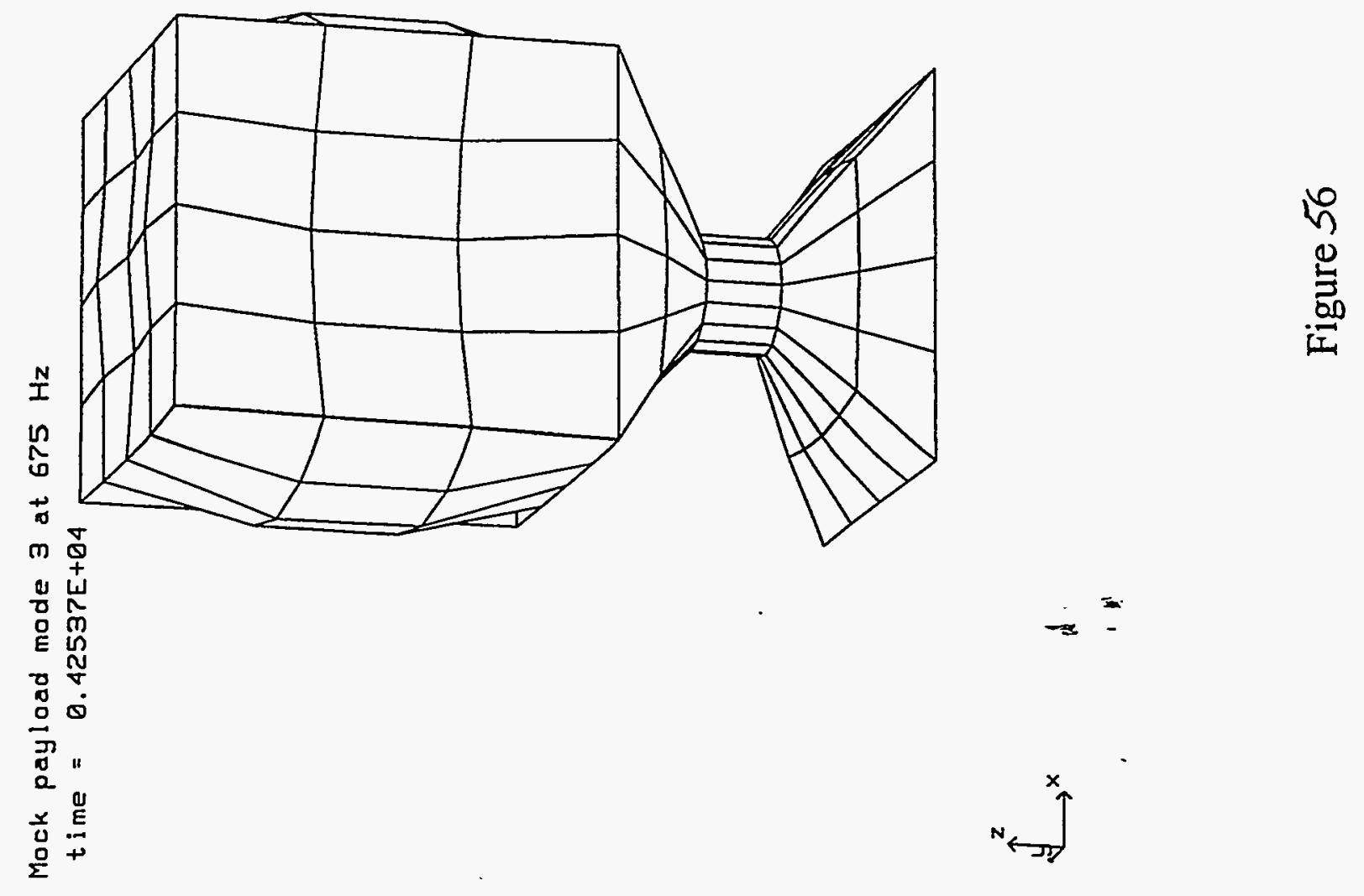




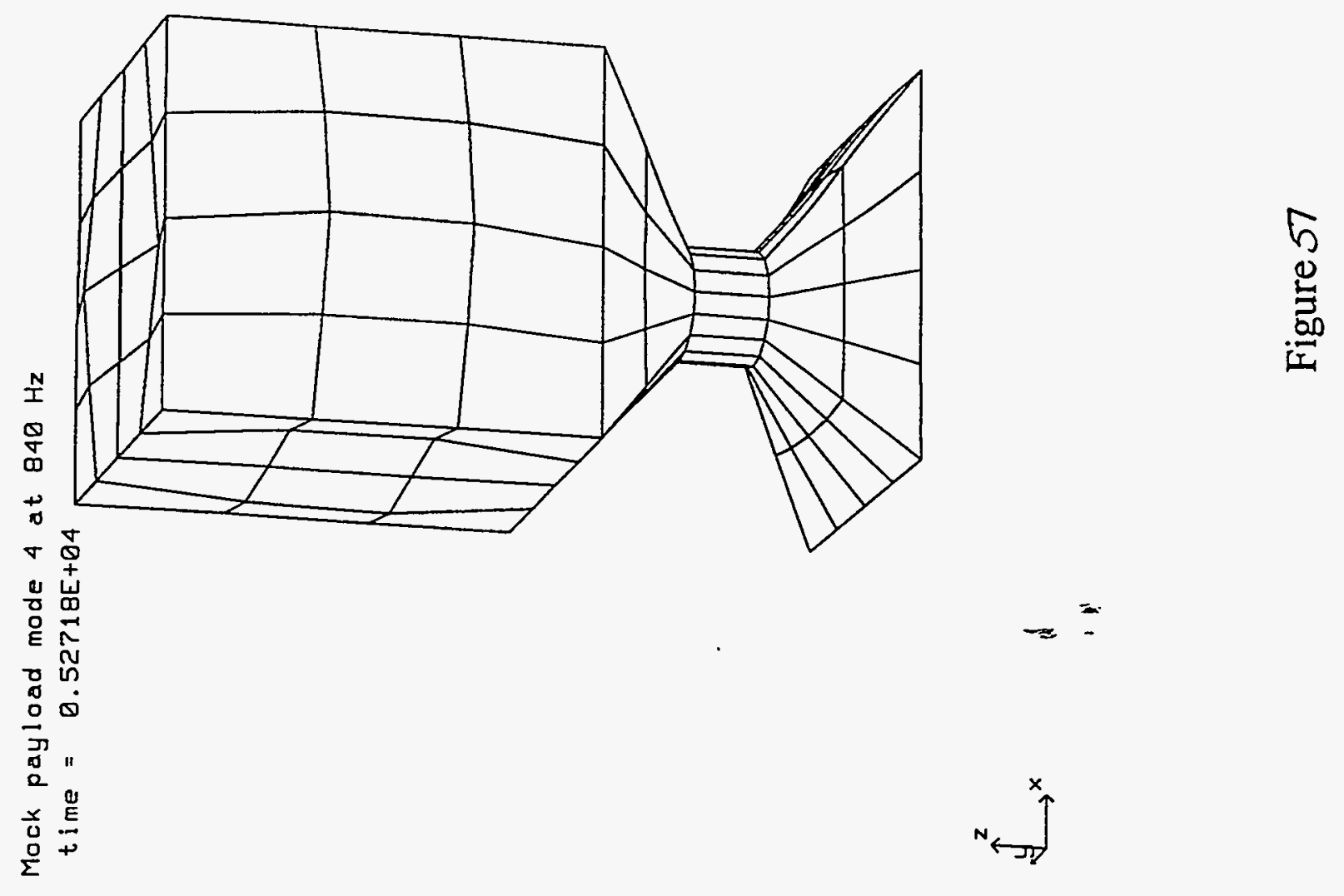




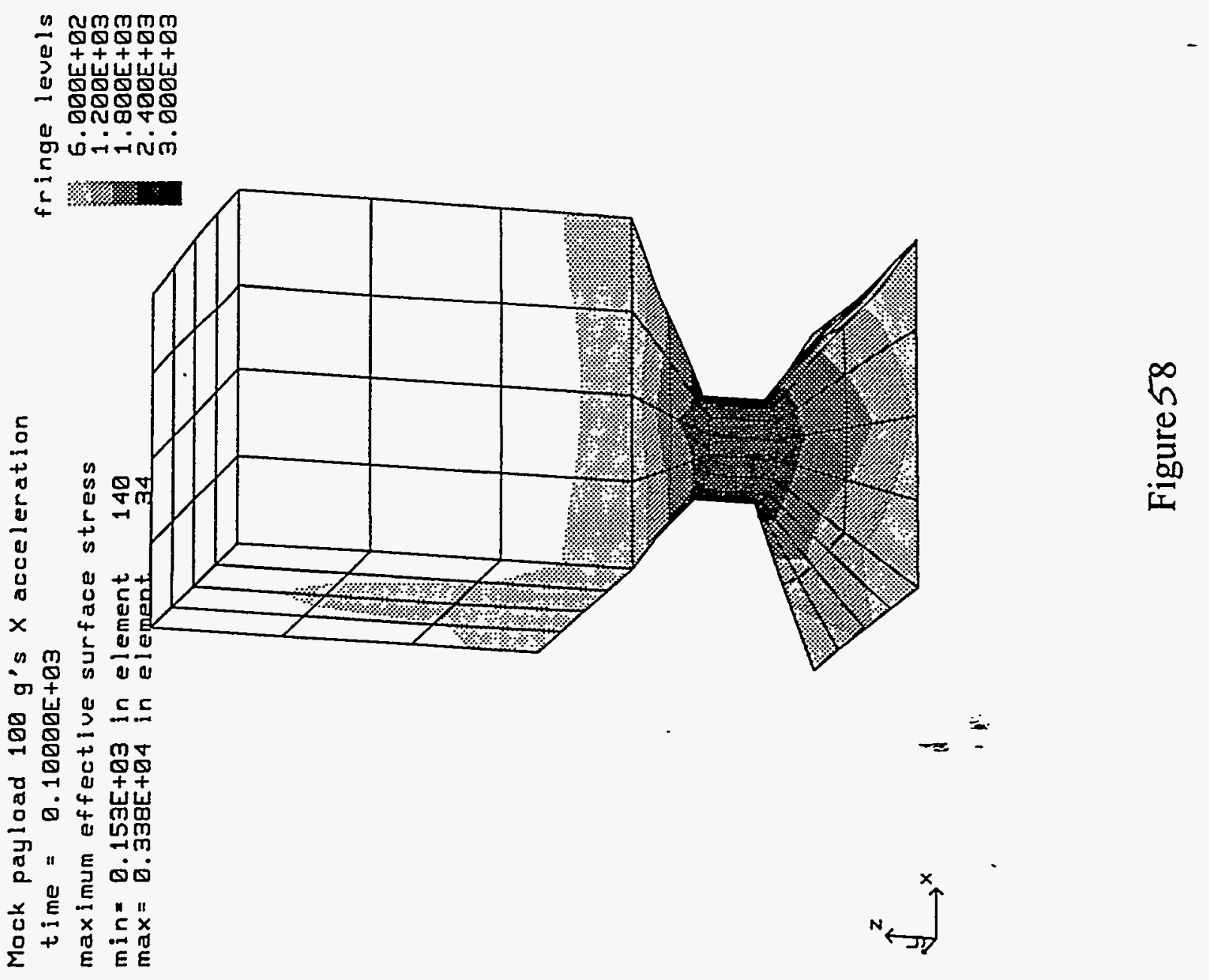




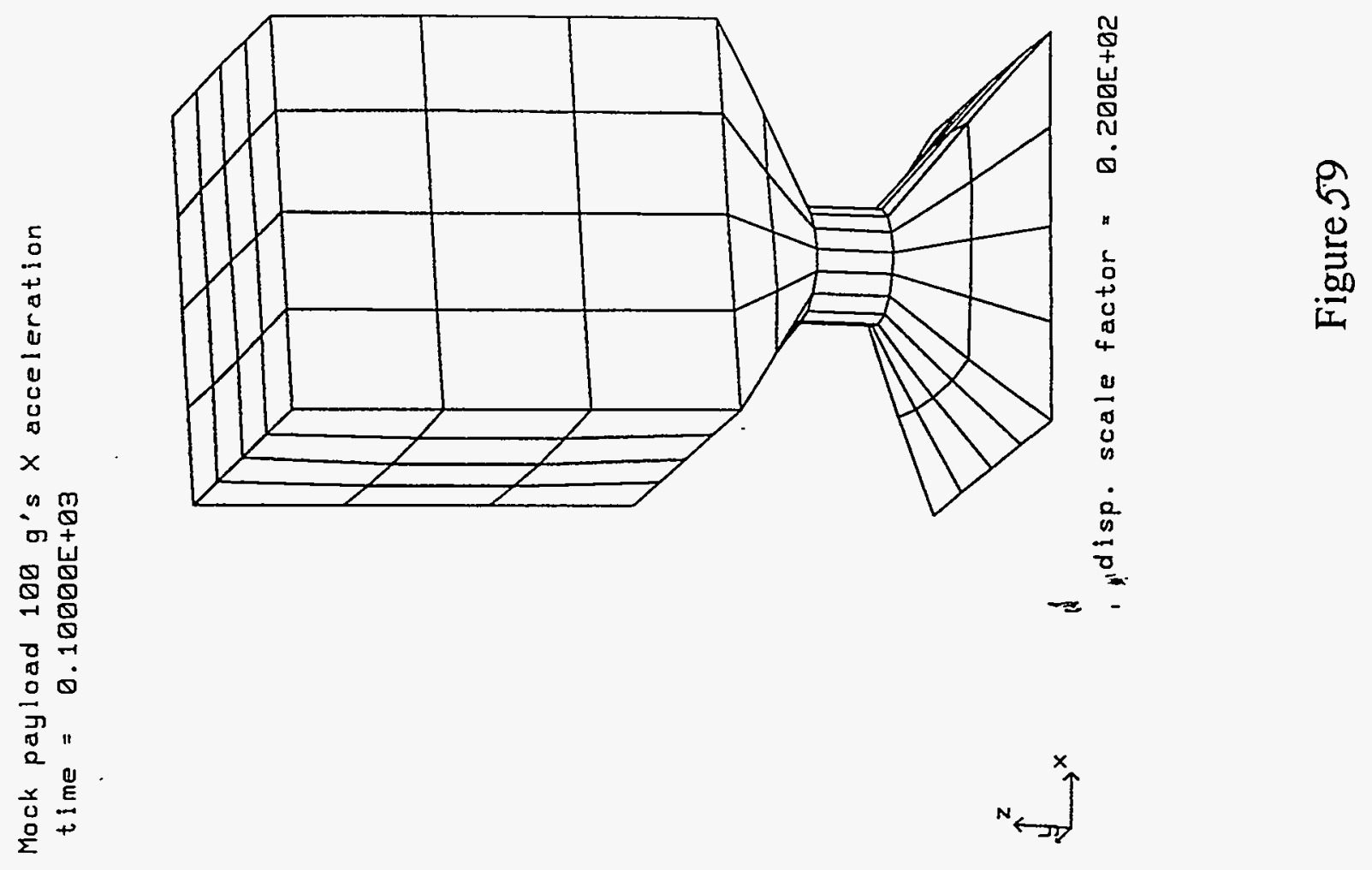




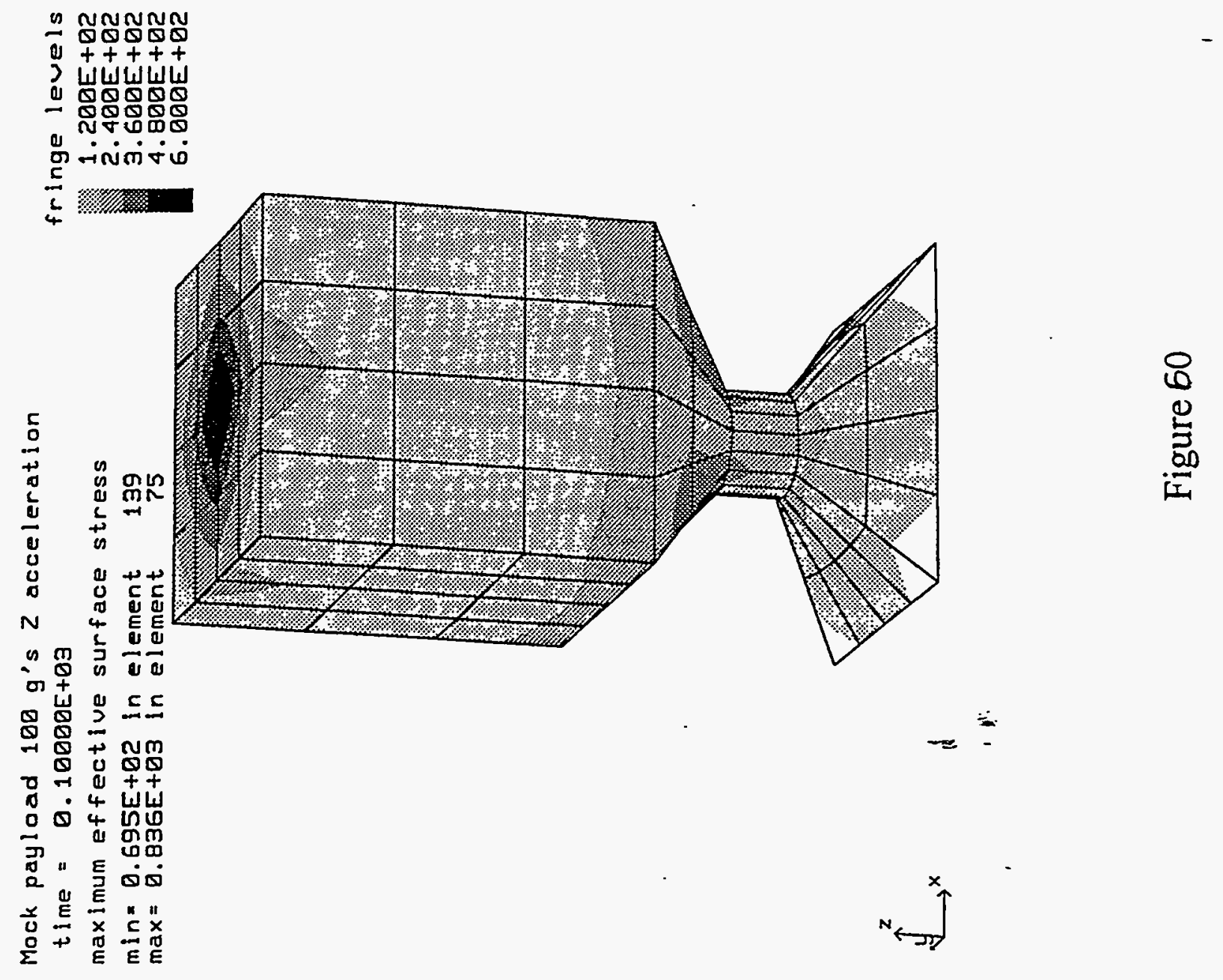




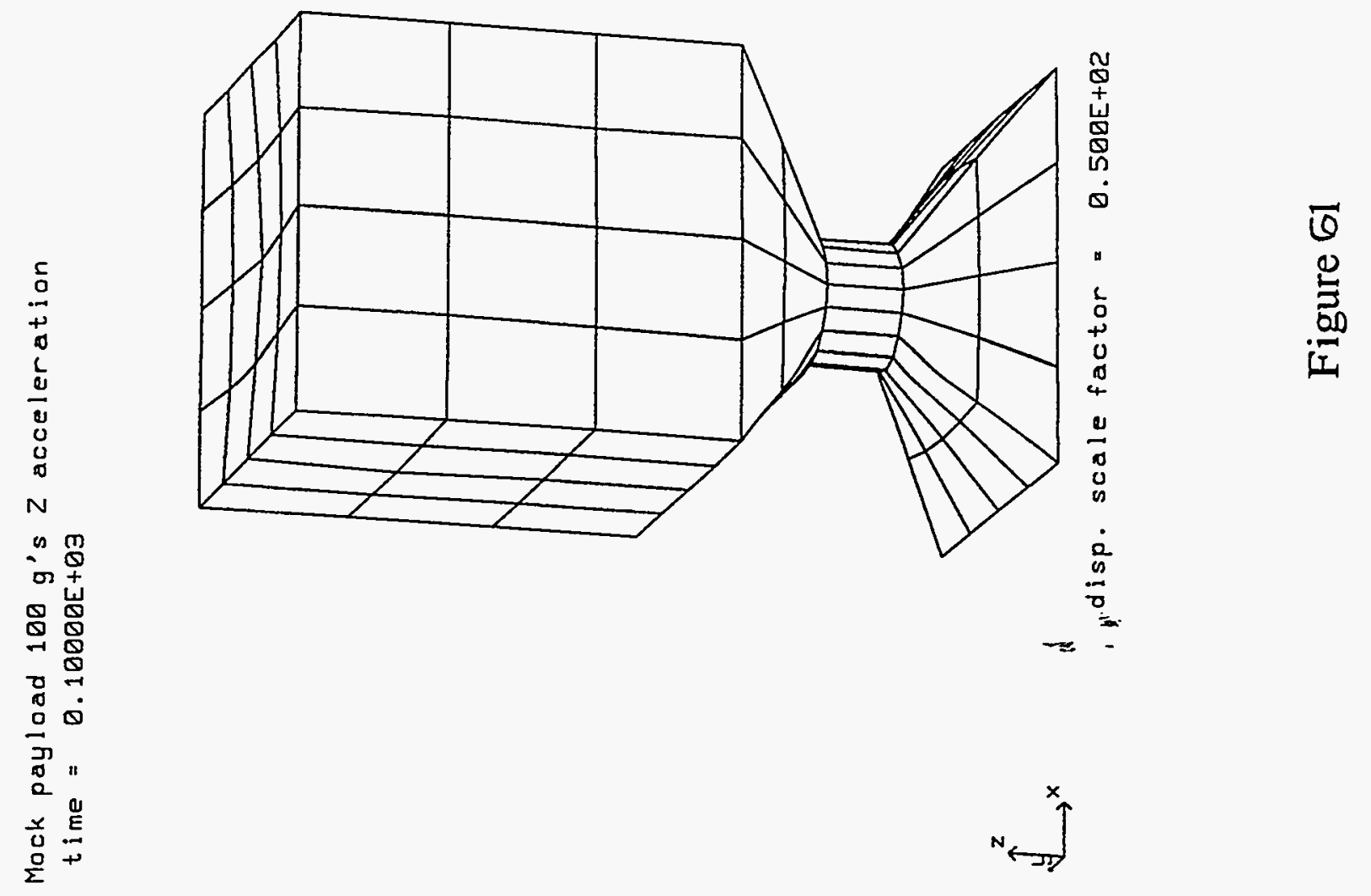




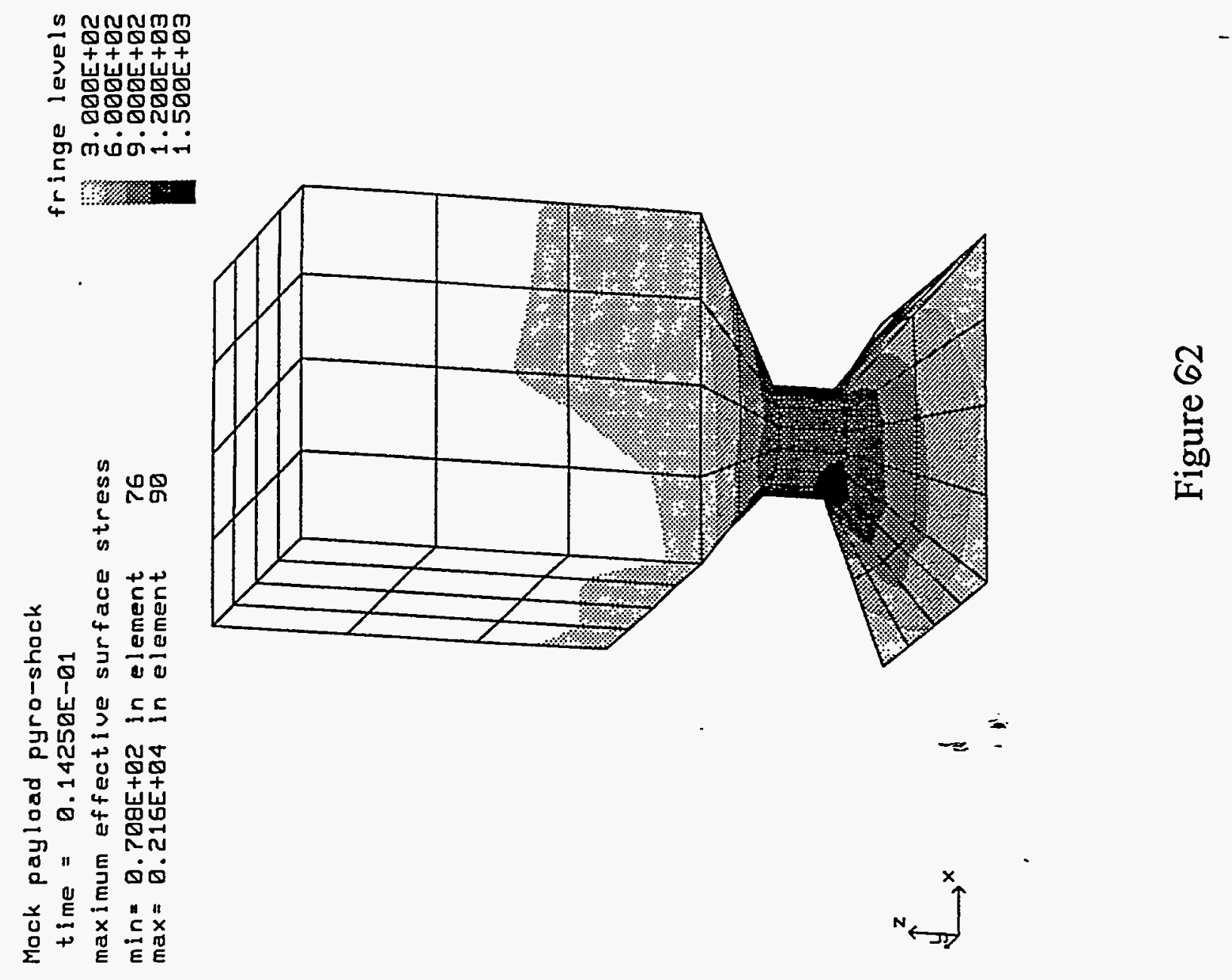




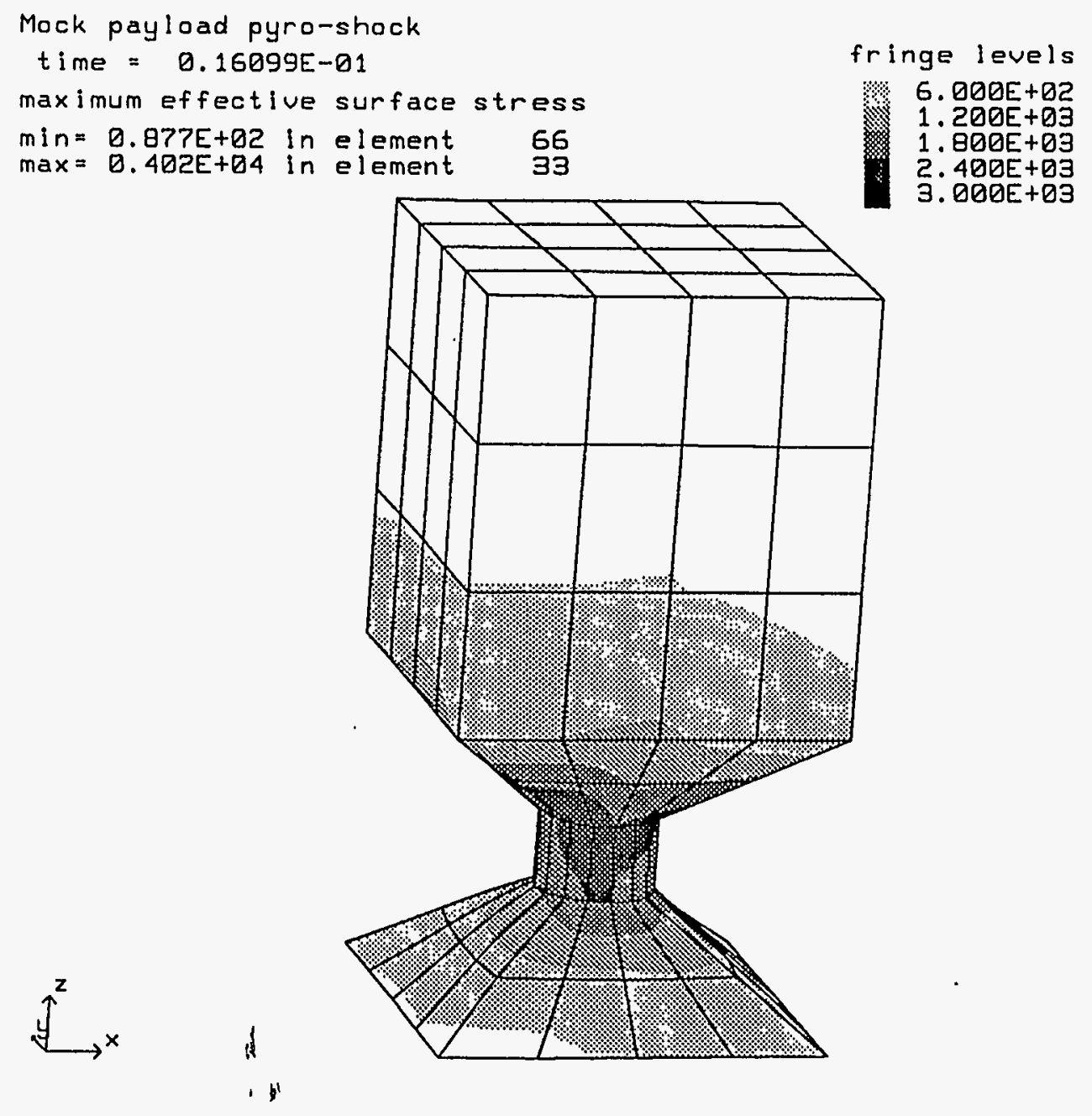

Figure 63 
Mock payload pyro-shock

time = 0.75997E-02

fringe levels

max.imum effective surface stress

$\min =0.699 \mathrm{E}+02$ in element 106

$\max =0.162 \mathrm{E}+04$ in element 22

* 3. $000 E+02$

6.0000E+05

G. 000E+05

- DUe+UC

$1 \cdot 200 E+03$
$1 \cdot 500 E+03$

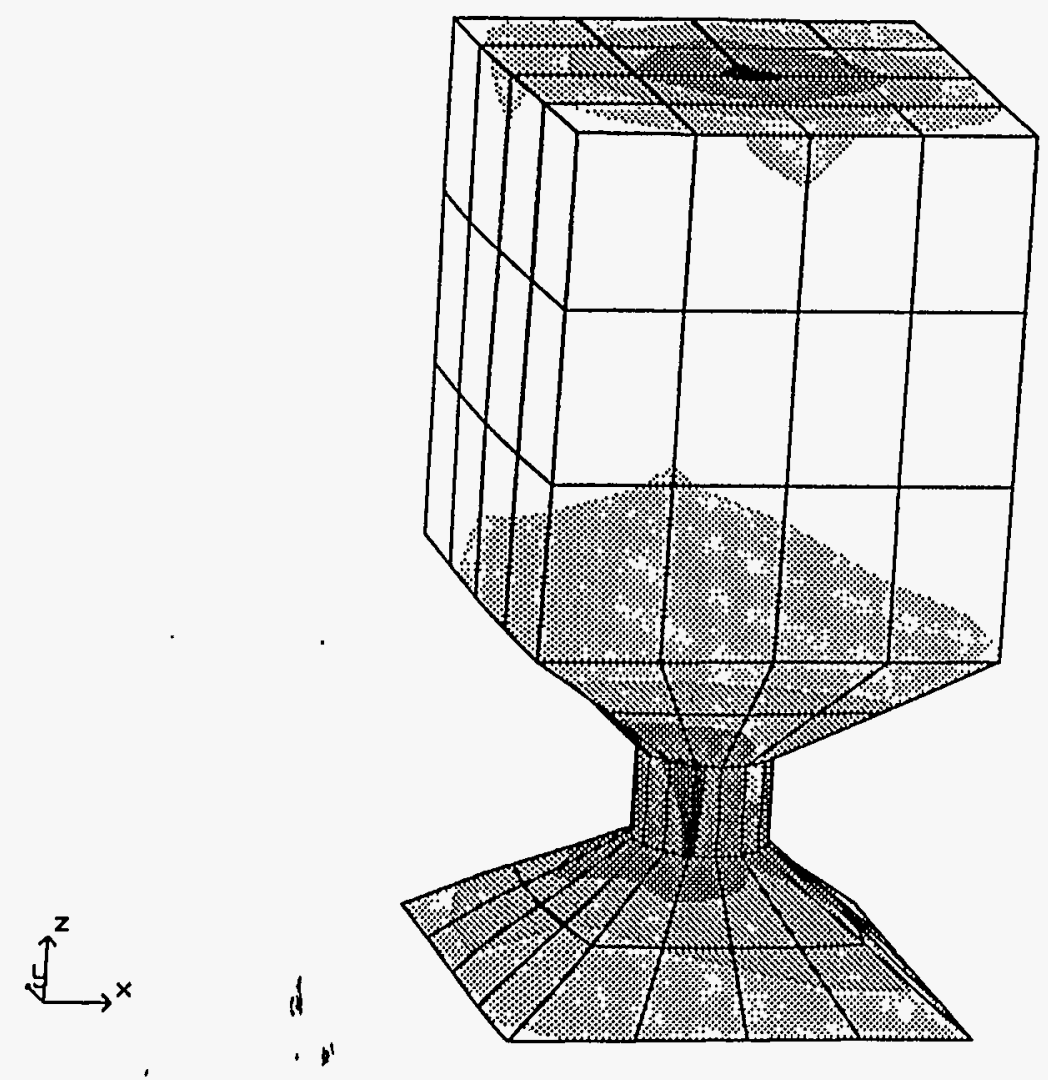

Figure 64 


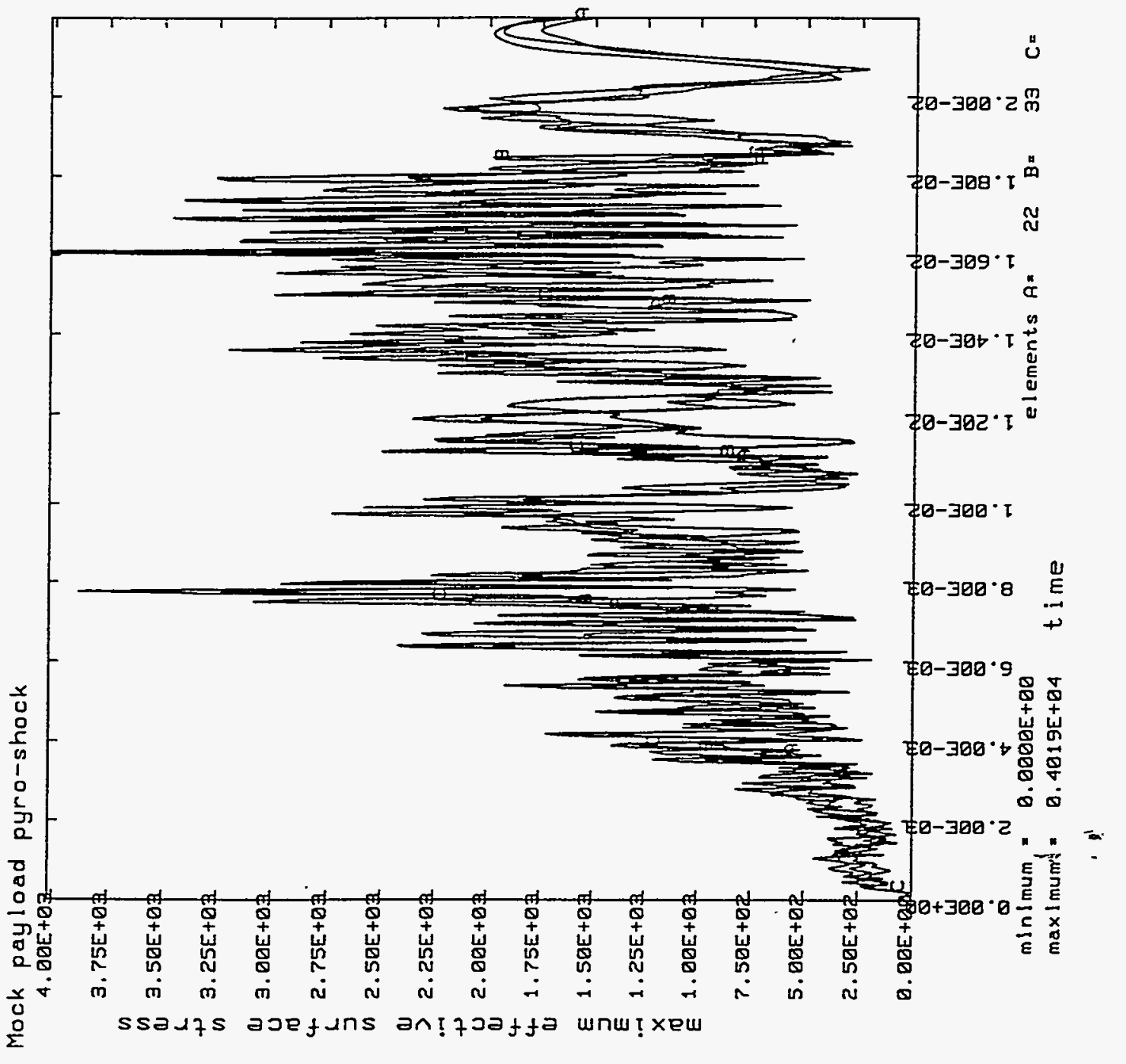




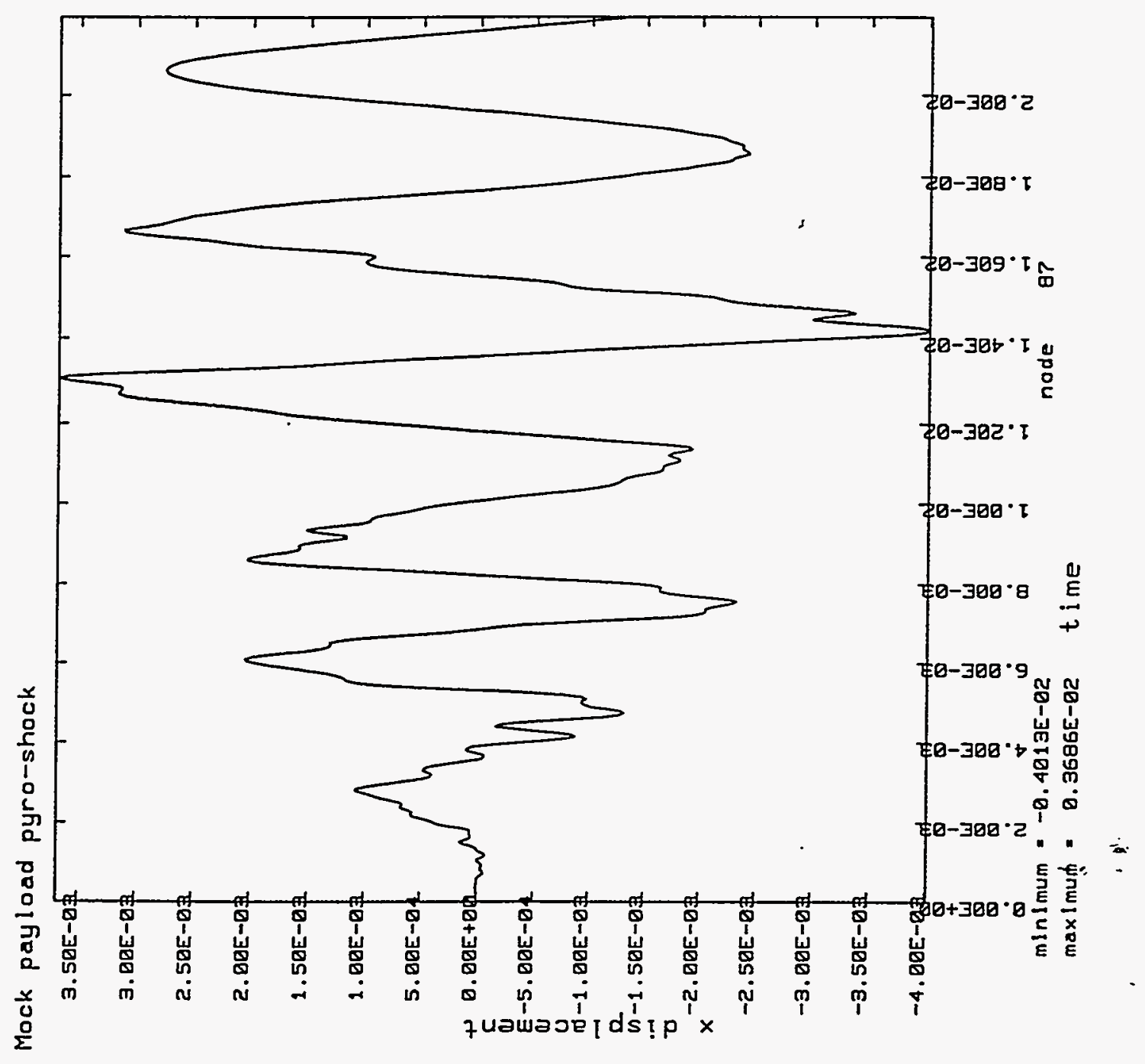

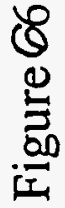


2
0
0
0
0
0

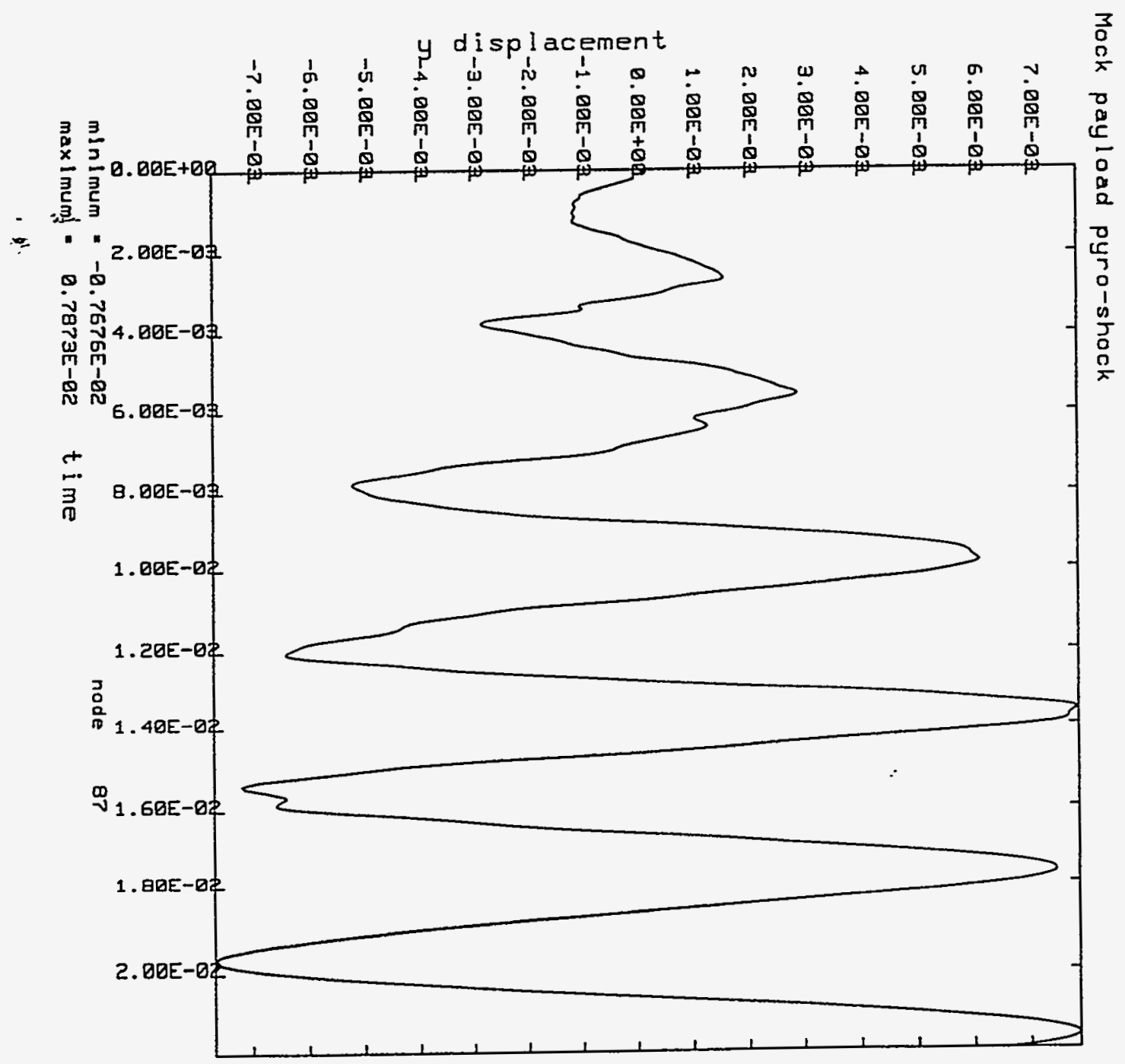




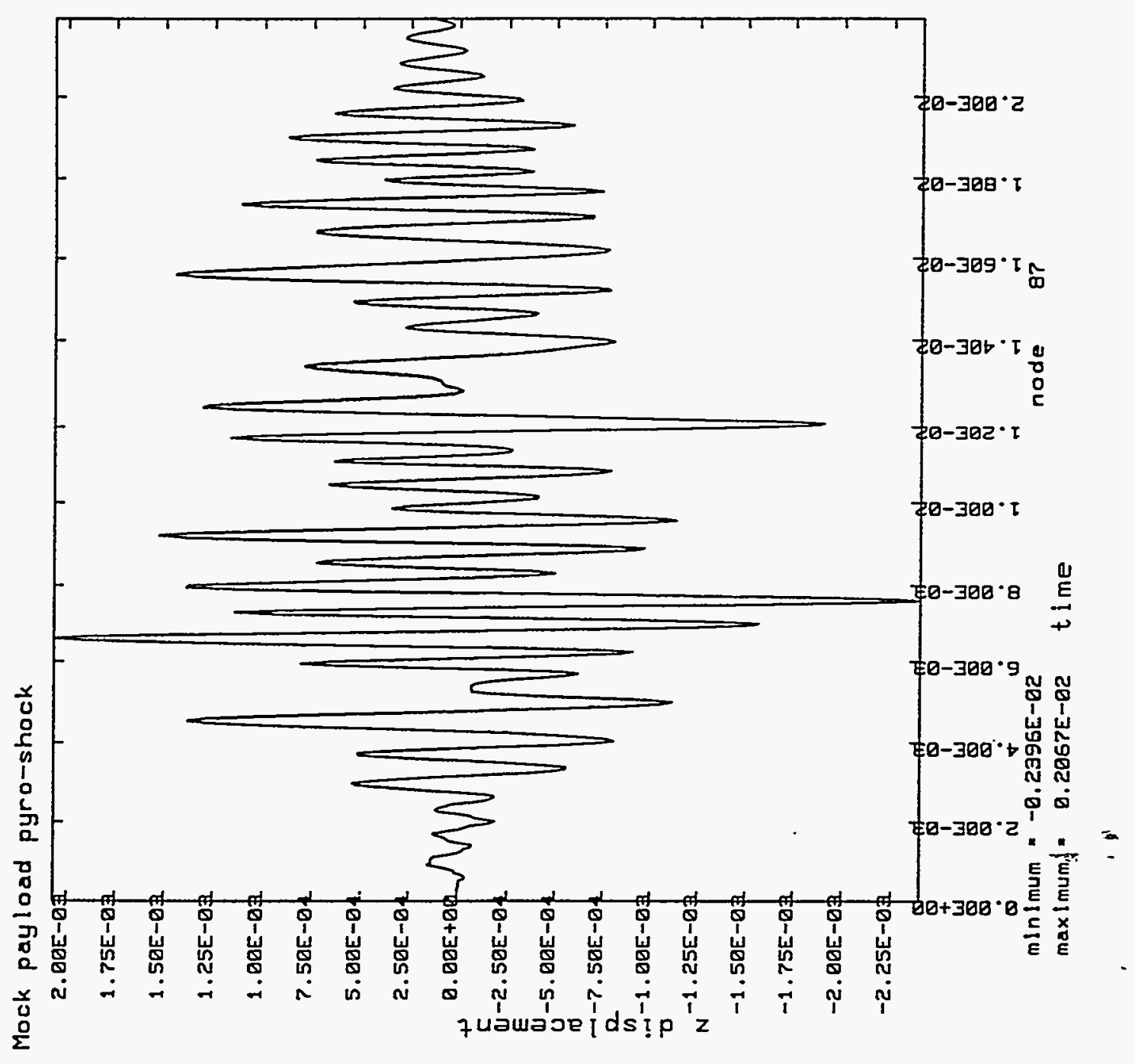

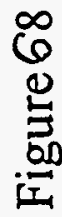


Mock payload Clementine $14 \mathrm{grm}$

time $=0.48800 E-01$

maximum effective surface stress

min $=0.686 E+02$ in element 74

$\max =0.358 E+04$ in element 18

fringe levels

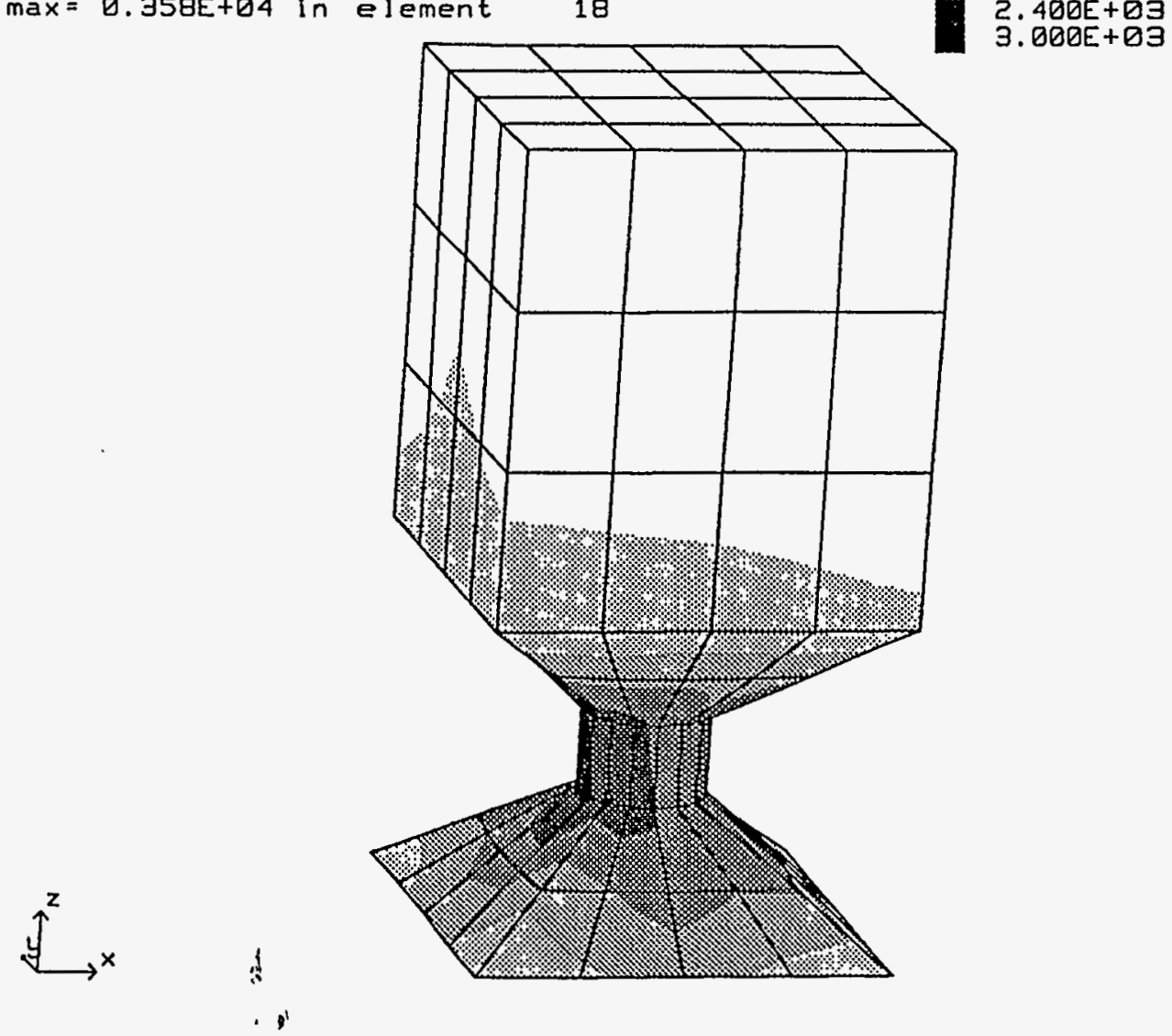

Figure 69 


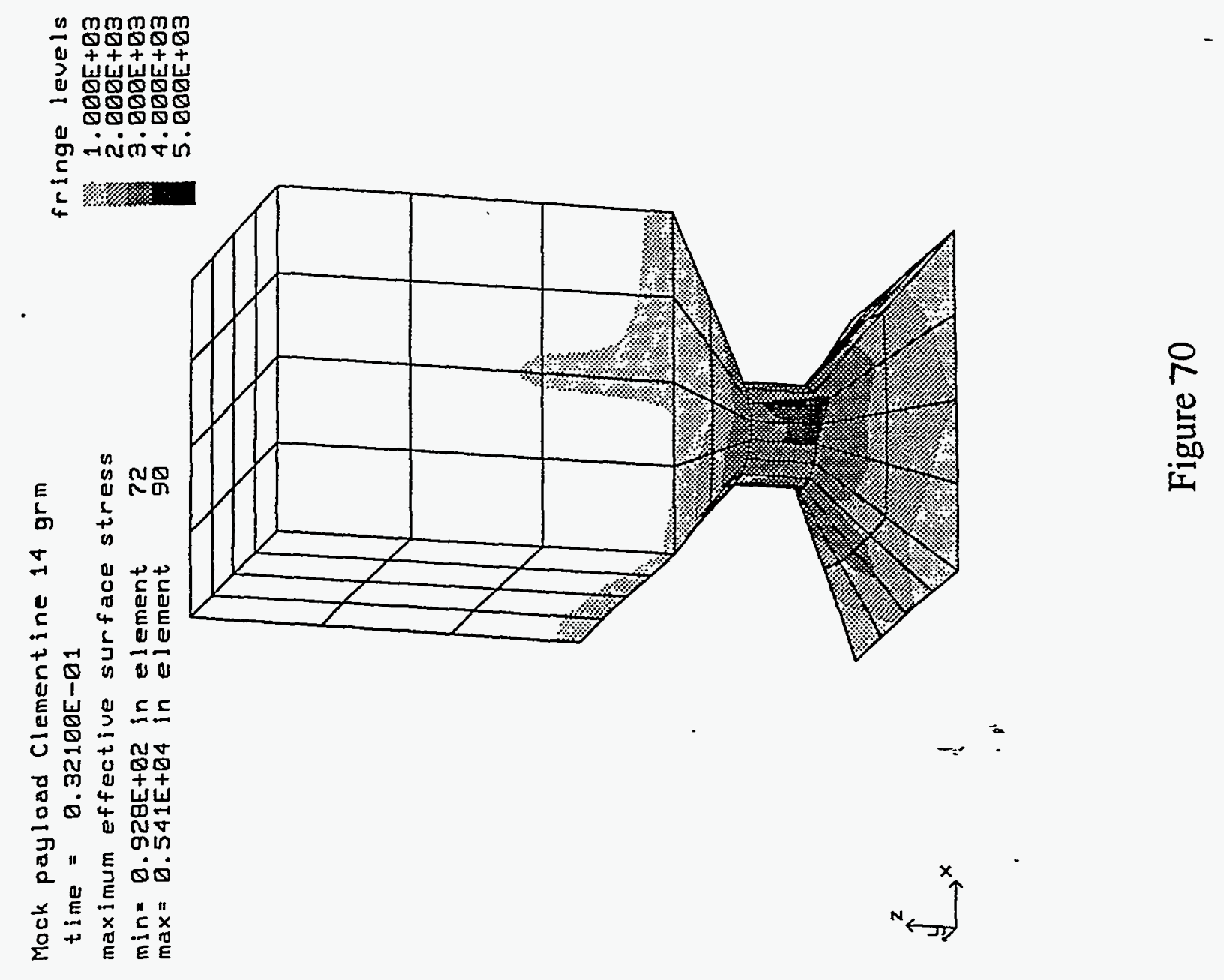


Mock payload Clementine $14 \mathrm{grm}$

time $=0.12495 \mathrm{E}-02$

fringe levels

maximum effective surface stress

min:0.236E+02 in element 138

$\max =0.687 \mathrm{E}+03$ in element 71

\% 1.200E +02

1. $200 E+02$

$3.600 E+05$
$4.600 E+05$

4. $B 00 E+02$

6. $000 E+02$

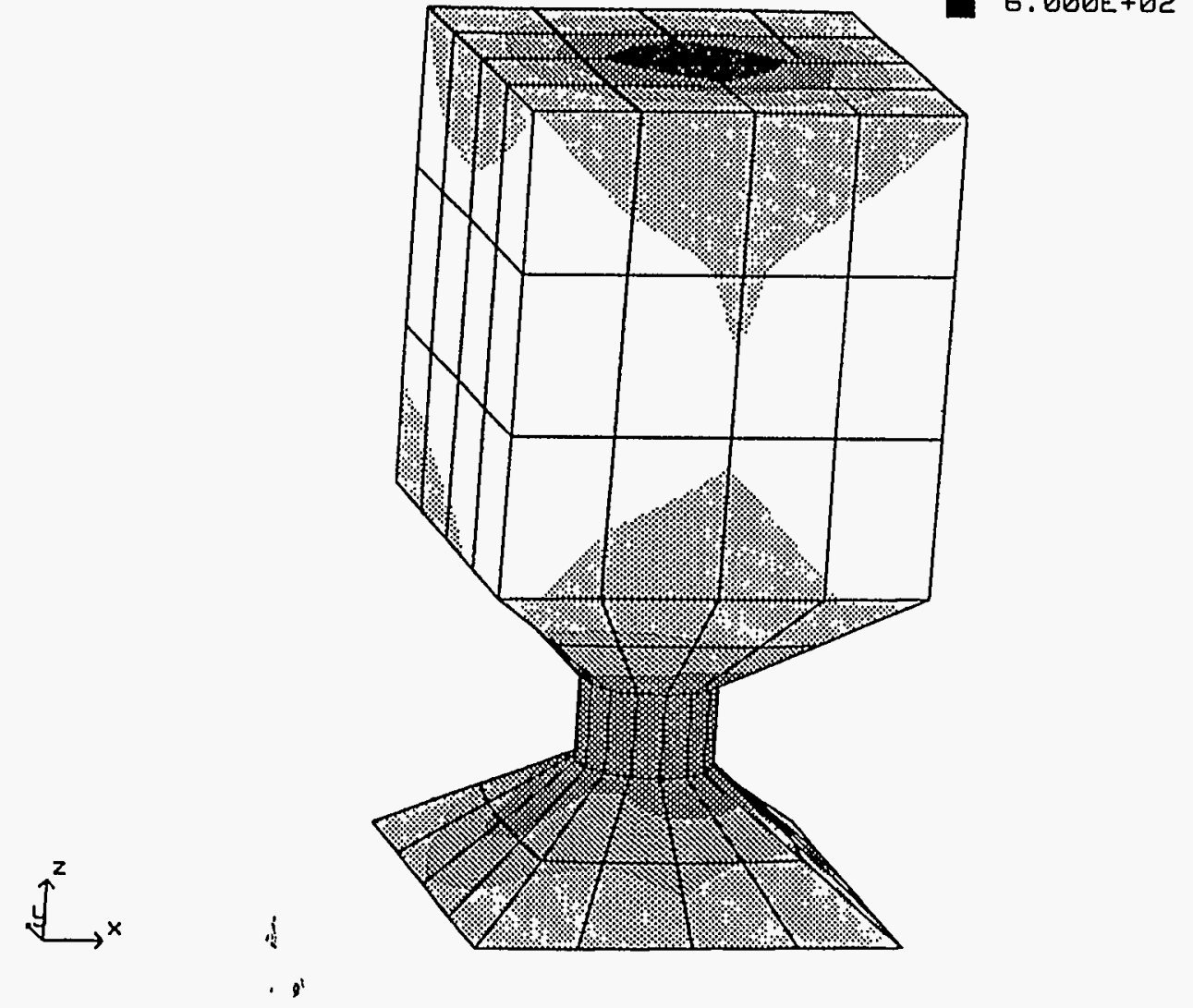

Figure 71 


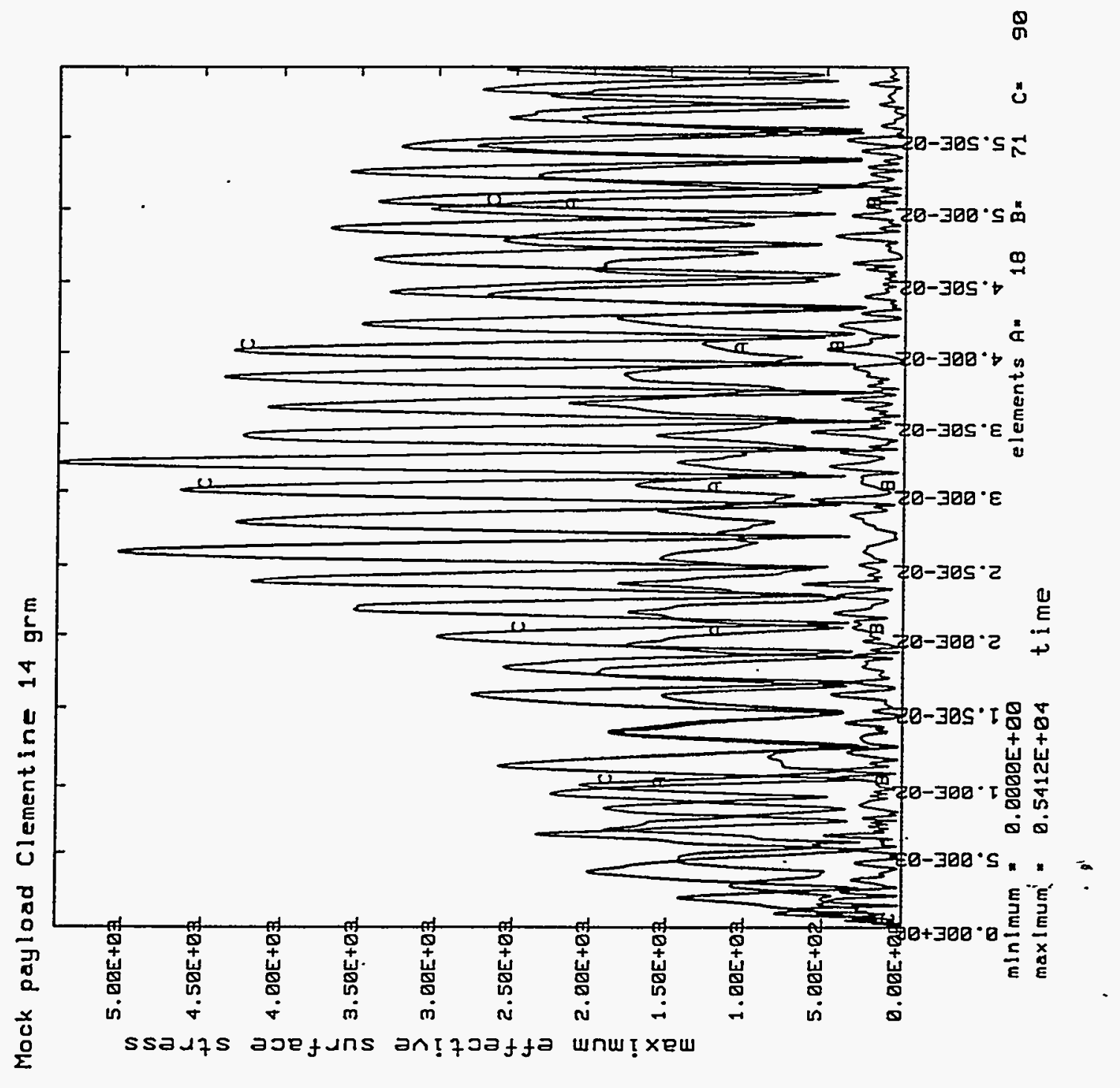

N 


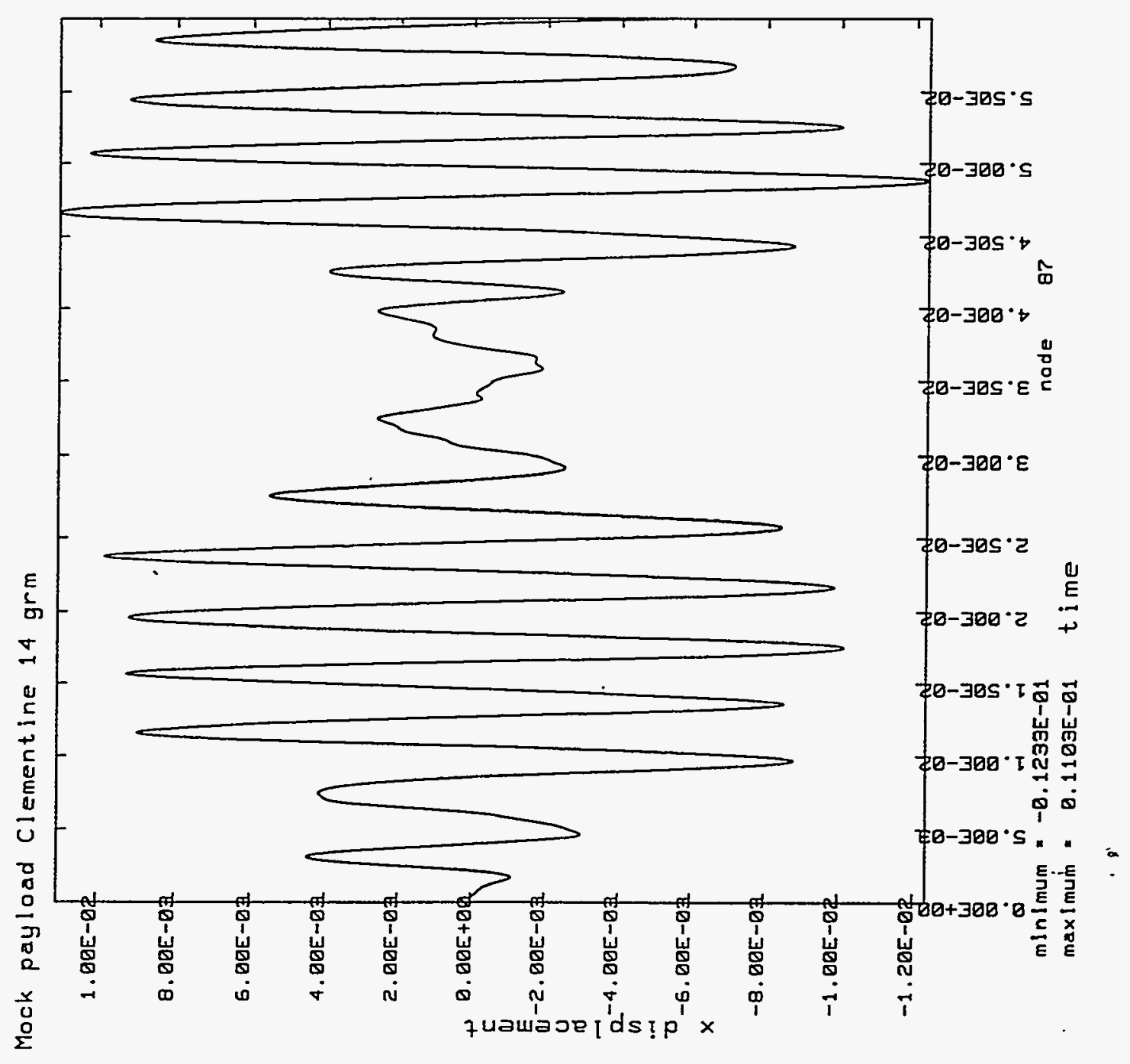

R 


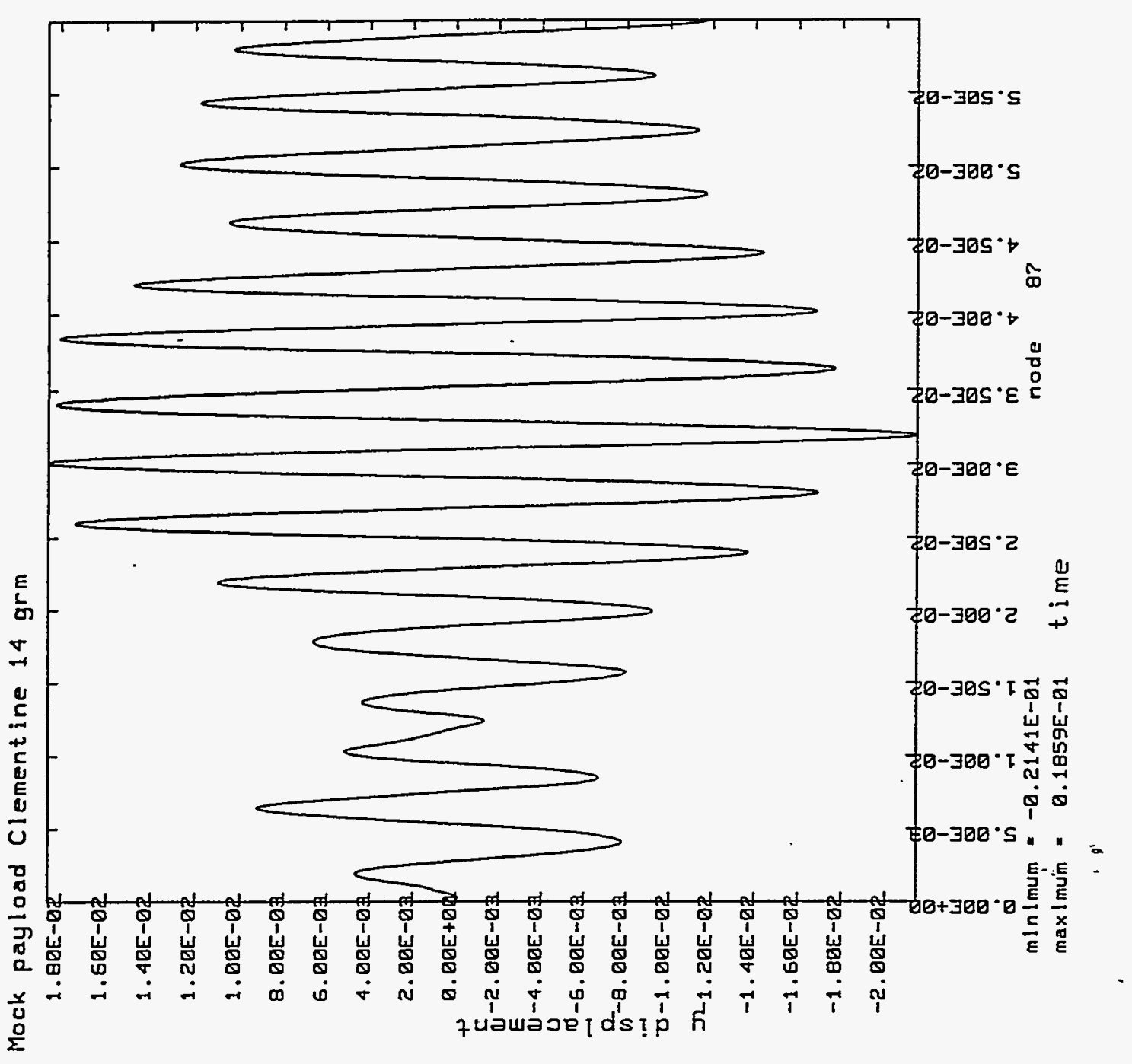




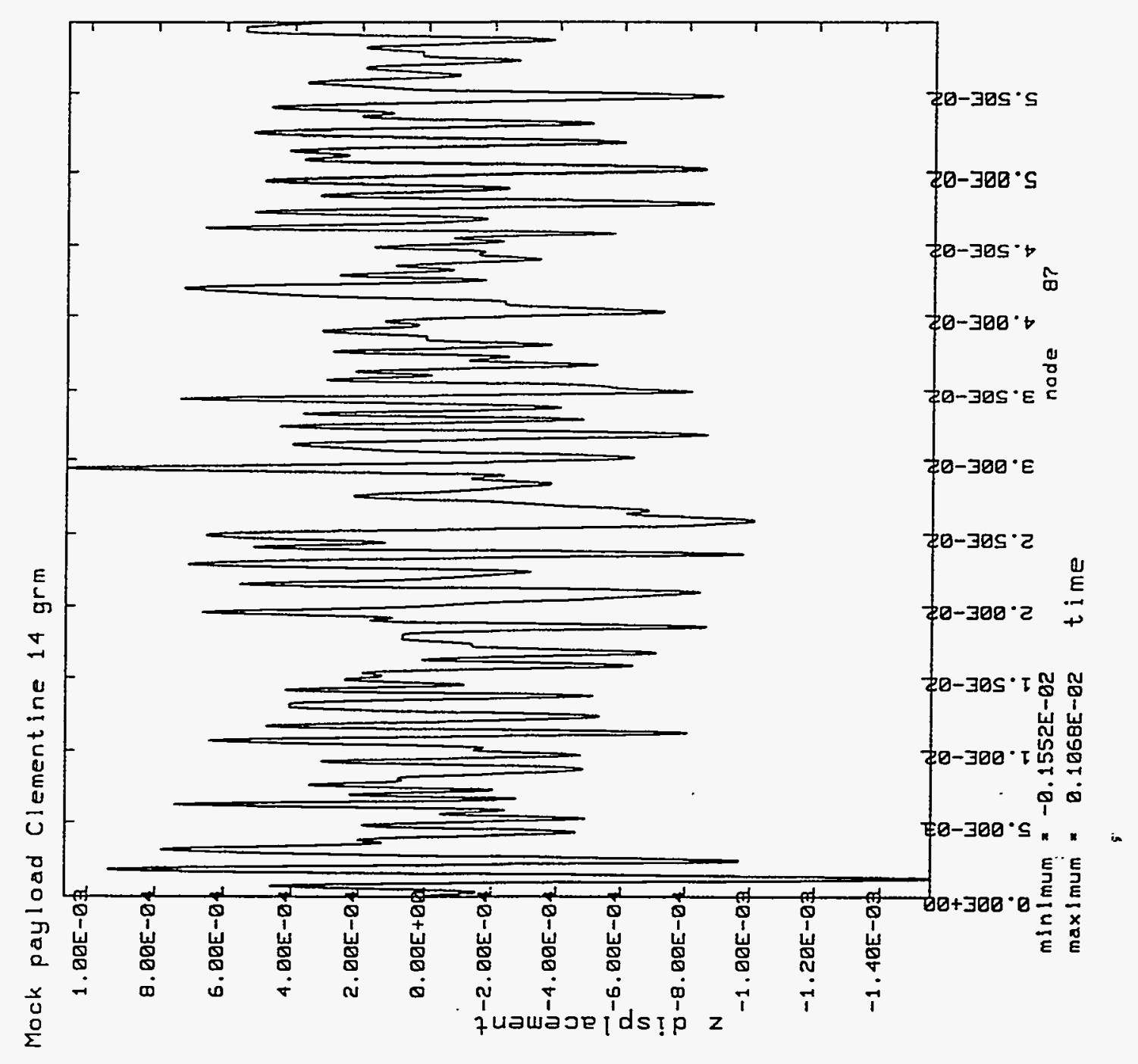

$\underset{n}{n}$ 


\section{Appendix E.2 \\ Mechanical Drawing Package}


UNIESS OTHERWI: - MED.

1. All OAmensio

2. OIMENSIONINA $N$ INCMES

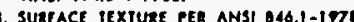

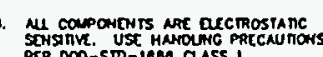
PER DOO-STD-18BS cuss

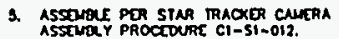

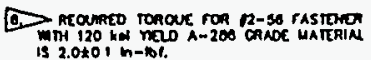

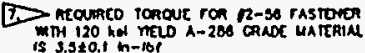

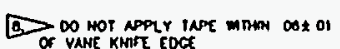

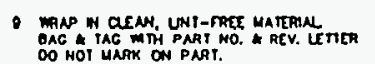

$4(3 ! 211)$

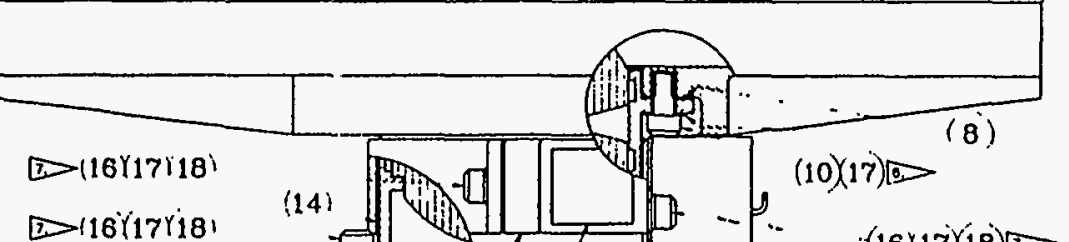

(14)

(10)(17) [as

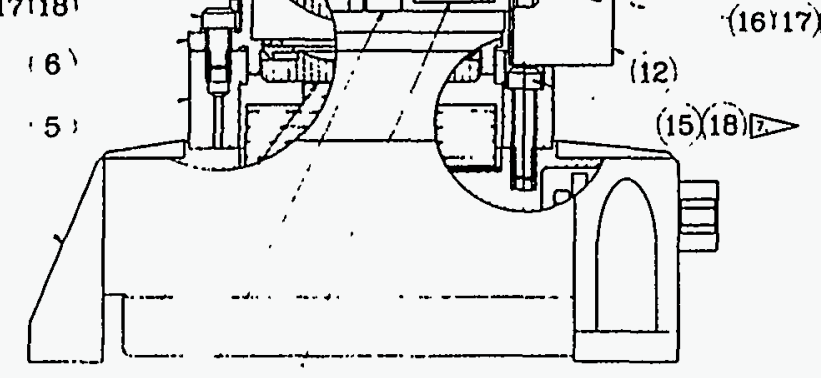

1173

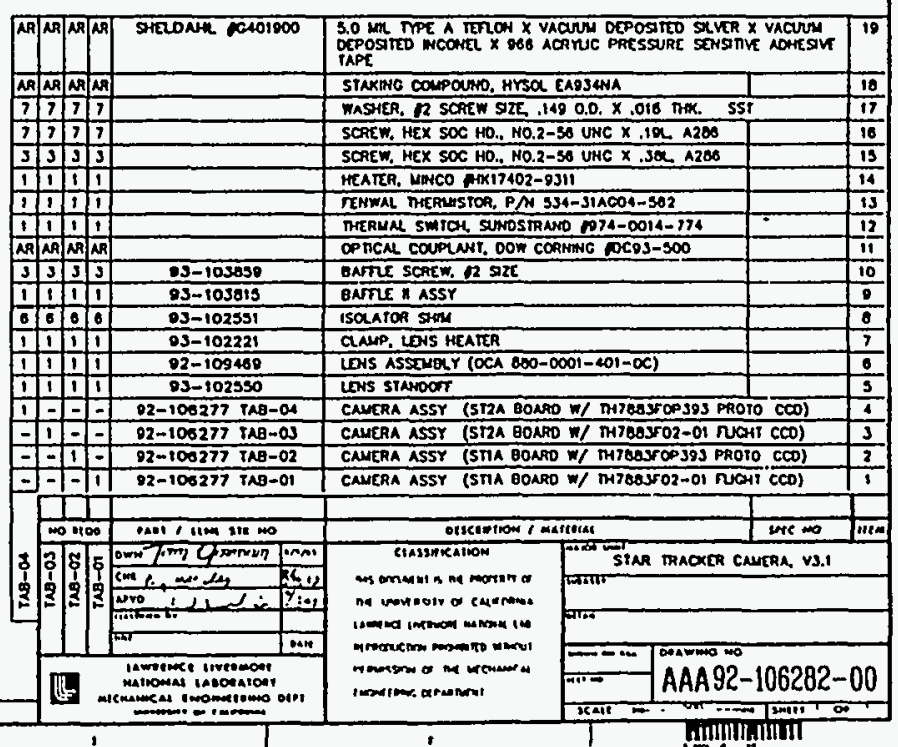




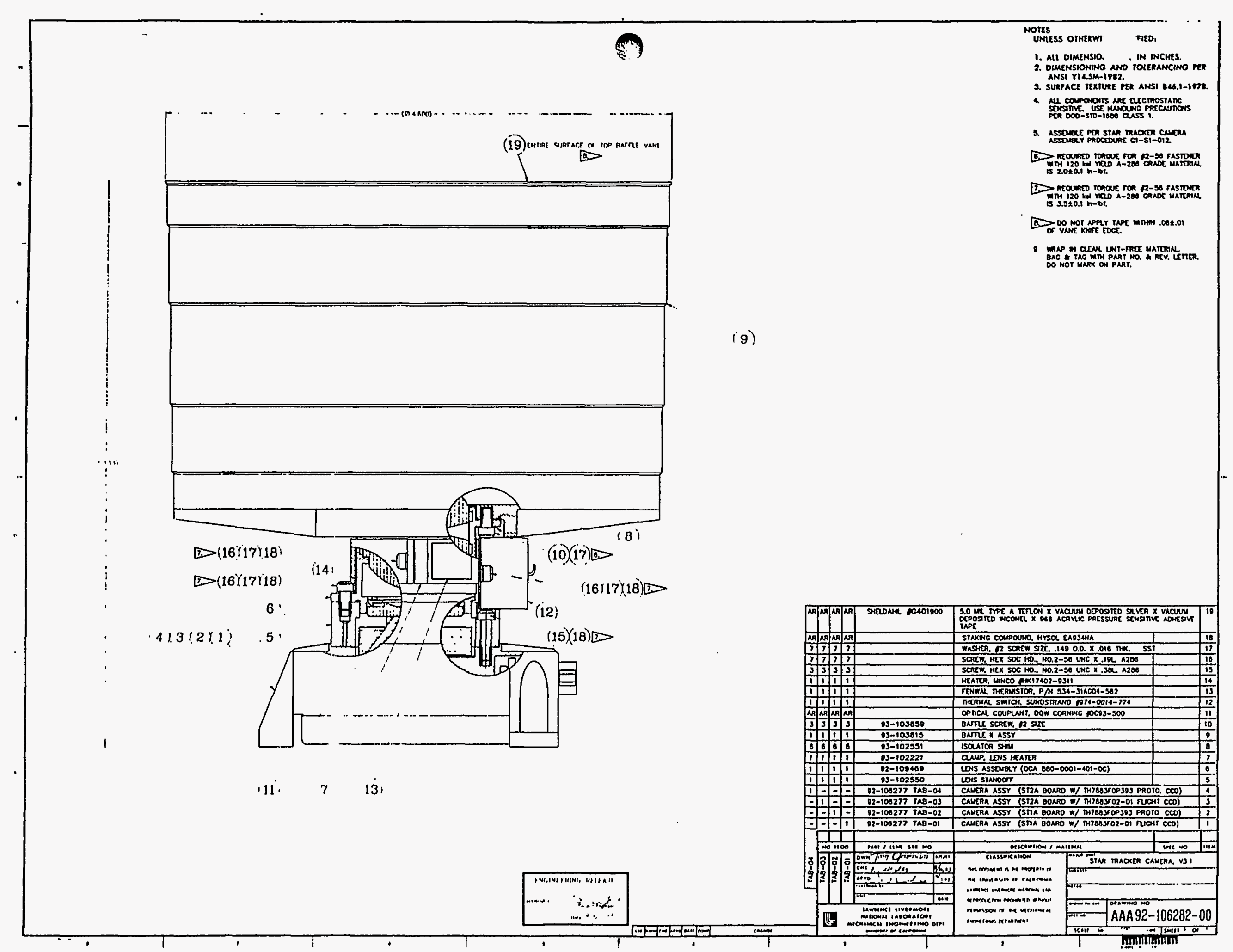




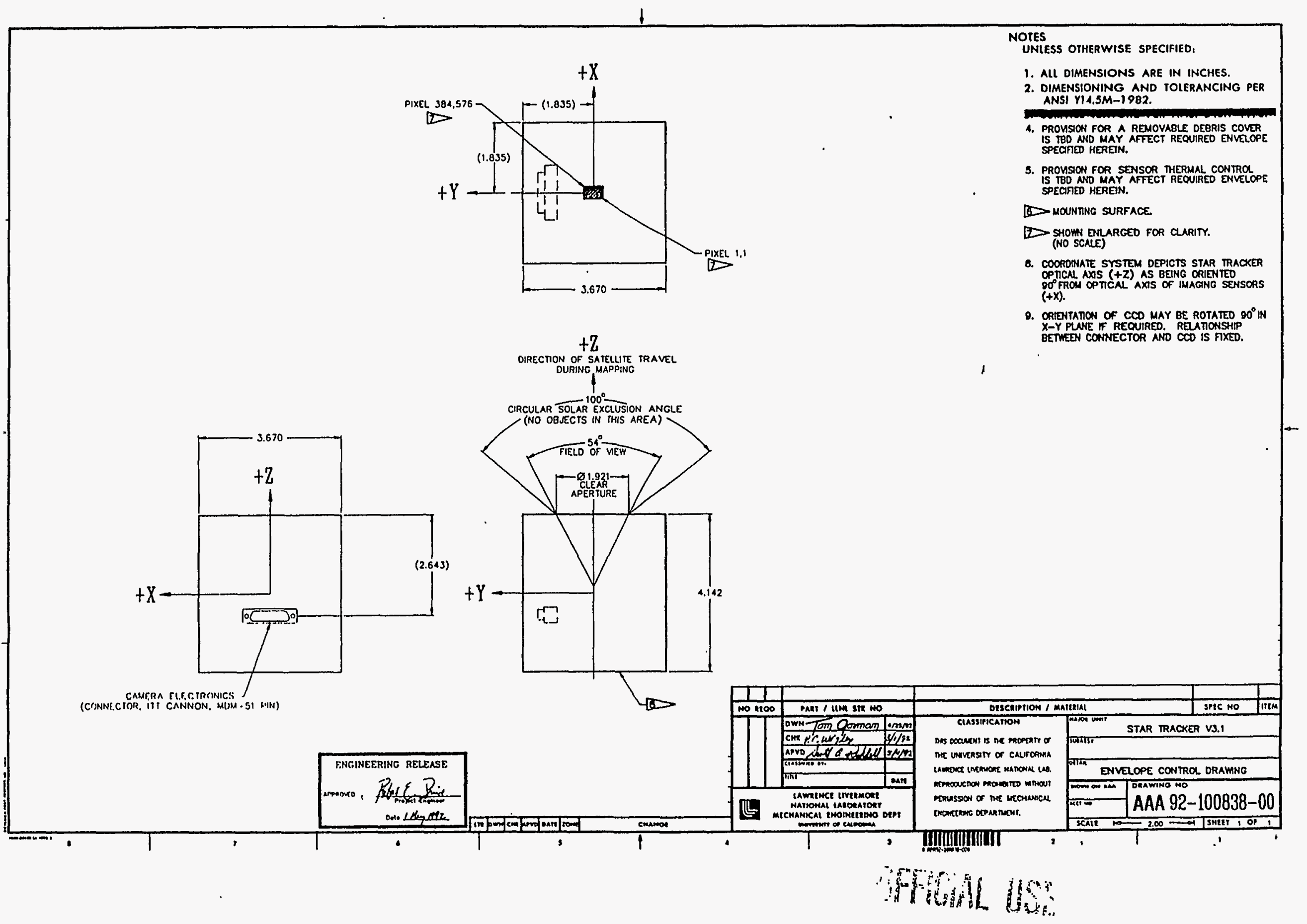


ISก TVIDIJJO

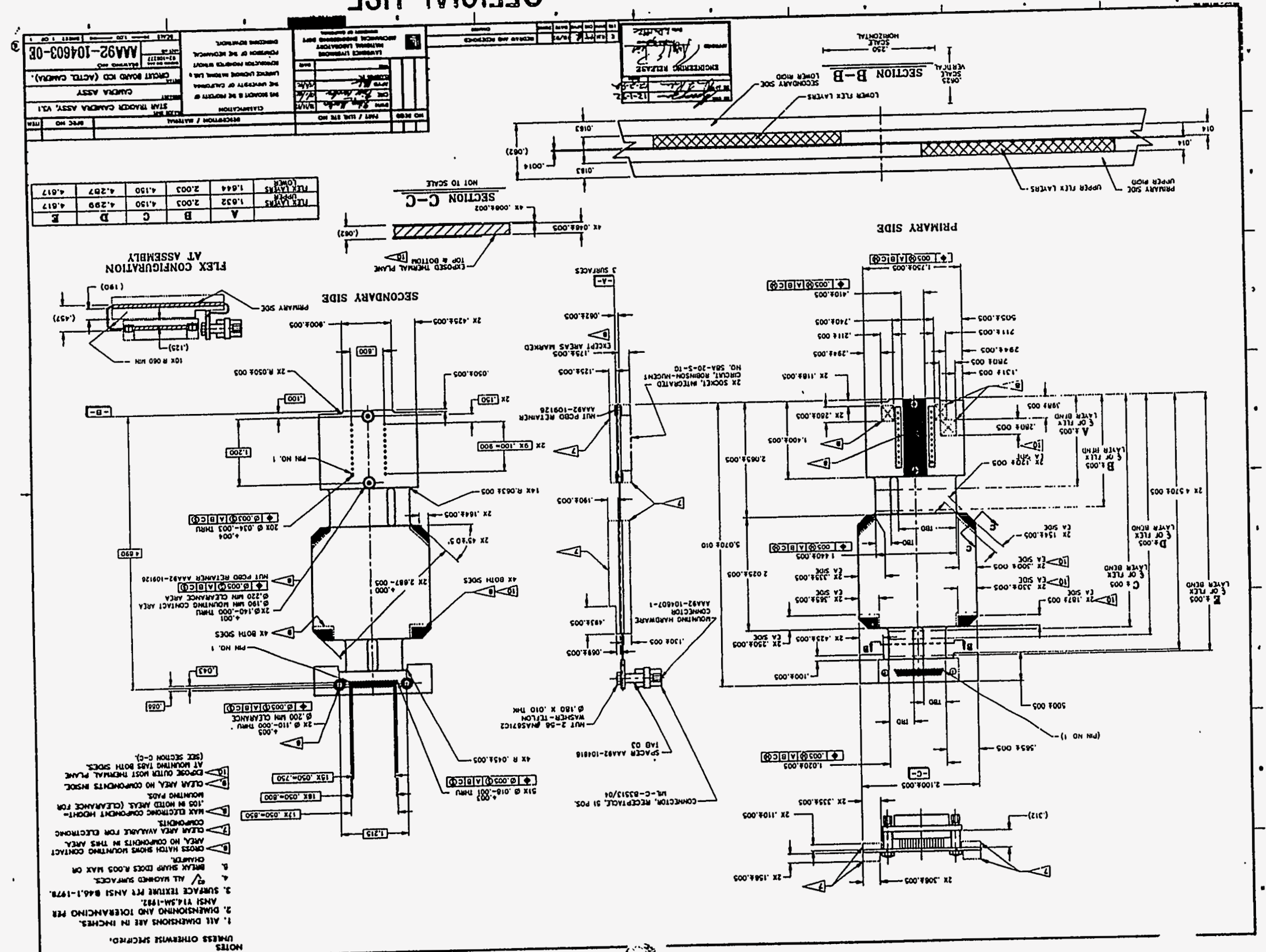




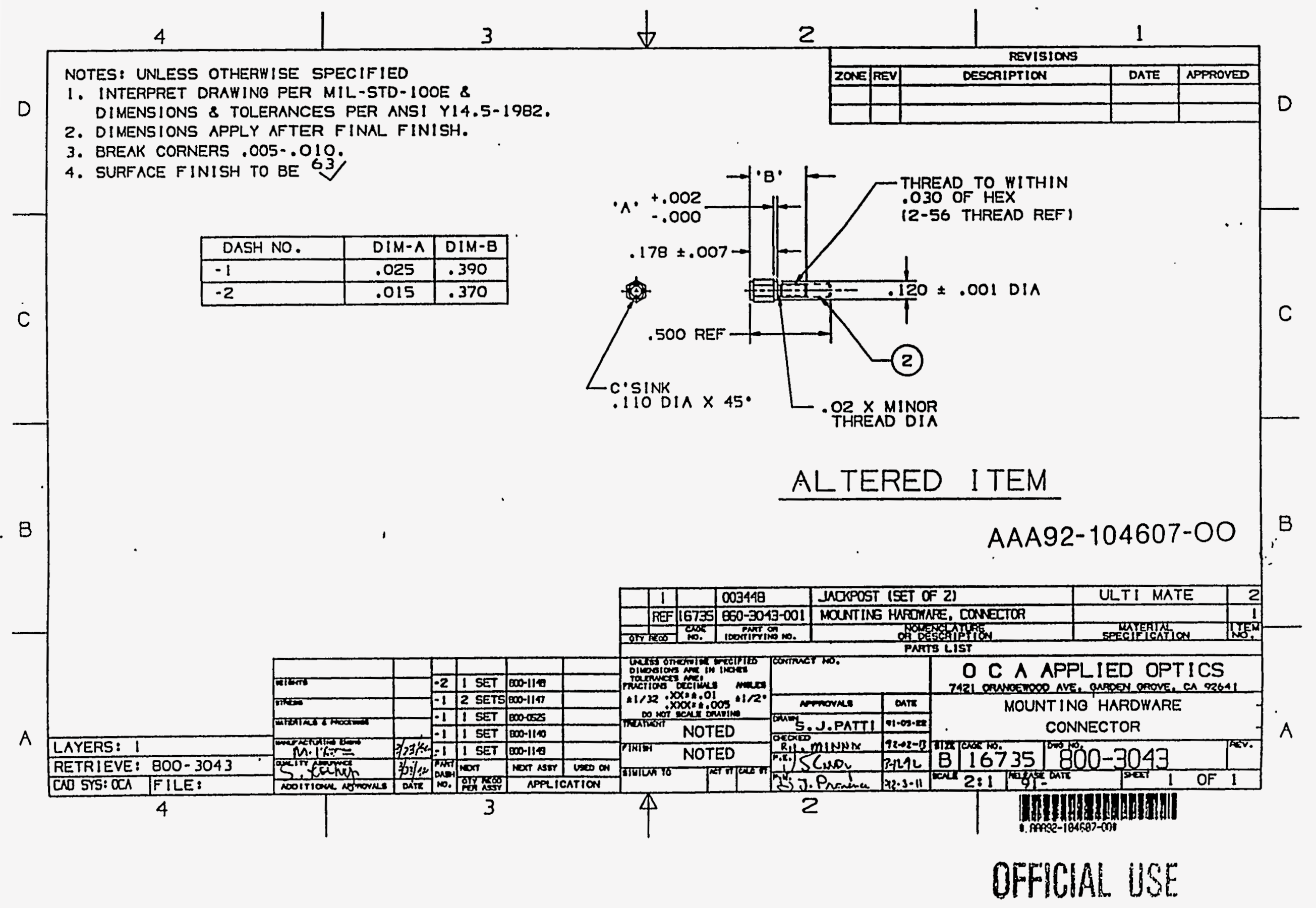


2

NOTES: UNLESS OTHERWISE SPECIFIED

1. INTERPRET DRAWINO PER MIL-STD-1OOE \&

DIMENSIONS \& TOLERANCES PER ANSI Y14.5-1982.

2. DIMENSIONS APPLY AFTER FINAL FINISH.

3. BREAK CORNERS .005-.010.

4. SURFACE FINISH TO BE 63

5 FINISH: CHEMICAL CONVERSION COATINO PER MIL-C-5541, CLASS IA

6 THE TWO JACKPOST'S THAT COME

WITH THE CONNECTOR 'KIT ARE TO
BE ALTERED AS PER DWG. BOO-3043
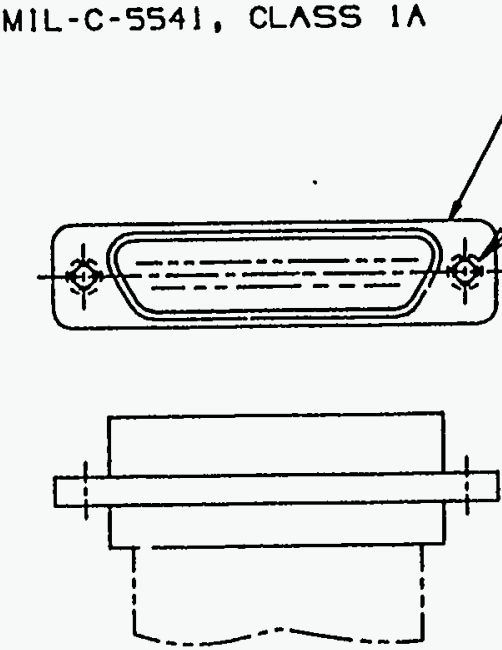

\section{ALTERED ITEM}

AAA92-104976-00

6

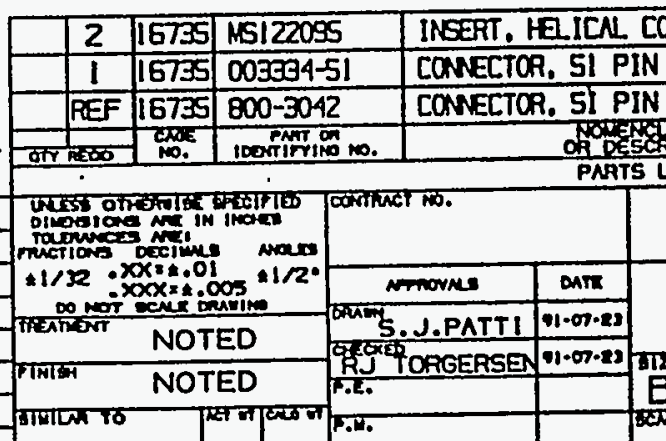

\begin{tabular}{l}
\hline LAYERS: 1 \\
\hline RETRIEVE: $800-3042$ \\
\hline CADSYSOCA
\end{tabular}

CND SYS: 0CA FILE:

4

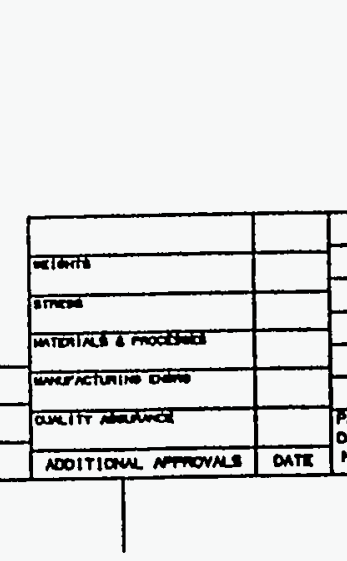

3
2
$2-56 \times 1011$ THREAD THRU FOR HEL ICAL INSERT PER MS 3353 LE: Nom

\begin{abstract}
3
\end{abstract}

\section{OFFICIAL USE}




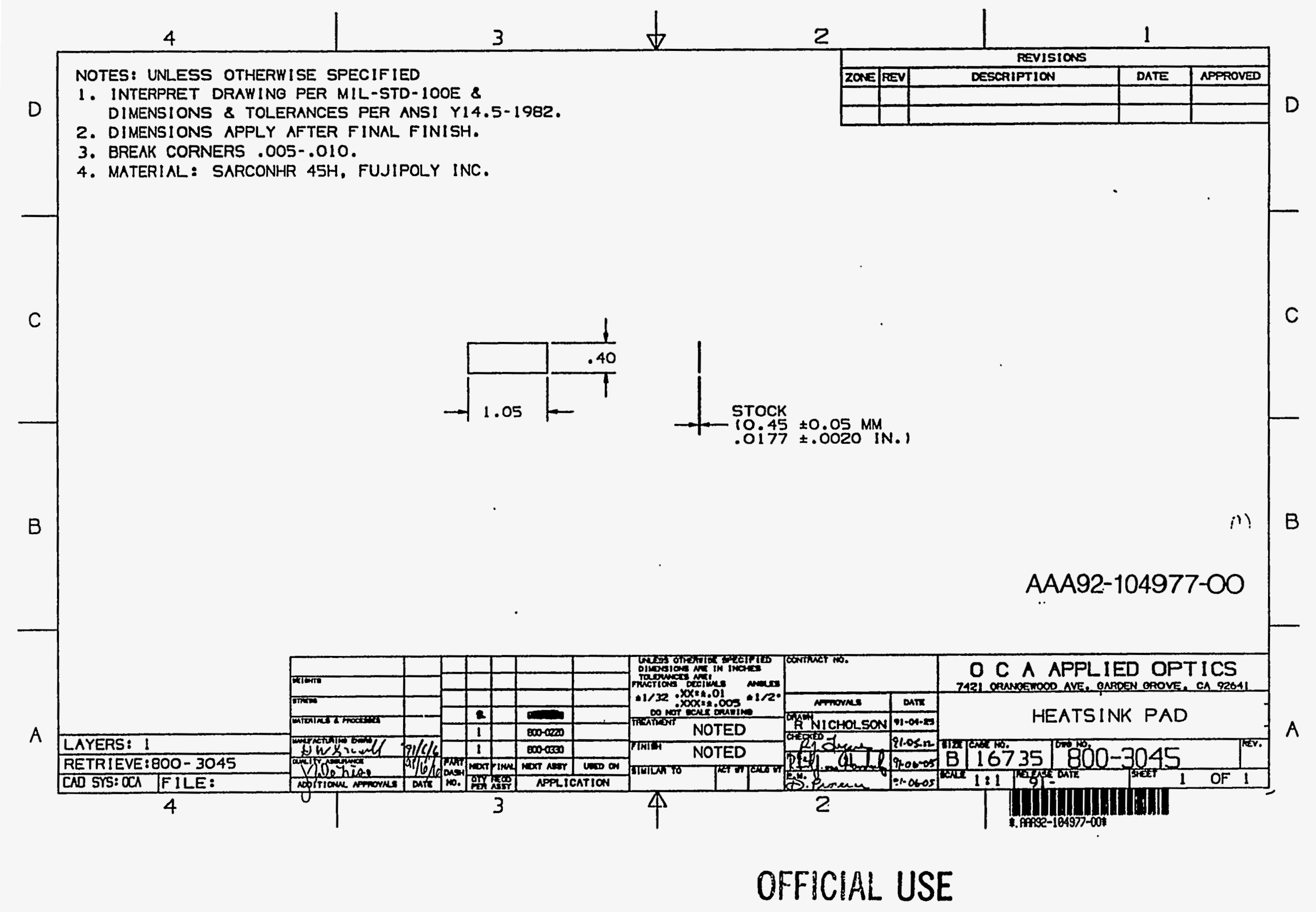




\section{?}

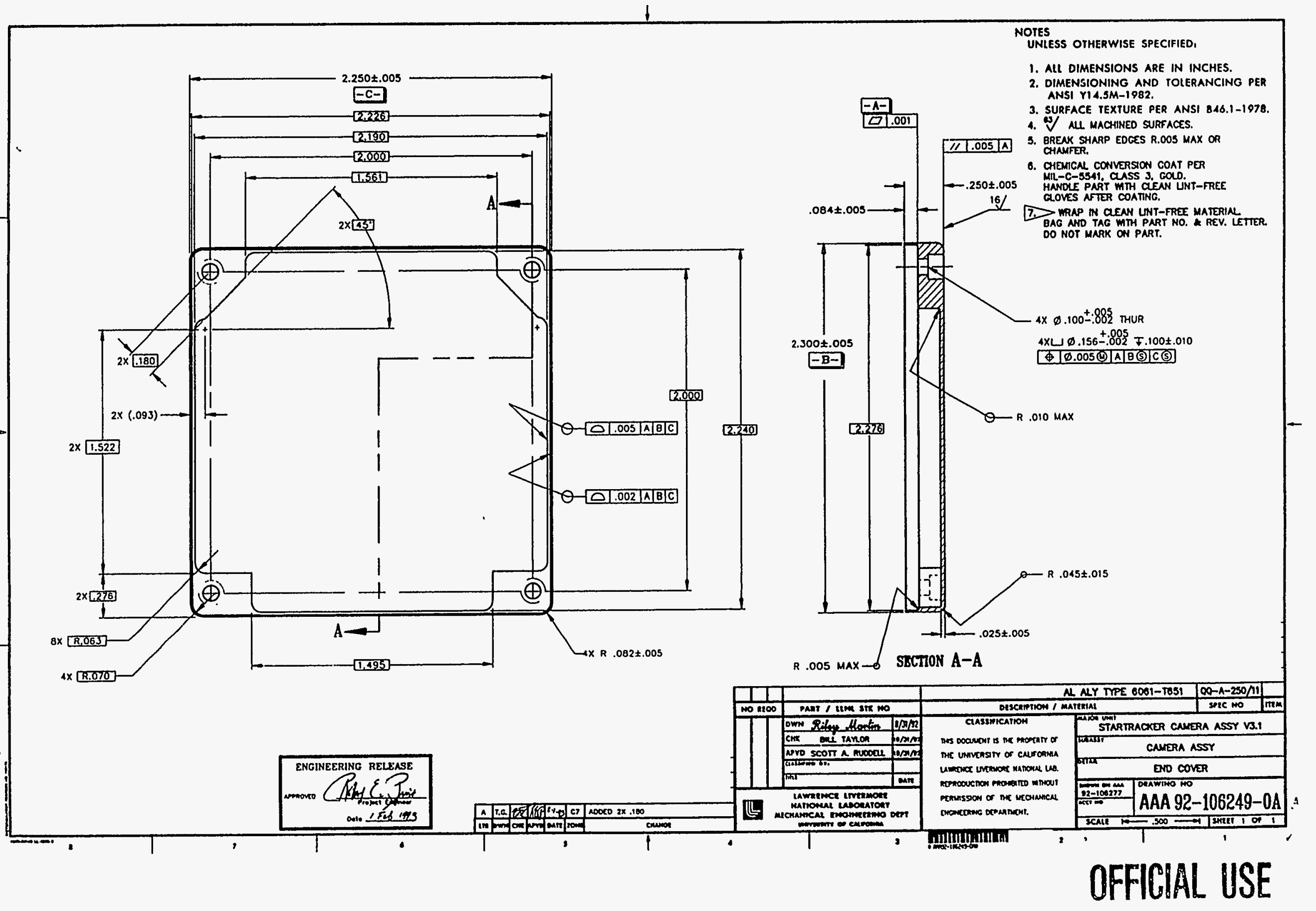




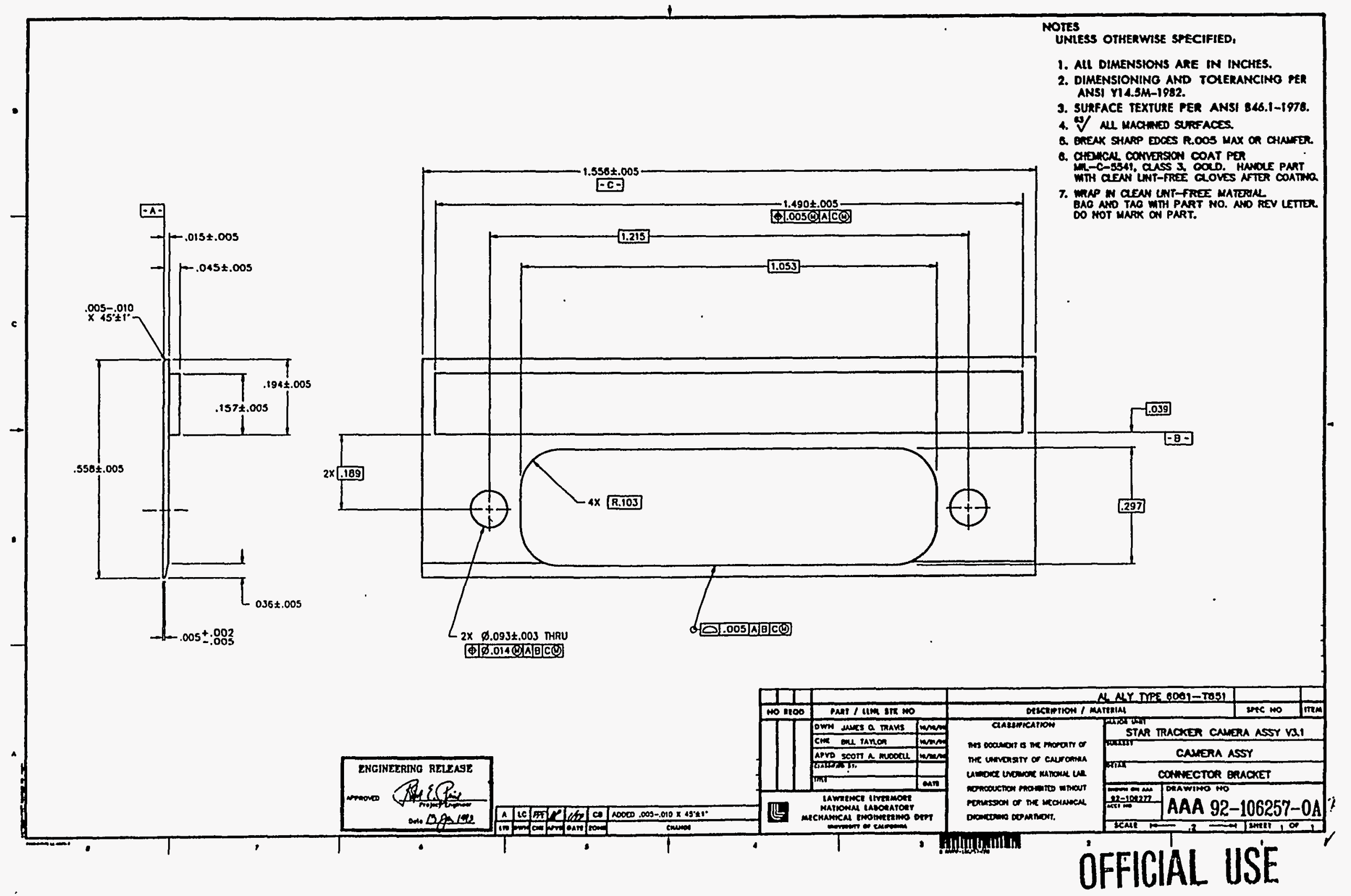




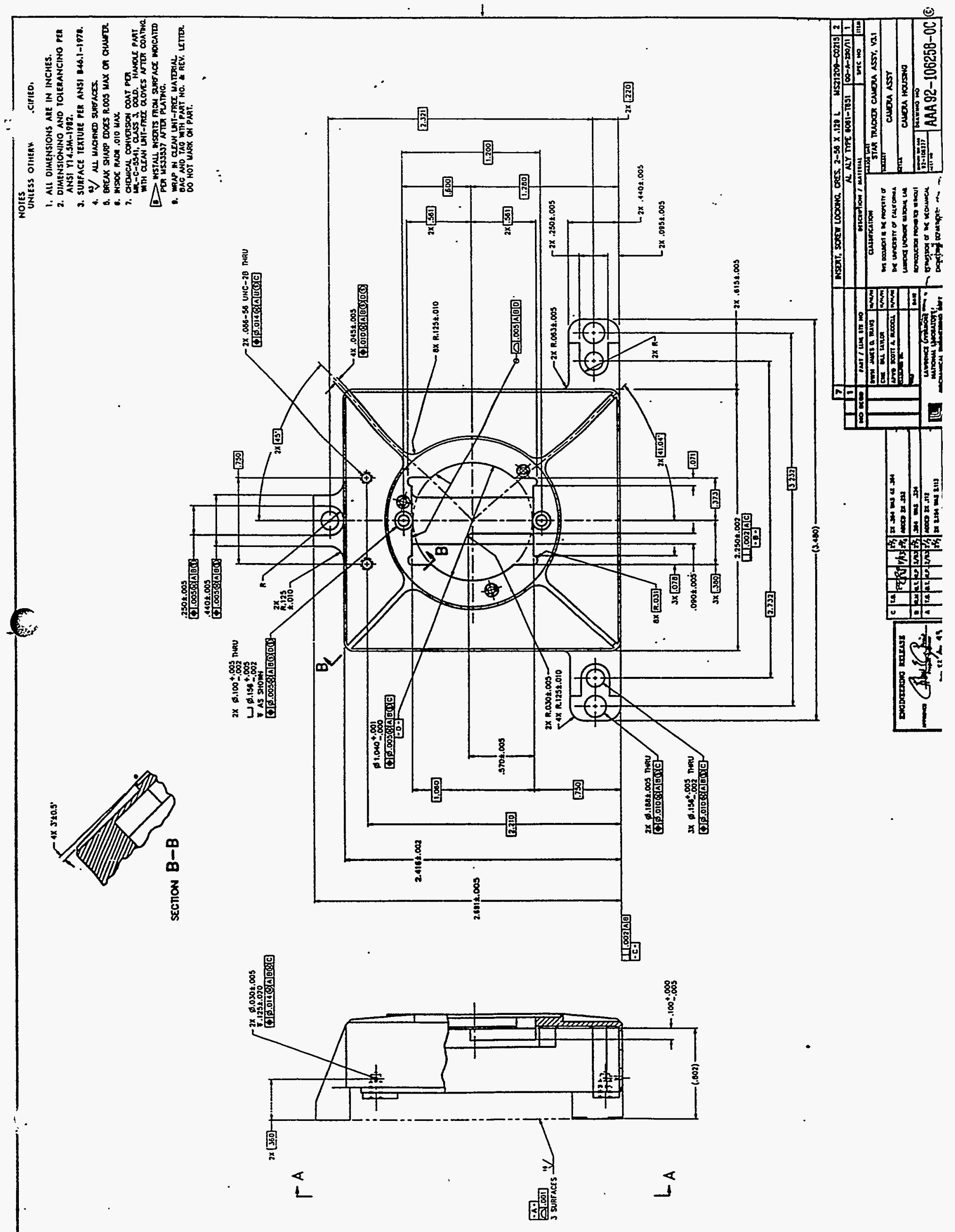




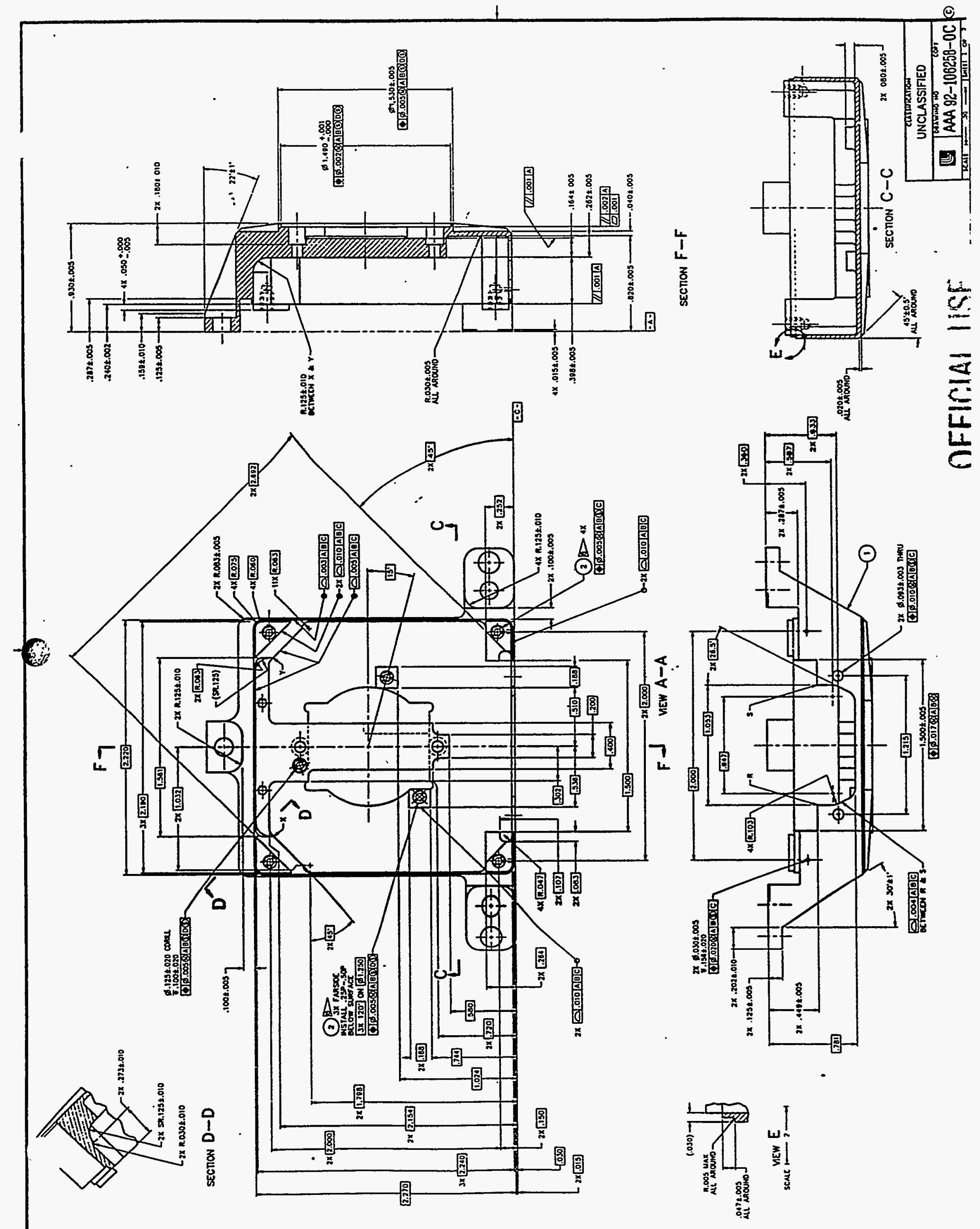





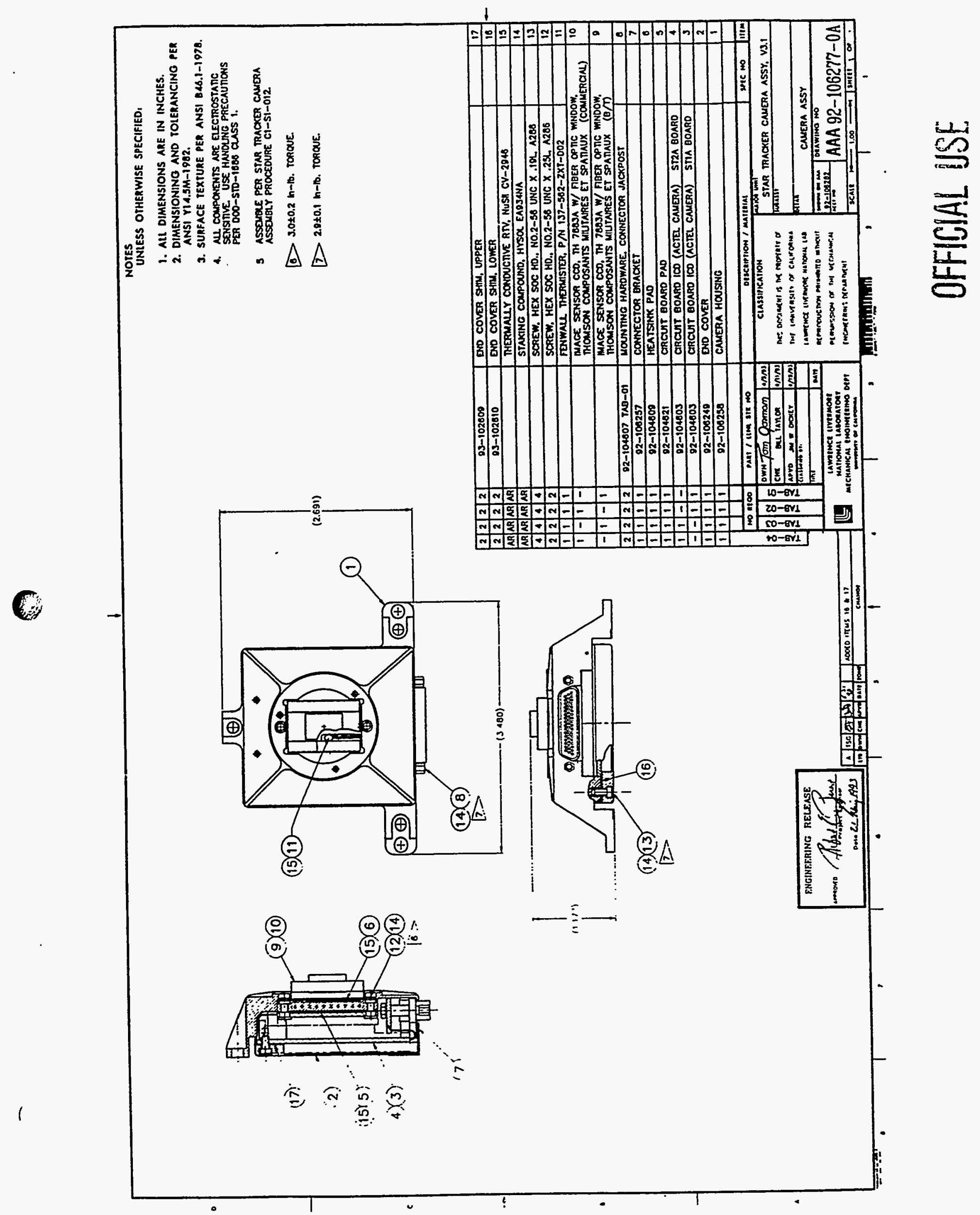




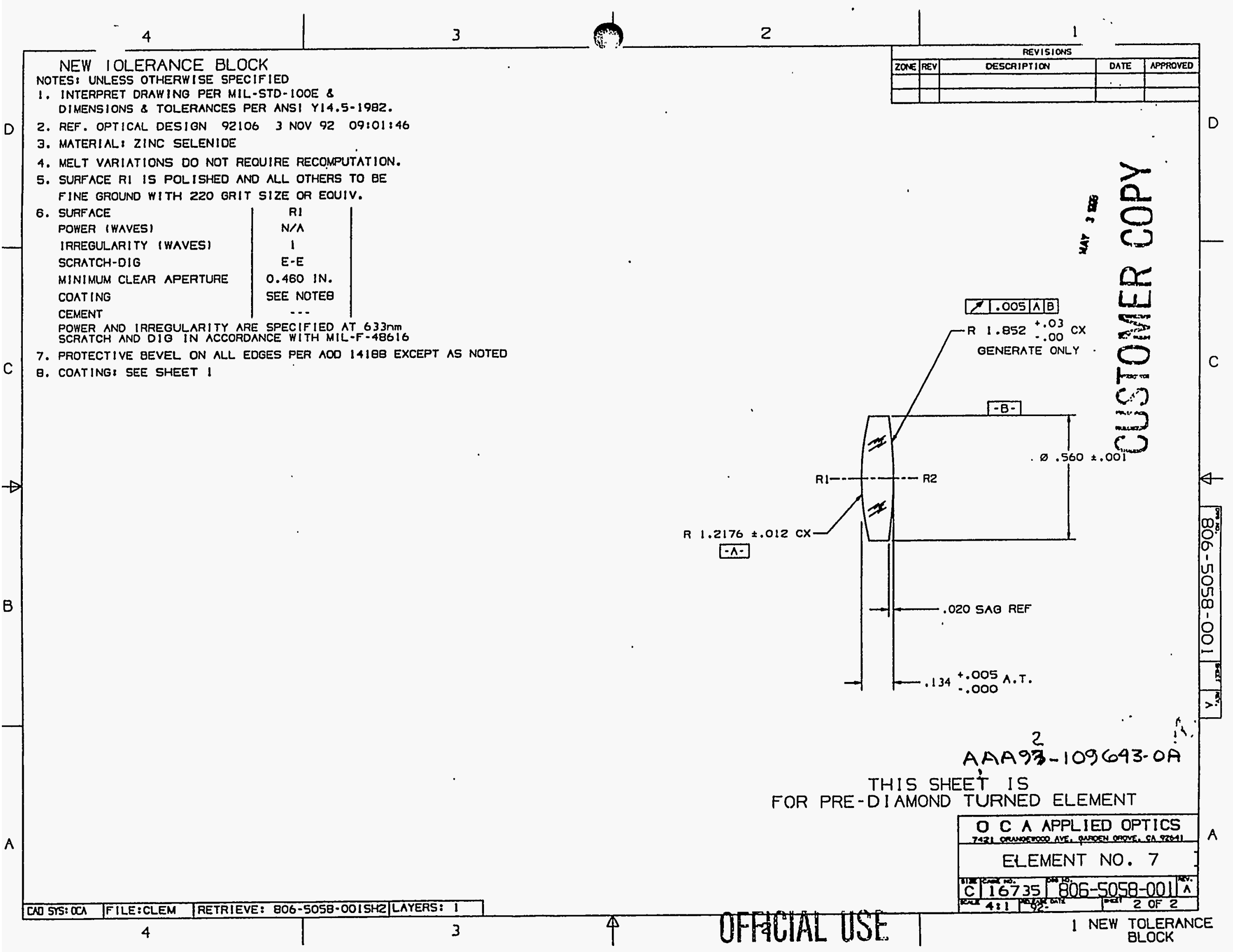




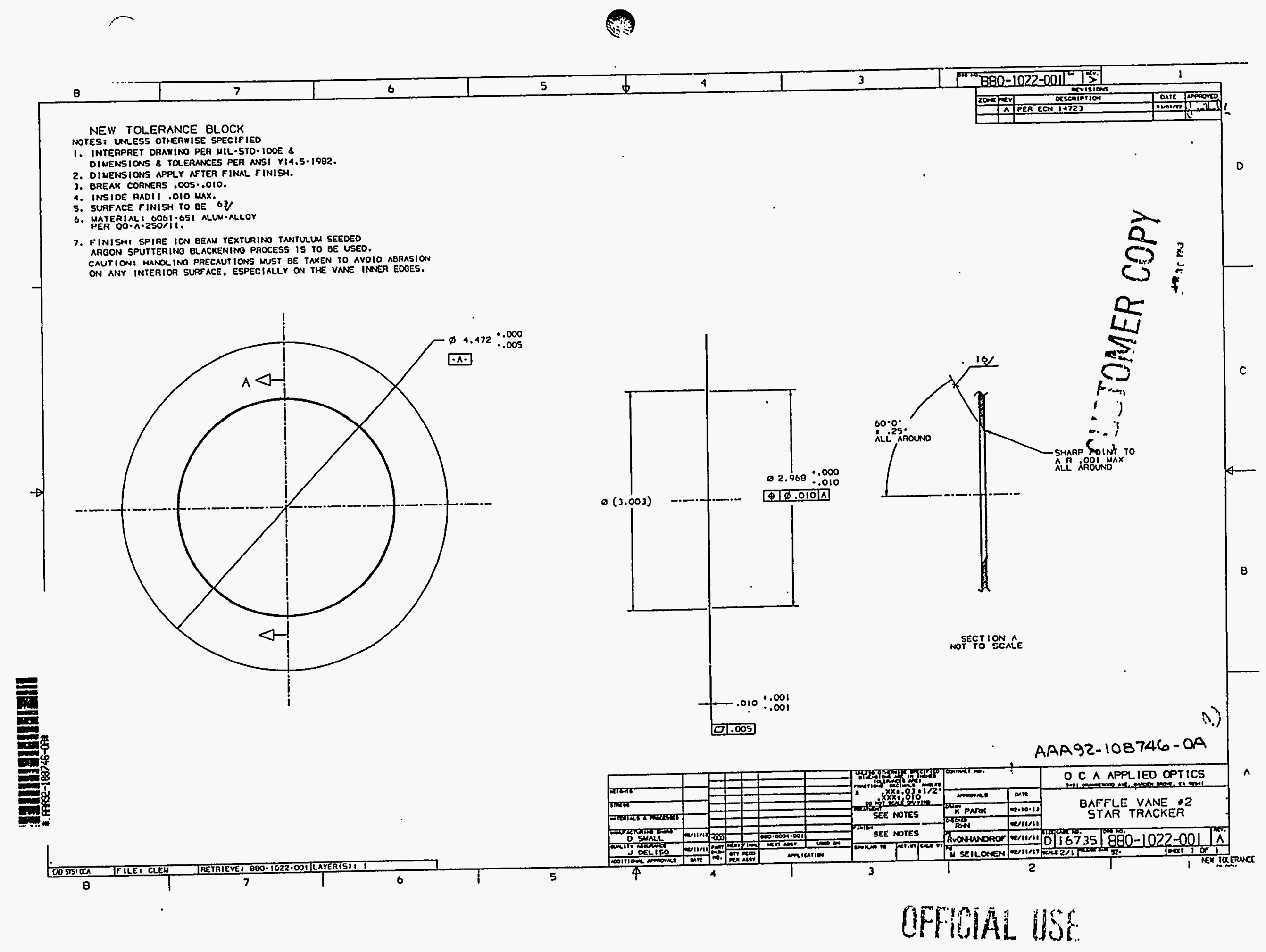




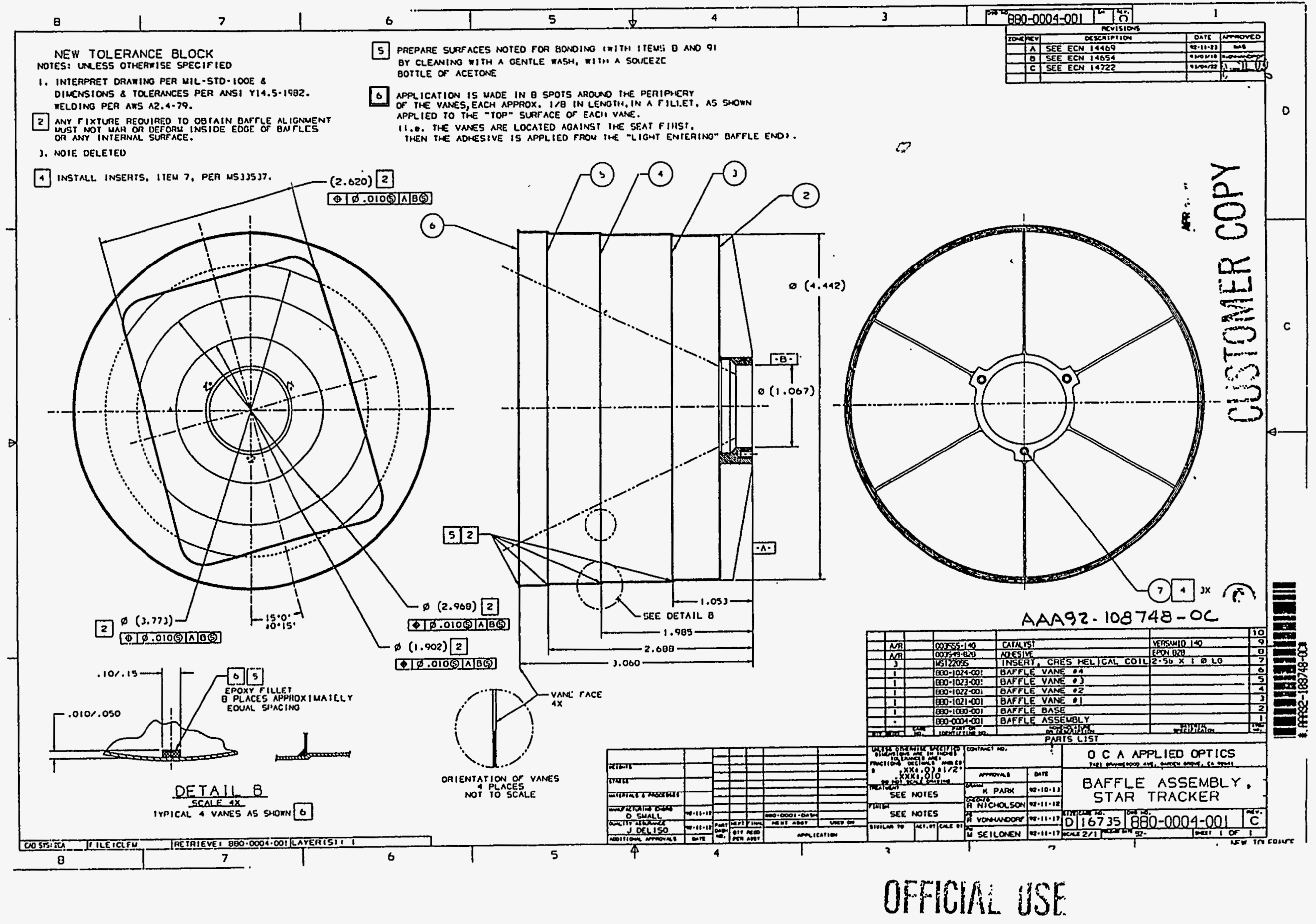




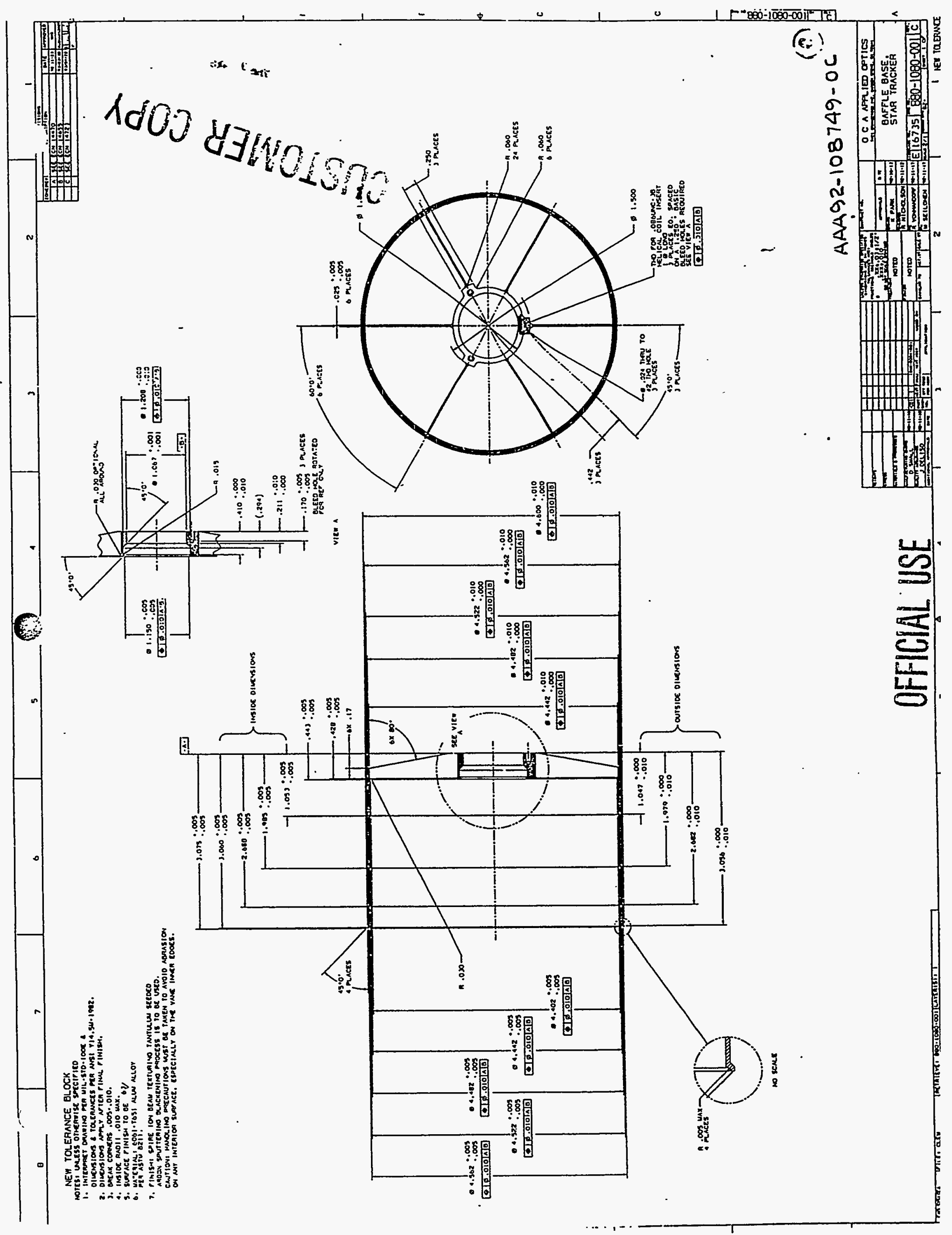




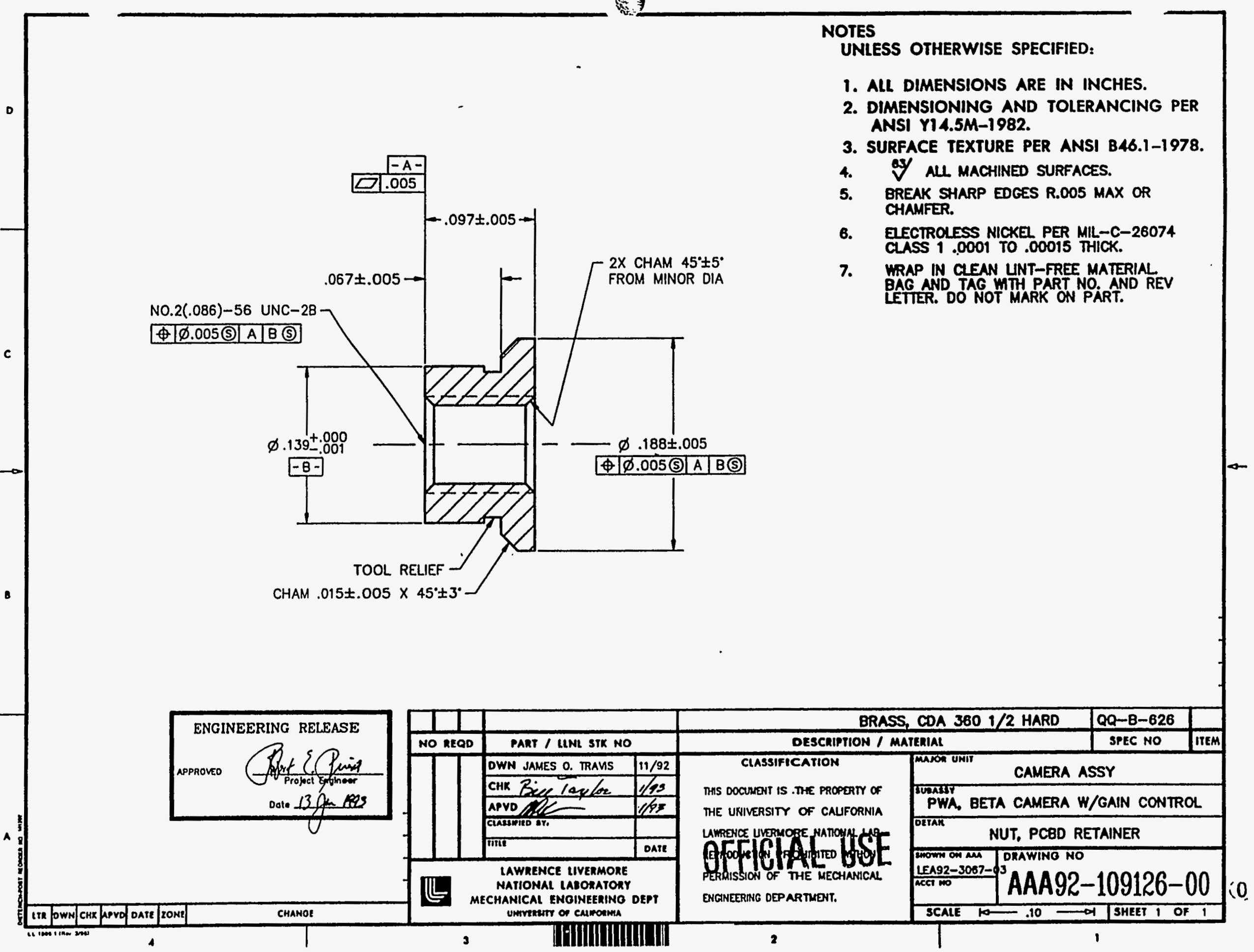


NEW TOLERANCE BLOCK

NOTES: UNLESS OTHERWISE SPECIFIED

1. INTERPRET DRAWINO PER MIL-STD-10OE \&

DIMENSIONS \& TOLERANCES PER ANSI YI4.5-1982.

2. REF. OPTICAL DESIGN OCA 17073, 15 DEC 92, 8:12:59

3. CEMENT ELEMENTS TOGETHER USING ITEM 6 IN ACCORDANCE OCA 14384, CLASS I REF.. NOMINAL THICKNESS BETHEEN ELEMENTS TO BE .0005.

4. DELETED

5. SEAL ITEM 6 ICEMENTI USING ITEMS 12 ANO 13 PER OCA 14385.

6. GLACKEN ALL GROUND SURFACES USING ITEM 7 PER AOD 14023 AFTER SEALING CEMENT PER NOTE 5. VACUUM BAKE AT $70^{\circ} \mathrm{C}$ FOR Q HOURS.

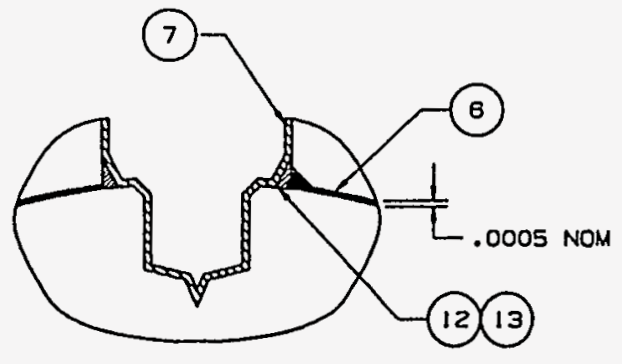

NO SCALE

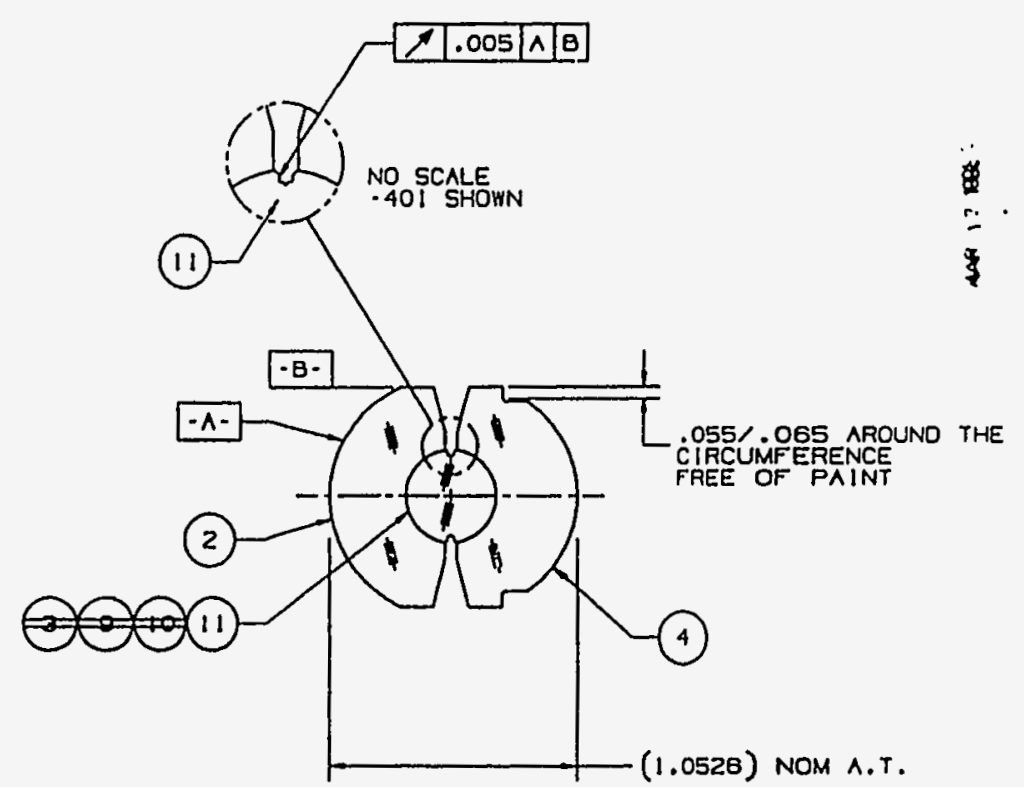

(1)

C

AAA92-109462-0C
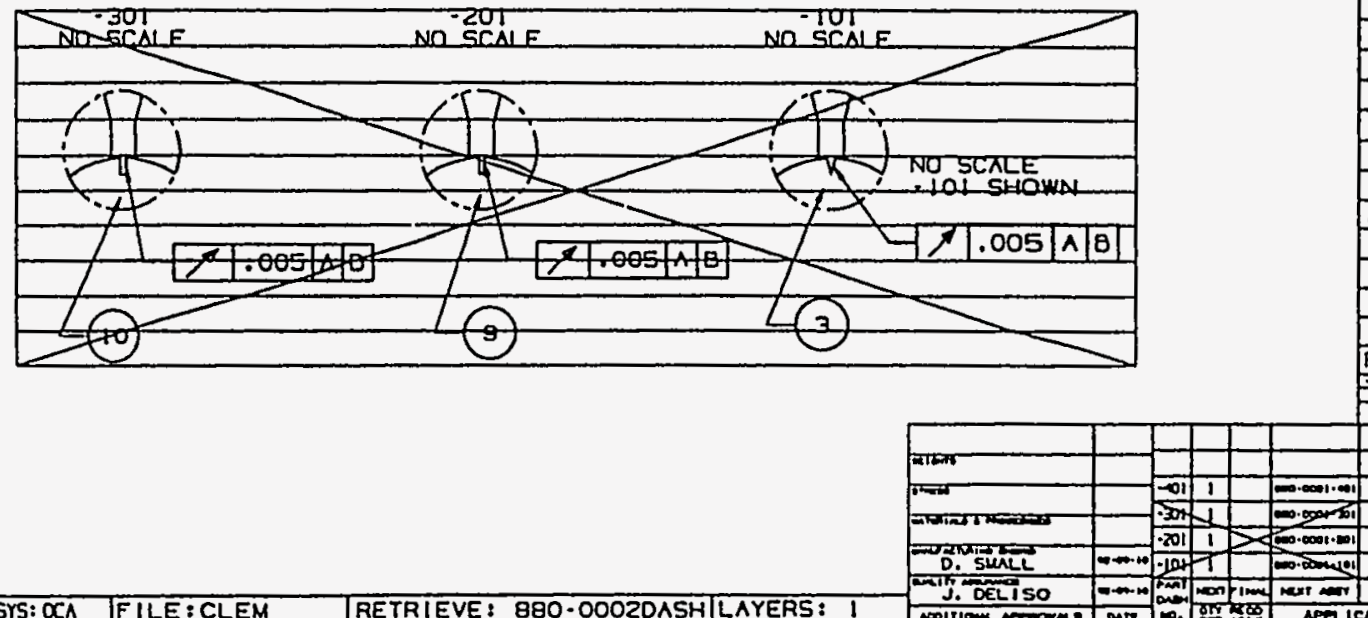

T. DELISO 
NEW TOLERANCE BLOCK

NOTES: UNLESS OTHERWISE SPECIFIED

1. INTERPRET DRAWINO PER MIL-STD-100E \&

DIMENSIONS \& TOLERANCES PER ANSI Y14.5-1982.

2. REF. OPTICAL DESIGN OCA 17073, 15 DEC 92, 8:12:59

3. MATERIAL: OPTICAL GLASS, TYPE SFGG05, 809-253,

4. MELT VARIATIONS DO NOT REOUIRE RECOMPUTATION

5. SURFACES RI AND RZ TO BE POLISHED AND ALL OTHERS TO BE FINE GROUND WITH 220 GRIT SIZE OR EOUIV.

POWER (WAVES)

IRREGLLARITY (WAVESI P-V SEE NOTE 9 SEE NOTE 10

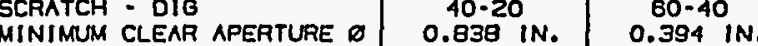

COATINO

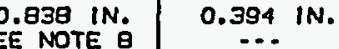

C | POWER AND IRREGULARITY ARE SPECIFIED AT $833 \mathrm{~nm}$

7. PROTECTIVE BEVEL ON EDGE PER $A O D 14188$

8. COATINO: A/R COAT USING MgFZ TO REDUCE REFLECTANCE

IN THE SPECTRAL RANGE 450-1000NM.

SEVERE ABRASION REOUIREMENTS OF MIL-C-4B497A

$\rightarrow$ 9. LESS THAN I FRINGE IRREGULARITY OVER ANY. DIAMETER GREATER THAN 0.55 IN.

10. LESS THAN I FRINGE IRREGULALRITY OVER ANY DIAMETER GREATER THAN 0.260 IN.

11 DIMENSIONS TO BE MEASURED AND RECORDED TO NEAREST.

B

4-PLACE DECIMAL FOR CEMENTING PURPOSES AT NEXT ASSY

$A$

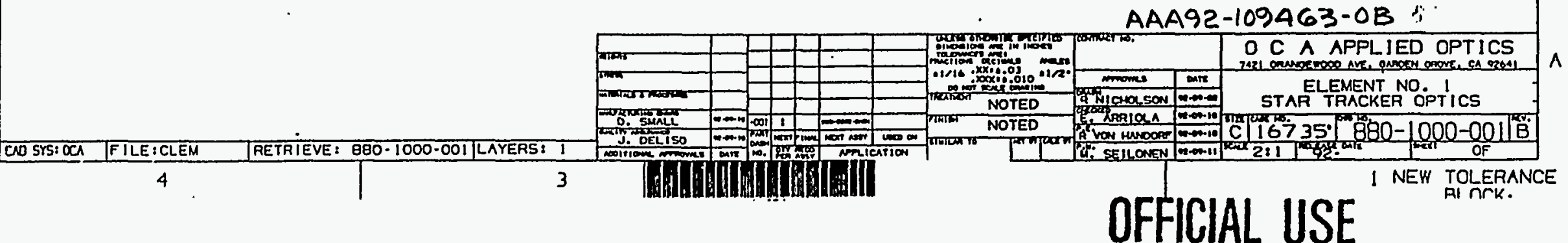


NEW TOLERANCE BLOCK

NOTES: UNLESS OTHERWISE SPECIFIED

INTERPRET DRAWING PER MIL-STD-100E \&

DIMENSIONS \& TOLERANCES PER ANSI Y14.5.1982.

2. REF. OPTICAL DESIGN OCA 17073, 15 DEC 92, 9:12:59

3. MATERIAL: OPTICAL GLASS. TYPE LAK9G15, 691-547, GRADE A PER MIL-G-174, FINE ANNEAL

4. MELT VARIATIONS DO NOT REOUIRE RECOMPUTATION

5. SURFACES RI AND R2 TO BE POL ISHED AND ALL OTHERS TO BE FINE GROUND WITH 220 GRIT SIZE OR EOUIV.

6. SURFACE

\begin{tabular}{l|r|r} 
POWER (WAVES) & NOTEO & NOTED \\
IRREGULARITY (WAVES) P-V & SEE NOTE a & SEE NOTE
\end{tabular}

SCRATCH - DIG $60.40 \quad 60.40$

MINIMUM CLEAR APERTURE $\oslash \quad 0.394 \mathrm{IN}$. $0.376 \mathrm{IN}$

COATING

$\begin{array}{ccc}080.1000 & \text { R1, } 880-1002\end{array}$ POHER AND IRREGULARITY ARE SPECIFIED AT $633 \mathrm{~mm}$.

7 DIMENSION TO BE MEASURED AND RECORDED TO NEAREST

8. LESS THAN I FRINGE IRREGULALRITY OVER ANY DIAMETER GREATER THAN 0.260 IN.

$\phi$

9 MANUFACTURE GROOVE IN ACCORDANCE WITH OCA 14382.

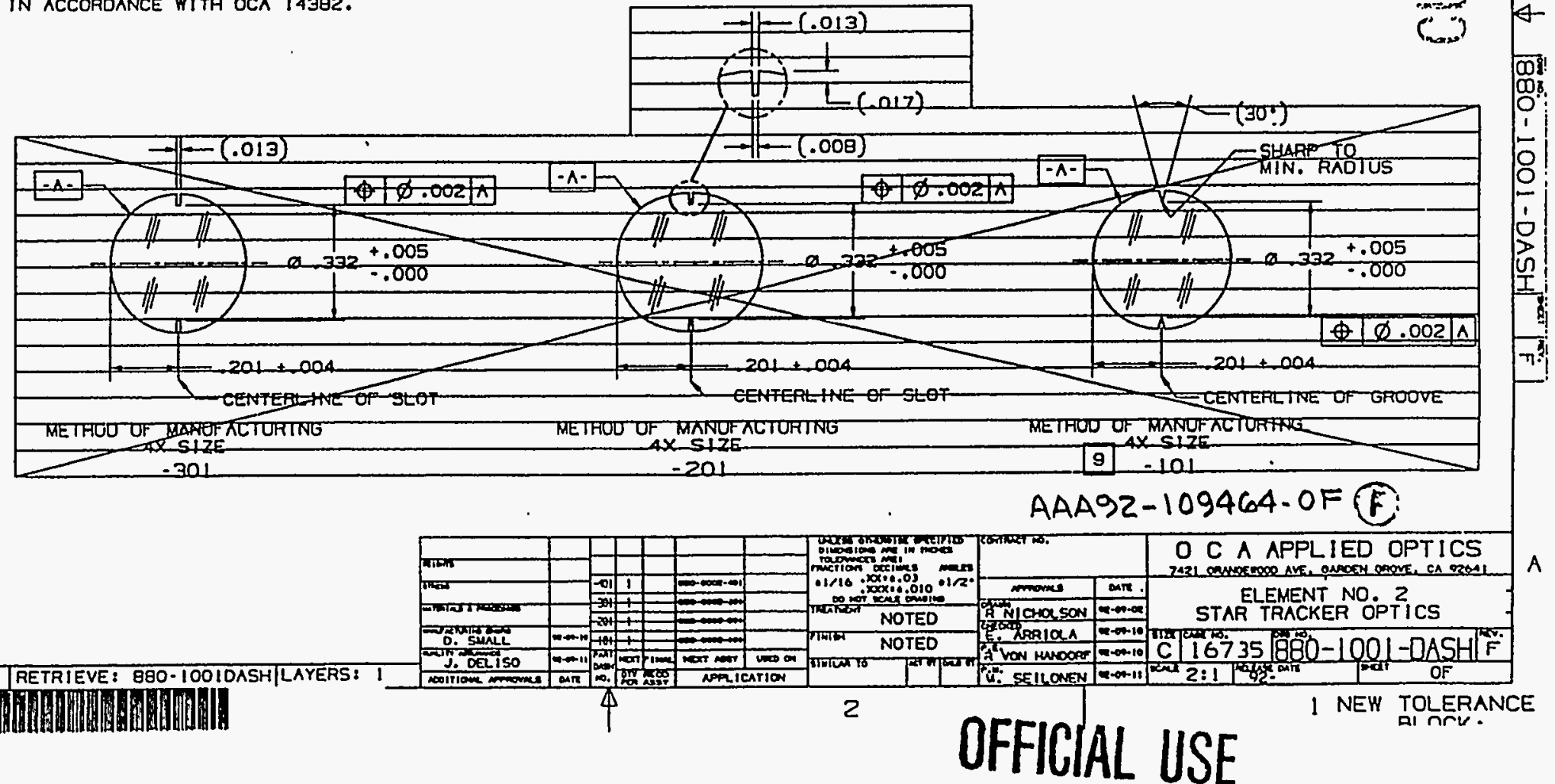

AAA92-109464-OF F 
1. INTERPRET DRAWING PER MIL-STD-IOOE \&

DIMENSIONS \& TOLERANCES PER ANSI Y14.5-1982,

2. REF. OPTICAL DESIGN OCA 17073, I5 DEC 82, 8:12:59

3. MATERIAL: OPTICAL GLAS5, TYPE LAK9615, 691-547, GRADE A PER MIL-G-174, FINE ANNEAL

4. MELT VARIATIONS DO NOT REOUIRE RECOMPUTATION

5. SURFACES RI AND RZ TO BE POLISHED AND ALL OTHERS TO BE FINE GROUND WITH 220 GRIT SIZE OR EOUIV.

\section{B. SURFACE} \begin{tabular}{l|c|c|} 
POHER (YMVESI & NOTED & NOTEO \\
IRREGULARITY (HAVESI P.V & SEE NOTE a & SEE NOTE 10
\end{tabular} \begin{tabular}{l|c|c} 
SCRATCH - DIO & $60-40$ & $40-20$ \\
MINIMUM CLEAR APERTURE $\varnothing$ & $0.378 \mathrm{IN}$. & $0.598 \mathrm{IN}$.
\end{tabular} COATING R2, 880-1001 CEMTN

7. PROTECTIVE BEVEL ON EDGE PER $A O D 14188$

日. COATINOI A/R COAT USING MgFZ TO REDUCE REFLECTANCE

IN THE SPECTRAL RANGE 150-1000NM.

COATINO TO MEET THE DURABILTY, ADHESION AND

SEVERE ABRASION REOUIREMENTS OF MIL-C-48497A

$\rightarrow$ 9. LESS THAN I FRINGE IRREgULARITY OVER ANY DIAMETER GREATER THAN 0.260 IN.

10. LESS THAN I FRINGE IRREGULALFITY OVER ANY DIAMETER GREATER THAN 0.550 IN.

11. DIMENSIONS TO be MEASUREo ANO RECORDED to nEAREST

B 4-PLACE DECIMAL FOR CEMENTING PURPOSES AT NEXT ASSY
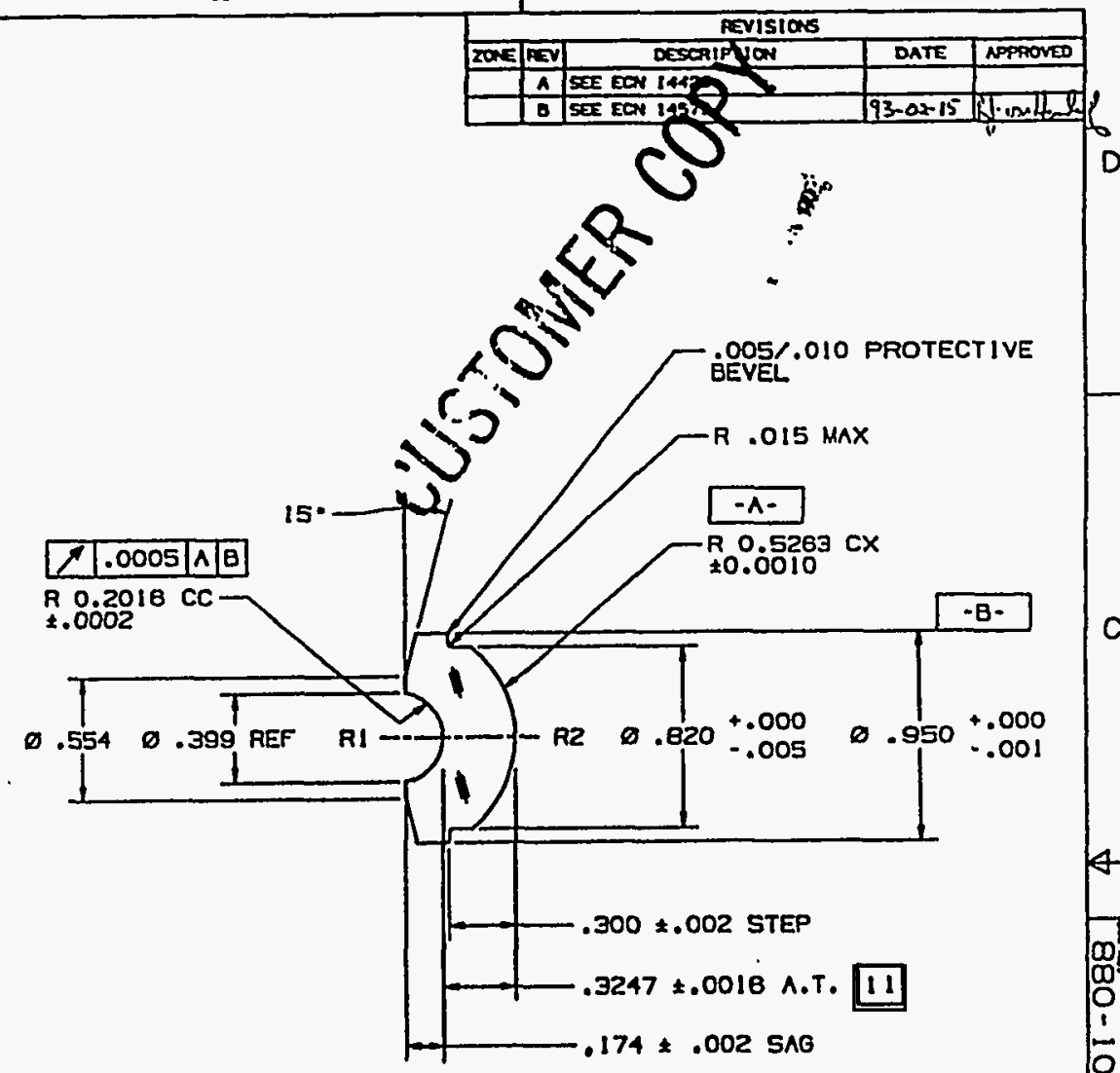

AAA92-109465-OB (B)

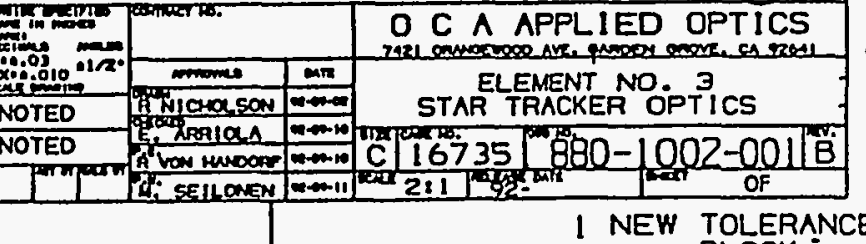

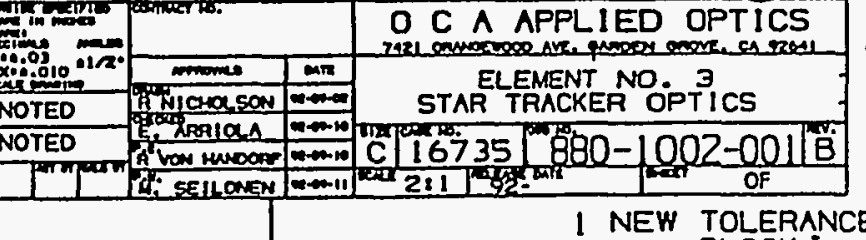
OFFICIAL USE 
NEW TOLERANCE BLOCK

NOTES: UNLESS OTHERWISE SPECPFIED

INTERPRET DRAHING PER MIL-STD-100E \&

DIMENSIONS \&OLERANCES PER ANSI Y14.5-1982.

D 2. REF. OPTICAL DESIGN OCA 17073, 15 DEC 92, 8:12:59

1. MATERIAL: MAKE FROM P/N 8BO-1003.

2. FINE GRIND WITH 220 GAIT SIZE OR EOUIV.

3. SURFACE

FINISH

POWER I HAVES

IRREGULARITY (WAVES)

SCAATCH - DIO

MINIMUM CLEAR APERTURE

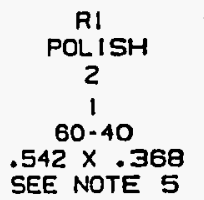

\begin{tabular}{|} 
R2 \\
POLISH \\
1 \\
0.25 \\
$60-40$ \\
0.680 IN. \\
NONE
\end{tabular}

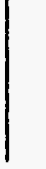

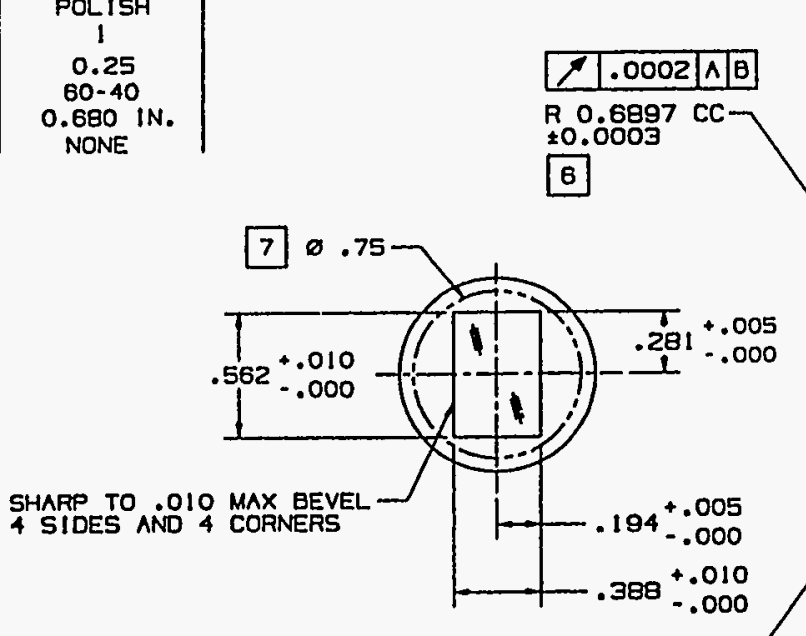

SHARP TO .O1O MAX BEVEL

$4 \times 2.015$ MAX

5. COATING: A/R COAT USING MgFZ TO REDUCE REFLECTANCE

IN THE 450 TO $1000 \mathrm{~nm}$ SPECTAL RANGE.

COATING TO MEET THE OURABILTY, ADHESION ANO

SEVERE ABRASION REOUIREMENTS OF MIL-C-48497A

\section{1}

\begin{tabular}{|c|c|c|c|c|}
\hline \multicolumn{5}{|c|}{ Revistons } \\
\hline 20EE & & DESCAIPTION & DATE & APPROVEO \\
\hline & A & SEE ECN $[152\}$ & $92 \cdot 1 \cdot 7$ & Ruth \\
\hline & 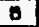 & SEE ECN 14576 & $3 \cdot 3 \cdot 2-1$ & (रत्ent. \\
\hline
\end{tabular}

RI -
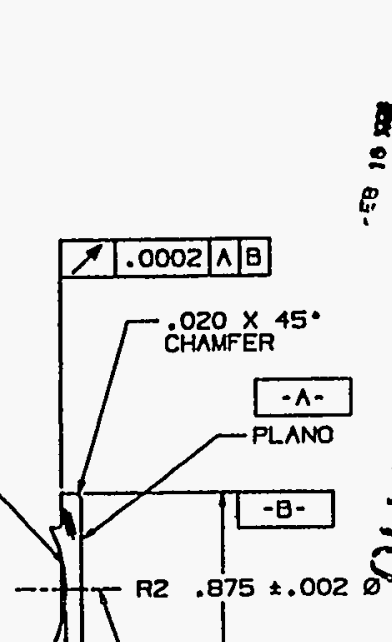

6 MEASURE AND RECORD RAOIUS OF CURVATURE OF RI TO .0001 INCH.

7 ALL GROUND SURFACES WITHIN DIAMETER NOTED TO BE BLACKENED PER AOD 14023. IINCLUDING SIDES OF RECTANGLE)

AAA92-109466-OB' $($ )

A

\begin{tabular}{|c|c|c|c|c|c|c|c|c|c|}
\hline & & & & & & tion & sentuxt & & O C A APPLIED OPTICS \\
\hline & & & & & & 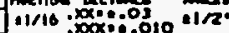 & & & \\
\hline דו & & & & & & & 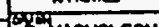 & $-\infty$ & IE FIBER OPTICS \\
\hline & $=\infty$ & & & & & NOTED & goceravez & $=0.100$ & 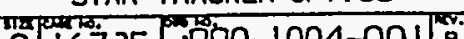 \\
\hline DELiso & $=0$ & $\operatorname{mon}_{0}$ & $\operatorname{senth}$ & tor an & $\sin x$ & (15) & A van mudoos: & $=0.100-0$ & of \\
\hline
\end{tabular}

4 H. H H

2

OFFICIAL USE

1 NEW TOLERANCE
BLOCK. 



?

2

NEW TOLERANCE BLOCK

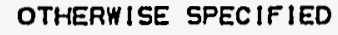

- INTERPRET DRAHINO PER MIL-STD-100E \&

OIMENSIONS \& TOLERANCES PER ANSI Y14.5-1982.

2. REF. OPTICAL DESION 921026 3 NOV 92 09:01:46

3. MATERIAL: ZINC SELENIDE

4. MELT VARIATIONS DO NOT REOUIRE RECOMPUTATION.

5. SURFACE R2 AND SURFACES NOTEO TO BE DIAMONO TURNED, RI WIAS POLISHED ON SHEET 2, ALL OTHERS ARE FINE GROUND

6. SURFACE

POWER (HAVES)

IRREGULARITY I HAVESI

SCRATCH-DIS

MINIMUM CLEAR APERTURE

CONTING

\begin{tabular}{|c|c|}
\hline \multirow{5}{*}{$\begin{array}{c}\text { RI } \\
\text { SEE SHEET } 2 \\
\text { SEE SHEET } 2 \\
\text { SEE SHEET } 2 \\
\text { SEE SHEET } 2 \\
\text { SEE NOTE } 8\end{array}$} & R2 \\
\hline & $\mathrm{N} / \mathrm{A}$ \\
\hline & .5 \\
\hline & $\begin{array}{c}E-E \\
0.442 \text { IN. }\end{array}$ \\
\hline & $\begin{array}{c}\text { SEE NOTE } ~ \\
\ldots .-\end{array}$ \\
\hline
\end{tabular}

CEMENT

...

$033 \mathrm{~nm}$

POWER AND IRREGULARITY ARE SPECIFIED ATT $6333 \mathrm{~nm}$

7. PROTECTIVE BEVEL ON ALL EDGES PER AOD 1418 EXCEPT AS NOTEO

日. AR COATING FROM 8.O TO 9.5UM HITH ANGLES OF INCIDENCE REFLECTIVITY OVER THE SPECIFIED AND AND ANGES OF INCJDENCE. CORASION REOUIREMENTS OF MIL-C-4Q497A.

9 EXISTING RADIUS GENERATED PER SHEET 2.

10 DIAMOND TURNED ASPHERIC SURFACE

ASPHERIC CONSTANTS:

VERTEX RADIUS $=-1.7066$

$\hat{A}^{2}=0.000000 \mathrm{~A}^{4}=0$.

$A 8=-1,382198 \mathrm{E}+01$.

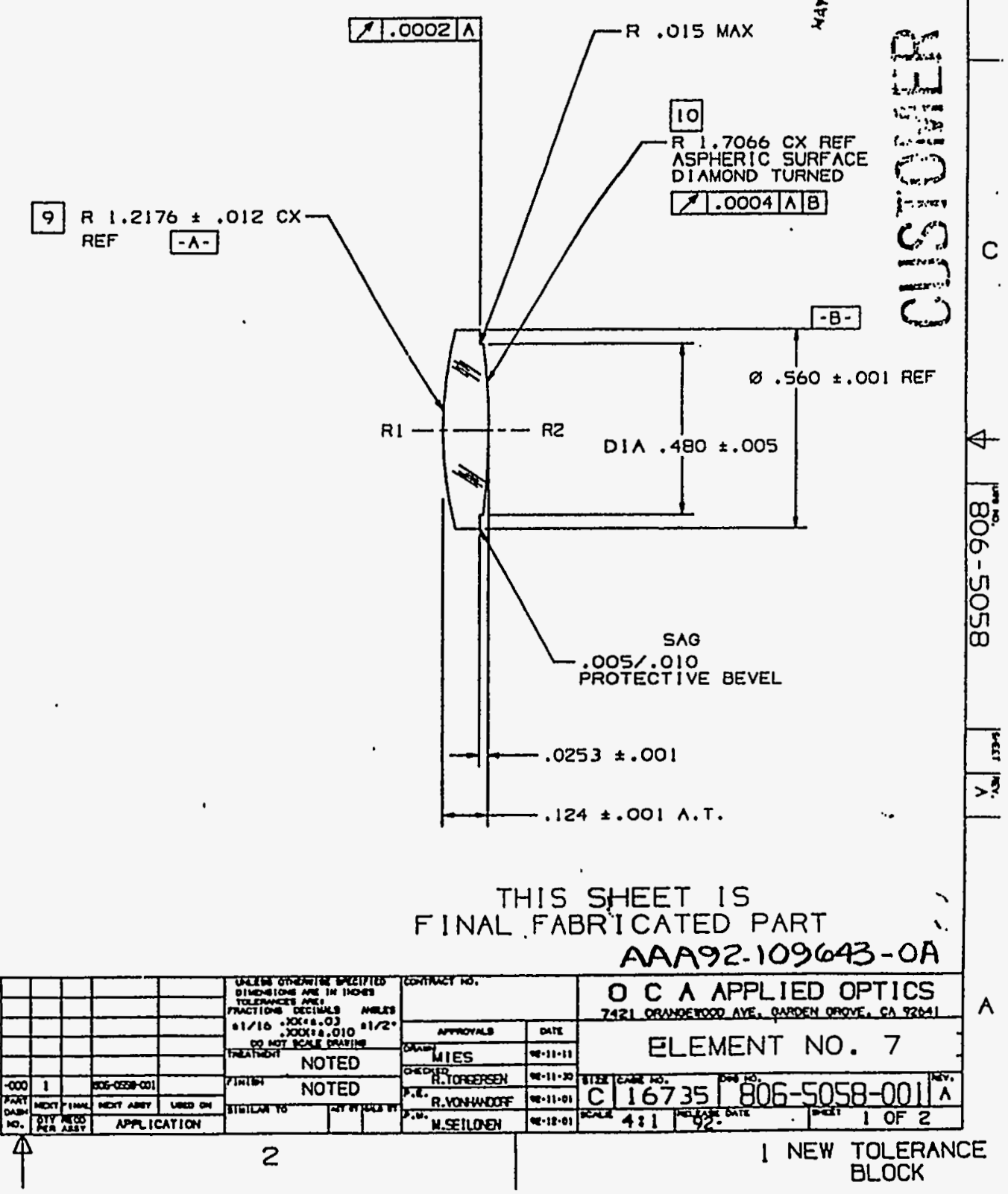

THIS SHEET IS

AAA92.109643-OA 


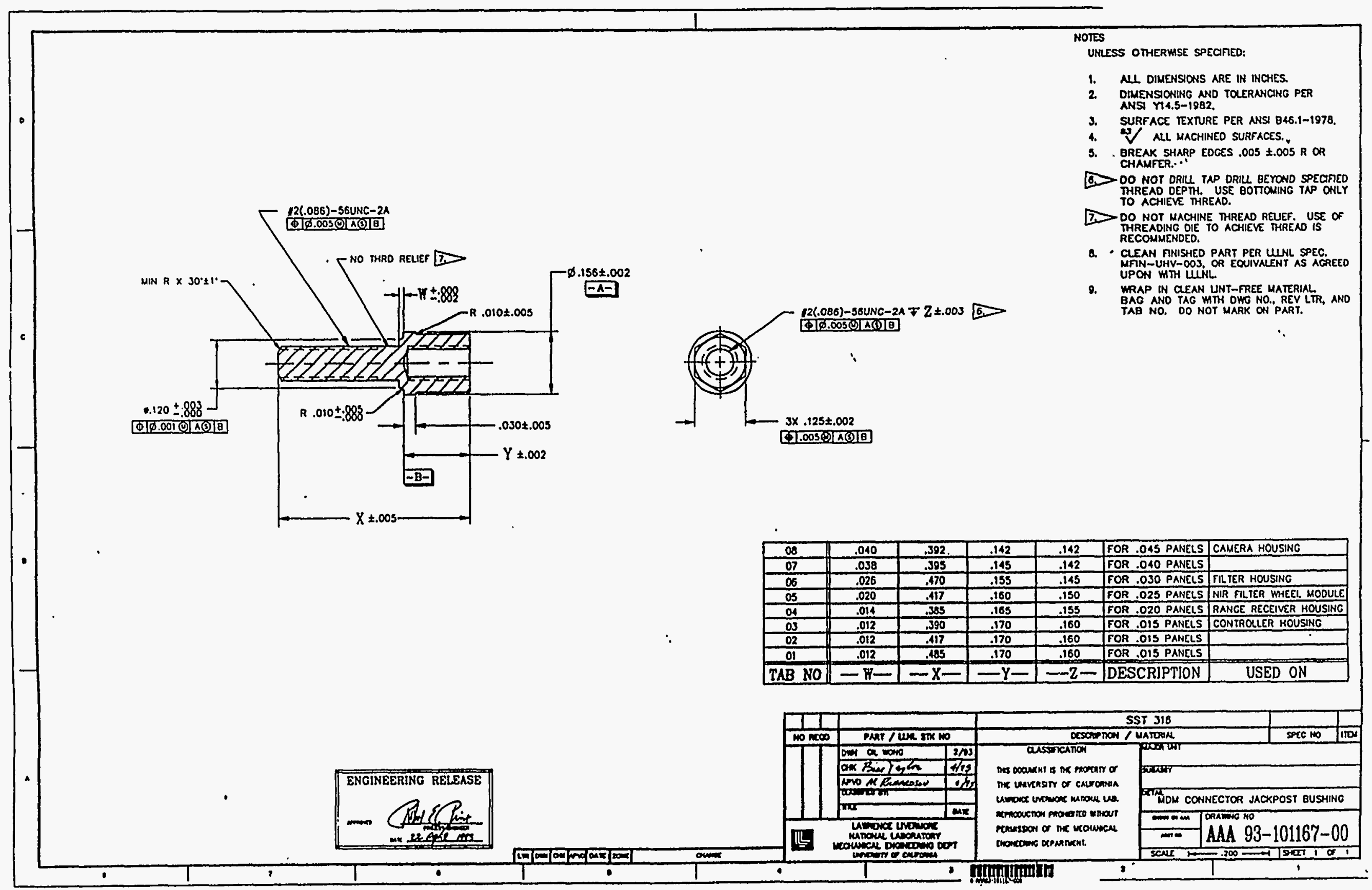

\section{IFFISIA 13}



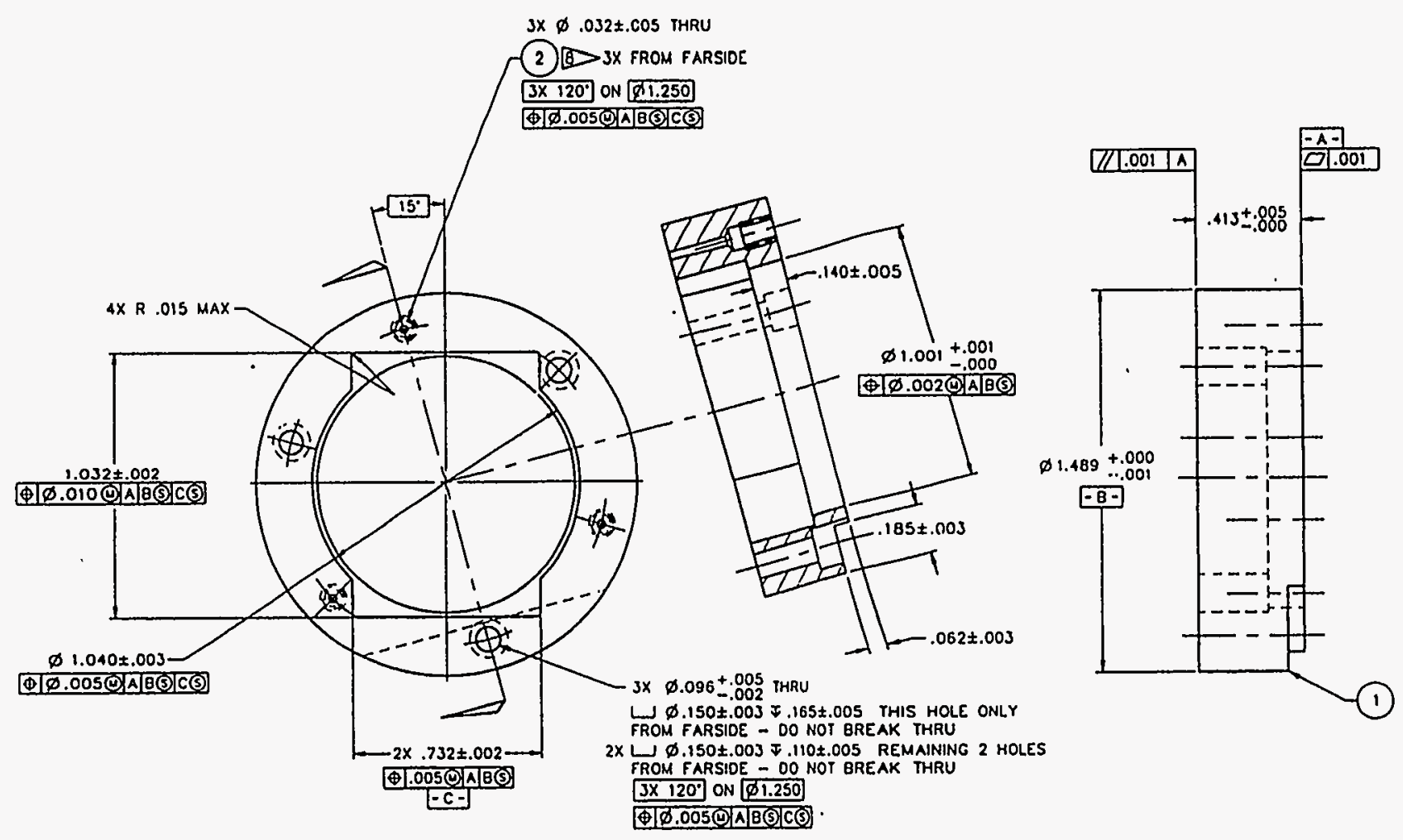

UNIESS OIHERWISE SPECIFIED,

1. All OIMENSIONS ARE IN INCHES

2. DIMENSIONING AND TOLERANCING PER ANSI YIA,3M-1 PB2.

3. SURFACE TEXTURE PER ANSI B $26.1-1978$

4. WV NLL MACHINEO SURFACES.

5. BREAK SHARP EDGES R.005 MAX OR CHAMFER.

6. INSDE RADII .OIO MAX.

7. CHENICAL CONYERSON COAT PER

MIL-C-5541, CASS 3, COLD. HANDLE PART 8 INSTNII INSERTS FROM SURFACE INDICATED PER MSJSJJ N NTER COATNO.

0. KRAP IN CLEAN LUNT-FREE MATERIAL DO NOT MARK ON PART.

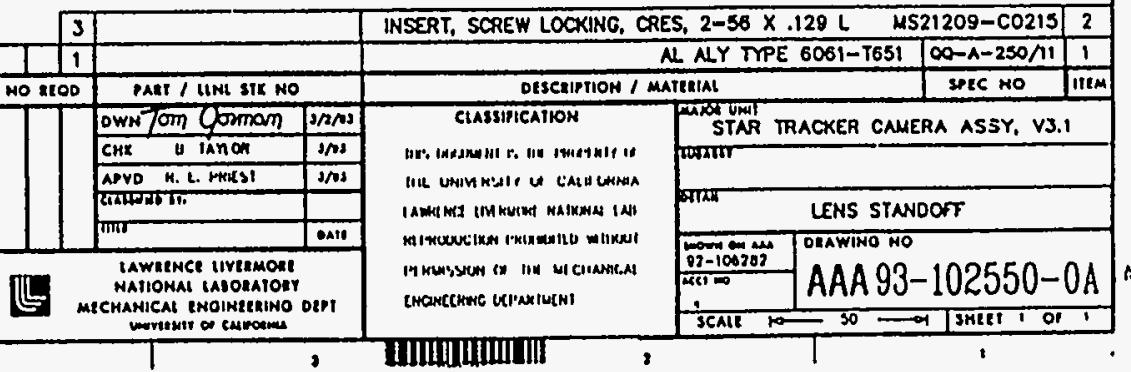




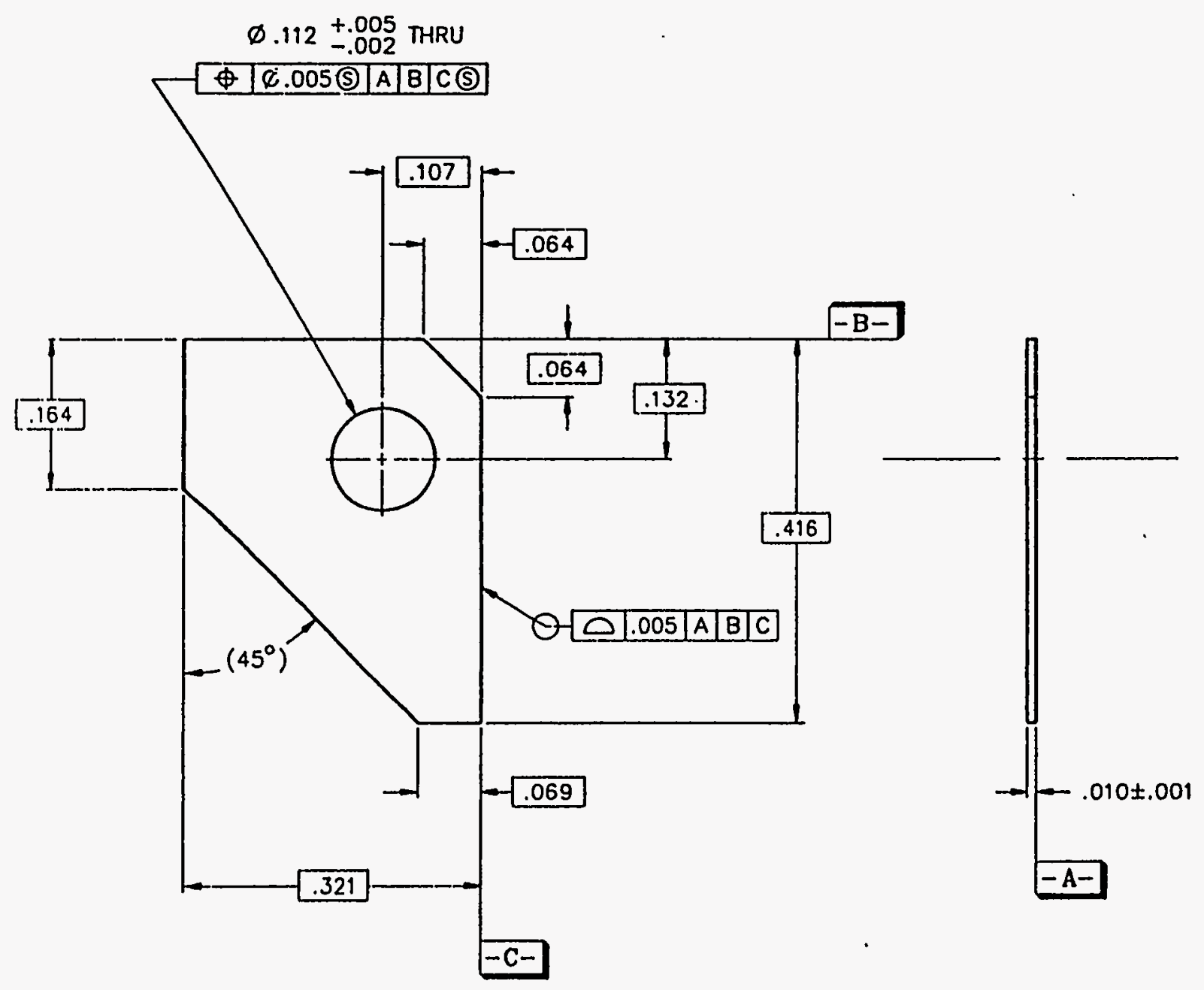

UNIESS OTHERWISE SPECIFIED:

1. ALL DIMENSIONS ARE IN INCHES.

2. DIMENSIONING AND TOLERANCING PER ANSI YI 4.5M-1982.

3. SURFACE TEXTURE PER ANSI 846.1-1978.

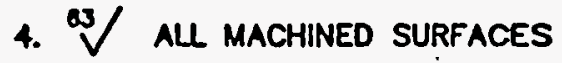

5. BREAK SHARP EDGES $R$.005 MAX OR CHAMFER

6. CHEMICAL CLEAN PART PER

MEL84-001723-00. HANDLE PART WITH CLEAN UNT-FREE GLOVES AFTER CLEANING.

7. WRAP IN CLEAN UNT-FREE MATERIAL. BAG \& TAG WIT PART NO. \& REV LETIER. DO NOT MARK ON PART.

ENGINEERING RELEASE

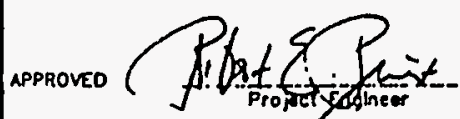
Dal. ZA Aor 93

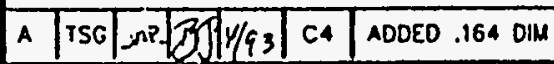

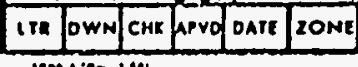
CHANGE

\begin{tabular}{|c|c|c|}
\hline$\frac{1}{1}{ }_{\text {NO RESO }}$ & \multicolumn{2}{|l|}{ PART / LINL STK NO } \\
\hline & DWN Tom Qoman & $4 / 21 / 03$ \\
\hline & CHK J. ROBINSON & $4 / 22 / 03$ \\
\hline & APVD R. E. PRIEST & $4 / 23 / 83$ \\
\hline & atassitito or & \\
\hline & IIIT) & oAte \\
\hline & $\begin{array}{l}\text { IAWRENCE LIVERMORE } \\
\text { NATIONAI LABORAYOR } \\
\text { HANICAL ENGINEERING } \\
\text { UNIVESHIY OF CAIHOINIA }\end{array}$ & \\
\hline
\end{tabular}

\section{HALF HARD COPPER (UNS-C11000)} DESCRIPTION / MATERIAL

CLASSIFICATION

THIS DOCUMENT IS THE PROPERT OF THE UNIVERSITY OF CALIFORNIA LAMRENCE UUERMORE MATONAL LAB.

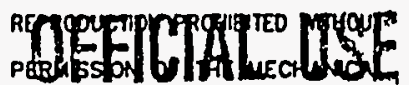
ENGNEERING DEPARTMENT.

\section{TIIIIIIIIIIIIIIII}

\begin{tabular}{|c|c|}
\hline \multicolumn{2}{|c|}{$\begin{array}{l}\text { SAMO UNIT } \\
\text { STAR TRACKER CAMERA, V3.1 }\end{array}$} \\
\hline \multicolumn{2}{|r|}{ CAMERA ASSY } \\
\hline \multicolumn{2}{|r|}{ END COVER SHIM, UPPER } \\
\hline $\begin{array}{l}92-106277 \\
\text { acti not }\end{array}$ & $\begin{array}{l}\text { DRAWING NO } \\
\text { AAA 93-102609-0A }\end{array}$ \\
\hline SCALE & $\begin{array}{l}200 \Longrightarrow \text { C } \\
\end{array}$ \\
\hline
\end{tabular}




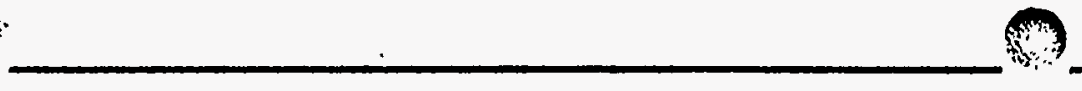

\section{NOTES}

UNLESS OTHERWISE SPECIFIED:

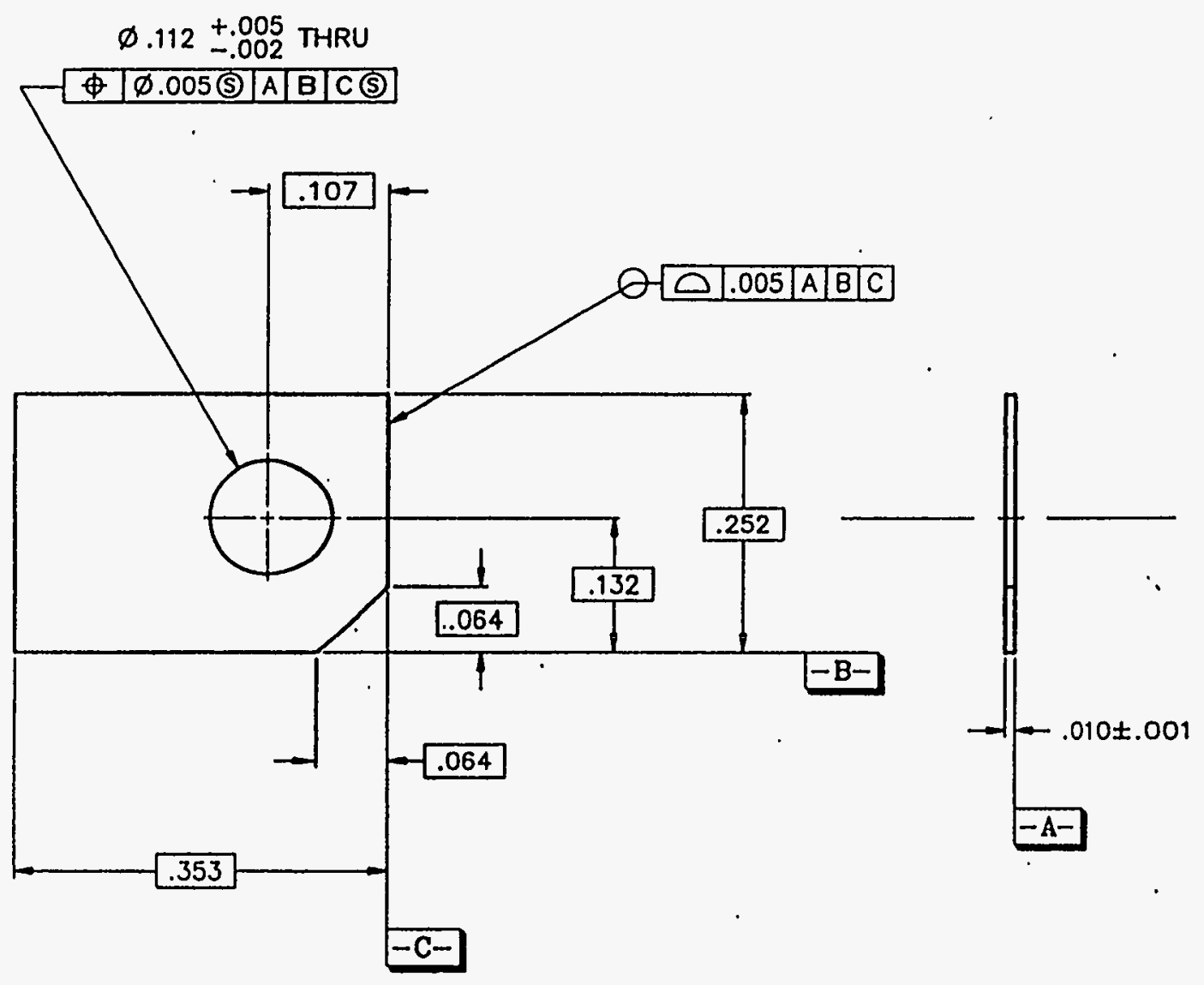

1. ALL DIMENSIONS ARE IN INCHES.

2. DIMENSIONING AND TOLERANCING PER ANSI Y14.5M-1982.

3. SURFACE TEXTURE PER ANSI B46.1-1978.

4. $\sqrt{ }$ ALL MACHINED SURFACES

5. BREAK SHARP EDGES $R$.005. MAX OR CHAMFER

6. CHEMICAL CLEAN PART PER MEL84-001723-00. HANDLE PART MTTH CLEAN LINT-FREE GLOVES AFTER CLEANING.

7. WRAP IN CLEAN UNT-FREE MATERIAL BAG \& TAG WTH PART NO. \& REV LETTER. DO NOT MARK ON PART.

ENGINEERING RELEASE

APPROVED

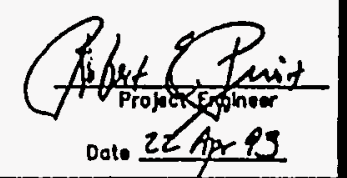

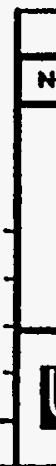

CHANOE

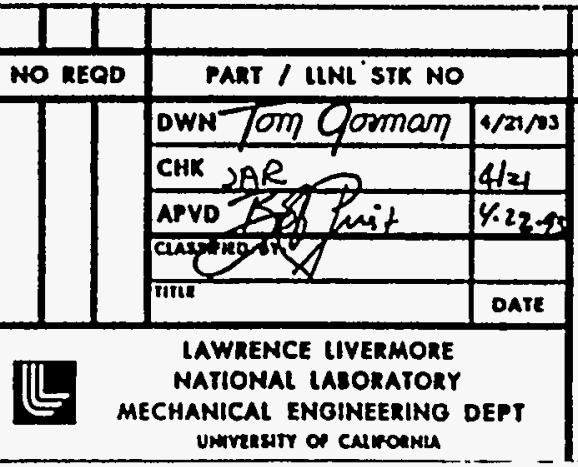
unvenser of curoents

\begin{tabular}{|c|c|c|c|c|}
\hline \multicolumn{3}{|c|}{ HALF HARD COPPER (UNS-C11000) } & $Q Q-C-576$ & \\
\hline \multicolumn{3}{|c|}{ DESCRIPIION / MATERIAL } & SPEC NO & ITEM \\
\hline \multirow{5}{*}{ 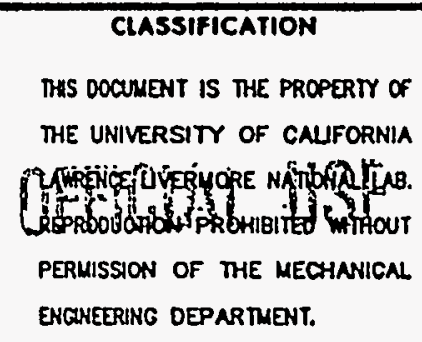 } & \multicolumn{4}{|c|}{$\begin{array}{l}\text { MASOK UNIT } \\
\text { STAR TRACKER CAMERA, V3.1 }\end{array}$} \\
\hline & \multicolumn{4}{|c|}{ CAMERA ASSY } \\
\hline & \multicolumn{4}{|c|}{ END COVER SHIM, LOWER } \\
\hline & 92-106277 & \multirow{2}{*}{\multicolumn{3}{|c|}{ AAAWING NO $93-102610-00$}} \\
\hline & & & & \\
\hline
\end{tabular}




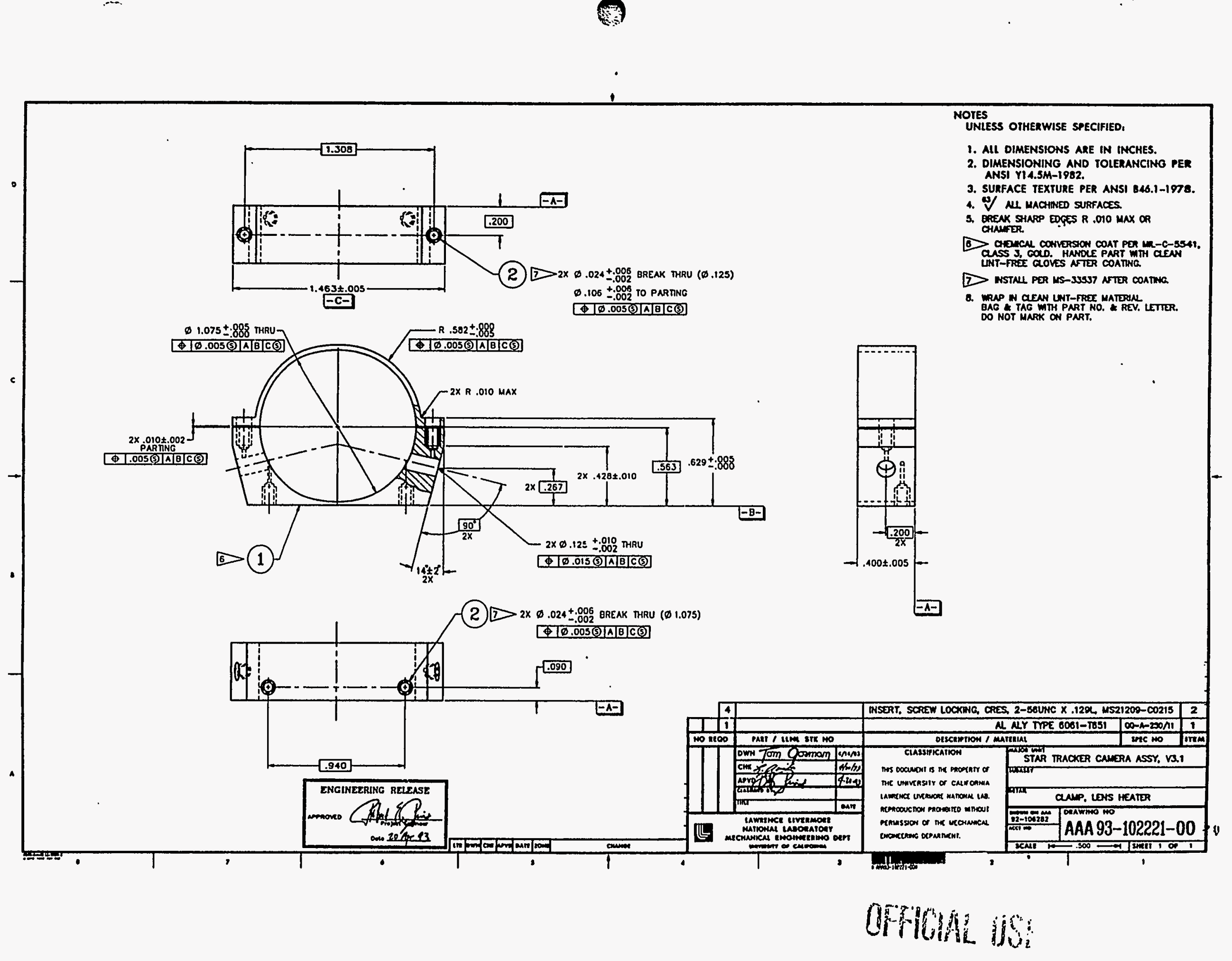




\section{Appendix F Calibration}




\section{Appendix F.1 \\ ST 313 Calibration Summary}




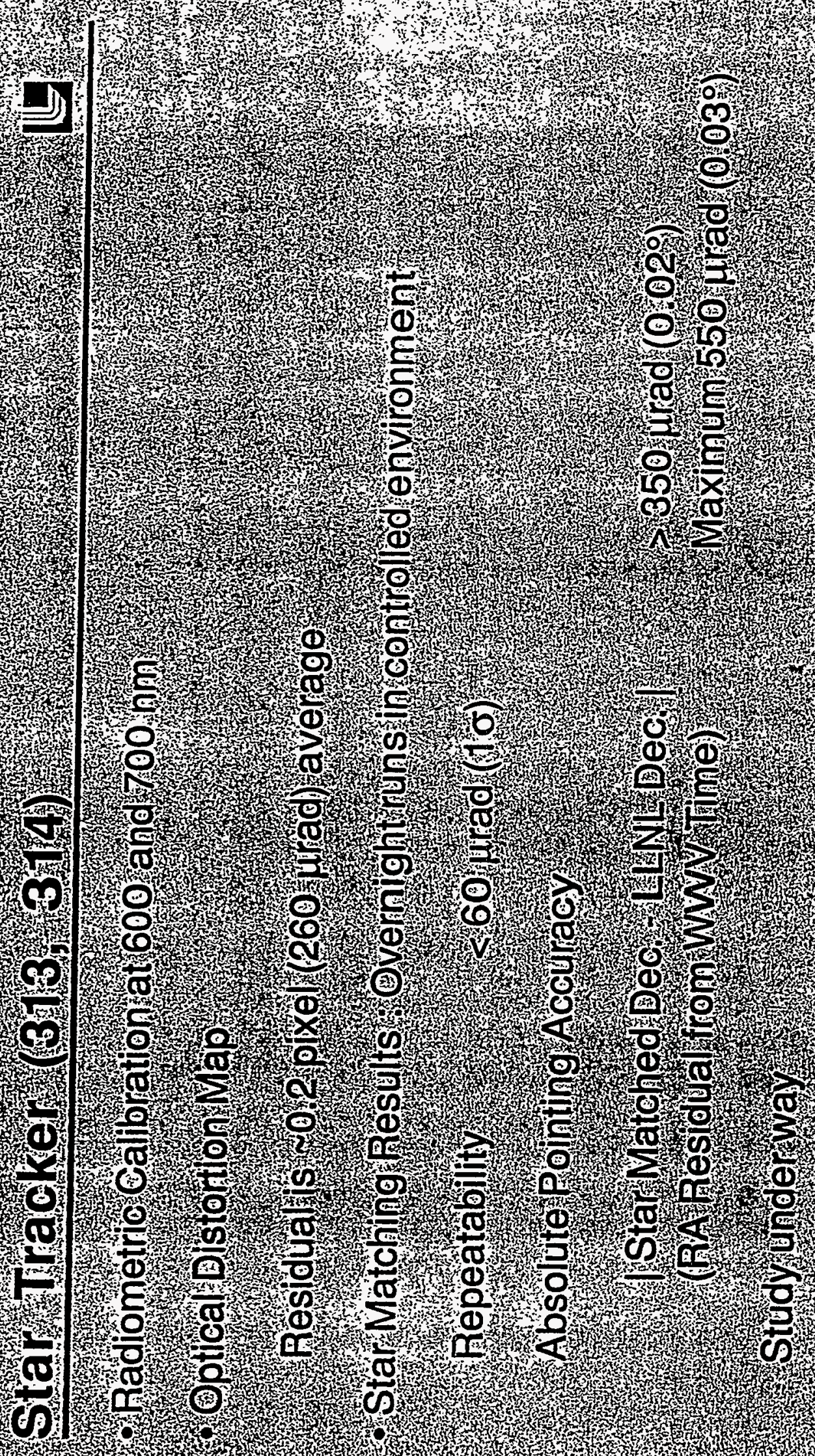




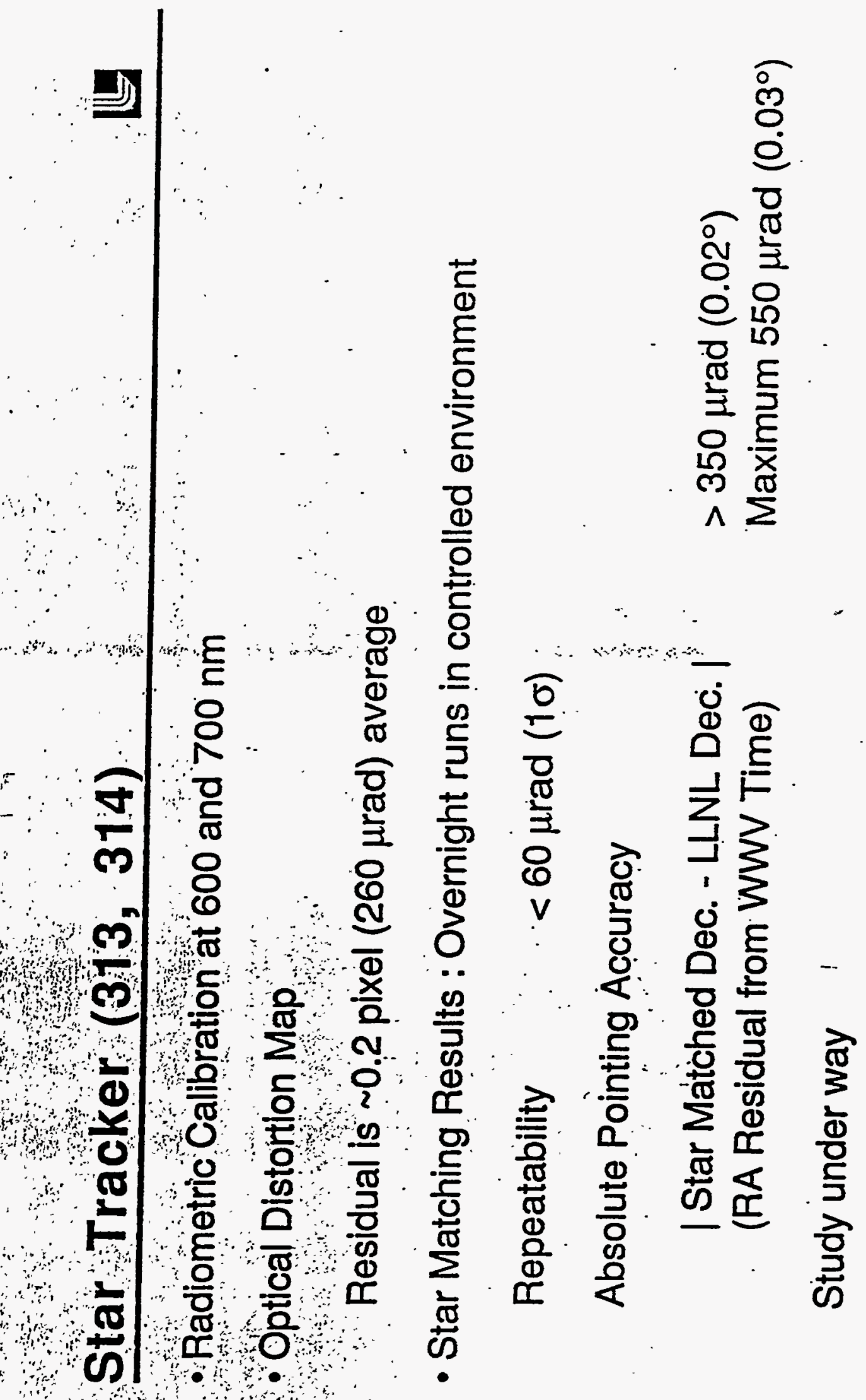




\section{Star Tracker $(313,314)$}

- Radiometric Calibration at 600 and $700 \mathrm{~nm}$

- Optical Distortion Map

Residual is $~ 0.2$ pixel ( $260 \mu \mathrm{rad})$ average

- Star Matching Results : Overnight runs in controlled environment

Repeatability

$$
<60 \mu \mathrm{rad}(1 \sigma)
$$

Absolute Pointing Accuracy

| Star Mátched Dec. - LLNL Dec.| (RA Residual from WWV Time)

\section{$>350 \mu \mathrm{rad}\left(0.02^{\circ}\right)$}

Maximum $550 \mu \mathrm{rad}\left(0.03^{\circ}\right)$

Study under way 


\section{Star Tracker $(313,314)$}

- Radiometric Calibration at 600 and $700 \mathrm{~nm}$

- Optical Distortion Map

Residual is $\sim 0.2$ pixel $(260 \mu \mathrm{rad}$ ) average

- Star Matching Results : Overnight runs in controlled environment

Repeatability $<60 \mu \mathrm{rad}(1 \sigma)$

Absolute Pointing Accuracy

| Star Matched Dec. - LLNL Dec. | $>350 \mu \mathrm{rad}\left(0: 02^{\circ}\right)$ (RA Residual from WWV Time) Maximum $550 \mu \mathrm{rad}\left(0.03^{\circ}\right)$

Study under way 


\section{Star Tracker $(313,314)$}

- Radiometric Calibration at 600 and $700 \mathrm{~nm}$

- Optical Distortion Map

Residual is $\sim 0.2$ pixel (260 $\mu \mathrm{rad}$ ) average

- Star Matching Results : Overnight runs in controlled environment

Repeatability $\quad<60 \mu \mathrm{rad}(1 \sigma)$

Absolute Pointing Accuracy

| Star Matched Dec. - LLNL Dec. | (RA Residual from WWV Time)
$>350 \mu \mathrm{rad}\left(0.02^{\circ}\right)$

Maximum $550 \mu \mathrm{rad}\left(0.03^{\circ}\right)$

Study under way 


\section{Star Tracker $(313,314)$}

- Radiometric Calibration at 600 and $700 \mathrm{~nm}$

- Optical Distortion Map

Residual is $\sim 0.2$ pixel $(260 \mu \mathrm{rad})$ average

- Star Matching Results : Overnight runs in controlled environment

Repeatability

$$
<60 \mu \mathrm{rad}(1 \sigma)
$$

Absolute Pointing Accuracy

| Star Màtched Dec. - LLNL Dec. | (RA Residual from WWV Time)
$>350 \mu \mathrm{rad}\left(0.02^{\circ}\right)$ Maximum $550 \mu \mathrm{rad}\left(0.03^{\circ}\right)$

Study under way 


\section{Star Tracker $(313,314)$}

- Radiometric Calibration at 600 and $700 \mathrm{~nm}$

- Optical Distortion Map

Residual is $\sim 0.2$ pixel (260 $\mu \mathrm{rad}$ ) average

- Star Matching Results : Overnight runs in controlled environment

Repeatability $\quad \therefore<60 \mu \mathrm{rad}(1 \sigma)$

Absolute Pointing Açcuracy

| Star Màtched Dec. - LLNL Dec.| (RA Residual from WWV Time)
$>350 \mu \mathrm{rad}\left(0.02^{\circ}\right)$

Maximum $550 \mu \mathrm{rad}\left(0.03^{\circ}\right)$

Study under way 


\section{Star Tracker $(313,314)$}

- Radiometric Calibration at 600 and $700 \mathrm{~nm}$

- Optical Distortion Map

Residual is $\sim 0.2$ pixel $(260 \mu \mathrm{rad})$ average

- Star Matching Results : Overnight runs in controlled environment

Repeatability ... $<60 \mu \mathrm{rad}(1 \sigma)$

Absolute Pointing Açcuracy

| Star Màtched Dec. - LLNL Dec. | $>350 \mu \mathrm{rad}\left(0.02^{\circ}\right)$ (RA Residual from WWV Time) Maximum $550 \mu \mathrm{rad}\left(0.03^{\circ}\right)$

Study under way 
- Radiometric Calibration at 600 and $700 \mathrm{~nm}$

- Optical Distortion Map

Residual is $\sim 0.2$ pixel ( $260 \mu \mathrm{rad}$ ) average

- Star Matching Results : Overnight runs in controlled environment

Repeatability $\quad \therefore<60 \mu \mathrm{rad}(1 \sigma)$

Absolute Pointing Accuracy

| Star Màtched Dec. - LLNL Dec. | (RA Residual from WWV Time)
$>350 \mu \mathrm{rad}\left(0.02^{\circ}\right)$

Maximum $550 \mu \mathrm{rad}\left(0.03^{\circ}\right)$

Study under way 

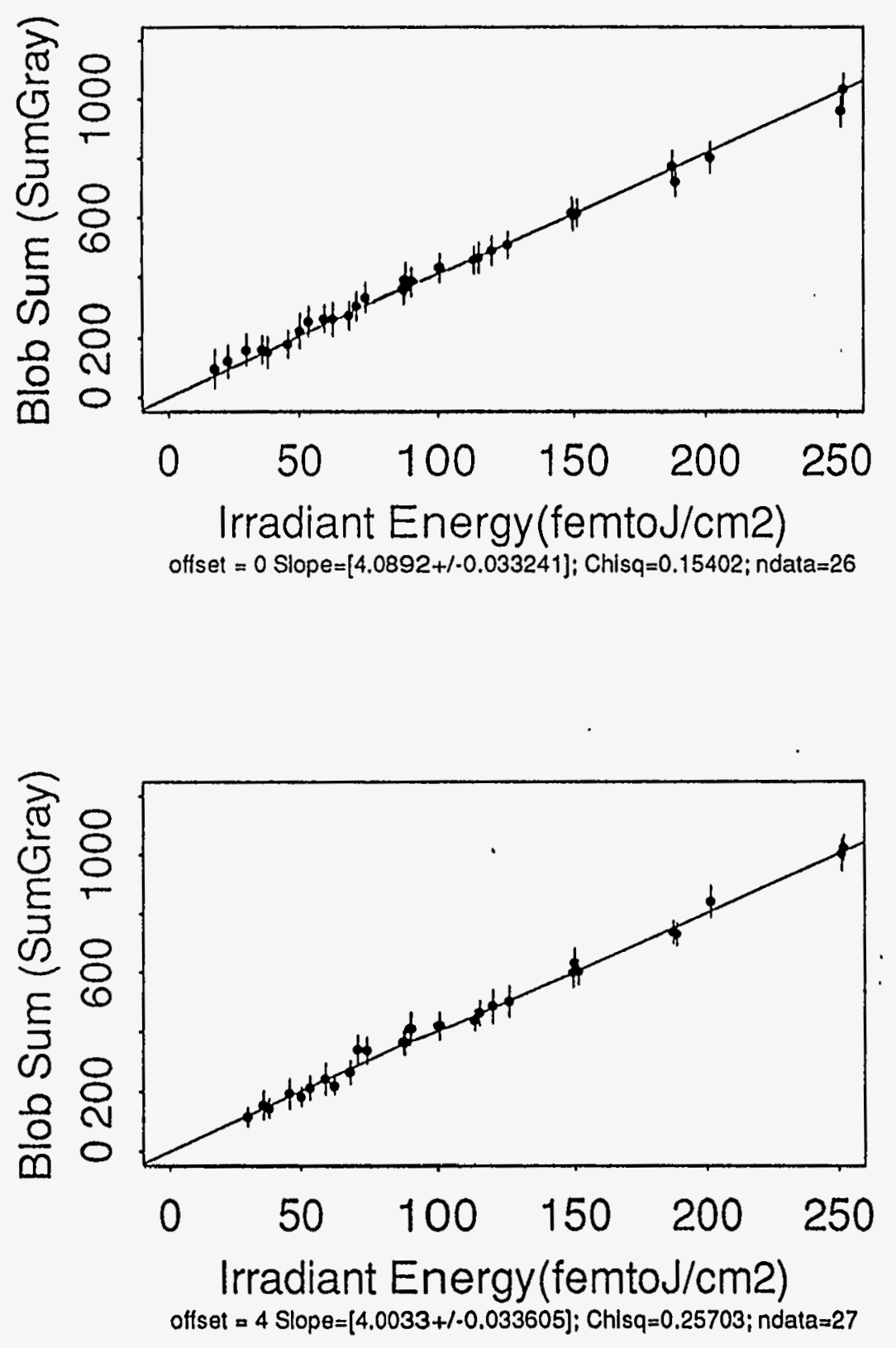

Clementine Star Tracker Camera

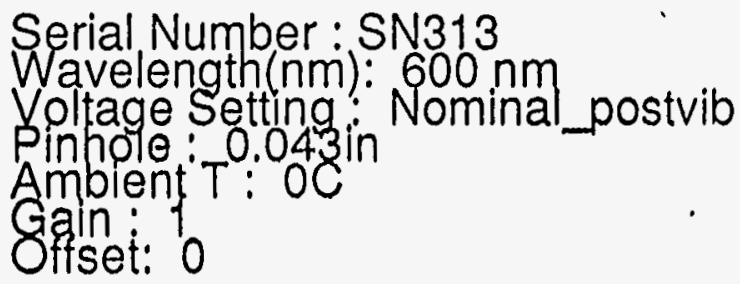

Serial Number : SN313

Wavelength $(\mathrm{nm}): 600 \mathrm{~nm}$

Voltage Setting: Nominal postvib Pinhole: $0.043 \mathrm{in}$

Ambient $T: 0 C$

Gain: 10

Clementine Star Tracker Camera

Serial Number : SN313

Wavelength $(\mathrm{nm}): 600 \mathrm{~nm}$

Voltage Setting: Nominal_postvib

Pinhole : 0.043 in

Ambient $T$ : OC

Gain : 1 

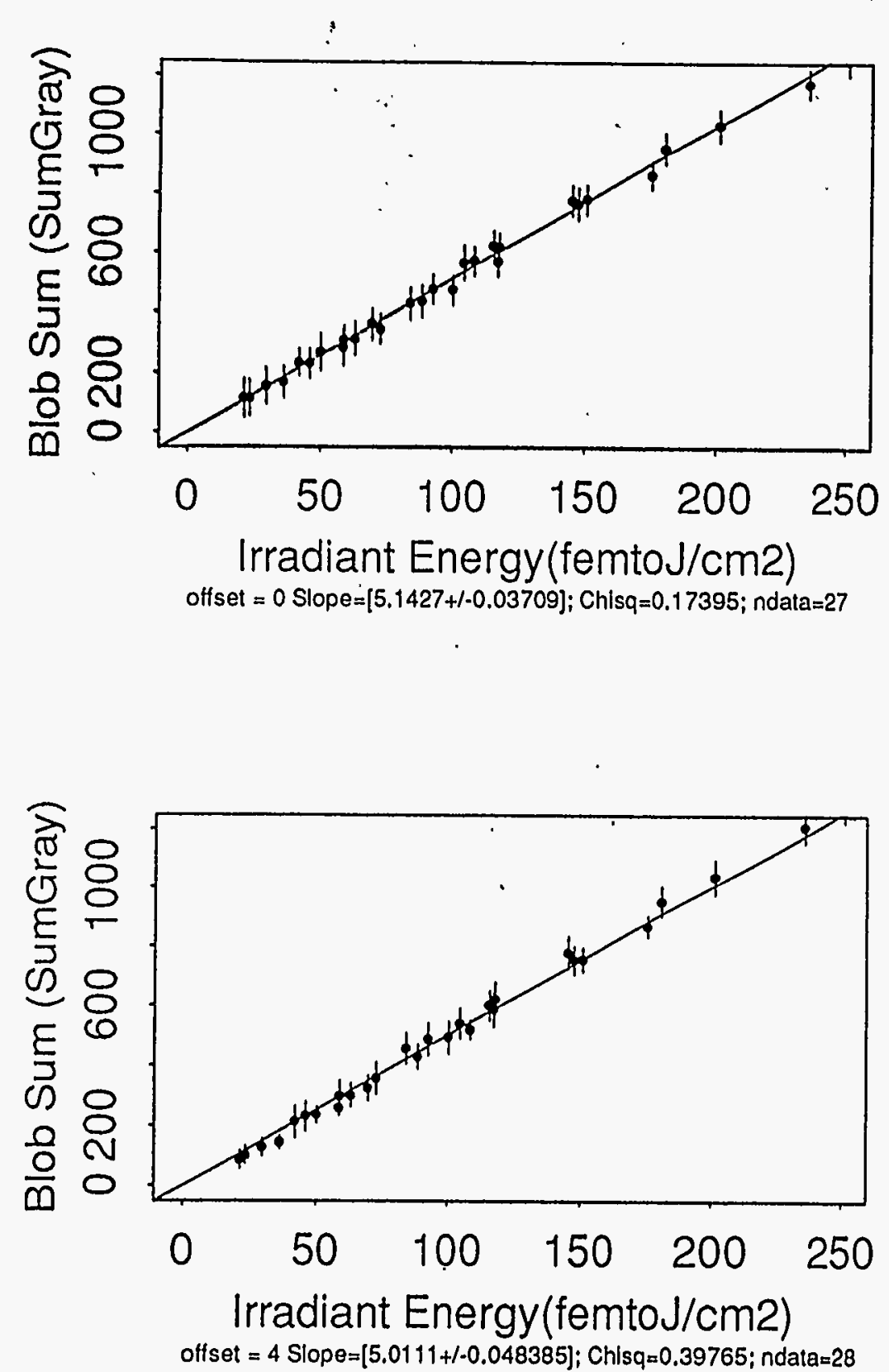

offset $=4$ Slope $=[5.0111+/-0.048385] ;$ Chlsq $=0.39765 ;$ ndata $=28$
Clementine Star Tracker Camera

Serial Number : SN313

Wavelength $(\mathrm{nm}): 700 \mathrm{~nm}$

oltage Setting: Nominal_postvib

Pinhole: 0.04 in

Ambient $T$ : OC

Ofalnet: 0

Clementine Star Tracker Camera

Serial Number : SN313

Wavelength(nm): $700 \mathrm{~nm}$

Voltage Setting: Nominal postvib

Pinhole : 0.04 zin

Ambient $T: 0 C$

Gain: 1 


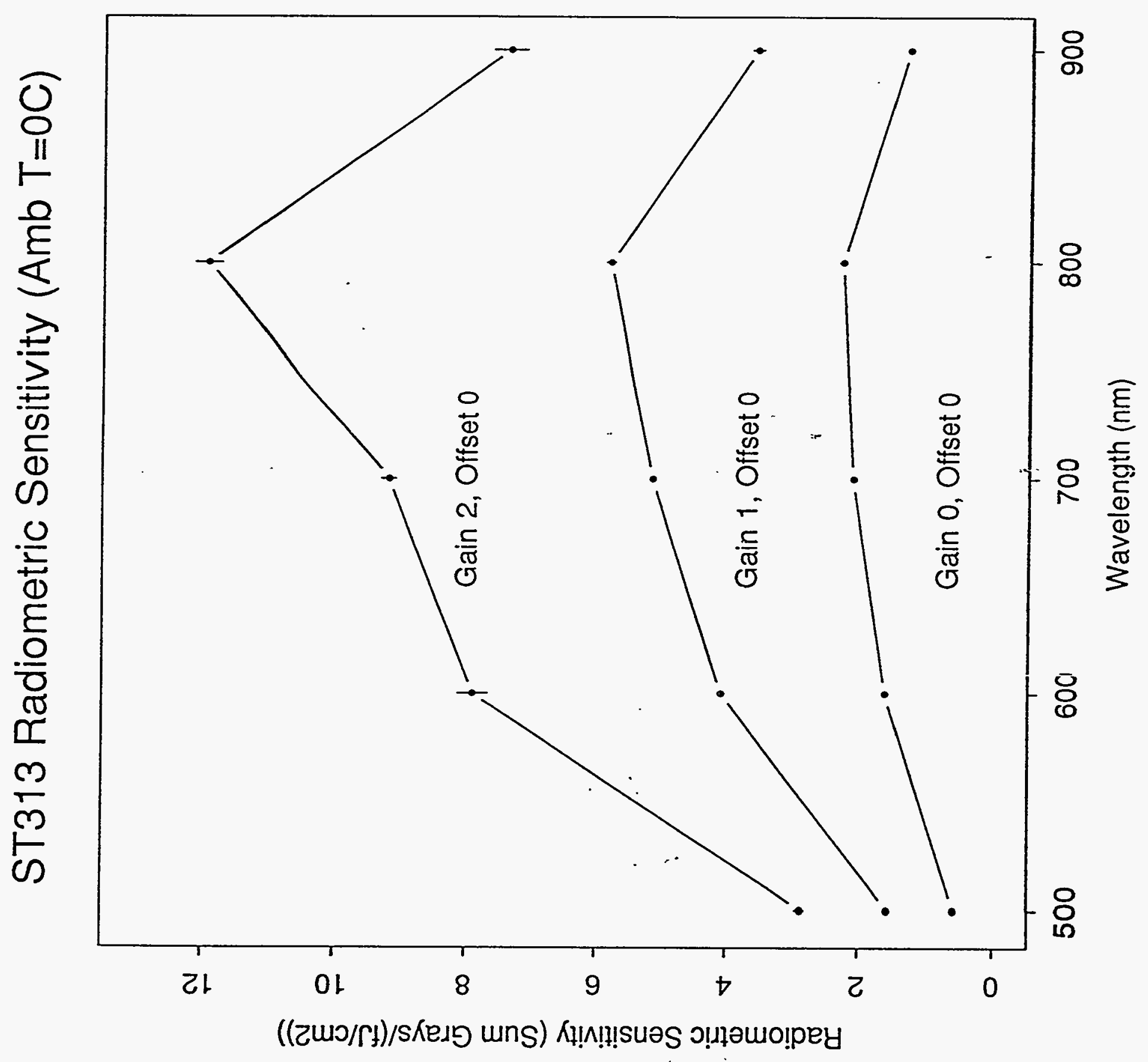




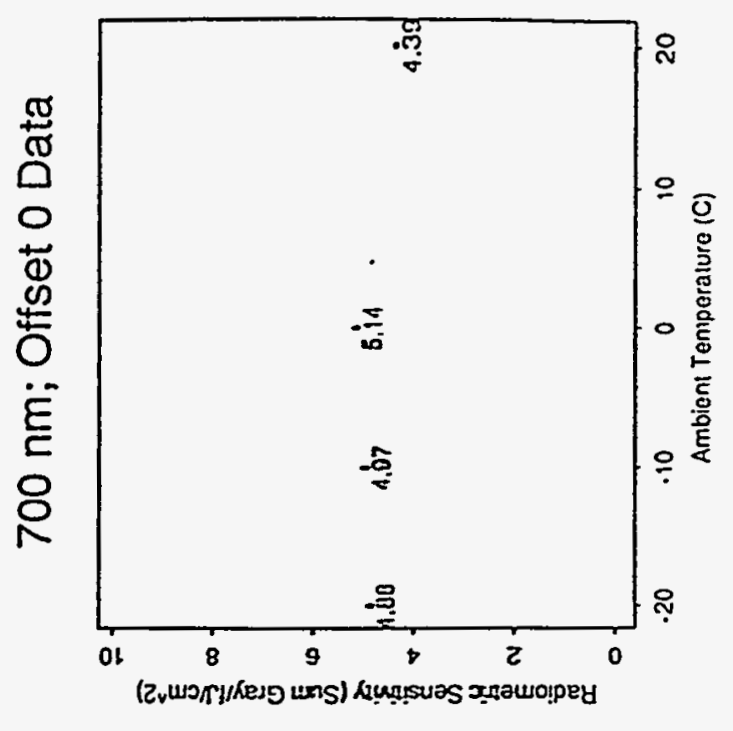

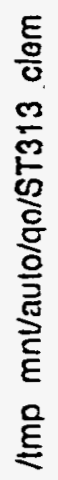
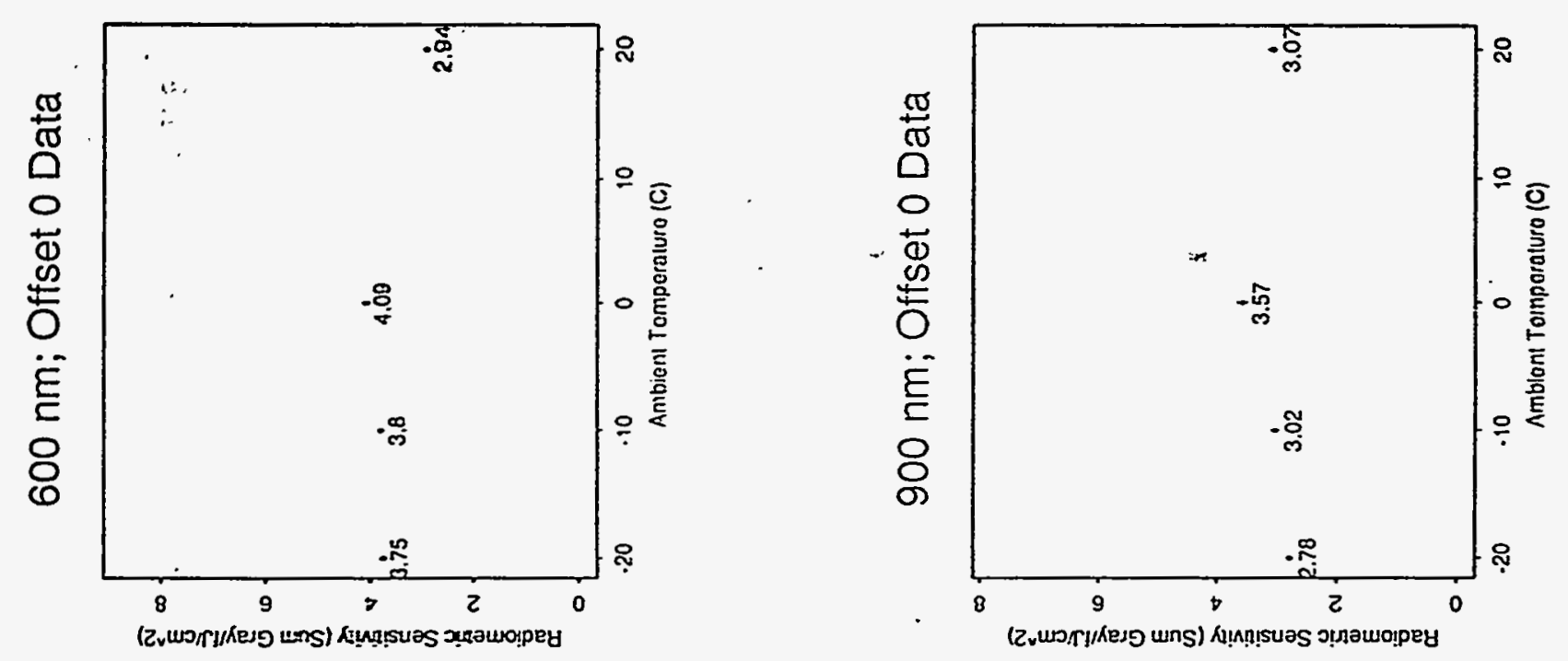

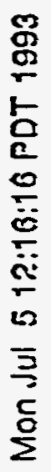
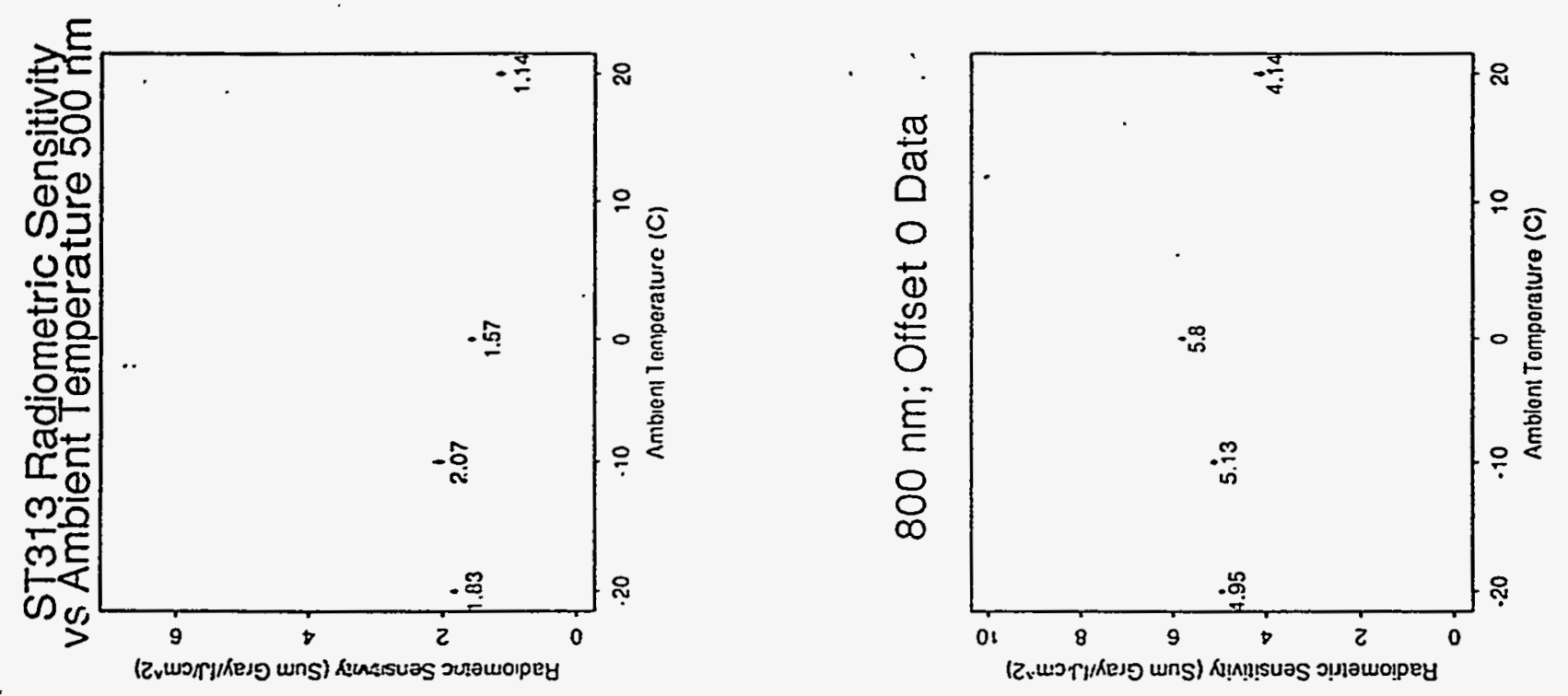

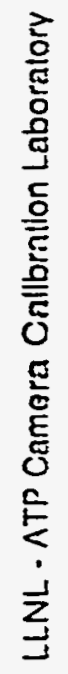



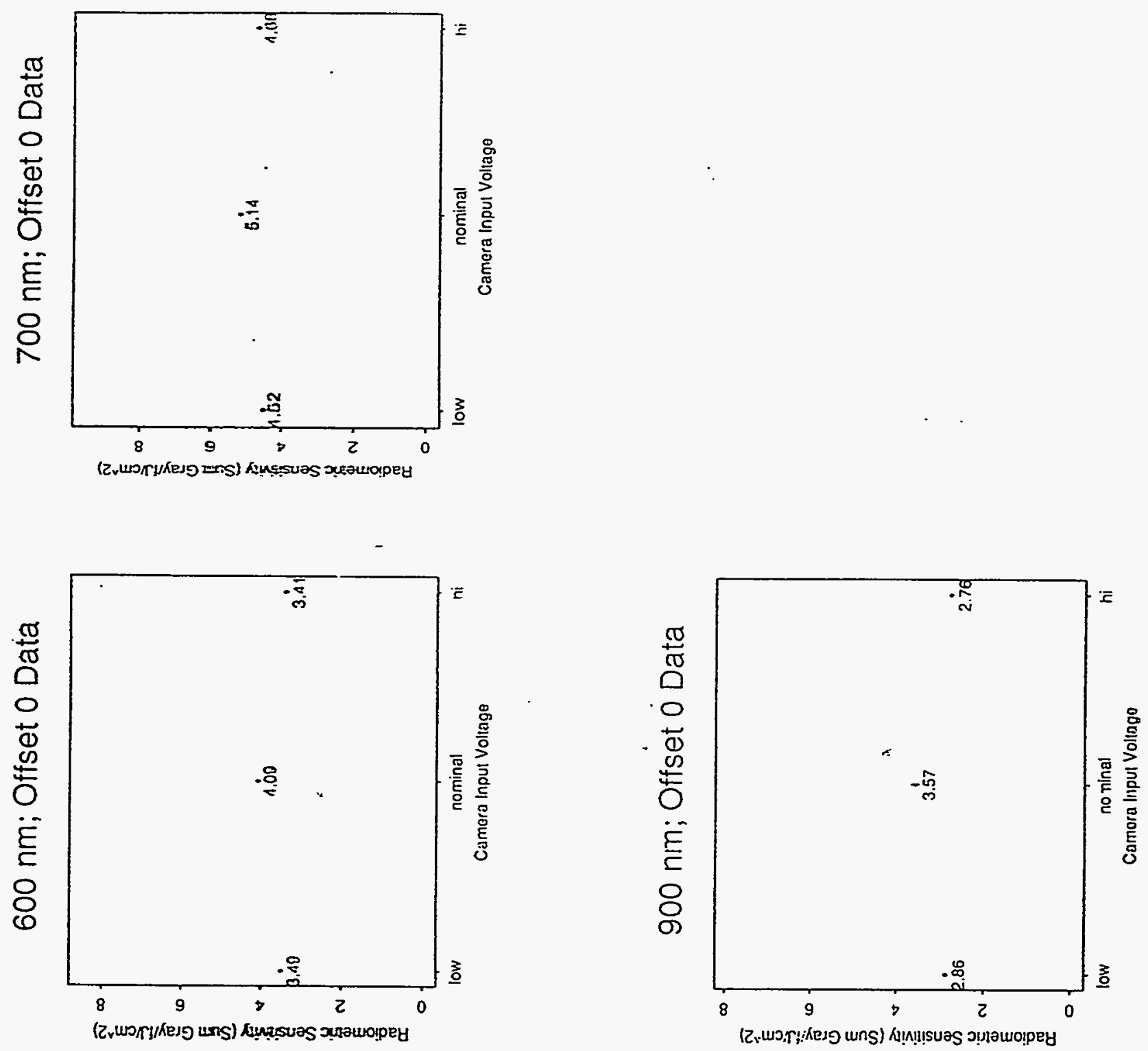

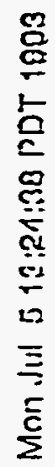
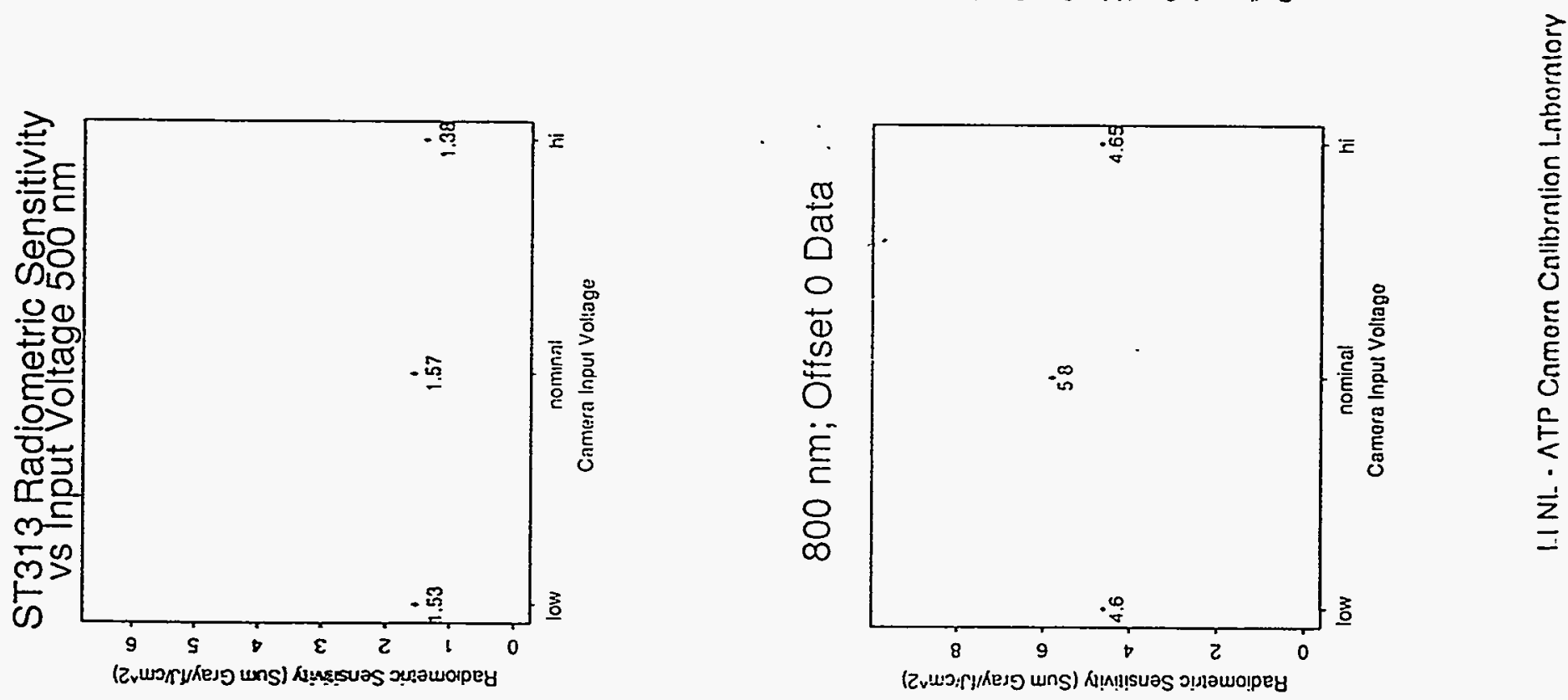


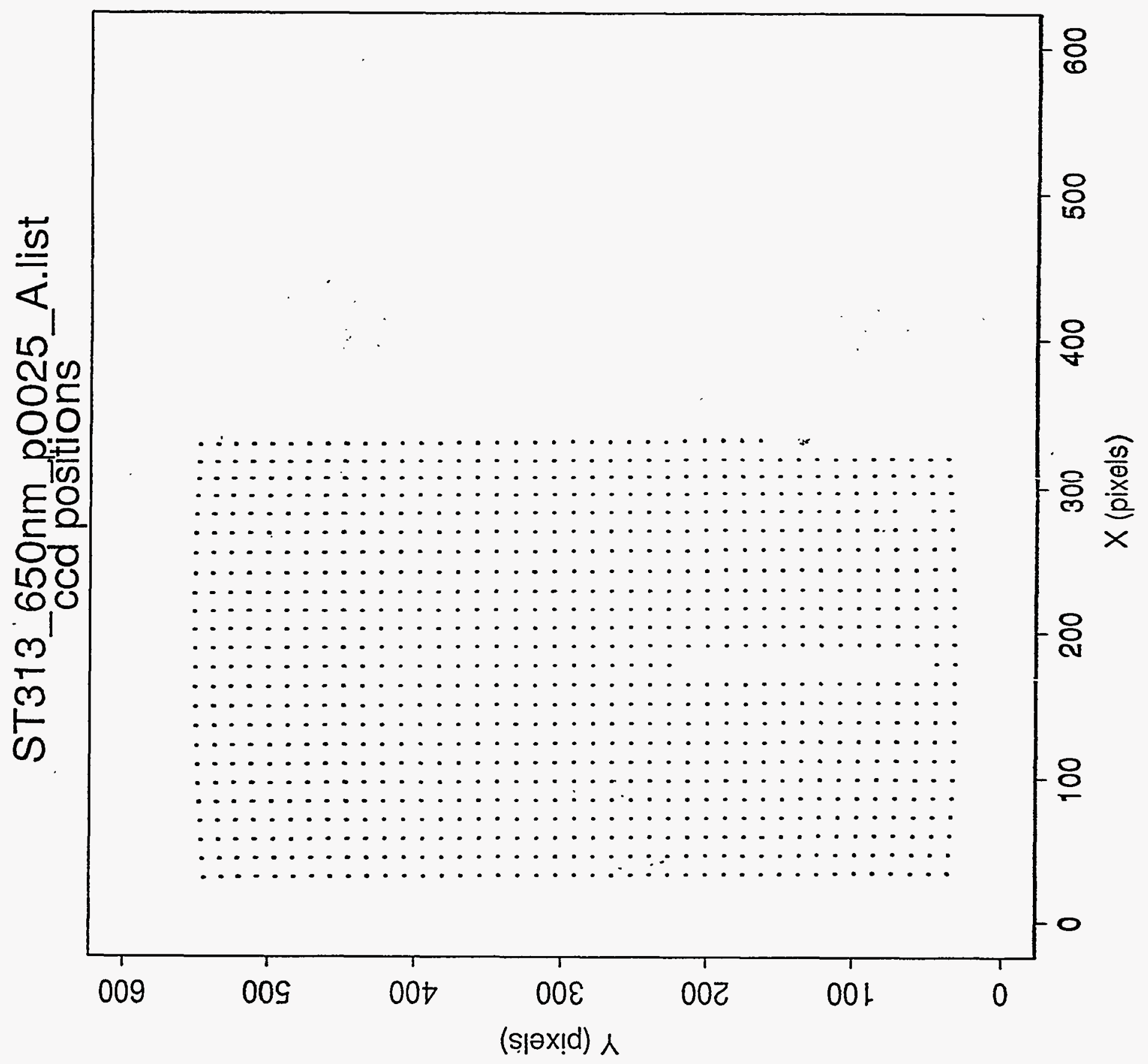



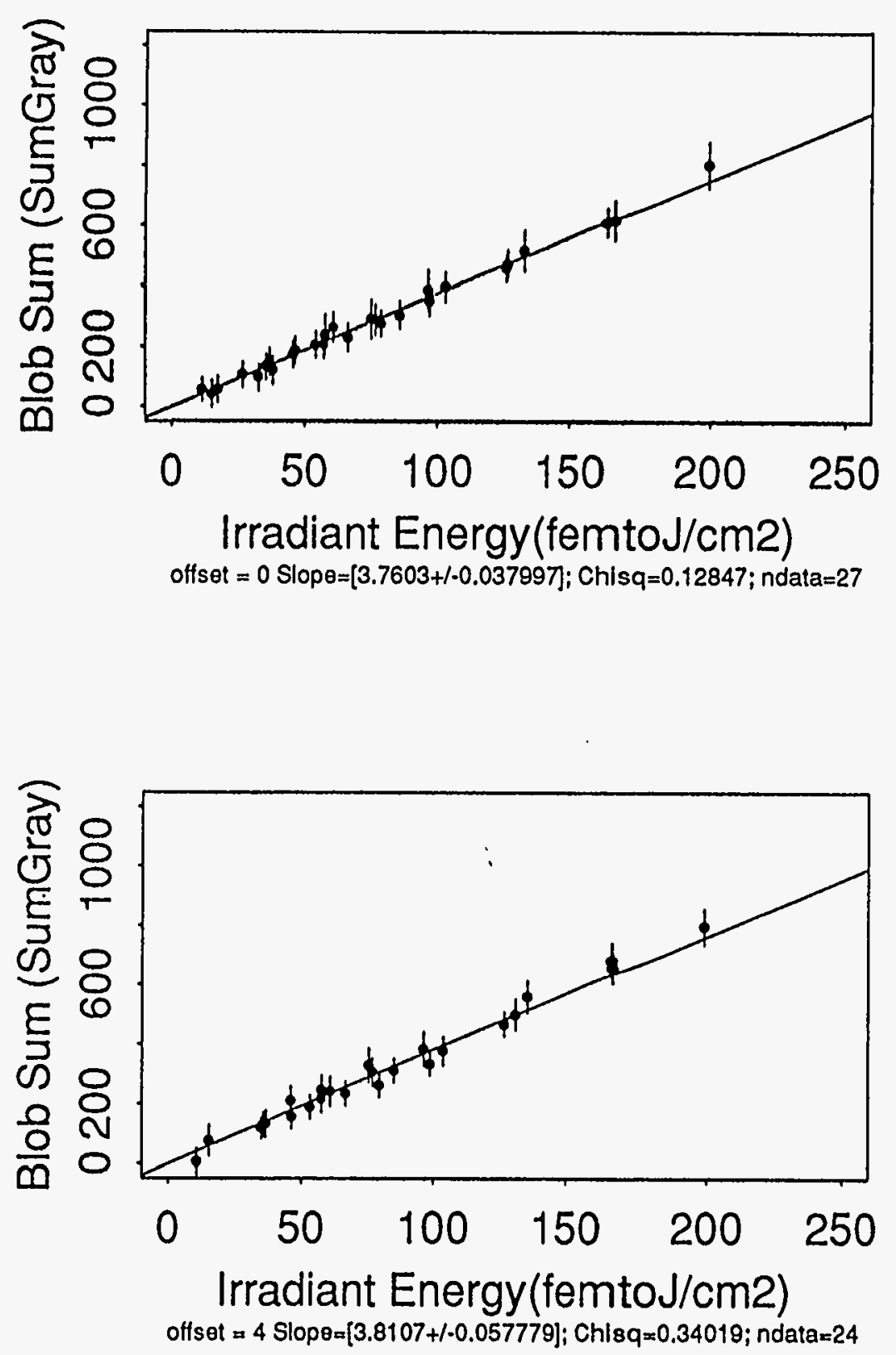

\section{Clementine Star Tracker Camera}

Serial Number : ST314

Wavelength $(\mathrm{nm}): 600 \mathrm{~nm}$

oltage Setting: nominal

Pin ole: 0.043 in

Amblent $T: 0 C$

Galn : 10
Clementine Star Tracker Camera

Serial Number : ST314

Wavelength $(\mathrm{nm}): 600 \mathrm{~nm}$

oltage Setting nomina

innole: $0.043 \mathrm{in}$

Ambient $T$ : OC

Gain: 1 


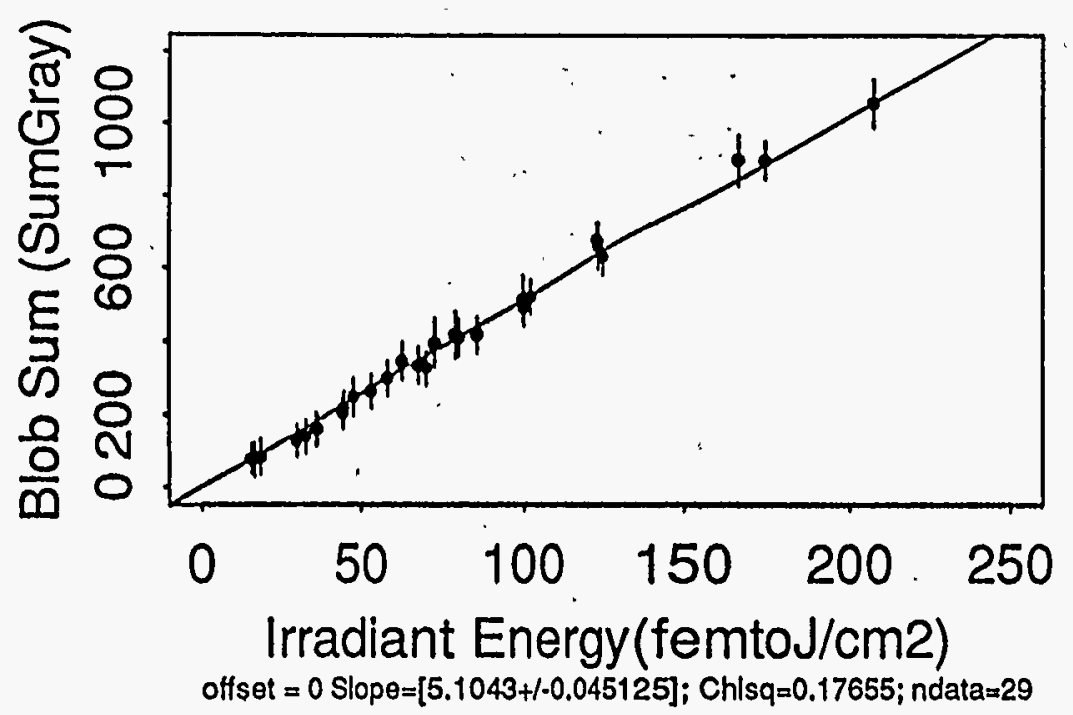

Clementine Star Tracker Camera

Serial Number : ST314

Wavelength(nm): $700 \mathrm{~nm}$

Voltage Setting nominal

Pinnole: $0.04 \mathrm{sin}$

Ambient $T: 0 \mathrm{C}$

Ginst: 0

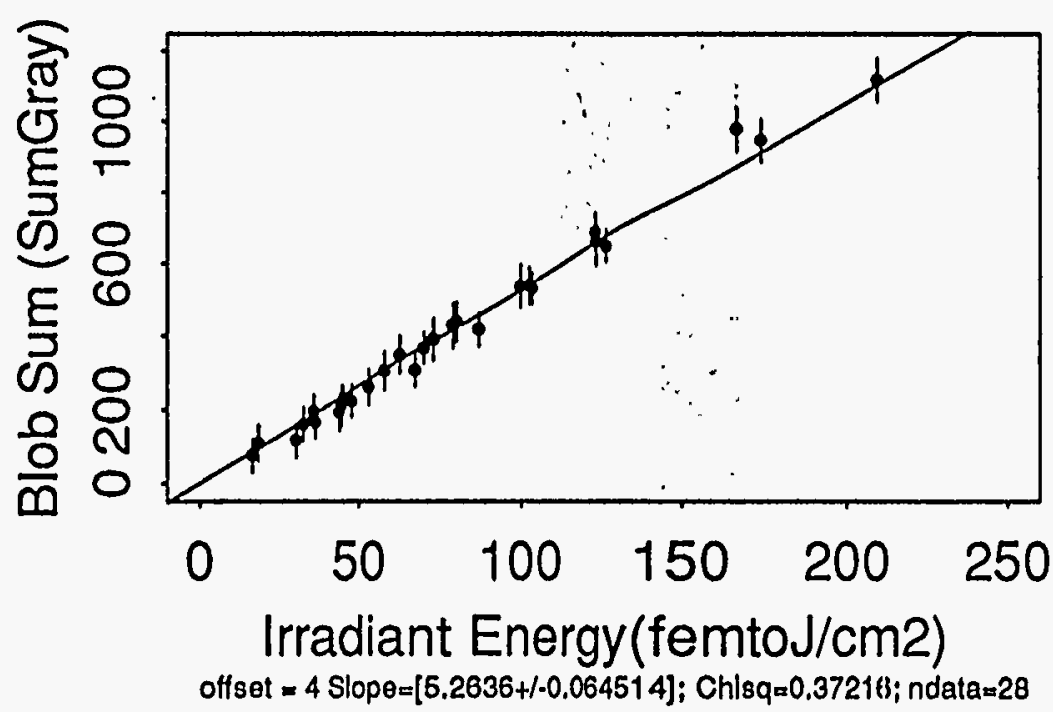

Clementine Star Tracker Camera

Serial Number: ST314

Wavelength(nm): $700 \mathrm{~nm}$

Voltage Setting: nomina

innole: 0.043 in

Ambient $T$ : $0 \mathrm{C}$

Oain : 1 


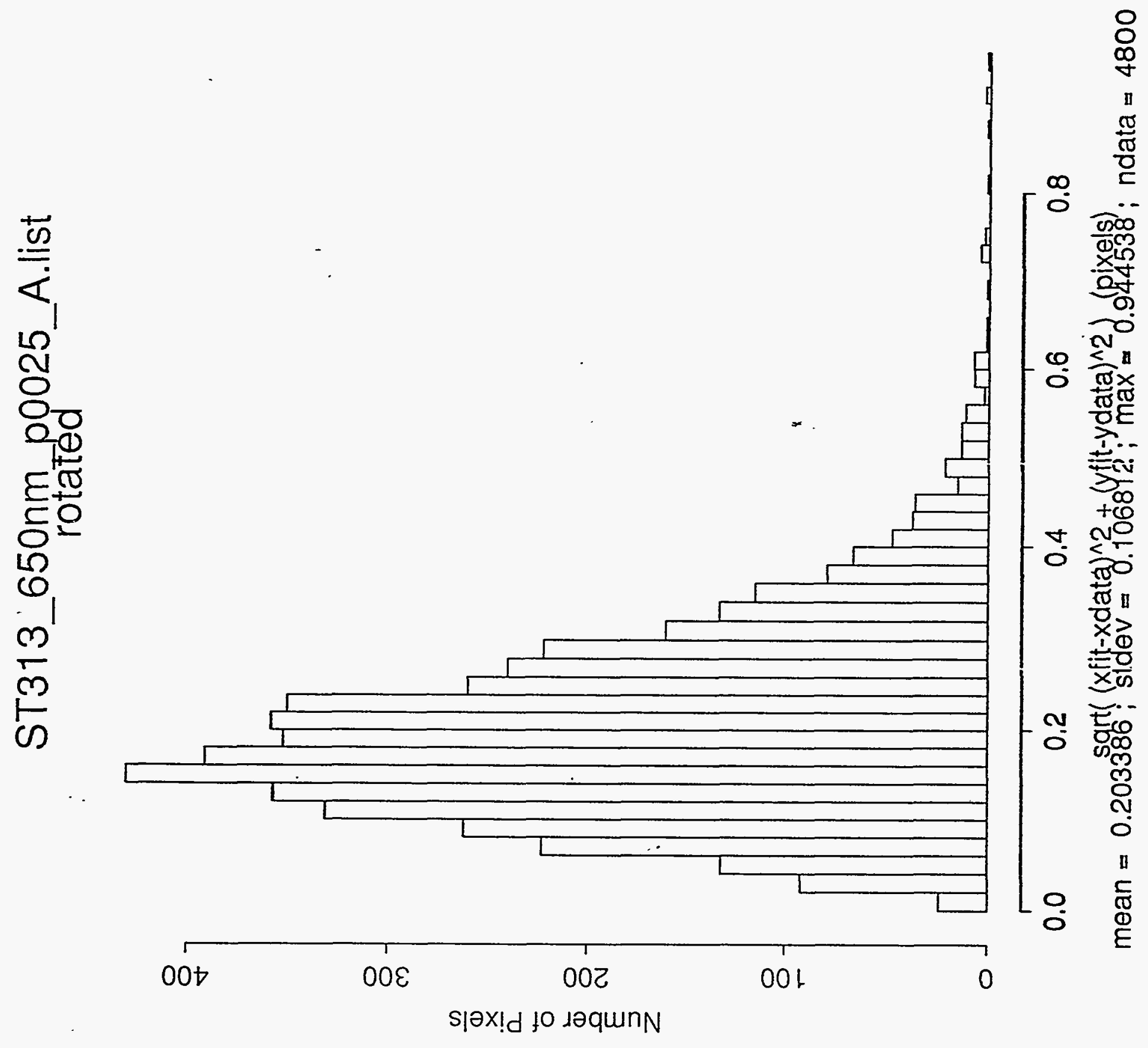




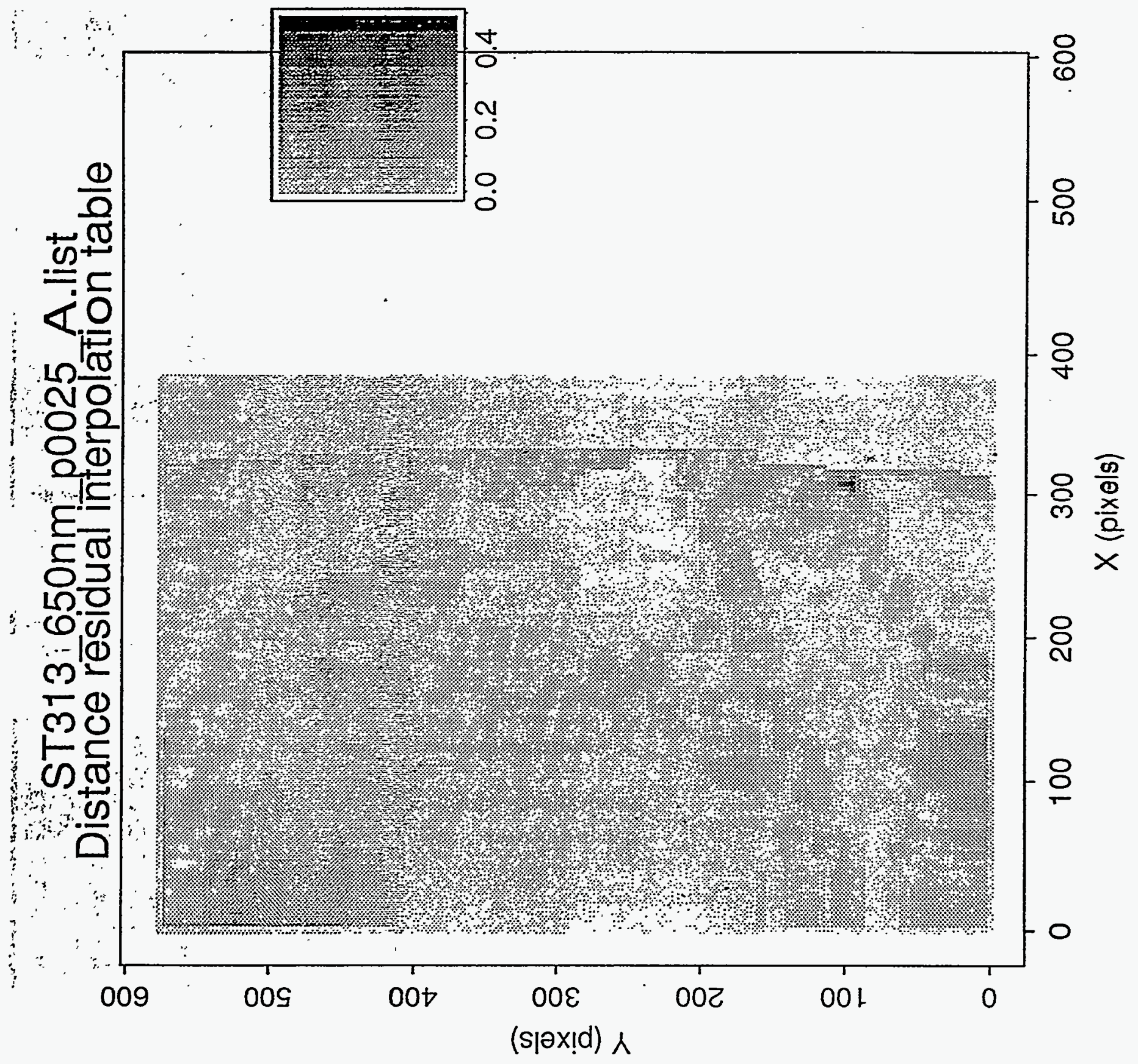




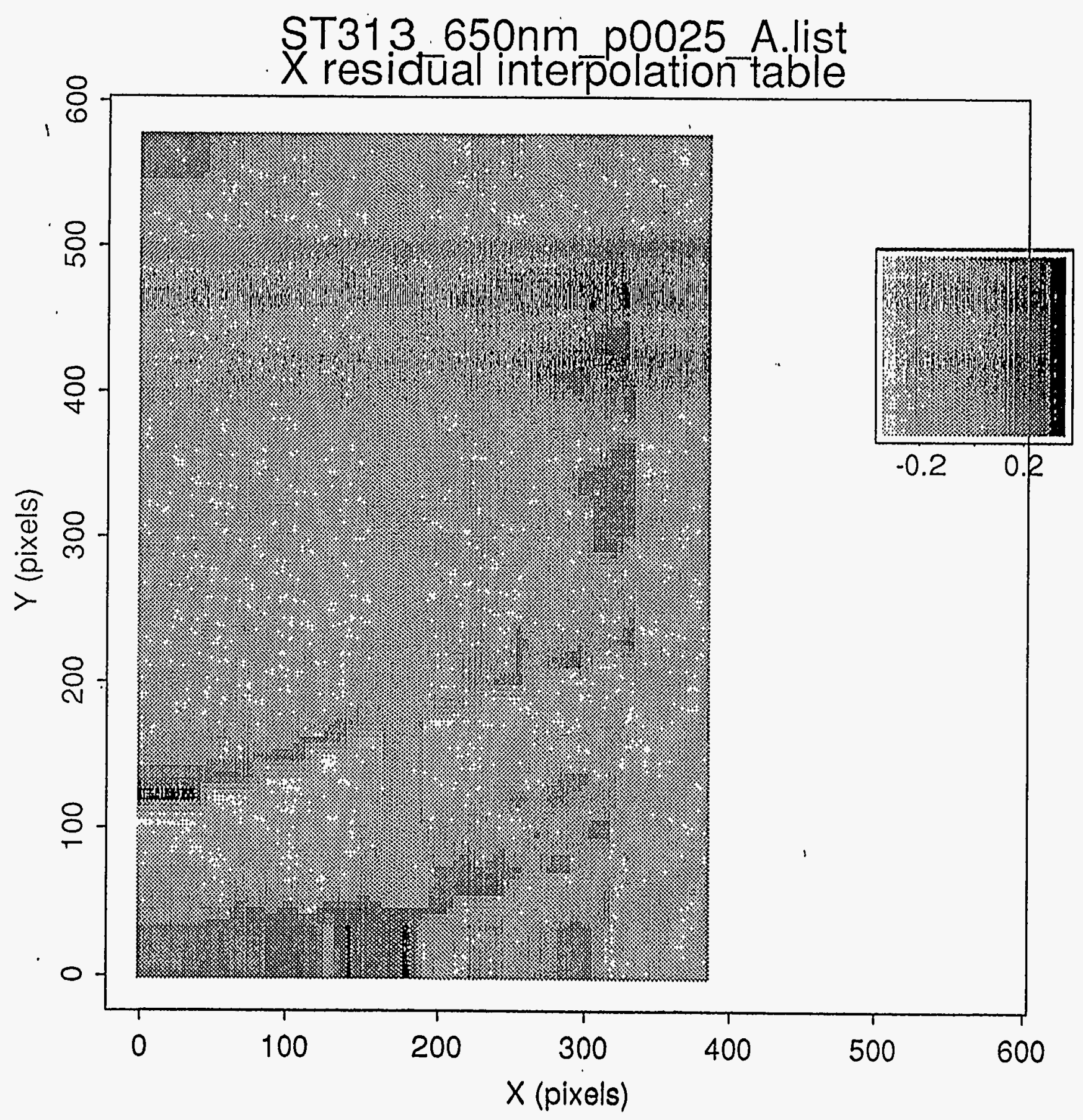




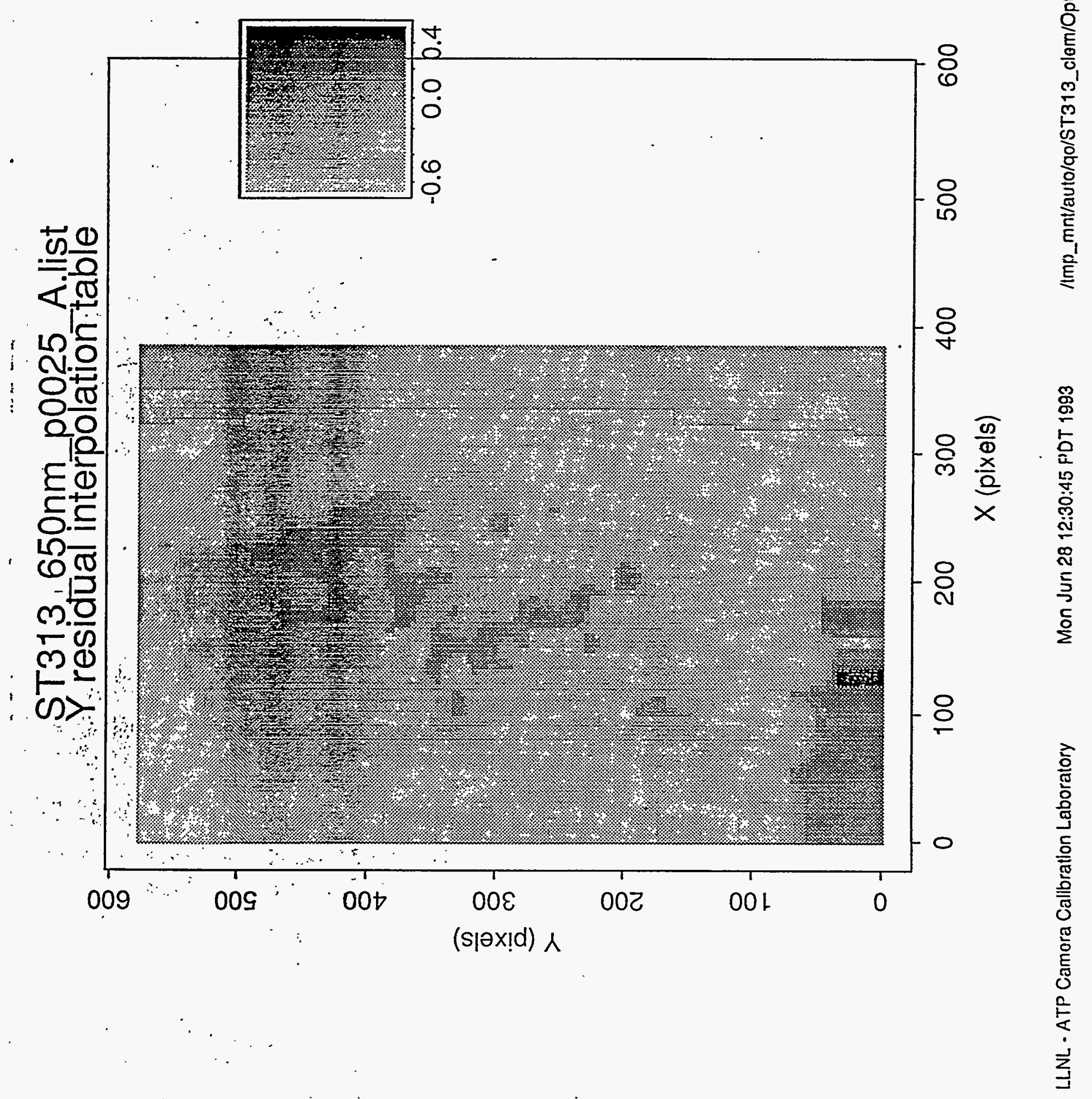




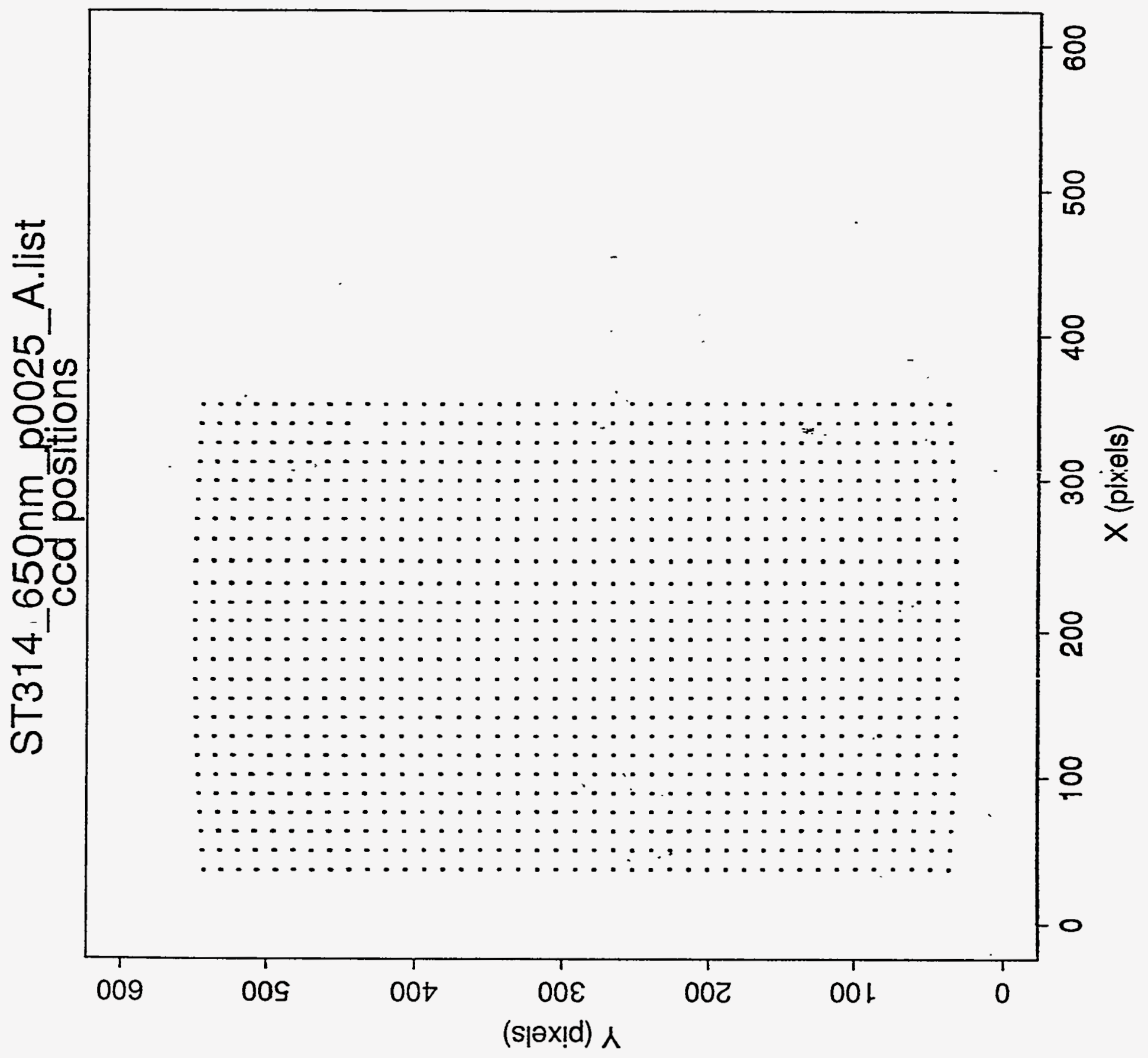




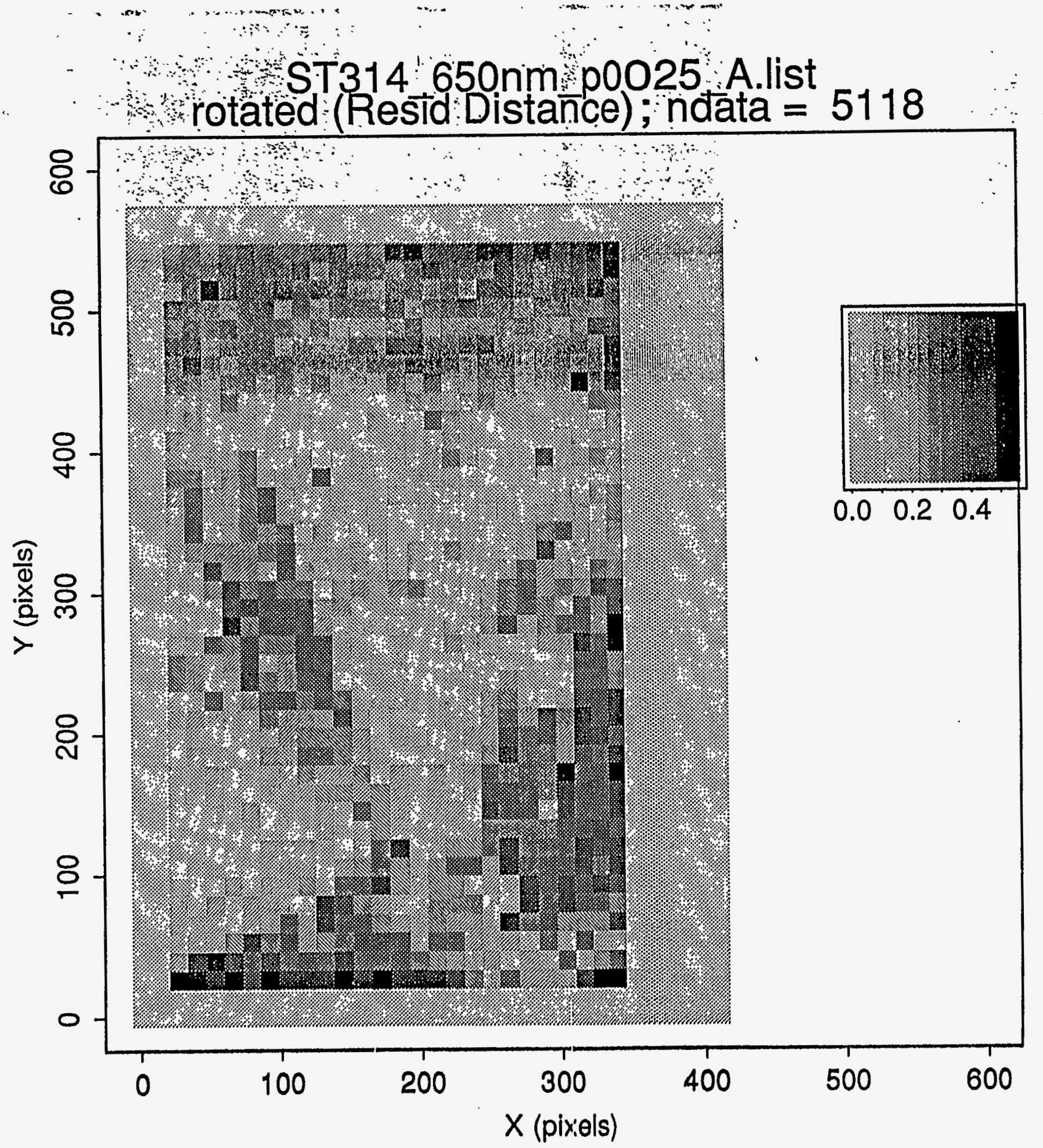




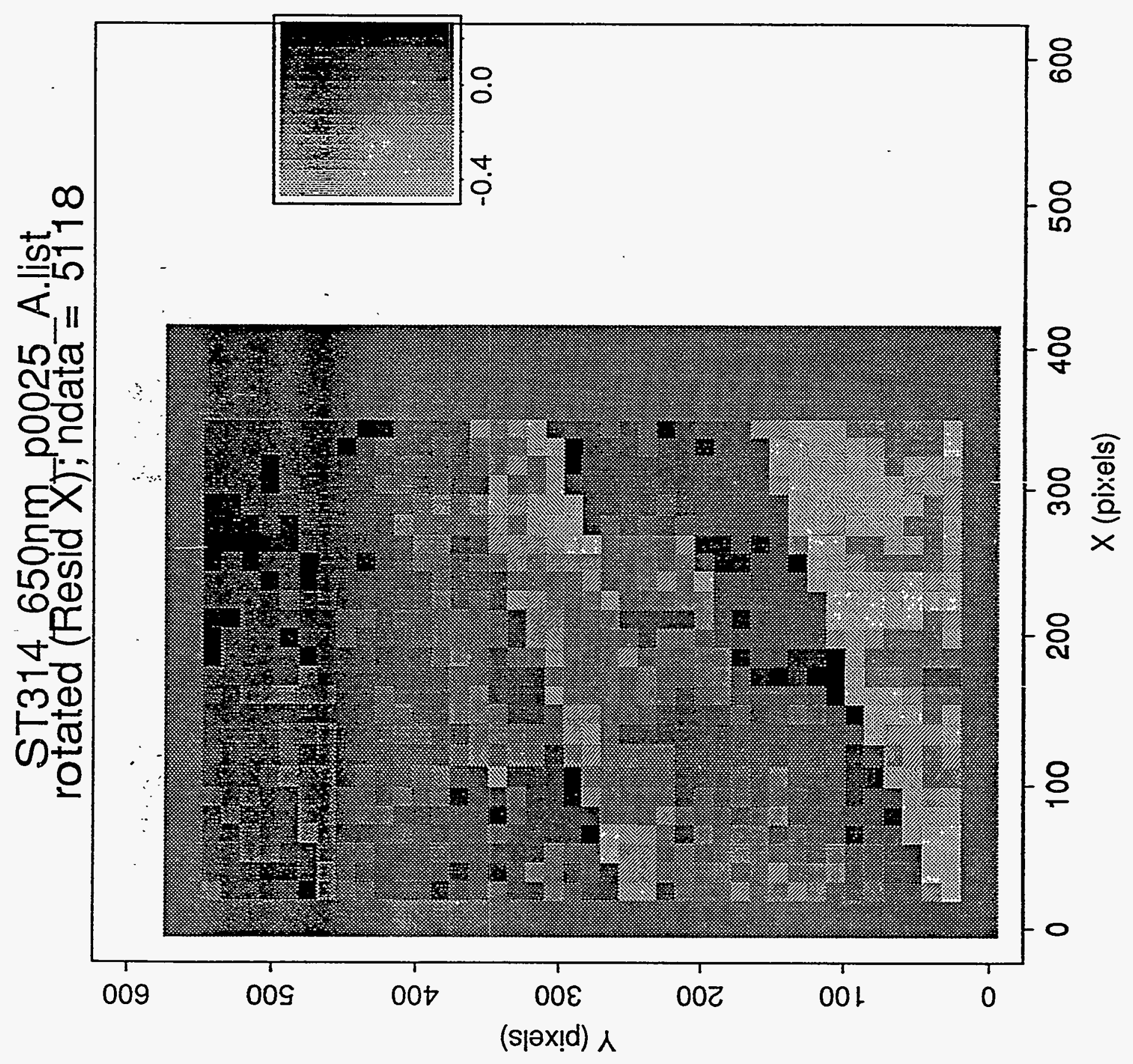




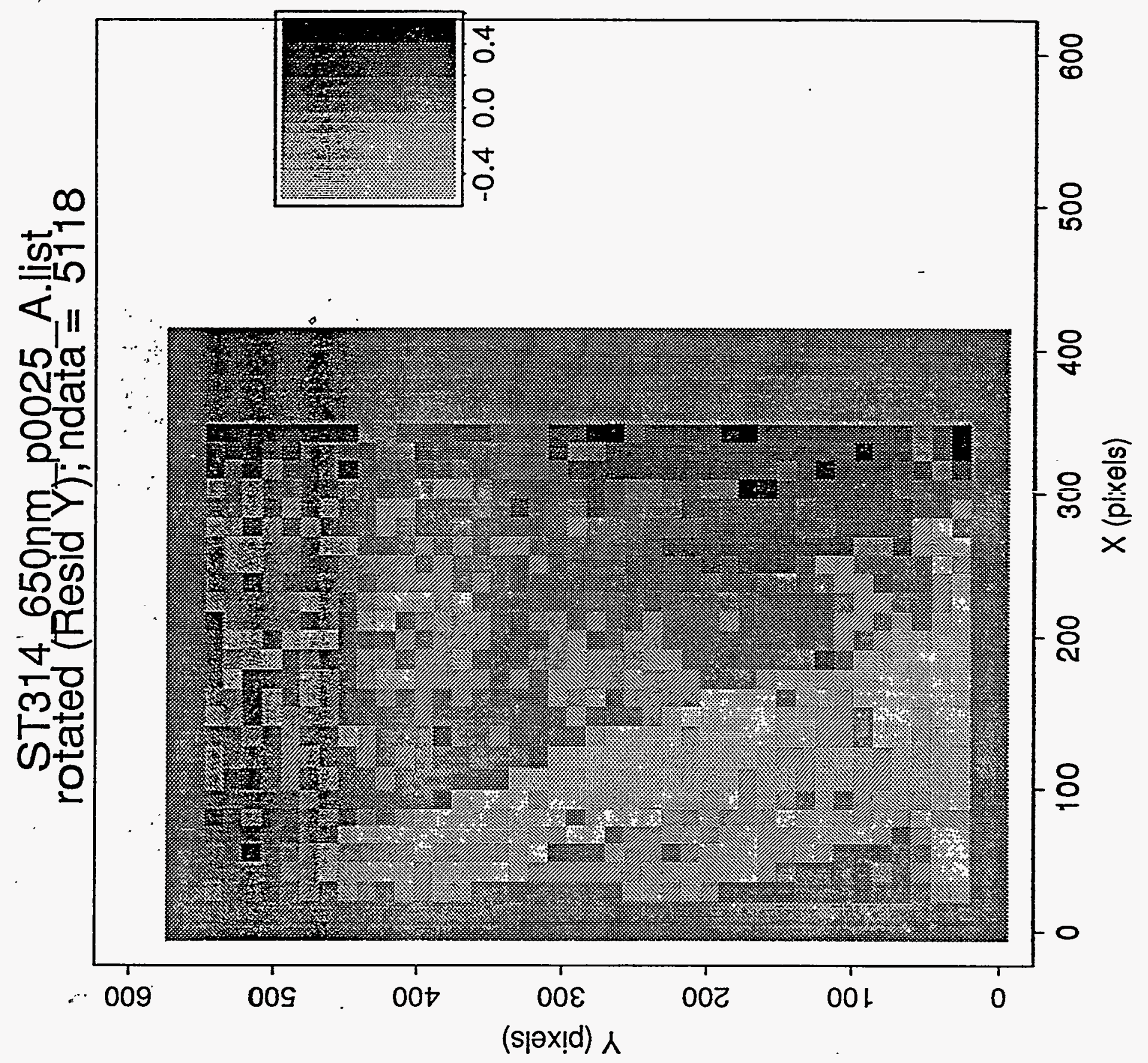


LLNL DeC $=37.6909^{\circ}$

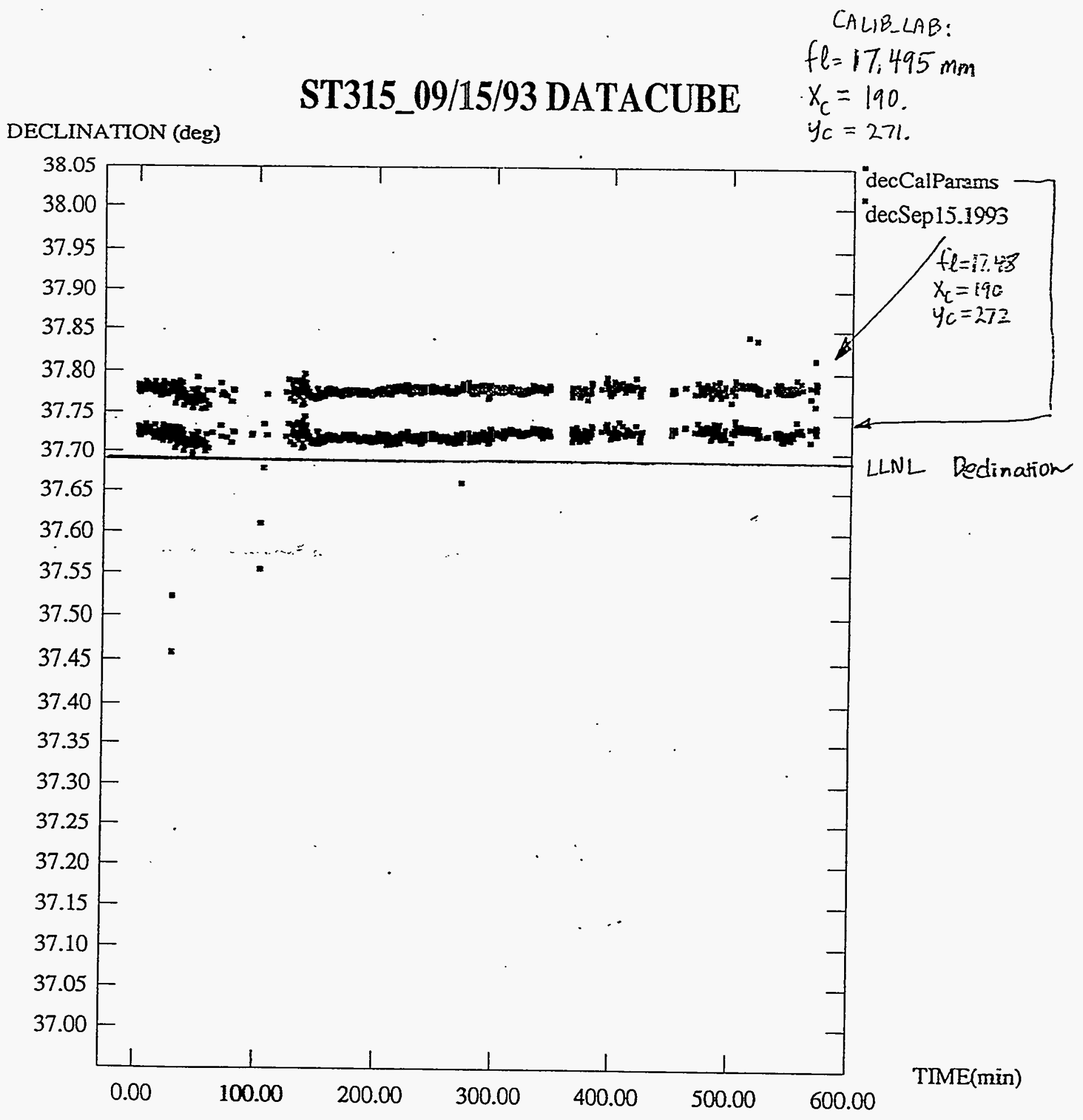




\section{ST316_350ms_g1_06 11/18/93 (star16c)}

DECLINATION (deg)

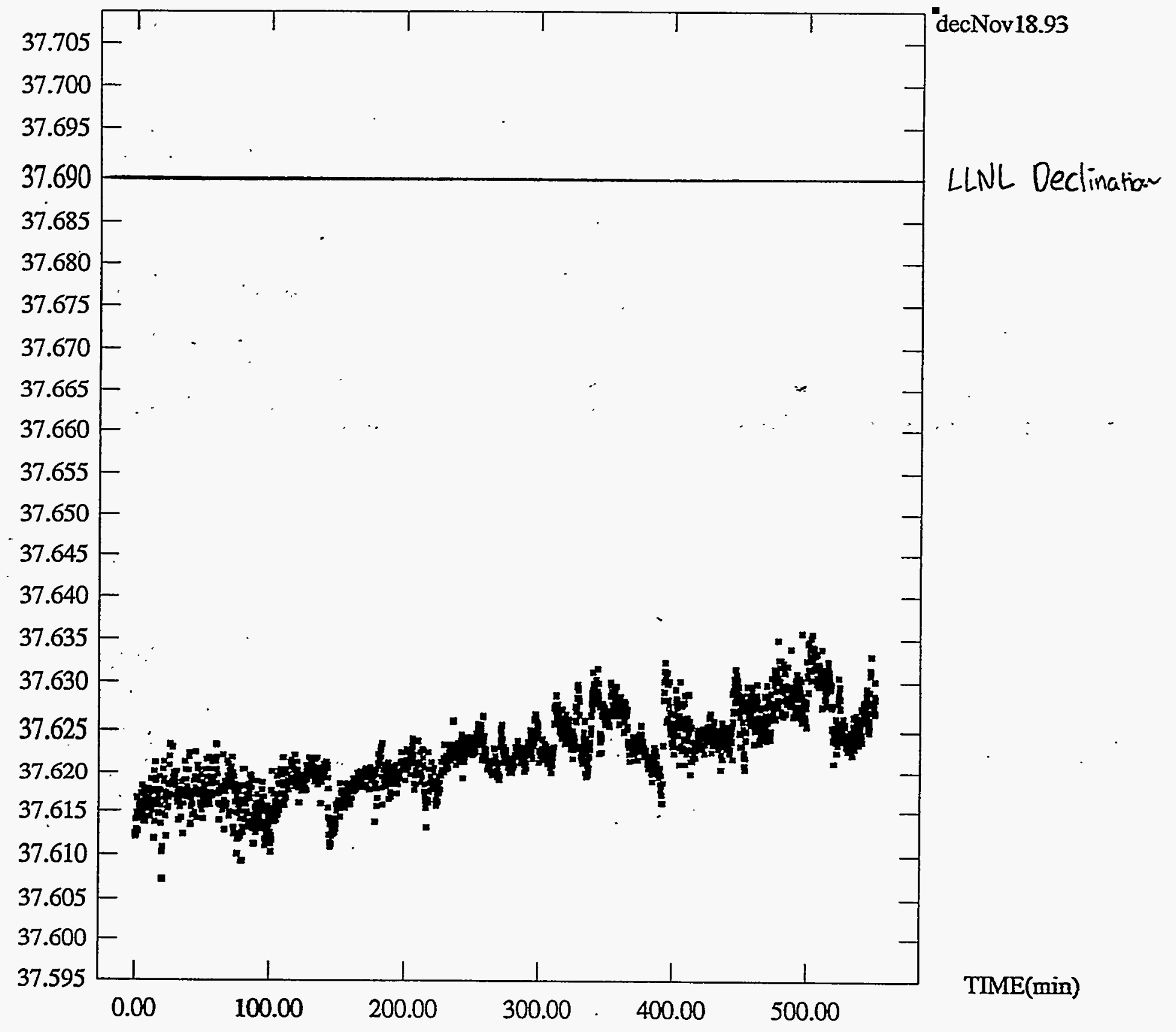




\section{ST316_350ms_g1_06 11/18/93 (star16c)}

R.A. Residual (deg) $\times 10^{-3}$

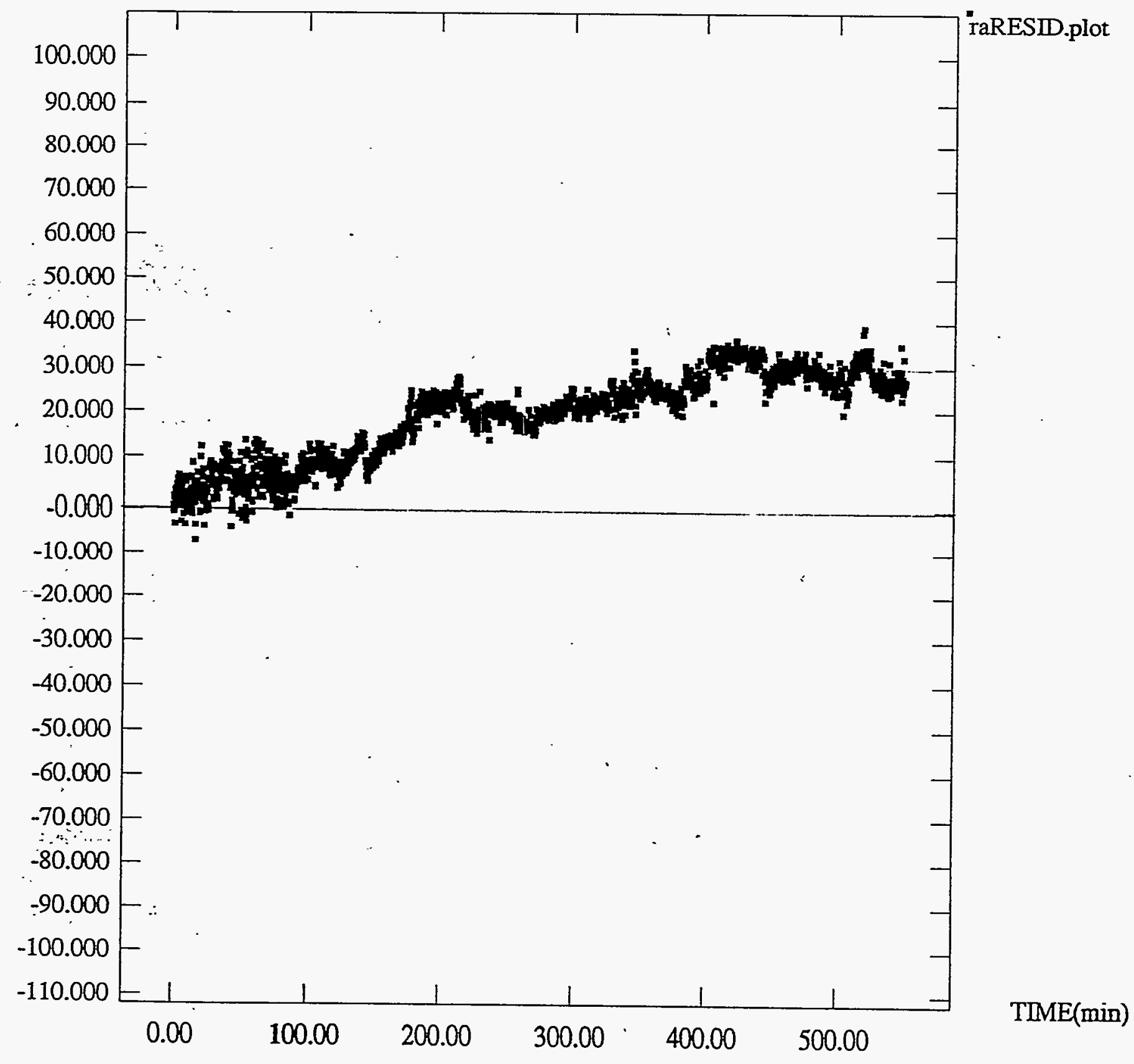




\section{UV314 Dark Noise \\ Temperature Dependence}

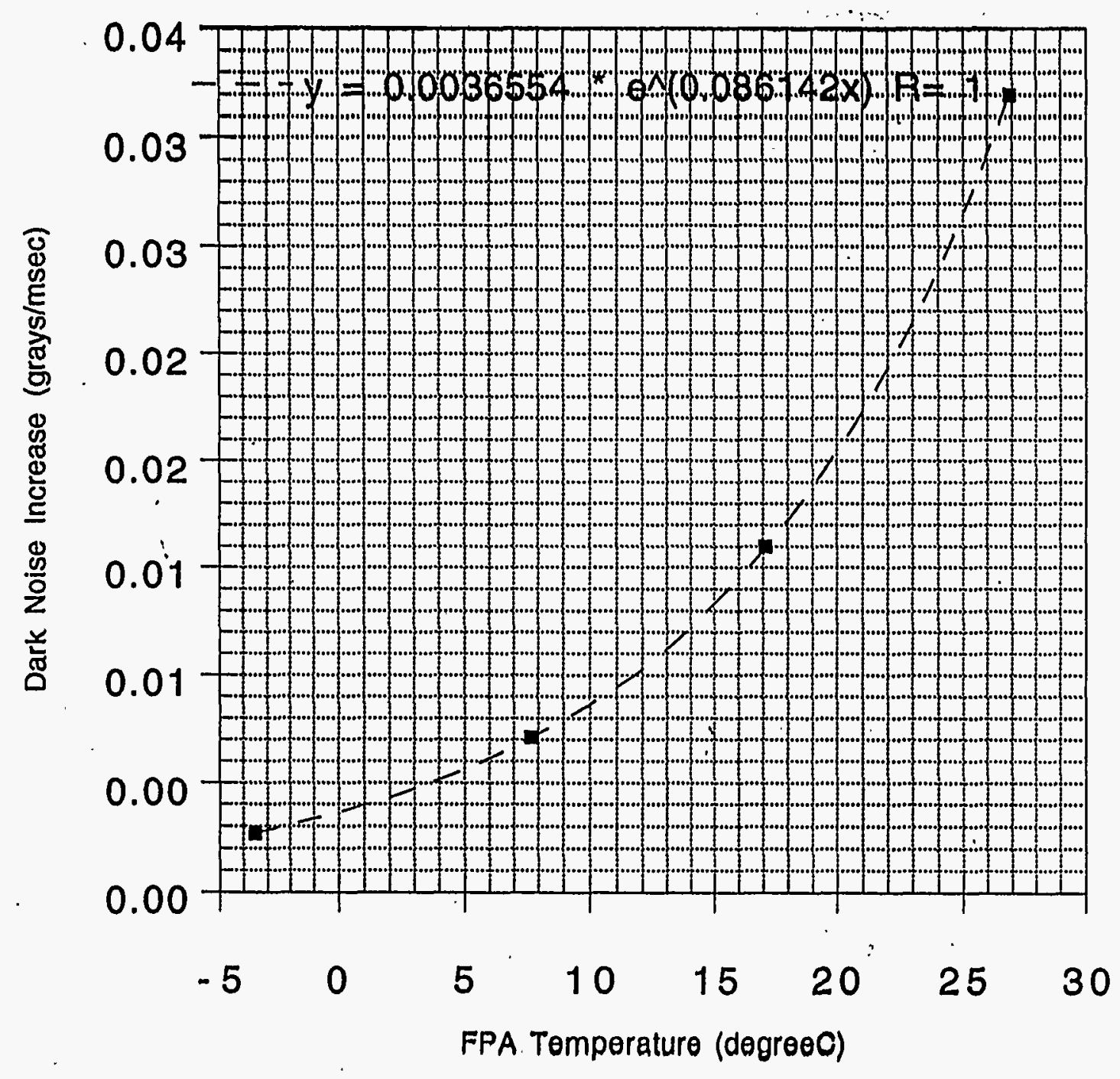




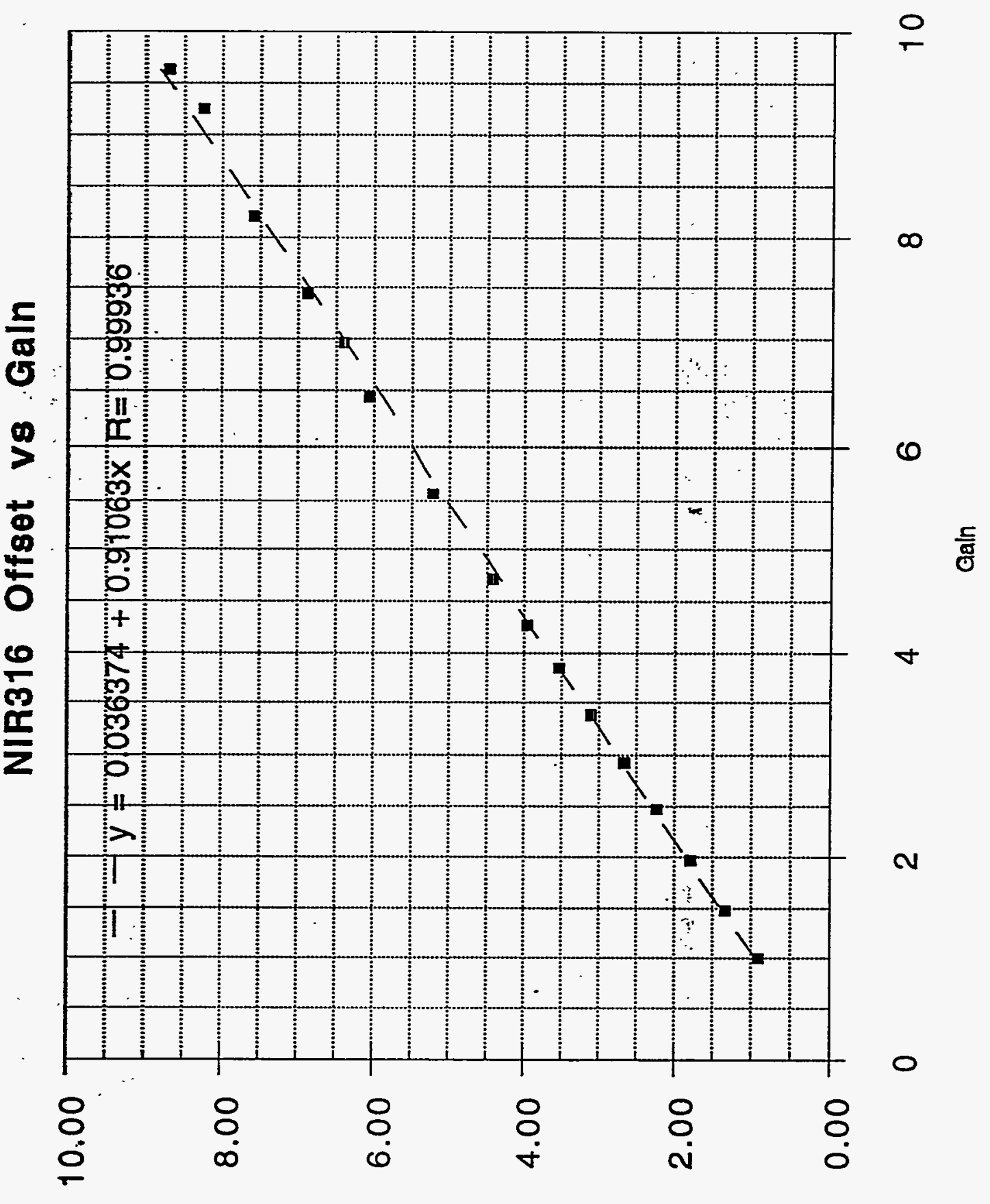


Appendix G

Certification Log for StarTracker B (ST 313) 


\section{StarTracker Camera}

Document No. C1-AAA92-106282, Tab 01

Flight No. 1

Serial No. ST-313

May 3, 1993 


\section{Appendix G.1}

\section{Summary Technical Data}




\section{Summary Technical Data}

\section{ST 313}

\begin{tabular}{|l|l|l|}
\hline Parameter & Specification & Measured Value \\
\hline Mass & $<483 \mathrm{~g}$ & $280 \mathrm{~g}$ \\
\hline $\begin{array}{l}\text { Current at } 22^{\circ} \mathrm{C} \\
+5 \mathrm{Vdc} \text { analog }\end{array}$ & $<155 \mathrm{~mA}$ & \\
$+5 \mathrm{Vdc}$ digital 1 & $<140 \mathrm{~mA} /<410 \mathrm{~mA}$ & $109.2 \mathrm{~mA} / 109.2 \mathrm{~mA}$ \\
$-5 \mathrm{Vdc}$ & $<60 \mathrm{~mA}$ & $39.6 \mathrm{~mA} / 300 \mathrm{~mA}$ \\
$+15 \mathrm{Vdc}$ & $<140 \mathrm{~mA}$ & $111 \mathrm{~mA} / 111 \mathrm{~mA}$ \\
$-15 \mathrm{Vdc}$ & $<30 \mathrm{~mA}$ & $14 \mathrm{~mA} / 13.96 \mathrm{~mA}$ \\
& & \\
\hline $\begin{array}{l}\text { Lens Heater Resistance at } \\
22^{\circ} \mathrm{C} \quad \text { (ST ONLY) }\end{array}$ & $450 \pm 45 \Omega$ & $455 \Omega$ \\
\hline
\end{tabular}

1 These values are with data bus disabled / data bus enabled with150 ohm termination. 
Appendix G.2

Board Assembly Log 


\section{Appendix G.2.1 Operations Sheet}




\section{Clementine Operations Sheet, Assembly}

Assembly Log \#

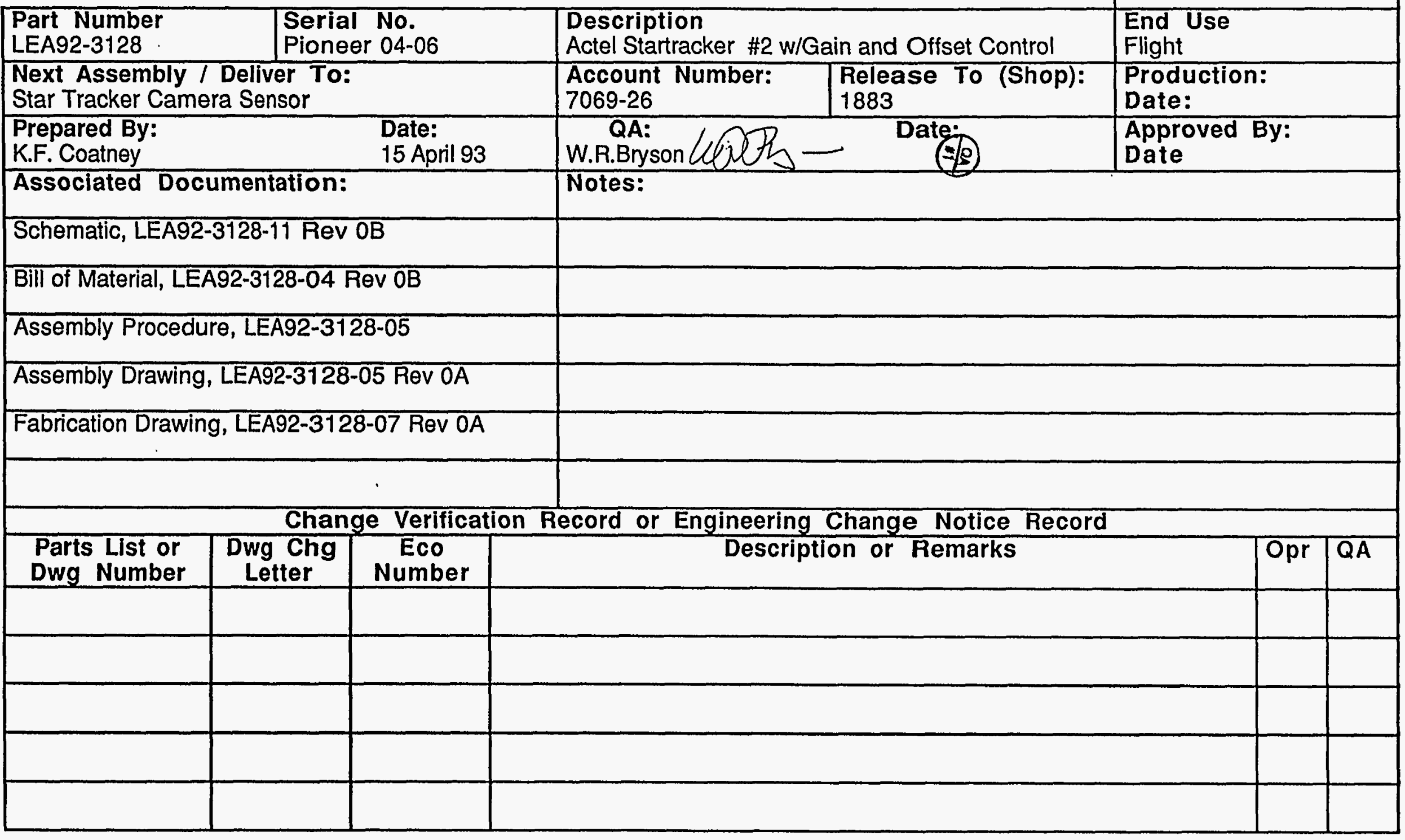


Appendix G.2.2

Work Sheets 


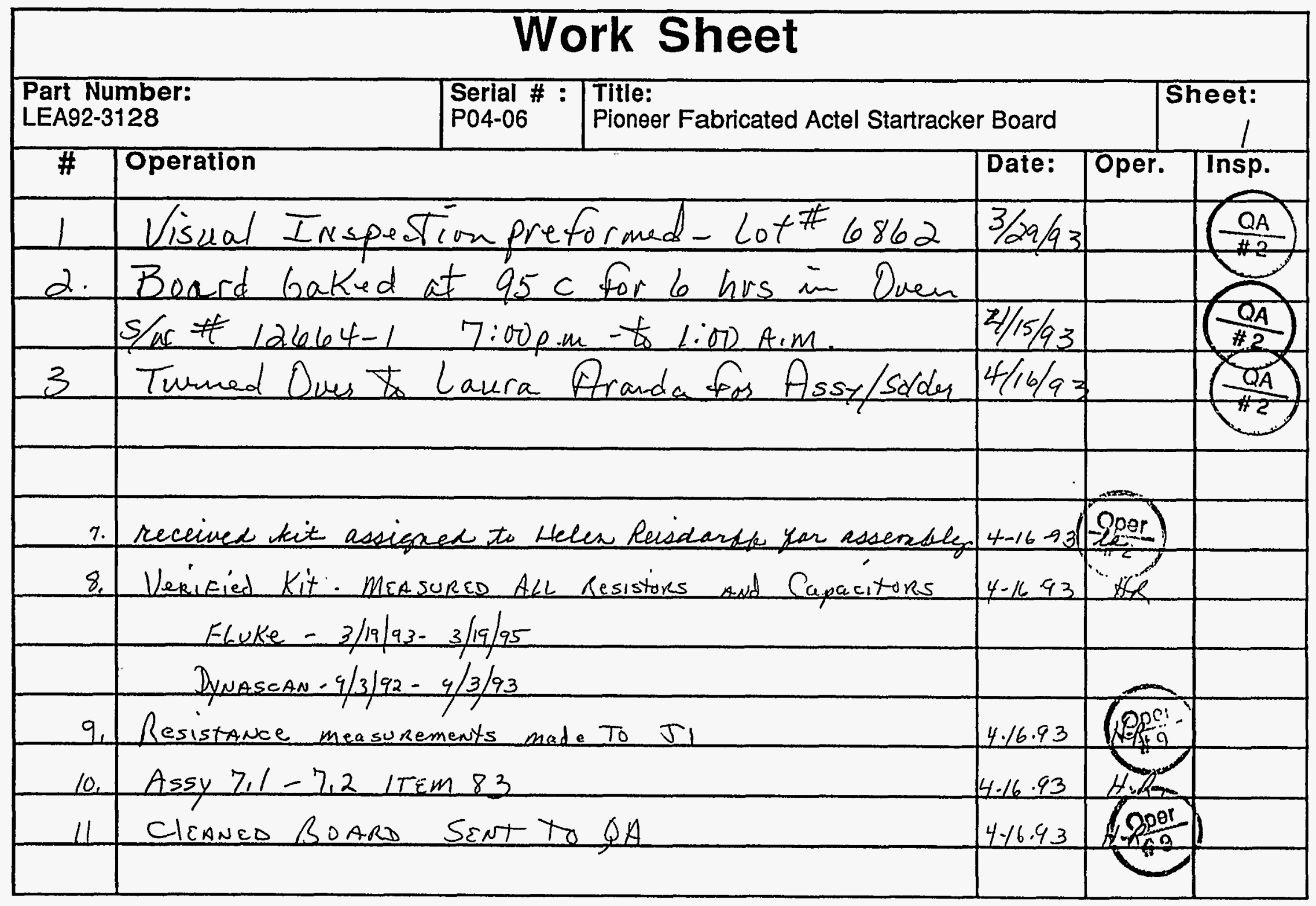




\begin{tabular}{|c|c|c|c|c|}
\hline & Work Sheet & & & \\
\hline 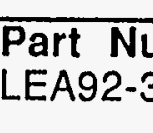 & \begin{tabular}{|l|l|}
$\begin{array}{l}\text { Serial \# \# } \\
\text { P04-06 }\end{array}$ & $\begin{array}{l}\text { Title: } \\
\text { Pioneer Fabricated Actel Startrack }\end{array}$ \\
\end{tabular} & r Board & & $\begin{array}{c}\text { Sheet } \\
2\end{array}$ \\
\hline$\#$ & Operation & Date: & & \\
\hline 13 & Assy /Solder Oper's 7-11-OK & $4 / 18 / 93$ & & \\
\hline 14 & Baked Board at $95 \mathrm{c}$ for $6 \mathrm{hrs}$ in & & & \\
\hline 15 & Qven $S / w \# 12664-1-5: 00$ - $\# 11: 00$ p. & $4 / 18 / 93$ & & \\
\hline 16 & Assy 7.2-Itan 28-7.5 Item 40 & $4.21-9$. & & \\
\hline 12 & Cléned BOARD - Sent to DA $A$ & 4.21 .93 & & \\
\hline 18 & BAKED BOARS at $95 \mathrm{C}$ For $6 \mathrm{hrs}$ in OVen & 4.21 .93 & & \\
\hline & $S / N \# 12664-1-9: 00$ P.M - L:00 A.M. & & $\frac{e r}{5}$ & \\
\hline 19 & Assy $2.5-\operatorname{Tten} 41-712$ Item 18 & 4.22 .93 & 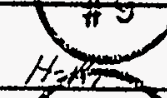 & \\
\hline 20 & Cleaned BoARs Sent to $Q A$ & 4.22 .93 & $\left(\frac{\rho g e r}{2}\right)$ & \\
\hline 22 & Inspected Assy/solder Oper.'s 7.2-7.12 & $4 / 22 / 93$ & & \\
\hline 23 & C24- + side All9-Contamincate $4^{3}$ Dama & & & \\
\hline 24 & C122-Alla Contaminates & & & \\
\hline 25 & A 12,13 of 14 -Residue on Component & $4 / 20 / 93$ & & \\
\hline
\end{tabular}




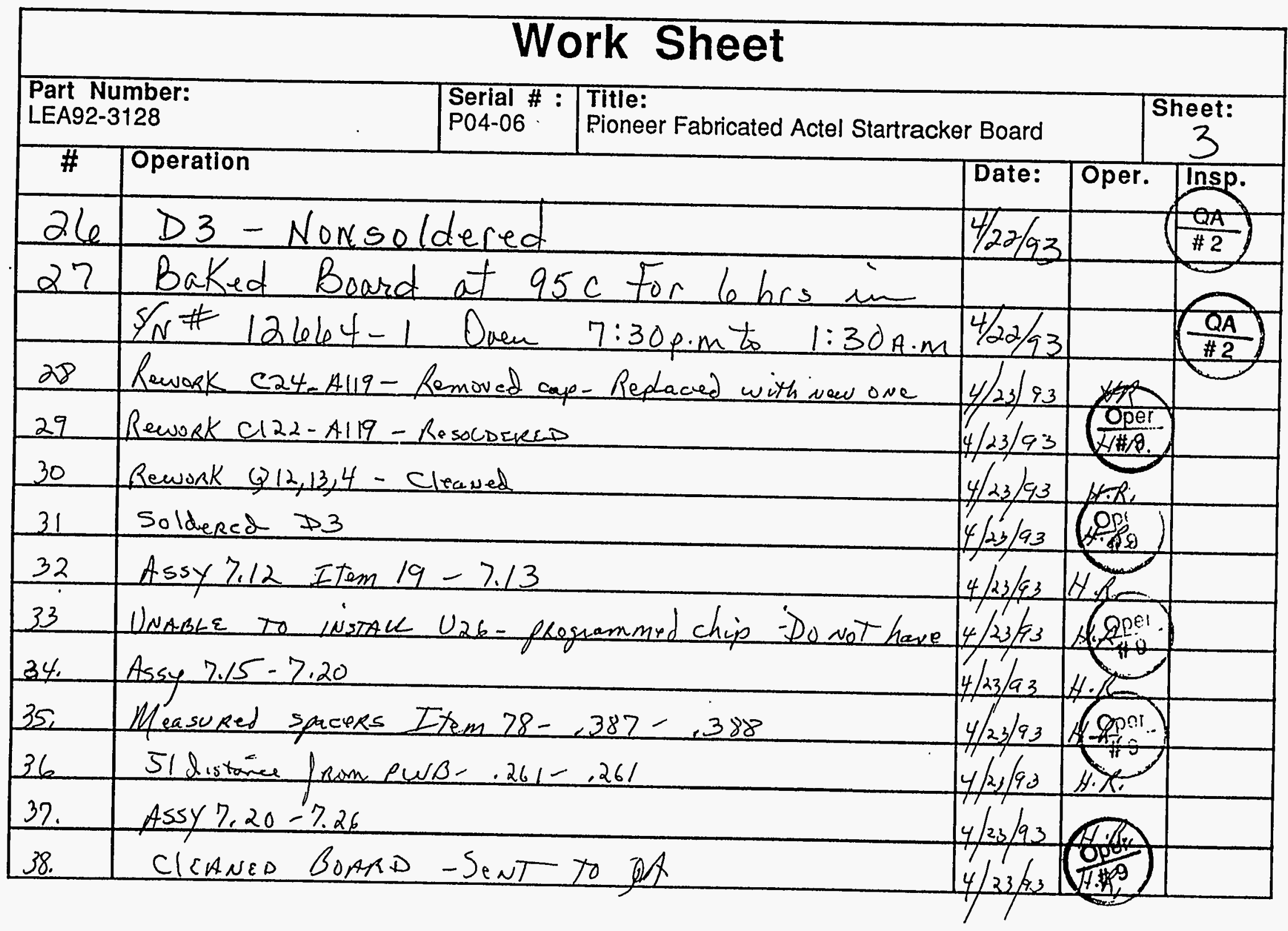




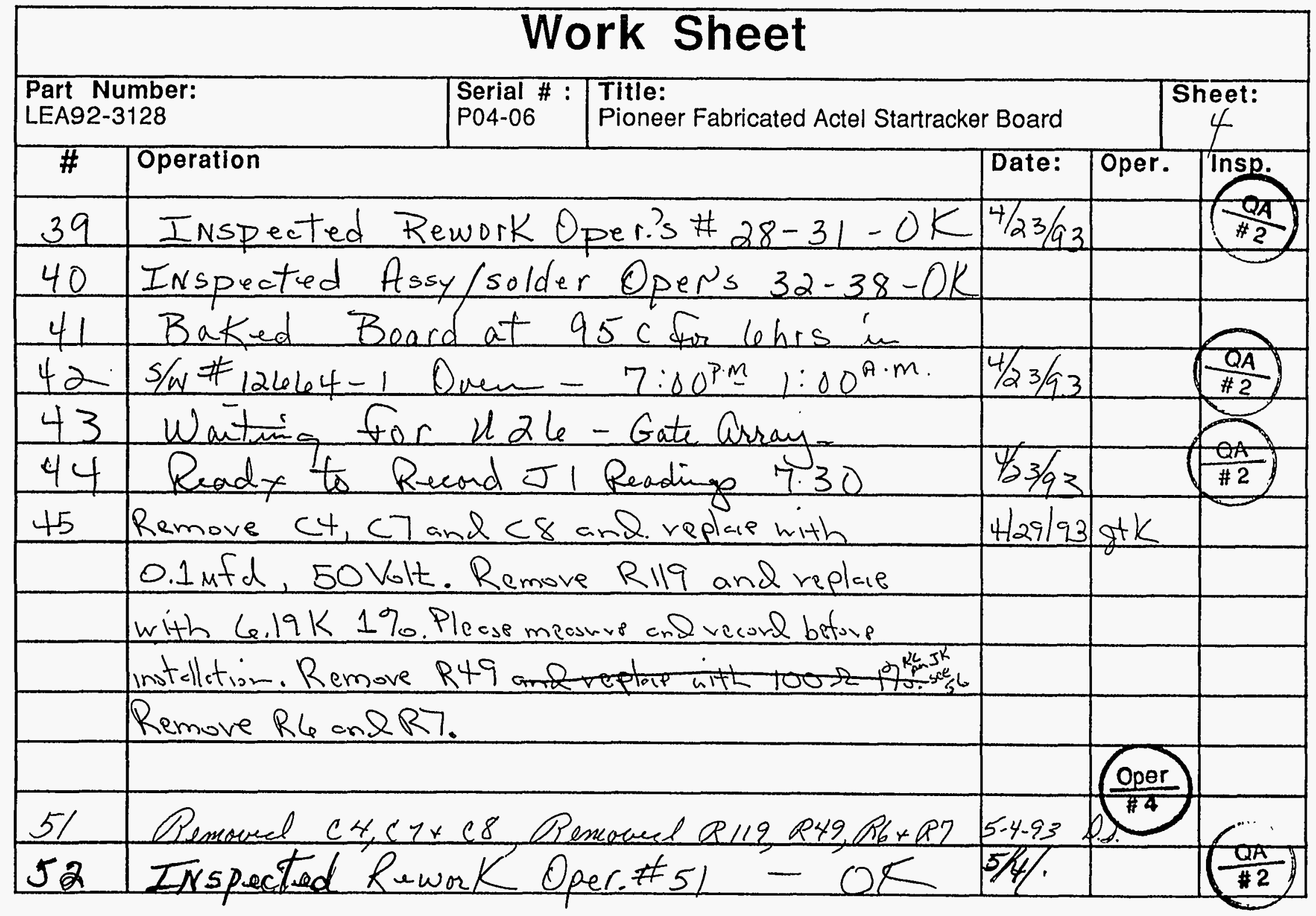




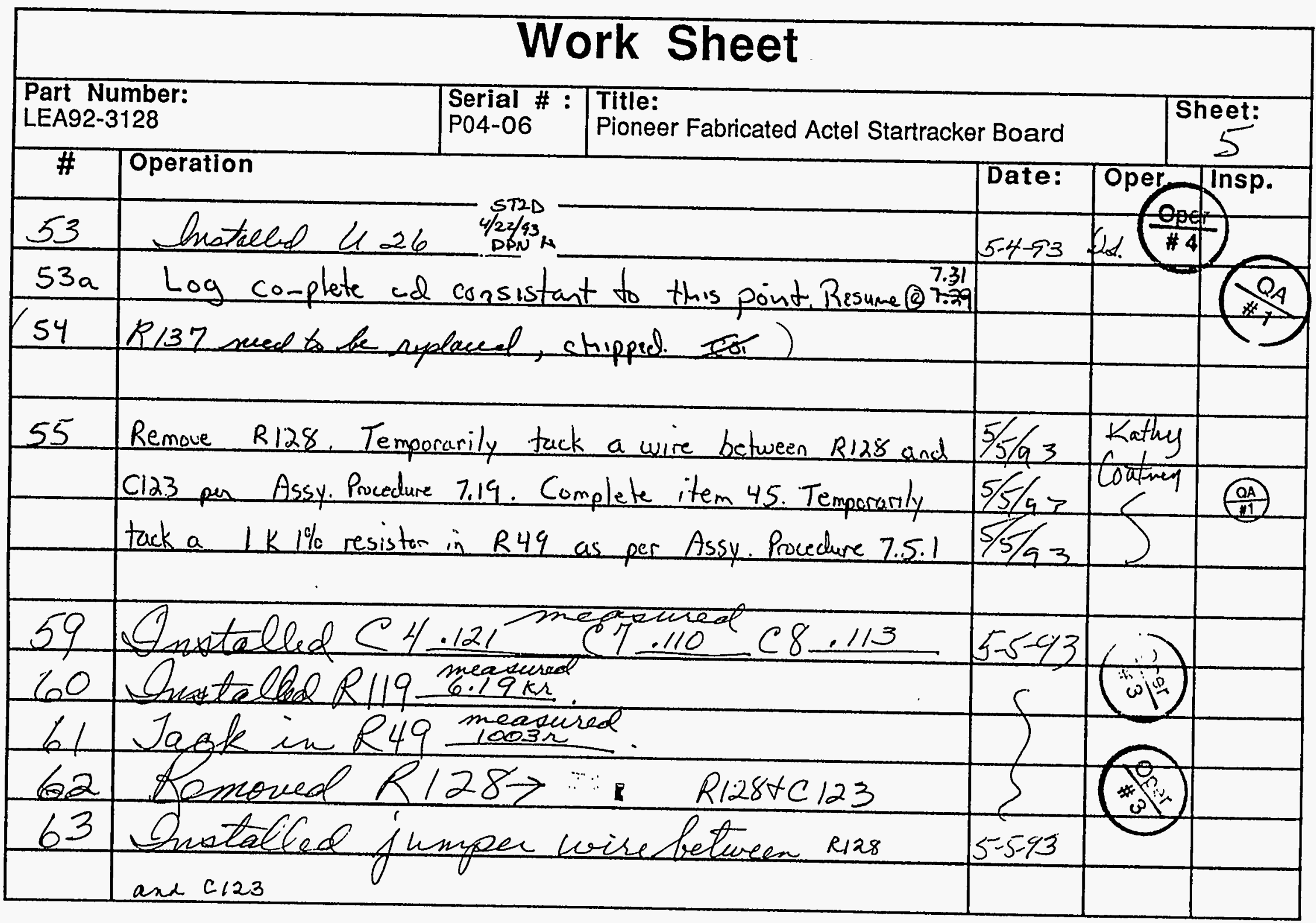




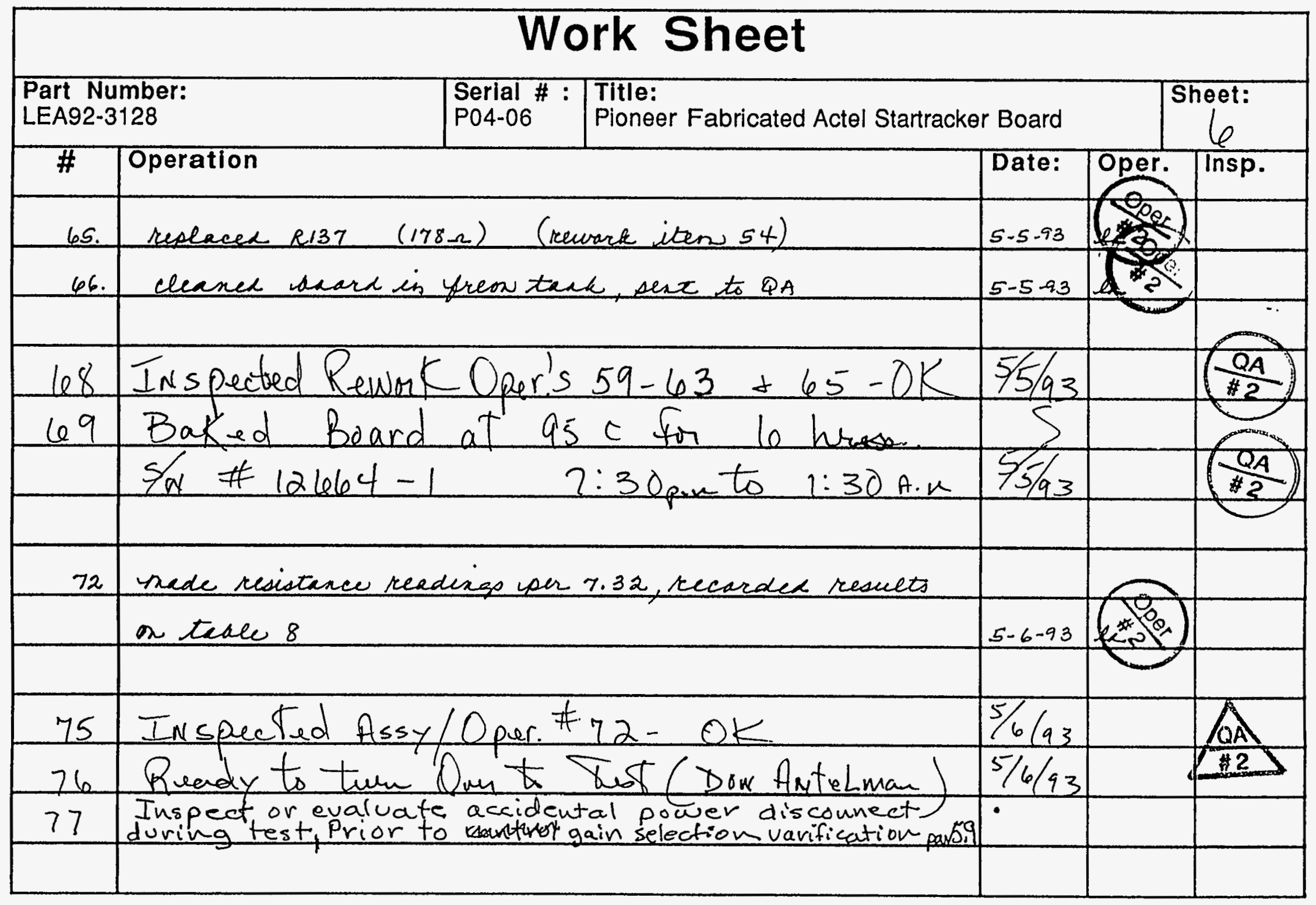




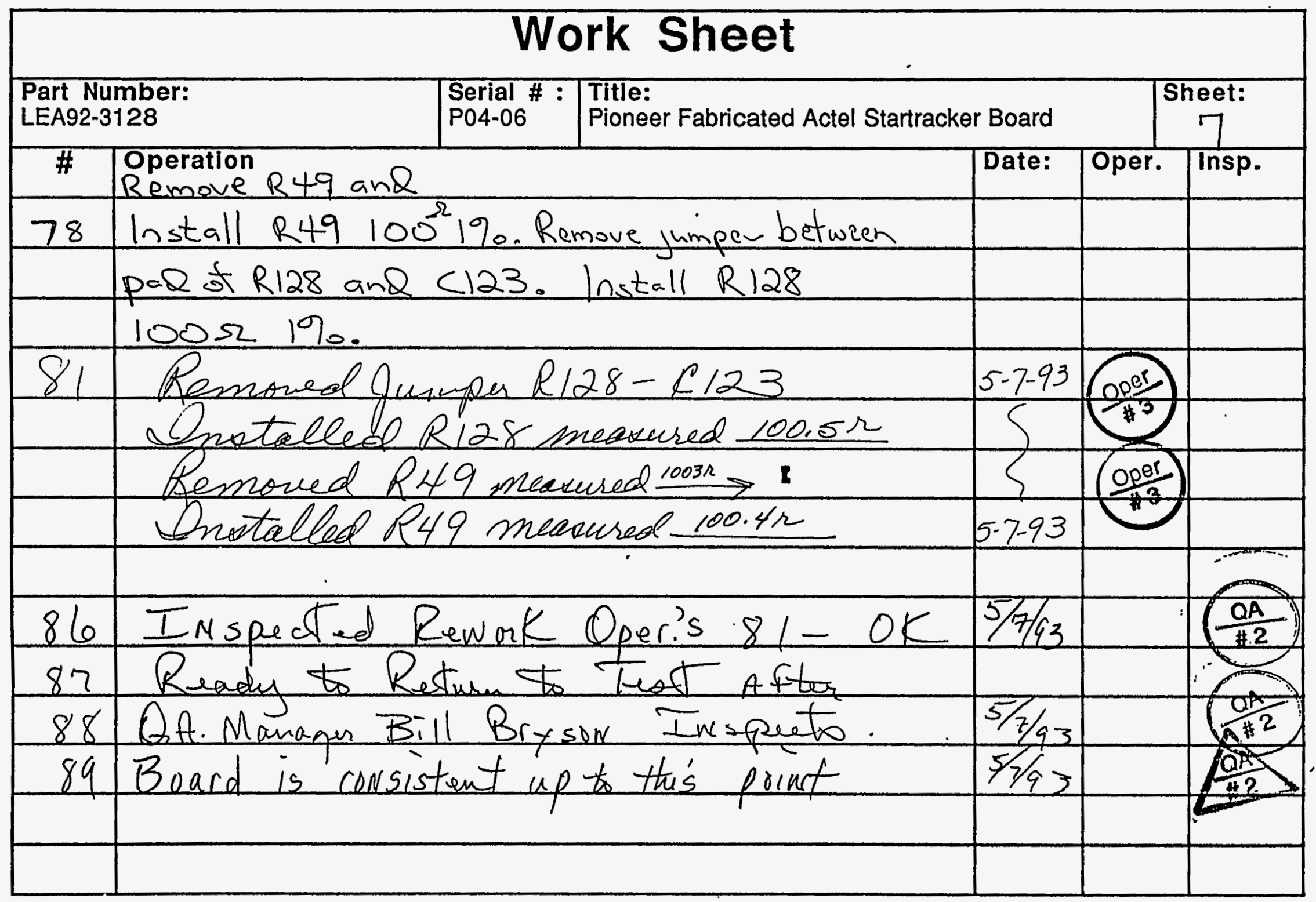




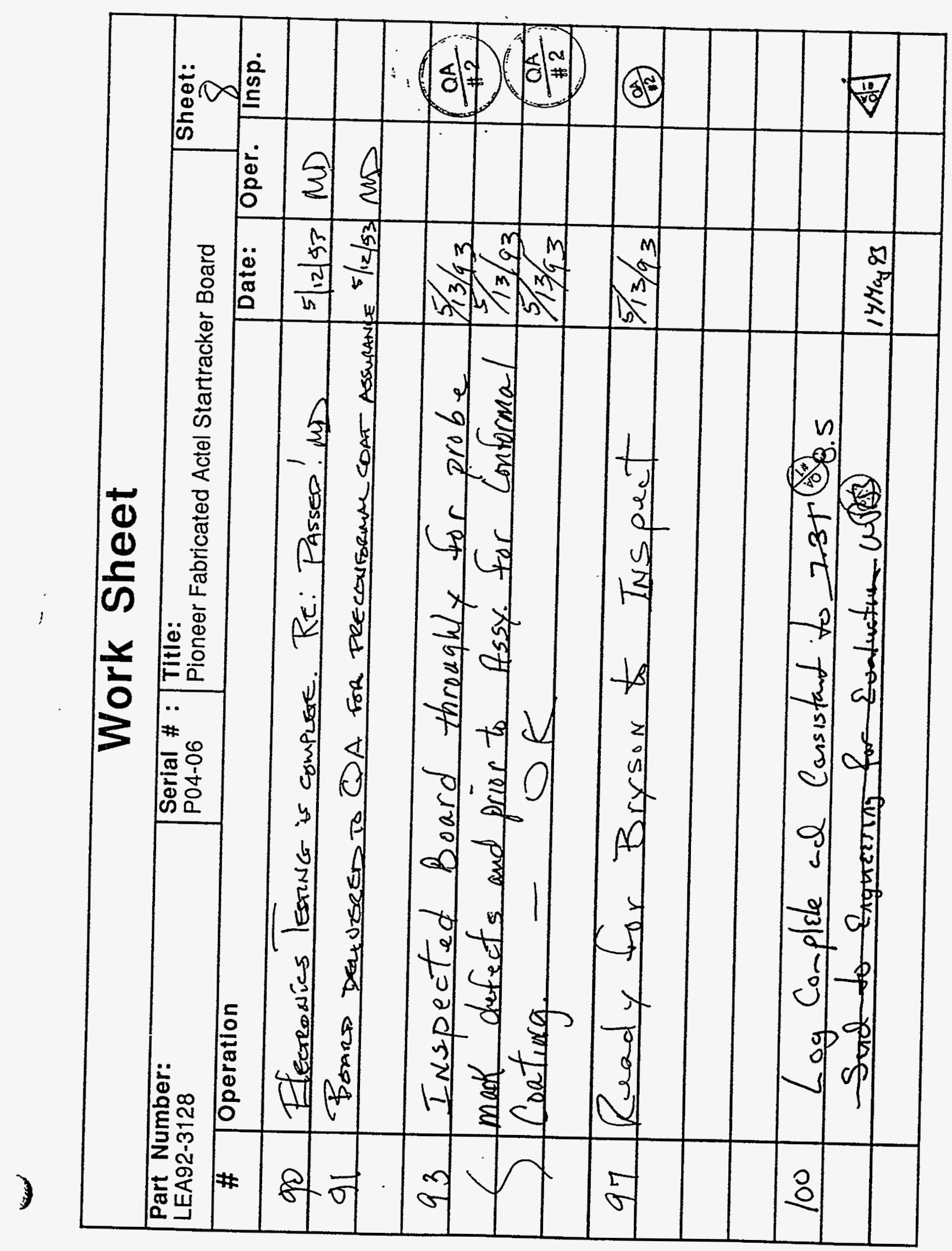




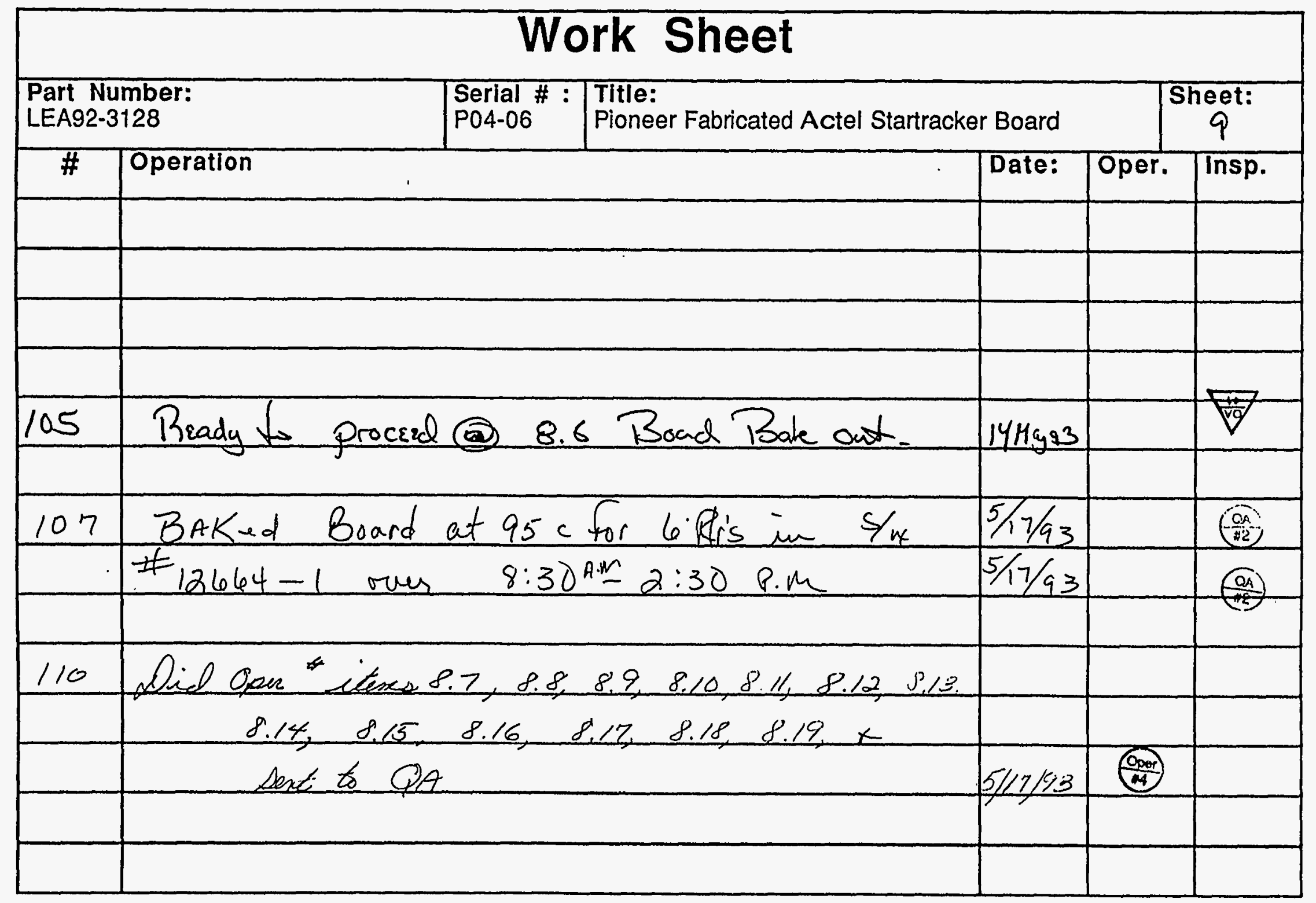




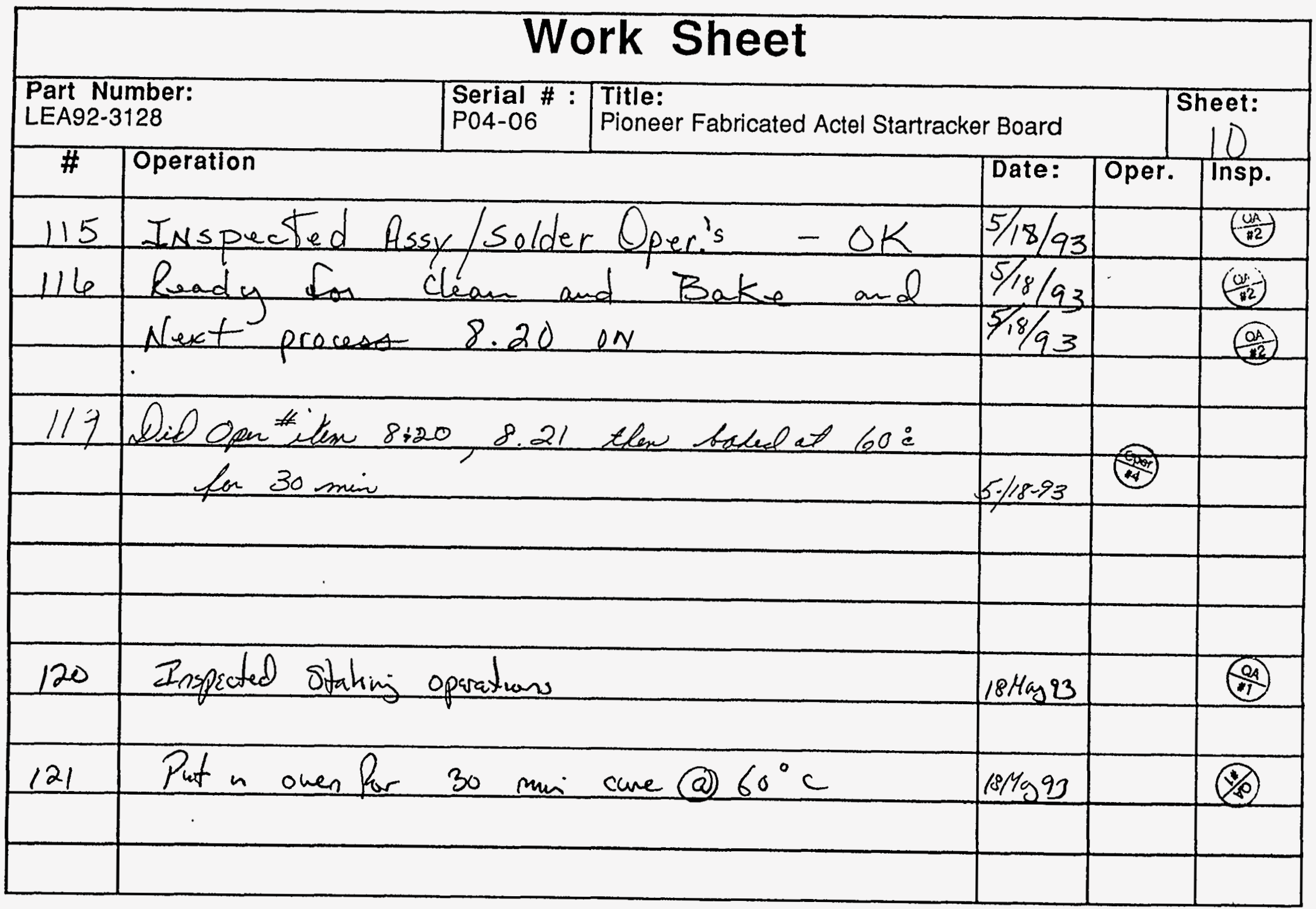




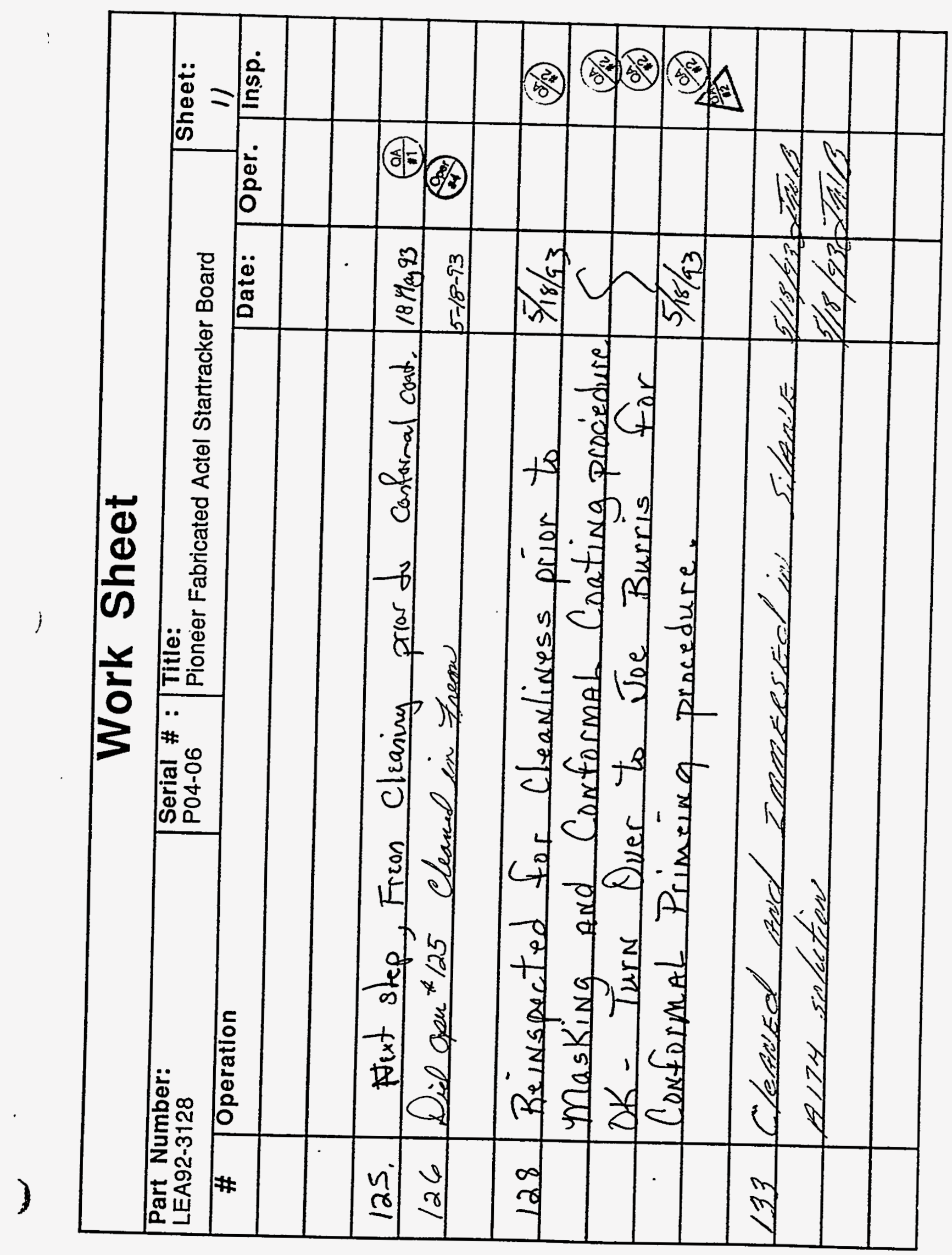




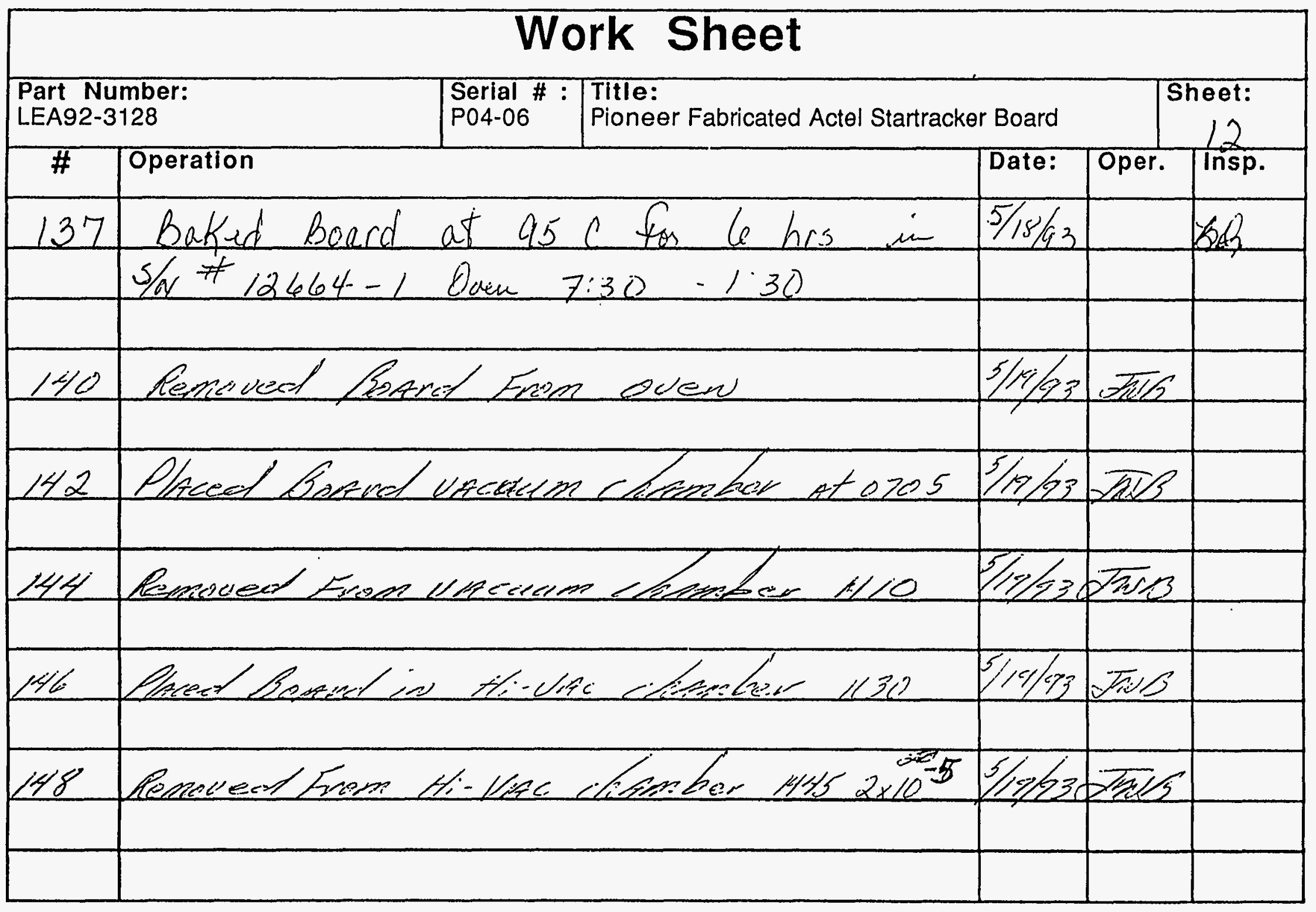




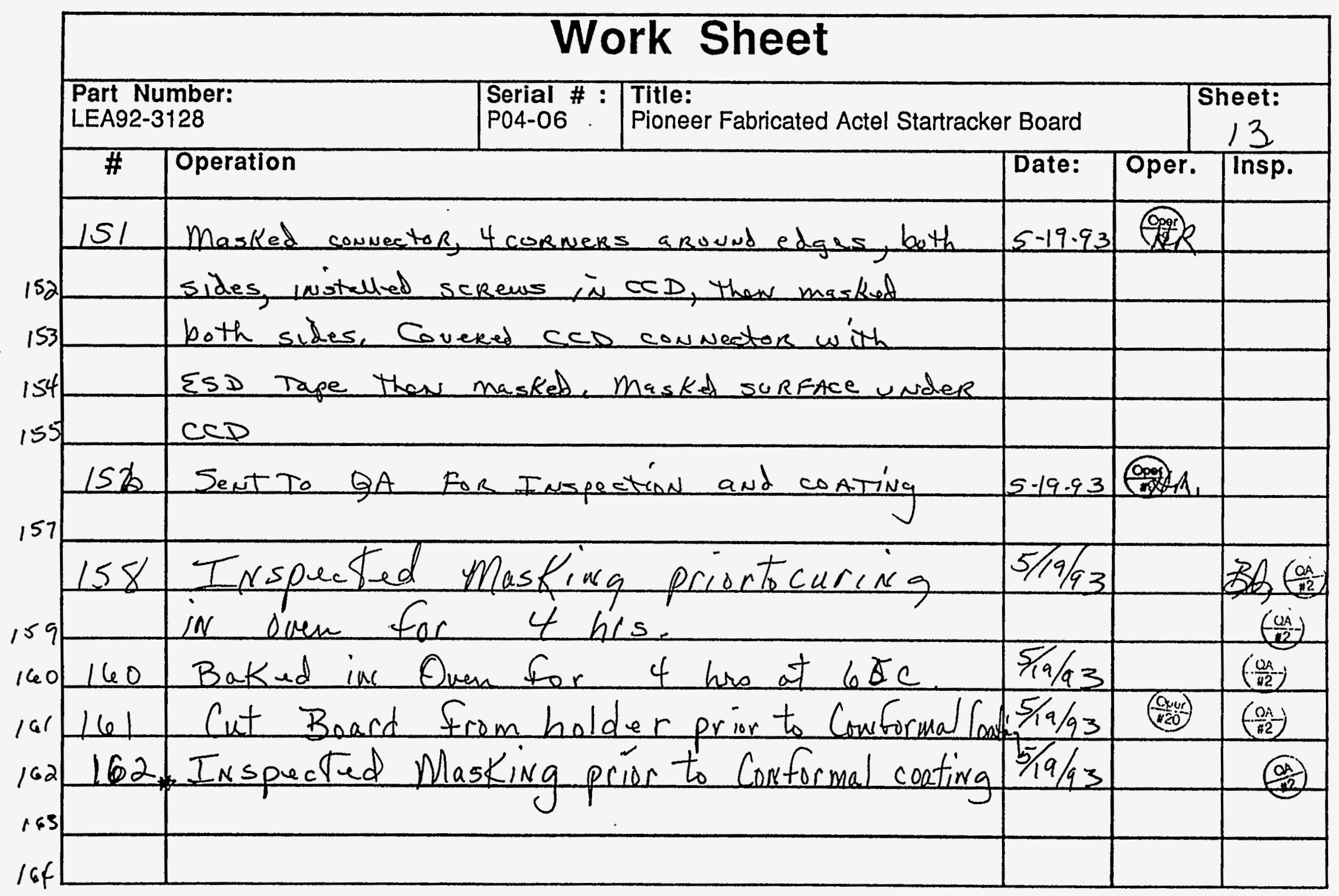




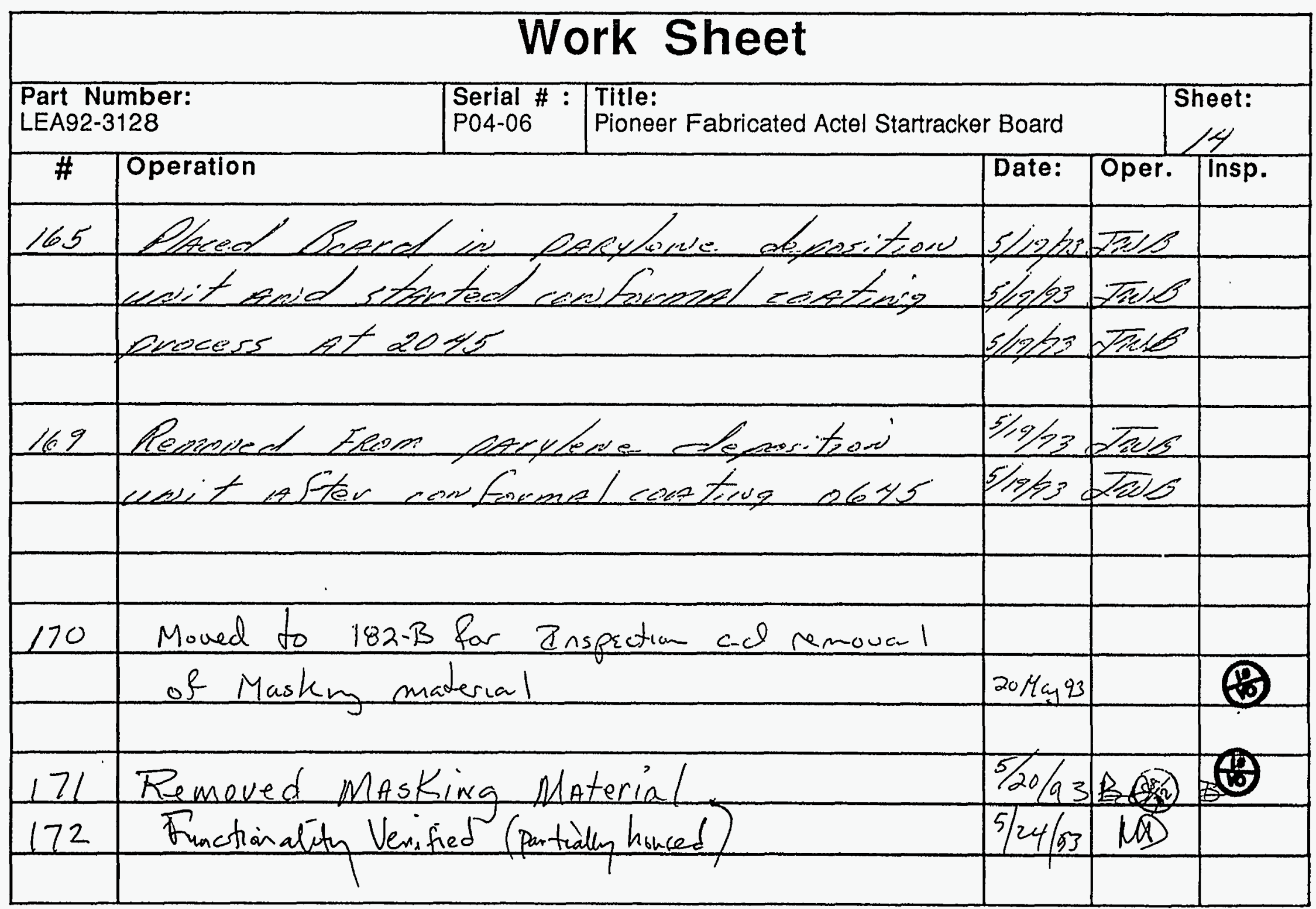




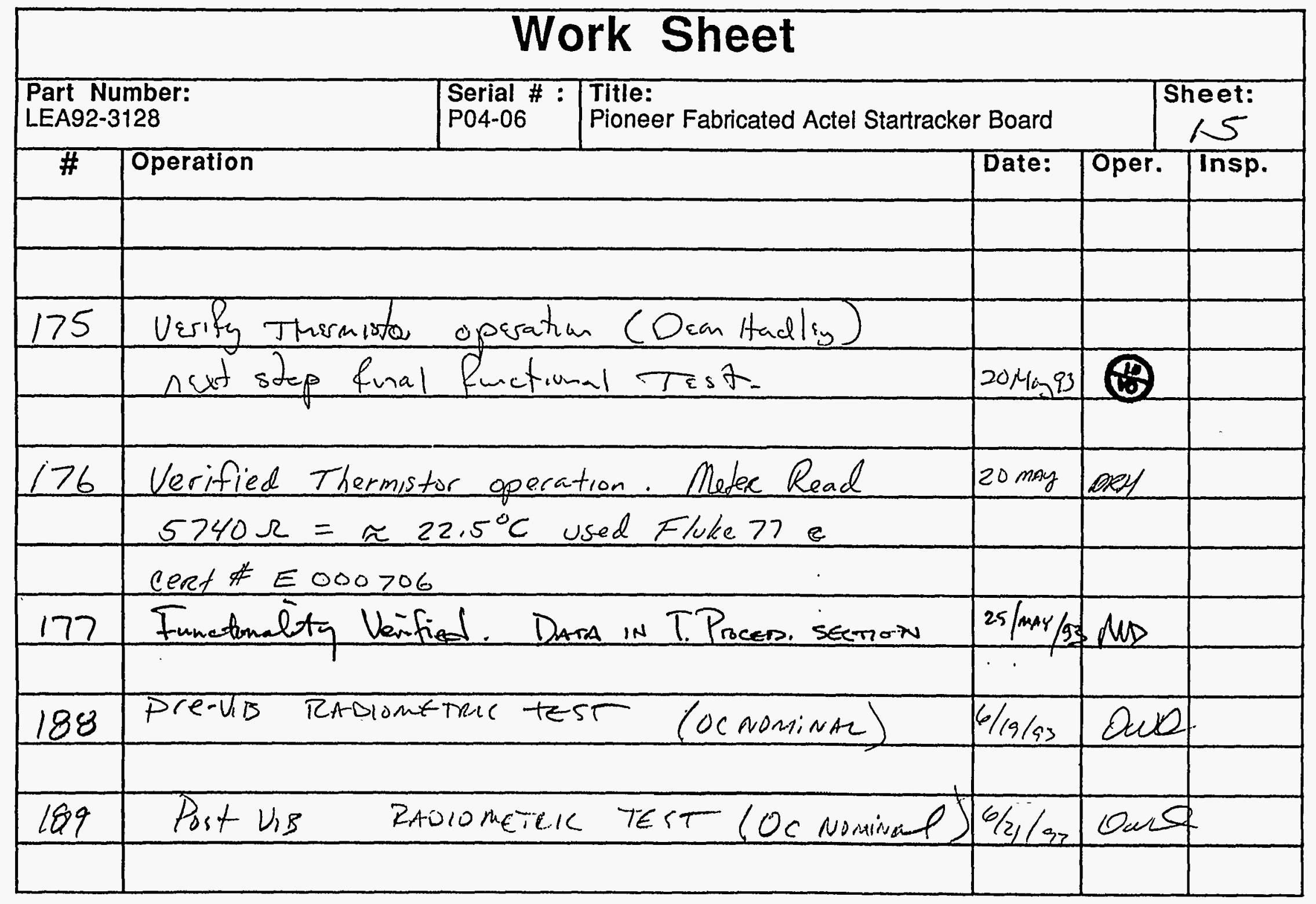




\begin{tabular}{|c|c|c|c|c|c|c|}
\hline \multicolumn{7}{|c|}{ Work Sheet } \\
\hline \multicolumn{2}{|c|}{$\begin{array}{l}\text { Part Number: } \\
\text { LEA92-3128 }\end{array}$} & \multirow[t]{2}{*}{$\begin{array}{l}\text { Serial \#: } \\
\text { P04-06 }\end{array}$} & \multicolumn{2}{|c|}{$\begin{array}{l}\text { Title: } \\
\text { Pioneer Fabricated Actel Startracker Board }\end{array}$} & \multicolumn{2}{|c|}{$\begin{array}{l}\text { Sheet: } \\
16\end{array}$} \\
\hline$\#$ & Operation & & & Date: & Oper. & \\
\hline 190 & $20 c$ Nonisnal & post & vit & $6 / 19 / 93$ & Oen & \\
\hline 191 & $70 \mathrm{C}$ Nominal & & & $6 / 21 / 43$ & Deve & \\
\hline 192 & $-20 C$ Nominal & & & $6 / 22 / 53$ & 2ur & t \\
\hline & & & & & & \\
\hline & & & & & & \\
\hline & & & & & & \\
\hline & & & & & & \\
\hline & & & & & & \\
\hline & & & & & & \\
\hline & & & & & & \\
\hline & & & & & & \\
\hline & & & & & & \\
\hline
\end{tabular}




\section{Appendix G.2.3}

\section{Bill of Materials}




\section{Actel Camera with Gain and Offset Control}

Startracker Configuration

Rev. 00 Printed Wiring Board

Bill of Materials, Rev. 00

LEA92-3128-04

\begin{tabular}{|c|c|c|c|c|}
\hline & Date & Rev. & Date & Approval \\
\hline Prepared by: K. F. Coathey & $30 \mathrm{mar} 43$ & $O A$ & 13Apr. $/ 93$ & Wu $\triangle B K$ \\
\hline Reviewed by: W. R. Bryson & $30140 \mathrm{ar} 93$ & $O \beta$ & 16 Aprol 93 & $\omega_{L} \subseteq D$ \\
\hline Reviewed by: Q. F. Kordas & $|30-\operatorname{Man}-73|$ & $O C$ & $-2 A_{p v} 93$ & O Koudas \\
\hline Reviewed by: M.L. Dickerson & $3131 / 93$ & $O D$ & $5 \mathrm{mac}_{\mathrm{a}}, 93$ & R. Coatrey \\
\hline Reviewed by: E.H. Schmit & $4 / 2 / 93$ & & & \\
\hline Reviewed by: Kll stannen & $4 / 2 / 9 \pm$ & & & \\
\hline $\begin{array}{l}\text { University of California } \\
\text { Lawrence Livermore } \\
\text { National Laboratory }\end{array}$ & \multicolumn{2}{|c|}{$\begin{array}{l}22 \text { March } 1993 \\
\text { Actel Startracker } \\
\text { Bill of Materials }\end{array}$} & \multicolumn{2}{|c|}{$\begin{array}{l}\text { LEA92-3128-04 } \\
\text { Revision } 00\end{array}$} \\
\hline
\end{tabular}




\section{Actel Camera with Gain and Offset Control Startracker Configuration Rev. 00 Printed Wiring Board Bill of Materials, Rev. 00 LEA92-3128-04}

\begin{tabular}{|c|c|c|c|c|}
\hline & Date & Rev. & Date & Approval \\
\hline Prepared by: Ki K. Coathey & $30 \operatorname{mar} 43$ & CA & $13 . \hat{p}_{0}, 193$ & 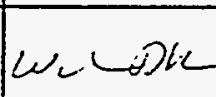 \\
\hline Reviewed by: W. R. Byson & $30 \operatorname{Mar} 93$ & $O B$ & 16 Apr. $/ 93$ & $\omega_{L} \subseteq \infty$ \\
\hline Reviewed by: Q.F.Kordas & $\mid 30-$ MOR- $73 \mid$ & $O C$ & $22 A_{\rho v} 93$ & Chodos \\
\hline Reviewed by: M.L. Dickerson & 3131.93 & & & \\
\hline Reviewed by: E.H. S. Schmitut & $4 / 2 / 93$ & & & \\
\hline Reviewed by: Hf S S annen & $4 / 2 / 93$ & & & \\
\hline & & & & \\
\hline $\begin{array}{c}\text { University of California } \\
\text { Lawrence Livermore } \\
\text { National Laboratory }\end{array}$ & \multicolumn{2}{|c|}{$\begin{array}{l}22 \text { March } 1993 \\
\text { Actel Startracker } \\
\text { Bill of Materials }\end{array}$} & \multicolumn{2}{|c|}{$\begin{array}{l}\text { LEA92-3128-04 } \\
\text { Revision } 00\end{array}$} \\
\hline
\end{tabular}




\subsection{Scope}

This document is the bill of materials for the Actel Camera with Gain and Offset Control for use in the Startracker, Rev 00 Printed Wiring Board, LEA92-3128-04, Rev 00.

\subsection{Parts}

Where a dual part number listing exists, the first number listed is a commercial part suitable for prototype work only. If the MIL-SPEC part is not available at the time flight boards are assembled, Quality assurance must OK the use of the commercial part on a part by part basis in writing.

Parts may not be substituted without the written permission of the Quality Assurance Group.

\begin{tabular}{|c|c|c|c|c|c|}
\hline Item & Qty. & Designator & Description & Case & $\begin{array}{l}\text { Mfg. / } \\
\text { Part Number }\end{array}$ \\
\hline 1 & 44 & $\begin{array}{c}\text { C1,C3,C5,C6, } \\
\text { C15,C21, } \\
\text { C23,C25,C26, } \\
\text { C30,C31,C33, } \\
\text { C34,C } 38, C 39, \\
\text { C40,C42,C44, } \\
\text { C45,C47,C } 48, \\
\text { C54,C56,C57, } \\
\text { C58,C59,C60, } \\
\text { C63,C64,C66, } \\
\text { C67,C70,C } 11, \\
\text { C92,C98,C } 102, \\
\text { C103,C } 104, C 106, \\
\text { C109,C } 112, C 114, \\
\text { C121,C } 124\end{array}$ & $\begin{array}{c}0.039 \mu \mathrm{F} \\
50 \mathrm{~V}, 10 \% \\
\mathrm{FR}=0.01 \% / \\
1000 \mathrm{hr}\end{array}$ & RM1206 & CDR32BX393AKUR \\
\hline 2 & 5 & $\begin{array}{c}\mathrm{C} 2, \mathrm{C} 51, \mathrm{C} 61, \mathrm{C} 62 \\
\mathrm{C} 122\end{array}$ & $\begin{array}{c}4.7 \mu \mathrm{fd}, \text { Tant, } \\
\text { 10V, } 10 \% \text {, } \\
\text { WFR }=0.01 \% / \\
1000 \mathrm{hr}\end{array}$ & H-CASE & CWR06FH475KC \\
\hline 3 & 1 & C9 & $\begin{array}{l}47 \mu f d, \text { Tant, } \\
20 \mathrm{~V}, 10 \%\end{array}$ & R-CASE & $\begin{array}{c}\text { Sprague / } \\
\text { 195D476X9020R2T }\end{array}$ \\
\hline
\end{tabular}




\begin{tabular}{c|c|c|c|c|c} 
Item & Qty. & Designator & Description & Case & Mfg. I \\
Part Number
\end{tabular}




\begin{tabular}{|c|c|c|c|c|c|}
\hline Item & Qty. & Designator & Description & Case & $\begin{array}{l}\text { Mfg. / } \\
\text { Part Number }\end{array}$ \\
\hline 13 & 5 & $\begin{array}{c}\mathrm{C73}, \mathrm{C} 74, \mathrm{C} 75, \\
\mathrm{C} 76, \mathrm{C} 77\end{array}$ & $\begin{array}{c}3300 \mathrm{pf} \\
50 \mathrm{~V}, 10 \% \\
\mathrm{FR}=0.001 \% \mathrm{~m} \\
1000 \mathrm{hr}\end{array}$ & $\begin{array}{l}\mathrm{RC} 0402 \\
\mathrm{RC} 0505\end{array}$ & $\begin{array}{c}\text { Novacap / } \\
\text { 0402B332K500N } \\
\text { CDR11BP332AKUS }\end{array}$ \\
\hline 14 & 1 & $\mathrm{C} 83$ & $\begin{array}{c}0.01 \mu \mathrm{fd}, \\
100 \mathrm{~V}, 10 \%, \\
\mathrm{FR}=0.01 \% d \\
1000 \mathrm{hr}\end{array}$ & RM1206 & CDR32BX103BKUR \\
\hline 15 & $T$ & C111 & $\begin{array}{c}47 \mathrm{pf}, \\
100 \mathrm{~V}, 5 \% \\
\mathrm{FR}=0.01 \% \mathrm{~d} \\
1000 \mathrm{hr}\end{array}$ & RM1206 & CDR32PB470BJUR \\
\hline 16 & 2 & $\mathrm{C} 115, \mathrm{C} 116$ & $\begin{array}{c}270 \mathrm{pf}, \\
100 \mathrm{~V}, 10 \%, \\
\mathrm{FR}=0.01 \% / \\
1000 \mathrm{hr}\end{array}$ & RM1206 & CDR32BP271BKUR \\
\hline 17 & 1 & D1 & $\begin{array}{c}\text { Diode, } \\
\text { Switching, } \\
50 \mathrm{~V}, 200 \mathrm{~mA} \\
\text { MBAV74 }\end{array}$ & SOT-23 & $\begin{array}{l}\text { Motorolal } \\
\text { MBAV74L } \\
\text { siv } \\
0,201\end{array}$ \\
\hline 18 & 1 & D2 & $\begin{array}{l}\text { Diode, } \\
\text { Voltage } \\
\text { Reference } \\
\text { LM285-1.2 }\end{array}$ & SOIC-8 & $\begin{array}{l}\text { Linear I } \\
\text { LM285MX-1.2 } \\
S_{N} \cdot 1501 \\
{ }_{0}{ }^{1}\end{array}$ \\
\hline 19 & 1 & D3 & $\begin{array}{l}\text { Reference, } \\
\text { Voltage, } \\
\text { Precision, } \\
\text { 10V, } \\
\text { REF-01 }\end{array}$ & SOIC-8 & $\begin{array}{l}\text { PMII } \\
\text { REF01CS } \\
\mathrm{S}^{\mathrm{in}} \mathrm{O}^{420}\end{array}$ \\
\hline 20 & 2 & $\mathrm{D} 4, \mathrm{D} 5$ & $\begin{array}{c}\text { Diode, } \\
\text { Schottky, } 30 \mathrm{~V} \\
\text { BAT54S }\end{array}$ & SOT-23 & $\begin{array}{ll} & \text { Phillips I } \\
\text { Swi's } & \text { BAT54S } \\
03514 & 0,5>18\end{array}$ \\
\hline 21 & 9 & $\begin{array}{l}\text { JP4,JP6,JP7,JP9, } \\
\text { JP11,JP13,JP14, } \\
\text { JP15,JP16 }\end{array}$ & $\begin{array}{l}\text { Jumper, } \\
0 \Omega, 1 \% \text {, } \\
1 / 4 \text { Watt }\end{array}$ & RM1206 & D55342K07B00DOS \\
\hline 22 & 3 & $\mathrm{~L} 1, \mathrm{~L} 3, \mathrm{~L} 4$ & $\begin{array}{l}\text { Inductor, } \\
100 \mu \mathrm{H}\end{array}$ & LQH4 & $\begin{array}{l}\text { MuRata Erie / } \\
\text { LQH4N101K-TA }\end{array}$ \\
\hline
\end{tabular}




\begin{tabular}{|c|c|c|c|c|c|}
\hline Item & Qty. & Designator & Description & Case & $\begin{array}{c}\text { Mfg. / } \\
\text { Part Number }\end{array}$ \\
\hline 23 & 1 & L5 & $\begin{array}{l}\text { Inductor, } \\
10 \mu \mathrm{H}\end{array}$ & LQH4 & $\begin{array}{l}\text { MuRata Erie / } \\
\text { LQH4N100K-TA }\end{array}$ \\
\hline 24 & 1 & $\mathrm{J1}$ & $\begin{array}{l}\text { Connector, } \\
51 \text { Contact, } \\
\text { Socket }\end{array}$ & MDM51 & M83513/04-G06N \\
\hline 25 & 5 & $\begin{array}{c}\text { Q1,Q4,Q9, } \\
\text { Q10,Q11 } \\
\text { sus' } \\
04701,04702,04703\end{array}$ & $\begin{array}{c}\text { Transistor, } \\
\text { FET, } \\
\text { SST215 } \\
04704 \text { 04705 }\end{array}$ & SOT-143 & $\begin{array}{c}\text { Calogic / } \\
\text { No Substitute } \\
\text { Calogic No. SST215E }\end{array}$ \\
\hline 26 & 3 & $\begin{array}{l}\text { Q2,Q3,Q8 } \\
\text { SNS } \\
00020,00019,00018\end{array}$ & $\begin{array}{l}\text { Transistor, } \\
\text { 2N3904 }\end{array}$ & SOT-23 & $\begin{array}{c}\text { Motorola / } \\
\text { MMBT3904 } \\
\text { No Substitute }\end{array}$ \\
\hline 27 & 3 & $\begin{array}{l}\text { Q12,Q13,Q14 } \\
\text { SNis } \\
50920,00918,00919\end{array}$ & $\begin{array}{l}\text { Transistor, } \\
2 \text { N7002 }\end{array}$ & SOT-23 & $\begin{array}{l}\text { Motorola / } \\
2 \text { 2N7002 } \\
\text { No Substitute }\end{array}$ \\
\hline 28 & 2 & $R 3, R 66$ & $\begin{array}{c}7.5 \mathrm{~K} \Omega, 1 \% \text {, } \\
1 / 4 \mathrm{Watt}, \\
100 \mathrm{ppm}, \\
\mathrm{FR}=0.01 \% \\
1000 \mathrm{hr}\end{array}$ & $\overline{R M 1206}$ & D55342K07B7E50R \\
\hline 29 & & $\begin{array}{l}\text { This space left } \\
\text { intentionally blank }\end{array}$ & & & \\
\hline 30 & 2 & $R 14, R 31$ & $\begin{array}{c}243 \Omega, 1 \% \\
1 / 4 \text { Watt, } \\
100 p p m \\
\text { FR=0.01\%/ } \\
1000 \mathrm{hr}\end{array}$ & RM1206 & D55342K07B243DR \\
\hline 31 & 2 & R15,R32 & $\begin{array}{c}1.82 \mathrm{~K} \Omega, 1 \% \text {, } \\
1 / 4 \mathrm{Watt}, \\
100 \mathrm{ppm}, \\
\mathrm{FR}=0.01 \% / \\
1000 \mathrm{hr}\end{array}$ & RM1206 & D55342K07B1E82R \\
\hline
\end{tabular}




\begin{tabular}{|c|c|c|c|c|c|}
\hline Item & Qty. & Designator & Description & Case & $\begin{array}{c}\text { Mfg. / } \\
\text { Part Number }\end{array}$ \\
\hline 32 & 5 & $\begin{array}{c}R 16, R 116, R 130 \\
\text { R133,R136 }\end{array}$ & $\begin{array}{c}49.9 \Omega, 1 \% \text {, } \\
1 / 4 \text { Watt, } \\
100 \mathrm{ppm}, \\
\text { FR=0.01\% } \\
1000 \mathrm{hr}\end{array}$ & RM1206 & D55342K07B49D9R \\
\hline 33 & 5 & $\begin{array}{l}\text { R17,R21,R49, } \\
\text { R74,R94,R95 } \\
\text { TEMPORARILY } \\
\text { LOAD R49 }\end{array}$ & $\begin{array}{c}1.0 \mathrm{~K} \Omega, 1 \% \text {, } \\
1 / 4 \mathrm{Watt} \\
100 \mathrm{ppm} \\
\text { FR=0.01\%/ } \\
1000 \mathrm{hr}\end{array}$ & RM1206 & D55342K07B1E00R \\
\hline 34 & $T$ & R18 & $\begin{array}{c}2.49 \mathrm{~K} \Omega, 1 \% \\
1 / 4 \mathrm{Watt} \\
100 \mathrm{ppm} \\
\mathrm{FR}=0.01 \% \\
1000 \mathrm{hr}\end{array}$ & RM1206 & D55342K07B2E49R \\
\hline 35 & 1 & $\mathrm{R20}$ & $\begin{array}{c}2.7 \mathrm{~K} \Omega, 2 \% \\
1 / 4 \mathrm{Watt} \\
100 \mathrm{ppm} \\
\mathrm{FR}=0.01 \% / \\
1000 \mathrm{hr}\end{array}$ & $\mathrm{RM} 1206$ & D55342K07B2H70R \\
\hline 36 & 1 & R24 & $\begin{array}{c}1.62 \mathrm{~K} \Omega, 1 \% \\
1 / 4 \mathrm{Watt} \\
100 \mathrm{ppm} \\
\mathrm{FR}=0.01 \% \\
1000 \mathrm{hr}\end{array}$ & RM1206 & D55342K07B1E62R \\
\hline 37 & 7 & $\mathrm{R} 25$ & $\begin{array}{c}9.09 \mathrm{~K} \Omega, 1 \% \\
1 / 4 \mathrm{Watt} \\
100 \mathrm{ppm} \\
\text { FR=0.01\%/ } \\
1000 \mathrm{hr}\end{array}$ & RM1206 & D55342K07B9E09R \\
\hline 38 & 7 & R26 & $\begin{array}{c}24.3 \mathrm{~K} \Omega, 1 \% \text {, } \\
1 / 4 \mathrm{Watt} \\
100 \mathrm{ppm}, \\
\mathrm{FR}=0.01 \% / \\
1000 \mathrm{hr}\end{array}$ & RM1206 & D55342K07B24E3R \\
\hline
\end{tabular}

) 


\begin{tabular}{|c|c|c|c|c|c|}
\hline Item & Qty. & Designator & Description & Case & $\begin{array}{c}\text { Mfg. I } \\
\text { Part Number }\end{array}$ \\
\hline 32 & 5 & $\begin{array}{c}\text { R16,R116,R130 } \\
\text { R133,R136 }\end{array}$ & $\begin{array}{c}49.9 \Omega, 1 \%, \\
1 / 4 \text { Watt, } \\
100 \mathrm{ppm}, \\
\text { FR=0.01\%/ } \\
1000 \mathrm{hr}\end{array}$ & RM1206 & D55342K07B49D9R \\
\hline 33 & 5 & $\begin{array}{c}\text { R17,R21, } \\
\text { R74,R94,R95 }\end{array}$ & $\begin{array}{c}1.0 \mathrm{~K} \Omega, 1 \% \text {, } \\
1 / 4 \mathrm{Watt} \\
100 \mathrm{ppm} \\
\mathrm{FR}=0.01 \% \\
1000 \mathrm{hr}\end{array}$ & RM1206 & D55342K07B1E00R \\
\hline 34 & 1 & R18 & $\begin{array}{c}2.49 \mathrm{~K} \Omega, 1 \% \text {, } \\
1 / 4 \mathrm{Watt}, \\
100 \mathrm{ppm}, \\
\text { FR=0.01\%/ } \\
1000 \mathrm{hr}\end{array}$ & RM1206 & D55342K07B2E49R \\
\hline 35 & 1 & $\mathrm{R} 20$ & $\begin{array}{c}2.7 \mathrm{~K} \Omega, 2 \%, \\
1 / 4 \mathrm{Watt}, \\
100 \mathrm{ppm}, \\
\mathrm{FR}=0.01 \% \\
1000 \mathrm{hr}\end{array}$ & RM1206 & D55342K07B2H70R \\
\hline 36 & 1 & R24 & $\begin{array}{c}1.62 \mathrm{~K} \Omega, 1 \% \\
1 / 4 \mathrm{Watt}, \\
100 \mathrm{ppm} \\
\text { FR=0.01\% } \\
1000 \mathrm{hr}\end{array}$ & RM1206 & D55342K07B1E62R \\
\hline 37 & 1 & R25 & $\begin{array}{c}9.09 \mathrm{~K} \Omega, 1 \% \\
1 / 4 \mathrm{Watt}, \\
100 \mathrm{ppm} \\
\text { FR=0.01\%/ } \\
1000 \mathrm{hr}\end{array}$ & RM1206 & D55342K07B9E09R \\
\hline 38 & 1 & $\overline{\mathrm{R} 26}$ & $\begin{array}{c}24.3 \mathrm{~K} \Omega, 1 \% \text {, } \\
1 / 4 \mathrm{Watt} \\
100 \mathrm{ppm}, \\
\mathrm{FR}=0.01 \% / \\
1000 \mathrm{hr}\end{array}$ & $\mathrm{RM} 1206$ & D55342K07B24E3R \\
\hline
\end{tabular}




\begin{tabular}{|c|c|c|c|c|c|}
\hline Item & Qty. & Designator & Description & Case & $\begin{array}{c}\text { Mfg. / } \\
\text { Part Number }\end{array}$ \\
\hline 39 & 1 & R27 & $\begin{array}{c}7.68 \mathrm{~K} \Omega, 1 \% \\
1 / 4 \mathrm{Watt} \\
100 \mathrm{ppm}, \\
\mathrm{FR}=0.01 \% \\
1000 \mathrm{hr}\end{array}$ & $\mathrm{RM} 1206$ & D55342K07B7E68R \\
\hline 40 & 2 & R28,R91 & $\begin{array}{c}0 \Omega, 1 \%, \\
1 / 4 \mathrm{Watt}, \\
100 \mathrm{ppm}, \\
\mathrm{FR}=0.01 \% \mathrm{~d} \\
1000 \mathrm{hr}\end{array}$ & RM1206 & D55342K07BO0DOR \\
\hline 41 & 9 & $\begin{array}{l}\text { R29,R48,R101, } \\
\text { R102,R129,R132, } \\
\text { R135,R140,R141 }\end{array}$ & $\begin{array}{c}10 \mathrm{~K} \Omega, 1 \% \text {, } \\
1 / 4 \mathrm{Watt}, \\
100 \mathrm{ppm}, \\
\text { FR=0,01\% } \\
1000 \mathrm{hr}\end{array}$ & RM1206 & D55342K07B10E0R \\
\hline 42 & 1 & R30 & $\begin{array}{c}2.15 \mathrm{~K} \Omega, 1 \% \\
1 / 4 \mathrm{Watt} \\
100 \mathrm{ppm} \\
\mathrm{FR}=0.01 \% / \\
1000 \mathrm{hr}\end{array}$ & $\mathrm{RM} 1206$ & D55342K07B2E15R \\
\hline 43 & 4 & $\begin{array}{c}\text { R37,R115, } \\
\text { R49,R122,R128 } \\
\text { DO NOT LOAD } \\
\text { R49 OR R128 }\end{array}$ & $\begin{array}{c}100 \Omega, 1 \% \\
1 / 4 \mathrm{Watt} \\
100 \mathrm{ppm} \\
\text { FR=0,01\%/ } \\
1000 \mathrm{hr}\end{array}$ & RM1206 & D55342K07B100DR \\
\hline 44 & 1 & R38 & $\begin{array}{c}3.01 \mathrm{~K} \Omega, 1 \% \text {, } \\
1 / 4 \mathrm{Watt} \\
100 \mathrm{ppm} \\
\text { FR=0.01\%/ } \\
1000 \mathrm{hr}\end{array}$ & RM1206 & D55342K07B3E01R \\
\hline 45 & 2 & $\mathrm{R} 42, \mathrm{R} 43$ & $\begin{array}{c}30 \Omega, 2 \% \\
1 / 4 \mathrm{Watt} \\
100 \mathrm{ppm} \\
\mathrm{FR}=0.01 \% / \\
1000 \mathrm{hr}\end{array}$ & $\mathrm{RM} 1206$ & D55342K07B30G0R \\
\hline
\end{tabular}




\begin{tabular}{c|c|c|c|c|c} 
Item & Qty. & Designator & Description & Case & Mfg. I \\
Part Number
\end{tabular}




\begin{tabular}{|c|c|c|c|c|c|}
\hline Item & Qty. & Designator & Description & Case & $\begin{array}{l}\text { Mfg. I } \\
\text { Part Number }\end{array}$ \\
\hline 46 & 2 & R44,R93 & $\begin{array}{c}1.96 \mathrm{~K} \Omega, 1 \% \\
1 / 4 \mathrm{Watt}, \\
100 \mathrm{ppm} \\
\mathrm{FR}=0.01 \% / \\
1000 \mathrm{hr}\end{array}$ & RM1206 & D55342K07B1E96R \\
\hline 47 & $T$ & R46 & $\begin{array}{c}100 \mathrm{~K} \Omega, 1 \% \\
1 / 4 \mathrm{Watt}, \\
100 \mathrm{ppm}, \\
\mathrm{FR}=0.01 \% / \\
1000 \mathrm{hr}\end{array}$ & RM1206 & D55342K07B100ER \\
\hline 48 & 1 & R92 & $\begin{array}{c}20 \mathrm{~K} \Omega, 1 \% \\
1 / 4 \mathrm{Watt} \\
100 \mathrm{ppm} \\
\mathrm{FR}=0.01 \% / \\
1000 \mathrm{hr}\end{array}$ & RM1206 & D55342K07B20EOR \\
\hline 49 & 4 & $\begin{array}{c}\text { R96, R98,R118, } \\
\text { R120 }\end{array}$ & $\begin{array}{c}2.61 \mathrm{~K} \Omega, 1 \% \text {, } \\
1 / 4 \mathrm{Watt}, \\
100 \mathrm{ppm}, \\
\text { FR=0.01\%/ } \\
1000 \mathrm{hr}\end{array}$ & RM1206 & D55342K07B2E61R \\
\hline 50 & 1 & R97 & $\begin{array}{c}301 \Omega, 1 \%, \\
1 / 4 \mathrm{Watt}, \\
100 \mathrm{ppm}, \\
\text { FR }=0.01 \% / \\
1000 \mathrm{hr}\end{array}$ & RM1206 & $\overline{D 55342 \mathrm{~K} 07 \mathrm{~B} 301 \mathrm{DR}}$ \\
\hline 51 & 2 & R99,R119 & $\begin{array}{c}6.19 \mathrm{~K} \Omega, 1 \% \\
1 / 4 \mathrm{Watt}, \\
100 \mathrm{ppm}, \\
\text { FR=0.01\% } \\
1000 \mathrm{hr}\end{array}$ & RM1206 & D55342K07B6E19R \\
\hline 52 & $T$ & $\bar{R} 112$ & $\begin{array}{c}511 \Omega, 1 \%, \\
1 / 4 \text { Watt, } \\
100 \mathrm{ppm}, \\
\text { FR }=0.01 \% / \\
1000 \mathrm{hr}\end{array}$ & RM1206 & $\overline{D 55342 K 07 B 511 D R}$ \\
\hline
\end{tabular}

) 


\begin{tabular}{|c|c|c|c|c|c|}
\hline Item & Qty. & Designator & Description & Case & $\begin{array}{l}\text { Mfg. I } \\
\text { Part Number }\end{array}$ \\
\hline 53 & 1 & R117 & $\begin{array}{c}40.2 \Omega, 1 \% \\
1 / 4 \mathrm{Watt} \\
100 . \mathrm{ppm} \\
\text { FR=0.01\% } \\
1000 \mathrm{hr}\end{array}$ & RM1206 & D55342K07B40D2R \\
\hline 54 & 1 & R121 & $\begin{array}{c}649 \Omega, 1 \%, \\
1 / 4 \mathrm{Watt} \\
100 \mathrm{ppm}, \\
\text { FR=0.01\% } \\
1000 \mathrm{hr}\end{array}$ & RM1206 & D55342K07B649DR \\
\hline 55 & 1 & R124 & $\begin{array}{l}5.1 \Omega 1 \%, \\
1 / 8 \text { Watt }\end{array}$ & $\overline{R C 1206}$ & $\begin{array}{c}\text { KOA/ } \\
\text { RM73B2B5R1JT }\end{array}$ \\
\hline 56 & 1 & $\overline{\mathrm{R} 125}$ & $\begin{array}{c}499 \Omega, 1 \% \\
1 / 4 \mathrm{Watt}, \\
100 \mathrm{ppm}, \\
\mathrm{FR}=0.01 \% \\
1000 \mathrm{hr}\end{array}$ & RM1206 & D55342K07B499DR \\
\hline 57 & 1 & R131 & $\begin{array}{c}931 \Omega, 1 \%, \\
1 / 4 \mathrm{Watt}, \\
100 p p m, \\
\text { FR=0.01\%/ } \\
1000 \mathrm{hr}\end{array}$ & RM1206 & $\begin{array}{c}\text { Dale / } \\
\text { CRCW12069310FT }\end{array}$ \\
\hline 58 & 1 & $\overline{R 134}$ & $\begin{array}{c}383 \Omega, 1 \%, \\
1 / 4 \mathrm{Watt} \\
100 \mathrm{ppm}, \\
\text { FR=0.01\% } \\
1000 \mathrm{hr}\end{array}$ & RM1206 & $\begin{array}{c}\text { Rohm / } \\
\text { MCR12064420FT }\end{array}$ \\
\hline 59 & 2 & $\mathrm{R} 137, \mathrm{R} 49$ & $\begin{array}{c}178 \Omega, 1 \% \text {, } \\
1 / 4 \mathrm{Watt}, \\
100 \mathrm{ppm}, \\
\text { FR=0.01\% } \\
1000 \mathrm{hr}\end{array}$ & RM1206 & D55342K07B178DR \\
\hline
\end{tabular}




\begin{tabular}{|c|c|c|c|c|c|}
\hline Item & Qty. & Designator & Description & Case & $\begin{array}{c}\text { Mfg. / } \\
\text { Part Number }\end{array}$ \\
\hline 60 & 1 & R139 & $\begin{array}{c}20.0 \Omega, 1 \% \\
1 / 4 \mathrm{Watt} \\
100 \mathrm{ppm} \\
\text { FR=0.01\% } \\
1000 \mathrm{hr}\end{array}$ & RM1206 & D55342K07B20D0R \\
\hline 61 & 1 & T1 & $\begin{array}{c}\text { Sensor, } \\
\text { Temperature } \\
\text { 534-31AG04- } \\
562\end{array}$ & TO-52/3 & $\begin{array}{c}\text { Fenwell/ } \\
\text { LTN11 Type } \\
\text { 534-31AG04-562 }\end{array}$ \\
\hline 62 & 1 & U1 & $\begin{array}{l}\text { Amplifier,. } \\
\text { Operational, } \\
\text { Clamping } \\
\text { CLC501AJE }\end{array}$ & SOIC-8 & $\begin{array}{l}\text { Comlinear / } \\
\text { CLC501AJE } \\
S N \\
02870\end{array}$ \\
\hline 63 & 1 & $\overline{U 2}$ & $\begin{array}{l}\text { Receiver, } \\
\text { Line } \\
\text { Quad } \\
\text { DS34C86 }\end{array}$ & SOIC-16 & $\begin{array}{l}\text { National / } \\
\text { DS34C86M } \\
\text { sij }^{-5320}\end{array}$ \\
\hline 64 & 2 & $\mathrm{U} 3, \mathrm{U} 27$ & $\begin{array}{l}\text { Amplifier, } \\
\text { Dual, Wide } \\
\text { Band } \\
\text { LF353 }\end{array}$ & SOIC-8 & $\begin{array}{l}\text { National/ } \\
\text { LF353M } \\
\text { Siv } \\
01320,01319\end{array}$ \\
\hline 65 & $T$ & U5 & $\begin{array}{l}\text { Controller, } \\
\text { CCD } \\
\text { TH7990 }\end{array}$ & JLCC-44 & $\begin{array}{l}\text { Thomson-CSF I } \\
\text { sid TH7990C } \\
13\end{array}$ \\
\hline 66 & 4 & $\begin{array}{l}\text { U6,U7, } \\
\text { U12,U25 }\end{array}$ & $\begin{array}{l}\text { Driver, Line, } \\
\text { Quad } \\
\text { DS34C87 }\end{array}$ & SOIC-16 & 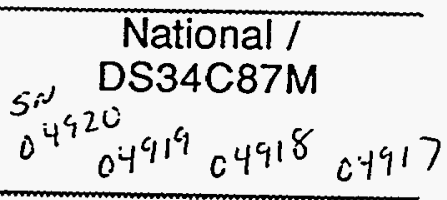 \\
\hline 67 & 1 & U8 & $\begin{array}{l}\text { Converter, } \\
\text { Analog to } \\
\text { Digital } 8 \text { bit } \\
\text { MP7684 }\end{array}$ & LCC-28 & $\begin{array}{c}\text { Micropower / } \\
\text { MP7684ATL/883 }\end{array}$ \\
\hline 68 & 4 & $\begin{array}{l}\text { U9,U10,U22 } \\
\text { U23 }\end{array}$ & $\begin{array}{l}\text { Driver, Dual } \\
\text { Inverting } \\
\text { TSC4426 }\end{array}$ & SOIC-8 & 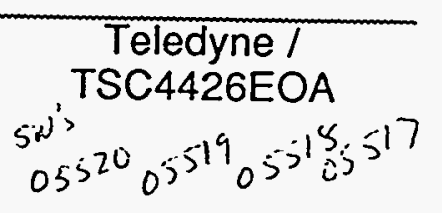 \\
\hline
\end{tabular}




\begin{tabular}{|c|c|c|c|c|c|}
\hline Item & Qty. & Designator & Description & Case & $\begin{array}{l}\text { Mfg. I } \\
\text { Part Number } \\
\end{array}$ \\
\hline 69 & 2 & U11,U30 & $\begin{array}{c}\text { Driver, } \\
\text { Differential, } \\
\text { Dual } \\
\text { TSC4428 }\end{array}$ & SOIC-8 & $\begin{array}{l}\text { Teledyne I } \\
\text { TSC4428EOA } \\
\text { Si's } \\
01820,01819\end{array}$ \\
\hline 70 & 1 & U14 & $\begin{array}{l}\text { Amplifier, } \\
\text { Operational, } \\
\text { LF356 }\end{array}$ & SOIC-8 & 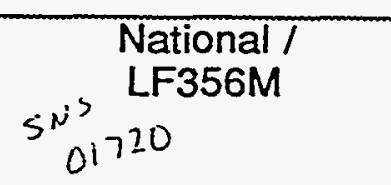 \\
\hline 71 & 2 & U17,U18 & $\begin{array}{l}\text { Regulator, } \\
\text { Voltage, } \\
\text { Adjustable } \\
\text { LM317 }\end{array}$ & SOIC-8 & 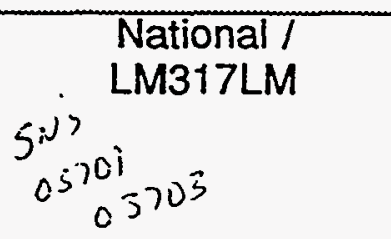 \\
\hline 72 & $T$ & $\begin{array}{c}\text { U19 } \\
\text { DO NOT KIT }\end{array}$ & $\begin{array}{l}\text { Charged } \\
\text { Coupled } \\
\text { Device } \\
\text { CCD } \\
7860 \text { or7863 }\end{array}$ & DIP-20 & $\begin{array}{l}\text { Type Chosen on } \\
\text { Camera Selection }\end{array}$ \\
\hline 73 & 1 & U24 & $\begin{array}{l}\text { Amplifier, } \\
\text { Operational, } \\
\text { Clamping } \\
\text { CLC502 }\end{array}$ & SOIC-8 & $\begin{array}{l}\text { Comlinear, } \\
\text { CLC502AJE } \\
\text { Sid }^{2} \\
02951\end{array}$ \\
\hline 74 & 1 & $\begin{array}{c}\text { U26 } \\
\text { DO NOT KIT }\end{array}$ & $\begin{array}{l}\text { Gate Array, } \\
\text { Field } \\
\text { Program, } \\
\text { ACT1020A }\end{array}$ & JLCC- 44 & $\begin{array}{c}\text { Actel/ } \\
\text { ACT1020A-1JQ44B }\end{array}$ \\
\hline 75 & 1 & U32 & $\begin{array}{c}\text { Converter, } \\
\text { Digital to } \\
\text { Analog } \\
\text { AD558TE/883 }\end{array}$ & LCC20 & $\begin{array}{c}\text { Analog Devices / } \\
\text { AD558TE/883 }\end{array}$ \\
\hline 76 & 1 & $\overline{X 1}$ & $\begin{array}{l}\text { Crystal, } \\
20 \mathrm{MHz} \\
\pm 50 \mathrm{ppm}\end{array}$ & CXAT & $\begin{array}{c}\text { MicroCrystal } \\
20.000 \mathrm{MHz} \\
\text { CXAT-T2 }\end{array}$ \\
\hline 77 & 2 & U19 Socket & $\begin{array}{l}\text { Socket Strip } \\
10 \text { pin }\end{array}$ & SIP-10 & $\begin{array}{c}\text { LLNLI } \\
5975-64700\end{array}$ \\
\hline
\end{tabular}




\begin{tabular}{|c|c|c|c|c|c|}
\hline Item & Qty. & Designator & Description & Case & $\begin{array}{l}\text { Mfg. I } \\
\text { Part Number }\end{array}$ \\
\hline 78 & 2 & N/A & Spacer & N/A & $\begin{array}{c}\text { AAA92-104616-OB } \\
\text { Tab-01 }\end{array}$ \\
\hline 79 & 2 & $\mathrm{~N} / \mathrm{A}$ & $\begin{array}{l}\text { Brass CCD } \\
\text { Mounting } \\
\text { Nuts }\end{array}$ & $\mathrm{N} / \mathrm{A}$ & $\begin{array}{c}\text { AAA92-109126 } \\
\text { REV } 00\end{array}$ \\
\hline 80 & 2 & $N / A$ & $\begin{array}{c}\# 2-56 \\
\text { Stainless } \\
\text { Steel Nut }\end{array}$ & N/A & NAS671C2 \\
\hline 81 & 2 & N/A & $\begin{array}{l}\text { Washer, } \\
\text { Stainless } \\
\text { Steel, \#2 }\end{array}$ & N/A & NAS620C-2 \\
\hline 82 & 2 & TP1,TP2 & Test Points & N/A & $\begin{array}{c}\text { LLNL/ } \\
5975-66833\end{array}$ \\
\hline 83 & 8 & $\begin{array}{c}\text { C4,C7,C8,C82, } \\
\text { C99,C100, } \\
\text { C101,C123 }\end{array}$ & $\begin{array}{c}0.1 \mu \mathrm{fd}, \\
50 \text { Volt, } 10 \%\end{array}$ & $\mathrm{RC1206}$ & $\begin{array}{c}\text { Rohm I } \\
\text { CE104K3NR-T2 }\end{array}$ \\
\hline 84 & 1 & $\mathrm{~L} 2$ & $\begin{array}{l}\text { Inductor, } \\
47 \mu \mathrm{H}\end{array}$ & LQH4 & $\begin{array}{l}\text { MuRata Erie I } \\
\text { LQH4N470K-TA }\end{array}$ \\
\hline
\end{tabular}




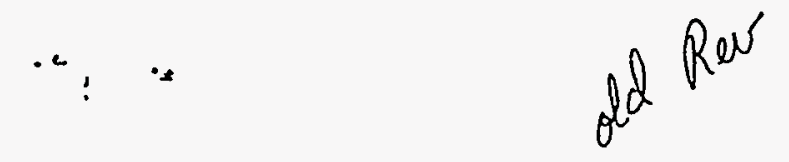

\section{Actel Camera with Gain and Offset Control Startracker Configuration Rev. 00 Printed Wiring Board Bill of Materials, Rev. 00 LEA92-3128-04}

\begin{tabular}{|c|c|c|c|c|}
\hline & Date & Rev. & Date & Approval \\
\hline Prepared by: K. FF. Coathey & $30 \mathrm{mar} 93$ & $O A$ & $13 \mathrm{Apr} / 93$ & $w_{c}(\Delta)$ \\
\hline Reviewed by: W. R. Bryson & $30 \operatorname{Mar} 93$ & $\sigma \beta$ & 16 Atoril 193 & $\omega_{L}<\Delta$ \\
\hline Reviewed by: Q. F. Kordas & 30-AAR-73 & & & \\
\hline Reviewed by: M.L. Dickerson & $3131 / 93$ & & & \\
\hline Reviewed by: E.H. Schingitt & $4 / 2 / 93$ & & & \\
\hline Reviewed by: Rh S S annen & $4 / 2 / 9$ & & & \\
\hline 710 & & & & \\
\hline $\begin{array}{l}\text { University of California } \\
\text { Lawrence Livermore } \\
\text { National Laboratory }\end{array}$ & \multicolumn{2}{|c|}{$\begin{array}{l}22 \text { March } 1993 \\
\text { Actel Startracker } \\
\text { Bill of Materials }\end{array}$} & \multicolumn{2}{|c|}{$\begin{array}{l}\text { LEA92-3128-04 } \\
\text { Revision } 00\end{array}$} \\
\hline
\end{tabular}




\subsection{Scope}

This document is the bill of materials for the Actel Camera with Gain and Offset Control for use in the Startracker, Rev 00 Printed Wiring Board, LEA92-3128-04, Rev 00.

\subsection{Parts}

Where a dual part number listing exists, the first number listed is a commercial part suitable for prototype work only. If the MIL-SPEC part is not available at the time flight boards are assembled, Quality assurance must OK the use of the commercial part on a part by part basis in writing.

Parts may not be substituted without the written permission of the Quality Assurance Group.

\begin{tabular}{|c|c|c|c|c|c|}
\hline Item & Qty. & Designator & Description & Case & $\begin{array}{c}\text { Mfg. I } \\
\text { Part Number }\end{array}$ \\
\hline 1 & 47 & $\begin{array}{c}\text { C1,C3,C4,C5,C6, } \\
\text { C7,C8,C15,C21, } \\
\text { C23,C25,C26, } \\
\text { C30,C31,C33, } \\
\text { C34,C38,C39, } \\
\text { C40,C42,C44, } \\
\text { C45,C47,C48, } \\
\text { C54,C56,C57, } \\
\text { C58,C59,C60, } \\
\text { C63,C64,C66, } \\
\text { C67,C70,C } 91, \\
\text { C92,C98,C102, } \\
\text { C103,C104,C106, } \\
\text { C109,C112,C114, } \\
\text { C121,C124 }\end{array}$ & $\begin{array}{c}0.039 \mu \mathrm{F} \\
50 \mathrm{~V}, 10 \% \\
\mathrm{FR}=0.01 \% \\
1000 \mathrm{hr}\end{array}$ & $\mathrm{RM} 1206$ & CDR32BX393AKUR \\
\hline 2 & 5 & $\begin{array}{c}\mathrm{C} 2, \mathrm{C} 51, \mathrm{C} 61, \mathrm{C} 62 \\
\mathrm{C} 122\end{array}$ & $\begin{array}{c}4.7 \mu \mathrm{fd}, \text { Tant, } \\
10 \mathrm{~V}, 10 \% \text {, } \\
\text { WFR }=0.01 \% \text { / } \\
1000 \mathrm{hr}\end{array}$ & H-CASE & CWR06FH475KC \\
\hline 3 & 1 & C9 & $\begin{array}{l}47 \mu f d, \text { Tant, } \\
20 \mathrm{~V}, 10 \%\end{array}$ & R-CASE & $\begin{array}{c}\text { Sprague / } \\
\text { 195D476X9020R2T }\end{array}$ \\
\hline
\end{tabular}




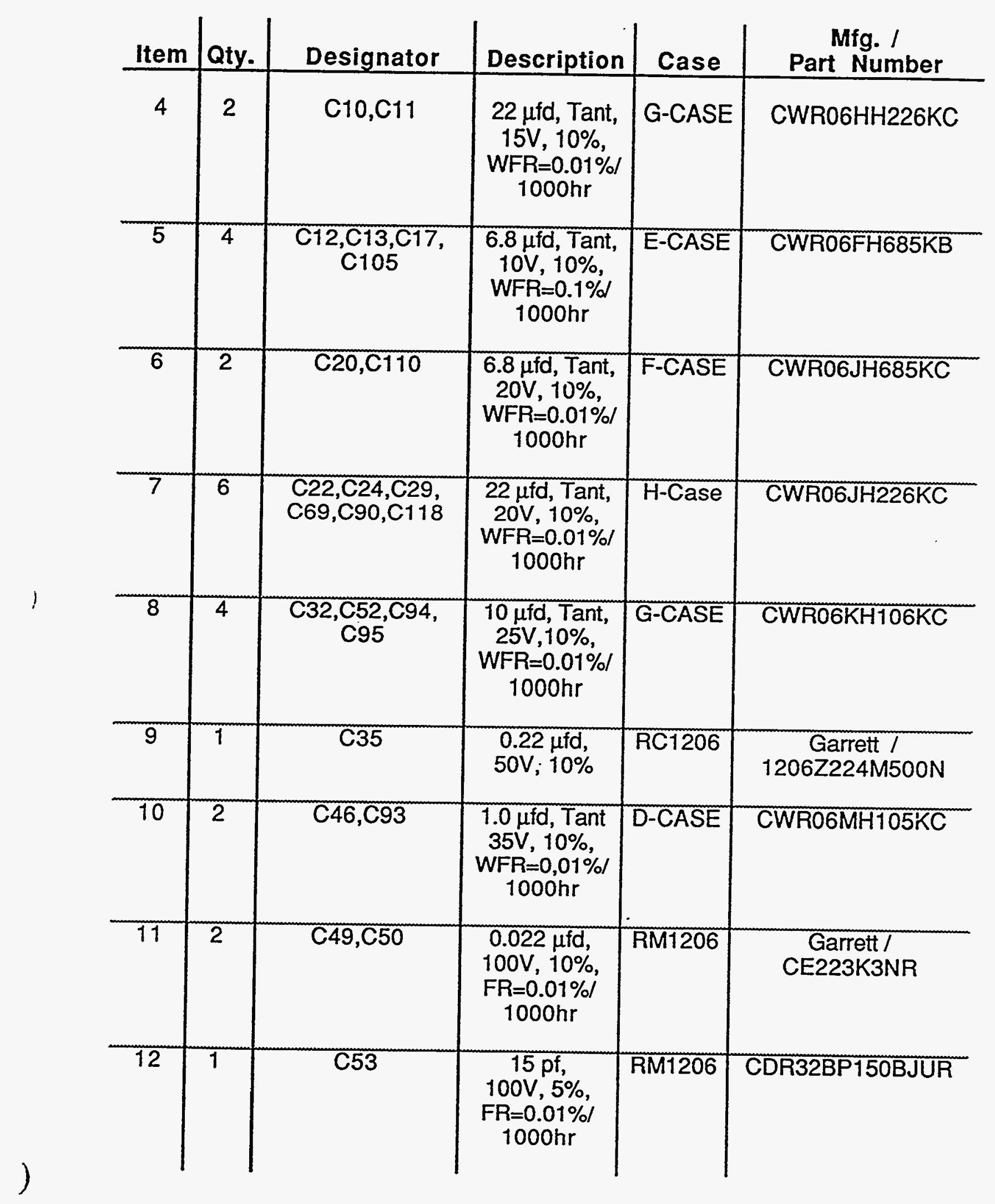




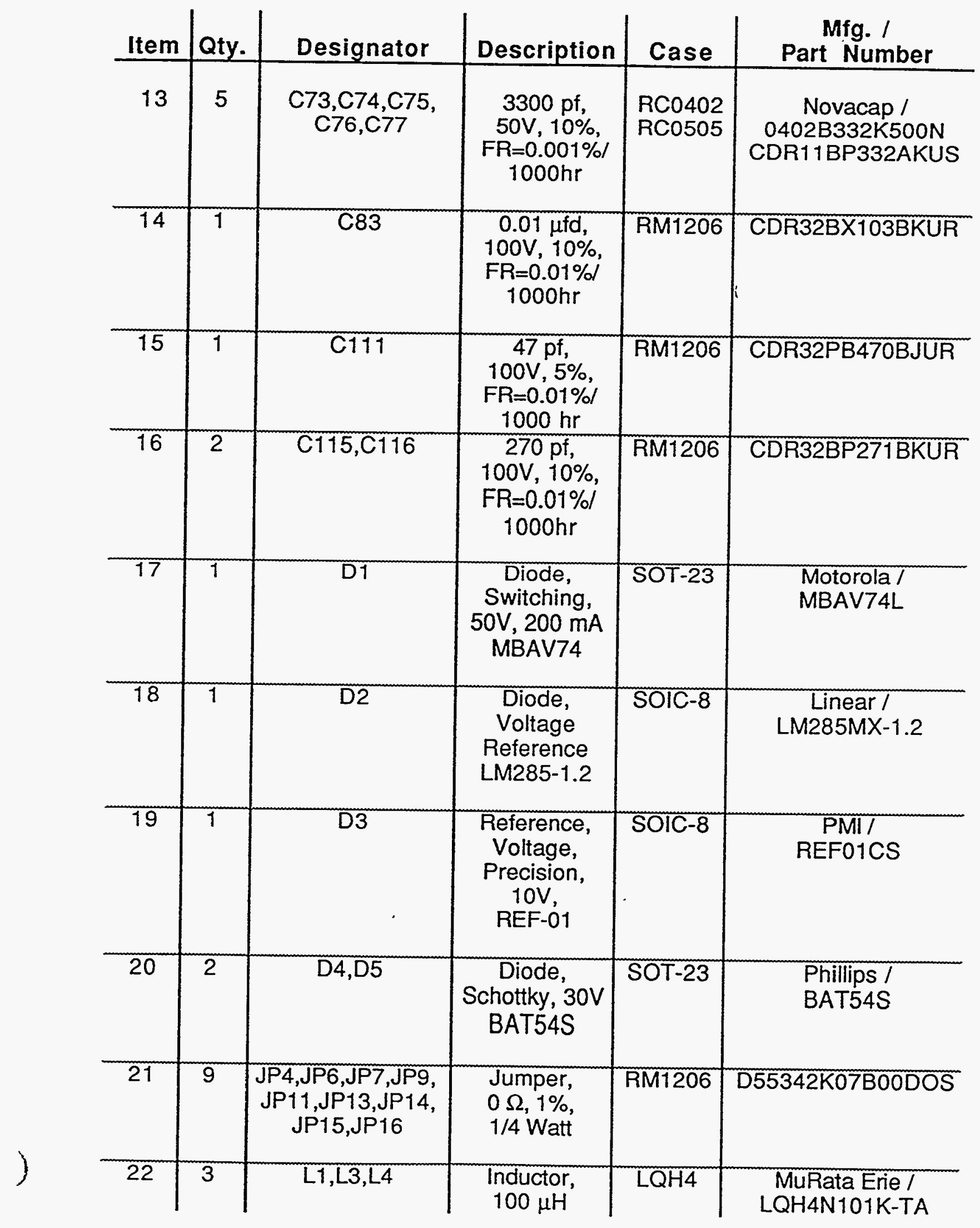




\begin{tabular}{|c|c|c|c|c|c|}
\hline Item & Qty. & Designator & Description & Case & $\begin{array}{l}\text { Mfg. I } \\
\text { Part Number }\end{array}$ \\
\hline 23 & 1 & L5 & $\begin{array}{l}\text { Inductor, } \\
10 \mu \mathrm{H}\end{array}$ & LQH4 & $\begin{array}{l}\text { MuRata Erie / } \\
\text { LQH4N100K-TA }\end{array}$ \\
\hline 24 & 1 & J1 & $\begin{array}{l}\text { Connector, } \\
51 \text { Contact, } \\
\text { Socket }\end{array}$ & MDM51 & M83513/04-G06N \\
\hline 25 & 5 & $\begin{array}{c}\text { Q1,Q4,Q9, } \\
\text { Q10,Q11 } \\
\text { sis } \\
04701,04702,04703,\end{array}$ & $\begin{array}{l}\text { Transistor, } \\
\text { FET, } \\
\text { SST } 215 \\
04704,0470,\end{array}$ & SOT-143 & $\begin{array}{c}\text { Calogic/ } \\
\text { No Substitute } \\
\text { Calogic No. SST215E }\end{array}$ \\
\hline 26 & 3 & $\begin{array}{c}\text { Q2,Q3,Q8 } \\
\sin ^{\mathrm{s}} \\
00020,00019,00018\end{array}$ & $\begin{array}{l}\text { Transistor, } \\
2 \text { N3904 }\end{array}$ & SOT-23 & $\begin{array}{c}\text { Motorola / } \\
\text { MMBT3904 } \\
\text { No Substitute }\end{array}$ \\
\hline 27 & 3 & $\begin{array}{l}Q 12, Q 13, Q 14 \\
510^{5}, 0098 \\
00920,0909919\end{array}$ & $\begin{array}{l}\text { Transistor, } \\
2 \text { N7002 }\end{array}$ & SOT-23 & $\begin{array}{c}\text { Motorola } 1 \\
2 \text { N7002 } \\
\text { No Substitute }\end{array}$ \\
\hline 28 & 2 & $\mathrm{R} 3, \mathrm{R} 66$ & $\begin{array}{c}7.5 \mathrm{~K} \Omega, 1 \% \\
1 / 4 \mathrm{Watt}, \\
100 \mathrm{ppm} \\
\mathrm{FR}=0.01 \% \\
1000 \mathrm{hr}\end{array}$ & RM1206 & D55342K07B7E50R \\
\hline 29 & 2 & $\mathrm{R} 6, \mathrm{R} 7$ & $\begin{array}{c}150 \Omega, 1 \% \\
1 / 4 \mathrm{Watt}, \\
100 \mathrm{ppm}, \\
\mathrm{FR}=0.01 \% / \\
1000 \mathrm{hr}\end{array}$ & RM1206 & $\overline{D 55342 K 07 B 150 D R}$ \\
\hline 30 & 2 & R14,R31 & $\begin{array}{c}243 \Omega, 1 \%, \\
1 / 4 \mathrm{Watt}, \\
100 \mathrm{ppm}, \\
\mathrm{FR}=0.01 \% / \\
1000 \mathrm{hr}\end{array}$ & RM1206 & $\overline{D 55342 K 07 B 243 D R}$ \\
\hline 31 & 2 & R15,R32 & $\begin{array}{c}1.82 \mathrm{~K} \Omega, 1 \%, \\
1 / 4 \mathrm{Watt}, \\
100 \mathrm{ppm}, \\
\mathrm{FR}=0.01 \% / \\
1000 \mathrm{hr}\end{array}$ & RM1206 & $\overline{D 55342 K 07 B 1 E 82 R}$ \\
\hline
\end{tabular}




\begin{tabular}{c|c|c|c|c|c} 
Item & Qty. & Designator & Description & Case & Mfg. I \\
Part Number
\end{tabular}

) 


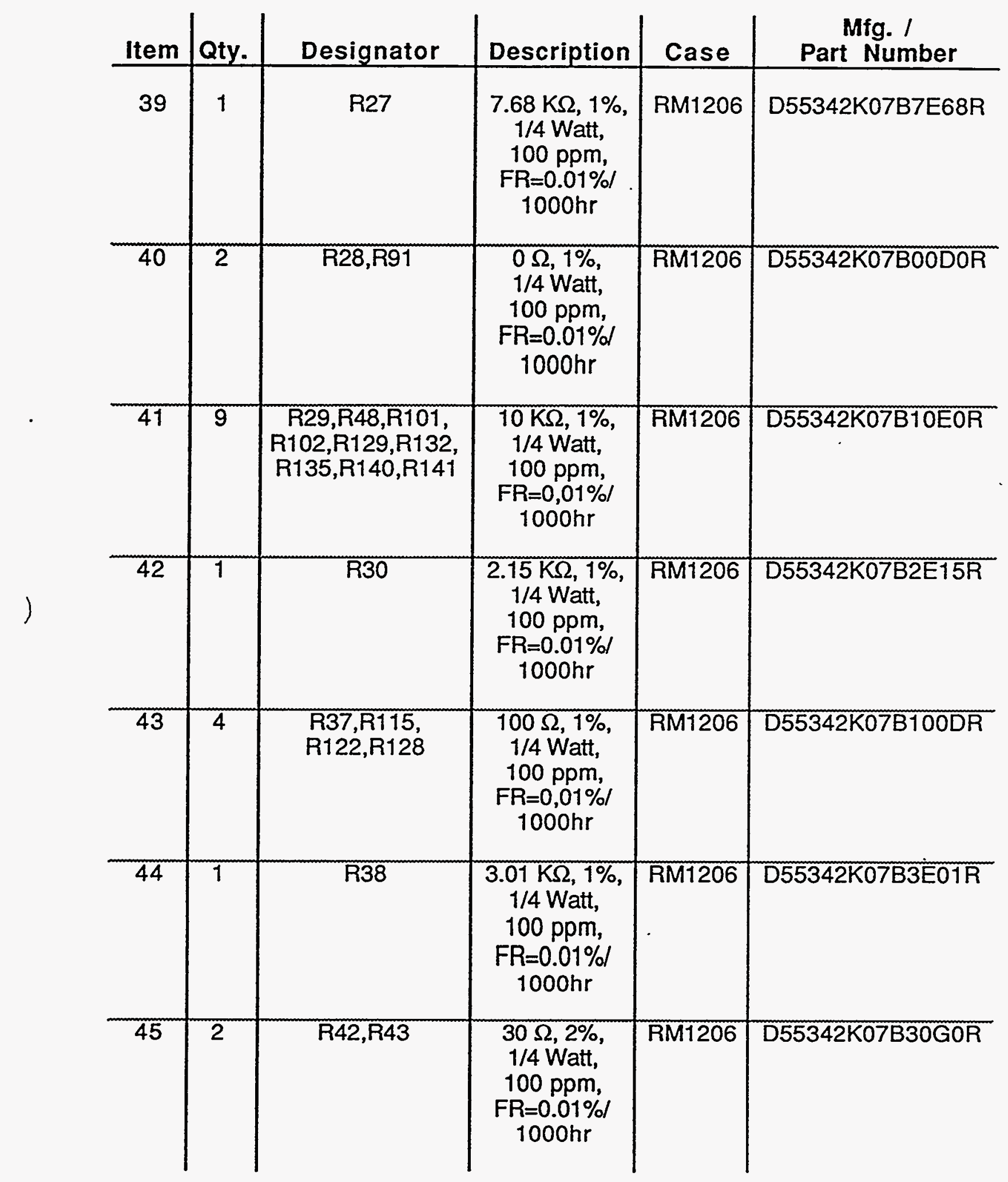

) 


\begin{tabular}{|c|c|c|c|c|c|}
\hline Item & Qty. & Designator & Description & Case & $\begin{array}{c}\text { Mfg. I } \\
\text { Part Number }\end{array}$ \\
\hline 46 & 3 & $R 44, R 93, R 119$ & $\begin{array}{c}1.96 \mathrm{~K} \Omega, 1 \% \\
1 / 4 \mathrm{Watt} \\
100 \mathrm{ppm} \\
\mathrm{FR}=0.01 \% \\
1000 \mathrm{hr}\end{array}$ & RM1206 & D55342K07B1E96R \\
\hline 47 & 1 & R46 & $\begin{array}{c}100 \mathrm{~K} \Omega, 1 \% \\
1 / 4 \mathrm{Watt} \\
100 \mathrm{ppm}, \\
\mathrm{FR}=0.01 \% \\
1000 \mathrm{hr}\end{array}$ & RM1206 & D55342K07B100ER \\
\hline 48 & 1 & R92 & $\begin{array}{c}20 \mathrm{~K} \Omega, 1 \%, \\
1 / 4 \mathrm{Watt}, \\
100 \mathrm{ppm}, \\
\mathrm{FR}=0.01 \% / \\
1000 \mathrm{hr}\end{array}$ & RM1206 & D55342K07B20E0R \\
\hline 49 & 4 & $\begin{array}{c}\text { R96,R98,R118, } \\
\text { R120 }\end{array}$ & $\begin{array}{c}2.61 \mathrm{~K} \Omega, 1 \%, \\
1 / 4 \mathrm{Watt}, \\
100 \mathrm{ppm}, \\
\mathrm{FR}=0.01 \% / \\
1000 \mathrm{hr}\end{array}$ & RM1206 & D55342K07B2E61R \\
\hline 50 & 1 & R97 & $\begin{array}{c}301 \Omega, 1 \%, \\
1 / 4 \mathrm{Watt}, \\
100 \mathrm{ppm}, \\
\text { FR=0.01\%/ } \\
1000 \mathrm{hr}\end{array}$ & RM1206 & D55342K07B301DR \\
\hline 51 & 1 & R99 & $\begin{array}{c}6.19 \mathrm{~K} \Omega, 1 \% \\
1 / 4 \mathrm{Watt} \\
100 \mathrm{ppm} \\
\text { FR=0.01\%/ } \\
1000 \mathrm{hr}\end{array}$ & RM1206 & D55342K07B6E19R \\
\hline 52 & 1 & $\mathrm{R} 112$ & $\begin{array}{c}511 \Omega, 1 \%, \\
1 / 4 \mathrm{Watt}, \\
100 \mathrm{ppm}, \\
\text { FR }=0.01 \% / \\
1000 \mathrm{hr}\end{array}$ & RM1206 & D55342K07B511DR \\
\hline
\end{tabular}




\begin{tabular}{|c|c|c|c|c|c|}
\hline Item & Qty. & Designator & Description & Case & $\begin{array}{l}\text { Mfg. / } \\
\text { Part Number }\end{array}$ \\
\hline 53 & 1 & $\mathrm{R} 117$ & $\begin{array}{c}40.2 \Omega, 1 \%, \\
1 / 4 \mathrm{Watt} \\
100 \mathrm{ppm}, \\
\text { FR=0.01\% } \\
1000 \mathrm{hr}\end{array}$ & RM1206 & D55342K07B40D2R \\
\hline 54 & 1 & $\overline{R 121}$ & $\begin{array}{c}649 \Omega, 1 \% \\
1 / 4 \mathrm{Watt} \\
100 \mathrm{ppm}, \\
\text { FR=0.01\% } \\
1000 \mathrm{hr}\end{array}$ & RM1206 & D55342K07B649DR \\
\hline 55 & 1 & R124 & $\begin{array}{l}5.1 \Omega 1 \% \\
1 / 8 \text { Watt }\end{array}$ & RC1206 & $\begin{array}{c}\text { KOA/ } \\
\text { RM73B2B5R1JT }\end{array}$ \\
\hline 56 & 1 & $\overline{R 125}$ & $\begin{array}{c}499 \Omega, 1 \%, \\
1 / 4 \mathrm{Watt}, \\
100 \mathrm{ppm}, \\
\text { FR=0.01\%/ } \\
1000 \mathrm{hr}\end{array}$ & RM1206 & D55342K07B499DR \\
\hline 57 & 1 & R131 & $\begin{array}{c}931 \Omega, 1 \%, \\
1 / 4 \mathrm{Watt}, \\
100 p p m \\
\text { FR=0.01\%/ } \\
1000 \mathrm{hr}\end{array}$ & RM1206 & $\begin{array}{c}\text { Dale / } \\
\text { CRCW12069310FT }\end{array}$ \\
\hline 58 & 1 & $\overline{R 134}$ & $\begin{array}{c}383 \Omega, 1 \%, \\
1 / 4 \mathrm{Watt} \\
100 \mathrm{ppm}, \\
\text { FR=0.01\%/ } \\
1000 \mathrm{hr}\end{array}$ & RM1206 & $\begin{array}{c}\text { Rohm / } \\
\text { MCR12064420FT }\end{array}$ \\
\hline 59 & 1 & R137 & $\begin{array}{c}178 \Omega, 1 \%, \\
1 / 4 \mathrm{Watt}, \\
100 \mathrm{ppm}, \\
\text { FR=0.01\%/ } \\
1000 \mathrm{hr}\end{array}$ & $\mathrm{RM} 1206$ & D55342K07B178DR \\
\hline
\end{tabular}




\begin{tabular}{|c|c|c|c|c|c|}
\hline Item & Qty. & Designator & Description & Case & $\begin{array}{c}\text { Mfg. / } \\
\text { Part Number } \\
\end{array}$ \\
\hline 60 & 1 & R139 & $\begin{array}{c}20.0 \Omega, 1 \%, \\
1 / 4 \mathrm{Watt}, \\
100 \mathrm{ppm}, \\
\mathrm{FR}=0.01 \% / \\
1000 \mathrm{hr}\end{array}$ & $\mathrm{RM} 1206$ & D55342K07B20D0R \\
\hline 61 & 1 & T1 & $\begin{array}{c}\text { Sensor, } \\
\text { Temperature } \\
534-31 \mathrm{AG04-} \\
562\end{array}$ & TO-52/3 & $\begin{array}{c}\text { Fenwell I } \\
\text { LTN11 Type } \\
\text { 534-31AG04-562 }\end{array}$ \\
\hline 62 & 1 & U1 & $\begin{array}{l}\text { Amplifier,. } \\
\text { Operational, } \\
\text { Clamping } \\
\text { CLC501AJE }\end{array}$ & SOIC-8 & $\begin{array}{l}\text { Comlinear / } \\
\text { CLC501AJE }\end{array}$ \\
\hline 63 & 1 & U2 & $\begin{array}{l}\text { Receiver, } \\
\text { Line } \\
\text { Quad } \\
\text { DS34C86 }\end{array}$ & SOIC-16 & $\begin{array}{c}\text { National / } \\
\text { DS34C86M }\end{array}$ \\
\hline 64 & 2 & U3,U27 & $\begin{array}{l}\text { Amplifier, } \\
\text { Dual, Wide } \\
\text { Band } \\
\text { LF353 }\end{array}$ & SOIC-8 & $\begin{array}{l}\text { National/ } \\
\text { LF353M }\end{array}$ \\
\hline 65 & 1 & U5 & $\begin{array}{l}\text { Controller, } \\
\text { CCD } \\
\text { TH7990 }\end{array}$ & JLCC -44 & $\begin{array}{c}\text { Thomson-CSF I } \\
\text { TH7990C }\end{array}$ \\
\hline 66 & 4 & $\begin{array}{l}\text { U6,U7, } \\
\text { U12,U25 }\end{array}$ & $\begin{array}{l}\text { Driver, Line, } \\
\text { Quad } \\
\text { DS34C87 }\end{array}$ & SOIC-16 & $\begin{array}{c}\text { National/ } \\
\text { DS34C87M }\end{array}$ \\
\hline 67 & 1 & $\mathrm{U} 8$ & $\begin{array}{l}\text { Converter, } \\
\text { Analog to } \\
\text { Digital } 8 \text { bit } \\
\text { MP7684 }\end{array}$ & LCC-28 & $\begin{array}{c}\text { Micropower / } \\
\text { MP7684ATL/883 }\end{array}$ \\
\hline 68 & 4 & $\begin{array}{l}\text { U9,U10,U22 } \\
\text { U23 }\end{array}$ & $\begin{array}{l}\text { Driver, Dual } \\
\text { Inverting } \\
\text { TSC4426 }\end{array}$ & SOIC-8 & $\begin{array}{l}\text { Teledyne / } \\
\text { TSC4426EOA }\end{array}$ \\
\hline
\end{tabular}




\begin{tabular}{|c|c|c|c|c|c|}
\hline Item & Qty. & Designator & Description & Case & $\begin{array}{l}\text { Mfg. I } \\
\text { Part Number } \\
\end{array}$ \\
\hline 69 & 2 & U11,U30 & $\begin{array}{c}\text { Driver, } \\
\text { Differential, } \\
\text { Dual } \\
\text { TSC4428 }\end{array}$ & SOIC-8 & $\begin{array}{c}\text { Teledyne I } \\
\text { TSC4428EOA }\end{array}$ \\
\hline 70 & 1 & U14 & $\begin{array}{l}\text { Amplifier, } \\
\text { Operational, } \\
\text { LF356 }\end{array}$ & SOIC-8 & $\begin{array}{l}\text { National I } \\
\text { LF356M }\end{array}$ \\
\hline 71 & 2 & $\mathrm{U17,U18}$ & $\begin{array}{l}\text { Regulator, } \\
\text { Voltage, } \\
\text { Adjustable } \\
\text { LM317 }\end{array}$ & SOIC-8 & $\begin{array}{l}\text { National/ } \\
\text { LM317LM }\end{array}$ \\
\hline 72 & 1 & $\begin{array}{c}\text { U19 } \\
\text { DO NOT KIT }\end{array}$ & $\begin{array}{c}\text { Charged } \\
\text { Coupled } \\
\text { Device } \\
\text { CCD } \\
7860 \text { or7863 }\end{array}$ & DIP-20 & $\begin{array}{l}\text { Type Chosen on } \\
\text { Camera Selection }\end{array}$ \\
\hline 73 & 1 & $\mathrm{U} 24$ & $\begin{array}{l}\text { Amplifier, } \\
\text { Operational, } \\
\text { Clamping } \\
\text { CLC502 }\end{array}$ & SOIC-8 & $\begin{array}{l}\text { Comlinear, } \\
\text { CLC502AJE }\end{array}$ \\
\hline$\overline{74}$ & 1 & $\begin{array}{c}\text { U26 } \\
\text { DO NOT KIT }\end{array}$ & $\begin{array}{c}\text { Gate Array, } \\
\text { Field } \\
\text { Program, } \\
\text { ACT1020A }\end{array}$ & JLCC-44 & $\begin{array}{c}\text { Actel } / \\
\text { ACT1020A-1JQ44B }\end{array}$ \\
\hline 75 & 1 & $\mathrm{U} 32$ & $\begin{array}{c}\text { Converter, } \\
\text { Digital to } \\
\text { Analog } \\
\text { AD558TE/883 }\end{array}$ & LCC20 & $\begin{array}{c}\text { Analog Devices / } \\
\text { AD558TE/883 }\end{array}$ \\
\hline 76 & 1 & $\overline{x 1}$ & $\begin{array}{l}\text { Crystal, } \\
20 \mathrm{MHz} \\
\pm 50 \mathrm{ppm}\end{array}$ & CXAT & $\begin{array}{l}\text { MicroCrystal/ } \\
20.000 \mathrm{MHz} \\
\text { CXAT-T2 }\end{array}$ \\
\hline 77 & 2 & U19 Socket & $\begin{array}{l}\text { Socket Strip } \\
10 \text { pin }\end{array}$ & SIP-10 & $\begin{array}{c}\text { LLNLI } \\
5975-64700\end{array}$ \\
\hline
\end{tabular}




\begin{tabular}{|c|c|c|c|c|c|}
\hline Item & Qty. & Designator & Description & Case & $\begin{array}{c}\text { Mfg. I } \\
\text { Part Number }\end{array}$ \\
\hline 78 & 2 & N/A & Spacer & N/A & $\begin{array}{c}\text { AAA92-104616-OB } \\
\text { Tab-01 }\end{array}$ \\
\hline 79 & 2 & $\overline{N / A}$ & $\begin{array}{l}\text { Brass CCD } \\
\text { Mounting } \\
\text { Nuts }\end{array}$ & N/A & $\begin{array}{l}\text { AAA92-109126 } \\
\text { REV } 00\end{array}$ \\
\hline 80 & 2 & N/A & $\begin{array}{l}\text { \#2-56 } \\
\text { Stainless } \\
\text { Steel Nut }\end{array}$ & N/A & NAS671C2 \\
\hline 81 & 2 & N/A & $\begin{array}{l}\text { Washer, } \\
\text { Stainless } \\
\text { Steel, \#2 }\end{array}$ & $\overline{N / A}$ & NAS620C-2 \\
\hline 82 & 2 & TP1,TP2 & Test Points & N/A & $\begin{array}{c}\text { LLNL/ } \\
5975-66833\end{array}$ \\
\hline 83 & 5 & $\begin{array}{c}\mathrm{C} 82, \mathrm{C} 99, \mathrm{C} 100 \\
\text { C101,C123 }\end{array}$ & $\begin{array}{c}0.1 \mu \mathrm{fd}, \\
50 \text { Volt, } 10 \%\end{array}$ & RC1206 & $\begin{array}{c}\text { Rohm / } \\
\text { CE104K3NR-T2 }\end{array}$ \\
\hline 84 & 1 & R49 & $\begin{array}{c}200 \Omega, 5 \%, \\
1 / 4 \mathrm{Watt}, \\
100 \mathrm{ppm}, \\
\text { FR=0,01\%/ } \\
1000 \mathrm{hr}\end{array}$ & RM1206 & D55342K07B200JR \\
\hline 85 & 1 & $\mathrm{~L} 2$ & $\begin{array}{l}\text { Inductor, } \\
47 \mu \mathrm{H}\end{array}$ & LQH4 & $\begin{array}{c}\text { MuRata Erie I } \\
\text { LQH4N470K-TA }\end{array}$ \\
\hline
\end{tabular}


Appendix G.2.4

Assembly Procedures 


\section{Assembly Procedure for \\ ACTEL Camera with Gain and Offset Control, StarTracker Configuration}

Address: -2

\begin{tabular}{|l|l||l|l|l|}
\hline & Date: & Rev.: & Date: & Approval: \\
\hline Prepared by: W. R. Bryson & & & & \\
\hline Reviewed by: M. L. Dickerson & & & & \\
\hline Reviewed by: J.F. Kordas & & & & \\
\hline Reviewed by: R. E. Priest & & & & \\
\hline Reviewed by: E.H. Schmitt & & & & \\
\hline Approved by: M.J. Shannon & & & & \\
\hline
\end{tabular}

\begin{tabular}{|l|c|c|}
\hline $\begin{array}{l}\text { University of California } \\
\text { Lawrence Livermore } \\
\text { National Laboratory }\end{array}$ & $\begin{array}{c}13 \text { May 93 } \\
\text { Assembly Procedure } \\
\text { Actel Camera with Gain } \\
\text { and Offset Control }\end{array}$ & $\begin{array}{c}\text { LEA92-3128-05 } \\
\text { Revision 00 }\end{array}$ \\
\hline
\end{tabular}




\subsection{Scope}

This document describes the assembly procedure for the Actel Camera with Gain and Offset Control, StarTracker Configuration, Rev 00 printed wiring board. This procedure has been written for hand assembly, workmanship standards shall be MIL-STD-2000.

\subsection{Required and Related Documents and General Notes}

2.1 Required documents:

Bill of Materials, LEA92-3128-04 Actel Camera with Gain and Offset Control, StarTracker Configuration, Rev 00 Printed Wiring Board

Assembly Drawing, LEA92-3128-03 Actel Camera with Gain and Offset Control, StarTracker Configuration, Rev 00 Printed Wiring Assembly

Adhesive Compounds and Optical Couplets, C1-S0-005

Preparation of Gold Plated Leads, C1-EE-023

Polyimide Based Printed Wiring Board Conditioning Methods, C1-EE-029

2.2 Related documents:

MIL-STD-1686A

Clementine Quality Assurance Program Plan, C1-S0-007

Clementine Sensor Suite Waiver Procedure, C1-S0-006

Clementine Failure Reporting, Analysis and Corrective Action System, C1-EE-0021

\subsection{General Notes}

1) All measuring devices used during the assembly of the Actel Camera board with Gain and Offset Control must be in current calibration. The calibration expiration date must be far enough in the future to allow completion of this assembly.

2) Printed wiring boards are to be stored in an airtight, antistatic bag with a desiccant at all times the board is not being loaded, cleaned, inspected or baked.

3) Clean and inspect, followed by printed wiring board bake are inserted at recommended locations. More or less components may be installed between clean and inspect points at the discretion of the QAG. It is mandatory that the printed wiring board is baked after solvent cleaning operations prior to continued solder assembly. 


\subsection{Visual Inspection}

3.1 The printed wiring board shall have been inspected by the Quality Assurance Group (QAG) prior to loading. Record inspectors name both below and in the certification log work sheets by paragraph number

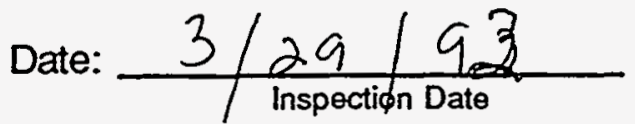

QA:

$$
\frac{\left(\frac{Q A}{\# 2}\right)}{\text { QA Stamp }}
$$

3.2 Record the manufacturer, serial number and manufactures lot code of the printed wiring board to be used in this assembly. Record both below and in the certification log work sheets by paragraph number.

Manufacturer fio weer lircuits

Serial \#:

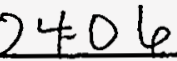

Lot Code: $\operatorname{la} 862$

3.3 Mount the printed wiring board in an Actel Camera printed wiring board carrier.

\subsection{Printed Wiring Board Bake Out}

4.1 The printed wiring board shall be baked at $130 \pm 5^{\circ} \mathrm{C}$ for a minimum of 6 hours prior to loading, per Polyimide Based Printed Wiring Board Conditioning Methods, C1-EE-029. Prior to baking the printed wiring board, verify that the oven to be used is in current calibration and has been verified by the QAG. The start and end times along with the start and end temperatures shall be recorded. The oven temperature profile shall be recorded, using a strip chart recorder, for the duration of the bake out. Record the date, assembly, serial number, assembly step and operator on the chart and insert in the certification section of the assembly log. The make, model and serial number of the oven used for bake out shall be recorded. Record both below and in the ceftification log work sheets by paragraph number.

Oven Calibration and Certification Current:

$\left(\frac{Q}{\$ 2}\right)$
Start Time:
End.Time:
Operator or QA Stamp
Start Temp:
95 ${ }^{\circ} \mathrm{C}$
End Temp:

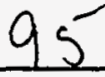
Oven Make: Versa Tema II
Oven Serial \#: $12664-1$
Date:

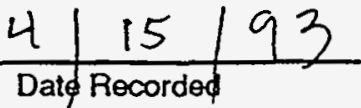
Oven Model: $I+I R$

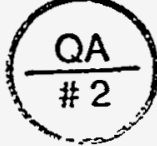
Operator:
Operator or QA Stamp ${ }^{\circ} \mathrm{C}$ 
Note: Printed wiring boards are to be stored in an airtight, antistatic bag with a desiccant at all times the board is not being loaded, cleaned, inspected, tested or baked.

\subsection{Parts Verification}

5.1 Verify that all measuring devices to be used in 5.2 are in current calibration. Record both here and in the Assembly Log work sheets.

Equipment is in current calibration. Fluke - 3/19/93-3/19/95
Dyna SCAN. $9 / 3 / 92-9 / 3 / 93$

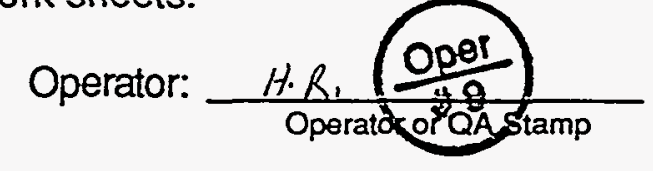

5.2 Verify that parts have been kitted per the bill of materials, LEA92-3128-04.

This includes verification that all resistors and capacitors are within proper tolerance as specified in the bill of materials. Record both below and in the certification log work sheets by paragraph number.

Date:

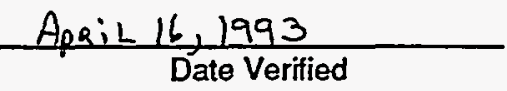

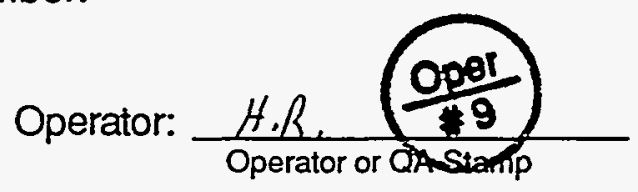

\subsection{Resistance Measurements}

6.1 Resistance measurements are to be made at $\mathrm{J1}$ prior to assembly. Make and record the measurements as indicated in table 1 . All readings must be greater than $10 \mathrm{Meg}$ ohms, except where noted. See figure 1 below for the location of pins in $\mathrm{J} 1$.

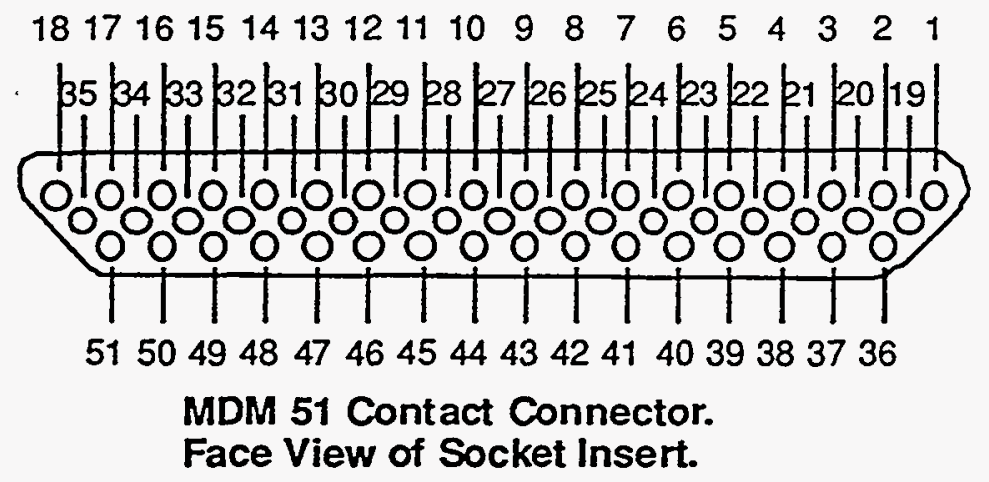

Figure 1. 


\begin{tabular}{|c|c|c|c|c|}
\hline $\begin{array}{c}\text { Meter } \\
\text { Common } \\
\end{array}$ & Signal & $\begin{array}{l}\text { Meter } \\
\text { Signal } \\
\end{array}$ & Signal & Actual \\
\hline$J 1-5$ & AGND & J1-39 & $+15 \mathrm{VDC}$ & \\
\hline$J 1-5$ & $\overline{A G N D}$ & $\sqrt{1-4}$ & $-15 V D C$ & $0 . \mathrm{L}$ \\
\hline J1-5 & AGND & $\sqrt{1-37}$ & $+5 \mathrm{VDC}$ & 0.2 \\
\hline$\sqrt{1-5}$ & AGND & $\sqrt{1-3}$ & $-5 V D C$ & 0.1 \\
\hline$\sqrt{1-5}$ & AGND & $\sqrt{1-40}$ & +5 VIN & $0, h$ \\
\hline$\sqrt{1-5}$ & AGND & $J 1-20$ & DCAOn & 0.2 \\
\hline$\sqrt{1-20}$ & DGND & & & $0 . L$ \\
\hline & & $\sqrt{1-39}$ & $+15 V D C$ & $0 . L$ \\
\hline$J 1-20$ & DGND & $\sqrt{1-4}$ & $-15 \mathrm{VDC}$ & \\
\hline$\sqrt{1-20}$ & DGND & J1-37 & $+5 \mathrm{VDC}$ & 0.5 \\
\hline$\sqrt{11-20}$ & DGND & $\sqrt{1-3}$ & $-5 V D C$ & $0 . L$ \\
\hline$\sqrt{1-20}$ & $\overline{D G N D}$ & $\sqrt{1-40}$ & $+5 \mathrm{VIN}$ & 0.6 \\
\hline$\sqrt{1-39}$ & $+15 \mathrm{VDC}$ & $\sqrt{1-4}$ & $-15 V D C$ & 0.1 \\
\hline$\sqrt{1-39}$ & $+15 \mathrm{VDC}$ & $\sqrt{1-37}$ & $+5 \mathrm{VDC}$ & $0 . L$ \\
\hline J1-39 & $+15 \mathrm{VDC}$ & $\sqrt{1-3}$ & & $0 . L$ \\
\hline$\sqrt{1-39}$ & $+15 \mathrm{VDC}$ & $J 1-40$ & & 0.2 \\
\hline$\sqrt{1-4}$ & $-15 \mathrm{VDC}$ & $\sqrt{1-37}$ & $+5 V I N$ & 0.2 \\
\hline$\sqrt{1-4}$ & $-15 V D C$ & 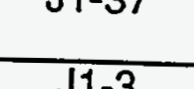 & $+5 \mathrm{VDC}$ & $0 . b$ \\
\hline & & $\sqrt{1-3}$ & $-5 V D C$ & 0.1 \\
\hline$\sqrt{1-4}$ & $-15 V D C$ & $\sqrt{11-40}$ & $+5 \mathrm{VIN}$ & \\
\hline$\sqrt{\mathrm{J} 1-37}$ & $+5 V D C$ & $\sqrt{1-3}$ & $-5 \mathrm{VDC}$ & $0 . L$ \\
\hline$\sqrt{1-37}$ & $+5 \mathrm{VDC}$ & $J 1-40$ & $+5 \mathrm{VIN}$ & $0 . L$ \\
\hline$\sqrt{1-3}$ & $-5 V D C$ & $\sqrt{1-40}$ & +5 VIN & $0, L$ \\
\hline & & & & 0.2 \\
\hline
\end{tabular}

Table 1. 


\subsection{Detailed assembly}

7.1 Installation of item 79, brass CCD mounting nuts, AAA92-109126-00.

7.1.1 Insert item 79 from the secondary side of the printed wiring board as shown in figure 2 below.

\section{Secondary Side View}

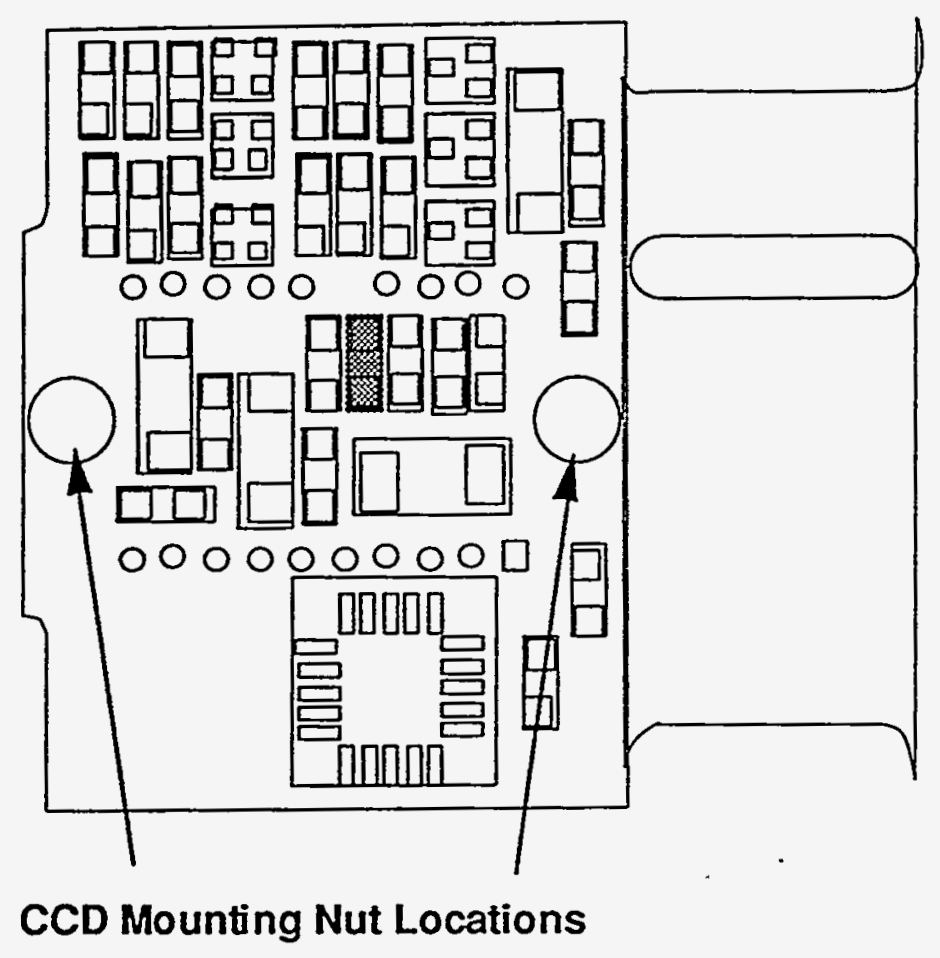

Figure 2.

7.1.2 Verify that the flange on the CCD nut is flush with the surface of the printed wiring board.

7.1.3 Solder the CCD mounting nuts in place.

Note: Use caution to prevent solder from entering the threaded area of the CCD nut.

7.2 Install the items listed in the table 2 below: 


\begin{tabular}{|c|c|c|c|c|}
\hline Item & Qty & Designator & Description & Case \\
\hline 1 & 44 & $\begin{array}{c}\mathrm{C} 1, \mathrm{C} 3, \mathrm{C} 5, \mathrm{C} 6, \mathrm{C} 15, \mathrm{C} 21, \\
\text { C23,C25,C26, } \\
\text { C30,C31,C33,C34,C38, } \\
\text { C39,C40,C42,C44,C45, } \\
\text { C47,C48,C54,C56,C57, } \\
\text { C58,C59,C60,C63,C64, } \\
\text { C66,C67,C70,C91,C92, } \\
\text { C98,C102,C103,C } 104, \\
\text { C106,C109,C112,C114, } \\
\text { C121,C } 124\end{array}$ & $\begin{array}{c}0.039 \mu \mathrm{F}, \\
100 \mathrm{~V}, 10 \%\end{array}$ & RM1206 \\
\hline 9 & 1 & C35 & $\begin{array}{c}0.22 \mu f d \\
50 \mathrm{~V}, 10 \%\end{array}$ & RM1206 \\
\hline 11 & 2 & C49,C50 & $\begin{array}{l}0.022 \mu \mathrm{fd} \\
100 \mathrm{~V}, 10 \%\end{array}$ & RM1206 \\
\hline 12 & 1 & $\mathrm{C} 53$ & $\begin{array}{c}15 \mathrm{pf} \\
100 \mathrm{~V}, 5 \%\end{array}$ & RM1206 \\
\hline 13 & 5 & C73,C74,C75,C76,C77 & $\begin{array}{l}3300 \mathrm{pf} \\
50 \mathrm{~V}, 10 \%\end{array}$ & $\begin{array}{l}\text { RC0402 } \\
\text { RC0505 }\end{array}$ \\
\hline 14 & 1 & $\mathrm{C} 83$ & $\begin{array}{c}0.01 \mu \mathrm{fd} \\
100 \mathrm{~V}, 10 \%\end{array}$ & RM1206 \\
\hline 15 & 1 & C111 & $\begin{array}{c}47 \mathrm{pf} \\
100 \mathrm{~V}, 5 \%\end{array}$ & RM1206 \\
\hline 16 & 2 & $\mathrm{C} 115, \mathrm{C} 116$ & $\begin{array}{c}270 \mathrm{pf} \\
100 \mathrm{~V}, 10 \%\end{array}$ & RM1206 \\
\hline 83 & 8 & $\begin{array}{l}\text { C4,C7,C8,C82,C99, } \\
\text { C100, C101,C123 }\end{array}$ & $\begin{array}{c}0.1 \mu \mathrm{fd}, \\
50 \text { Volt, } 10 \%\end{array}$ & RC1206 \\
\hline 28 & 2 & R3,R66 & $7.5 \mathrm{~K} \Omega, 1 \%$ & RM1206 \\
\hline 30 & 2 & $\mathrm{R} 14, \mathrm{R} 31$ & $243 \Omega, 1 \%$ & RM1206 \\
\hline 31 & 2 & R15,R32 & $1.82 \mathrm{~K} \Omega, 1 \%$ & RM1206 \\
\hline
\end{tabular}

Table 2. 


\begin{tabular}{|c|c|c|c|c|}
\hline Item & Qty & Designator & Description & Case \\
\hline 1 & 47 & $\begin{array}{c}\mathrm{C} 1, \mathrm{C} 3, \mathrm{C} 4, \mathrm{C} 5, \mathrm{C} 6, \mathrm{C} 7, \mathrm{C} 8, \\
\mathrm{C} 15, \mathrm{C} 21, \mathrm{C} 23, \mathrm{C} 25, \mathrm{C} 26, \\
\mathrm{C} 30, \mathrm{C} 31, \mathrm{C} 33, \mathrm{C} 34, \mathrm{C} 38, \\
\mathrm{C} 39, \mathrm{C} 40, \mathrm{C} 42, \mathrm{C} 44, \mathrm{C} 45, \\
\mathrm{C} 47, \mathrm{C} 48, \mathrm{C} 54, \mathrm{C} 56, \mathrm{C} 57, \\
\mathrm{C} 58, \mathrm{C} 59, \mathrm{C} 60, \mathrm{C} 63, \mathrm{C} 64, \\
\mathrm{C} 66, \mathrm{C} 67, \mathrm{C} 70, \mathrm{C} 91, \mathrm{C} 92, \\
\mathrm{C} 98, \mathrm{C} 102, \mathrm{C} 103, \mathrm{C} 104, \\
\mathrm{C} 106, \mathrm{C} 109, \mathrm{C} 112, \mathrm{C} 114, \\
\mathrm{C} 121, \mathrm{C} 124\end{array}$ & $\begin{array}{c}0.039 \mu \mathrm{F} \\
100 \mathrm{~V}, 10 \%\end{array}$ & RM1206 \\
\hline 9 & 1 & C35 & $\begin{array}{l}0.22 \mu \mathrm{fd} \\
50 \mathrm{~V}, 10 \%\end{array}$ & RM1206 \\
\hline 11 & 2 & C49,C50 & $\begin{array}{l}0.022 \mu \mathrm{fd} \\
100 \mathrm{~V}, 10 \%\end{array}$ & RM1206 \\
\hline 12 & 1 & C53 & $\begin{array}{c}15 \mathrm{pf} \\
100 \mathrm{~V}, 5 \%\end{array}$ & RM1206 \\
\hline 13 & 5 & $\mathrm{C} 73, \mathrm{C} 74, \mathrm{C} 75, \mathrm{C} 76, \mathrm{C} 77$ & $\begin{array}{l}3300 \mathrm{pf} \\
50 \mathrm{~V}, 10 \%\end{array}$ & $\begin{array}{l}\text { RC0402 } \\
R C 0505\end{array}$ \\
\hline 14 & 1 & $\mathrm{C83}$ & $\begin{array}{c}0.01 \mu \mathrm{fd} \\
100 \mathrm{~V}, 10 \%\end{array}$ & RM1206 \\
\hline 15 & 1 & $\mathrm{C} 111$ & $\begin{array}{c}47 \mathrm{pf} \\
100 \mathrm{~V}, 5 \%\end{array}$ & RM1206 \\
\hline 16 & 2 & C115,C116 & $\begin{array}{c}270 \mathrm{pf} \\
100 \mathrm{~V}, 10 \%\end{array}$ & RM1206 \\
\hline 83 & 5 & $\begin{array}{c}\mathrm{C} 82, \mathrm{C} 99, \mathrm{C} 100 \\
\mathrm{C} 101, \mathrm{C} 123\end{array}$ & $\begin{array}{c}0.1 \mu \mathrm{fd} \\
50 \text { Volt, } 10 \%\end{array}$ & $\overline{\mathrm{RC1206}}$ \\
\hline 28 & 2 & R3,R66 & $7.5 \mathrm{~K} \Omega, 1 \%$ & RM1206 \\
\hline 29 & 2 & $\mathrm{R} 6, \mathrm{R7}$ & $150 \Omega, 1 \%$ & RM1206 \\
\hline 30 & 2 & $\mathrm{R} 14, \mathrm{R31}$ & $243 \Omega, 1 \%$ & RM1206 \\
\hline 31 & 2 & R15,R32 & $1: 82 \mathrm{~K} \Omega, 1 \%$ & RM1206 \\
\hline
\end{tabular}

Table 2. 
7.3 Clean and inspect all solder joints per MIL-STD-2000. Rework any substandard solder joints. Record inspection both here and in the eprtification log worksheets.

Date:

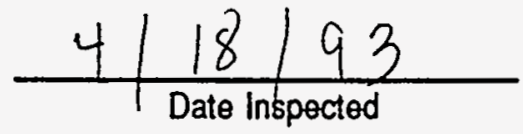

QA: ( $\frac{\mathrm{QA}}{\mathrm{Z}}$

QA Stamp

7.4 The printed wiring board shall be baked at $130 \pm 5^{\circ} \mathrm{C}$ for a minimum of 6 hours prior to loading, per Polyimide Based Printed Wiring Board Conditioning Methods, C1-EE-029. Prior to baking the printed wiring board, verify that the oven to be used is in current calibration and has been verified by the QAG. The start and end times along with the start and end temperatures shall be recorded. The oven temperature profile shall be recorded, using a strip chart recorder, for the duration of the bake out. Record the date, assembly, serial number, assembly step and operator on the chart and insert in the certification section of the assembly log. The make, model and serial number of the oven used for bake out shall be recorded. Record both below and in the certification log work sheets by paragraph number.

Calibration and Certification Current, Initial:

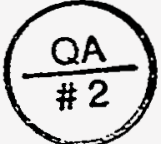
Operator or QA Stamp

Start Time: $5: 00 p \cdot m$ End Time: 11:00 p.w Start Temp:

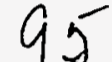
${ }^{\circ} \mathrm{C}$ End Temp: 95 ${ }^{\circ} \mathrm{C}$ Oven Make: Versu Tenv II Oven Model: $T H J R$

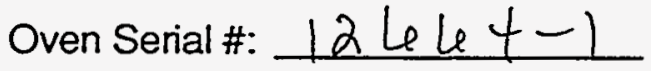

Date:
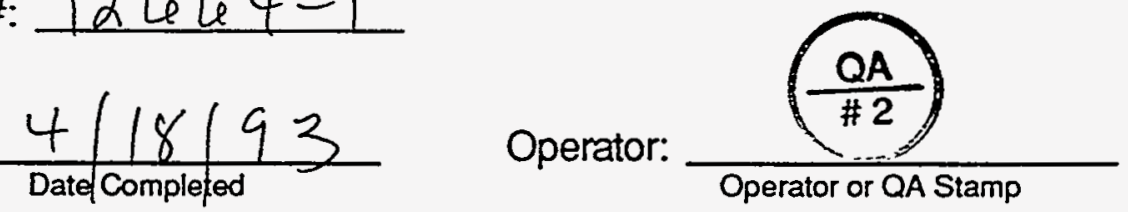

Note: Printed wiring boards are to be stored in an airtight, antistatic bag with a desiccant at all times the board is not being loaded, cleaned, inspected, tested or baked. 
7.5 Install the items listed in tables $3 a$ and $3 b$ below.

\begin{tabular}{|c|c|c|c|c|}
\hline Item & Qty & Designator & Description & Case \\
\hline 32 & 5 & $\begin{array}{l}\text { R16,R116,R130, } \\
\text { R133,R136 }\end{array}$ & $49.9 \Omega, 1 \%$ & RM1206 \\
\hline 33 & 5 & R17,R21,R74,R94,R95 & $1.0 \mathrm{~K} \Omega, 1 \%$ & RM1206 \\
\hline 34 & 1 & $\mathrm{R} 18$ & $2.49 \mathrm{~K} \Omega, 1 \%$ & RM1206 \\
\hline 35 & 1 & $\mathrm{R} 20$ & $2.7 \mathrm{~K} \Omega, 5 \%$ & RM1206 \\
\hline 36 & 1 & $\mathrm{R} 24$ & $1.62 \mathrm{~K} \Omega, 1 \%$ & RM1206 \\
\hline 37 & 1 & R25 & $9.09 \mathrm{~K} \Omega, 1 \%$ & RM1206 \\
\hline 38 & 1 & R26 & $24.3 \mathrm{~K} \Omega, 1 \%$ & RM1206 \\
\hline 39 & 1 & R27 & $7.68 \mathrm{~K} \Omega, 1 \%$ & RM1206 \\
\hline 40 & 2 & R28,R91 & $0 \Omega, 1 \%$ & RM1206 \\
\hline 41 & 9 & $\begin{array}{c}\text { R29,R48,R101,R102,R129, } \\
\text { R132,R135,R140,R141 }\end{array}$ & $10 \mathrm{~K} \Omega, 1 \%$ & RM1206 \\
\hline 42 & 1 & $\mathrm{R} 30$ & $2.15 \mathrm{~K} \Omega, 1 \%$ & RM1206 \\
\hline 43 & 3 & R37,R115, R122 & $100 \Omega, 1 \%$ & RM1206 \\
\hline 44 & 1 & R38 & $3.01 \mathrm{~K} \Omega, 1 \%$ & RM1206 \\
\hline 45 & 2 & R42,R43 & $30 \Omega, 2 \%$ & RM1206 \\
\hline 46 & 2 & R44,R93 & $1.96 \mathrm{~K} \Omega, 1 \%$ & RM1206 \\
\hline 47 & 1 & R46 & $100 \mathrm{~K} \Omega, 1 \%$ & RM1206 \\
\hline 48 & 1 & R92 & $20 \mathrm{~K} \Omega, 1 \%$ & RM1206 \\
\hline 49 & 4 & $\mathrm{R} 96, \mathrm{R} 98, \mathrm{R} 118, \mathrm{R} 120$ & $2.61 \mathrm{~K} \Omega, 1 \%$ & $\overline{R M 1206}$ \\
\hline 50 & 1 & R97 & $301 \Omega, 1 \%$ & RM1206 \\
\hline
\end{tabular}

Table 3a. 
7.5 Install the items listed in tables $3 a$ and $3 b$ below.

\begin{tabular}{|c|c|c|c|c|}
\hline Item & Qty & Designator & Description & Case \\
\hline 32 & 5 & $\begin{array}{l}\text { R16,R116,R130, } \\
\text { R133,R136 }\end{array}$ & $49.9 \Omega, 1 \%$ & $\mathrm{RM} 1206$ \\
\hline 33 & 5 & $\mathrm{R} 17, \mathrm{R} 21, \mathrm{R} 74, \mathrm{R} 94, \mathrm{R} 95$ & $1.0 \mathrm{~K} \Omega, 1 \%$ & RM1206 \\
\hline 34 & 1 & R18 & $2.49 \mathrm{~K} \Omega, 1 \%$ & RM1206 \\
\hline 35 & 1 & $\mathrm{R} 20$ & $2.7 \mathrm{~K} \Omega, 5 \%$ & $\overline{R M 1206}$ \\
\hline 36 & 1 & $\overline{\mathrm{R} 24}$ & $1.62 \mathrm{~K} \Omega, 1 \%$ & RM1206 \\
\hline 37 & 1 & $\mathrm{R} 25$ & $9.09 \mathrm{~K} \Omega, 1 \%$ & RM1206 \\
\hline 38 & 1 & $\mathrm{R} 26$ & $24.3 \mathrm{~K} \Omega, 1 \%$ & RM1206 \\
\hline 39 & 1 & R27 & $7.68 \mathrm{~K} \Omega, 1 \%$ & RM1206 \\
\hline 40 & 2 & $\mathrm{R} 28, \mathrm{R} 91$ & $0 \Omega, 1 \%$ & RM1206 \\
\hline 41 & 9 & $\begin{array}{c}\text { R29,R48,R101,R102,R129, } \\
\text { R132,R135,R140,R141 }\end{array}$ & $10 \mathrm{~K} \Omega, 1 \%$ & $\overline{\mathrm{RM} 1206}$ \\
\hline 42 & 1 & $\mathrm{R} 30$ & $2.15 \mathrm{~K} \Omega, 1 \%$ & RM1206 \\
\hline 43 & 4 & $\mathrm{R} 37, \mathrm{R} 115, \mathrm{R} 122, \mathrm{R} 128$ & $100 \Omega, 1 \%$ & RM1206 \\
\hline 44 & 1 & $\mathrm{R} 38$ & $3.01 \mathrm{~K} \Omega, 1 \%$ & RM1206 \\
\hline 45 & 2 & $\mathrm{R} 42, \mathrm{R} 43$ & $30 \Omega, 2 \%$ & RM1206 \\
\hline 46 & 3 & R44,R93,R119 & $1.96 \mathrm{~K} \Omega, 1 \%$ & $\overline{R M 1206}$ \\
\hline 47 & 1 & R46 & $100 \mathrm{~K} \Omega, 1 \%$ & RM1206 \\
\hline 48 & 1 & $\overline{\mathrm{R} 92}$ & $20 \mathrm{~K} \Omega, 1 \%$ & $\overline{R M 1206}$ \\
\hline 49 & 4 & $\mathrm{R} 96, \mathrm{R} 98, \mathrm{R} 118, \mathrm{R} 120$ & $2.61 \mathrm{~K} \Omega, 1 \%$ & $\mathrm{RM} 1206$ \\
\hline 50 & 1 & R97 & $301 \Omega, 1 \%$ & RM1206 \\
\hline
\end{tabular}

Table 3a. 


\begin{tabular}{r|c|c|r|l} 
Item & Qty & Designator & Description & Case \\
\hline 51 & 2 & R99,R119 & $6.19 \mathrm{~K} \Omega, 1 \%$ & RM1206 \\
\hline 52 & 1 & $\mathrm{R} 112$ & $511 \Omega, 1 \%$ & RM1206 \\
\hline 53 & 1 & $\mathrm{R} 117$ & $40.2 \Omega, 1 \%$ & RM1206 \\
\hline 54 & 1 & $\mathrm{R} 121$ & $649 \Omega, 1 \%$ & RM1206 \\
\hline 55 & 1 & $\mathrm{R} 124$ & $5.1 \Omega 1 \%$ & RM1206 \\
\hline 56 & 1 & $\mathrm{R} 125$ & $499 \Omega, 1 \%$ & RM1206 \\
\hline 57 & 1 & $\mathrm{R} 131$ & $931 \Omega, 1 \%$ & RM1206 \\
\hline 58 & 1 & $\mathrm{R} 134$ & $383 \Omega, 1 \%$ & RM1206 \\
\hline 59 & 1 & $\mathrm{R} 137$ & $178 \Omega, 1 \%$ & RM1206 \\
\hline 60 & 1 & $\mathrm{R} 139$ & $20.0 \Omega, 1 \%$ & RM1206
\end{tabular}

Table 3b.

7.5.1 Temporarily install a $1 \mathrm{~K} 1 \%$ RM1206 resistor for R49. Tack this part only do not fully solder.

7.6 Clean and inspect all solder joints per MIL-STD-2000. Rework any substandard solder joints. Record inspection both here and in the certification log worksheets.

Date: $4 / 22 / 93$ Sue dd page 10 Date Inspected

QA:

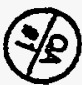

7.7 The printed wiring board shall be baked at $130 \pm 5^{\circ} \mathrm{C}$ for a minimum of 6 hours prior to loading, per Polyimide Based Printed Wiring Board Conditioning Methods, C1-EE-029. Prior to baking the printed wiring board, verify that the oven to be used is in current calibration and has been verified by the QAG. The start and end times along with the start and end temperatures shall be recorded. The oven temperature profile shall be recorded, using a strip chart recorder, for the duration of the bake out. Record the date, assembly, serial number, assembly step and operator on the chart and insert in the certification section of the assembly log. The make, model and serial number of the oven used for bake out shall be recorded. Record both below and in the certification log work sheets by paragraph number. 


\begin{tabular}{c|c|c|c|l} 
Item & Qty & Designator & Description & Case \\
\hline 51 & 1 & R99 & $6.19 \mathrm{~K} \Omega, 1 \%$ & RM1206 \\
\hline 52 & 1 & R112 & $511 \Omega, 1 \%$ & RM1206 \\
\hline 53 & 1 & $R 117$ & $40.2 \Omega, 1 \%$ & RM1206 \\
\hline 54 & 1 & R121 & $649 \Omega, 1 \%$ & RM1206 \\
\hline 55 & 1 & R124 & $5.1 \Omega 1 \%$ & RM1206 \\
\hline 56 & 1 & R125 & $499 \Omega, 1 \%$ & RM1206 \\
\hline 57 & 1 & R131 & $931 \Omega, 1 \%$ & RM1206 \\
\hline 58 & 1 & R134 & $383 \Omega, 1 \%$ & RM1206 \\
\hline 59 & 1 & R137 & $178 \Omega, 1 \%$ & RM1206 \\
\hline 60 & 1 & R139 & $20.0 \Omega, 1 \%$ & RM1206 \\
\hline 84 & 1 & R49 & $200 \Omega, 5 \%$ & RM1206 \\
& & & &
\end{tabular}

Table 3b.

7.6 Clean and inspect all solder joirts per MIL-STD-2000. Rework any substandard solder joints. Record inspection both here and in-the certification log worksheets.

Date:
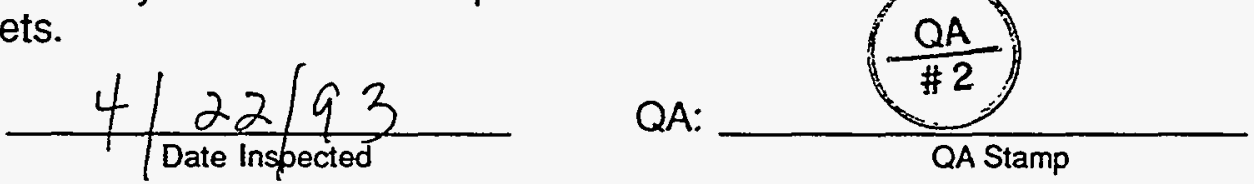

7.7 The printed wiring board shall be baked at $130 \pm 5^{\circ} \mathrm{C}$ for a minimum of 6 hours prior to loading, per Polyimide Based Printed Wiring Board Conditioning Methods, C1-EE-029. Prior to baking the printed wiring board, verify that the oven to be used is in current calibration and has been verified by the QAG. The start and end times along with the start and end temperatures shall be recorded. The oven temperature profile shall be recorded, using a strip chart recorder, for the duration of the bake out. Record the date, assembly, serial number, assembly step and operator on the chart and insert in the certification section of the assembly log. The make, model and serial number of the oven used for bake out shall be recorded. Record both below and in the certification log work sheets by paragraph number.

Calibration and Certification Current, Initial:

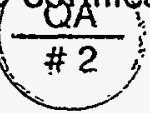


Start Time:

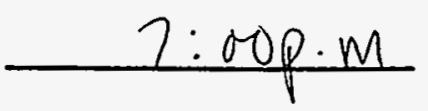

End Time:

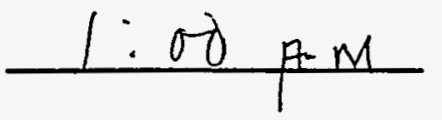

Start Temp:

95 ${ }^{\circ} \mathrm{C}$

End Temp:

95 ${ }^{\circ} \mathrm{C}$

Oven Make: Lersa Gem II

Oven Model: $T H J R$

Oven Serial \#

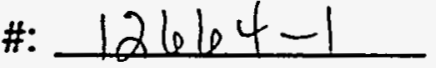

Date:

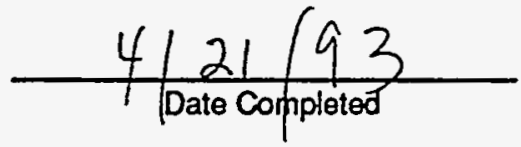

Operator:

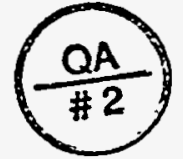

Note: Printed wiring boards are to be stored in an airtight, antistatic bag with a desiccant at all times the board is not being loaded, cleaned, inspected, tested or baked.

7.8 Install the items listed in tables $4 a$ and $4 b$ below.

\begin{tabular}{|c|c|c|c|c|}
\hline Item & Qty & Designator & Description & Case \\
\hline 2 & 5 & C2,C51,C61,C62,C122 & $\begin{array}{l}4.7 \mu f d, \text { Tant, } \\
10 \mathrm{~V}, 10 \%\end{array}$ & D-CASE \\
\hline 3 & 1 & $\mathrm{C9}$ & $\begin{array}{c}47 \mu f d, \text { Tant, } \\
20 \mathrm{~V}, 10 \%\end{array}$ & R-CASE \\
\hline 4 & 2 & $\mathrm{C} 10, \mathrm{C11}$ & $\begin{array}{c}22 \mu \mathrm{fd}, \text { Tant, } \\
15 \mathrm{~V}, 10 \%\end{array}$ & G-CASE \\
\hline 5 & 4 & $\mathrm{C} 12, \mathrm{C} 13, \mathrm{C} 17, \mathrm{C} 105$ & $\begin{array}{l}6.8 \mu \mathrm{fd}, \text { Tant, } \\
10 \mathrm{~V}, 10 \%\end{array}$ & E-CASE \\
\hline 7 & 6 & $\begin{array}{c}\mathrm{C} 22, \mathrm{C} 24, \mathrm{C} 29, \mathrm{C} 69, \mathrm{C} 90 \\
\mathrm{C} 118\end{array}$ & $\begin{array}{l}22 \mu \mathrm{fd}, \text { Tant, } \\
20 \mathrm{~V}, 10 \%\end{array}$ & H-CASE \\
\hline 8 & 4 & C32,C52,C94, C95 & $\begin{array}{l}10 \mu \mathrm{fd}, \text { Tant, } \\
25 \mathrm{~V}, 10 \%\end{array}$ & G-CASE \\
\hline 10 & 2 & C46,C93 & $\begin{array}{l}1.0 \mu \mathrm{fd}, \text { Tant } \\
35 \mathrm{~V}, 10 \%\end{array}$ & D-CASE \\
\hline
\end{tabular}

Table 4a. 


\begin{tabular}{|c|c|c|c|c|}
\hline Item & Qty & Designator & Description & Case \\
\hline 17 & 1 & D1 & $\begin{array}{l}\text { Diode, } \\
\text { Switching, } \\
\text { MBAV74 }\end{array}$ & SOT-23 \\
\hline 20 & 2 & D4,D5 & $\begin{array}{c}\text { Diode, } \\
\text { Schottky, } 30 \mathrm{~V} \\
\text { BAT54S }\end{array}$ & SOT-23 \\
\hline 26 & 3 & Q2,Q3,Q8 & $\begin{array}{l}\text { Transistor, } \\
2 \text { N3904 }\end{array}$ & SOT-23 \\
\hline 27 & 3 & Q12,Q13,Q14 & $\begin{array}{l}\text { Transistor, } \\
\text { 2N7002 }\end{array}$ & SOT-23 \\
\hline 22 & 3 & $\overline{L 1, L 3, L 4}$ & $\begin{array}{l}\text { Inductor, } \\
100 \mu \mathrm{H}\end{array}$ & LQH4 \\
\hline 23 & 1 & L5 & $\begin{array}{c}\text { Inductor, } \\
10 \mu \mathrm{H}\end{array}$ & LQH4 \\
\hline 84 & 1 & $\mathrm{~L} 2$ & $\begin{array}{l}\text { Inductor, } \\
47 \mu \mathrm{H} \text { or } \\
39 \mu \mathrm{H}\end{array}$ & LQH4 \\
\hline 25 & 5 & $\begin{array}{l}\text { Q1,Q4,Q9, } \\
\text { Q10,Q11 }\end{array}$ & $\begin{array}{l}\text { Transistor, } \\
\text { FET, } \\
\text { SST215 }\end{array}$ & $\overline{\text { SOT-143 }}$ \\
\hline 76 & 1 & $\overline{X 1}$ & $\begin{array}{l}\text { Crystal, } \\
20 \mathrm{MHZ}\end{array}$ & CXAT \\
\hline
\end{tabular}

Tabie 4b.

7.8.1 The landing pattern for item 6 was incorrectly designed on some boards. If so, item 6 must be installed on its side. Install item 6 as listed in table 5 below.

\begin{tabular}{c|c|c|c|c} 
Item & Qty & Designator & Description & Case \\
\hline 6 & 2 & C20,C110 & $\begin{array}{c}6.8 \mu f d, T a n t, ~ \\
20 \mathrm{~V}, 10 \%\end{array}$ & F-CASE
\end{tabular}

Table 5. 
7.9 Install the jumpers indicated in table 6 below. These parts are located as shown in Figure 3 on the primary side of the printed wiring board and in Figure 4 on the secondary side of the printed wiring board.

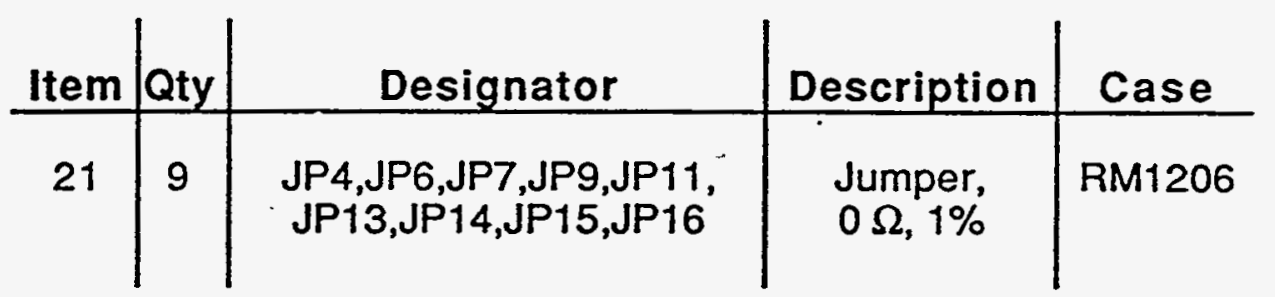

Table 6.

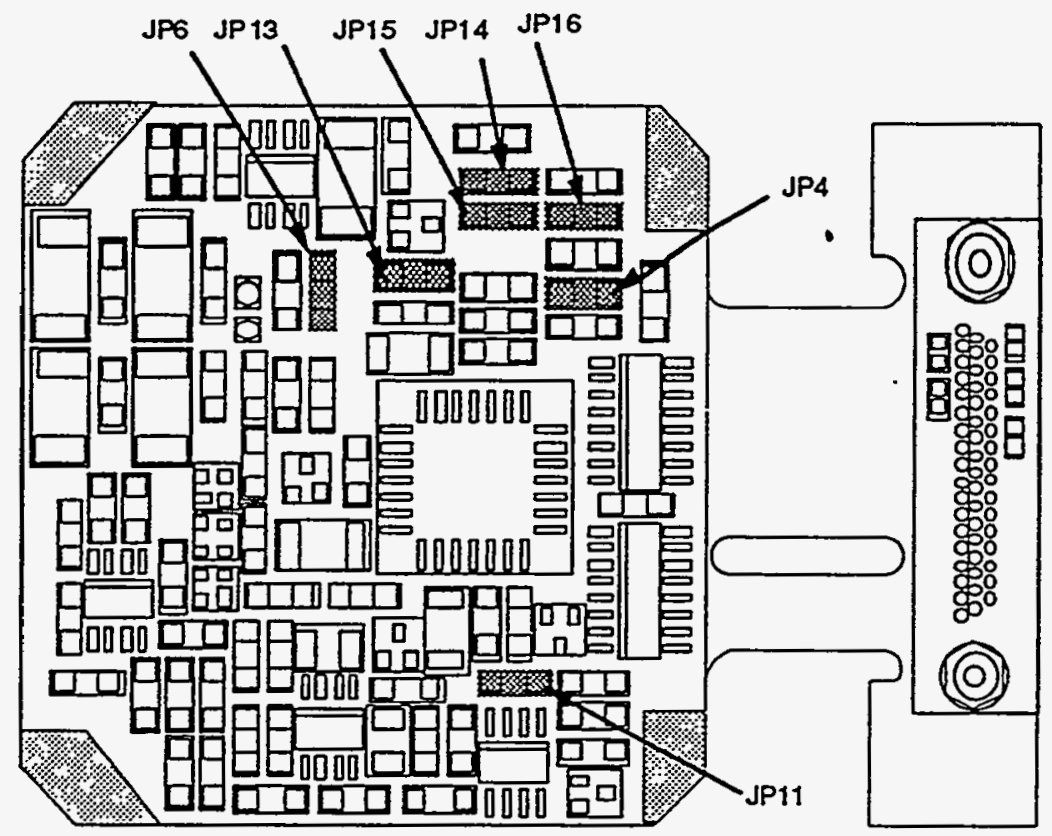

Figure 3, Primary Side View.

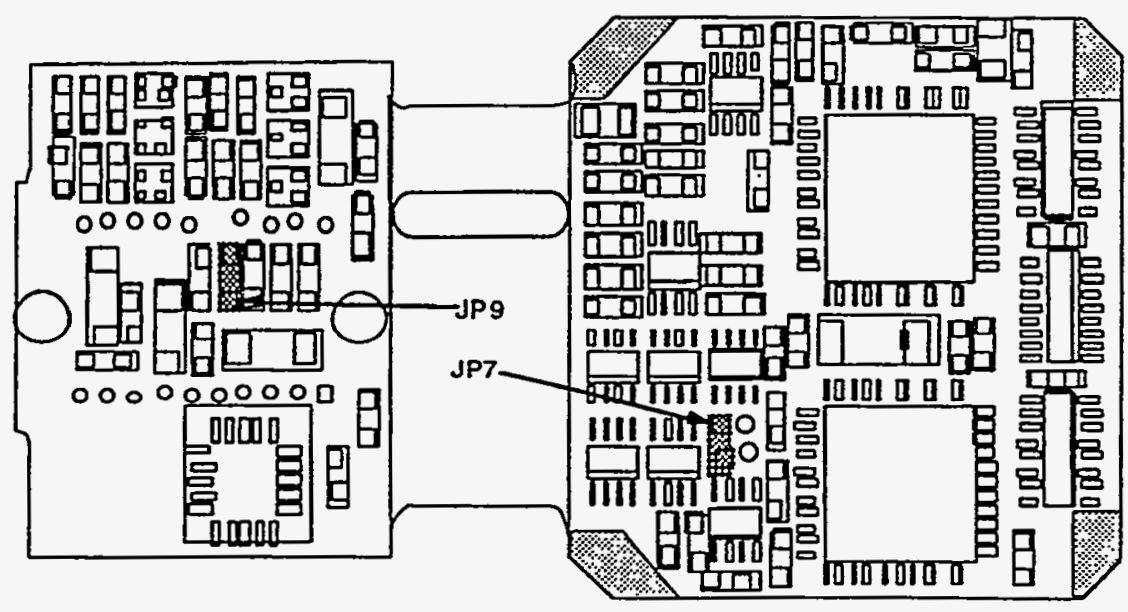

Figure 4, Secondary Side View. 
7.10 Clean and inspect all solder joints per MIL-STD-2000. Rework any substandard solder joints. Record inspection both here and in the certification log worksheets.
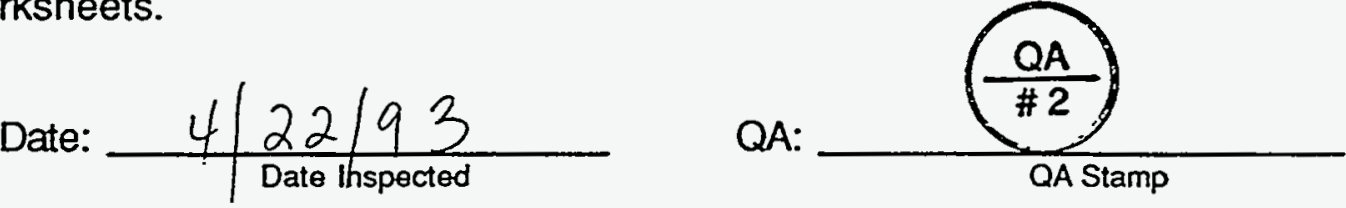

7.11 The printed wiring board shall be baked at $130 \pm 5^{\circ} \mathrm{C}$ for a minimum of 6 hours prior to loading, per Polyimide Based Printed Wiring Board Conditioning Methods, C1-EE-029. Prior to baking the printed wiring board, verify that the oven to be used is in current calibration and has been verified by the QAG. The start and end times along with the start and end temperatures shall be recorded. The oven temperature profile shall be recorded, using a strip chart recorder, for the duration of the bake out. Record the date, assembly, serial number, assembly step and operator on the chart and insert in the certification section of the assembly log. The make, model and serial number of the oven used for bake out shall be recorded. Record both below and in therentrifcation log work sheets by paragraph number.

Calibration and Certification Current, Initial:

Start Time:

$7: 30 \mathrm{p} \cdot \mathrm{m}$.

End Time:

$1: 30$ A.M

Start Temp:

95 ${ }^{\circ} \mathrm{C}$

End Temp:

95 ${ }^{\circ} \mathrm{C}$

Oven Make: Lersa Thu II

Oven Model: $T H J R$

Oven Serial\#: 1266 $4-1$

Date:
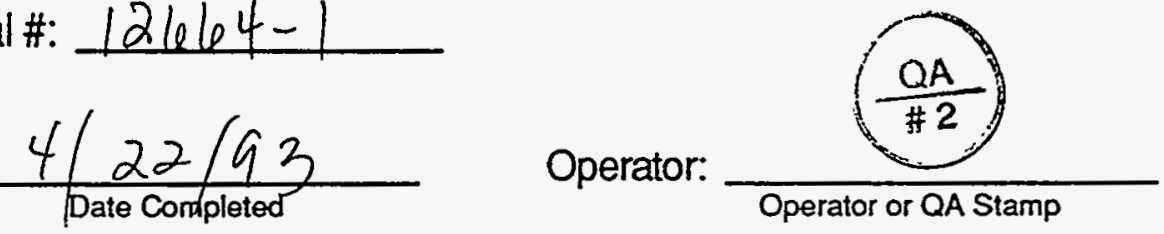

Note: Printed wiring boards are to be stored in an airtight, antistatic bag with a desiccant at all times the board is not being loaded, cleaned, inspected, tested or baked. 
7.12 Install the items listed in tables $7 \mathrm{a}$ and $7 \mathrm{~b}$ below.

\begin{tabular}{|c|c|c|c|c|}
\hline Item & Qty & Designator & Description & Case \\
\hline 4 & 1 & D2 & $\begin{array}{l}\text { Diode, } \\
\text { Voltage } \\
\text { Reference } \\
\text { LM285-1.2 }\end{array}$ & SOIC-8 \\
\hline 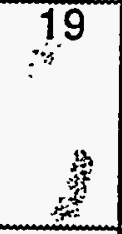 & 1 & D3. & $\begin{array}{l}\text { Reference, } \\
\text { Voltage, } \\
\text { Precision, } \\
\text { 10V, REF-01 }\end{array}$ & SOIC-8 \\
\hline 62 & 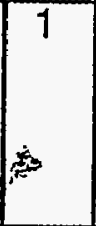 & U1 & $\begin{array}{l}\text { Amplifier,. } \\
\text { Operational, } \\
\text { Clamping } \\
\text { CLC501AJE }\end{array}$ & SOIC-8 \\
\hline $64^{\circ}$ & 2 & $\mathrm{U} 3, \mathrm{U} 27$ & $\begin{array}{c}\text { Amplifier, } \\
\text { Dual, Wide } \\
\text { Band } \\
\text { LF353 }\end{array}$ & SOIC-8 \\
\hline 68 & 4 & $\begin{array}{l}\text { U9,U10,U22- } \\
\text { U23: }\end{array}$ & $\begin{array}{c}\text { Driver, Dual } \\
\text { Inverting } \\
\text { TSC4426 }\end{array}$ & SOIC-8 \\
\hline 69 & 2 & $\mathrm{U} 11, \mathrm{U} 30$ & $\begin{array}{c}\text { Driver, } \\
\text { Differential, } \\
\text { Dual } \\
\text { TSC4428 }\end{array}$ & SOIC-8 \\
\hline 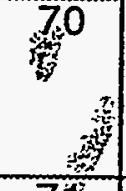 & 1 & U14: & $\begin{array}{l}\text { Amplifier, } \\
\text { Operational, } \\
\text { LF356 }\end{array}$ & SOIC-8 \\
\hline 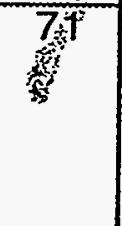 & 2 & U17,U18 & $\begin{array}{l}\text { Regulator, } \\
\text { Voltage, } \\
\text { Adjustable } \\
\text { LM317 }\end{array}$ & SOIC-8 \\
\hline
\end{tabular}

Table 7a. 


\begin{tabular}{|c|c|c|c|c|}
\hline Item & Qty & Designator & Description & Case \\
\hline $\begin{array}{l}9.95 \\
73 \\
7\end{array}$ & 1 & U24 = & $\begin{array}{l}\text { Amplifier, } \\
\text { Operational, } \\
\text { CLC502 }\end{array}$ & SOIC-8 \\
\hline $63^{\prime}$ & 1 & .02 & $\begin{array}{l}\text { Receiver, } \\
\text { Line, Quad } \\
\text { DS34C86 }\end{array}$ & SOIC-16 \\
\hline 66 & 4 & $\begin{array}{l}\text { U6,U7; } \\
\text { U12,U25. }\end{array}$ & $\begin{array}{l}\text { Driver, Line, } \\
\text { Quad } \\
\text { DS34C87 }\end{array}$ & SOIC-16 \\
\hline 67 & 1 & U8 & $\begin{array}{l}\text { Converter, } \\
\text { Analog to } \\
\text { Digital } 8 \text { bit } \\
\text { MP7684 }\end{array}$ & LCC-28 \\
\hline $\begin{array}{l}75 \\
\vdots \\
\vdots \\
\vdots \\
\vdots\end{array}$ & 1 & $\mathrm{U} 32$ & $\begin{array}{l}\text { Converter, } \\
\text { Digital to } \\
\text { Analog } \\
\text { AD558TE/883 }\end{array}$ & LCC20 \\
\hline 65 & 1 & U5 & $\begin{array}{c}\text { Controller, } \\
\text { CCD } \\
\text { TH7990 }\end{array}$ & $\mathrm{JLCC-44}$ \\
\hline
\end{tabular}

Table 7b.

7.13 Item 74, U26, an Actel ACT1020A is a programmed device. Due to its critical function in the operation of the Actel Camera it is not provided until requested. QA verification of the Actel array is required. Record below and in the Assembly Log work sheets the identifying information for the Actel gate array. Record the address on the front page of this document.

File Name: ST2D Luk File Date

Programming Date: $\frac{y-\operatorname{May} 93}{93} \quad$ StarTracker Address $\frac{2}{\# 1 \text { or } \# 2}$

Device Supplied By: DPN

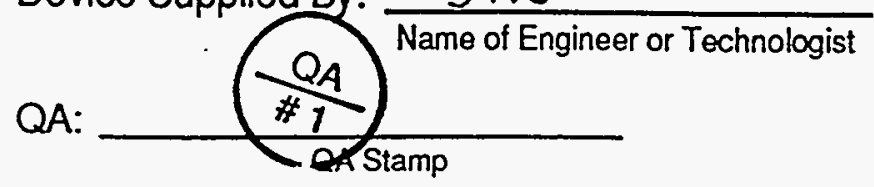


7.14 Install item 74, U26, ACTEL ACT1020A.

7.15 Cut pin number 16 of Item 77, socket strip for U19. Important! The cut must be flush with the base of the taper. See figure 5 below.

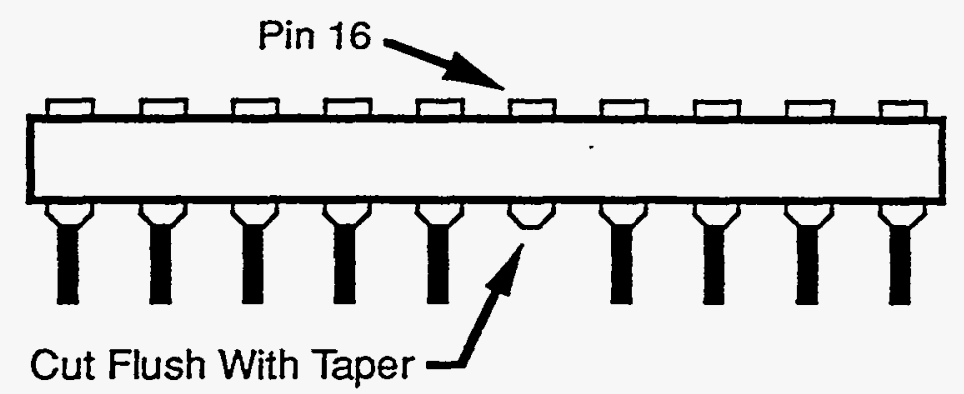

Figure 5.

7.16 Insert both strips of item $77, \mathrm{U} 19$ socket, through the printed wiring board. Insert a dummy 20 pin DIP into the socket strips. Verify that the dummy DIP is completely seated in the socket strips and that the strips sit square and flat to the printed wiring board. Solder the socket strips to the printed wiring board. Remove the dummy DIP from the socket strips.

7.17 Pretin the leads of item 82 TP1 and TP2, two pin terminal strips per C1-EE-023, Preparation of Gold Plated Leads.

7.18 Install Item 82, two pin terminal strips

7.19 Temporarily tack a wire between the outermost pads of R128 and C123. See figure 6 below.

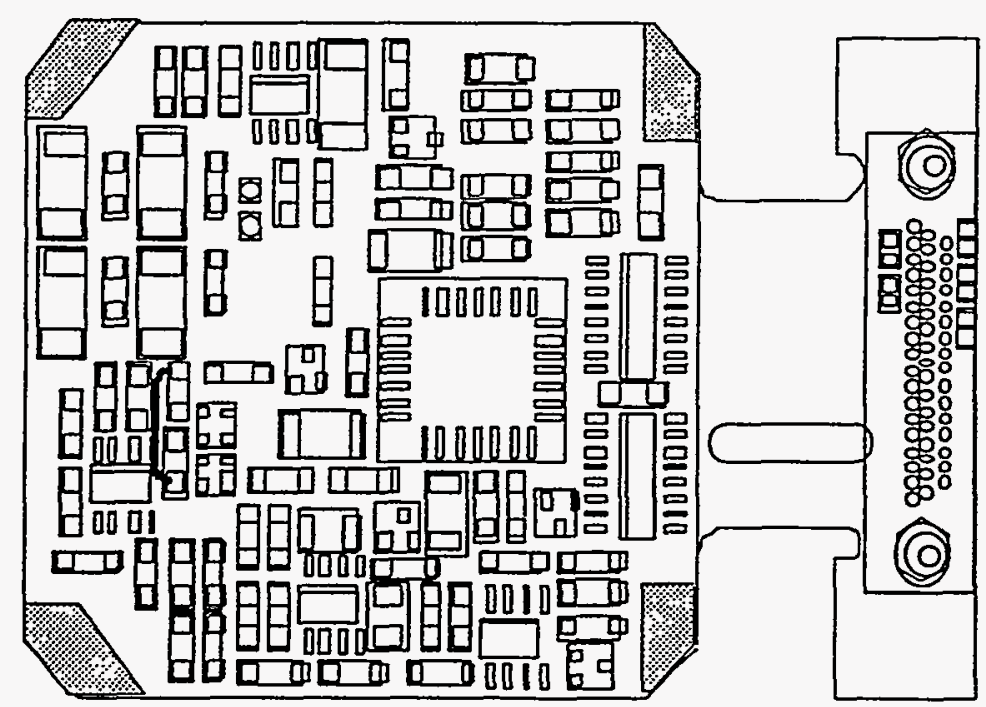

Figure 6. 
7.14 Install item 74, U26, ACTEL ACT1020A.

$\stackrel{3}{3}$

7.15 Cut pin number 16 of Item 77 , socket strip for U19. Important! The cut must be flush with the base of the taper. See figure 5 below.

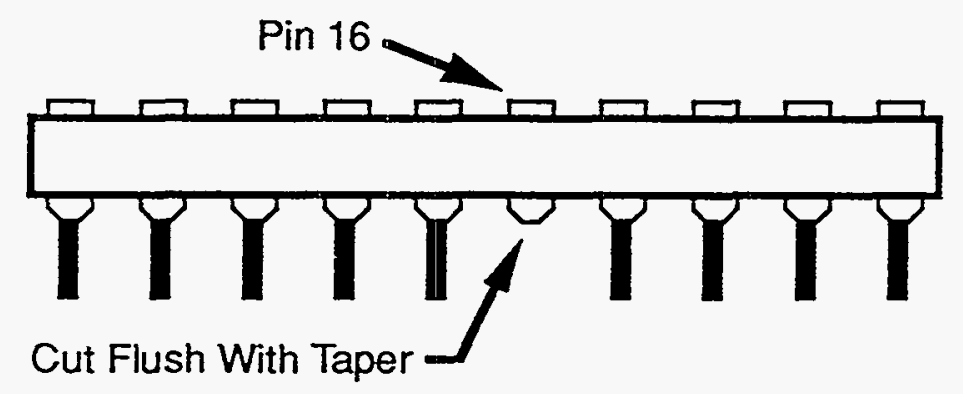

䒺

Figure 5.

7.16 Insert both strips of item $77, \mathrm{U} 19$ socket, through the printed wiring board. Insert a dummy 20 pin DIP into the socket strips. Verify that the dummy DIP is completely seated in the socket strips and that the strips sit square and flat to the printed wiring board. Solder the socket strips to the printed wiring board. Remove the dummy DIP from the socket strips.

7.17

7.17 Pretin the leads of item 82 TP1 and TP2, two pin terminal strips per C1-EE-023, Preparation of Gold Plated Leads.

7.18 Install Item 82, two pin terminal strips

3

7:19 Pretin the leads of item 24, J1 per C1-EE-023, Preparation of Gold Plated Leads.

公

720 Measure the longest dimension of item 78, spacers, AAA92-104616-0B

TAB 01. They should be $0.385+0.005,-0.000$ inch long. Record the measurement both here and in the assembly log work sheets.

Length of Spacers
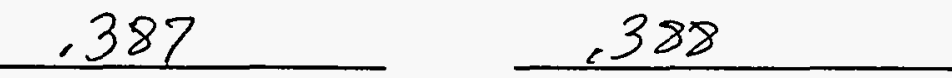

7.21 Assemble 2 each spacers, 2 each \#2 stainless steel washers, item 81, and 2 each \#2-56 stainless steel nuts, item 80 , through the printed wiring board as shown in figure 6. Spacers are mounted from the primary side with nuts and washers on the secondary side. Using a calibrated tool, torque nuts to $40.0 \pm 2$ oz-in.

$$
\begin{gathered}
\text { Torqued nuts to } 40.0 \text { oziin. - Used an uncalibratad Tooh } \\
\text { MHR }
\end{gathered}
$$




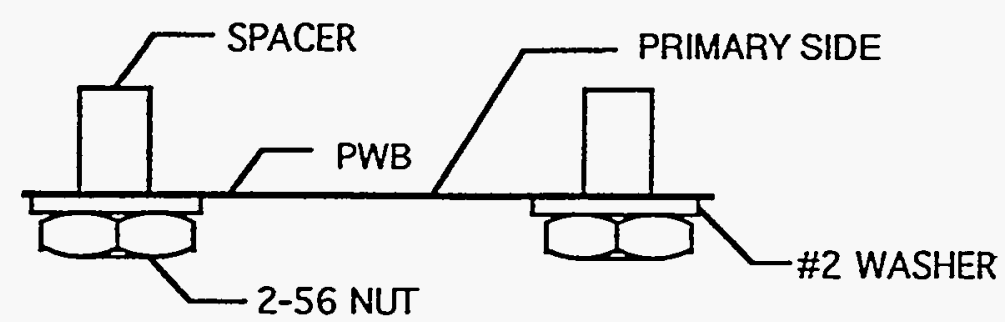

Figure 6.

7.22 Insert the leads of $\mathrm{J1}$ through the printed wiring board. The connector J1 sits on top of the standoffs.

7.23 Assemble $\mathrm{J1}$ to the spacers using 2 each \#2-56 $\times .25$ long. screws as shown in figure 7. Finger tighten only, do not torque.
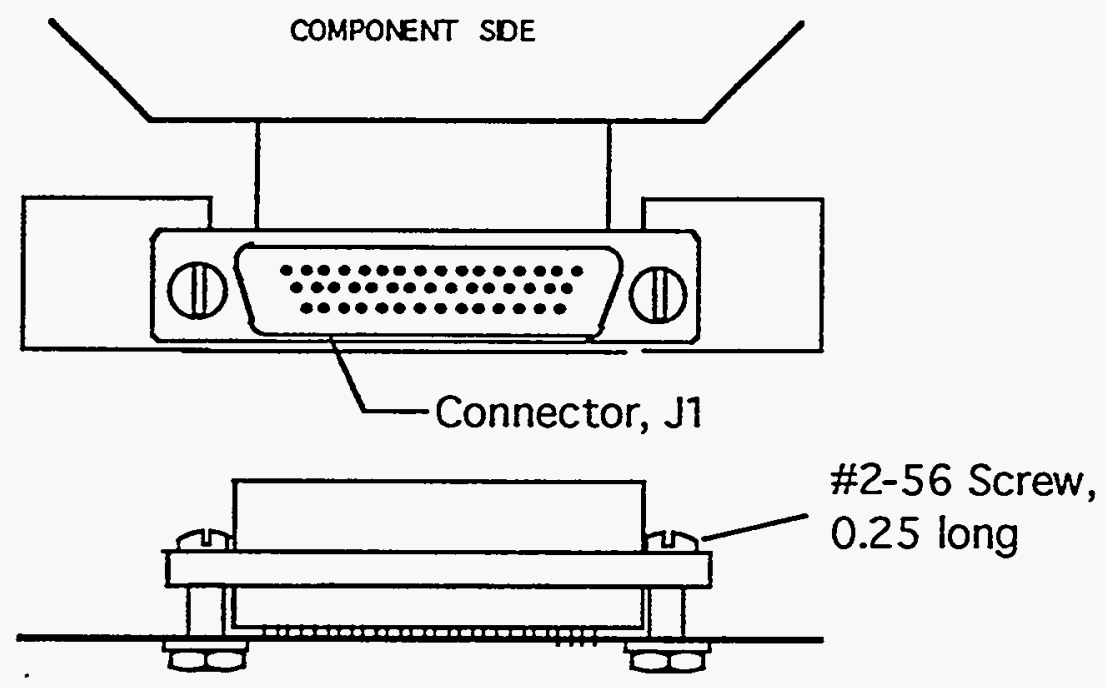

Figure 7.

7.24 Trim the leads of $\mathrm{J} 1$ such that they extend thru the printed wiring board by 0.020 to 0.040 inch.

7.45

7.25 Verify that the bottom surface of the flange of $\mathrm{J} 1$ is $0.257 \pm .005$ inch from the surface of the printed wiring board at both ends of the connector. Record the spacing both here and in the work sheet section of the assembly log.

J1 Bottom Surface distance from PWB: 126$)$

J1 Bottom Surface distance fromRWB: 1261

Operator:

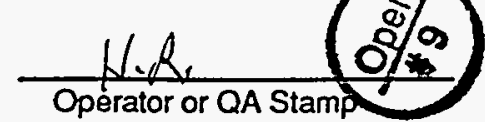


7.19 Temporarily tack a wire between the outermost pads of R128 and C123. See figure 6 below.

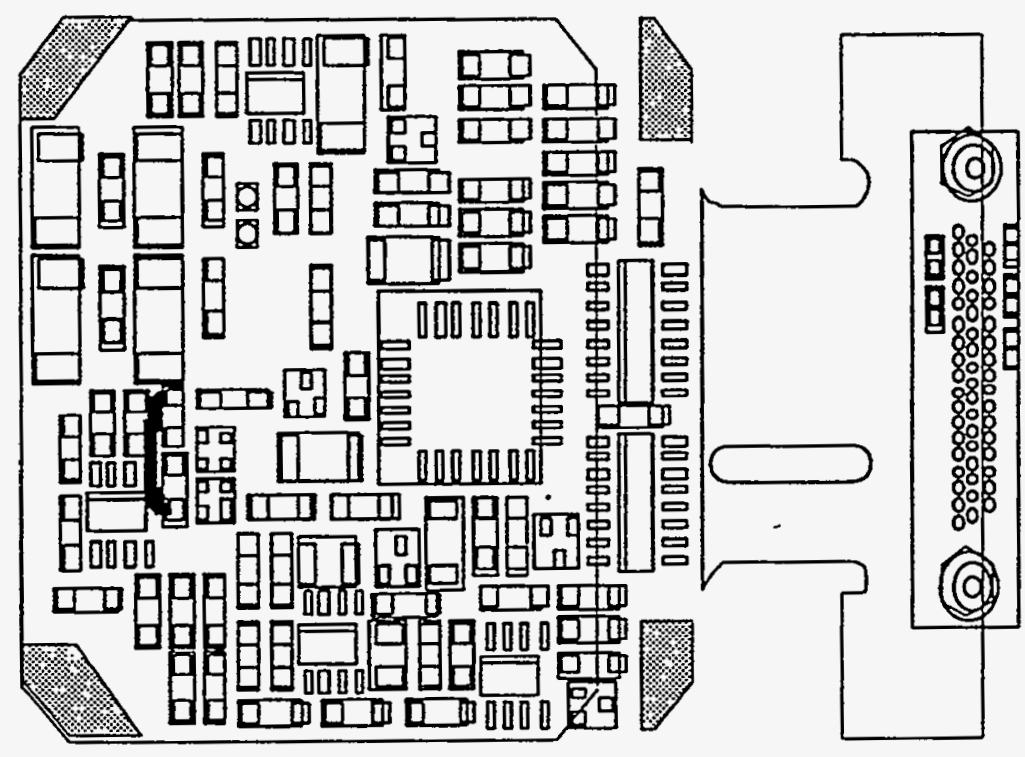

Table 6.

7.20 Pretin the leads of item 24, J1 per C1-EE-023, Preparation of Gold Plated Leads.

7.21 Measure the longest dimension of item 78, spacers, AAA92-104616-0B TAB 01. They should be $0.385+0.005,-0.000$ inch long. Record the measurement both here and in the assembly log work sheets.
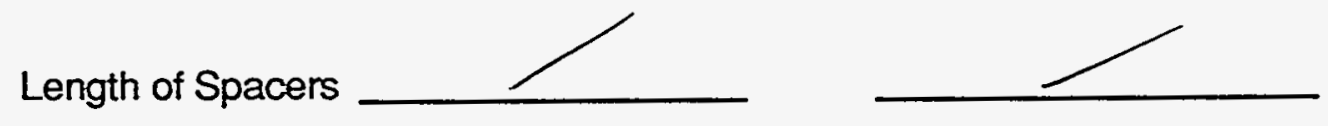

7.22 Assemble 2 each spacers, 2 each \#2 stainless steel washers, item 81 , and 2 each \#2-56 stainless steel nuts, item 80 , through the printed wiring board as shown in figure 7. Spacers are mounted from the primary side with nuts and washers on the secondary side. Using a calibrated tool, torque nuts to $40.0 \pm 2$ oz-in. 
Solder the leads of $\mathrm{J} 1$ to the printed wiring board.

7.27 Installation of item $61, \mathrm{T1}$, thermistor will be done after completion of engineering evaluation.

7.28 Clean and inspect all solder joints per MIL-STD-2000. Rework any substandard solder joints. Record inspection both here and in the certification log worksheets.

Date: $\frac{4 \mid 23 / 93}{\text { BaKed Bd. at }}$

QA: $\frac{\left(\frac{\mathrm{QA}}{\# 2}\right)}{\text { OA Stamp } \theta_{\text {ven }} 5 / N / 2664-1}$

Note: Printed wiring boards are to be stored in an airtight, antistatic bag with a desiccant at all times the board is not being loaded, cleaned, inspected, tested or baked.

7.29 Install a connector saver on $\mathrm{J1}$.

7.30 Resistance measurements are to be made at $\mathrm{J} 1$ at this time. Make and record the measurements as indicated in table 8 . All readings must be greater than $1 \mathrm{~K} \Omega$, except where noted. See figure 8 below for the location of pins in $\mathrm{J} 1$.

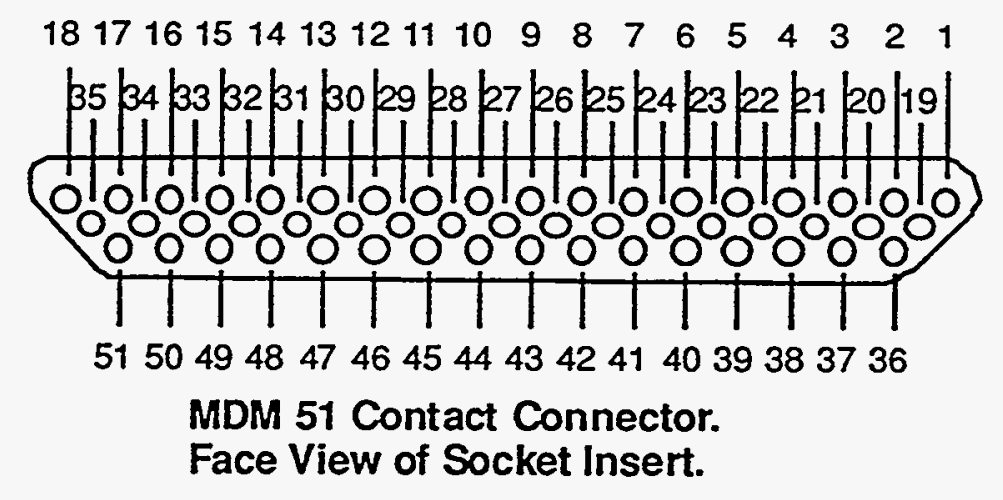

Figure 8. 


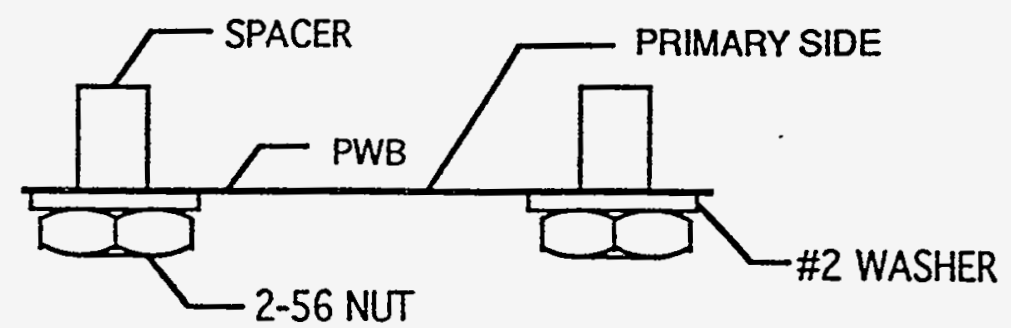

Figure 7.

7.23 Insert the leads of $\mathrm{J} 1$ through the printed wiring board. The connector $\mathrm{J1}$ sits on top of the standoffs.

7.24 Assemble $\mathrm{J} 1$ to the spacers using 2 each \#2-56 $\times .25$ long. screws as shown in figure 8 . Finger tighten only, do not torque.

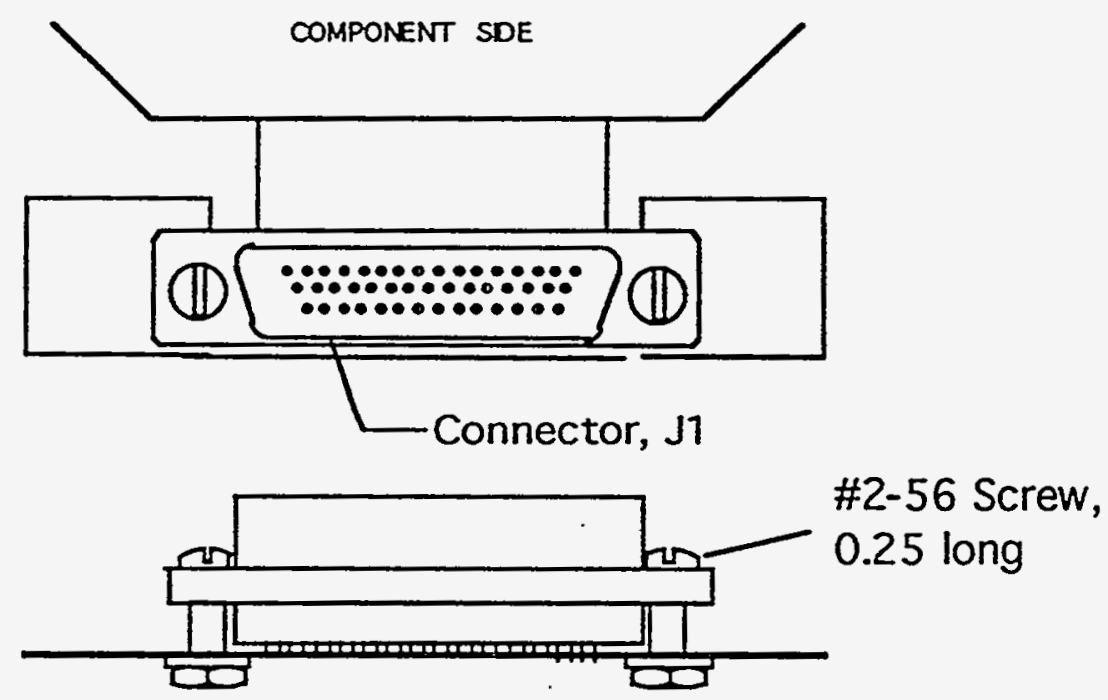

Figure 8.

7.25 Trim the leads of $J 1$ such that they extend thru the printed wiring board by 0.020 to 0.040 inch. 
7.26 Verify that the bottom surface of the flange of $\mathrm{J} 1$ is $0.257 \pm .005$ inch from the surface of the printed wiring board at both ends of the connector. Record the spacing both here and in the work sheet section of the assembly log.

J1 Bottom Surface distance from PWB:

J1 Bottom Surface distance from PWB:

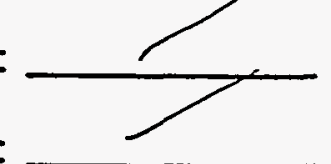

Operator:

$$
\text { Operator or QA Stamp }
$$

7.27 Solder the leads of $J 1$ to the printed wiring board.

7.28 Installation of item $61, T 1$, thermistor will be done after completion of engineering evaluation.

7.29 Installation of items listed in table 8 below will be done after test.

\begin{tabular}{|c|c|c|c|c|}
\hline Item & Qty & Designator & Description & Case \\
\hline 43 & 2 & $R 49, R 128$ & $\begin{array}{c}100 \Omega, 1 \% \\
1 / 4 \mathrm{Watt}, \\
100 \mathrm{ppm}, \\
\mathrm{FR}=0.01 \% / \\
1000 \mathrm{hr}\end{array}$ & $\mathrm{RM} 1206$ \\
\hline
\end{tabular}

Table 8.

7.30 Clean and inspect all solder joints per MIL-STD-2000. Rew̃örk any substandard solder joints. Record inspection both here and in the certification log worksheets.

Date:

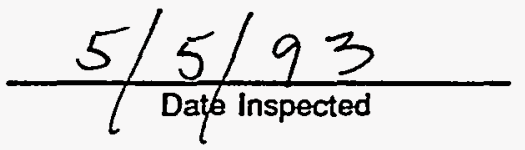

QA:

Note: Printed wiring boards are to be stored in an airtight, antistatic bag with a desiccant at all times the board is not being loaded, cleaned, inspected, tested or baked.

7.31 Install a connector saver on $\mathrm{J1}$. 
7.20 Pretin the leads of item 24, J1 per C1-EE-023, Preparation of Gold Plated Leads.

7.21 Measure the longest dimension of item 78, spacers, AAA92-104616-OB TAB 01. They should be $0.385+0.005,-0.000$ inch long. Record the measurement both here and in the assembly log work sheets.

Ser del paye 17

Length of Spacers .387

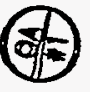

7.22 Assemble 2 each spacers, 2 each \#2 stainless steel washers, item 81, and 2 each \#2-56 stainless steel nuts, item 80 , through the printed wiring board as shown in figure 7. Spacers are mounted from the primary side with nuts and washers on the secondary side. Using a calibrated tool, torque nuts to $40.0 \pm 2$ oz-in.

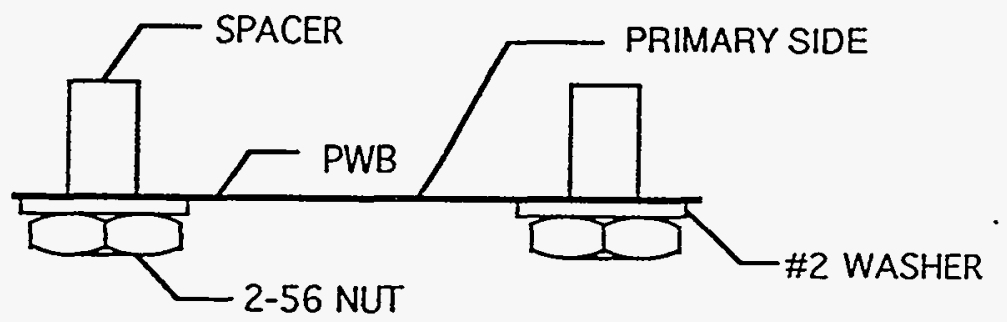

Figure 7.

7.23 Insert the leads of $\mathrm{J} 1$ through the printed wiring board. The connector $\mathrm{J} 1$ sits on top of the standoffs.

7.24 Assemble $\mathrm{J1}$ to the spacers using 2 each \#2-56 $\times .25$ long. screws as shown in figure 8 . Finger tighten only, do not torque.

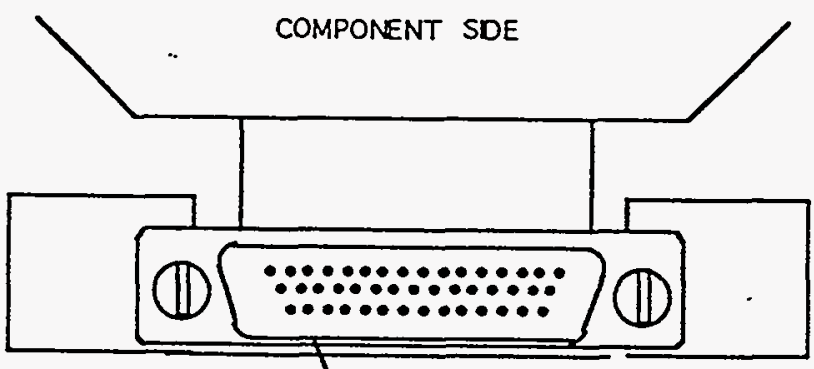

Connector, J1

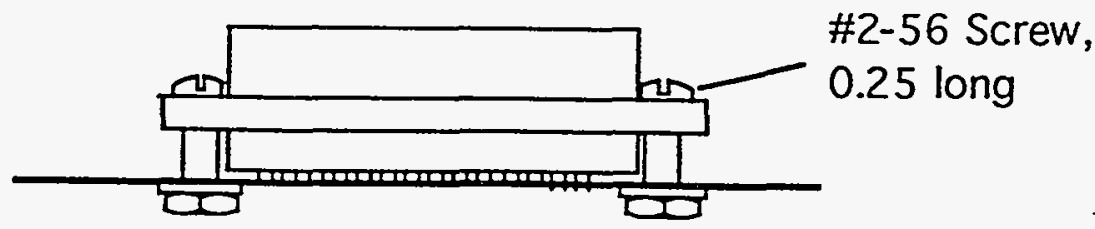

Figure 8. 
7.25 Trim the leads of $J 1$ such that they extend thru the printed wiring board by 0.020 to 0.040 inch.

7.26 Verify that the bottom surface of the flange of 11 is $0.257 \pm .005$ inch from the surface of the printed wiring board at both ends of the connector. Record the spacing both here and in the work sheet section of the assembly log.

J1 Bottom Surface distance from PWB: $\frac{.261}{.261}$

7.27 Solder the leads of $\mathrm{J1}$ to the printed wiring board.

7.28 Installation of item $61, \mathrm{T1}$, thermistor will be done after completion of engineering evaluation.

7.29 Installation of items listed in table 8 below will be done after engineering evaluation.

\begin{tabular}{|c|c|c|c|c|}
\hline Item & Qty & Designator & Description & Case \\
\hline 43 & 2 & $R 49, R 128$ & $\begin{array}{c}100 \Omega, 1 \% \\
1 / 4 \mathrm{Watt}, \\
100 \mathrm{ppm}, \\
\mathrm{FR}=0.01 \% / \\
1000 \mathrm{hr}\end{array}$ & RM1206 \\
\hline
\end{tabular}

Table 8.

7.30 Clean and inspect all solder joints per MIL-STD-2000. Rework any substandard solder joints. Record inspection both here and in the certification log worksheets.

Date: $\frac{4 / 23 / 93 \text { Sic old paye } 19 \text { (A) }}{\text { Date Inspected }}$

Note: Printed wiring boards are to be stored in an airtight, antistatic bag with a desiccant at all times the board is not being loaded, cleaned, inspected, tested or baked.

7.31 Install a connector saver on $\mathrm{J1}$.

7.32 The printed wiring assembly now goes to engineering for evaluation. 


\section{Post Evaluation Assembly}

8.1 The printed wiring board shall be baked at $130 \pm 5^{\circ} \mathrm{C}$ for a minimum of 6 hours prior to loading, per Polyimide Based Printed Wiring Board Conditioning Methods, C1-EE-029. Prior to baking the printed wiring board, verify that the oven to be used is in current calibration and has been verified by the QAG. The start and end times along with the start and end temperatures shall be recorded. The oven temperature profile shall be recorded, using a strip chart recorder, for the duration of the bake out. Record the date, assembly, serial number, assembly step and operator on the chart and insert in the certification section of the assembly log. The make, model and serial number of the oven used for bake out shall be recorded. Record both below and in the certification log work sheets by paragraph number.

Calibration and Certification Current, Initial:

$$
\begin{array}{r}
\text { This bake out step, } \\
\text { was skipped }
\end{array}
$$

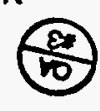

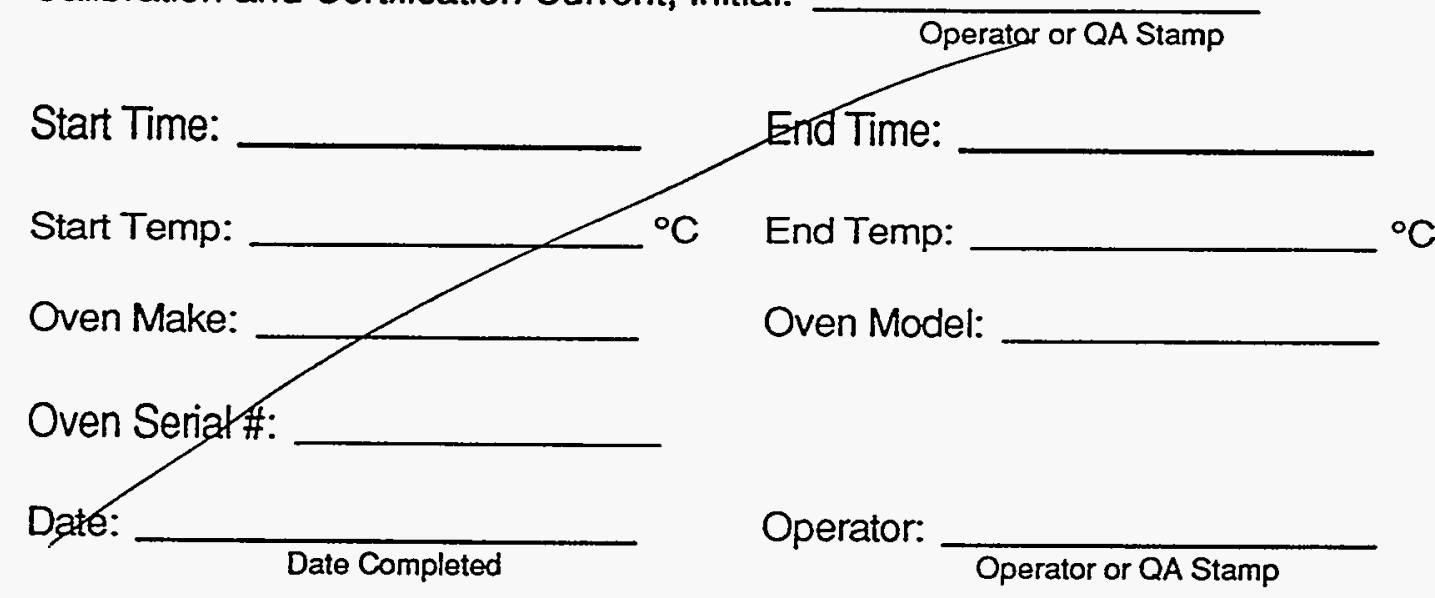

Note: Printed wiring boards are to be stored in an airtight, antistatic bag with a desiccant at all times the board is not being loaded, cleaned, inspected, tested or baked.

8.2 Remove the jumper from outermost pads of R128 and $\mathrm{C} 123$ that was installed at step 7.19

8.3 Install the items listed in table 9 below.

\begin{tabular}{c|c|c|c|c} 
Item & Qty & Designator & Description & Case \\
\hline \multirow{2}{*}{43} & 2 & R49,R128 & $100 \Omega, 1 \%$ & RM1206 \\
& 2 & & $1 / 4$ Watt, & \\
& & & $\begin{array}{c}100 \mathrm{ppm}, \\
\text { FR=0.01\%/ } \\
1000 \mathrm{hr}\end{array}$ &
\end{tabular}

Table 9. 
8.4 Clean and inspect all solder joints per MIL-STD-2000. Rework any substandard solder joints. Record inspection both here and in the certification log worksheets.

Date: $\frac{5 / 5 / 93 \text { Siz worh shert } 68 \text { QA: }}{\text { Date inspected }}$

8.5 The printed wiring assembly now goes to engineering for additional evaluation. 
8.6 The printed wiring board shall be baked at $130 \pm 5^{\circ} \mathrm{C}$ for a minimum of 6 hours prior to loading, per Polyimide Based Printed Wiring Board Conditioning Methods, C1-EE-029. Prior to baking the printed wiring board, verify that the oven to be used is in current calibration and has been verified by the QAG. The start and end times along with the start and end temperatures shall be recorded. The oven temperature profile shall be recorded, using a strip chart recorder, for the duration of the bake out. Record the date, assembly, serial number, assembly step and operator on the chart and insert in the certification section of the assembly log. The make, model and serial number of the oven used for bake out shall be recorded. Record both below and in the certification log work sheets by paragraph number.

Calibration and Certification Current, Initial:

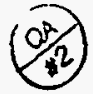

Operator or QA Stamp

Start Time: $8: 30$ A.M End Time: $2 \cdot 30$ P.m

Start Temp: 95 ${ }^{\circ} \mathrm{C}$

Oven Make: Versa Tem II End Temp: 95 ${ }^{\circ} \mathrm{C}$

Oven Serial \#: $12664-1$ Oven Model: $T H J R$

Date:

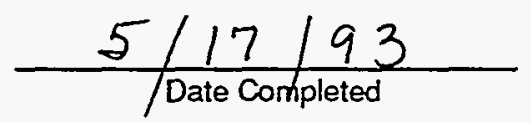

Operator:

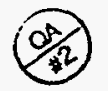

Operator or QA Stamp

Note: Printed wiring boards are to be stored in an airtight, antistatic bag with a desiccant at all times the board is not being loaded, cleaned, inspected, tested or baked.

8.7 Trim and form the leads of TR1 and TR2 as shown in figure 10 below.
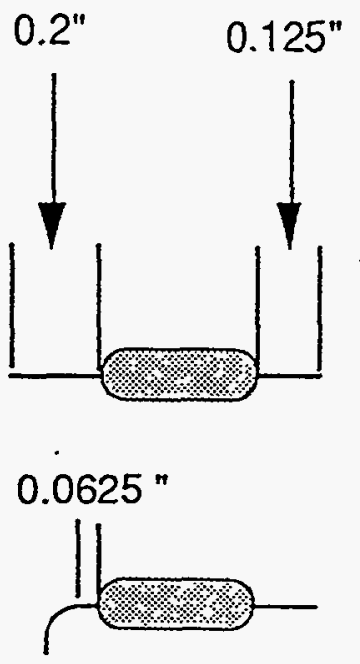

Figure 10. 
8.8 Place, do not solder at this point, TR1 and TR2 on the secondary side of the board as shown in figure 11 below.

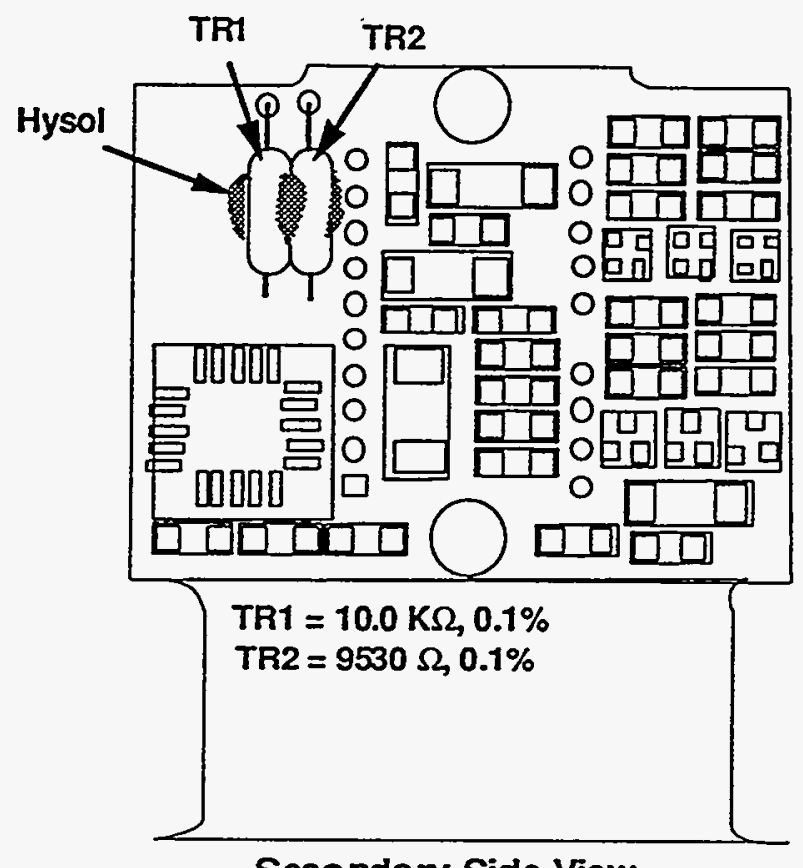

Secondary Side View

Figure 11.

8.9 Bond TR1 and TR2 to the printed wiring board as shown in figure 11 using EA 934 (reference, Eng. Note C1-S0-005). Bake for 30 minutes at $60^{\circ} \mathrm{C}$.

8.10 Identify the leads of item $61, T 1$, thermistor. Lead $L 1$ is the longest lead, $L 4$ is the shortest and L2/L3 is in between. Verify the lead identity by making resistance measurements as shown in figure 12.

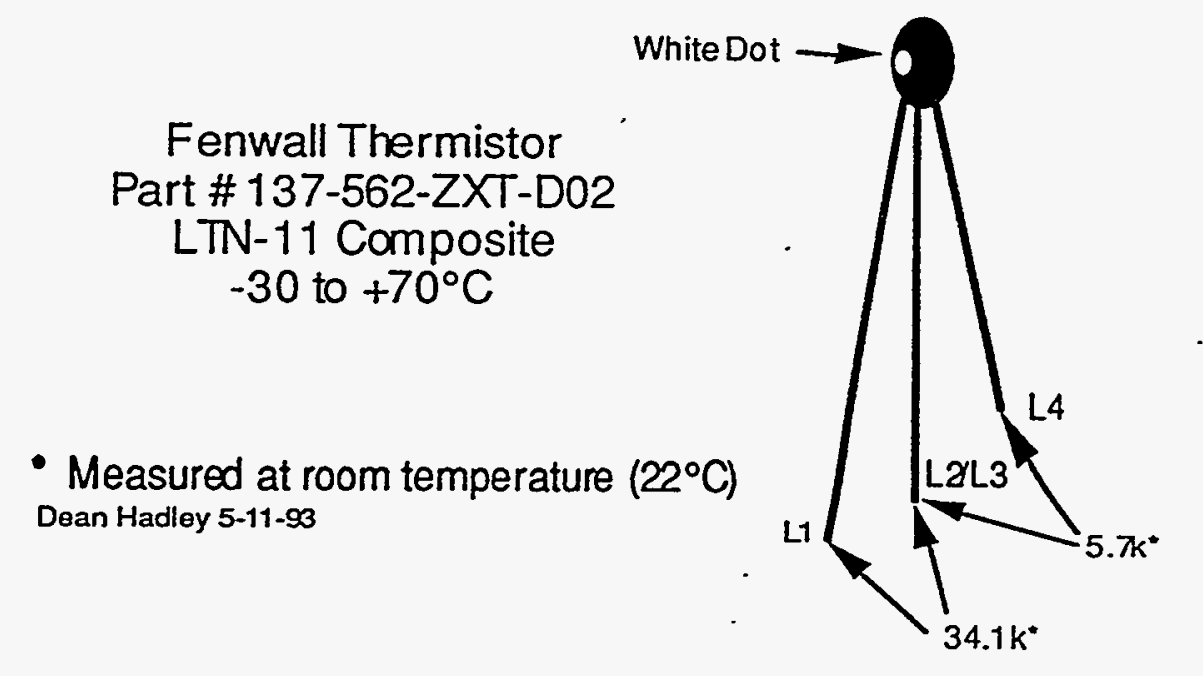

Figure 12. 
8.11 Using \#28 wire wrap wire insulation, insulate lead $L 4$ and $L 1$ to a length of 0.75 inch. Insulate leads $L 2 / L 3$ to a length of 1.5 inch. Use a different color insulation for each lead.

8.12 Insert the lead for $L 4$, from the primary side, through the hole indicated in figure 13. The lead from TR2 is also in this hole. Allow 0.75 inch of lead length between the printed wiring board and the body of the thermistor. See figure 14 for detail.

8.13 Insert the lead for $L 1$, from the primary side, through the hole indicated in figure 13. The lead from TR1 is also in this hole. Allow 0.75 inch of lead length between the printed wiring board and the body of the thermistor. See figure 14 for detail.

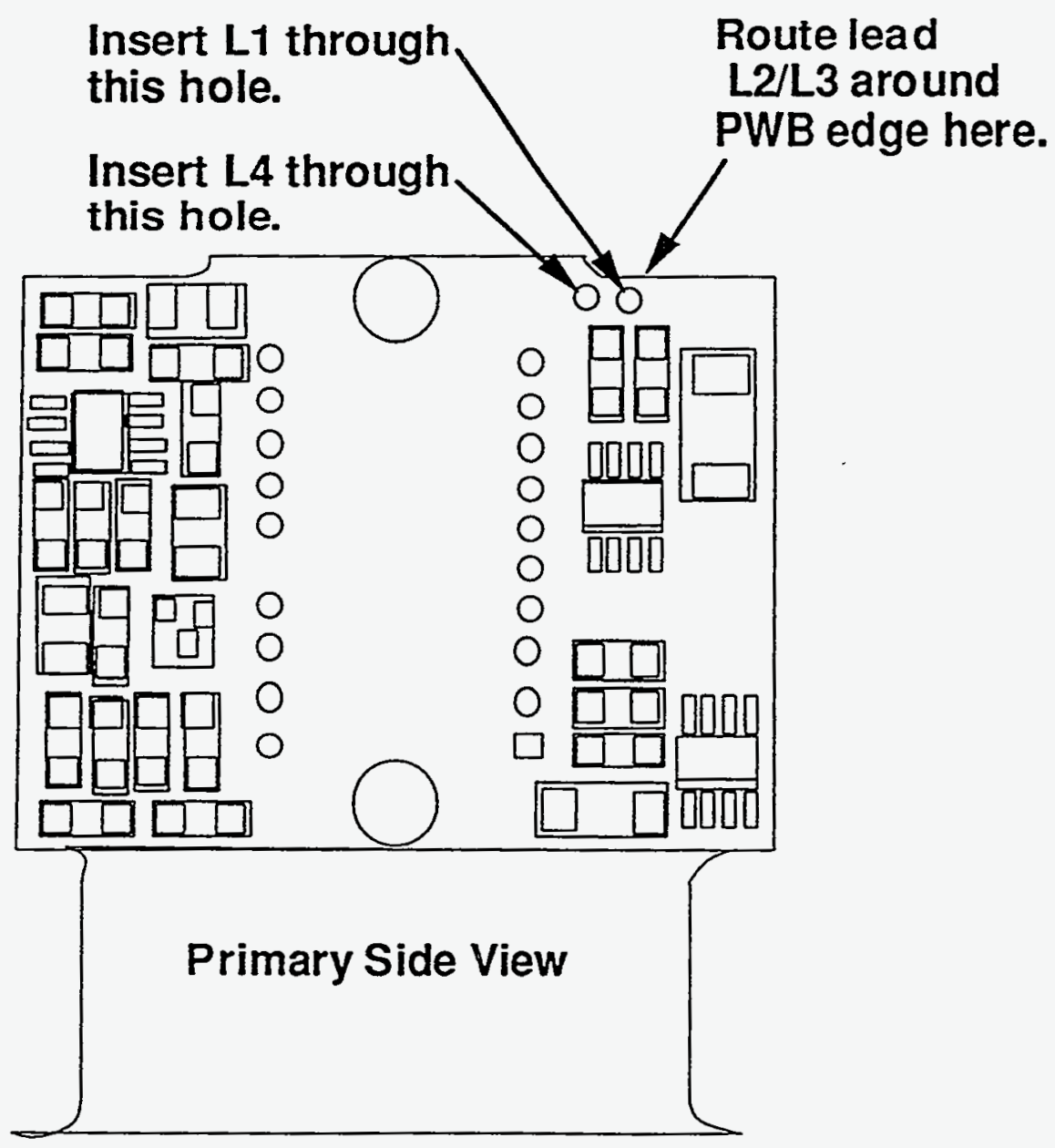

Figure 13. 


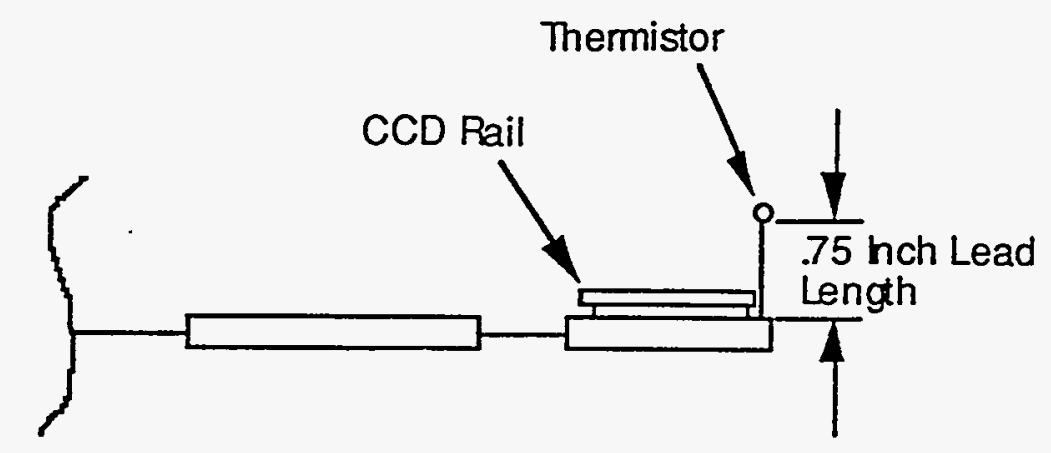

Figure 14.

8.14 Trim L4 to the correct length and solder it along with TR2. Do not trim the lead L1.

8.15 Without trimming the lead, solder L1 and TR1.

8.16 Route lead L2/L3 of $T 1$ around the edge of the printed wiring board and to TR1 as shown in figures 13 and 15. Route lead L1 to TR2 as shown in figure 15.

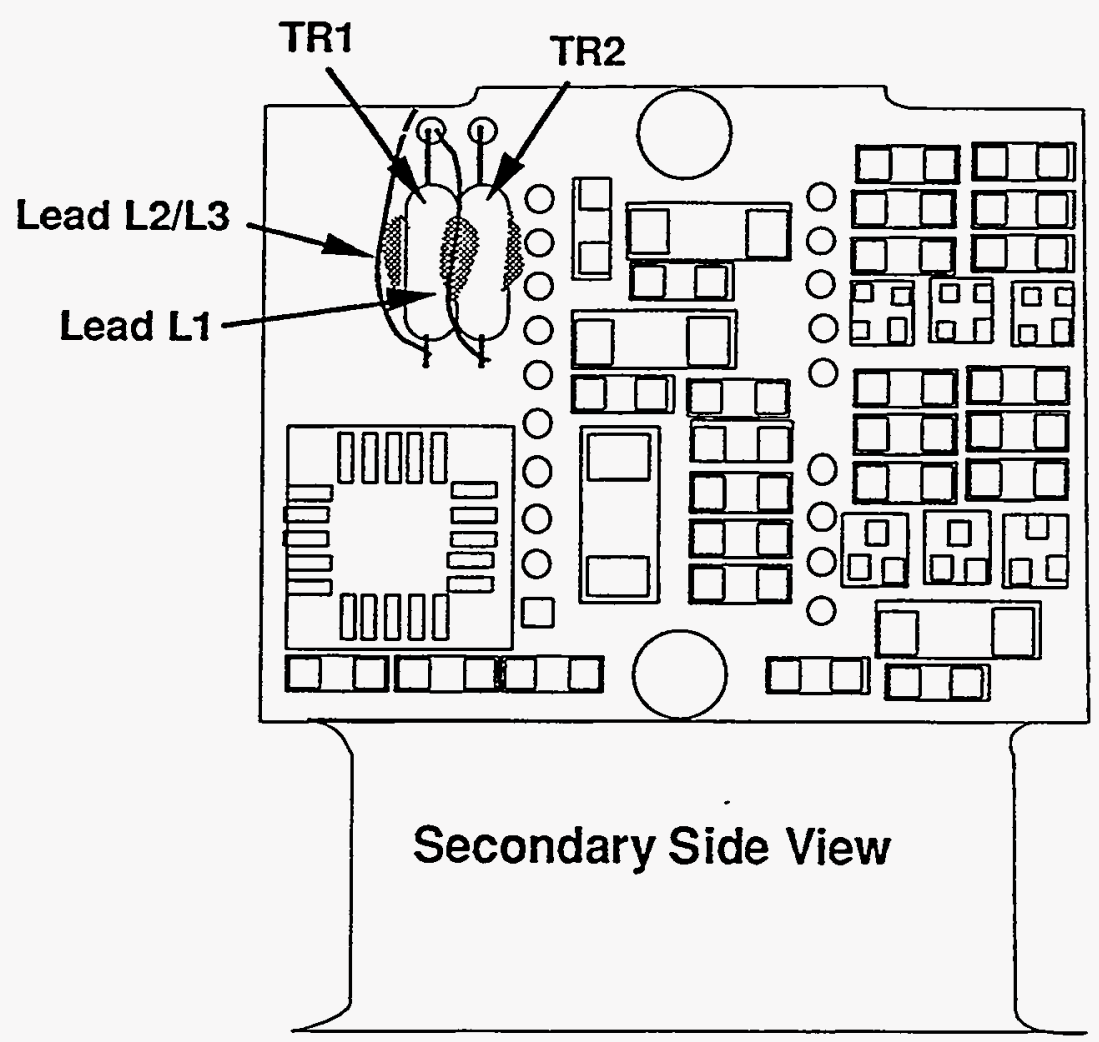

Figure 15. 
8.17 Dress the thermistor wires around the end of the CCD rail as shown in figure 16 below.

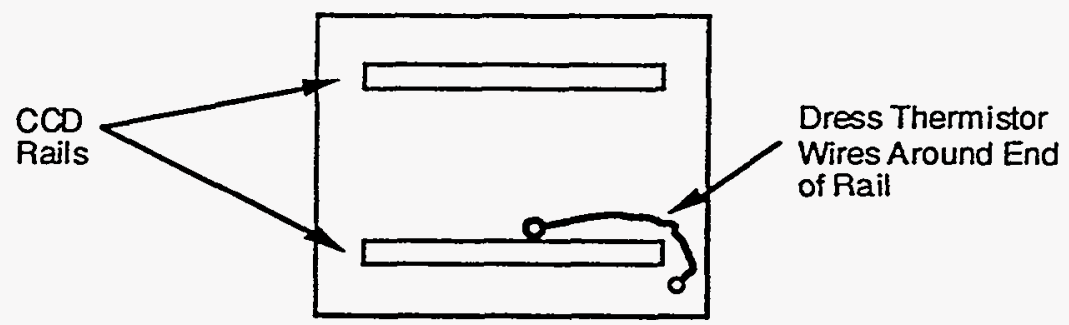

Primary Side View

Figure 16.

8.18 Solder the leads of the thermistor to the leads of TR1 and TR2 as shown in figure 15. The leads of T1 must be wrapped at least 3 times around the lead of TR1 or TR2. Wrap the leads in the middle of the resistor lead.

8.19 Clean and inspect all solder joints per MIL-STD-2000. Rework any substandard solder joints. Record inspection both here and in the certification log worksheets.

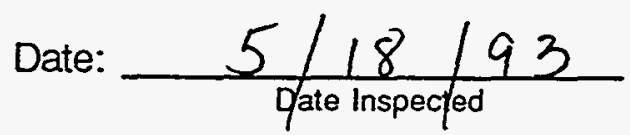

QA:

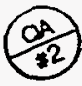

8.20 Stake the thermistor wires, using EA 934 (reference, Eng. Note C1-SO$005)$, on the secondary side of the printed wiring board as shown in figure 17. Keep the staking on the edge of the printed wiring board as thin a practical.

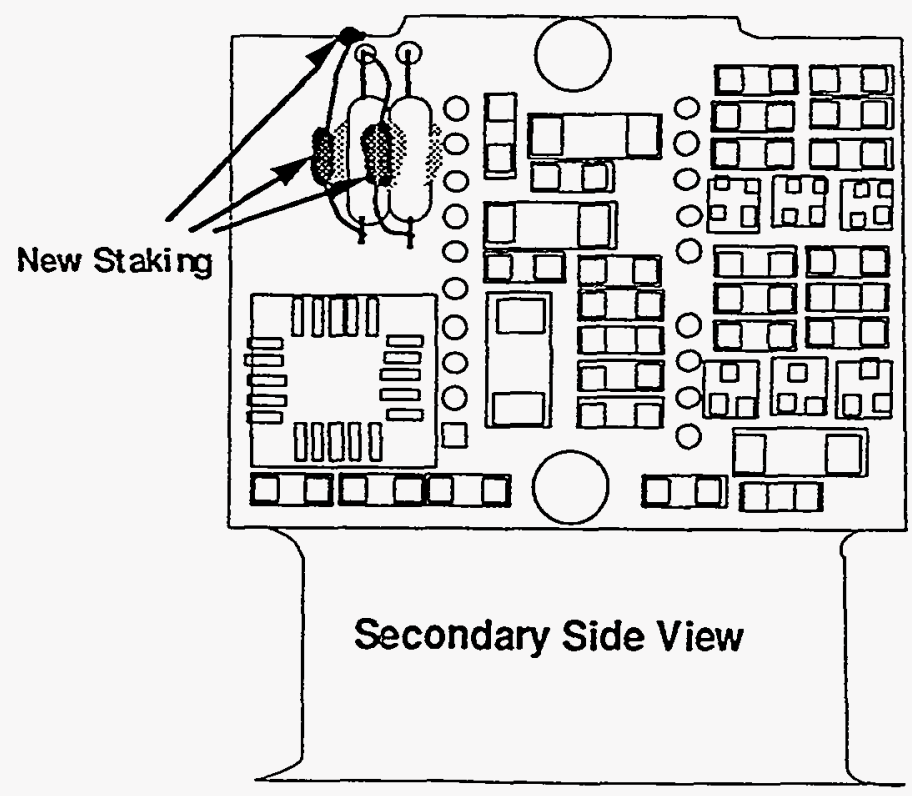

Figure 17. 


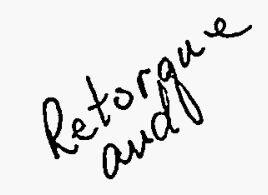

$$
\text { Hardware to board }
$$

8.21 Stake the connector standoff Quality Assurance. Bake for 30 minutes @ $60^{\circ} \mathrm{C}$.

8.22 Inspect all staking operations. Record inspection both here and in the certification log worksheets.

Date: $\frac{5 / 18 / 93}{\text { Date Inspected }}$

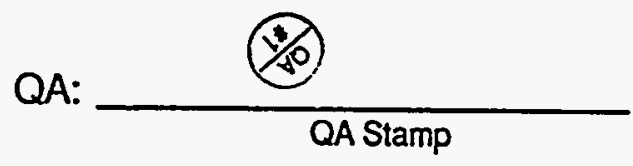

Note: Printed wiring boards are to be stored in an airtight, antistatic bag with a desiccant at all times the board is not being loaded, cleaned, inspected, tested or baked. 


\section{Appendix G.2.5 Certificates of Conformance}


7

3.6 Pre-Test Operations

CAUTION

ESD SENSITIVE HARDWARE.

HANDLE PER MIL-STD-1686 Class 1

_X (1) Assure readiness to test, including the following items:

(a) Visual examination of the test item and its interfaces, including any special test instrumentation .

(b) Calibration is current for measuring instruments

(c) Proper edition of the procedure, and QA approval of any unincorporated redlines.

(d) Notification of QA of the time that testing will begin.

X(2) Record the "Occasion for Test" on all Data Sheets.

$X$ (3) On the applicable data sheets, record the required information for measuring equipment to be used in the test. Verify that all such equipment bears current calibration stickers, and that calibration will not expire prior to the end of the test.

X (4) Have completed Actel Camera Array Test Board Certification C1-EE-033.

X(5) Solicit and obtain the QA Inspector's "OK to Continue."

$$
\begin{aligned}
& \text { ST ID } \\
& 4 / 22 / 43
\end{aligned}
$$

DP N

Startarakes $\$ 2$ aron

Aloes bet $\#$ 14-6b ;

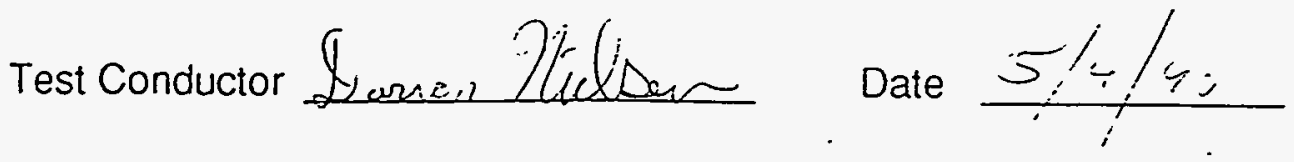




\subsection{TEST}

Test Start Date: $5 / 4 / 43 \quad$ Test Completion Date: $5 / 4 / s_{3}$

Equipment Used

TDS540 S/N $\operatorname{mac} 2 x$

Calibration In-date BO23760 01/ $\theta_{c t} / 43$

Enter Name of LabView programs to Use Name Date Created Actel Test Progrom.1 4/29/93 Date Modified 3/3/43

\section{NOTES:}

Test Conductors:

Name: Eirrsen Hetian Name:
Initials: DPNDate $5 / 4 / 45$ Initials: Date 
Functions to Be tested

\section{Sasi Functions}

Check bits can be set and cleared and read back.

Name:

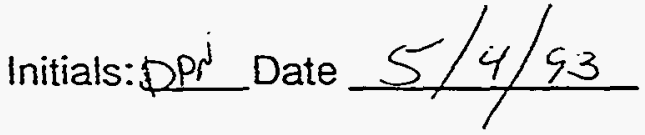

2. Double Correlated Sampling

TP14 is OL2

TP15 is ORfet

TP16 is OR

Name:

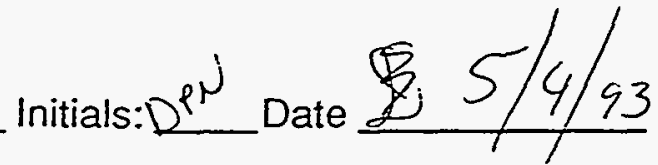

3. Precision Integration mode Check and Frame Enable \{frame xfer of UV-vis arrays\}

TP9 SM1

TP10 SMO

TP11 EOL

TP.3 VSync \{rame enable $\}$

TP13 VTC

Name:

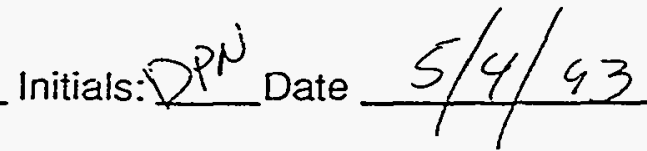

4. Test Initialization

TP8 T2
TP7 Init $2 / 4 \cdot 6, s-W i d t h$

Name:

initials: Dof Date $5 / 4 / 53$

DATA is to go in certification log of camera that array is going into. 


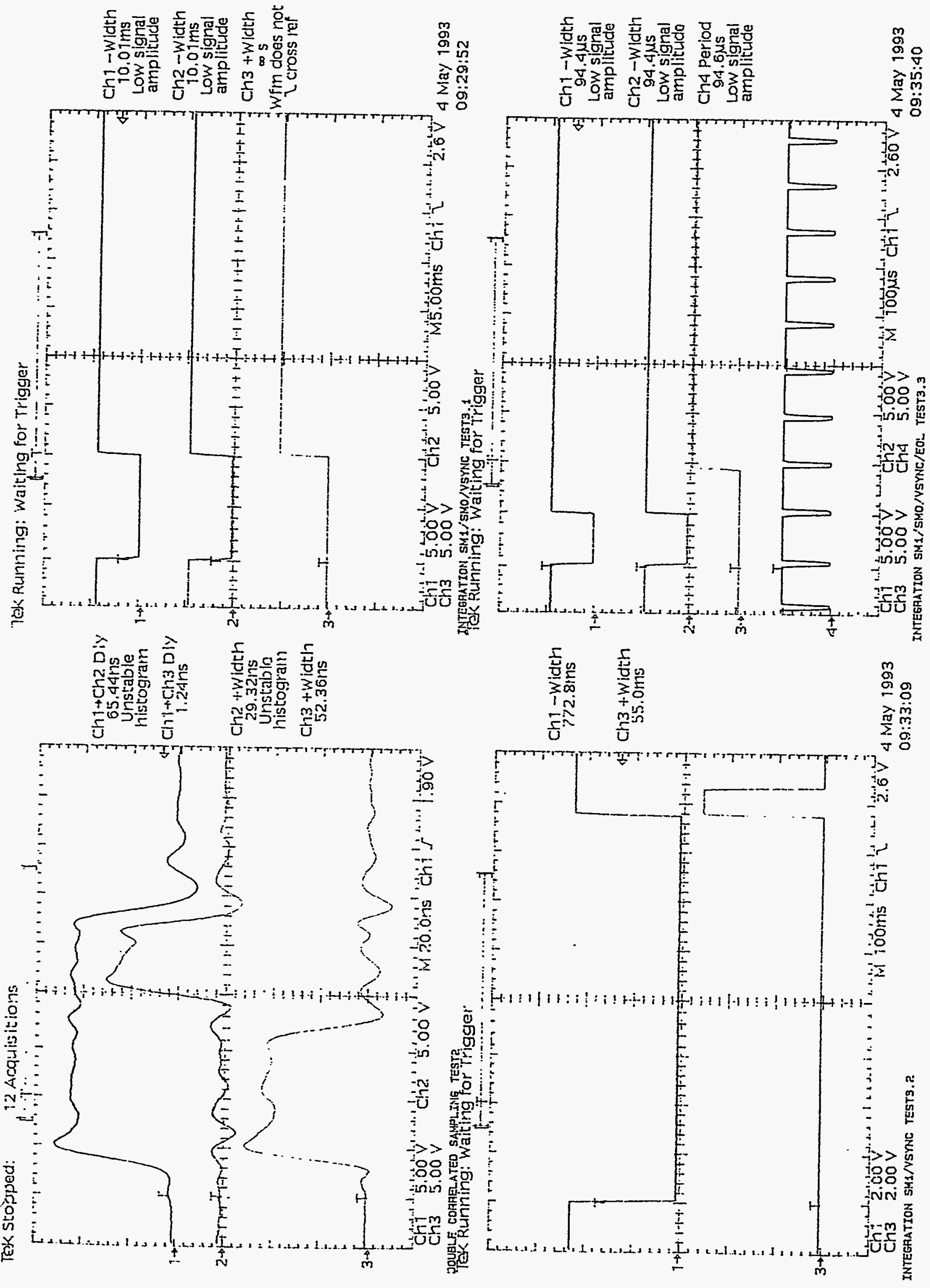




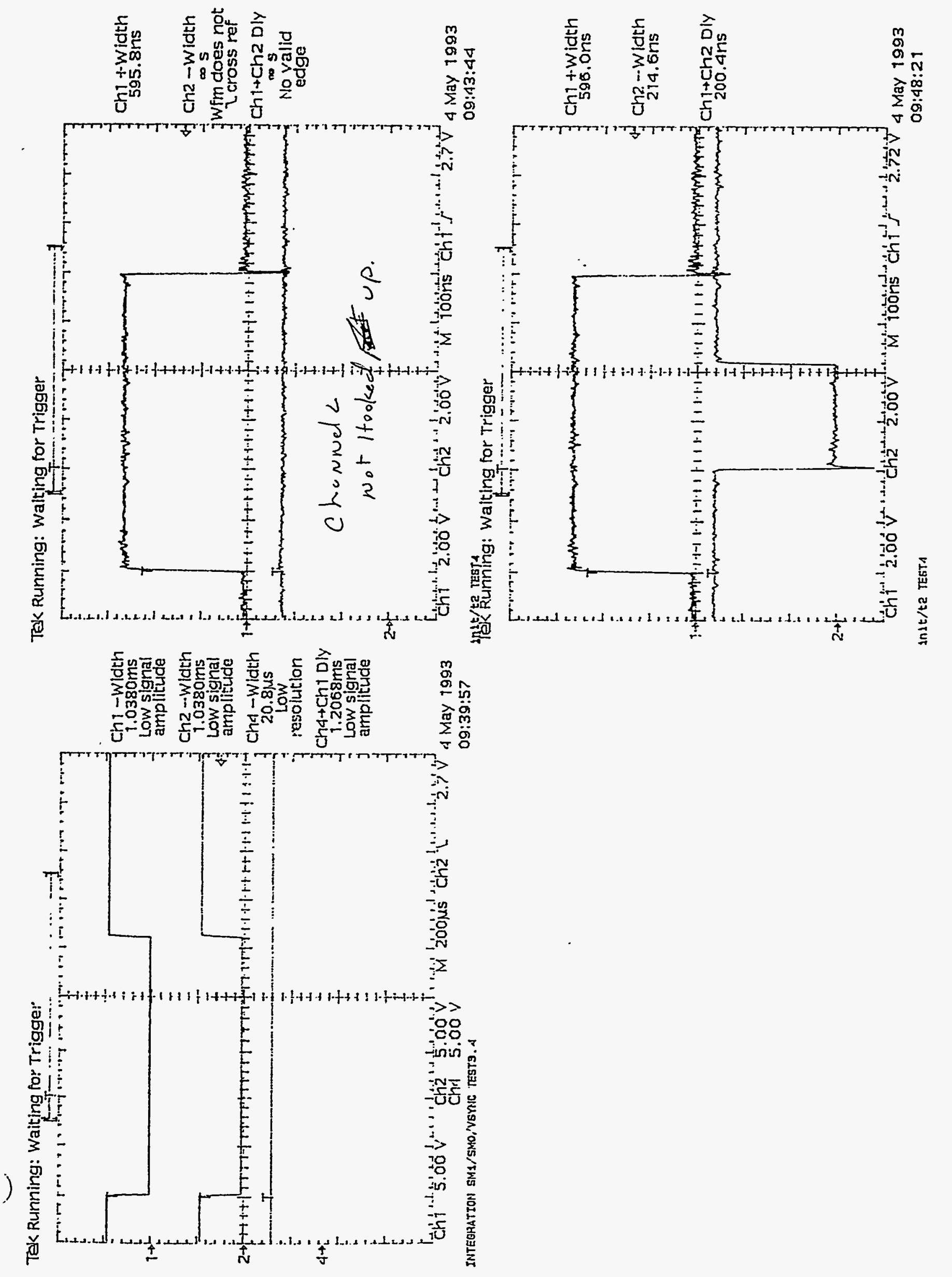


ACTEL CAMERA ARRAY TEST

PROGRAM OF ARRAY AND DATE CODE

:2d

$4-22-93$

TESTER NAME DARRON NIELSEN

$5 / 4 / 93$

$9: 23$

SASI BIT TEST 1

SASI BIT TEST 1 PASSED

$5 / 4 / 93$

$9: 24$

DOUBLE CORRELATED SAMPLING TEST2

DOUBLE CORRELATED SAMPLING TEST 2 PASSED

$\mathrm{CH} 1 \rightarrow \mathrm{CH} 2$ DELAY

$6.54 \mathrm{E}-8 \mathrm{~s}$

$\mathrm{CH} 1 \rightarrow \mathrm{CH} 3$ DELAY

1.24E-9s

$\checkmark \mathrm{H} 2+$ WIDTH

2.93E-8s

$\mathrm{CH} 3+$ WIDTH

5.24E-8s

$\mathrm{CH} 1+$ WIDTH

9.90E-8s

$5 / 4 / 93$

$9: 28$

INTEGRATION SM1/SMO/VSYNC TEST3.1

PASSED

PARM ID $O 9$

PARM ID 11

PARM ID $26 \mathrm{~A}$

PARM ID 30

PARM ID $51 \mathrm{~F}$

$\mathrm{CH} 1$-WIDTH

$1.00 E-2 s$

त2 -WIDTH 
$1.00 \mathrm{E}-2 \mathrm{~s}$

$\mathrm{CH} 3+$ WIDTH

$9.90 \mathrm{E} 37 \mathrm{~s}$

$5 / 4 / 93$

$9: 32$

INTEGRATION SM1/NSYNC TEST3.2

PASSED

PARM ID 09

PARM ID 11

PARM ID 2 FF

PARM ID $31 F$

PARM ID $51 \mathrm{~F}$

CH1 -WIDTH

7.73E-1s

$\mathrm{CH} 3+$ WIDTH

5.50E-2s

$5 / 4 / 93$

$9: 35$

'TEGRATION SM1/SMONSYNC/EOL TEST3.3

rASSED

PARM ID 09

PARM ID 11

PARM ID 21

PARM ID 30

PARM ID $51 \mathrm{~F}$

CH1 -WIDTH

9.44E-5s

$\mathrm{CH} 2+$ WIDTH

9.44E-5s

$\mathrm{CH} 4$ PERIOD

9.46E-5s

$5 / 4 / 93$

$9: 38$

INTEGRATION SM1/SMO/VSYNC TEST3.4

PASSED

PARM ID 09

- RRM ID 11 
PARM ID $2 \mathrm{~B}$

PARM ID 30

PARM ID 5 IF

. 11 -WIDTH

$1.04 \mathrm{E}-3 \mathrm{~s}$

CH2 -WIDTH

1.04E-3s

CH4 -WIDTH

2.08E-5s

$/ \mathrm{CH} 4 \rightarrow / \mathrm{CH} 1$ delay

1.21E-3s

$5 / 4 / 93$

- $9: 42$

init/t2 TEST4

PASSED

CH1 -WIDTH

5.96E-7s

$\mathrm{CH} 2$-WIDTH

9.90E37s $214.6 N 5$ 
CONCORD, NEW HAMPQHIRE $1-8-93^{7 / 16 / 82}$

CONCORD, NEY HAMPQHIRE $1-8-93^{7 / 16 / 82}$

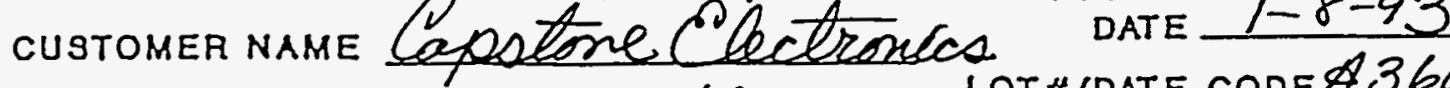
CUSTOMER ORDER \#6X/2344000 CUSTOMER PART \# CUROGFH475KC LOTHIDATE CODE $\$ 3607-/ 9302 T$ BPRAGUE M.O. 75397401 SUMMARY OF TEST DATA MIL-C- $56305 \mathrm{C}$

SROUP A UNPPECTION DATA (Welbull) C

\begin{tabular}{|c|c|c|c|c|}
\hline QUEGRQUP I (10ex) & $\begin{array}{l}\text { BEE } \\
\text { PABA. }\end{array}$ & $\begin{array}{l}\text { AMOUNT } \\
\text { IESTED }\end{array}$ & $\frac{\text { AMQUNI }}{\text { EALLED }}$ & $\begin{array}{l}\text { ALLQWEQ } \\
\text { EAILURES }\end{array}$ \\
\hline Helbull Llfe & 1.7 .17 & $100 \%$ & $F / R=.005$ & $\because N / A$ \\
\hline $\begin{array}{l}\text { SUBaBQUP } \\
\text { DC Leakaga }\end{array}$ & 4.7 .4 & PPH & 0 & 0 \\
\hline Capaollano & 1.7 .6 & Sampling & 0 & 0 \\
\hline Dleslpallon Faolor & 4.7 .0 & $L$ & 0 & 0 \\
\hline EBR (when appllosble) & 4.7 .10 & & 0 & 0 \\
\hline Mochanloal Exam $\cdots$ & 4.7 .2 & $\downarrow$ & 0 & e. \\
\hline $\begin{array}{l}\text { QURGBQUP WU } \\
\text { VI:UAI Ex:m }\end{array}$ & 4.7 .2 & 13 & 0 & 0 \\
\hline QUBGBQUP IY & & & & j \\
\hline $\begin{array}{l}\text { Olabllity al Low \& } \\
\text { High Temporalura }\end{array}$ & 1.7 .12 & 13 & 0 & 0 \\
\hline $\begin{array}{l}\text { SUBGREUP Y } \\
\text { solderablllly... }\end{array}$ & 4.7 .16 & 13 & 0 & 0 \\
\hline
\end{tabular}

SURORQUP

CRQUP C INSPESTION DATA

Vibrellon. High frequenoy,

$4.7 .7 \quad 12$

Thermal shook

1.7 .8

SURGROUP H

Reslalence To Bolder Hosl

$:$

Molsture Roslstanoe

4.7 .8

18

QUBGBQUP Ш

Lilo (2000 hrs. $+1280 \mathrm{C})$

4.7.11

AMOUNT BHIPPED

275

\section{7}

SUBQROUP $Y$

Roololanoe to Bolvento

(whon appllosblo)

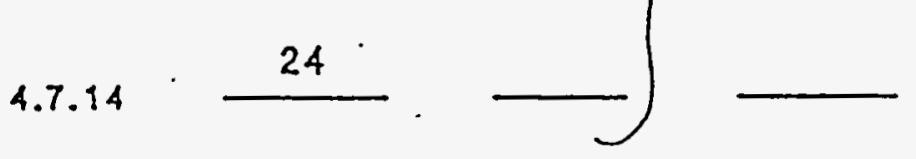

4.7.18 N/A

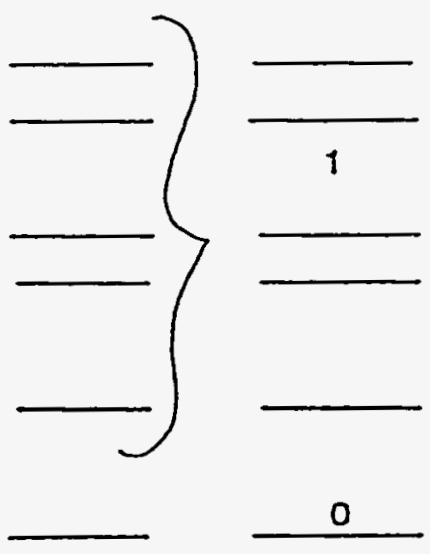

HOTE, Capsoltora lurnlehed agalnat the applloxble epeolflostlon and at repreanted by thla

toet data meet all requiremente.

- N/a lo gold plalod lermination finishos.

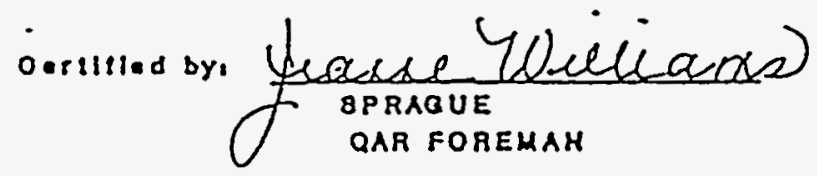


SPRAQUE

$P Q P * 37$

$7 / 16 / 82$

\section{CONCOAD, NEW HAMPSHIAE}

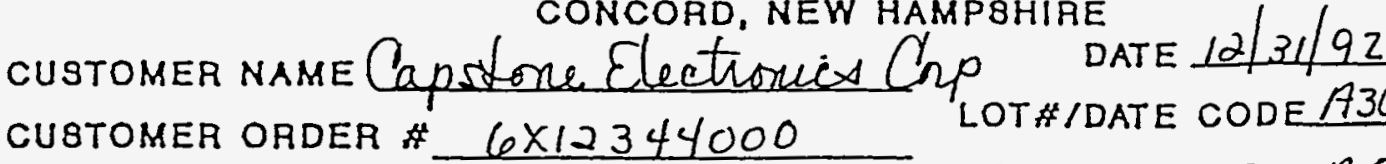

LOT HIDATE CODEA3628-1/9301T

CUBTOMER PART $\mathrm{g}$ SURO6 $\mathrm{HH} 226 \mathrm{KC}$

SPRAQUE M.O. A53974-03

SUMSARY OF TEST DATA

MIL-C- $55305 \mathrm{C}$

QROUP A INSPECTION DATA (WeIbUUi)

\begin{tabular}{|c|c|c|c|c|}
\hline SUEGREUP I (10ex) & $\begin{array}{l}\text { BEE } \\
\text { PABA. }\end{array}$ & $\begin{array}{l}\text { AMQUNT } \\
\text { IESTED }\end{array}$ & $\begin{array}{l}\text { AMQUNI } \\
\text { EALED }\end{array}$ & $\begin{array}{l}\text { ALLOKED } \\
\text { EALLUBES }\end{array}$ \\
\hline Helbull Llfe & 1.7 .1 .7 & $100 \%$ & $F / R=, 0001$ & $N / A$ \\
\hline DC Leakage & 474 & PPM & 0 & 0 \\
\hline Cappollano: & 4.7 .8 & sampling & $\frac{0}{0}$ & $\frac{0}{0}$ \\
\hline $\begin{array}{l}\text { Dlesipallon Faotor } \\
\text { EBR (whon applloabie) }\end{array}$ & 4.7 .0 & + & $\frac{0}{0}$ & 0 \\
\hline Moohanlosl Exam & 1.7 .2 & $\downarrow$ & 0 & e \\
\hline $\begin{array}{l}\text { SURGBQUP UU } \\
V I=U=1 \text { Ex=m }\end{array}$ & 4.7 .2 & 13 & 으 & 0 \\
\hline SUBARQUP IX & & & & 1 \\
\hline $\begin{array}{l}\text { Otabllity at Low } \\
\text { HIon Temperature }\end{array}$ & 4.7 .12 & 13 & 0 & 0 \\
\hline $\begin{array}{l}\text { UBGBQUP Y } \\
\text { solderabllly .. }\end{array}$ & 4.7 .16 & 13 & 0 & 0 \\
\hline
\end{tabular}

SUBGRQUP]

gReUP C WISECTIENDATA

Vibrallon, High Froquenoy,

$4.7 .7 \quad 12$

Thermal 8nook

4.7 .8

sUegreUe U

Feslatanoe To Bolder Hoal

Molslure Resiatenos

AMOUNT BHIPPED

125

.


SPRAGUE

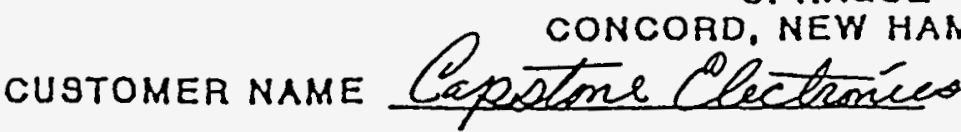
CU8TOMER ORDER :6X12344200 CUBTOMER PART \#

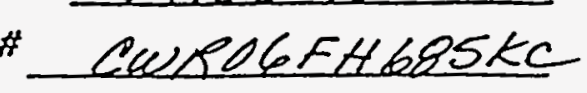
SUMMARY OF TEBT DATA

$M I L-C-553 \theta 5 C$

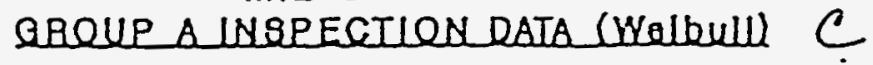

\section{\&UBGBQUP L (10ex)}

Welbull Lifo

SUBGRQUP U

DC Leakage

Diaslpation Faotor

EQR (whon epplloable) :

Meohanloa! Exam

suraboue U

VIsual Exam

Otablilly al Low \&

High Tomperalure

SuEGRQUP $Y$

' Bolderabllity..

\section{SUBGRQUP}

Yibratlon, High Froquenoy,

Thermal 8hook

SUBQRQUP H

Raslotenio To Boldor Hoal

Molsiuró Resletanoo

Lllo (2000 hrs. $+1200 \mathrm{C})$

\section{SUBCROUP $Y$}

hosistanoe lo Bolvonlo

(when applloable)
Capeollanoe

SUBQBQUP IY

SUBQRQUP UII

BEF AMQUNT AMQUNT PARA. IESTED EALLED

4.7 .17

4.7 .1

4.7 .6

4.7 .0

4.7 .10

4.7 .2

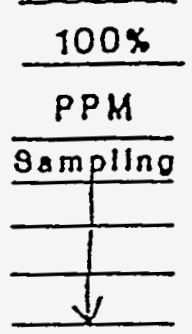
$F / R=$

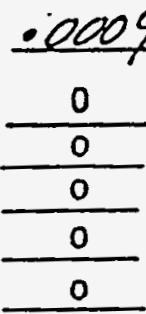

ALLQWER EALLUREB $\because N / A$ LOT IDATE CODE $\angle 5823-1 / 9397$ BPRAQUE M.O. A5397402 AMOUNT BHIPPED 175

DATE $3 / 4 / 03$

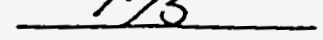

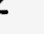

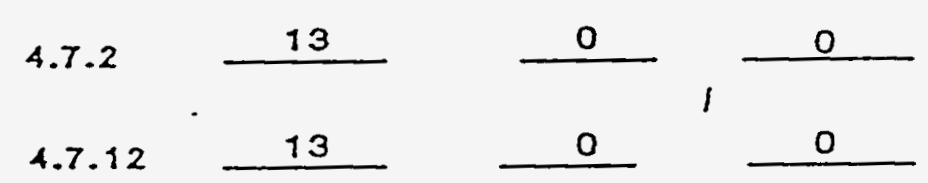

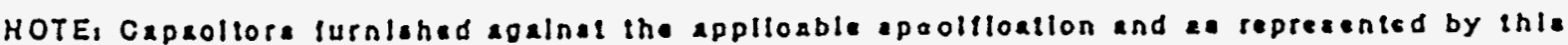
lant data meet all requiramense.

- N/A lo gold plalod terminallon ilnishos.
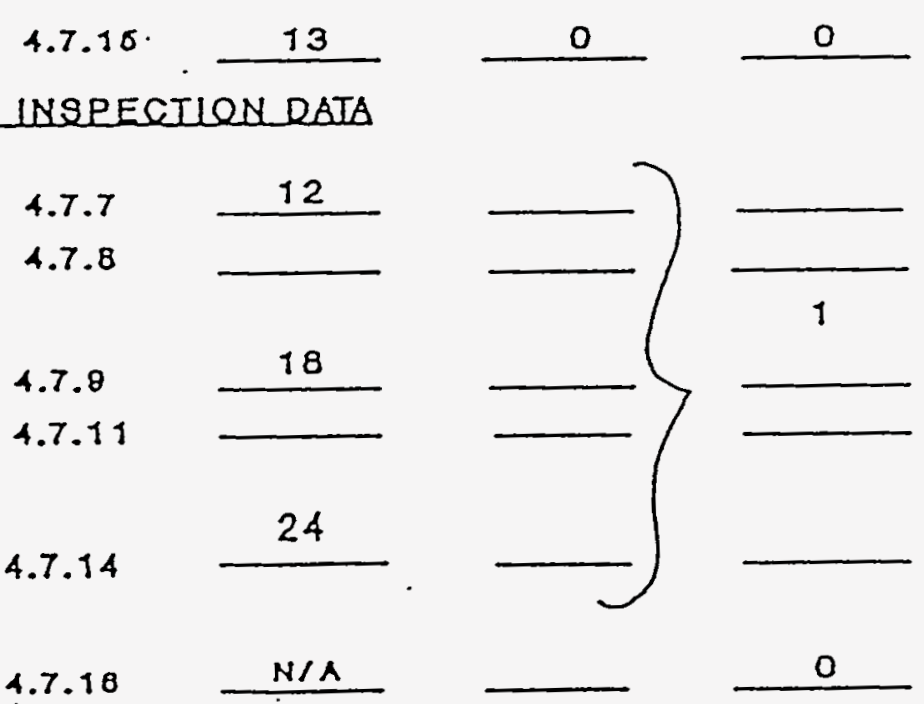

SRQUP E INYPECILN RATA 


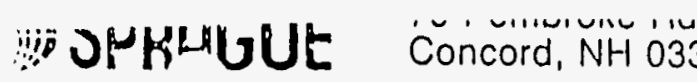

iu rembroke Ha.

Concord,' '03301

IIELU!LLE. WY LI747

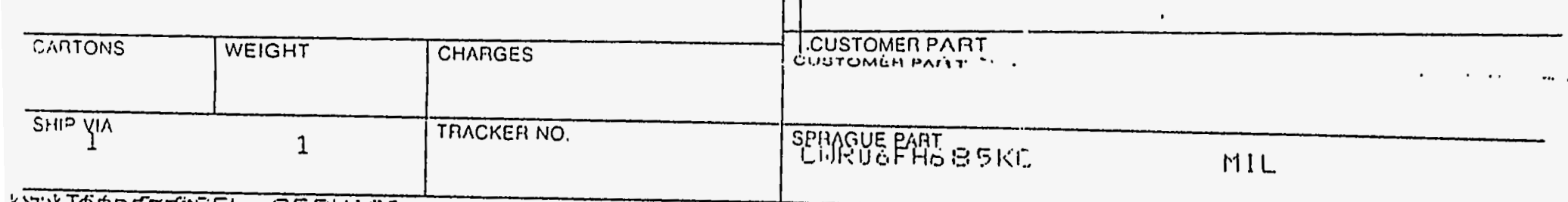

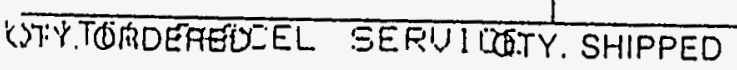

OTY BACK QRDG OTVES

195

$\because \because:-$ DUDTE \#4S177

: : E BEFTS REOUIRED 
SPRAQUE

customer name Capazone Clectróces

CUSTOMER ORDER \#

$6 \times 12344000$

CUBTOMER PART \# CUPDG FH685KC BPRAQUE M.O

$P Q P * 37$

$7 / 16 / 82$

- SUMMARY OF TEBT DATA

MIL-C-56305C

gReUP A HRPECTUEN DATA (Wolbull) C

QURGReUP L (Teer)

Helbull LIfe

SUBRBQUP U

DG Leakage

Capeollanoe

Disalpallon Faotor

EBR (whon applloable)

Heohanloal Exam

\&UBGBQUP 山

VIsUal EXam

SUBGEQUP IY

olabllily al Low a

High Tomporaturo

sUBeBQUP $Y$

soldorablllty..

SUBGROUP

Yibralion. High Froquenoy,

Thermal shook

subareup 4

Resislanod To Bolder Hoot.

Molstura Reslatanoe

SUReroup WI

Llle (2000 hrs. +1200C)

SURGBRUP $Y$

Roslolance lo Bolvonto

(when applloablo)
BEE AMQUNT AMQUNT

BARA. IESTER EALLER"

SLLWED

4.7.17

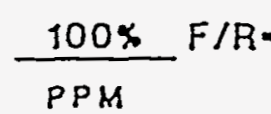

4.7 .4

$\frac{P P M}{\text { Sampling }}$

4.7 .6

4.7 .10

1.7 .2

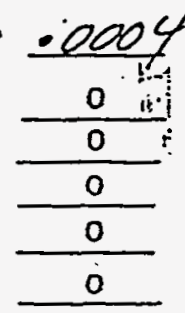

EAILURES

$\because N / A$

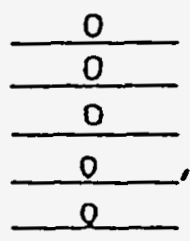

4.7 .2
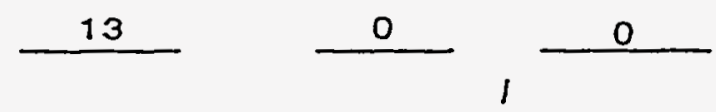

1.7.12
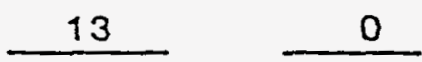

0

0

4.7 .18

13

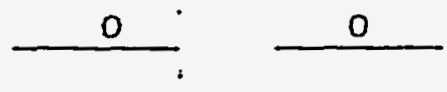

\section{SRQUP CINSPESTION DATA}
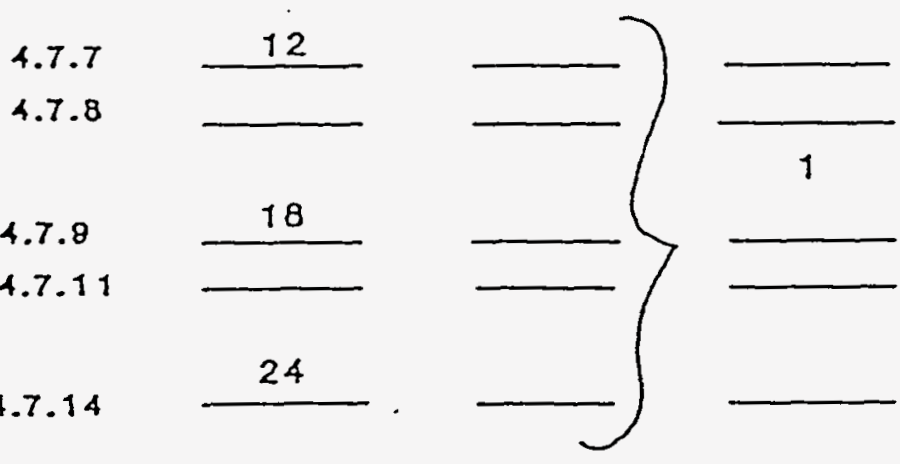

$4.7 .8 \quad 18$

1.7.11

24

4.7 .14

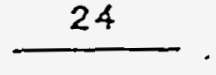

1.7 .10

$N / A$

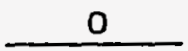

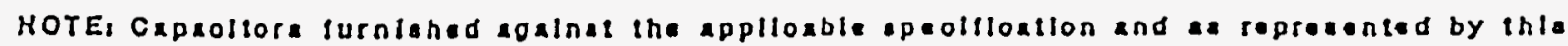
talt deta mees all requitamente.

- N/A lo gold plalod torminalion flaishos.

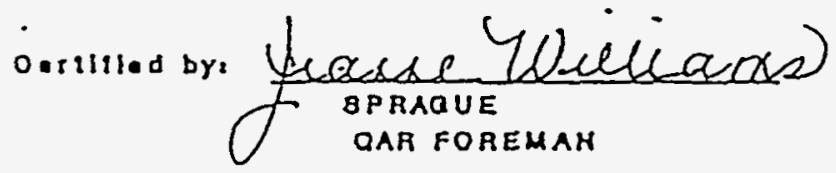


SPRAQUE

$P Q P * 97$

CONCORD, NEW HAMPQHIRE

CUSTOMER NAME Capstone Oectronico

CUBTOMER ORDER

DATE $1-22-93$

$7 / 10 / 82$

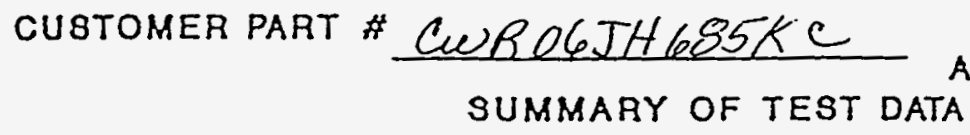

BEE

AMQUSI AMQUNT

BLLEWED

BARA. IESTER EALLED EALLUREQ

Helbull Lifo

SUBRBQUP ل

4.7.17

$100 \times$ F/R.

.005

$\because$ N/A

DC Leakrge

4.7 .4
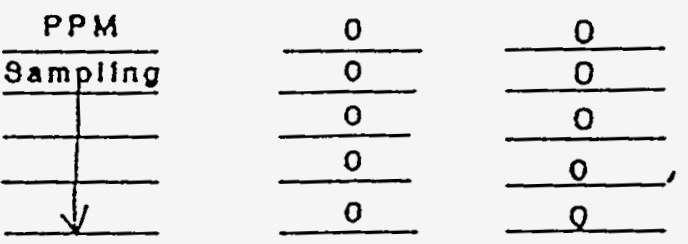

Disslostlon Fsotor

4.7 .6

4.7 .0

4.7 .10

Meohanloal Exam

1.7.2

13
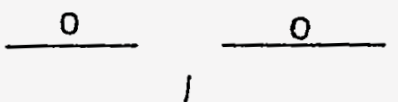

Visual Exam

4.7 .2

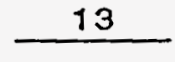

4.7.12

13

olablilty at Low a

High Temperature
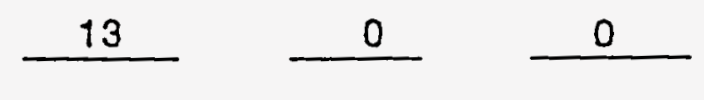

SURGRQUP $Y$

solderabllily...

4.7 .15

13

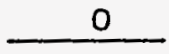

0

\section{SURGRQUP}

BRQUP SINSPECTIEN DATA

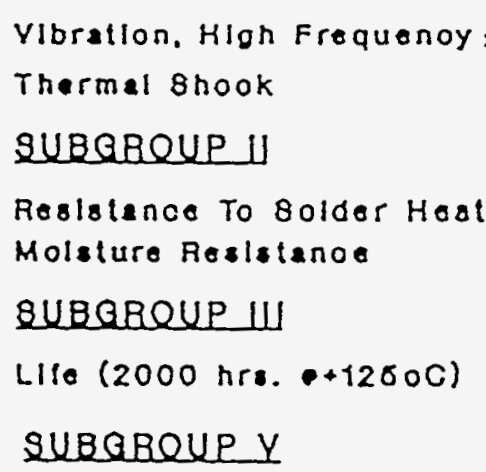

4.7 .7

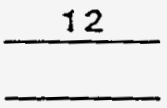

4.7 .8

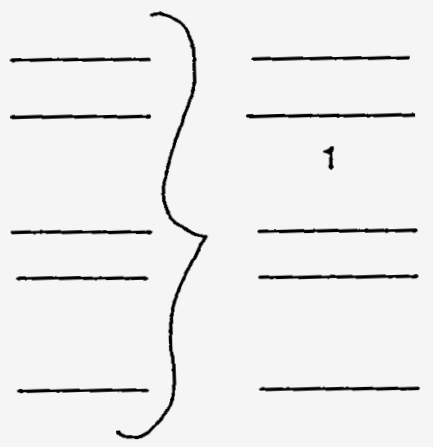

Fesislanoe to Boivento

4.7.8

18

(whon applloablo)

$$
4.7 .11
$$

4.7 .14

24

4.7 .18

N/A

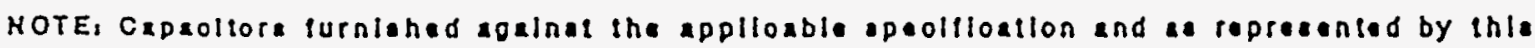
leot detx mees all requiraments.

- N/A lo gold platod tarmination finishos.

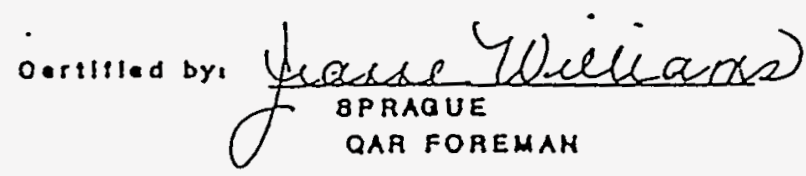


SPRAQUE

custoiner NAME Capatone blectronúcs DATE $1-21-93$

CUSTOMER ORDER 6 GX12344001

CUSTOMER PART \# CURPOGJH226KC
LOTHIDATE CODEA3598-/ $/ 9302 T$

OPRAQUE M.O. A539720I

\section{SUMMARY OF TEST DATA}

$$
\text { MIL-C- } 56386 \mathrm{C}
$$

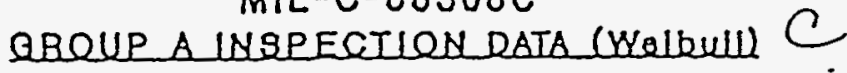

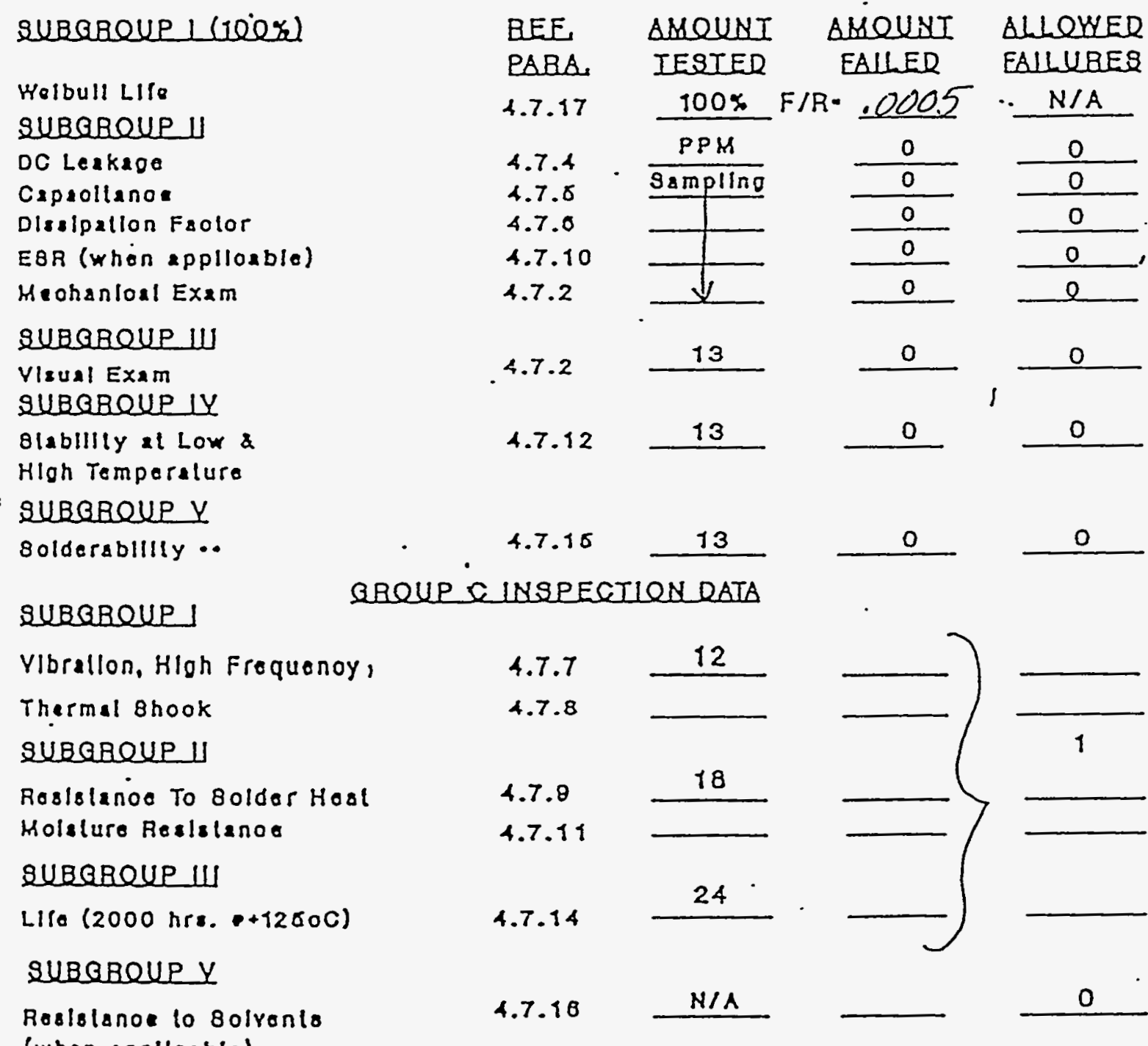

(xhon appllosbla)

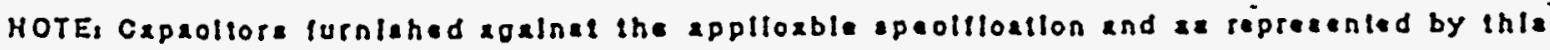
lest data meet all requtremante.

- Nia lo gold plalod termination tinishos.

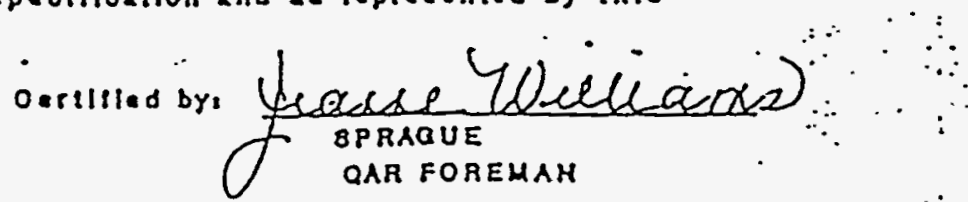




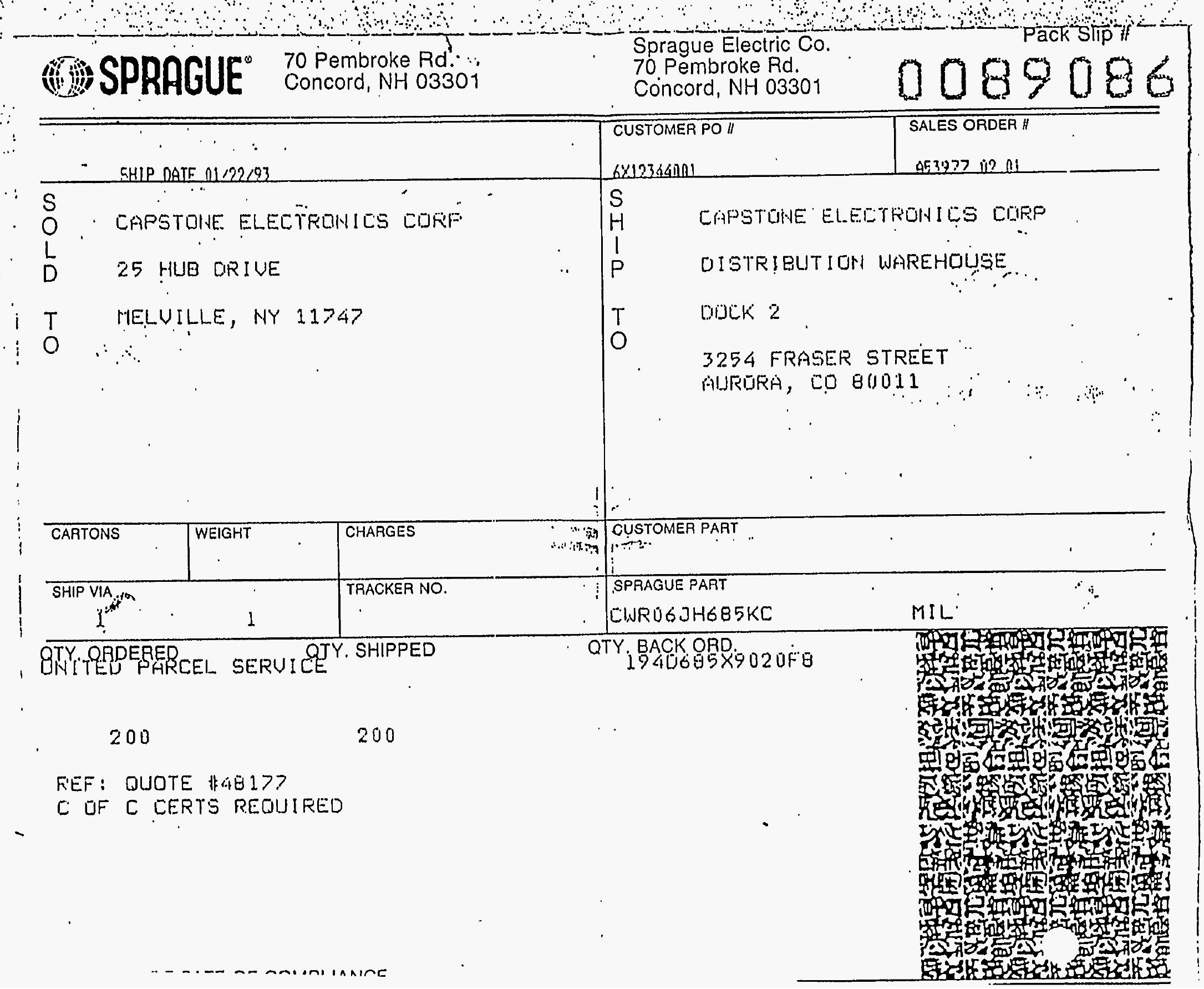




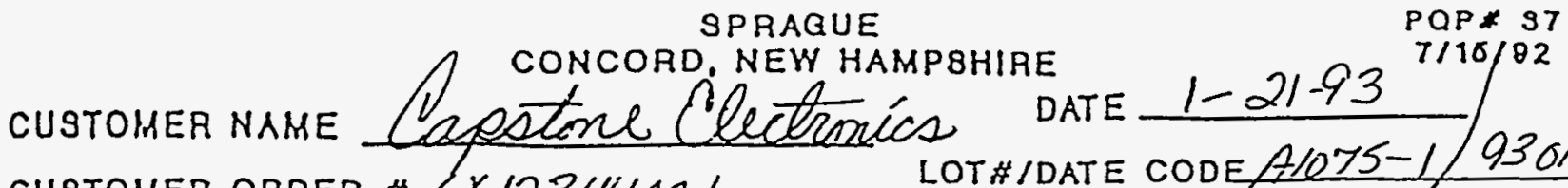

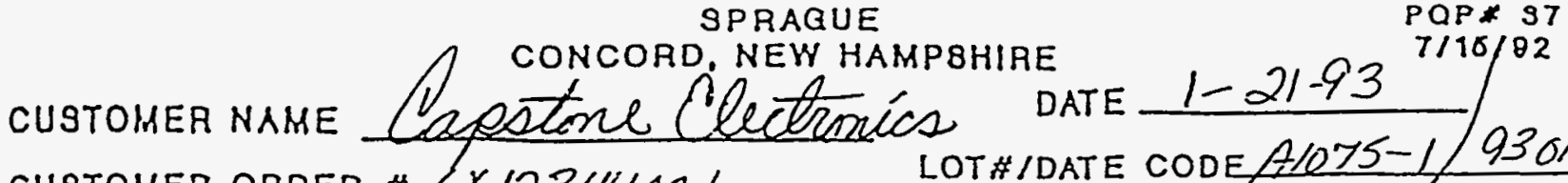
CUSTOMER ORDER \# $6 \times 12344001$ LOT\#IDATE CODEA1075-1/9301T CUSTOSER PART * BPRAQUE M.O. A539770l BPRAQUE M.O. 15397 SUMSARY OF TEST DATA MIL-C-56365C

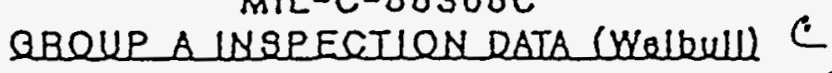

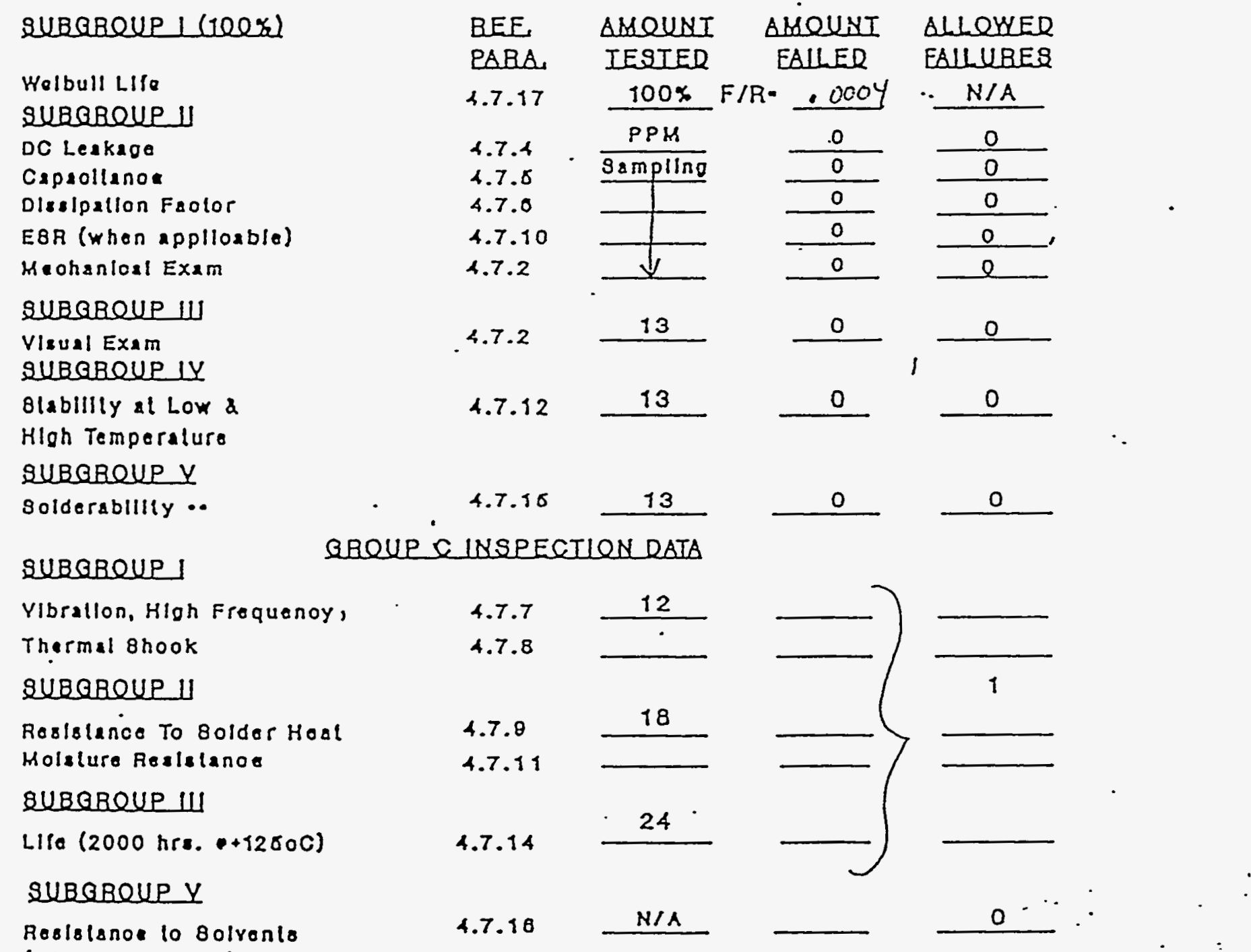

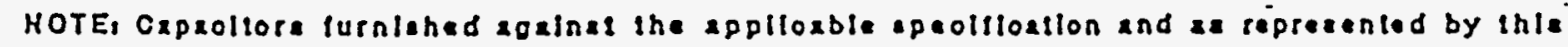
tel dain meet all requiremente.

- h/a lo gold plaled lerminallon flinienos.

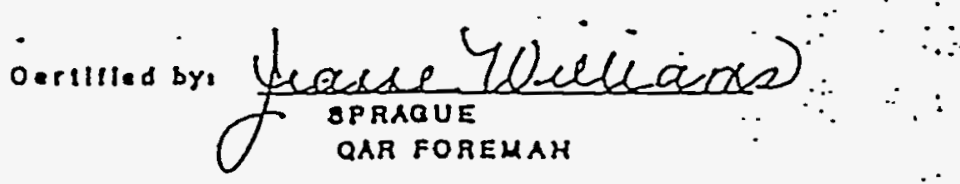


(fin SPDQGUE - enuroke Rd.

UPRGUE concord, NH 03301

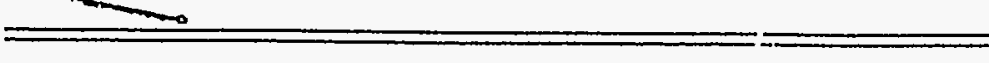

SHIP OAIE Q1/21/93

S CAPSTONE ELECTRIONICS CORF

L 25 HUE DRIVE

T MELUILLE, NY 1174 ?

O

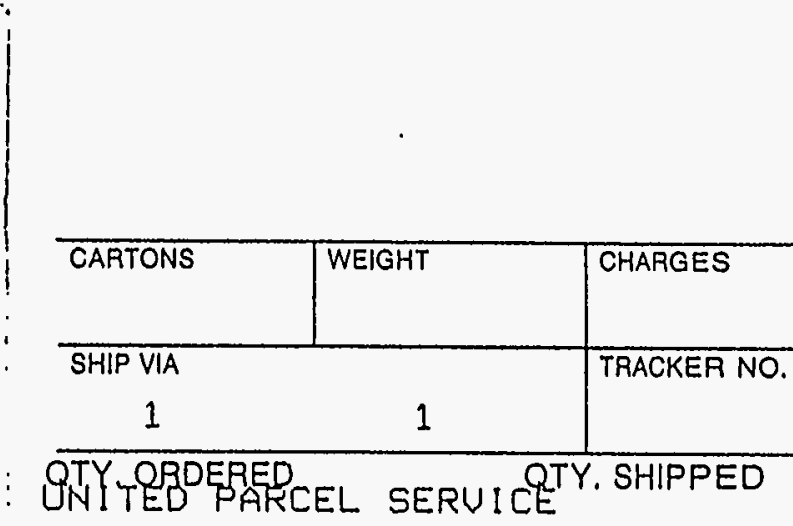

412

REF : QUOTE 非 48177

C OF C CERTS REQUIRED
Sprague Electric Co.

70 Pembroke Rd.

Concord, NH 03301

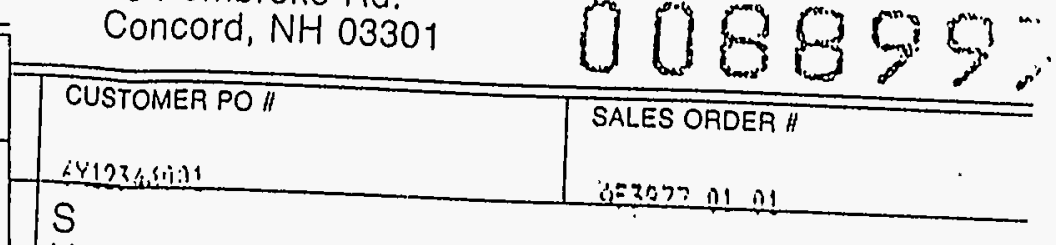

CHFETUME ELECTRIDHISS DERF

DISTRIBUTI DN WAREHOUSE

LiUK 2

3254 FRASER STREET

AHIROIIA, CO BOO11 


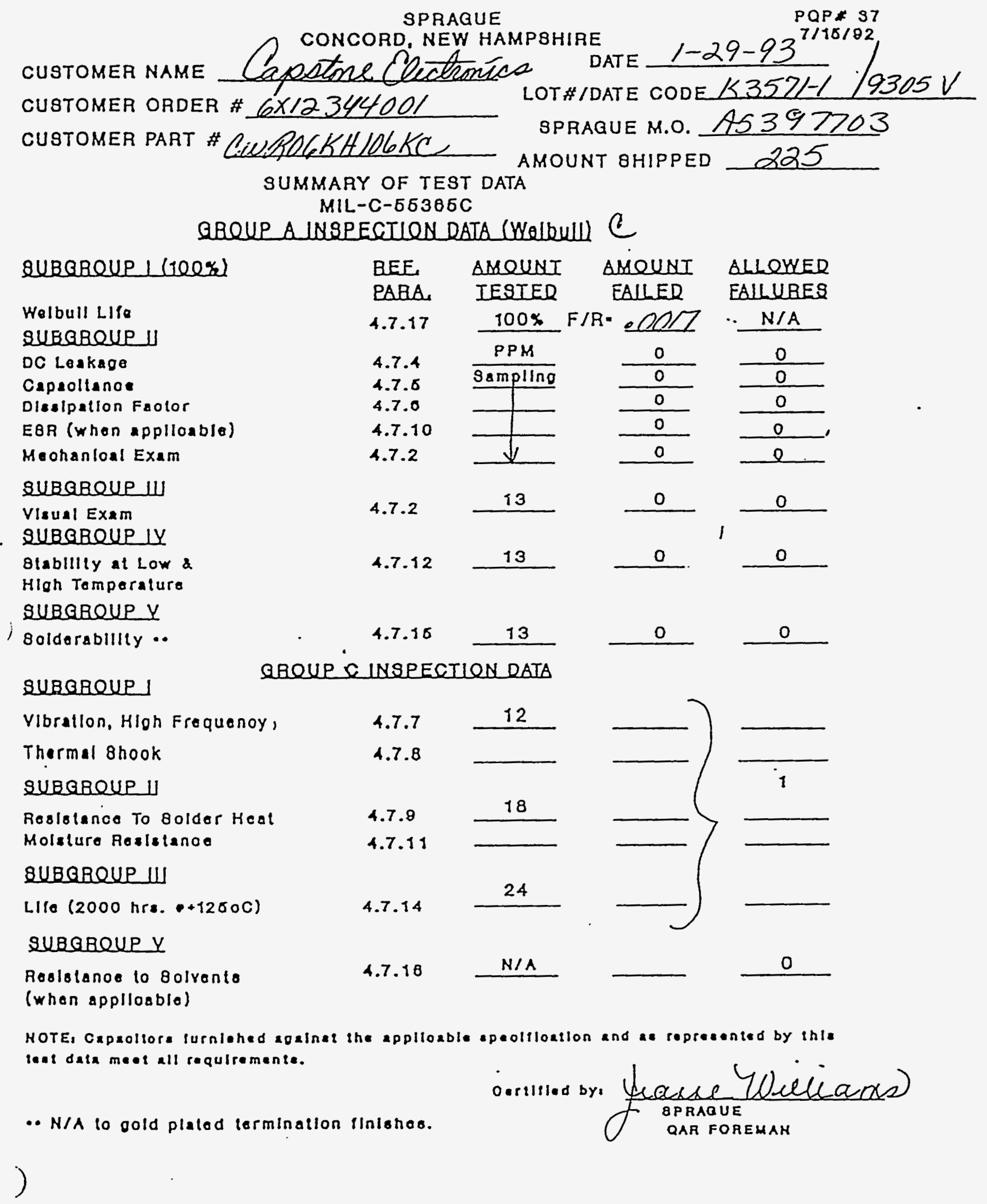




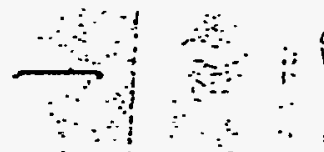
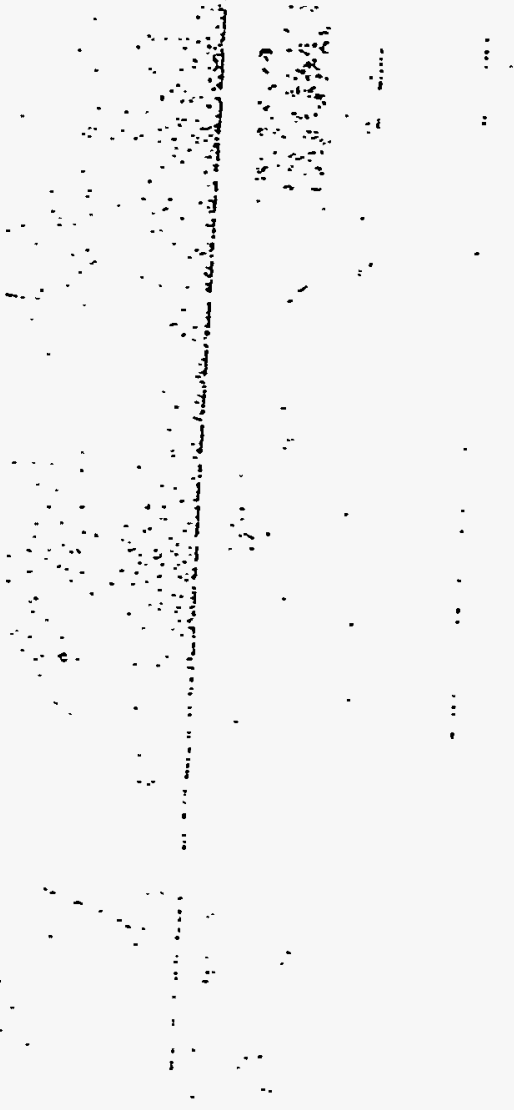

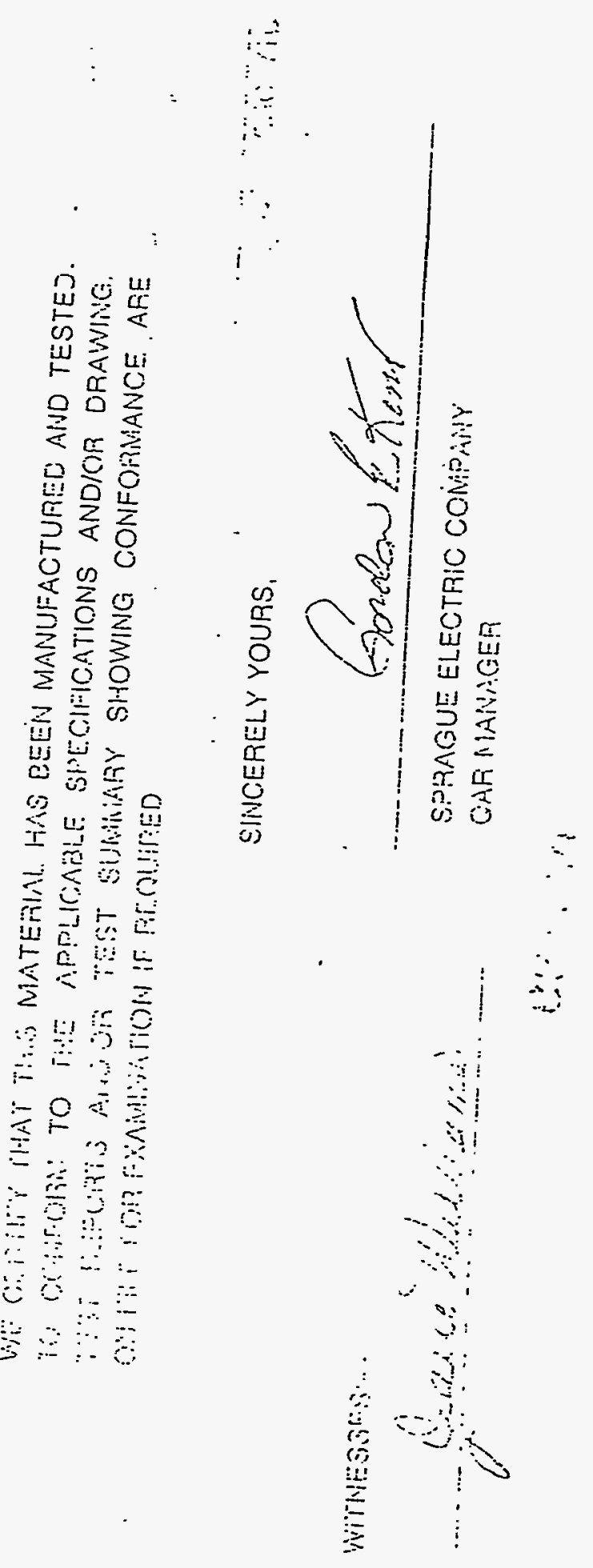

i 


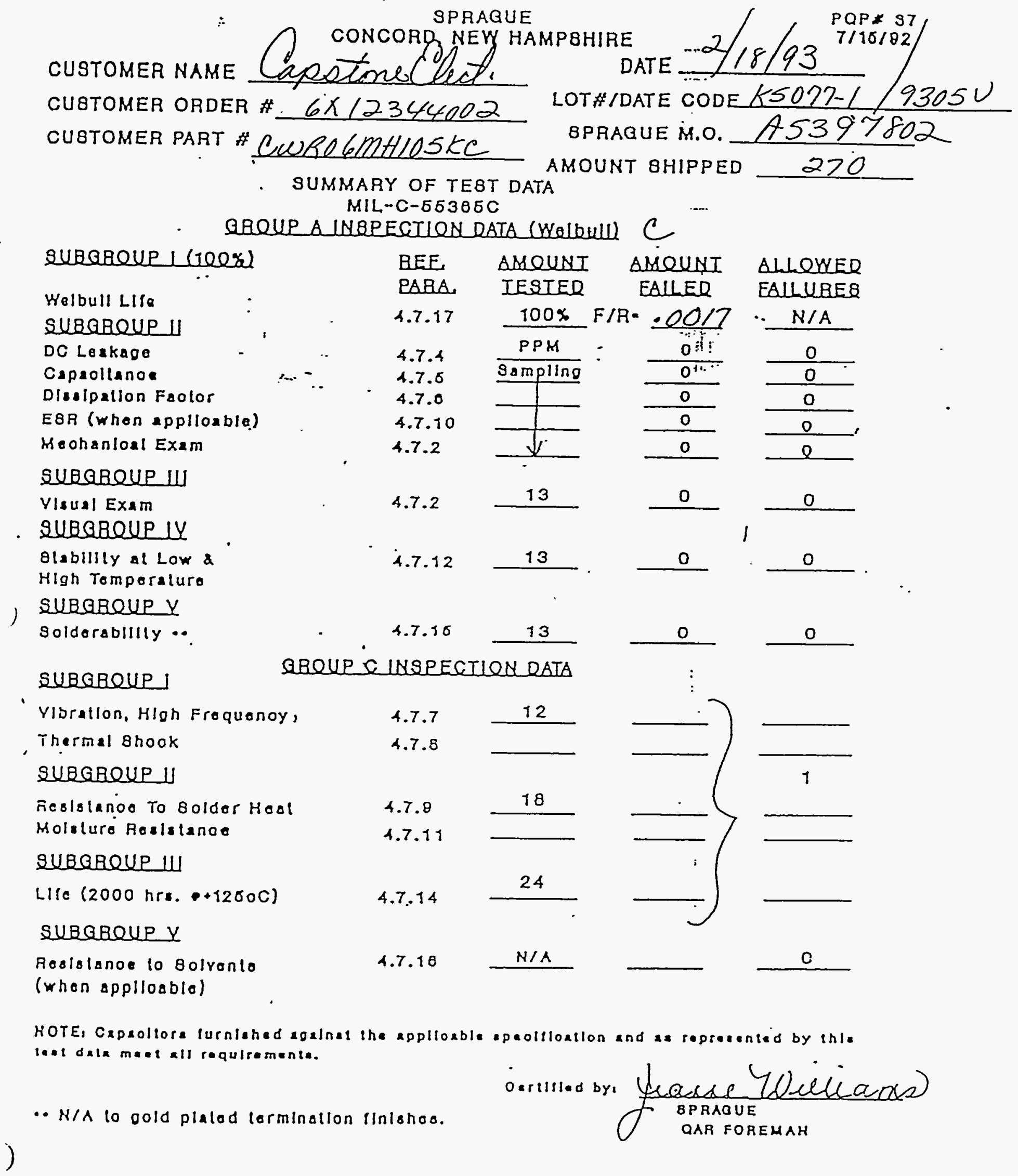


CALIFORNIA CAPACITOR, INC.

\section{CARIIICAITE OF COULIIANCE}

DATE: $1 / 25 / 93$

PURCHASERI :IAWRENCE IIVERMORE IABS

ORDER : 3231974

ITEM: \#2 500pc8. CDR32BX333AKUS

\#4 500PCS. CDR32BX103BKUS

THIS IS TO CERTIFY THAT THE MATERIATS, FROCEBEES AND FINISHED PARTS USED IN TEE MANDFACMURE OF THESB ITEMS WERE CONTROLIED AND TESTED IN ACCORDANCE WITH THE APPIICABIE SPECIFICATIONS.

OBJECTIVE QUALITX EVIDENCE AND SUBSTANTIATIVE TEET DATA IS ON FIIE FOR EXAMINATION UPON REQUEST.
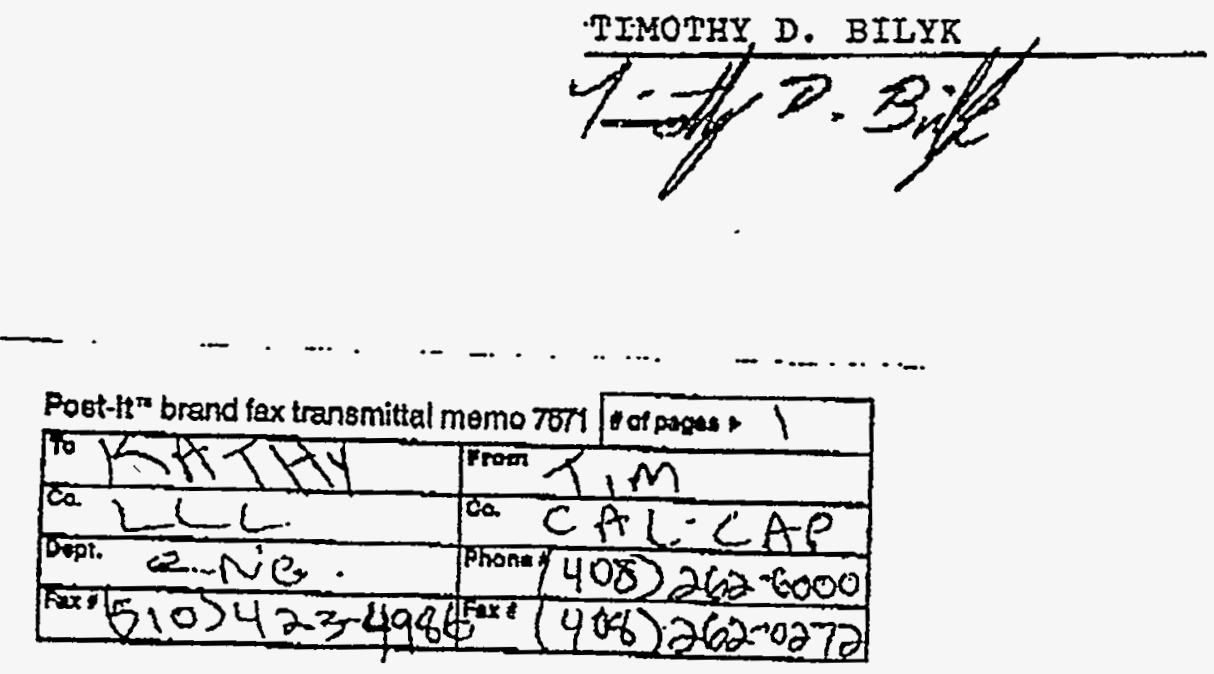


$$
=\ldots
$$

BILLTO

LAWRENCE LIVERMURE LABS PO' REX 5 USI/ACCT. DEPT.
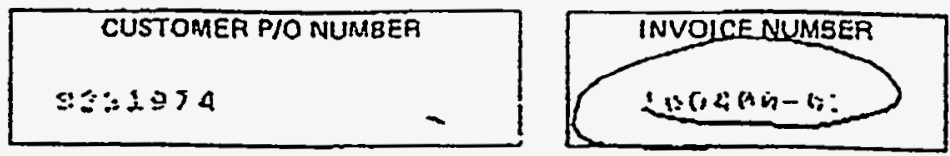
LIUERMORE, CA.

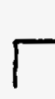

$\therefore \quad 94550$.
SHIP TO

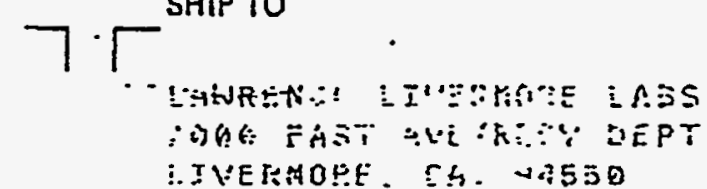

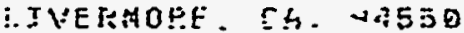

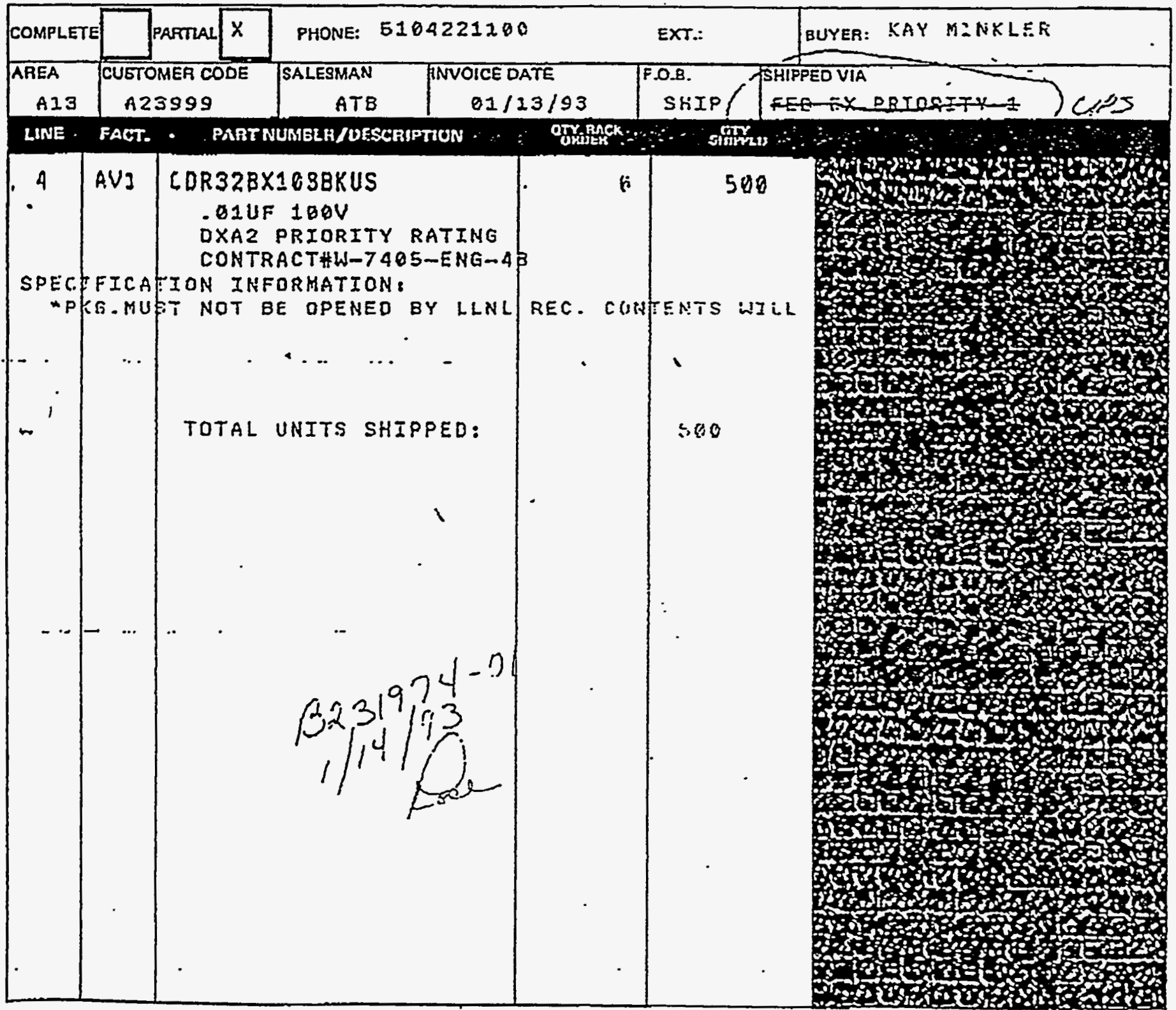

PACKING SLIP

ALL CLAIMS MUST BE MADE IN WAITINO WITHIN FIVE DAYS AFTER RECEIPT OF GOODS $\therefore)^{\circ} \cdot \ldots$

GAEEN -SHP/ACRD, YELLOW - PACKING SLIP, WHITE - SALES $\therefore \because$ RETURN NO GOODS WITHOUT OUR PREVIOUS WRITTEN AUTHORIZATION 


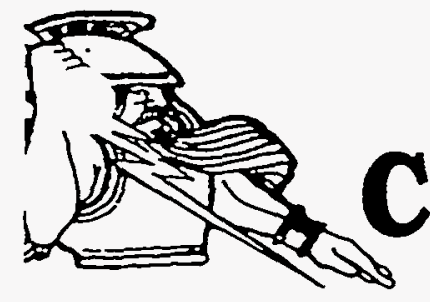

ITTENTION: QUALITY ASSURANCE DEPARTMENT

\section{military distribution specialists}

Certificate of Conformance and Procurement Traceability

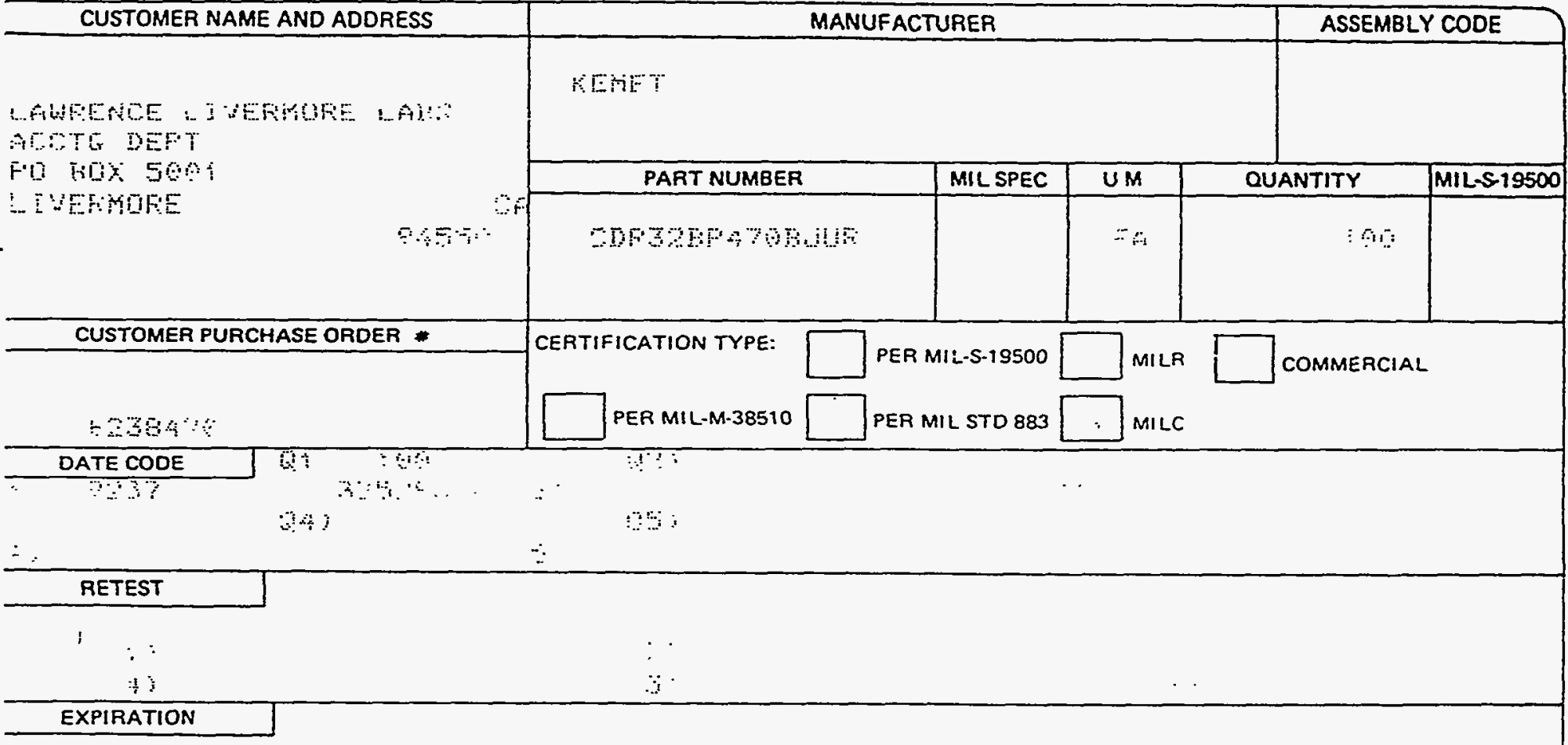

The undersigned certifies that all articles included in each shipment under the above purchase order are in accordance with said purchase order and with all requirements, specifications and drawings referenced therein; and that records of inspection and test providing objective evidence of the foregoing are on file at this facility, or at the manufacturer's plant, and are available upon request. Certification that this shipment is a part of the shipment covered by the manufacturer's documentation.

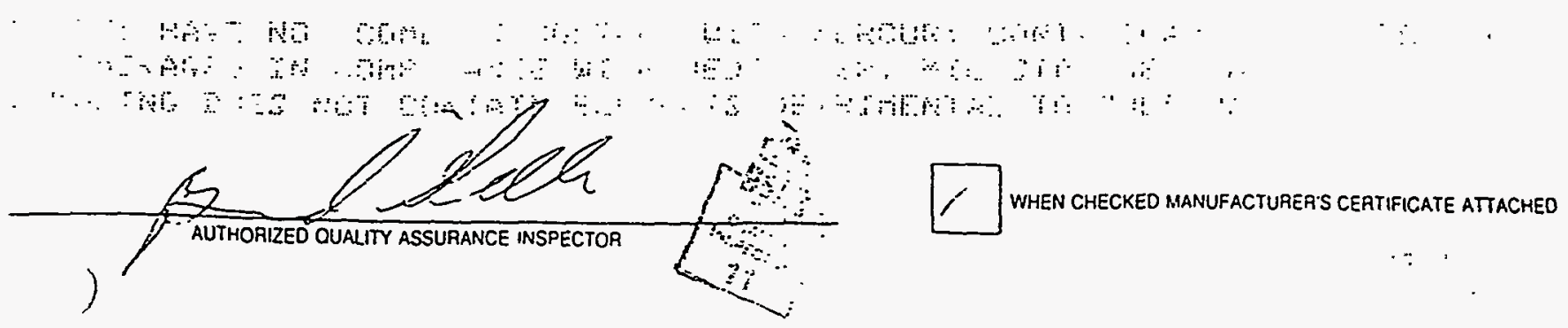

NOTICE REGARDING RETURN ACCEPTANCE OF MATERIAL.

ZEUS cannot accept the return of this lot or any part of this lot which does not include the original or copies of this and other documents supplied with this shipmeni. 
KEHET ELECTRONICS CURPORATIDN

H.CEHWAY 3855 . E.

GREENUTLLE, SOUTH CARDLINA 29006

803/963-6300 - FAX: 803/963-6322 - TELEX: 570496 - TWX: 610/287-2536

ADDRESS REPLY TO:

P. Q. BOX 5938

GREENUILLE, S. C. $2968>6$

\section{CERTIFICATE GF COMFLIATCE ;}

TO: ZEUS SEMICAP, INC.

REF : PURTHASE DRDER NIMAEER: 749137

WE HEREBY CERTIFY THAT THE CAPACTTORS SUPPLIED TO THE ABOWE MAHED COMPANY AGAINST THE REFERENCES FURCHASE ORDER WERE MATUIJACTURED ZN ACCORDANCE WITH THAT PURCHASE DRUER AND ALL APPLICABLE DOCUTAENTS.

KEMET PART NUMBER: CA2OSNA7OHIERH7SOG

CUSTOMER FART NUMBER IIF APPLICABLE: : C12OSNATOJIERHTEOS6

DATEMLOT CONESS:

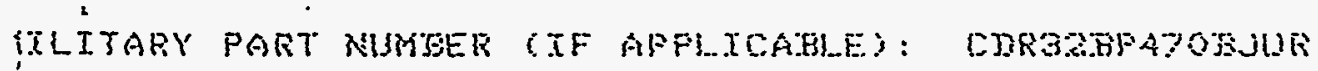

MILITARY INSPECTION LOT NUMBERSS) (IF APPLILABLE): 92372H

TUTAL GULATITY SHIPFED: $\quad 150$

INUDICE NUMBER: SOUUSGS LTNE: 10AA

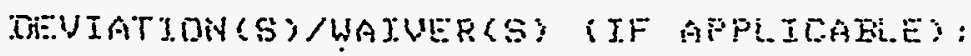

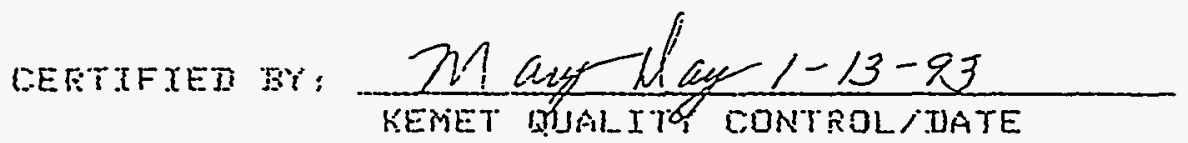

$75068(10 / 16 / 91)$

) 


\section{Certificate of Campliance}

To: Iniversity of california

Iawrence Iimermore Iab

7000 East Rive.

Livermore, CA 94550

Date $10-0-92$.

It is hereby certified that the products (Model numbers listed below) supplied to Lawrence Livermore Lab on Purchase Order No. B227575. ore in conformonec with all your purchas order requirements, including applicable government, your or other specifications and drawings, to the extent specified.

The required test and/or inspection reports resulting from compliance with applicable purchase order requirements are on file and available for review by your representative or government inspectors at any reasonable time.

ANA.LOG DEVICES, INC.

(97 Do) Refolcs

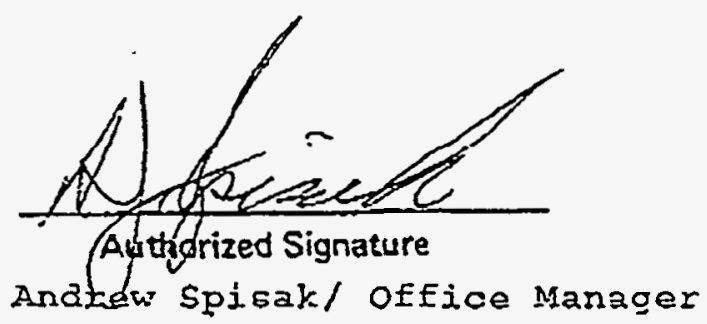




\section{Certificate of Campliance}

To: Inniversity of California

iavirence $I$ i:zermare $L a b$

7000 East Rve.

Livermore, CA 94550

Date $30-0-9$ ?.

It is hereby certified that the products (Model numbers listed below) supplied to Lawrence Iivermore lab on Purchase Order No. B227575 are in conformance with alf your purchase order requirements, including applicable government, your or other specifications and drawings, to the extent specified.

The required test and/or inspection reports resulting from compliance with applicable purchase order reouirements are on file and available for review by your representative or government inspectors at any reasonable time.

ANALOG DEVICES, INC.

(97 go) ReEclss

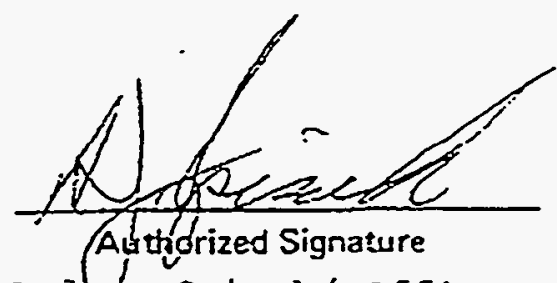

Anater: Spisak/ Office Manager 


\section{Certificate of Campliance}

To: Iniversity of California

iaurence Iivermore Lab

7000 East five.

Iivermore, CA 94550

Date $10-0-92$.

It is hereby certified that the products (Model numbers listed below) supplied to Lawrence Iivermore Lab on Purchase Order No. B227575. are in conformonoc with aH your purchase order requirements, including applicablo government, your or other specifications and drawings, to the extent specified.

The required test and/or inspection reports resslting from compliance with applicable purchase order reauirements are on file and available for review by your representative or government inspectors at any reasonable time.

ANA.LOG DEVICES, INC.

(97 DC) ReEClCS

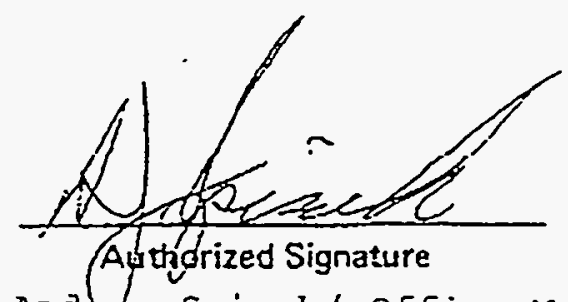

Andtew Spigak/ Office Manzger 
ACCEPTANCE DATA

\begin{tabular}{|c|c|}
\hline CUSTOMER P.O.\# B243053 & M.E.C. JOB\# \\
\hline CUSTOMER PAR & M.E.C. PART \#M83513/04-GO6N \\
\hline
\end{tabular}

LOT S.IZE 32 pCS DATE CODE OR LOT \# 2308

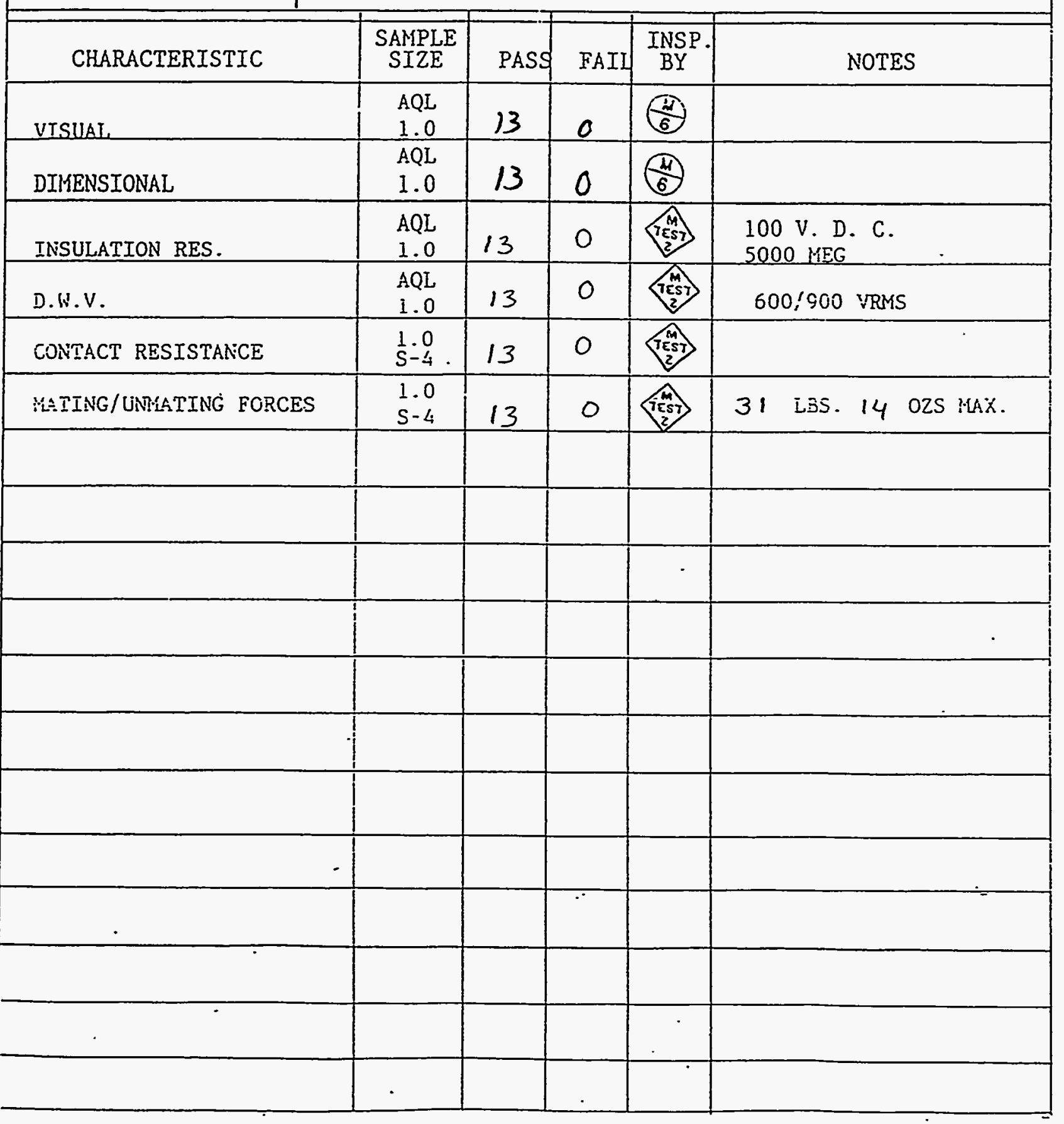

DATE. $\quad 2-25-93$ 


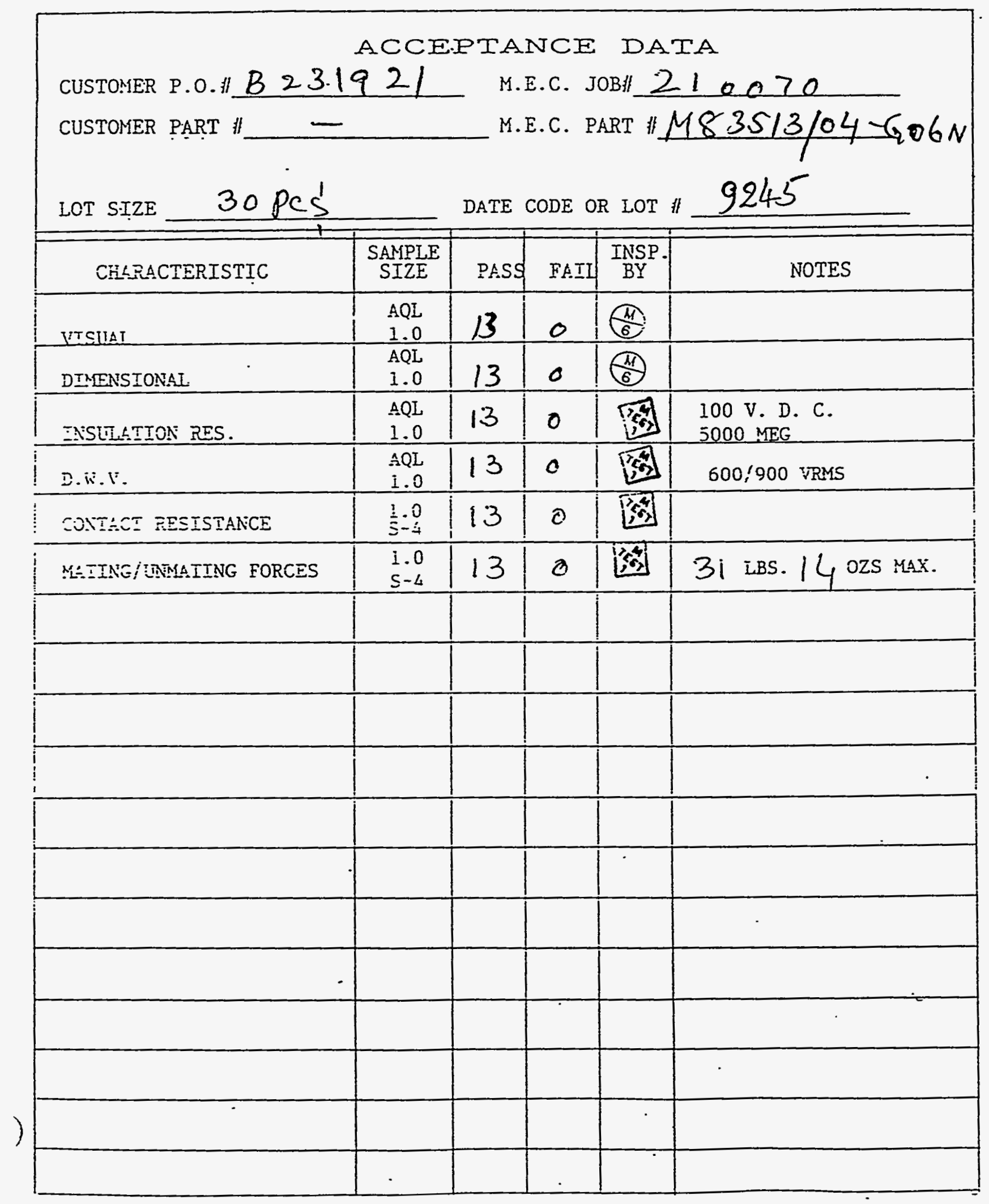




\section{Certificate of Compliance}

It is hereby certified that the parts furnished on this Certificate of Compliance have been manufactured in conformance with the requirements of all applicable drawings and specifications as defined by the purchase order.

Customer Part Number

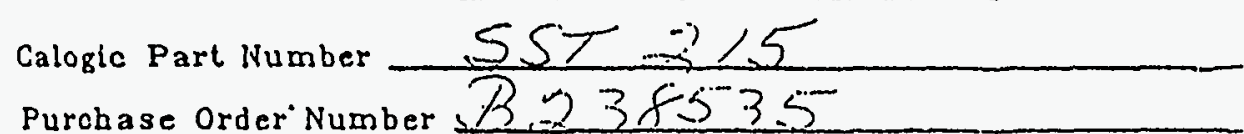

Purohase Order Number $\beta 238535$

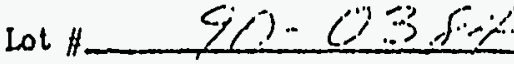

Quantily $10<\%$

Halers(s) $\not$

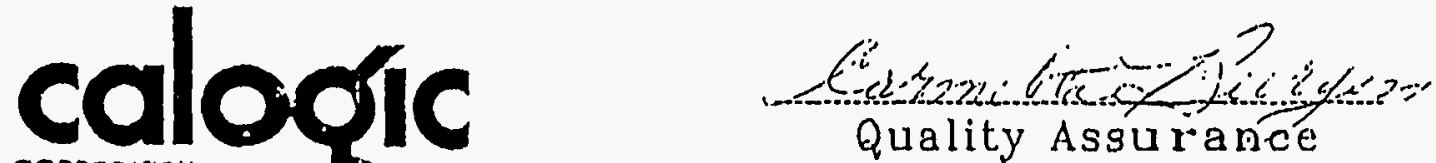

CORPORAIION Quality Assurancé

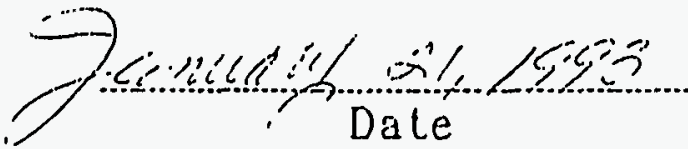




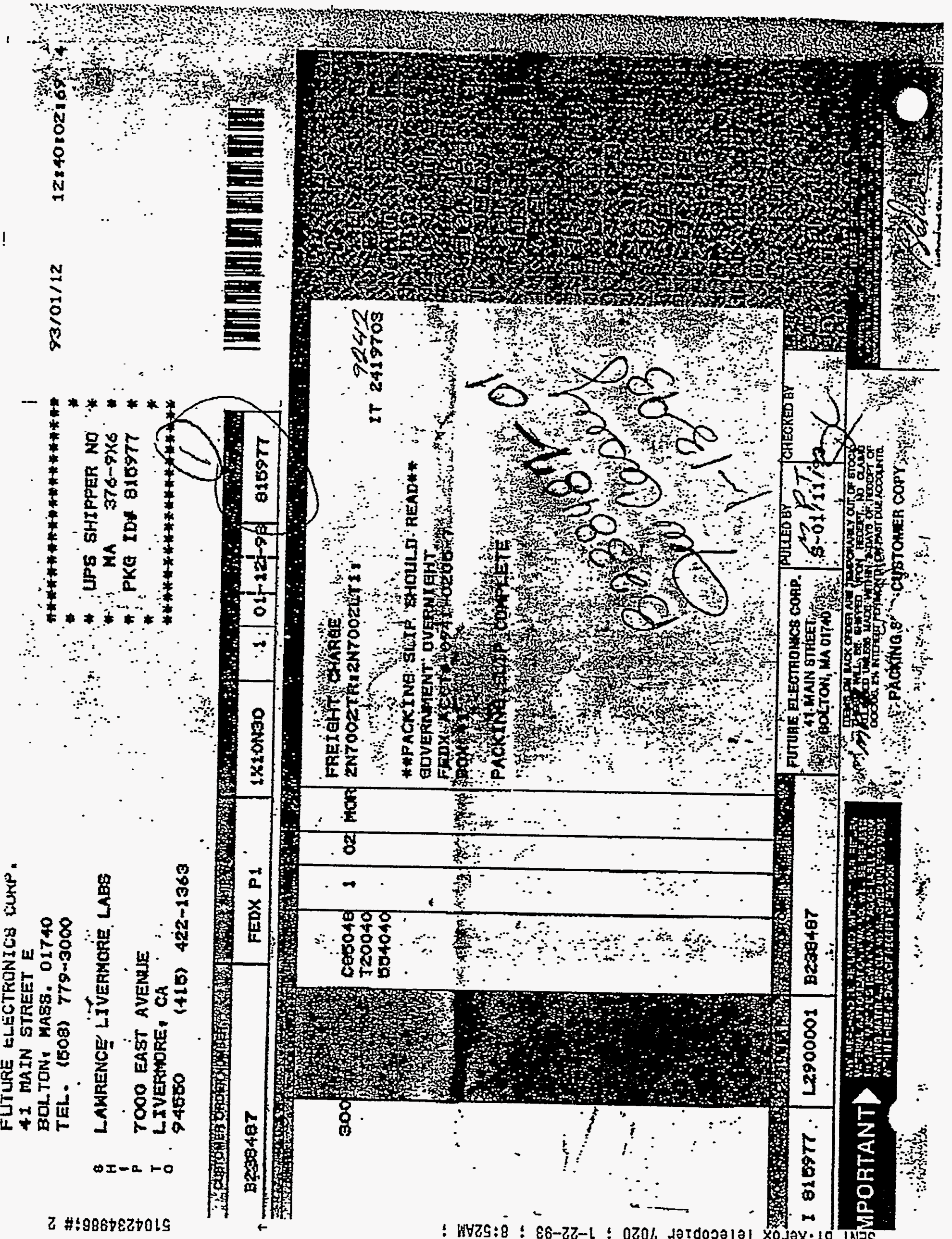




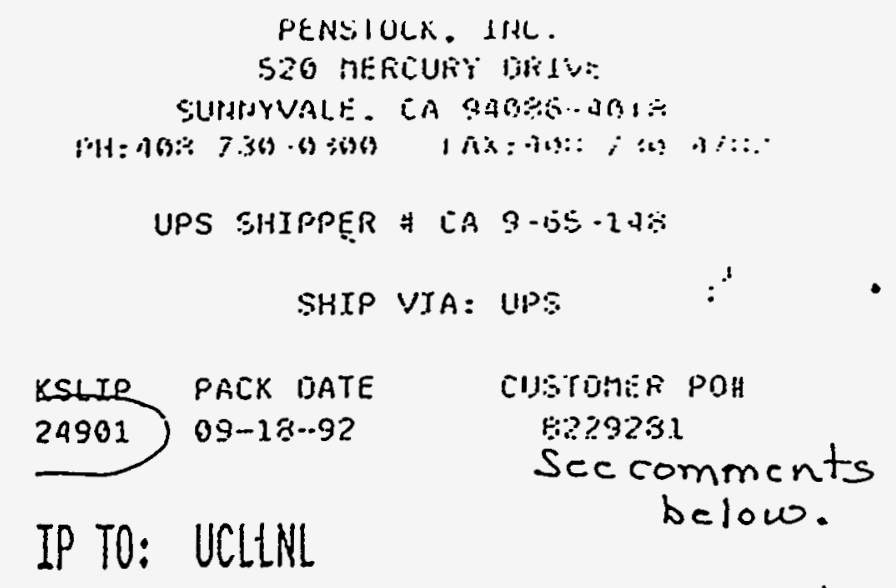

7000 EAST AVENUE

LIVERMORE CA 94550 order referenced below has been manufactured. tested, andor inspected in accordance with the requirements of the applicable specifications. tho metallic arcicury compounds are used in the process or in the parts
furnished herein. Inspections indoor tests have been performed as furnished herein. Inspections and $/ 0$ tests have been performed as 列 accordance vita the requirements of .I I-STD- $\$ 5662$. on file and are available upon request.

BILL TO: UNIV. CAL. LAWRENCE NAT.

P. O. BOX 5601

LIVERMORE CA 94550

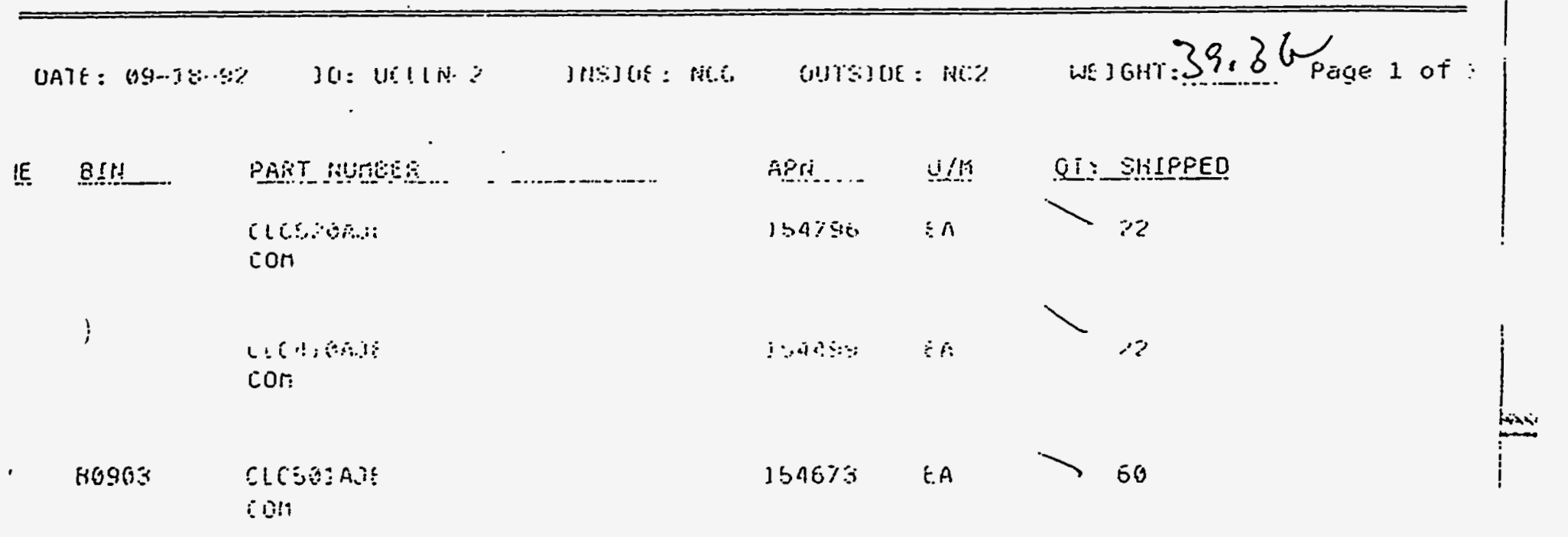

package must not be opened by ULNNiL receiving

Static Sensitive Products Enclosed

OISCREPANIES MUST ER REPORTED WITHIN S DAYS.

Requester will verify all contents 


\title{
OHOMSON COMPONENTS AND TUBES CORPORATION THOMSON MILITARY AND SPACE COMPONENTS DIVISION
}

\author{
4OG Commerce Way \\ Post Office Box $54 \mathrm{C}$ \\ Totowa, New Jersey 07511 \\ Telepnone $201812-9000$ \\ FAX 201-812-9550
}

CERTIFICATE OF CONEORMAKCE

$\mathrm{OSC2}-$

TO:_LINL

DATE: $10-13-92$

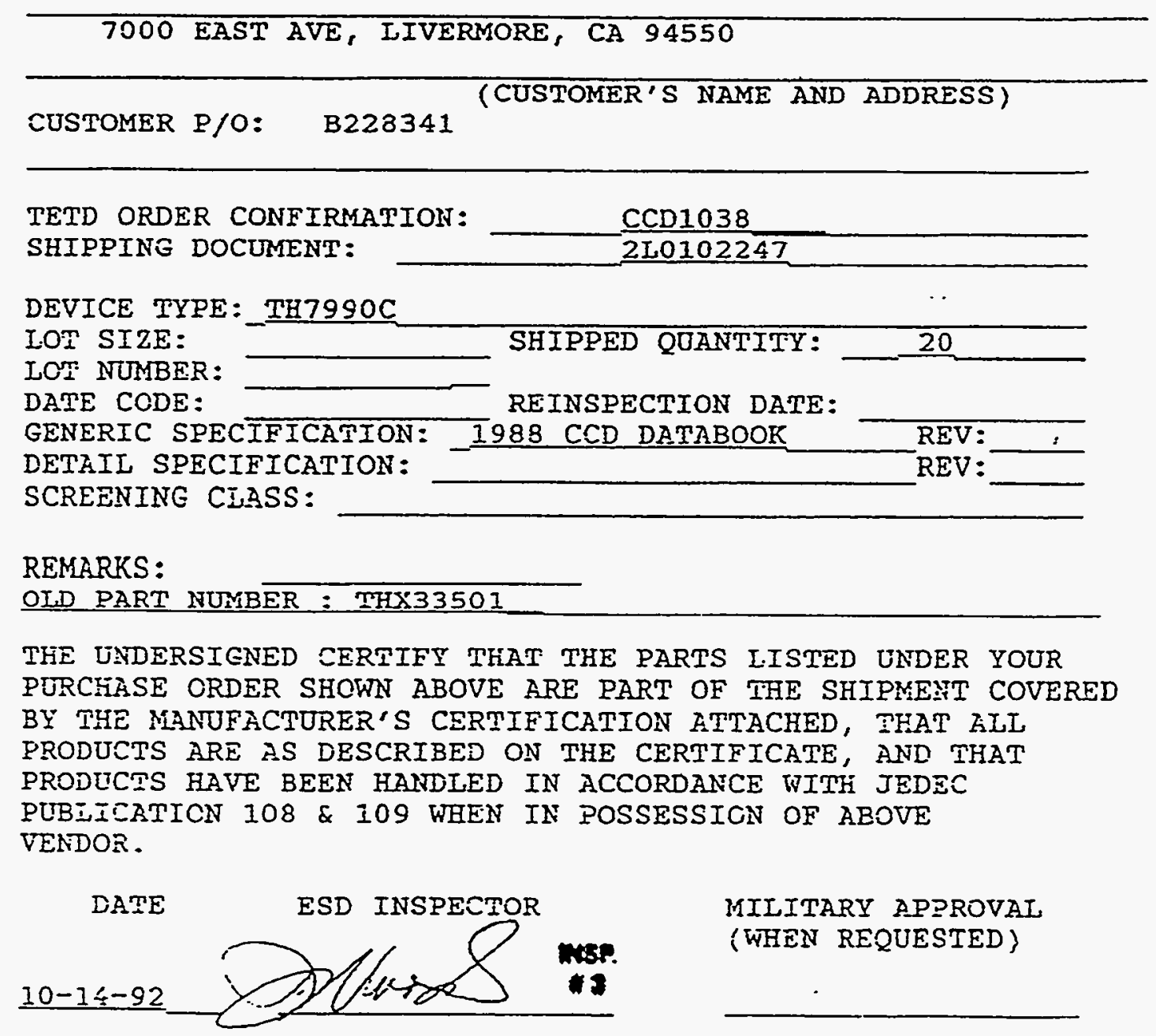

NOTE: WHEN REFERRING TO THESE PARTICULBR DEVICES, PLEASE MENTION THE FOLLOWING INSPECTION NUMBER:

2D10034/2L.102247 


\title{
1 THOMSON COMPONENTS AND TUBES CORPORATION THOMSON MILITARY AND SPACE COMPONENTS DIVISION
}

\author{
40, C Commerce Way \\ Post Office Box 540 \\ Totowa, New Jersey 07511 \\ Telephone 201812.9000 \\ FAX 201-812.9350
}

\section{CERTIPICATE OF CONFORHARCE} -

TO:_LLRL

DATE: $10-13-92$

7000 EAST AVE, IIVERMORE, CA 94550

CUSTOMER P/O: B228341

(CUSTOMER'S NAME AND ADDRESS)

TETD ORDER CONFIRMATIOH:

SHIPPINE DOCUMENT:

$\operatorname{CCD} 1038$

210102247

DEVICE TYPE: TH7990C

IOT SIZE:

IOT NUMBER:

DATE CODE:

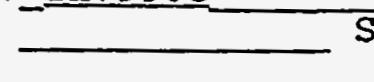
SHIPPED QUANTITY:

20

GENERIC SPECIEICATION: _ 1988 CCD DATIBOOK

DETAIL SPECIFICATION:

SCREENINE CIASS:

REMARKS :

OLD PART WUMBER: THX33501

THE INDERSIGNED CERTIEY THAT THE PARTS L.ISTED UNDER YOUR PURCTIASE ORDER SHOWN ABOVE ARE PART OF THE SHIPMENT COVERED

BY THE MANUFACTORER'S CERIIEICATION FTTACHED, THAT hIL FRODUCTS ARE AS DESCRIBED ON THE CERTIFICATE, AND THAT PRODUCSS HAVE BEEN HANDIED IN ACCORDANCE WITH JEDEC PUBIICRTICN $108 \& 109$ WHEN IN POSSESSIGN OF ABOVE VENDOR.

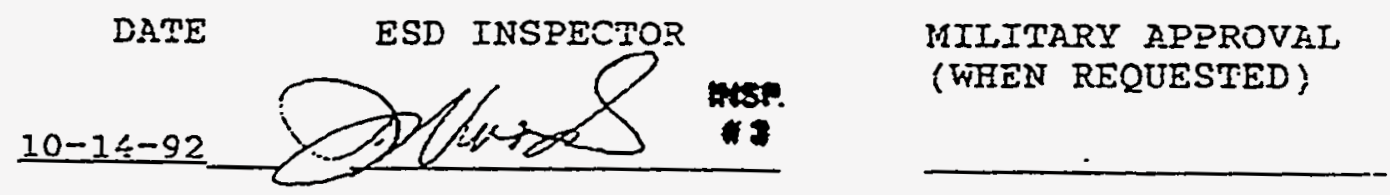

WOTE: WHEN REFERRING TO THESE PARTICULAR DEVICES, PLEASE MENTION THE FOLIOWING INSPECTION NUMBER:

$2 D 10034 / 2 \mathrm{I} \cdot 102247$ 


\section{CERTIFICATE OF CONFORMANCE}

To: UC Lamence Livermore Labs
7000 East Aveme
Livermore CA.94550:

DATE: Act. 15,1992

SALES ORDER NO: $38676^{\prime}$

PURCHASE ORDER NO: $\frac{D 3390689}{\text { CUSTOMER PART NO: MP 7684ATL/883 }}$

CUSTOMER DWG NO:

MPS PART NO:

$7684 A-\pi-883$

LOT NO: $7688084 \mathrm{Al}-4-1$

COUNTRY OF ORIGIN:

U.SA

QUANTITY:

DATE CODE: $2 B 9226$

LAST ELECTRICAL TEST DATE: $10 / 9 / 92$

SELLER CERTIFIES THAT:

1. The parts furnished against this purchase order were produced in conformance with all contractually applicable specifications.

2. Data taken to characterize the final product under the above purchase order is available for examination by duly authorized personnel.

SELLER: MICRO POWER SYSTEMS, INC.

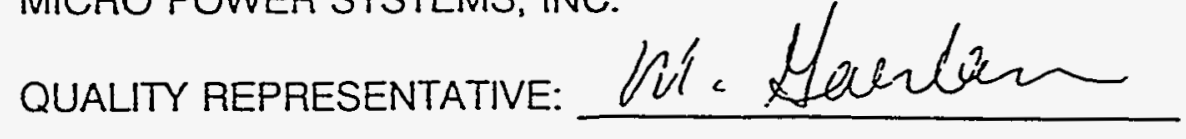

TITLE: QA Specialist

P.O. Box 5*\$65, 31C: Ahred Street, Santa Clara 950940965

Telephone: (4cE: 727-5250 Fax: (4C8) 562-3605 
Micro Power Systems

\section{CERTIFICATE OF CONFORMANCE}

TO: UC Lamenence Livermore Labs.

7000 EAST AVE.

Liverimore CA.94550

DATE: Sept.30,1992

SALES ORDER NO: 38676

PURCHASE ORDER NO: D 3390689

CUSTOMER PART NO: MUP F684 ATL/883

CUSTOMER DWG NO:

MPS PART NO:

COUNTRY OF ORIGIN:

$7684 A-\pi--883$

LOT NO: $7688084 \mathrm{Al}-3$

QUANTITY: 50

DATE CODE: $2 B \quad 9226$

LAST ELECTRICAL TEST DATE: $\not 128 / 92$

SELLER CERTIFIES THAT:

1. The parts furnished against this purchase order were produced in conformance with all contractually applicable specifications.

2. Data taken to characterize the final product under the above purchase order is available for examination by duly authorized personnel.

SELLER: MICRO POWER SYSTEMS, INC.

QuALITY REPRESENTATIVE: N1. Hapllaw

TITLE: QA Specialist

)

P.O. Box 54965, 3100 Alfred Street, Santa Clara 950940965

Telephone: (408) 727-5350 Fax: (408) 5623605

Exhibit ॥

SPECIFICATION NUMBER: QA 303, Rev. F. Page 1 of 12 


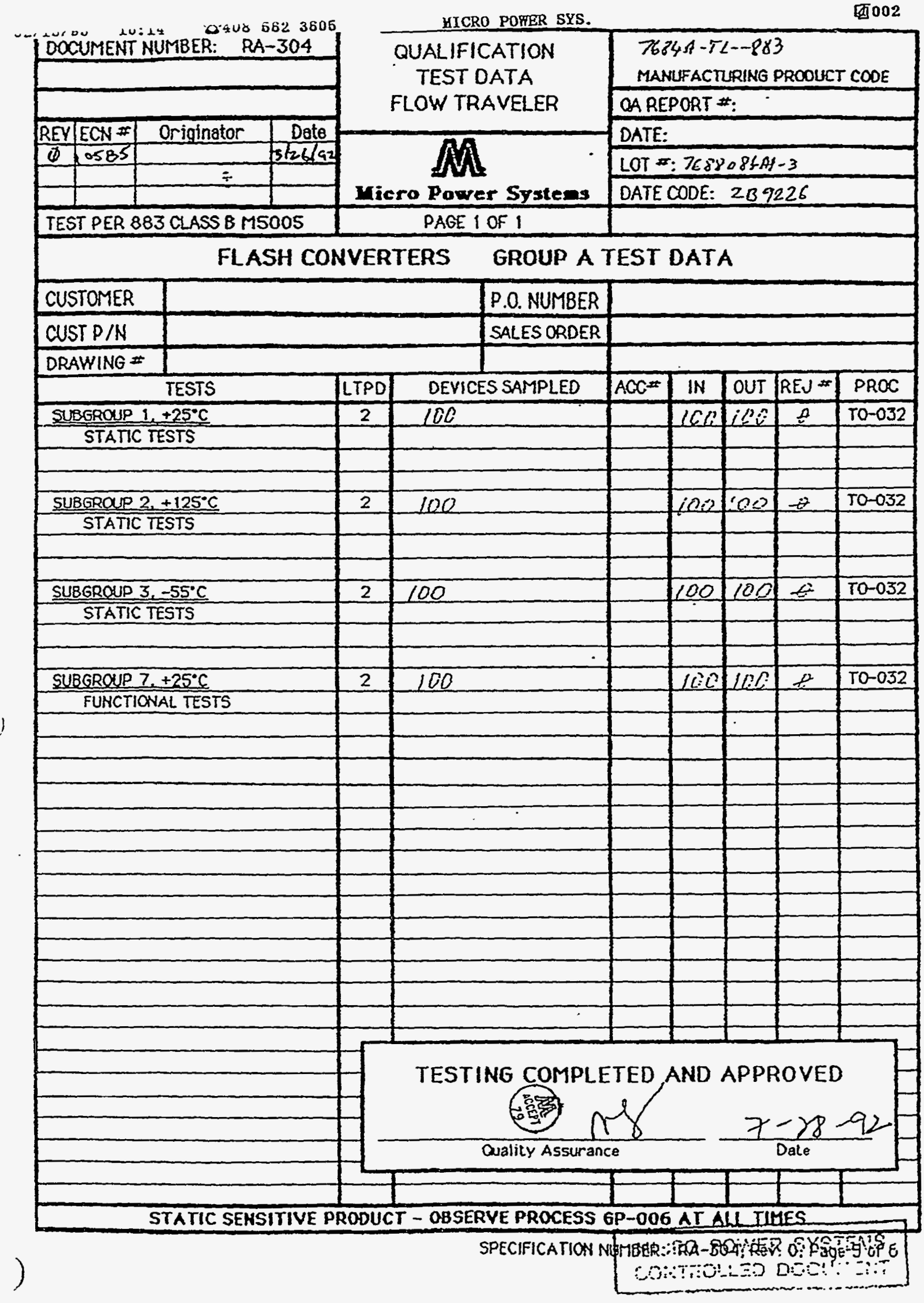


Plicto Hower Systems

\section{CERTIFICATE OF CONFORMANCE}

TO: UC haurence Livermore Labs

7000 East Aneme

Livermore CA.94550

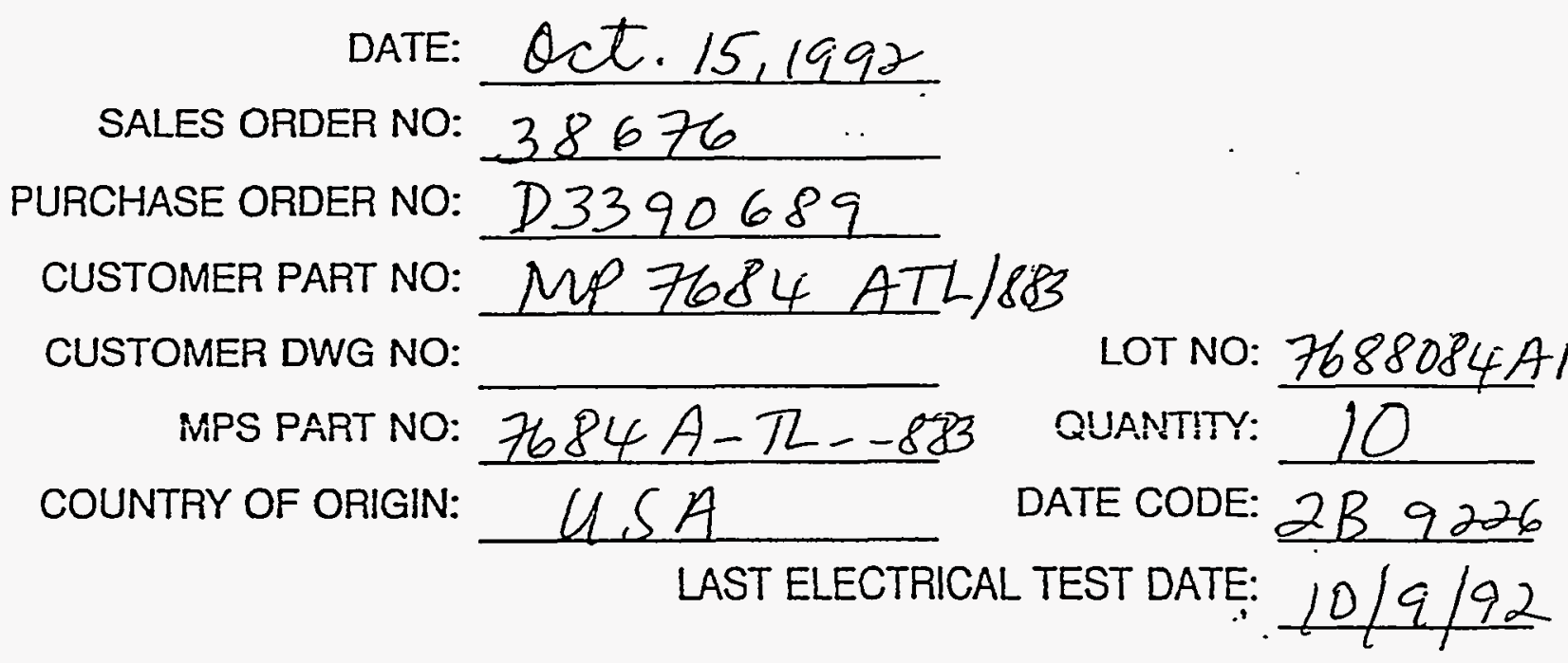

SELLER CERTIFIES THAT:

1. The parts furnished against this purchase orcer were produced in conformance with all contractually applicable specifications.

2. Data taken to characterize the final product under the above purchase order is available for examination by duly authorized personnel.

SELLER: MICRO POWER SYSTEMS, INC.

QUALITY REPRESENTATIVE: Vú c Yaudun

TITLE: QA Specialist

)

P.O. Box 54965, 3100 Alfred Street, Santa Clara 95094-0965

Telephone: (408) 727.5250 Fex: («3) 562.3605

Exhibit II

SPECIFICATONO NUMBER: QA-303, Rev. F, Page 1 oi 12 
13229988

\title{
Micro Power Systems
}

\section{CERTIFICATE OF CONFORMANCE}

\author{
TO: UC Lamerence Livermore Labs.

$\frac{7000 \text { EAST AVE. }}{\text { Livermore CA.94550 }}$

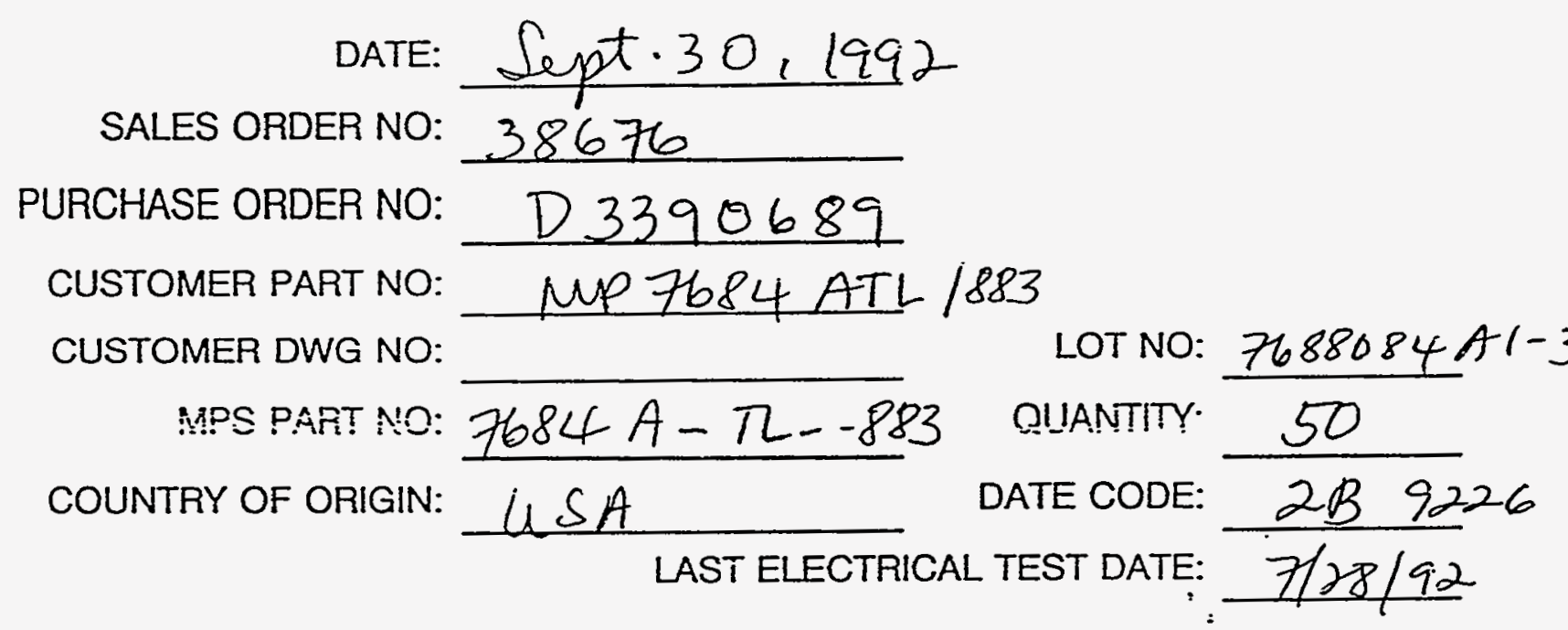

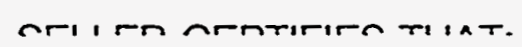

uced in conformance

Colle $\operatorname{sen}^{2} \sin ^{2}$

1e purchase order is

in 


\title{
ALLAMERICAN
}

a quality electronics distributor

16085 N.W. 52ND AVENUE, MLAMI, FLORIDA 33014-9317

\section{CERTIFICATE OF CONFORMANCE}

\author{
CUSTOMER NAME UNIV. CALIF LIVERMORE \\ AND ADDRESS LIVER MORE NAT'L LABS \\ 7000 EAST AVENUE, RECEIVING \\ LIVERMORE, CA 94550
}

ALL AMERICAN CERTIFIES THAT THE MATERIAL SUPPLIED ON YOUR PURCHASE ORDER $B D 227573$

IS DESIGNED TO MEET SPECIFICATIONS PER:

1) $\square$ MIL-S-19500/

$\begin{array}{lll}\text { 2) } \square \text { MIL-M-38510 } & \text { 3) } \square \text { MIL-STD-883 }\end{array}$

4) $\square$ DESC DRAWING NO

5) DCOMMERCIAL

QUANTITY 250

PART NUMBER TC 4428 EOA

MANUFACTURER TEL

DATE CODE

DATE SHIPPED $10-6-92$

INSPECTION DATE

ALL AMERICAN SEMICONDUCTOR CERTIFIES THAT ALL ARTICLES INCLUDED IN EACH SHIPMENT UNDER THE ABOVE PURCHASE ORDER(S) ARE MANUFACTURED IN ACCORDANCE WITH ALL MANUFACTURER'S AND/OR APPLICABLE MILITARY SPECIFICATIONS SO DESIGNATED ON SUBJECT PURCHASE ORDER, AND FURTHER CERTIFIES THAT THIS SHIPMENT IS A PART OF THE SHIPMENT COVERED BY THE MANUFACTURER'S DOCUMENTATION. TEST REPORTS FOR MATERIAL SUPPLIED ARE ON FILE, AND ARE AVAILABLE FOR EXAMINATION AT THE POINT OF MANUFACTURE.

)

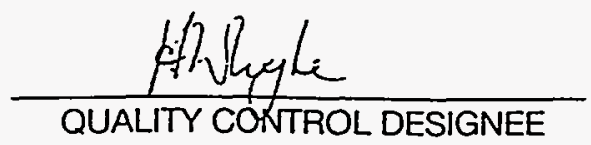




\section{ALLAMERICAN}

a quality electronics distributor

16085 N.W. 52ND AVENUE, MIAMI, FLORIDA 33014-9317

\section{CERTIFICATE OF CONFORMANCE}

CUSTOMER NAME UNIV. CAL IF LIVERMORE

AND ADDRESS LIVER MORE NAT'L LABS

7000 EAST AVENUE, RECEIVING

LIVERMORE, CA 94550

ALL AMERICAN CERTIFIES THAT THE MATERIAL SUPPLIED ON YOUR PURCHASE ORDER $B B 227573$ IS DESIGNED TO MEET SPECIFICATIONS PER:

1) $\square$ MIL-S-19500/

2) $\square$ MIL-M-38510

3) $\square$ MIL-STD-883

4) $\square$ DESC DRAWING NO

5) DCOMMERCIAL

QUANTITY 250
PART NUMBER TC 4426 EOA
MANUFACTURER TEL
DATE CODE
DATE SHIPPED IU-6-92
INSPECTION DATE

ALL AMERICAN SEMICONDUCTOR CERTIFIES THAT ALL ARTICLES INCLUDED IN EACH SHIPMENT UNDER THE ABOVE PURCHASE ORDER(S) ARE MANUFACTURED IN ACCORDANCE WITH ALL MANUFACTURER'S AND/OR APPLICABLE MILITARY SPECIFICATIONS SO DESIGNATED ON SUBJECT PURCHASE ORDER, AND FURTHER CERTIFIES THAT THIS SHIPMENT IS A PART OF THE SHIPMENT COVERED BY THE MANUFACTURER'S DOCUMENTATION. TEST REPORTS FOR MATERIAL SUPPLIED ARE ON FILE, AND ARE AVAILABLE FOR EXAMINATION AT THE POINT OF MANUFACTURE.

)

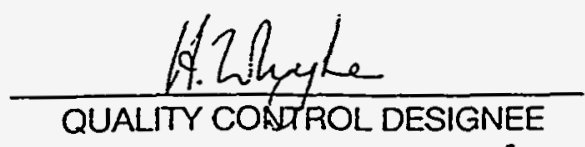


520 MERCURY DRIVE

NYVALE, CA 94086-4018

PH: $408-730-0300$ FAX:408-730-4782

UPS SHIPPER \# CA 9-63-148

SHIP VIA: UPS'

PACKSLIP PACK DATE CUSTOMER PO\#

P9324902 10-01-92 B229281

SHIP TO: UCLLNL

7090 EAST AVENUE

LIVERFORE CA 94550

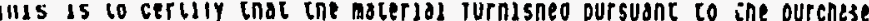
order referenced bo as been manufactured, tested, and/or inspected in accordance ulth the -ryulrenents of the appllcable speciflestlons.

Ho metallic aercury compounds are used in the process or In the parts furnlshed hereln. Inspectlons and/or tests have been perforned as applicable, on both a varlable and 60-\$0-60 basls, utilizing equipaent in accordance with the requlienants of KI-STD-15662.

Documentary evidence In the form of test and/or Inspection reports are on flle and are avallable upon request.

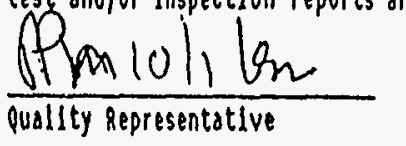

BILL TO: UNIV. CAL. LAWRENCE NAT.

P. O. BOX 5001

LIVERMORE CA 94560

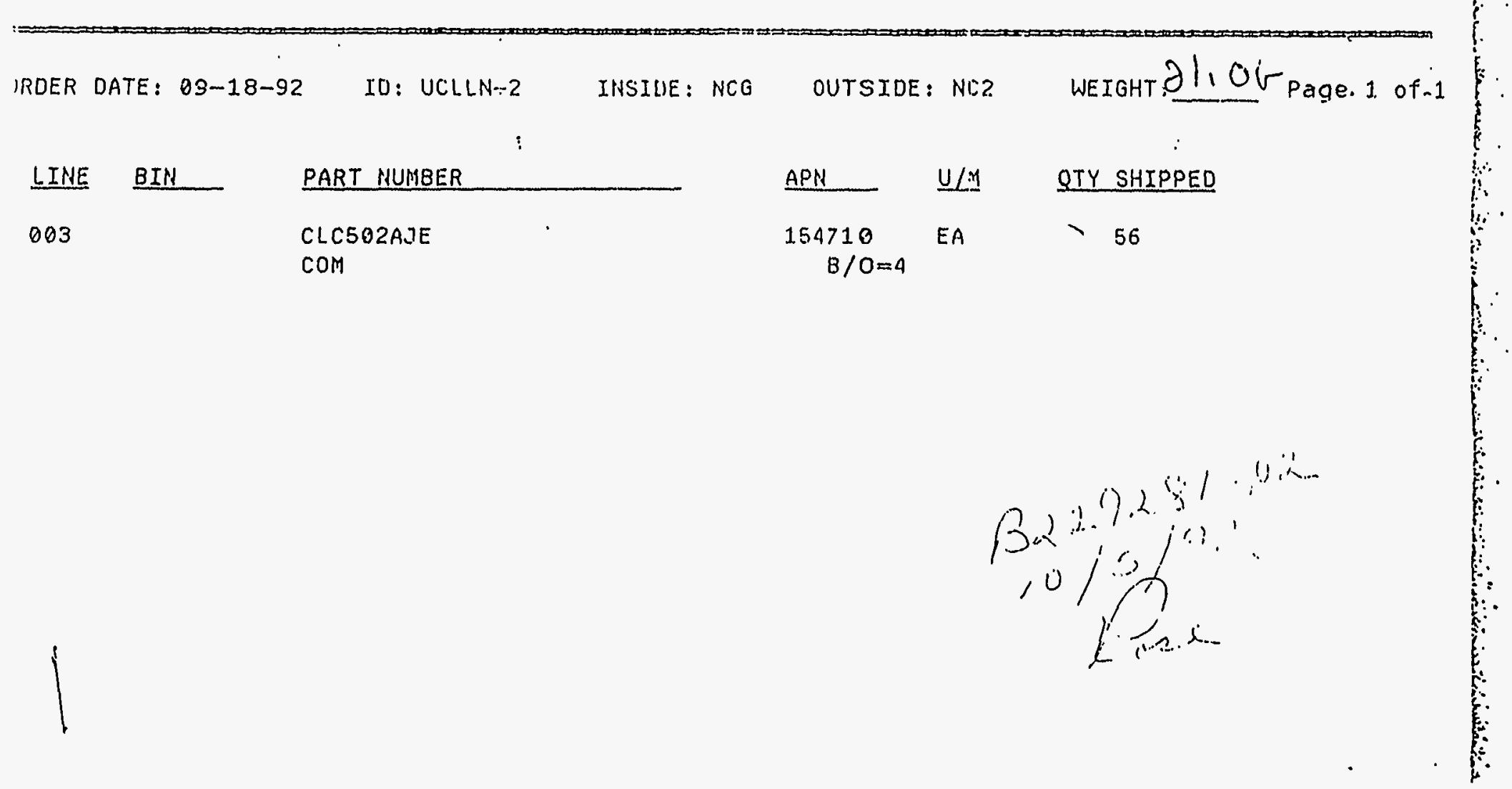




\section{Uertiftrate af Urmentliantre}

D. ANALOG DEVICES, INC.

SUNIUERSITY OF CALIFDRNIA

$\neg$

3 TECHNOLOGY WAY - NORWOOD, MASSACHUSETTS 02062 - TEL: 617/329-4700

LAWRENCE LIUERMORE LABORATORY

UNIV OF CALIFORNIA

ACCOUNTING DFFICE

$P$ O BOX 5001

T

LIUERMORE

CA $94551 \quad 1015$ YS

LAWRENCE LIIVERMORE LAB

7000 EAST AVE

\section{LIUERMORE}

CA 94550

1015

\#REPRIi

CUSTOMER PURCHASE ORDER NO.
B243191

DATE OF ORDER

02117193

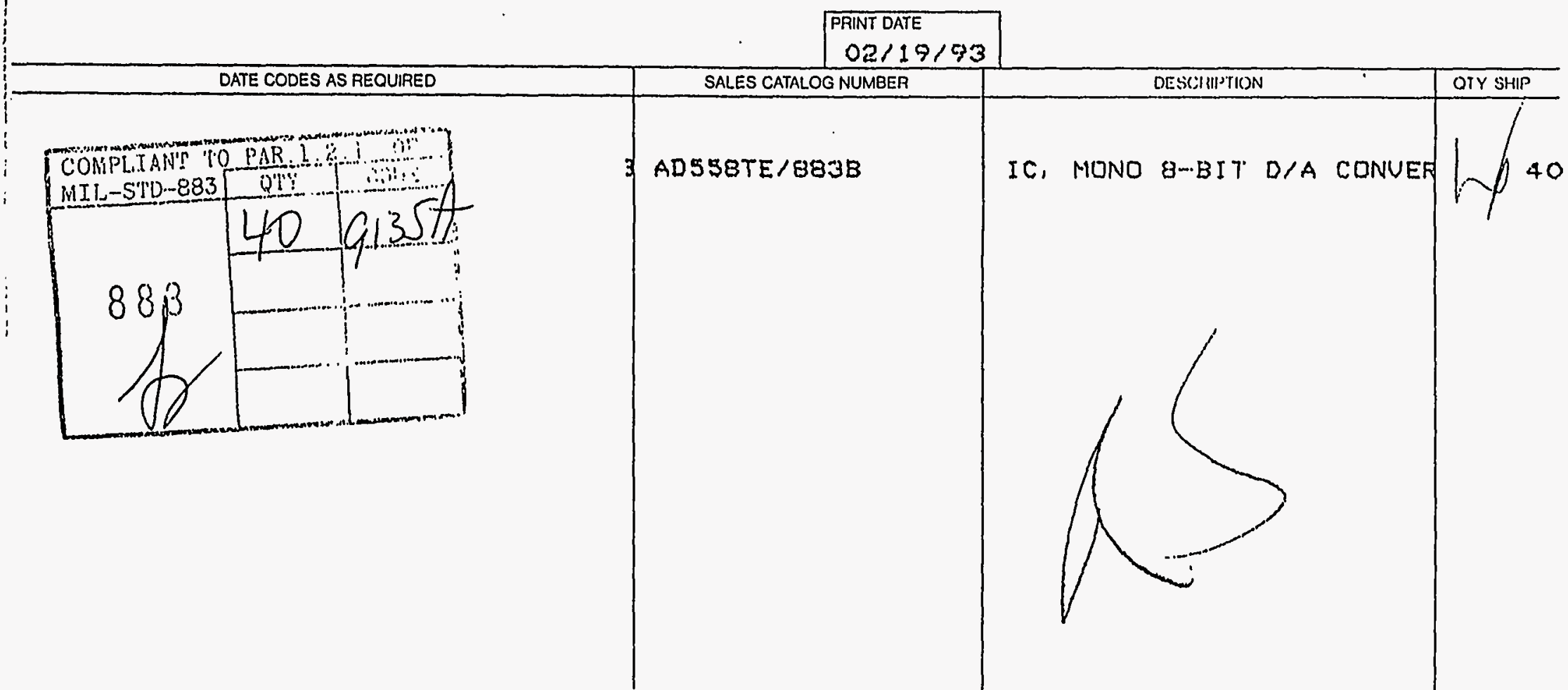

It is hereby cerlified that the products (Model numbers listed above) supplied on the above referenced purchase order, are in conformance with all purchase order requirements, including applicable government, or oller specificalions and drawings, to the extent specilled. All 883 producl is compliant to paragraph 1.2.1 of MIL. STD-883.

The required lest and traceability documentation resulting from compliance with applicable requirements are on file and available

for review by your represenlative or government inspectors at any reasonable lime. 


\section{Uertiftuate af (tomtulitatre}

SUNIUERSITY DF CALIFORNIA

O LAWRENCE LIUERMORE LABORATORY

D ACCOUNTING OFFICE

T'

LIVERMORE

CA 94551

1015 YS

$\neg$

口

ANALOG DEVICES, INC.

3 TECHNOLOGY WAY • NORWOOD, MASSACHUSETTS 02062 • TEL: 617/329-4700

CUSTOMER PURCHASE ORDER NO.

B22754

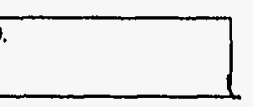

DATE OF ORDER

09181932

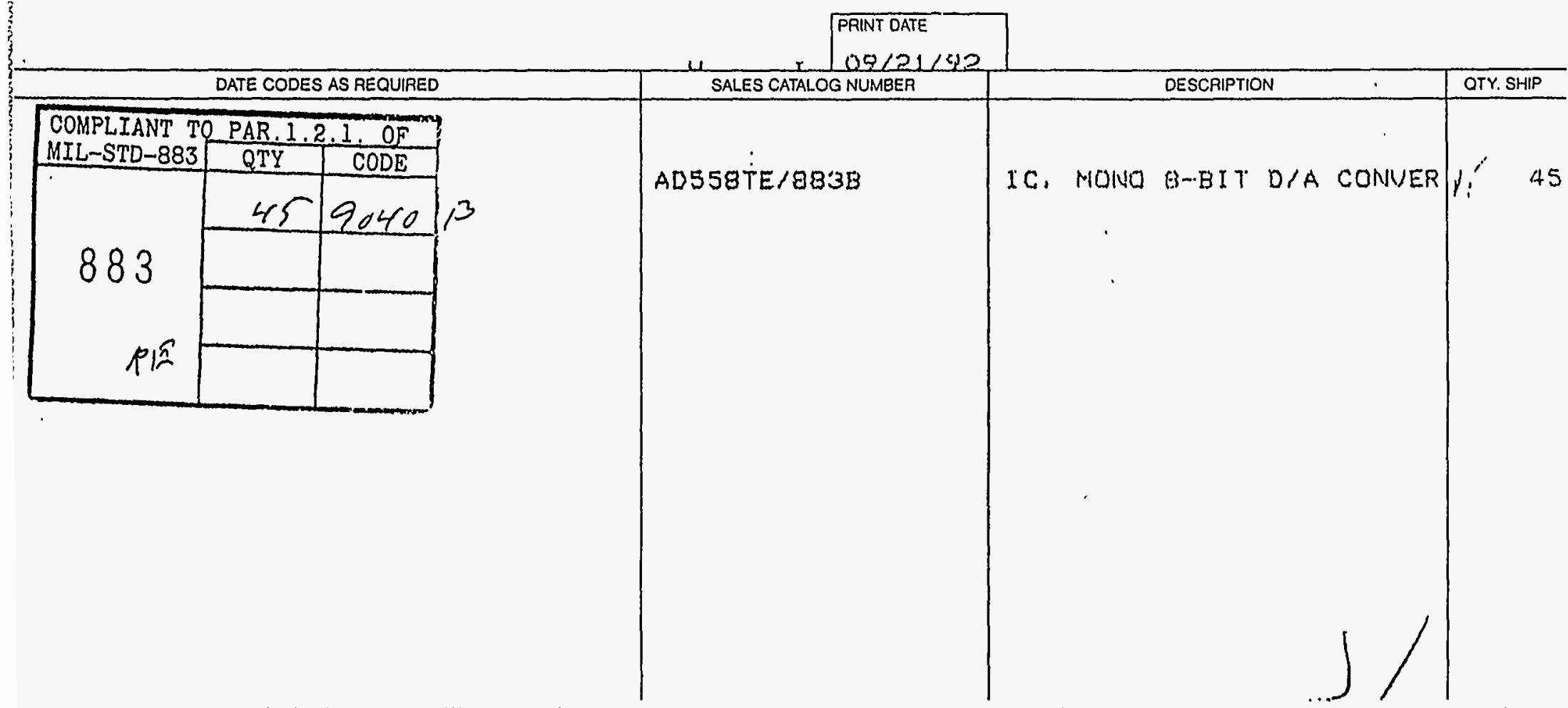

It is hereby certified that the products (Model numbers listed above) supplied on the above referenced purchase order, are in conformance with all purchase order requirements, including applicable government, or other specilications and drawings. to the extent specilied. All 883 product is compliant to paragraph 1.2.1 of MIL-STD-883.

The required lest and traceability documentation resulling from compliance with applicable requirements are on file and available for review by your representative or government inspectors at any reasonable time.

THORIZED ANALOG DEVICES OUALITY CONTROL REPRESENTATIVE

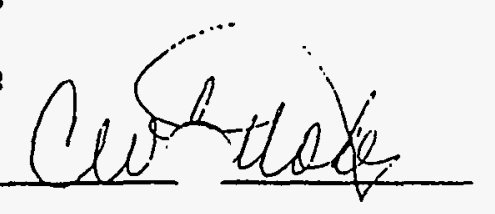




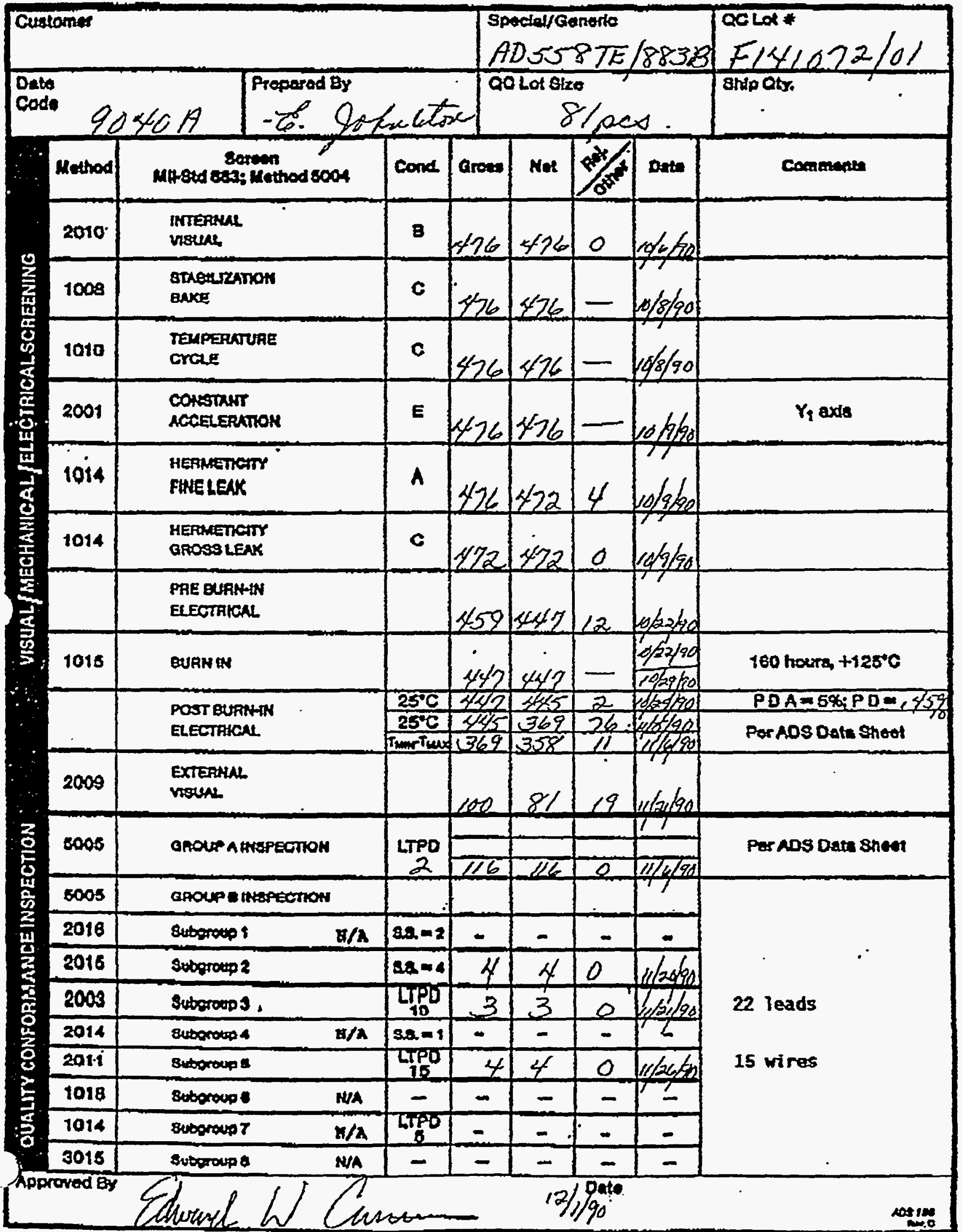




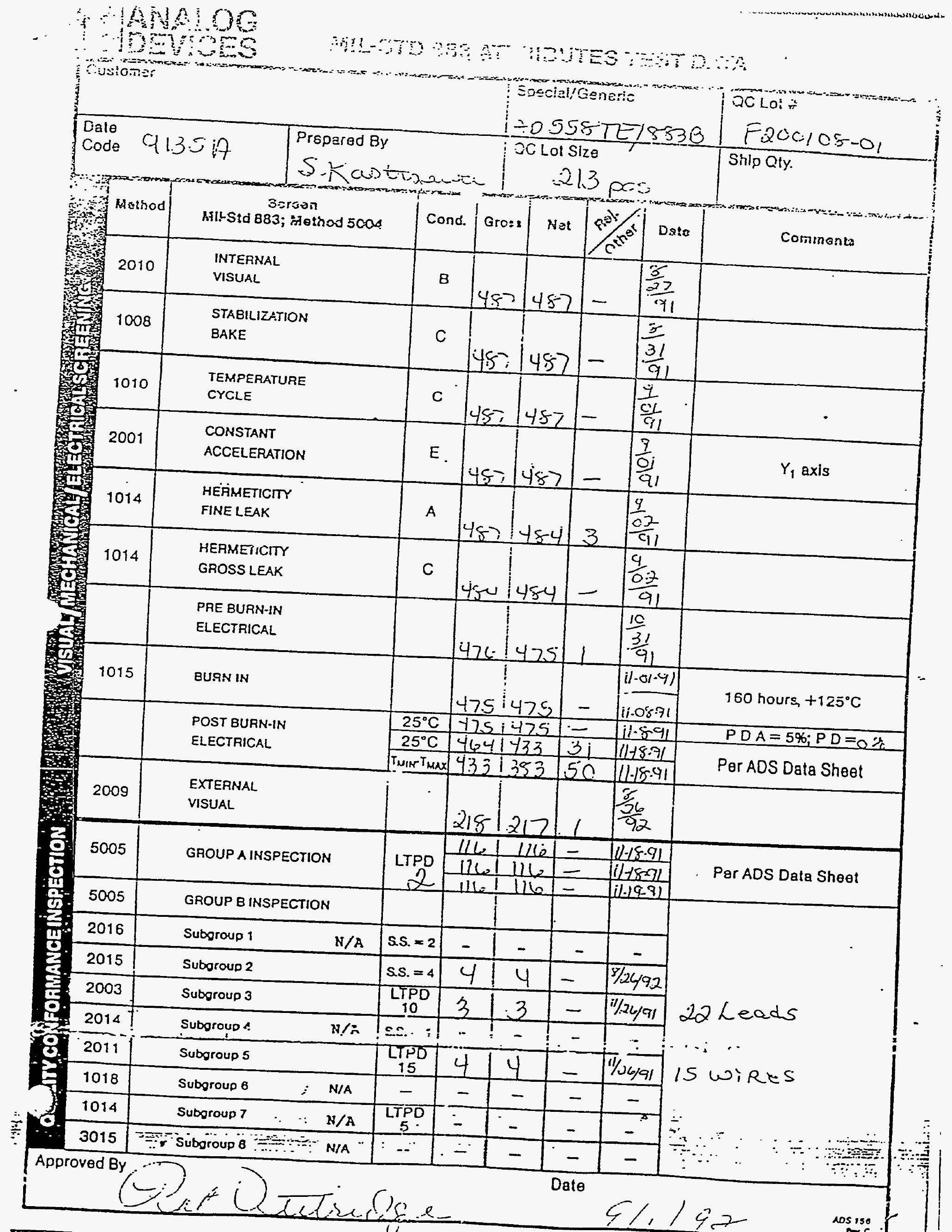




\section{QUALTTY CONFORMANCE INSPECTION MUL-C-3098 G}

\begin{tabular}{|c|c|}
\hline cUSTOMER Uni of California & PO.No. B243124 \\
\hline CXAT-TZ & PCS 25 \\
\hline \multicolumn{2}{|l|}{ Lor No.: $\mathrm{CQOO} 1176$} \\
\hline FREQUENCY $\quad 20.0 \mathrm{HHZ} \quad[\mathrm{kH}=1$ & FREQ.TOLERANCE \\
\hline LOAD CAPACITANCE $C_{L} \quad 20 \quad\left[\begin{array}{lll}\mathrm{pF} & ]\end{array}\right.$ & SHUNT CAPACITANCE Co $3.20[\mathrm{pF}]$ \\
\hline SERIES RESISTANCE R $10.050[\mathrm{k} \Omega]$ & OPERAT.TEMP.RANGE $-55^{\circ} \div+125^{\circ} \mathrm{C}$ \\
\hline DRIVE LEVEL MAX & MARKING MC $20.000 \mathrm{MT}$ \\
\hline MEASURING EQUIPMENT No.QC-TesterII & OSCILLATOR No. 999 \\
\hline
\end{tabular}

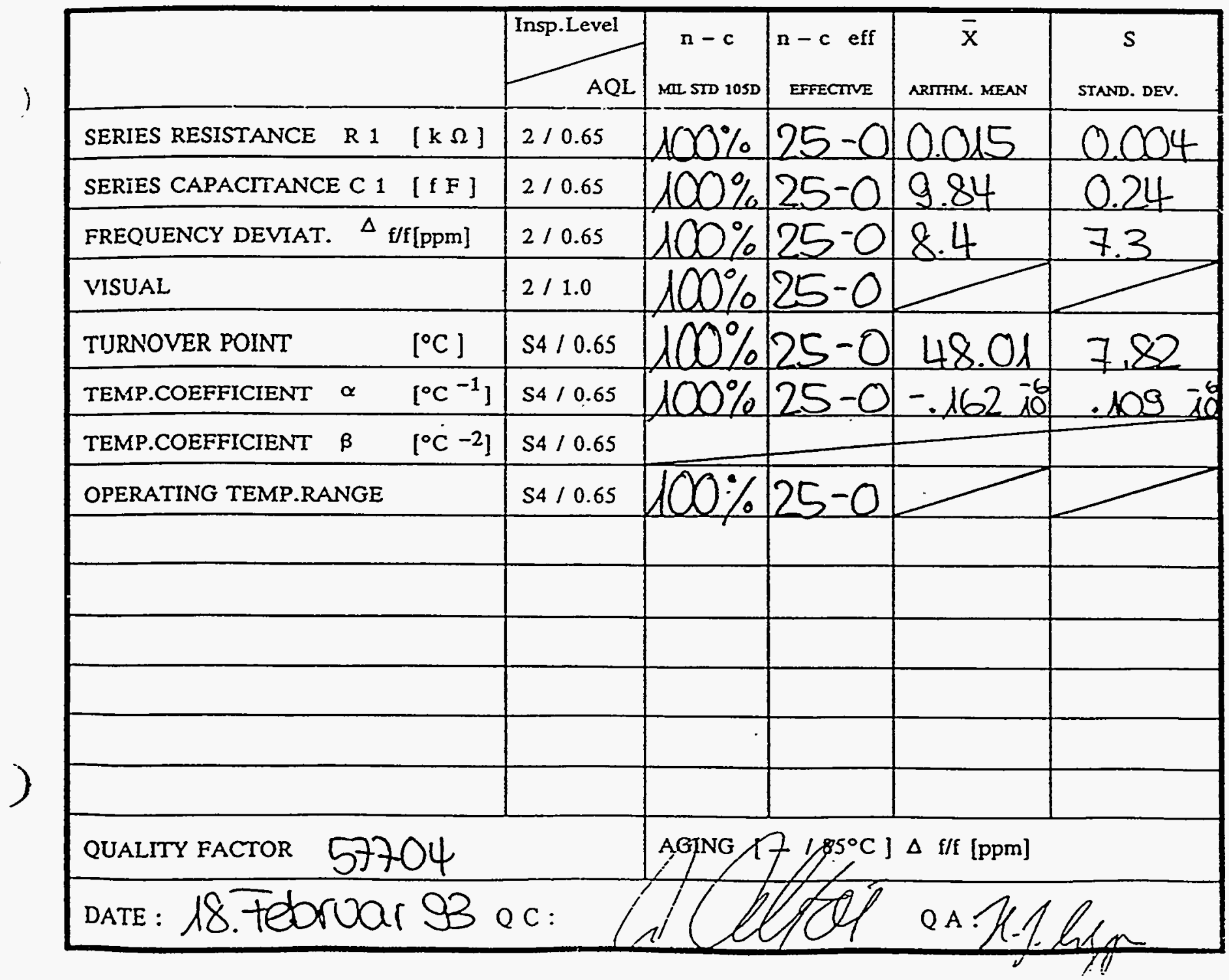


Appendix G.2.6

Artwork 


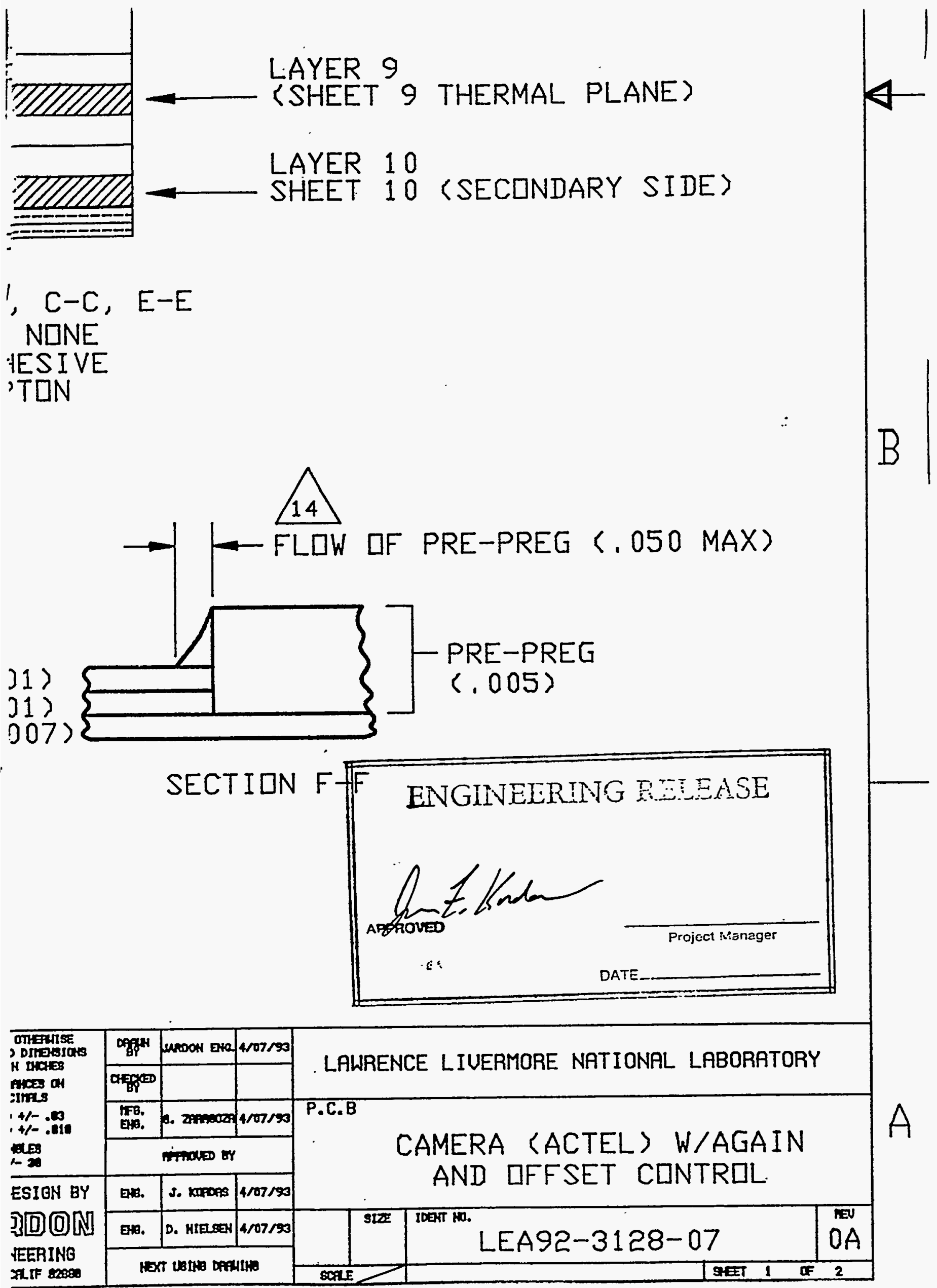



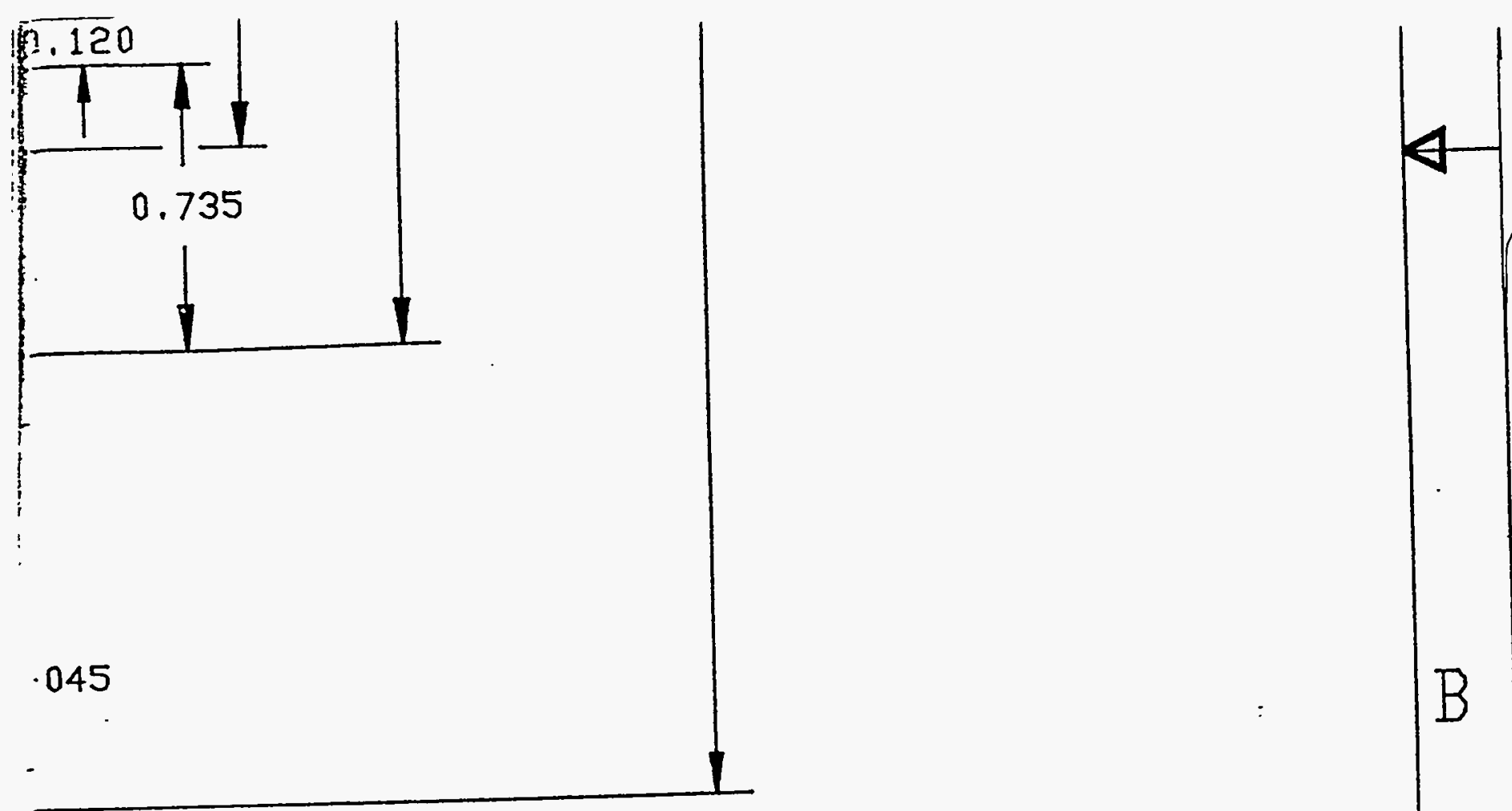

IDE

ENGINEERING RELEASE

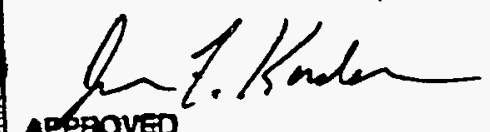

Ap POOVEO

Project Miznager

A

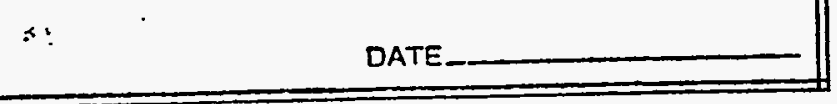

\begin{tabular}{|l|l|l|l|l|}
\hline & 8I2E & SDET Wo. & LEA92-3128-07 & OA \\
\hline & & & \\
\hline
\end{tabular}




\section{Appendix G.2.7 \\ Electronic Test Data}




\section{Appendix G.2.7.1 \\ Electronic Test Procedure: \\ Actel Camera, PWA with Gain and Offset Control}




\section{Electronic Test Procedure}

\section{Actel Camera, PWA with Gain and Offset Control}

SN\# $\frac{O 4-06}{\text { (ST2 configured) }}$

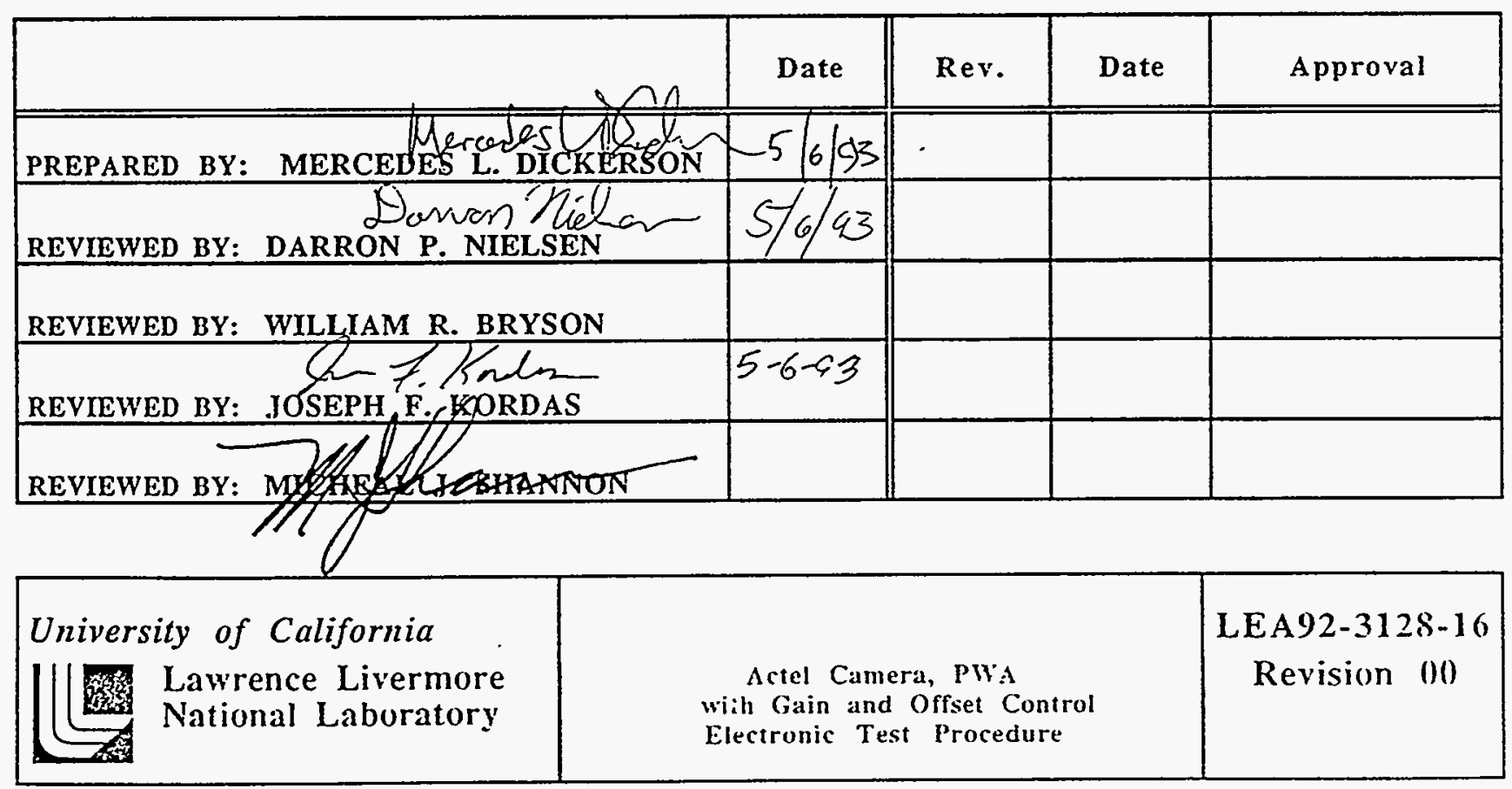




\section{Table of Contents}

1. Scope

2. Required Documents and Tesi Equipment

2.1 Required Documents

2.2 Required Test Equipment

3. Conditions and Requirements

3.1 Precautions

3.4 Cleanliness and Environment

3.5 Quality Assurance (QA) Provisions

4. SUN Test Station Setup

5. Printed Wiring Assembly Specificity

5.1 Inspection

5.2 Power Plane Resistance Measurements

5.3 Power Plane Voltage Measurements

5.4 CCD Bias Voltage Measurements

5.5 Reference Voltage Measurements

5.6 Video Clamping Voltage Measurements

5.7 DC Steady State Current Measurements

5.8 Offset Digital-To-Analog (D/A) Verification

5.9 Gain Selection Verification

6. Video Amplifier Gain Verifications

6.1 Test Board Configuration

6.2 HP4194 Analyzer Configuration and Connection.

6.3 Gain and $3 \mathrm{~dB}$ Bandwith Acquisition.

7. Clocking Measurements (with $\mathrm{CCD}$ installed)

$7.1 \varnothing \mathrm{L} 2, \varnothing \mathrm{L} 1$

$7.2 \varnothing \mathrm{L} 2, \varnothing \mathrm{R}$, and $\varnothing \mathrm{RFET}$

$7.3 \varnothing \mathrm{P} 1, \varnothing \mathrm{P} 3$

$7.4 \varnothing \mathrm{P} 1, \varnothing \mathrm{P} 2$

$7.5 \varnothing \mathrm{P} 1, \varnothing \mathrm{P} 4$

7.6 P1A, P3

7.7 P1A, P2

7.8 P1A, P4

7.9 PIA, P1B

8. Double Correlated Sampling Functionality Verification

9. Analog to Digital (A/D) Converter

10. Video Interface Timing Confirmation

10.1 Logic Analyzer Setup

10.2 Timing acquisitions

11. Dark Noise Measurement 
Table of Contents cont.

12. Thermal Test

12.1. Thermal Test Setup

12.2 Thermal Measurement Acquisition

12.3 Thermal Data and Graphs

13. Flat Field Linearity Test

13.1. Linearity Test Setup

13.2 Linearity Measurement Acquisition

13.3 Linearity Data Collection.

13.4 Linearity Data Processing

14. Offset Linearity Test

14.1. Offset Linearity Test Setup

14.2 Offset Linearity Measurement Acquisition

14.3 Offset Linearity Data and Graph

15. Laser Test

16. Tests Required after Conformal Coating 
1. Scope.

This document specifies equipment and procedures required to verify the electrical performance of the ACTEL Camera Printed Wiring Assembly (LEA92-3128-12) in the startracker configuration.

Oscilloscope camera photos and graphs should be attached to the test procedure. Other printer data should be placed in a document protector and inserted in this certification log.

Section 16 describes those tests that are required after conformal coating.

2. Required Documents and Test Equipment.

2.1 Required Documents:

Actel Camera PWB Schematic. LEA92-3128-01-0C OR LEA92-3128-11-OC

Actel Camera PWB Assembly Drawing, LEA92-3128-03

SUN DatacubeTest Station

A Short Guide to Running hspcuhe , C1-S1-002

2.2 Required Test Equipment:

SUN DatacubeTest Station includes: Protomax Interface

S1/S2 Data Interface Power Supply, AIT EE-0090-10

Engineering TH7883 CCD for test purposes

Digital voltmeter such as Fluke model 77

AM 503 Current Probe (2ea) powered by a TM502A Power Supply

Tektronix 2465B Analog Oscilloscope with P6106A probes (4ea)

Oscilloscope recording camera

Tektronix TDS540 Digital Oscilloscope

Hewlett Packard Desk Jet 500 Printer

HP 4194 Impedance Gain-Phase Analyzer, with probe and RG 58 cabling

Tektronix HC100 color plotter

Philips PM 3585, $200 \mathrm{MHz}$ Logic Analyzer

TV Optoliner Model K-4000 (with neutral density (ND) filters) and Lamphead

HeNe Laser, $1 \mathrm{~mW}$ at $632.8 \mathrm{~nm}$ (with ND filters)

Surface mount testing probes,

Tektronix 20-pin and 44-pin SMQK1 PLCC

Actel Camera board carrier mount, to prevent carrier/pc card flexing

PC board holder/clamp

Video Copier Processor Tektronix Model HCO2

Environmental chamber

Timer

Black cloth or an opaque cover for the CCD

Packing Foam

Breakout Connector, 51 contact miniD

The above listed test equipment MUST have calibration dates within one year of test integration. Calibration records should also be available for inspection.

Any fabricated testing hardware, such as the 51-pin breakout connector,MUST have quality assurance tagging and records stating such. 
3. Conditions and Requirements

\subsection{Precautions}

(1) Responsibility for Safetv. All personnel are responsible for maintaining a sate work environment. The Test Conductor or cognizant operator shall assure that appropriate safe practices are implemented during these operations. and that operations are performed in a proper order.

(2) ESDS Equipment. The test specimen contains electrostatic- sensitive devices which are exposed at the electrical interfaces. Therefore, it shall be handled per MIL-STD1686 Class 1 . The test specimen, the test operator (using wrist straps). and related electrical test equipment shall be connected to a common ground before any electrical mating or de-mating operations, and during the use of any electrical test equipment probes. There shall be no "hot-plugging" of the test specimen with any test equipment.

(3) Examine Connectors. Before mating any flight connector, examine the connector and the connector with which it is to be mated, to assure that there are no interferences at the pin interface. Connector savers will be used at all times.

\subsection{Cleanliness and Environment}

(1) Standard laboratory conditions of atmospheric temperature, pressure, and humidity are acceptable for the testing defined herein.

(2) Normal housekeeping standards will be required. If appropriate, the unit may be cleaned prior to installation into the next assembly, or prior to return to storage.

\subsection{Quality Assurance (QA) Provisions}

QA provisions operative during activities defined in this procedure shall be as specified in the project's QA Flan. This section identifies the interfaces between QA and test personnel. QA and test personnel are jointly responsible for the effectiveness of these interfaces in implementing the QA provisions.

(1) QA shall be notified, in advance, of performance of any activities described in this procedure. A QA Inspector may monitor those activities as is deemed necessary or appropriate, in accordance with the project QA Plan. The inspector shall verify that the proper revision of this procedure is used, and that the required Certification Log is in proper order. QA will then give the "OK to Test" prior to the start of test activities.

(2) The QA Inspector shall verify: that calibration is current for all measuring equipment used in these operations, and will not expire prior to completion of these operations; that applicable project-specific electrical support test equipment (STE) has been properly certified and tagged; and that applicable lifting and handling STE has been properly proof tested and tagged. 


\section{Quality Assurance (QA) Provisions (continuation)}

(3) The QA Inspector may assist in assuring that the precautionary and en ironmenol requirements stated in 3.1 and 3.2 are met. He shall also, at his discretion, assist in the inspection of test setups prior to application of power to a test specimen. and prior to any mechanism-assisted lifts or moves.

(4) Upon the occurrence of a test anomaly (any event that deviates from the planned procedures, exceeds normal variations, or generates unexpected data), operation of the test article shall be stopped immediately. All other test conditions and parameters shall be maintained (except as those conditions may pose an immediate hazard). The Q.A Inspector shall be notified that a test anomaly has occurred.

(5) The QA Inspector or Test Conductor (with QA concurrence) shall note each test anomaly on the Failure Reporting And Corrective Action System (FRACAS). The Inspector and the Test Conductor shall review the anomaly. Minor troubleshooting may be done to determine the cause of the anomaly; however, no disassembly or other actions that present a risk to the test article shall be allowed. Li the anomaly is found to result from human error or test equipment problems that have not affected the test article, corrective action shall be taken and testing may continue. All troubleshooting steps and results shall be recorded on the FRACAS. The Test Conductor shall supervise any troubleshooting or retesting required in resolving test anomalies.

(6) If a test anomaly cannot be resolved as described above, the Project Engineer shall be notified. If the action indicates that a rework or repair may be required, the anomaly and troubleshooting results shall be noted in the Action Item List (AIL) portion of the Certification Log, Fracus report and a Material Discrepancy Report (MDR) shall be initiated (if required) and processed as prescribed in the QA Plan.

(7) The QA Inspector shall stamp log entries as appropriate, attesting to the proper completion of these operations as previously approved in this procedure document. 


\section{SUN Datacubet Test Station}

The LLNL SUN' Test Station layout looks like this:

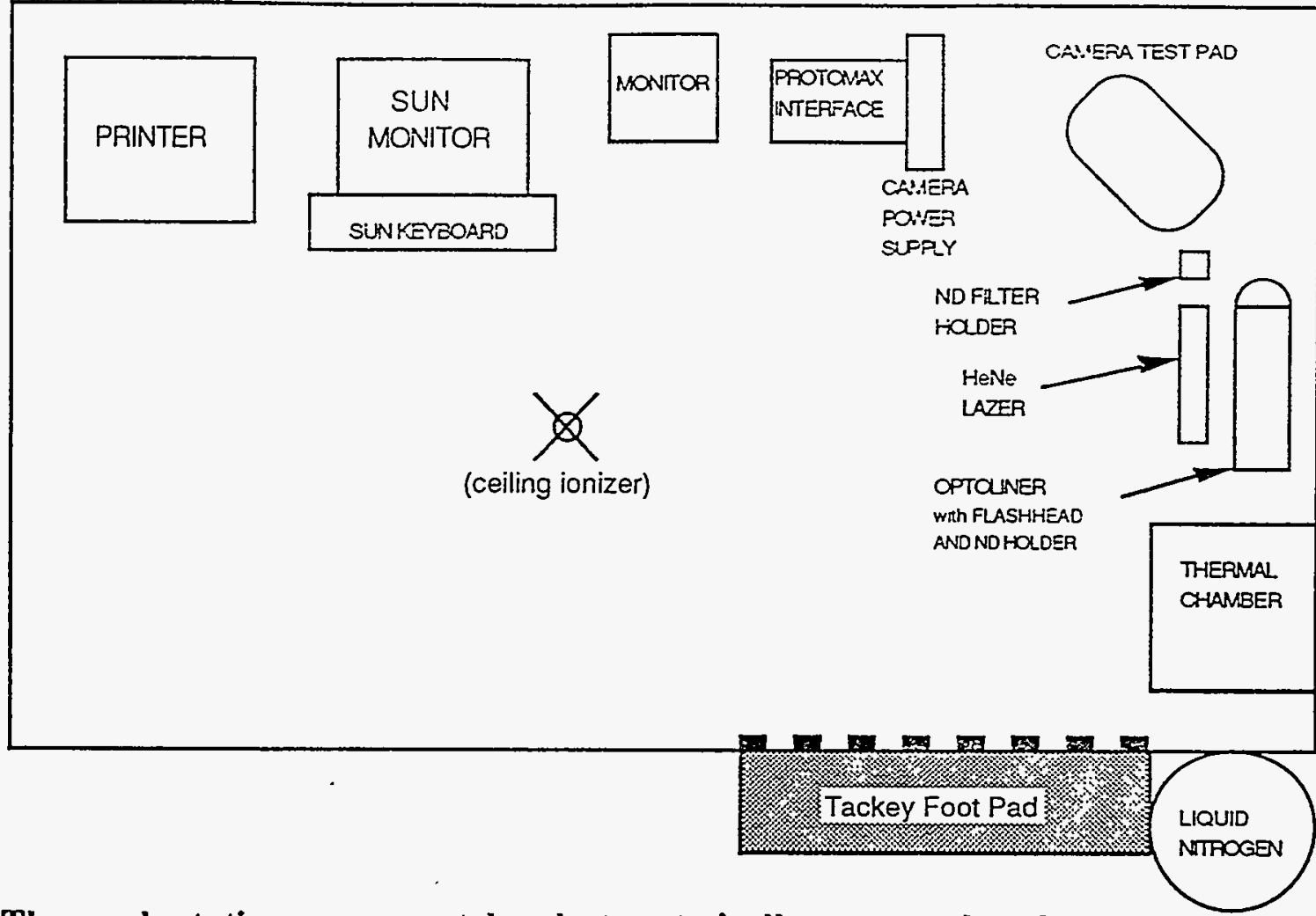

The work station area must be electro-statically protected and approved.

A Short Guide to Running hspcube, C1-S1-002, by Ray Aley, Hye-Sook Park, and Eric Parker explains the Sun3 Computer-Datacube workstation and the software imaging options for the Startracker (S1), UV-Visible (S2), and Lidar (S4) modes.

\section{Printed Wiring Assembly Specificity}

\subsection{Inspection}

Inspect the carrier mounted Actel board for any conflict with the configuration table, assembly drawing or obvious fabrication flaws. Inspect the action item list of the certification log for any anomalies. NOTE!! The camera board should remain attached to the carrier mount until ultimately bent and housed.!!

SN\# $04-06$ Inspection completed By_ DRa

Date $5 / 6 / 93$ 
5.2 Power Plane Resistance Measurements

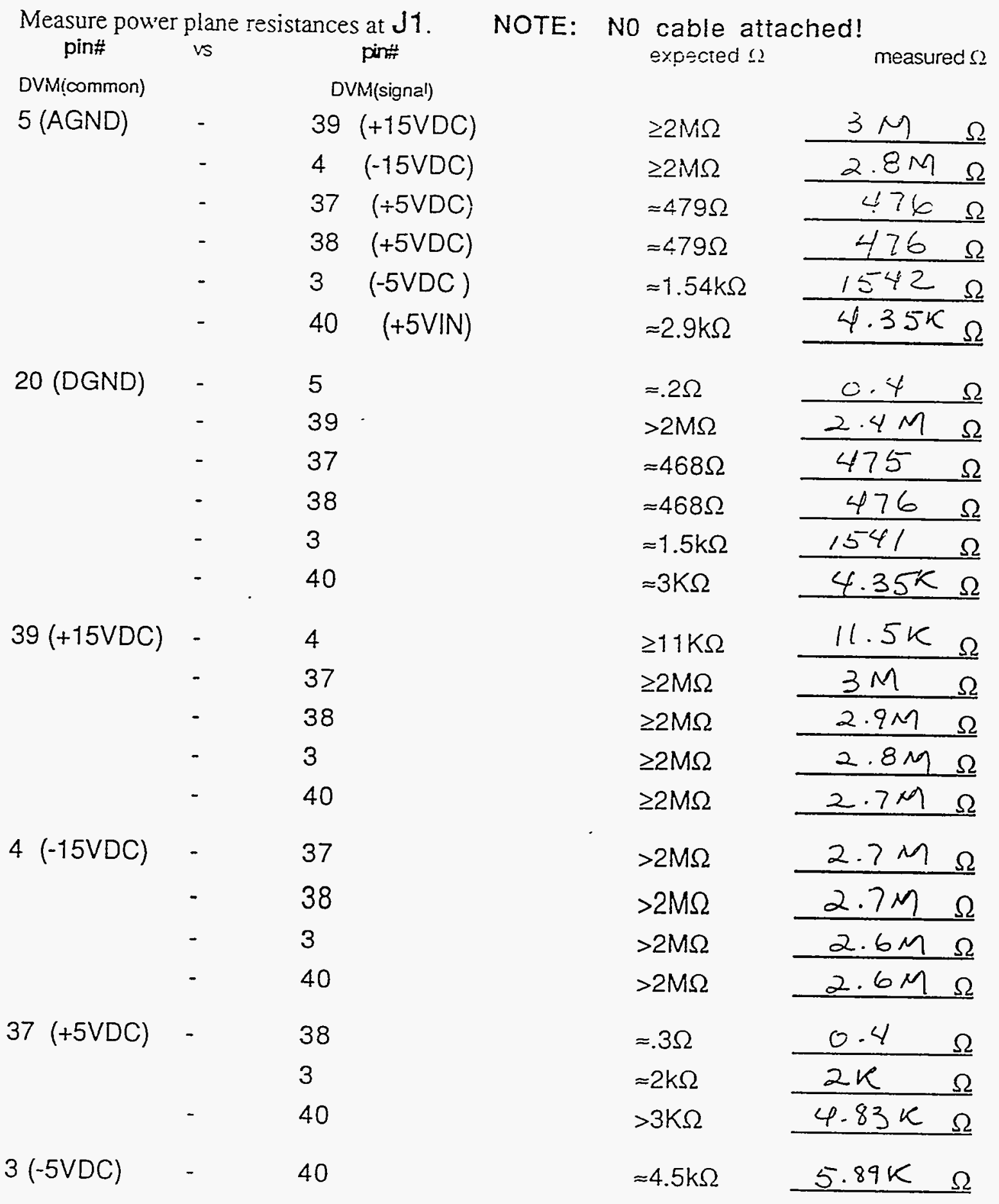




\subsection{Power Plane Voltage Measurements}

Lising a flight certified breakout connector. verify power voltages at camera connector before attaching it to the camera board. Complete the table below, then turn off the power. Use J1-pin

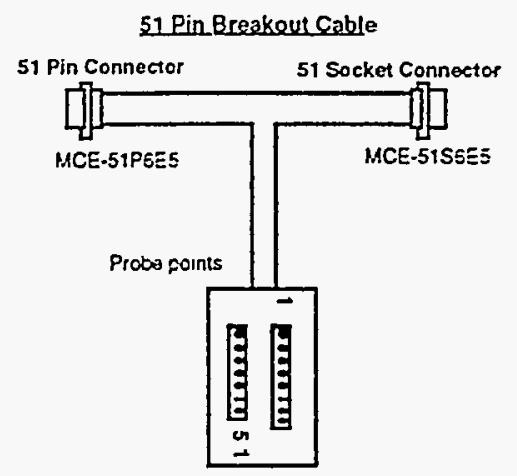
20 for DVM ground.

$$
\text { Using P.S. S/N\% }
$$

$$
\begin{aligned}
& \mathrm{J} 1 \text { pin } \# \quad \text { Expected V } \quad \text { Measured V } \\
& 39 \\
& 4 \quad-15 \mathrm{~V}-15.18 \\
& 37.38+5 V D C+5.15 \\
& 3 \quad-5 V \quad-5 \cdot 30 \\
& 40 \quad+5 \mathrm{VAIN}+5.15
\end{aligned}
$$

Cable voltages satisfied, now measure the power plane voltages. Connect camera side of the breakout connector to the camera board. Once the breakout is attached to the camera board, leave it in place throughout the testing procedure to save the board's connector.

Power up the camera board and record the voltages between single point ground (SPG) or TP1 and indicated voltage points:

$$
\begin{aligned}
& \text { PRIMARY SIDE } \\
& \frac{+5.0 \mathrm{~V}}{\mathrm{U} 12-\mathrm{pin}} 16+5.06 \mathrm{v} \\
& \text { U25-pin } 16+5.06 v
\end{aligned}
$$$$
+\mathrm{C} 10
$$$$
+5.06 v
$$

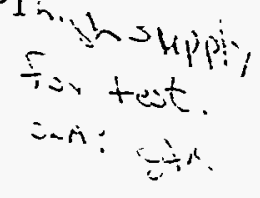

$$
\begin{aligned}
& \pm 5.0 \mathrm{VA} \\
& +\mathrm{C} 11 \\
& +4.94 \mathrm{v}
\end{aligned}
$$$$
\text { U2-pins 4, } 9 \text {, }
$$$$
15,16+5.06 v
$$$$
\text { U26-pins } 3,14,
$$$$
16,25,35+5.06 v
$$$$
\text { U5-pin } 22+5.06 v
$$$$
\text { U6-pin } 16+5.06 v
$$$$
\text { U7-pin } 16+5.06 v
$$

U32-pin14 $+4.92 v$ 


\section{PRIMARY SIDE}

$-5.0 \mathrm{VA}$

$\frac{-5.0 \mathrm{VA}}{-\mathrm{C} 12}=5.21 \mathrm{~V}$

Ut-pin $4 \quad-5.21 v$

U24-pin $4 \quad-5.21 v$

Q1-pin $4 \quad-5.2 i v$

Q4-pins $4 \quad-5 \cdot 2 ! v$

$\pm 15,0 \mathrm{~V}$

Q2-pin $3 \pm 15.02 v$

U17-pin $1+15.08 v$

U14-pin $7+15.02 v$

$-15.0 \mathrm{~V}$

U14-pin $4 \quad-15.17 \mathrm{v}$

$-\mathrm{C} 52$

U3-pin $4 \quad-15.17 v$

U27-pin $4 \quad-15.17 v$

\subsection{CCD Bias Voltage Measurements}

\begin{tabular}{|c|c|c|c|}
\hline$S 2 \& \frac{S 1-}{S 4-}$ & $\begin{array}{l}\cong 0 \mathrm{~V} V s s \\
\cong-3.0 \mathrm{~V} V \mathrm{ss}\end{array}$ & & \\
\hline $\begin{array}{c}\text { U19-pins } 1,10 \\
\text { and } 17\end{array}$ & $0.0 \mathrm{v}$ & U3-pin 1 & 0.0 \\
\hline $\begin{array}{l}\text { S1- } \\
\text { S2 \&S4- } \\
\text { U19-pin } 20 \\
\approx 13.0 \mathrm{~V} \quad \mathrm{Vdr}\end{array}$ & $\begin{array}{l}\approx 1.5 \mathrm{v} \text { Vas } \\
=2.5 \mathrm{v} \mathrm{vgs} \\
\frac{1.516 \mathrm{v}}{1.516 \mathrm{eq}}\end{array}$ & & \\
\hline U19-pin 18 & $\pm 13.16 v$ & U3-pin 7 & $+13.16 v$ \\
\hline 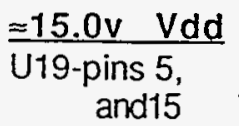 & $+15.0 x v$ & & \\
\hline
\end{tabular}


PRIMARY SIDE

5.5 Reference Voltage Measurements

$10.0 \mathrm{~V}$ ref

0.1V DARK REF

$$
\begin{aligned}
& \text { U17-pin } 3+10.78 v \\
& \text { U11-pin } 6+10.78 v \\
& \text { U30-pin } 6+10.78 v
\end{aligned}
$$

10.7VA clocking ref (ØL1, ØR, ØRFET)

10.7VB clocking ref $(P, \varnothing P)$

\section{SECONDARY SIDE}

$$
\begin{aligned}
& \text { D3-pin } 6+10.00 v \\
& \text { +C93+0.099v Check aftor R128 installe } \\
& \text { Sea }=: ? !: 3 \\
& \text { U27-pin } 3+0.099 v
\end{aligned}
$$

$\begin{array}{ll}\text { U18-pin } 3 & +10.63 v \\ \text { U9-pin } 6 & +10.63 v \\ \text { U10-pin } 6 & +10.63 v \\ \text { U22-pin } 6 & +10.63 v \\ \text { U23-pin } 6 & +10.63 v\end{array}$

Analog to digital (A/D) converter reference voltages:

$\approx 2.5 \mathrm{~V}$ A/D ref

$$
\text { expected volts U27-pin } 5 \frac{+2.496}{\text { measured volts }}
$$

U8-pin 6

$=0.620 \mathrm{v}$

$=1.245 \mathrm{~V}$

$=1.875 \mathrm{~V}$

U8-pin 9

U8-pin 17

$\approx 2.500 \mathrm{v}$

5.6 Video Clamping Voltage Measurements

expected volts

U1-pin 8

U24-pin 8

U1-pin 5

U24-pin 5
$=2.0 \mathrm{v} 3.5$ erea

$=3.5 \mathrm{v}$

$=-1.0 \mathrm{~V}$

$=-0.5 \mathrm{v}$

$$
\begin{array}{r}
+0.618 v \\
+1.246 v \\
+1.826 v \\
+2.498 v
\end{array}
$$

measured volts

$+3.45 v$

$+3.45 v$

$-1.031 v$

$-0.535 v$

Turn off the test fixture. 


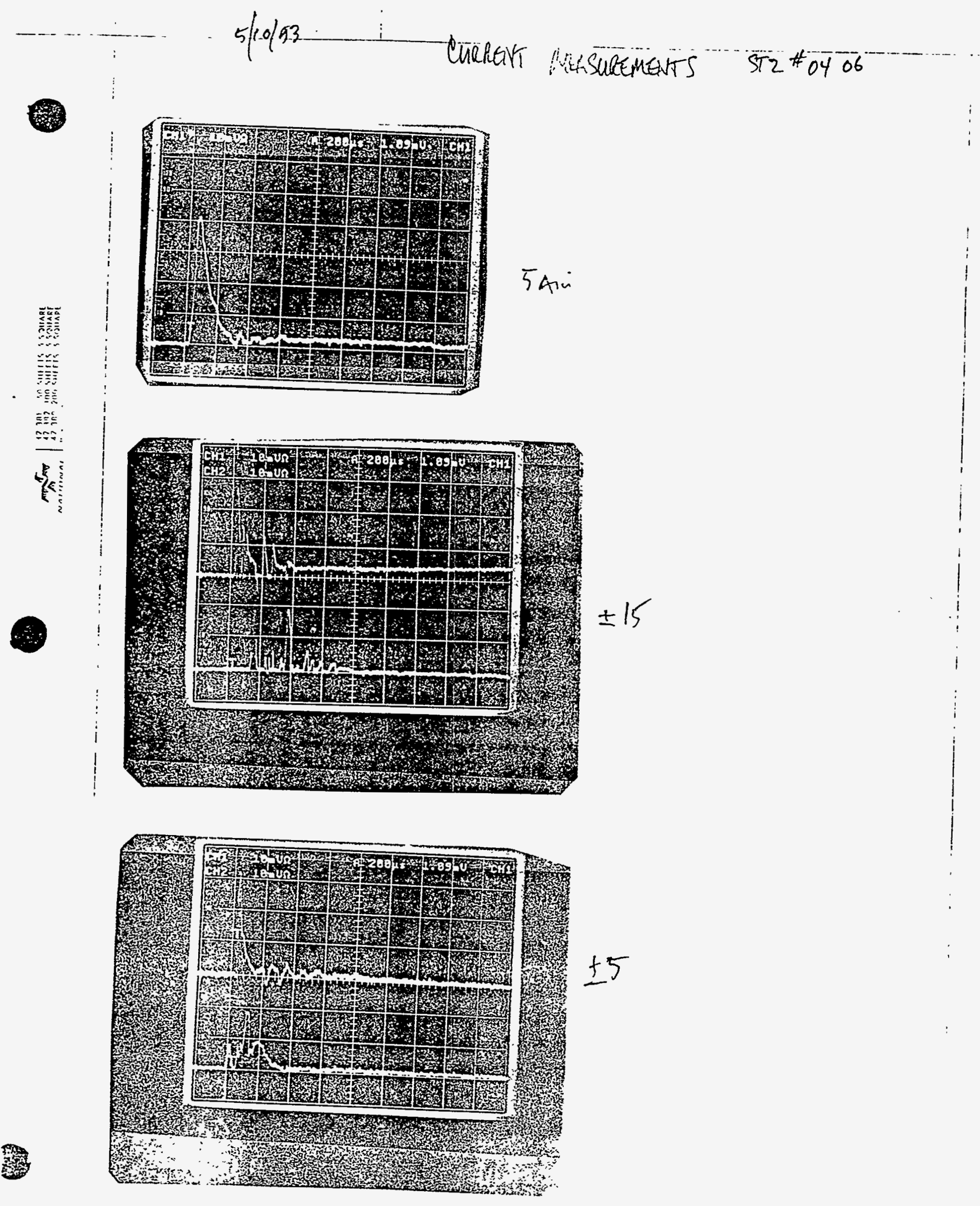




\subsection{Steady State Current Measurements:}

These measurements require an oscilloscope and the AM503 Current Probe powered by a TM502A.

Operation of the AM 503 requires that the oscilloscope be set at $10 \mathrm{mV} / \mathrm{div}$ and that the probe be in the locked position.

Isolate and label the camera wiring harness with respect to the individual power voltages.

Note!! There are two +5VDC wires\#37\&38 so isolate these wires together.

Power up the camera board. Using the appropriate menu based on the camera board's configuration (Startracker) disable the Video bus. Consult $A$ Short Guide to Running hspcube, C1-S1-002 for the necessary SASI or SUN keyboard commands.

With the Probe and Oscilloscope functional, attach the current probe around each input voltage wire and in the case of the $+5 V D C$ the wire pair, each time acquiring and recording the oscilloscope display. Note the units/div used at the AM503 so that the current can be calculated.

Consult $A$ Short Guide to Running hspcube, C1-S1-002 for the necessary SASI command to enable the Video bus. Repeat the current measurements. Each time acquiring and recording the oscilloscope display and recording the units/div used at the AM503 so that the current can be calculated.

Calculate the currents under each Video bus state and complete the table below.

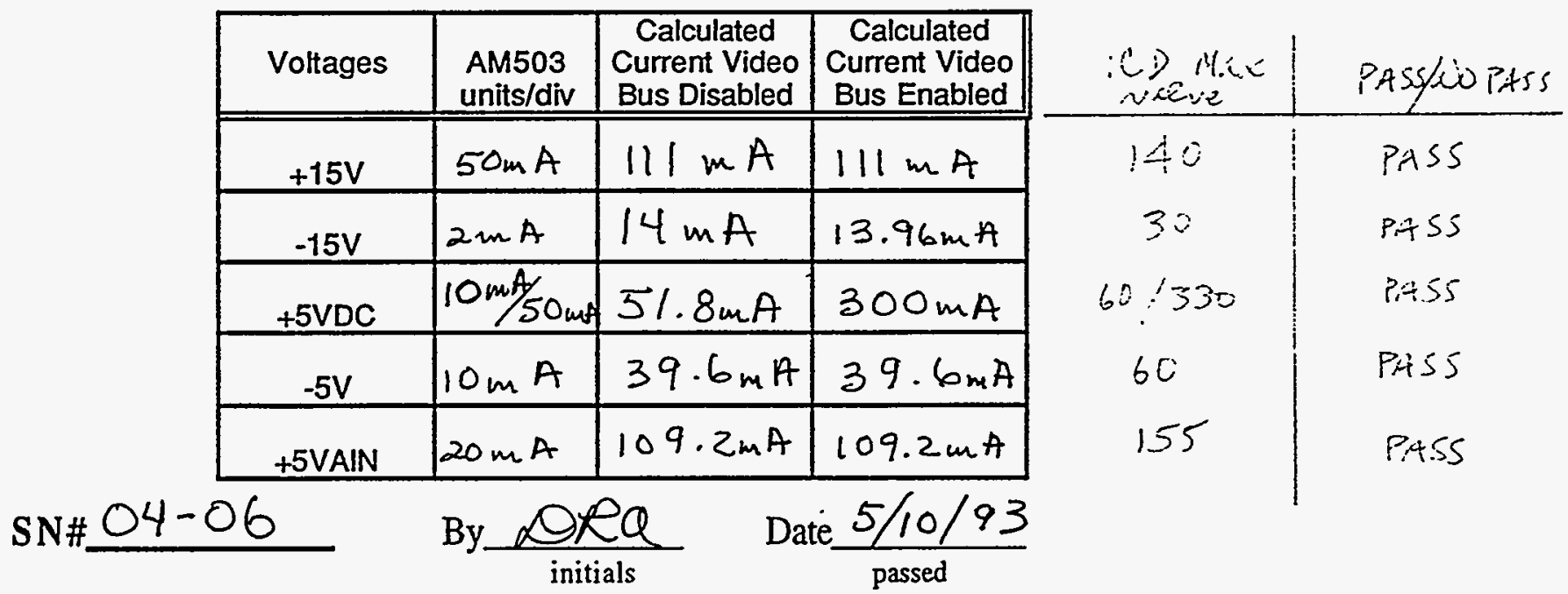

REMEMBER to attach your recorded documentation to this test procedure!

(A document protector is advised) 


\subsection{Offset Digital-to-Analog (D/A) Verification}

To verify data transfer and D/A output voltage, a Fluke 77 or voltmeter is needed.

Within the appropriate menu select and send the indicated offset data via the SASI . Measure the output voltage of U32, AD558TE pins 19, 20. Record the results in the table below.

IMPORTANT: All readings must meet indicated tolerances!

\begin{tabular}{|c|c|c|}
\hline $\begin{array}{c}\text { Decimal } \\
\text { Data Input }\end{array}$ & Expected Voltage & $\begin{array}{c}\text { Measured } \\
\text { Voltage Out }\end{array}$ \\
\hline 00 & $0.0 \mathrm{~V} \pm 10 \mathrm{mV}$ & .002 \\
\hline 01 & $80 \mathrm{mV} \pm 10 \mathrm{mV}$ & .082 \\
\hline 02 & $160 \mathrm{mV} \pm 10 \mathrm{mV}$ & .162 \\
\hline 04 & $320 \mathrm{mV} \pm 10 \mathrm{mV}$ & 32 \\
\hline 08 & $640 \mathrm{mV} \pm 10 \mathrm{mV}$ & $: 641$ \\
\hline 16 & $1.28 \mathrm{~V} \pm 10 \mathrm{mV}$ & 1.281 \\
\hline 20 & $1.61 \mathrm{~V} \pm 10 \mathrm{mV}$ & 1.600 \\
\hline 26 & $2.09 \mathrm{~V} \pm 10 \mathrm{mV}$ & 2.079 \\
\hline 31 & $2.49 \mathrm{~V} \pm 10 \mathrm{mV}$ & 2.477 \\
\hline
\end{tabular}

$$
\begin{aligned}
& \text { out of Tol by } 1 \mathrm{mV} \\
& \text { ot of Tol by } 3 \mathrm{mV}
\end{aligned}
$$

SN\#_04.06 By $\frac{\text { MD } / D A}{\text { inftials }}$ Date $\frac{4 \cdot 7 \cdot 93}{\text { passed }}$

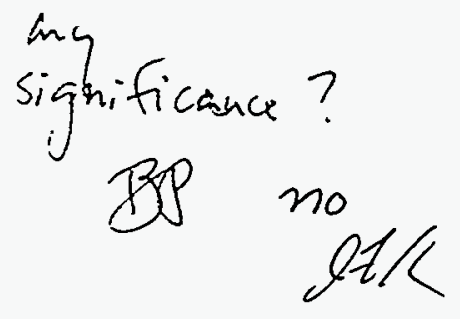




\subsection{Gain Selection Verification}

To verify proper data transfer of gain setting, use a Fluke 77 voltmeter.

Within the appropriate menu select and send the indicated gain data via the SASI. Measure the voltage at Q11,Q10 and Q9 gates. Record the results in the table below.

\begin{tabular}{|c|c|c|c|}
\hline & $\mathrm{msb}$ & & $1 \mathrm{sb}$ \\
\hline S1 & $75 \mathrm{e} / \mathrm{bit}$ & $150 \mathrm{e} / \mathrm{bit}$ & $350 \mathrm{e} / \mathrm{bit}$ \\
\hline $\begin{array}{c}\text { INPUT } \\
0 \\
\end{array}$ & $\begin{array}{r}\text { Q11 } \\
.08 \\
\end{array}$ & $\begin{array}{l}\text { Q10 } \\
08 \\
\end{array}$ & $\begin{array}{c}\mathrm{Q} 9 \\
.08 \\
\end{array}$ \\
\hline 0 & .08 & .08 & 15.17 \\
\hline 2 & .08 & 15.17 & .08 \\
\hline 3 & .08 & 15.17 & 15.17 \\
\hline 生 & 15.17 & .08 & 68 \\
\hline 5 & $15 \cdot 17$ & .08 & $15 \cdot 17$ \\
\hline 5 & $15 \cdot 17$ & 15.17 & .08 \\
\hline I & 15.17 & 15.17 & 15.17 \\
\hline 年 & & & \\
\hline SN\#_ & & $\frac{A}{s}$ & $\frac{7}{\text { ed }}$ \\
\hline
\end{tabular}




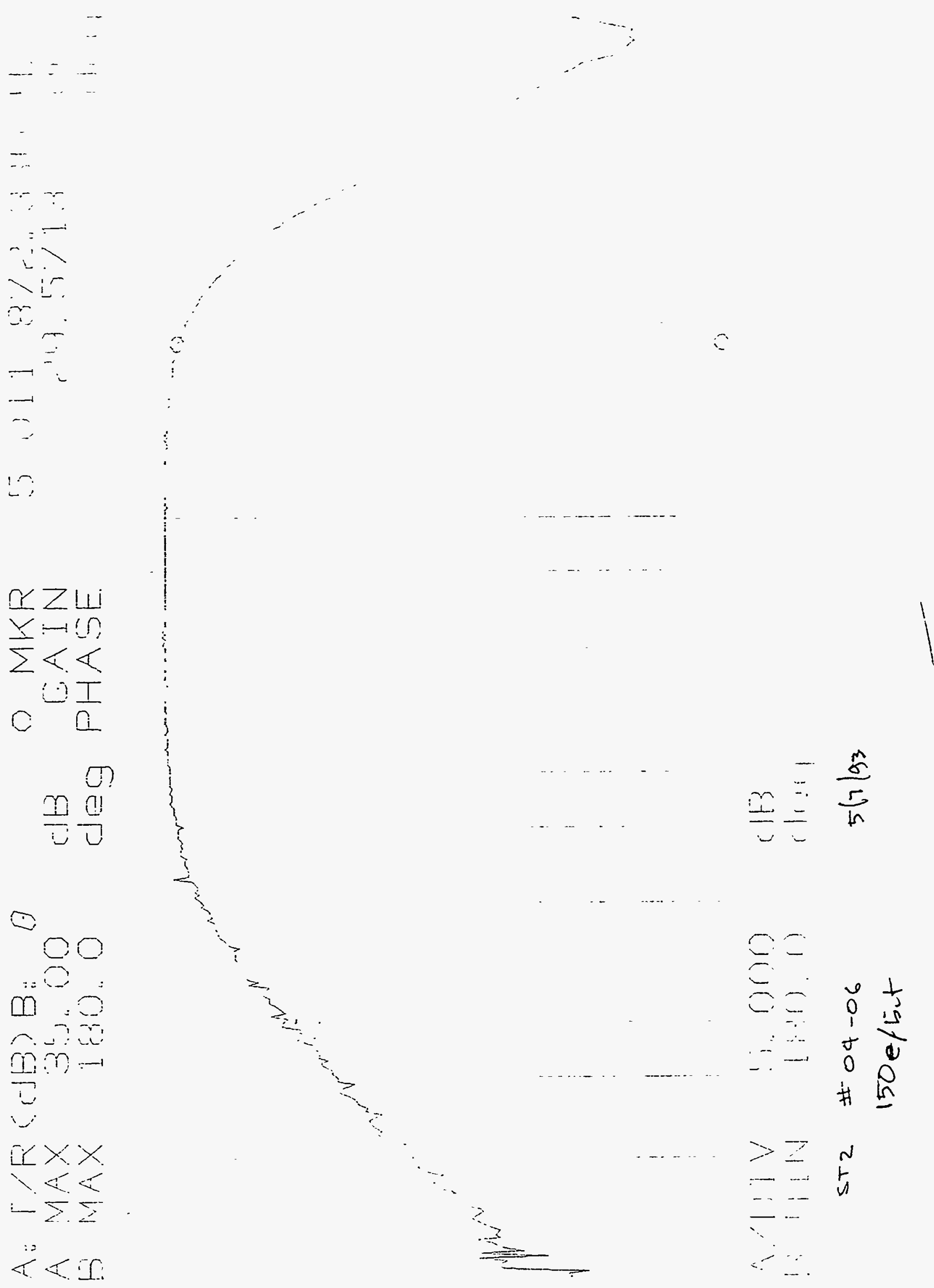



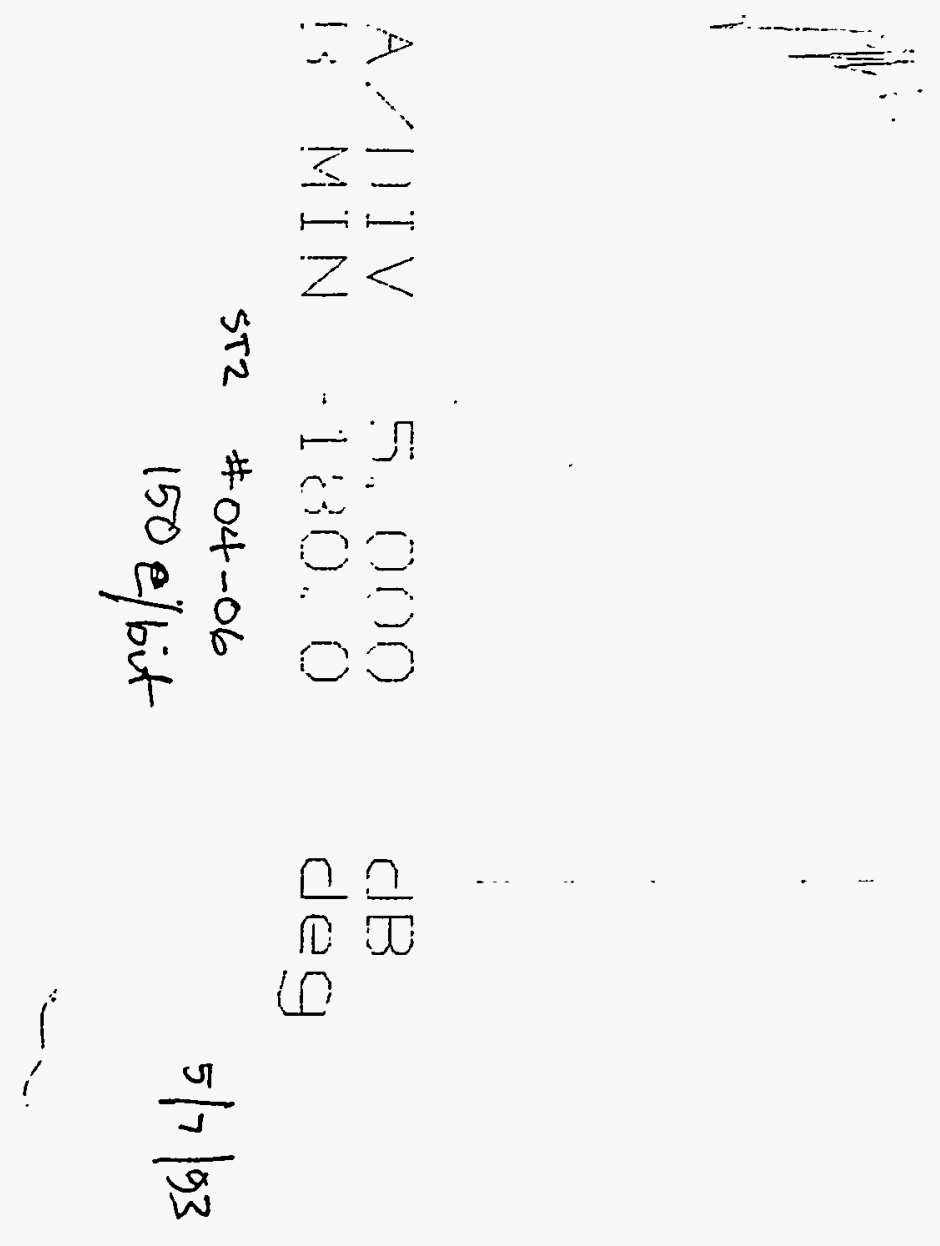

0

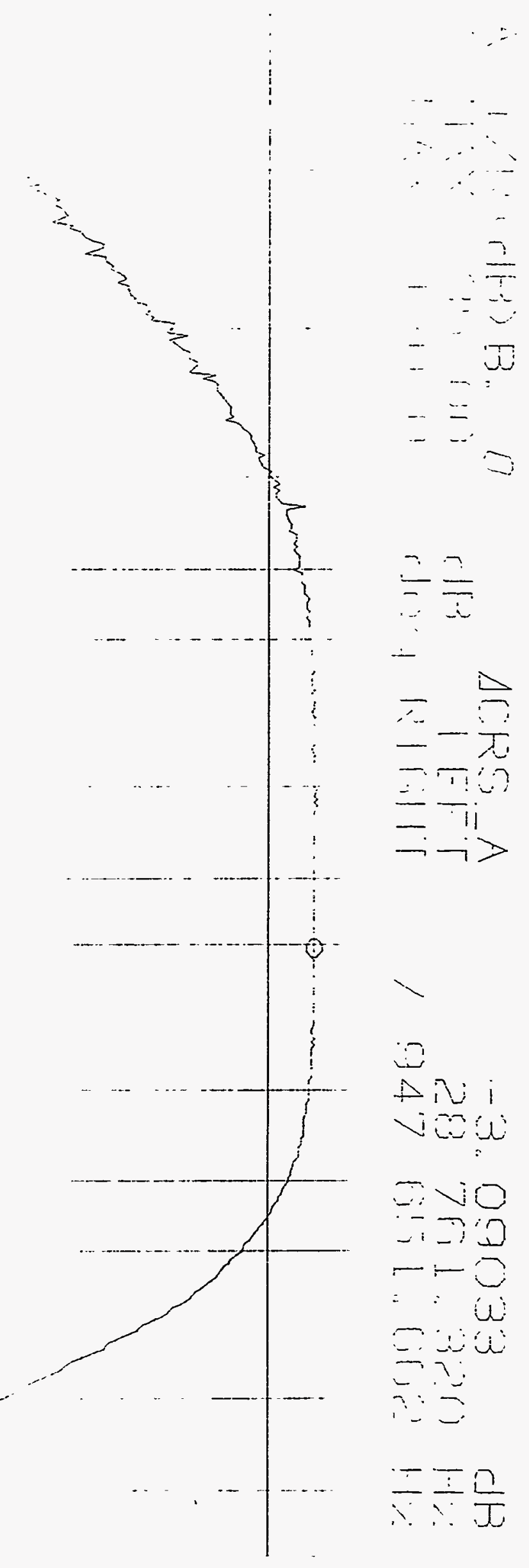




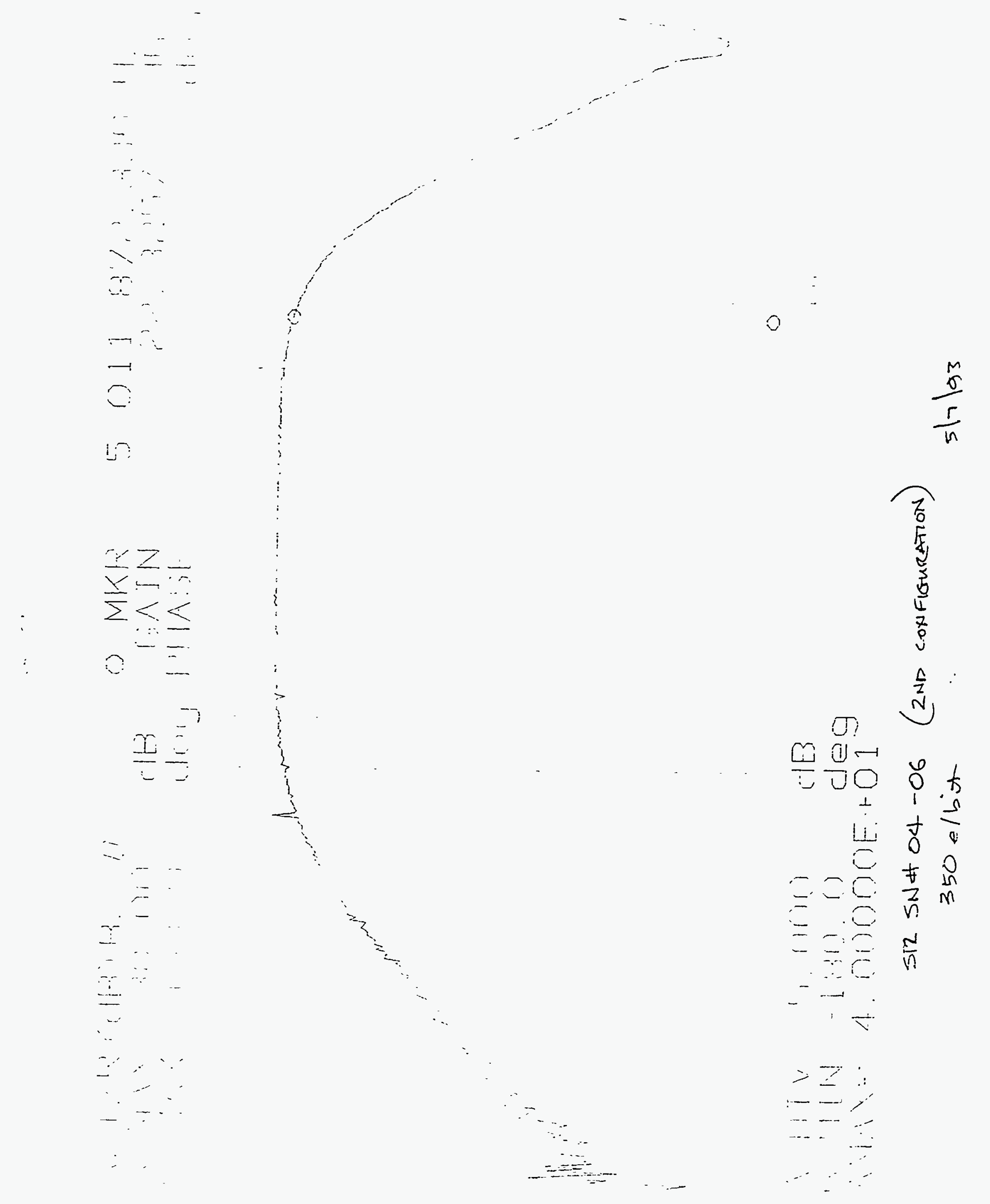




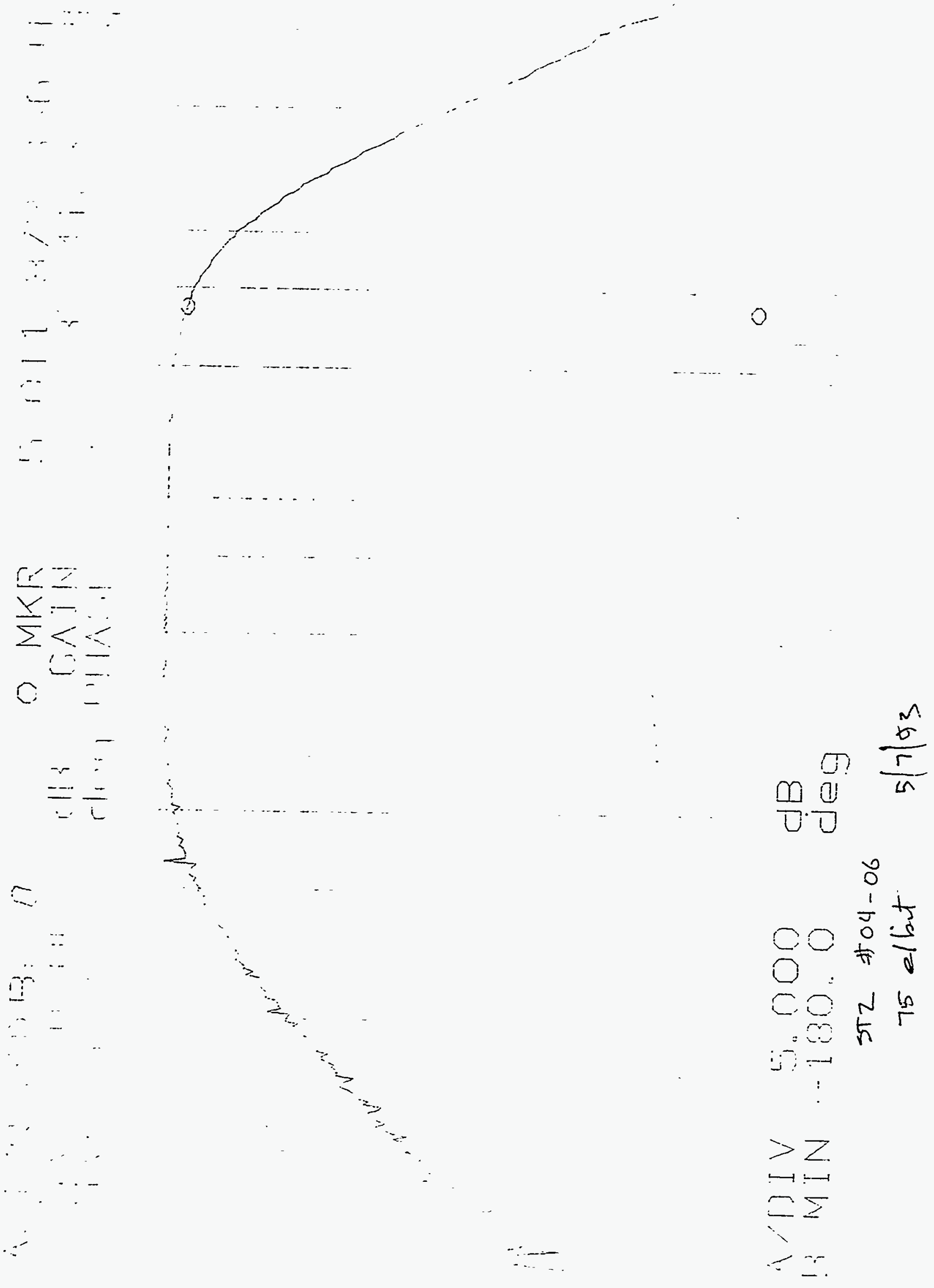




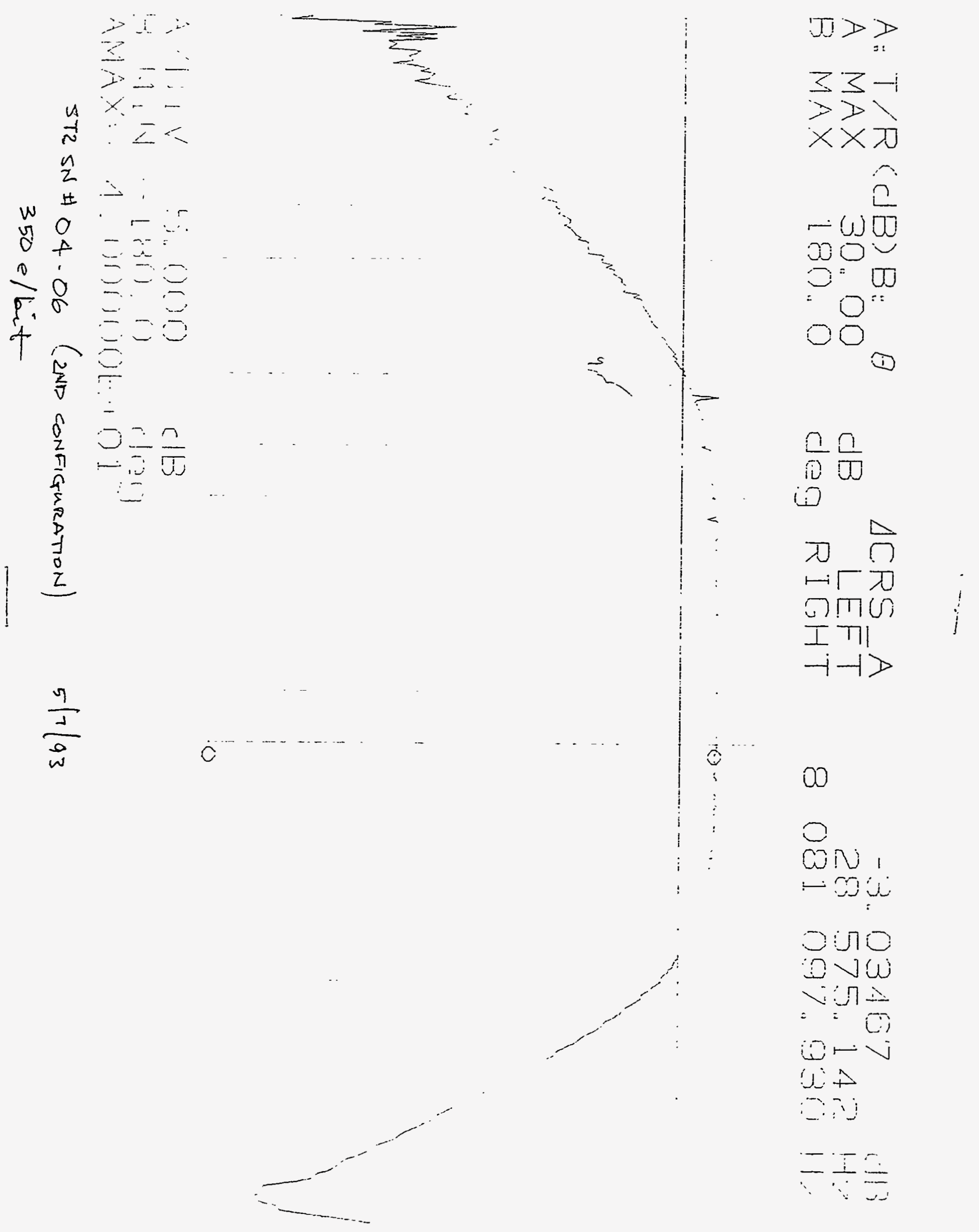




\subsection{Video Amplifier Gain Verifications.}

The video gain measurements require use of the HP4194 Impedance Gain/Phase Analyzer.

\subsection{Test Board Configuration}

Configure the board under test as follows:

Replace R49 with a $1.0 \mathrm{Kohm} 1 \%$ resistor.

Remove R128 and connect R128's outermost pad with C123's outermost pad. This grounds Q1 and Q4 gates.

Disable the $20 \mathrm{MHz}$ oscillator by connecting U5 pins 5 and 23 together.

\subsection{HP4194 Analyzer Configuration and Connection.}

Configure the HP4194 Analyzer as follows:

Gain/Phase measurement,

A Scale linear and AutoScale,

Log Sweep, $1 \mathrm{KHz}$ to $100 \mathrm{MHz}$,

Oscillator Level equal to $-45 \mathrm{dBm}$.

Insert a $1 \mathrm{Kohm}$ resistor from U19 pin 18 to U19 pin 16. Attach the HP4194 oscillator output to U19 pin 16 and its ground to the ground test point.

\subsection{Gain and 3dB Bandwith Acquisition.}

Measure and store the reference level. Then measure the gain at $5 \mathrm{MHz}$ and $3 \mathrm{~dB}$ frequency at US pin 28 for all three gain settings. Record the measured values in the following table and attach the data plots in a document protector.

\begin{tabular}{|c|c|c|c|c|}
\hline $\begin{array}{c}\text { Gain } \\
\text { Setting }\end{array}$ & $\begin{array}{c}\text { Expected } \\
\text { Gain dB }\end{array}$ & $\begin{array}{c}\text { Measured } \\
\text { Gain dB }\end{array}$ & $\begin{array}{c}\text { Expected } \\
\mathbf{3 d B} \\
\text { bandwidth(MHz) }\end{array}$ & $\begin{array}{c}\text { Measured } \\
\mathbf{3 d B} \\
\text { bandwidth(MHz) }\end{array}$ \\
\hline 4 & $35.5 \pm 0.5$ & 35.41 & $7.5 \pm 0.5$ & 7.7 \\
\hline 2 & $29.5 \pm 0.5$ & 29.57 & $7.5 \pm 0.5$ & 7.9 \\
\hline 1 & $22.2 \pm 0.5$ & 22.33 & $7.5 \pm 0.5$ & $8.1 /$ feck \\
\hline
\end{tabular}




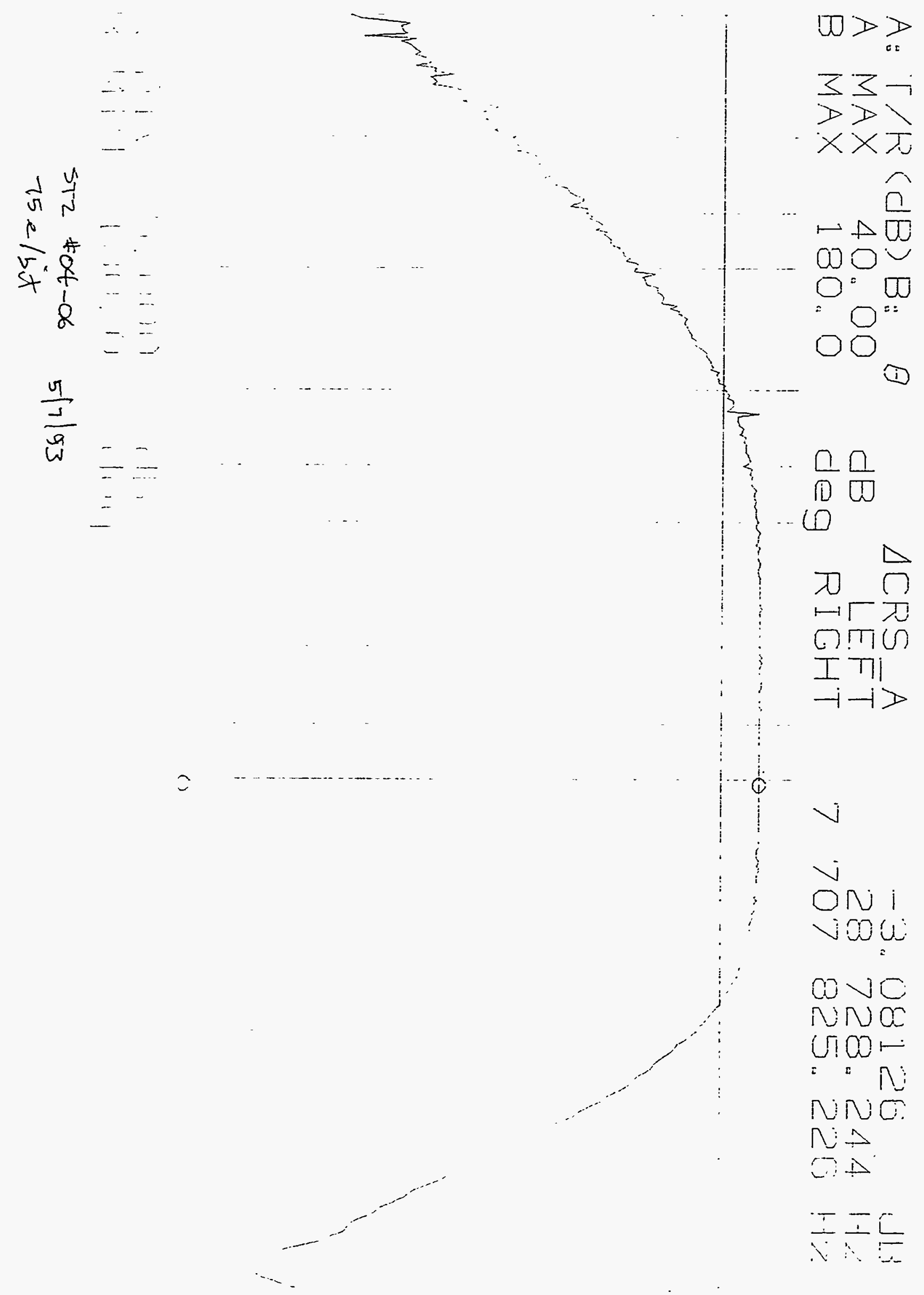


7. Clocking Measurements with $\mathrm{CCD}$ installed

Verify that U19 pin 16 is not shorted to ground.

Measured $4.5 \mathrm{M} \Omega(>1 \mathrm{M} \Omega)$

Insert the appropriate prototype TH7883 CCD inic location U19.

\section{Carefully Check CCD Orientation!!}

7.1 Acquire and record the $\emptyset \mathrm{L} 2$ and $\emptyset \mathrm{L} 1$ clocks:

Make these scope probe connection:

\begin{tabular}{c|c} 
Probe & Location \\
\hline Channel 1 & U19 pin 2 \\
Channel 2 & U19 pin 3
\end{tabular}

Change the scope horizontal sweep frequency to $50 \mathrm{~ns}$ per division.
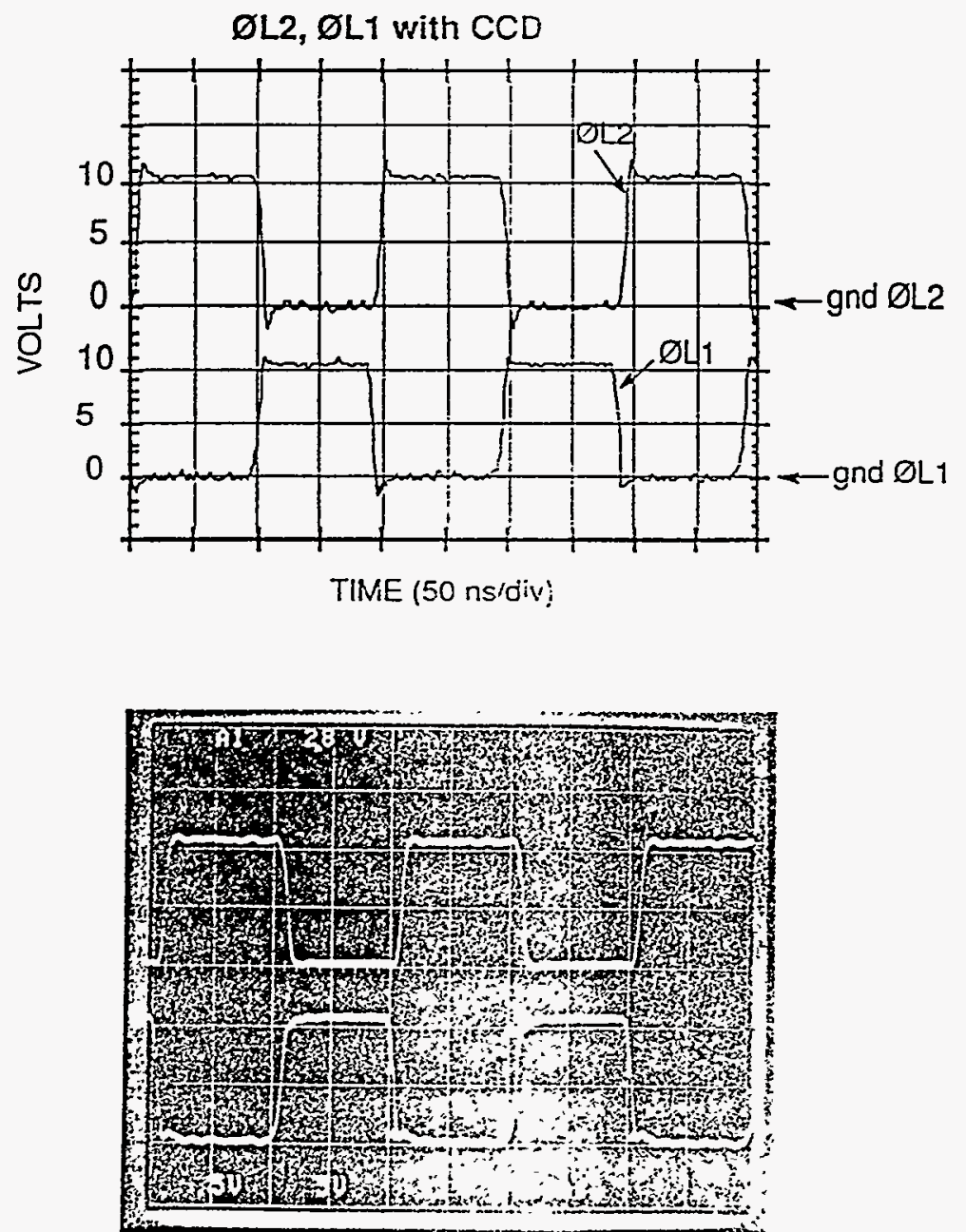
7.2. Acquire and record the $\emptyset \mathrm{L} 2, \emptyset \mathrm{R}$, and $(\xi \mathrm{kFET}$ clocks:

Move the scope $\emptyset \mathrm{R}$, and $\varnothing \mathrm{RFET}$ probe to these lociations:

\begin{tabular}{c|c} 
Probe & Location \\
\hline Channel 2 & U19 pin 19 \\
Channel 3 & R128 Q1 gate side
\end{tabular}
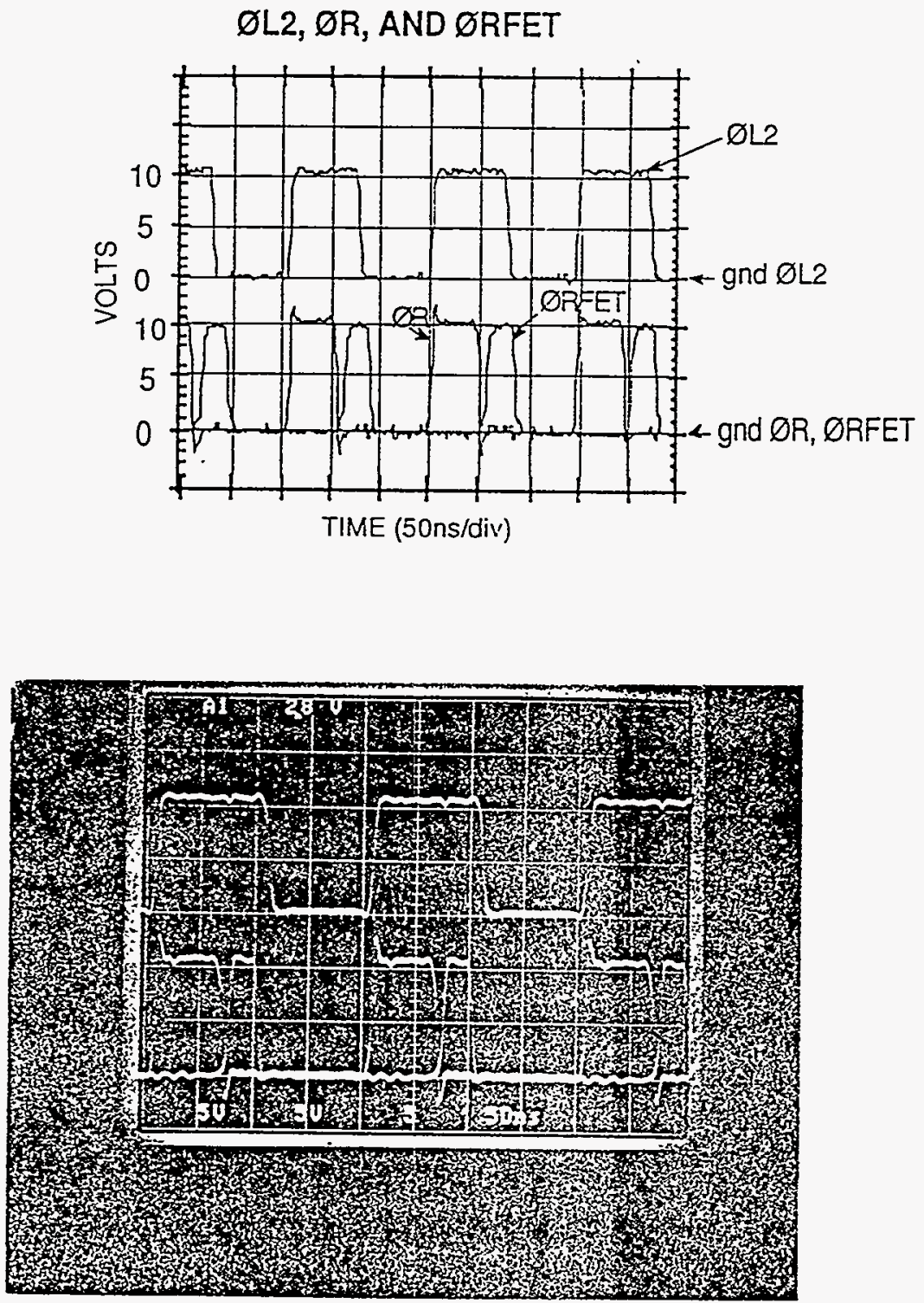
7.3 Acquire and record the $\emptyset \mathrm{P} 1$, and $\emptyset \mathrm{P} 3$ clucks:

Move the scope probes to these locations:

\begin{tabular}{c|c} 
Probe & Location \\
\hline Channel 1 & U19 pin 14 \\
Channel 2 & U19 pin 13
\end{tabular}

Shift the horizontal sweep frequency to $200 \mathrm{~ns}$ per division.
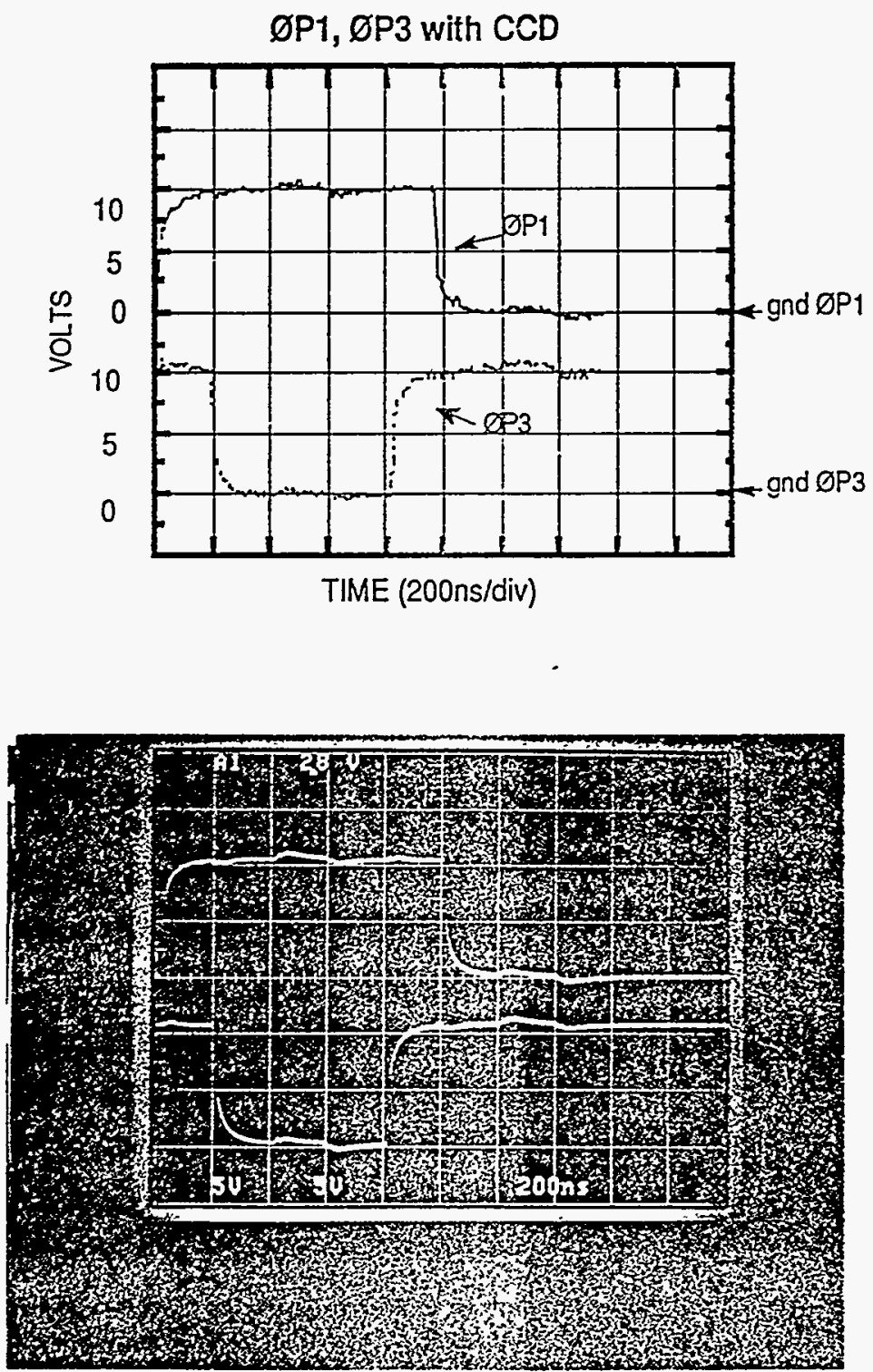
7.4 Acquire and record the $\emptyset \mathrm{P} 1$, and $\emptyset \mathrm{P}_{2} 2$ clocks:

Move the scope probe to this location:

\begin{tabular}{c|c} 
Probe & Location \\
\hline Channel 2 & U19 pin 12
\end{tabular}
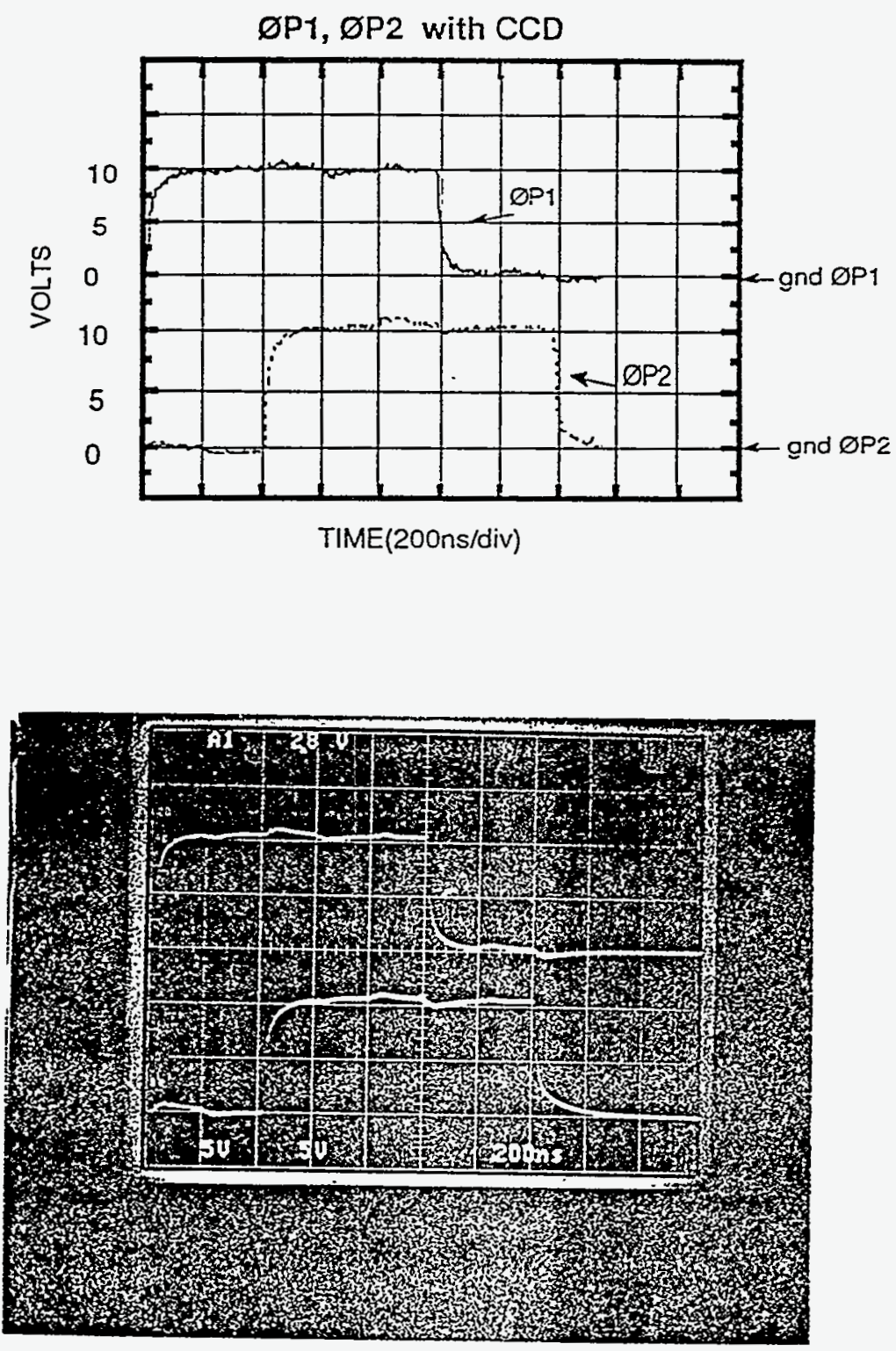
7.5 Acquire and record the $\emptyset \mathrm{P} 1$, and $\emptyset \mathrm{P} 4$ clocks:

Move the scope probe to the location indicated:

\begin{tabular}{c|c} 
Probe & Location \\
\hline Channel 2 & U19 pin 11
\end{tabular}
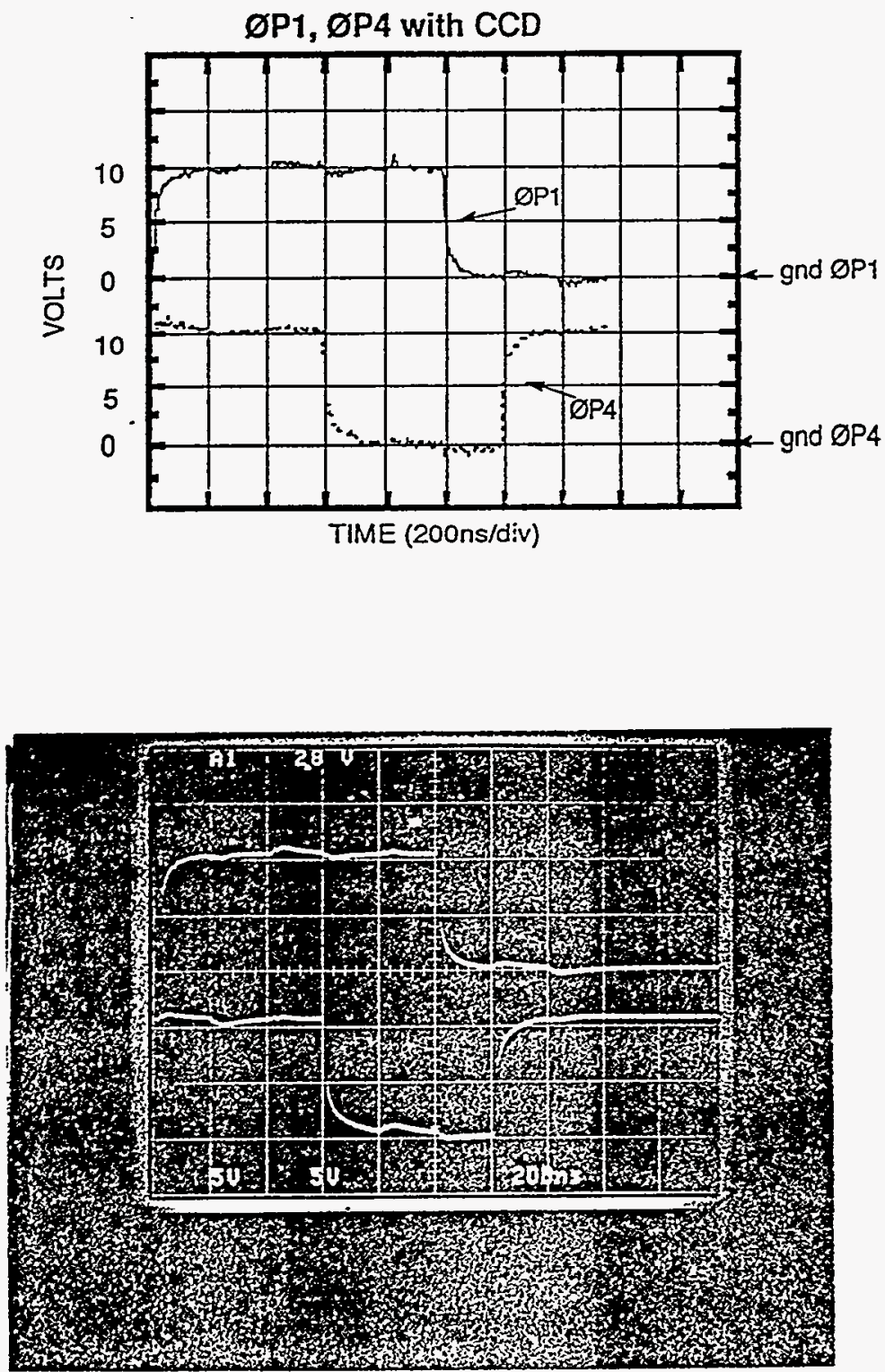
7.6 Acquire and record the P1A, and P3 clucks:

Nicve the scope probes to these locations:

\begin{tabular}{c|c} 
Probe & Location \\
\hline Channel 1 & U19 pin 9 \\
Channel 1 & U19 pin 8
\end{tabular}
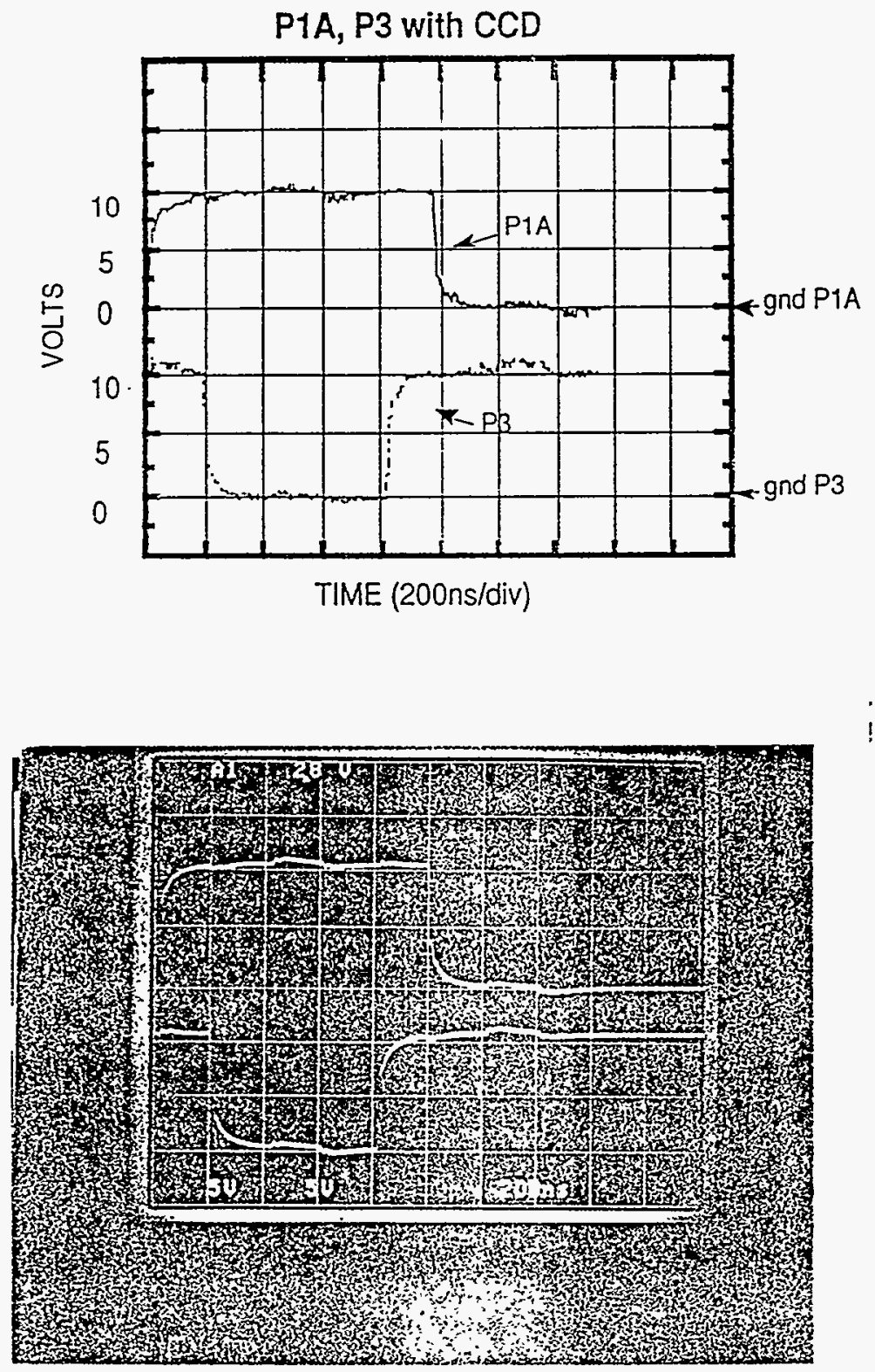
7.7 Acquire and record the P1A, and P2 clocks:

Move the scope probe to this location:

\begin{tabular}{c|c} 
Probe & Location \\
\hline Channel 2 & U19 pin 7
\end{tabular}
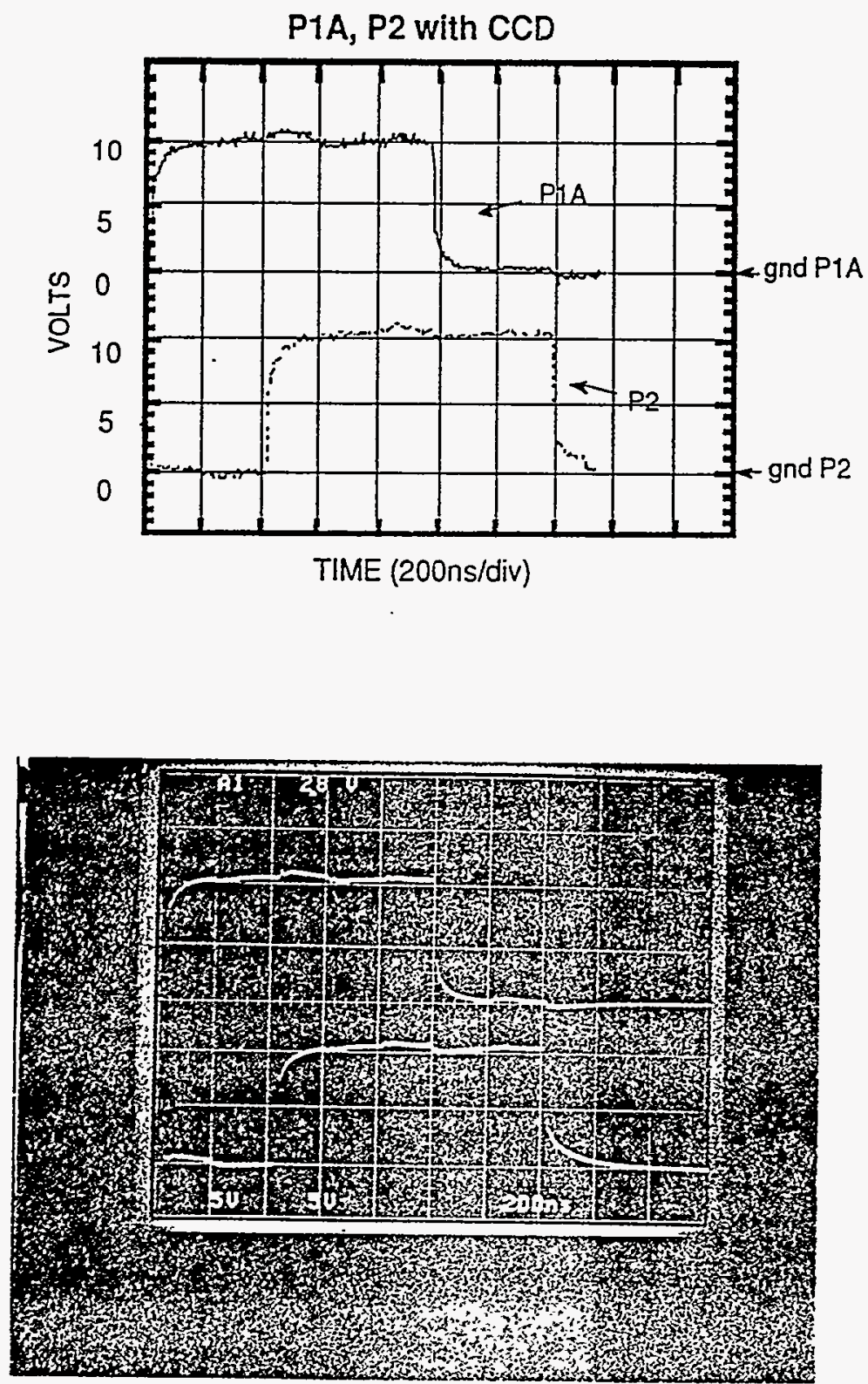
7.8 Acquire and record the PIA, and P'4 clocks:

Move the scope probe to this location:

\begin{tabular}{c|c} 
Probe & Location \\
\hline Channel 2 & U19 $\operatorname{pin} 6$
\end{tabular}
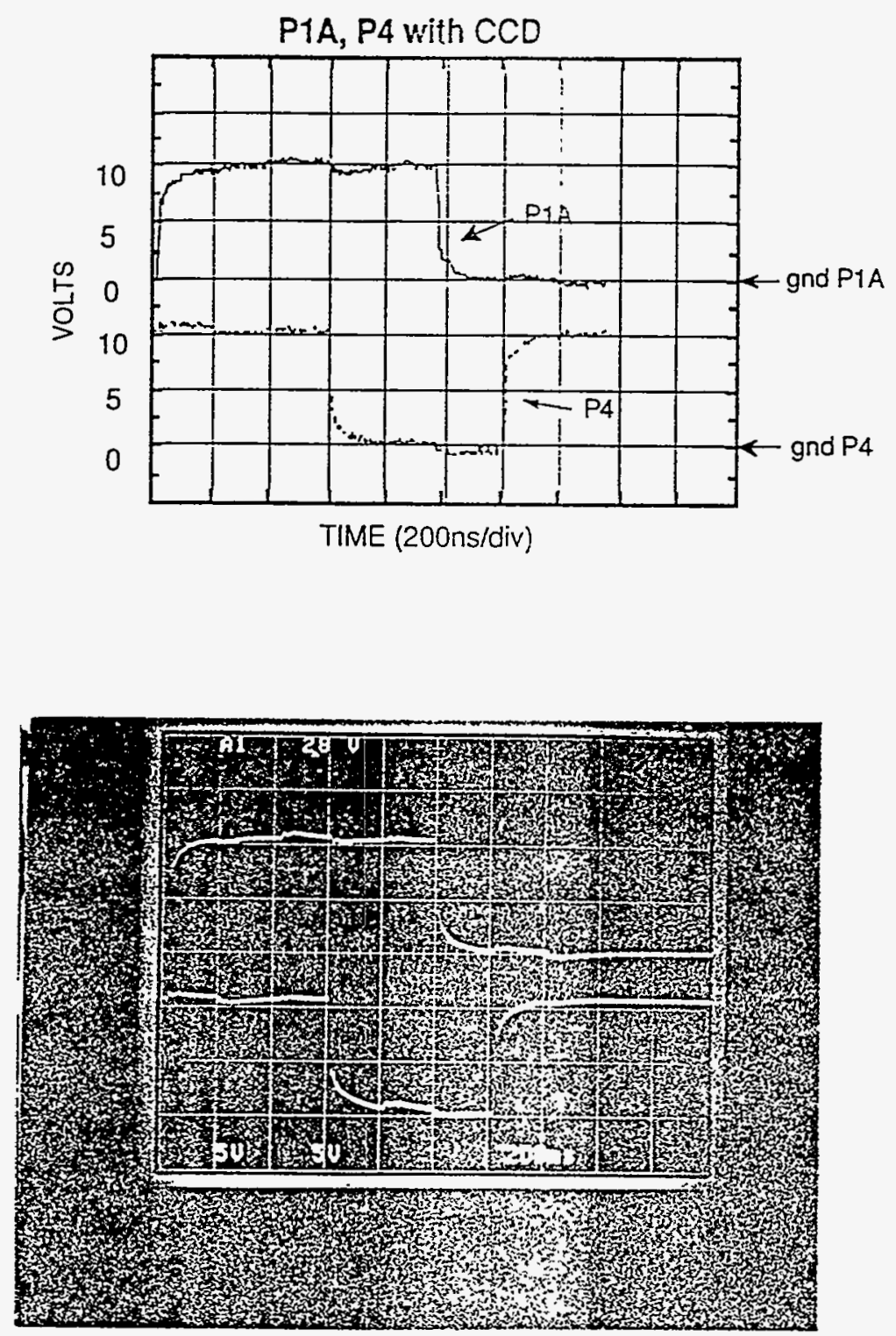

鹠 
7.9 Acquire and record the P1A, and PIB clucks:

Move the scope probe to this location:

\begin{tabular}{c|c} 
Probe & Location \\
\hline Channel 2 & U19 pin 4
\end{tabular}

P1A, P1B with CCD
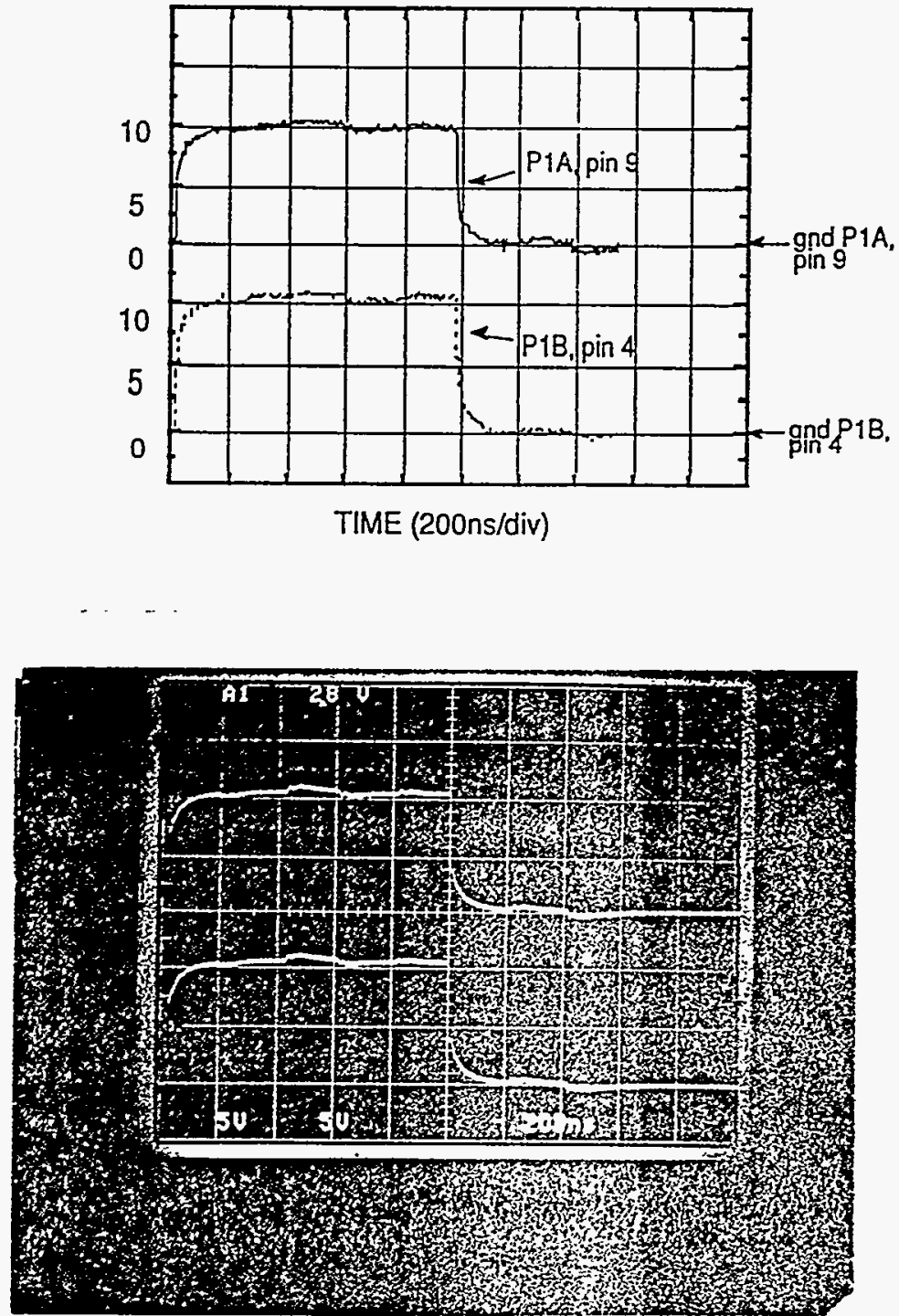


$$
5 / 10 / 93
$$
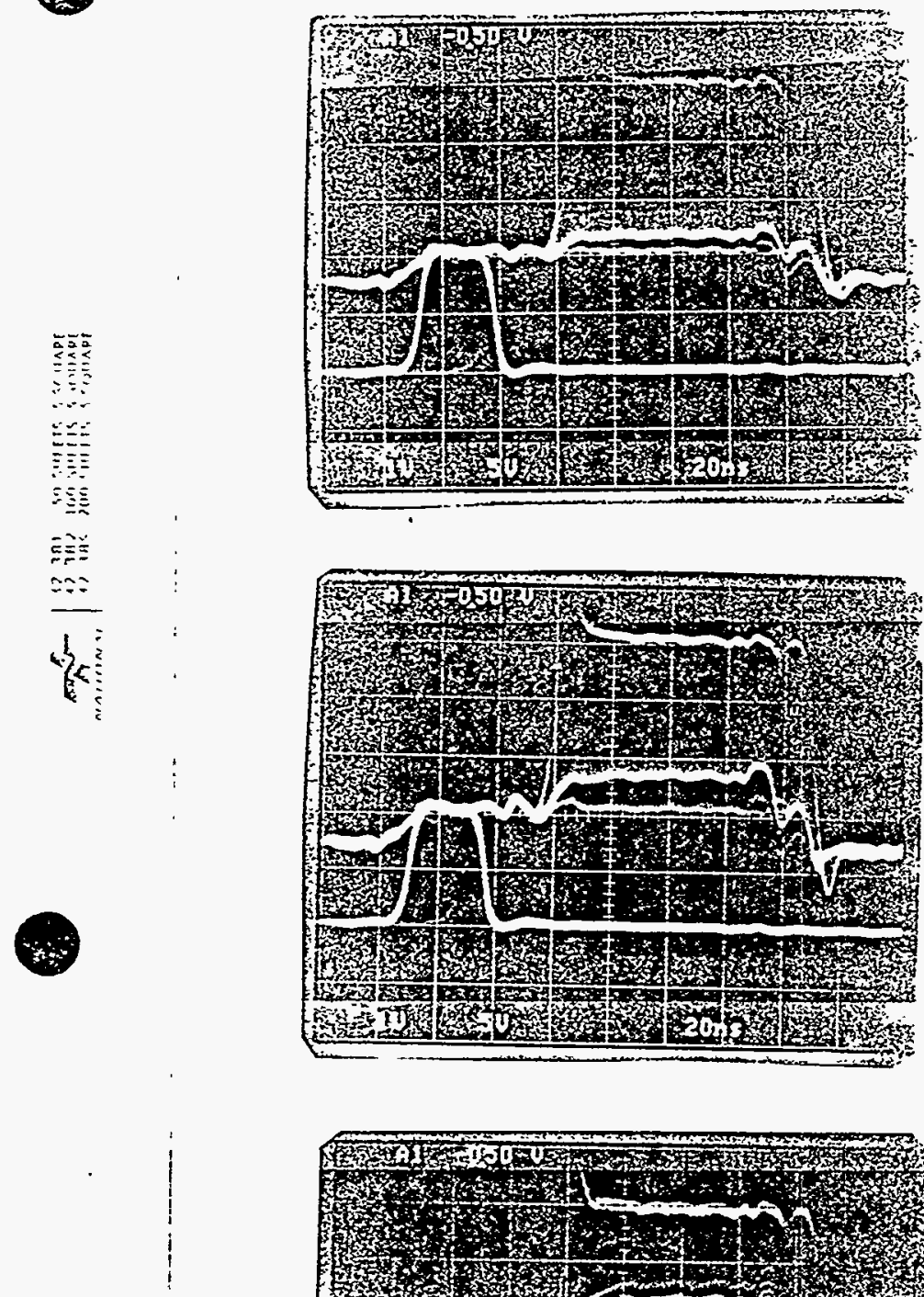

$350 \mathrm{c} / \mathrm{but}$

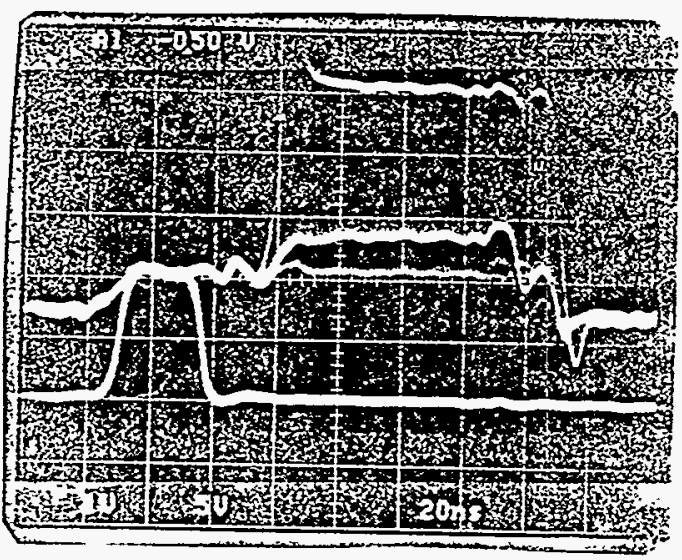

150 eliat

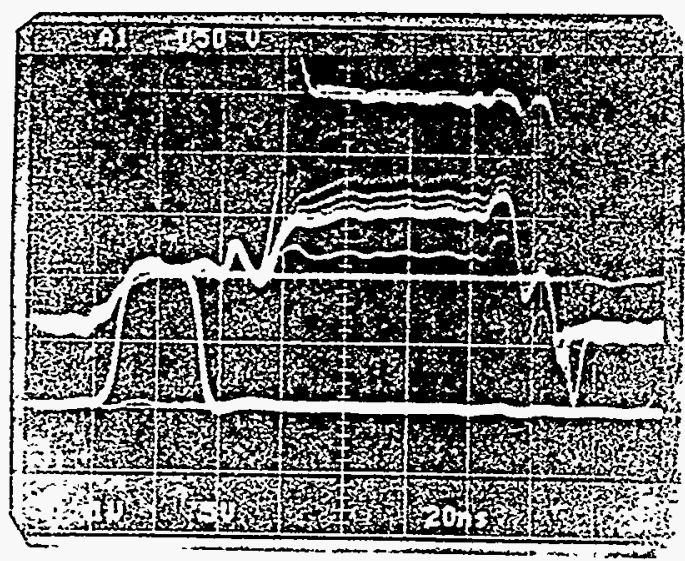

75 elet 


\section{Double Correlated Sampling Functionality Verification}

This measurement requires the use of a Tektronix $2465 \mathrm{~B}$-or like-oscilloscope.

Verify the gain of the camera is $150 \mathrm{e} / \mathrm{bit}$ via the SASI.

Make these scope probe connection:

\begin{tabular}{c|c} 
Probe & Location \\
\hline Channel 2 & U24 pin 3 \\
Channel 3 & R128 Q1 gate side
\end{tabular}

Adjust the time base to 20ns per division.

Acquire and record the Q1 or $\varnothing \mathrm{RFET}$ vs Video signals:

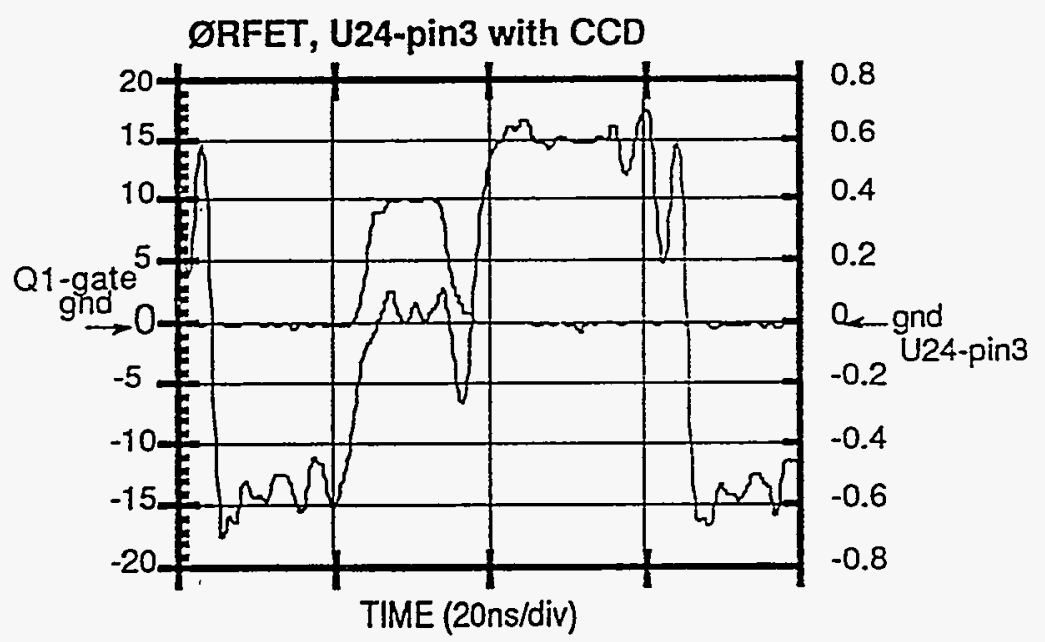

Make the same measurement at 350e/bit and 1000e/bit.

Note: During the Q1 or $\varnothing \mathrm{RFET}$ pulse, the video signal should be $=0 \mathrm{v}$ or ground. At high gains, the sensor may require cool down by non-operation and:or an opaque covering to acquire this measurement. 
9. Analog to Digital (A/D) Converter Clock v's U24-pin 6 \& U8-pin 28

This measurement requires the Tektronix $2465 \mathrm{~B}$ analog-or like-oscilloscope.

Set the scope to trigger on channel 1 .

Set the horizontal sweep to 50ns/division.

Move the scope probes to these locations:

\begin{tabular}{c|c|c} 
Probe & Location & Vertical Gain \\
\hline Channel 1 & U8 pin 1 & 2 V/division \\
Channel 2 & U8 pin 28 & $500 \mathrm{mV} /$ division
\end{tabular}
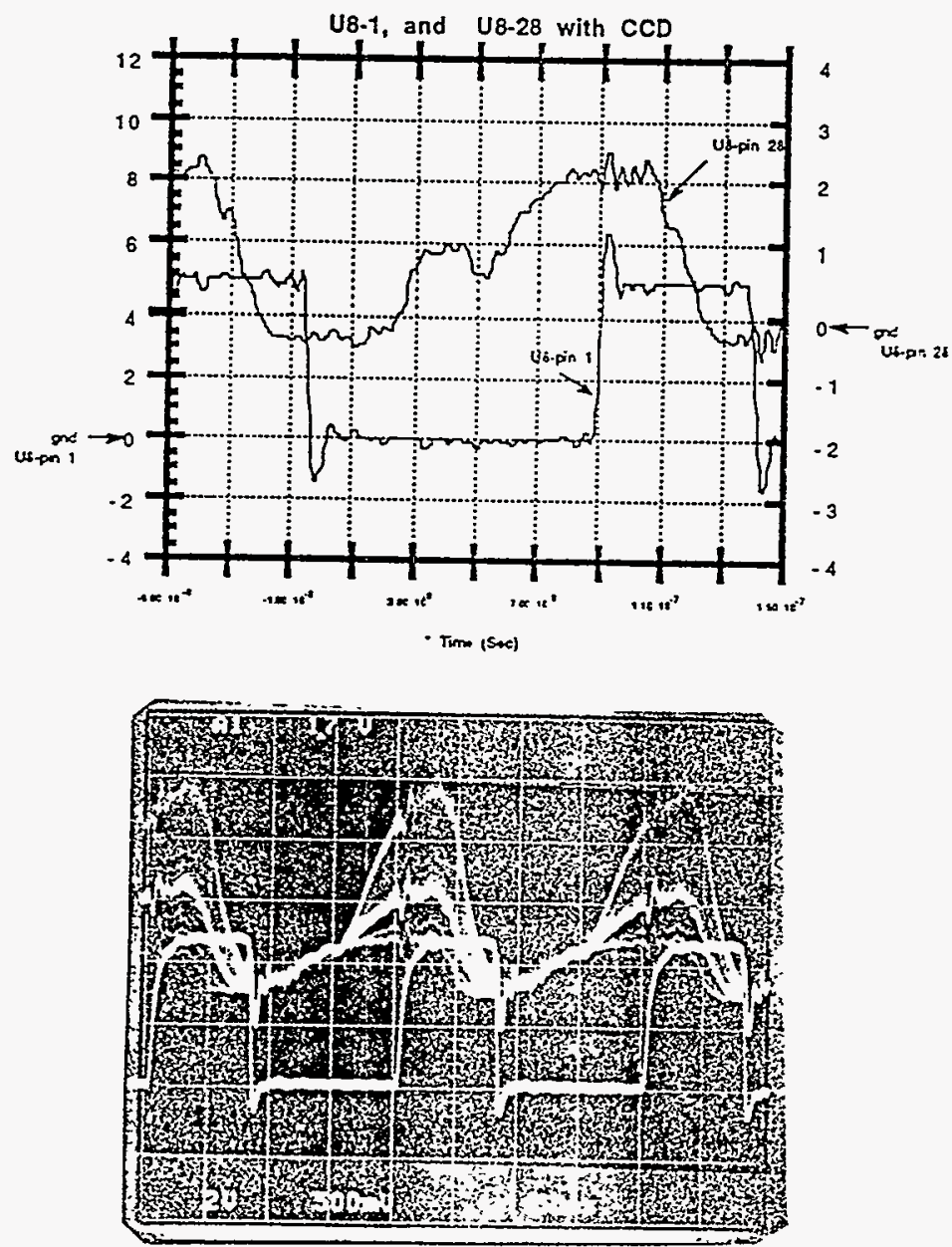


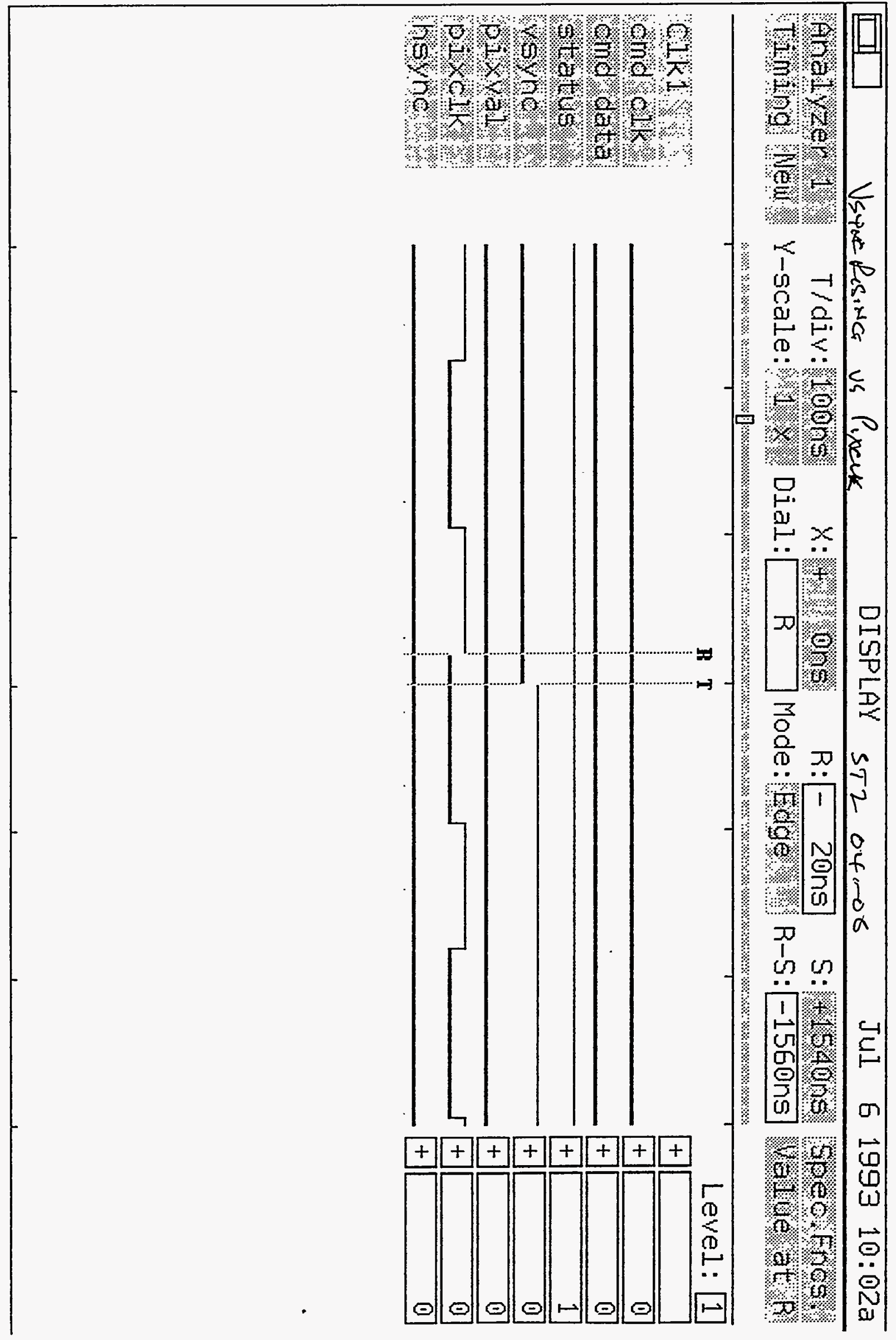




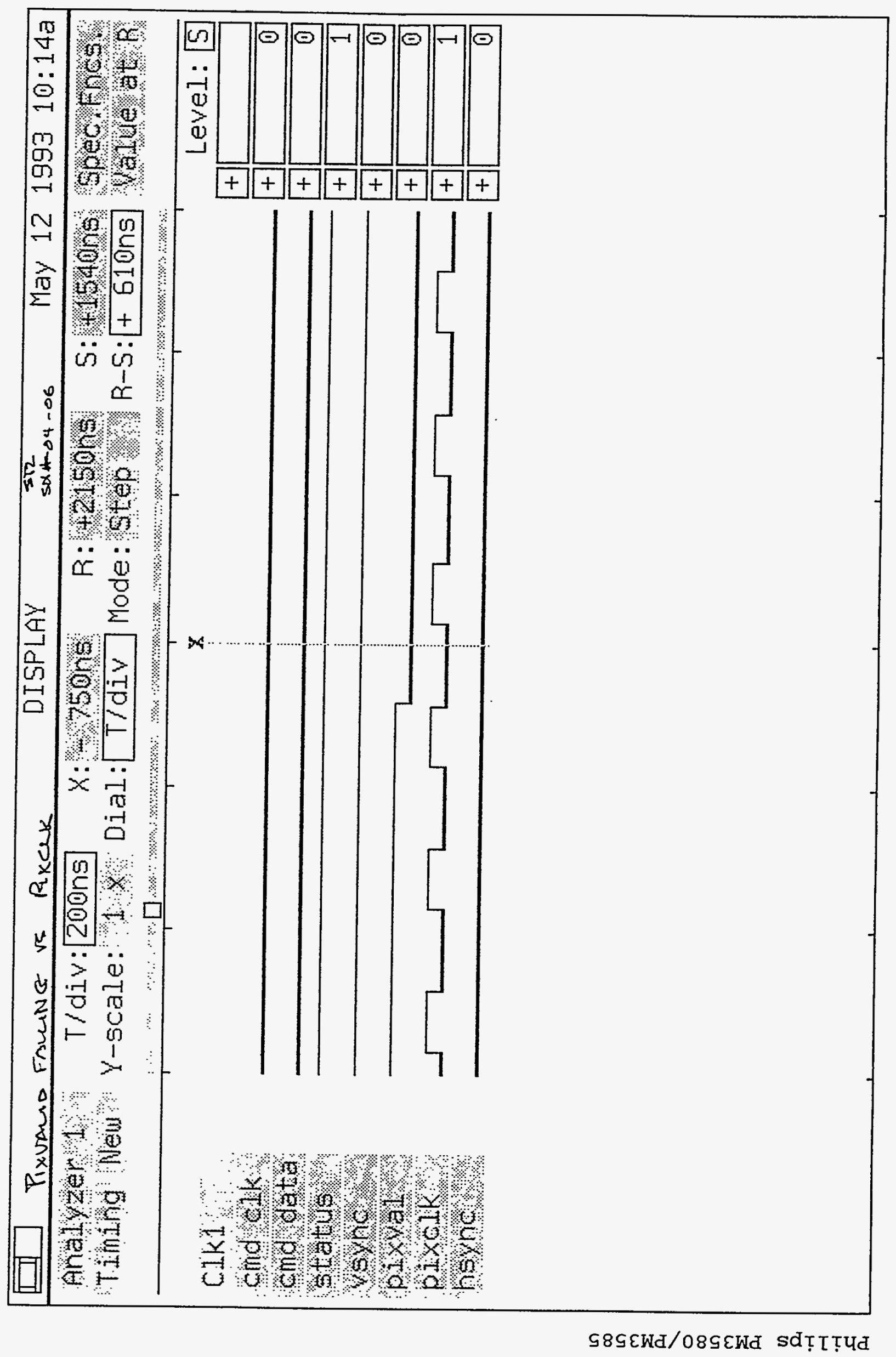




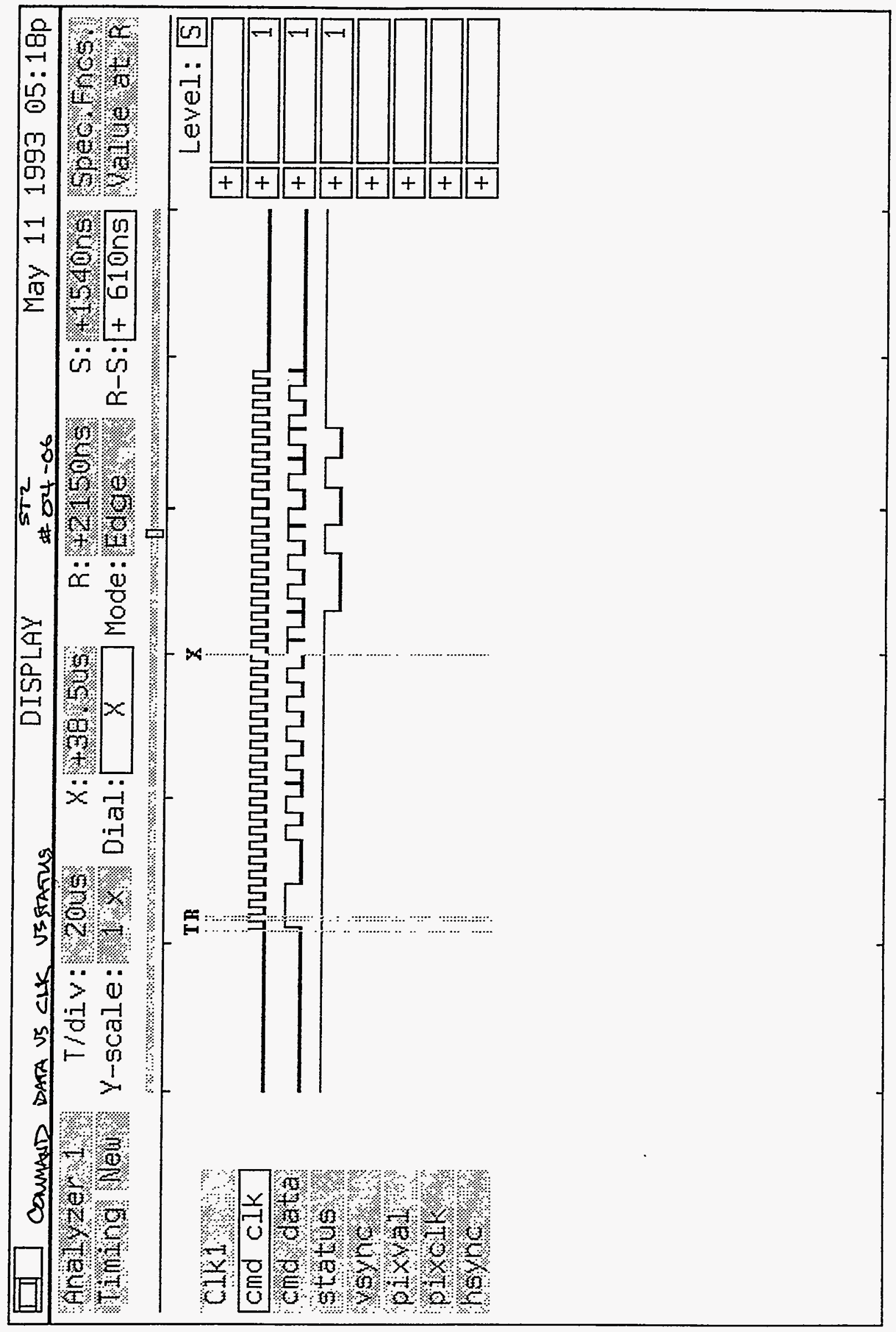




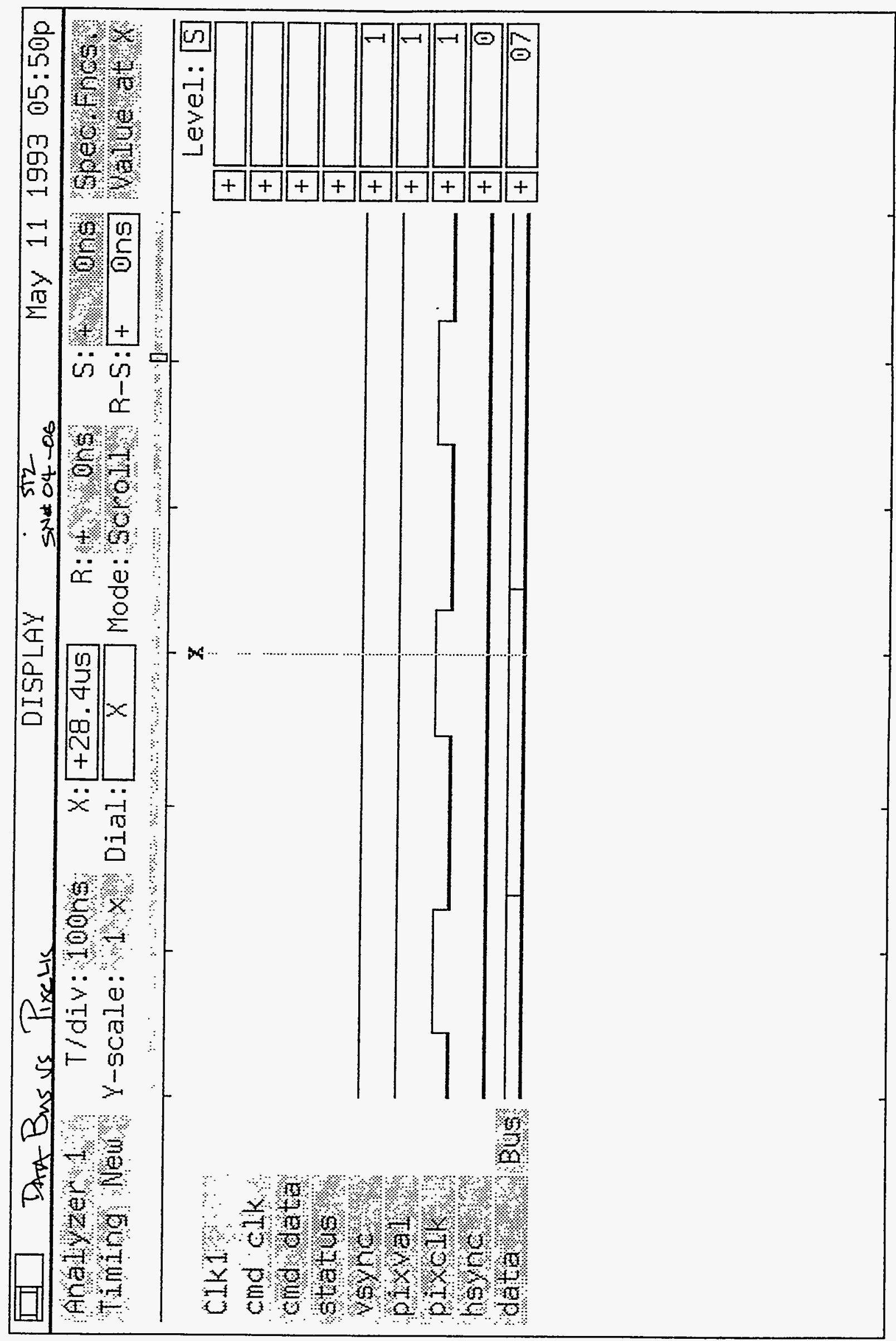




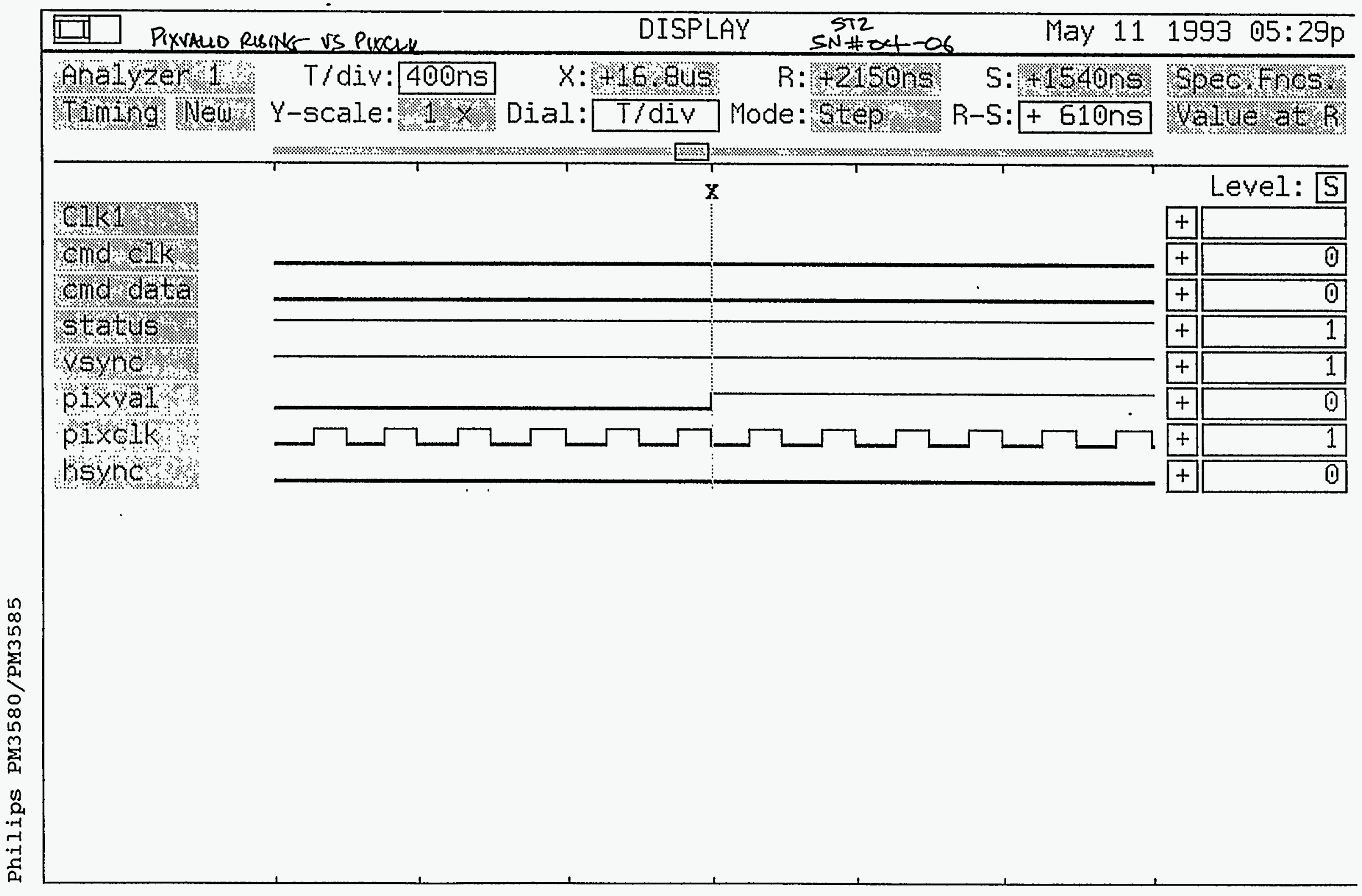




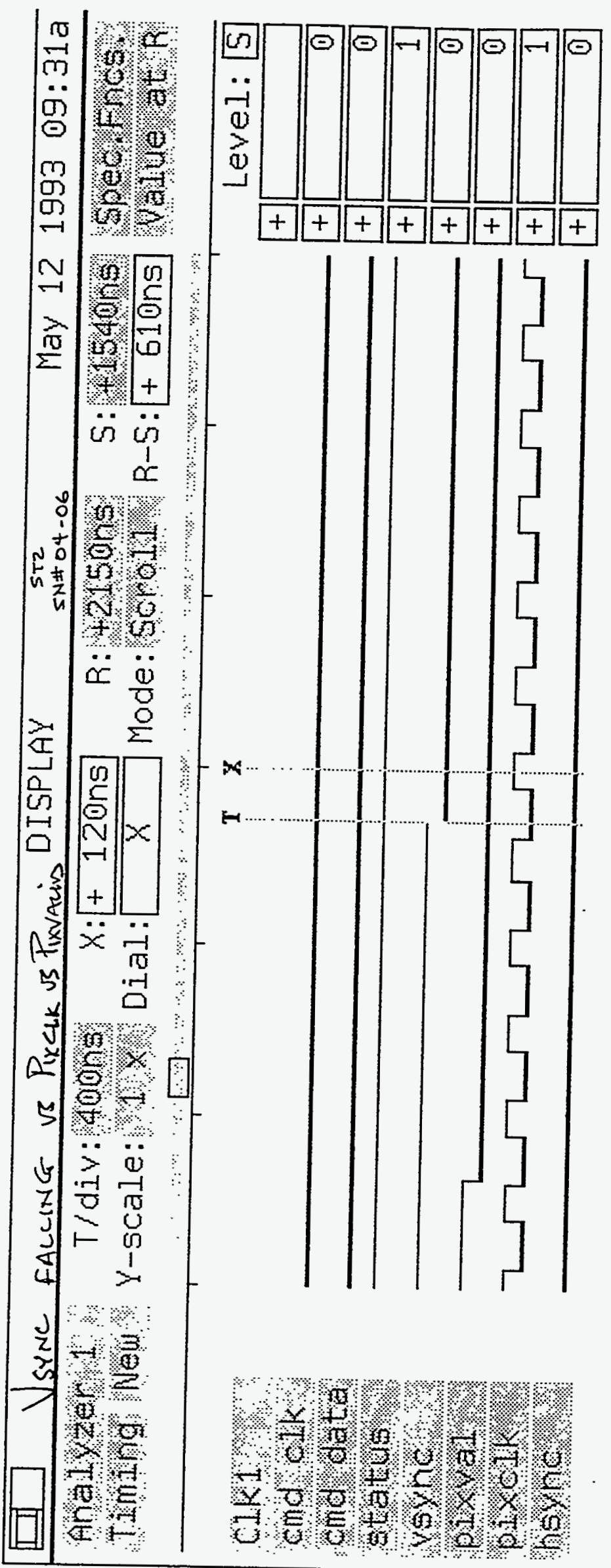




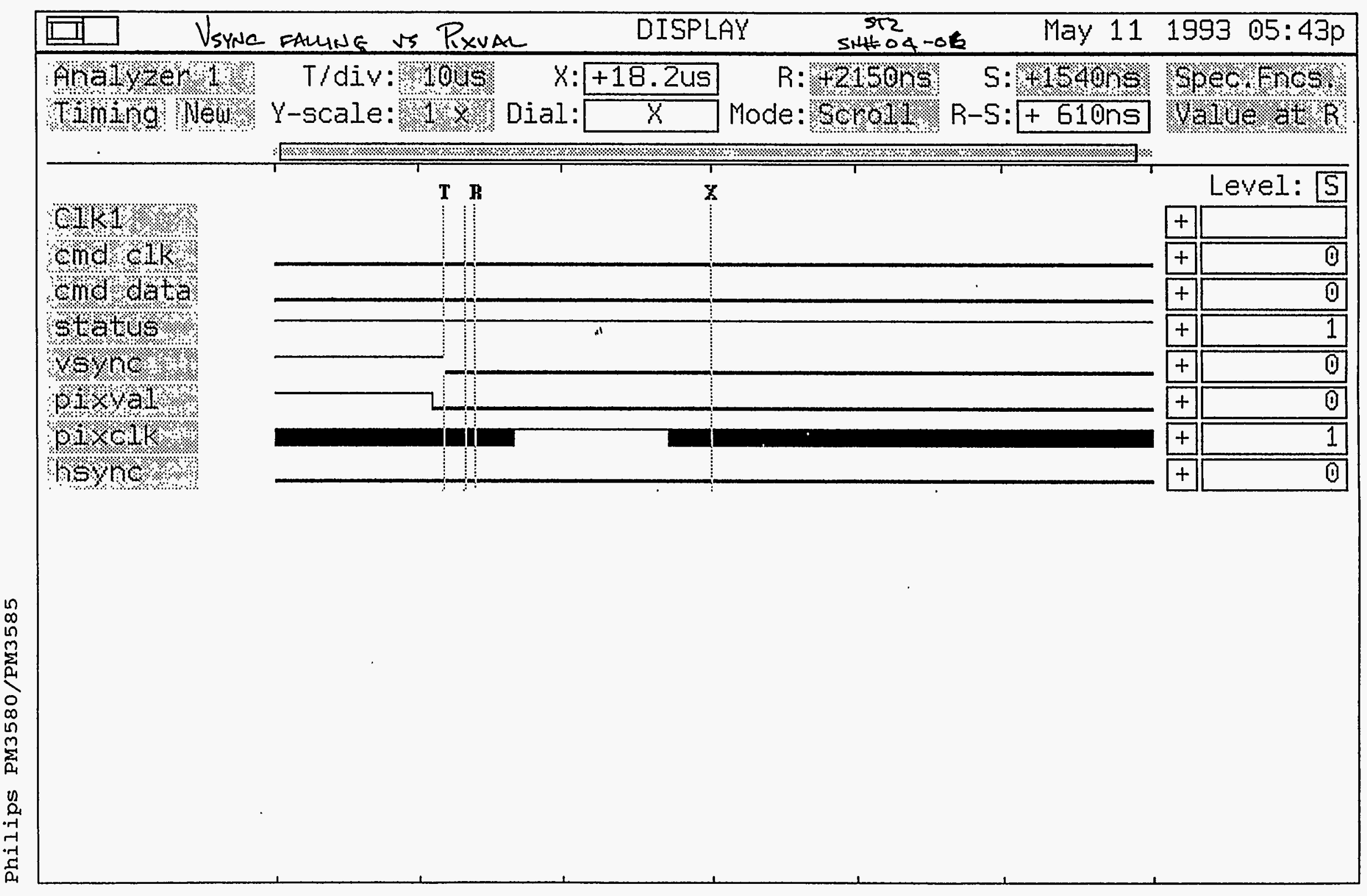




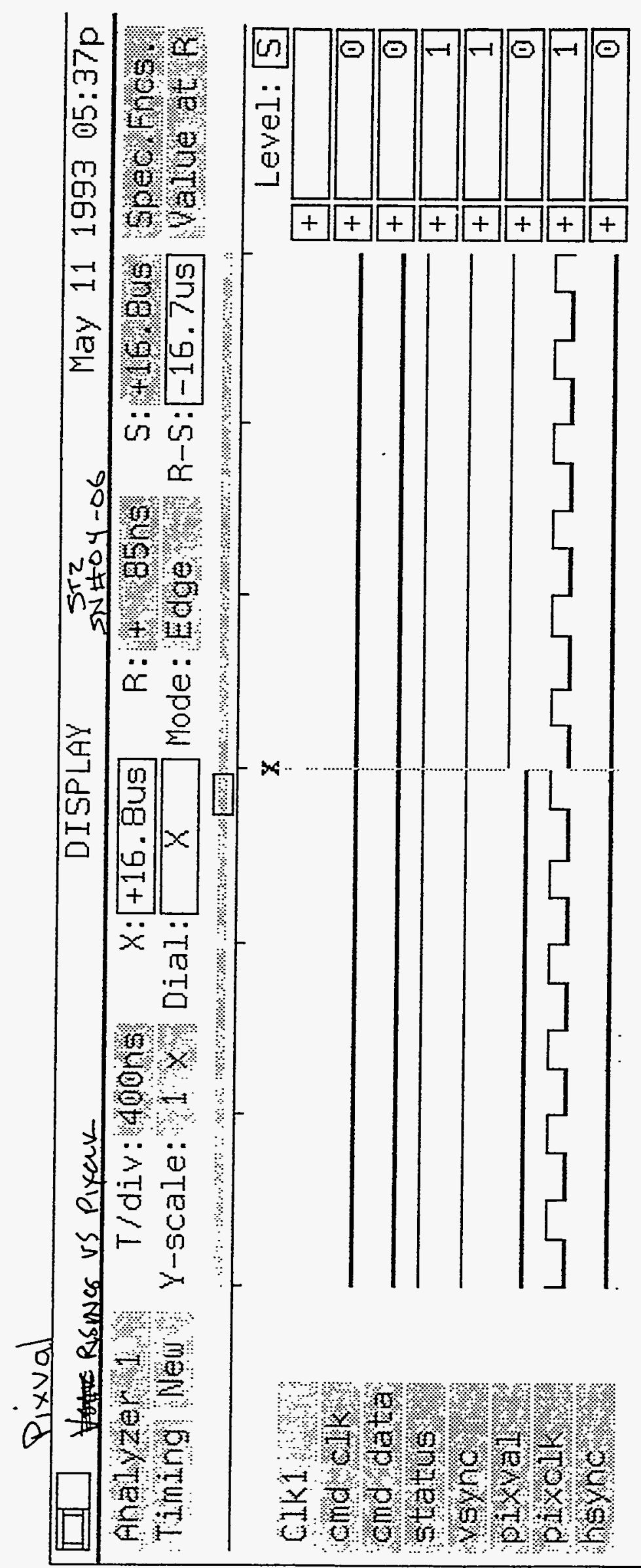




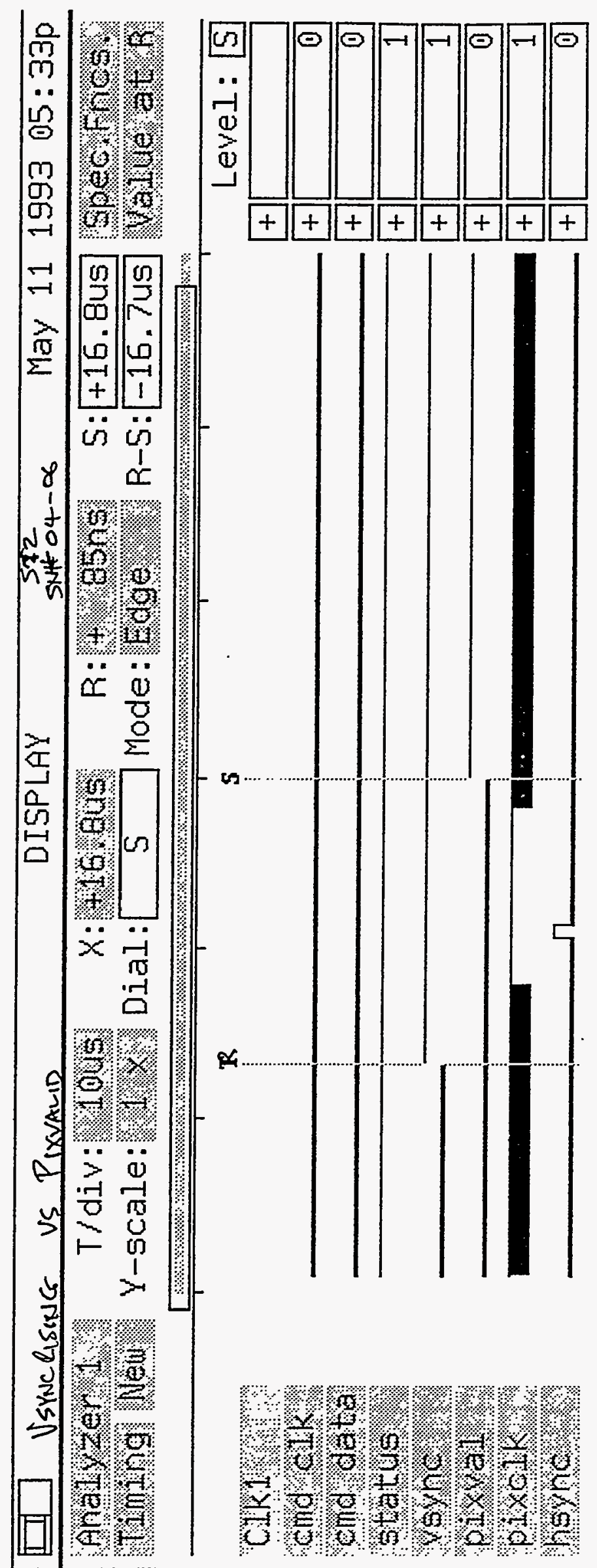




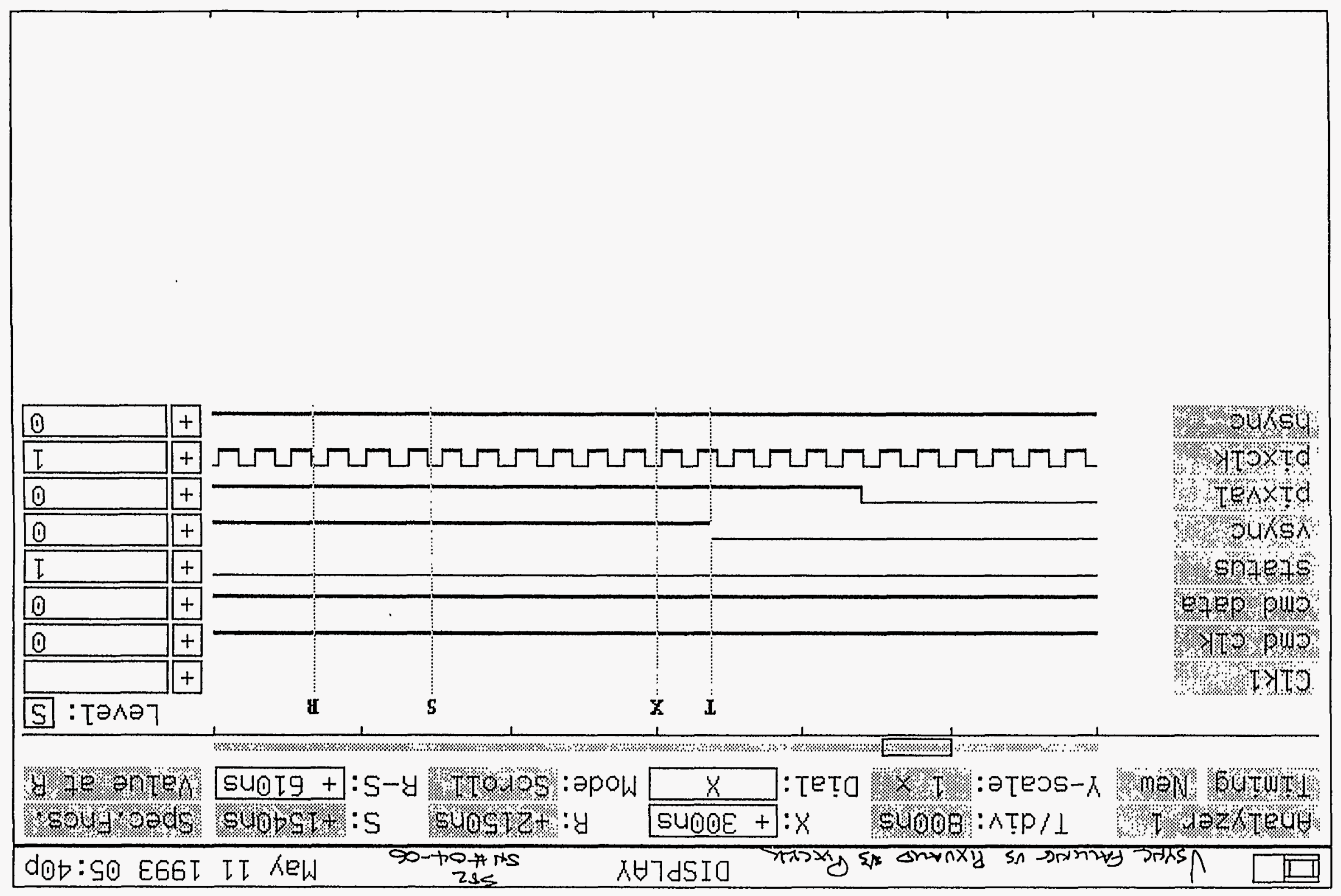




\section{Video Interface Timing Confirmation}

This test requires the use of the Phillips PM 3585 Logic Analyzer.

\subsection{Logic Analyzer Setup}

Move the analyzer pod probes to the following locations at the Datacube interface card connectors designated as P9 and P10:

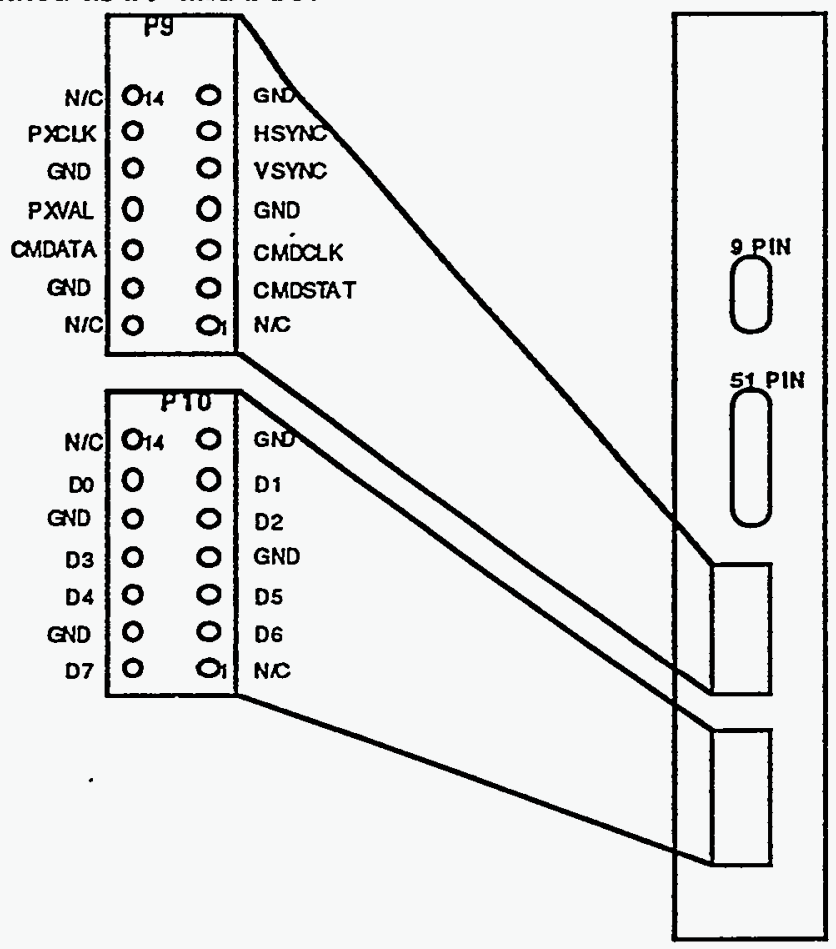

channel 1-CMDCLK

channel 2-CMDDATA

channel 3-CMDSTAT

channel 4-VSYNC

channel 5-PIXVAL

channel 6-PIXCLK

channel 7-HSYNC

channel 9-16-DATA BUS

Attach the pod ground to any of the GND pins indicated.

\subsection{Timing acquisitions:}

Pixclk vs Data

Vsync vs Pixvalid (condensed and expanded at the beginning of line \& frame)

(condensed and expanded at the end of line \& frame)

SASI Command (this is CMDDATA while a SASI is sent from the SUN keyboard)

Rising and falling edges at Vsync vs Pixclk

Rising and falling edges at Pixval vs Pixclk

REMEMBER to attach your recorded documentation to this test procedure!

(A document protector is advised) 
ST Camera: ST2 04-06 PreC: int_time= 50ms, offset= 0, gain=1 ( 350 e/bit) Tue May 11 15:05:45 1993 Pixel Values Min 40 Max 45 Mean 41.5 Sigma $0.51 \times 10^{3}$

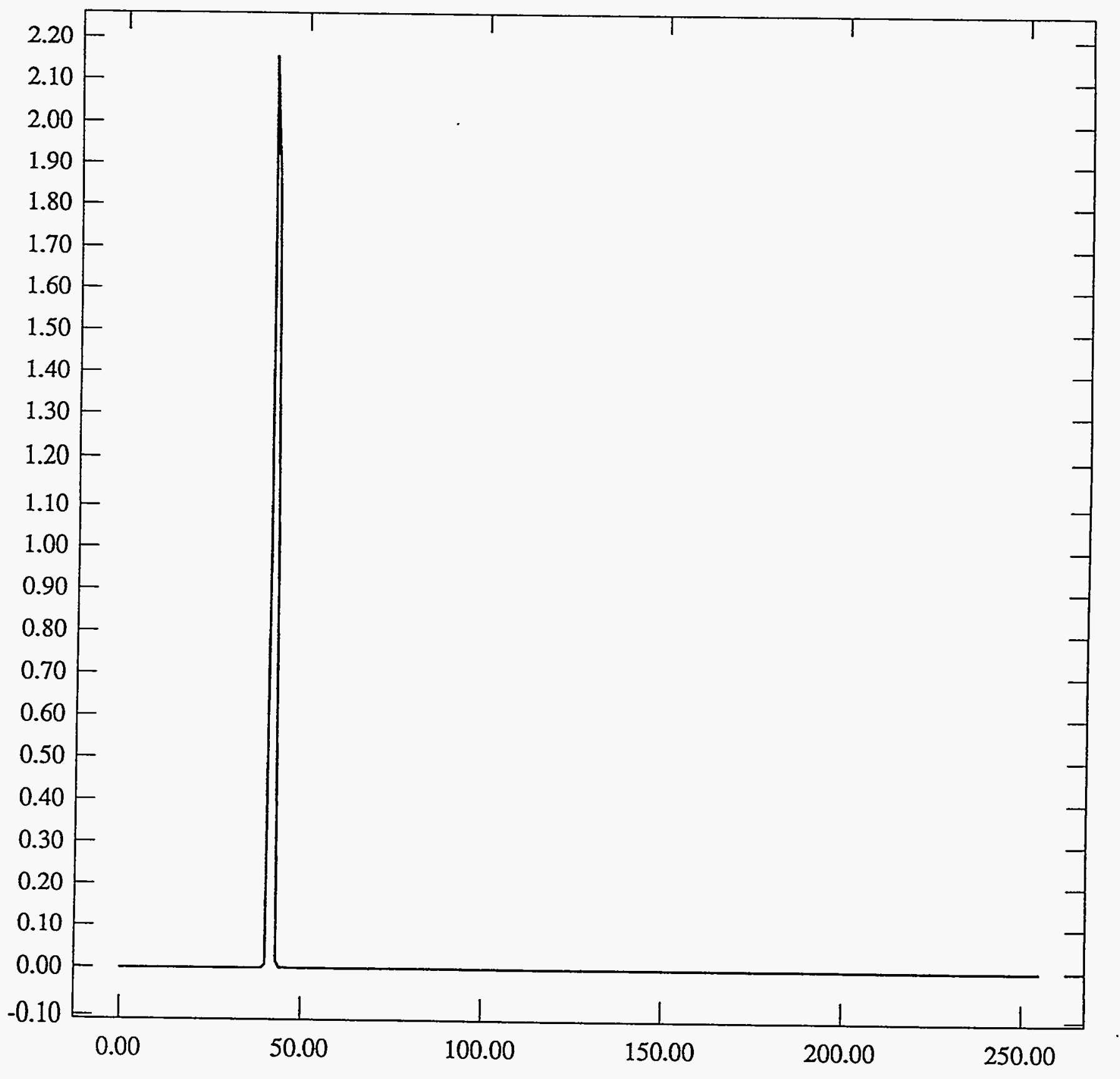




\section{Dark Noise Measurements.}

This measurement requires only the SUN Datacube Test Station and its image processing capabilities and an opaque covering.

Remove all test probes and place an opaque cover over the test CCD. turn the camera on and collect the dark frames as quickly as possible and record histograms.

Verify the gain of the camera is $4(75 \mathrm{e} / \mathrm{bit})$ and the integration time is $50 \mathrm{msec}$ and offset is 0 via the SASI.

Make the same measurement at gain level $2(150 \mathrm{e} / \mathrm{bit})$ and $1(350 \mathrm{e} / \mathrm{bit})$.

Fill in the Mu/Sigma values in the table below:

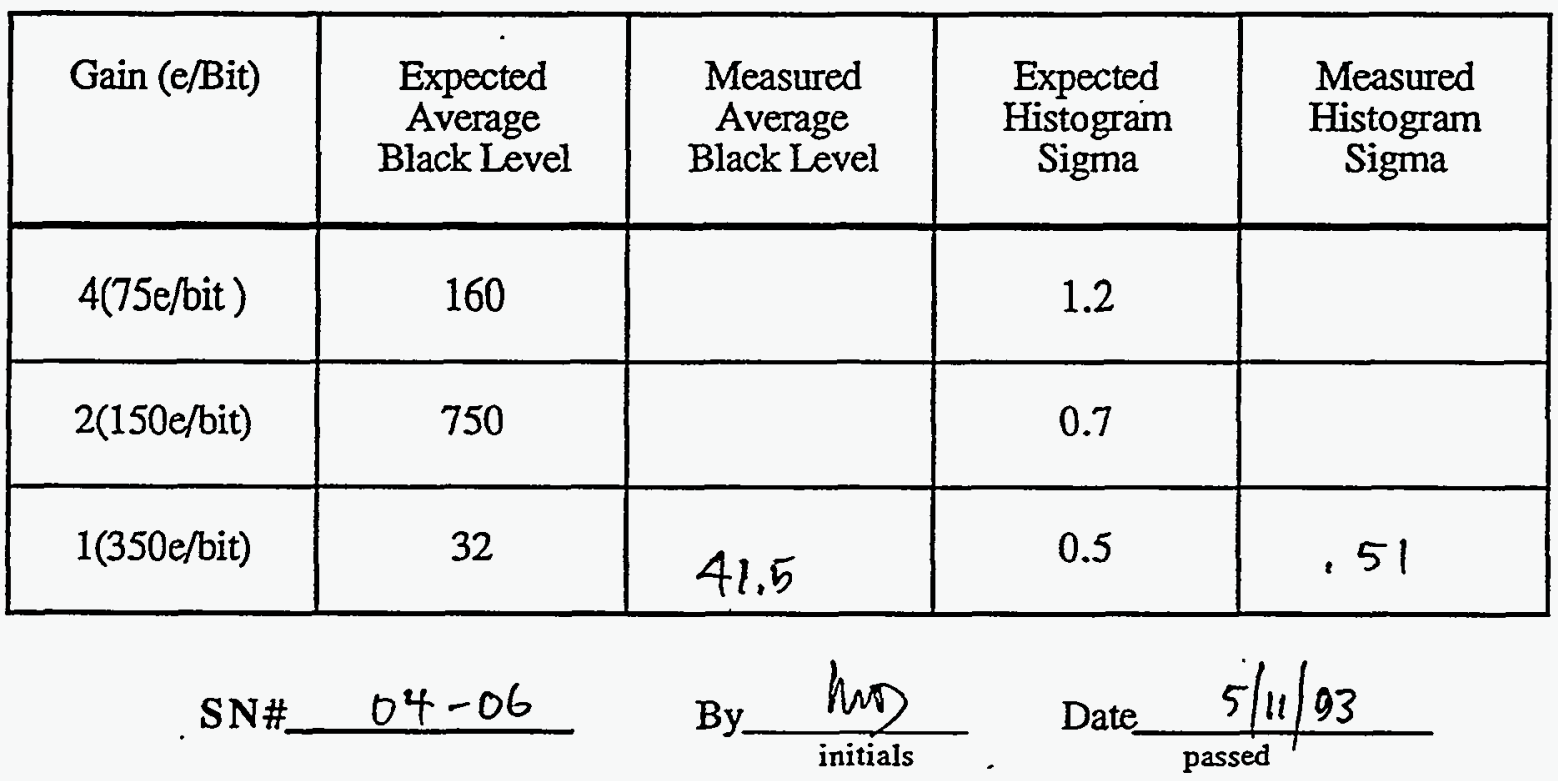

Turn off the test fixture.

REMEMBER to attach your recorded documentation to this test procedure!

(A document protector is advised) 
12. Thermal Test

This test requires the SUN Datacube and its image processing capabilities, an environmental chamber with limit, rate controls, and a timer.

\section{Carefully Insert The Flight CCD Into The Test Board. \\ Check Its Orientation}

\subsection{Thermal Test Setup}

Secure the carrier mounted Actel board in a PC board holder and place the holder in the environmental chamber. Care should be taken so that the board does not short to chamber walls.

Attach the camera cable harness to the Actel board via a feed-through hole. Wrap a piece of foam around the cable harness. Squeeze the wrapped harness into the feed-through so that the hole is sealed and there is no strain on the inside/outside cabling.

Place an opaque cover over the CCD.

Power-up and confirm a functioning camera/acquisition system by capturing a frame. At room temperature this should resemble the dark measurement histogram acquired in SECTION 11.

Turn-off the camera board under test

Seal the environmental chamber.

Set chamber temperature ramp rate at $2^{\circ} \mathrm{C} / \mathrm{min}$.

Set chamber temperature deviation limit to $2^{\circ} \mathrm{C}$.

Set chamber soak time to 20 minutes.

Start the thermal sequence at $-20^{\circ} \mathrm{C}$ or at a ${ }^{\circ} \mathrm{C}$ determined by your requester. 
ST2\#04-061CDT1350日

TEMP (degrees C) $50 \mathrm{~ms} / \mathrm{mu} 50 \mathrm{~ms} / \mathrm{sigma} 100 \mathrm{~ms} / \mathrm{mu} \quad 100 \mathrm{~ms} / \mathrm{sigma} 200 \mathrm{~ms} / \mathrm{mu} 200 \mathrm{~ms} / \mathrm{sigma}$

-20
-10
0
10
20
30

34.10

35.30

36.20

38.10

41.30

47.10

0.33
0.71
0.45
0.34
0.46
0.59

34.20

35.50

36.70

39.00

43.50

52.00

$\begin{array}{ll}0.39 & 34.30 \\ 0.74 & 35.70 \\ 0.44 & 37.50 \\ 0.26 & 40.80 \\ 0.53 & 48.00 \\ 0.72 & 61.80\end{array}$

0.46

0.48

0.51

0.43

0.68

0.89
Thu, May 13, 1993 10:56 AM

NOTES:

$5 / 11 / 93$

Flight F.0. CCD\#2

$3500 / b i t$

$R 49=100 \Omega$ 
ST Camera: ST2 04-06 -20C: int_time= 50ms, offset= 0, gain=1 ( 350 e/bit) Tue May 11 15:33:24 1993 Pixel Values Min 33 Max 35 Mean 34.1 Sigma $0.33 \times 10^{3}$

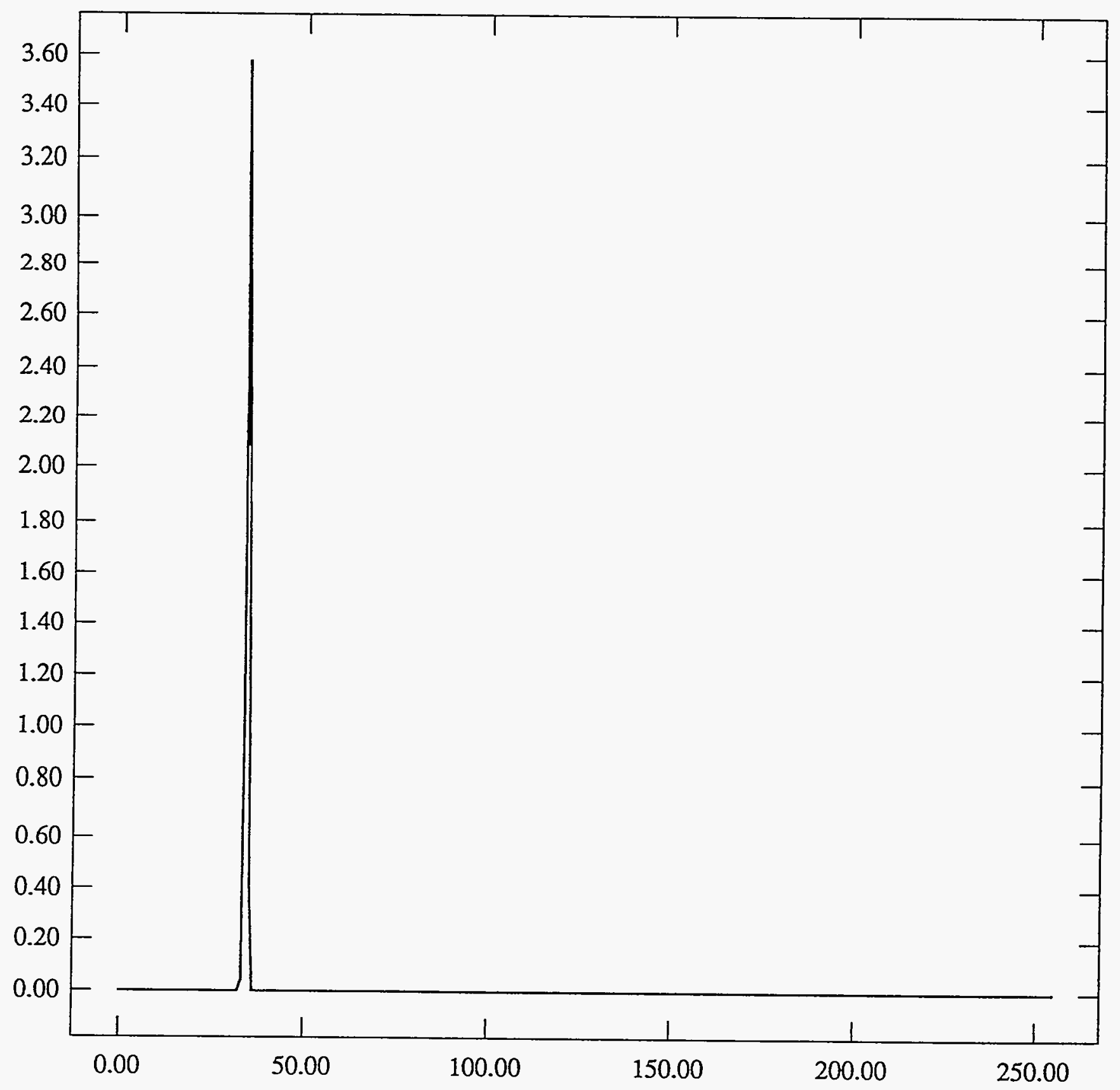


ST Camera: ST2 04-06 -20C: int_time $=100 \mathrm{~ms}$, offset= 0, gain=1 ( $350 \mathrm{e} / \mathrm{bit}$ ) Tue May 11 15:34:47 1993 Pixel Values Min 33 Max 36 Mean 34.2 Sigma $0.39 \times 10^{3}$

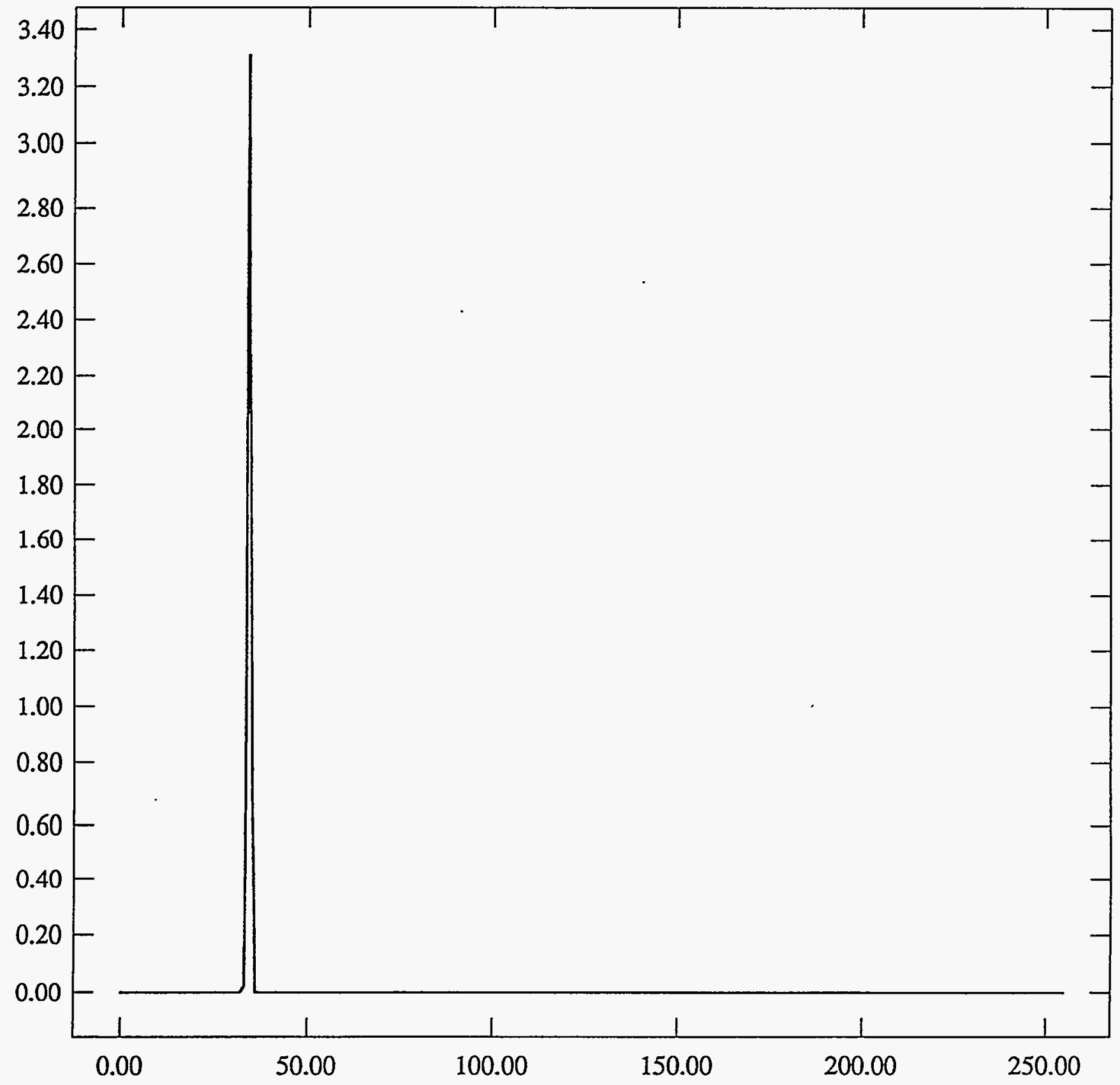




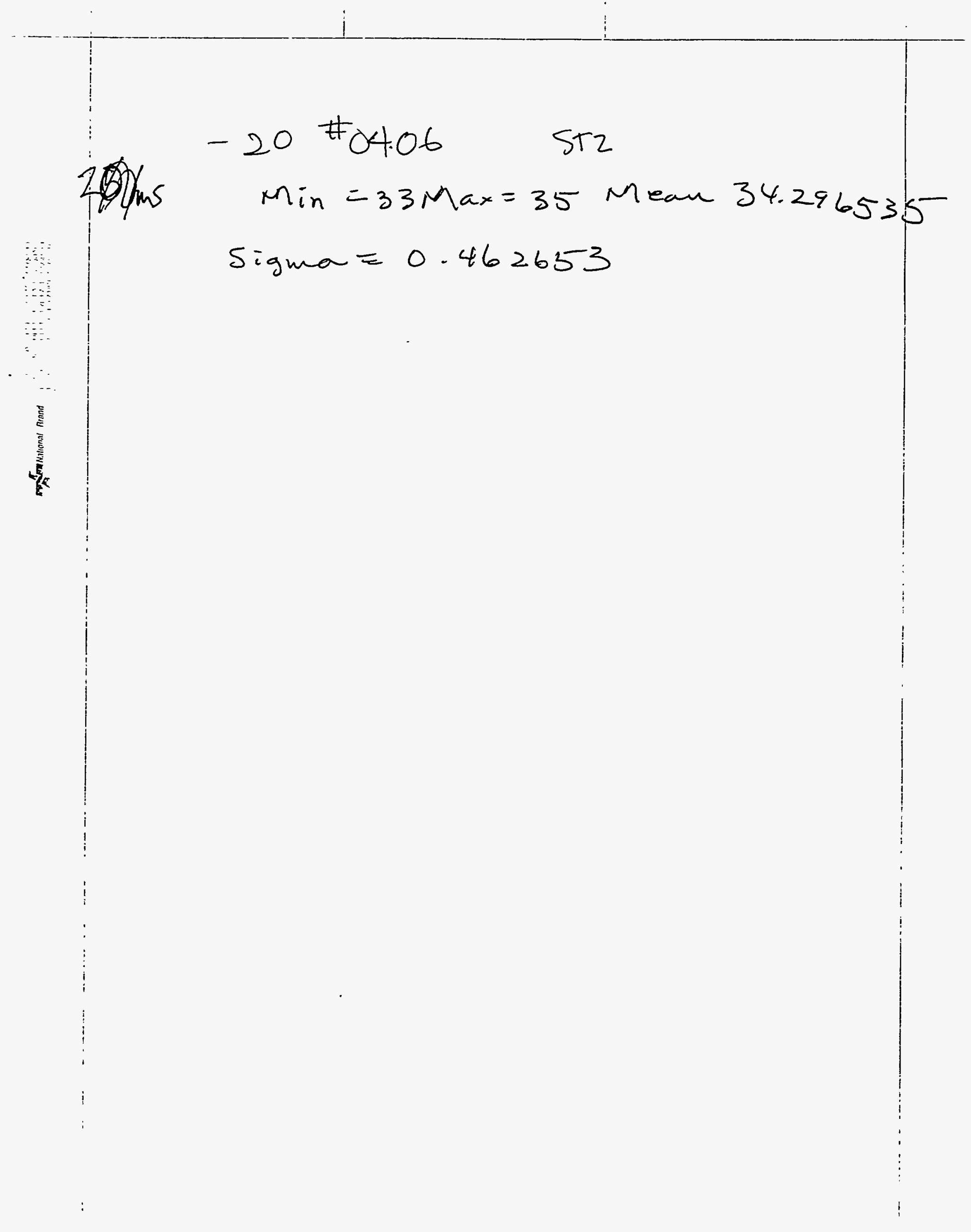


ST Camera: ST2 04-06 -10C: int_time= 50ms, offset= 0, gain=1 ( 350 e/bit) Tue May 11 15:50:25 1993 Pixel Values Min 32 Max 39 Mean 35.3 Sigma $0.71 \times 10^{3}$

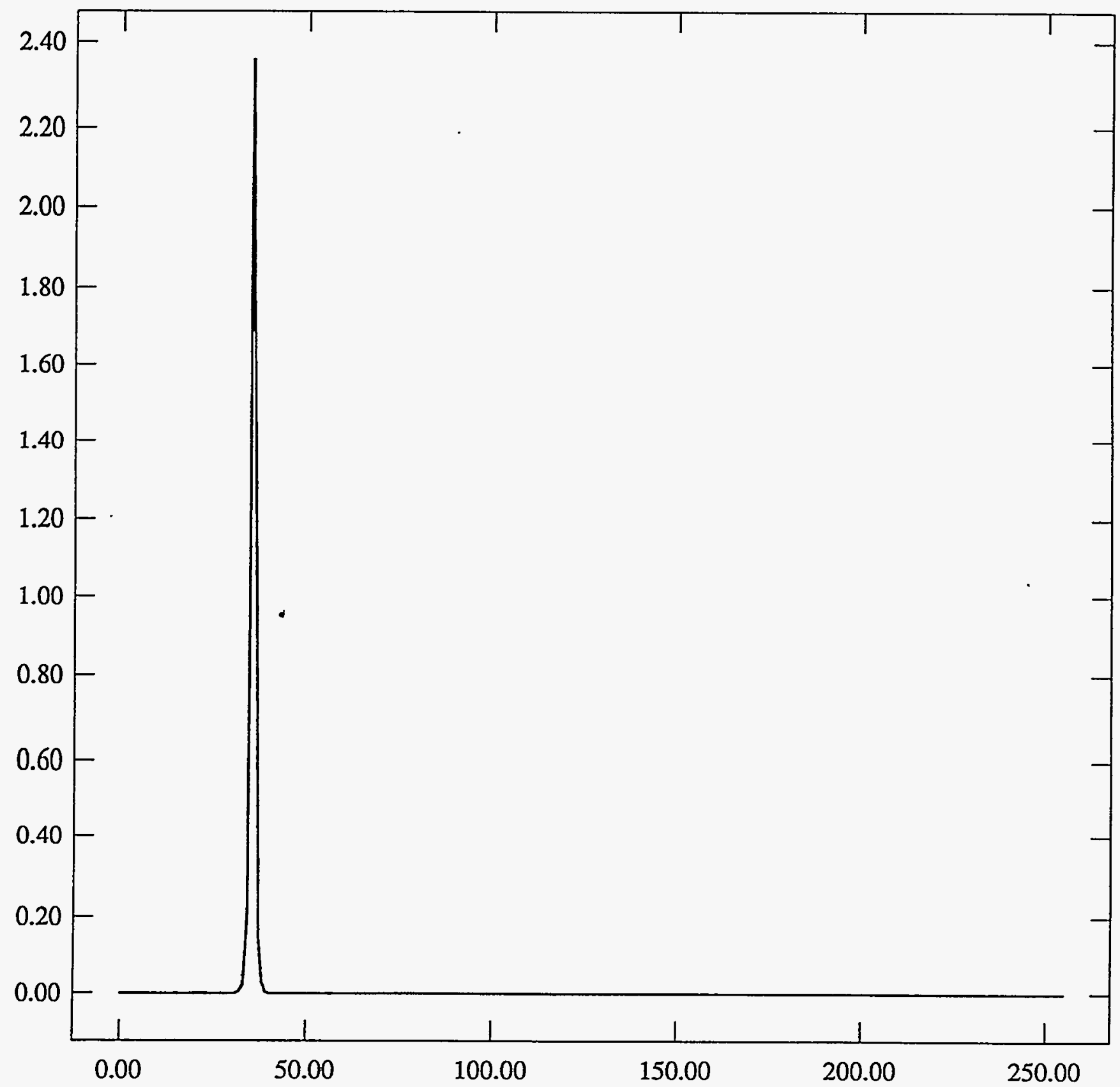


ST Camera: ST2 04-06 -10C: int time=100ms, offset= 0, gain=1 ( $350 \mathrm{e} / \mathrm{bit}$ ) Tue May 11 15:51:15 1993 Pixel Values Min 32 Max 39 Mean 35.5 Sigma $0.74 \times 10^{3}$

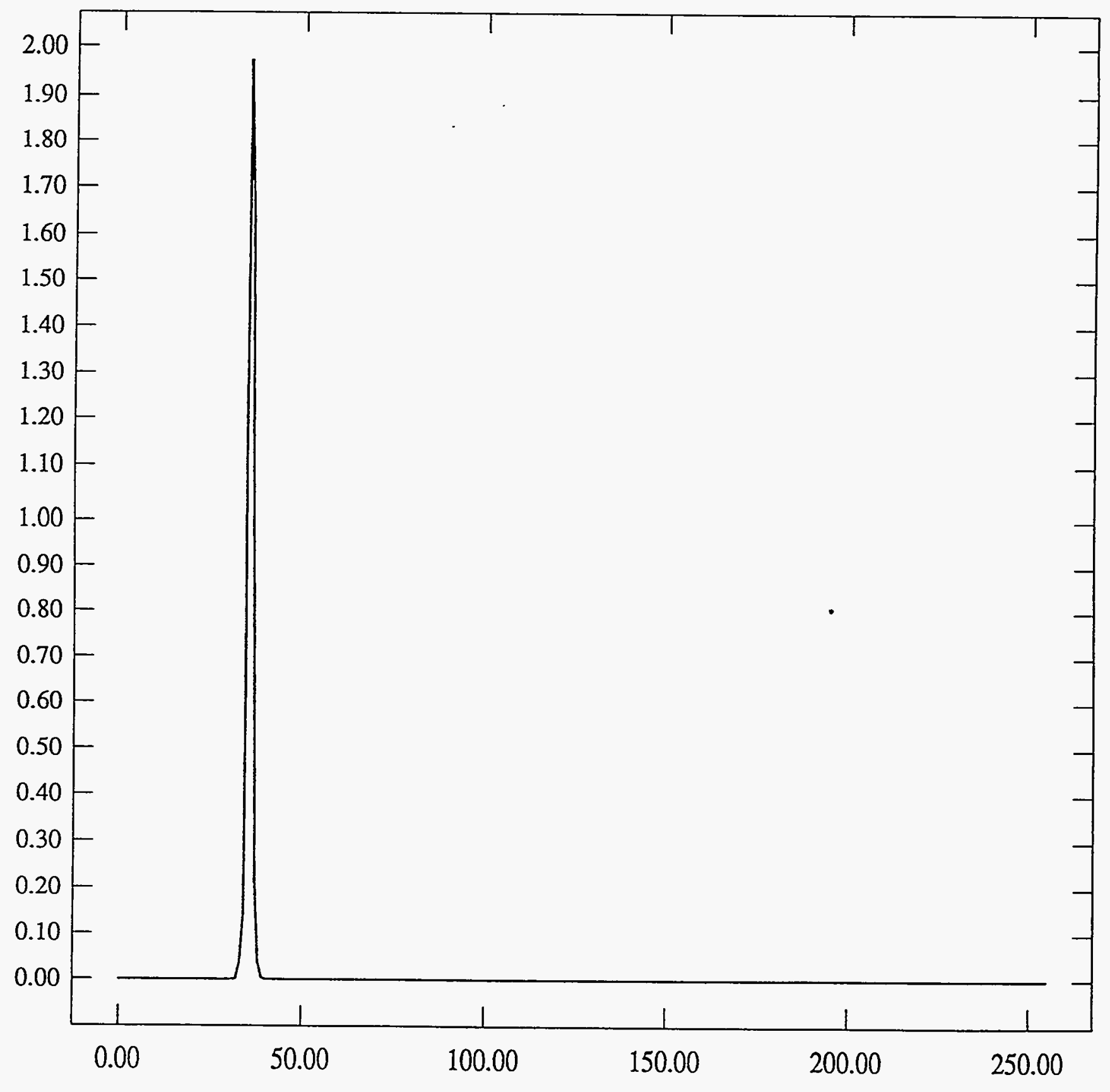


ST Camera: ST2 04-06 -10C: int_time=200ms, offset= 0, gain=1 ( 350 e/bit) Tue May 11 15:51:52 1993 Pixel Values Min 35 Max 37 Mean 35.7 Sigma $0.48 \times 10^{3}$

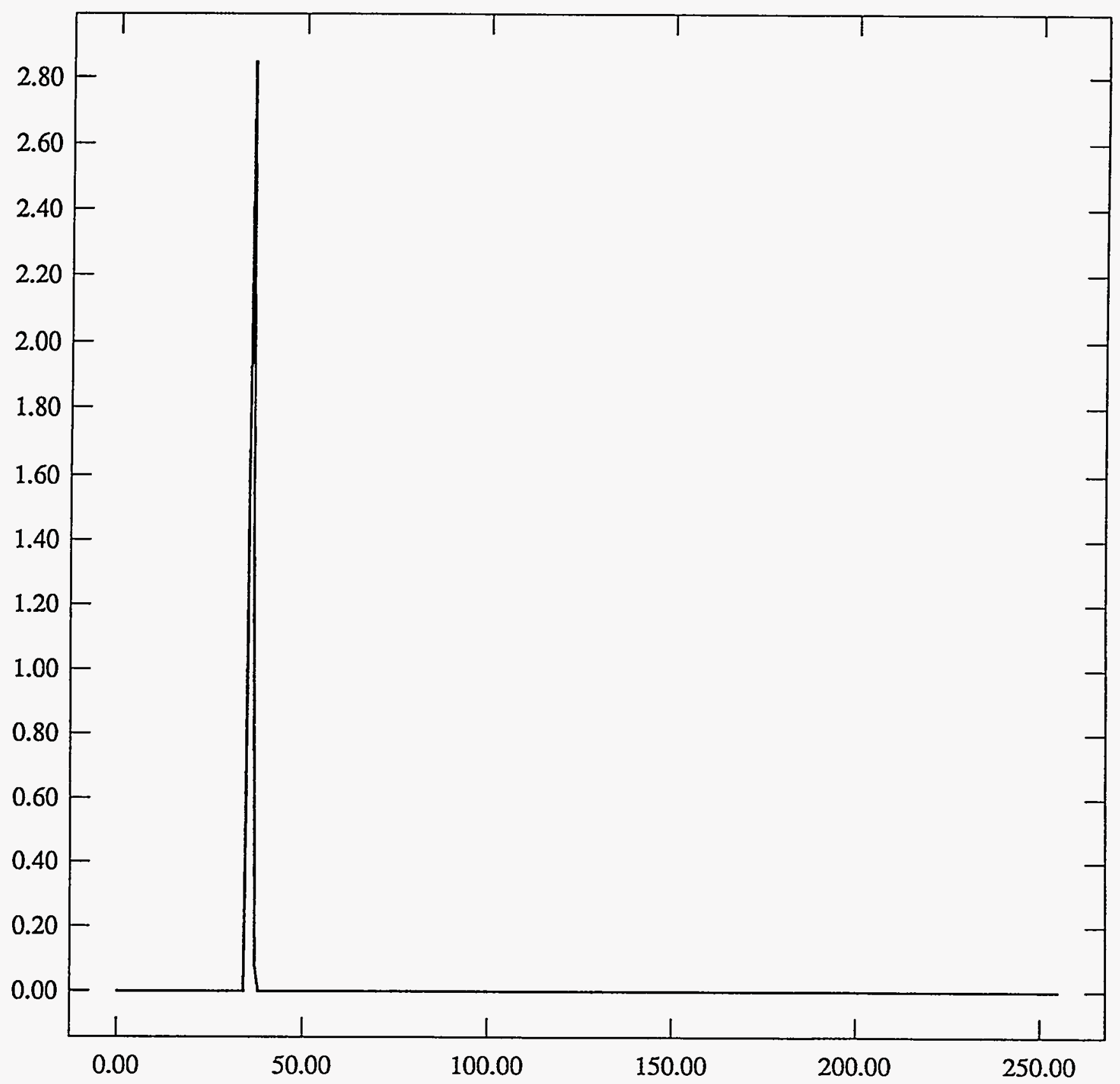


ST Camera: ST2 04-06 0C: int_time= 50ms, offset= 0, gain=1 ( 350 e/bit) Tue May 11 16:06:56 1993

Pixel Values Min 35 Max 37 Mean 36.2 Sigma $0.45 \times 10^{3}$




ST Camera: ST2 04-06 0C: int_time=100ms, offset= 0, gain=1 ( $350 \mathrm{e} / \mathrm{bit}$ ) Tue May 11 16:07:59 1993 Pixel Values Min 35 Max 38 Mean 36.7 Sigma $0.44 \times 10^{3}$

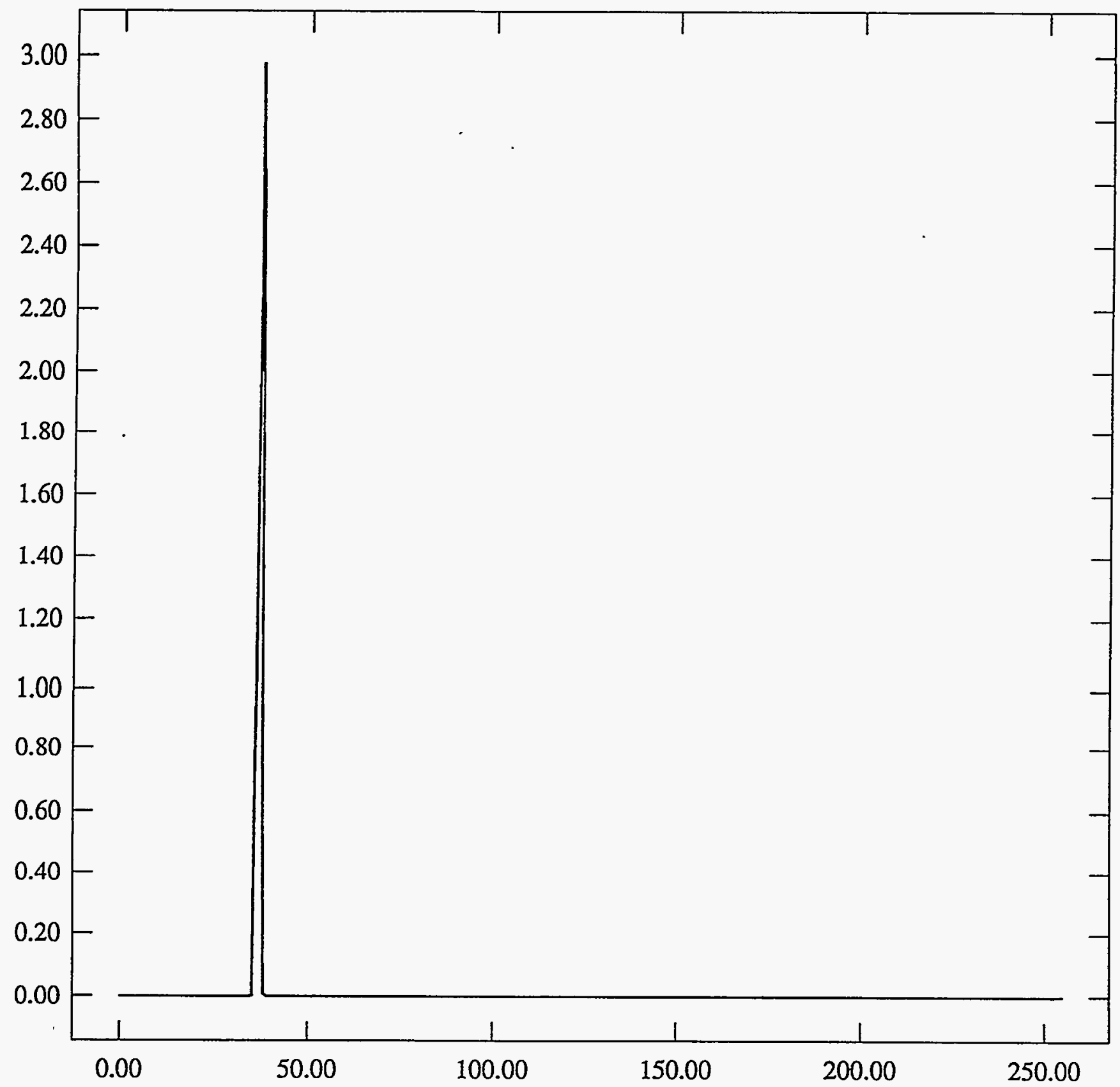


ST Camera: ST2 04-06 0C: int_time=200ms, offset= 0, gain=1 ( $350 \mathrm{e} / \mathrm{bit}$ ) Tue May 11 16:08:37 1993

Pixel Values Min 36 Max 40 Mean 37.5 Sigma $0.51 \times 10^{3}$

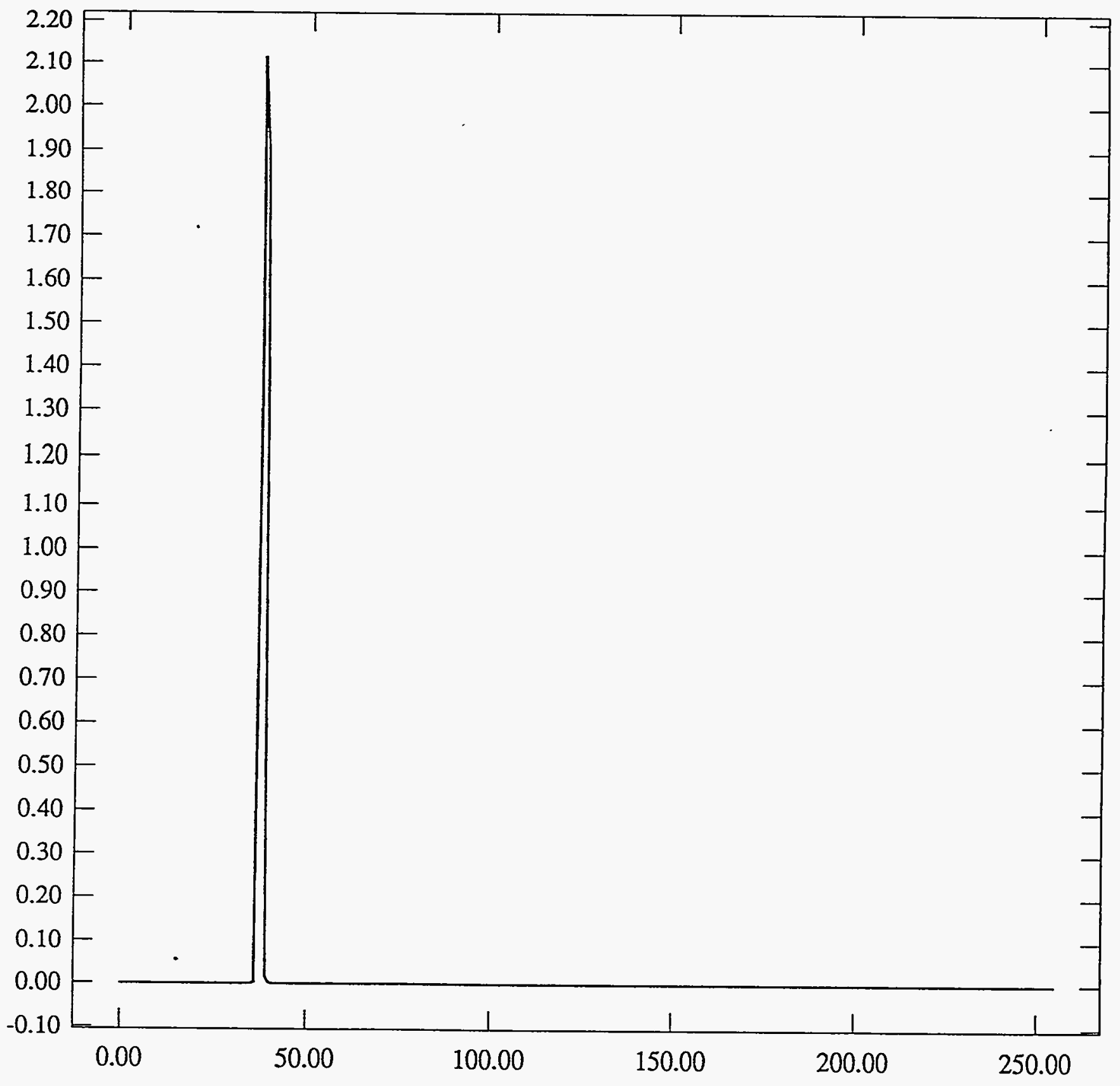


ST Camera: ST2 04-06 +10: int_time $=50 \mathrm{~ms}$, offset= 0, gain=1 ( 350 e/bit) Tue May 11 16:24:02 1993

Pixel Values Min 37 Max 39 Mean 38.1 Sigma $0.34 \times 10^{3}$

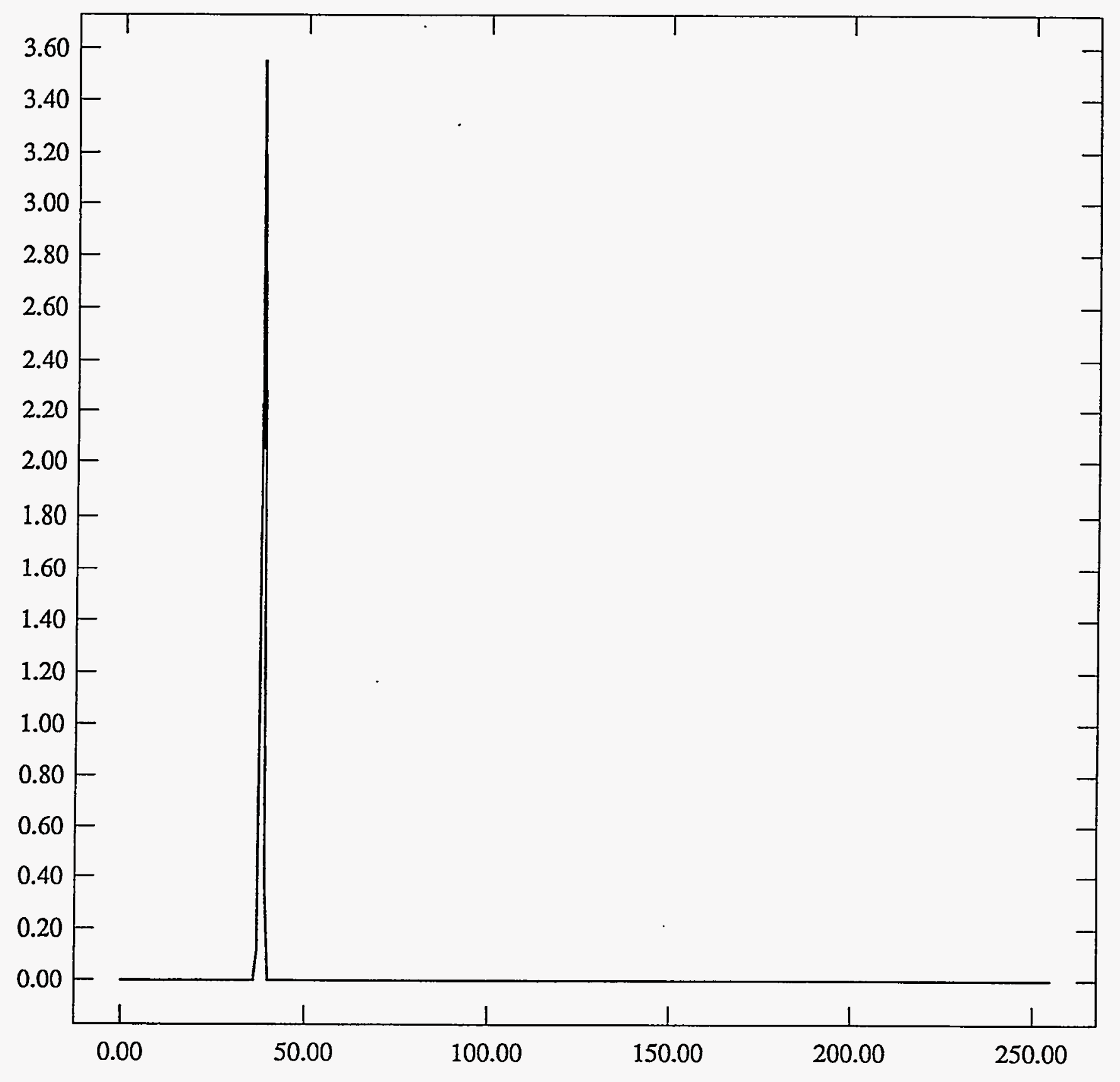


ST Camera: ST2 04-06 +10: int_time=100ms, offset= 0, gain=1 ( $350 \mathrm{e} / \mathrm{bit}$ ) Tue May 11 16:24:40 1993

Pixel Values Min 38 Max 41 Mean 39.0 Sigma $0.26 \times 10^{3}$

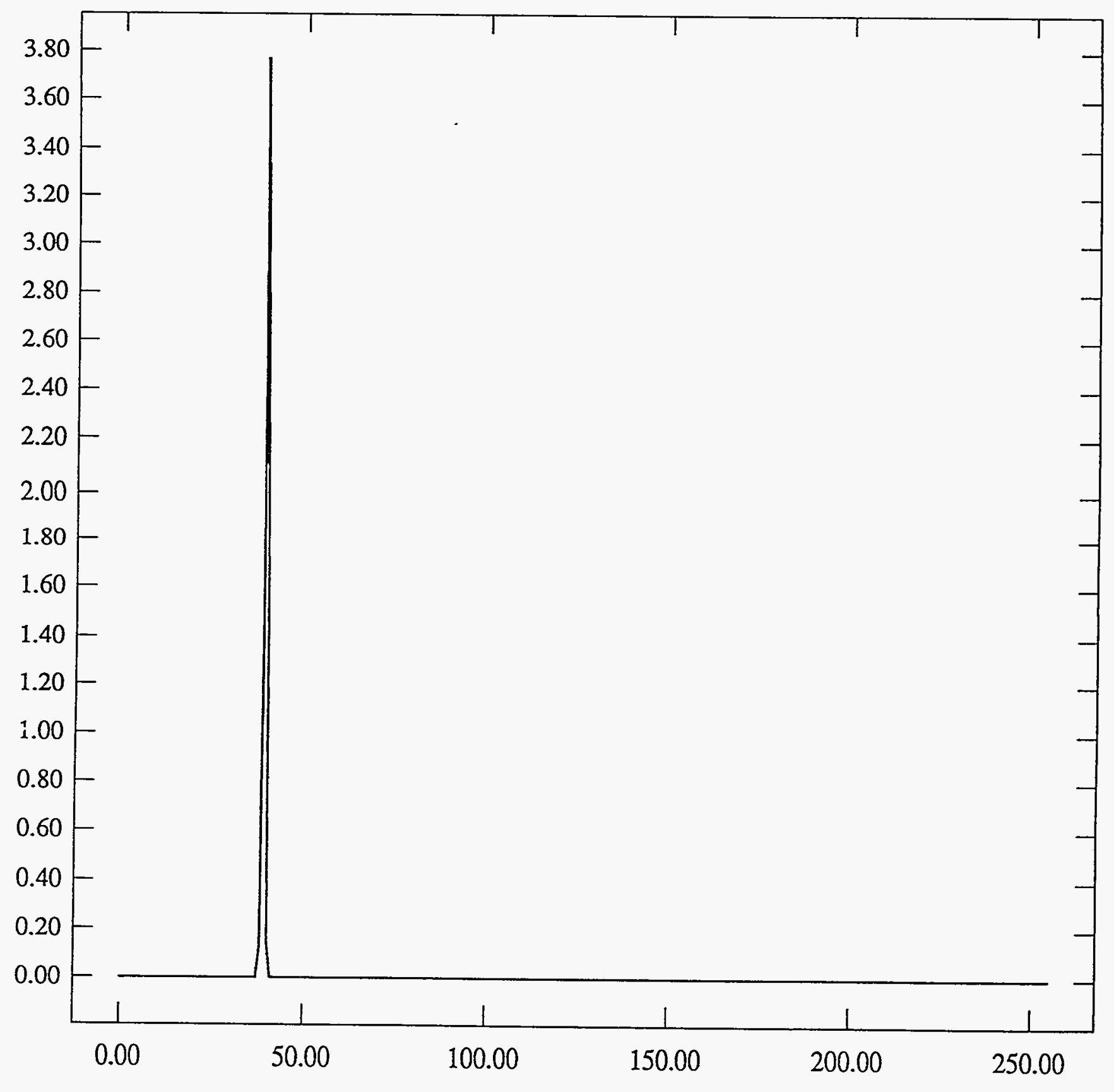


ST Camera: ST2 04-06 +10: int_time=200ms, offset= 0, gain=1 ( 350 e/bit) Tue May 11 16:25:37 1993 Pixel Values Min 39 Max 44 Mean 40.8 Sigma $0.43 \times 10^{3}$

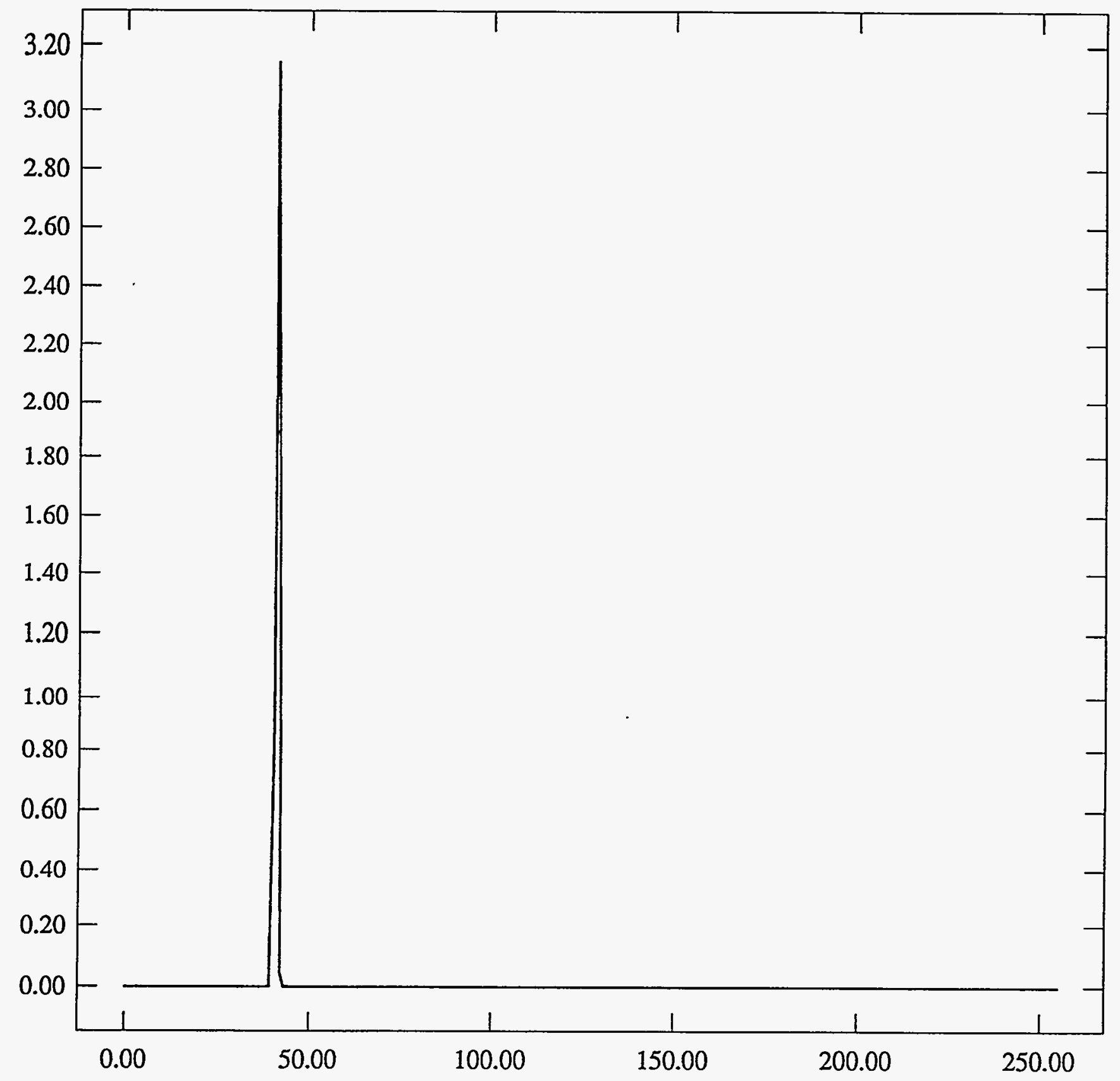


ST Camera: ST2 04-06 +20: int_time $=50 \mathrm{~ms}$, offset $=0$, gain $=1$ ( $350 \mathrm{e} / \mathrm{bit}$ ) Tue May 11 16:41:22 1993 Pixel Values Min 40 Max 43 Mean 41.3 Sigma $0.46 \times 10^{3}$

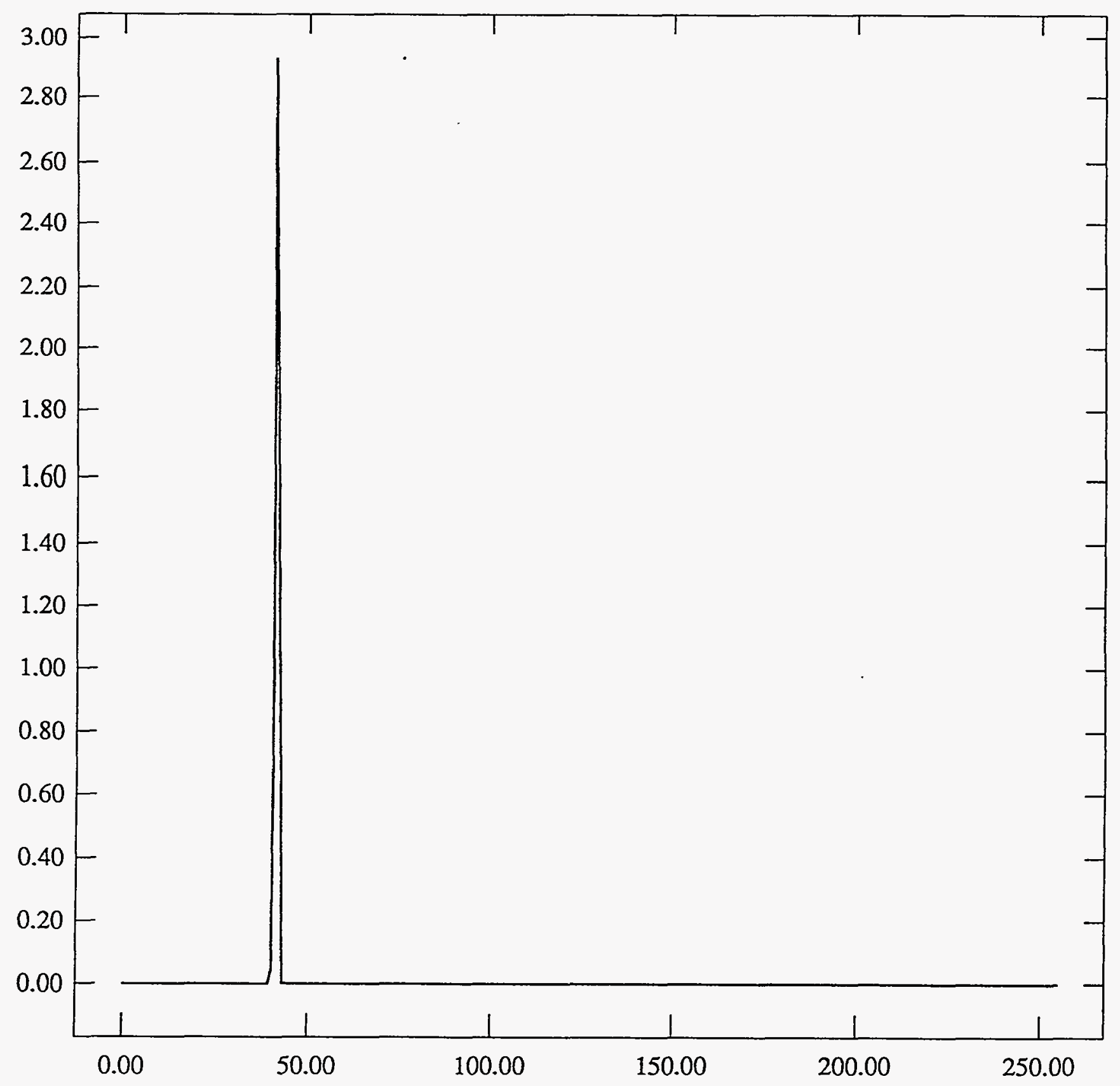


ST Camera: ST2 04-06 +20: int_time=100ms, offset= 0, gain=1 ( $350 \mathrm{e} / \mathrm{bit}$ ) Tue May 11 16:42:03 1993 Pixel Values Min 42 Max 47 Mean 43.5 Sigma $0.53 \times 10^{3}$

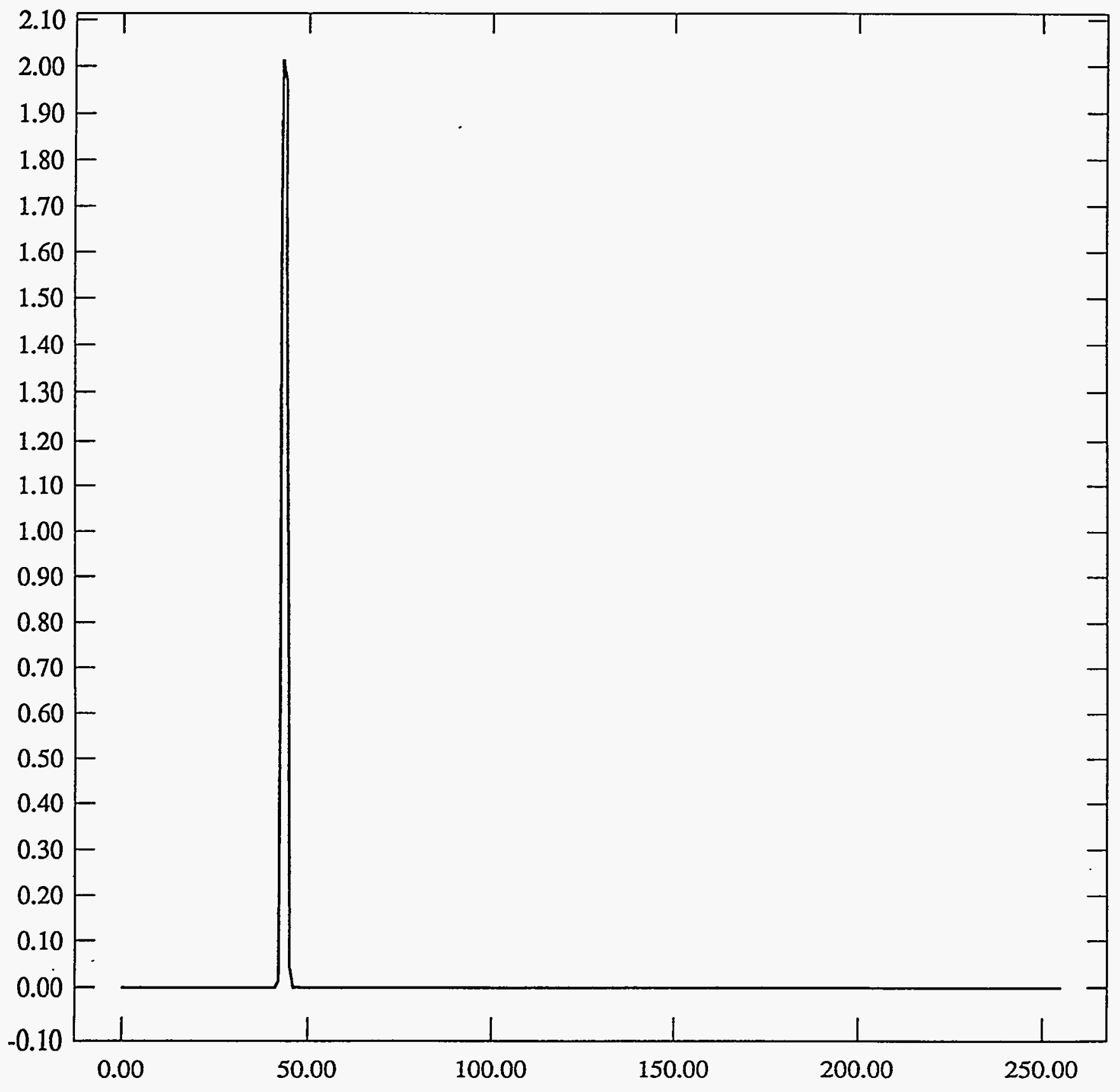


ST Camera: ST2 04-06 +20: int_time=200ms, offset= 0, gain=1 ( 350 e/bit) Tue May 11 16:42:42 1993 Pixel Values Min 46 Max 54 Mean 48.0 Sigma $0.68 \times 10^{3}$

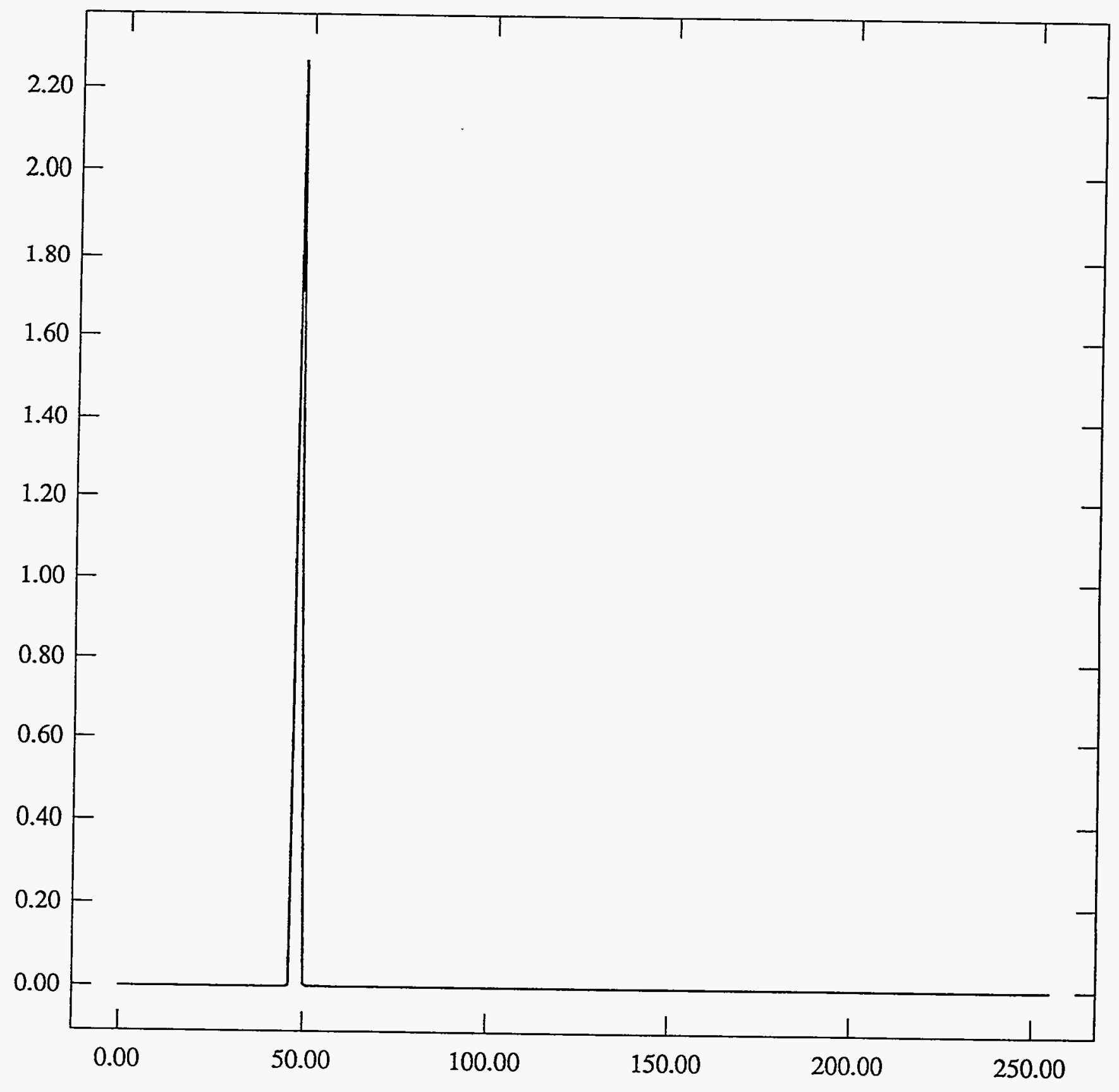


sea

ST Camera: ST2 04-06 +30: int_time= 50ms, offset= 0, gain=1 ( 350 e/bit) Tue May 11 16:59:10 1993

Pixel Values Min 44 Max 51 Mean 47.1 Sigma $0.59 \times 10^{3}$

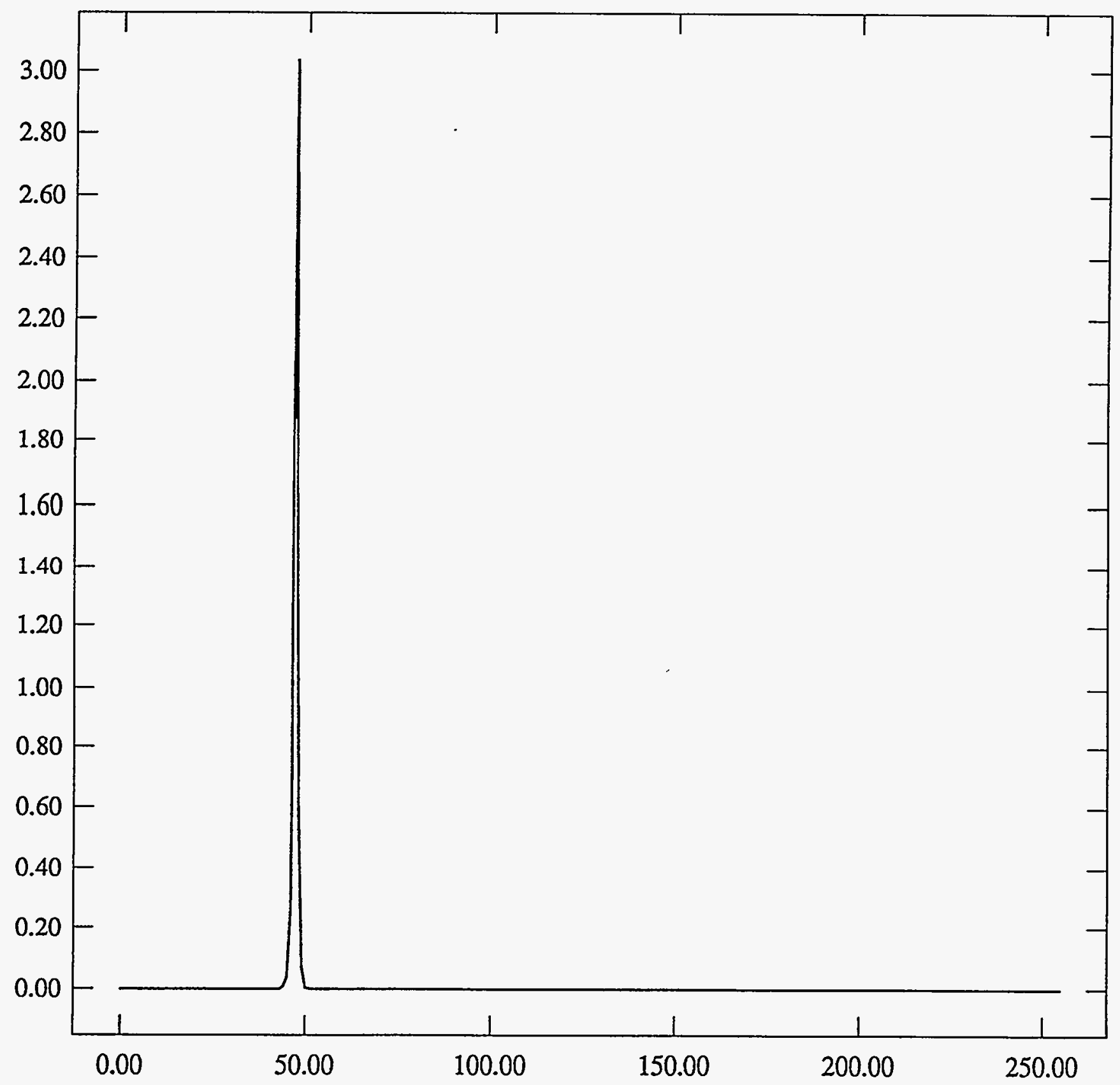


ST Camera: ST2 04-06 +30: int_time=100ms, offset= 0, gain=1 ( 350 e/bit) Tue May 11 17:01:09 1993 Pixel Values Min 50 Max 58 Mean 52.0 Sigma $0.72 \times 10^{3}$

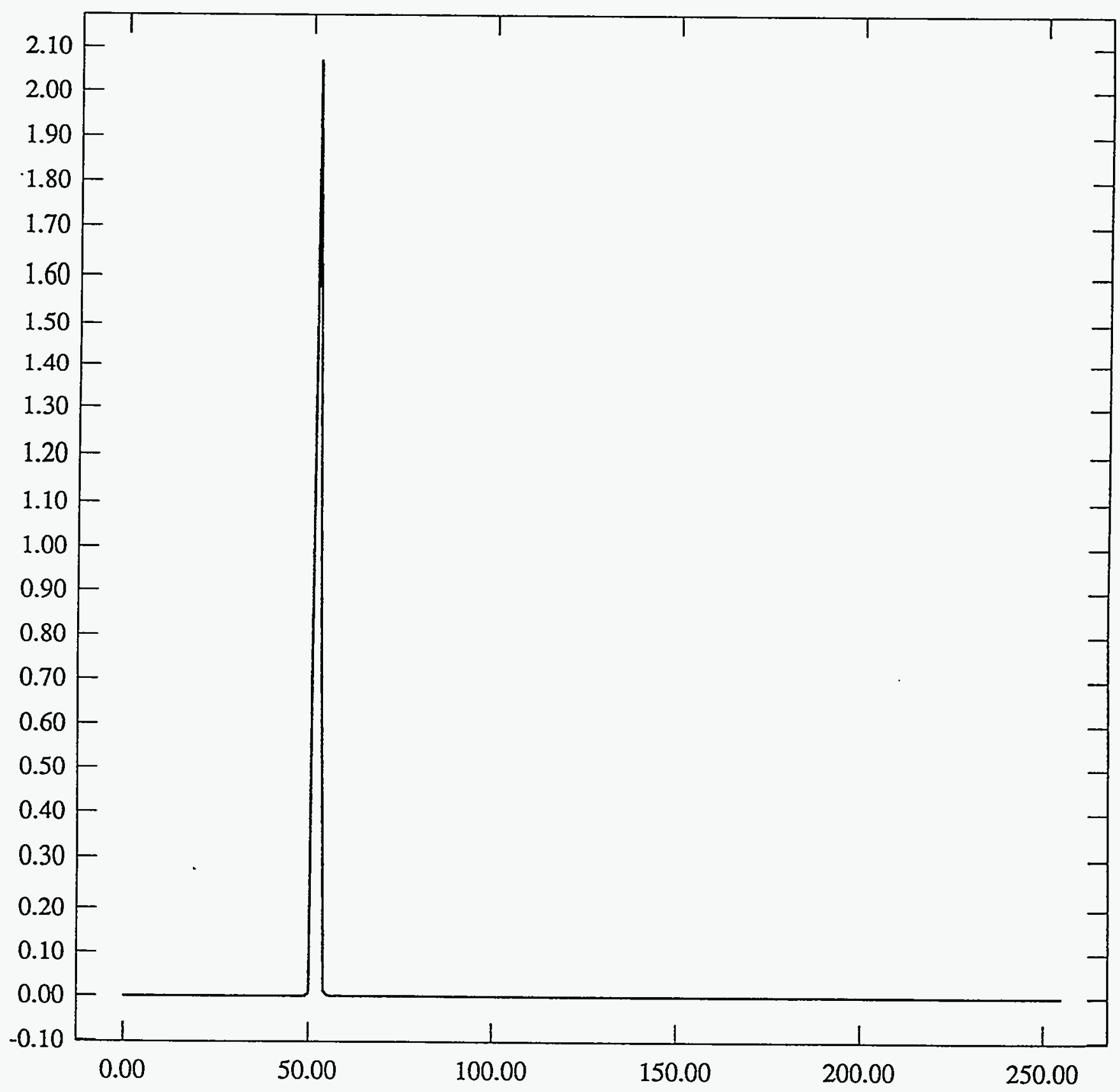


ST Camera: ST2 04-06 +30: int_time=200ms, offset= 0, gain=1 (350 e/bit) Tue May 11 17:01:49 1993 Pixel Values Min 59 Max 76 Mean 61.8 Sigma $0.89 \times 10^{3}$

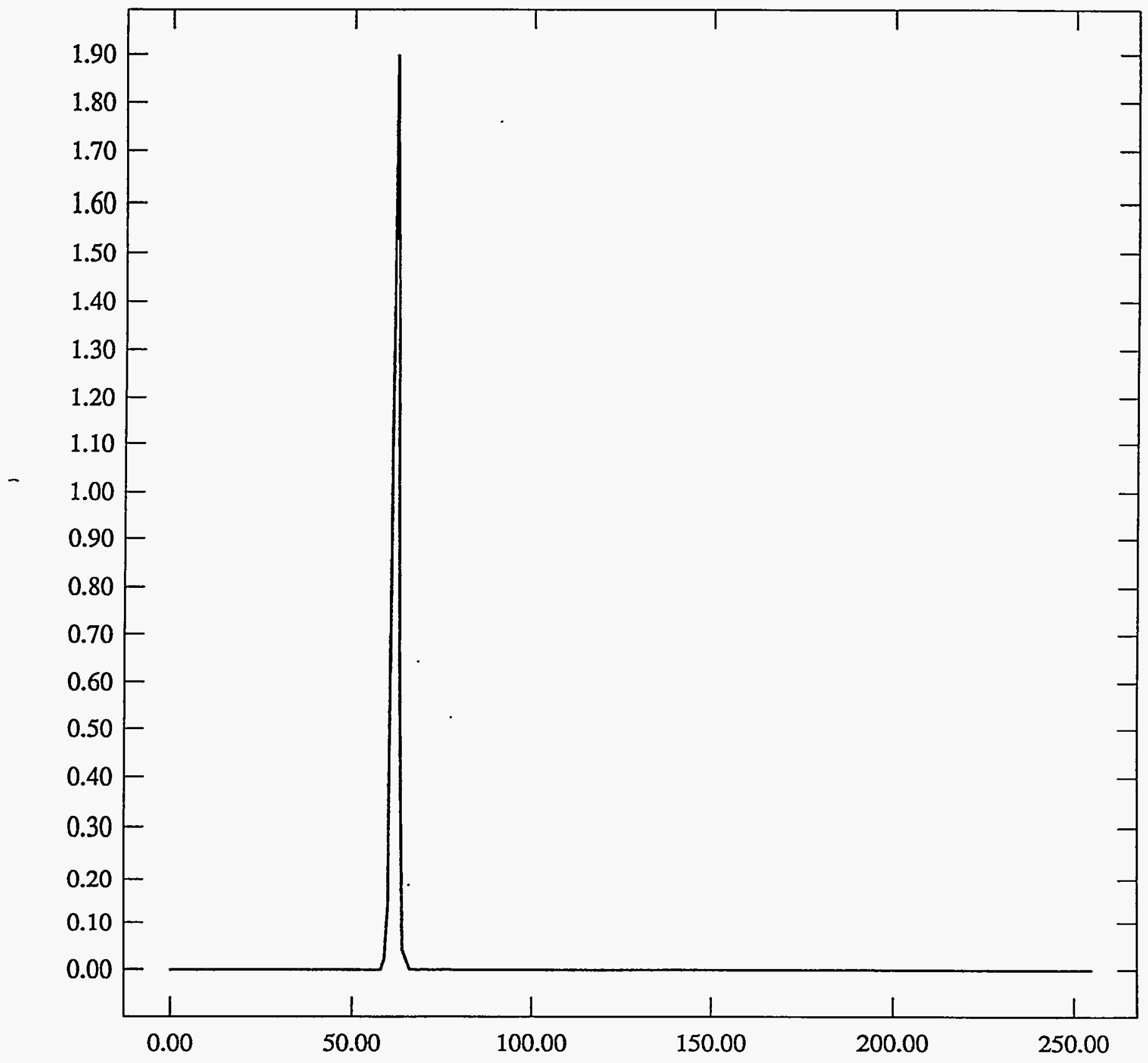


ST2\#04-06 350e/bit $\mathrm{Mu}{ }^{\circ} \mathrm{C}$ Graph

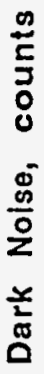
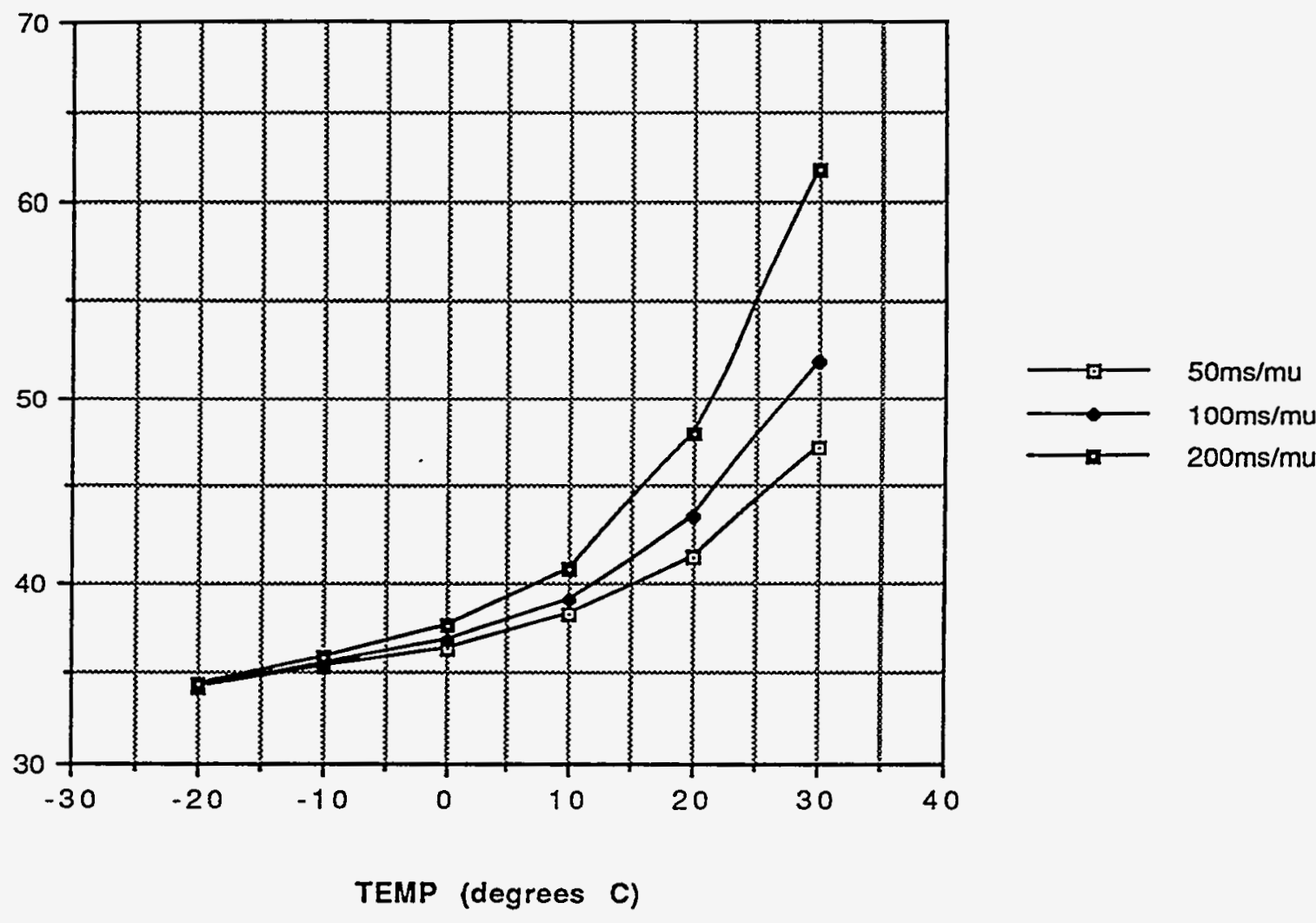

ST2\#04-06 350e/bit Sigma ${ }^{\circ} \mathrm{C}$ Graph

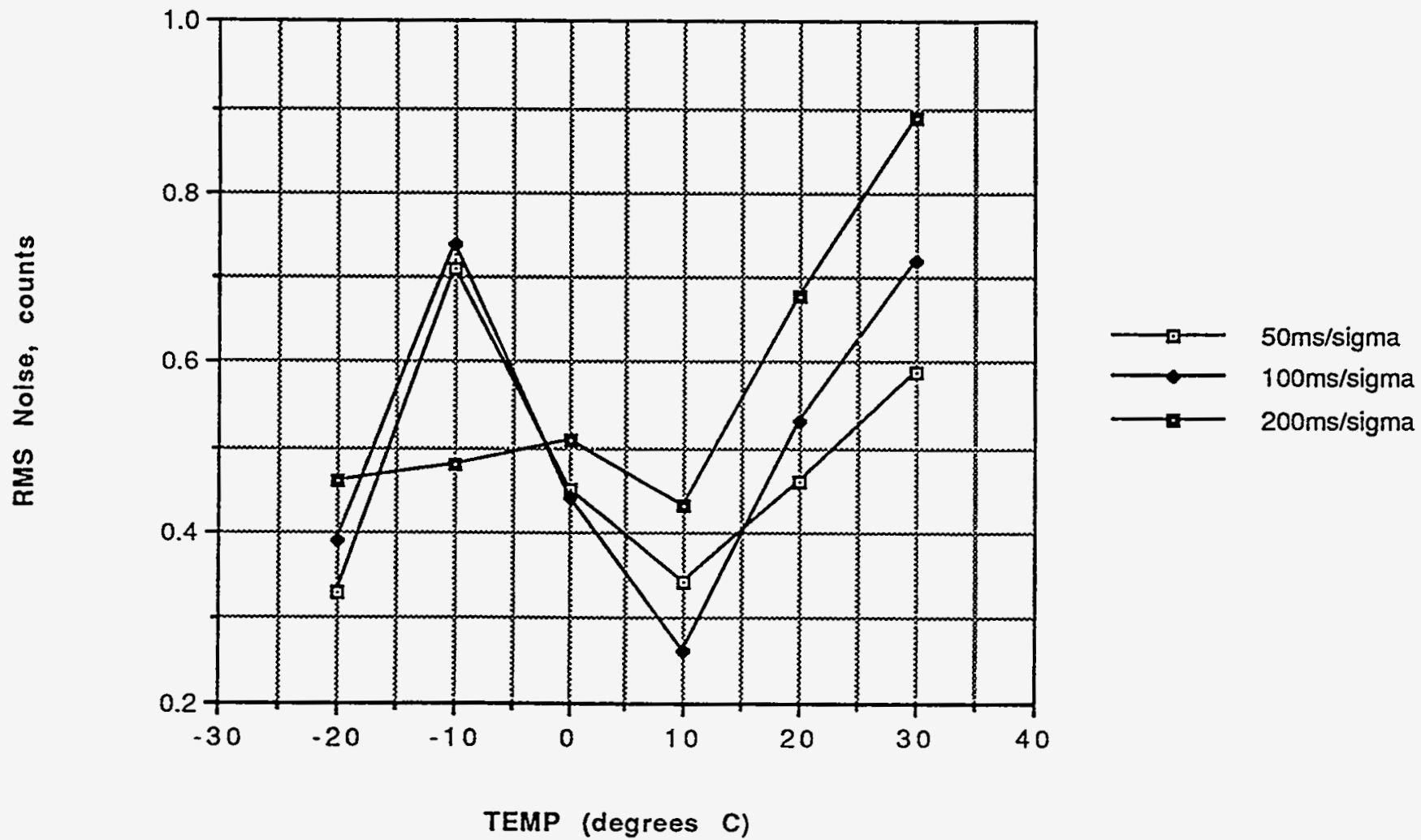


TEMP (degrees C) $50 \mathrm{~ms} / \mathrm{mu} 50 \mathrm{~ms} / \mathrm{sigma} 100 \mathrm{~ms} / \mathrm{mu} \quad 100 \mathrm{~ms} / \mathrm{sigma} 200 \mathrm{~ms} / \mathrm{mu} 200 \mathrm{~ms} / \mathrm{sigma}$

NOTES:

\begin{tabular}{|c|c|c|c|c|c|c|c|}
\hline .20 & 74.10 & 0.58 & 74.30 & 0.59 & 74.50 & 0.57 & $5 / 11 / 93$ \\
\hline-10 & 76.50 & 0.81 & 76.80 & 0.64 & 77.30 & 0.51 & Flight F.0. CCD\#2 \\
\hline 0 & 79.20 & 0.74 & 80.10 & 0.66 & 81.70 & 0.58 & \\
\hline 10 & 83.40 & 0.62 & 85.60 & 0.63 & 89.50 & 0.70 & $\cdot 150 \mathrm{e} / \mathrm{blt}$ \\
\hline 20 & 90.90 & 0.81 & 96.30 & 0.76 & 106.80 & 1.11 & $R 49=100 \Omega$ \\
\hline 30 & 104.00 & 0.91 & 115.60 & 1.10 & 139.30 & 2.33 & \\
\hline
\end{tabular}


ST Camera: ST2 04-06 -20C: int_time= 50ms, offset= 0, gain=2 ( $150 \mathrm{e} / \mathrm{bit})$ Tue May 11 15:36:48 1993 Pixel Values Min 72 Max 75 Mean 74.1 Sigma $0.58 \times 10^{3}$

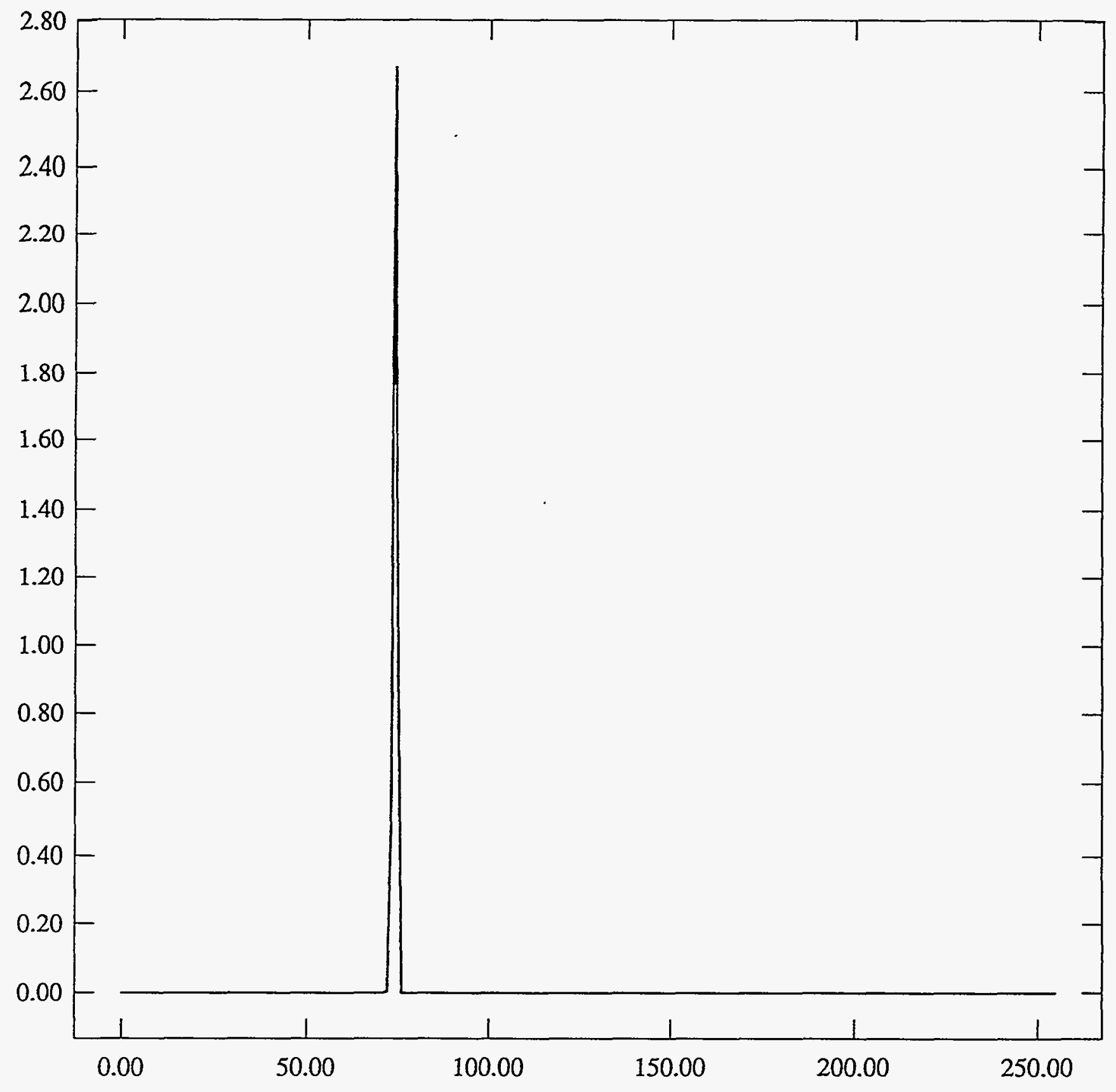


ST Camera: ST2 04-06 -20C: int_time=100ms, offset= 0, gain=2 ( $150 \mathrm{e} / \mathrm{hit}$ ) Tue May 11 15:38:25 1993 Pixel Values Min 73 Max 76 Mean 74.3 Sigma $0.59 \times 10^{3}$




ST Camera: ST2 04-06 -20C: int_time=200ms, offset= 0, gain=2 (150 e/bit) Tue May 11 15:39:05 1993 Pixel Values Min 73 Max 76 Mean 74.5 Sigma $0.57 \times 10^{3}$

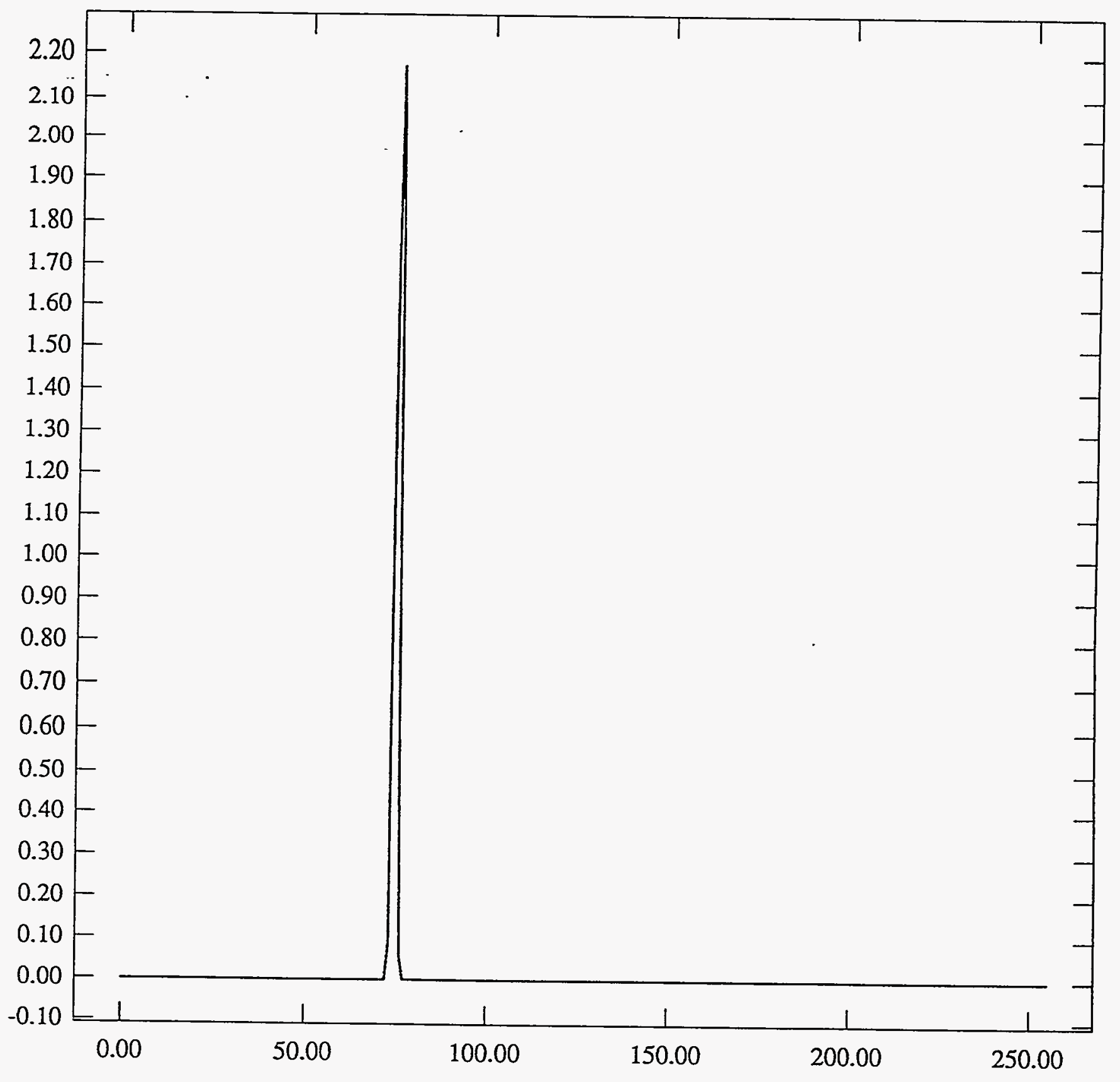


ST Camera: ST2 04-06 -10C: int_time $=50 \mathrm{ms,} \mathrm{offset=} \mathrm{0,} \mathrm{gain=2} \mathrm{(} 150$ e/bit) Tue May 11 15:52:24 1993 Pixel Values Min 72 Max 81 Mean 76.5 Sigma $0.81 \times 10^{3}$

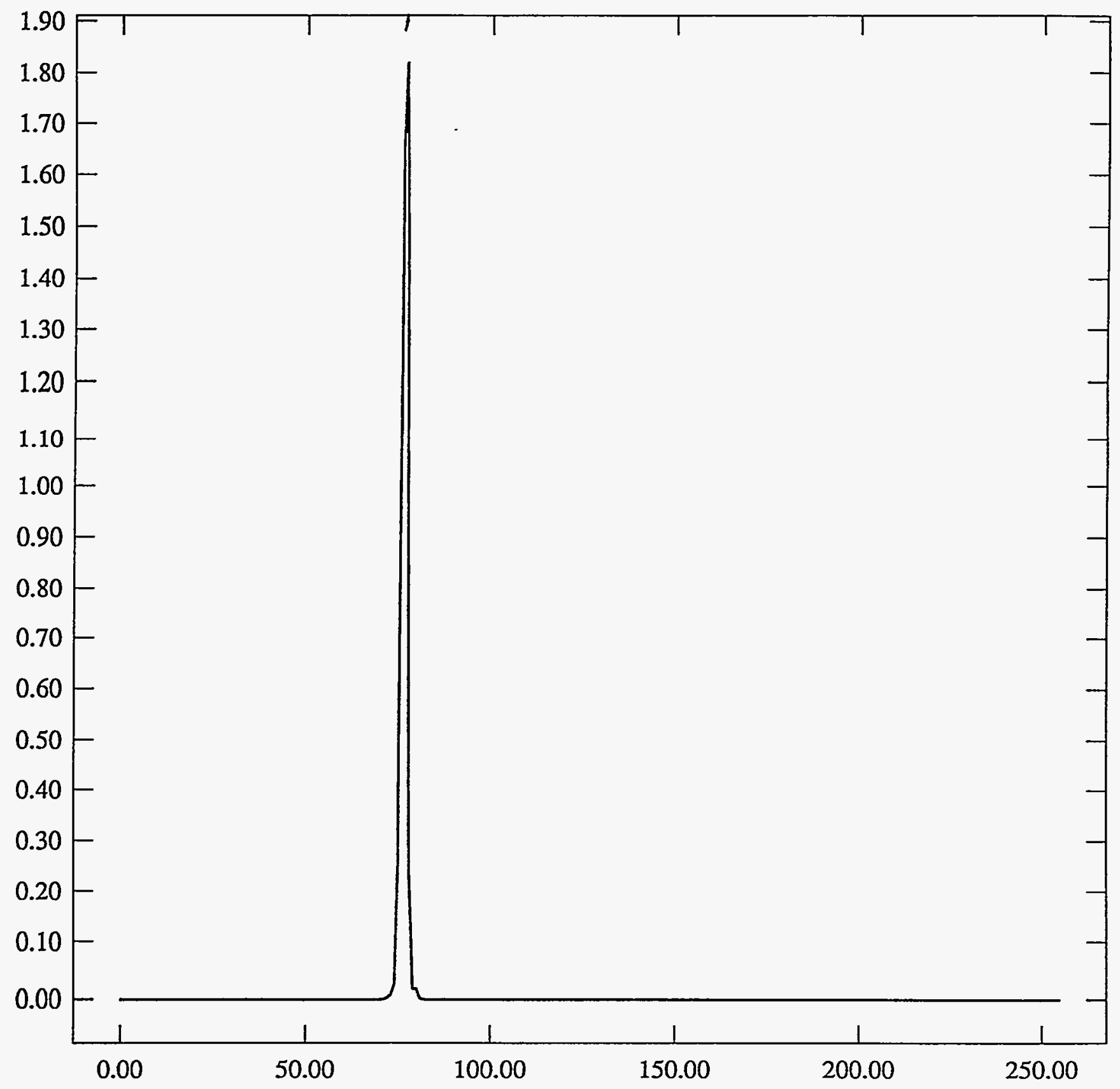


ST Camera: ST2 04-06 -10C: int_time=100ms, offset= 0, gain=2 ( $150 \mathrm{e} / \mathrm{bit}$ ) Tue May 11 15:52:57 1993 Pixel Values Min 72 Max 81 Mean 76.8 Sigma $0.64 \times 10^{3}$

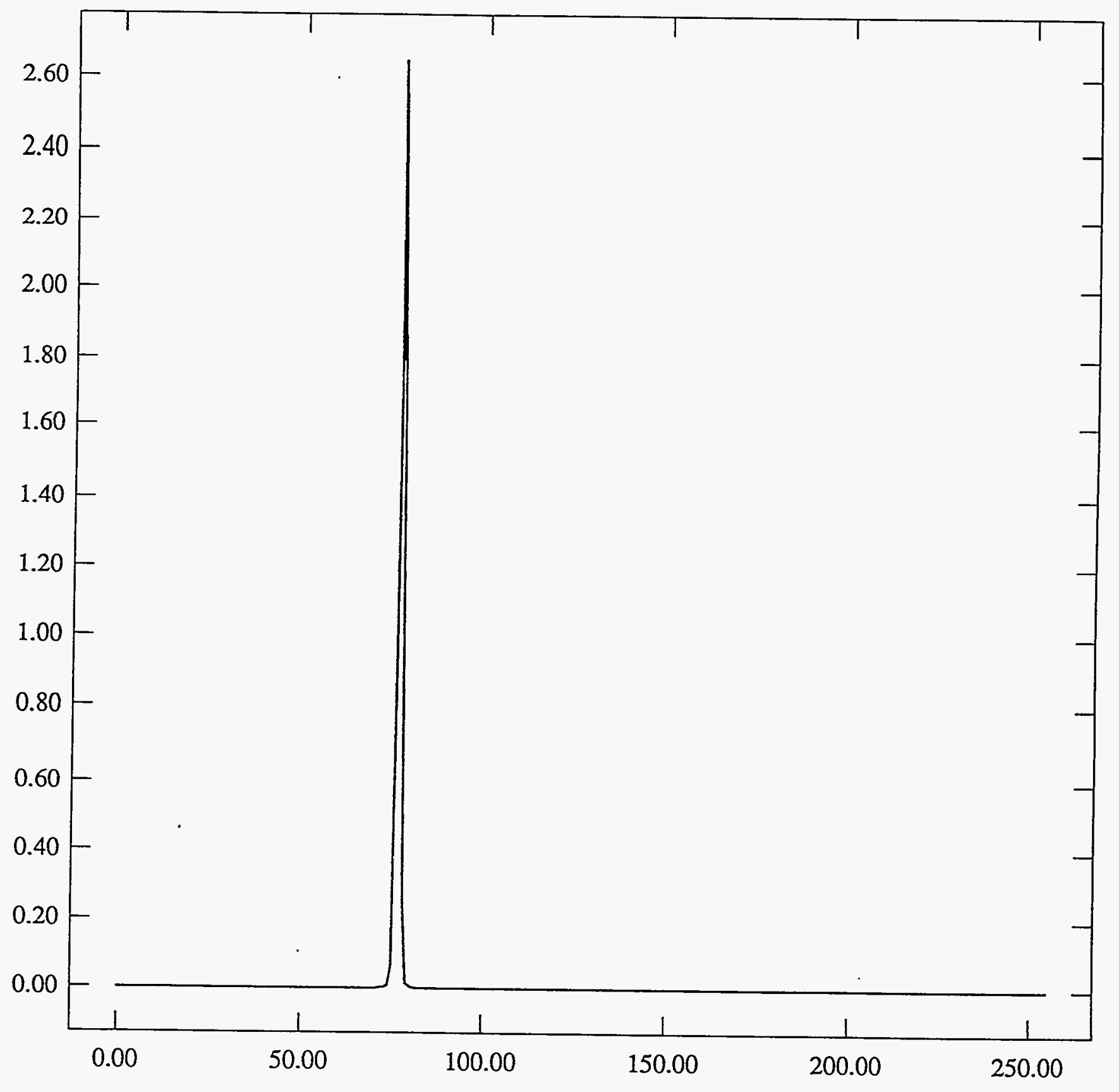


ST Camera: ST2 04-06 -10C: int_time=200ms, offset= 0, gain=2 (150 e/bit) Tue May 11 15:53:29 1993 Pixel Values Min 76 Max 79 Mean 77.3 Sigma 0.51 x $10^{3}$

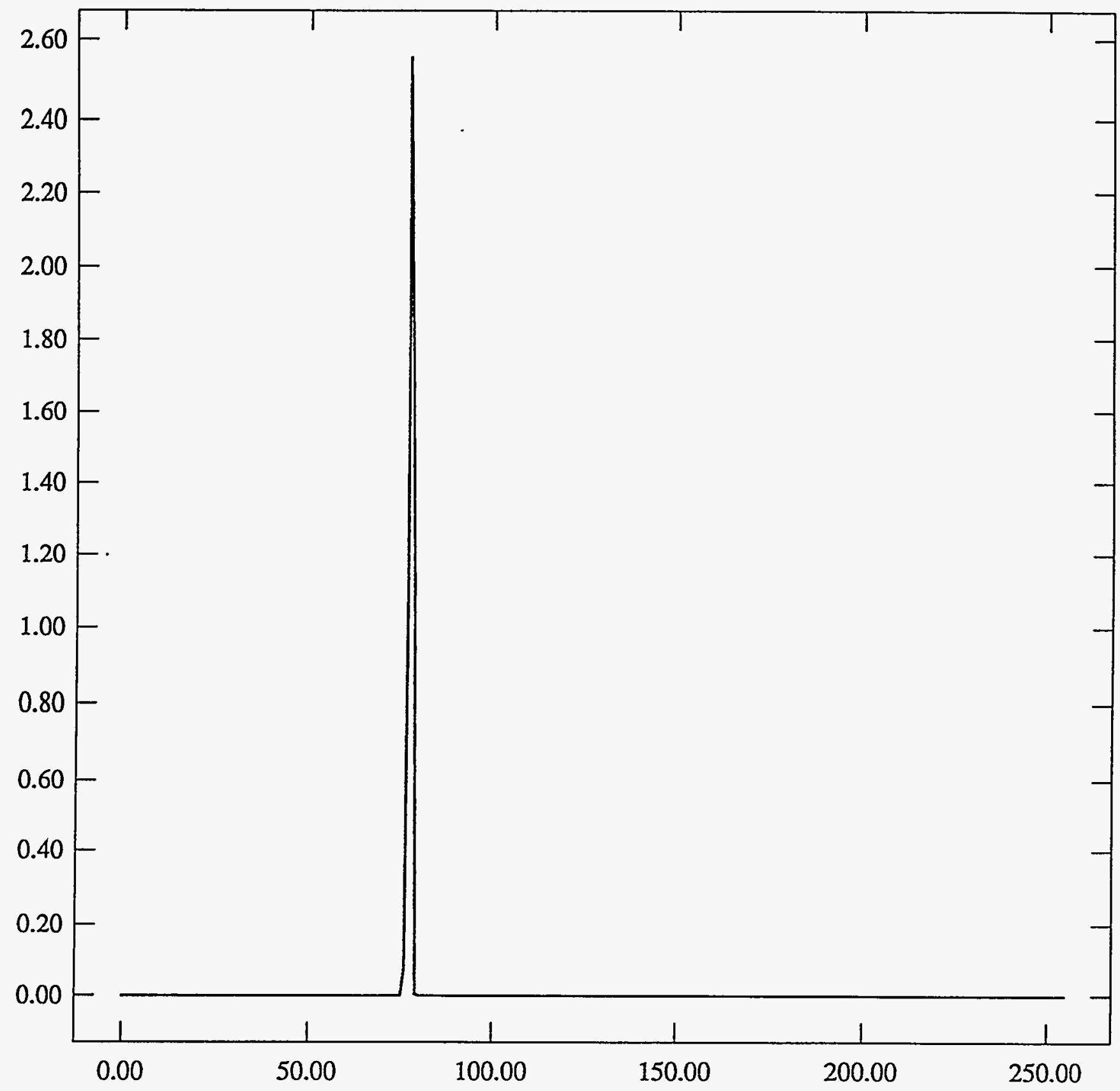


ST Camera: ST2 04-06 0C: int_time= 50ms, offset= 0, gain=2 ( $150 \mathrm{e} / \mathrm{bit}$ ) Tue May 11 16:09:12 1993 Pixel Values Min 77 Max 81 Mean 79.2 Sigma $0.74 \times 10^{3}$

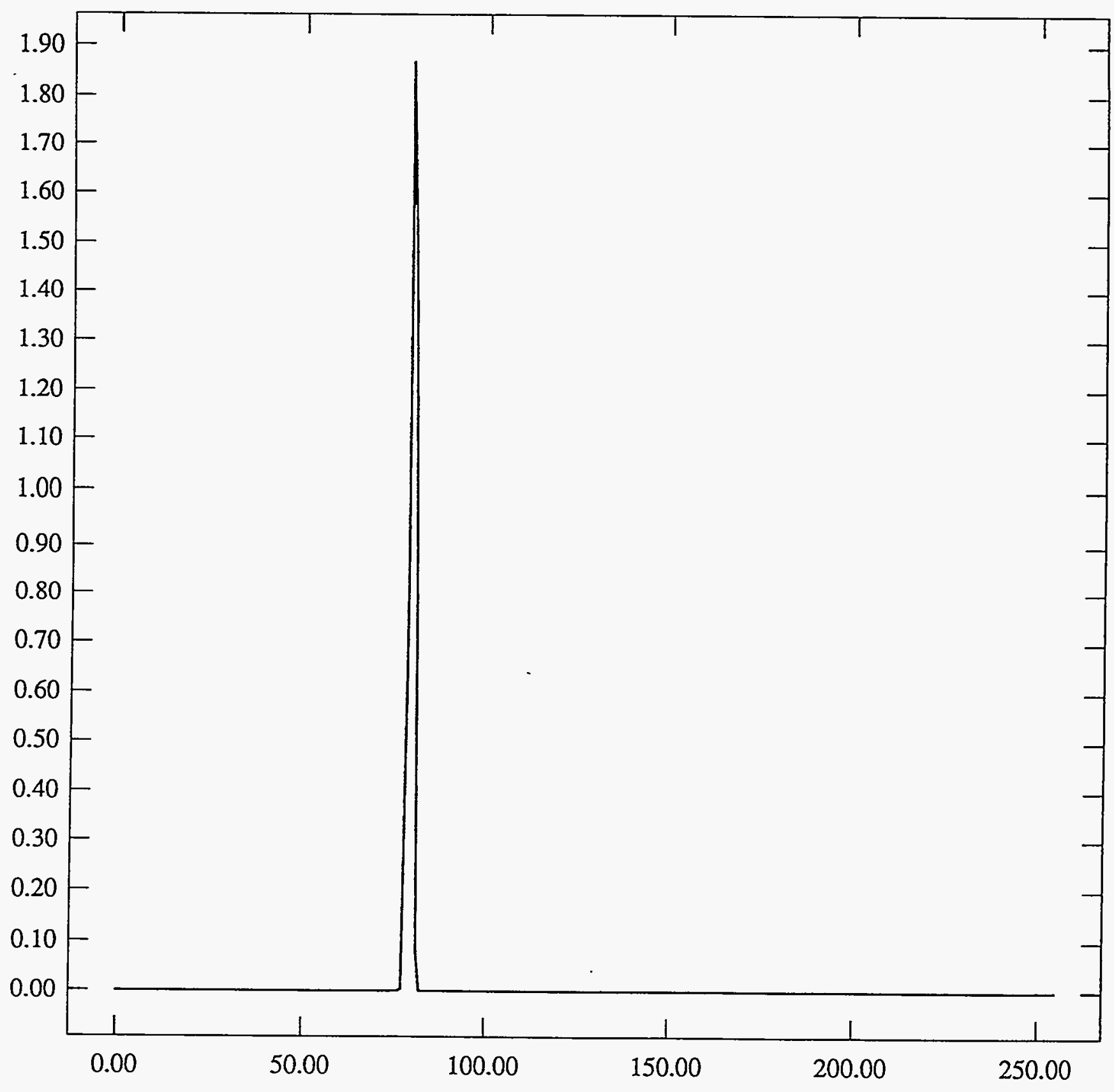


ST Camera: ST2 04-06 0C: int_time=100ms, offset= 0, gain=2 (150 e/bit) Tue May 11 16:09:55 1993 Pixel Values Min 78 Max 82 Mean 80.1 Sigma $0.66 \times 10^{3}$

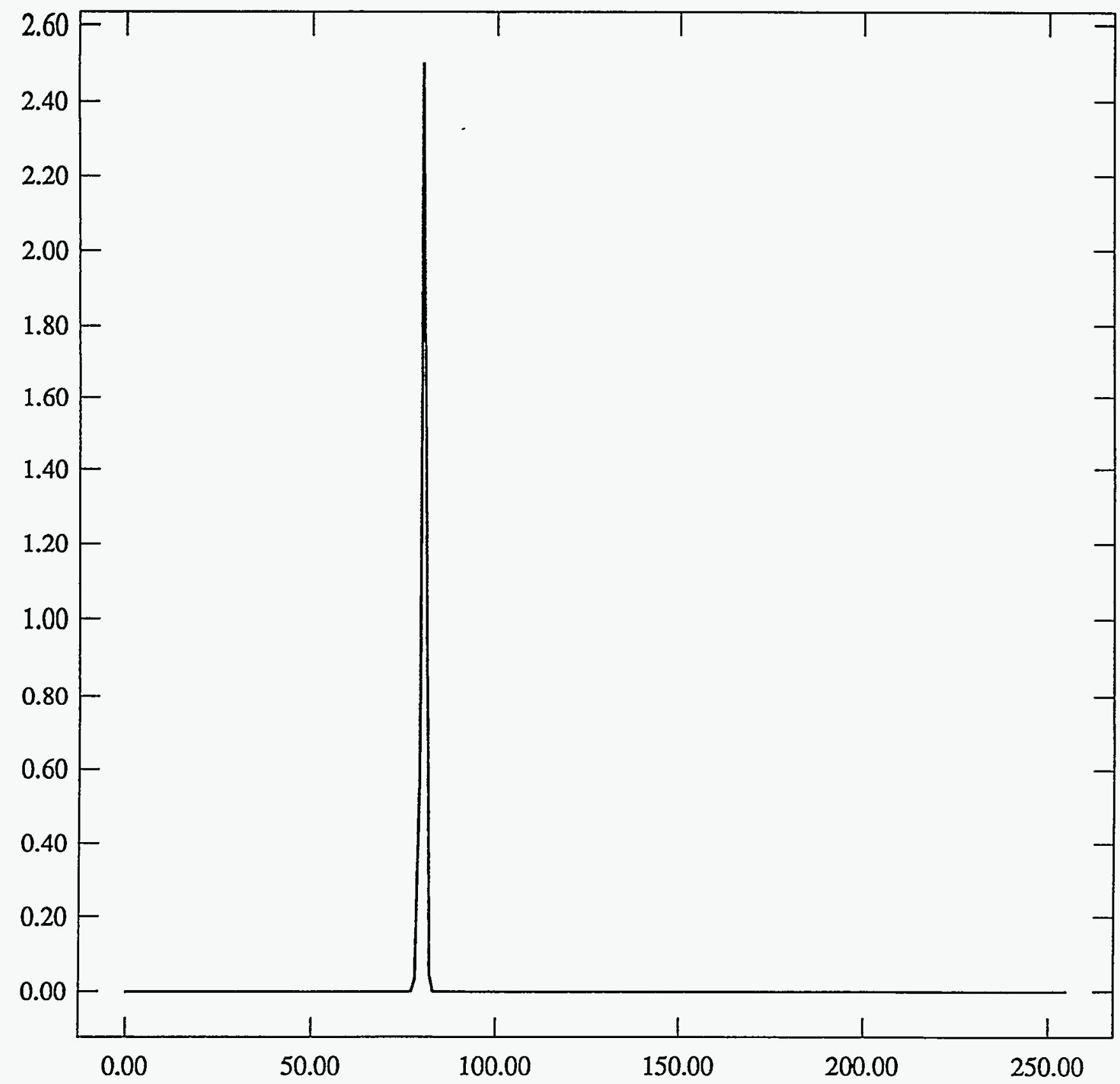


ST Camera: ST2 04-06 0C: int_time=200ms, offset= 0, gain=2 ( $150 \mathrm{e} / \mathrm{bit}$ ) Tue May 11 16:10:26 1993 Pixel Values Min 79 Max 86 Mean 81.7 Sigma $0.58 \times 10^{3}$

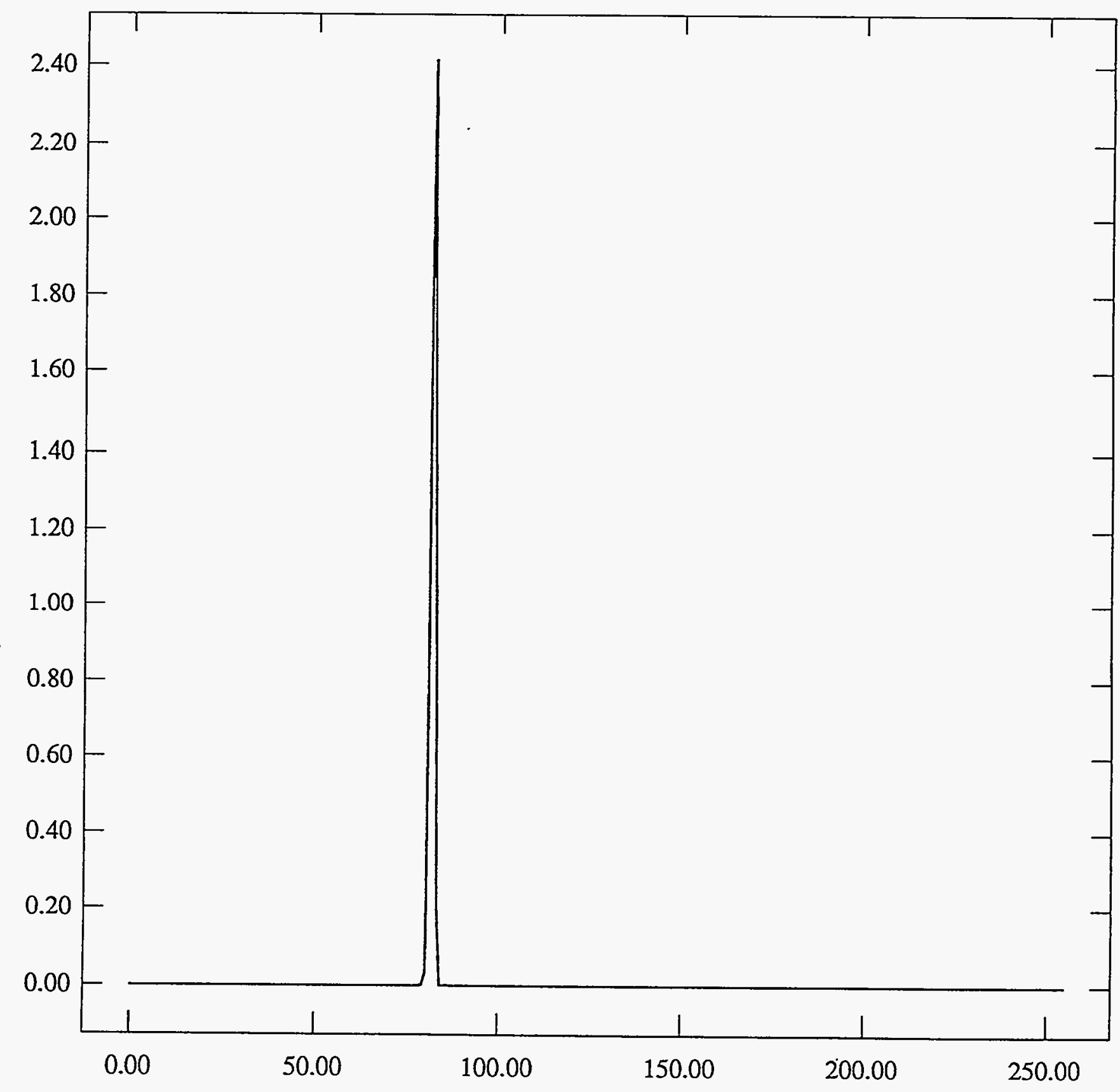


ST Camera: ST2 04-06 +10: int_time $=50 \mathrm{ms,} \mathrm{offset=} \mathrm{0,} \mathrm{gain=2} \mathrm{(150} \mathrm{e/bit)} \mathrm{Tue} \mathrm{May} \mathrm{11} \mathrm{16:26:24} 1993$ Pixel Values Min 82 Max 85 Mean 83.4 Sigma $0.62 \times 10^{3}$

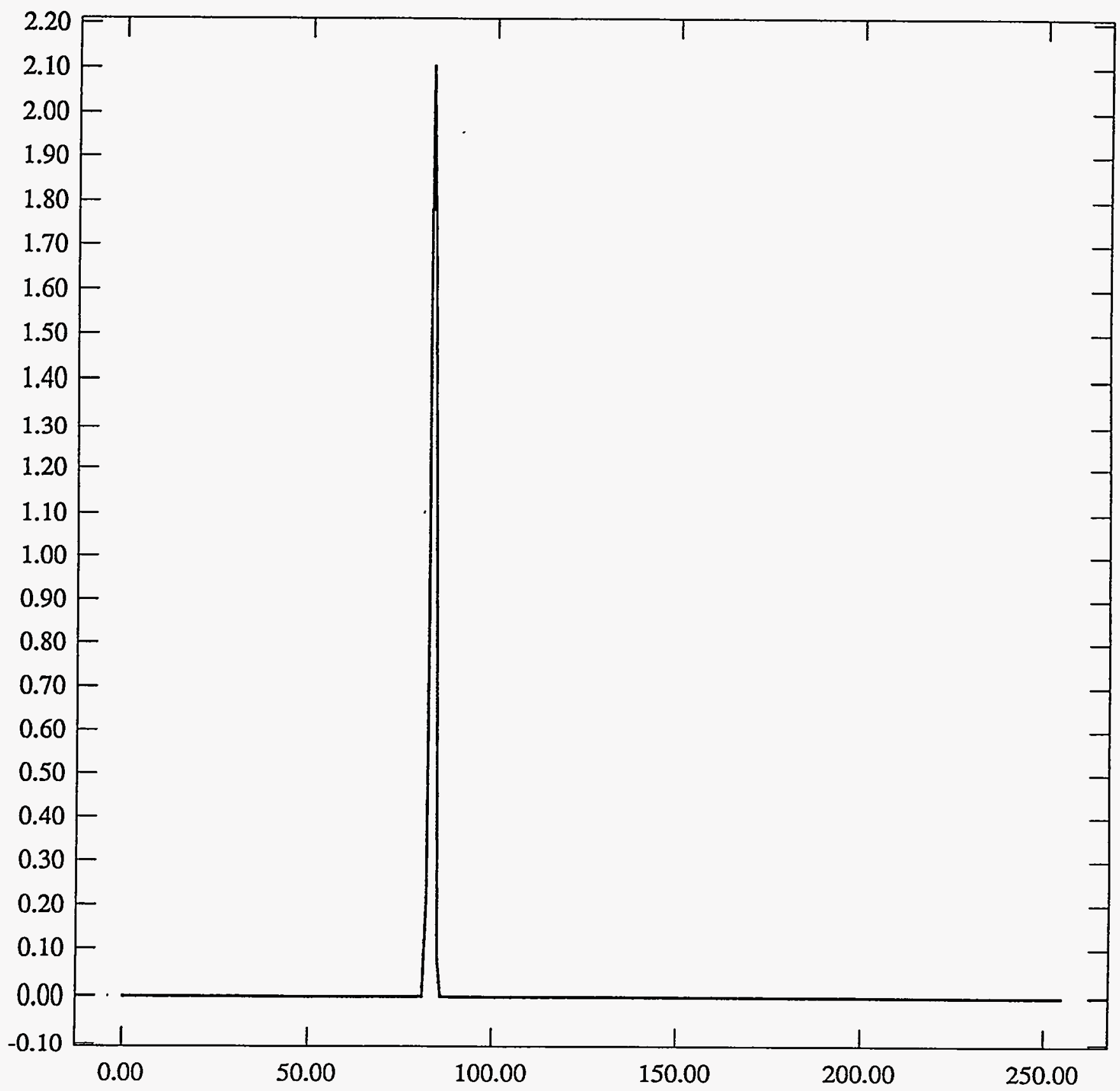


ST Camera: ST2 04-06 +10: int_time=100ms, offset= 0, gain=2 ( 150 e/bit) Tue May 11 16:27:54 1993 Pixel Values Min 83 Max 90 Mean 85.6 Sigma $0.63 \times 10^{3}$

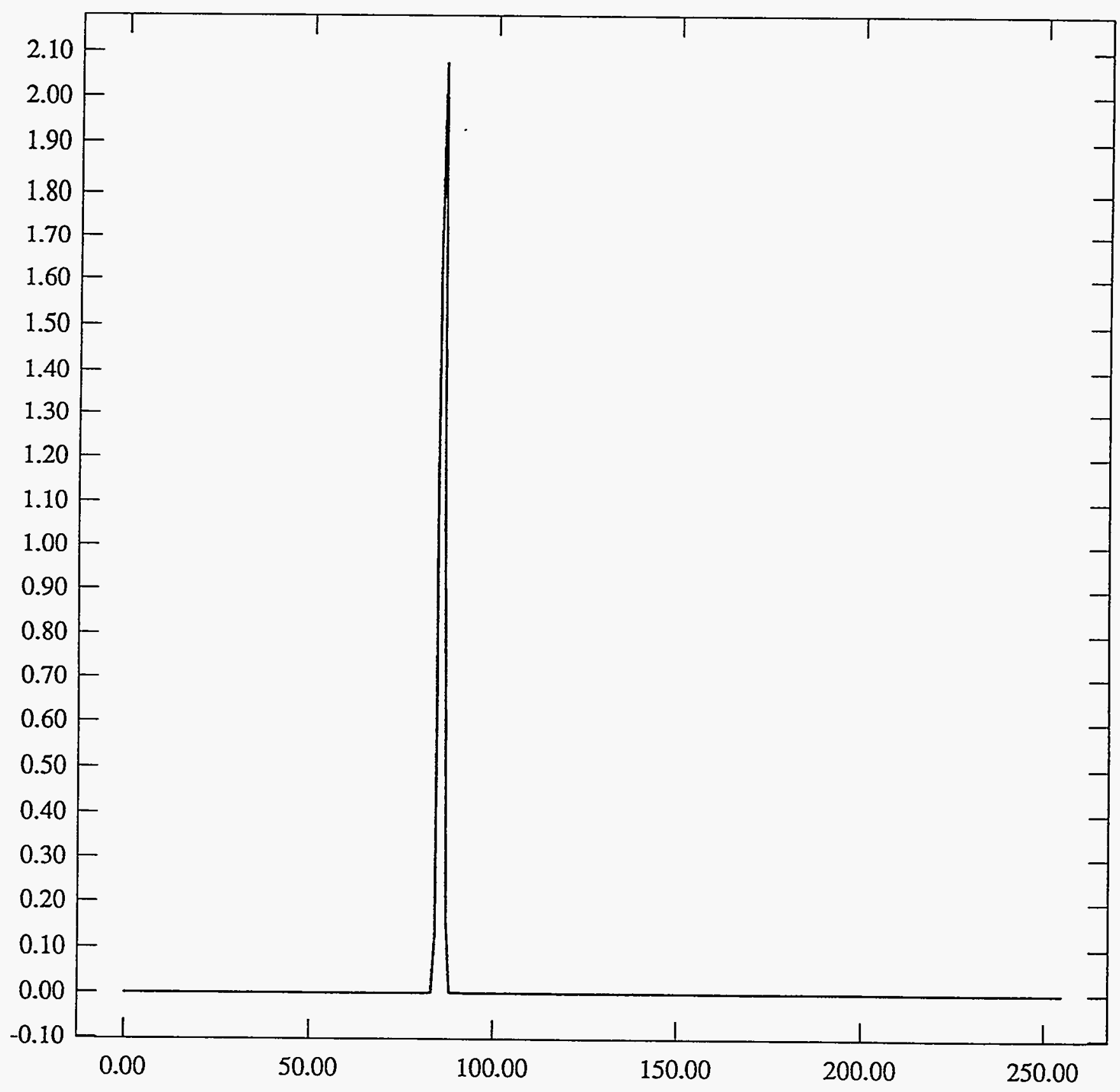


ST Camera: ST2 04-06 +10: int_time=200ms, offset= 0, gain=2 (150 e/bit) Tue May 11 16:28:59 1993 Pixel Values Min 88 Max 98 Mean 89.5 Sigma $0.70 \times 10^{3}$

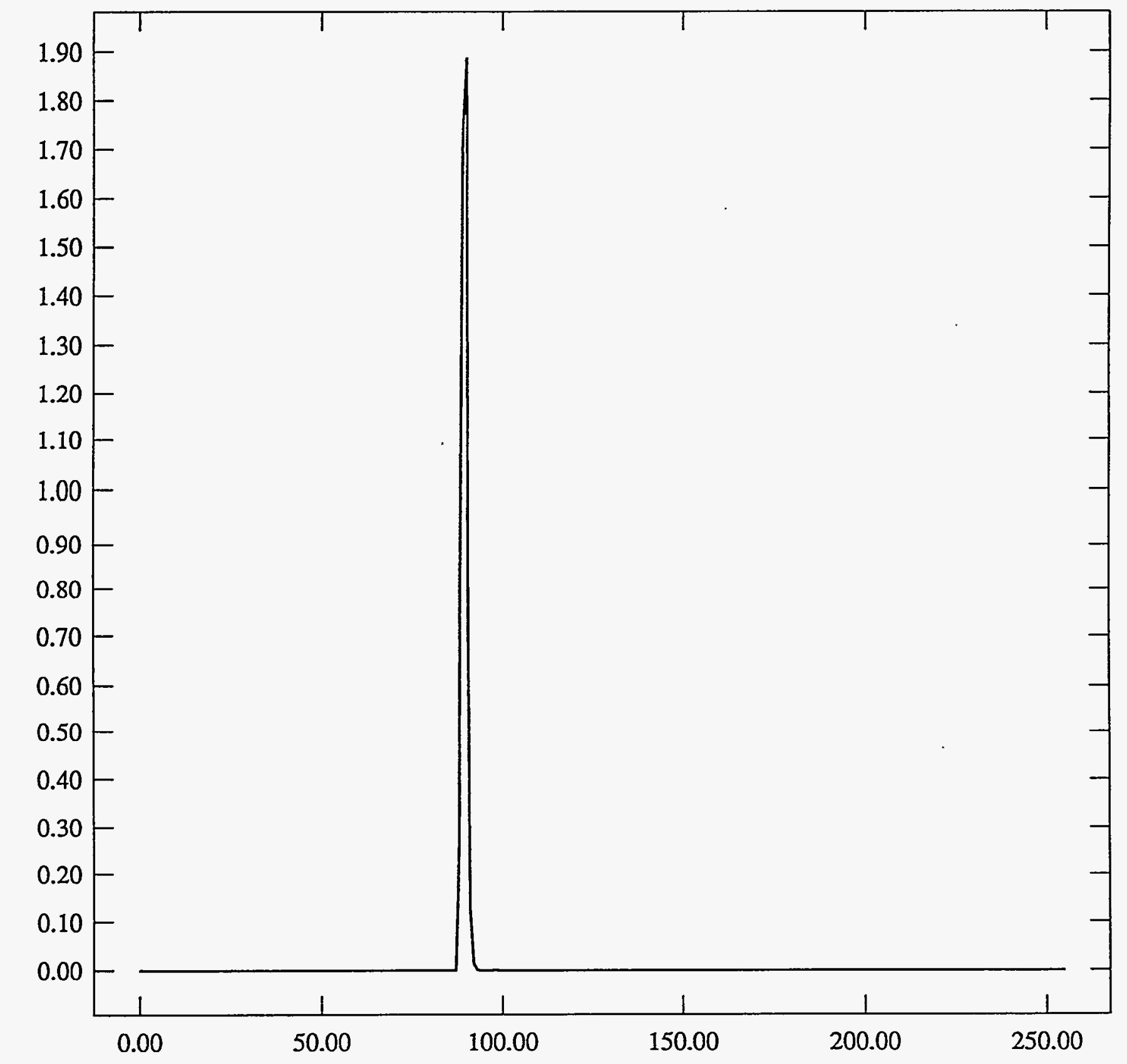


ST Camera: ST2 04-06 +20: int_time $=50 \mathrm{~ms}$, offset= 0, gain=2 (150 e/bit) Tue May 11 16:43:16 1993 Pixel Values Min 88 Max 93 Mean 90.9 Sigma $0.81 \times 10^{3}$

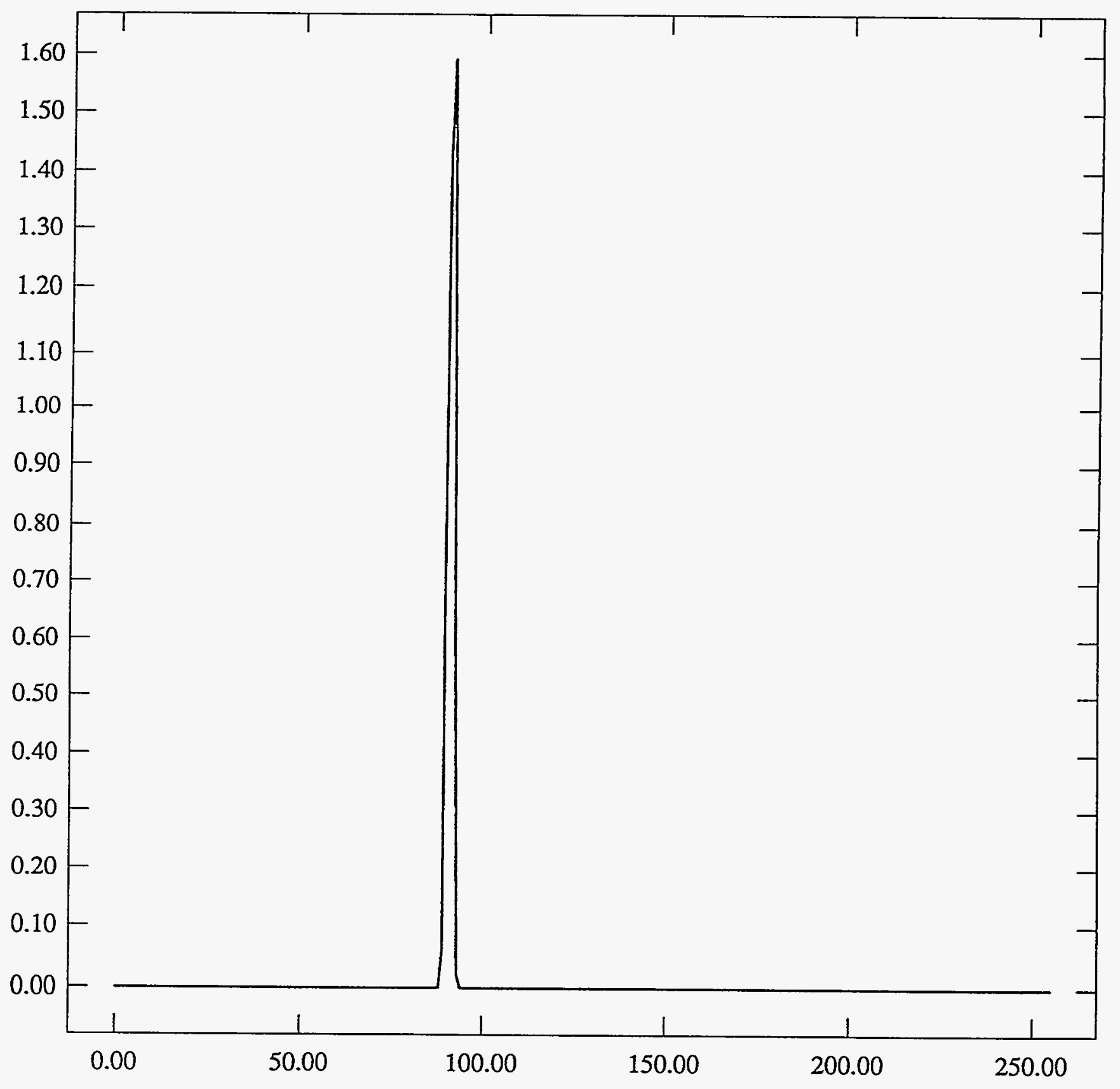


ST Camera: ST2 04-06 +20: int_time=100ms, offset= 0, gain=2 (150 e/bit) Tue May 11 16:43:50 1993 Pixel Values Min 94 Max 103 Mean 96.3 Sigma $0.76 \times 10^{3}$

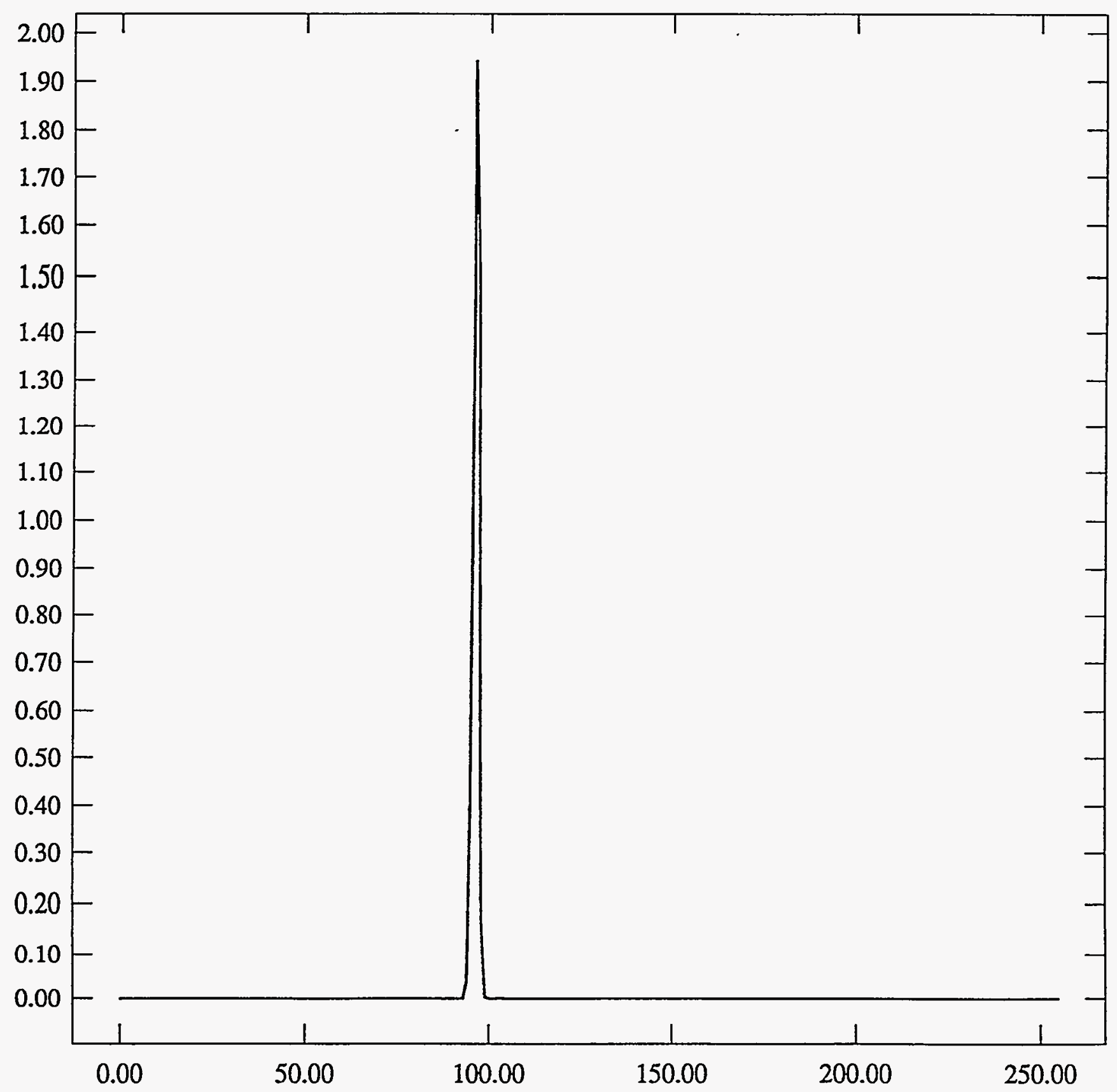


ST Camera: ST2 04-06 +20: int_time=200ms, offset= 0, gain=2 (150 e/bit) Tue May 11 16:44:24 1993 Pixel Values Min 103 Max 122 Mean 106.8 Sigma $1.11 \times 10^{3}$

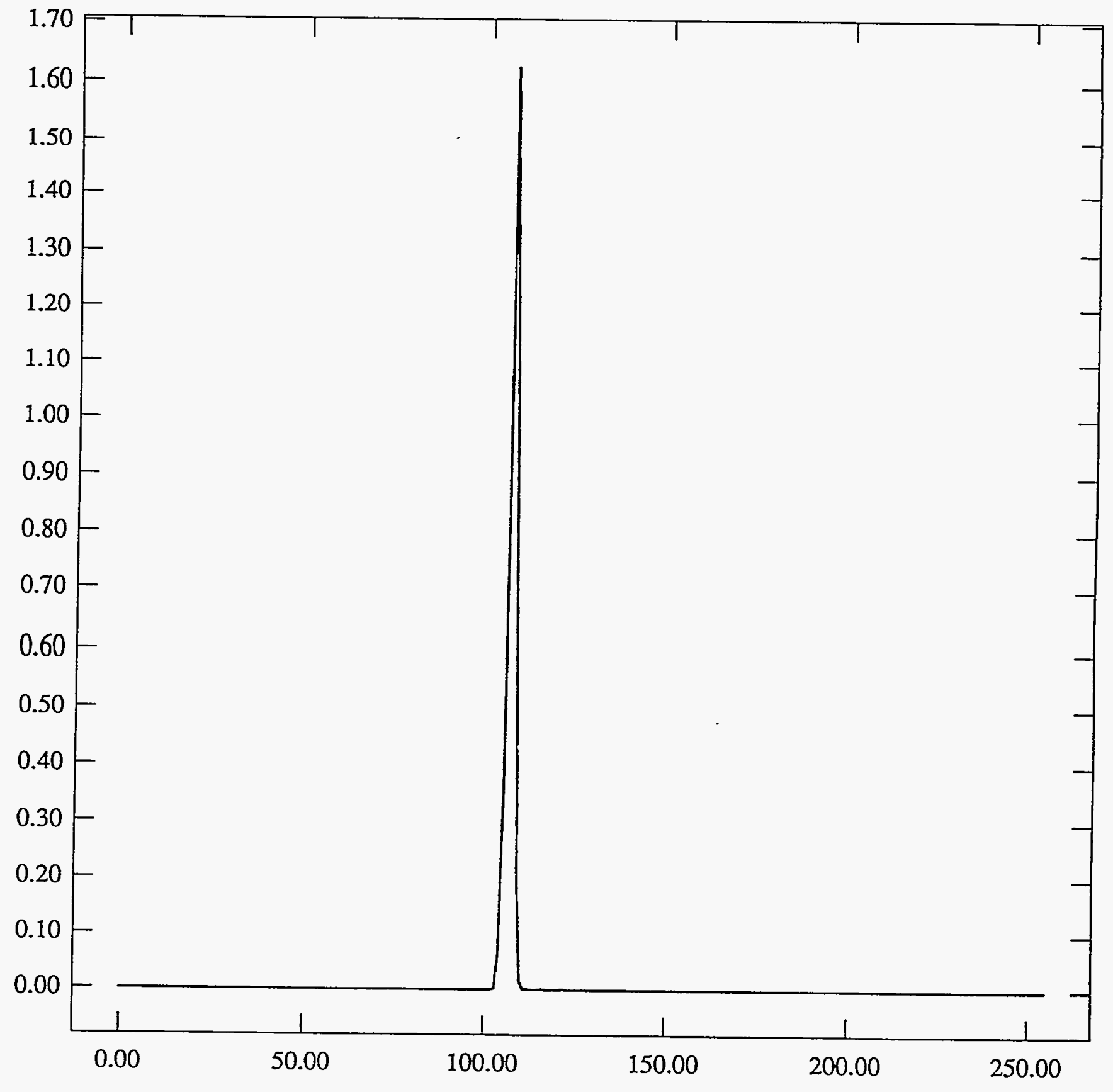


ST Camera: ST2 04-06 +30: int_time $=50 \mathrm{~ms}$, offset= 0, gain=2 (150 e/bit) Tue May 11 17:02:41 1993 Pixel Values Min 99 Max 112 Mean 104.0 Sigma $0.91 \times 10^{3}$

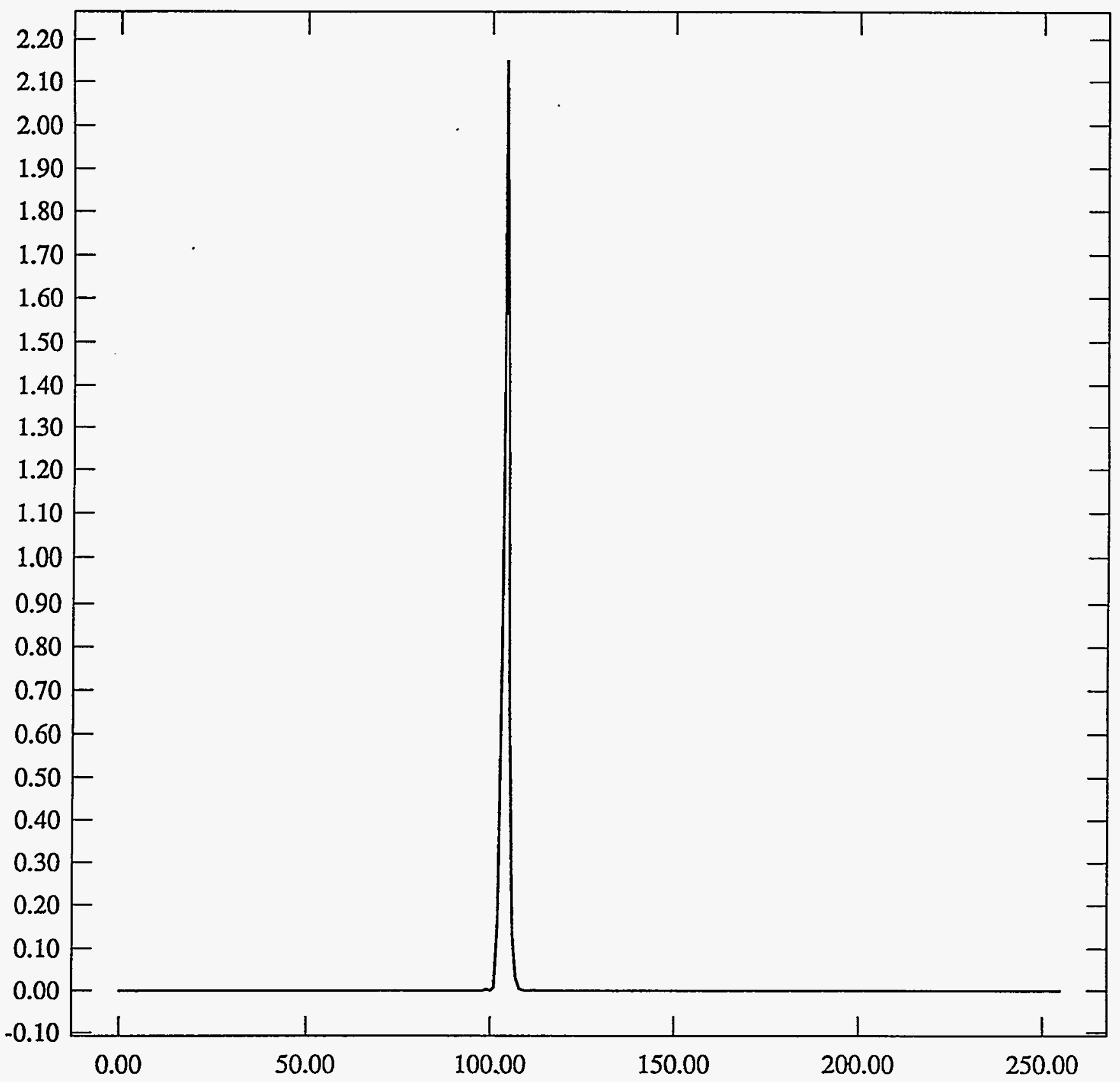


ST Camera: ST2 04-06 +30: int_time=100ms, offset= 0, gain=2 ( $150 \mathrm{e} / \mathrm{bit})$ Tue May 11 17:03:23 1993 Pixel Values Min 112 Max 132 Mean 115.6 Sigma $1.10 \times 10^{3}$

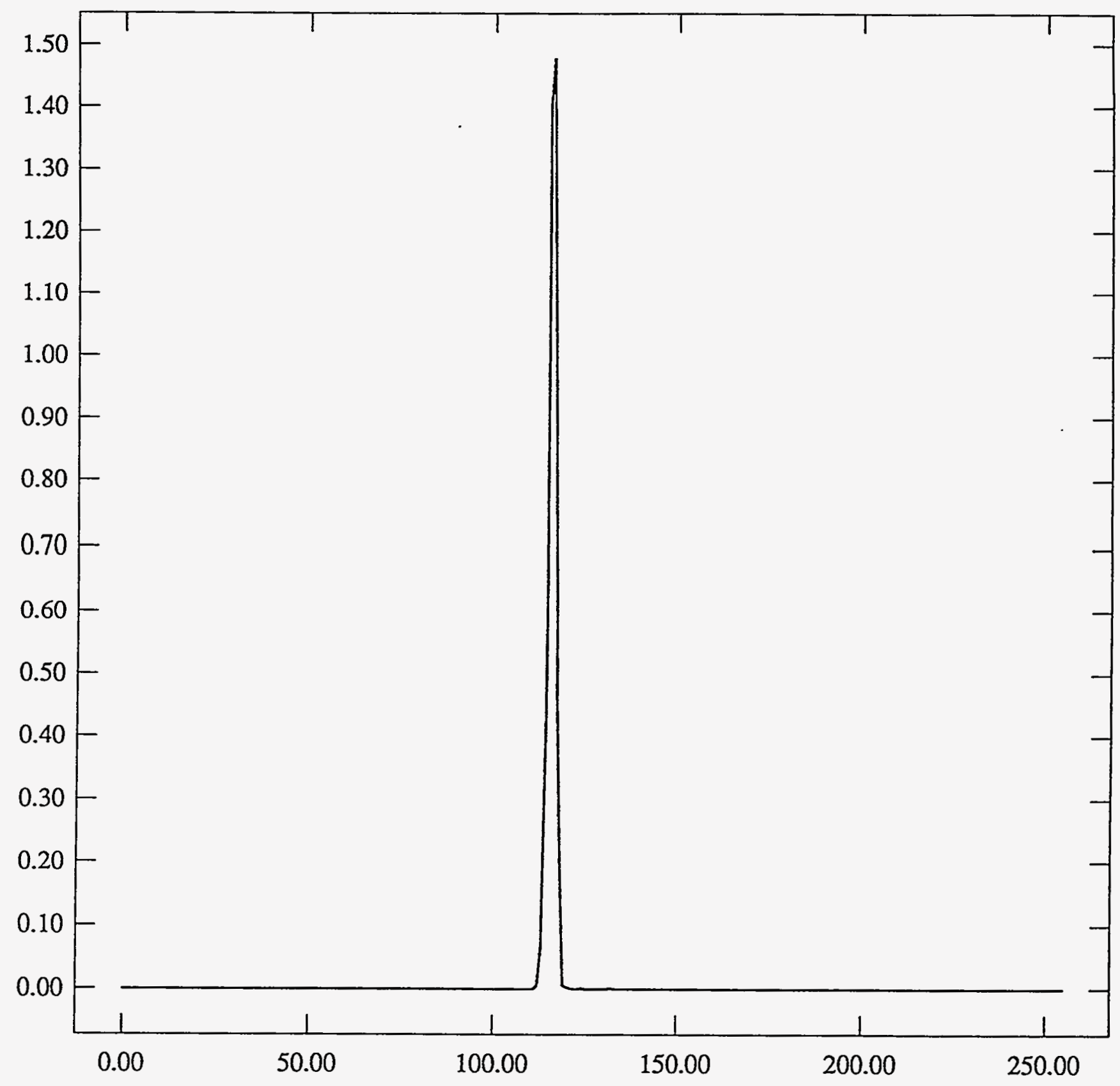


ST Camera: ST2 04-06 +30: int_time $=200 \mathrm{ms,} \mathrm{offset=} \mathrm{0,} \mathrm{gain=2} \mathrm{(150} \mathrm{e/bit)} \mathrm{Tue} \mathrm{May} \mathrm{11} \mathrm{17:04:31} 1993$ Pixel Values Min 132 Max 172 Mean 139.3 Sigma $2.33 \times 10^{3}$

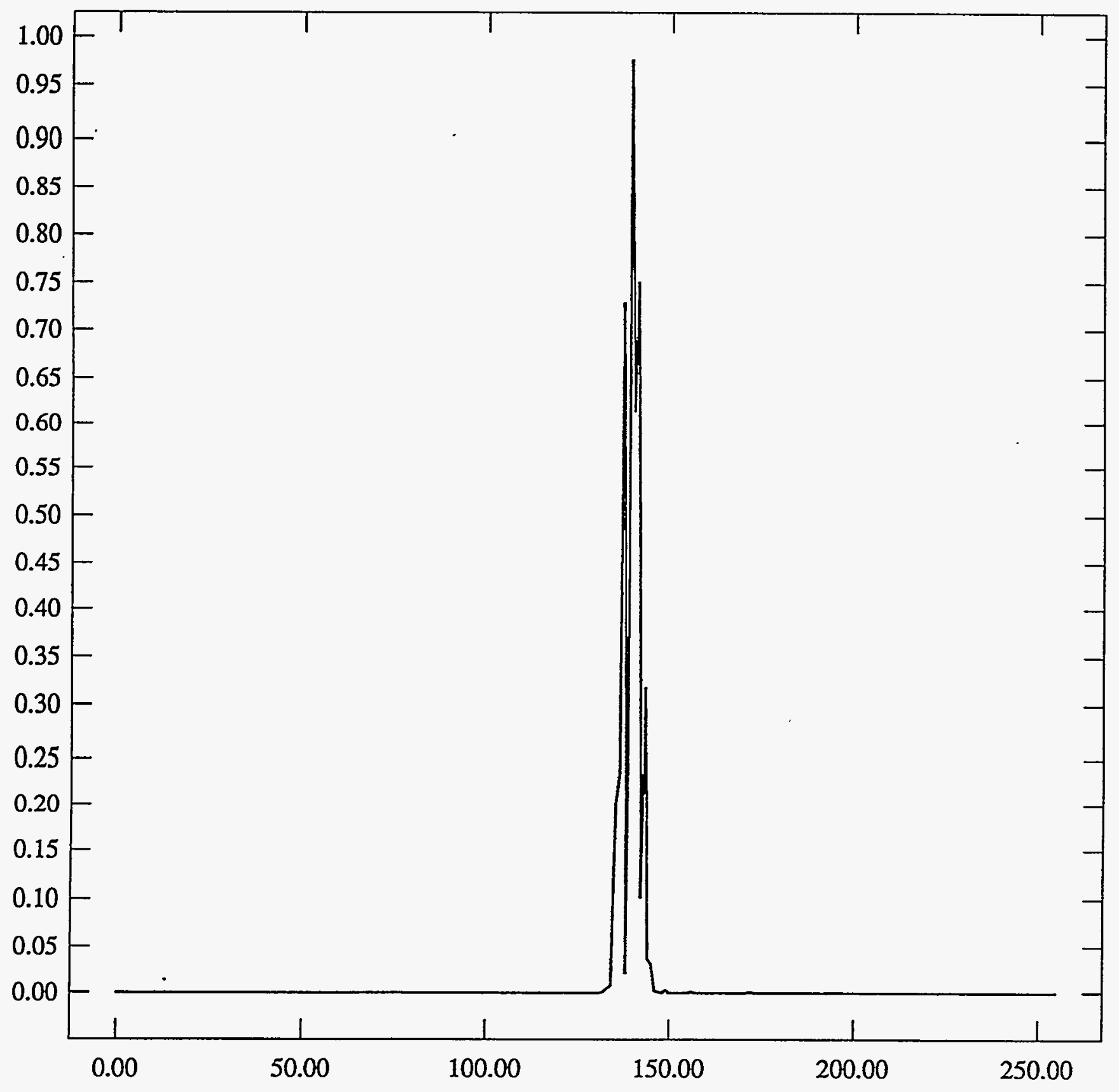


ST2\#04-06 150e/bit Mu ${ }^{\circ} \mathrm{C}$ Graph

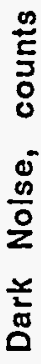
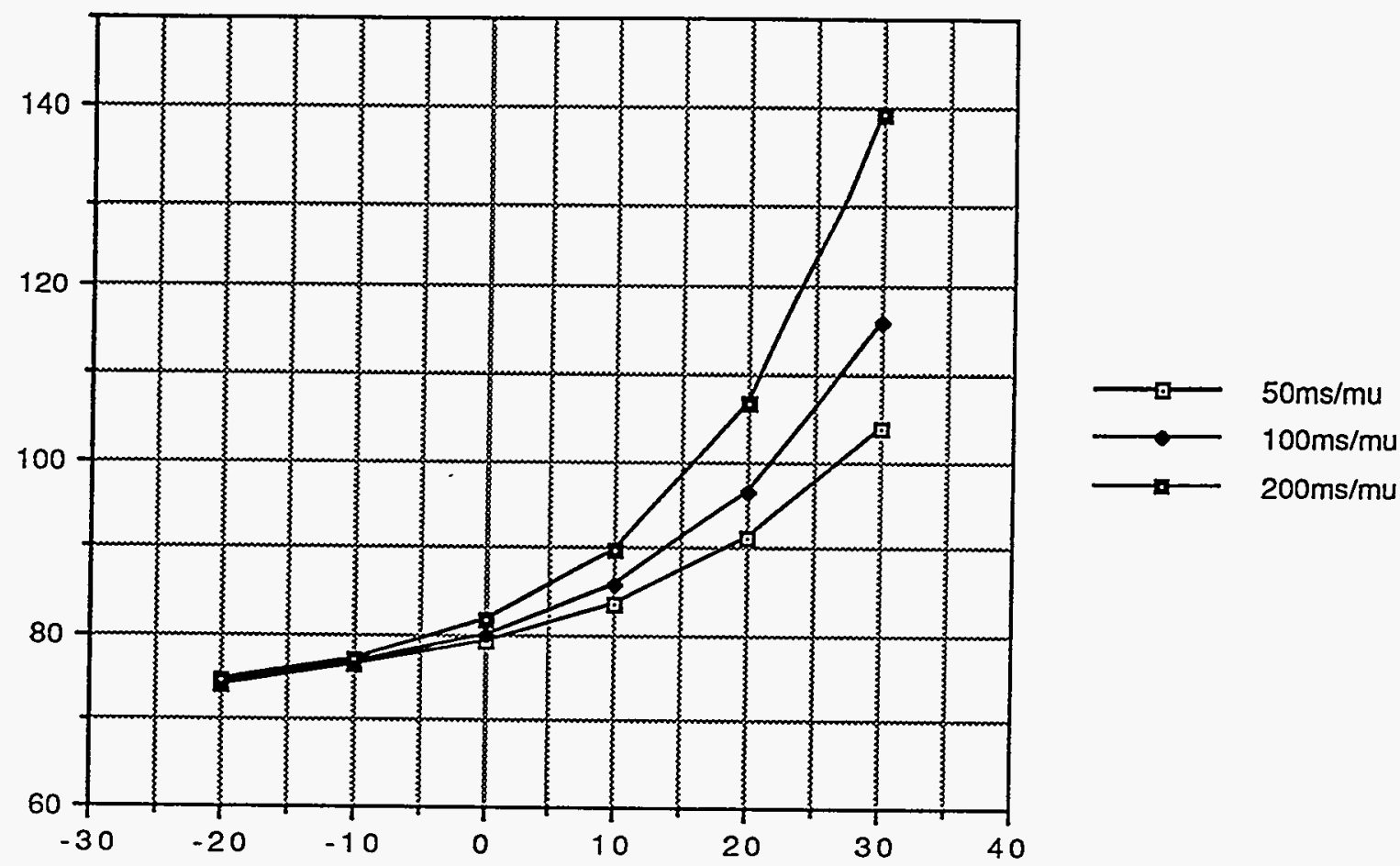

TEMP (degrees C)

ST2\#04-06 150e/bit Sigma ${ }^{\circ} \mathrm{C}$ Graph

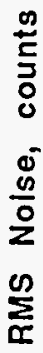

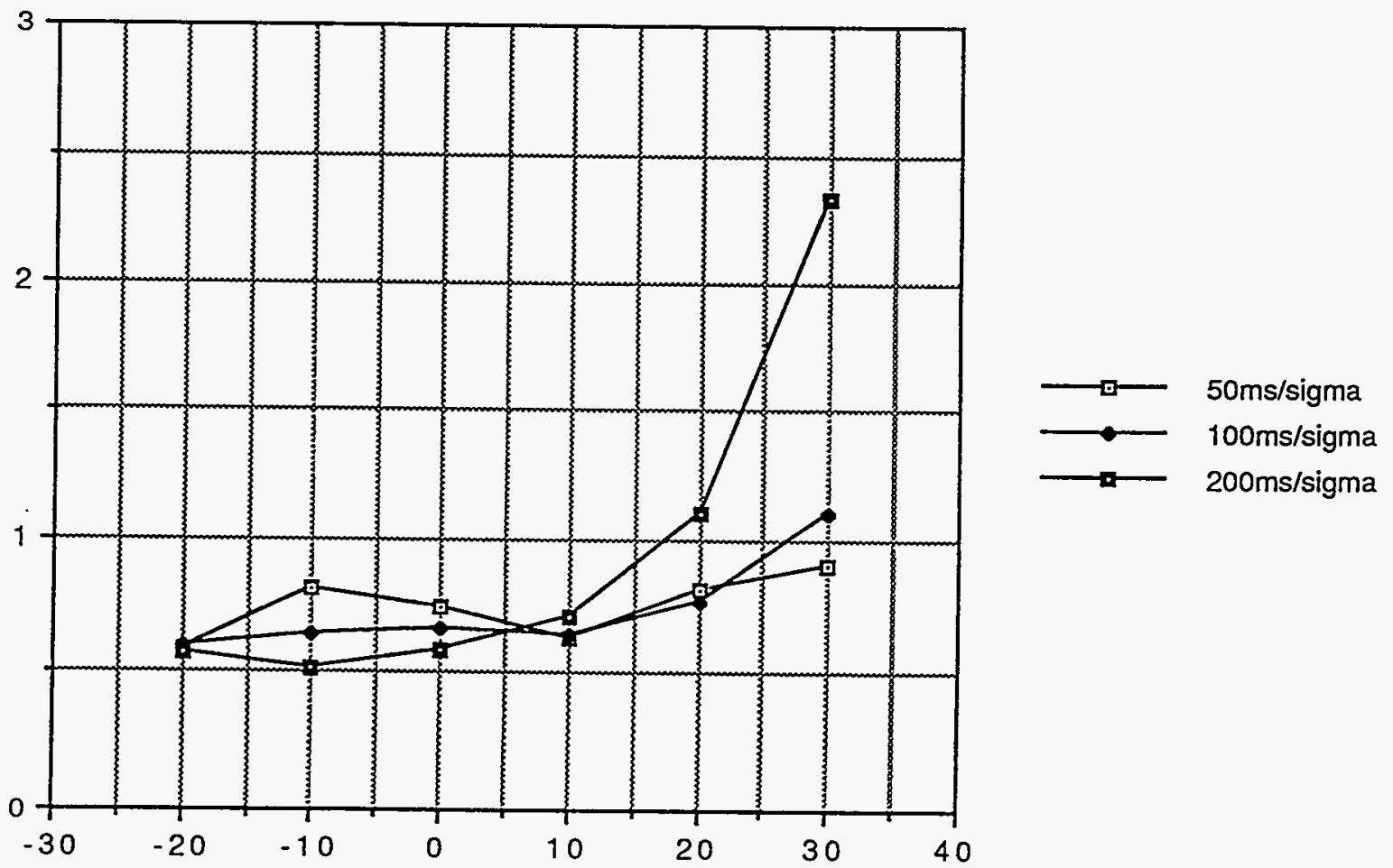

TEMP (degrees C) 
TEMP (degrees C) $50 \mathrm{~ms} / \mathrm{mu} 50 \mathrm{~ms} / \mathrm{sigma} 100 \mathrm{~ms} / \mathrm{mu} \quad 100 \mathrm{~ms} / \mathrm{sigma} 200 \mathrm{~ms} / \mathrm{mu} \quad 200 \mathrm{~ms} / \mathrm{sigma}$

$\begin{array}{ccccc}.20 & 147.40 & 0.72 & 147.70 & 0.76 \\ .10 & 151.70 & 0.85 & 152.20 & 0.86 \\ 0 & 156.70 & 0.78 & 158.30 & 0.93 \\ 10 & 164.80 & 1.17 & 168.50 & 1.06 \\ 20 & 179.30 & 0.90 & 188.70 & 1.33 \\ 30 & 203.10 & 1.49 & 226.10 & 2.14\end{array}$

148.10

153.30

161.30

176.60

209.40
NOTES:

$5 / 11 / 93$

Flight F.0. CCD\#2

$75 \mathrm{e} / \mathrm{bit}$

$R 49=100 \Omega$ 
ST Camera: ST2 04-06 -20C: int_time= 50ms, offset= 0, gain=4 ( 75 e/bit) Tue May 11 15:39:41 1993 Pixel Values Min 145 Max 150 Mean 147.4 Sigma $0.72 \times 10^{3}$

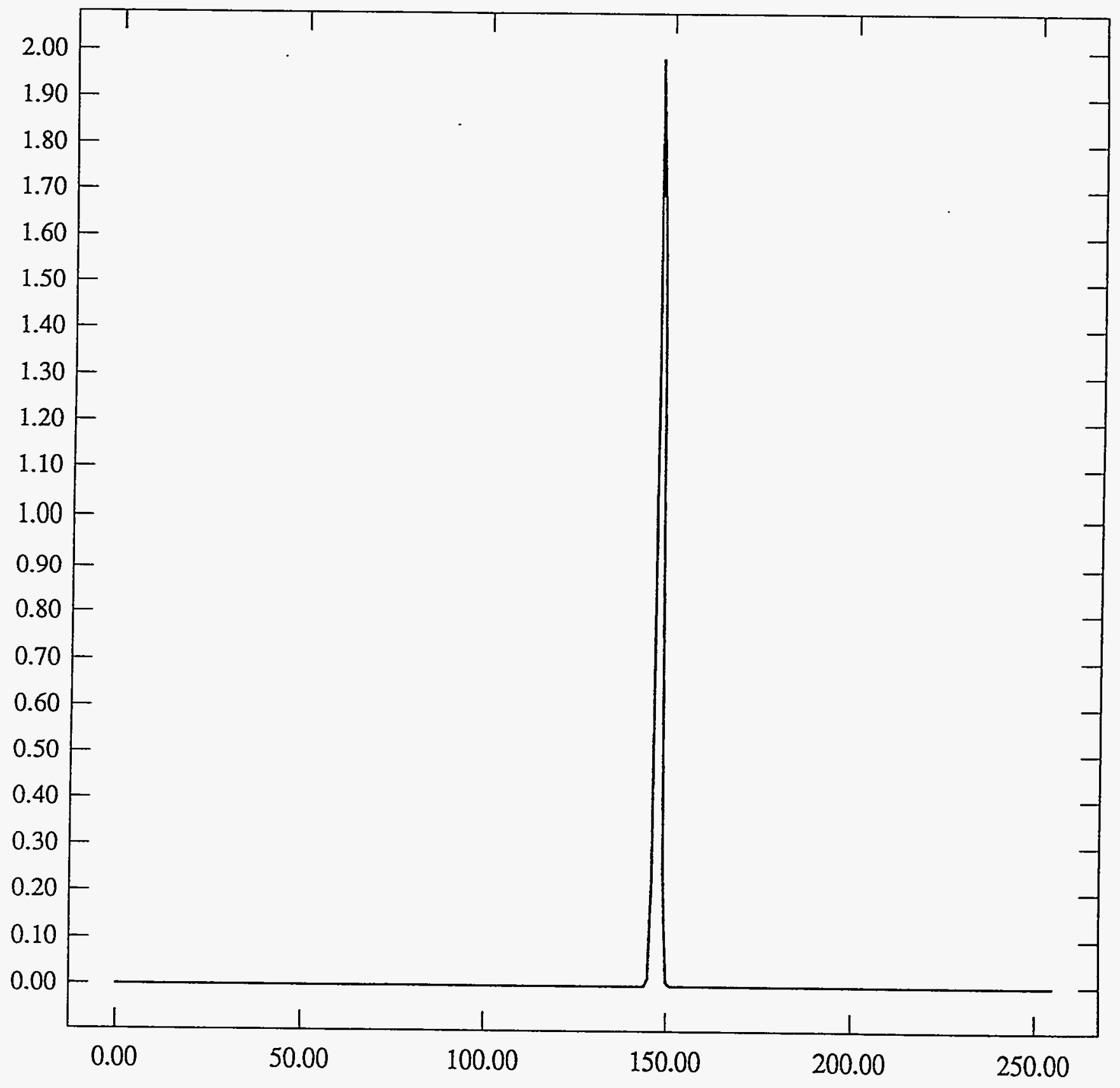


ST Camera: ST2 04-06 -20C: int_time=100ms, offset= 0, gain=4 ( 75 e/bit) Tue May 11 15:40:19 1993 Pixel Values Min 145 Max 151 Mean 147.7 Sigma $0.76 \times 10^{3}$

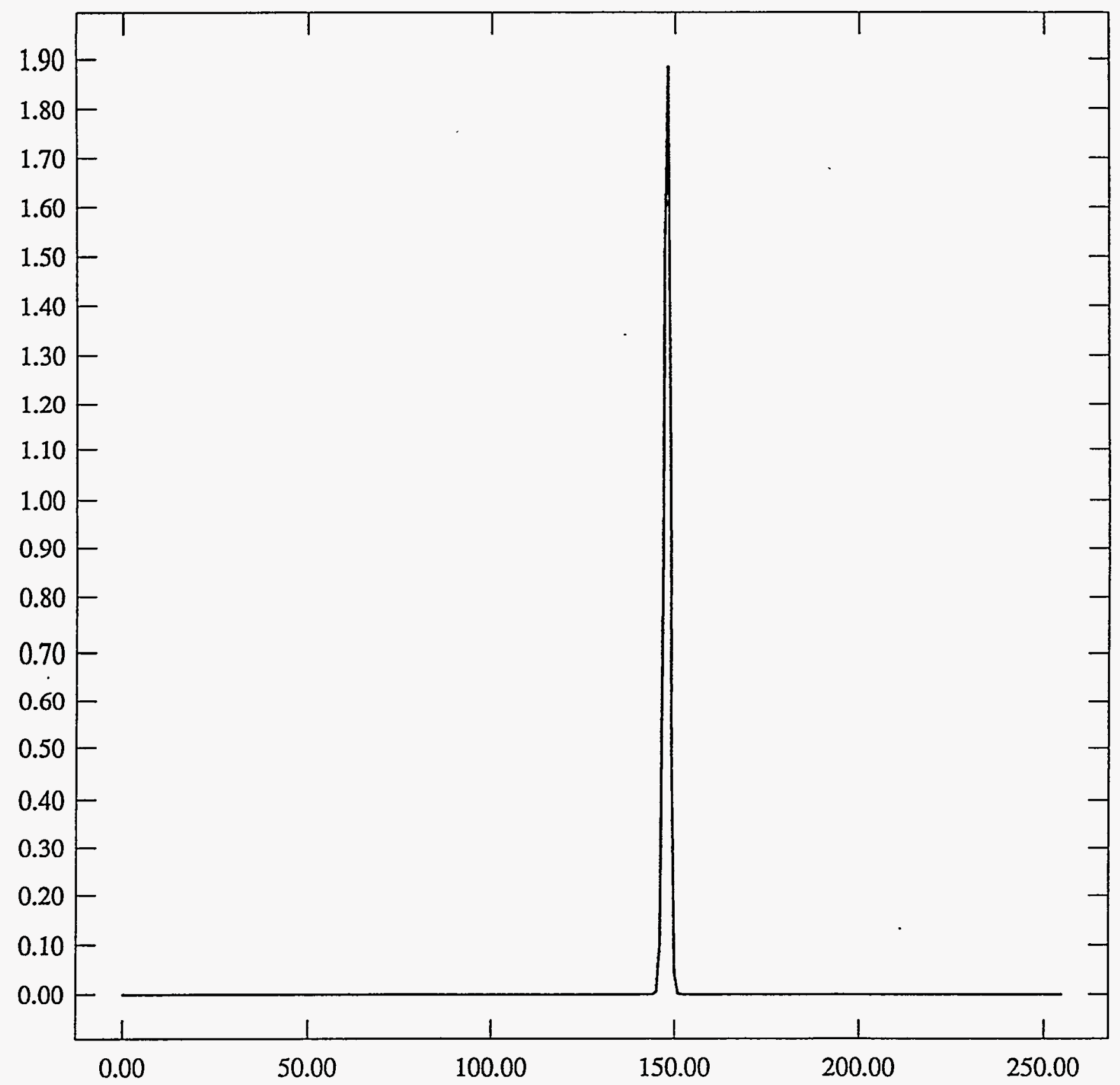


ST Camera: ST2 04-06 -20C: int time=200ms, offset= 0, gain=4 ( $75 \mathrm{e} / \mathrm{bit}$ ) Tue May 11 15:40:55 1993 Pixel Values Min 146 Max 151 Mean 148.1 Sigma $0.81 \times 10^{3}$

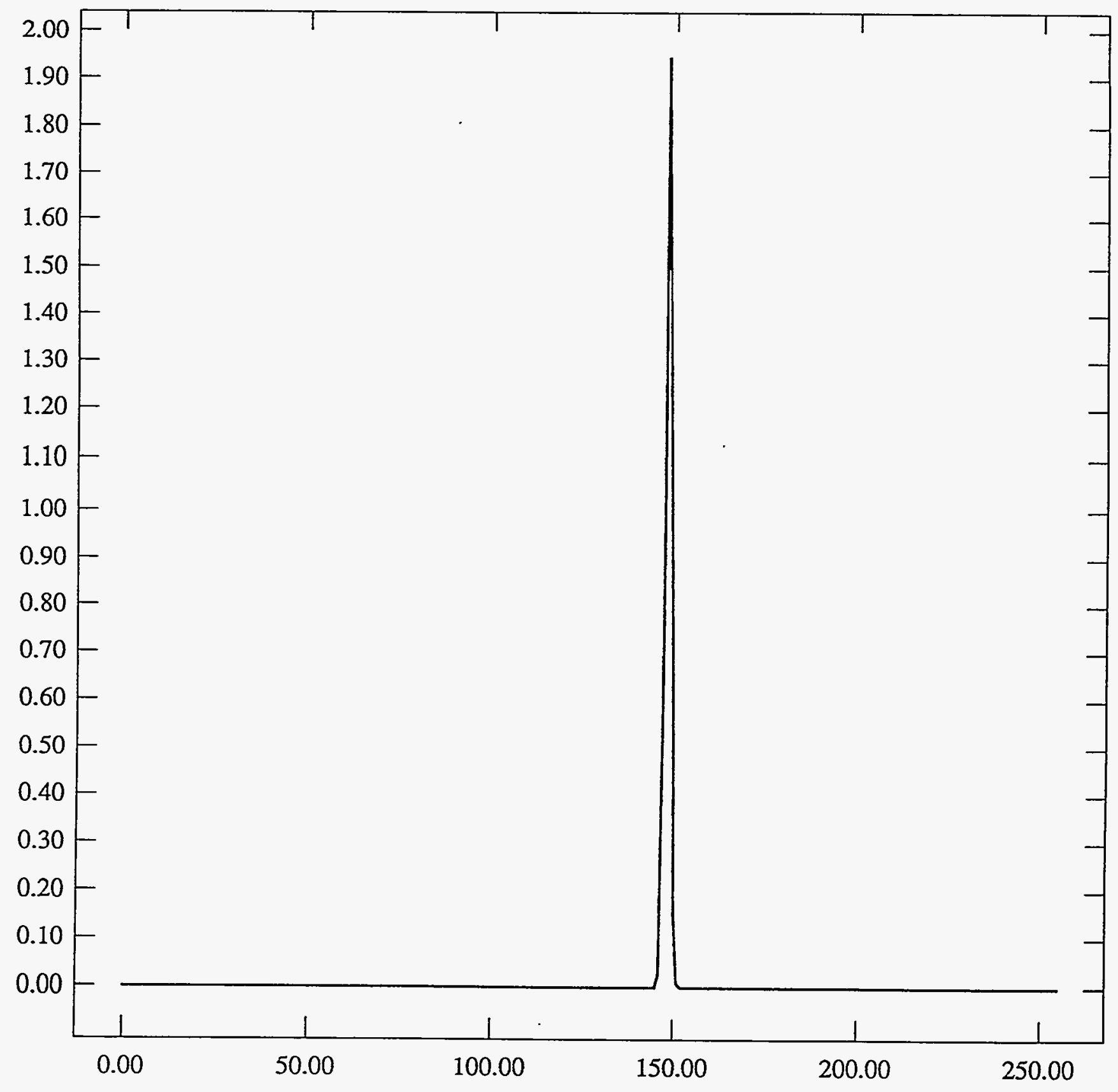


ST Camera: ST2 04-06 -10C: int_time= 50ms, offset= 0, gain=4 ( 75 e/bit) Tue May 11 15:54:04 1993 Pixel Values Min 149 Max 155 Mean 151.7 Sigma $0.85 \times 10^{3}$

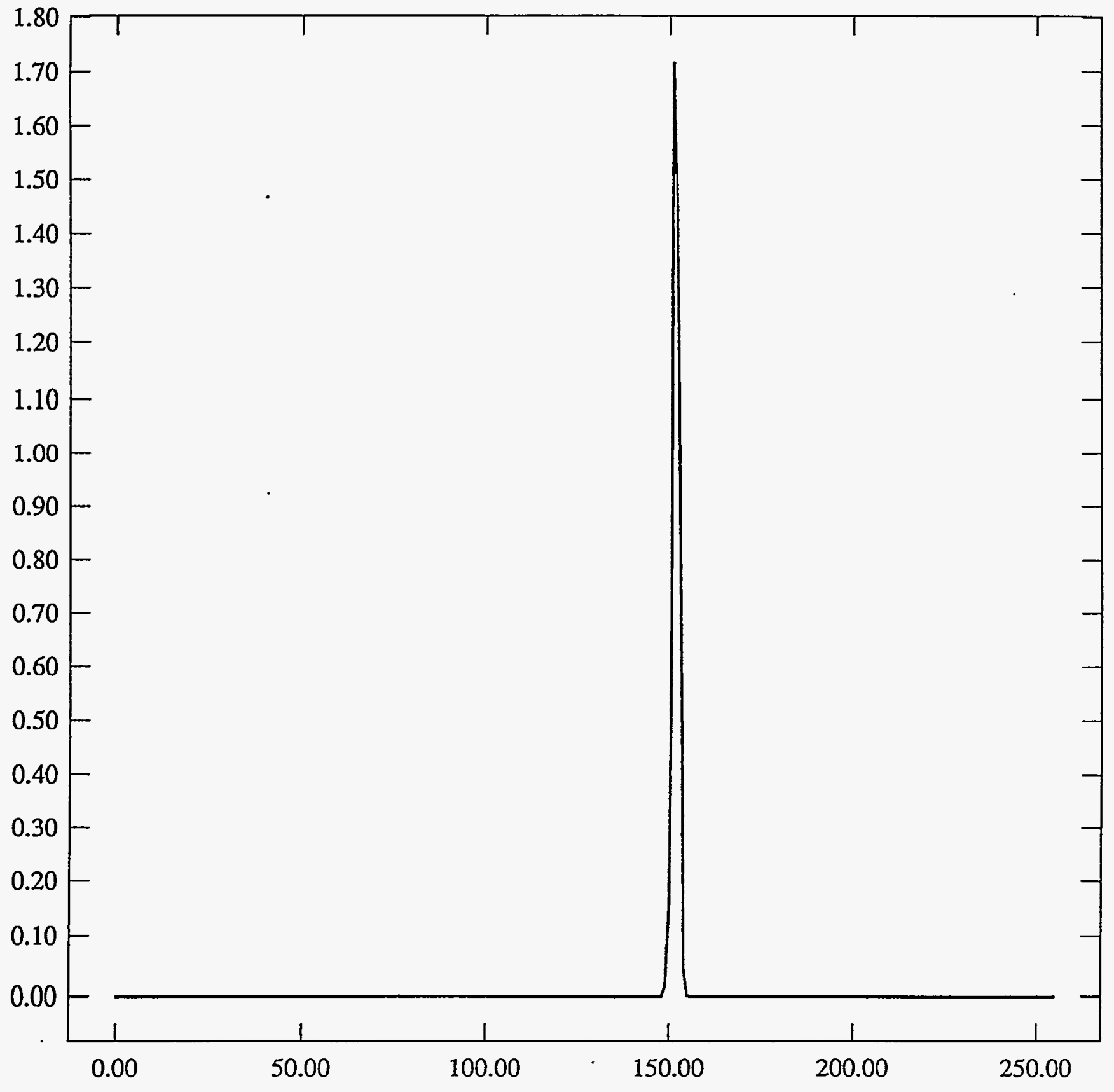


ST Camera: ST2 04-06 -10C: int_time=100ms, offset= 0, gain=4 ( 75 e/bit) Tue May 11 15:54:39 1993 Pixel Values Min 149 Max 155 Mean 152.2 Sigma $0.86 \times 10^{3}$

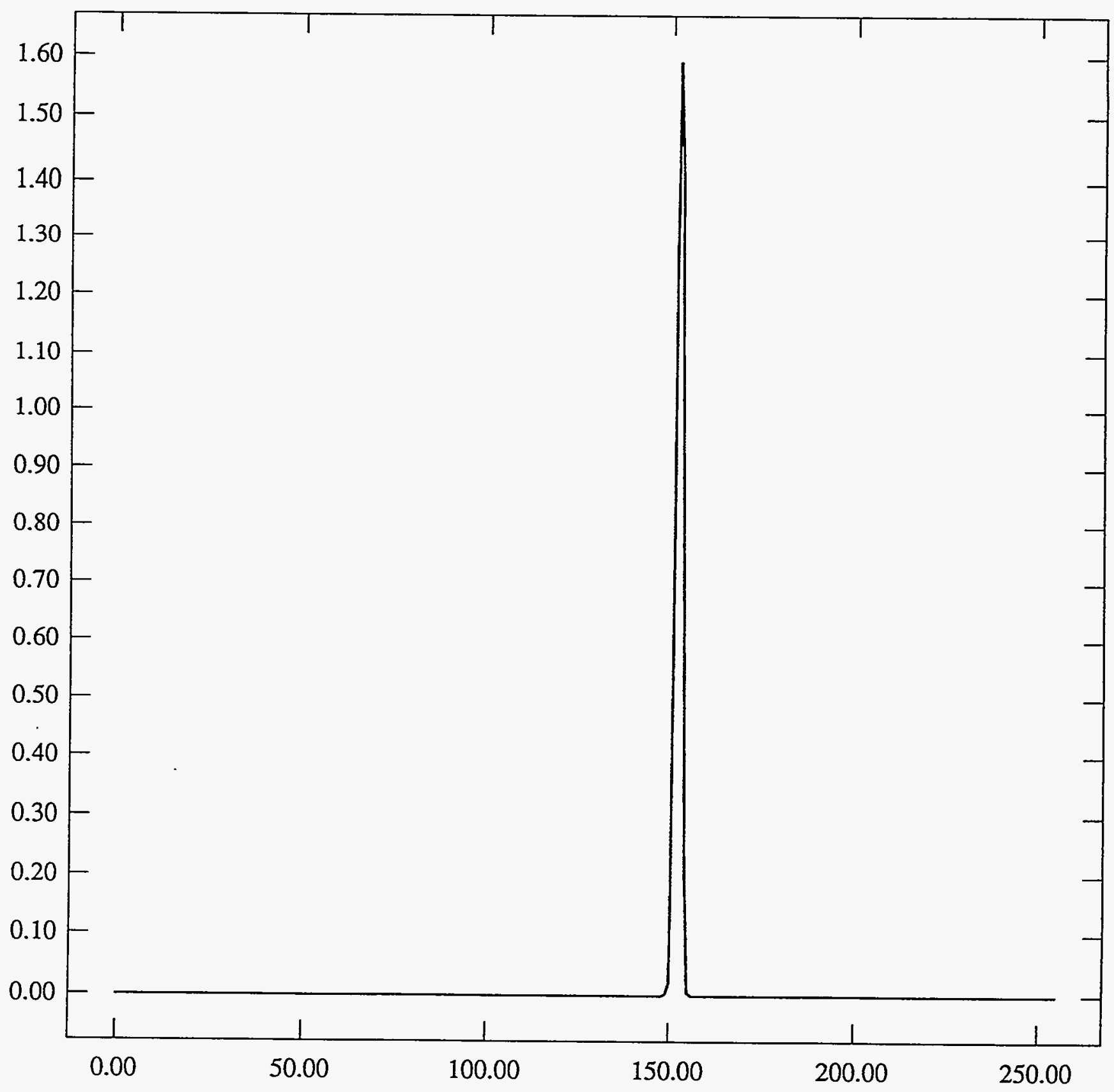


ST Camera: ST2 04-06 -10C: int_time=200ms, offset= 0, gain=4 ( $75 \mathrm{e} / \mathrm{bit}$ ) Tue May 11 15:55:28 1993 Pixel Values Min 151 Max 156 Mean 153.3 Sigma $0.75 \times 10^{3}$

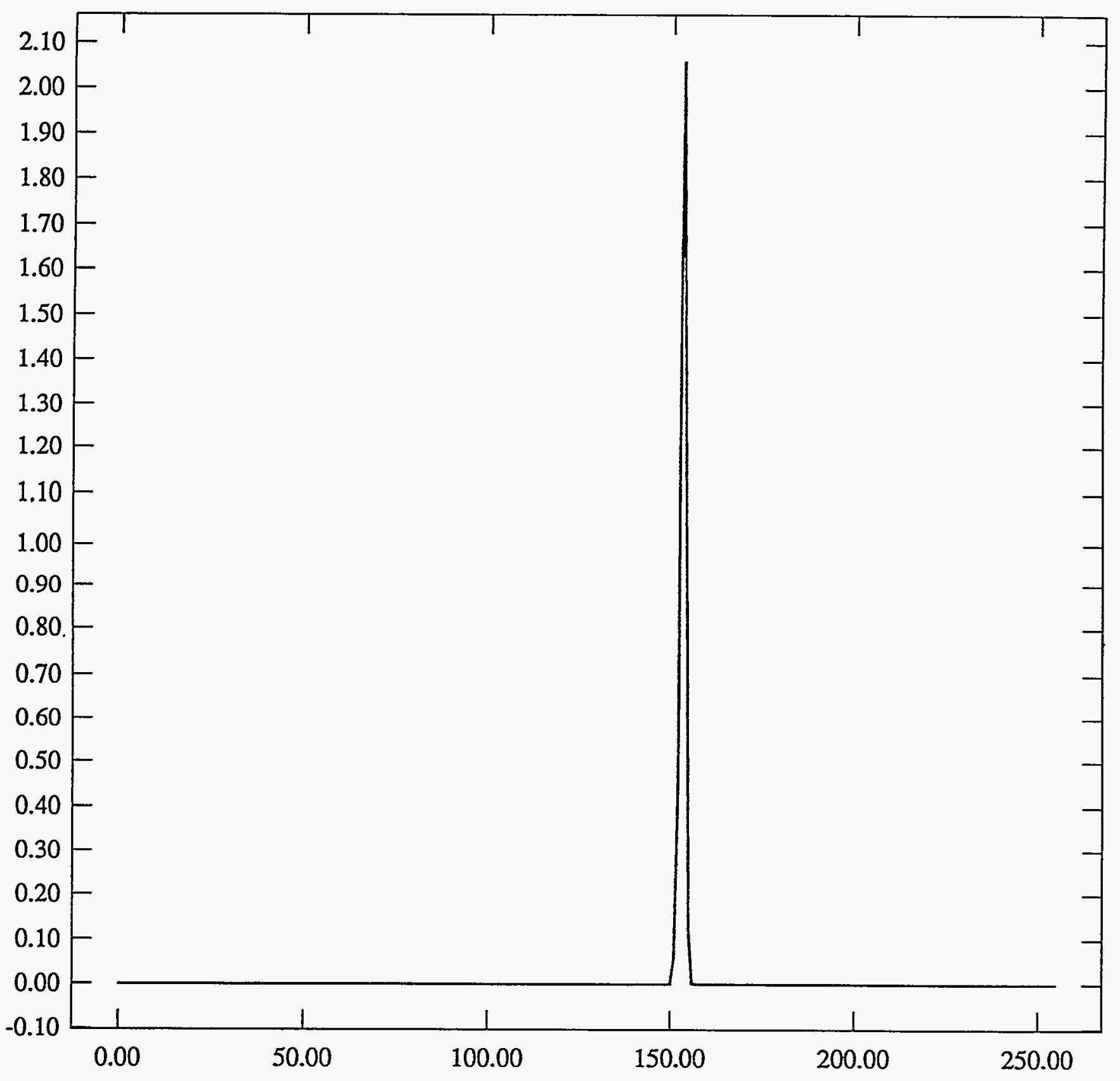


ST Camera: ST2 04-06 0C: int time $=50 \mathrm{~ms}$, offset= 0, gain=4 ( 75 e/bit) Tue May 11 16:10:59 1993 Pixel Values Min 154 Max 160 Mean 156.7 Sigma $0.78 \times 10^{3}$

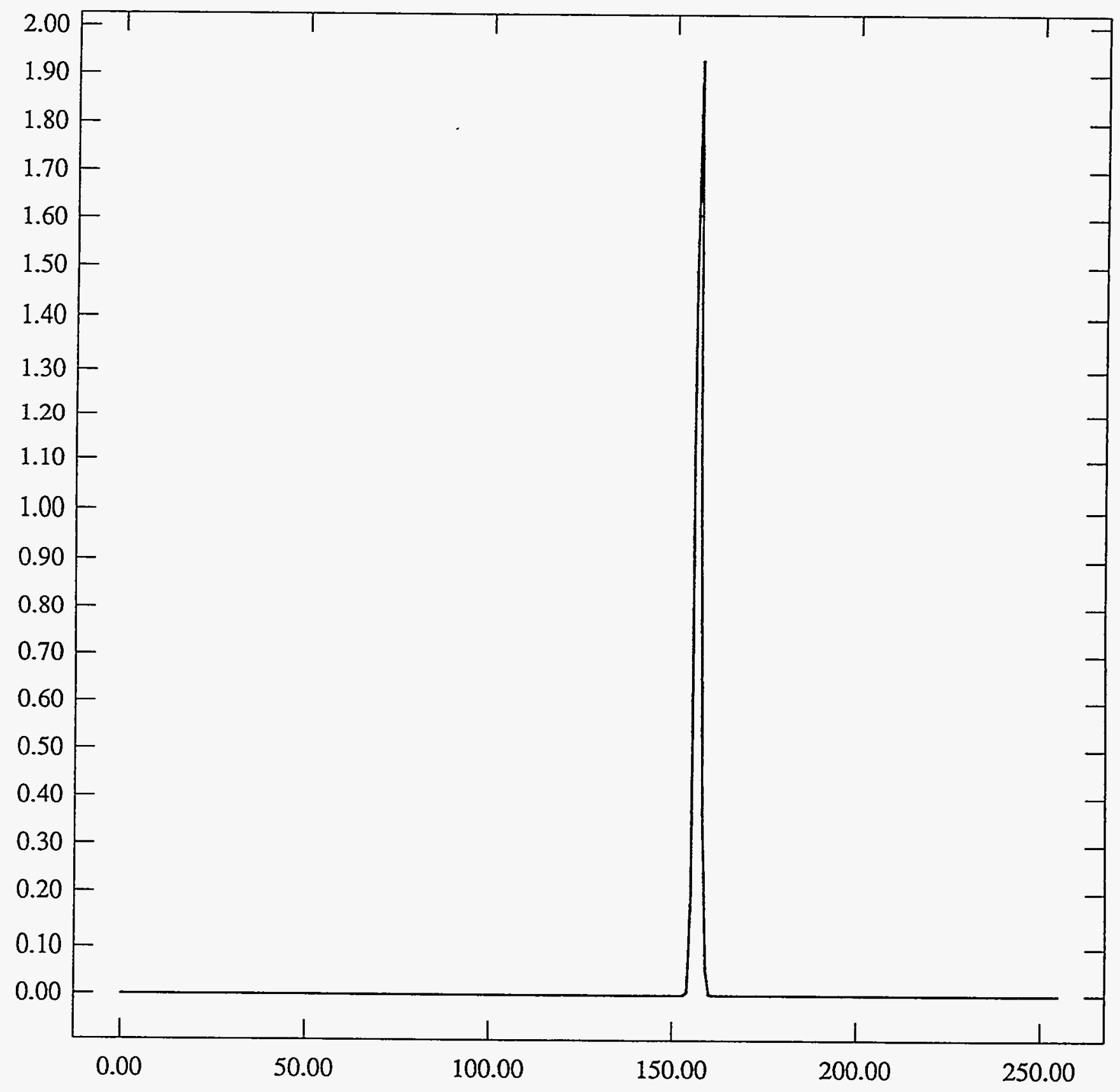


ST Camera: ST2 04-06 0C: int_time=100ms, offset= 0, gain=4 ( 75 e/bit) Tue May 11 16:11:36 1993

Pixel Values Min $155 \operatorname{Max} 162$ Mean 158.3 Sigma $0.93 \times 10^{3}$

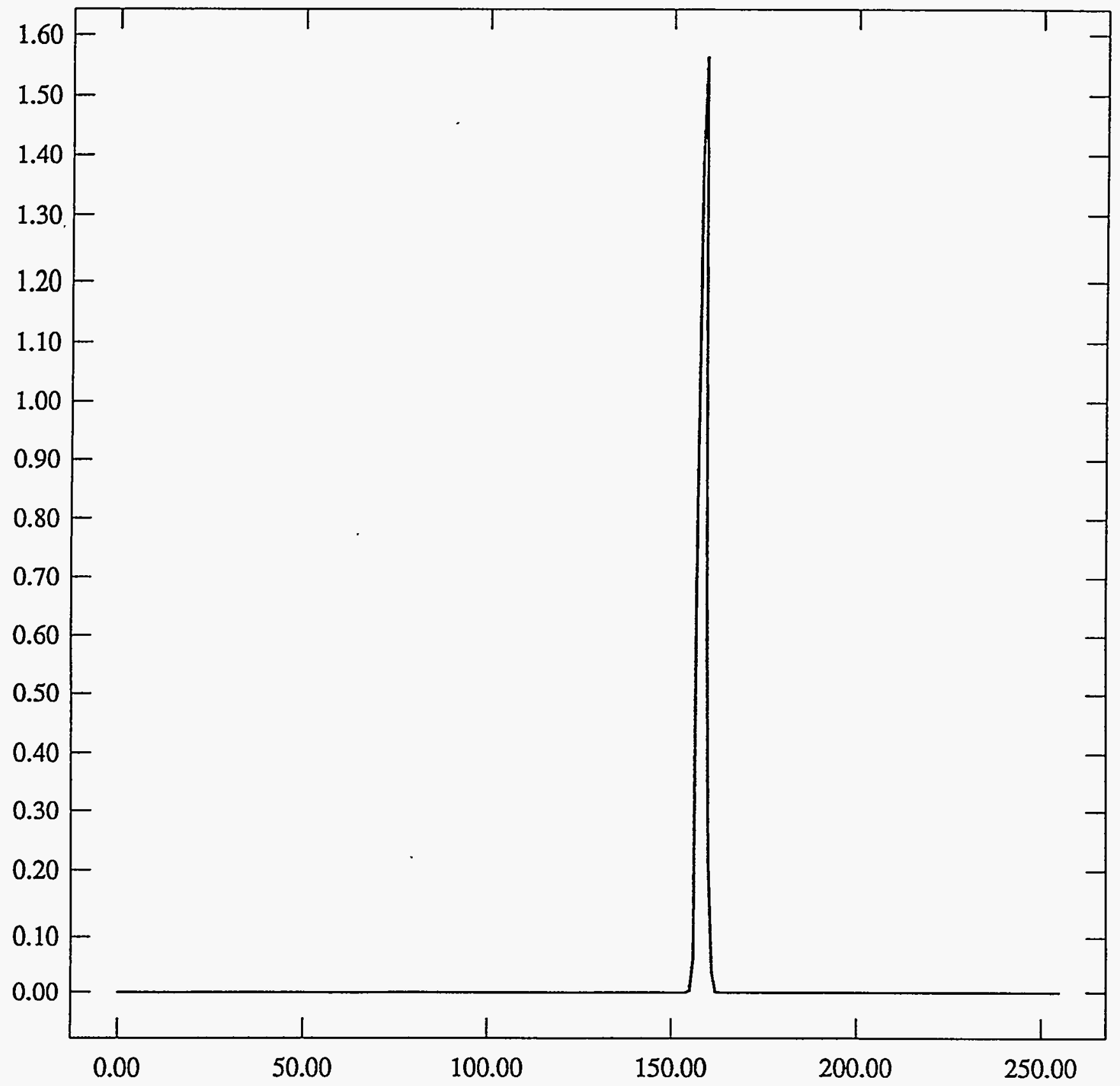


ST Camera: ST2 04-06 0C: int_time=200ms, offset= 0, gain=4 ( 75 e/bit) Tue May 11 16:12:13 1993 Pixel Values Min 159 Max 169 Mean 161.3 Sigma $0.85 \times 10^{3}$

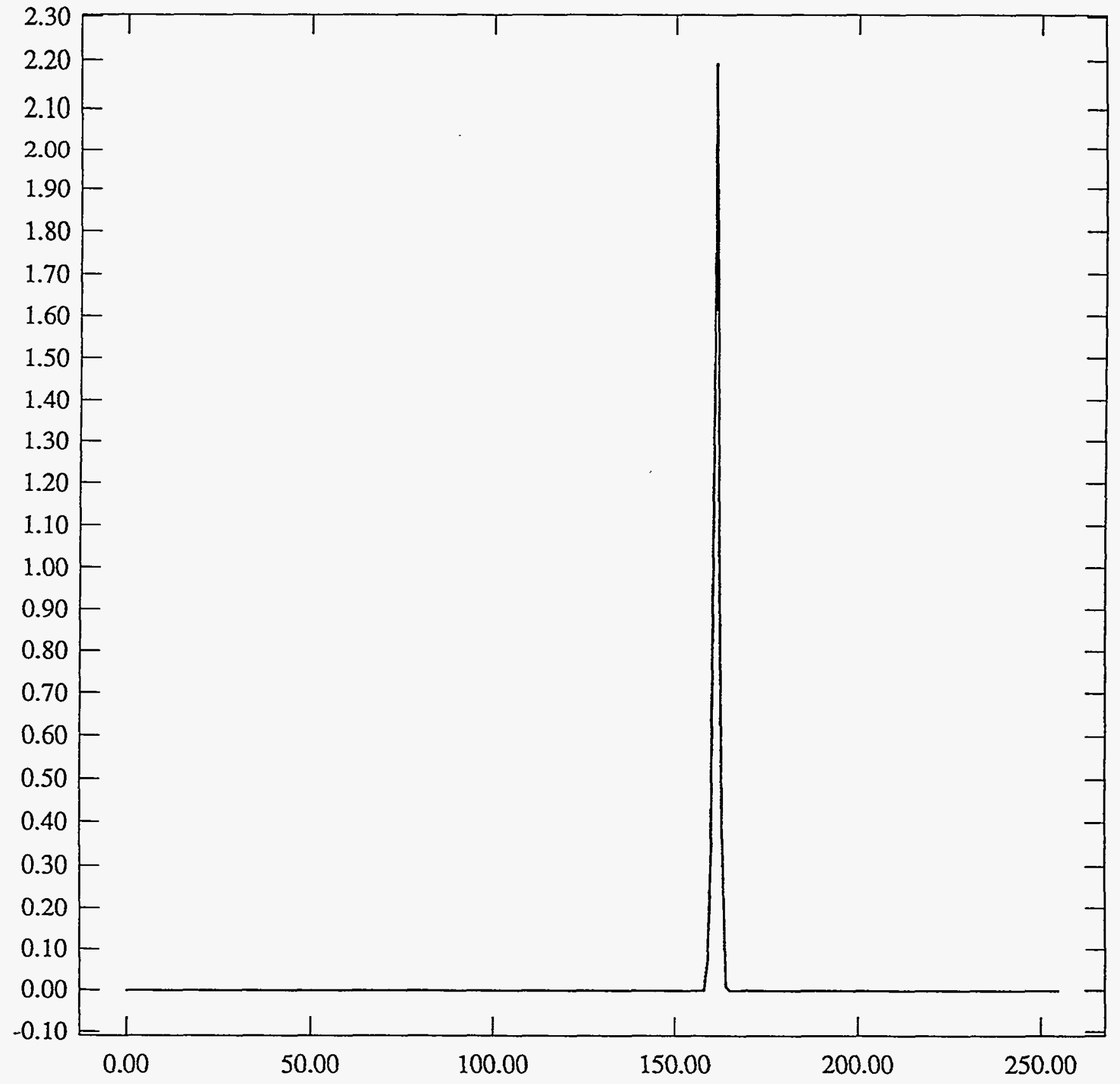


ST Camera: ST2 04-06 +10: int_time $=50 \mathrm{ms,} \mathrm{offset=} \mathrm{0,} \mathrm{gain=4} \mathrm{(} 75$ e/bit) Tue May 11 16:29:36 1993 Pixel Values Min 160 Max 170 Mean 164.8 Sigma $1.17 \times 10^{3}$

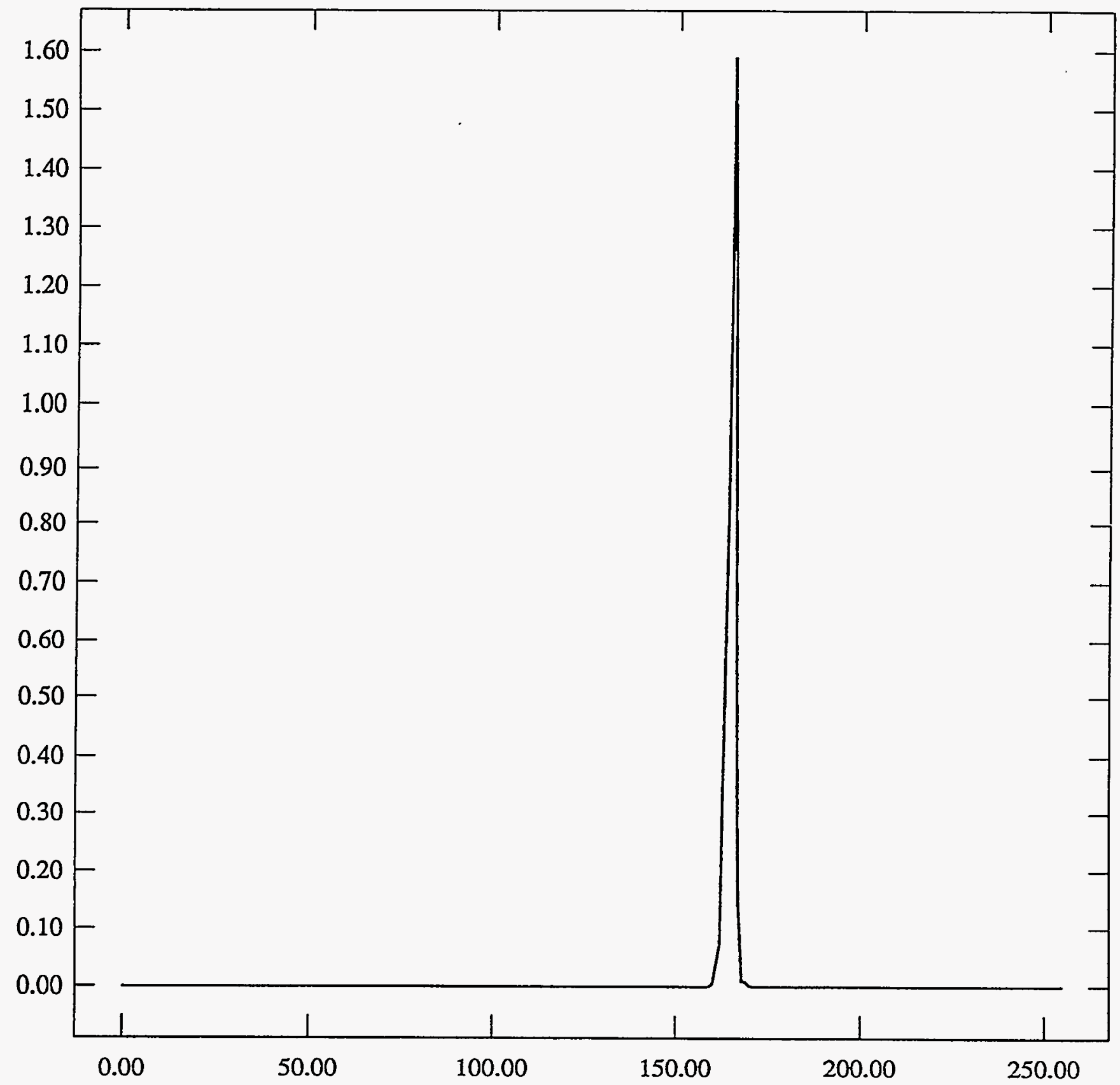


ST Camera: ST2 04-06 +10: int_time=100ms, offset= 0, gain=4 ( $75 \mathrm{e} / \mathrm{bit}$ ) Tue May 11 16:30:11 1993 Pixel Values Min 165 Max 179 Mean 168.5 Sigma $1.06 \times 10^{3}$

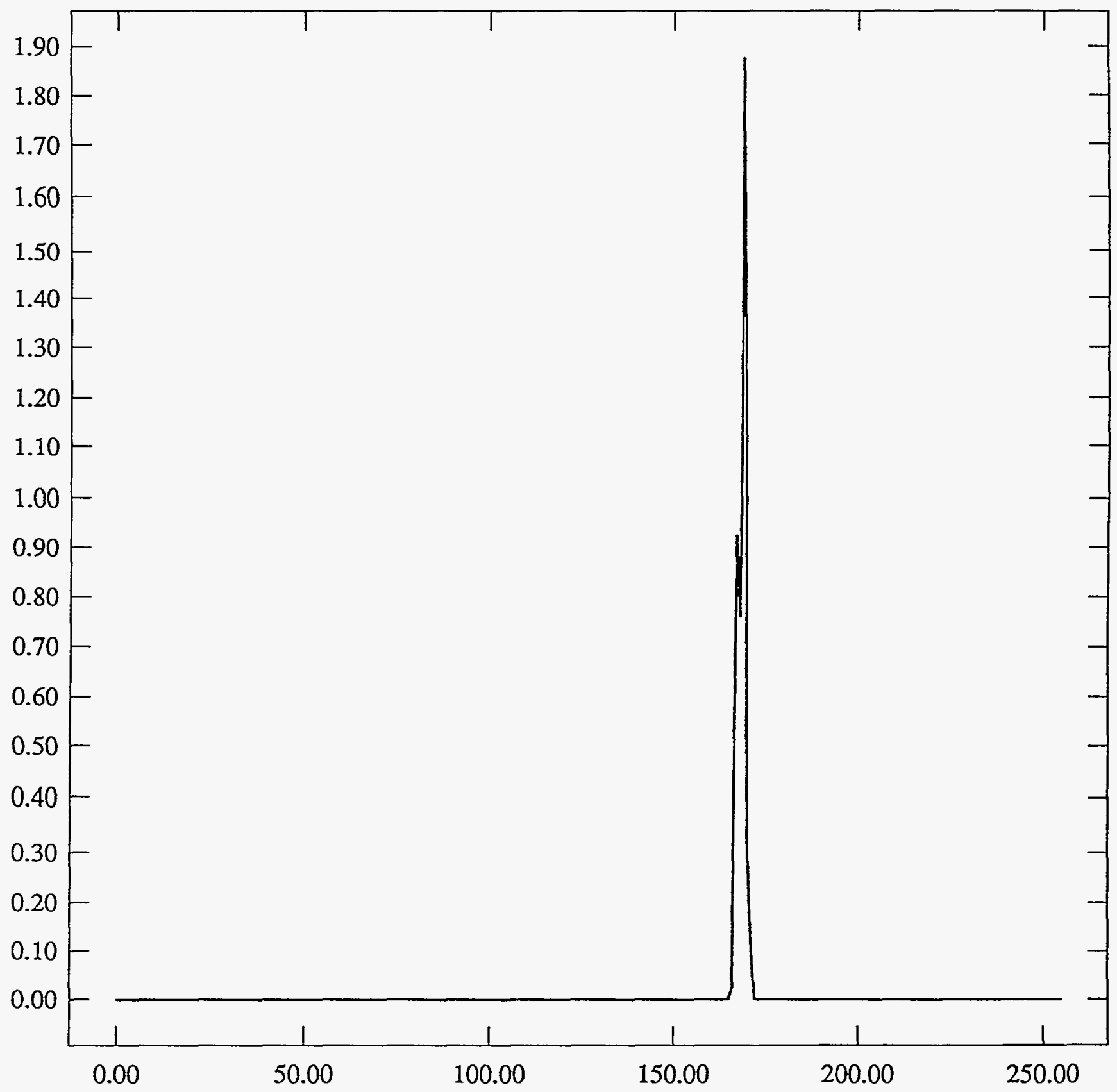


ST Camera: ST2 04-06 +10: int_time=200ms, offset= 0, gain=4 ( $75 \mathrm{e} / \mathrm{bit}$ ) Tue May 11 16:30:46 1993 Pixel Values Min 172 Max 196 Mean 176.6 Sigma $1.57 \times 10^{3}$

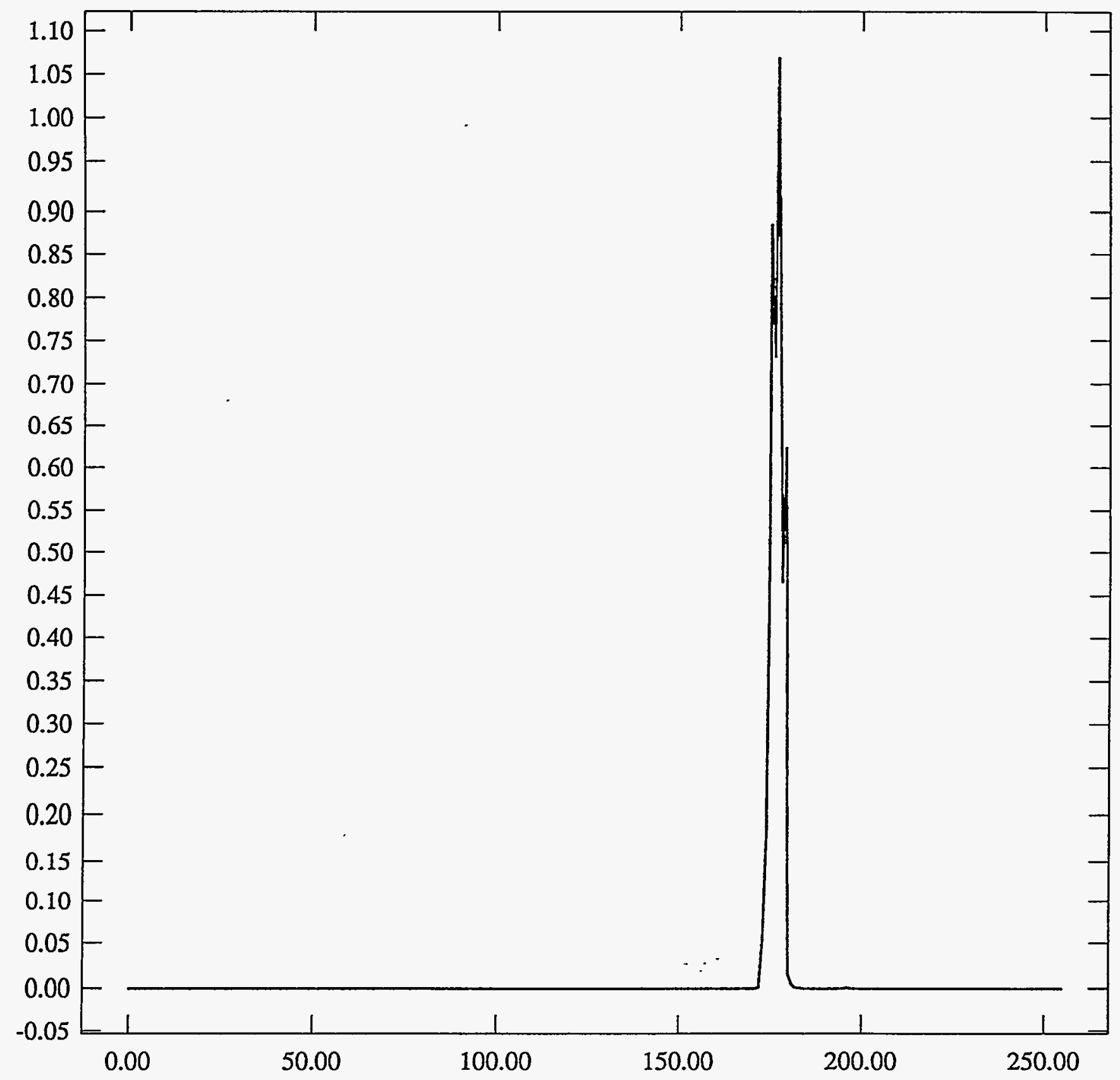


ST Camera: ST2 04-06 +20: int_time= 50ms, offset= 0, gain=4 ( $75 \mathrm{e} / \mathrm{bit})$ Tue May 11 16:44:58 1993

Pixel Values Min 175 Max 187 Mean 179.3 Sigma $0.90 \times 10^{3}$

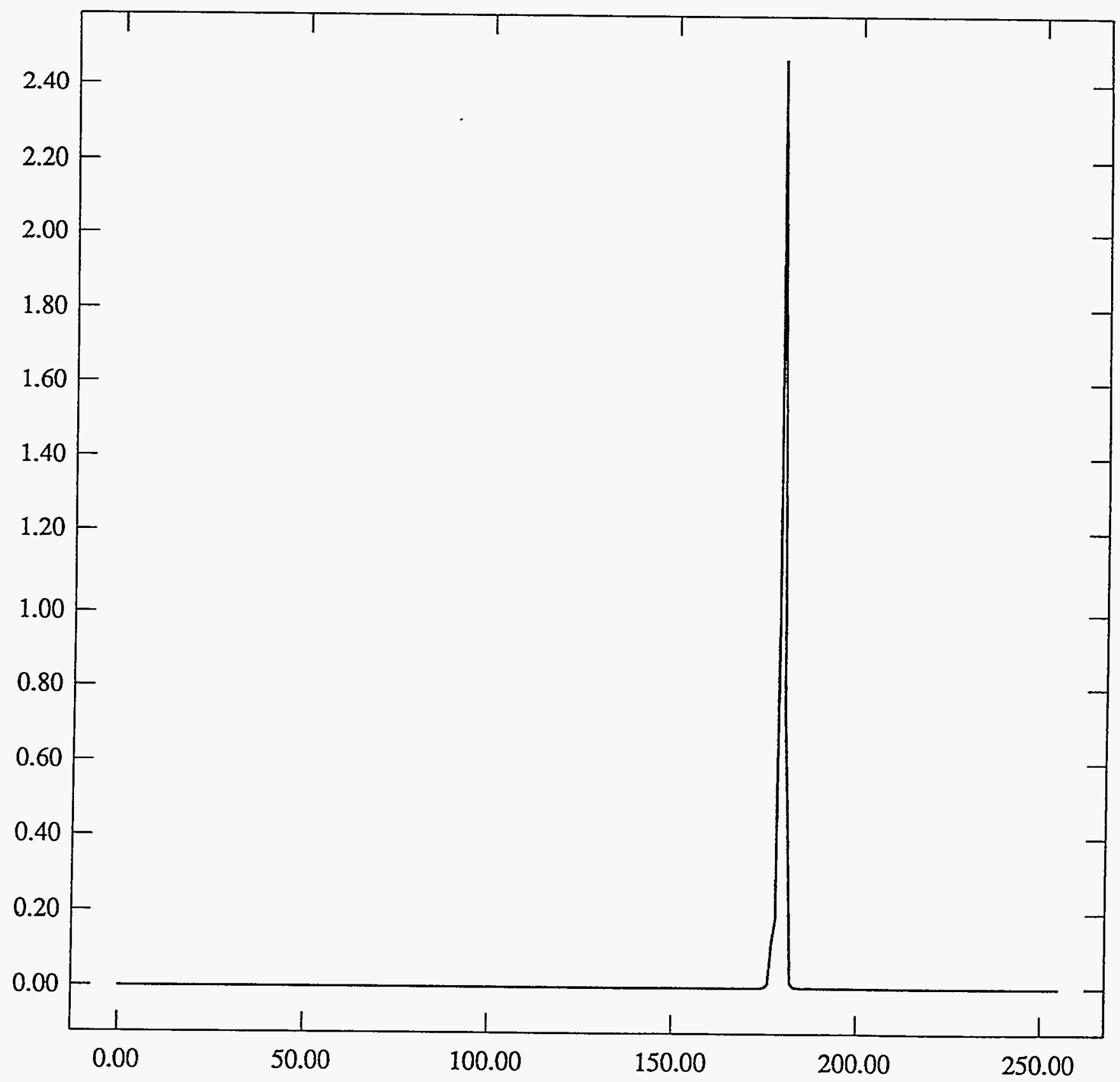


ST Camera: ST2 04-06 +20: int_time=100ms, offset= 0, gain=4 ( 75 e/bit) Tue May 11 16:45:31 1993 Pixel Values Min 185 Max 201 Mean 188.7 Sigma $1.33 \times 10^{3}$

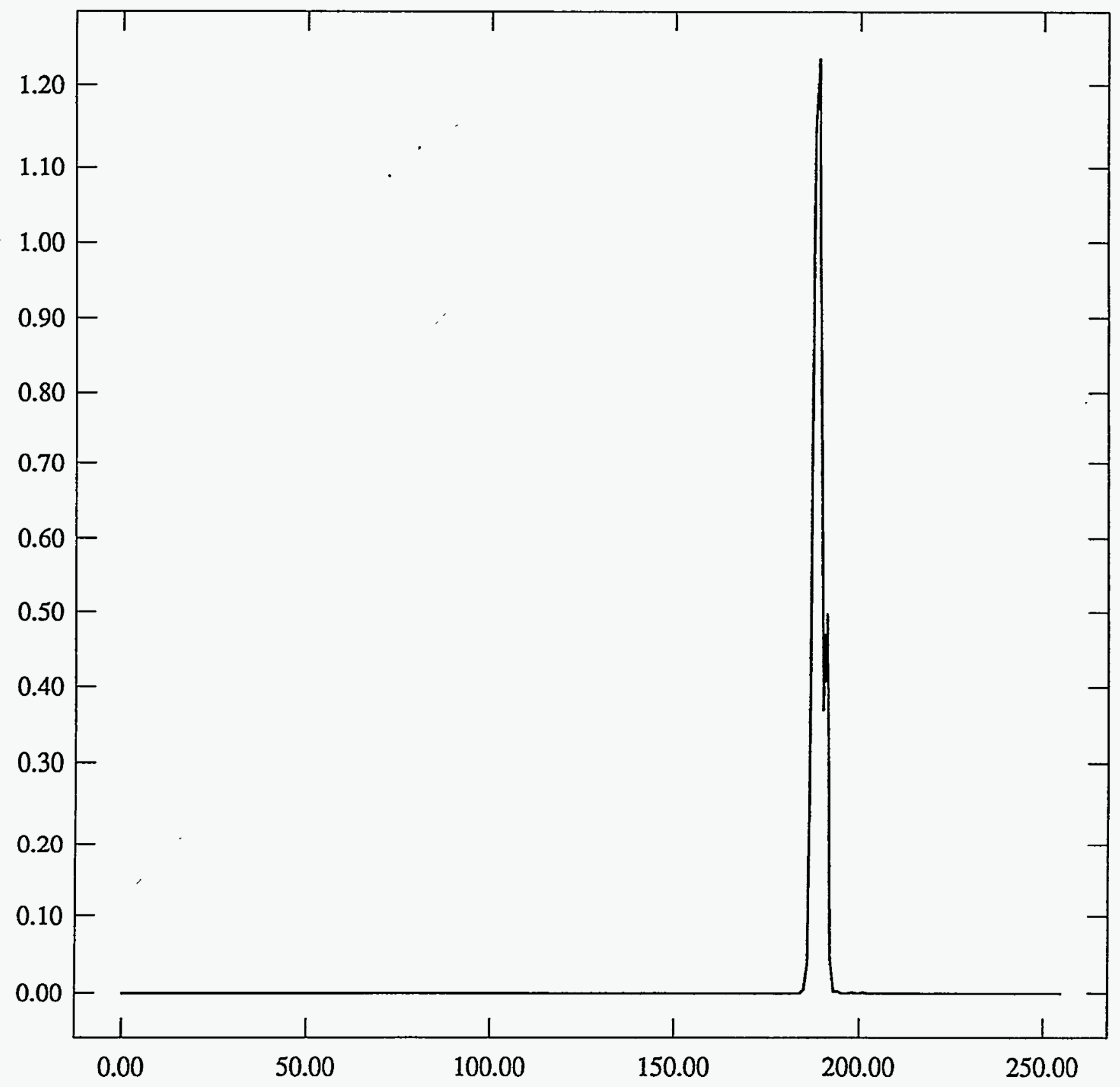


ST Camera: ST2 04-06 +20: int_time=200ms, offset= 0, gain=4 ( 75 e/bit) Tue May 11 16:46:03 1993 Pixel Values Min 204 Max 242 Mean 209.4 Sigma 2.04

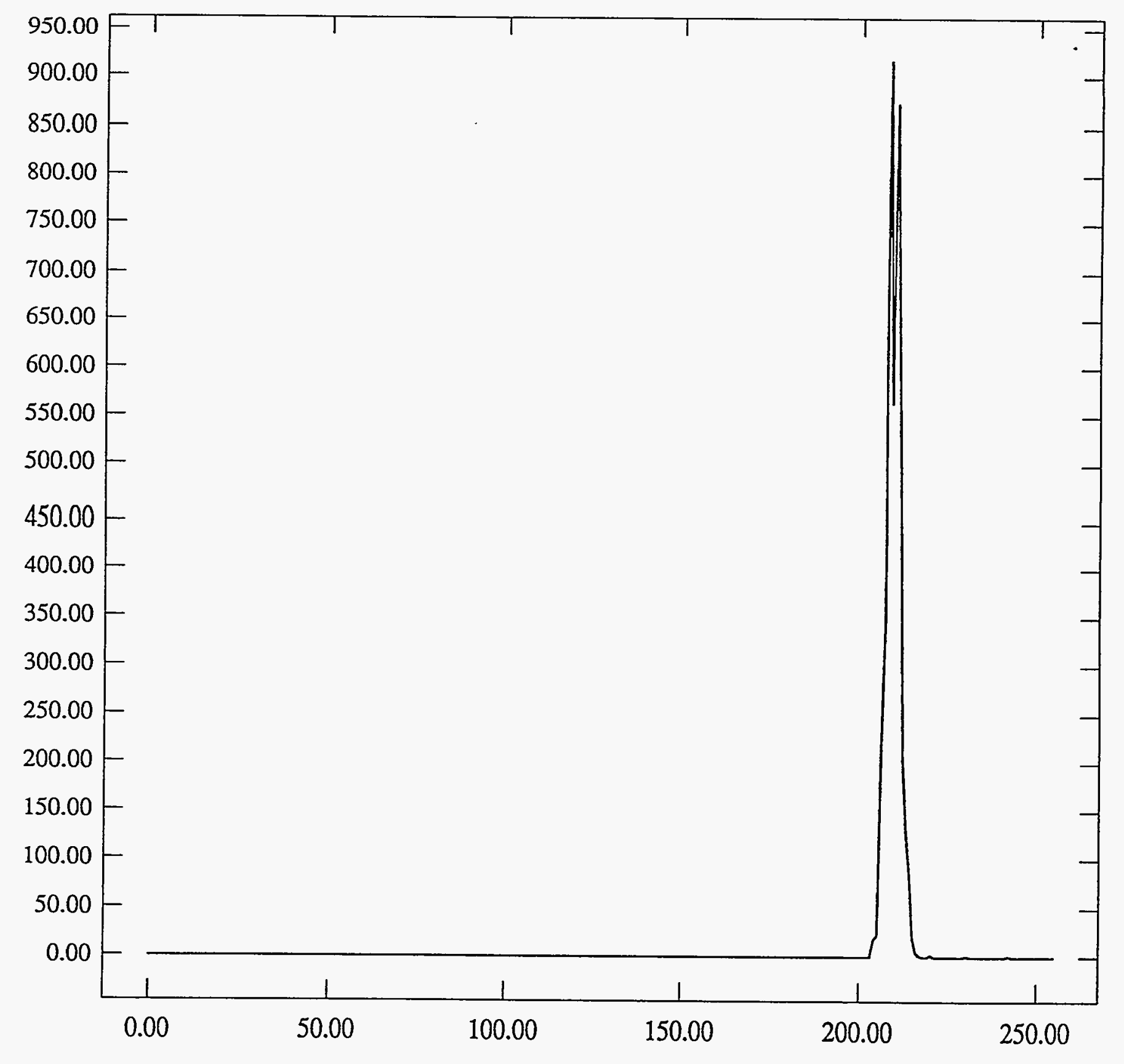


ST Camera: ST2 04-06 +30: int_time $=50 \mathrm{~ms}$, offset= 0, gain=4 ( 75 e/bit) Tue May 11 17:05:07 1993 Pixel Values Min 199 Max 219 Mean 203.1 Sigma $1.49 \times 10^{3}$

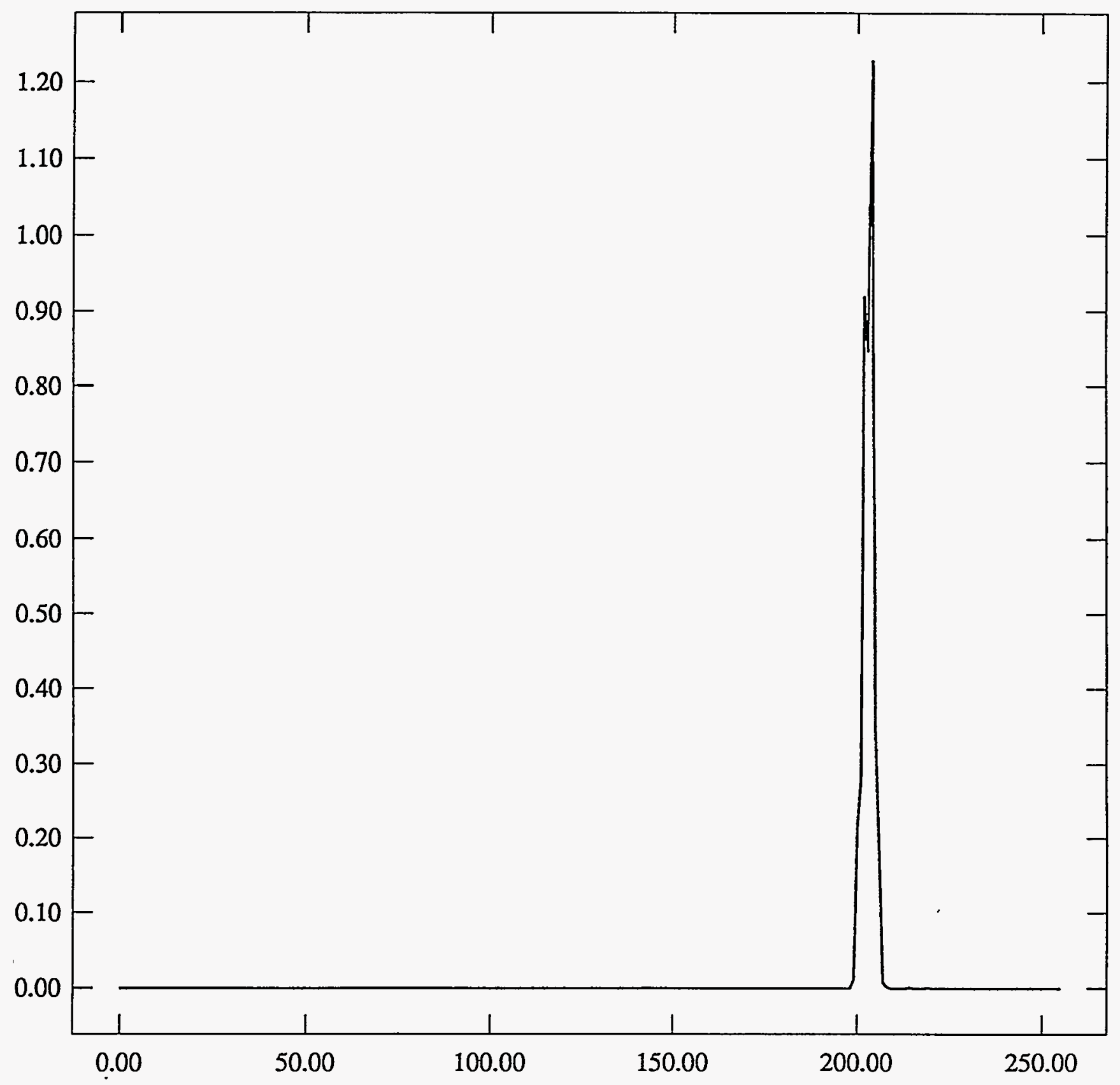


ST Camera: ST2 04-06 +30: int_time=100ms, offset= 0, gain=4 ( $75 \mathrm{e} / \mathrm{bit}$ ) Tue May 11 17:06:07 1993 Pixel Values Min 220 Max 253 Mean 226.1 Sigma 2.14

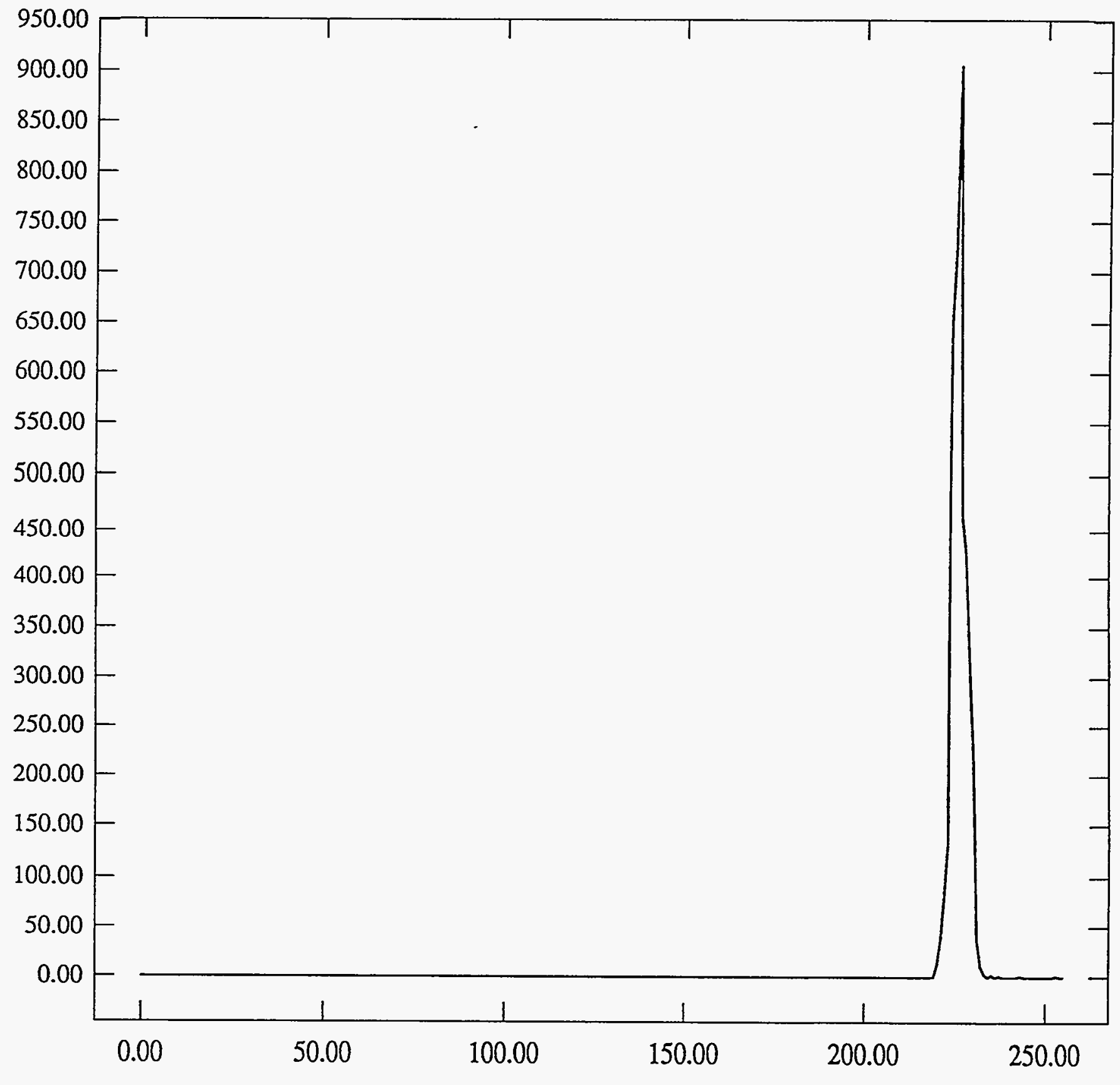


ST Camera: ST2 04-06 +30: int_time=200ms, offset= 0, gain=4 ( 75 e/bit) Tue May 11 17:07:04 1993 Pixel Values Min 255 Max 255 Mean 255.0 Sigma $0.00 \times 10^{3}$

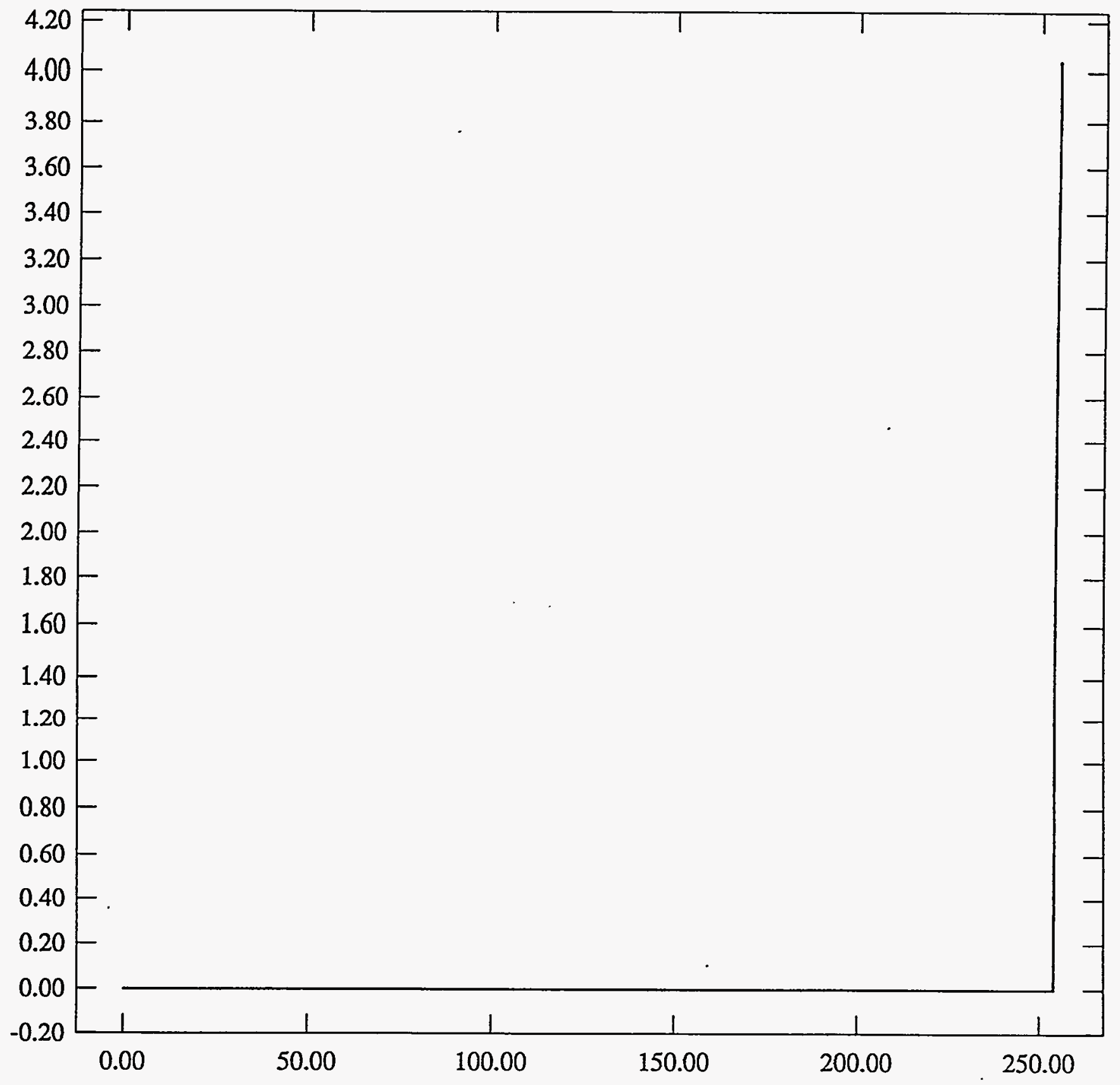


ST2\#04-06 75e/bit $\mathrm{Mu}{ }^{\circ} \mathrm{C}$ Graph

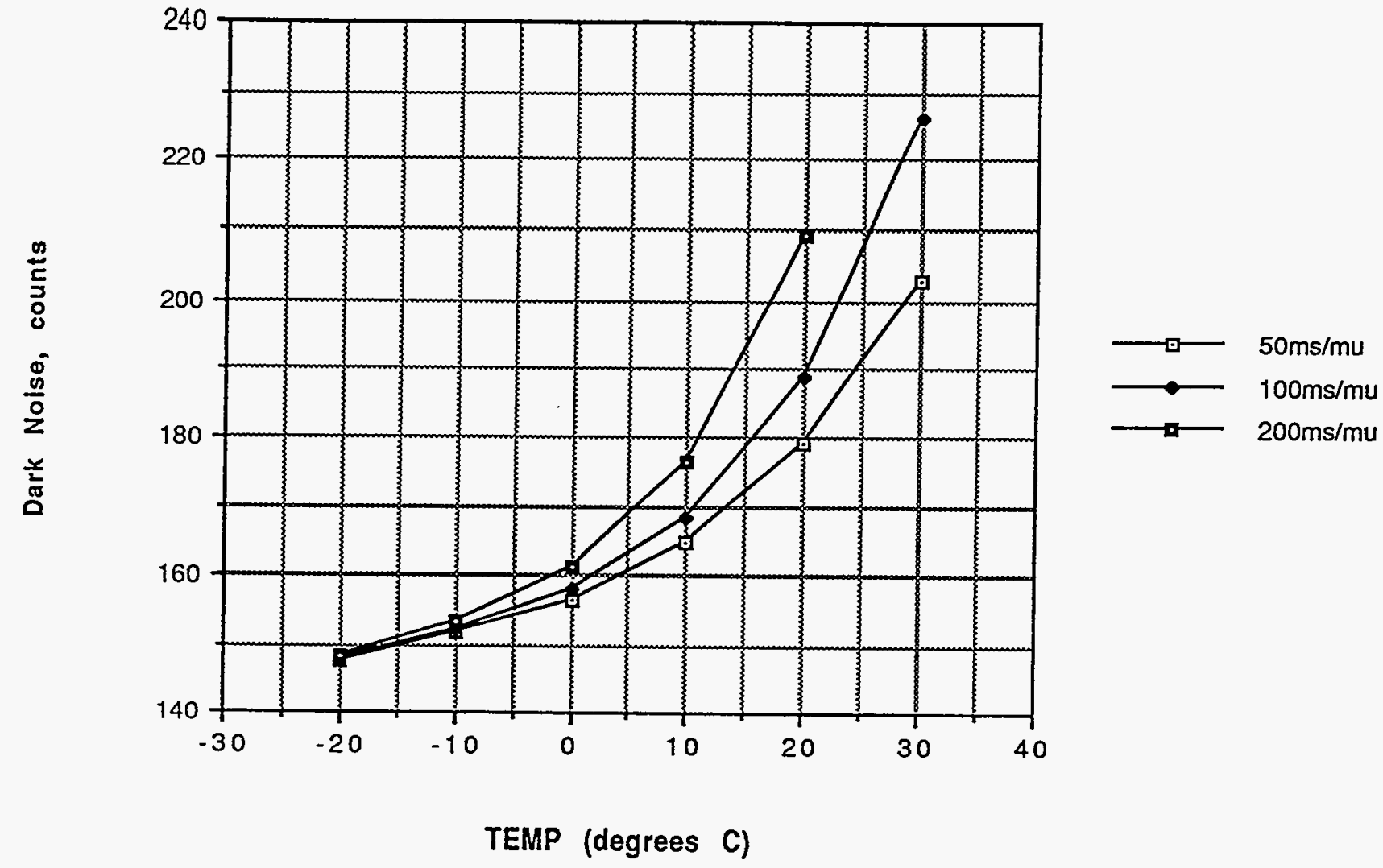

ST2\#04-06 75e/bit Sigma ${ }^{\circ} \mathrm{C}$ Graph

$\frac{0}{5}$
$\frac{5}{3}$
0
0
00
$\frac{0}{0}$
$\sum$
$\sum_{0}^{\infty}$

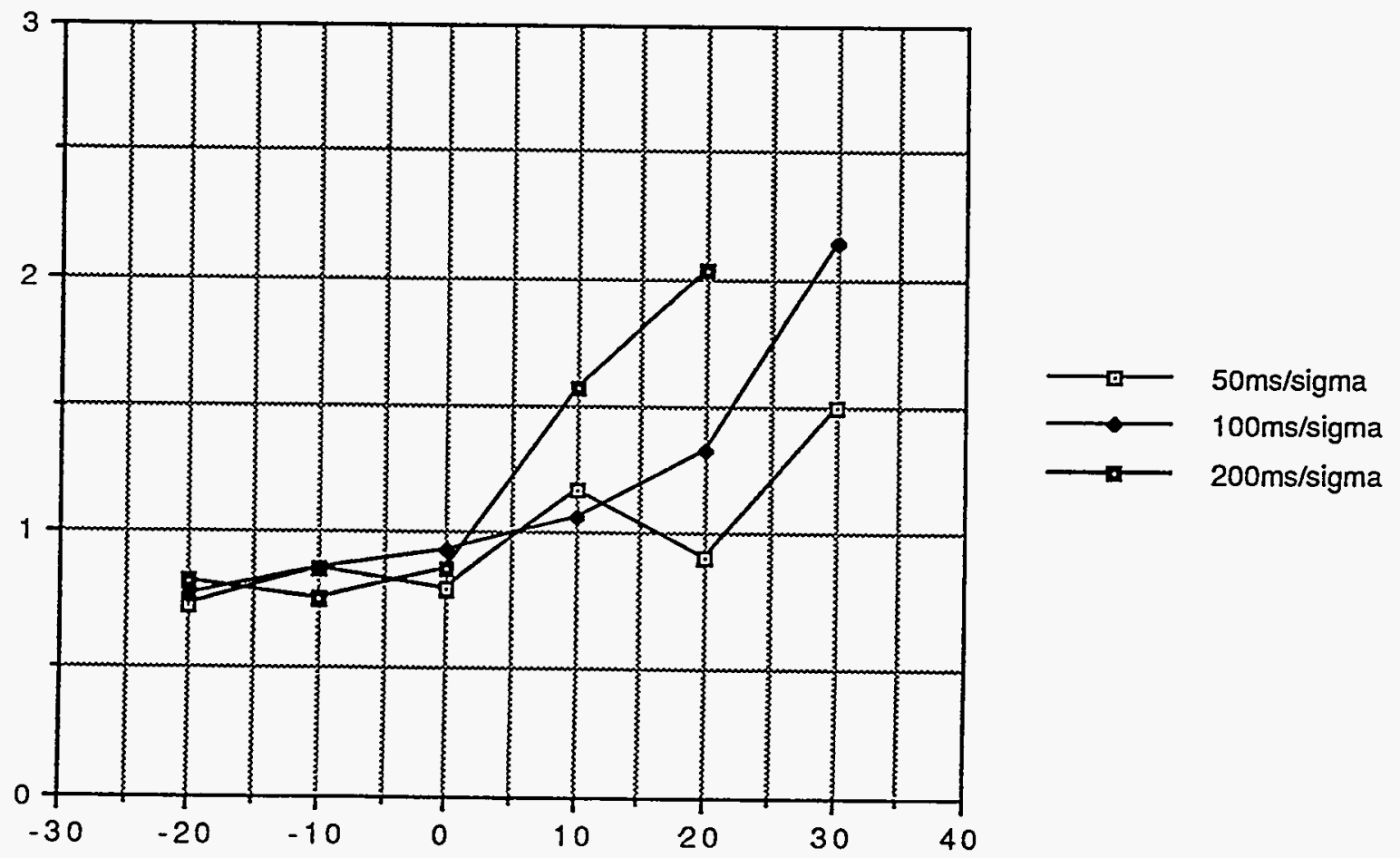

TEMP (degrees C) 


\subsection{Thermal Measurement Acquisition}

The Guide to running hspcube, C1-S1-002 explains a Fast 9 image capture. This program module automatically grabs a $50 \mathrm{~ms}, 100 \mathrm{~ms}$ and $200 \mathrm{~ms}$ integration time images at all three gains. It then does a histogram of those images using a region of interest specified by the user.

Repeat Fast 9 completing your needed temperature range.

Fill in the Table below.

\begin{tabular}{|c|c|c|c|c|c|c|}
\hline & $50 \mathrm{~ms}$ & $50 \mathrm{~ms}$ & $100 \mathrm{~ms}$ & $100 \mathrm{~ms}$ & $200 \mathrm{~ms}$ & $200 \mathrm{~ms}$ \\
\hline Temp & Mu & Sigma & Mu & Sigma & Mu & Sigma \\
\hline \hline$-20^{\circ} \mathrm{C}$ & & & & & & \\
\hline$-10^{\circ} \mathrm{C}$ & & & & & & \\
\hline $0^{\circ} \mathrm{C}$ & & & & & & \\
\hline $10^{\circ} \mathrm{C}$ & & & & & & \\
\hline $20^{\circ} \mathrm{C}$ & & & & & & \\
\hline $30^{\circ} \mathrm{C}$ & & & & & & \\
\hline
\end{tabular}




\subsection{Thermal Data and Graphs}

Graphing techniques will vary with software. However, if you use Cricketgraph, use the "line" graph format.

Plot Mu vs Temperature as below:

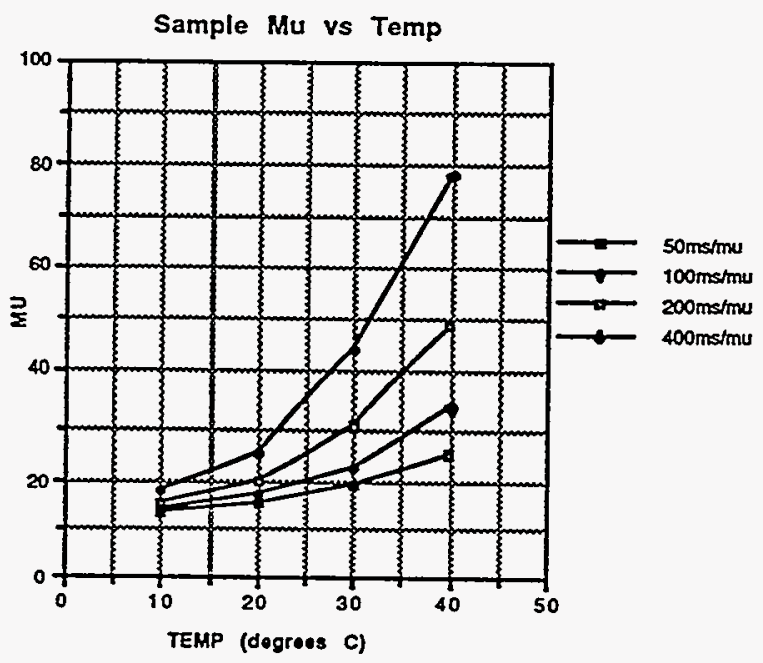

Plot Sigma vs Temperature like this:

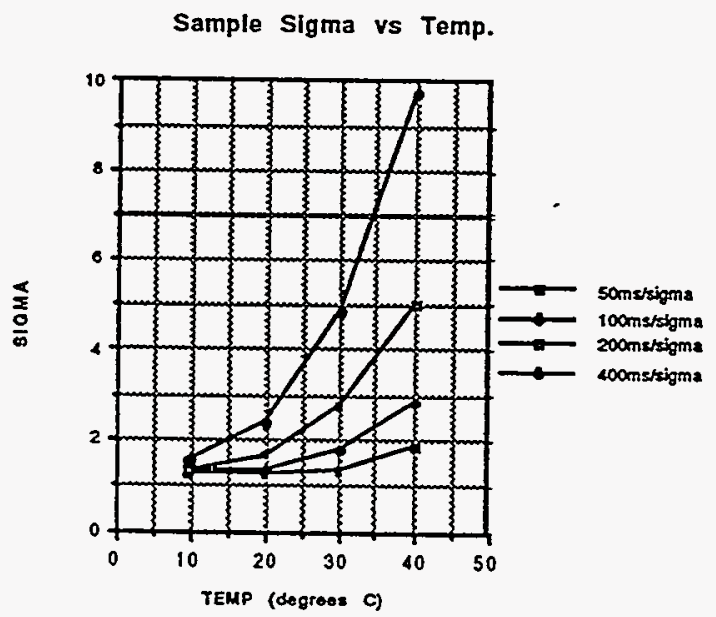

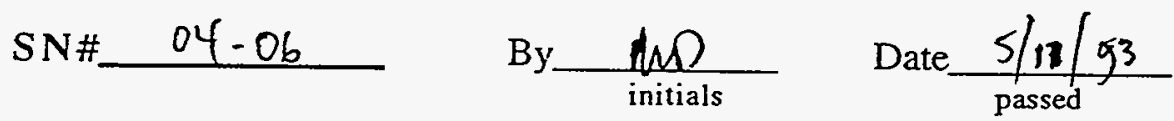

Remember to attach graphs and associated data to test procedure!

(a document protector is advised) 


\section{Flat Field Linearity Test}

This test requires the use of the SUN Datacube and its image processing capabilities, a TV Optoliner Model $\mathrm{K}-4000$ with neutral density(ND) filters ranging from 0.8 to 2.8 , and a resolution chart for focusing.

\subsection{Linearity Test Setup}

Using alcohol and Q-tips clean the installed CCD.

Verify a properly connected camera acquisition system by acquiring an image. Always use a connector saver.

Turn on the test fixture.

Put the SUN Datacube in the Acquire mode, see Guide to Running hspcube-C1-S1-002.

Install a total $0.8 \mathrm{ND}$ filter and test pattern in the T.V. Optoliner.

Adjust the camera board so that the test pattern image is centered and focused on the CCD.

NOTE: Once focused, neither the camera nor the optoliner can be moved. Allow the T.V. Optoliner and camera to warm up under continuous operation for $\approx 1$ hour before proceeding. Keeping the camera's environmental temperature constant and allowing a long warm up requires only one background histogram for linearity computation.

Remove the test pattern and replace with a flat field image.

With $0.8 \mathrm{ND}$ filtering installed in the optoliner, adjust the T.V. Optoliner lamp voltage so that you get a Mu count between 235 and 250 .

\subsection{Linearity Measurement Acquisition}

Use the SUN Datacube "Acquire and build histogram Sequence " to capture a frame and process a defined region of interest. Then obtain its histogram. 

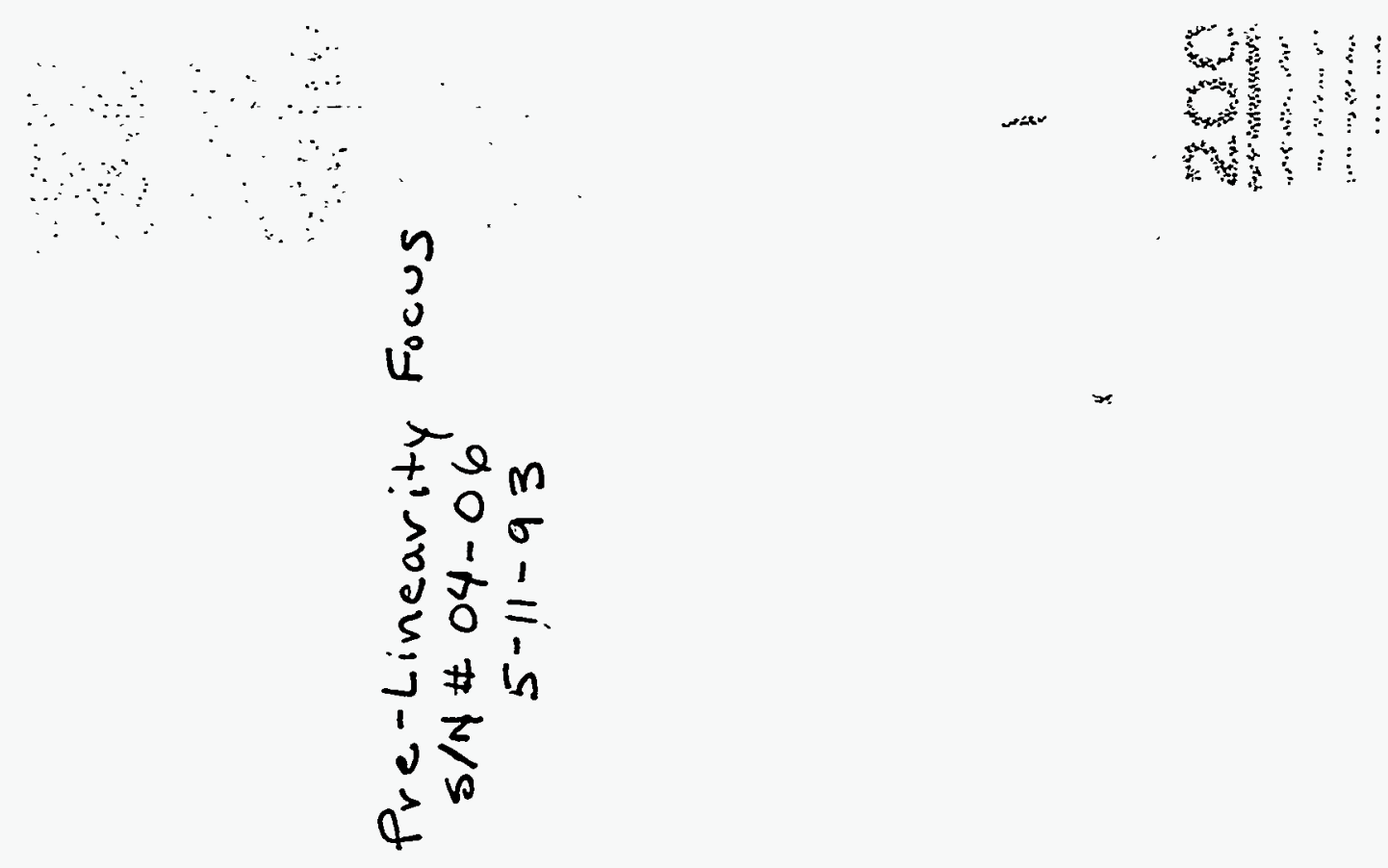

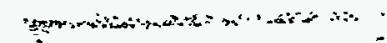

$\therefore \cdots 4$ 


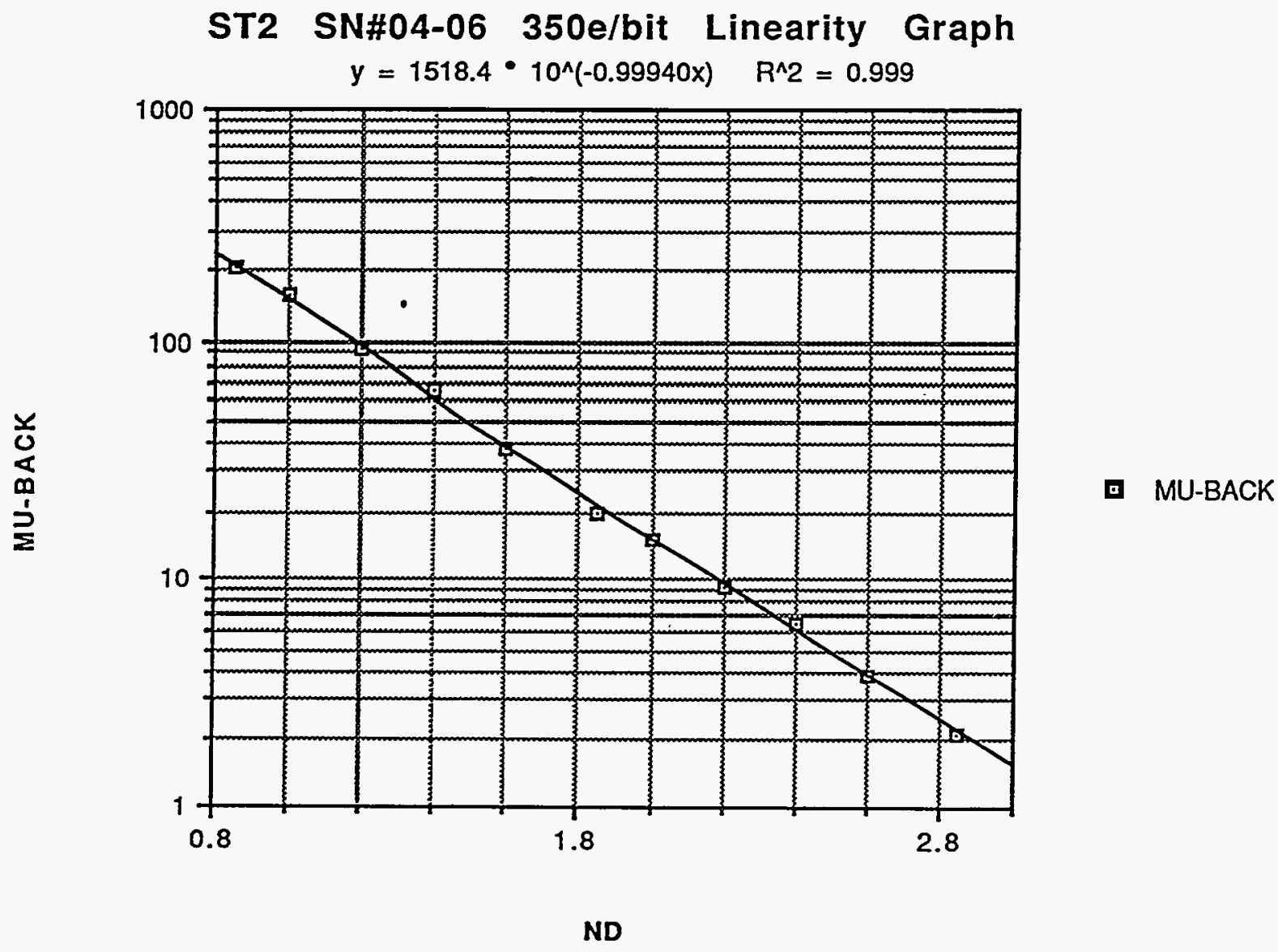


N

0.85

1.00

1.20

1.40

1.60

1.85

2.00

2.20

2.40

2.60

2.85
MU

224.40

175.34

113.20

83.92

55.98

38.68

33.91

27.93

25.20

22.50

20.72
BACK

18.43

18.43

18.43

18.43

18.57

18.57

18.57

18.57

18.64

18.64

18.64
MU-BACK Colu

NOTES:

$5 / 11 / 93$

ST2 SN\#04-06

$14.0 \mathrm{~V}$

94.77

65.49

37.41

20.11

15.34

9.36

6.56

3.86

2.08

SUNDATACUBE offset $=3$ $350 \mathrm{e} / \mathrm{bit}$ P.S.\#5008

HEAD\#4163 


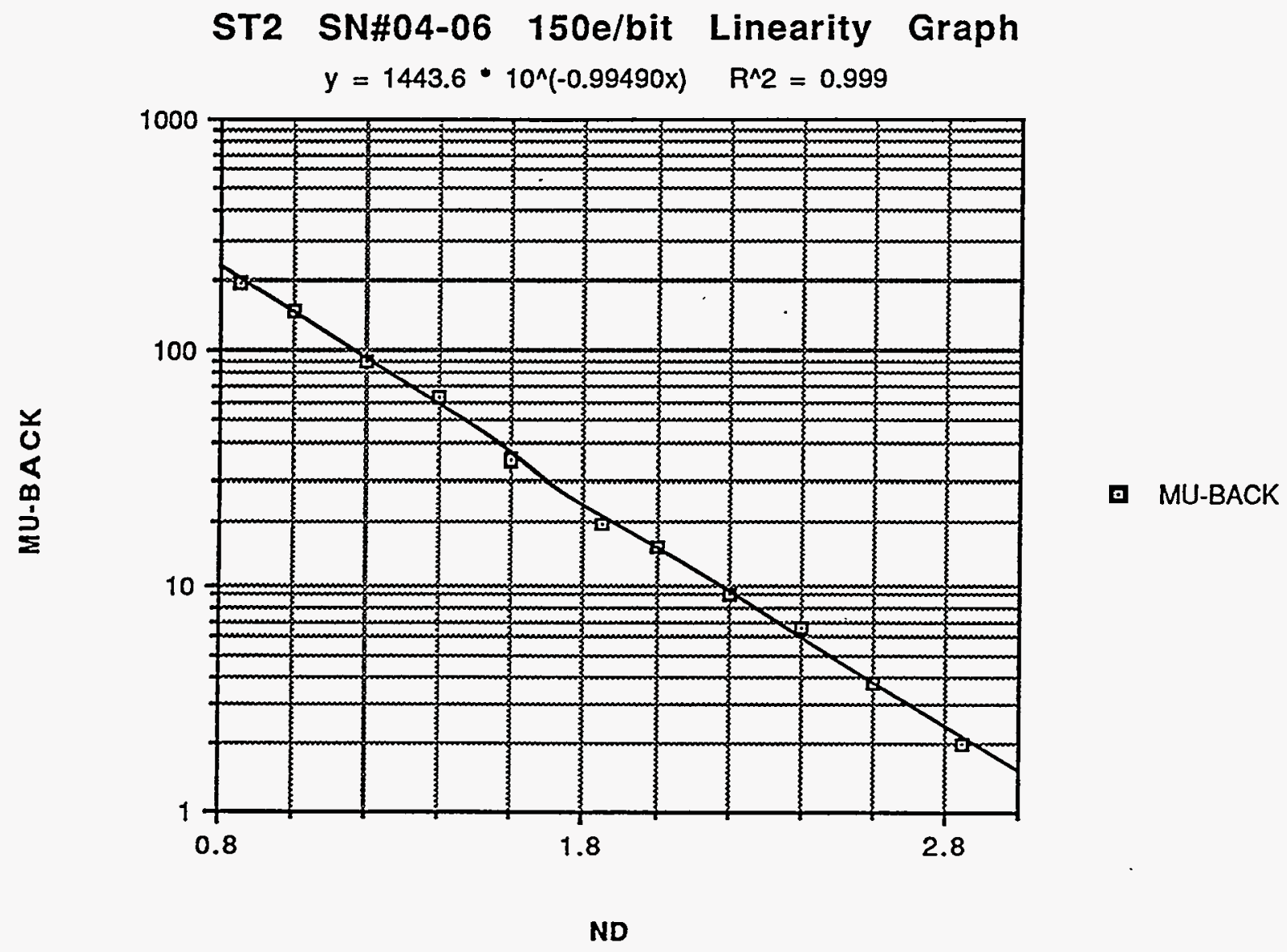


ST2/SN\#04-06/150e/LNDT

MU

BACK

219.05

172.99

113.87

85.77

58.26

41.86

37.52

31.55

29.05

26.25

24.54
22.35

22.35

22.35

22.35

22.46

22.46

22.46

22.46

22.52

22.52
22.52

MU-BACK Colu
196.70

150.64

91.52

63.42

35.80

19.40

15.06

9.09

6.53

3.73

2.02

NOTES:

$5 / 11 / 93$

ST2 SN\#04-06

$12.0 \mathrm{v}$

SUNDATACUBE

offse $t=9$

$150 \theta / b i t$

P.S. \#5008

HEAD\#4163

$\begin{array}{ll}12 & 2.60\end{array}$ 


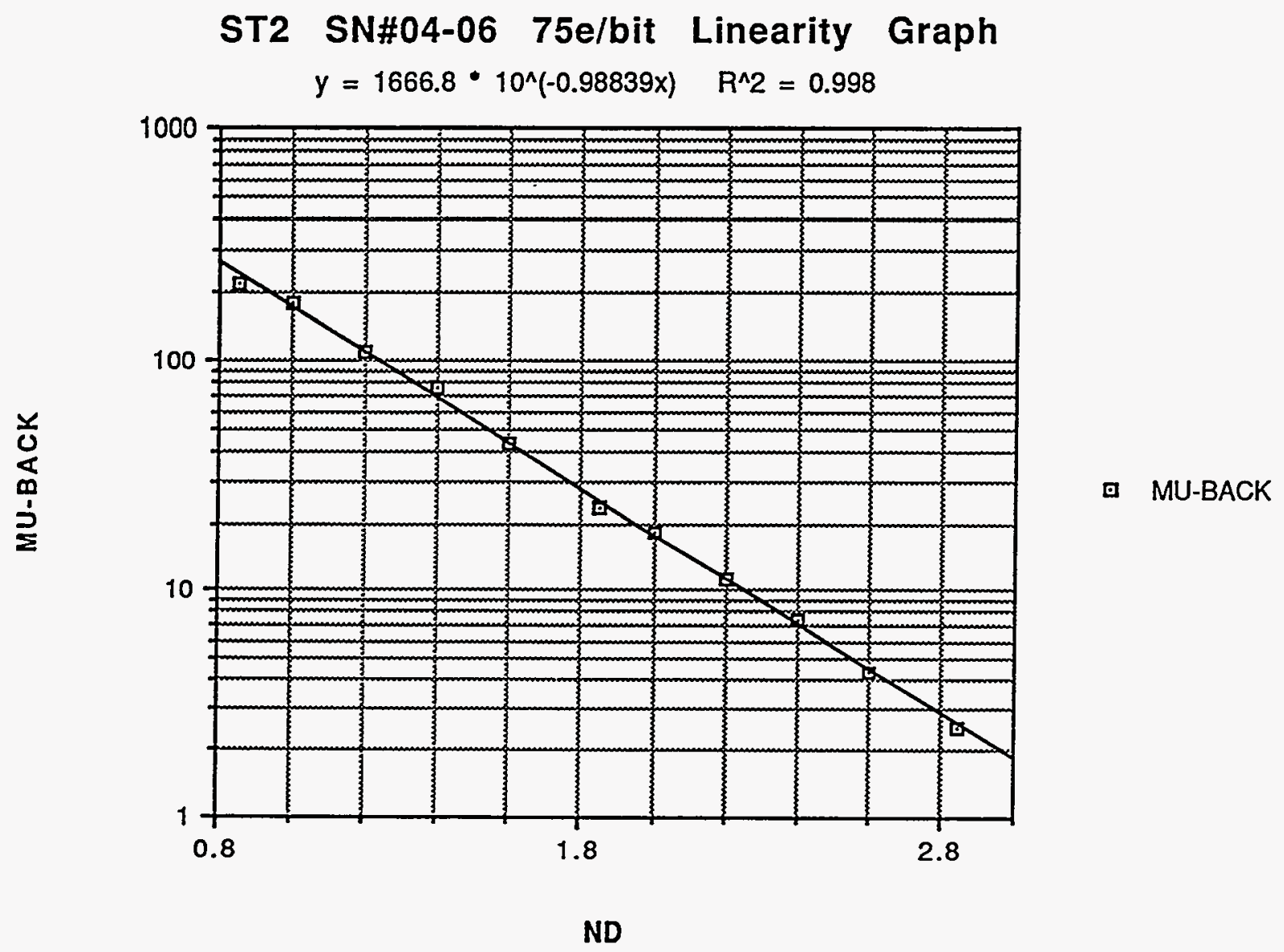




\begin{tabular}{|c|c|c|c|c|c|c|}
\hline & $N$ & MU & BACK & MU-BACK & Colu & NOTES: \\
\hline \multicolumn{7}{|l|}{1} \\
\hline 2 & 0.85 & 241.40 & 26.93 & 214.47 & & $5 / 11 / 93$ \\
\hline 3 & 1.00 & 207.14 & 26.93 & 180.21 & & ST2 SN\#04-06 \\
\hline 4 & 1.20 & 135.97 & 26.93 & 109.04 & & $11.3 v$ \\
\hline 5 & 1.40 & 103.32 & 26.93 & 76.39 & & \\
\hline 6 & 1.60 & 70.91 & 27.53 & 43.38 & & SUNDATACUBE \\
\hline 7 & 1.85 & 50.68 & 27.53 & 23.15 & & offset=20 \\
\hline 8 & 2.00 & 45.94 & 27.53 & 18.41 & & $75 e / b i t$ \\
\hline 9 & 2.20 & 38.69 & 27.53 & 11.16 & & P.S. \#5008 \\
\hline 10 & 2.40 & 35.44 & 27.99 & 7.45 & & HEAD\#4163 \\
\hline 11 & 2.60 & 32.36 & 27.99 & 4.37 & & \\
\hline 12 & 2.85 & 30.43 & 27.99 & 2.44 & & \\
\hline
\end{tabular}




\subsection{Linearity Data Collection.}

Select the first gain setting.

Begin by taking a background level. Use an ND of 8.0 for background. Adjust the Offset so that the black level is equal to 20 counts and readjust the lamp voltage so that the average is equal to $240-250$ counts with an ND of 0.85 .

Starting with $0.8 \mathrm{ND}$, increment the ND filter value with 0.2 steps until MU almost equals the background. Acquire, build histogram, and record $\mathrm{mu} /$ sigma information for each ND value. Repeat this sequence for all 3 Gain settings.

Turn off power.

Sample data table:

Actual data table for gain of $4=75 e / b i t$ $\begin{array}{lcr}\text { SN\# } 04-06 & \text { Date } 5 / 1103 \\ \text { Offset_.P.S.Volt_11.34 } & 20\end{array}$

\begin{tabular}{|c|c|c|c|}
\hline ND & Mu & Backgnd & Mu-Back \\
\hline 0.85 & 249 & 82 & 167 \\
\hline 1.0 & 211 & 82 & 129 \\
\hline 1.2 & 159 & 82 & 77 \\
\hline 1.4 & 136 & 82 & 54 \\
\hline 1.6 & 113 & 82 & 31 \\
\hline 1.85 & 99 & 82 & 17 \\
\hline 2.0 & 95 & 82 & 13 \\
\hline 2.2 & 90 & 82 & 8 \\
\hline 2.4 & 87 & 82 & 5 \\
\hline 2.6 & 85 & 82 & 3 \\
\hline 2.85 & 84 & 82 & 2 \\
\hline
\end{tabular}

\begin{tabular}{|c|c|c|c|}
\hline ND & Mu & Backgnd & Mu-Back \\
\hline 0.85 & & & \\
\hline 1.0 & 240.40 & 25.93 & \\
\hline 1.2 & 207.14 & & \\
\hline 1.4 & 135.97 & & \\
\hline 1.6 & 105.32 & & \\
\hline 1.85 & 50.68 & & \\
\hline 2.0 & 45.94 & & \\
\hline 2.2 & 39.69 & & \\
\hline 2.4 & 35.44 & 27.99 & \\
\hline 2.6 & 32.36 & & \\
\hline 2.85 & 30.43 & & \\
\hline
\end{tabular}


Actual data table for gain of 2 isoelbit Actual data table for gain of $1356 \mathrm{e} / \mathrm{b}$ it

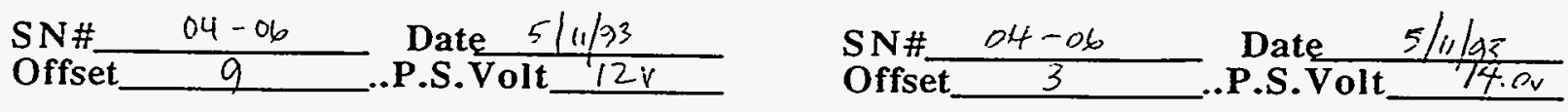

\begin{tabular}{|c|c|c|c|}
\hline ND & Mu & Backgnd & Mu-Back \\
\hline 0.85 & 29.05 & 22.35 & \\
\hline 1.0 & 172.99 & & \\
\hline 1.2 & 113.87 & & \\
\hline 1.4 & 85.77 & & \\
\hline 1.6 & 58.26 & 22.46 & \\
\hline 1.85 & 44.86 & & \\
\hline 2.0 & 37.52 & & \\
\hline 2.2 & 31.55 & & \\
\hline 2.4 & 29.05 & 22.52 & \\
\hline 2.6 & 26.25 & & \\
\hline 2.85 & 24.54 & & \\
\hline
\end{tabular}

\begin{tabular}{|c|c|c|c|}
\hline ND & Mu & Backgnd & Mu-Back \\
\hline 0.85 & 224.40 & 18.43 & \\
\hline 1.0 & 195.34 & & \\
\hline 1.2 & 113.20 & & \\
\hline 1.4 & 83.42 & & \\
\hline 1.6 & 55.98 & 18.57 & \\
\hline 1.85 & 38.68 & & \\
\hline 2.0 & 33.91 & & \\
\hline 2.2 & 27.93 & & \\
\hline 2.4 & 25.20 & 18.64 & \\
\hline 2.6 & 22.50 & & \\
\hline 2.85 & 20.72 & & \\
\hline
\end{tabular}




\subsection{Linearity Data Processing}

Graphing techniques will vary with software. If you use Cricketgraph, select the "scatter" graph format. Note: $Y$ axis $=M u-B a c k ; X$ axis $=N D$.

Choose a logarithmic $Y$ axis and an exponential curve fit.

Here is a flat field linearity graph using Cricketgraph:

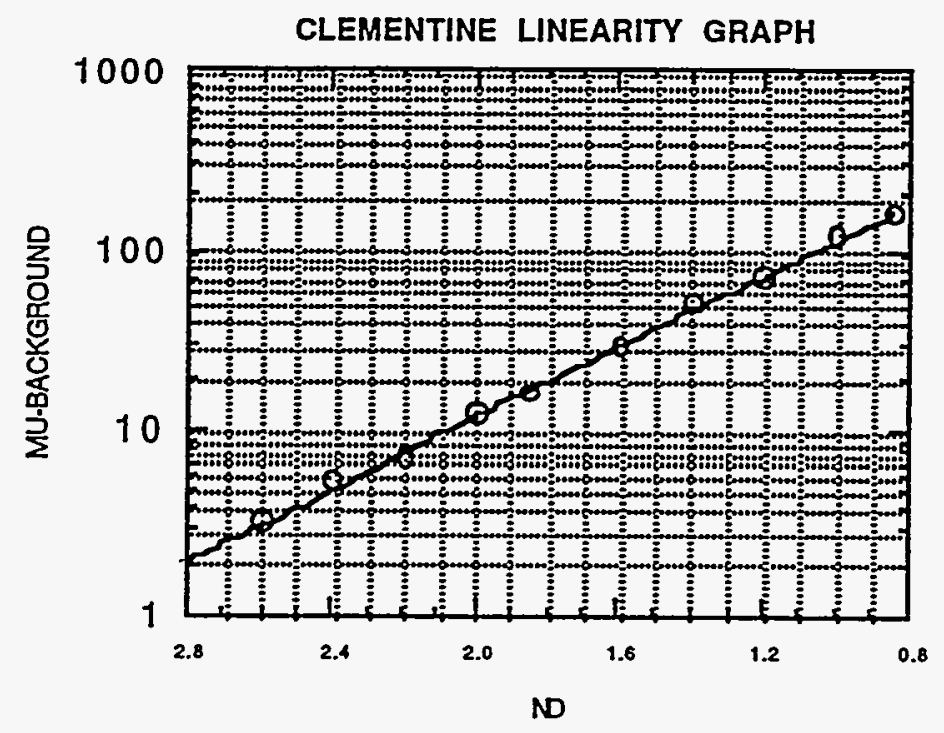

Confirm your linear results:

$S N \#$ OY - O6
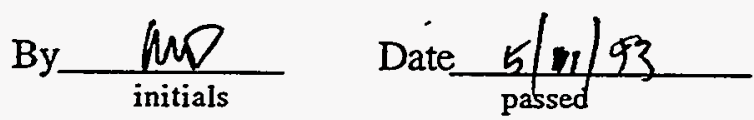

REMEMBER to include your recorded documentation in the test procedure! (a document protector is advised) 


\section{Offset Linearity Test}

This test requires the use of the SUN Datacube and its image processing capabilities, a TV Optoliner Model K-4000 with neutral density(ND) filters ranging up to 1.8, and a resolution - chart for focusing.

\subsection{Offset Linearity Test Setup}

Using alcohol and Q-tips, clean the installed CCD.

Verify a properly connected camera acquisition system.

Power up the test fixture.

Put the frame grabber in the grab mode.

Install a total 0.8 Neutral Density (ND) filter and test pattern in the T.V. Optoliner.

Adjust the camera board so that the test pattern image is focused on the CCD.

NOTE: With the focal plane now established, neither the camera nor the optoliner can be moved.

Remove test pattern for a flat field image.Set the board gain to gain setting of 2 .

Remove all ND $(\mathrm{ND}=0.0)$ and input a HEX offset of 00 .

Adjust the T.V. Optoliner lamp voltage so that you get a $M U$ of $\approx 250$ counts.

Allow the T.V. Optoliner and camera to warm up under continuous operation for $\approx 1$ hour before proceeding. Keeping the camera's environmental temperature constant and allowing a long warm up requires only one background histogram for linearity computation. 


\section{ST2 SN\#04-10 Offset Linearity Graph}

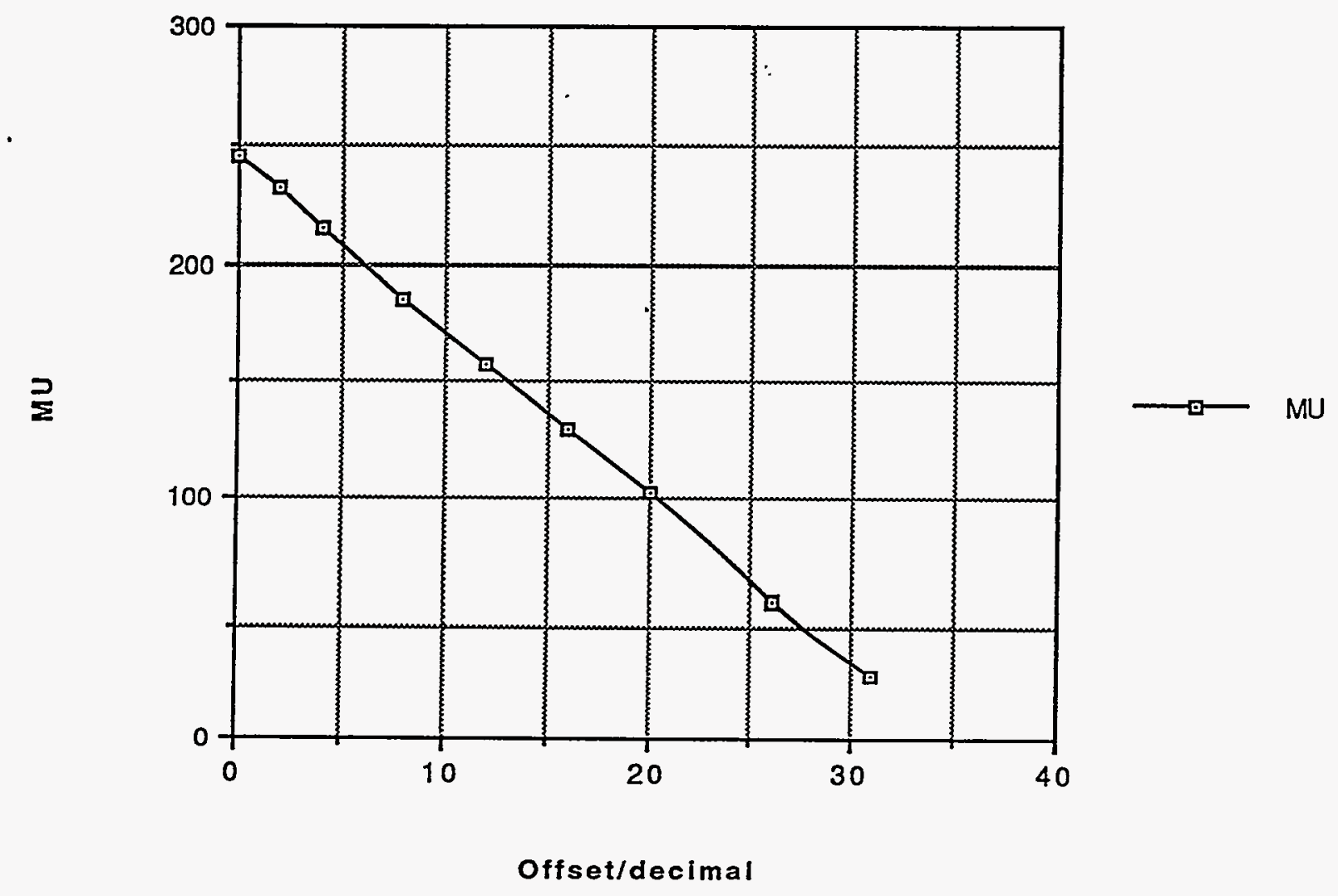


ST2/SN\#04-06/OffLNDT

$\begin{array}{cccc}\text { Offset/decimal } & M U & \text { Colum } & \text { Column } 4 \\ 1 & & & \\ 2 & 0 & 244.71 & 5 / 10 / 93 \\ 3 & 2 & 231.80 & \text { ST2 SN\#04-06 } \\ 4 & 4 & 215.30 & \text { P.S. }=14.0 \mathrm{~V} \\ 5 & 8 & 185.76 & \text { CCD\#8846 } \\ 6 & 12 & 157.43 & \text { SUNDATACUBE } \\ 7 & 16 & 129.87 & \\ 8 & 20 & 102.70 & 350 \mathrm{e} / \mathrm{bit} \\ 9 & 26 & 60.23 & \text { P.S. \#5008 } \\ 0 & 31 & 28.37 & \text { HEAD } \$ 4163\end{array}$

Thu, May 13, 1993 2:22 PM 


\subsection{Offset Linearity Measurement Acquisition}

Use the SUN Datacube " Acquire and build histogram Sequence " to capture a frame and process a defined region of interest and to analyze for $\mathrm{mu} / \mathrm{sigma}$ histograms.

\subsection{Offset Linearity Data and Graph}

Begin by taking a background level. Use an ND of 8.0 for background.

Input the offset values listed in the table below recording a histogram of the defined region of interest each time.

Power down the test fixture.

\begin{tabular}{|c|c|c|c|}
\hline Offset & Mu & Backgnd & Mu-Back \\
\hline 00 & & & \\
\hline 02 & 244.7 & & \\
\hline 04 & 231.80 & & \\
\hline 08 & 215.30 & & \\
\hline 12 & 185.76 & & \\
\hline 16 & 157.43 & & \\
\hline 20 & 129.87 & & \\
\hline 26 & 102.70 & & \\
\hline 31 & 60.23 & & \\
\hline
\end{tabular}


Graphing techniques will vary with software. If you use Cricketgraph, select the "scatter" graph format. Plot MU-BACKGROUND vs OFFSET

Choose a linear $\mathrm{Y}$ axis and linear curve fit.

Here is an offset linearity graph using Cricketgraph:

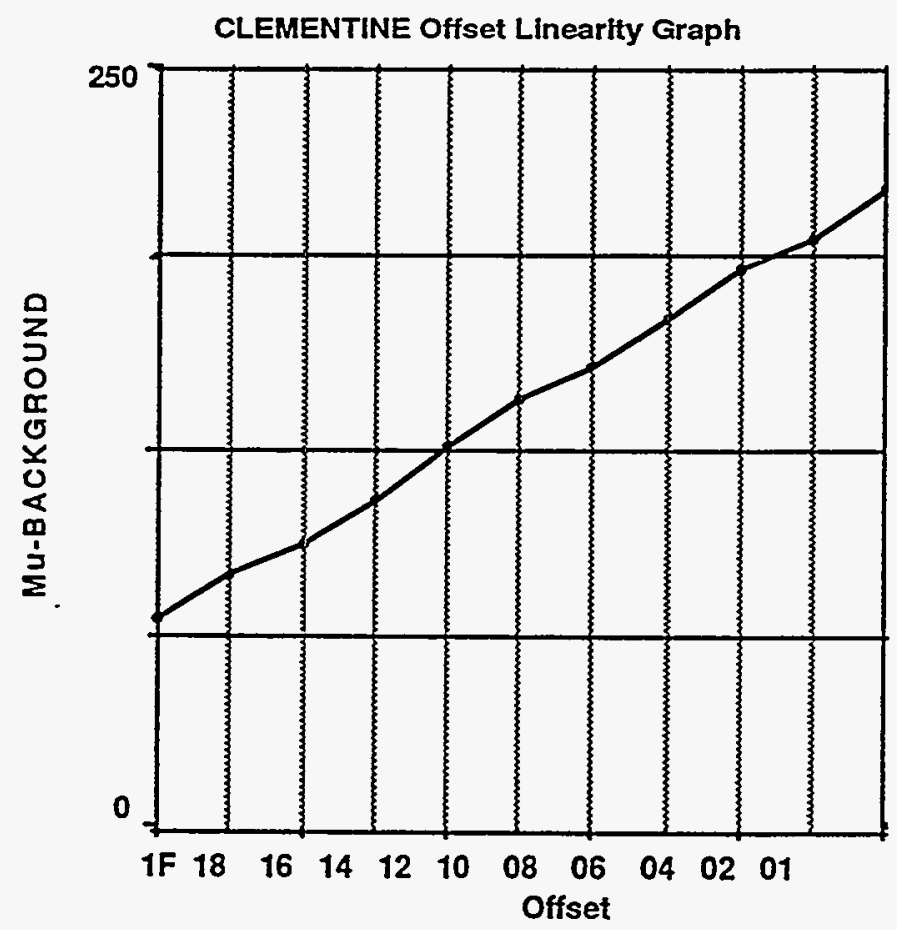

SN\#_04-66 By $\frac{\text { mit }}{\text { initials }}$ Date $\frac{5|10| 96}{\text { passed }}$

REMEMBER to include your recorded documentation in the test procedure! (a document protector is advised) 


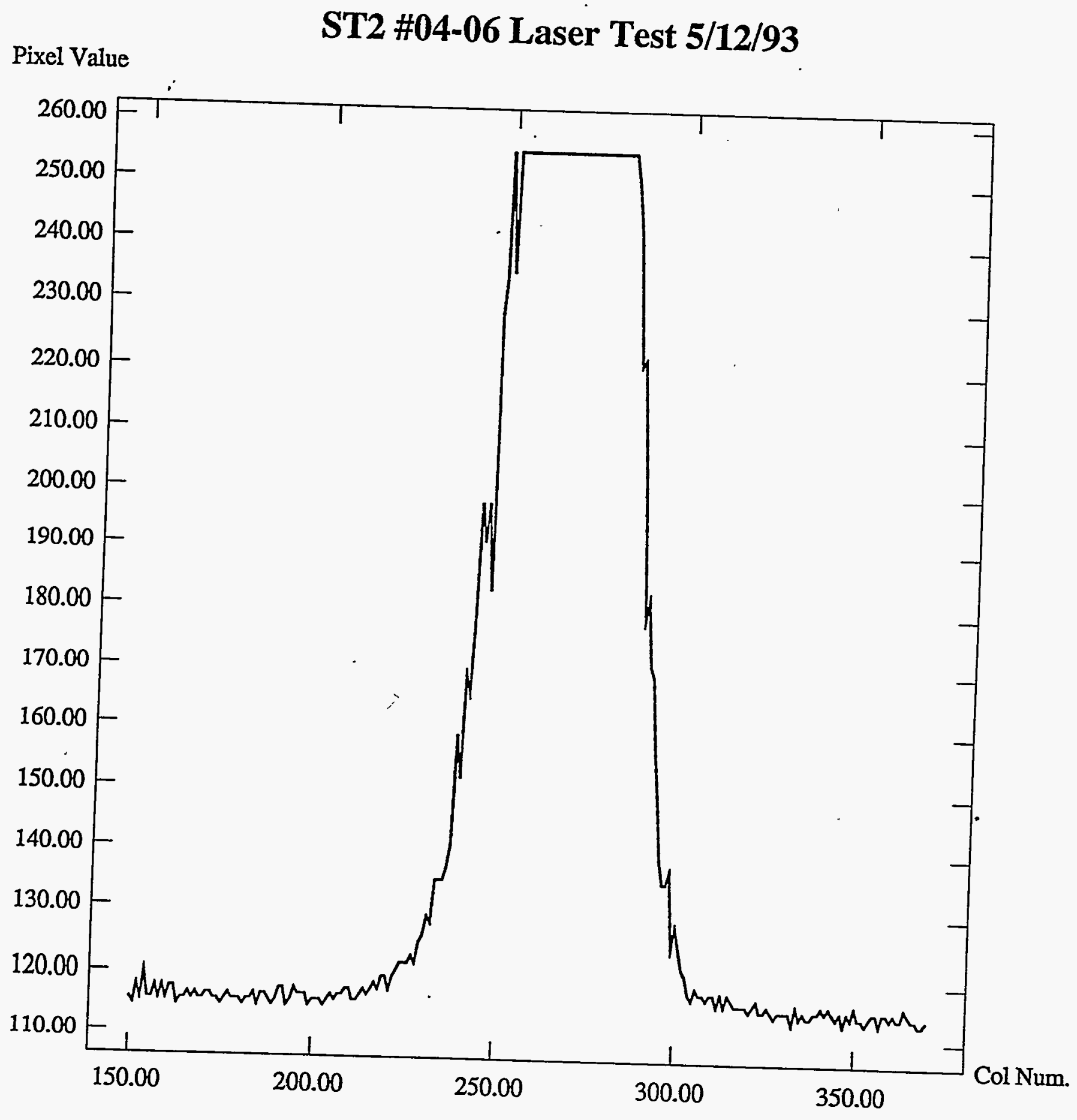




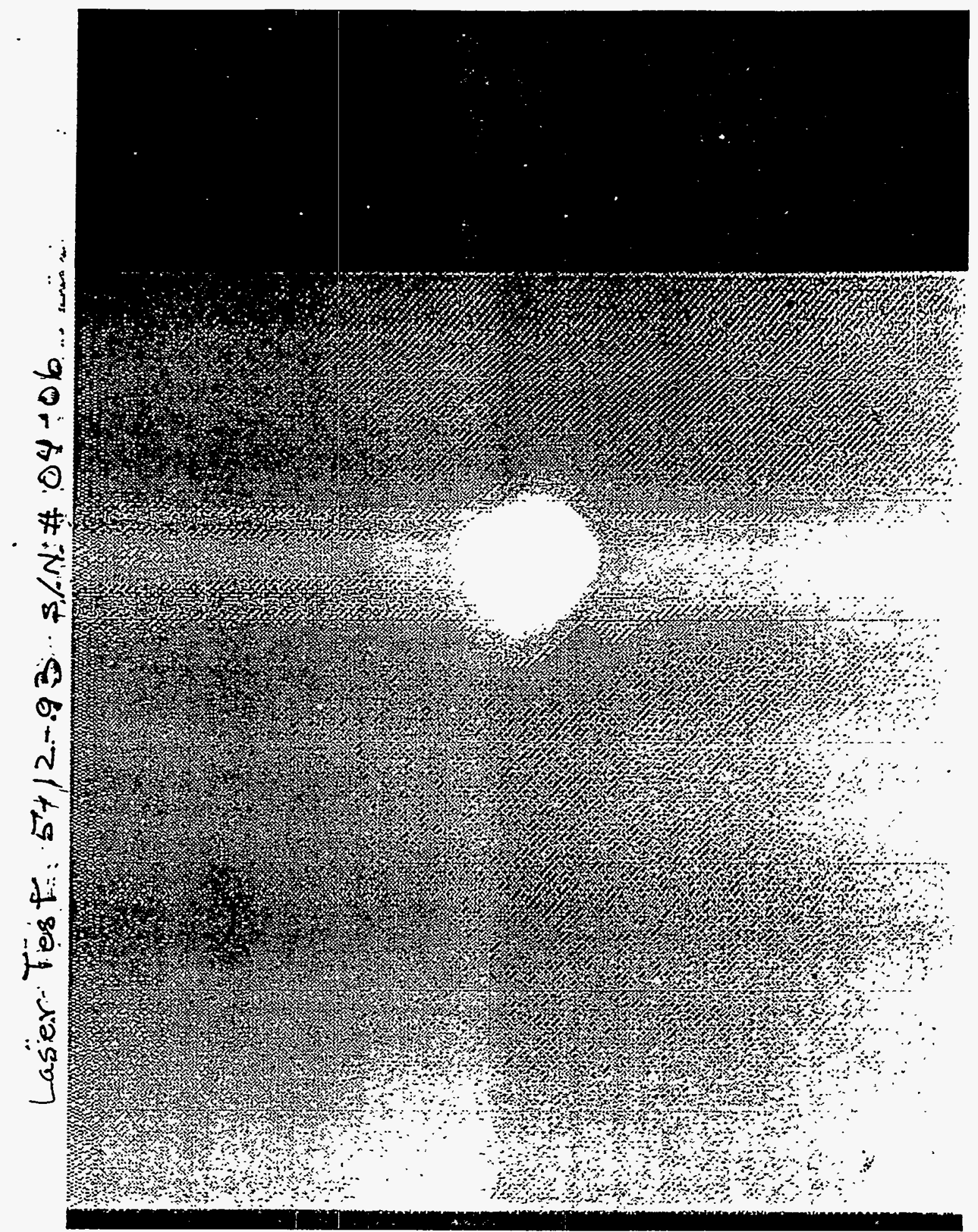




\section{Laser Test}

This test requires the use of the SUN Datacube and its image processing capabilities, a HeNe Laser, $1 \mathrm{~mW}$ at $632.8 \mathrm{~nm}$ appropriate ND filters ranging from 2.0 to 6.0 or combinations equaling such.

Verify a working camera system.

Turn off camera power.

Position a.HeNe Laser on the approximate center of the CCD.

Place an optical ND filter holder in the path of the laser beam.

Power the camera.

Place the SUN Datacube in the Acquire mode.

Do a Print Pixel-see Guide to Running hspcube, C1-S1-002-to check pixel values of illuminated area.

Install sufficient optical ND to reduce the intensity of the laser light to the saturation level of the $\mathrm{CCD}$ or 255 counts.

Do a Get Row Lineout plot-see Guide to Running hspcube,C1-S1-002-through the illuminate area.

Note: There should be no oscillations or tailing around the saturated spot.

Use the video copier to record the non-oscillating saturated laser spot image.

SN\#_04-06
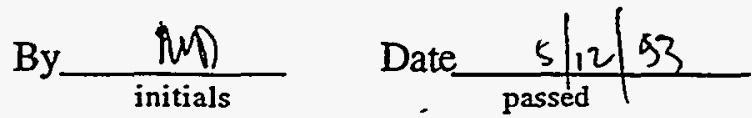

REMEMBER to include your recorded documentation in the test procedure! (a document protector is advised) 


\section{Tests Required after Conformal Coating}

Archive/record a post conformal coat:

1) Dark Noise Measurement (Section 11).

2) A focused test pattern image using the TV Optoliner.

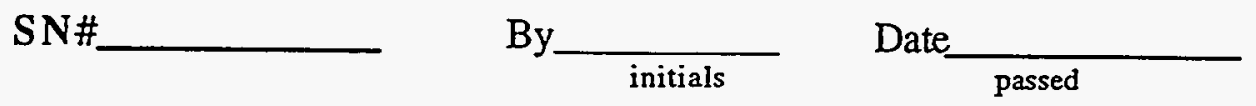

REMEMBER to include your recorded documentation in the test procedure! (a document protector is advised)

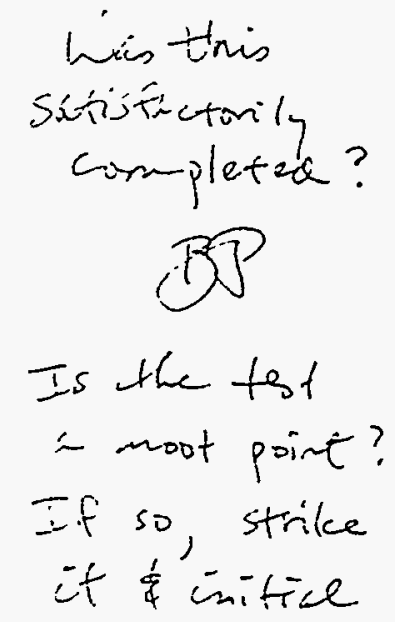

$\frac{1}{2}:$ 


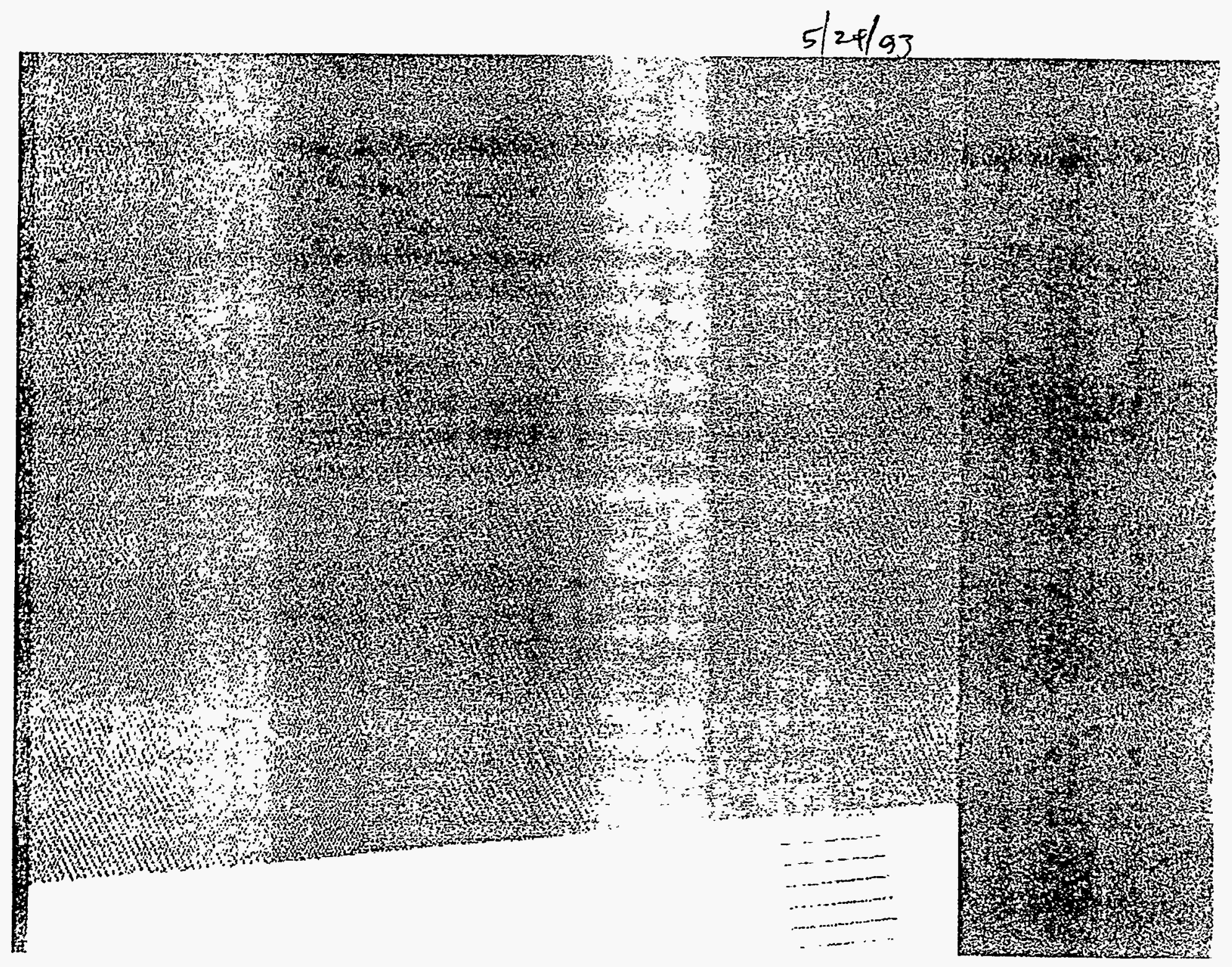


ST Camera: sn\#04-06: int_time= 50ms, offset= 0, gain=1 ( $350 \mathrm{e} / \mathrm{bit}$ ) Mon May 24 09:52:09 1993 Pixel Values Min 30 Max 33 Mean 31.2 Sigma $0.43 \times 10^{3}$

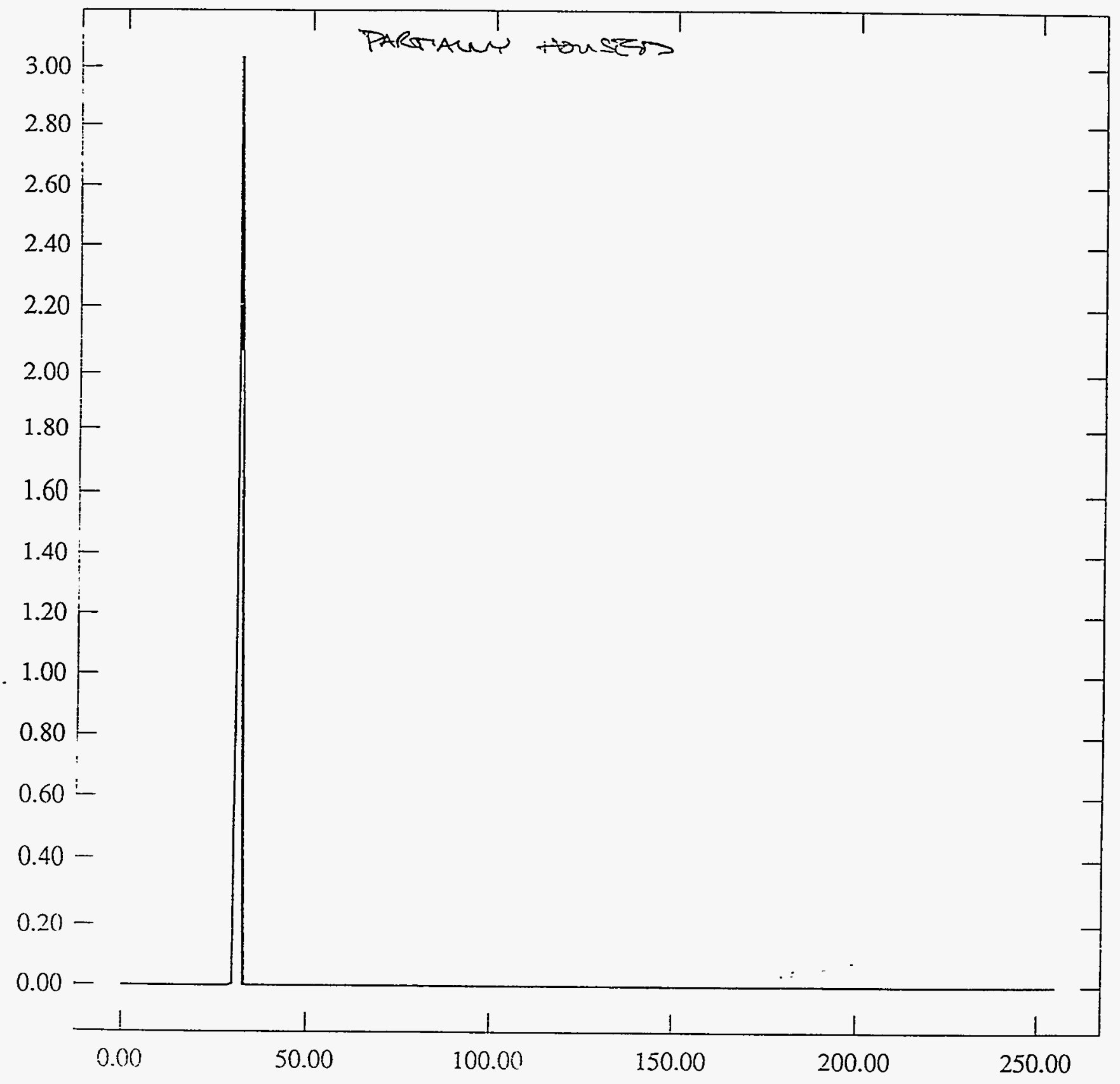


ST Camera: $\mathrm{SN}$ \#04-06hsdFO\#1: int_time $=50 \mathrm{~ms}$, offset=0, gain=1 ( $350 \mathrm{e} / \mathrm{bit})$ Mon May 24 23:09:27 1993 Pixel Values Min $42 \operatorname{Max} 46$ Mean 44.5 Sigma $0.60 \times 10^{3}$

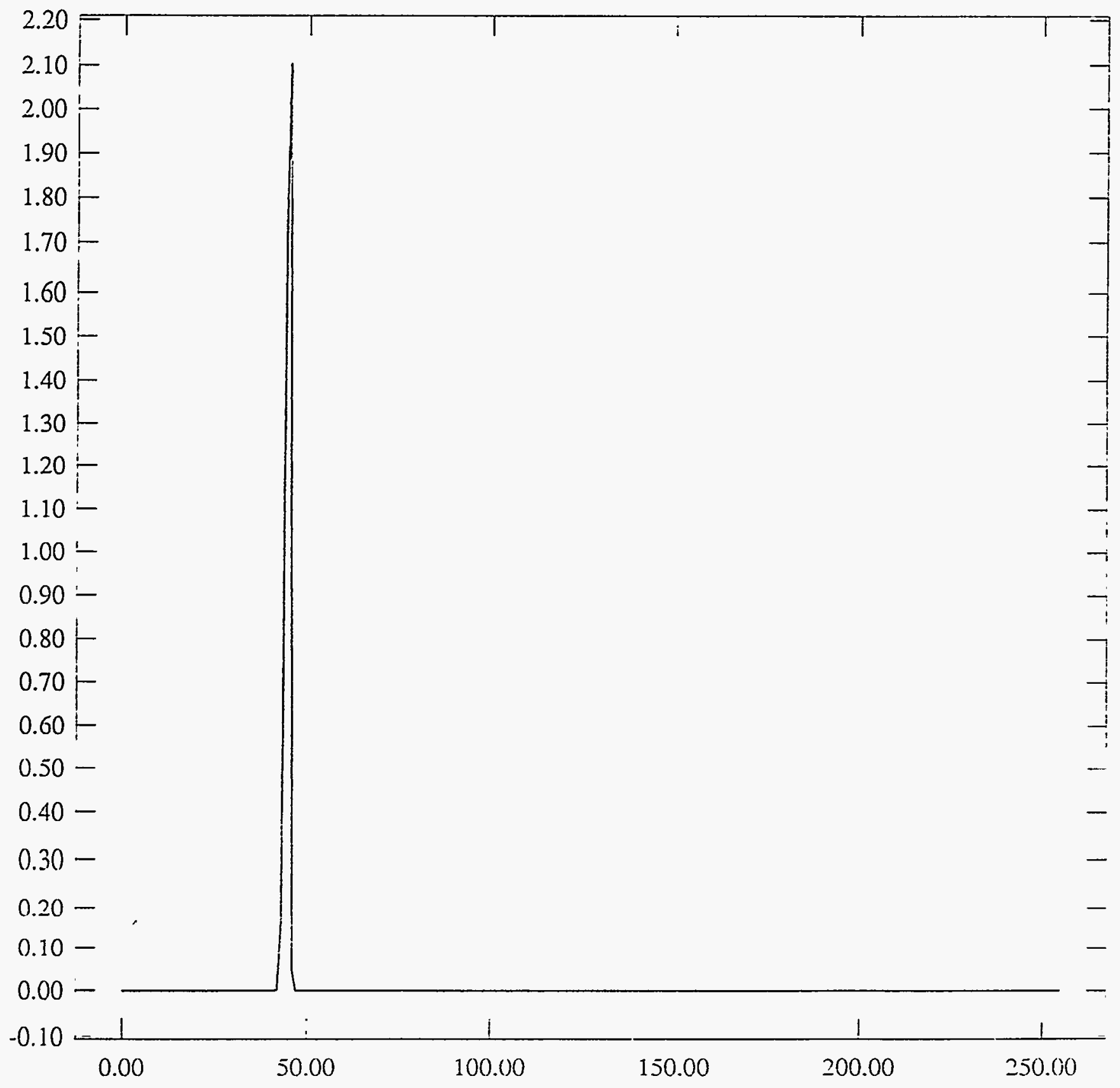


ST Camera: SN\#04-06hsdFO\#1: int_time $=50 \mathrm{~ms}$, offset= 0. gain=2 ( $150 \mathrm{e} / \mathrm{bit})$ Mon May 24 23:10:51 1993 Pixel Values Min 95 Max 103 Mean 97.5 Sigma $0.64 \times 10^{3}$

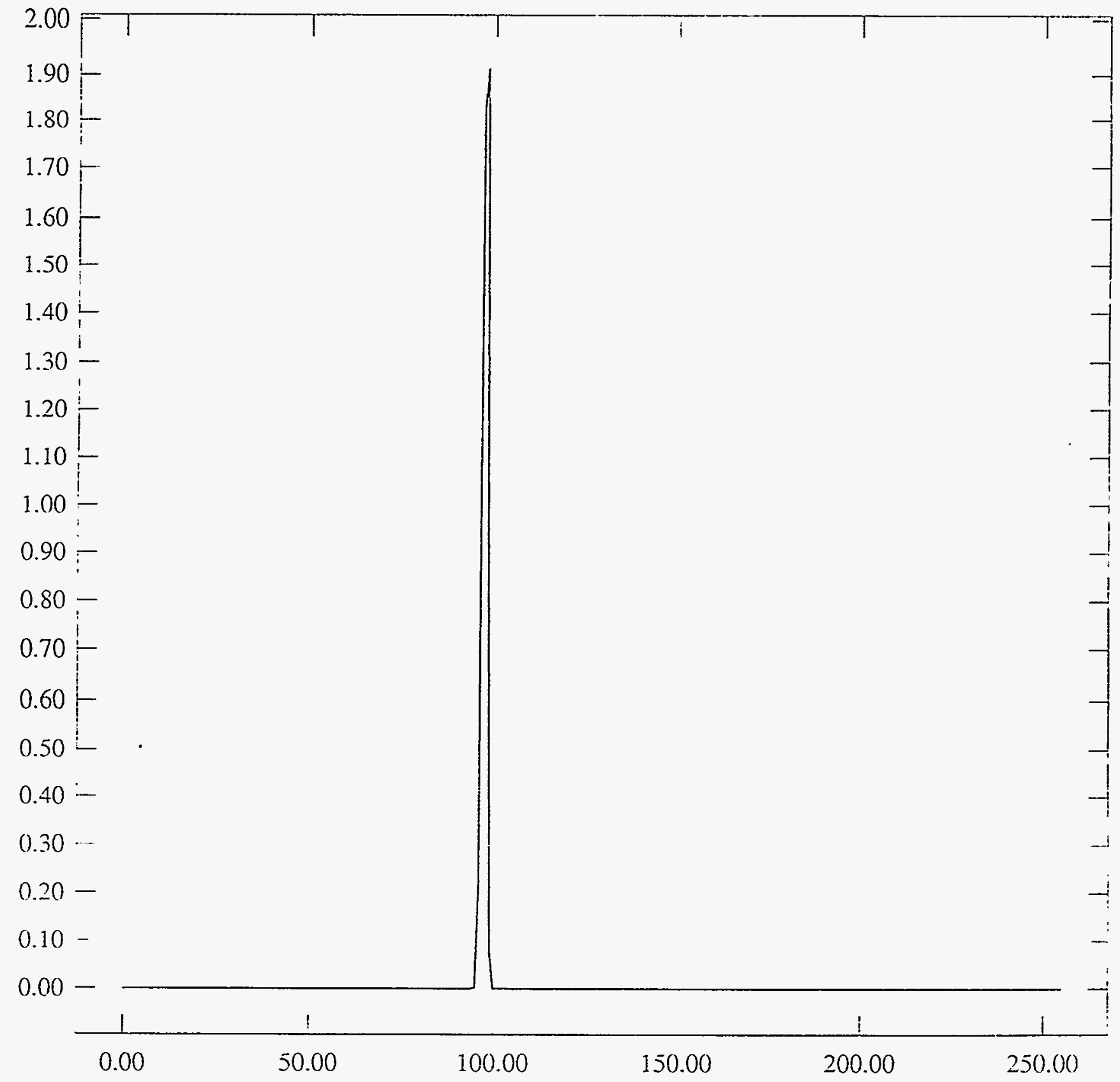


ST Camera: SN\#04-06hsdFO\#1: int_time= 50ms. offset = 0. gain=4 ( 75 e/bit) Mon May 24 23:12:29 1993 Pixel Values Min 184 Max 196 Mean 189.1 Sigma $1.27 \times 10^{3}$

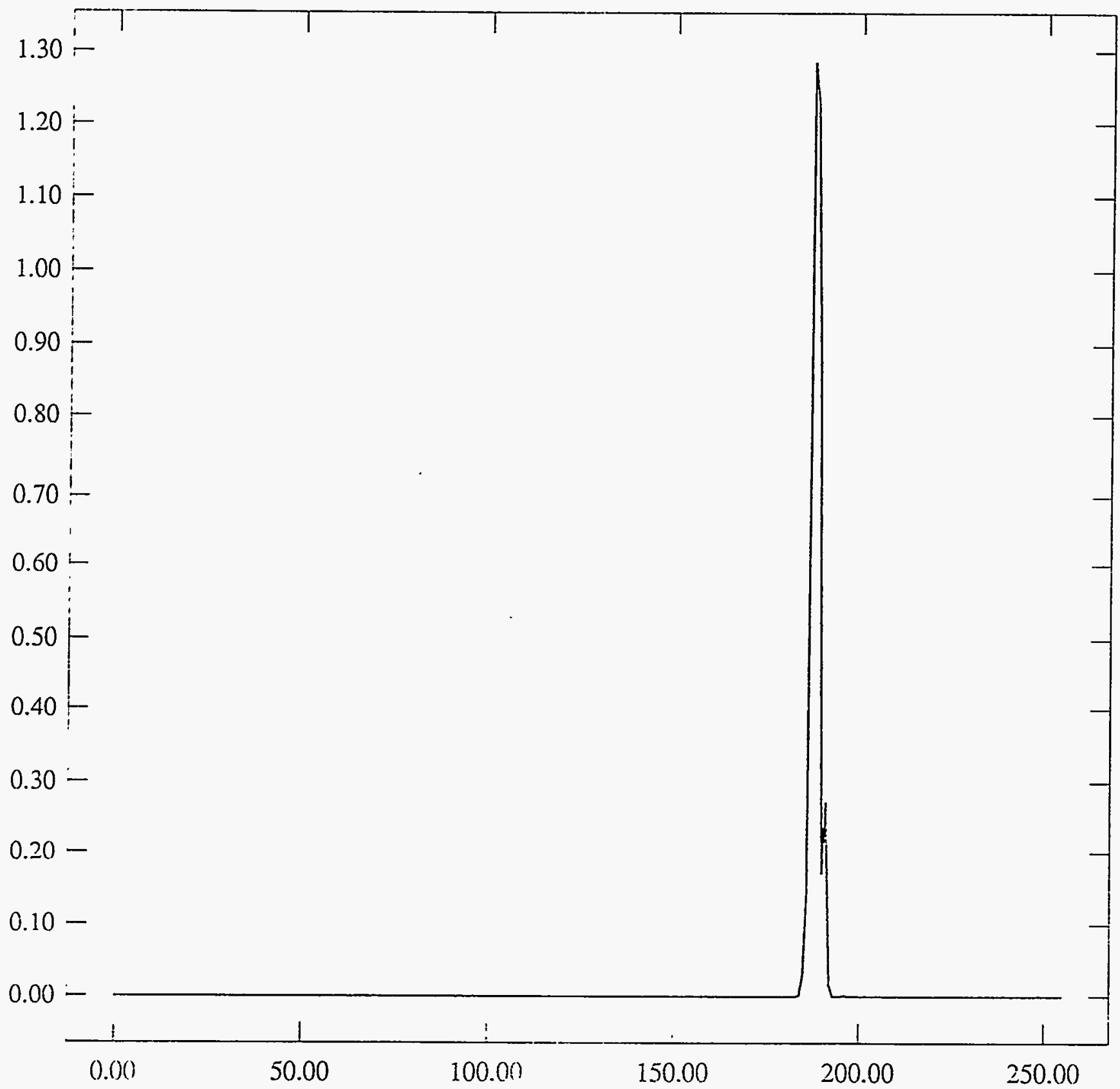




\section{Sub and Final Assembly Resistance and Voltage Specificity prior to Power-up}

Inspect the camera for connector saver and shorting plug. If one or both of these are not present obtain them. A 51-contact breakout should be aitached to the connector saver to perform this test. The 51-contact shorting plug should be attached to the connector saver for transport or storage once this test is complete.

Using a flight certified breakout connector-

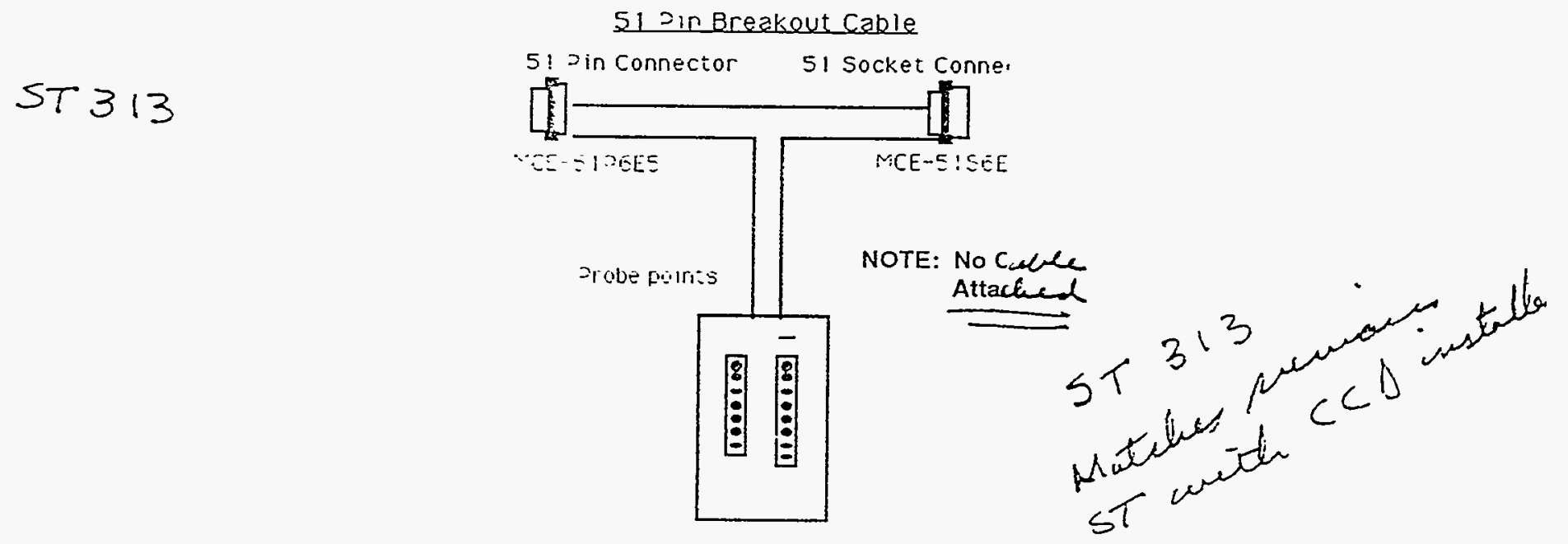

-Verify these resistances:

\begin{tabular}{|c|c|c|c|c|c|c|}
\hline \multicolumn{7}{|c|}{ pin\# } \\
\hline DVM(common) & & DVM(signal) & expected & \multicolumn{3}{|l|}{ measured $\Omega$} \\
\hline \multirow[t]{6}{*}{5 (AGND) } & - & $39(+15 \vee D C)$ & $>400 \Omega$ & \multicolumn{3}{|l|}{$487 \Omega$} \\
\hline & - & $4 \quad(-15 \vee D C)$ & $>12 K \Omega$ & \multicolumn{3}{|l|}{$1 z_{k}$} \\
\hline & - & $37 \quad(+5 \mathrm{VDC})$ & $>400 \Omega$ & \multicolumn{3}{|l|}{$429 \Omega$} \\
\hline & - & $38 \quad(+5 \vee D C)$ & $>400 \Omega$ & \multicolumn{3}{|l|}{$429 \Omega$} \\
\hline & - & $3 \quad(-5 \vee D C)$ & $>1 \mathrm{k} \Omega$ & \multicolumn{3}{|l|}{$1.5 \mathrm{~K} \Omega$} \\
\hline & - & $40 \quad(+5 \mathrm{VIN})$ & $>4 k \Omega$ & \multicolumn{3}{|c|}{$4 k \Omega$} \\
\hline \multirow[t]{6}{*}{20 (DGND) } & - & 5 & $\leq 1 \Omega$ & \multicolumn{3}{|l|}{$.3 \Omega$} \\
\hline & - & 39 & $><00 \Omega$ & \multicolumn{3}{|l|}{48112} \\
\hline & - & 37 & $>\angle 00 \Omega$ & \multicolumn{3}{|l|}{$429 \Omega$} \\
\hline & - & 38 & $>-00 \Omega$ & \multicolumn{3}{|l|}{4290} \\
\hline & - & 3 & $>\div K \Omega$ & \multicolumn{3}{|l|}{$1.53^{\prime}(8)$} \\
\hline & - & 40 & $>\angle K \subseteq 2$ & $4.3 K \Omega$ & 否 & \\
\hline \multirow[t]{5}{*}{$39(+15 V D C)$} & - & 4 & $>11 K \Omega$ & \multicolumn{3}{|l|}{$11.8(6)$} \\
\hline & - & 37 & $>: O K \Omega$ & $258 \Omega$ & 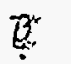 & $? 958$ \\
\hline & - & 38 & $>^{-} \partial K \Omega$ & $958 \Omega$ & $?$ & $\therefore \quad \varphi \leq \tau$. \\
\hline & - & 3 & $=-E$ ris. & $z K I I$ & $?$ & $?=5=$ \\
\hline & - & 40 & $>i \Xi K \Omega !$ & 4.84! & $?$ & $\therefore<.816$ \\
\hline
\end{tabular}




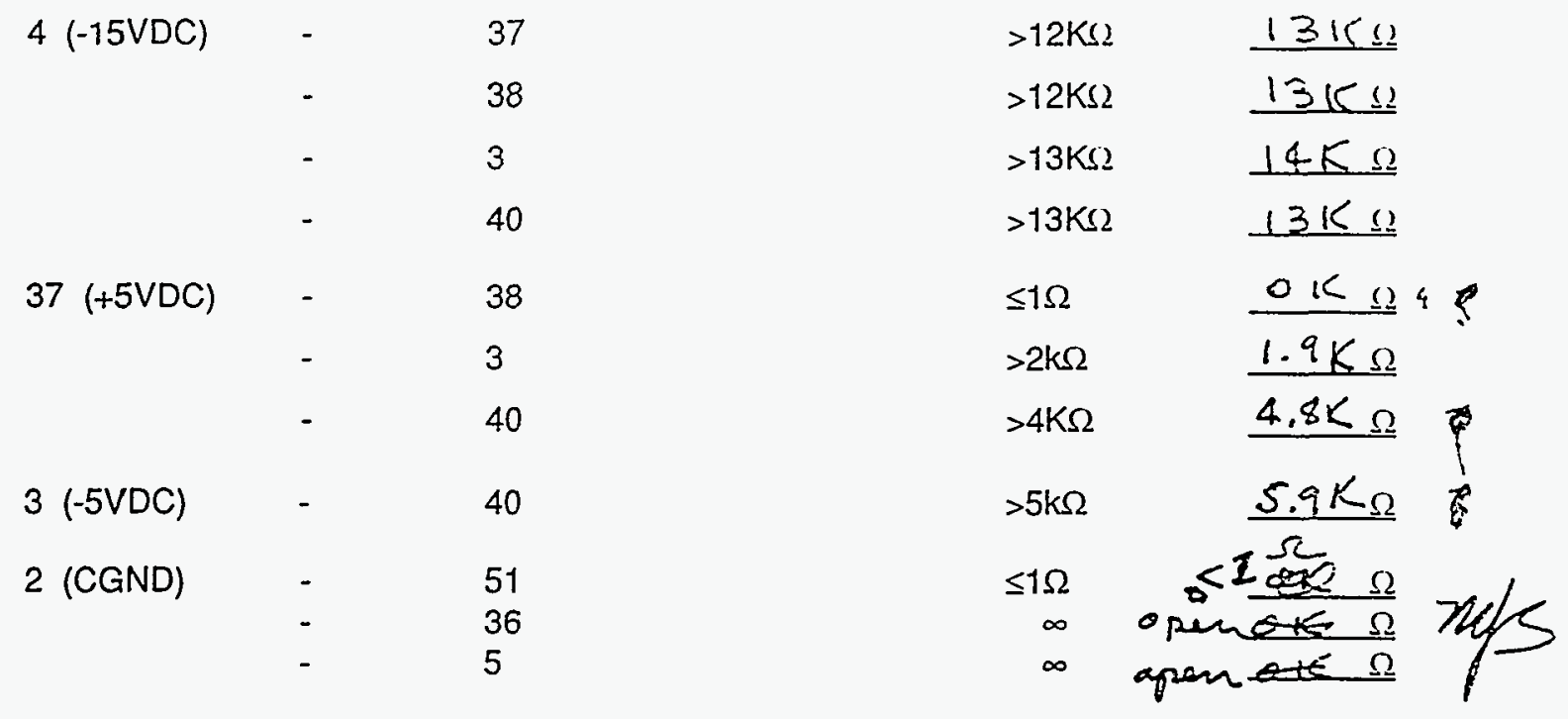

Using a flight certified breakout connector, verify power voltages at cable connector-camera end-before attaching it to the camera board. Use $\mathrm{J1}$-pin 20 for multimeter ground and complete the following table.

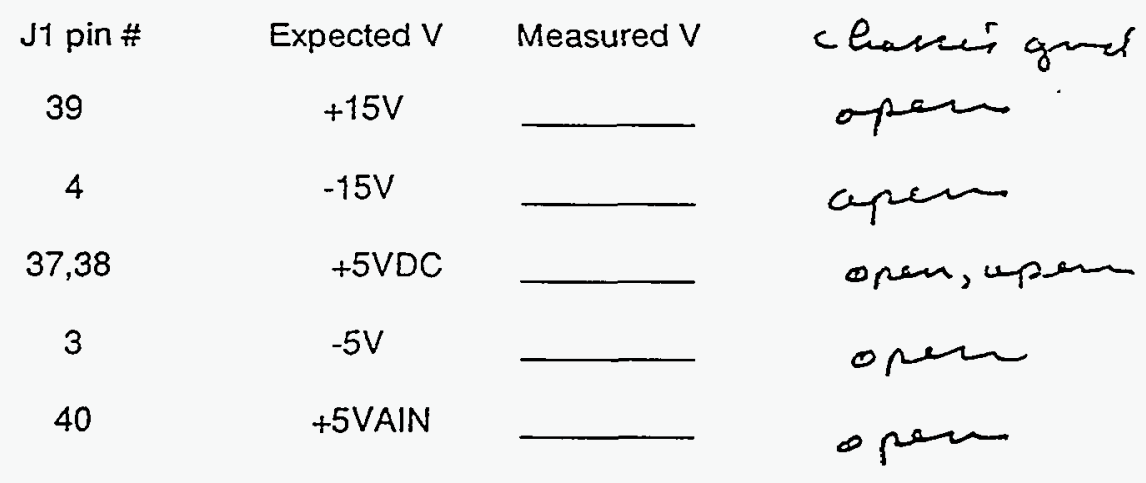

Turn off the power. Specificity verified, the camera and cabling are ready for power-up.

SN\# ST3/3

By

initials

Date $\frac{6 / 15 / 93}{\text { passed }}$ 


\section{Room Temperature Dark Measurement Data}

Connect a quality assured data acquisition system and cabling with the resistance verified camera to be tested.

Acquire images at all three gain values-1.2. and 4 -using a $50 \mathrm{~ms}$ integration time and 0 ofíset.

Turn off power.

Using the same region of interest for each acquired image, process a histogram resulting in MU and SIGMA values. These values should correspond to those taken at $=20^{\circ} \mathrm{C}$ during the Thermal Test. Therefore. review the $50 \mathrm{~ms}$ data for all three gains at $20^{\circ} \mathrm{C}$. NOTE: This assumes the thermal test was performed with the same CCD now housed.

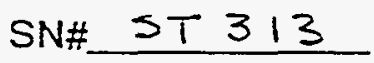

By

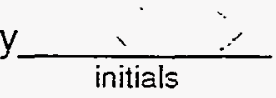

Date $\frac{(\therefore i}{\text { passed }}(0 / 15 / 43$

\section{Imaging Verification}

With adequate lensing, capture an image with the Startracker or UV-Vis camera and verify that it does image.

Place an image-on-clear or text-on-clear transparency against the Lidar intensifier and gaie the intensifier appropriately to capture a Lidar image.

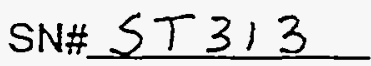

By

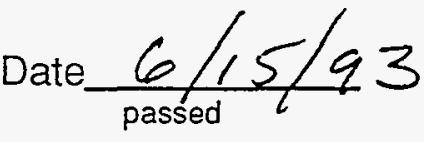

REMEMBER to attach your recorded documentation to this test procedure!

(A documen: protector is advised) 

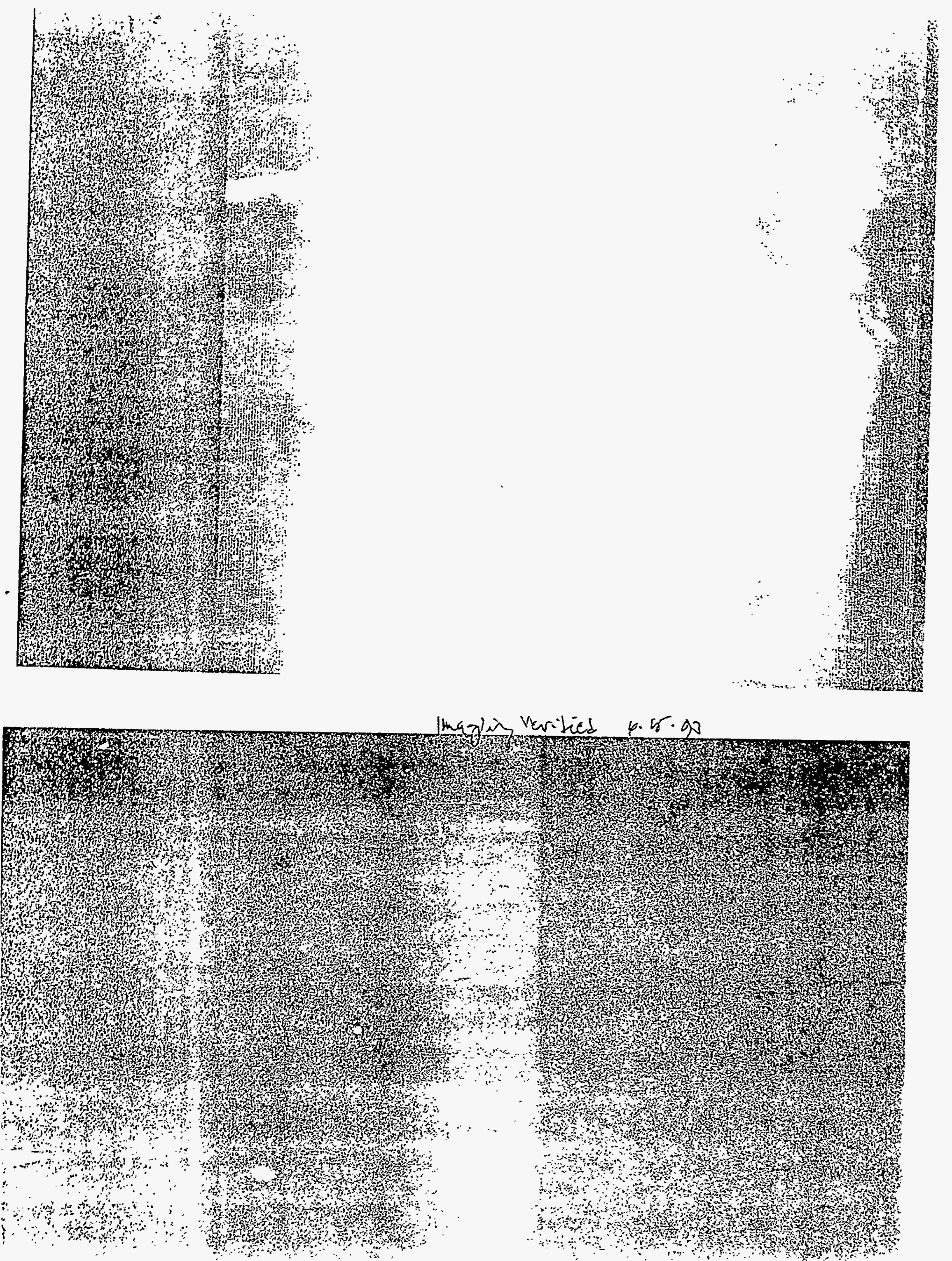
Parte meas. = Hor Carmeza

ST Camera: SN\#04-06 HSD: int_time= 50ms, offset= 0, gain=4 ( $75 \mathrm{e} / \mathrm{bit}$ ) Tue Jun 15 12:39:11 1993

Pixel Values Min 181 Max 196 Mean 184.0 Sigma $1.13 \times 10^{3}$

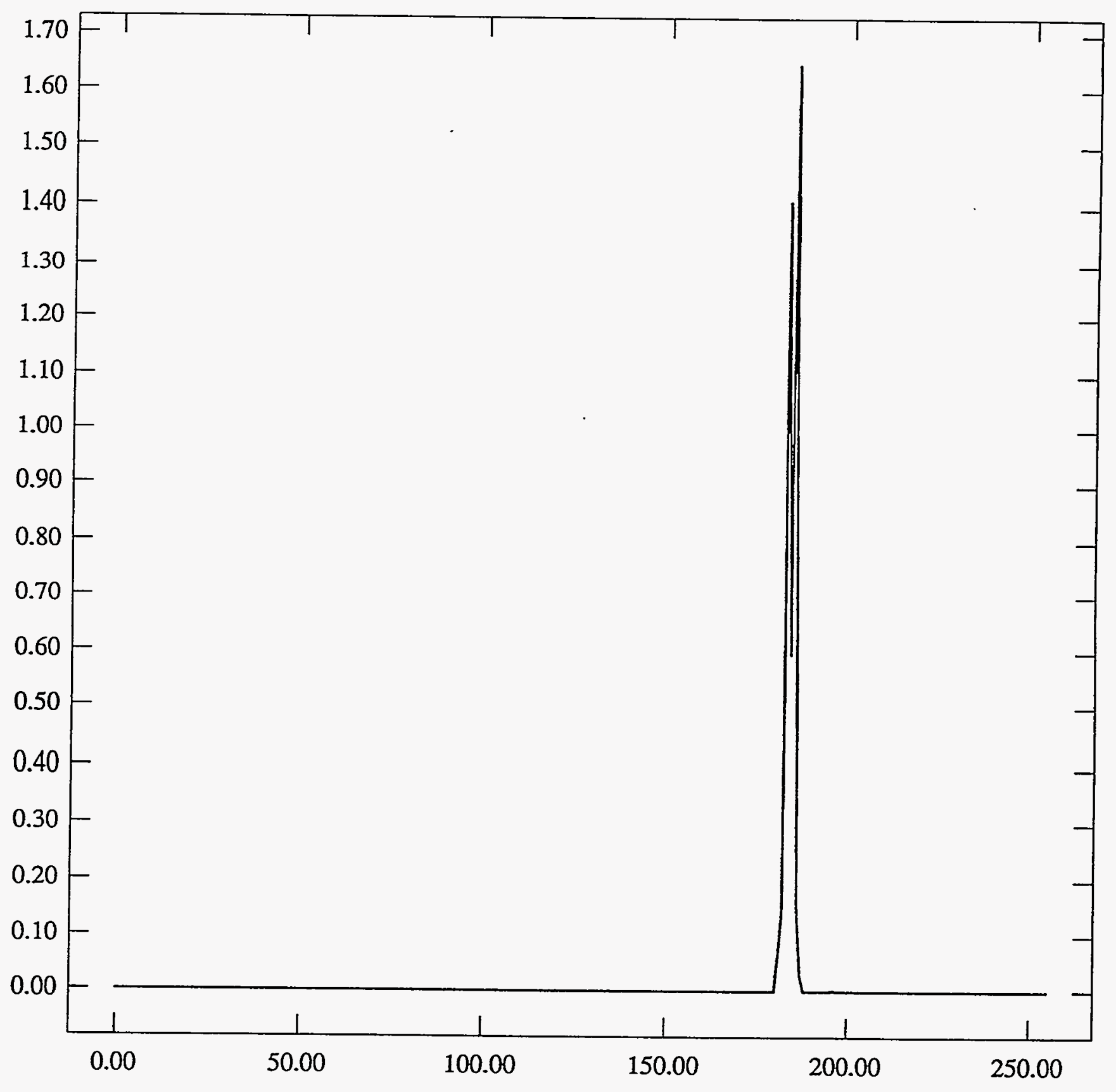


Dare areas. HoT Caswera

ST Camera: SN\#04-06 HSD: int_time= 50ms, offset= 0, gain=2 ( 150 e/bit) Tue Jun 15 12:38:11 1993

Pixel Values Min 93 Max 99 Mean 95.0 Sigma $0.75 \times 10^{3}$

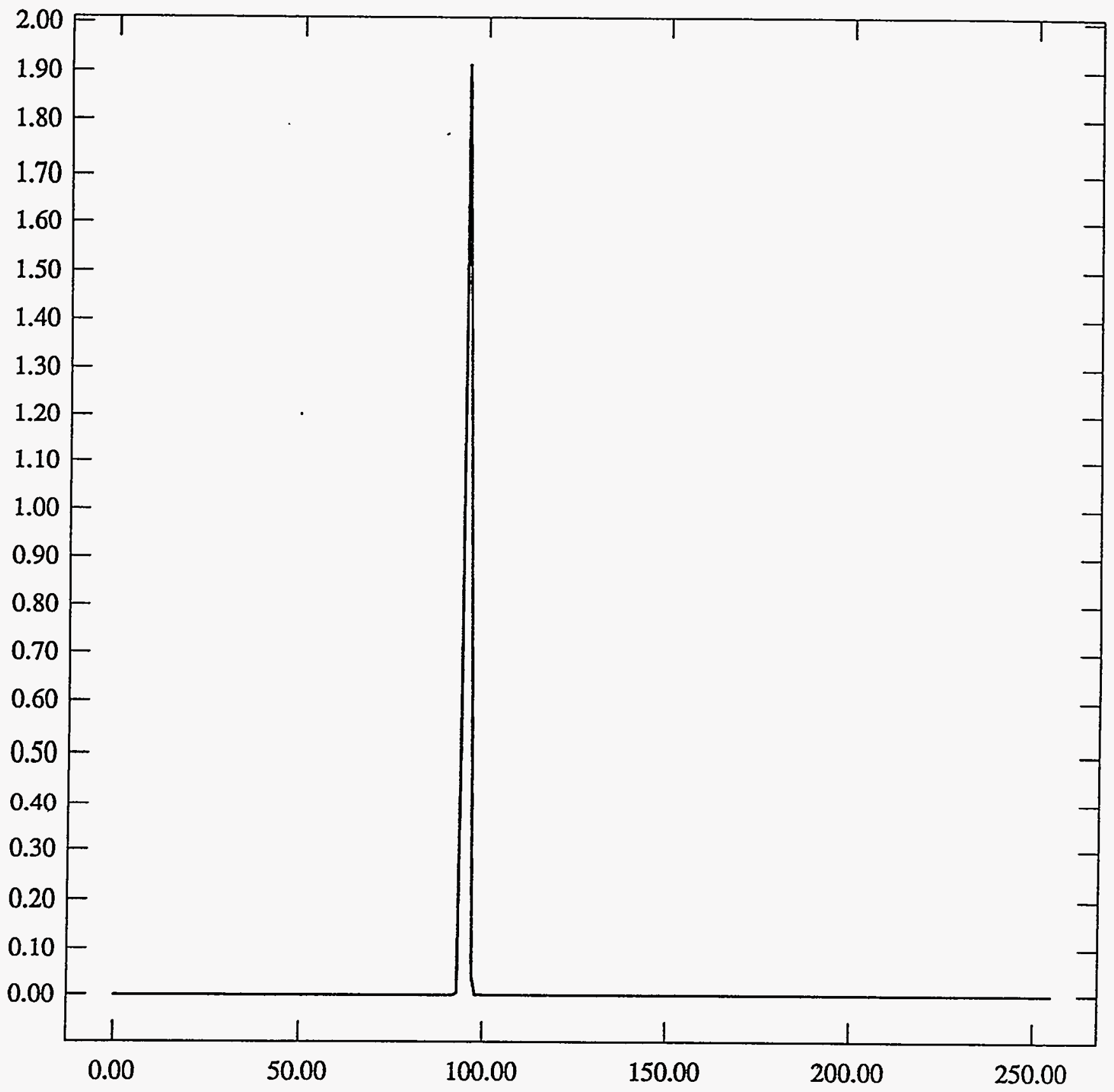


Dark thoor = Hor cAncera

ST Camera: SN\#04-06 HSD: int_time= 50ms, offset= 0, gain=1 ( 350 e/bit) Tue Jun 15 12:37:04 1993 Pixel Values Min 42 Max 45 Mean 43.0 Sigma $0.22 \times 10^{3}$.

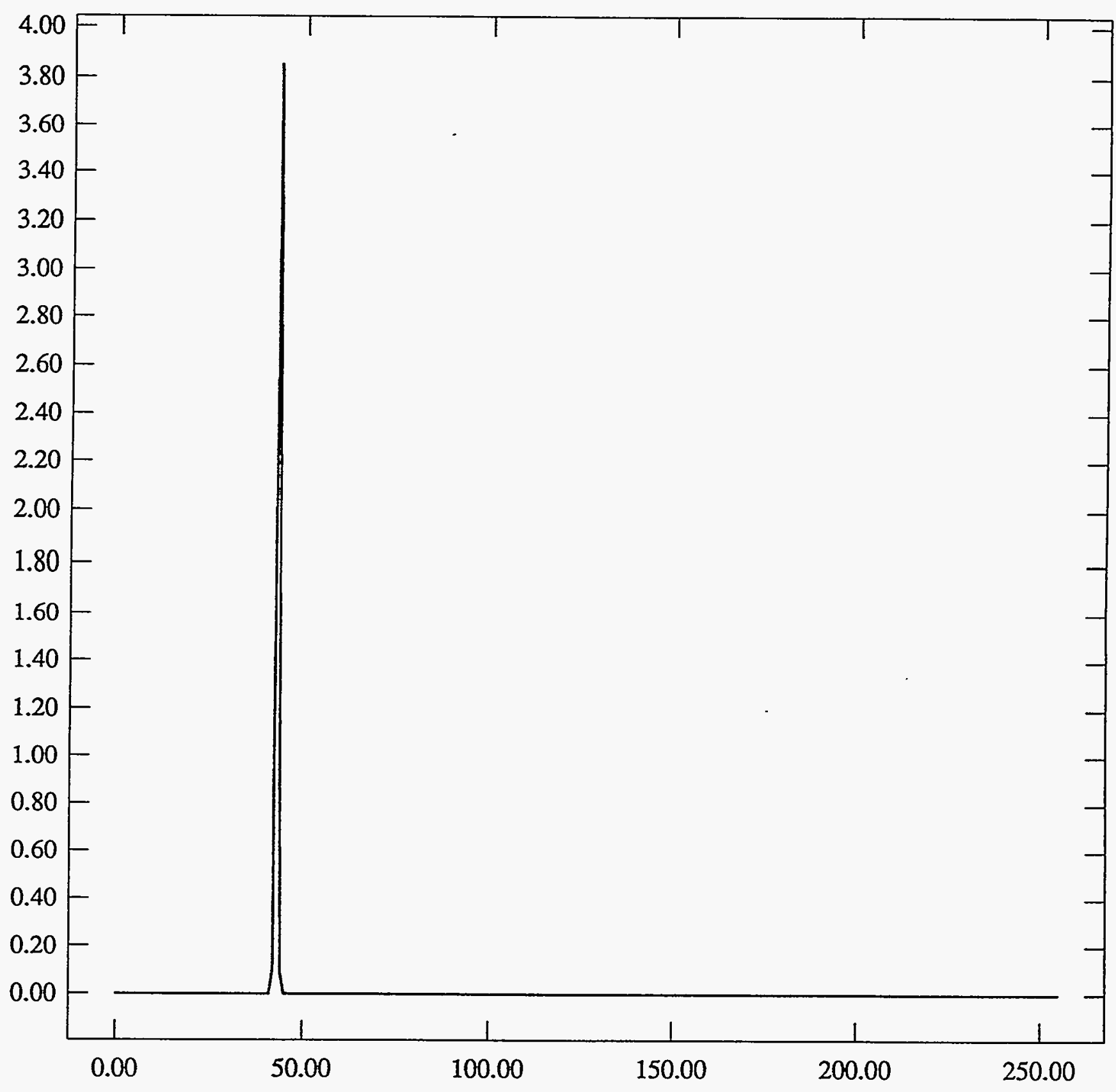


Appendix G.3 Mechanical Assembly Log 
Appendix G.3.1

Operations Sheet 


\section{Clementine doperations St_cet, Certification}

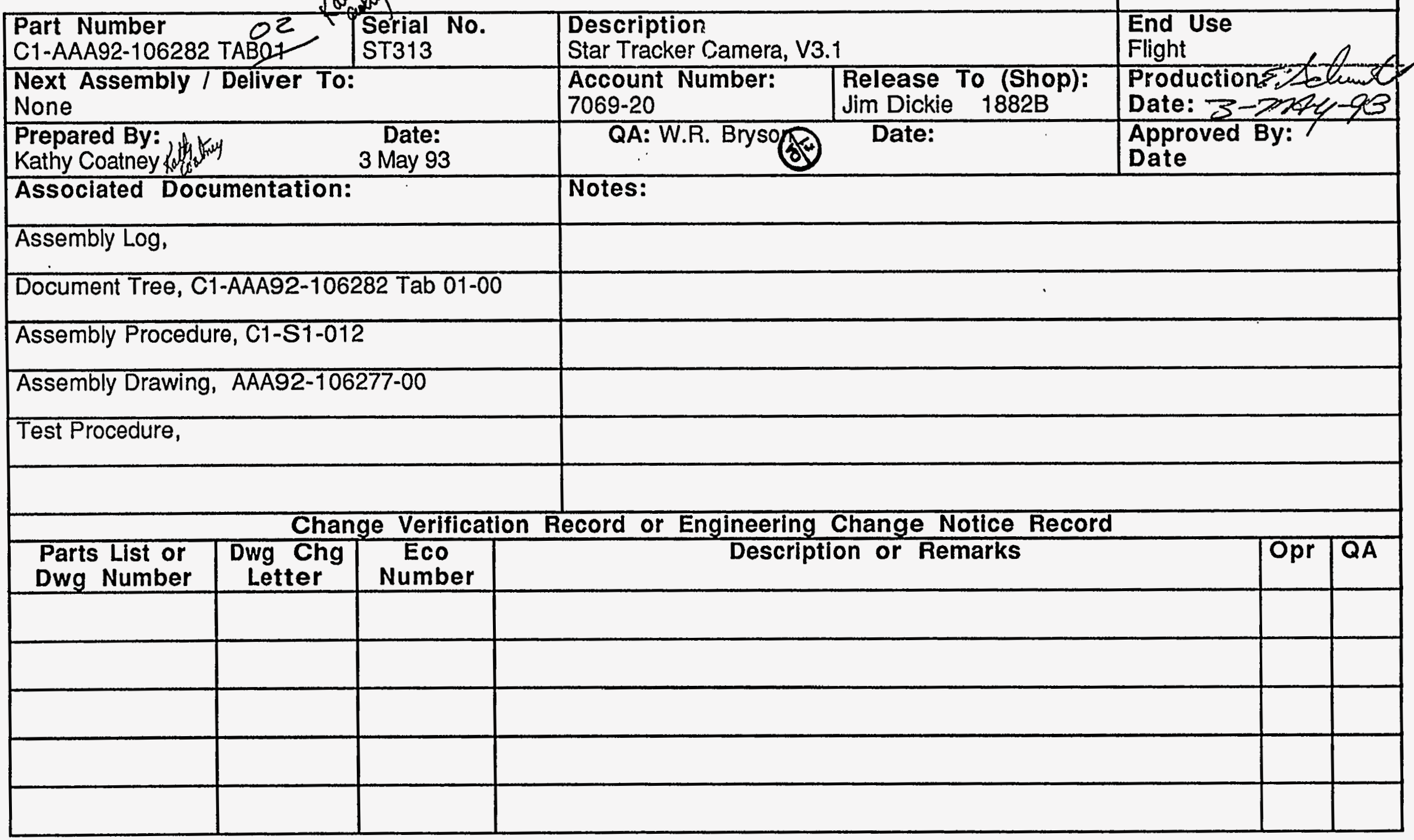




\section{Appendix G.3.2}

\section{Work Sheets}




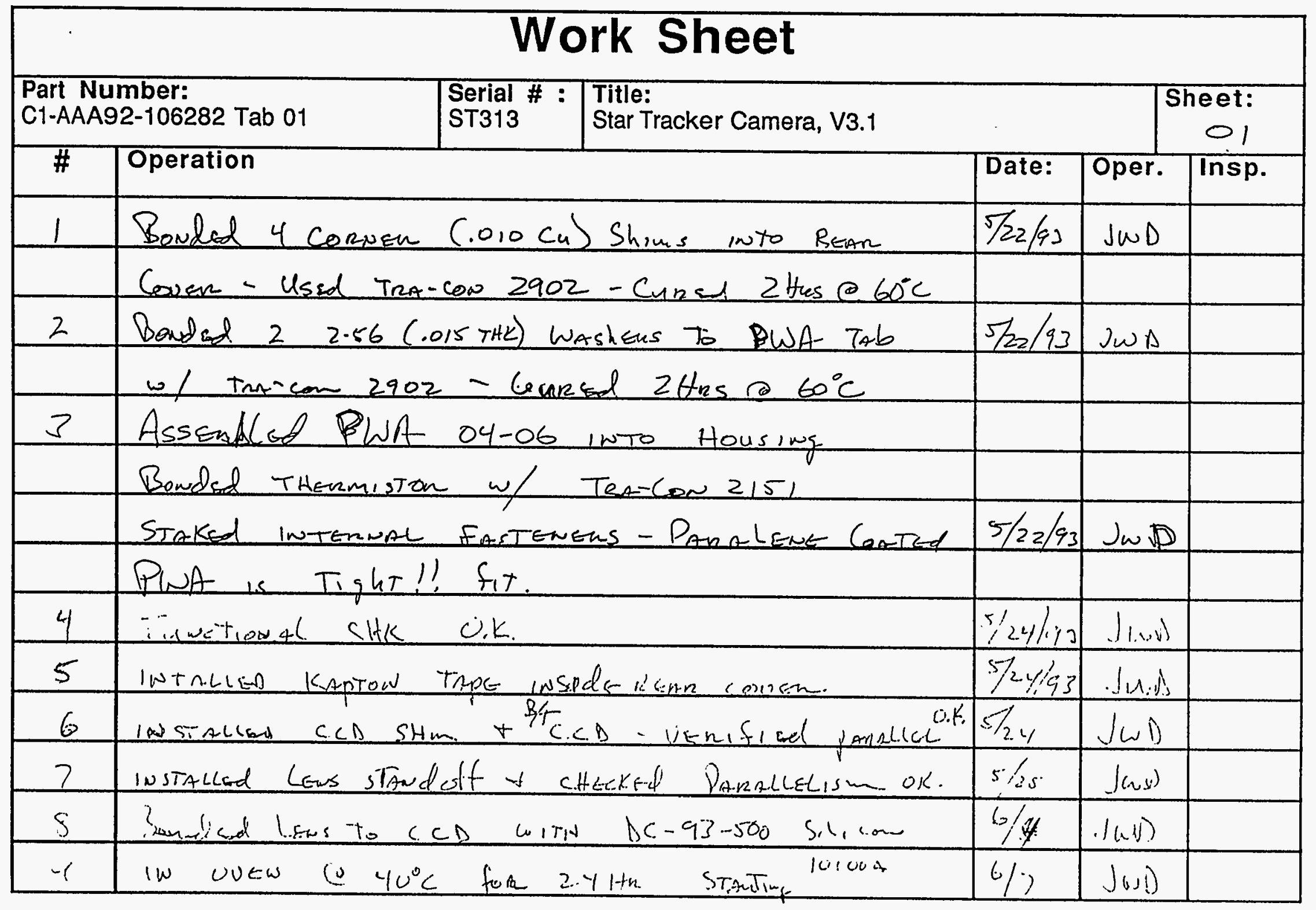




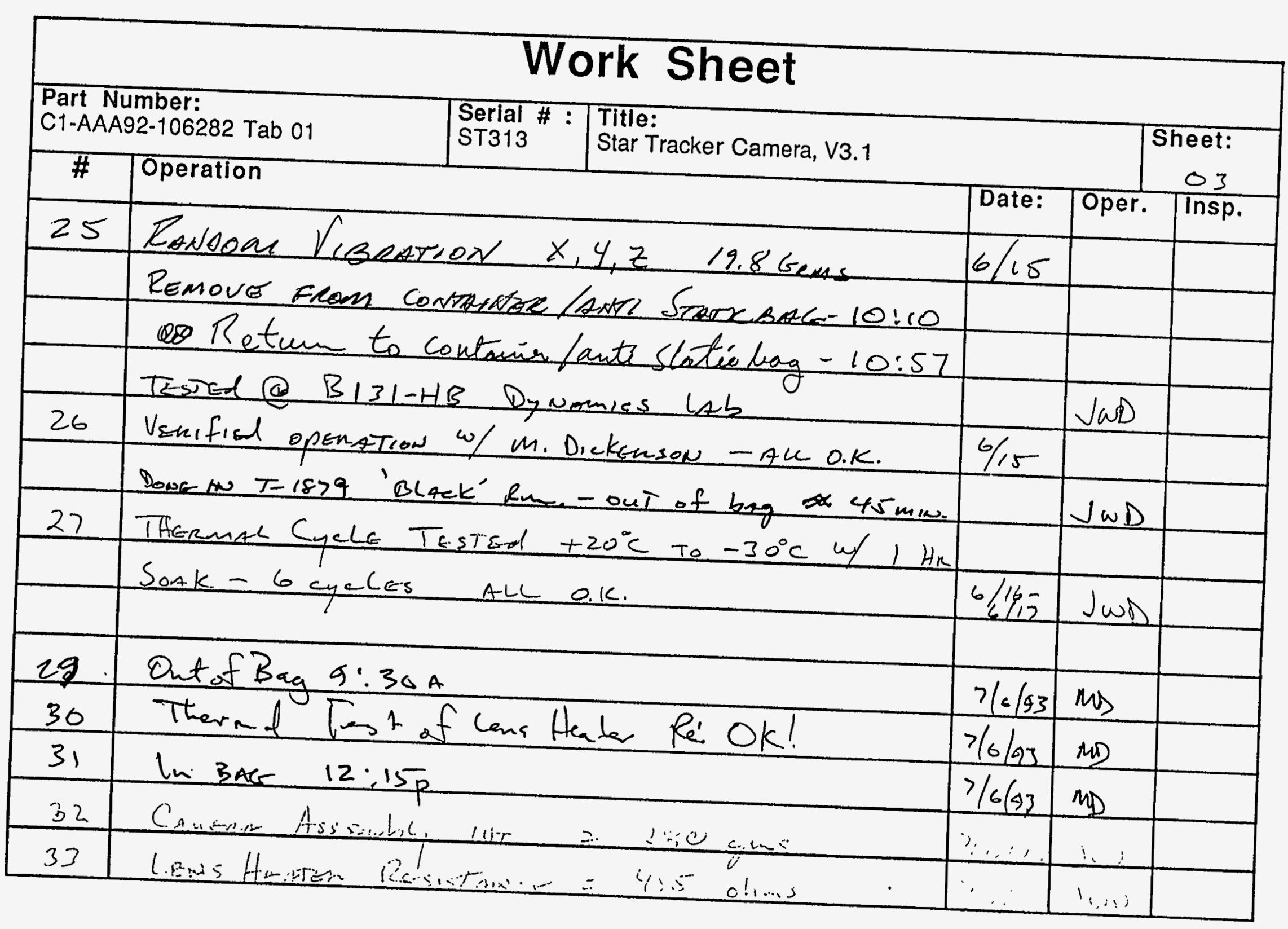




\section{Appendix G.3.3 Bill of Materials}



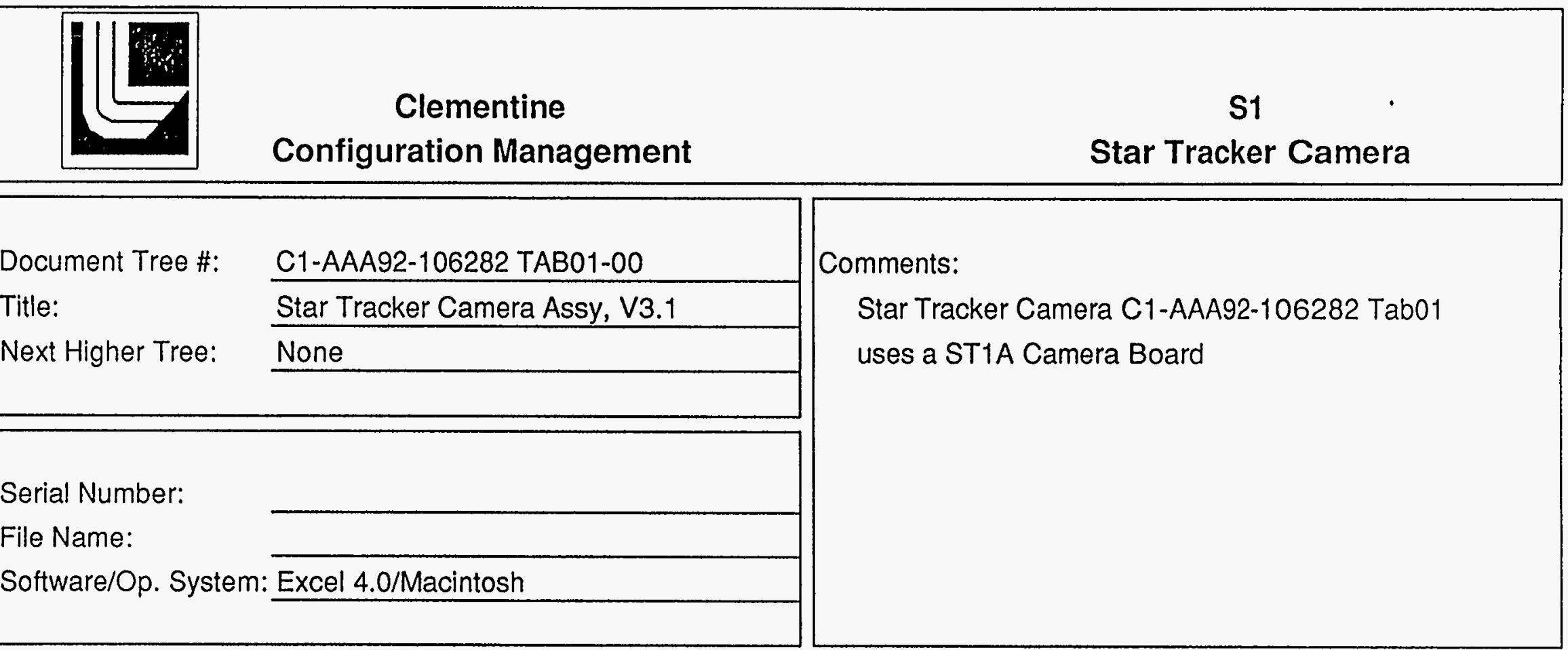

\section{Serial Number:}

File Name:

Software/Op. System: Excel 4.0/Macintosh

\section{Star Tracker Camera}

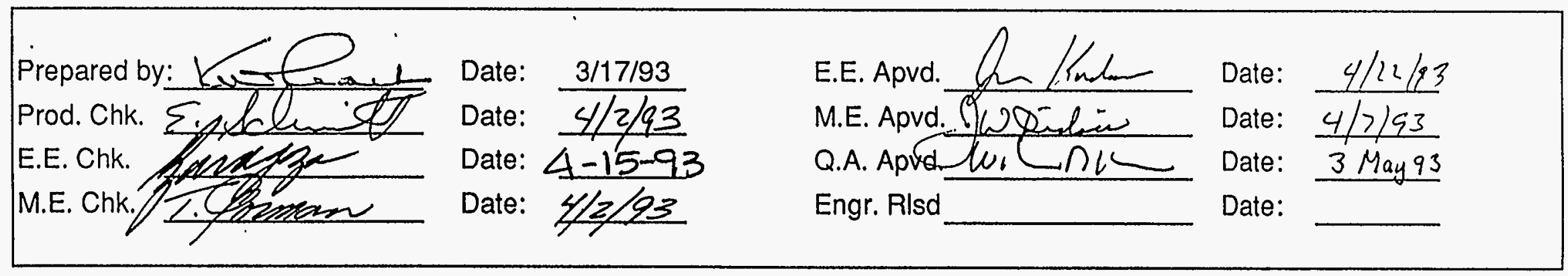

\begin{tabular}{|c||c|c|c|c|c|c|c|c|c|c|c|}
\hline \multicolumn{9}{|c|}{ REVISION HISTORY } & & & \\
\hline Level & 00 & & & & & & & & & & \\
\hline Date & & & & & & & & & & & \\
\hline & & & & & & & & & & & \\
\hline
\end{tabular}




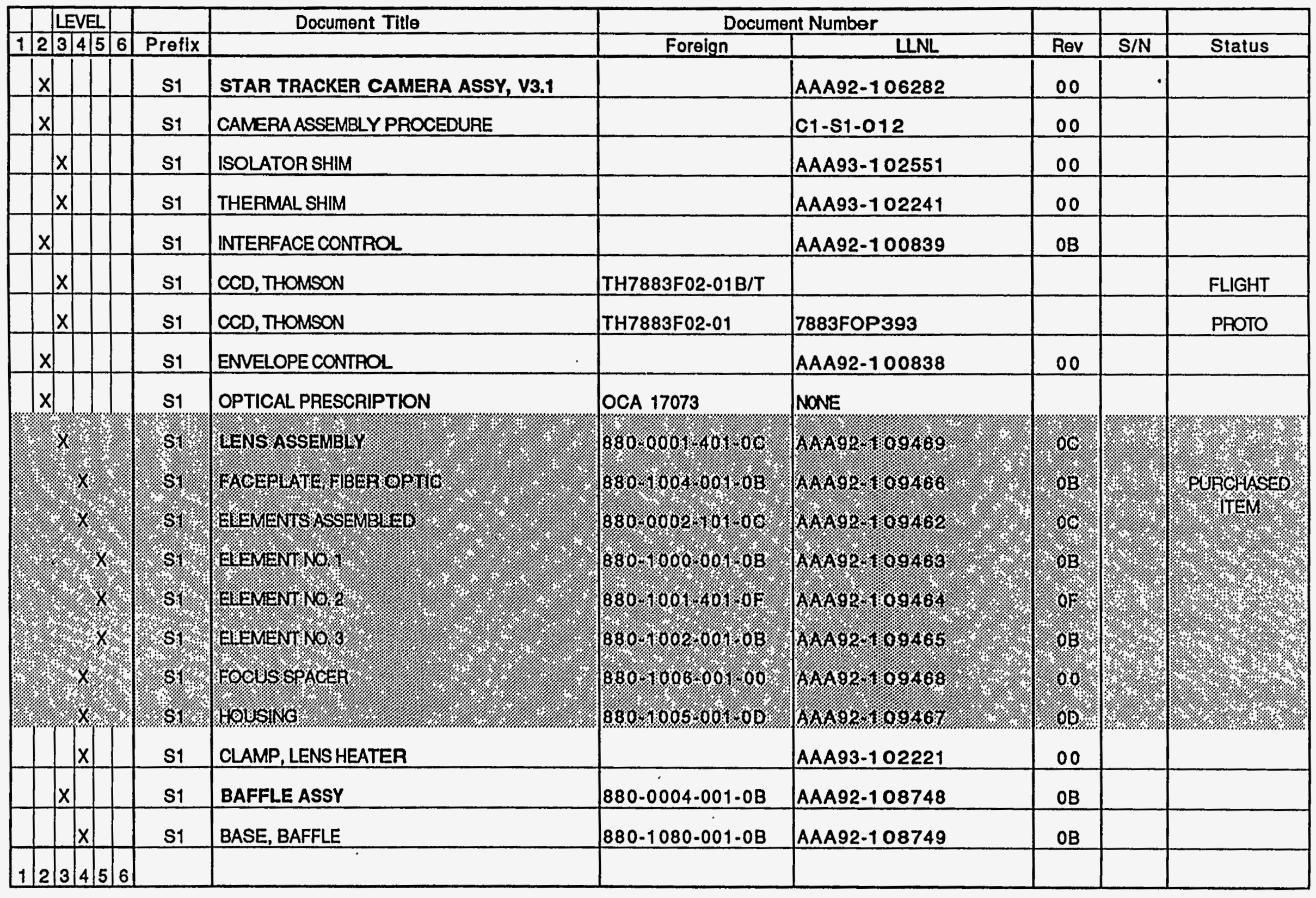




\begin{tabular}{|c|c|c|c|c|c|c|c|c|}
\hline \multirow{2}{*}{\multicolumn{2}{|c|}{\begin{tabular}{|l|l|l|l|l|l|} 
& LEVEL \\
12 & 2 & 4 & 5 & 6 \\
\end{tabular}}} & & Document Title & \multicolumn{2}{|c|}{ Document Number } & \multirow[b]{2}{*}{ Rev } & \multirow[b]{2}{*}{$\mathrm{S} / \mathrm{N}$} & \multirow[b]{2}{*}{ Status } \\
\hline & & Preflx & & Forelgn & $\quad$ LLNL & & & \\
\hline & $x$ & s1 & COVER & & AAA93-102598 & 00 & & \\
\hline & $x$ & s1 & VANE NO. 1 & $880.1021-001$ & AAA92-108747 & 00 & & \\
\hline & $x$ & s1 & VANENO. 2 & $880-1022-001$ & AAA92-108746 & 00 & & \\
\hline & $x$ & s1 & VANENO. 3 & $880.1023-001$ & AAA92-108745 & 00 & & \\
\hline & $x$ & s1 & VANE NO. 4 & $880-1024-001$ & AAA92-108744 & 00 & & \\
\hline $\mathrm{x}$ & & s1 & CAMERA ASSY & & AAA92-106277 & 00 & & \\
\hline & $x$ & s1 & CAMERAHOUSING & & AAA92-106258 & oc & & \\
\hline & $\mathrm{x}$ & $s_{1}$ & BUSHING, JACKPOST, MDM CONN. & & AAA93-101167 TAB08 & 00 & & \\
\hline & $x$ & s1 & CIRCUIT BOARD PAD & $800-3068$ & AAA92-104621 & 00 & & \\
\hline & $x$ & $s_{1}$ & END COVER & & AAA92-106249 & $O A$ & & \\
\hline & $x$ & si & SHIM, LOWER, END COVER & & AAA93-102610. & 00 & & \\
\hline & $x$ & s1 & SHIM, UPPER, END COVER & & AAA93-102609 & $O A$ & & \\
\hline & $x$ & s1 & CONNECTORBRACKET & & AAA92-106257 & $O A$ & & \\
\hline & $x$ & s1 & PAD, CCD THERMAL & & AAA93-102243 & 00 & & \\
\hline & $x$ & s1 & ICD, CAMERA & & AAA92-104603 & $O E$ & & \\
\hline & $x$ & s1 & STIA CAMERA ASSY, W.GAIN \& OFFSET CON & & LEA92-3128-03 & $O A$ & & IN FILE \\
\hline & $x$ & s1 & SCHEMATIC, CAMERA & & LEA92-3128-01 & $O B$ & & IN FILE \\
\hline & $\mathrm{x}$ & s1 & ARTWORK & & LEA92-3128-02 & 00 & & IN FILE \\
\hline & $|x|$ & s1 & BILL OF MATERIALS & & LEA92-3128-04 & oc & & IN FILE \\
\hline$\left.12\right|_{3}$ & $\left.4\right|_{5} 6$ & & & & & & & \\
\hline
\end{tabular}




\begin{tabular}{|c|c|c|c|c|c|c|c|c|c|c|}
\hline \multicolumn{4}{|c|}{ LEVEL } & & Document Title & \multicolumn{2}{|c|}{ Document Number } & & & \\
\hline 12 & $3 \sqrt{4}$ & $4 \sqrt{5}$ & 6 & Prefix & & Foreign & LLNL & Rov & S/N & Status \\
\hline & & & $x$ & s1 & SPACER (CONN. STANDOFF) & & AAA92-104616-TAB01 & OC & - & \\
\hline & & & $x$ & s1 & NUT, PCB RETAINER & & AAA92-109126 & $O A$ & & \\
\hline & & & $x$ & s1 & MTG. HARDWARE & $800-3043$ & AAA92-104607-TAB01 & 00 & & \\
\hline & & $x$ & & s1 & ASSEMBLY PROCEDURE & & LEA92-3128.05 & 08 & & IN FILE \\
\hline & & $x$ & & st & TEST.PROCEDURE & & LEA92-3128-06 & 00 & & N/A \\
\hline & & $x$ & & S1 & FAB DRAWING & & LEA92-3128.07 & OA & & IN FILE \\
\hline & & $x$ & & s1 & ARRAY DOCUMENTATION-U26 & & LEA92-3128-08 & 00 & & NOT SIGNED \\
\hline & $x$ & $x$ & & s1 & THERMISTER, FENWALL & 137-562-ZXT-DO2 & & & & \\
\hline & $x$ & $x$ & & s1 & LENS STANDOFF & & AAA93-102550 & $O A$ & & \\
\hline $1 / 2$ & 3 & 45 & 6 & & & & & & & \\
\hline
\end{tabular}

